Johannes Arndt

\title{
Herrschaftskontrolle durch Öffentlichkeit
}

Die publizistische Darstellung politischer Konflikte im Heiligen Römischen Reich $1648-1750$

\section{Vandenhoeck \& Ruprecht}
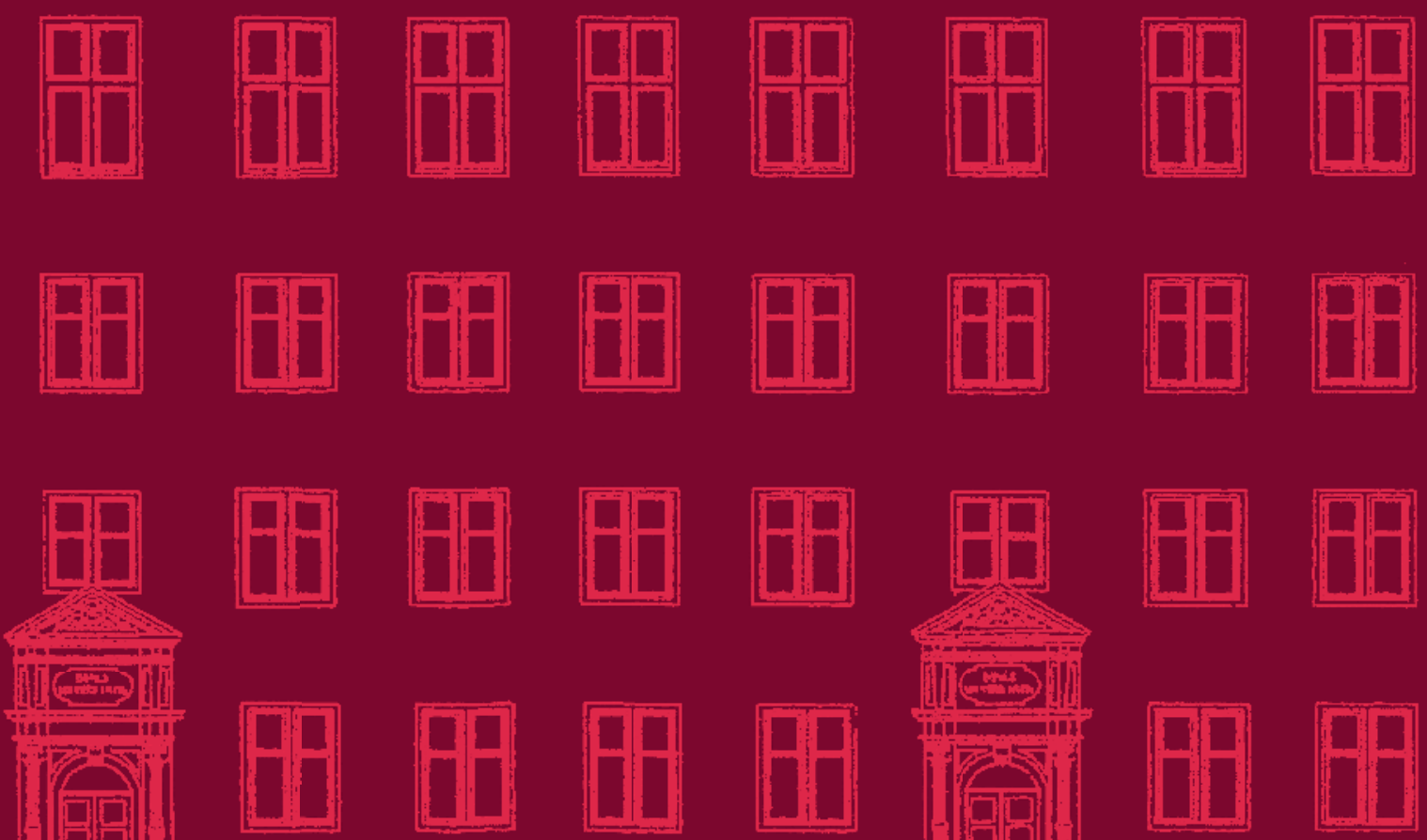


\section{V\&R}

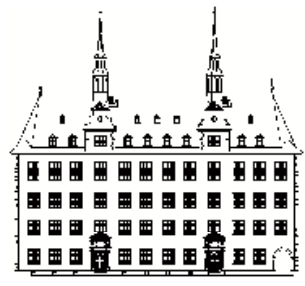




\section{Veröffentlichungen des \\ Instituts für Europäische Geschichte Mainz}

Abteilung für Universalgeschichte

Herausgegeben von Heinz Duchhardt

Band 224

Vandenhoeck \& Ruprecht 


\title{
Herrschaftskontrolle durch Öffentlichkeit
}

Die publizistische Darstellung politischer Konflikte im Heiligen Römischen Reich 1648-1750

\author{
von \\ Johannes Arndt
}

Vandenhoeck \& Ruprecht 
Bibliografische Information der Deutschen Nationalbibliothek

Die Deutsche Nationalbibliothek verzeichnet diese Publikation in der Deutschen Nationalbibliografie; detaillierte bibliografische Daten sind im Internet über http://dnb.de abrufbar.

ISBN (Print) 978-3-525-10108-7

ISBN (OA) 978-3-666-10108-3

https://doi.org/10.13109/9783666101083

(C) 2013, Vandenhoeck \& Ruprecht GmbH \& Co. KG, Göttingen / Vandenhoeck \& Ruprecht LLC, Bristol, CT, U.S.A.

www.v-r.de

Dieses Material steht unter der Creative-Commons-Lizenz Namensnennung - Nicht kommerziell - Keine Bearbeitungen 4.0 International. Um eine Kopie dieser Lizenz zu sehen, besuchen Sie http://creativecommons.org/licenses/by-nc-nd/4.0/.

Satz und Redaktion: Vanessa Brabsche

Gesamtherstellung: $\oplus$ Hubert \& Co, Göttingen 


\section{Inhalt}

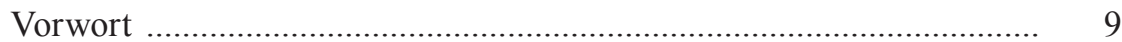

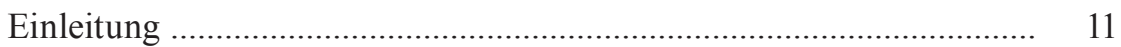

1. Zur Forschungsentwicklung ................................................... 11

2. Zur Methodologie der Studie ................................................ 29

3. Verwendete Quellen ............................................................... 46

\section{HauptTeil I: Das FRÜHMOderne Mediensystem}

1. Zur Zirkularität des Nachrichtensystems ......................................... 53

2. Die Ausdifferenzierung der Medien im Alten Reich ....................... 63

2.1 Vor- und frühperiodische politischen Medien im Heiligen Römischen Reich ................................................................. 63

2.1.1 Nachrichtenbriefe - geschriebene Zeitungen ................. 63

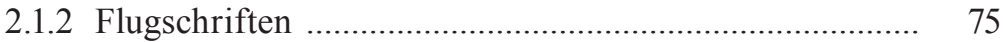

2.1.3 Messrelationen ............................................................ 86

2.2 Die Entwicklung der Zeitung zum Leitmedium der politischen Publizistik ............................................................ 90

2.2.1 Grundbegriffe und -phänomene ..................................... 90

2.2.2 Die ersten Zeitungen:

Entstehung und obrigkeitliche Rezeption ........................ 93

2.2.3 Die weitere Entwicklung der Zeitungen ......................... 100

2.3 Die Entstehung der politisch-historischen Zeitschriften .......... 103

2.4 Historienschriften und Reichspublizistik .............................. 126

3. Produktion: Autoren, Drucker, Verleger ......................................... 141

3.1 Autorenschaft und Originalität der Texte ................................ 141

3.2 Daniel Hartnack und Philipp Balthasar Sinold von Schütz frühe Zeitungs- und Zeitschriftenherausgeber .......................... 151

3.3 Weitere Periodika-Editoren:

Andreas Stübel und Johann Ehrenfried Zschackwitz ............... 154

3.4 David Fassmann - Herausgeber der Totengespräche ................ 158

3.5 Die Honorierung des Autors ................................................... 166

3.6 Fazit: Frühmoderne Autoren von politischen Periodika ........... 168

4. Distribution: Buchhandel und Postwesen ......................................... 171

4.1 Messen, Buchführer und Kolporteure ................................... 172

4.2 Die Zeitungs- und Zeitschriftenproduktion ............................. 181

4.3 Frühe Zeitungsproduktion in Hamburg ................................... 188 
4.4 Post und Zeitungswesen .......................................................... 191

5. Leserschaft ............................................................................. 201

5.1 Zur Forschungsentwicklung .................................................. 201

5.2 Adel und Hof ................................................................... 210

5.3 Das gebildete Bürgertum und die Verwaltung ………............. 220

5.4 Der gemeine Mann in der Stadt ........................................... 226

\section{Hauptteil II: Das Reichssystem Und die Fallstudien}

1. Reichssystem und Öffentlichkeit ................................................. 241

2. Reichsvikariatsstreit zwischen Kurbayern und Kurpfalz ................ 261

2.1 Historischer Hintergrund des Vikariatsstreits ......................... 261

2.2 Der Vikariatsstreit in den Deduktionen ................................ 267

2.3 Berichte in den Zeitungen .................................................. 281

2.4 Berichte in den Zeitschriften ................................................. 289

2.5 Berichte in den Historienwerken und
juristischen Textsammlungen .................................................. 292

2.6 Zusammenfassung .............................................................. 295

3. Neunte Kurwürde für den Herzog von Braunschweig-

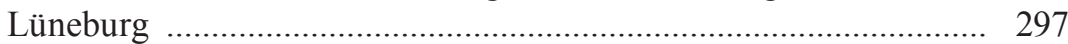

3.1 Historischer Hintergrund ......................................................... 297

3.2 Deduktionen und Flugschriften zum Reichsrechtsstreit .......... 311

3.3 Berichte in den Zeitungen ..................................................... 321

3.4 Raisonnement in den Zeitschriften ......................................... 326

3.5 Behandlung in den Reichsrechtssammlungen und
Historienschriften ............................................................. 334

3.6 Zusammenfassung ............................................................. 337

4. Ächtung Kurfürst Max Emanuels von Bayern ............................... 339

4.1 Dimensionen des Konflikts ................................................... 339

4.2 Darstellung des Konflikts in den Deduktionen und Zeitungen . 348

4.3 Darstellung des Konflikts in den Zeitschriften ....................... 368

4.4 Darstellung des Konflikts in den Historienschriften ............... 387

4.5 Zusammenfassung ............................................................. 392

5. Siegener Konfessionsstreit ......................................................... 395

5.1 Dimensionen des Konflikts ................................................... 395

5.2 Deduktionen und Zeitungsberichte ........................................ 406

5.3 Darstellung in den Zeitschriften ........................................... 414

5.4 Historienschriften und Reichsrechtskompilatorien .................. 423

5.5 Zusammenfassung ............................................................ 427

6. Suspendierung Herzog Karl Leopolds von

Mecklenburg-Schwerin 
6.1 Historischer Hintergrund .......................................................... 431

6.2 Deduktionen und Flugschriften ............................................ 448

6.2.1 Prolog: Drucksachen zum Ehekonflikt Herzog Karl Leopolds .................................................... 448

6.2.2 Deduktionen über den Ständekonflikt bis 1719 .............. 450

6.2.3 Deduktionen über die kaiserliche Kommissionsregierung und die Bemühungen Herzog Karl Leopolds, zur Landesherrschaft zurückzugelangen ........................ 459

6.3 Darstellung in den Zeitungen ................................................. 467

6.4 Darstellung in den Zeitschriften ............................................ 479

6.5 Darstellung in den Reichsrechtssammlungen .......................... 490

6.6 Darstellung in den Historienschriften ..................................... 495

6.7 Zusammenfassung ............................................................. 499

Abschließende Betrachtungen .......................................................... 505

ANHANG

1. Data-Liste der Prüfdaten für die inneren Konflikte im Reich ........ 529

1.1 Liste der Daten (nach Konflikten sortiert) .............................. 529

1.1.1 Reichsvikariatsstreit zwischen Kurbayern und Kurpfalz . 529

1.1.2 Neunte Kurwürde für den Herzog von Braunschweig-Lüneburg ............................................... 529

1.1.3 Ächtung Kurfürst Max Emanuels von Bayern ............... 530

1.1.4 Siegener Konfessionsstreit ........................................... 530

1.1.5 Suspendierung Herzog Karl Leopolds von Mecklenburg-Schwerin ............................................... 531

1.2 Liste der Daten (chronologisch sortiert) ................................. 532

2. Abkürzungsverzeichnis ........................................................... 535

3. Quellen- und Literaturverzeichnis .............................................. 541

3.1 Flugpublizistik und Traktate ................................................ 541

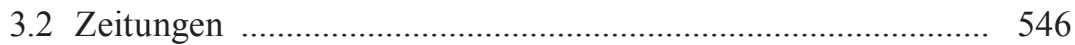

3.3 Zeitschriften ..................................................................... 547

3.4 Sonstige Quellenwerke und -editionen .................................... 549

3.5 Sekundärliteratur ............................................................... 557

4. Personen- und Ortsregister ........................................................... 595 



\section{Vorwort}

Diese Studie ging aus einem Forschungsprojekt hervor, das die DFG von 2001 bis 2003 und 2006/ 07 förderte. Mehrere Lehrstuhlvertretungen in Berlin, Vechta, Düsseldorf, Gießen und Freiburg i.Br. verzögerten die Fertigstellung, schufen aber auch Gelegenheiten zur vertieften Reflexion und Rezeption der sich schnell entwickelnden Forschung zur Medien- und Kommunikationsgeschichte. Der Dank des Verfassers gilt vor allem Heinz Duchhardt, unter dessen Patronat das Werk als »Sachmittelbeihilfe« organisatorisch vorangetrieben wurde und der den fertigen Text in die Schriftenreihe seines Mainzer Instituts aufnahm. Viele Anregungen verdankt der Text der Zentralen Wissenschaftlichen Einrichtung deutsche Presseforschung an der Universität Bremen, besonders Holger Böning und Johannes Weber. Recherchen fanden in mehreren Archiven und Bibliotheken im In- und Ausland statt, auch den dortigen Mitarbeiterinnen und Mitarbeitern sei herzlich gedankt. Freundschaftlichen und kollegialen Rat zur Konzeption erhielt der Verfasser insbesondere von Ronald G. Asch, Volker Bauer, Frank Bösch, EstherBeate Körber, Peter Nitschke, Marcus Weidner und Martin Wrede, zahlreiche andere mussten Einzelfragen und Statements des Verfassers zum Projekt im Ganzen oder in seinen Teilen ertragen.

Meine Eltern haben die Mühe auf sich genommen, das Gesamtmanuskript zu redigieren, und damit für die Einhaltung der sprachlichen Formen und gleichzeitig für die Verstehbarkeit über die Fachkreise hinaus gesorgt, dafür sei ihnen doppelt gedankt. Das Lektorat im Leibniz-Institut für Europäische Geschichte besorgte in gewohnter Umsicht Vanessa Brabsche.

Münster, im Juni 2012

Johannes Arndt 



\section{Einleitung}

\section{Zur Forschungsentwicklung}

In modernen demokratischen Gesellschaften besteht ein gewohntes Zusammenspiel zwischen den Trägern politischer Entscheidungsverfahren und der Vermittlung des politischen Prozessierens durch die Presse in ihren gedruckten (Zeitungen, Zeitschriften), akustischen (Radio), visuellen (Fernsehen) und digitalen Erscheinungsformen (Internet-Newsdienste). Dass dieses Zusammenspiel nicht selten konflikthaft abläuft, bestätigt nur seine Normalität. Die Gesamtheit der medial vermittelten Publizistik ist rechtlich stark verankert und kann daher nicht von den Mandatsträgern nach Belieben gesteuert werden, auch wenn Manipulationen und Manipulationsversuche immer wieder vorkommen und unausrottbar sind.

Ein wichtiger Bereich innerhalb dieser Publizistik ist die Darstellung und Kommentierung innenpolitischer Konflikte. Dabei handelt es sich um Auseinandersetzungen, bei denen verschiedene staatliche, wirtschaftliche oder kulturelle Institutionen um Machtchancen miteinander streiten oder einzelne Bürger, eventuell in Gruppen organisiert, gegen diese Institutionen vorgehen. Im demokratischen Rechtsstaat bilden normalerweise der kontroverse politische Willensbildungsprozess oder der Rechtsweg den Rahmen für den Austrag der Konflikte. Allerdings sind in jüngerer Zeit andere Austragsformen hinzugetreten, dazu gehören direkte Proteste (Streiks, Demonstrationen), Aktionen von Nicht-Regierungsorganisationen (z.B. Blockaden oder demonstrative Akte, etwa von Greenpeace) sowie Pressekampagnen von Organisationen oder finanzkräftigen Interessenten.

In der vorliegenden Studie soll der Blick gerichtet sein auf die Berichterstattung zu innenpolitischen Themen im Jahrhundert nach dem Westfälischen Frieden. Zwei Forschungsstränge sollen insbesondere zusammengeführt werden: die Medien- und Kommunikationsgeschichte, die sich mit den ökonomischen, sozialen und kulturellen Prozessen der Nachrichtengewinnung, -verarbeitung und -verbreitung befasst, und die Verfassungs- und Sozialgeschichte des Heiligen Römischen Reiches, die die Grundordnung des politischen Gemeinwesens der Deutschen untersucht. Die »Öffentlichkeit« stellt dabei die Verbindungsbrücke zwischen diesen beiden Strömungen her.

Die Medien- und Kommunikationsgeschichtsschreibung zur Frühen Neuzeit besteht bislang aus zwei »Bergen« und einem »Tal«: Während die Medienproduktion zur Reformation, zum Konfessionellen Zeitalter und zur Aufklärung als recht gut erforscht bezeichnet werden kann, gilt dies für die dazwischenliegende Epoche nicht. Hier bestehen nicht nur Lücken, sondern 
über weite Strecken ist die Herstellung von Druckprodukten für diese Zeit noch gar nicht als eigenständige Thematik wahrgenommen worden. Im dreibändigen Sammelwerk Propaganda and Communication in World History von 1980 folgt in Band 2 auf den Artikel The Impact of Reformation Era von Nancy L. Roelker direkt der Beitrag The Enlightenment as a Communication Universe von Peter Gay'. So liegt das Schwergewicht der vorliegenden Studie ausdrücklich auf dem Zeitabschnitt zwischen dem Westfälischen Frieden und der Mitte des 18. Jahrhunderts. Dabei stellt der Aachener Friede von 1748, der den Österreichischen Erbfolgekrieg beendete, nur einen politikgeschichtlichen Anhaltspunkt dar. Wichtiger ist die Annahme, dass die Hochaufklärung in Deutschland erst anschließend einsetzte und dass während der Epoche davor zwar Elemente einer »Frühaufklärung« konstatierbar sind, diese allerdings in stetigem Spannungsverhältnis zu gegenreformatorischen und barocken Phänomenen standen ${ }^{2}$.

Das Zeitalter, das auf den Westfälischen Frieden folgte, ist seit Langem »Absolutismus« genannt worden, eine Zuschreibung, gegen die aus gutem Grund Einwände vorgebracht worden sind. Nach der Studie The Myth of Absolutism von Nicholas Henshall sollte der Begriff mangels Substanz nicht mehr als Epochenbezeichnung verwendet werden ${ }^{3}$. Auf einer Münsteraner Tagung 1994 erhielt Henshall mehrheitlich Zustimmung ${ }^{4}$. Heinz Duchhardt, einer der markantesten Kritiker des früheren Begriffs, hat inzwischen

1 Harold D. Lasswell/Daniel Lerner/Hans Speier (Hg.), Propaganda and Communication in World History, 3 Bd., Honolulu 1979-1980, hier Bd. 2.

2 Einführungen und Forschungsüberblicke: Jürgen WiLKE, Grundzüge der Medien- und Kommunikationsgeschichte. Von den Anfängen bis ins 20. Jahrhundert, Köln/Weimar/Wien 2000; Rudolf STÖBER, Mediengeschichte. Die Evolution »neuer« Medien von Gutenberg bis Gates. Eine Einführung, Bd. 1: Presse - Telekommunikation, Wiesbaden 2003; Andreas Würgler, Medien in der Frühen Neuzeit, München 2009. - Zum weiteren Kontext der Mediengeschichte als Buchdruckgeschichte: Michael Giesecke, Der Buchdruck in der frühen Neuzeit. Eine historische Fallstudie über die Durchsetzung neuer Informations- und Kommunikationstechnologien, Frankfurt a.M. 1991.

3 Nicholas Henshall, The Myth of Absolutism. Change and Continuity in Early Modern European Monarchy, London/New York 1992.

4 Vgl. zu Henshalls Thesen den Tagungsband von Ronald G. Asch/Heinz DuchHardt (Hg.), Der Absolutismus - ein Mythos? Strukturwandel monarchischer Herrschaft, Köln/Weimar/Wien 1996. Vgl. auch Richard Bonney, The Limits of Absolutism in Ancien Régime France, Aldershot 1995. Zum Forschungsstand: Wolfgang Schmale, The Future of »Absolutism« in Historiography. Recent Tendencies, in: Journal of Early Modern History 2 (1998), S. 192-202. Vgl. zur älteren Forschungsentwicklung über das »Nichtabsolutistische im Absolutismus«: Johannes Kunisch, Absolutismus. Europäische Geschichte vom Westfälischen Frieden bis zur Krise des Ancien Régime, Göttingen ${ }^{2} 1999$, S. 179-188. Die folgende Kontroverse über die Reichweite des Absolutimus als Phänomen und als Forschungsparadigma wurde zwischen Peter Baumgart und Heinz Duchhardt ausgetragen: Peter BAUMgart, Absolutismus ein Mythos? Aufgeklärter Absolutismus ein Widerspruch? Reflexionen zu einem kontroversen Thema gegenwärtiger Frühneuzeitforschung, in: ZHF 27 (2000), S. 573-589; Heinz DuchHardt, Die Absolutismusdebatte - eine Antipolemik, in: HZ 275 (2002), S. 323-331. 
die vierte Auflage seines elften Bandes der Reihe Oldenbourg Grundri $\beta$ der Geschichte umbenannt von Das Zeitalter des Absolutismus in Barock und Aufklärung und damit dem Begriffswandel Rechnung getragen ${ }^{5}$. Allerdings gibt es keinen Konsens in der Forschung in Richtung auf eine vollständige Überwindung der überkommenen Begriffsbildung. Dagmar Freist ließ ihren Forschungsüberblick über die Epoche zwischen Westfälischem Frieden und Aufklärung 2007 unter dem Titel Absolutismus erscheinen, ohne indes eine Abrechnung mit den Absolutismus-Kritikern vorzunehmen ${ }^{6}$. Im vorliegenden Band soll daher, ungeachtet verschiedener Einwände der Forschung gegen die Begriffsalternative, der Zeitabschnitt zwischen 1648 und $1750 »$ Barockepoche« genannt werden. Gerade unter einem erweiterten Verständnis von Kulturgeschichte erscheint es legitim, eine aus der Kultur (Literatur, bildende Kunst, Musik) stammende Bezeichnung auch als Epochenbezeichnung zu verwenden. Dies gilt umso mehr, als der Quellenkontext der gedruckten Publizistik zu politischen Fragen als Kulturphänomen verstanden werden kann. Die Eckdaten sind allerdings nur auf diese Studie bezogen. Damit soll keineswegs festgeschrieben werden, dass die Barockzeit durch diese beiden Zeitpunkte vollständig und für jede Fragestellung eingrenzbar ist.

Die Mehrzahl der Medienhistoriker zur Frühmoderne hat einen Themenschwerpunkt auf dem Aufklärungszeitalter. Aufklärungshistoriographie ist aus der Perspektive von heute auf die »Sattelzeit« (Reinhart Koselleck) gerichtet betrieben worden. Nur wenige der historiographischen Interessenten besaßen Erfahrung in der quellengestützten Untersuchung von Zeitaltern, die vor 1750 lagen. Meistens lag für diesen Deutungsansatz in der Zeit davor das »Ancien Régime«, wahrgenommen als eine düstere Zeit, in der die "gewöhnlichen« Untertanen von despotischen Fürsten unterdrückt und ausgebeutet worden seien. Die ständische Gesellschaft wurde per se als ungerechte Herrschaft betrachtet ${ }^{7}$. So konnte politische Berichterstattung leicht als Hofberichterstattung etikettiert werden, »Zensur« bedeutete stetig gegenwärtige Gefahr von Unterdrückung, selbst Geschichtsschreibung diente demnach vor allem dem Herrscherlob. Frühere Entwicklungsprozesse wurden kaum beachtet, von der Ur- und Frühgeschichte bis zur Barockzeit bestand eine gerade, modernisierungsfreie Linie.

5 Heinz Duchnardt, Das Zeitalter des Absolutismus, München 1989; jetzt: Barock und Aufklärung, München ${ }^{4} 2007$.

6 Dagmar FreIst, Absolutismus, Darmstadt 2008.

7 Paradigmatisch dafür steht der erste Band der »Deutschen Gesellschaftsgeschichte " von Hans-Ulrich Wehler, einem Historiker mit Schwerpunkt auf der Geschichte des 19. Jahrhunderts, der trotz enorm detaillierter Nachweislage der Dichotomie Französische Revolution=Moderne, Ancien Régime= Despotie nicht entfliehen kann: Hans-Ulrich WeHLER, Deutsche Gesellschaftsgeschichte, Bd. 1: Vom Feudalismus des Alten Reiches bis zur Defensiven Modernisierung der Reformära 1700-1815, München 1987. 
Dem entgegen standen die vorwärtsweisenden Elemente vor allem im Denken aufklärerischer Schriftsteller. Wo immer »Vernunft« im Text auftauchte, musste es sich demnach um Aufklärung handeln. Ein Blick in ältere Standardwerke erweist leicht, dass der Begriff »Vernunft « schon lange in der europäischen Ideengeschichte eine zentrale Rolle gespielt hat, nur ist darunter zu verschiedenen Zeiten Unterschiedliches verstanden worden. In der Großen Konkordanz zur Luther-Bibel wird beispielsweise nachgewiesen, dass der Begriff »Vernunft« achtmal auftaucht, der Begriff »vernünftig « vierundzwanzigmal - niemand würde deshalb die Bibel als Referenzwerk der Aufklärung bezeichnen ${ }^{8}$. So sollte auch Verfassern wissenschaftlicher oder publizistischer Werke zugestanden werden, mit dem Begriff »Vernunft« zu operieren, ohne gleich Aufklärer sein zu müssen. Die Barockzeit sollte eine eigene Epoche sein dürfen, ohne von der nachfolgenden vereinnahmt zu werden. Eine solche Vorannahme schärft den Blick für die Eigenheiten dieses Zeitabschnitts außerhalb der höfischen Kultur, die als Proprium der Barockzeit gilt.

Eine vermittelnde Position wird inzwischen von Hans-Erich Bödeker vertreten, dessen Interpretation der »Frühaufklärung« von einer geistes- und kulturgeschichtlichen Denkrichtung innerhalb des barocken Kosmos ausgeht. Die Frühaufklärer zielten auf eine Ablösung der unbefragten Fortsetzung von Traditionen aller Art. Diese Denkrichtung konnte zwar zu keiner Zeit eine kulturelle Hegemonie errichten, erzielte aber dennoch eine beträchtliche Wirkung in den Diskursen der Zeit und insbesondere in den schriftlichen, gedruckten Hinterlassenschaften ${ }^{9}$. Insbesondere entwickelte sich die politische Öffentlichkeit im Reich dadurch entscheidend weiter, bevor die Hochaufklärung den Prozess beschleunigte ${ }^{10}$. An das Interpretament der Frühaufklärung knüpfen inzwischen neuere angelsächsische Positionen an, die zwischen einer systemerhaltenden Frühaufklärung und einer radikalen, systemsprengenden Denkrichtung unterscheiden, ohne dass diese Strömungen nur aufeinander folgend gedacht werden mussten: Radical Enlightenment setzte, so Jonathan I. Israel, ebenfalls bereits im 17. Jahrhundert ein, war aber lange eine kleine Nebenströmung, ehe sie sich zum zerstörerischen Sturzbach für die alte Ordnung entwickeln konnte ${ }^{11}$.

8 Berthold Ввонм, Große Konkordanz zur Luther-Bibel, Stuttgart ${ }^{3} 1993$, S. 1498f.

9 Vgl. vor allem Hans Erich BöDEKER, Strukturen der deutschen Frühaufklärung (1680-1720). Thesen, in: Ders. (Hg.), Strukturen der deutschen Frühaufklärung 1680-1720, Göttingen 2008, S. 9-20.

10 Bödeker konstatiert: »Trotz des Absolutismus gab es im Reich eine lebendige politische Öffentlichkeit«: Ebd., These XII, S. 17.

11 Israel hat seine diesbezüglichen Überlegungen inzwischen in drei voluminösen Monographien ausgeführt: Jonathan I. IsRaEL, Radical Enlightenment. Philosophy and the Making of Modernity, 1650-1750, Oxford/New York 2001; ders., Enlightenment Contested. Philosophy, Modernity, and the Emancipation of Man 1670-1752, Oxford/New York 2006; ders., A Revo- 
Diese Studie möchte nicht das Lob der aufklärerischen Modernisierung verstärken, sondern die Eigendynamik der politischen Berichterstattung während der vorangehenden Epoche in den Mittelpunkt rücken. Dabei wird die ständische Gesellschaft der Frühmoderne als soziale Ausgangssituation genommen ${ }^{12}$. Unter mediengeschichtlicher Perspektive stehen die politischen Berichtsmedien im Vordergrund, die sich seit dem Reformationsjahrhundert entwickelten. Auch wird die Entwicklung der vormodernen Kommunikation berücksichtigt, wie sie besonders durch Studien von Wolfgang Behringer über das Postwesen erhellt worden ist ${ }^{13}$. Demnach konnte keine Mitteilung schneller sein als die Post, vielfach war die Post schneller als die Reiterstafetten der Fürsten. Dabei gelang der Thurn und Taxis-Post schon im 16. Jahrhundert eine enorme Beschleunigung des Briefverkehrs in ganz Zentraleuropa. Diese von Behringer als »Medienrevolution« bezeichnete Entwicklung schuf erst die Voraussetzungen dafür, dass Zeitungen in immer kürzeren Intervallen aus allen Teilen der bekannten Welt berichten konnten und dabei viele Teile erst bekannt werden ließen.

Die politische Ordnung im Heiligen Römischen Reich ist seit ca. vier Jahrzehnten intensiv erforscht worden ${ }^{14}$. Nachdem das Reich sich während seines Bestehens positiver Anerkennung durch die Deutschen erfreut hatte, rückte es später unter nationalistischer Perspektive in den Hintergrund und wurde negativ eingefärbt. Gerade der Dreißigjährige Krieg und die folgende französische Kulturhegemonie in Europa wurden als deutsche Erniedrigung wahrgenommen. Nachdem zunächst der preußische und später der nationalsozialistische Machtstaat gescheitert waren, erlangte das Reich seine positive Bewertung zurück. Karl Otmar Freiherr von Aretin ${ }^{15}$ und Friedrich Her-

lution of the Mind. Radical Enlightenment and the Intellectual Origins of Modern Democracy, Princeton 2010.

12 Eine Gesamtdarstellung, die die theoretische Fundierung der ständischen Gesellschaft im Spannungsverhältnis zur gesellschaftlichen Realität analysiert, fehlt bislang. Vgl. die verschiedenen Deutungsentwürfe bei Winfried Schulze (Hg.), Ständische Gesellschaft und soziale Mobilität, München 1988; ders., Die ständische Gesellschaft des 16./ 17. Jahrhunderts und die moderne historische Forschung, in: Hans Erich BöDeKeR/Ernst HinRichs (Hg.), Alteuropa - Ancien Régime - Frühe Neuzeit?, Stuttgart 1991, S. 51-77. - Zahlen dazu trotz komplizierter Quellenlage: Diedrich SAALFELD, Die ständische Gliederung der Gesellschaft Deutschlands im Zeitalter des Absolutismus. Ein Quantifizierungsversuch, in: VSWG 67 (1980), S. 457-483.

13 Neben zahlreichen Aufsätzen vgl. vor allem Wolfgang BeHRinger, Im Zeichen des Merkur. Reichspost und Kommunikationsrevolution in der Frühen Neuzeit, Göttingen 2003.

14 Zum Überblick: Helmut Neunaus, Das Reich in der frühen Neuzeit, München 1997; Axel Gotthard, Das Alte Reich, 1495-1806, Darmstadt 2003; Anton Schindling, Kaiser, Reich und Reichsverfassung 1648-1806. Das neue Bild vom Alten Reich, in: Olaf AsBach/Klaus MalettKe/Sven Externbrink (Hg.), Altes Reich, Frankreich und Europa. Politische, philosophische und historische Aspekte des französischen Deutschlandbildes im 17. und 18. Jahrhundert, Berlin 2001, S. 25-54.

15 Karl Otmar Freiherr von Aretin, Heiliges Römisches Reich 1776-1806. Reichsverfassung und 
mann Schubert ${ }^{16}$ stießen die Reichstagsforschung an, Volker Press ${ }^{17}$ betonte die sozialen Bindungen, die innerhalb der adligen und hochadligen Eliten im Reich bestanden und die Fortdauer der Herrschaftsordnung erst ermöglichten. Die Verknüpfung von Reichssystem, Geschichtsbewußtsein und Rechtswesen betonten unter verschiedenen Perspektiven Bernd Roeck ${ }^{18}$, Notker Hammerstein ${ }^{19}$ und Bernhard Diestelkamp ${ }^{20}$ - letzterer regte die systematische Erforschung der obersten Reichsgerichte an. Peter Blickle ${ }^{21}$ und Winfried Schulze ${ }^{22}$ arbeiteten heraus, in welchem Umfang selbst die bäuerliche Bevölkerung das Rechtssystem des Reiches nutzen konnte, um für ihre Vorstellung von gerechter Herrschaft und auskömmlicher Nahrung zu streiten. Heinz Schilling und Wolfgang Reinhard analysierten, wie sich die reformatorische Konfessionsspaltung mit den Prozessen der Sozialdisziplinierung in den Reichsterritorien verknüpfte ${ }^{23}$. Heinz Duchhardt legte sein Augenmerk auf die internationalen Beziehungen des Reiches und seiner Mitglieder in

Staatssouveränität, 2 Bd., Wiesbaden 1967; ders., Das Alte Reich 1648-1806, 3 Bd. und ein Registerbd., Stuttgart 1993-1997.

16 Friedrich Hermann SchUBERT, Die deutschen Reichstage in der Staatslehre der frühen Neuzeit, Göttingen 1966.

17 Vgl. bes. die beiden posthum erschienenen Sammelbände von Volker Press, Das Alte Reich. Ausgewählte Aufsätze, hg. v. Johannes Kunisch, Berlin 1997; ders., Adel im Alten Reich. Gesammelte Vorträge und Aufsätze, hg. v. Franz Brendle/ Anton Schinduing, Tübingen 1998.

18 Bernd Roeck, Reichssystem und Reichsherkommen. Die Diskussion über die Staatlichkeit des Reiches in der politischen Publizistik des 17. und 18. Jahrhunderts, Stuttgart 1984.

19 Notker Hammerstein, Jus und Historie. Ein Beitrag zur Geschichte des historischen Denkens an deutschen Universitäten des späten 17. und 18. Jahrhunderts, Göttingen 1972.

20 Bernhard Diestelkamp, Rechtsfälle aus dem Alten Reich. Denkwürdige Prozesse vor dem Reichskammergericht, München 1995; ders. (Hg.), Oberste Gerichtsbarkeit und Zentrale Gewalt im Europa der Frühen Neuzeit, Köln/Wien/Weimar 1996; ders./Ingrid ScheurmanN (Hg.), Friedenssicherung und Rechtsgewährung. Sechs Beiträge zur Geschichte des Reichskammergerichts und der obersten Gerichtsbarkeit im alten Europa, Bonn/Wetzlar 1997.

21 Peter BLICKLE, Landschaften im Alten Reich. Die staatliche Funktion des Gemeinen Mannes in Oberdeutschland, München 1973; ders., Unruhen in der ständischen Gesellschaft 13001800, München 1988; ders., Kommunalismus. Skizzen zu einer gesellschaftliche Organisationsform, Bd. 1: Oberdeutschland, Bd. 2: Europa, München 2000.

22 Winfried Schulze, Bäuerlicher Widerstand und feudale Herrschaft in der frühen Neuzeit, Stuttgart 1980; ders., Die veränderte Bedeutung sozialer Konflikte im 16. und 17. Jahrhundert, in: Ders. (Hg.), Europäische Bauernrevolten der frühen Neuzeit, Frankfurt a.M. 1982, S. 276-308; ders., Das Reich und der Gemeine Mann, in: Heinz Schilling / Werner Heun / Jutta Götzmann (Hg.), Heiliges Römisches Reich Deutscher Nation 962-1806. Altes Reich und neue Staaten 1495-1806. 29. Ausstellung des Europarats im Deutschen Historischen Museum Berlin, Bd. 2: Essays, Dresden 2006, S. 69-79.

23 Heinz Schilling (Hg.), Die reformierte Konfessionalisierung in Deutschland. Das Problem der »Zweiten Reformation«, Gütersloh 1986; Wolfgang Reinhard/Heinz Schilling (Hg.), Die katholische Konfessionalisierung, Gütersloh 1995. - Der dritte Sammelband in diesem Denkzusammenhang wurde herausgegeben von Hans-Christian Rublack (Hg.), Die lutherische Konfessionalisierung in Deutschland. Wissenschaftliches Kolloquium des Vereins für Reformationsgeschichte 1988, Gütersloh 1992. 
der Frühmoderne ${ }^{24}$. Seit einiger Zeit erweitert Barbara Stollberg-Rilinger ${ }^{25}$ das Wissen um die hohe Bedeutung der politisch-sakralen Symbolordnung im Reich, durch die jahrhundertelang die divergierenden Einzelinteressen eingebunden und eine Unterminierung und Sprengung des Systems vermieden werden konnte.

Bislang haben Reichshistorie und Mediengeschichtsschreibung kaum Bezug aufeinander genommen. Vergleicht man die Literaturverzeichnisse der einschlägigen Studien, so hat es bislang den Anschein, dass die verschiedenen Richtungen nicht einmal die Namen der Kollegen des anderen Teilgebiets kennen oder sie nicht wahrnehmen. Dies ist umso erstaunlicher, als sie dieselben Zeitalter behandeln. Entsprechend holzschnittartig sind denn auch die Vorstellungen, die sich viele Verfassungshistoriker von der medialen Öffentlichkeit und die Medienhistoriker vom Reichssystem machen. Jürgen Wilke stellt für das frühmoderne Reich nach dem Dreißigjährigen Krieg einen »starken Partikularismus « fest, den er gegen das zentralistische Frankreich abgrenzt ${ }^{26}$. Aktuelle Debatten über die Reichsstruktur und über Grenzen des Absolutismus spielen für ihn keine Rolle. Für Frankreich kann er sich allerdings aus Sicht der Mediengeschichte bestätigt sehen, weil dort das Druckwesen - nach bisherigem Forschungsstand - in der Tat zwei eindeutige Schwerpunkte in Paris und Lyon besa $\beta^{27}$. Eine andere jüngere Mediengeschichte, die Studie Medien zwischen Herrschaft und Revolte von Werner Faulstich, behandelt den Zeitabschnitt 1400 bis 1700 und orientiert sich zwar an den Teilepochen des Spätmittelalters und der Frühen Neuzeit, ohne jedoch die jeweiligen Besonderheiten von Humanismus, Reformation, Konfessionellem Zeitalter oder Barock in ein Verhältnis zur gleichzeitigen Medienentwicklung zu stellen ${ }^{28}$. Derselbe Verfasser hat inzwischen auch die Mediengeschichte der anschließenden Epoche untersucht und periodisiert sie - ohne

24 Heinz Duchhardt, Altes Reich und europäische Staatenwelt 1648-1806, München 1990; ders., Balance of Power und Pentarchie. Internationale Beziehungen 1700-1785, Paderborn u.a. 1997.

25 Barbara Stollberg-Rilinger, Des Kaisers alte Kleider. Verfassungsgeschichte und Symbolsprache des Alten Reiches, München 2008; dies. (Hg.), Was heißt Kulturgeschichte des Politischen?, Berlin 2005.

26 WiLke, Grundzüge der Medien- und Kommunikationsgeschichte, S. 50.

27 Zur französischen Pressegeschichte: Claude Bellanger u.a. (Hg.), Histoire générale de la presse française, 5 Bd., Paris 1969-1978; Jack R. Censer, The French Press in the Age of Enlightenment, London/New York 1994; Henri Duranton/Pierre Retat (Hg.), Gazette et information politique sous l'Ancien Régime, St. Etienne 1999; Jean-Paul BerTAud, La presse et le pouvoir de Louis XIV à Napoléon I ${ }^{\text {er }}$, Paris 2000; Gilles Feyel, L'annonce et la nouvelle. La presse d'information en France sous l'Ancien Régime (1630-1788), Oxford 2000. - Vgl. zu Lyon als Druckort: Sabine Vogel, Kulturtransfer in der Frühen Neuzeit. Die Vorworte Lyoner Drucker des 16. Jahrhunderts, Tübingen 1999.

28 Werner Faulstich, Medien zwischen Herrschaft und Revolte. Die Medienkultur der frühen Neuzeit zwischen 1400 und 1700, Göttingen 1998. 
Rücksicht auf politische Zäsuren - von 1700 bis $1830^{29}$. Kürzlich hat Frank Bösch sein Überblickswerk zur Mediengeschichte vorlegt und unterscheidet zwischen dem »Durchbruch des typographischen Drucks« (Zeitraum ca. 1440 bis 1600), der »Etablierung von Periodika« (Zeitraum ca. 1600-1760) und »Medien und de[m] Weg zur Moderne« (nach 1760); damit misst er der frühmodernen periodischen Berichterstattung eine epochensetzende Rolle $\mathrm{zu}^{30}$.

In den neueren Überblicksdarstellungen zur Allgemeinhistorie und zur Reichsgeschichte des Betrachtungszeitraums dieser Studie wird die Rolle der Medien bislang zumeist marginalisiert ${ }^{31}$. In den weitverbreiteten Taschenbuchausgaben über das Zeitalter des Absolutismus von Christof Dipper ${ }^{32}$ und Johannes Kunisch ${ }^{33}$ sucht man vergeblich nach diesem Aspekt. Immerhin hat Kunisch an anderer Stelle auf die Bedeutung von Öffentlichkeit für die Machtpolitik der Höfe hingewiesen, auch wenn der Aspekt der höfischen Lenkung der Medienproduktion einen ganz übergewichtigen Stellenwert gegenüber der sonstigen Publizistik einnimmt ${ }^{34}$. Ernst Hinrichs hat vor einigen Jahren eine Studie vorgelegt, die sich gerade vor dem Hintergrund der Henshall-Debatte um eine Neubestimmung des Absolutismus bemüht. Unter dem Oberbegriff »Strukturmerkmale « finden sich die dynastische Legitimität des Herrschers, die Bürokratie, der Hof, die Finanzen und die Wirtschaft, das Heer und - »im Schatten des Staats« - die Kirchen, doch die Medien fehlen ${ }^{35}$.

Ernsthafte Bestrebungen, die mediale Vermittlung politischer Inhalte in normativer wie in praktischer Hinsicht in die historiographischen Überlegungen einzubeziehen, sind bei Johannes Burkhardt, Heinz Duchhardt und Wolfgang Burgdorf konstatierbar. Burkhardt hat den ersten konsequenten Versuch unternommen, das Reformationsjahrhundert vorrangig aus mediengeschichtlicher Perspektive zu rekonstruieren ${ }^{36}$. Auch seinem Handbuchband

29 Werner Faulstich, Die bürgerliche Mediengesellschaft (1700-1830), Göttingen 2002.

30 Frank Bösch, Mediengeschichte. Vom asiatischen Buchdruck zum globalen Fernsehzeitalter, Frankfurt a.M. u.a. 2011, pas.

31 Dieses Defizit stellt auch Martin Welke bedauernd fest: Martin Welke, Johann Carolus und der Beginn der periodischen Tagespresse. Versuch, einen Irrweg der Forschung zu korrigieren, in: Ders. / Jürgen WiLKe (Hg.), 400 Jahre Zeitung. Die Entwicklung der Tagespresse im internationalen Kontext, Bremen 2008, S. 9-116, bes. S. 17f.

32 Christof Dipper, Deutsche Geschichte 1648-1789, Frankfurt a.M. 1991. - Hier finden sich nur ein paar Bemerkungen über Volksaufklärung: Ebd., S. 193f.

33 Kunisch, Absolutismus, pas.

34 Johannes KunISCH, Absolutismus und Öffentlichkeit, in: Hans-Wolf JäGER (Hg.), »Öffentlichkeit« im 18. Jahrhundert, Göttingen 1997, S. 33-49.

35 Ernst Hinrichs, Fürsten und Mächte. Zum Problem des europäischen Absolutismus, Göttingen 2000.

36 Johannes Burkhardt, Das Reformationsjahrhundert. Deutsche Geschichte zwischen Medienrevolution und Institutionenbildung 1517-1617, Stuttgart 2002. 
zur Geschichte des 18. Jahrhundert ist eine längere Reflexion über das $\gg$ Reich der Schriftlichkeit « inseriert ${ }^{37}$. Duchhardt widmet in seiner Studie zu den internationalen Beziehungen im 18. Jahrhundert der medialen Propaganda der Höfe und Regierungen ein ganzes Unterkapitel ${ }^{38}$. Burgdorf untersucht vorzugsweise gedruckte Traktate des 18. Jahrhunderts zur Reform des Reiches, wobei er zwangsläufig auf den Medienmarkt der Zeit stößt, ohne den die Schriften bedeutungslos geblieben wären ${ }^{39}$. Die Rahmenbedingungen einer Annäherung an den Gegenstand »Medien und Politik im 18. Jahrhundert« demonstrieren deutlich, wie nötig es ist, den blinden Fleck zu beseitigen. Dies erscheint nicht nur unter der modischen »kulturalistischen Pespektive « erforderlich, sondern gerade deshalb, weil zu befürchten steht, dass das politische System als Ganzes nicht zutreffend verstanden werden kann, wenn seine Formen der inhaltlichen (und auch symbolischen) Vermittlung über große Räume hinweg - und ohne Telefon, Fax, Fernsehen und Internet aus den wissenschaftlichen Betrachtungen ausgeblendet bleiben.

Die Distanz zwischen Reichs- und Medienhistorikern wird auch an anderer Stelle deutlich. So blieb ungeachtet des Perspektivwechsels in der Bewertung des Heiligen Römischen Reiches der Topos von der "Zersplitterung" des Reiches erhalten. Er passte zur nationalstaatlichen Kritik am politischen Zustand Deutschlands vor der Reichseinigung von 1871 und wurde von vielen Forschern mit mediengeschichtlicher Fragestellung nachvollzogen, ohne die Konsequenzen zu Ende zu denken. Julius Otto Opel stimmte noch ganz mit der Geschichtsforschung zu seiner Zeit überein, wenn er von »Verworrenheit«, von »schwachen Banden« sprach, die der Westfälische Frieden zerrissen habe ${ }^{40}$. Fast hundert Jahre später klang das aber erstaunlicherweise noch genauso. Für Helmuth Kiesel und Paul Münch setzte sich das Reich aus »einer zersplitterten Fülle halbautonomer Gebiete und Städte zusammen ${ }^{41}$, hingegen war die Zensur eine »unüberschaubare und monströse Institution [...] im territorial und konfessionell zersplitterten Deutschland nach der Reformation $\aleph^{42}$. Wer allerdings der Träger dieser allmächtigen Zensur gewesen sein sollte, wenn alle politischen Instanzen schwach waren, über dieses

37 Johannes Burkhardt, Vollendung und Neuorientierung des frühmodernen Reiches, 16481763, Stuttgart 2006, Kap. 14: Das Reich der Schriftlichkeit - das politische Deutschland als Gedächtnis- und Kommunikationsraum, S. 442-460.

38 Duchhardt, Balance of Power und Pentarchie, Kap. I/ 5: Propaganda und öffentliche Meinung, S. 66-72.

39 Wolfgang Burgdorf, Reichkonstitution und Nation. Verfassungsreformprojekte für das Heilige Römische Reich Deutscher Nation in politischen Schriften von 1648 bis 1806, Mainz 1998.

40 Julius Otto Opel, Anfänge der deutschen Zeitungspresse 1609-1650, Leipzig 1879, S. 265.

41 Helmuth Kiesel/Paul MüNCH, Gesellschaft und Literatur im 18. Jahrhundert. Voraussetzungen und Entstehung des literarischen Markts in Deutschland, München 1977, S. 19.

42 Ebd., S. 106. 
Paradox haben beide nicht weiter nachgedacht. Für Werner Faulstich glich um $1700 »$ Europa einem Flickenteppich sehr unterschiedlich strukturierter, im Prinzip aber gleicher, ebenbürtiger Territorialstaaten $\aleph^{43}$.

Erst spät wurden positive Urteile zum frühmodernen Kulturföderalismus in Deutschland zu Papier gebracht. Bei genauerem Hinsehen erkannten einige Forscher, dass die »Zersplitterung« keineswegs der Nachteil für das Medienwesen war, als der er früher hingestellt worden war. Der Begriff bekam daher eine differenziertere Bedeutung, auch wenn er weiterhin verwandt wurde. Möglicherweise war Nils Eckhardt der erste, der den Nutzen der Polykratie im Reich für die Medienproduktion erkannte. 1987 konstatierte er die »Zerrissenheit des Deutschen Reiches nach dem Dreißigjährigen Krieg« als Vorteil für die Entstehung von Zeitschriften ${ }^{44} .1991$ schrieb Paul Raabe, dass die »Aufsplitterung des Reiches« positive Folgen für die Produktion von Druckwerken besa $\beta^{45}$. Dieser veränderten Interpretation folgten seitdem Annett Volmer ${ }^{46}$ und Karin Angelike ${ }^{47}$. Neuerdings hat auch ein wichtiger medienhistorischer Sammelband vom alten Paradigma Abstand genommen. Die Herausgeber von Vom Almanach zur Zeitung schreiben in ihrer Einleitung:

Das Heilige Römische Reich deutscher Nation mit seinen weit mehr als 300 Einzelgebieten bot gerade der Entwicklung einer breiten, differenzierten, »bürgernahen« Medienkultur besondere Möglichkeiten. Eingebunden in territorial oder lokal geprägte Lesekulturen, wurden Defizite der Kleinstaaterei von dieser Medienkultur kompensiert, ja in Tugenden verwandelt ${ }^{48}$.

43 Werner Faulstich, Medien zwischen Herrschaft und Revolte. Die Medienkultur der frühen Neuzeit zwischen 1400 und 1700, Göttingen 1998, S. 29.

44 Nils EcKHARdT, Arzt, Medizin und Tod im Spiegel der von David Fassmann (1683-1744) in den Jahren von 1718 bis 1739 herausgegebenen Zeitschrift »Gespräche in dem Reiche derer Todten«, Diss. Düsseldorf 1987, S. 5.

45 Paul RaABe, Pseudonyme und anonyme Schriften im 17. und 18. Jahrhundert, in: Ders. (Hg.), Der Zensur zum Trotz. Das gefesselte Wort und die Freiheit in Europa. Ausst.-Kat., Weinheim 1991, S. 53-58, hier S. 53.

46 »Die politische Zersplitterung Deutschlands begünstigte die Entwicklung des Zeitschriftenwesens «: Anett Volmer, Presse und Frankophonie im 18. Jahrhundert. Studien zur französischsprachigen Presse in Thüringen, Kursachsen und Rußland, Leipzig 2000, S. 27.

47 Politische Freiräume in den Niederlanden, der Schweiz und Deutschland »sind vielmehr Folge einer territorialen wie politischen Zersplitterung, die das Entstehen einer starken Zentralgewalt im Ansatz verhindert. Das Fehlen eines überregional wirksamen Kontroll- und Verwaltungsapparates fördert die Entwicklung eines dezentralen und vielfältigen Pressewesens, das sich in den zahlreichen Stadtrepubliken und Territorien unterschiedliche politisch-rechtliche Rahmenbedingungen nutzbar machen kann«: Karin AngeLIKe, Louis-François Mettra. Ein französischer Zeitungsverleger in Köln (1770-1800), Köln/Weimar/Wien 2001, S. 13.

48 Ernst Fischer/Wilhelm Haefs/York-Gothart Mix (Hg.), Vom Almanach zur Zeitung. Ein Handbuch der Medien in Deutschland 1700-1800, München 1999, hier Einleitung, S. $17 f$. 
Überkommene Interpretationsschemata konnten lange als hinreichend erklärungskräftig gelten, soweit Begriff und Phänomen der Öffentlichkeit dogmatisiert waren und Gültigkeit besaßen. Vormoderne Politik wurde als reines Elitenphänomen gesehen. Der Teil, der nicht zum erweiterten Kreis der Herrschaftsträger gehörte, war Objekt obrigkeitlichen Handelns und paternalistischer Bemühungen mit pädagogischem Beigeschmack. Die Meinung der Untertanen war für den Prozess der politischen Entscheidungsfindung unerheblich, gelegentlich geäußerte Vorstellungen oder Willensäußerungen von unten lösten überlegenes Lächeln oder strafrechtliche Suppression aus.

Nun konnte niemand infrage stellen, dass Herrschaftsträger bereits vor dem Aufklärungszeitalter »öffentlich « in Erscheinung getreten waren und dabei kommunikative Beziehungen zwischen ihnen und den Herrschaftsunterworfenen stattgefunden hatten. Zur Deutung dieser Beziehungen formulierte Jürgen Habermas in seiner 1962 publizierten Habilitationsschrift das Konzept der »repräsentativen Öffentlichkeit ${ }^{49}$. Habermas orientierte sich am Abfolgemodell des Historischen Materialismus und wies den vier mittleren Marx'schen Gesellschaftsformationen je eine besondere Form der Öffentlichkeit zu. Für die »Sklavenhaltergesellschaft« war demnach die Trennung von Oikos und Polis konstitutiv, und die ihr gemäße Form der Interaktion im öffentlichen Raum war die »hellenische« Öffentlichkeit. Später wurde diese Form der Öffentlichkeit vom Römischen Reich übernommen. Während der Renaissance gelangte sie zusammen mit antikem Gedankengut und römischen Rechtsvorstellungen nach Alteuropa ${ }^{50}$.

Während des »Feudalismus« im Mittelalter und der Frühen Neuzeit - so Habermas - habe sich Öffentlichkeit gewandelt und sei zur »repräsentativen Öffentlichkeit« geworden. Mit diesem Begriff bezeichnet Habermas keinen sozialen Raum, sondern ein Statusmerkmal, das den hohen Funktionsträgern der alteuropäischen Gesellschaft eigen war. Der Herrschaftsträger repräsentierte seinen Status öffentlich, er stellte sich als Inhaber einer höheren Gewalt dar. Diese Form der Darstellung schloß Päpste, Kaiser, Könige und Fürsten ein, aber auch den mittelalterlichen Hausvater, wobei sich Habermas vom Repräsentationsverständnis Hans-Georg Gadamers leiten lässt ${ }^{51}$. Nicht die Vertretung eines Staates durch Minister oder Diplomaten ist gemeint, sondern die Repräsentation einer unsichtbaren, höheren Entität, die einer

49 Jürgen Habermas, Strukturwandel der Öffentlichkeit. Untersuchungen zu einer Kategorie der bürgerlichen Gesellschaft, Neuwied 1962 (ND Frankfurt a.M. 1990, mit einem ausführlichen Vorwort des Verfassers zum Verlauf der durch ihn ausgelösten Kontroversen versehen).

50 Ebd., S. 56f. Zur Rezeption des römischen Rechts in Europa: Peter G. SteIN, Römisches Recht und Europa. Die Geschichte einer Rechtskultur, Frankfurt a.M. 1996.

51 Hans-Georg Gadamer, Wahrheit und Methode, Tübingen 1960, S. 134, Anm. 2, zit. bei HaBerMAS, Strukturwandel der Öffentlichkeit, S. 60, Anm. 10. 
öffentlichen Zurschaustellung würdig ist: Begriffe wie »Größe«, »Hoheit«, »Majestät«, »Ruhm«, »Würde« oder »Ehre« erfüllten die Bedingung, repräsentationsfähig zu sein. Die Folge dieser Formen der Distinktion sei gewesen, so Habermas, dass eine wirkliche Beteiligung an der politischen Herrschaft auf nur wenige Personen beschränkt geblieben sei: An die Stelle einer früheren Mitwirkung der intermediären Gewalten sei mehr und mehr die fürstliche Arkanpolitik getreten ${ }^{52}$. Zwar konzediert Habermas, dass es weiterhin ständische Versammlungen gegeben habe, doch hätten diese zur fürstlichen Selbstdarstellung, zur Demonstration seiner Allmacht gedient, nicht mehr zur tatsächlichen Verständigung über politische Fragen ${ }^{53}$.

Erst mit dem Aufstieg des Bürgertums im 18. Jahrhundert habe sich eine »bürgerliche Öffentlichkeit« gebildet, die interessanterweise dem »Kapitalismus« als Gesellschaftsformation im Marx’schen Sinne zeitlich vorgelagert war. Durch die Französische Revolution sei sie endgültig an die Stelle ihrer Vorgängerform getreten und präge die öffentlichen Verhältnisse bis in die demokratischen Gesellschaften der Gegenwart. Habermas meint hier, auch wenn das nicht ausdrücklich so geschrieben wird, ein ökonomisches Erstarken, im Gegensatz zu Reinhart Koselleck, dessen bürgerliche Forderung nach Öffentlichkeit sich aus der Erringung und Festigung der persönlichen Gewissensfreiheit herleitet, die durch den Westfälischen Frieden gestiftet worden sei ${ }^{54}$. Beide Forscher sehen die Mitte des 18. Jahrhunderts als Zeit des Durchbruchs für diesen Öffentlichkeitstyp. Frühere Zeichen von bürgerlicher Öffentlichkeit werden von Habermas als Vorformen marginalisiert. So wie Habermas konzediert, dass es bereits seit dem 13. Jahrhundert einen »frühen Finanz- und Handelskapitalismus « gegeben habe, der von den oberitalienischen Städten aus nach Mittel- und Westeuropa eingedrungen sei, so geht er auch davon aus, dass die bürgerliche Öffentlichkeit

52 Zur Arkanpolitik: Michael Stolleis, Arcana Imperii und Ratio Status. Bemerkungen zur politischen Theorie des frühen 17. Jahrhunderts, Göttingen 1980; Anja Victorine Hartmann, Arcana Imperii und Theatrum Mundi. Überlegungen zur Bedeutung des Geheimnisses in der Frühen Neuzeit, in: GWU 53 (2002), H. 7/8, S. 434-443; Ernst Opgenoorth, Publicum privatum - arcanum. Ein Versuch zur Begrifflichkeit frühneuzeitlicher Kommunikationsgeschichte, in: Bernd Sösemann (Hg.), Kommunikation und Medien in Preußen vom 16. bis zum 19. Jahrhundert, Stuttgart 2002, S. 22-44.

53 Habermas, Strukturwandel der Öffentlichkeit, S. 61f. Es wird deutlich, dass Habermas in seiner Konstruktion dieses Typus vom Repräsentationssystem des französischen Hofes unter Ludwig XIV. inspiriert ist: »In der Etikette Ludwigs XIV. erreicht repräsentative Öffentlichkeit die raffinierte Pointe ihrer höfischen Konzentration«: Ebd., S. 65.

54 Reinhart Koselleck, Kritik und Krise. Ein Beitrag zur Pathogenese der bürgerlichen Welt, Freiburg i.Br., München 1959. Vgl. zu Ähnlichkeiten und Unterschieden der Konzeptionen von Koselleck und Habermas: Lucian HöLscher, Die Öffentlichkeit begegnet sich selbst. Zur Struktur öffentlichen Redens im 18. Jahrhundert zwischen Diskurs- und Sozialgeschichte, in: JÄGER, »Öffentlichkeit« im 18. Jahrhundert, S. 11-31, hier S. 16f. 
ihre Vorläufer hatte, z.B. in den Verkehrs- und Nachrichtenverbindungen. Für ihn stehen jedoch die wirtschaftlich nutzbaren Informationen in »Neuen Zeitungen« und Briefmitteilungen im Vordergrund, während die öffentliche Funktion der Presse erst eintritt, »seitdem die regelmäßige Berichterstattung öffentlich, wiederum: dem Publikum allgemein zugänglich wird. Das aber geschieht erst Ende des 17. Jahrhunderts « ${ }^{55}$. Im weiteren Verlauf des 18. Jahrhunderts sei auch eine »plebejische Öffentlichkeit« entstanden, so Habermas, doch diese sei noch keine kritische Gegenöffentlichkeit gewesen, die auf die spätere Geschichtsformation des »Sozialismus« verwiesen habe, sondern eine unterdrückte Variante unterhalb der bürgerlichen Hauptform ${ }^{56}$.

Die Habermas'sche Modellbildung ist schon auf den ersten Blick allenfalls auf Frankreich anwendbar, kaum aber auf die gänzlich anderen Verhältnisse im Hl. Römischen Reich. Widerspruch ist daher auch nicht ausgeblieben. Lucian Hölscher verweist darauf, dass es einen Begriff der »Öffentlichkeit«, der mit dem heutigen vergleichbar wäre, vor dem 18. Jahrhundert noch nicht gegeben habe ${ }^{57}$. "Öffentlich« kam in Verbindung mit Verben wie »öffentlich kundtun « vor, nicht aber als Substantivierung. Auch der lateinische Parallelbegriff »publicus « deckt sich nicht mit dem heutigen Wortsinn von »öffentlich«, sondern mit der Verwendungsweise, die sich noch in »Öffentlichem Recht« findet, nämlich bezogen auf obrigkeitliche Institutionen mit ihren herrschaftlichen Ansprüchen, Rechten und Freiheiten ${ }^{58}$. Das Substantiv »Öffentlichkeit« tauchte hingegen, soweit bislang bekannt, erstmals im Jahre 1765 beim österreichischen Kameralisten Joseph von Sonnenfels ${ }^{59}$ auf, um 1777 als Begriff ins »Grammatisch-kritischen Wörterbuch« von Johann

55 Habermas, Strukturwandel der Öffentlichkeit, S. 70-72, Zitat S. 72. Habermas stützt sich dabei auf die Thesen von Helmut FISCHER, Die ältesten Zeitungen und ihre Verleger, Augsburg 1936.

56 Habermas, Strukturwandel der Öffentlichkeit, S. 52.

57 Lucian HöLscher, Öffentlichkeit und Geheimnis. Eine begriffsgeschichtliche Untersuchung zur Entstehung der Öffentlichkeit in der frühen Neuzeit, Stuttgart 1979, S. 12. Hölscher greift diese Überlegungen in einer späteren Studie erneut auf und führt sie fort: Ders., Die Öffentlichkeit begegnet sich selbst, bes. S. 22-31. Vgl. auch Falko SchneIDER, Öffentlichkeit und Diskurs. Studien zu Entstehung und Struktur der Öffentlichkeit im 18. Jahrhundert, Bielefeld 1992, S. 9-13.

58 Ein Beispiel dafür ist »ecclesia publica«: HöLschER, Öffentlichkeit und Geheimnis, S. 28f. Die Bedeutungen der Begriffe »öffentlich« und »publicus« verschmolzen seit dem 17. Jahrhundert miteinander: Ebd., S. 36.

59 Joseph von Sonnenfels, Grundsätze der Policey-, Handlung- und Finanzwissenschaft, 3 Bd., Wien 1765-1776, hier Bd. 1, S. 82. Hier heißt es im Kontext der Zensur als Policeyaufgabe: »Sie [= die Zensur] erstrecket sich daher nicht nur auf Bücher, sondern auch auf Schauspiele, Lehrsätze, Zeitungen, alle öffentlichen, an das Volk gerichteten Reden, Bilder und Kupferstiche, und was sonst immer eine Art von Oeffentlichkeit, wenn man so sagen darf, an sich hat«. Der auf den Kernbegriff folgende Nebensatz deutet darauf hin, dass Sonnenfels ihn als Neologismus versteht. 
Christoph Adelung ${ }^{60}$ aufgenommen $\mathrm{zu}$ werden. Durchgesetzt wurde er anschließend durch Jean Paul und durch Joachim Heinrich Campe ${ }^{61}$.

Ein weiteres Problem besteht darin, dass »Öffentlichkeit« in der Verwendung durch die Aufklärer keine wissenschaftliche, sondern eine politischpublizistische Bedeutung beinhalten sollte: Ludwig Fischer verweist darauf, dass »Öffentlichkeit« ein Kampfbegriff mit der Absicht war, den feudalen Herrschafts- und Kommunikationsstrukturen, die Jürgen Habermas als »repräsentative Öffentlichkeit« bezeichnet hat, die Grundlage ihrer Berechtigung zu entziehen ${ }^{62}$. »Öffentlichkeit« verband sich in diesem Kontext mit den Vorstellungen »natürliche Rechte«, »Gleichheit aller«, »Vernünftigkeit« und »volonté générale«. Im Konkreten wurde der Begriff etwa verwendet, wenn es darum ging, Geschworenengerichte zu befürworten als modernen Ersatz für eine vermeintliche frühere Geheimjustiz ${ }^{63}$. Im Folgenden wird »Öffentlichkeit« daher in der Weise verwendet, dass es sich dabei um eine »Beschreibungskategorie für bestimmte soziale und politische Strukturen« handelt ${ }^{64}$.

Auch die Begriffe »repräsentativ« oder »bürgerlich« im Zusammenhang mit »Öffentlichkeit« werden kritisch kommentiert, da sie zwei unterschiedlichen Wortfeldern entstammen: »Repräsentativ«, so konstatiert Michael Schilling, sei eine Funktionskategorie, während »bürgerlich« dagegen ein soziologischer Gattungsbegriff $\mathrm{sei}^{65}$. Habermas geht zudem nicht auf Begriffsbildungen wie »kommunale« oder »reformatorische« Öffentlichkeit ein, in denen die innerhalb der Feudalgesellschaft fortschrittlichere Entwicklung hätte einbezogen werden können. Überlegungen in dieser Hinsicht sind bereits in den Dreißiger Jahren von Ernst Manheim angestellt worden, doch Habermas griff sie nicht auf ${ }^{66}$.

60 Johann Christoph Adelung (Hg.), Versuch eines vollständigen grammatisch-kritischen Wörterbuchs der hochdeutschen Mundart, mit beständiger Vergleichung der übrigen Mundarten, besonders aber der oberdeutschen, 5 Bd., Leipzig 1774-1786, hier Bd. 3, Sp. 893: »Die Öffentlichkeit, plur. inusit. die Eigenschaft einer Sache, da sie öffentlich ist, oder geschiehet, in allen Bedeutungen dieses Wortes $\ll$.

61 Vgl. zur begriffsgeschichtlichen Entwicklung: Wolfgang SETTEKoRn, Überlegungen zur Konzeptionalisierung von »Öffentlichkeit«, in: Werner Faulstich / Knut Hickethier (Hg.), Öffentlichkeit im Wandel. Neue Beiträge zur Begriffsklärung, Bardowick 2000, S. 15-33, hier S. 16.

62 Ludwig FISCHER, Wirkliche Öffentlichkeiten? Reflexionen mit Rücksicht auf Pierre Bourdieus Kultursoziologie, in: Faulstich/Hickethier, Öffentlichkeit im Wandel. Neue Beiträge zur Begriffsklärung, S. 63-74, hier S. 63.

63 Auf diesen Zusammenhang verweist: SETTEKoRn, Überlegungen zur Konzeptionalisierung von »Öffentlichkeit«, S. 16.

64 Zum Begriffsverständnis als »Beschreibungskategorie«: HöLschER, Öffentlichkeit und Geheimnis, S. 8f.

65 Michael Schilling, Bildpublizistik der frühen Neuzeit. Aufgaben und Leistungen des illustrierten Flugblattes in Deutschland um 1700, Tübingen 1990, S. $160 f$.

66 Vgl. Ernst Manheim, Die Träger der Öffentlichen Meinung. Studien zur Soziologie der Öffentlichkeit, Brünn u.a. 1933 (spätere Ausgabe: Aufklärung und öffentliche Meinung. Studien zur 
Auch wenn der heute gebräuchliche Begriff noch nicht zur Verfügung stand, so ist das Phänomen, das wir als Öffentlichkeit bezeichnen, bereits im Spätmittelalter als solches wahrgenommen worden. In der Analyse des Begriffs »Gemain Sag« konnte Martin Bauer feststellen, dass die Wahrnehmung und Kommentierung politischer Verhältnisse und Entscheidungen durch die Untertanen bereits im Spätmittelalter eine wichtige Rolle gespielt haben. Dabei fand eine Rückbindung der beobachteten politischen Phänomene durch die Herrschaftsunterworfenen an den allgemeinen Rahmen der politischen Normen und Wertvorstellungen statt, wodurch Legitimationszwänge aufgebaut und eine herrschaftsbegrenzende Funktion erzielt wurde ${ }^{67}$. Wenn Papst Johannes XXII. im Jahre 1323 die Akten des kurialen Prozesses gegen König Ludwig den Bayern publizierte, so sollte dieser Appell an die Öffentlichkeit der Reichsstände zum Zusammenbruch der antipäpstlich ausgerichteten königlichen Herrschaft führen, indem die Diskrepanz zwischen dem Handeln des Königs und den politischen Normvorstellungen der Fürsten öffentlich gemacht wurde ${ }^{68}$.

Spätestens seit der Durchsetzung der Reformation in beträchtlichen Teilen des Hl. Römischen Reiches muss von einem verhältnismäßig breiten Lesepublikum ausgegangen werden, das als Käuferschaft von Traktaten politischer und religiöser Inhalte infrage kam. Angesichts der Auflagenstärke der Schriften Luthers kann als gesichert gelten, dass die Rezipienten weit über den Kreis der akademisch gebildeten Bewohnerschaft der Reichsterritorien hinausreichten. So war es für Peter Ukena, Rainer Wohlfeil und Johannes Burkhardt konsequent, von einer »reformatorischen Öffentlichkeit« zu sprechen $^{69}$. Rezipienten, das hat Rudolf Schlögl betont, waren nicht nur die lesefähigen Erwerber, sondern im Zusammenhang einer »Kommunikation unter Anwesenden« auch diejenigen, denen die Texte vorgelesen oder sinngemäß vorgetragen wurden und die anschließend darüber diskutierten ${ }^{70}$. Der nieder-

Soziologie der Öffentlichkeit im 18. Jahrhundert, Stuttgart-Bad Cannstatt 1979). - Manheim steht bei Habermas im Literaturverzeichnis, wird aber in diesem Zusammenhang nicht eingearbeitet: Habermas, Strukturwandel der Öffentlichkeit, S. 371.

67 Martin Bauer, Die »Gemain Sag« im späten Mittelalter. Studien zu einem Faktor mittelalterlicher Öffentlichkeit und seinem historischen Aussagewert, Diss. Erlangen 1981, S. 1-8.

68 Vgl. Martin Kaufhold, Öffentlichkeit im politischen Konflikt. Die Publikation der kurialen Prozesse gegen Ludwig von Bayern in Salzburg, in: ZHF 22 (1995), S. 435-454.

69 Peter Ukena, Tagesschrifttum und Öffentlichkeit im 16. und 17. Jahrhundert, in: Elger Blühm/Hartwig Gebhardt (Hg.), Presse und Geschichte, Bd. 1, München u.a. 1977, S. 35-53, hier S. 37f.; Rainer Wohlfeil, Art. »Reformatorische Öffentlichkeit«, in: Ludger GrenzMAnN/Karl Stackmann (Hg.), Literatur und Laienbildung im Spätmittelalter und in der Reformationszeit. Symposium Wolfenbüttel 1981, Stuttgart 1984, S. 41-52; BurkhardT, Das Reformationsjahrhundert, bes. 48-64 (Erster T1., Kap. 4: Das Geheimnis der reformatorischen Öffentlichkeit).

70 Rudolf SchLÖGL, Politik beobachten. Öffentlichkeit und Medien in der Frühen Neuzeit, in: ZHF 35 (2008), S. 581-616, bes. S. 593f. - Vgl. dazu auch die Überlegungen bei dems., Kom- 
ländische Aufstand und der schwedische Ein- und Vormarsch Gustav Adolfs in Mitteleuropa während des Dreißigjährigen Krieges fanden unter großer publizistischer Begleitung statt, wobei durchaus von einem »Medienkrieg « gesprochen werden darf, denn gezielte Steuerung von Meinungsbeeinflussung durch die Interessenten Wilhelm von Oranien und später Gustav Adolf ging einher mit dem Erscheinen von Publikationen, die ihre Existenz dem merkantilen Interesse von Buchdruckern und -händlern verdankten ${ }^{71}$.

1997 hat Konrad Repgen den Westfälischen Friedenskongress und den schließlich dort verabschiedeten Frieden als Medienereignis vorgestellt und in diesem Zusammenhang aufschlussreiche Überlegungen zum Lesepublikum in Mitteleuropa angestellt ${ }^{72}$. Repgen ist der Ansicht, dass eine politische Öffentlichkeit um 1648 tatsächlich bestand, auch wenn für dieses Phänomen der heute gebräuchliche Begriff noch nicht verwendet wurde. Dabei räumt er ein, dass das Prinzip der Arcana imperii die politisch-diplomatische Kommunikation dominierte, doch dass entscheidende Herrschaftshandlungen überall im Abendland der öffentlichen Verkündigung bedurften. Repgen hat diese Notwendigkeit bereits 1985 anhand der Kriegslegitimationen nachgewiesen $^{73}$, um nun auch die Publikationspflicht von Friedensschlüssen und ihren Vorläufern, den Teilvereinbarungen, zu demonstrieren. Außenpolitik generell gehörte zu den Bereichen, für die die Fürstenstaaten im 17. Jahrhundert Öffentlichkeit herstellten. Bei Verhandlungen zwischen Staaten oder Territorien Gesagtes oder schriftlich Ausgetauschtes konnte später von der Gegenseite im jeweils opportunen Kontext veröffentlicht werden. Daher achteten die Verhandlungsführer in ihrem Sprechen und Handeln darauf, dass dem Gegner nicht durch unbedachte Äußerungen Munition für die weitere Auseinandersetzung geliefert wurde. Repgen formuliert dies wie folgt: »Auf diese Weise saß die Öffentlichkeit als Drohgespenst und Appellationsinstanz ständig mit am Verhandlungstisch und zwang die Diplomaten, zum Fenster

munikation und Vergesellschaftung unter Anwesenden. Formen des Sozialen und ihre Transformation in der Frühen Neuzeit, in: GuG 34 (2008), S. 155-224.

71 Niederlande: Johannes ARNDT, Das Heilige Römische Reich und die Niederlande 15661648. Politisch-konfessionelle Verflechtung und Publizistik im Achtzigjährigen Krieg, Köln/Wien/Weimar 1998. Schweden: Diethelm BöTtcheR, Die schwedische Propaganda im protestantischen Deutschland, 1628-1634, in: ARG 44 (1953), S. 181-203; Kurt JoHANNESSON, The Renaissance of the Goths in Sixteenth-Century Sweden. Johannes and Olaus Magnus as Politicians and Historians, Berkeley 1991; Sverker Oredsson, Geschichtsschreibung und Kult. Gustav Adolf, Schweden und der Dreißigjährige Krieg, Berlin 1994.

72 Konrad Repgen, Der Westfälische Friede und die zeitgenössische Öffentlichkeit, in: HJb 117/I (1997), S. 38-83; auch abgedruckt in: Ders., Dreißigjähriger Krieg und Westfälischer Friede. Studien und Quellen, hg. v. Franz Bosbach u. Christoph Kampmann, Paderborn u.a. 1998, S. 723-765.

73 Konrad RePGEN, Kriegslegitimationen in Alteuropa. Entwurf einer historischen Typologie, in: HZ 241 (1985), S. 27-49. 
hinaus zu sprechen ${ }^{74}$. Es war im Übrigen nicht allein das geschriebene oder gedruckte Wort, welches Arkana zu veröffentlichen imstande war, sondern frühneuzeitliche Öffentlichkeit bezog auch den gesamten nonverbalen Anteil der Kommunikation mit ein, wozu vor allem die druckgraphischen Verbildlichungen gehörten ${ }^{75}$.

Repgen unterscheidet vier inhaltlich-funktionale Flugschriften-Typen, die besonders dem staatlichen Vermittlungsinteresse für außenpolitische Handlungen gedient haben: A. Staatsschriften (Deduktionen und Manifeste), B. Streitschriften, C. Verhandlungsakten, und D. Vertragstexte ${ }^{76}$. Als Markt für die Flugschriften nimmt Repgen zum einen die aktiv oder berichtend Beteiligten am politischen Geschehen an, die allerdings alle die lateinische Sprache beherrschten. Für sie allein wäre daher die Publikation lateinischer Traktate ausreichend gewesen. Der Grund für die große Zahl deutschsprachiger Drucke muss in einem darüber hinausreichenden Interesse durch Leser bestanden haben. Hierfür kamen die Leser der Zeitungen infrage, die sich seit dem frühen 17. Jahrhundert im deutschsprachigen Raum etabliert hatten. Nur hier war ein inhaltlich interessiertes und hinreichend zahlenstarkes Potenzial vorhanden, um die geschätzten Auflagenhöhen der gedruckten Vertragsexemplare des Osnabrücker (IPO) und des Münsteraner Friedensinstruments (IPM) abzunehmen: Repgen schätzt die Auflagenzahlen auf 28.000 bis $42.000^{77}$.

Auf derselben Ebene der Publizität von Außenpolitik behandelt Markus Baumanns das Öffentlichkeitsproblem in seiner Studie über die österreichische Diplomatie im ludovizianischen Zeitalter ${ }^{78}$. Er geht von den Traktaten des österreichischen Spitzendiplomaten Franz Paul Freiherr von Lisola aus, der der kaiserlichen Administration Leopolds I. nicht nur unschätzbare diplomatische Dienst leistete, sondern durch seine virtuose Handhabung des gedruckten Wortes auch maßgeblich dafür mitverantwortlich war, dass die kaiserliche Politik im späten 17. Jahrhundert im Reich wieder Vertrauen schaffen konnte. Von Öffentlichkeit diplomatischer Bemühungen und Vereinbarungen handelt auch die Studie Absolutismus und Öffentlichkeit von

74 Repgen, Der Westfälische Friede und die zeitgenössische Öffentlichkeit, S. 48.

75 Vgl. die Überlegungen dazu bei Andreas Gestrich, Absolutismus und Öffentlichkeit. Politische Kommunikation zu Beginn des 18. Jahrhunderts, Göttingen 1994, S. 248f., Anm. 90.

76 Vgl. die Definitionen bei RePGEN, Der Westfälische Friede und die zeitgenössische Öffentlichkeit, S. 52-77.

77 Zur methodischen Ermittlung dieser geschätzten Zahlen: Ebd., S. 77-83. In einem Nachtrag, den Repgen der Publikation des Beitrags im Sammelband seiner Aufsätze hinzufügt, verweist er darauf, dass inzwischen noch 12 weitere Vertragsausgaben aufgefunden worden sind. Die Gesamtzahl der herausgekommenen Drucke dürfte sich damit erhöhen: Ders., Dreißigjähriger Krieg und Westfälischer Friede, S. 765.

78 Markus Baumanns, Das publizistische Werk des kaiserlichen Diplomaten Franz Paul Freiherr von Lisola (1613-1674). Ein Beitrag zum Verhältnis von Absolutistischem Staat, Öffentlichkeit und Mächtepolitik in der Frühen Neuzeit, Berlin 1994. 
Andreas Gestrich ${ }^{79}$. Nach einer eingehenden Auseinandersetzung mit Habermas untersucht Gestrich insbesondere den öffentlichen Niederschlag der internationalen Kontakte zwischen den europäischen Mächten in den 1720er Jahren. Die »höfische Öffentlichkeit« ist von Aloys Winterling am Beispiel des Bonner Hoflebens der Kölner Kurfürsten exemplifiziert worden. Dabei betonte Winterling, dass der öffentliche Prunk nicht der Machtdarstellung, sondern der Kompensation von Ohnmacht gedient habe ${ }^{80}$. Diese Öffentlichkeit war in der Tat zunächst auf das anwesende Publikum ausgerichtet, wie Volker Bauer herausarbeitet, allerdings blieb sie nicht darauf beschränkt ${ }^{81}$.

Esther-Beate Körber und Andreas Würgler haben innerterritoriale öffentliche Diskursformen im Herzogtum Preußen und in süddeutschen und schweizerischen Städten untersucht. Dabei stellt Körber bereits für das 16. Jahrhundert fest, dass die starke Ständepräsenz im Herzogtum zu einem politischen Diskurs führte, der über das engere Umfeld des herzoglichen Regierungsapparats hinausreichte und den herrscherlichen Wünschen nach einer Arkanpolitik enge Grenzen zog ${ }^{82}$. Würglers Zeitschwerpunkt liegt im ausgehenden 18. Jahrhundert. In den von ihm untersuchten Städten sind mehrfach Unruhen ausgebrochen, nachdem die Anliegen der Opponenten gegen den Magistrat bereits durch Pamphlete formuliert worden waren. Forderungen betrafen z.B. die Publikation von Herrschaftsverträgen, Einblick der Öffentlichkeit in die Stadtrechnungen, das freie Versammlungsrecht der Bürger und deren erweiterte Teilhabe am politischen Leben ${ }^{83}$. Martin Wrede hat die innerreichischen publizistischen Debatten über die französischen, türkischen und schwedischen Feinde des Reiches untersucht, wobei die Gelegenheitspamphletistik als Quellengrundlage diente, während Periodika nur eine subsidiäre Rolle ausfüllten ${ }^{84}$.

79 Gestrich, Absolutismus und Öffentlichkeit, pas.

80 Aloys Winterling, Der Hof der Kurfürsten von Köln, 1688-1794. Eine Fallstudie zur Bedeutung »absolutistischer Hofhaltung«, Bonn 1986.

81 Bauer unterscheidet vier konstitutive Merkmale der höfischen Öffentlichkeit: 1. Exklusivität statt Publizität, 2. Singularität statt Periodizität, 3. Okkasionalität statt Aktualität, 4. Universalität der Mittel statt Universalität des Stoffes: Volker BAUER, Höfische Gesellschaft und höfische Öffentlichkeit im Alten Reich. Überlegungen zur Mediengeschichte des Fürstenhofs im 17. und 18. Jahrhundert, in: Jahrbuch für Kommunikationsgeschichte 5 (2003), S. 29-68, bes. S. $52-54$.

82 Esther-Beate KÖRBER, Öffentlichkeiten der frühen Neuzeit. Teilnehmer, Formen, Institutionen und Entscheidungen öffentlicher Kommunikation im Herzogtum Preußen von 1525 bis 1618, Berlin/New York 1998.

83 Andreas WÜRGLER, Unruhen und Öffentlichkeit. Städtische und ländliche Protestbewegungen im 18. Jahrhundert, Tübingen 1995.

84 Martin Wrede, Das Reich und seine Feinde. Politische Feindbilder in der reichspatriotischen Publizistik zwischen Westfälischem Frieden und Siebenjährigem Krieg, Mainz 2004. 
Inzwischen ist die Forschung in einem solchen Maße über Habermas' Positionen hinweggegangen, dass Peter Ukena seine Kritik vor dem Hintergrund eigener Forschungen zu Flugschriften und Zeitungen wie folgt formulierte:

Was Habermas über die frühen Formen der wichtigsten Kommunikationsmittel (Flugschriften, periodische Zeitungen) zu sagen weiß, ist im Faktischen falsch und daraus folgend in der Funktionsbestimmung fragwürdig, so dass der »Strukturwandel der Öffentlichkeit« auch aufgrund unzureichender Quellenkenntnis des Verfassers anfechtbar erscheint ${ }^{85}$.

Wolfgang Behringer schloss sich dieser Deutung an und formulierte: »Bereits im ersten Viertel des siebzehnten Jahrhunderts entstand eine räsonnierende Öffentlichkeit, nicht erst im 18. Jahrhundert, wie Jürgen Habermas geglaubt hat ${ }^{86}$. An anderer Stelle formulierte Behringer ausführlicher zur Frage der frühen Zeitungen und ihrer gesellschaftlichen Bedeutung:

Eine Unterdrückung des neuen Mediums war aufgrund der Zeitungsgründungswelle bereits bei Beginn des Dreißigjährigen Krieges nicht mehr möglich. Alle Ansichten, es habe sich bei den Zeitungen entweder um ein wertneutrales oder um ein politisch gesteuertes Medium gehandelt, müssen ins Reich der Legende verwiesen werden. Die Bemühungen, das Entstehen einer öffentlichen Meinung früher zu datieren, sind daher in vollem Gange ${ }^{87}$.

\section{Zur Methodologie der Studie}

Zwei Fragen stehen im Vordergrund der Überlegungen: Wie war die Öffentlichkeit beschaffen, die für den Betrachtungszeitraum untersucht werden soll? Welche Art der Herrschaftskontrolle ${ }^{88}$ konnte unter den damaligen

85 Ukena, Tagesschrifttum und Öffentlichkeit, hier S. 35f.

86 Wolfgang BeHRINGER, Nachrichten sind Geld. Ein Wundermann des Fortschritts: Johann Carolus und die Erfindung der Zeitung, in: Michael Jeismann (Hg.), Das 17. Jahrhundert. Krieg und Frieden, München 2000, S. 43-47, hier S. 43.

87 Wolfgang Behringer, »Die Welt in einen andern Model gegossen«. Das frühneuzeitliche Postwesen als Motor der Kommunikationsrevolution, in: GWU 53 (2002), H. 7/ 8, S. 424-433, hier S. 429.

88 »Herrschaftskontrolle« hat keine elaborierte begriffsgeschichtliche Tradition, sondern wird als »Kontrolle von Herrschaft» durch dem Herrscher Gleichgestellte und Untergebene verstanden. Der Begriff taucht m.W. nur in einer neueren Studie im Titel auf: Moritz Isenmann, Legalität und Herrschaftskontrolle (1200-1600). Eine vergleichende Studie zum Syndikatsprozess. Florenz, Kastilien und Valencia, Frankfurt a.M. 2010. Hier ist er bezogen auf die Prozessform des Syndikatsprozesses, durch den leitende Verwaltungsbeamte und Magistrate nach Ablauf ihrer Amtszeit hinsichtlich der Rechtsmäßigkeit ihrer Handlungen überprüft wer- 
Umständen durch die Öffentlichkeit ausgeübt werden? Das Spannungsverhältnis zwischen dem Herrschafts-Arkanum einerseits, das der Theorie und dem fürstlichen Anspruch nach die gesamte Frühneuzeit hindurch beachtet und gewahrt werden sollte - dazu dienten u.a. die »Geheimen« Räte ebenso wie das Prinzip der Amtsverschwiegenheit an Höfen und in Verwaltungen -, und der öffentlichen Verhandlung politischer Themen und Sachverhalte, später auch der Normen und Hoffnungen andererseits soll neu bestimmt werden. Zur Beantwortung dieser Fragen besteht die Studie aus zwei Hauptteilen, deren erster das frühmoderne Mediensystem näher beleuchten soll, soweit es die politische Berichterstattung betrifft, und deren zweiter fünf ausgewählte innenpolitische Konflikte anhand der publizistischen Überlieferung und Bedeutung analysiert.

Während sich das Heilige Römische Reich methodologisch durch die frühmoderne Verfassungs- und Sozialgeschichte, seit kürzerem erweitert durch die »Kulturgeschichte des Politischen«, zufriedenstellend beschreiben lässt, gilt das für die politische Publizistik in der Frühmoderne nicht. Das »mediale System der politischen Publizistik«, das im Folgenden kurz »Mediensystem « genannt werden soll, ist kein Begriff des 17. oder 18. Jahrhunderts, sondern eine historiographische Rekonstruktion. Es soll versucht werden, eine Fülle von Einzelbeobachtungen und Zusammenhängen auf eine Weise in einen größeren Kontext einzuordnen, wie er bislang noch nicht beschrieben worden ist. Dazu wird eine theoretische Anleihe in der Soziologie genommen: Die Systemtheorie, besonders in der Ausarbeitung von Talcott Parsons und Niklas Luhmann, soll den Hintergrund dafür bilden, das Mediensystem als System zu entwickeln. Es ist nicht beabsichtigt, in dieser Studie gleich noch eine Fortschreibung der Systemtheorie vorzulegen. Auch wird die Luhmann'sche Lust am Paradoxieren nicht in diese Studie übernommen, da sonst Unlesbarkeit eintreten würde oder ein längeres erkenntnistheoretisches Vorschaltkapitel erforderlich wäre ${ }^{89}$. Aber einige Grundkategorien, die für ein System konstitutiv sind, die sein Operieren und seine strukturellen Koppelungen zu anderen Systemen ausmachen, werden zur Hilfe genommen.

Die Systemtheorie hat für die hier entwickelte Fragestellung einige Vorteile. Zum einen erlaubt sie eine Synthese aller gemachten Einzelbeobachtungen. Zum anderen bietet sie Gelegenheit, gegenüber früheren Forschungs-

den konnten. Isenmann stützt sich dabei vor allem auf Vorstellungen von Max Weber zur Herrschaftskontrolle in bürokratischen Systemen: Ebd., S. 26.

Zur Problemstellung: Niklas Luhmann, Tautologie und Paradoxie in den Selbstbeschreibungen der modernen Gesellschaft, in: ZfS 16 (1987), S. 161-174. Zur Anwendung innerhalb des Wissenschaftssystems: Ders., Die Wissenschaft der Gesellschaft, Frankfurt a.M. ${ }^{2} 1994$, S. 486-493. - Einige grundlegende Überlegungen hierzu wurden bereits publiziert: Johannes ARNDT, Gab es im frühmodernen Heiligen Römischen Reich ein »Mediensystem der politischen Publizistik«? Einige systemtheoretische Überlegungen, in: Jahrbuch für Kommunikationsgeschichte 6 (2004), S. 74-102. 
interpretationen zur Mediengeschichte, die unter neomarxistischen oder anderen ideologischen Vorannahmen durchgeführt wurden, einen Gegenentwurf zu präsentieren. Zum dritten löst die Systemtheorie sich völlig von personalistischen oder empathiebeladenen Deutungen, die für den hier zu behandelnden Gegenstand wenig zielführend sind: Der leidende Autor, ein Grundmotiv der literaturwissenschaftlichen Medienforschung zum 18. und 19. Jahrhundert, muss nicht in den Mittelpunkt gerückt werden. Auch wird hinter den sichtbaren Phänomenen kein großer Marionettenspieler vermutet, der die Medien im Geheimen steuert. Zum vierten ermöglicht die Systemtheorie die Gelegenheit, die Asymmetrie zwischen Politik (=oben) und Mediensystem (= unten) etwas zu relativieren: Zwar spielt für die vormoderne Gesellschaftsformation, die sog. »stratifikatorische Gesellschaft«, die Leitdifferenz von »oben/unten« eine wichtige Rolle, doch bietet das evolutionäre Geschichtsverständnis, das in der Theorie angelegt ist, die Möglichkeit, diesen Unterschied entweder in den Hintergrund zu rücken und stattdessen von der Leitdifferenz »Information/Nichtinformation« auszugehen oder zumindest ein Abschwächen der Asymmetrie im zeitlichen Verlauf anzunehmen $^{90}$. Zum fünften bietet die zirkuläre Struktur der Systemtheorie die Möglichkeit, immer wiederkehrende Phänomene in einen sinnvollen Zusammenhang zu stellen (z.B. das periodische Erscheinen einer Zeitung jede Woche und später jeden Tag, wobei die Zeitung immer dieselbe bleibt und gleichzeitig jedesmal eine andere wird).

Niklas Luhmann hat in seinem Buch Die Realität der Massenmedien die Medienwirklichkeit der 1980er und 1990er Jahre theoretisch aufgearbeitet $^{91}$. Wichtige Beobachtungen werden hier nun daraufhin untersucht, wie sie sich vor 300 Jahren darstellten. Da der Luhmannsche Entwurf ausdrücklich eine Zeitdimension enthält, innerhalb derer sich Differenzierungsprozesse abspielen, lassen sich in umgekehrter Blickrichtung auch Phänomene zurückliegender Zeitalter dadurch interpretieren, als die Differenzierungsprozesse noch nicht so weit fortgeschritten waren.

Ein kompletter Geschichtsentwurf Luhmanns liegt nicht vor: Es gibt weder eine »Geschichte der Gesellschaft« noch ein »Systemtheorie der Historiographie«. Allerdings spielt die Zeitachse im Denken des Bielefelder Soziologen insofern eine Rolle, als Prozesse der Ausdifferenzierung Zeit in Anspruch nehmen: Unterscheidungen und immer weitere Unterscheidungen folgen aufeinander, was sich als Wandel beschreiben lassen muss. Demnach hat es in der Geschichte der Gesellschaftssysteme zunächst eine Epoche der »seg-

90 Zur Einführung vgl. »Der Geschichtsentwurf der Systemtheorie« bei Frank BECKER/Elke Reinhardt-Becker, Systemtheorie. Eine Einführung für die Geschichts- und Kulturwissenschaften, Frankfurt a.M. 2001, S. 80-90. Zur »stratifikatorischen Gesellschaft«: S. 81-85.

91 Niklas Luhmann, Die Realität der Massenmedien, Opladen ${ }^{2} 1996$. 
mentären Differenzierung« gegeben: Sie deckte sich mit der Zeit der frühen Menschheitsentwicklung bis zur Herausbildung der ersten Hochkulturen. Dabei zeichnete sie sich durch eine Gliederung der Gesellschaft in Teile aus, die prinzipiell dieselben Aufgaben der materiellen Selbstversorgung und des gemeinschaftlichen Schutzes (vor wilden Tieren, den Unbilden der Natur und vor allem vor aggressiven Artgenossen) wahrnahmen. Gesellschaft zerfiel zunächst in Familien und Clans, später nach der Sesshaftwerdung auch in Nachbarschaften und Dörfer unter Beibehaltung der Organisation als Personengruppen. Wirtschaftlicher und kultureller Austausch mit anderen Segmenten war die Ausnahme. Eine Arbeitsteilung hatte sich allenfalls innerhalb der Geschlechterrollen ausgeprägt. Die Komplexität war gering, was zur Folge hatte, dass jeder Teilnehmer noch sein Gesamtsystem überblicken konnte ${ }^{92}$.

Die anschließende Epoche, die die orientalischen Hochkulturen, die klassische Antike, das Mittelalter und die Frühe Neuzeit umfasste, war geprägt durch die »stratifikatorische Differenzierung «, worunter Luhmann den Kommunikationszusammenhang einer Ständeordnung mit sozialer und ökonomischer Arbeitsteilung versteht. Den Übergang der Formationen versteht er evolutionär und arbeitet ihn nicht markant heraus. Soziale und wirtschaftliche Rollen hatten sich ausgeprägt in Priester, Adlige/Krieger, Schriftgelehrte, Bauern und schließlich auch in Stadtbewohner einerseits, in unterschiedliche Berufsgruppen andererseits. Gesellschaft wurde fortan durch ungleiche, nicht mehr durch gleiche Teilsysteme konstituiert. Die herrschende soziale Ungleichheit durchzog alle Kommunikationen dergestalt, dass es nicht darauf ankam, was gesagt wurde, sondern wer was sagte ${ }^{93}$. Konflikte entstanden daher sowohl aus sachlichen Gründen als auch um Rangfragen. Die Klärung der Rangfolge präfigurierte oft anschließend zu treffende sachliche Entscheidungen, ein Aspekt, der im Rahmen der jüngeren Forschung zur symbolischen Kommunikation in der Vormoderne unter kulturalistischer Perspektive untersucht wird: Die Interpretationen korrespondieren weitgehend mit dem systemtheoretischen Grundkonzept, ohne dass dieses die Ausgangsposition für die Untersuchungen gewesen ist ${ }^{94}$.

92 Niklas Luhmann, Die Gesellschaft der Gesellschaft, 2 Teilbd., Frankfurt a.M. 1997, hier Bd. 2, S. 634-663.

93 Luhmann, Die Gesellschaft der Gesellschaft, Bd. 2, S. 678-707 (»Stratifizierte Gesellschaften«) u. 707-743 (»Ausdifferenzierung von Funktionssystemen« mit Überlegungen zur Übergangsepoche der Frühen Neuzeit). - Vgl. dazu: Becker/Reinhardt-Becker, Systemtheorie, S. 81-85.

94 Die zeremoniellen Formen der sozialen Differenzierung im Reich wurden im Rahmen des Sonderforschungsbereichs 496 (»Symbolische Kommunikation und gesellschaftliche Wertesysteme vom Mittelalter bis zur Französischen Revolution«) in Münster erforscht: Gerd ALTHOFF/Ludwig SIEP, Symbolische Kommunikation und gesellschaftliche Wertesysteme vom Mittelalter bis zur Französischen Revolution, in: Jahrbuch für Kommunikationsgeschichte 3 
Zusätzliche Stabilität gewannen die meisten stratifikatorischen Gesellschaften dadurch, dass sie ihre Ordnung durch religiöse Gesamtentwürfe verdoppelten: Die weltliche Königsherrschaft war der himmlischen Königsherrschaft Gottes nachgeformt (für Agnostiker: die göttliche Herrschaft wurde der weltlichen Herrschaft nachkonstruiert). Das zementierte die soziale Differenzierung, bot aber gleichzeitig die Ventilfunktion, dass ausnahmslos jedes Mitglied der Gesellschaft heilsfähig war. Für die Einhaltung der Regeln, für das Verbleiben im eigenen Stand und die Erfüllung der Pflichten wurde nicht nur irdischer Schutz vor Konsequenzen angeboten, sondern auch himmlischer Lohn ${ }^{95}$.

Durch zunehmende Differenzierung entwickelte sich aus der stratifikatorischen schließlich die moderne Gesellschaft, die Luhmann die »funktional differenzierte Gesellschaft « nennt ${ }^{96}$. Die Gesellschaft arbeitet weltweit arbeitsteilig, und alle Systeme gelten als gleichrangig, während die alten ständischen Unterschiede, also die Differenz von »oben/unten«, verschwunden sind. Die Persönlichkeit der Individuen, die nun »psychische Systeme« heißen, differenziert sich ebenfalls immer weiter aus, was derartige theoretische Probleme aufwirft, dass Luhmann die Personen aus seinen Kommunikationssystemen in die Umwelt verbannt (von wo aus sie weiterhin kommunizieren bzw. beobachten, allerdings als Rollenträger in struktureller Koppelung zu verschiedenen Systemen). Dass der fortdauernde ökonomische Unterschied »reich/arm« auch einen sozialen Unterschied »oben/unten« konstituiert, wird bei Luhmann nicht in den Vordergrund gerückt. Für die Reichsgeschichte ist bedeutsam, dass Luhmann die Epoche der Frühen Neuzeit als Zeit des Übergangs sieht, in der die stratifikatorische Gesellschaftsformation

(2001), S. 210-230. Vg1. zum frühneuzeitlichen Zeitabschnitt: Barbara StollBerg-Rilinger, Zeremoniell als politisches Verfahren. Rangordnung und Rangstreit als Strukturmerkmale des frühneuzeitlichen Reichstags, in: Johannes KunISCH (Hg.), Neue Studien zur frühneuzeitlichen Reichsgeschichte, Berlin 1997, S. 91-132; Barbara Stollberg-Rilinger, Zeremoniell, Ritual, Symbol. Neue Forschungen zur symbolischen Kommunikation in Spätmittelalter und Früher Neuzeit, in: ZHF 27 (2000), S. 388-405; dies. (Hg.), Vormoderne politische Verfahren, Berlin 2001; dies., Die zeremonielle Inszenierung des Reiches, oder: Was leistet der kulturalistische Ansatz für die Reichsverfassungsgeschichte?, in: Matthias Schnettger (Hg.), Imperium Romanum - Irregulare Corpus - Teutscher Reichs-Staat. Das Alte Reich im Verständnis der Zeitgenossen und der Historiographie, Mainz 2002, S. 233-246. - Zum Zeremoniell aus literaturwissenschaftlicher und rechtshistorischer Perspektive: Jörg Jochen BERns (Hg.), Zeremoniell als höfische Ästhetik im Europa des 15. bis 18. Jahrhunderts, Tübingen 1995; Miloš VEC, Zeremoniellwissenschaft im Fürstenstaat. Studien zur juristischen und politischen Theorie absolutistischer Herrschaftsrepräsentation, Frankfurt a.M. 1998.

95 Auf diese Doppelung weist Frank Becker ausdrücklich hin: Becker/Reinhardt-Becker, Systemtheorie, S. 83. Vgl. Luhmanns Entwurf zur Religion: Niklas Luhmann, Funktion der Religion, Frankfurt a.M. 1977 (ND 1996).

96 Zur »funktional-differenzierten Gesellschaft«: BECKER/REINHARDT-BECKER, Systemtheorie, S. 85-90. 
langsam verblasst und durch den gesellschaftlichen Differenzierungsdruck in die funktional-differenzierte Formation überführt wird. Wieder wird ein evolutionärer Übergang angenommen, der sich über drei Jahrhunderte oder ggf. noch etwas länger hingezogen haben mag, je nach Systembereich.

Zudem gibt es die systemtheoretischen Aussagen zum politischen System, die sich auch auf das frühmoderne Politikprozessieren anwenden lassen ${ }^{97}$. Allerdings ist nicht beabsichtigt, das Reichssystem komplett zu »luhmannisieren «: Zum einen steht für diese Studie das Kommunikationssystem auf der Reichsebene im Mittelpunkt, und das umfasste nicht den gesamten Politikbereich innerhalb des Alten Reiches. Eine systemtheoretische Analyse der Reichspolitik müsste die Politik in und zwischen den Territorien ebenfalls einbeziehen. Dies kann und soll hier nicht geleistet werden, sondern es werden für das Reichssystem nur einige begriffliche Adaptionen vorgenommen, die eine »strukturelle Koppelung « mit dem Mediensystem erlauben.

Auch das Mediensystem der Frühmoderne soll - mit Schwerpunkt auf dem 17. und frühen 18. Jahrhundert - unter systemtheoretischer Perspektive aufgefasst werden. Es ist nicht beabsichtigt, ein Nebeneinander der Einzelkomponenten der bunten Medienwelt (Autor, Verleger, Drucker, Leser, etc.) zu präsentieren, sondern die Verdeutlichung der Dynamik, mit der das System sich selbst konstituierte und immer wieder erneuern konnte. Erst durch das Augenmerk auf diese fortdauernde Dynamik wird begreiflich, an welchen Stellen das System sich fortentwickeln und auf kurzfristige Einwirkungen von außen adäquat reagieren konnte. Auch ohne eine neue materialistische Deutung aufzuwerfen, ist es hilfreich, zunächst die ökonomische Seite des Systems zu betonen ${ }^{98}$. Um es vereinfachend zu formulieren: Die Beteiligten am medialen System waren in erster Linie Kaufleute, die mit dem immateriellen Gut »Nachrichten« handelten. Ihre Güter hatten mit Obst und Gemüse gemeinsam, dass sie verderben konnten: Geschwindigkeit war erforderlich, um sie an den Endverbraucher zu bringen, bevor ihr Wertverfall einsetzte. Eine Nachricht war dann überholt, wenn sie bereits bekannt war: Wer als erster eine »Neuigkeit« brachte, konnte dafür Geld verlangen; käme dann

97 Niklas Luhmann, Macht, Stuttgart 1975 ( $\left.{ }^{2} 1988\right)$; ders., Staat und Staatsräson im Übergang von traditionaler Herrschaft zu moderner Politik, in: Ders., Gesellschaftsstruktur und Semantik, Bd. 3, Frankfurt a.M. 1989, S. 65-148; ders., Die Politik der Gesellschaft, hg. v. André KiEserLING, Frankfurt a.M. 2000.

98 Die ältere Studie von Helmuth Kiesel und Paul Münch änderte nichts an der verbreiteten Neigung, die Frage nach der ökonomischen Bedeutung des Mediensystems als Randfrage zu behandeln: Kiesel/MüNCH, Gesellschaft und Literatur im 18. Jahrhundert, pas. - Neuerdings misst das Kap. »Der Literaturbetrieb als Markt« in Werner Faulstichs neuester Studie zur Mediengesellschaft des 18. Jahrhunderts diesem Phänomen den gebotenen Stellenwert bei: Werner Faulstich, Die bürgerliche Mediengesellschaft (1700-1830), Göttingen 2002, S. 177-224. 
noch ein zweiter Bote mit demselben Inhalt, »so würde er ein schlechtes Trinkgelt von seiner Nachricht zu gewarten haben $\ll^{99}$.

Das Mediensystem lässt sich vor diesem Hintergrund als ein autopoietisches Kommunikationssystem beschreiben, das den Luhmannschen Anforderungen an Systeme entspricht. Es ist dies im doppelten Sinn: Zum einen ist es das Trägersystem zentraler Kommunikationsprozesse in der Gesellschaft und für sie. Zum anderen weist es eine eigene Kommunikation auf, die seine Existenz und Funktionsfähigkeit gewährleistet. In beiderlei Hinsicht reproduziert das System seine eigenen Bestandteile immer wieder neu. Zunächst ist das Mediensystem nicht zu sehen als Teil einer Hierarchie, sondern als ein Teilsystem der frühmodernen Gesellschaft, das sich gleichrangig neben zahlreichen anderen Teilsystemen befindet. Ein Teilsystem der Streitkräfte oder der Nahrungsmittelproduzenten wäre auf dieselbe Weise beschreib$\operatorname{bar}^{100}$. In dieser Hinsicht entwickelte das Mediensystem eine eigene Dynamik und auch Logik, die sich der direkten Einwirkung durch einzelne Personen wie auch durch andere Systeme zu entziehen suchte.

Diese innere Dynamik lässt sich erkennen, wenn man den Nachrichtendurchlauf als Prozess verfolgt. Als Voraussetzung diente ein Ereignis, das zur Nachricht erst durch die Vertextung wurde. Dabei war es bedeutsamer, dass der Text überhaupt ins Mediensystem eingespeist wurde, als von wem er stammte. Durch Weitergabe per Brief, Kurier oder Post wurde eine Nachricht zunächst mit anderen Nachrichten akkumuliert, dann sortiert und schließlich distribuiert. Hier galt die Regel, dass Nachrichten, die einen hohen Nachrichtenwert im Sinn der Systemlogik des Mediensystems besaßen, honorierungsfähig waren. Diese praktische Bedeutung stand den Mitwirkenden stets vor Augen. Die theoretische Ausarbeitung des Begriffs »Nachrichtenwert« wurde allerdings erst in der Habilitationsschrift von Jürgen Wilke vorgelegt $^{101}$. Von der honorierungsfähigen Nachricht unterschied sich die lancierte Nachricht, die in erster Linie systemfremden Interessen dienen sollte und daher nicht honoriert wurde.

99 Auf den Aspekt der Leichtverderblichkeit und damit auf die notwendige Geschwindigkeit in der Nachrichtenverarbeitung verweist bereits Kaspar StIELER, Zeitungs Lust und Nutz. Vollständiger ND der Originalausgabe von 1695, hg. v. Gert Hagelweide, Bremen 1969, bes. S. 47f. u. $113 \mathrm{f}$.

100 Die Systemtheorie wurde - aufbauend auf dem amerikanischen Soziologen Talcott Parsons in einem Zyklus von Studien von Niklas Luhmann entwickelt; Ausgangslage und theoretische Vollendung finden sich in zwei Werken: Niklas Lummann, Soziale Systeme. Grundriß einer allgemeinen Theorie, Frankfurt a.M. 1984 ( $\left.{ }^{2} 1987\right)$; ders., Die Gesellschaft der Gesellschaft, 2 Bd., Frankfurt a.M. 1997.

101 Jürgen WiLke, Nachrichtenauswahl und Medienrealität in vier Jahrhunderten. Eine Modellstudie zur Verbindung von historischer und empirischer Publizistikwissenschaft, Berlin/New York 1984. 
Im Zuge der Erforschung der Mediengeschichte wurde die Frage aufgeworfen, wer die Träger der Verbreitung von Nachrichten waren: Buchdrucker? Buchhändler? Verleger? Postmeister? Die Auswertung der Quellen lässt hier keinen zufriedenstellenden terminologischen Befund zu, denn zu viele der Beteiligten übten gleichzeitig mehrere Beschäftigungen aus, die heute zu verschiedenen Berufsbildern gerechnet würden. Zum einen war die Grenze Drucker-Verleger-Buchhändler fließend. Zum anderen konnte jedermann, der sich im Nachrichtenhandel betätigte, problemlos fremde Expertisen hinzukaufen. So ließen Buchhändler wie Postmeister sowohl Beauftragte Nachrichten sammeln als auch Lohndruck herstellen oder korrigieren. Zum dritten sammelten sich im Mediensystem Personen, die keinen geraden Karriereweg zurückgelegt hatten. Besonders ausgebildete Theologen und Juristen ohne Festanstellung brachten ihre Fähigkeiten im Umgang mit Texten in das System ein. Dies ist in der Forschung auch erkannt worden, doch wurden diese Personen als »Gelehrte« oder »Intellektuelle« zumeist individualisiert, während das dahinterstehende System der Medienproduktion nicht weiter reflektiert wurde ${ }^{102}$. Als Beispiel mag hier Daniel Hartnack dienen. Er war nach seinem Theologiestudium an unterschiedlichen Orten als Lehrer tätig, ließ sich aber mehrfach auf fachliche und religiöse Kontroversen mit Kollegen, externen Widersachern und selbst Vorgesetzten ein, was zu einigen erzwungenen Stellenwechseln führte. Hartnack gab neben mehreren selbstständigen Schriften die in Hamburg erschienene Zeitung Relation aus dem Parnasso heraus ${ }^{103}$.

Neben der großen Vielfalt der Autoren und Herausgeber sind für den Vertrieb von Schriften und Periodika hauptsächlich zwei Varianten erkennbar: über die Buchverleger und über die Postmeister. Es gehörte zu den Privilegien der Postmeister, dass sie kostenfrei im Logistiksystem der gesamten Reichspost Sendungen verschicken konnten. Postmeister wirtschafteten auf eigene Rechnung, mussten sich aber an vorgegebene Zeiten, Formate, Stan-

102 »Gelehrte« heißen sie zumeist in der germanistischen Forschung. Zu den Gelehrten und ihrer »Republik«: Wilhelm KüHLManN, Gelehrtenrepublik und Fürstenstaat. Entwicklung und Kritik des deutschen Späthumanismus in der Literatur des Barockzeitalters, Tübingen 1982; Helmut Zedelmaier/Martin Mulsow (Hg.), Die Praktiken der Gelehrsamkeit in der frühen Neuzeit, Tübingen 2001. - Der Begriff »Intellektueller« oder »Intelligenz« wurde zum thematischen Gegenstand der älteren Studie von Hans GerTH, Bürgerliche Intelligenz um 1800. Zur Soziologie des deutschen Frühliberalismus, Göttingen 1935 (21976). Neuere Annäherungen an Begriff und Phänomen: Jutta Held (Hg.), Intellektuelle in der Frühen Neuzeit, München 2002; Luise Schorn-Schütte (Hg.), Intellektuelle in der Frühen Neuzeit, Berlin 2011. Als Merkmale intellektuellen Wirkens sieht Luise Schorn-Schütte die Netzwerkbildung in potenzieller Distanz zur traditionalen Ordnungen, die Schaffung neuer Kommunikationskanäle sowie die Absicht, mit den eigenen Meinungen in die Gesellschaft hinein wirken zu wollen: Ebd., S. 9.

103 Johannes Weber, Daniel Hartnack. Ein gelehrter Streithahn und Avisenschreiber am Ende des 17. Jahrhundert. Zum Beginn politisch-kommentierender Zeitungspresse, in: GutJb 1993, S. 140-158. Zu Biographie und Wirken siehe in dieser Studie S. 151f. 
dards und Preise halten ${ }^{104}$. Sie waren in der Regel auf Lohndrucker angewiesen, wenn sie nicht direkt verschiedene Formen der Kooperation mit Verlegern suchten. Wie der dezentralisierte Nachrichtenverkehr in den großen Pressestädten des Reiches verlief, hat der Zeitungskritiker Paul Jacob Marperger 1726 erläutert. Am Beispiel von Hamburg wies er auf sog. »AvisenBuden « oder »Avisen-Boutiquen« hin, in denen Zeitungsverleger, Zeitungsverkäufer, Nachrichtenhändler und Kunden zusammentrafen. Hier wurden sowohl Zeitungen gehandelt (per Abonnement) oder gegen Gebühr vor Ort gelesen als auch neue Informationen eingebracht, z.B. durch Kaufleute, die ihre Neuigkeiten erzählten, die sie auf dem Korrespondenzwege erfahren hatten ${ }^{105}$.

Die Leserschaft lässt sich in drei Gruppen teilen: Die Gebildeten stellten die Hauptgruppe des bisherigen Forschungsinteresses dar. Daneben sind allerdings die Fürsten und ihre Höfe zu beachten, ferner der »gemeine Mann«. Der Preußenkönig Friedrich Wilhelm I. ist derjenige Fürst im 18. Jahrhundert, bei dem Medienkritik und Medienrezeption am besten dokumentiert sind. Zwar war der König eigentlich ein Gegner einer freien Berichterstattung, die seinem Staatsverständnis zuwiderlief. Den Avisenschreiber Johann Hermann Ortgies ließ er - nach dessen jahrelanger Tätigkeit als professioneller Nachrichtenlieferant - 1735 durch seine Sicherheitsorgane inhaftieren und verwies ihn aus allen preußischen Landen ${ }^{106}$. Doch duldete er, dass Residenten anderer Fürsten - wie der Braunschweiger Wilhelm Stratemann nicht nur an ihren Hof berichteten, sondern Kopien auch an andere Höfe versandten bzw. verkauften ${ }^{107}$. Der König selbst bezog viele Zeitungen; sie lagen beim allabendlichen Tabakskollegium auf dem Tisch ${ }^{108}$. Der mündliche Vortrag aus den Zeitungen wurde als Aufgabe an einen »Zeitungsvorleser« ver-

104 Vgl. zu den Betriebsabläufen bei der Post: Martin Dallmeier (Hg.), 500 Jahre Post. Thurn und Taxis. Ausstellung anläßlich der 500jährigen Wiederkehr der Anfänge der Post in Mitteleuropa 1490-1990. Fürstliches Marstallmuseum Regensburg, Regensburg 1990; Wolfgang Behringer, Thurn und Taxis. Die Geschichte ihrer Post und ihrer Unternehmen, München/Zürich 1990.

105 Paul Jacob Marperger, Anleitung zum rechten Verstand und nutzbarer Lesung Allerhand sowohl gedruckter als geschriebener [...] Ordentlicher und Außerordentlicher Zeitungen oder Avisen, o.O. 1726, hier S. 21.

106 Zur Nachrichten-Diensttätigkeit Ortgies': Ernst FriedlaEnder (Hg.), Berliner geschriebene Zeitungen: Aus den Jahren 1713 bis 1717 und 1735. Ein Beitrag zur preußischen Geschichte unter König Friedrich Wilhelm I., Berlin 1902, bes. S. XIV-XVII.

107 Die Stratemann-Berichte für den Zeitraum 1728-1732 hat Richard Wolff herausgegeben: Richard Wolff (Hg.), Vom Berliner Hofe zur Zeit Friedrich Wilhelms I. Berichte des Braunschweigischen Gesandten in Berlin, 1728-1733, Berlin 1914.

108 Schon David Fassmann hatte in seiner Biographie des Königs darauf hingewiesen: David Fassmann, Leben und Thaten des Allerdurchlauchtigsten und Großmächtigsten Koenigs von Preussen Friderici Wilhelmi Biss auf gegenwertige Zeit aufrichtig beschrieben [...], Hamburg/Breslau 1735, S. 1044. Friedrich Förster bestätigt diese Mitteilung: Französische, niederländische und deutsche Zeitungen aus Hamburg, Frankfurt, Breslau, Leipzig und Wien 
geben, ein Amt, zu dem der König bevorzugt Historiker verpflichtete. Diese durften auf Anordnung auch gleich ihre politisch-historischen Kommentare abgeben. Es gehört zu den dramatischen Seiten dieses Herrschers, dass die gebildeten Zeitungsvorleser für ihn zugleich die Rolle des IntellektuellenHofnarren spielen mussten. Prominenteste Inhaber dieser Rolle waren der Historiker Jacob Paul Gundling, der erst kürzlich in einer Biographie von Martin Sabrow gewürdigt wurde, sowie der Herausgeber der Gespräche im Reiche der Todten, David Fassmann ${ }^{109}$.

Die letzte Stelle im System des Nachrichtendurchlaufs war der »gemeine Mann«, der Handwerker auf der Straße oder der Bauer in der Schänke. Nur weil es eine Kundschaft gab, die bereit war, für Neuigkeiten in schriftlicher Form Geld zu bezahlen, konnte es auch ein Mediensystem geben. Die Neugier als Triebfeder des Systems haben übrigens die sog. »Zeitungskritiker«, die Teilnehmer an einer Debatte im ausgehenden 17. Jahrhundert ${ }^{110}$, sehr klar hervorgehoben: Während der lutherische Theologe Ahasver Fritsch (16291701) die Neugier als Laster verurteilte, hielt sie der Sprachwissenschaftler und Medienkritiker Kaspar Stieler (1632-1707) für eine nützliche Grundeigenschaft, der Gesellschaft und Staat Rechnung tragen sollten ${ }^{111}$. In diesem Sinn befürwortete Stieler, dass das Zeitungswesen »Lust und Nutz« gleichermaßen vermitteln wollte, Unterhaltung und Information, heute modern »Infotainment « genannt ${ }^{112}$. Ein Mangel an Lesefähigkeit, wie früher ange-

seien laufend gehalten worden: Friedrich Förster, Friedrich Wilhelm I., König von Preußen, 3 Bd., Potsdam 1834-1835, hier Bd. 1, S. 249.

109 Zur Biographie von Jacob Paul Gundling: Martin SABrow, Herr und Hanswurst. Das tragische Schicksal des Hofgelehrten Jacob Paul von Gundling, Stuttgart/München 2001. - Zu Fassmann: Ludwig LindenBerg, Leben und Schriften David Fassmanns (1683-1744) mit besonderer Berücksichtigung seiner Totengespräche, Diss. Berlin 1937; zu seiner vorgesehenen Rolle und seiner Flucht vgl. verschiedene »Berichte aus Berlin« vom Frühjahr 1731: WoLfF, Vom Berliner Hofe, S. 228-230 u. 240-242.

110 Vgl. zur »Zeitungsdebatte« die Editionen: Karl KuRTh (Hg.), Die ältesten Schriften für und wider die Zeitung, Brünn u.a. 1944; Elger BlüHm/Rolf Engelsing (Hg.), Die Zeitung. Deutsche Urteile und Dokumente von den Anfängen bis zur Gegenwart, Bremen 1967. Zur Bewertung der Debatte: Jens Gieseler, Vom Nutzen und richtigen Gebrauch der frühen Zeitungen. Zur sogenannten Pressedebatte des 17. Jahrhunderts, in: Gerd Fritz/Erich Strassner (Hg.), Die Sprache der ersten deutschen Wochenzeitungen im 17. Jahrhundert, Tübingen 1996, S. 259-285; Hedwig Pompe, Die Neuheit der Neuheit. Der Zeitungsdiskurs im späten 17. Jahrhundert, in: Albert Kümmel/Leander Scholz/Eckhard Schumacher (Hg.), Einführung in die Geschichte der Medien, Paderborn 2004, S. 35-63.

111 Fritsch beginnt sein erstes Kap. mit der Neugier unter der Überschrift »De curiositate hominum in audiendis \& recensendis Novellis«: Ahasver Fritsch, Discursus de Novellarum, quae vocant Neue Zeitunge/hodierno usu et abusu, o.O. 1676. Kaspar Stieler macht gute oder schlechte Qualität der Neugier von den Umständen abhängig: STIELER, Zeitungs Lust und Nutz (1695/1969), S. 8-12.

112 Die Formel »Lust und Nutz« nahm Stieler folgerichtig in seinen Titel auf: STIELER, Zeitungs Lust und Nutz. - Den Begriff »Infotainment« im mediengeschichtlichen Zusammenhang verwendet auch Elke MAAR, Bildung durch Unterhaltung. Die Entdeckung des Infotainment 
nommen, war übrigens kein Hindernis für die periodischen Druckmedien, sich auszubreiten: Selbst wenn die Zahl der Zeitungsrezipienten im Laufe des 18. Jahrhunderts von ca. 250.000 auf ca. 3 Millionen stieg und damit nicht die Hälfte der deutschen Bevölkerung ausmachte, so erreichten die Druckmedien immerhin den städtischen Bereich (20\% der Einwohnerschaft) fast vollständig. Die Zeitungs- und Unterhaltungslektüre durch Handwerker und häusliches Dienstpersonal ist für das 18. Jahrhundert vielfach bezeugt ${ }^{113}$.

Das Mediensystem reproduzierte sich im Sinn der Systemtheorie selbst. Aus der ständigen Aktualisierung von Nachrichtenerwerb, Weiterleitung und Verteilung an den Kunden erfuhren die Medienproduzenten, ob ihr Produkt vom Markt angenommen wurde. Stockte der Verkauf, dann stimmte etwas am Produkt nicht. Stieg dagegen die Auflage, bestärkte dies die Richtungsentscheidung der Hersteller. Die quantitative Rezeption durch das zahlende Publikum war viel wichtiger als die Ansicht, die die kontrollierende Obrigkeit äußerte. Letztere wurde eigentlich nur als Nachrichtenlieferant und als Kunde gebraucht: Das System an sich funktionierte auch ohne herrschaftliche Steuerung. Der Modus der ständigen Rückkopplung zwischen Produktgestaltung und Kundenrezeption durch den Kaufakt sicherte eine fortlaufende Anpassung an eventuelle Änderungen des Käufergeschmacks. Erleichtert wurde die Entwicklung durch kontinuierliche Wachstumstendenzen des Gesamtmarktes, was für alle Arten von Druckmedien während des späten 17. und des 18. Jahrhunderts galt ${ }^{114}$.

Politisches System und Mediensystem berührten sich durch strukturelle Koppelungen. Dabei wird von einer wechselseitigen Beeinflussung ausgegangen: Eine völlige Steuerung der Medien durch die Politik darf als obsolet gelten, ebenso eine durchgängige Manipulation der politisch Handelnden durch die ihnen übergeordneten religiösen Deutungs- und sozialen Disziplinierungsmuster. Vielmehr folgten beide Systeme und die in ihnen handelnden und sie tragenden Personen der Logik ihres jeweiligen Systems: Die Herrschaftspersonen bedurften der ständigen Informationszufuhr von außen. Natürlich besaß ein Herrscher wie König Friedrich Wilhelm I. weit-

in der Aufklärung. Hallenser und Wiener Moralische Wochenschriften in der Blütezeit des Moraljournalismus, 1748-1782, Pfaffenweiler 1995.

113 Zur Leseforschung: Rolf Engelsing, Die Perioden der Lesergeschichte in der Neuzeit. Das statistische Ausmaß und die soziokulturelle Bedeutung der Lektüre, in: AGB 10 (1970), Sp. 9451002; ders., Der Bürger als Leser. Lesergeschichte in Deutschland 1500-1800, Stuttgart 1974; Martin WelKe, Die Legende vom »unpolitischen Deutschen«. Zeitungslesen im 18. Jahrhundert als Spiegel des politischen Interesses, in: Jahrbuch der Wittheit zu Bremen 25 (1981), S. 161-188, bes. S. 163f.; vgl. zum aktuellen Forschungsstand: Helmut Zedelmaier, Lesetechniken. Die Praktiken der Lektüre in der Neuzeit, in: Zedelmaier/Mulsow, Die Praktiken der Gelehrsamkeit in der frühen Neuzeit, S. 11-30.

114 Dies bestätigt Werner Faulstich in seinen Ausführungen zu Verlagswesen und Buchhandel im 18. Jahrhundert: FAULSTICH, Die bürgerliche Mediengesellschaft, S. 190-206. 
aus mehr Informationsquellen als sein gewöhnlicher Untertan, doch profitierte er - und sein Tabakskollegium - nicht nur von Agentenberichten, sondern eben auch vom ständig reproduzierten Nachrichtenstrom der kommerziellen Medien. Die strukturelle Koppelung zeigt sich besonders dort, wo eine Person oder ein Schriftstück eine Rolle in beiden Systemen spielen kann - wenn auch nicht dieselbe. Am Beispiel der Flugschrift Pflicht $=m a ̈ s-$ siger Bericht von dem Secreto comitiali aus dem Jahre 1713 zeigte sich, dass ein fiktiver Brief eben nicht einen Reichsstand informieren sollte. Vielmehr stellte der Brief eine öffentliche Satire auf einen politischen Missstand dar, den flagranten Geheimnisverrat durch subalterne Bedienstete der Reichstagsgesandten an die Presse ${ }^{115}$.

Andererseits unterlagen Medien der herrschaftlichen Zensur. Zensur stellt ein intensiv bearbeitetes Feld der Buchdruck-, Publizistik- und Mediengeschichtsschreibung dar. Vorherrschend war lange die Perhorreszierung der Zensur: Der »arme Poet« der Literaturwissenschaft stand als Opfer dem mächtigen Staat gegenüber ${ }^{116}$. Als typischer Protagonist wird der schwäbische Dichter und Publizist Christian Friedrich Daniel Schubart (1739-1791) angeführt, der wegen seiner Kritiken an der aufgeklärt-absolutistischen Territorialherrschaft im Allgemeinen und an Herzog Carl Eugen von Württemberg im Speziellen zehn Jahre lang auf dem Hohenasperg einsa $\beta^{117}$. Die Studien im Rahmen dieses Projekts ergeben ein anderes Bild: Zensur war ein Teil des öffentlichen Lebens. Wenn Staatlichkeit bedeutet, dass eine rationale Herrschaftsordnung im Sinn Max Webers zur Regelung aller Lebensbereiche berechtigt ist, dann gehört dazu eben auch der Bereich des öffentlich geschriebenen oder gesprochenen Wortes. Zensur in der Frühen Neuzeit war ein System der verhältnismäßig milden Kontrolle: Bestimmte Bereiche waren der kritischen Berichterstattung und Kommentierung entzogen, vor allem die Bereiche der Religion, der Ehre des Herrschers ${ }^{118}$ (die auswärtige

$115 » P$ Plicht=mässiger Bericht Von dem Secreto Comitiali«, o.O. $1713\left(8^{\circ}, 12\right.$ S.). Interpretation: Johannes ARNDT, »Pflicht=mässiger Bericht $\ll$. Ein medialer Angriff auf die Geheimnisse des Reichstags aus dem Jahr 1713, in: Jahrbuch für Kommunikationsgeschichte 4 (2002), S. 1-31.

116 Zur Frage der Zensur aus literaturwissenschaftlicher Sicht: Dieter BReuer, Geschichte der literarische Zensur in Deutschland, Heidelberg 1982; RaABE, Der Zensur zum Trotz, pas. Demgegenüber betonen jüngere Studien die stets begrenzte Reichweite von Zensur in der Frühmoderne: Stephan Fitos, Zensur als Mißerfolg. Die Verbreitung indizierter deutscher Druckschriften in der zweiten Hälfte des 16. Jahrhunderts, Frankfurt a.M. u.a. 2000; Edoardo Tortarolo, Zensur als Institution und Praxis im Europa der Frühen Neuzeit. Ein Überblick, in: Zedelmaier / Mulsow, Die Praktiken der Gelehrsamkeit in der frühen Neuzeit, S. 277-294.

117 Typisch für diesen Interpretationsplot: Wilfried F. Schoeller, Schubart. Leben und Meinungen eines schwäbischen Rebellen, den die Rache seines Fürsten auf den Asperg brachte. Mit einer Auswahl seiner Schriften, Berlin 1979. Vgl. demgegenüber die sachliche Studie von Bernd J. WARnEKEN, Schubart. Der unbürgerliche Bürger, Frankfurt a.M. 2009.

118 Vgl. dazu Wolfgang WeBer, Honor, fama, gloria. Wahrnehmungen und Funktionszusammenhänge der Ehre in der Herrschaftslehre des 17. Jahrhunderts, in: Sibylle BaCKMANN u.a. (Hg.), 
Herrscher einschloss) sowie der »guten Sitten«, was immer jedes Zeitalter darunter verstand. Für Zeitungen kam hinzu, dass sie nicht über die Stadt berichteten, in der der Verleger oder Produzent seinen Hauptsitz hatte. Diese Zensur besaß im Übrigen eine breite Zustimmung unter den Medienproduzenten: Auch sie profitierten von »Ordnung« im abstrakten Sinn, auch wenn für sie der Ordnungsaspekt am ehesten greifbar wurde, wenn es um den eigenen Schutz vor störenden Nachdruckern durch die rechtssetzende und -schützende Staatsgewalt ging ${ }^{119}$. Sicherlich gab es Grauzonen, in denen ein Medienproduzent ein persönliches Risiko einging, aber normalerweise wusste er, was er durfte und was nicht. Strafen wegen Zensurverstößen sind daher oft relativ milde gewesen. Zensurgeschichte kann nicht mehr anhand von Zensuredikten geschrieben werden. Diese herrscherlichen Willensbekundungen wurden mitunter jahrhundertelang systematisch ignoriert, z.B. wurde die Impressumspflicht im Reich und außerhalb nur bei Büchern, nicht aber bei Zeitschriften, Zeitungen oder Flugschriften erfüllt. Dass dies selbst bei Periodika beobachtbar ist, die von der Politik mühelos zu normenkonformem Verhalten hätten veranlasst werden können, kennzeichnet die Situation vor $1789^{120}$.

Im zweiten Hauptteil sollen die Aussagen zur Funktionsweise des Mediensystems in fünf Fallstudien exemplifiziert werden. Fallstudien werden methodisch gern verwendet, wenn ein Untersuchungsgegenstand zu groß ist, um ihn in Gänze empirisch zu bearbeiten. Fallstudien stellen Hybride dar aus dem erzählten Einzelfall und seiner allgemeinen Bedeutung. Mindestens der zweite Teilbereich ist dabei eine interpretatorische Konstruktion. Der typische Charakter der ausgewählten Beispiele wird normalerweise postuliert, ohne völlig bewiesen werden zu können, weil das wieder die Bearbeitung des Gesamtgegenstandes voraussetzen würde. Johannes Süßmann, Susanne Scholz und Gisela Engel haben kürzlich die theoretische Problematik der Arbeit mit Fallstudien im Rahmen einer Tagung verhandeln lassen und anschließend die Erträge publiziert ${ }^{121}$.

Ehrkonzepte in der Frühen Neuzeit. Identitäten und Abgrenzungen, Berlin 1998, S. 70-98, hier S. 71.

119 Nachdruckproblematik: Reinhard Wittmann, Geschichte des deutschen Buchhandels. Ein Überblick, München 1991, bes. S. 120-125; ders., Der gerechtfertigte Nachdrucker, in: Giles BARBER/Bernhard FABIAN (Hg.), Buch und Buchhandel in Europa im 18. Jahrhundert, Hamburg 1981, S. 293-320; FAulstich, Die bürgerliche Mediengesellschaft, S. 202f.

120 Diese Sicht der milden Zensurpraxis vor 1789 im Gegensatz zur viel schärferen Zensur während der napoleonischen Fremdherrschaft und des Vormärz wird inzwischen breit vertreten und gelangt in literaturgeschichtlichen Handbüchern an: Wilhelm HaEFs/York-Gothart Mix (Hg.), Zensur im Jahrhundert der Aufklärung. Geschichte - Theorie - Praxis, Göttingen 2007; Volker MEID, Die deutsche Literatur im Zeitalter des Barock. Vom Späthumanismus zur Frühaufklärung, München 2009, S. 49-51.

121 Johannes Süssmann/Susanne Scholz/Gisela Engel (Hg.), Fallstudien. Theorie, Geschichte, Methoden, Berlin 2007. 
Die folgenden innenpolitischen Konflikte sind in dieser Studie untersucht worden:

1. Der Streit um das Reichsvikariat zwischen Kurbayern und Kurpfalz. Dabei handelte es sich um einen Verfassungskonflikt: Nach der Übertragung der Kurwürde von Kurpfalz an Kurbayern im Dreißigjährigen Krieg und der Schaffung der »achten« Kurwürde 1648 war strittig, welche der beiden Wittelsbacherlinien das früher pfälzische Vikariat auszuüben hatte. Erstmals wurde der Streit 1657/58 nach dem Tod Kaiser Ferdinands III. ausgetragen. Kursachsen - als anderer Reichsvikar - optierte übrigens für Bayern, weil die albertinischen Wettiner 1547 ebenfalls von einer innerfamiliären Kurübertragung profitiert hatten und dabei stillschweigend in den Genuss des Vikariats gelangt waren. Der neue Kaiser Leopold I. erkannte die bayerischen Vikariatsakte an, die pfälzischen nicht, ohne dadurch eine Grundsatzentscheidung für die Zukunft zu treffen. 1711 war Kurbayern geächtet, so dass Kurpfalz das strittige Vikariat allein ausüben konnte. 1724 verständigten sich die Wittelsbacher im Rahmen eines Hausvertrags darauf, bei der nächsten Kaiservakanz ein gemeinschaftliches Vikariat zu führen, und setzten diesen Beschluss 1740-42 in die Tat um. $\mathrm{Da}$ es von Seiten einiger Reichsstände deutliche Proteste gab - mit dem Ziel einer Befassung des Reichstags mit dieser Frage -, einigten sich die Wittelsbacher anschließend auf eine alternative Vikariatsführung: Bei jeder künftigen Vakanz kam der jeweils andere an die Reihe; 1745 fing Kurbayern an. In den fraglichen Jahren (außer 1711) ist ein starker Ausstoß an Flugschriften zu diesem Streit überliefert. In Zeitschriften und selbst in einigen Zeitungen wurde die Frage aufgeworfen und in kompetenter Weise knapp behandelt. Es handelte sich dabei nicht um ein abgehobenes Reichsproblem, sondern es ging alle Reichsuntertanen an: Reichsvikare führten ein sog. »Reichsvikariats-Hofgericht«, und klagewillige Parteien mussten wissen, an wen sie sich ordnungsgemäß zu wenden hatten. Die Medien belehrten sie über den jeweils aktuellen Stand.

2. Die Errichtung der Neunten Kurwürde für den Herzog von BraunschweigLüneburg. Auch dieser Streit war ein Verfassungsstreit. Kaiser Leopold I. hatte seit den späten 1680er Jahren dem Drängen des Herzogs Ernst August von Braunschweig-Lüneburg (und gleichzeitigen Bischof von Osnabrück) auf Erhebung zum Kurfürsten positive Rückmeldungen gegeben. 1692 erfolgte die Kurbelehnung, wobei der neu Kreierte sowohl umfängliche Hilfe zum Türkenkrieg leisten als auch die künftige Loyalität seines Hauses gegenüber den Habsburgern bei Kaiserwahlen versprechen musste. Die Erhebung wurde mit Zeitverzug den Mitkurfürsten, anschließend den übrigen Reichsständen mitgeteilt. Während der Protest einiger Kurfürsten relativ bald beigelegt werden konnte, entwickelte sich bei einigen ambiti- 
onierten Fürstendynastien langfristiger Unwillen, der die Reichstagsverhandlungen für mehr als ein Jahrzehnt belastete. Wichtigster Gegner war die verwandte Linie Braunschweig-Wolfenbüttel, die als älteste welfische Linie ihren Vorrang in der Haushierarchie einbüßte. Eine phasenweise militärische Kooperation Herzog Anton Ulrichs von Braunschweig-Wolfenbüttel mit Frankreich wurde 1702 von den Hannoveraner Verwandten durch Besetzung des Wolfenbütteler Territoriums niedergeschlagen. Der Reichsverfassungskonflikt schlug ebenso wie der welfische Hauskonflikt erhebliche Wellen in den Flugschriften, Zeitungen und Zeitschriften. Erst 1708 konnte die feierliche Introduktion Kurhannovers in den Kurfürstenrat stattfinden. Kaiser Leopold und sein Sohn Josef I. hatten die Gelegenheit genutzt, im Zuge der Veränderung die böhmische Kurstimme zu reaktivieren, was ebenfalls strittig gewesen war. Auch die sog. »böhmische Readmission« wurde am selben Septembertag 1708 vollzogen.

3. Die Reichsacht gegen Kurfürst Max Emanuel von Bayern und seinen Bruder. Nach fortgesetzter bewaffneter Kollaboration mit dem Reichsfeind Frankreich wurden die wittelsbachischen Kurfürsten Max Emanuel von Bayern und Josef Clemens von Köln 1704 zunächst militärisch besiegt und ins französische Exil getrieben, anschließend 1706 durch ein förmliches Reichsachtverfahren ihrer Lehen für verlustig erklärt. Sowohl die Militäraktionen als auch besonders die feierliche Absetzungszeremonie vom 29. April 1706 sowie deren öffentliche Proklamationen an verschiedenen Orten im Reich fanden ein lebhaftes Medienecho, bis hinein in die Bildpublizistik. Später ließen die Exilierten von Zeit zu Zeit durch Schriftsätze von sich hören, z.B. bei der Kaiserwahl 1711, von der sie allerdings trotz ihrer Protestankündigung ausgeschlossen blieben. Durch die Friedensschlüsse von Rastatt und Baden 1714 wurden beide als Kurfürsten restituiert, diesmal unter weniger großer Anteilnahme der Medien.

4. Der Konfessionskonflikt im Fürstentum Nassau-Siegen. Fürst Wilhelm Hyazinth von Nassau-Siegen sah sich seit 1700 berufen, zum einen die Nachfolge in der bevorstehenden oranischen Erbschaft anzutreten und damit in den Kreis der »souveränen« europäischen Herrscher zu gelangen, zum anderen als Landesherr einen homogenen katholischen Untertanenverband zu formen. Für das erste fehlten ihm die finanziellen Mittel, für das zweite die reichsrechtliche Grundlegung. Die Folge war eine schnell wachsende Verschuldung, die zu Schikanen und einer extrem überhöhten Besteuerung besonders der protestantischen Untertanen im Territorium führte. 1707 setzte Kaiser Josef I. eine Kommissionsregierung in Siegen ein. Zwar ging der Fürst außer Landes, ohne hinlängliche Unterstützung für eine Restitution erlangen zu können. Stattdessen übte die Administration, politisch geleitet durch Deputierte des Kölner Domkapitels und militärisch gestützt durch ein Kreiskontingent unter kurpfälzischem Kom- 
mando, die Regierungsgeschäfte weiterhin in Richtung auf eine Rekatholisierung des Landes aus, unterstützt durch den Jesuitenkonvent in Siegen. Zwei gewaltsame Zusammenstöße zwischen dem Kreiskontingent und protestantischen Untertanen 1712 und 1716 machten die Lage im ganzen Reich bekannt. In den Druckmedien wurden die Aktionen mit dem Fürsten verbunden, der allerdings keinen direkten Einfluß mehr besaß. Die Verhandlungen des Falles Siegen vor dem Corpus Evangelicorum machten aus dem Streit einen Konfessionskonflikt, der parallel zu den Konfessionsstreitigkeiten der Pfälzer Kurfürsten mit ihren protestantischen Untertanen verhandelt wurde. Zwar erschien eine große Zahl von gedruckten Traktaten, und auch in den Zeitschriften wurde über Siegen geschrieben, weit weniger allerdings in den Zeitungen, die bei Konfessionskonflikten zurückhaltender berichteten als bei Verfassungsfragen. Erst der Tod des Fürsten Wilhelm Hyazinth 1743 und der Übergang seines Teilterritoriums an den calvinistischen Prinzen Wilhelm (IV.) von Oranien-Nassau beendeten den Konflikt.

5. Der Ständekonflikt im Herzogtum Mecklenburg-Schwerin. Der Streit des Herzogs Karl Leopold von Mecklenburg-Schwerin mit seiner Ritterschaft und der Stadt Rostock fand während des Nordischen Kriegs statt. Obwohl die "heiße« Phase der Auseinandersetzungen nur von 1713 bis Anfang 1719 dauerte, dürfte dieser Konflikt mit Abstand das meiste beschriebene Papier von allen hier verhandelten Reichsauseinandersetzungen produziert haben: Nicht nur ist die Zahl der Traktate und Deduktionen Legion (eine Quellenausgabe der mecklenburgischen Landstände von 1719 umfasste bereits fast 900 Schriftstücke ${ }^{122}$ ), sondern auch vor dem Reichshofrat in Wien wurden zu zahlreichen Fragen mehr als 100 Einzelklagen anhängig gemacht. Während die Zeitschriften bereits in den Jahren 1715 und 1716 berichteten, finden sich in den Zeitungen nur vereinzelte Hinweise, die dem Leser noch kaum ein geschlossenes Bild der Verhältnisse im Herzogtum vermittelten. Es war die Exekution des Niedersächsischen Reichskreises vom Februar 1719, die den Konflikt reichsweit bekannt machte. Herzog Karl Leopold, der erst von der Herrschaft suspendiert, dann 1728 dauerhaft durch seinen jüngeren Bruder Christian Ludwig als Regent ersetzt wurde, war im öffentlichen Ansehen völlig als Gewalttäter, Verfassungsbrecher und notorischer Querulant gegenüber Kaiser, Reichstag und fürstlichen Standesgenossen diskreditiert. Sein Ansehen war so weit gesunken, dass selbst viele Zeitungen ihm in der Berichterstattung

122 [Johann Schevius], Höchst=gemüßigter Historischer=Acten-mäßiger Bericht von dem, was von Anfange der, im Monath Augusto 1713. angetretenen Regierung Herrn Carl Leopold, Hertzogen zu Mecklenburg, biß zu der, im Monat Martio und April 1719. ergangenen Kayserl. Execution von dem Fürstl. Mecklenburgischen Ministerio wider die Mecklenburgische Ritterschafft und Stadt Rostock vorgenommen worden (mit Beylagen von Num. 1-885), o.O. 1719. 
nicht mehr die förmlichen Kuralien gaben (»des Hertzogs von Mecklenburg Hochfürstliche Durchlaucht«), sondern einfach von »der Hertzog« sprachen - was bei anderen Reichsfürsten unüblich war. Karl Leopold erfüllte die ihm zugedachte Rolle, indem er bis zu seinem Tod uneinsichtig blieb, aber Kaiser und Reichsstände von Zeit zu Zeit mit Bittschriften um seine Restitution überhäufte. Paradoxerweise konnte er trotz seiner Suspendierung in Schwerin und Dömitz einen kleinen Herrschaftsbereich behaupten, während die Administrationsregierung von Rostock aus den größten Teil des Territoriums kontrollierte. Erst der Tod des Herzogs 1747 machte dem Konflikt ein Ende und führte zur politischen Konsolidierung seines Bruders.

Zunächst stellt sich bei der Analyse der Quellen die Frage, welche Informationen überhaupt in die Medien gelangten. Damit verbunden ist der Zeitpunkt der Ersterwähnung. Es hat den Anschein, als bedurfte es einer bestimmten Konfliktschärfe, um in den Fokus der Nachrichtenproduzenten zu gelangen. Wenn ein Konflikt und seine Protagonisten hingegen eingeführt waren, konnten ständig weitere Meldungen nachgeschoben werden. Neben der sachlichen Ebene ist die normative Qualität des Konflikts bedeutsam. Die Deduktionen und Streitschriften argumentierten normalerweise vor dem Hintergrund des politischen Normengefüges im Heiligen Römischen Reich, mit seiner göttlichen Stiftung und der dadurch legitimierten hierarchischen Ordnung vom Kaiser über die rangmäßig abgestuften Reichsfürsten, sonstigen Stände, adligen und stadtbürgerlichen Herrschaftsträger auf der Mittelebene bis hinunter zum Meister eines Gewerbebetriebes, Inhaber eines Bauernhofes und Hausvater. Dabei gab es zwar keine Theorie des allgemeinen sozialen Konflikts, aber ein Herkommen des Konfliktaustrages, wofür politische Gremien einerseits (besonders die Reichs- und Landesversammlungen) und Gerichte andererseits zuständig waren. Diese Instanzen besaßen eine so große Legitimität, dass ein Verweigern einer Konfliktregulierung durch sie bereits ein Austreten aus der politischen und sozialen Vergemeinschaftung bedeuten konnte. Vollends ins Unrecht setzte sich jeder Stand und jede Person, wenn Gewalt ohne die dazu erforderliche Beauftragung angewandt wurde.

Eine weitere Frage ist die nach der Ehre der Konfliktparteien. Für viele höhere Standespersonen im Reich konnte ein Angriff durch eine rangniedrigere Person bereits eine Ehrverletzung darstellen. Dies galt bei einem gewaltsamen oder rechtlichen Angriff ebenso wie bei öffentlicher Kritik in den Druckmedien. So forderten zahlreiche frühmoderne Herrscher Satisfaktion, wenn sie - ihrer Ansicht nach - zu Unrecht in Flugschriften, Zeitungen oder Zeitschriften negativ bewertet worden waren. Ein beträchtlicher Teil der Zensurverfahren drehte sich um die Modalitäten, wie dem Angegriffenen Genugtuung geleistet wurde, meistens symbolisch, und zwar auf 
folgende Weise: Der Verursacher - Autor, Drucker oder Verleger - wurde in Haft genommen, aber wenige Tage später wieder freigelassen. Geldbußen wurden verhängt, aber mitunter nicht in voller Höhe eingetrieben. Auch eine Verweisung des Urhebers aus der Stadt war eine mögliche Satisfaktion, nicht selten zeigen die Quellen an, dass der Gemaßregelte kurze Zeit später zurückgekehrt sein musste. In allen Fällen war die schnelle Satisfaktionshandlung entscheidend, auf die Nachhaltigkeit der Strafe kam es hingegen nicht an, was den Medienproduzenten nutzte.

In den Konflikten, die in dieser Studie vorgestellt werden, führte die Medienberichterstattung ein breites Bekanntwerden herbei. Der erste der Konflikte blieb ungelöst durch die Reichsinstitutionen, schließlich erarbeiteten die Konfliktparteien, die wittelsbachischen Linien, einen Kompromiss. Im zweiten Fall setzte der Kaiser die Kurerhebung Hannovers durch, die öffentliche Kritik konnte das nicht verhindern. In den drei restlichen Fällen Bayern, Siegen und Mecklenburg wurde der Verursacher des jeweiligen Konflikts identifiziert, die Zuschreibung von Schuld hatte seine Isolierung (Ächtung, Suspendierung) zur Folge.

\section{Verwendete Quellen}

Viele der hier gestellten Fragen haben die Zeitgenossen im 17. und 18. Jahrhundert in gelehrten Diskursen abgehandelt, teilweise sind sie in dicken Büchern dargelegt worden, verborgen für die große Mehrzahl der möglichen Interessenten in allen Ständen. Der hier gewählte Zugang erfolgt über das Erdgeschoss der Wissensgesellschaft, das sich in ephemeren und periodischen Druckwerken für den Sofortverzehr materialisierte. Diese Werke lassen sich in vier Gruppen gliedern. Zunächst sind die hier verhandelten Konflikte ganz oder teilweise in Deduktionen der betroffenen Parteien veröffentlicht worden. In einer Deduktion wurden reichs-, territorial- oder dynastierechtliche Ansprüche formuliert ${ }^{123}$. In der Regel wurden diese Ansprüche im engeren oder weiteren Sinne historisch hergeleitet, die Narratio dominierte daher stark, was heute den Quellenwert ausmacht. Derartige Publikationen entsprachen den Gepflogenheiten des Rechtssystems im Heiligen Römischen Reich, das eine öffentliche Formulierung berechtigter Ansprüche für die anderen Reichsmitglieder gebot. Wer einem gegen ihn gerichteten Anspruch eines anderen nicht per Deduktion widersprach, geriet in den Verdacht, das strittige Gut unrechtmäßig innezuhaben. In der großen Mehrzahl

123 Kuno Lorenz, Art. »Deduktion«, in: Joachim Ritter (Hg.), HWP, 14 Bd., hier Bd. 2, Darmstadt 1972, S. 29f. - Zur Begriffsabgrenzung: REPGEN, Der Westfälische Friede und die zeitgenössische Öffentlichkeit, S. 52f. 
der Fälle sind Deduktionen durch den Interessenten finanziert worden, nur der kleine Rest wurde von - staatsrechtlichen - Unterstützern des Interessenten verfasst und produziert, vielfach mit dem Hintersinn, sich eine Belohnung oder ein Amt im Dienst dieses Fürsten zu erschreiben.

Die zweite Gruppe der Quellen sind die Flugschriften ${ }^{124}$. Thematisch sind sie vielfältiger als die Deduktionen, ihre Zweckbestimmung muss in jedem Einzelfall ermittelt werden. Im Normalfall war die Flugschrift ein Text, der vom Käufer finanziert werden sollte. Autoren, Drucker und Verleger waren stets auf der Suche nach Themen, die sich vermarkten ließen. Dazu gehörten politische und religiöse Konflikte, Satiren, Sensationsberichte, moralische Texte und vieles andere. Es konnte sich um Streitschriften handeln, die politische Ziele argumentativ verfochten und dafür Anhänger suchten ${ }^{125}$. Aber auch ein Schlachtenbericht war eine Flugschrift wert, mit oder ohne Parteinahme, mit moralischer Bewertung oder ohne sie. Vom Einblattdruck bis zum Traktat von mehreren hundert Seiten reichte die Spannbreite, auch die Illustrationen waren nur durch Kostenkalkulationen begrenzt. Der Übergang zwischen Deduktion und Flugschrift war in der Regel fließend.

Die dritte Quellengruppe sind die Zeitungen ${ }^{126}$. Sie entstanden kurz vor dem Dreißigjährigen Krieg und setzten sich bis zu dessen Ende in ganz Mittel- und Westeuropa durch. Leider gibt es keine geschlossene Überlieferung, da Zeitungen zu dieser Zeit nicht als überlieferungswürdige Medienprodukte angesehen wurden. Die herausgebenden Verlage konnten keine Kontinuität bis heute wahren, sodass mit ihrem Untergang (in einigen Fällen erst im 19. Jahrhundert) Archivalien zur Betriebsführung sowie Belegexemplare der eigenen Tätigkeit verloren gingen. Auch Höfe, Regierungen oder fürstliche Bibliotheken legten keine systematischen Sammlungen der Zeitungen an, nicht einmal in den Fällen, in denen die Exemplare eines Jahrgangs paginiert erschienen und damit bereits für eine spätere Sekundärlektüre aufbereitet worden waren. Die Zentrale Wissenschaftliche Einrichtung »Deutsche Presseforschung« stellt seit fünf Jahrzehnten in mühevoller Kleinarbeit eine

124 Johannes Schwitalla, Flugschrift. Eine Einführung, Tübingen 1999; Wolfgang Adam, Theorien des Flugblatts und der Flugschrift, in: Joachim-Felix LeOnHARD u.a. (Hg.), Medienwissenschaft. Ein Handbuch zur Entwicklung der Medien und Kommunikationsformen, Bd. 1, Berlin/New York 1999, S. 132-143.

125 Zur Definition einer Streitschrift: REPGEN, Der Westfälische Friede und die zeitgenössische Öffentlichkeit, S. 55f.

126 Zeitungen werden seit Langem erforscht, wobei mehrere diskontinuierliche Stränge zu berücksichtigen sind. Vgl. zur Forschungsentwicklung bis in die Gegenwart vor allem WeLKE/WiLKE, 400 Jahre Zeitung; Astrid Blome/Holger Böning (Hg.), Presse und Geschichte. Leistungen und Perspektiven der historischen Presseforschung, Bremen 2008; Volker Bauer/Holger Böning (Hg.), Die Entstehung des Zeitungswesens im 17. Jahrhundert. Ein neues Medium und seine Folgen für das Kommunikationssystem der Frühen Neuzeit, Bremen 2011. - Zu den Beziehungen der deutschsprachigen Zeitungspublizistik mit anderen Sprachräumen: Welke/Wilke, 400 Jahre Zeitung, pas. 
retrospektive Sammlung aller überlieferten Zeitungsbestände in deutscher Sprache für das 17. und 18. Jahrhundert zusammen und erforscht ihre Entstehungsgeschichte und mediengeschichtliche Entwicklung. Trotz europaweiter Recherchen dürften kaum mehr als $15-20 \%$ aller tatsächlich gedruckten Exemplare auffindbar sein. Für die vorliegende Untersuchung liegt daher auch nur ein Teil der Berichte zu den Themen der Fallstudien vor. Die tatsächlichen Funde sind allerdings bemerkenswert genug, um untersucht zu werden. Die in Schiffbek erschienene Zeitung Der Hamburgische Unpartheyische Correspondente ist erst seit 1712, später ab 1721 kontinuierlich herausgekommen, entwickelte sich schnell zur wichtigsten deutschsprachigen Zeitung und ist für das weitere 18. Jahrhundert komplett überliefert ${ }^{127}$. Für die Zeit davor müssen fragmentarische Überlieferungen aus zahlreichen verschiedenen Zeitungen als Quellengrundlage dienen ${ }^{128}$.

Die politisch-historischen Zeitschriften ${ }^{129}$ stellen die vierte Gruppe der Quellen dar, die hier untersucht werden. Sie entstanden knapp hundert Jahre nach den Zeitungen an der Wende vom 17. zum 18. Jahrhundert. Aufgrund ihres weit größeren Umfangs gegenüber den Zeitungen benötigten sie eine dichte Überlieferungslage, die erst zu dieser Zeit durch das Mediensystem regelmäßig bereitgestellt werden konnte. Ein Zeitschriftenheft hatte gut 100 Seiten Umfang monatlich, der Text musste thematisch vom Redakteur regelmäßig erhoben und aufbereitet werden. Nur wenige Zeitschriften im deutschen Sprachraum haben eine Kontinuität über einige wenige Jahrgänge hinaus erreicht. Für diese Studie liegt das Schwergewicht auf dem Augsburger Monatlichen Staats-Spiegel, der Leipziger Europäischen Fama sowie auf dem Periodikum Gespräche im Reiche der Todten, das zwischen 1718 und 1739 von David Fassmann herausgegeben wurde ${ }^{130}$.

Für beide Gruppen der Periodika wurde eine Data-Liste angefertigt, die die kalendarischen Angaben der Hauptereignisse beinhaltet, die als berichtenswert infrage kamen. Für den Vikariatsstreit waren dies insbesondere die Todestermine der vorigen Kaiser, der Beginn des Wahlverfahrens, der Wahltermin und der Krönungstermin. Diese Termine wurden jeweils auf Einträge überprüft ${ }^{131}$. Bei den Zeitungen wurde normalerweise ein Monat nach dem Termin durchsucht, bei den Zeitschriften die beiden Monatshefte, die nach

127 Zu Eigenschaften und Bedeutung der Zeitung: Holger BönIng, Periodische Presse, Kommunikation und Aufklärung. Hamburg und Altona als Beispiel, Bremen 2002, bes. S. 17-36.

128 Vgl. die Liste der ausgewerteten Zeitungen im Quellenverzeichnis dieser Arbeit, S. 544-555.

129 Joachim Kirchner, Das deutsche Zeitschriftenwesen. Seine Geschichte und seine Probleme, 2 Bd., Wiesbaden 1958; ders. (Hg.), Bibliographie der Zeitschriften des deutschen Sprachgebietes bis 1900, 4 Bd., Stuttgart 1968-1989; Wilmont HaAcke, Die Zeitschrift - Schrift der Zeit, Essen 1961; ders., Die politische Zeitschrift 1665-1965, 2 Bd., Stuttgart 1968-1982.

130 Vgl. die Liste der ausgewerteten Zeitschriften im Literaturverzeichnis dieser Arbeit, S. 545547.

131 Fragen: 1. Erwähnung ja/nein? 2. Welche Aspekte werden berichtet? 3. Wird das jeweilige 
dem Termin lagen. Wenn positive Einträge erfolgten, dann lagen sie fast ausschließlich innerhalb dieser Fristen ${ }^{132}$. Wenn sich dort keine Einträge finden ließen, wurde davon ausgegangen, dass über das Ereignis nicht berichtet wurde. Allerdings ist die Unschärfe zu beklagen, dass viele Zeitungen nicht komplett überliefert sind, sodass die gesuchten Informationen auch in den fehlenden Ausgaben sein könnten.

Eine weitere Ausarbeitung der Fallstudien unter Zuhilfenahme der archivalischen Überlieferung hat sich als nicht praktikabel erwiesen für ein Projekt mit nur dreijähriger Laufzeit und begrenztem Reiseetat. Daher sind nur an wenigen Stellen Archivalien herangezogen worden.

Konfliktproblem erkannt? 4. Ändert sich durch das Ereignis der Nachrichtenwert des Konflikts?

132 Die Data-Liste wird im Anhang vor dem Literaturverzeichnis abgedruckt: S. 529-534. 

HauptTeil I:

Das frühmoderne Mediensystem 



\section{Zur Zirkularität des Nachrichtensystems}

Im Rahmen der Untersuchungen zur frühmodernen politischen Publizistik hat sich herausgestellt, dass ein Verfahrensprozessieren in zirkulärer Weise - systemtheoretisch auch »autopoietisches Prozessieren« genannt - in markanter Weise feststellbar ist. Im Gegensatz zu früheren Überlegungen ist an vielen Stellen beobachtbar, dass politische, administrative und militärische Prozesse nicht nur von Herrschaftsträgern und ihren verbeamteten Dienern beachtet und beschrieben wurden, sondern auch von Personen außerhalb der Herrschaftsapparate, die mit dem Nachrichtensammeln ihr Brot verdienten ${ }^{1}$.

Nach dem Blick auf die Zeitungsproduzenten stellt sich die Frage: Wo kamen eigentlich die Nachrichten her? Gerade die abstrakten Elemente, die zirkulierenden Bestandteile des Systems, machten Kommunikation innerhalb des Mediensystems aus. Aus dem politischen und militärischen Handeln, das in diesem Zusammenhang interessiert, gingen ständig Nachrichten hervor. Der Begriff »Nachrichten« wird hier bewusst verwendet, um eine kommunizierbare Information innerhalb des politischen, militärischen oder höfischen Systems zu bezeichnen: Nachrichten im Sinne dieser Überlegungen sind vorjournalistische Bedeutungsinhalte, die noch einer fachlichen Bearbeitung bedurften. Nachrichten waren übrigens keineswegs Produkte des frühmodernen Mediensystems: Schon in der Antike und im Mittelalter gab es überlieferte Neuigkeiten, sie sind damit älter als dieses System.

Diese Nachrichten gelangten als Elemente der Fremdreferenz von außen in das politische Mediensystem hinein. Außerhalb, im politischen System, vollzogen sich laufend Ereignisse, von denen einige, bei Weitem nicht alle, ins Mediensystem übernommen wurden. Durch diese Übernahme (input) begannen sie ihre »Medienkarriere«, den Umlauf durch das System. Die Nachrichten entstammten mehrheitlich nicht der systematischen Recherche durch Journalisten, sondern der Zusendung von Informanten. Dies konnten Mitarbeiter von Behörden oder der Schreibstelle von Streitkräften sein, Insider aus geistlichen, weltlichen oder gewerblichen Korporationen sowie Presseagenten in einer fernliegenden Stadt. Auch konnten Nachrichten in herrschaftlichem Auftrag bereitgestellt werden oder sogar mit einer Publikationsanordnung in den Kreislauf eingespeist werden.

1 An dieser Stelle sei auf die Überlegungen zur Kommerzialität des frühmodernen Medienwesens bei Karl Tilman Winkler verwiesen: Karl Tilman WinkLeR, Wörterkrieg. Politische Debattenkultur in England 1695 bis 1750, Stuttgart 1998, bes. der Hauptteil II: Ökonomie und Diskurs, S. 117-320. 
Sieht man von der letzten Art der Nachricht ab, die im Medium reproduziert werden musste, wurden die anderen Nachrichten durch die Person des »Gate Keepers « - so genannt von Kurt Lewin ${ }^{2}$ - zunächst doppelt bearbeitet: Zum einen fand eine Übersetzungsleistung statt, die aus der Nachricht einen Bericht machte, das symbolisch generalisierte Kommunikationsmedium im frühmodernen politischen Mediensystem. Dieser Prozess fand als die selbstreferenzielle Einfügung der Nachricht in die Usancen des Verfahrensprozessierens im politischen Mediensystem statt, es handelt sich damit um eine $»$ Konstruktion von Wirklichkeit ${ }^{3}$. Im systemtheoretischen Sinne beschreibt sich dieser Prozess als die Erstellung von Differenz, wobei die Leitdifferenz in der Unterscheidung von Information und Nichtinformation besteht ${ }^{4}$. Sie bezieht sich nicht nur auf Nachrichten, die neu ins Informationssystem eintraten (bzw. nicht aufgenommen wurden), sondern auch auf solche, die schon im System herumgereicht worden waren und durch ihren »Verbrauch«, d.h. durch ihr Bekanntsein, an Berichtswert verloren hatten und in letzter Konsequenz zu Nichtinformationen wurden ${ }^{5}$. Der Ort der Transformation von der Nachricht zum Bericht war nicht festgelegt: Er konnte schon beim Nachrichtenmakler liegen, aber auch erst beim Zeitungsredakteur. Dabei handelte es sich ausdrücklich nicht um eine Manipulation, sondern um eine Notwendigkeit, um die Berichte verständlich zu halten: Nur durch Reduktion von Komplexität war die Zeitung lesbar und verstehbar ${ }^{6}$. Um diese Qualität zu erhalten, musste der Bericht zunächst einmal in die Denkwelt des Zeitungs- oder Zeitschriftenredakteurs passen.

Zum anderen erforderte der schnell eintretende Überfluss an übersetzbaren Nachrichten eine Reihung nach Wichtigkeit mit dem Ziel, die wichtigsten Nachrichten zu Berichten umzuarbeiten. Das Kriterium für diese Rei-

2 Zur Begriffsbildung, ihrer Entstehung und Bedeutung: Andreas BöHn/Andreas SEIDLER, Mediengeschichte. Eine Einführung, Tübingen 2008, S. 68. - Zur Forschungsentwicklung: David Manning White, The »Gate Keeper«. A Case Study in the Selection of News, in: Journalism Quarterly 27 (1950), S. 383-390; Joachim Friedrich StAAB, Nachrichtenwert-Theorie. Formale Struktur und empirischer Gehalt, Freiburg/München 1990, S. 12-26. - Zur praktischen Anwendung der Gate-Keeper-Funktion in modernen Nachrichtenagenturen: Jürgen Wilke/Bernhard RosenBERger, Die Nachrichten-Macher. Zu Strukturen und Arbeitsweisen von Nachrichtenagenturen am Beispiel von AP und dpa, Köln/Weimar/Wien 1991, S. 25.

3 Darauf machte bereits Walter Lippmann 1922 aufmerksam: Walter LiPPMANN, Public Opinion, New York 1922, S. 338-347, zit. nach STAAB, Nachrichtenwert-Theorie, S. 40f.

4 Die binäre Codierung setzt sich bis in die moderne Massenpresse fort: Luhmann, Die Realität der Massenmedien, S. 36f.

5 Zum Zeitfaktor, durch den Nachrichten der Inaktualität oder eingetretenen Bekanntheit verfallen: ebd., S. 41.

6 Zur »Konstruktion der Realität«: ebd., S. 138-157. Die vermeintliche »Manipulation« der Presse ist übrigens ein Schema der Öffentlichen Meinung: Luhmann, Die Politik der Gesellschaft, S. 303. 
hung wird als »Nachrichtenwert « bezeichnet ${ }^{7}$. Entscheidend waren in diesem Zusammenhang ebenfalls zunächst nicht politische Vorgaben (die eher als Fremdreferenzen zu betrachten sind), sondern die systemimmanenten Traditionen der Nachrichtenverarbeitung. Was gebracht wurde und was nicht, was an prominentere Stelle rückte und was an eine Randposition, das entschieden die beteiligten Herausgeber und Verleger der politischen Druckschriften. Die Groth'schen Kategorien der Aktualität, Periodizität, Universalität und Publizität wurden dabei stets mitgedacht und boten Entscheidungshilfen ${ }^{8}$.

Es ist wichtig, darauf hinzuweisen, dass nicht die Zensur am Beginn der Nachrichtenauswahl stand, sondern das Phänomen des Überschusses an Meldungen und des begrenzten Platzes beim anschließenden Medium. Der horror vacui, die Vorstellung des Verfassers vor dem leeren Blatt, dem kein Satz einfällt, stammt eher aus dem Kontext der fiktionalen Literatur - keinesfalls aus dem Innenbereich der Journalistik. Hier war stets mehr an interessantem Geschehen berichtenswert, als später gedruckt werden konnte. Das Blatt war in Umkehrung des Bildes vom unglücklichen Literaten eher voll, und es waren noch Meldungen übrig. Dies bot dem Zeitungsherausgeber die Gelegenheit, zu den nicht übertragenen Nachrichten diejenigen zu zählen, deren Publikation Anstoß erregen konnte - beim Leser, bei den Berufskollegen und nicht zuletzt bei den Obrigkeiten. Das, was später mit der Metapher »Schere im Kopf« bezeichnet worden ist, hat die Zeitungsherstellung seit jeher begleitet. Ob es als eine so schwere Last auf den Prozessbeteiligten gelegen hat, dass es ihre Freiheit der Berichterstattung einschränkte, darüber muss an gesonderter Stelle nachgedacht werden. Vieles spricht dafür, dass die obrigkeitliche Medienkontrolle nicht über das Maß an Reglementierung hinausreichte, das die frühmodernen Untertanen auch sonst in ihrer alltäglichen Lebensführung erfuhren und hinzunehmen hatten'. Mit der Hochaufklärung änderte sich die Perspektive, die Reglementierung nahm zu, allerdings auch der Widerstand dagegen.

7 Jürgen Wilke hat in seiner Habilitationsschrift die Kriterien für den Nachrichtenwert in einer neuzeitübergreifenden Längsschnittstudie herausgearbeitet: WILKE, Nachrichtenauswahl und Medienrealität in vier Jahrhunderten, pas. - Hierfür wird manchmal der Begriff »Agenda setting« verwendet, der sich aber auch als manipulativer Eingriff der Politik oder wirtschaftlicher Public Relations-Bemühungen verstehen lässt. Vgl. dazu die diskussionswürdigen Ausführungen bei BöHN/SEIDLER, Mediengeschichte, S. 69.

8 Vgl. zu den vier Kategorien: Otto Groth, Geschichte der deutschen Zeitungswissenschaft. Probleme und Methoden, München 1948, S. 339f.

9 Dieser Befund wird bestätigt durch jüngere Tagungsergebnisse zur Frage der Zensur im Aufklärungszeitalter, inbesondere durch die Beiträge von Jürgen WiLKE, Pressezensur im Alten Reich, in: Haefs/Mix, Zensur im Jahrhundert der Aufklärung, S. 27-44 u. Ernst Fischer, »Immer schon die vollständigste Preßfreiheit«? Beobachtungen zum Verhältnis von Zensur und Buchhandel im 18. Jahrhundert, in: Ebd., S. 61-78. 
Ein weiteres Unterscheidungskriterium ergab sich aus der Personalisierung: Was immer Personen betraf, die entweder ein hohes Amt innehatten oder über die schon früher berichtet worden war, das konnte gebracht werden. Daneben wurden Nachrichten goutiert, die entweder eine anschlussfähige Angelegenheit betrafen, zahlenmäßige Quantitäten beinhalteten oder mit Konflikten oder Normenverstößen zusammenhingen ${ }^{10}$. Im Unterschied zur heutigen Presse war der Lokalbereich aus der Berichterstattung ausgeschlossen; darin sind sich Presseprivilegien und auch spätere politische und gerichtliche Interventionen einig ${ }^{11}$. In der früheren Forschung war lange angenommen worden, dass dies eine Folge der Zensur gewesen sei. Inzwischen betont Holger Böning hingegen, dass es angesichts der personellen Überschaubarkeit der Ober- und Mittelschichten in den deutschen Städten der Frühmoderne nicht vorrangig gewesen sei, kommunale Ereignisse in der Zeitung zu reproduzieren, die vielfach schon vor Erscheinen der nächsten Ausgabe auf mündlichem Wege allgemein bekannt geworden seien ${ }^{12}$.

Durch die Umwandlung von Nachrichten in Berichte und die Reihung nach Nachrichtenwert wurde Anschlussfähigkeit für das Gesamtsystem erzielt. Das Vorverständnis und Vorwissen auf beiden Seiten der politischen Medienproduktion, bei den Verlegern und Herausgebern ebenso wie bei der adligen und bürgerlichen Kundschaft, schuf die Voraussetzung dazu, dass weitere Nachrichten portionsweise eingespeist und angeschlossen werden konnten $^{13}$.

Für die Verarbeiter der Berichte über politische, höfische oder militärische Sachverhalte gab es noch keine feste berufliche Zuordnung. Ein »Zeitunger«, wie der Betreiber eines Periodikums im 17. Jahrhundert gelegentlich genannt wurde, war zunächst nicht nur der Herausgeber eines Periodikums, sondern schon der Sammler von Neuigkeiten mit der Absicht, diese gegen Geld zu verbreiten. Dies konnte ein Buchdrucker, ein Verleger, ein Postmeister oder eine Person mit anderer Hauptbeschäftigung sein. Viele Personen, die in diesem Bereich des Mediensystems arbeiteten, hatten gleichzeitig oder nacheinander verschiedene Funktionen.

10 Die Auflistung der frühmodernen Zeitungsinhalte stimmt weitgehend mit Luhmanns Beobachtungen hinsichtlich der modernen Massenpresse überein: LuHMANN, Die Realität der Massenmedien, S. 58-72.

11 Dies galt von Anbeginn der Presseberichterstattung mit der Ausnahme der Wiener »Ordentlichen Postzeitungen« (seit 1622): Welke, Johann Carolus und der Beginn der periodischen Tagespresse, S. 31.

12 Holger Böning, Welteroberung durch ein neues Publikum. Die deutsche Presse und der Weg zur Aufklärung. Hamburg und Altona als Beispiel, Bremen 2002, S. 171f.

13 Karl Tilman Winkler beschreibt die Zirkularität der Tagespresse im Oranier-England mit den Worten: »Man verkaufte serielles und nicht-serielles Tagesschrifttum über mehrere Schritte, als ob es eine Kette durchlief«: WINKLER, Wörterkrieg, S. 317. 
Das System des systematischen Nachrichtensammelns hatte sich bereits im 16. Jahrhundert herausgebildet. Zwar gab es noch keine regelmäßig erscheinenden Periodika: Hinter dem zeitgenössischen Begriff »Neue Zeitungen« verbargen sich ephemere Druckschriften berichtenden oder räsonnierenden Inhalts, die sich zu aktuellen politischen, militärischen oder konfessionellen Themen äußerten. Daneben berichteten sie über allerlei Sensationsthemen, die heute dem journalistischen Bereich des Boulevards zugeordnet würden ${ }^{14}$. In beispielhafter Weise profitierte das Straßburger Verlagshaus des Bern(h)ard Jobin (vor 1545-1593) von der günstigen Lage an der Schnittstelle politischer Mächte und verschiedener europäischer Sprachen ${ }^{15}$. Straßburg lag nicht nur an der Sprachgrenze zwischen dem Deutschen und dem Französischen, sondern auch der Rhein als Verkehrsader zwischen Oberitalien und den Niederlanden inmitten der $» B l u e-B a n a n a-R e g i o n$ bot weitreichende Verbindungen für den Verkehr mit materiellen wie immateriellen Gütern ${ }^{16}$. In den Studien über Jobins Schwager, Autor und Korrektor Johann Fischart (1546-1590) lässt sich die Systematik ersehen, mit der im Straßburger Medienunternehmen Schriften aus England, Frankreich, den Niederlanden und dem Heiligen Römischen Reich so komplett wie möglich erworben wurden, um durch deren Auswertung neue Texte zu erstellen. Dabei lag das Schwergewicht noch auf der Mediengattung der Flugschrift. Aber auch Historienschriften oder - wie besonders im Fall Fischarts - Satiren politischer und religiöser Art konnten hier konzipiert, verfasst und anschließend gedruckt und vertrieben werden ${ }^{17}$. Zusätzlich übersetzte Fischart Werke von

14 Vgl. dazu: Helmut W. Lang, Die Neue Zeitung des 15. bis 17. Jahrhunderts. Entwicklungsgeschichte und Typologie, in: Blühm/Gebhardt, Presse und Geschichte, Bd. 2, S. 57-60; Kristina Pfarr, Die neue Zeitung. Empirische Untersuchung eines Informationsmediums der frühen Neuzeit unter besonderer Berücksichtigung von Gewaltdarstellungen, Diss. Mainz 1994; Doris Stoll, Die Kölner Presse im 16. Jahrhundert. Nicolaus Schreibers »Neue Zeitungen aus Cöllen«, Wiesbaden 1991. - Für das Spätmittelalter: Birgit Studt, Neue Zeitungen und politische Propaganda, in: ZGO 143 (1996), S. 145-219.

15 Der Vorname findet sich in französischer und deutscher Schreibweise. - Biographischer Überblick: Josef Benzing, Bernhard Jobin, in: NDB, Bd. 10, Berlin 1974, S. 444.

16 Zum »Blue-Banana«-Interpretament: Roger Brunet, Les villes Européennes, Paris 1989; ders., Lignes de force de l'espace européen, in: Mappe Monde 66 (2002), H. 2, S. 14-19.

17 Zu Bernard Jobin: Wittmann, Geschichte des deutschen Buchhandels, S. 65. Zu Johann Fischart und seiner Tätigkeit für Jobin: Adolf Hauffen, Johannes Fischart. Ein Leitbild aus der Zeit der Gegenreformation, 2 Bd., Berlin/Leipzig 1922, bes. Bd. 2, S. 21; Wolfgang Rainer, Johann Fischart 1546-1590, in: Heinz-Dietrich Fischer (Hg.), Deutsche Publizisten des 15. bis 20. Jahrhunderts, München 1971, S. 59-69; Harry Oelke, Konfessionelle Bildpropaganda des späten 16. Jahrhunderts. Die Nas-Fischart-Kontroverse 1568/71, in: ARG 87 (1996), S. 149200. Zu Fischart aus literaturwissenschaftlicher Sicht: Wilhelm KüHLmann, Johann Fischart, in: Stephan Füssel (Hg.), Deutsche Dichter der Frühen Neuzeit. Ihr Leben und Werk (14501600), Berlin 1993, S. 589-612. - Zur Straßburger Buchdruckkultur im 16. Jahrhundert: Miriam Usher Chrisman, Lay Culture, Learned Culture. Books and Social Change in Strasbourg, 1480-1599, New Haven/London 1982. 
Justus Lipsius oder Philipp van Marnix aus dem Lateinischen oder Niederländischen ins Deutsche ${ }^{18}$.

Es darf davon ausgegangen werden, dass diese Methoden sich in den beiden folgenden Jahrhunderten zwar verfeinert, aber nicht grundlegend geändert haben. Darauf verweist auch Else Bogel am Beispiel der Züricher Bodmer-Zeitung. Dieses Periodikum, das die Familie Bodmer seit 1628 herausbrachte, war das bedeutendste Schweizer Blatt des 17. Jahrhunderts. Die Redaktion dieser Zeitung war ebenfalls über andere Zeitungswerke bestens informiert. In Züricher Sammelbänden von Zeitungsbänden des 17. Jahrhunderts finden sich zweimal je drei Zeitungen zusammengebunden: Neben der Bodmer-Zeitung waren dies die Straßburger Relation und die Frankfurter Postzeitung. Die Exemplare der Straßburger und Frankfurter Zeitungen waren mit handschriftlichen Notizen versehen, die sich bei näherem Hinsehen als Druckanweisungen erwiesen. Tatsächlich sind in der Bodmer-Zeitung der jeweils nächsten Folge die redigierten Texte aus den beiden anderen Periodika eingerückt auffindbar. Dabei war diese Form der medialen Sekundärverwertung weder anrüchig noch verboten, solange das eigene Periodikum nicht vollständig daraus bestand. Die Ausgaben der Bodmer-Zeitung von 1633 und 1634 trugen den Hinweis in ihren Titeln: »[...] auß allerhand glaubwürdigen anderstwo getruckten Zeitungen/vnd gewissen Sendbriefen $\aleph^{19}$.

Das nächste Element der Zirkulation war die Distribution der Berichte. Aus Nachrichten waren inzwischen Berichte geworden, formuliert und ausgewählt nach vorgegebenen Kriterien. Um diese Berichte der Leserschaft zukommen zu lassen, bedurfte es der Mithilfe anderer gesellschaftlicher Teilsysteme. Auch zu Zeiten des etablierten gedruckten Zeitungswesens wurden die Nachrichten auf zweierlei Weise weitergegeben: Für den gewöhnlichen Erwerber der gedruckten Blätter, den Abonnenten, wurde nach einem etwas anderem Schema selektiert als für den privilegierten Empfänger von zusätzlichen Briefmitteilungen. Ein Disproportionierungsprozess ist beobachtbar: Alles, was gedruckt publizierbar war, schied bald aus den geschriebenen Berichten aus, die dazu tendierten, nur noch das »Undruckbare« zu vermitteln, d.h. jene Informationen, die in irgendeiner Weise hätten Anstoß erregen können, wenn sie auf dem freien Medienmarkt vermittelt worden wären.

Nachdem die Entscheidungen über die Berichte im Verlagshaus in zweierlei Gestalt gefallen waren, mussten die Texte nun ihren Weg zum Leser finden. Die Aufgabe des Transfers von Zeitungen übernahm das frühmoderne Postwesen, das damit eine zentrale Rolle für die Mediengeschichte

18 Wittmann, Geschichte des deutschen Buchhandels, S. 65.

19 Dies gilt besonders für die Bände Q 478 und Q 481 in der Zentralbibliothek Zürich: Else Bogel, Schweizer Zeitungen des 17. Jahrhunderts. Beiträge zur frühen Pressegeschichte von Zürich, Basel, Bern, Schaffhausen, St. Gallen und Solothurn, Bremen 1973, S. 16. 
einnahm ${ }^{20}$. Auf die Geschichte dieses Prozesses wird später noch einzugehen sein. Hier ist die Bedeutung für die Zirkulation der Berichte wichtig. Die Beteiligung der Post an der geregelten Zeitung war medienhistorisch ein Novum: Der Verkauf von Büchern und der Vertrieb von Flugschriften gehörte nämlich nicht zum klassischen Postgeschäft. Die klassischen »Buchführer « bedurften noch keiner fremden Logistik, sondern sie handelten mit ihren gefalteten, aber noch nicht gebundenen Druckbögen auf Messen, um das erstandene gemischte Sortiment nach Rückkehr an das Lesepublikum der eigenen Stadt zu veräußern. Traktate und Bildflugblätter wurden hingegen durch sog. »Kolporteure«, fahrende Kleinhändler, meist junge Männer, gelegentlich auch handeltreibende Frauen, vertrieben. Auch Hausierer, Bilder-, Kalender- oder Landkartenträger verbreiteten Traktate, vor allem solche, die mit dem Aberglauben der Bevölkerung in einen Zusammenhang gebracht werden konnten. Gerade im Reformationsjahrhundert bot diese Form des Verkaufs am ehesten die Gelegenheit, unliebsamen Reaktionen der kirchlichen und weltlichen Obrigkeiten auf die missliebigen Texte aus dem Weg zu gehen ${ }^{21}$. Die fest etablierten Buchhändler scheuten oft das Risiko, offen brisante Flugschriften zu vertreiben, sondern legten den Schwerpunkt ihrer Kontroversliteratur auf die Texte, die im Sinne der eigenen Landesoder Stadtobrigkeit argumentierten ${ }^{22}$.

Die Post beförderte Briefe, Druckwerke und später auch Personen. Einmal mehr bestätigt sich der Zusammenhang von Brief und Zeitung: Beide nutzten dasselbe Vertriebssystem. Während der Brief der klassische Transportgegenstand der Post war, bürgerte sich bei der Zeitung der Abonnementsverkauf durch den jeweiligen Postmeister ein. Die Preise für ein Jahresabonnement einer Zeitung lagen günstigenfalls bei zwei Gulden ${ }^{23}$. Die Postmeister waren damit Kommunikatoren in beide Richtungen: Sie erfuhren nicht nur, was in der Welt geschah, so dass viele von ihnen selbst Zeitungen gründeten, sondern sie erfuhren auch, was die Leser der Zeitungen erfahren wollten. Daher betrieben sie nicht nur Werbung für die Abonnements (die sie zu Partizipanten der Einkünfte aus dieser Mediengattung werden ließen), sondern sie hörten auch die Rückmeldung der Kundschaft. Die ansonsten unvermeidliche Anonymisierung der periodischen Medienproduktion wurde hier aufgelöst:

20 BeHRinger, Im Zeichen des Merkur, pas. Hier wird auch die Forschungsentwicklung ausführlich erläutert.

21 Beispiele bei Wittmann, Geschichte des deutschen Buchhandels, S. 48f.

22 Beispiele: Annette Schreiber-Eickhoff, Die Bücher- und Pressezensur im Herzogtum Württemberg (1495-1803), Diss. Hagen 1981, S. 199; Stoll, Die Kölner Presse im 16. Jahrhundert, S. 18; Harry OetKe, Die Konfessionsbildung des 16. Jahrhunderts im Spiegel illustrierter Flugblätter, Berlin 1992, S. 121-125.

23 Rudolf STÖBER, Deutsche Pressegeschichte. Einführung, Systematik, Glossar, Konstanz 2000, S. 69-72. 
Während im Gegensatz zum Briefzeitungssystem gedruckte Zeitungen für eine möglichst große anonyme Leserschaft produziert wurden, kannte der Postmeister vor Ort tatsächlich den (abonnierenden) Leser ${ }^{24}$.

Der intendierte Leser stellt die Schlüsselfigur innerhalb der Zirkularität des Systems der politischen Publizistik dar: Von seiner Reaktion, von seiner Neigung, weitere Exemplare einer Zeitung oder gar ein neues Abonnement zu kaufen, hing die Funktionsweise des Mediensystems entscheidend ab. Im systemtheoretischen Sinn bietet der Käufer die Möglichkeit der operativen Schließung des Systems. Dieser Umstand wurde bereits von Hans Natonek anerkannt, der formulierte: »Über jedem Redaktionspult schwebt der Geist des Zeitungslesers, nicht des Redakteurs « ${ }^{25}$. Auch Martin Welke betont diesen Umstand, wobei er konzediert, dass sich dies »entgegen einer verbreiteten Auffassung « so verhielt ${ }^{26}$. Durch die Entscheidung zum Kauf bzw. zum Weiterbezug eines Periodikums signalisierte der Kunde Einverständnis, durch die Abwendung vom Produkt sein Missfallen über das, was ihm geboten worden war. Der Herausgeber einer Zeitung konnte durch die Summe der Rezeptionsakte ersehen, ob er auf Zustimmung stieß oder nicht, ob der Grad der Zustimmung wuchs oder abnahm. Waren die Kunden zufrieden, konnte der Herausgeber sein Produkt belassen oder vorsichtig optimieren, ansonsten musste er etwas verändern oder vom Markt verschwinden.

Dieser Zusammenhang hat einen ökonomischen und einen konstruktivistischen Hintergrund: Unter ökonomischen Gesichtspunkten ging es darum, ob gekauft wurde oder nicht ${ }^{27}$. Diese Entscheidung war stets eine Marktentscheidung von unten. Kein »Kapitalist« entschied darüber, wie im marxisti-

24 Margit Dorn/Andreas Vogel, Geschichte des Pressevertriebs in Deutschland. Mit einem Schwerpunkt auf der Entwicklung des Pressehandels, Baden-Baden 2001, S. 24; vgl. auch Konrad Schwarz, Der Postzeitungsvertrieb in der deutschen Postgeschichte, Berlin 1936, S. 48. Die Aufschläge konnten zwischen $1 / 2$ und 4 Gulden pro Jahresabonnement liegen: Martin Dallmeier, Die kaiserliche Reichspost zwischen Zeitungsvertrieb und Zensur im 18. Jahrhundert, in: Blühm/GeBhardt, Presse und Geschichte, Bd. 2, S. 233-258, hier S. 238.

25 Hans Natonek, Zeitung und Zeitschrift, in: Die Schaubühne, 12. Jg., 1916, Bd. II, S. 403f., zit. nach Otto Groth, Die Zeitung. Ein System der Zeitungskunde (Journalistik), 4 Bd., Mannheim u.a. 1928-1930, hier Bd. 1, S. 112.

26 »Entgegen einer verbreiteten Auffassung war und ist die Zeitung keineswegs das alleinige Erzeugnis von Verlegern, Journalisten und Druckern. Von der ersten Stunde des Zeitungswesens an steht über jeder Zeile, die in einer Redaktion geschrieben wird, die Frage >Was könnte den Leser interessieren?^ So ist die Zeitung zwar unmittelbar das Geschöpf derer, die sie schreiben und drucken, mittelbar wird sie aber seit eh und je von ihrem Publikum mitgestaltet«: Martin Welke, Das Publikum der frühen periodischen Tagespresse in Deutschland, in: Dittmar Dahlmann (Hg.), Die Kenntnis Rußlands im deutschsprachigen Raum im 18. Jahrhundert. Wissenschaft und Publizistik über das russische Reich, Göttingen 2006, S. 11-24, Zitat S. 19.

27 In der Terminologie der Systemtheorie heißt dies »Zahlen oder Nicht-Zahlen«, wie Niklas Luhmann die Leitdifferenz des Wirtschaftssystems bezeichnet hat: Niklas LuHmann, Die Wirtschaft der Gesellschaft, Frankfurt a.M. 1988, S. 136f. 
schen Weltbild angenommen, sondern der Publikumsgeschmack. Niemand konnte dem Kunden ein Produkt verkaufen, das dieser nicht haben wollte, in diesem Fall ein Zeitungsabonnement ${ }^{28}$. Manipulation der Kaufentscheidung war zwar stets beobachtbar, war aber gerade kein Zeichen für Stärke der Medienmacher, sondern ein implizites Eingeständnis ihrer Schwäche: Wenn offizielle Willensäußerung kein Verhalten der Käuferseite im eigenen Sinn zur Folge hatte, blieb nur noch der Weg über die Unaufrichtigkeit. Die Alternative war, der Kundschaft die Zeitungen zu schenken - zahlreiche Intelligenzblätter etwa wurden im Aufklärungszeitalter ganz oder teilweise subventioniert. Wieweit sie gelesen wurden, ist schwieriger ermittelbar als bei Periodika, deren Marktposition durch messbare Nachfrage bestimmt werden kann ${ }^{29}$.

Unter konstruktivistischer Perspektive gab es keine objektiven Maßstäbe dafür, was eine »gute« oder eine »schlechte« Zeitung war, sondern nur für ein erfolgreiches oder ein weniger erfolgreiches Periodikum. Entscheidend dafür war eine im Geschmack der Leserschaft jeweils neu gebildete Haltung: Hierin vollzog sich die autopoietische Erneuerung in der systemtheoretischen Logik des Mediensystems ${ }^{30}$. Diese Haltung entstand nicht durch staatliche Vorgaben und auch nicht durch das Bildungssystem (jedenfalls nicht allein), sondern durch den gesamten traditionellen oder kulturellen Hintergrund der frühmodernen Gesellschaft. Das Leserinteresse war damit eine weitgehend unabhängige Größe, die keinesfalls den Entscheidungen der Medienproduzenten ausgeliefert war. Im Gegenteil hatte sich jeder Zeitungsmacher nicht nur zu Beginn seiner Tätigkeit um den Geschmack seiner Leser zu kümmern, sondern auch stets Entwicklungen innerhalb dieses Geschmacks aufmerksam zu beobachten, um sein Blatt eventuellen Veränderungen anzupassen ${ }^{31}$.

28 Vgl. zur Art und Weise, wie die systemimmanenten Selektoren freie Entscheidungen aller Produzenten einschränkten: Luhmann, Die Politik der Gesellschaft, S. 309.

29 Die »Lippischen Intelligenzblätter« beispielsweise bedurften ständiger staatlicher Subventionierung, um Redaktion und Produktion zu finanzieren: Friedrich Hunecke, Die »Lippischen Intelligenzblätter« (Lemgo 1767-1799). Lektüre und gesellschaftliche Erfahrung, Bielefeld 1989, S. 60-62. Speziell zu Intelligenzblättern, ungeachtet des umfassenderen Titels ihre Sammelbandes, vgl. Sabine Doering-Manteuffel/Josef Mancal/Wolfgang Wüst (Hg.), Pressewesen der Aufklärung. Periodische Schriften im Alten Reich, Berlin 2001.

30 Luhmann bezeichnet diese Logik der Selbsterneuerung als »Sinn«: Luhmann, Die Gesellschaft der Gesellschaft, hier Bd. 1, S. 44-59.

31 Vgl. zum Wahrnehmungsstreit zwischen »Konstruktivisten« und »Realisten« unter Bezug auf Gesellschaftswissenschaften im allgemeinen und Mediengeschichte im besonderen: Paul Watzlawick (Hg.), Die erfundene Wirklichkeit. Wie wissen wir, was wir zu wissen glauben? Beiträge zum Konstruktivismus, München ${ }^{7} 1991$; Armin SchOLl (Hg.), Systemtheorie und Konstruktivismus in der Kommunikationswissenschaft, Konstanz 2002; Marcus WiLLASCHEK (Hg.), Realismus, Paderborn 2000; Luhmann, Die Realität der Massenmedien, pas. 
Dieser Umstand wurde schon 1688 bei Daniel Hartnack erwähnt, ohne dass dieser weiterreichende theoretische Folgerungen daraus gezogen hätte. Hartnack zitierte eine Passage aus Caesars Gallischem Krieg, in der die Gallier (bei Hartnack »Franzosen« genannt) vorbeiziehende Kaufleute anhielten, um von ihnen Neuigkeiten zu erfahren. Die Kaufleute hätten den Galliern dann regelmäßig das gesagt, was diese hören wollten. Dies verweist auf die Selbstreferenzialität der Medienübermittlung: Es ging nicht allein darum, absolute Informationen weiterzugeben, sondern es spielte stets eine große Rolle, Erwartungen der Zuhörer resp. der späteren Leserschaft zu befriedigen ${ }^{32}$.

Das Grundprinzip des Verfahrens, wie Nachrichten gewonnen und zu Berichten umgeformt wurden, wie diese Berichte gereiht und anschließend in feste Formate von Zeitungen oder Zeitschriften mit ihren vorgegebenen Satzspiegeln und Seitenzahlen eingepasst wurden, wie die Leserschaft auf das Präsentierte reagierte, das machte die Autonomie des politischen Mediensystems aus. Zudem war es von nicht zu unterschätzender Bedeutung, dass die Herstellung von Periodika sich selbst wirtschaftlich tragen musste und dies normalerweise auch tat. Eingriffe durch politische, kirchliche oder ökonomische Instanzen waren fremdreferenziell und lassen sich als »Störungen« in mehrfacher Hinsicht betrachten: für politische und kirchliche Eingriffe wurde der Begriff »Zensur« verwendet, ökonomische Eingriffe gelten als »Werbung « oder in heutiger anglizistischer Terminologie »Public relations«. Eine staatliche Beeinflussung im Sinne einer Lenkung von Finanzmitteln spielte hingegen im normalen Herstellungsprozess von Flugschriften, Zeitungen oder Zeitschriften vor Entstehung der Intelligenzblätter keine Rolle.

32 Daniel Hartnack, Erachten von Einrichtung Der alten Teutschen und neuen Europäischen Historien, Celle 1688, S. 65f. 


\section{Die Ausdifferenzierung der Medien im Alten Reich}

\subsection{Vor- und frühperiodische politische Medien im Heiligen Römischen Reich}

\subsubsection{Nachrichtenbriefe - geschriebene Zeitungen}

Politische Herrschaft, die über Räume hinweg wirksam sein wollte, benötigte schriftliche Medien, um den herrscherlichen Willen an entfernte Untergebene vermitteln zu können und von dort Berichte zu empfangen. Die traditionelle Form der Überlieferung war der Brief, wie er in vielfältiger Weise als offizielle diplomatische Mitteilung zwischen politischen Potenzen vorkam. Der Brief benötigte keinen personellen Apparat, sondern nur das Vorhandensein der Trägermaterialien Feder, Tinte und Papier sowie die Beherrschung der Kulturtechnik des Schreibens. Schreibfähigkeit kann bei adligen und bürgerlichen Elitenangehörigen beiderlei Geschlechts für den Untersuchungszeitraum angenommen werden. Der Brief war nicht auf herrschaftliche Korrespondenz beschränkt, sondern kam auch als wirtschaftliche Information, als wissenschaftlicher Fachbeitrag, als bloßer persönlicher Kontakt oder in zahlreichen anderen Varianten vor ${ }^{1}$.

Während normalerweise ein Brief einen Verfasser mit einem Adressaten verband, ging es beim Nachrichtenbrief darum, eine größere Anzahl von Personen mit seinem Inhalt vertraut zu machen. Der Aspekt der Multiplikation von Informationen führte zur Institutionalisierung und Kommerzi-

1 Zur allgemeinen kulturgeschichtlichen Bedeutung: Werner BüNGEL, Der Brief. Ein kulturgeschichtliches Dokument, Berlin 1939; Franz-Josef Worstвrock (Hg.), Der Brief im Zeitalter der Renaissance, Weinheim 1993. Zum Briefwesen im Spätmittelalter: Heinz-Dieter HeImann / Ivan HlaváceK (Hg.), Kommunikationspraxis und Korrespondenzwesen im Mittelalter und in der Renaissance, Paderborn u.a. 1997; Cornel ZwIERLEIN, Gegenwartshorizonte im Mittelalter. Der Nachrichtenbrief vom Pergament- zum Papierzeitalter, in: Jahrbuch für Kommunikationsgeschichte 12 (2010), S. 3-60. - Zum Kaufmannsbrief: Marianne GebeLE, Geschichte des deutschen Kaufmannsbriefes bis zum Ende des 18. Jahrhunderts, Diss. München 1949 (Mschr.); Theodor Gustav Werner/Friedrich-Wilhelm HenNing (Hg.), Das kaufmännische Nachrichtenwesen im späten Mittelalter und in der frühen Neuzeit und sein Einfluß auf die Entstehung der handschriftlichen Zeitung, in: Scripta mercaturae 2 (1975), S. 3-51. Der Brief im ausgebildeten Mediensystem der Frühmoderne: Wolfgang Behringer, Postamt und Briefkasten, in: Klaus Beyrer/Hans-Christian TÄUBrich (Hg.), Der Brief. Eine Kulturgeschichte der schriftlichen Kommunikation. Ausstellung des Museums für Post und Kommunikation Frankfurt a.M. und Nürnberg (1996/97), Heidelberg 1996, S. 55-63; Angelika ЕвREснт u.a. (Hg.), Brieftheorie des 18. Jahrhunderts. Texte, Kommentare, Essays, Stuttgart 1990. 
alisierung des Mediums: Diese Interessenten waren bereit, für die regelmäBige Erhebung und Bereitstellung der Informationen zu zahlen - der einfache Briefempfänger zahlte hingegen normalerweise nicht, sondern antwortete mit einem eigenen Brief.

Die politischen Publizisten, seit dem ausgehenden Mittelalter »Avisenschreiber« oder »Novellisten « genannt, beobachteten fortwährend den Nachrichtenstrom, der aus politischem und militärischem Handeln im weitesten Sinne überall entstand. Die Beobachtung verlief arbeitsteilig, d.h. Nachrichten konnten in mündlicher oder schriftlicher Form zufällig an einen Publizisten gelangen, oder sie konnten auch bewusst durch Korrespondenten erhoben werden. Das bewusste Nachrichtensammeln war dabei eine »Arbeit« in dem Sinne, dass sie honorierungsfähig war. Die Erhebung von Nachrichten verursachte damit Kosten, ein wichtiger Aspekt, der später für den Gedanken eines Eigentums an Informationen wieder aufgegriffen werden soll. Wer nur Informationen bearbeitete, für die er nichts bezahlt hatte, wer sich nur aus anderen gedruckten Medien mit Stoff für sein eigenes Periodikum versorgte, zog sich die Kritik derer zu, die die Kosten für ihre Korrespondenten hatten aufbringen müssen ${ }^{2}$.

Informanten konnten viele sein: Gemeint sind hier weniger professionelle Diplomaten ${ }^{3}$, sondern vielmehr waren Reisende, Kaufleute, private Briefschreiber ebenso dabei wie angestellte Personen in fremden Regierungen oder Armeen. Mit zunehmender Zeit gewannen allerdings spezialisierte Kräfte immer mehr an Gewicht, die als Mittler für Nachrichten auftraten: Sie verfügten über Kontakte in ihrem Umfeld, durch die sie Nachrichten erhielten, bei hinreichendem Geschick auch solche, die eigentlich nicht für die Medienvermittlung gedacht waren. Die Gruppe dieser Nachrichtenmakler, in der Regel Einzelpersonen und noch keine Agenturen, ist bislang nur in einigen Beispielen bekannt und bedarf noch weiterer systematischer Untersuchungen ${ }^{4}$. Allerdings weiß man von vielen Einzelpersonen, dass sie auch

2 In der Zeitungsbranche hieß dies: Zeitungen »ausschreiben«, eine verächtliche Charakterisierung vor allem kleiner Blätter durch Kritiker, die für ihre Produktionen größeren Aufwand betrieben.

3 Zur Diplomatie und den Diplomaten: Matthew S. Anderson, The Rise of Modern Diplomacy 1450-1919, London/New York 1993; Duchhardt, Balance of Power und Pentarchie, bes. S. 19-40. - Zur kaiserlichen Diplomatie: Erwin MAтsch, Der Auswärtige Dienst von Österreich (-Ungarn) 1720-1920, Köln/Wien 1986.

4 Für diesen Hinweis danke ich Johannes Weber, Zentrale Wissenschaftliche Einrichtung Deutsche Presseforschung an der Universität Bremen. - Überblicke über Forschungsstand und Desiderate: Jürgen WiLke, Korrespondenten und geschriebene Zeitungen, in: Johannes Arndt/Esther-Beate Körber (Hg.), Das Mediensystem im Alten Reich der Frühen Neuzeit 1600-1750, Göttingen 2010, S. 59-72; Holger BöNING, »Gewiss ist es / dass alle gedruckten Zeitungen erst geschrieben seyn müssen«. Handgeschriebene und gedruckte Zeitung im Spannungsfeld von Abhängigkeit, Koexistenz und Konkurrenz, in: Daphnis 37 (2008), S. 203-242; vgl. auch die darauf aufbauenden Überlegungen: Ders., Handgeschriebene und 
oder zeitweise als Nachrichtenmakler tätig gewesen sind. Darunter konnten Personen sein, die selbst in einem öffentlichen Dienstverhältnis standen (Verwaltungsbeamte, subalterne Höflinge, Schreiber bei militärischen Einheiten) oder solche, die selbstständig waren, aber viele Kontakte in die Behörden besaßen 5 .

Diese Personengruppe konnte für einzelne Nachrichten bezahlen, normalerweise genügten allerdings die kommunikativen Kontakte, um Informationen zu bekommen. Erst die Weitergabe der Nachrichten von den Maklern an die organisierten Nachrichtenverbreiter wurde bezahlt. Dabei bürgerte sich ein, dass die Nachrichtenmakler befristete Pauschalhonorare erhielten (oft für ein viertel, ein halbes oder ein ganzes Jahr), und dafür in vereinbarter Frequenz (z.B. einmal pro Woche) einen Bericht für ihren Auftraggeber verfassten. Diese Tätigkeit berührte die Aufgaben der sog. »Agenten«: Viele Fürsten, Ständeversammlungen oder Städte unterhielten an politisch wichtigen Orten Verbindungen zu Personen, die dort ihre Interessen unterhalb der politischen Entscheidungsebene vertraten. Zu dieser Tätigkeit gehörte auch das Verfassen regelmäßiger Berichte. Agenten konnten in erweiterter Form für ihre Auftraggeber tätig werden, indem sie z.B. Kunstgegenstände oder Bücher beschafften ${ }^{6}$.

Bislang wurde in der Forschung vor allem auf die offizielle diplomatische Ebene geblickt, wo akkreditierte Diplomaten ihre Regierungen vertraten und zu diesem Zweck über offizielle Beglaubigungen und zahlreiche Rechte verfügten. Im 16. und 17. Jahrhundert konnten sich die deutschen Reichsstände ein weitverzweigtes Diplomatennetz in Europa nicht leisten. An den großen königlichen Höfen wären ihre Vertreter wegen des bestehenden Standesunterschieds auch kaum akkreditiert worden. Ein inoffizieller »Agent« hingegen hatte den Vorteil, dass man ihn weder offiziell einstellen noch schulen musste, sondern dass man auf bereits tätige Personen vor Ort zurückgreifen konnte. Nachrichtenagenten wirkten vielfach für mehrere Auftraggeber und versorgten diese mit Informationen. Nicht die hochoffizielle Aktion war ihr

gedruckte Zeitung im Spannungsfeld von Abhängigkeit, Koexistenz und Konkurrenz, in: Holger BöNING/Volker BAUER (Hg.), Die Entstehung des Zeitungswesens im 17. Jahrhundert. Ein neues Medium und seine Folgen für das Kommunikationssystem der Frühen Neuzeit, Bremen 2011, S. 23-56. Dazu im selben Sammelband: Heiko Droste, »Einige Wiener briefe wollen noch publiciren«. Die Geschriebene Zeitung als öffentliches Nachrichtenmedium, in: Ebd., S. 1-22.

5 Kaspar Stieler rechnet die »Zeitungsschriften« zu den höfischen Informationsschreiben, die um der Einfachheit willen von den strengen Regularien der Titulaturen freigestellt waren: Kaspar Stieler, Teutsche Sekretariat=Kunst: was sie sey, wovon sie handele [...], 2 Bd. in 4 Tlen., Nürnberg 1673/74, hier Bd. 1, T1. 3, S. 624, zit. nach BAUER, Höfische Gesellschaft und höfische Öffentlichkeit im Alten Reich, S. 32.

6 Zu Agenten mit kulturellem Beschaffungsauftrag: Hans Cools/Marika KeBlusEK/Badeloch Noldus (Hg.), Your Humble Servant. Agents in Early Modern Europe, Hilversum 2006. Leider spielen Nachrichtenagenten in diesem Sammelband keine prominente Rolle. 
Aufgabenbereich, sondern nur die reine Information. Diese konnte normalerweise ohne Interessenkonflikte erfüllt werden.

Dies lässt sich am Beispiel einiger Briefzeitungen zeigen, wie Ludwig Salomon bereits vor über hundert Jahren nachgewiesen hat ${ }^{7}$. Als Zentren hatten sich schon im 15. und 16. Jahrhundert mehrere größere Handelsstädte im Reich herauskristallisiert, vor allem Wien (für den Balkan), Augsburg (für Italien, Schweiz und über Venedig für den Orient), Köln (für die Niederlande, England, Frankreich und Spanien), Hamburg (für Skandinavien) sowie Danzig, Breslau und Prag (für Osteuropa) ${ }^{8}$. Die Korrespondenten versorgten allerdings zunächst nur konkrete Auftraggeber; idealiter schrieb ein Korrespondent für einen Auftraggeber exklusiv9 . Aus dem wirtschaftlichen Bereich sind in diesem Zusammenhang die Korrespondenzen des Handelshauses Fugger, die sog. Fugger-Zeitungen, bekannt. Aus wirtschaftlicher Motivation heraus wurde über politische und kirchenpolitische Belange berichtet, soweit sie Hinweise auf künftige Knappheiten lieferten ${ }^{10}$.

Auf der politischen Ebene ist von Herzog August d.J. von BraunschweigWolfenbüttel (1579-1666) bezeugt, dass er mindestens 18 Korrespondenten an verschiedenen wichtigen Orten in Europa unterhielt. Für deren Dienste gab er jährlich 1.750 Rtl. aus ${ }^{11}$. Lore Sporhan-Krempel konnte den Nürnberger Korrespondenten Georg Forstenheuser namhaft machen, der einer von Herzog Augusts Briefzeitungsschreibern war ${ }^{12}$. Alle Briefpartner des Her-

7 Ludwig Salomon geht zwar davon aus, dass das Genre »Briefzeitung« im frühen 18. Jahrhundert wiederbelebt worden sei, doch erscheint es angesichts der Verwandtschaft mit dem regulären diplomatischen Residentenwesen wahrscheinlicher, dass es mit unterschiedlicher Intensität während der gesamten Frühen Neuzeit bestanden hat: Ludwig SALOMON, Geschichte des deutschen Zeitungswesens von den ersten Anfängen bis zur Wiederaufrichtung des deutschen Reiches, 3 Bd., Oldenburg 1900-1906, hier S. 170-174. Vgl. dazu auch Margot Lindemann, Deutsche Presse bis 1815. Geschichte der deutschen Presse, T1. 1, Berlin 1969, S. 15-22.

8 Ebd., S. 27.

9 Zur politischen Frühberichterstattung durch Briefzeitungen vgl. auch Richard WoLfF, Berliner geschriebene Zeitungen aus dem Jahr 1740. Der Regierungsanfang Friedrich des Großen, Berlin 1912, S. VIII.

10 Editionen: Viktor van Klarvill (Hg.), Fugger-Zeitungen. Ungedruckte Briefe an das Haus Fugger aus den Jahren 1568-1605, Wien/Leipzig/München 1923; Christl KarneHm/Maria Gräfin von Preysing (Hg.), Die Korrespondenz Hans Fuggers von 1566-1594. Regesten der Kopierbücher aus dem Fugger-Archiv, 3 Bd., München 2003. - Interpretationen: Regina DAUSER, Informationskultur und Beziehungswissen. Das Korrespondentennetz Hans Fuggers (1531-1598), Tübingen 2008; Oswald BAUER, Zeitungen vor der Zeitung. Die Fuggerzeitungen (1568-1605) und das frühmoderne Nachrichtensystem, Berlin 2011; Christl KarneHM, Das Korrespondenznetz Hans Fuggers (1531-1598), in: Johannes Burkhardt/Christine WerkStEtTer (Hg.), Kommunikation und Medien in der Frühen Neuzeit, München 2005, S. 301-311.

11 Elger BLÜhm, Die deutschen Fürstenhöfe des 17. Jahrhunderts und die Presse, in: August BucK u.a. (Hg.), Europäische Hofkultur im 16. und 17. Jahrhunderts, Bd. 3, Hamburg 1981, S. 595 600, hier S. 595.

12 Zu Georg Forstenheuser: Lore Sporhan-Krempel, Nürnberg als Nachrichtenzentrum zwischen 1400 und 1700, Nürnberg 1968, S. 107. 
zogs übten diese Tätigkeit im Nebenamt aus, während sie normalerweise als Beamte, Diplomaten oder Kaufleute ihr Auskommen hatten. Nicht nur handschriftliche Briefe allein gingen in Wolfenbüttel ein, sondern auch Druckwerke, die die Korrespondenten vor Ort erstanden hatten und dem hochadligen Auftraggeber als erweiterte Informationen zukommen ließen.

Aus diesem bezahlten Korrespondententum für jeweils einen Potentaten entwickelte sich eine Versachlichung der Korrespondenz: Dabei verfasste jeder Korrespondent seine Texte zunächst für wenige weitere zahlende Empfänger, die ihn im Erfolgsfalle weiterempfehlen konnten. Ob der ständische Unterschied, der in Nürnberg festzustellen ist zwischen Angehörigen der Oberschichten, die an auswärtige Fürsten schrieben, und den »Novellanten«, die als Schreibkundige aus der Mittelschicht Berichte an jeden gegen Bezahlung schickten, auch für andere Städte gilt, bedarf noch weiterer Studien ${ }^{13}$. Die Frequenz der Texte war nicht willkürlich, sondern hing in der Regel vom Postkursus ab, der normalerweise an den medienrelevanten Standorten wöchentlich verlief ${ }^{14}$.

Der limitierende Faktor für geschriebene Zeitungen war dabei das Quantum, das ein Korrespondent im Laufe einer Woche eigenhändig leisten konnte, und dies waren kaum mehr als 10 bis $15 \mathrm{Kopien}^{15}$. Allerdings sind auch zahlreichere Korrespondenzen von bis zu 60 Kopien pro Woche bekannt geworden, vermutlich hatte der Korrespondent dafür mehrere Schreiber unter Vertrag $^{16}$. Der Personalaufwand wirkte sich auf den Preis aus, so dass der Zugang zu diesen Informationen nur zahlungskräftigen Kunden offenstand. Während des 17. Jahrhunderts kosteten geschriebene Zeitungen aus Nürnberg - dort entstand erst 1673 eine gedruckte Zeitung - durchgängig zwischen 8 und 10 Gulden im Jahresabonnement ${ }^{17}$. Jeder Interessent konnte sich gegen Honorar mit Berichten aus ganz Europa beliefern lassen. Lore Sporhan-Krempel nennt mehrere Beispiele, bei denen sich einige Personen zu einer frühen Zeitungslesegesellschaft zusammenschlossen und das jeweilige Exemplar umlaufen ließen ${ }^{18}$. Die frühere Vorstellung, in den geschriebenen Zeitungen habe das Geheime gestanden, in den gedruckten der langweilige

13 Lore Sporhan-Krempel teilt die Briefzeitungsschreiber in dieser Weise auf: SPORHAN-KREMPEL, Nürnberg als Nachrichtenzentrum zwischen 1400 und 1700, S. 77-112 (16 »Korrespondenten«) u. 113-127 (14»Novellanten«).

14 BöNING, Handgeschriebene und gedruckte Zeitung, S. 208.

15 Johannes WeBER, Galerie der Zeitungspresse im 17. Jahrhundert mit dem Schwerpunkt: Geschichte der frühen Leipziger Zeitungen, in: Arnulf KuTsch/ ders. (Hg.), 350 Jahre Tageszeitung. Forschungen und Dokumente, Berlin 2002, S. 23-136, hier S. 33.

16 Susanne Friedrich, Drehscheibe Regensburg. Das Informations- und Kommunikationssystem des Immerwährenden Reichstags um 1700, Berlin 2007, S. 412 mit mehreren Nachweisen.

17 Vgl. Sporhan-Krempel, Nürnberg als Nachrichtenzentrum zwischen 1400 und 1700, S. $126 f$. und Tab. 1, S. 200.

18 Vgl. Sporhan-Krempel, Nürnberg als Nachrichtenzentrum zwischen 1400 und 1700, S. $126 f$. 
Rest, ist nach jüngsten Forschungen unzutreffend: Beide Mediengattungen unterlagen der herrschaftlichen Zensur, wie auch in beiden Fällen die jeweilige Obrigkeit gegenüber anderen, sich beleidigt fühlenden Obrigkeiten für Satisfaktion sorgen musste ${ }^{19}$.

Ein Dreischritt aufeinander folgender Korrespondenzen ist konstatierbar, wobei jede neue Korrespondenz nicht die frühere ersetzte, sondern zu ihr hinzutrat: 1. personalisierte Korrespondenz zwischen zwei Partnern; 2. versachlichte Korrespondenz zwischen mehreren bis vielen Partnern, die immerhin noch namentlich benannt wurden; 3. kommerzialisierte Korrespondenz zwischen einer großen Zahl von Marktteilnehmern, die über Handels- und Logistikorganisationen miteinander Kaufbeziehungen unterhielten, ohne sich persönlich oder namentlich zu kennen ${ }^{20}$.

Handschriftliche Zeitungen oder Briefzeitungen werden mit Bedacht diesem Kapitel zugeordnet: Zwar sind sie in einigen prominenten Fällen als Vorläufer gedruckter Zeitungen bekannt geworden - der Inhaber des ersten frühesten bislang bekannten Zeitungsprivilegs, Johann Carolus aus Straßburg, war zuvor Briefzeitungsproduzent ${ }^{21}$ - doch wichtig ist in diesem Zusammenhang, dass sie auch im Zeitungszeitalter weiterhin eine bedeutende Rolle spielten. Es handelt sich damit um einen Ausdifferenzierungsprozess, wie er in der Medienentwicklung vielfach auftrat: Das Medium des Briefes wurde technisch optimiert und vervielfältigt, daneben blieb der Brief als Handschrift, d.h. als Unikat mit allenfalls einigen eigenhändigen Abschriften des Verfassers, als altes Medium weiterhin erhalten. Für künftige Briefzeitungsschreiber bedeutete das eine Entlastung: Was in den allgemeinen gedruckten Zeitungen stand, musste nicht mehr kommuniziert werden, das Schwergewicht rückte auf darüber hinausgehende, spezielle Informationen. Zudem war es beispielsweise für einen Hamburger Residenten nicht mehr erforderlich, seinem Auftraggeber in Wien mitzuteilen, was er über Venedig oder Nürnberg erfahren hatte, denn diese Nachrichten dürften dort schon früher eingetroffen $\operatorname{sein}^{22}$. Allenfalls legte der Resident über sonstige Neuigkeiten, die er erfuhr, seinem Auftraggeber ein Exemplar der diesbezüglichen gedruckten Zeitung als Anlage bei. Zahlreiche Zeitungsexemplare aus dem 17. Jahrhundert haben sich auf diese Weise als Einzelstücke in herrschaftlichen Archiven erhalten ${ }^{23}$. Eine der wichtigsten Sammlungen von Brief-

19 BönInG, Handgeschriebene und gedruckte Zeitung, S. 228.

20 Vgl. dazu Dorn/Vogel, Geschichte des Pressevertriebs, S. 15.

21 Vgl. die Schilderung der Laufbahn Carolus' als Zeitungsmacher bei Johannes WeBER, »Untherthenige Supplication Johann Caroli/Buchtruckers«. Der Beginn gedruckter politischer Wochenzeitungen im Jahre 1605, in: AGB 38 (1992), S. 257-265.

22 Auf diesen Spezialisierungseffekt verweist Karl Heinz Kranhold, Frühgeschichte der Danziger Presse, Münster 1967, S. 183.

23 Vgl. zu einigen frühen Exemplaren der »Danziger Ordinari Freytags Zeitung« von $1667 \mathrm{im}$ Königlichen Archiv in Stockholm: Kranhold, Frühgeschichte der Danziger Presse, S. 189. 
zeitungen, von den Herzögen von Braunschweig-Wolfenbüttel hinterlassen, liegt im Staatsarchiv Wolfenbüttel und wurde bereits vor mehreren Jahrzehnten von Johannes Kleinpaul ausgewertet ${ }^{24}$.

Ein Brief konnte durchaus Aufsehen erregen, vor allem wenn er ein Geheimnis zu beinhalten schien. So berichtete die Zeitungsbeilage zur Mercurii Relation im Februar 1692 von einem verschlüsselten Brief, der in Heidelberg angelangt war. Die Kurpfalz war damals wegen der umstrittenen Erbansprüche Ludwigs XIV. Kriegsgebiet, und das Interesse an militärisch relevanten Informationen war existenziell. Die Pressenachricht lautete:

Auß Heydelberg/vom 5. Februar. - Verschinen Freytag und Sambstag hatten wir allhier einen grossen Allarm/welcher aus dem intercipirten/und mit lauter Ziffern geschribenen Briff entstanden/woraus man nach geschehener Dezifferirung so vil vernommen/daß eine grosse Verrätherey auff hiesige statt/Mayntz und Franckfurt vorhanden gewesen/weßhalben man die Verräther/mit allem Fleiß auffzusuchen getrachtet $^{25}$.

Eine Woche später wurde die Mitteilung nachgeschoben, dass in Frankfurt einige Verdächtige bereits verhaftet worden seien und dass die Hauptperson noch in Mainz vermutet und dort gesucht würde.

Das Schreiben von Briefzeitungen war überall in Europa gebräuchlich, während die Maßnahmen der Regierungen, diesen Nachrichtenfluss zu unterbrechen, periodischen Schwankungen unterlagen. In der Europäischen Fama wird berichtet, dass gerade im Verlauf des Spanischen Erbfolgekrieges in Paris eine besonders scharfe Verfolgung der Novellisten erfolgte. Die Zeitschrift kommentiert die Bemühungen der französischen Regierung mit Häme:

Damit man vor dem Volcke, und vielleicht auch vor dem Könige selbsten, den wahren Zustand der auswärtigen Begebenheit verbergen möchte, so seyend alle geschriebenen Zeitungen, welche in Paris pflegen herumgetragen zu werden, ernstlich verboten worden; inmasen man dem bereits 50 biß 60 Zeitungs=Schreiber in Verhafft genommen

24 Johannes Kleinpaul, Der Nachrichtendienst der Herzöge von Braunschweig im 16. und 17. Jahrhundert, in: Zeitungswissenschaft 5 (1930), S. 82-94. Vgl. von Kleinpaul auch den Vergleich mit anderen Höfen der Zeit: Ders., Das Nachrichtenwesen der deutschen Fürsten im 16. und 17. Jahrhundert. Ein Beitrag zur Geschichte der Geschriebenen Zeitungen, Leipzig 1930. Vgl. zur Vernachlässigung der Forschung auch: Dorn/Vogel, Geschichte des Pressevertriebs, S. $15 \mathrm{f}$.

25 Beilage »Extract Schreiben/Auß Wien/Ungarn/Pariß/Engeland/Polen/Heydelberg/Berlin und Cöln/etc. Mitbringend: Was weiter Neues in diesen Orthen vorbey gangen«, o.O. 1692 (Februar 16). 
hat. So verhindert man auch auf alle ersinnliche Weise, dass keine Zeitungen aus dem Königreich in andere Länder verschicket werden; dahero man alle Briefe auff der Post beschauet, und alle diejenigen, welche verdächtig seyend, eröffnet $^{26}$.

Zwei Jahre später taucht das Thema erneut in der Europäischen Fama auf, und wieder ernten die Bemühungen der französischen Regierung um symbolische Kriegführung gegen die Medienmacher Spott und Hohn des Herausgebers Sinold von Schütz: »Warum wollen sich aber Se. Allerchristlichste Maj. deswegen schämen, daß Dero Krieges=Glücke nur auf drey Beinen gehet, und warum seynd Sie so sorgfältig, die Schwindsucht Ihres Staates $\mathrm{zu}$ verbergen ${ }^{27}$ ?

Zentrum der Briefzeitungsproduktion im Reich des 17. und 18. Jahrhundert dürfte Regensburg gewesen sein, spätestens, seit dort der Reichstag in Permanenz tagte. Johann Peter von Ludewig vermerkte 1705, dass in der Stadt der Reichstage »[...] viel hundert Personen durch [...] geschrieben Correspondentzen ihr Brot« verdient haben sollen ${ }^{28}$. Die kommunikativen Zusammenhänge sind inzwischen durch eine ältere und eine jüngst erschienene Studie gut erhellt. 1936 konstatierte Hans Gstettner, dass von Geheimhaltung keinerlei Rede sein konnte: »Von dem Netz politischen Nachrichtendienstes, das von Regensburg aus über ganz Deutschland, ja über Europa gesponnen war, haben wir den erhaltenen Fäden nach kaum eine zu große Vorstellung « ${ }^{29}$. Inzwischen hat Susanne Friedrich eine voluminöse Dissertation über Regensburg als »Drehscheibe« der politischen Kommunikation im Reich und in Europa vorgelegt und dabei die Schwatzhaftigkeit als Prinzip mit zahlreichen Beispielen bestätigt ${ }^{30}$. Der politische Geheimnisverrat vor allem durch subalterne Kanzleibedienstete der reichsfürstlichen Gesandten war epidemisch und viel beklagt, konnte aber durch periodisch wiederkehrende Verbote nicht eingedämmt werden ${ }^{31}$. Der englische Kanzleisekretär Hugh Hughes brachte es auf den Punkt, als er schrieb, man müsse einem deutschen Bediensteten nur etwas als geheim anvertrauen, wenn man wolle,

26 Zum Verbot des Briefzeitungsschreibens: »Die europäische Fama, welche den gegenwärtigen Zustand der vornehmsten Höfe entdecket [...]«, begründet durch Philipp Balthasar Sinold von Schütz, 30 Bd. (360 T1.), Leipzig 1702-1735, hier 58 (1706), S. 820f.

27 Spott über versuchte Medienkontrolle der Pariser Regierung: Ebd. 82 (1708), S. 765f.

28 Johann Peter von Ludewig, Vom Gebrauch und Mißbrauch Der Zeitungen/Bey Eröffnung eines Collegii geführet. Anno 1700, Halle a.d. Saale 1705, S. 88, zit. nach Elger BLÜHM, Über Regensburgs älteste Zeitung (T1. 1), in: VHVOPf 123 (1983), S. 259-275, hier S. 259.

29 Hans Gstettner, Regensburger Reichstags-Korrespondenzen. Ein Stück Pressepolitik des Heiligen Römischen Reiches deutscher Nation, München 1936, S. 20.

30 Susanne Friedrich, Drehscheibe Regensburg. Das Informations- und Kommunikationssystem des Immerwährenden Reichstags um 1700, Berlin 2007, bes. S. 199-205 u. 407-419 (geschriebene Zeitungen) u. 504-515 (Grenzen der Geheimhaltung).

31 Fallstudie: ARndT, »Pflicht=mässiger Bericht«, S. 1-31. - Dazu und zu weiteren Praktiken auch FRIEDRICH, Drehscheibe Regensburg, S. 238-241. 
dass es bekannt würde ${ }^{32}$. In den 1790er Jahren waren die Verhältnisse dergestalt, dass die Reichstagskurien besondere Vorkehrungen treffen mussten, damit der Kaiser von den Reichsgutachten nicht eher aus der Presse als durch offizielle Kuriere erfuhr ${ }^{33}$. Auch von den »Residenten, Agenten und Räten von Hause aus« bei landesherrlichen Spitzenverwaltungen ist durch Kaspar Stieler bekannt, dass sie die eingehenden Berichte aus geschriebenen Zeitungen weiterverkauften ${ }^{34}$. Susanne Friedrich nennt für das späte 17. Jahrhundert sogar die Preise, für die ausländische Gesandte sich Protokolle und andere Papiere am Regensburger Reichstag verschafften: So zahlte der französische Gesandte Louis Verjus Comte de Crécy 600 livres tournois für einen Jahrgang der Fürstenratsprotokolle, während der englische Gesandte Sir George Etherege für die Akten der Sessionsperiode September 1687 bis Mai 168820 Pfund Sterling abrechnete ${ }^{35}$.

Gleichzeitig war Regensburg auch Empfängerin eines starken Nachrichtenstroms aus allen Teilen Europas. Susanne Friedrich wertete die einkommenden geschriebenen Zeitungen für die Jahre 1699 bis 1701 systematisch aus und kam auf Sendungen aus 77 Korrespondenzorten, von denen Köln, Den Haag und Hamburg die häufigsten waren ${ }^{36}$. Für Augsburg, Regensburg und Nürnberg lässt sich konstatieren, dass zwei Nachrichtenzusammenhänge bestanden: Ein Postliniensystem Hamburg/Skandinavien/Sachsen, und ein anderes aus Niederlande/Köln/Frankfurt/Elsass / Schweiz ${ }^{37}$.

Auch für Brandenburg-Preußen sind zahlreiche Briefzeitungen aufbewahrt worden, um im frühen 20. Jahrhundert in Quelleneditionen einzugehen. So hat Ernst Friedlaender eine wenig beachtete Quellenedition herausgegeben, in der er Berliner Briefzeitungen zusammengestellt hat ${ }^{38}$. Auch wenn die preußische Monarchie nicht zu den Fallbeispielen dieser Studie gehört, so verdienen die Befunde aus diesen Quellen dennoch Beachtung, weil sie cum grano salis generalisierbar erscheinen. Friedlaender deutet die Brief-

32 Schreiben von Hugh Hughes an einen unbekannten Adressaten, 6. Februar 1687: Frederick Bracher (Hg.), Letters of Sir George Etherege, Berkeley/Los Angeles 1974, S. 304, zit. nach FrIEDRICH, Drehscheibe Regensburg, S. 238, Anm. 1347.

33 »Mit Dictierung der Schlüße der drei Reichstagscollegien und der daraus entstandenen Reichsgutachten, die immer zusammen an einem Tage geschieht, pfleget man es gemeiniglich solange anstehen zu lassen, bis letztere am kaiserlichen Hof eingetroffen sein können, damit dieser das auf dem Reichstage beschlossene nicht gar noch früher aus öffentlichen Zeitungen, als aus Gesandtschaftlichen Absendungen vernimmt«: GsTETTNER, Regensburger ReichstagsKorrespondenzen, S. 17.

34 Stieler, Zeitungs Lust und Nutz (1695/1969), S. 16.

$35 \mathrm{Zu}$ diesen und weiteren Zahlen: FrIEDRICH, Drehscheibe Regensburg, S. 237. - Für Inländer waren sie offenbar preiswerter, denn der Nürnberger Gesandte Georg Sigmund Richter bekam ihre Abschrift für 12 Gulden pro Jahr: Ebd., S. 508, Anm. 2919.

36 Friedrich, Drehschreibe Regensburg, S. 414, Tab. S. 556-558.

37 Ebd., S. 415f.

38 FriedLAENDER, Berliner geschriebene Zeitungen, pas. 
zeitungen im Sinne seiner Zeit als ein Elitenphänomen: Die beiden Schreiber - Zacharias Grübel und Johann Hermann Ortgies - hatten jeweils einen Auftrag des Fürsten Georg Albrecht von Ostfriesland erhalten, ein- bis zweimal wöchentlich alle bedeutsamen Informationen aus Berlin an den Hof nach Aurich zu übermitteln. Diese Tätigkeit nahmen beide nacheinander von 1713 bis 1717 wahr. Für Ortgies ist auch später noch eine Briefschreiber-Tätigkeit nachgewiesen, doch fehlt die Überlieferung bis 1735. Grübel erhielt vom Fürsten 50 Rtl. jährlich (zuzüglich Postgeld), Ortgies konnte 100 Rtl. verlangen und bekam $\operatorname{sie}^{39}$.

Preußen war 1713 sehr medienträchtig: Zum einen bot ein neuer Herrscher wie König Friedrich Wilhelm stets ein großes Berichtspotenzial, zum anderen machte sich dieser Hohenzoller schnell einen europaweiten Namen als Verwaltungsrevolutionär, der in einer Art forciertem Finanzsanierungsprogramm am Tag nach der Beerdigung seines Vaters den halben Hofstaat entlassen und einige Behörden aufgelöst hatte und in dessen Wahrnehmung Tänzer, Musiker, Intellektuelle und Medienmacher auf einer Stufe rangierten ${ }^{40}$.

So verwundert es nicht, dass der König keine freie Berichterstattung über seine Arkana schätzte. Als im November 1713 Verstimmung mit den niederländischen Generalstaaten entstand, weil ein Briefschreiber aus Berlin Einzelheiten über preußische Truppenbewegungen übermittelt hatte, die der Republik nicht offiziell bekannt waren, leitete der König eine Fahndung nach dem Urheber ein ${ }^{41}$. Auch verfügte der König 1715 ein generelles Verbot, Nachrichten über seine Person und seine Regierungshandlungen an das »Ausland « zu schreiben. Das hieß im Sprachgebrauch der Zeit an alle außerpreußischen Territorien im Reich und an alle fremden $\operatorname{Staaten}^{42}$.

Friedrich Wilhelm I. scheint allerdings nicht sehr erfolgreich in der Jagd nach dem schreibfreudigen Berliner gewesen zu sein, denn zum einen ist keine spektakuläre Aktion gegen einen Journalisten aus dieser Zeit bekannt, zum andern schrieb Ortgies offenbar ungerührt weiter seine Briefzeitungen. Mit zunehmender Zeit beschränkte er sich nicht auf Ostfriesland, sondern sandte Kopien seiner Texte an ca. 10 weitere Empfänger, von denen er jeweils Honorare zugesagt bekam (auch wenn die Gelder nur unvollständig

39 Friedlaender, Berliner geschriebene Zeitungen, S. VI-X.

40 Zum neuen Forschungsstand über Friedrich Wilhelm I.: Peter Baumgart, Friedrich Wilhelm I. (1713-1744), in: Frank-Lothar Kroll (Hg.), Preußens Herrscher. Von den ersten Hohenzollern bis Wilhelm II., München 2000, S. 134-159. Zum Verhältnis dieses Herrschers zu Intellektuellen und Zeitgenossen aus dem Mediensektor: SABRow, Herr und Hanswurst, pas.

41 Bericht aus $»$ Berlin, den 18ten November 1713«: FriedLAEndER, Berliner geschriebene Zeitungen, S. 56-58.

42 Ulrich Buindow, Berliner geschriebene Zeitungen des 18. Jahrhunderts, Diss. Berlin 1939, S. 51. 
eingingen ${ }^{43}$. Offenbar hatte sich Ortgies inzwischen in ein Netzwerk von Korrespondenten begeben, die sich wechselseitig unterrichteten und sich bei unterschiedlichen Herren ins Gespräch brachten, um weitere Abnehmer ihrer Briefzeitungen zu akquirieren.

Ortgies war bei Weitem nicht der einzige, der mit amtlichen Informationen in Berlin Geschäfte machte. Auch der Protegé des Königs, Zeitungsverleger Johann Andreas Rüdiger, verlegte zwar ab 1721 die Berlinische privilegierte Zeitung, die der Zensur unterlag, aber daneben vertrieb er auch in eigener Regie Briefzeitungen an alle Zahlungskräftigen in Europa ${ }^{44}$. Es ist erwiesen, dass den König die Berichterstattung mit zunehmender Dauer immer mehr ärgerte. $\mathrm{Ob}$ er Rüdiger nicht überführen konnte, oder ob er ihn persönlich schonen wollte, bleibt unklar. Jedenfalls war Friedrich Wilhelm I. keineswegs zimperlich, wenn es um die Einschüchterung von Medienmachern ging. Es kam gelegentlich vor, dass auf des Königs Anordnung ein ausländischer Verleger von gedungenen Schlägern verprügelt wurde ${ }^{45}$.

Offenbar griff der König erst wirklich durch, als auch die gezeigten Methoden das Problem des Informationsabflusses nicht beheben konnten. Opfer wurde Johann Hermann Ortgies, dessen Tätigkeit am 12. Februar 1735 abrupt endete. An diesem Tag ließ ihn die Berliner Regierung festnehmen. Er wurde mit seinen letzten acht Briefzeitungen konfrontiert, die abgefangen und erbrochen worden waren, und wegen falscher und halbwahrer Meldungen sowie fortgesetzten Verstoßes gegen das königliche Gebot inhaftiert. Ein regulärer Prozess fand nicht statt, dennoch wurde der Briefschreiber nach fünf Monaten auf königlichen Befehl aus Preußen ausgewiesen ${ }^{46}$. Dieser Akt ließ bei den Briefzeitungen aus Preußen eine Unterbrechung eintreten. Offenbar hielt es selbst Johann Andreas Rüdiger für angeraten, für einige Zeit das Briefzeitungsschreiben zurückzustellen ${ }^{47}$.

43 Vgl. die Namensliste der Briefempfänger, von denen der Herzog von Württemberg und der Fürst von Schwarzburg-Sondershausen die prominentesten waren: FriEdLAENDER, Berliner geschriebene Zeitungen, S. XIIf. Der Fürst von Schwarzburg hatte ihm sogar den Titel eines Rates verliehen: SALOMON, Geschichte des deutschen Zeitungswesens, Bd. 1, S. 171f.

44 Zu Rüdiger: Ernst Consentius, Die Berliner Zeitungen bis zur Regierung Friedrichs des Großen, Berlin 1904, S. 71-77. Wenn Ulrich Blindow den Verleger als »skrupellosen Geschäftsmann« bezeichnet, dann skizziert er damit ungewollt die Rationalität des Zeitungswesens: Der Verleger sorgt für den Absatz, wobei er sich so weit wie möglich von moralischen Vorgaben externer politischer Potenzen unabhängig zu machen versucht: BLINDow, Berliner geschriebene Zeitungen, S. 26.

45 Vgl. den Fall eines niederländischen Verlegers, den Ulrich Blindow schildert: BLındow, Berliner geschriebene Zeitungen, S. 51f. Im Ancien Régime war dies eine gebräuchliche Methode, um Ehrkonflikte mit Personen auszutragen, die als nicht satisfaktionsfähig betrachtet wurden.

46 Friedlaender, Berliner geschriebene Zeitungen, S. XIV-XVII; Salomon, Geschichte des deutschen Zeitungswesens, Bd. 1, S. 172.

47 Buindow, Berliner geschriebene Zeitungen, S. 26. 
Eine weitere Edition über Briefzeitungen aus Berlin liegt aus der Feder von Richard Wolff vor ${ }^{48}$. Wolff stellte am Vorabend des Ersten Weltkriegs die Berichte des Braunschweig-Wolfenbütteler Residenten Wilhelm Stratemann für den Zeitraum von 1728 bis 1732 zusammen. Zwar war der Soldatenkönig zu dieser Zeit bereits seit 15 Jahren König, doch hatte er offenbar noch nichts von seiner Attraktivität eingebüßt, was die Berichterstattung über ihn anging.

Wichtiger als die Einzelheiten, die der Resident schrieb, waren die personellen und mediengeschichtlichen Umstände, unter denen er es tat. Wilhelm Stratemann war nämlich von Hause aus kein Diplomat, sondern Rechtsanwalt. Er besaß die Gunst und das Vertrauen des Preußenkönigs in hohen Maße, denn sonst hätte dieser ihm wohl kaum erlaubt, ein Engagement als Wolfenbütteler Resident in der Hauptstadt anzutreten. Von seiner Advokatur wurde Stratemann derweil vorübergehend beurlaubt, um die gesellschaftlichen Termine wahrnehmen zu können, die die Grundlage seiner Berichte darstellten. Interessanterweise waren die Stratemann-Berichte im Staatsarchiv Wolfenbüttel nicht mehr vorhanden, als Wolff den Fall untersuchte. Dafür fand er komplette Ausgaben in Hannover und in Detmold. Als er diesem Befund nachging, stellte sich heraus, dass der hannoversche Sekretär Voigt die Kopien für die kurfürstliche Regierung angefertigt hatte, während die lippischen Kopien von Stratemanns Kanzleibeamten Gerhardi stammten und noch teilweise mit den eigenhändigen Korrekturen des Residenten versehen worden waren.

Ob der Preußenkönig davon wusste, wer alles die Berichte noch erhielt, ist unklar. Als sicher kann gelten, dass Stratemann für das Kopieren zusätzliche Einnahmen verbuchen konnte. Der Resident galt als vermögend, besa $\beta$ er doch ein Haus an der Spandauer Straße in bester Berliner Lage. Allein aus Braunschweig erhielt er ein Gehalt, das von 200 Rtl. im Laufe der Jahre auf 700 Rtl. stieg ${ }^{49}$. Wolff weist in seiner Einführung in die Edition darauf hin, dass Stratemann neben den direkten Informationen bei Hofe von zwei anderen wichtigen Quellen zehrte: Zum einen unterhielt er einen ausgezeichneten persönlichen Kontakt zum kaiserlichen Gesandten in Berlin, Graf Seckendorff; zum anderen füllte er seine Berichte mit Informationen auf, die er anderen Zeitungen entnommen hatte, waren sie nun handschriftlich oder gedruckt an ihn gekommen. Ein Resident war im Mediensystem keineswegs nur Nachrichtenstifter, sondern auch Nachrichtenvermittler und damit Beteiligter am Informationskreislauf ${ }^{50}$.

48 Richard Wolff (Hg.), Vom Berliner Hofe zur Zeit Friedrich Wilhelms I. Berichte des Braunschweigischen Gesandten in Berlin, 1728-1733, Berlin 1914.

49 WolfF, Vom Berliner Hofe, S. III-V.

50 Ebd., S. IV. 
Solange die höfische Gesellschaft fortbestand, gab es auch geschriebene Zeitungen im weiteren Sinne. Die Entstehung anderer politischer Medien blieb - trotz deren publizistischen und ökonomischen Erfolges für die Briefkorrespondenz stets von subsidiärer Bedeutung, von der Verdrängung oder dem Absterben der älteren Medienart kann daher keine Rede sein.

\subsubsection{Flugschriften}

Die Vorstellung von der Zirkularität ${ }^{1}$ der politischen Berichterstattung ist entwickelt worden am Phänomen der periodischen Presse, wie sie sich seit kurz vor Ausbruch des Dreißigjährigen Krieges von Deutschland ausgehend in ganz Europa verbreitet hat. Da sich historische Entwicklung - so unvollkommen sie in der Systemtheorie auch ausgebreitet worden ist - als evolutionärer Prozess der Ausdifferenzierung darstellt, muss es folgerichtig auch ein »Davor« gegeben haben. Diesen Medienverhältnissen gilt der folgende Überblick.

Als Johannes Gutenberg um 1440 sein Handgießgerät für Bleilettern erfand, hatte er noch keine Revolutionierung der politischen Publizistik im $\mathrm{Sinn}^{52}$. Ihm ging es darum, auf einfachere Weise und in größerer Zahl als bis dahin Bücher (z.B. Bibeln) oder Gebrauchstexte (Liedblätter, Ablasszettel etc.) vor allem für kirchliche Kunden herzustellen ${ }^{53}$. Die Flugschrift, die sich zum Leitmedium des 16. Jahrhunderts entwickeln sollte, konnte auf den vorhandenen technischen Möglichkeiten aufbauen. Flugschriften werfen zwei Probleme auf: Zum einen war ihre Erscheinungsform sehr unterschiedlich. Zum anderen gibt es ein beträchtliches begriffliches Durcheinander, was überhaupt eine Flugschrift ist. Werner Faulstich konstatiert, dass selten zwischen Flugschrift und Flugblatt methodisch sinnvoll unterschieden

51 Vgl. vorn Hauptteil I, Kap. 1, S. 53-62.

52 Zur Person: Stephan Füssel, Johannes Gutenberg, Reinbek b. Hamburg 1999. - Zu seinem Wirken: Wolfgang Dobras (Red.), Gutenberg - aventur und kunst. Vom Geheimunternehmen zur ersten Medienrevolution. Katalog zur Ausstellung der Stadt Mainz, 14. April bis 3. Oktober 2000, Mainz 2000; Paul RaABE (Hg.), Gutenberg. 550 Jahre Buchdruck in Europa. Ausstellung im Zeughaus der Herzog August Bibliothek Wolfenbüttel, Weinheim 1990; Wolfgang Sснмітz, Gutenberg und die Ausbreitung des Buchdrucks zu seinen Lebzeiten, in: Marginalien 164 (2001), H. 4, S. 18-34; Stephan Füssel, Gutenberg und seine Wirkung, Frankfurt a.M. 1999 (22004).

53 Zur Druckpraxis in der zweiten Hälfte des 15. Jahrhunderts: Volker Honemann u.a. (Hg.), Einblattdrucke des 15. und frühen 16. Jahrhunderts. Probleme, Perspektiven, Fallstudien, Tübingen 2000; Falk Eisermann, Bevor die Blätter fliegen lernten. Buchdruck, politische Kommunikation und die »Medienrevolution« des 15. Jahrhunderts, in: Karl-Heinz SiIEss (Hg.), Medien der Kommunikation im Mittelalter, Stuttgart 2003, S. 289-313. 
wird; zusätzlich werden weitere Begriffe wie »Pamphlet« oder »Neue Zeitung « verwendet, auch »Buch« oder »Büchlein« sind gebräuchlich ${ }^{54}$.

Wichtige Forschungsimpulse stammen von Hans-Joachim Köhler, der sich als Analyst und Herausgeber von Flugschriften in den letzten Jahrzehnten einen Namen gemacht hat ${ }^{55}$. Eine Flugschrift wird auf dieser Grundlage verstanden als »eine selbständige, nicht periodische Druckschrift, die aus mehreren Blättern besteht, in der Regel ungebunden ist, nur Text enthält, sich als Mittel der Massenkommunikation an die gesamte Öffentlichkeit wendet und offen agitiert oder beeinflussen will $\aleph^{56}$. Damit ist die Flugschrift, mehr als andere Medien der Zeit, auf Meinungsbildung und -beeinflussung ausgerichtet. Paul Roth hat schon früher Flugschriften in sechs inhaltliche Gruppen gegliedert, ohne den Agitationsaspekt zu betonen:

1. Chroniken (Schilderung in epischer Breite oder Berichterstattung über zusammenhängende Tatsachenreihen).

2. Anschläge von Amts- oder Verordnungsblättern in der Form von Flugschriften.

3. Private Druckschriften, die Anliegen in Gestalt von Aufforderungen, Predigten, Thesen, Widerrufen etc. beinhalten.

4. Politische und theologische Tendenzschriften.

5. Satirische Flugschriften (Famosschriften, bzw. Famoslibelle).

6. Historische Volkslieder ${ }^{57}$.

54 Faulstich, Medien zwischen Herrschaft und Revolte, S. 160. Weitere Bezeichnungen wie »Pasquille« oder »Broschüre« sind ebenfalls anzutreffen: WiLKe, Grundzüge der Medien- und Kommunikationsgeschichte, S. 25. Zu verwandten Begriffen sowie zur Begriffsgeschichte der »Flugschrift«: Schwitalla, Flugschrift, S. 2-7.

55 Hans-Joachim KöHLER, Die Flugschriften. Versuch einer Präzisierung eines geläufigen Begriffs, in: Horst RABE u.a. (Hg.), Festgabe für Ernst Walter Zeeden zum 60. Geburtstag, Münster 1976, S. 36-61; Hans-Joachim KöHLER, Fragestellungen und Methoden zur Interpretation frühneuzeitlicher Flugschriften, in: Ders. (Hg.), Flugschriften als Massenmedium der Reformationszeit, Stuttgart 1981, S. 1-27; Hans-Joachim KöHLER, Das Tübinger Flugschriftenprojekt. Bibliographie, Inhaltserschließung, Textpublikation der Flugschriften des frühen 16. Jahrhunderts, in: Wolfenbütteler Notizen zur Buchgeschichte 9 (1984), S. 3-22. Flugschriften-Editionen: Hans-Joachim KöHLER (Hg.), Flugschriften des frühen 16. Jahrhunderts (1501-1530). Microfiche-Serie, Leiden 1989ff.; Hans-Joachim KöHLER (Hg.), Flugschriften des späteren 16. Jahrhunderts (1531-1600). Microfiche-Serie, Leiden 1990ff. - Dazu die Bibliographien: Hans-Joachim KÖHLER (Hg.), Bibliographie der Flugschriften des 16. Jahrhunderts, Tl. 1: Das frühe 16. Jahrhundert (1501-1530), 6 Bd., Tübingen 1989ff.; ders. u.a. (Hg.), Bibliographie der deutschen und lateinischen Flugschriften des frühen 16. Jahrhunderts, Tübingen 1978.

56 Zit. nach: Faulstich, Medien zwischen Herrschaft und Revolte, S. 160f. Vgl. dazu auch Johannes Schwitalla, Deutsche Flugschriften 1460-1525. Textsortengeschichtliche Studien, Tübingen 1983, S. 14ff.

57 Paul Rотн, Die Neuen Zeitungen in Deutschland im 15. und 16. Jahrhundert, Leipzig 1914, S. 2-4. 
Jürgen Wilke hält die Flugschriften für einen Vorläufer der Yellow Press ${ }^{58}$. Marktschreierische Titel und die bevorzugte Darstellung von Begebenheiten, die mit Gewalt zu tun hatten, lassen sich durchgängig beobachten und legen die Ansicht nahe, dass es dafür eine kontinuierliche Nachfrage gab. Dies schloss militärische Aktionen ebenso ein wie die Darstellung von Verbrechen und Hinrichtungen sowie weitere Themen, die Grusel und Schaudern auslösen konnten ${ }^{59}$. Besonders in frühmodernen Städten ging die Flugpublizistik eine intensive Wechselbeziehung ein mit der »Kommunikation zwischen Anwesenden«, wobei die soziale Grenze zwischen gelehrt und ungelehrt verwischte ${ }^{60}$.

Flugschriften eigneten sich in besonderem Maße dazu, die beiden publizistischen Dimensionen der Unterhaltung und der Information miteinander zu verknüpfen. Die Drucke vermittelten zum einen kurzweilige Unterhaltung für den sofortigen »Verbrauch«. Das Medium wurde nach der Lektüre entweder weitergereicht, weggeworfen oder verbrannt, jedenfalls nur in seltenen Fällen systematisch aufbewahrt oder gar gesammelt. Flugschriften konnten zum anderen durch ihre potenzielle Allgegenwart bzw. durch ihre tatsächliche Flüchtigkeit in idealer Weise als Medium für solche Informationen dienen, deren Verbreitung obrigkeitlichen Widerspruch zu befürchten hatte. In der vormodernen Gesellschaft, die einen prohibitiven Charakter trug, bot der Flugschriftenmarkt ein Ventil, das auszudrücken, was ansonsten ungesagt bleiben musste. Olaf Mörke betont diesen Charakter, wenn er einen wichtigen Teil der Flugschriften mit dem »Pamphlet«-Begriff belegt. Damit meint er eine »Gelegenheitsschrift [...], die ein aktuelles Problem in agitatorischer oder propagandistischer Absicht aufnahm $\aleph^{61}$. Das Räsonnement, die politische oder konfessionspolitische Meinungsbildung und -beeinflussung ist damit bereits im Reformationszeitalter Teil des Schriftenprogramms, keineswegs erst zur Zeit der Aufklärung. Auch entstand durch die schriftliche Reaktion auf Pamphlete anderer ein Kommunikationsprozess, der Meinungsgruppen nach innen festigte, indem er sie nach außen abgrenzte.

In welcher Weise differenzierte sich das Mediensystem des Reformationszeitalters gegenüber dem Spätmittelalter durch die Flugschrift aus? Werner Faulstich betont, dass es sich bei der Flugschrift hinsichtlich des Umfangs um eine Zwischenform zwischen den im Mittelalter gebräuchlichen Medien

58 Wilke, Grundzüge der Medien- und Kommunikationsgeschichte, S. 23f.

59 Vgl. zur Darstellung von Gewalt: Pfarr, Die neue Zeitung, bes. S. 155f.

60 Vgl. die dahinweisenden Ergebnisse der Dissertation von Daniel BelLingradt, Flugpublizistik und Öffentlichkeit um 1700. Dynamiken, Akteure und Strukturen im urbanen Raum des Alten Reiches, Stuttgart 2011, bes. S. 369-379.

61 Olaf Mörke, Pamphlet und Propaganda. Politische Kommunikation und technische Innovation in Westeuropa in der Frühen Neuzeit, in: Michael NorTH (Hg.), Kommunikationsrevolutionen im 16. und 19. Jahrhundert, Köln/Weimar/Wien 1995, S. 15-32, Zitat S. 17. 
Blatt und Buch handelt. Heute würde man diese neue Medienform »Heft« nennen, und Nachfolger des Mediums sind in der Tat bis jetzt im Handel ${ }^{62}$. Weiter vereinigte die Flugschrift drei frühere Gattungen: Das Printspeichermedium, den Predigttypus (»Sermon«) und den Rundbrief bzw. »offenen Brief«, der in der Renaissance bereits vorkam und im Reformationszeitalter erhalten blieb. Auch führt Faulstich drei Erzähltypen auf, die sich in der Flugschrift wiederfinden: die »objektive« Zustandsbeschreibung (bzw. der allgemeingültige Zeitbefund), die appellative Belehrung der Zeitgenossen sowie die subjektive Betroffenheitsschilderung (bzw. die Darstellung privaten Engagements) - eine Trias, die es bis dahin noch nicht gegeben hatte. Ein dritter Aspekt wird von Faulstich besonders betont: Die Dekonstruktion des »Menschmediums«. Faulstich hat einen übergreifenden Entwicklungsplan für die Mediengeschichte entworfen, bei dem in den vormodernen, besonders in den oralen Kulturen, das »Menschmedium «, d.h. der Mensch als Vermittler zwischem wem auch immer, eine zentrale Rolle spielte. Reformatorische Flugschriften, so Faulstich, griffen nun die Menschmedien in der Kirche an. Zum einen negierte Luther in seinen Sendschreiben und den drei reformatorischen Hauptschriften von 1520 den Opfercharakter und damit die Heilswirksamkeit der Hl. Messe. Zum anderen bestritt er dem Priester seine herausragende Rolle als Vermittler zwischen Mensch und Gott. An die Stelle der Messe trat der Wortgottesdienst, der dem »Sola-Scriptura«-Prinzip entsprach. An die Stelle des klerikalen Vermittlers zwischen der göttlichen und der irdischen Sphäre trat das »Priestertum aller Gläubigen«. Das untergrub traditionelle Orientierungs- und Herrschaftsmechanismen. Der Bruch wurde allerdings dadurch aufgefangen, dass Luther an die Stelle der gestürzten Medien zwei neue setzte: Zum einen Christus als Menschmedium, und zum anderen die Bibel als Steuerungs- und Orientierungsmedium. Faulstich betont, nicht die Anwendung des Buchdrucks sei die mediale Revolution des Reformationszeitalters gewesen, sondern der Wechsel von der oralen zur literalen Medienkultur - Faulstich wörtlich: »Die Drucktechnik eines Gutenberg darf medienhistorisch nicht gedacht werden ohne die Flugschrift eines Luther ${ }^{63}$.

Auch für das Verhältnis von Brief und gedruckter Flugschrift galt das »Riepl'sche Gesetz«. Wolfgang Riepl hatte bereits 1913 das dauerhafte Fortbestehen einfacher Elemente des Nachrichtenwesens auch dann postuliert, wenn höhere Entdeckungen aufkamen; letztere traten einfach an deren Seite $^{64}$. Der Brief war hinsichtlich seines Schreibers und seines Empfängers

62 Hierzu und zu den folgenden Überlegungen: Faulstich, Medien zwischen Herrschaft und Revolte, S. 161-163.

63 Ebd., S. 162.

64 »Andererseits ergibt sich gewissermaßen als ein Grundgesetz der Entwicklung des Nachrichtenwesens, daß die einfachsten Mittel, Formen und Methoden, wenn sie nur einmal eingebür- 
normalerweise spezifiziert und individualisiert: Serienbriefe und Umlaufbriefe waren zwar auch schon vor dem Druckzeitalter bekannt, doch auch in diesen Fällen bestand normalerweise ein präzises Verständnis dafür, von welcher Person oder Institution der Brief stammte und wie der Empfängerkreis bestimmt war. Da das Wesen des Briefes im Dialog bestand, gab der Verfasser seine Identität an: Er wollte eine Antwort bekommen. Eine Impressumspflicht für Briefe wäre allen Beteiligten absurd vorgekommen ${ }^{65}$. Öffentlichkeit war daher von vornherein eingeschränkt: Briefe verliefen im »privaten« Verkehr, wie immer dieser im Spätmittelalter bestimmbar war, oder richteten sich an eine beschreibbare Teilöffentlichkeit.

Die Flugschrift hingegen war von Anfang an auf Öffentlichkeit hin ausgerichtet. Auch wenn der Begriff der Öffentlichkeit zu Zeiten Luthers noch nicht bestand, so ist das Phänomen klar erkennbar. Rainer Wohlfeil hat schon vor längerer Zeit von einer »reformatorischen Öffentlichkeit« gesprochen, als er die Formen der öffentlichen Wahrnehmung und der daran anschließenden Wortgefechte zu Texten der Lutherzeit analysierte ${ }^{66}$. Diese Öffentlichkeit war nicht mehr nur die Öffentlichkeit der Eliten: Wenn sich zwischen 1519 und 1521 das Verhältnis der lateinischen zu den deutschsprachigen Flugschriften von 3:1 auf 1:3 umkehrte, dann war dies ein deutliches Zeichen dafür, dass die Medienhersteller eine Kundschaft ansprachen, die über den Kreis der Gelehrten weit hinausreichte ${ }^{67}$.

Die medialen Möglichkeiten waren ganz außerordentlich. Johannes Burkhardt hat kürzlich in einer Analyse die kommunikationsgeschichtliche Bedeutung der Reformation umrissen, die ohne die druckpublizistischen Möglichkeiten der frühen 1520er Jahre kaum derart zum Durchbruch gelangt wäre ${ }^{68}$. Technische Voraussetzungen allerdings hätten nichts genutzt, wenn nicht handelnde Personen die Chancen erkannt hätten, die in den neuen Medien lagen. Burkhardt schreibt:

gert und brauchbar befunden worden sind, auch von den vollkommensten und höchst entwickelten niemals wieder gänzlich und dauernd verdrängt und außer Gebrauch gesetzt werden können, sondern sich neben diesen erhalten, nur daß sie genötigt werden, andere Aufgaben und Verwertungsgebiete aufzusuchen«: Wolfgang RiePL, Das Nachrichtenwesen des Altertums. Mit besonderer Rücksicht auf die Römer, Leipzig 1913 (ND Hildesheim 1972), S. 5.

65 Der anonyme Brief stellte die Ausnahme dar, die hier nicht weiter verfolgt wird.

66 WoHLFEIL, Reformatorische Öffentlichkeit, S. 41-52.

67 1519: $72 \%$ lateinische und 28\% deutschsprachige Flugschriften; 1521: knapp 26\% lateinische und 74\% deutschsprachige Drucke: Hans-Joachim KöHLER, Die Flugschriften der Frühen Neuzeit. Ein Überblick, in: Werner Arnold/Wolfgang Dittrich/Bernhard Zehler (Hg.), Die Erforschung der Buch- und Bibliotheksgeschichte in Deutschland. Fs. für Paul Raabe zum 60. Geburtstag, Wiesbaden 1987, S. 307-345, hier S. 331, zit. nach WiLKE, Grundzüge der Medien- und Kommunikationsgeschichte, S. 26.

68 Burkhardt, Das Reformationsjahrhundert, bes. S. 30-64. 
Vor allem aber der reformatorische Mythos geht auf das unglaubliche Geschick zurück, mit dem schon Luther, seine Mitarbeiter und Parteigänger mit dem neuen Medium des Druckes umgingen und so ihre Lesart der Dinge nicht nur bewusst verbreiteten, sondern der Gedächtniskultur der Nachwelt überlieferten. Darum wird die Reformationsgeschichte hier als der erste große Geschichtsmythos aus der Druckerpresse erschlossen.

[...] Was Luther sagte, war wichtig, aber wie er es sagte und unter die Leute brachte, war das eigentlich Moderne an der Reformation. Nicht in ihren Inhalten, sondern in den Druckmedien und der Kulturfertigkeit, mit der sie hier erstmals zum Einsatz kommen, gründet der innovatorische Impuls der Zeit ${ }^{69}$.

Es ist vielfach betont worden, dass Luther und seine Anhänger gar nicht den Bruch der Kirche erreichen, am wenigsten eine neue Kirche errichten wollten. Die Abkehr von der römischen Lehre entwickelte sich demnach erst, als die alte Kirche den inhaltlichen Diskurs verweigerte und stattdessen den Machtdiskurs eröffnete: Sie forderte bedingungslosen Gehorsam und drohte die Durchsetzung mit den Mitteln der geistlichen und weltlichen Gewalt an. Eines aber wollte Luther ganz gewiss: Alle Möglichkeiten nutzen, um seine Lehre zu verbreiten, weit über den engen Kreis der mitteldeutschen Kleriker hinaus, die von 95 lateinischen Thesen vielleicht erreicht worden wären. Die Legende vom Thesenanschlag, die von der Forschung inzwischen widerlegt worden ist (Erwin Iserloh ${ }^{70}$ u.a.), wird mediengeschichtlich zu einem Rührstück: Der Reformator mit einem Blatt sowie Hammer und Nägeln vor der schweren Holztüre der Schlosskirche in Wittenberg an einem düsteren Herbsttag, vermutlich mit einem traurigen Gesichtsausdruck, wenn er daran dachte, wie wenige seiner Zeitgenossen den Text wohl verstehen mochten. Nein, diese Legende vom »Thesenanschlag« leistete für das Andenken des Reformators unschätzbare Dienste, aber die eigentliche Revolution bestand darin, dass Luther sich nach der Publikation der lateinischen Thesen in seinen theologischen Fachkreisen dazu entschloss, eine deutschsprachige Fassung zu schreiben und diese gedruckt zu verbreiten. Die Medienrevolution begann daher im Grunde mit dem Sermon von Ablass und Gnade (1518), denn dieser Text wurde zum ersten großen Medienerfolg des Wittenberger Augustinermönches und Theologieprofessors ${ }^{71}$.

69 Ebd., S. 14f.

70 Erwin IserLoh, Luthers Thesenanschlag. Tatsache oder Legende?, Wiesbaden 1962.

$71 \mathrm{Zu}$ den Thesen und dem Sermon als Programmschriften: Jens WolfF, Programmschriften, in: Albrecht Beutel (Hg.), Luther Handbuch, Tübingen 2005, S. 265-277, bes. S. 265f. - Zu den Thesen als Ursprungsmythos des Protestantismus: Burkhardt, Das Reformationsjahrhundert, S. 32-35. 
Die mediengeschichtliche Bedeutung der Ablass-Thesen betonte der protestantische Kirchenhistoriker Bernhard Lohse schon 1981. Lohse schreibt:

Die enorm schnelle Verbreitung der Thesen sowie der Diskussion um sie war nur möglich, weil es damals seit einigen Jahrzehnten die Buchdruckerkunst gab. Sie stellt neben den besonderen politischen und geistlichen Bedingungen, wie sie damals eigentlich nur in Deutschland gegeben waren, die entscheidende Voraussetzung für das ungeheure Echo auf Luthers Kritik dar. Die gewaltige Öffentlichkeitswirkung, die Luther auf diese Weise erhielt, verhinderte, dass Luther so rasch wie [Johannes] Hus beseitigt werden konnte. Die Buchdruckerkunst ist somit von erheblicher Bedeutung für das Ende der mittelalterlichen Einheitswelt und die Entstehung der pluriformen Neuzeit ${ }^{72}$.

Zum Ausdifferenzierungsprozess des Mediensystems gehört auch der Paradigmenwechsel von der Rückwärts- zur Vorwärtsgewandtheit. Martin Luther war in vieler Hinsicht ein rückwärtsgewandter Mensch, der zu Beginn seiner Karriere ganz spätmittelalterlich dachte, forschte und argumentierte. Sein Suchen nach einem gnädigen Gott, das intensive Streben, den zeitlichen Sündenstrafen und der ewigen Verdammnis im Jenseits zu entgehen, muten heute sehr fremd an. Verstärkt wurden seine Bemühungen durch die Angst, nicht mehr genug Zeit zur Buße und Umkehr zu haben: Ein baldiges Weltende stand ihm vor Augen, wie vielen seiner Zeitgenossen. Prognostiken, in mündlich überlieferter wie in schriftlicher, gedruckter Form, weisen darauf hin, dass mit einer gut begründeten Terminierung des Weltendes viel Eindruck und Geld zu machen war. In einer solchen Welt war die Zukunft die Apokalypse, während das Gute in der Vergangenheit zu suchen war. Auf dieser Grundlage ruhte das gewohnheitliche Herkommen und letztlich das gesamte Rechtsgefüge, oder - um es mit den Worten von Johannes Burkhardt auszudrücken: »Wer etwas ändern wollte, berief sich noch nicht auf eine bessere Zukunft, sondern auf eine bessere Vergangenheit, die es wiederherzustellen gelte $\ll^{73}$. Der gesamte Begriff »Re-formation « transportiert diesen Zusammenhang der Wiederherstellung von etwas vergangenem Guten, das durch schuldhaftes Handeln der Menschen verlorengegangen war.

In diese im Grunde rückwärtsgewandte Welt brach der Buchdruck ein, und Johannes Burkhardt betont zu Recht, dass es der wichtigste wirtschaftliche und gesellschaftliche Bereich war, der trotz seiner Neuigkeit positiv konnotiert war:

72 Bernhard LoHsE, Martin Luther. Eine Einführung in sein Leben und sein Werk, München 1981 (31997), S. 57.

73 Burkhardt, Das Reformationsjahrhundert, S. 16. 
Daß schon die Alten hätten Bücher drucken können, konnte man denn doch schlecht behaupten, die ars imprimiendi libros war ersichtlich eine »neue Art des Schreibens« (genus novum scribendi) oder "neue Kunst des Schreibens« (ars nova scribendi). Wenn von der »wunderbaren und früher nicht bekannten Kunst des Bücherdruckens« die Rede war, wurde das Neue zum Guten; es war eine Erfindung, aber eine inventio artificiosa, zu der man sich bekannte. Als »neue erfindungsreiche Kunst« (ars nova ingeniosa) wurde die Druckkunst bestaunt, als edle und nützliche Kunst, ja Kunst der Künste gefeiert. Dazu gehörte auch die Vervielfältigungsleistung (multiplicatio librorum) - häufig hieß es stolz, dass ein Drucker an einem Tag drucken könne, woran früher ein Schreiber ein Jahr lang geschrieben habe. Auch wenn das Medium als Wunder Gottes oder »letztes Geschenk Gottes« vor dem Weltuntergang gepriesen wurde, so war doch ersichtlich noch einmal etwas Neues in die Welt gekommen. Kritische Stimmen baten eher kleinlaut um Schonung für die geschriebenen Bücher. Oder aber man entdeckte erstaunt, dass auch die Gegner drucken konnten, und erklärte, das sei nun aber doch ein Missbrauch der Druckkunst. Das aber waren Anpassungsdiskussionen, die das neue typographische Prinzip nicht in Frage stellen konnten - schon weil auch sie gedruckt geführt wurden ${ }^{74}$.

Dieser Prozess vollzog sich nicht nur zufällig vor den Augen der Öffentlichkeit, sondern diese Öffentlichkeit sollte ausdrücklich daran teilhaben. Luther ließ die vorherige Grundhaltung weltlicher wie geistlicher Obrigkeiten hinter sich: In seinen Augen war der »gemeine Mann« nicht bloß ein herrschaftsunterworfenes Subjekt, sondern eine heilsfähige Persönlichkeit. Daher forderte er den unmittelbaren Kontakt jedes Christen zur Heiligen Schrift. Günther Lottes brachte es auf die Formel, durch die medial umgesetzte Reformation sei das Wort nicht zu Fleisch, wie im Johannes-Evangelium (Joh. 1,14) geschrieben, sondern es sei zu Papier geworden ${ }^{75}$. Dazu diente Luthers Übersetzung zunächst des neuen, dann des alten Testaments, und dazu diente die Einrichtung der Schrift für die massenhafte Reproduktion durch die Druckerpresse. Diese Sicht auf die Religion gewann naheliegenderweise große Attraktivität, nicht nur weil die alte Kirche, ihre Protagonisten und ihre Formen kritisiert wurden, sondern weil der Einzelne, das Individuum als bibelwürdig aufgewertet wurde: Der Leser durfte sich geschmeichelt fühlen, dass das Wort schnell in einer preiswerten Ausgabe zu ihm kam6.

Wenn der gewöhnliche Untertan schon den wichtigsten Text der frühmodernen alteuropäischen Kultur selbst lesen durfte, dann konnten die Obrig-

74 Ebd., S. 17, mit dem Nachweis der Begriffe und Zitate.

75 Günther Lottes, Reformation in Regensburg, in: Martin Angerer (Hg.), 450 Jahre Evangelische Kirche in Regensburg (1542-1992). Ausstellung im Museum der Stadt Regensburg, Regensburg 1992, S. 15-28, Zitat S. 24.

76 Vgl. zu diesen und weiterführenden Überlegungen: BURKHARDT, Reformationsjahrhundert, S. $47 \mathrm{f}$. 
keiten ihm andere Lektüre erst recht nicht mehr verbieten. Im Analogieverfahren mussten diesem aufgewerteten Individuum auch alle Texte mit politischen Inhalten zugänglich sein, weil sie innerhalb der Wertehierarchie der Zeit unterhalb der biblisch-religiösen Texte anzusiedeln waren. Der Weg zur allgemeinen Lektüre war damit eröffnet, wenn auch für die ersten Schritte, denn zunächst blieb die Zahl derjenigen, die die Kulturtechnik der Lesefähigkeit beherrschten, begrenzt. Die pädagogischen Bestrebungen der Reformatoren, das Lesen-Lernen weit über den Kreis der Lateingelehrten hinaus auszudehnen, beförderten denn auch beide Zwecke, das Lesen der Bibel und anderer Texte ${ }^{77}$.

Wesentliche Impulse verlieh dem Flugschriftenwesen der Umstand, dass religiöse Kontroversen in breiter Form im neuen Medium ausgetragen werden konnten. Nachdem sich schon Luther für eine breite Propaganda ausgesprochen hatte - ohne Rücksicht auf bestehende rechtliche Rahmenbedingungen wie Impressumspflicht und Verunglimpfungsverbot -, setzten die jeweiligen Obrigkeiten sowie die Druckproduzenten diese Verfahrensweise ungebrochen fort ${ }^{78}$. Der konfessionelle Gegner konnte, besonders in der Anfangsphase der Reformation, nach Belieben angegriffen oder auch satirisch verhöhnt werden. Interessanterweise setzte sich diese »Streitkultur» nicht für politische Konflikte durch: Die »doppelte Konkurrenz« zwischen den Mächten im Reich, die vertikale zwischen Kaiser und Reichsständen wie auch die horizontale zwischen Standesgleichen wurde nicht zum Gegenstand breiter Polemiken ${ }^{79}$. Rechtliche Deduktionen hingegen waren erlaubt, die meisten davon herrschaftlich induziert. Daher spielte sich die Gewohnheit ein, innenpolitische Konflikte als Rechtsstreite zu inszenieren. Bei den fünf im Folgenden zu verhandelnden Fallstudien handelt es sich um derartige Konflikte.

77 Bildungsbestrebungen bei Luther: Markus Wriedt, Kap.: Prägungen 1: Bildung, in: Albrecht Beutel (Hg.), Luther Handbuch, Tübingen 2005, S. 231-236; Bildungsbestrebungen bei Calvin: Stefan Ehrenpreis, Kap.: Bildung und Pädagogik, in: Herman Selderhuis (Hg.), Calvin Handbuch, Tübingen 2008, S. 422-431. - Vgl. dazu auch die folgenden Sammelbände, die besondere die reformatorischen Bemühungen im Elementarschulbereich berücksichtigen: Heinz Schilling/Stefan Ehrenpreis (Hg.), Erziehung und Schulwesen zwischen Konfessionalisierung und Säkularisierung. Forschungsperspektiven, europäische Fallbeispiele und Hilfsmittel, Münster u.a. 2003; Heinz Schilling/Stefan Ehrenpreis (Hg.), Frühneuzeitliche Bildungsgeschichte der Reformierten in konfessionsvergleichender Perspektive. Schulwesen, Lesekultur und Wissenschaft, Berlin 2007.

78 Thomas Kaufmann konstatiert bereits für die Kontroversen um die konfessionspolitische Stellung Magdeburgs während des Interims eine breite Missachtung der Impressumspflicht durch das Magdeburger Druckhaus Michael Lotter, das mit dieser Haltung typisch für fast alle anderen Druckproduzenten verfuhr: Thomas Kaufmann, Das Ende der Reformation. Magdeburgs »Herrgotts Kanzlei« (1548-1551/52), Tübingen 2003, S. 52f. 
Das gewöhnliche Medium für den Austrag dieser Kontroversen war die Deduktion. Sie erschien in der Form einer schriftlichen Eingabe im Rahmen eines Prozesses vor Gericht oder vor einem Reichsgremium. Zahlreiche Deduktionen erschienen auf dem offenen Markt für Druckwerke - Andreas Gestrich bezeichnet das als »sekundäre Rezeption ${ }^{80}$ - wobei nur selten feststellbar ist, ob der offene Verkauf vom Initiator angestrebt worden war, oder ob es sich um ein Versehen gehandelt hatte. Eine international gebräuchliche Form der Deduktion, das Kriegsmanifest, war ausdrücklich für die öffentliche Bekanntgabe der rechtlichen Gründe eines Waffenganges vorgesehen und wurde in aller Regel gedruckt in Umlauf gesetzt ${ }^{81}$.

Susanne Friedrich hat im Rahmen ihrer Studie über die Kommunikationsprozesse am Reichstag die Bedeutung der Deduktionen als Informationsquelle, aber auch als Mittel des Konfliktaustrags untersucht ${ }^{82}$. Wie sich aus dieser Schriftengattung im Laufe des 17. und 18. Jahrhunderts ein Instrument zum reichsöffentlichen Räsonnement über Schwächen und Entwicklungschancen des gesamten Gemeinwesens herausbildete, hat Wolfgang Burgdorf in seiner Monographie über Reichskonstitution und Nation herausgearbeitet. Anders als bei Prozessen, die idealiter irgendwann einmal abgeschlossen werden sollten, stellte sich die Reichsreformdiskussion als zeitlich unbefristeter Prozess dar. Burgdorf nennt den medialen Austrag dieser Debatte den »intergouvernementalen Diskurs «, der zwar außerhalb der Reichsgremien stattfand, aber dennoch zahlreiche Personen einbezog, die über einflussreiche Ämter am Kaiserhof, an Fürstenhöfen, in Reichsgremien oder Universitäten verfügten ${ }^{83}$. Da der Übergang von einer Deduktion zu einem reichspublizistischen Buch fließend war - bis heute gibt es keine Obergrenze für die Seitenzahl einer Flugschrift -, berührt dies die unten folgenden Überlegungen zum Zusammenhang zwischen Historienschriften und Reichsstaatsrechtslehre.

Für Deduktionen galten dieselben Anforderungen wie für andere Schriftstücke im internen wie im öffentlichen Gebrauch: Ein polemischer Angriff auf einen Fürsten beispielsweise war normalerweise erst dann erlaubt, wenn dieser militärisch geschlagen oder rechtlich geächtet worden war. Ein Beispiel dafür war die Propaganda gegen den geächteten Kurfürsten Friedrich V.

80 Gestrich, Absolutismus und Öffentlichkeit, S. 198.

81 Zur Gattung des Kriegsmanifests: REPGEN, Kriegslegitimationen in Alteuropa, S. 27-49. - Zur Begründungssprache des Krieges: Bernd Klesmann, Bellum solemne. Formen und Funktionen europäischer Kriegserklärungen des 17. Jahrhunderts, Mainz 2007.

82 Friedrich, Drehscheibe Regensburg, S. 206-215.

83 Zur Begriffsbildung: Burgdorf, Reichskonstitution und Nation, S. 502. Vgl. dazu auch die Überlegungen in Wolfgang Burgdorf, Der intergouvernementale publizistische Diskurs. Agitation und Emanzipation, politische Gelegenheitsschriften und ihre Bedeutung für die Entstehung politischer Öffentlichkeit im Alten Reich, in: ARnDT/KöRBER, Das Mediensystem im Alten Reich der Frühen Neuzeit, S. 67-87. 
von der Pfalz nach seiner Niederlage im böhmischen Krieg am Weißen Berg im November $1620^{84}$. Eine Folge dieser - wenn auch eingeschränkten - Förderung der Konfliktkultur war das Bemühen der Obrigkeiten um die Lesefähigkeit breiter Schichten der Untertanen. Hierdurch sollte erreicht werden, dass der "gemeine Mann« die geistliche Literatur der jeweils »richtigen" Seite wahrnehmen und die der Gegenseite erkennen und meiden sollte, um auf diese Weise eine Immunisierung gegen abweichende geistliche Konzeptionen herbeizuführen ${ }^{85}$.

Statt die komplizierten reichsrechtlichen Konflikte zu thematisieren, für deren Verständnis in der Regel tiefere historische und politisch-rechtliche Hintergrundkenntnisse erforderlich waren, bot sich eher die mediale Vermittlung der sichtbaren Politik an. Dazu gehörten vor allem militärische Auseinandersetzungen, aber auch politische Verträge samt deren Folgen oder höfisch-dynastische Veranstaltungen wie Feste, Geburten, Heiraten, Todesfälle etc. Über diese Themen zu berichten war verhältnismäßig unverdächtig: In der Regel handelte es sich um Ereignisse, die entweder keine nachteiligen Folgen hatten (wie familiäre Rituale) oder deren Folgen ohnehin nicht zu verbergen waren (wie verlorene Schlachten oder Gebietsverluste). Im Gegensatz zum Strukturkonflikt verfassungsgeschichtlicher Herkunft war hier der Interpretationsspielraum begrenzt: Es konnten sich kaum über längere Zeit zwei völlig entgegengesetzte Grundpositionen unverändert gegenüberstehen, ohne bald darauf verifizierbar oder falsifizierbar zu werden. Zudem bot die politische Berichterstattung die Möglichkeit der Sequenzialität: Immer wieder passierte etwas, was einen Bericht lohnte, und dabei konnte der Verfasser an vorheriges Geschehen (explizit oder implizit) anknüpfen. Je dichter die Berichterstattung über die europäische politische Welt in der zweiten Hälfte des 16. Jahrhunderts wurde, je mehr Flugschriften hergestellt und in fremde Sprachen übersetzt wurden, desto eher konnte der Gedanke der regelmäßigen Information des Publikums entstehen.

Die reichsrechtlichen Deduktionen waren ausdrücklich nicht für eine breitere Öffentlichkeit bestimmt. Allerdings dürften zwei Aspekte nicht übersehen werden: Zum einen wurden viele dieser Deduktionen von Druckern und Verlegern produziert, die ein ökonomisches Interesse an einem guten Absatz hatten, wobei es ihnen gleich war, aus welcher Schicht oder welchem Land

$84 \mathrm{Zu}$ Friedrich V. von der Pfalz: Peter BilhöFer, Nicht gegen Ehre und Gewissen. Friedrich V., Kurfürst von der Pfalz - der »Winterkönig« von Böhmen (1596-1632), Heidelberg 2004; Olivier Chaline, Die Schlacht am Weißen Berg (8. November 1620), in: Klaus Bussmann/Heinz Schilling (Hg.), 1648 - Krieg und Frieden in Europa. Katalog zur 26. Europaratsausstellung Münster/Osnabrück 1998, Textbd. 1, München 1998, S. 95-101; Reinhold KosER, Der Kanzleienstreit. Ein Beitrag zur Quellenkunde der Geschichte des Dreißigjährigen Krieges, Halle a.d. Saale 1874; Peter Wolf u.a. (Hg.), Der Winterkönig Friedrich von der Pfalz. Bayern und Europa im Zeitalter des Dreißigjährigen Krieges, Augsburg 2003.

WELKE, Die Legende vom »unpolitischen Deutschen«, hier S. 163. 
die Erwerber stammten. Zum anderen gehörten die Medienmacher in Gestalt der Verleger, Autoren und Redakteure von Periodika ebenfalls zu den Rezipienten, und die wandelten die Informationen anschließend in Berichte um, die auf expandierende Marktbreite abzielten.

\subsubsection{Messrelationen}

Der Zusammenhang von Flugschriften mit den Warenmessen der Frühmoderne erstaunt etwas, spielten Messen für die kontroverse und auch die politisch-aktuelle Berichterstattung doch bis dahin keine herausragende Rolle. Die Verwunderung wächst, wenn realisiert wird, dass es nicht die Messebetreiber, etwa in Frankfurt a.M. oder Leipzig waren, die die Messrelation als offizielles Organ »erfanden«, sondern dass ein Kölner Flugschriftenschreiber, Michael von Eitzing, diese Mediengattung erstmals besorgte ${ }^{86}$. Eitzing stammte aus einer österreichischen Ritterfamilie, hatte aber im Dienst Kaiser Maximilians II. nur untergeordnete Chargen im Hofdienst bekleidet. Er übersiedelte in den 1560er Jahren in die Niederlande. Seine Haupttätigkeit ist unbekannt; nebenbei war er als Schreiber politischer Texte tätig. Nachdem er unter dem Herzog von Alba einige Zeit inhaftiert worden war, konnte er sich in Köln niederlassen und dort eine rege Autorentätigkeit als politischer Publizist entfalten. Er unterhielt Kontakte zum Kölner Kurfürst Ernst von Bayern, den er mit Berichten aus den Niederlanden versorgte und in dessen Auftrag er Recherchen für größere Historienwerke anstellte. 1583 erschien eine erste Relatio über den Kölner Krieg ${ }^{87}$. Ein Jahr später folgte seine ausführlichere Darstellung über den Konflikt um das Kölner Erzstift, versehen mit

86 Zu Michael von Eitzing: Felix StIEve, Über die ältesten halbjährlichen Zeitungen oder Meßrelationen und insbesondere über deren Begründer Freiherr Michael von Aitzing, in: AHKBAW 16 (1883), 1. Abt., S. 177-265; Wilhelm BonACKer, Le baron Michael van Eitzing (ca. 15301598) et la »Belgici Leonis Chorographia«, in: RBPH 37 (1959), S. 950-967; ARNDT, Das Heilige Römische Reich und die Niederlande, S. 219-227. - Jüngere Forschungsarbeiten zu den Messrelationen: Klaus Bender (Hg.), Relationes historicae. Ein Bestandsverzeichnis der deutschen Meßrelationen von 1583 bis 1648, Berlin/New York 1994; Juliane GLÜER, Meßrelationen um 1600. Ein neues Medium zwischen aktueller Presse und Geschichtsschreibung. Eine textsortengeschichtliche Untersuchung, Göppingen 2000; Ulrich RossEAux, Die Leipziger Meßrelationen 1605-1730. Ein Beitrag zur Medien- und Kommunikationsgeschichte der Frühen Neuzeit, in: Leipziger Jahrbuch zur Buchgeschichte 12 (2003), S. 11-32; ders., Die Entstehung der Meßrelationen. Zur Entwicklung eines frühneuzeitlichen Nachrichtenmediums aus der Zeitgeschichtsschreibung des 16. Jahrhunderts, in: HJb 124 (2004), S. 97-123; Marina Stalluohann, Der Kaufmann im Fokus der Meßrelationen, in: Bauer/Böning, Die Entstehung des Zeitungswesens im 17. Jahrhundert, S. 115-134.

87 »Relatio historica dessen, so sich nach dem Abschied der Coellnischen Zusammen=Kunfft wegen der Niederländischen Pacification gehalten [...]«, Köln 1584. Trotz des auf die Niederlande bezogenen Titels handelt es sich um Konflikte im Niederrheinisch-Westfälischen Reichskreis. 
einem 159 Seiten starken Vorspann einer Weltgeschichte von der Erschaffung bis $1559^{88}$. Historiographischen Nachruhm erwarb der Publizist durch seine Studie mit dem Titel De Leone Belgico, eine Geschichte des niederländischen Aufstands bis $1583^{89}$. Gleichzeitig regte Eitzing den Kupferstecher Frans Hogenberg an, einen Stich der 17 niederländischen Provinzen auf eine Weise zu machen, dass die Karte aussah wie ein nach rechts blickender Löwe. Dieses Motiv wird von Kunsthistorikern und Kartographen ebenfalls Leo belgicus genannt ${ }^{90}$. Eitzing war auf der Höhe der Zeit hinsichtlich der Bedienung des Kundengeschmacks: Wo immer es sich anbot und finanzieren ließ, stattete er seine Werke mit Stichen und Karten aus. Seine Chorographia von 1587 war ein großes Kartenwerk der Niederlande, dem auch die Porträtstiche der Habsburgerherrscher und ihrer Statthalter beigegeben wurden, wobei die Abbildungen erneut von Frans Hogenberg stammten ${ }^{11}$.

Eitzing ließ im einen oder anderen Vorwort seiner Schriften durchblicken, dass er aus finanziellen Gründen gezwungen war, durch die Massenproduktion von Texten sein Auskommen zu finden. Der Absatz dürfte zufriedenstellend gewesen sein, denn seine Schriften wurden von verschiedenen Kölner Druckern bzw. Verlegern produziert. Ein weiteres Indiz für den publizistischen Erfolg war das Erscheinen von Nachahmern, die ebenfalls Marktchancen sahen, im Stile Eitzings Berichte herzustellen ${ }^{92}$.

Irgendwann kam Eitzing die Idee, halbjährliche Zusammenfassungen über das jüngste Zeitgeschehen zu verfassen und dies in den Titeln der Schriften zu vermerken: Die Leserschaft sollte darauf hingewiesen werden, dass eine Serialisierung geplant war und dass sie dem nächsten Heft in einem halben

88 Michael von EItZIng, Rerum Vaticiniis accomodata Historia: Das ist: Eine Hystorische Beschreibung oder Relation deß so sich nit allain under dem jetzt regier. Khayser Rudolpho II. [...] wegen Hinlegung und Abstellung der Niderländischen [...] Empoerung etc. verloffen, Köln 1584.

89 Michael von EitZING, De Leone Belgico eius Topographia atque historica descriptione liber [...], Köln 1583; deutsche Übertragung: ders., Niderländische Beschreibung/in Hochteutsch/und Historischer weiß gestellt/auff den Belgischen Löwen/der Sibenzehn Provintzen deß gantzen Niederlandts [...], 2 Bd., Köln 1584.

90 Abdruck in: James TANis / Daniel Horst (Hg.), Images of Discord. A Graphic Interpretation of the Opening Decades of the Eighty Year's War, Bryn Mawr 1993, S. 37. Vgl. dazu auch: Peter H. Meurer (Hg.), Atlantes Colonienses. Die Kölner Schule der Atlaskartographie 1570-1610, Bad Neustadt a.d. Saale 1988, S. 108-113.

91 Michael von Eitzing, Belgici Leonis Chorographia Das ist Ein Newe Landt beschreibung des Belgischen Lewen in XVII Prouincien des gantzen Niderlandts außgetheilet, Köln 1587. Der Betrachtungszeitraum ist 1559-1587; vgl. BonACKER, Le baron Michael von Eitzing (ca. 153098) et la »Belgici Leonis Chorographia«, pas.

92 In der posthum erschienenen Flugschrift »Relationum continuatio« von 1599 warnt Eitzing im Vorwort seine Leser, dass Nachahmer »schlechte Historien« verbreiteten: M. EYTZERINGERI, Historicarum Relationum Continuatio. Das ist historische Beschreibung was sich hin und wider durch gantz Europa gedenckwirdigs zugetragen [...], Köln 1599. 
Jahr entgegensehen sollte ${ }^{93}$. Das Zeitgeschehen ließ sich zu diesem Zweck in einem Umfang von ca. 100 Seiten pro Heft zusammenfassen. Dabei erfüllten die neuen Medien schon drei Kriterien, die später für Zeitungen maßgeblich werden sollten: Publizität, Periodizität und Universalität der Berichterstattung lassen sich nachweisen ${ }^{94}$. Allerdings war das keinesfalls ein förmlicher Gründungsakt eines neuen Mediums. Eitzing war offenbar, was die Redaktion anging, weiterhin ein »Ein-Mann-Betrieb«, und er konnte seinen Anspruch, ein europaweites Periodikum dauerhaft zu unterhalten, inhaltlich noch gar nicht einlösen. Weder standen ihm systematische Quellen zur Verfügung, noch reichte sein Sachverstand aus, um die politischen Probleme aus Spanien, Frankreich, England, Italien, Skandinavien oder dem Balkan mit gleichmäßiger Dichte und Durchdringung reproduzieren zu können. Daher dominierten in seiner Berichterstattung stets der Niederlande-Konflikt sowie die damit in Zusammenhang stehenden Begebenheiten im Rheinland und in Westfalen. Wie sehr er für »seinen « Markt schrieb, zeigt auch die starke probayerische Ausrichtung seiner Bewertungen insbesondere das Kölner Erzstift betreffend. Vermutlich ist der Übergang zur Messrelation, d.h. die systematische Bindung der Hefte an die Frankfurter Messetermine, das Resultat buchhändlerischer Überlegungen gewesen: Gerade in den 1580er Jahren, die sonst im Heiligen Römischen Reich verhältnismäßig konfliktarm verliefen, konnten kompetent und flüssig geschriebene Berichte über den Krieg im westlichen Nachbarland profitabel an Interessenten im ganzen Reich vermarktet werden.

Eitzings Messrelationen erschienen in der Regel anonym oder unter einem fiktiven Namen. Ebenso verfuhren seine erfolgreichen Konkurrenten, der Frankfurter Pfarrer Conrad Lautenbach ${ }^{95}$, der Kölner Publizist Caspar Ens ${ }^{96}$,

93 Zunächst hatten die Hefte noch keinen Markentitel, sondern im Stil der Buchproduktion noch eine Inhaltsbezeichnung auf dem Vorderblatt, versehen mit einem Berichtszeitraum: Michael vON Eitzing, Kurtzer Historischer Begriff und Inhalt/der Handel/so sich im Niederlandt/und Ertzstift Cölln/die nechsten sechs Monat anhero und etwas darvor/zugetragen/bis auff jetzt ablauffendts Monat Septembris / Anno 1586 [...], Köln 1586; ders., Kurzer Historischer Begriff und Inhalt der Haendel, so sich im Niederlandt unnd Ertzstifft Cölln/die nechsten sechs Monate anhero/und etwas davor/zugetragen/biß auff jetz ablauffendts Monat Septembris Anno 1586 [...], Köln 1587.

94 Wilke, Grundzüge der Medien- und Kommunikationsgeschichte, S. 30; GLÜER, Meßrelationen um 1600, S. 2.

95 Zur Person: Christian Gottlieb Jöcher/Johann Christoph AdELung (Hg.), Allgemeines Gelehrten-Lexicon, 4 Bd. (Forts. 7 Bd.), Leipzig 1750-1751 (Forts. bis 1897), hier Bd. 2, Sp. 2318. DBA 744, S. 336-338; ADB 18, S. 71f. - Zu den weiteren Messrelationen nach Michael von Eitzing: Lindemann, Deutsche Presse bis 1815, S. 82-84.

96 Caspar Ens, Annalium sive Commentariorum de bello Gallico Belgico tomi III [...], Köln 1606; Gaspar LoRchanus, Mercurii Gallobelgici succenturiati sive rerum in Gallia et Belgio [...] gestarum historicae narrationis continuatae tomus quartus [...], Köln 1603; Caspar ENs, Annalium Mercurio Gallobellico succenturiatorum tomus quintus [...], Köln 1606. Zum Autor 
der Straßburger Publizist Thomas Steger ${ }^{97}$ oder der Kölner Notar Wilhelm Riephan ${ }^{98}$. Personell fassbar hingegen ist der Frankfurter Drucker und Verleger Sigismund Latomus, der in den ersten drei Jahrzehnten des 17. Jahrhunderts an der Messrelationsherausgabe beteiligt war. Später setzte seine Witwe die Verlegertätigkeit dieses Mediums fort ${ }^{99}$. Die Leserschaft beschränkte sich keineswegs auf das Messepublikum im engeren Sinne, sondern schloss Hofgesellschaften und Adel mit ein. In der Sammlung der böhmischen Adelsfamilie von Rosenberg konnten die Relationen Eitzings ebenso nachgewiesen werden wie diejenigen, die unter den Verfassernamen Francus, Meurer, Frey, Chytraeus und Striegel herausgekommen waren ${ }^{100}$.

Die Messrelationen waren politische Druckmedien im Übergang: Auf Flugschriften und Historienschriften verwiesen sie zurück, auf die Zeitung wiesen sie hin. Bei allen genannten Verfassern von Messrelationen ist erkennbar, wie eng die verschiedenen im Gebrauch befindlichen politischen Druckmedien nebeneinander genutzt wurden: Dieselben Personen stellten Flugschriften, Messrelationen und Historienschriften her. Daneben nutzten sie Flugschriften für die Messrelationen und diese später mit etwas zeitlichem Abstand für ihre Historienschriften. Caspar Ens nutzte für seine Fama austriaca, eine große Historiendarstellung aus dem Jahre 1627, Druckschriften aus ganz Mitteleuropa, die den Zeitraum zwischen 1609 und 1627 betrafen ${ }^{101}$.

Der Durchlauf der Informationen durch die unterschiedlichen Mediengattungen ist hier, wie an anderer Stelle, gut zu erkennen. Kein Medium wurde durch ein anderes ersetzt, sondern jedes neue Medium fügte sich unter Förderung der Vielfalt ins »Konzert« der schon üblichen Arten der Berichter-

und seinen Verbindungen zu Druckgraphikproduzenten in Köln: Fritz Hellwig (Hg.), Franz Hogenberg - Abraham Hogenberg. Geschichtsblätter, Nördlingen 1983, S. 24.

97 Tobias Steger, Unpostreuterische/Das ist/Unpartheyhische Geschicht Schriften/So sich speder der nehesten Herbstmesse/in Spanien/England/Franckreich/Niederland/Böhmen/Polen/Ungern/Und fast in dem mehrer teil Europa zugetragen bis auff jetzigen September [...], Straßburg 1590.

98 Wilhelmus Riephan, Supplementum Epitomes. Das ist/Kurtze Warhaffte/unnd Eigentliche Historische beschreibung/deren glaubwürdigsten Händeln und Geschichten, die welche sich in [...] Hoch unnd Niederteutschland [...] zugetragen [...], Köln 1593. Zu Riephan: Bernard Antoon Vermaseren, Van nieuwsbericht tot geschiedwerk, in: Het Boek 28 (1944), S. 241-257, hier S. 254.

99 Vgl. das Impressum der Messezeitung »Relatio historicae semestralis Continuatio«, o.O. vom Herbst 1616, wo der Verfasser sich als »Sigismundum Latomum, alias Meurer, Francum, verlegt und continuirt« ausweist. Vgl. zu den Pseudonymen auch Dieter Scala in: Rainer Koch, Brücke zwischen den Völkern. Zur Geschichte der Frankfurter Messe, hier Bd. 3, S. 193.

100 Zdenek ŠIMECEK, Geschriebene Zeitungen in den böhmischen Ländern um 1600 und ihr Entstehungs- und Rezeptionszusammenhang mit den gedruckten Zeitungen, in: BLÜHM/GEBHARDT, Presse und Geschichte, Bd. 2, S. 71-82, hier S. 75, zit. nach GlÜER, Meßrelationen um 1600, S. 19, Anm. 37.

101 Caspar Ens, Fama austriaca, Das ist: Eigentliche Verzeichnuß denckwürdiger Geschichten/welche sich in den nechstverflossenen 16 Jahren hero biß auff und in das Jahr 1627 begeben haben [...], Köln 1627. 
stattung ein. Juliane Glüer hat fünf Typen von Messrelationen unterschieden, die »annalistische Relation«, die »Historia-Relation«, die »Flugschriftenrelation «, den »episodischen Typ « und den »Wochenzeitungstyp « ${ }^{102}$. Die beiden ersten Typen knüpften an die Geschichtsschreibung an, die beiden nächsten an die Flugschrift, während der letzte Typ Elemente enthielt, die später bei den Zeitungen eine wichtige Rolle spielen sollten. Der Ausdifferenzierungsprozess der politischen Berichterstattung war daher kein linearer Prozess, sondern vielfach ein Rückgriff auf frühere Medien: Historienschriftstellerei war seit der Antike bekannt, und aktuelle Berichte orientierten sich daher vielfach an antiken Plots. Als Übergangsmedium erweist sich die Messrelation auch hinsichtlich der Häufigkeit ihres Erscheinens: Sie war auf das konfessionelle Zeitalter konzentriert, wobei eine klare Häufung zwischen 1590 und 1620 lag. Anschließend nahm sie an Zahl schnell ab, ersetzt durch die Zeitung $^{103}$. Die Messrelationen in Frankfurt a.M. und Leipzig hingegen blieben bestehen. Sie bewahrten auch unter den veränderten Umständen ihren Charakter, Begebenheiten aus einem längeren Zeitabschnitt in einen Kontext zu bringen und derart zu präsentieren. Selbst der Übergang zur historisch-politischen Zeitschrift bedeutete nicht ihr Ende. Erst 1730 wurde die Leipziger Relation eingestellt, wobei der Verlag Grosse der zunehmenden Ausdifferenzierung auf dem Medienmarkt Rechnung trug ${ }^{104}$. Die Frankfurter Messrelationen hingegen bestanden bis $1806^{105}$.

\subsection{Die Entwicklung der Zeitung zum Leitmedium der politischen Publizistik}

\subsubsection{Grundbegriffe und -phänomene}

Auch im multimedialen und digitalen Zeitalter ist die Zeitung im allgemeinen Bewusstsein derart präsent, dass das Gefühl vorherrscht, es müsse sie schon immer gegeben haben. Dass sie das Ergebnis eines Ausdifferenzierungsprozesses gewesen ist, dass sie schon vor der Aufklärung, aber erst lange nach Luther entstand, dass sie in ihrem ersten Krieg, dem Dreißigjäh-

102 GLÜER, Meßrelationen um 1600, S. 14-23.

103 Statistische Auswertung: BENDER, Relationes historicae, zitiert und in eine Graphik übersetzt durch Wilke, Grundzüge der Medien- und Kommunikationsgeschichte, S. 31f.

104 Ernst Quentin, Die Leipziger Meßrelationen. Ein Beitrag zur Geschichte des ältesten deutschen Zeitungswesens, Leipzig 1941, S. 42; Klaus Bender, Die Frankfurter Meßrelationen und Michael Kaspar Lundorp. Neue Funde aus den Jahren 1620-1627, in: Wolfenbütteler Notizen zur Buchgeschichte 9 (1984), H. 3, S. 87-109, hier S. XI, zit. nach FrIEDRICH, Drehscheibe Regensburg, S. 476; Rosseaux, Die Leipziger Meßrelationen, S. $30 \mathrm{f}$.

105 Alexander Dietz, Frankfurter Handelsgeschichte, 3 Bd., Frankfurt a.M. 1921, hier Bd. 3, S. $99 \mathrm{f}$. 
rigen, nicht unterging, sondern erst recht aufblühte, das bedarf der Vermittlung und Erklärung.

In der Forschung wird die Abkunft der gedruckten Zeitung aus der geschriebenen Zeitung immer wieder betont: In der Person des Johann Carolus, des Inhabers der Jobinschen Offizin in Straßburg, stellte sich der Zusammenhang in wünschenswerter Klarheit dar ${ }^{106}$. Allerdings darf der personelle Aspekt gegenüber dem strukturellen nicht überbetont werden. Die schon vorgestellten Druckmedien der Flugschriften und der Messrelationen haben ebenfalls ihren Anteil daran, dass sich ein breiter Medienmarkt in Mitteleuropa entwickeln konnte, der überhaupt erst die Grundlage für die Aufnahme des neuen Mediums bot: Dass irgendwo immer irgendetwas Politisches geschah, das wusste man auch vorher. Es setzte sich erst im Laufe des 17. Jahrhunderts als allgemeines Wissen unter den Lesefähigen im ganzen Reich durch, dass es auch regelmäßig Berichterstattung über diese Begebenheiten gab und dass jeder interessierte Kunde in den Besitz dieser Berichte gelangen konnte.

Was war und ist überhaupt eine Zeitung? Der Begriff »Zeitung«, der sich von »Zidung« bzw. »Tydinge« (= allgemein-interessante Neuigkeit) herleiten lässt, bezog sich im 16. und 17. Jahrhundert nicht nur auf das Medium, sondern auf die Nachricht selbst ${ }^{107}$. Zahlreiche Flugschriften des 16. Jahrhunderts führten den Titel »Neue Zeitung«, stellten aber trotzdem Gelegenheitsschriften dar. Die griffigste Definition für das moderne Verständnis der Zeitung prägte Johannes Weber:

Als Zeitung bezeichnen wir jenes Druckmedium, das regelmäßig in kurzen Abständen, wenigstens aber wöchentlich erscheint, in verhältnismäßig hoher Auflage zu einem moderaten Preis öffentlich angeboten wird und damit ein ziemlich großes Publikum über wichtige aktuelle Ereignisse und Vorgänge aus aller Welt informieren $\mathrm{kann}^{108}$.

106 Zur Herleitung aus der Briefkorrespondenz: Stieler, Zeitungs Lust und Nutz (1695/1969), S. 15. - Zu Carolus: WeBer, "Untherthenige Supplication Johann Caroli/Buchtruckers«, S. 257-265. - Zur Entstehung des neuen Periodikums unter Aufarbeitung ihrer Mythogenese: WelKe, Johann Carolus und der Beginn der periodischen Tagespresse, S. 9-116. Welke bereitet eine Biographie zu Johann Carolus vor. - Abdruck des Privilegienantrags Carolus' an den Straßburger Magistrat vom Dezember 1605 samt Transkription: Kutsch/Weber, 350 Jahre Tageszeitung, S. 25-32.

107 Zur Abstammung des Begriffs: Friedrich KLugE (Hg.), Etymologisches Wörterbuch der deutschen Sprache, Berlin/New York ${ }^{22} 1989$, S. 808; KLeInPAul, Das Nachrichtenwesen der deutschen Fürsten im 16. und 17. Jahrhundert, S. 1. - Auch in archivalischen Quellen war »Zeitung« die Nachricht: Vgl. die Mitteilung des Gesandten des Niederrheinisch-Westfälischen Reichskreises an Graf Simon VI. zur Lippe, 27. Aug. 1580: StA Detmold, L 41, Nr. 5, S. 41f.

108 Johannes Weber, Straßburg 1605. Die Geburt der Zeitung, in: Jahrbuch für Kommunikationsgeschichte 7 (2005), S. 3-26, Zitat S. 3. Eine beinahe gleichlautende Definition findet sich bei 
Die klassischen vier Attribute einer Zeitung sind - nach Otto Groth - die Aktualität (= der Neuigkeitsbezug), die Periodizität (= regelmäßiges Erscheinen), die Universalität (= thematische Vielfalt) und die Publizität (= allgemeine Zugänglichkeit ${ }^{109}$. Wissenschaftliche Erforschung fanden die Zeitungen bereits im 19. Jahrhundert durch Robert E. Prutz und Julius Otto Opel ${ }^{110}$. Unter den Studien aus dem frühen 20. Jahrhundert über die Entstehung des Zeitungswesens sind vor allem die von Ludwig Salomon, Paul Roth, Otto Groth und Helmut Fischer bedeutsam. Ludwig Salomon stellte eine umfangreiche Materialsammlung in drei Bänden zusammen, die noch heute lesenswert ist ${ }^{111}$. Paul Roth äußerte sich 1914 in seiner knappen, aber gut gegliederten Arbeit über Quellen für Zeitungen. Eine wichtige Rolle spielen für ihn die Bereiche des frühneuzeitlichen Pressewesen, über die am schwersten gesicherte Erkenntnisse gewonnen werden können - im Besonderen über Auflagen, Preise und Vertriebsstrukturen der Presseerzeugnisse ${ }^{112}$. Otto Groth gilt als Begründer der modernen Zeitungswissenschaft im frühen 20. Jahrhunderts. Neben theoretischen Studien hat er eine vierbändige Geschichte des Zeitungswesens publiziert, die in vieler Hinsicht bis heute grundlegend geblieben ist ${ }^{113}$. Helmut Fischer verwandte 1936 den Begriff der Zeitung noch sehr unspezifisch, indem er bereits mit der Reformation begann und das Schrifttum einbezog, das heute unter dem Namen »Flugschriften« subsumiert wird. Im zweiten Teil zeichnete er einige Biographien von Zeitungsdruckern nach. Erst der dritte Teil hatte die periodischen Schriften des frühen 17. Jahrhunderts zum Gegenstand ${ }^{114}$.

Wolfgang Behringer spricht vom »Sieg des Neuen über das Alte«, wenn er den Beginn der periodischen gedruckten Presse untersucht. Er argumentiert, dass sich die historische Blickrichtung mit Erfindung der Zeitung geändert habe: »Die Buchproduzenten, orientiert an religiösen oder humanistischen

Johannes Weber, Avisen, Relationen, Gazetten. Der Beginn des europäischen Zeitungswesens, Oldenburg 1997, S. 7.

109 Groth, Geschichte der deutschen Zeitungswissenschaft, S. 339f.; vgl. auch Jürgen WiLke, Die Zeitung, in: Fischer/Haefs/Mix, Vom Almanach zur Zeitung, S. 388-402, Definition und Bedeutung: S. 388.

110 Robert E. Prutz, Geschichte des deutschen Journalismus, Bd. 1 (mehr nicht erschienen), Hannover 1845; OpeL, Anfänge der deutschen Zeitungspresse, pas.

111 Ludwig Salomon, Geschichte des deutschen Zeitungswesens von den ersten Anfängen bis zur Wiederaufrichtung des deutschen Reiches, 3 Bd., Oldenburg 1900-1906.

112 Rотн, Die Neuen Zeitungen in Deutschland, pas.

113 Otto Groth, Geschichte der deutschen Zeitungswissenschaft. Probleme und Methoden, München 1948; ders., Die Zeitung, 4 Bd., Mannheim 1928-1930.

114 Fischer, Die ältesten Zeitungen und ihre Verleger, pas. - Vgl. auch zur Forschungsentwicklung: Faulstich, Medien zwischen Herrschaft und Revolte, S. 210f.; Wilke, Grundzüge der Medien- und Kommunikationsgeschichte, S. 41-70. 
Normen, blickten in die Vergangenheit - die Zeitungsmacher und ihre Kunden dagegen in die Zukunft ${ }^{115}$. Es handelt sich also hier um die Verstetigung der Einführung von neuen Elementen in die vormoderne Gesellschaft. Nicht der einzelne Akt der Veränderung, oder systemtheoretisch gesprochen: die einzelne Neuerung, war das $»$ Fundamentale« (Behringer) an der Medienrevolution, sondern die vielfache Wiederholung, die Medienmacher und Medienrezipienten nicht nur an den Wandel gewöhnten, sondern die eine Haltung entstehen ließen, dass Wandel erwartet und am Ende sogar manchmal gewünscht wurde. Nur auf dieser Basis konnte eine Einstellung wie »Neugier« überhaupt Platz greifen: Sie war die Triebfeder des Medienwesens, und es war daher folgerichtig, dass sich die Denker der Zeit dieses Phänomens annahmen. Daher beginnt Kaspar Stieler sein Buch Zeitungs Lust und Nutz mit folgendem Satz:

Niemand ist wol dermassen hölzern und unbelebt/daß sich nicht ein natürlicher Trieb bey ihm finden solte/allerhand zu wissen/und berichtet zu seyn dessen/was ihm vorhin nicht kund gewesen: wie dann Aristoteles/der weise Heide/redet: Alle Menschen verlangen etwas zu wissen und zu erfahren ${ }^{116}$.

\subsubsection{Die ersten Zeitungen:}

Entstehung und obrigkeitliche Rezeption

Lange Zeit hielt man zwei deutschsprachige Zeitungen aus dem Jahre 1609 für die frühesten ihrer Art: Die Relation aller gedenkwürdigen Sachen von Johann Carolus aus Straßburg und der Aviso, Relation oder Zeitung, den Jacob Lucius d.J. in Helmstedt herausgab ${ }^{117}$. Beide verdienten den Namen Zeitungen im vollen Sinne, denn sie erschienen im fraglichen Jahr mit 51 bzw. 52 wochenweise produzierten Einzelnummern. Inzwischen wies JeanPierre Kintz aus Archivalien des Straßburger Stadtarchivs nach, dass Johann Carolus (1574-1634) bereits 1605 mit dem Druck der Relation begonnen hatte - leider konnte ein Exemplar der ersten vier Jahrgänge bislang nicht

115 Behringer, Im Zeichen des Merkur, S. 303.

116 Zitat: STIELER, Zeitungs Lust und Nutz (1695/1969), S. 8.

117 Die Straßburger »Relation« wurde 1876 durch den Historiker Julius Otto Opel in der UB Heidelberg wiederentdeckt. Der Wolfenbütteler »Aviso« wurde 1903 durch den Postrat Ferdinand Grimme in der Königlichen Bibliothek Hannover gefunden: Behringer, Im Zeichen des Merkur, S. 305. - Zur älteren Forschung: Fischer, Die ältesten Zeitungen, S. 77-79. Fischer stellt im Folgenden die beiden Zeitschriften ausführlich vor. - Zum »Aviso«, auf den hier nicht gesondert eingegangen wird: Martin Welke, Vom Elend der pressehistorischen Forschung in Deutschland. Dargestellt am Beispiel des Wolfenbütteler »Aviso«, in: BAUER / BöNING, Die Entstehung des Zeitungswesens im 17. Jahrhundert, S. 135-158. 
gefunden werden ${ }^{118}$. Carolus hatte von den Erben Bernard Jobins deren Druckerei und Verlagshaus gekauft und suchte nun nach einer Möglichkeit, seine frühere Beschäftigung als »Avisenschreiber« auf eine wirtschaftlich breitere Grundlage zu stellen. Statt 15-20 handschriftliche Kopien konnte er künftig 250-400 gedruckte Exemplare herstellen und vermarkten ${ }^{119}$. In diesem Zusammenhang wird die Kontinuität der Zeitungsproduktion deutlich: In der Person des Johann Carolus folgte die Zeitung als Schriftgattung nicht in erster Linie der gedruckten Flugschrift, sondern dem Nachrichtenbrief, wie er sich seit dem Spätmittelalter als Informationsmedium für zahlungskräftige politische und wirtschaftliche Interessenten herausgebildet hatte ${ }^{120}$. Die Karriere des Johann Carolus war keineswegs singulär, denn auch andere Zeitungsbegründer hatten als Avisenschreiber begonnen, z.B. der Leipziger Moritz Pörner, der in den 1630er Jahren mindestens eine gedruckte Zeitung gründete $^{121}$.

Die Straßburger Episode zeigt den wichtigen Umstand, dass Zeitungen nicht aufgrund obrigkeitlicher Anstiftung entstanden, sondern unternehmerischer Initiative folgten. Es war damit von Anfang an entscheidend, dass die Blätter einen Ertrag erwirtschafteten, der die Fortführung der Verlegertätigkeit ermöglichte. Daher mussten sie in ökonomischen Kategorien gedacht und auf den Markt ausgerichtet sein, d.h nicht nur auf das Informationsbedürfnis, sondern auch auf Leidenschaften und Vorurteile der Leserschaft Rücksicht nehmen $^{122}$. Politische Meinungs- und Willensbildung standen dabei nicht im Vordergrund, im Gegensatz zu vielen Flugschriften ging es gerade nicht um Agitation. Arrangements mit der politischen Macht wurden durch diese

118 Zum Anteil von Jean-Pierre Kintz, Martin Welke und Johannes Weber an der etappenweisen Publikation dieses Befunds: Welke, Johann Carolus und der Beginn der periodischen Tagespresse, S. 63-66. Archivalischer Nachweis für die Supplik und ihre Behandlung durch den Magistrat vom 21. Dezember 1605: Archives Municipales de Strasbourg, 1 R 84, fol. 336v. Vgl. WEBER, »Unterthenige Supplication Johann Caroli/Buchtruckers«, hier S. 257. Faksimilierte Wiedergabe der Supplik: Ders., Galerie der Zeitungspresse im 17. Jahrhundert, hier S. 26-29; Transkription: Ebd., S. 30-32. Vgl. auch die weitergehenden Informationen zum Werdegang Carolus' und zur weiteren Medienverlagstätigkeit seiner Nachfahren: BEHRINGER, Im Zeichen des Merkur, S. 347f.

119 Zum Multiplikator: WeBer, Galerie der Zeitungspresse im 17. Jahrhundert, S. 33.

120 Zur Erforschung der spätmittelalterlichen Kommunikationspraxis: HeImann/ HLavÁceK, Kommunikationspraxis und Korrespondenzwesen im Mittelalter und in der Renaissance, pas. Zum Übergang von der geschriebenen zur gedruckten Zeitung: Georg SteINHAUSEN, Die Entstehung der Zeitung aus dem brieflichen Verkehr, in: Archiv für Post und Telegraphie 23 (1895), S. 347-357; vgl. zum Nachrichtenbrief auch: WiLKE, Grundzüge der Medien- und Kommunikationsgeschichte, S. 18f.

121 Möglicherweise gab er seine Zeitung unter verschiedenen Titeln heraus: Johannes WeBER, Umriß der Zeitungsgeschichte Leipzigs im 17. Jahrhundert, in: Kutsch/WeBER, 350 Jahre Tageszeitung, hier S. 139.

122 Modische Klagen über die »Kommerzialisierung« der Zeitungen sind daher unangemessen, weil sie suggerieren, eine Berichterstattung unabhängig von den Interessen der Medienbetreiber sei möglich - dies war zu keinem Zeitpunkt in der Mediengeschichte der Fall. 
Grundhaltung erleichtert ${ }^{123}$. Zufällige Meinungsäußerungen eines Überzeugungsjournalisten (politischer oder religiöser Ausrichtung) konnten stets enthalten sein, z.B. in der Vorlage. Durch den wortgetreuen Abdruck einer Vorlage entschuldigte sich der Drucker in der Regel im Falle von obrigkeitlichen Protesten. Auch persönliche Anwürfe eigneten sich dazu, in Presseverlautbarungen zu erscheinen. Sie blieben jedoch in der frühen Presse Ausnahmen.

Die Produzenten standen zudem in Konkurrenz zueinander, obwohl sie in ihrer jeweiligen Heimatstadt oft ein herrschaftliches Privileg erwirkten, das aber stets lokal begrenzt blieb. Somit wirkte sich die politische Konkurrenz zwischen den Reichsterritorien auch auf die unternehmerische Konkurrenz der Medienproduzenten aus und befruchtete das Gesamtsystem. Viele Innovationen hinsichtlich der inhaltlichen Produktgestaltung, der Geschwindigkeit des Nachrichtenumsatzes und der Betriebsorganisation der Medienunternehmen lassen sich auf die Konkurrenzsituation zurückführen ${ }^{124}$.

Über die Anzahl der hergestellten Exemplare pro Zeitungsausgabe liegen wenige gesicherte Daten vor. Aus der Buchdruckforschung ist bekannt, dass ein gutes Team an einer Druckerpresse täglich ca. 300 Bögen bedrucken konnte ${ }^{125}$. Wenn man die Zeitung so montierte, dass auf jeder Seite des Bogens jeweils der gesamte Inhalt stand, dann erlangte man durch den fertig gedruckten, gefalteten und geschnittenen Bogen zwei Zeitungsexemplare. So verwundert es nicht, dass mehrfach Angaben mit Auflagen von 300 oder 600 Exemplaren genannt werden. Größere Auflagen dürften hingegen an mehreren Pressen gefertigt worden $\operatorname{sein}^{126}$.

Während Zeitungen zunächst als Wochenzeitungen erschienen, verstärkte sich im Laufe des 17. Jahrhunderts der Trend zu kürzeren Erscheinungsintervallen. Die reine Wochenzeitung verlor an Marktanteilen: 1625 erschienen noch $90 \%$ der Zeitungen wöchentlich, im Durchschnitt des zweiten Vierteljahrhunderts des 17. Jahrhunderts fiel die Zahl auf ca. $72 \%$, im dritten auf $46 \%$ und im letzten auf $26 \%{ }^{127}$. Demgegenüber nahm die Zahl der Zeitungen zu, die zwei- oder dreimal pro Woche erschienen. Wieder hing die Frequenz

123 Es lässt sich an vielen Beispielen sehen, dass frühmoderne Medienproduzenten zwar politische und religiöse Meinungen hatten, jedoch das druckten, was am Markt verkauft werden konnte (dies konnte auch eine abweichende Ansicht sein). Vgl. dazu die Überlegungen bei WiLke, Grundzüge der Medien- und Kommunikationsgeschichte, S. 38.

124 Vgl. zu den Wirkungen der Konkurrenz zwischen den Zeitungsproduzenten: BöNING, Welteroberung durch ein neues Publikum, S. 98.

125 Vgl. zu den Einzelheiten unten Hauptteil I, Kap. 4, S. 183.

126 Nachweise über 350 bis 600 Exemplare: Holger BönIng, Aufklärung und Presse im 18. Jahrhundert, in: JäGER, »Öffentlichkeit« im 18. Jahrhundert, S. 151-163, hier S. 152. - 350-400 Exemplare: WiLke, Gründzüge der Medien- und Kommunikationsgeschichte, S. 64; WeBER, Avisen, Relationen, Gazetten, S. 32. - 500-600 Exemplare: Gestrich, Absolutismus und Öffentlichkeit, S. 171. - 600-700 Exemplare: WürGLER, Unruhen und Öffentlichkeit, S. 219. Vgl. dazu auch die Überlegungen bei FrIEDRICH, Drehscheibe Regensburg, S. 428f.

127 Behringer, Im Zeichen des Merkur, S. 422. 
nicht allein vom Dafürhalten des Herausgebers ab, sondern von den Postverbindungen, über die neue Nachrichten die jeweilige Pressestadt erreichten. Die mehrfach in der Woche erscheinenden Zeitungen waren denn auch an Knotenpunkten des Postsystems beheimatet, etwa in Frankfurt a.M. (1620), Köln (1625), Hamburg (1630) oder in Leipzig (1631). Vom Erscheinungsintervall hing zudem der Preis für die Zeitungen ab, der für ein Jahresabonnement zwischen zwei Gulden und zehn Reichstalern liegen konnte ${ }^{128}$.

Der Ausdifferenzierungsprozess der Zeitungen nach Erscheinungshäufigkeit fand einen vorläufigen Abschluss mit der Herausgabe der ersten Tageszeitung 1650 in Leipzig. Dort besaß Timotheus Ritzsch seit 1642 - durch schwedische Verfügung - ein Zeitungsmonopol ${ }^{129}$. Nach dem Westfälischen Friedensschluss zogen die Schweden ab, und es lag nahe, dass sich Konkurrenten von Ritzsch bei der kursächsischen Regierung um die Privilegierung eines weiteren Blattes bemühen würden. Der Verleger wandte sich selbst nach Dresden und erreichte, dass seine Monopolstellung in Leipzig für 10 Jahre bestätigt wurde. Zudem verbot die Regierung den Nachdruck der Zeitung im ganzen Kurfürstentum ${ }^{130}$. Den Abzug der Schweden im Sommer 1650 nutzte Ritzsch, um am 1. Juli 1650 seine Einkommende Zeitungen zu publizieren, die montags bis samstags erschienen ${ }^{131}$.

Ungeachtet des Fortbestehens der bisherigen Druckmedien setzten sich die Zeitungen bereits zu Beginn des 17. Jahrhunderts als wichtigstes Medium der Kommunikation durch. Jürgen Wilke spricht von einem »raschen Aufschwung «, besonders im Heiligen Römischen Reich, wo zu dieser Zeit mehr Zeitungen gedruckt wurden als im Rest Europas zusammen. 1618 gab es bereits 20 Zeitungen im deutschsprachigen Raum, bis 1640 waren es dreimal so viele, wohlgemerkt während eines ruinösen Krieges, dem nachgesagt wurde, er habe alle geregelten Wirtschaftsbeziehungen in Deutschland zerstört ${ }^{132}$. Auch wenn manches Zeitungsunternehmen bald wieder einging, konnten sich bis zum Jahrhundertende ca. 60 Zeitungen gleichzeitig und dau-

128 Vgl. verschiedene Angaben bei FrIEDRICH, Drehscheibe Regensburg, S. 429.

129 Zur Zeitungsentwicklung in Leipzig: WeBER, Galerie der Zeitungspresse im 17. Jahrhundert, S. 62-94.

130 Faksimile und Transkription der Supplik Ritzschs vom 4. Juli 1649: ebd., S. 95-100.

131 Zur Leipziger Tageszeitung: Else HAUFF, Die »Einkommenden Zeitungen« von 1650. Ein Beitrag zur Geschichte der Tageszeitung, in: Gazette 9 (1963), H. 3, S. 227-235; der Beitrag wurde nachgedruckt in: Kutsch/WeBER, 350 Jahre Tageszeitung, S. 151-161; Holger BöNING / Johannes Weber, Politik für alle. Am 1. Juli 1650 erschien in Leipzig die erste Tageszeitung der Welt. Die Geheimniskrämerei der Mächtigen hatte ein Ende, in: Die Zeit, Nr. 27, 29. Juni 1997, S. 74; Weber, Galerie der Zeitungspresse im 17. Jahrhundert, S. 101-105 (mit faksimilierter Reproduktion).

132 Ulrich Rosseaux, Das Reich und seine Territorien als Kommunikationsraum im frühen 17. Jahrhundert, in: BDLG 137 (2001), S. 73-100, hier S. 83f. 
erhaft im Reich etablieren ${ }^{133}$. Im Laufe des 18. Jahrhunderts stieg die Summe der Zeitungsunternehmen kontinuierlich an.

Jürgen Wilke führt vier Gründe an, die für die rasche Ausbreitung des Zeitungswesens verantwortlich gewesen sind ${ }^{134}$ :

1. Der »Territorialismus« in Deutschland förderte durch die faktische Gewaltenteilung zwischen Kaiser und Fürsten die Vorteile der Konkurrenz zwischen den Zeitungsbetreibern.

2. Daraus folgte, dass die Zensurgesetzgebung und -praxis im Reich uneinheitlich wahrgenommen wurde; nicht selten wurde etwas in einem Territorium erlaubt, weil dies den Nachbarfürsten ärgerte. Schon die gewöhnliche Konkurrenz (etwa zwischen der dänischen Krone und dem Hamburger Magistrat) sorgte für Pressefreiheiten ${ }^{135}$.

3. Die Zentrallage Deutschlands führte zum Kreuzen vieler Postwege, was den Nachrichtenverkehr vervielfältigte: Viele Nachbarn produzierten und erforderten viele Informationen.

4. Die konfessionelle Spaltung verschaffte ein Interesse an kontroversen Darstellungen von religiösen Fragen (allerdings spielten Konfessionsfragen in Zeitungen nur eine untergeordnete Rolle; dieser Faktor traf eher auf die Flugschriften zu). Auch ist das Ungleichgewicht von vielen protestantischen und sehr viel weniger katholischen Zeitungen erklärungsbedürftig.

Nach Gutenbergs Handgießgerät für den Letterndruck war auch das Zeitungswesen in Deutschland »erfunden « worden, und dieser Umstand wirkte sich auf die Anzahl der Zeitungsstädte aus: Für das Jahr 1669 verteilten sich die Zeitungen in Europa auf 32 Städte, von denen 17 im Heiligen Römischen Reich (und 14 im heutigen Deutschland) lagen. Zu einem großen Teil waren die Zeitungsstädte gleichzeitig auch Zentralorte im Postnetz: Mitteleuropäische Zentren im späten 17. und frühen 18. Jahrhundert waren Amsterdam (4 Postämter und 5 Zeitungen) und Hamburg (Postmeistereien der Reichspost, des städtischen Botendienstes sowie für Schweden, Dänemark, Braunschweig-Lüneburg und Kurbrandenburg; 3 Zeitungen) $)^{136}$.

Bereits aus dem frühesten Jahr, aus dem Zeitungen bis heute überliefert sind, ist auch die Rezeption durch die kirchlichen und politischen Eliten bezeugt. Bezeichnenderweise befand sich die Straßburger Relation im

133 Weber, Straßburg 1605, S. 10. - Vgl. auch die Zahlen bei Susanne Friedrich, Drehscheibe Regensburg, S. 428f. mit Nachweisen.

134 Wilke, Grundzüge der Medien- und Kommunikationsgeschichte, S. 51.

135 Vgl. zur Praxis der frühmodernen Zensur auch den Tagungsband von HAEFs / Mix, Zensur im Jahrhundert der Aufklärung, pas.

136 Behringer, Im Zeichen des Merkur, S. 419f. 
Besitz der Zisterzienser-Abtei Salem, während sich der Wolfenbütteler Aviso im Bestand der früheren Klosterbibliothek des Abts von Loccum auffinden lie $\beta^{137}$. $\mathrm{Zu}$ den ersten Rezipienten gehörten damit bereits die Kleriker, hier die Zisterzienser. Die Bürgereliten zogen schnell nach. Für den Bürgermeister von Salzwedel ist schon für die Zeit seit 1609 bezeugt, dass er den Wolfenbütteler Aviso jahrelang im Abonnement bezog ${ }^{138}$. Dies gelang logistisch nicht jede Woche, sondern zumeist bekam er mehrere Exemplare auf einmal in einer zusammengebundenen Sendung. Für andere Leser der höheren Stände - Adel, Stadtpatriziat, aber auch Studenten - ist die schnelle Rezeption während der folgenden Jahre ebenfalls dokumentiert ${ }^{139}$. Wer als Hausvater früher seine Schutzbefohlenen mit Bibellektüre und Erbauungstexten bedacht hatte, ließ nicht selten die Zeitungen - in ausgewählten Beispielen - vortragen. Rolf Engelsing verweist in dieser Hinsicht auf einen Erfurter Professor für Mathematik, der in seiner Studentenpension am Mittagstisch vorlesen ließ - in Aufnahme einer alten Klostertradition, ergänzt um die Zeitungsinhalte seiner Zeit ${ }^{140}$.

Die Obrigkeiten folgten als Leserschaft. Kennzeichnend ist eine Episode, die sich 1661 zugetragen hat. Kurfürst Friedrich Wilhelm von Brandenburg hatte sich über den Bericht in einer Zeitung geärgert, der in nachteiliger Weise von der Mark Brandenburg handelte ${ }^{141}$. Die Berliner Regierung vermutete zunächst, der Bericht stamme aus dem schwedischen Stettin und spiegele die dortige antibrandenburgische Haltung der offiziellen Stellen wider. Ganz ungeprüft ging die Berliner Regierung davon aus, der Bericht sei staatlich gesteuert in Umlauf gesetzt worden - in dieser Wahrnehmung stellte sich Presse als verlängerter Arm der politischen Macht dar. Immerhin befragte man noch einheimische Pressekenner, und dabei stellte sich heraus, dass die Zeitung mitnichten aus Stettin stammte, sondern aus Hamburg. So richtete sich der kurfürstliche Protest an den Hamburger Magistrat, der den Bericht in Vernachlässigung seines Zensuramtes habe passieren lassen. Da zwischen der Elbmetropole und Kurbrandenburg keine konfliktträchtige Ausgangssituation bestand, wurde der Magistrat nicht verdächtigt, den Artikel lanciert

137 Ebd., S. 372; WiLKE, Grundzüge der Medien- und Kommunikationsgeschichte, S. 42.

138 Vgl. Wilhelm Hartmann, Wolfenbüttel als Druckort des »Aviso« von 1609, der ältesten periodisch gedruckten Zeitung, in: NJbLG 31 (1959), S. 175-189, hier S. 179. - Zur Forschungsentwicklung über den »Aviso«: Martin WeLKE, Vom Elend der pressehistorischen Forschung in Deutschland. Dargestellt am Beispiel des Wolfenbütteler »Aviso«, in: BAUER/BönING, Die Entstehung des Zeitungswesens im 17. Jahrhundert, S. 135-158.

$139 \mathrm{Vgl}$. die Nachweise aus den ersten vier Dekaden des 17. Jahrhunderts bei ENGELSING, Die Perioden der Lesergeschichte in der Neuzeit, hier Sp. 976.

140 Ebd., Sp. 977.

141 Die Geschichte wurde von Ernst Consentius publiziert, die zugrundeliegenden Archivalien sind offenbar nicht überliefert: Ernst Consentius, Ein Zeitungsschreiber im 17. Jahrhundert. Mit Benutzung von Akten des Geh. Staatsarchivs, in: Deutschland. Monatsschrift für die gesamte Kultur 6 (1905), S. 246-251. 
zu haben. Allerdings wurde die Bestrafung des Verursachers gefordert. Der Hamburger Rat ließ den Zeitungsschreiber Martinus Schumacher einbestellen. Dieser trug die in derartigen Situationen übliche Ausrede vor, er habe den Text nur abgeschrieben, sei daher im eigentlichen Sinne nicht der Autor ${ }^{142}$. Die Hamburger Inquisitoren beließen es einstweilen dabei und schickten die Einlassung des Zeitungsschreibers nach Brandenburg, nicht ohne zahlreiche beschwichtigende Worte im Begleitschreiben. Dabei wurde das vielzitierte Verdikt der Reichsstadt über das Zeitungsmachen zu Papier gebracht:

[...] möchten vnsers theilß gerne sehen, daß das eine Zeithero fast aller ohrten im heyl. Röm. Reiche eingeführtes Zeitung drücken, gäntzlich abgeschaffet würde, dan die Obrigkeit des ohrts, wo Sie gedrücket worden, allerhand nachrehde deßwegen leiden müßen, die sich ümb Ihre Amts verrichtungen vnd nicht ümb dergleichen Zeitung zu bemühen haben ${ }^{143}$.

Bei der fraglichen Zeitung soll es sich laut Holger Böning um die Wöchentliche Donnerstags-Zeitung gehandelt habe, die bereits 1618 als Wöchentliche Zeitung auß mehrerley örther gegründet worden war ${ }^{144}$.

Nur elf Jahre später hatte sich die herrscherliche Perspektive geändert. Nun war es ein anderer Kurfürst, nämlich Karl Ludwig von der Pfalz, der 1672 per Reskript das Wiedererscheinen einer Zeitung gebot. Die kurfürstliche Regierung ordnete sogar an, welche Quellen verwendet werden sollten, alles sollte nämlich aus den »Französischen, Italiänischen, Wienischen, Cöllnischen und Engelischen Schreiben und Zeitungen zusammengelesen, recht abgefaßt« werden. Zudem durfte die Frankfurter Zeitung nicht ausgeschrieben werden. Die Redaktionsarbeit erfolgte staatsnah, wenn die Beteiligten donnerstags zum Regierungsrat einbestellt wurden. Nach abgeschlossener Arbeit sollten die (noch handschriftlichen) Texte direkt an den Hof gesandt werden, damit sie am Freitagmorgen »beim ahnkleiden« den Herrschaften vorgelesen werden konnten. Samstags sollte dann der Druck erfolgen. Hier hatte ein kompletter Bewusstseinswandel stattgefunden: Wenn die »Novitäten« schon nicht zu verhindern waren, dann sollten sie auf eine Weise regu-

142 Protest des Kurfürsten, 11. März 1661: Consentius, Ein Zeitungsschreiber im 17. Jahrhundert, S. 248f. - Darlegung des Zeitungsschreibers Schumacher, 16. März 1661: Ebd.

143 Antwortschreiben des Hamburger Magistrats an den Großen Kurfürsten, 17. März 1661: CoNSENTIUS, Ein Zeitungsschreiber im 17. Jahrhundert, S. 250f. - Else Bogel und Elgar Blühm schreiben das Zitat irrtümlich der kurfürstlichen Regierung zu: BogEL/BLÜHM, Die deutschen Zeitungen, Bd. 1, S. X.

144 Holger Böning (Hg.), Deutsche Presse. Biobibliographische Handbücher zur Geschichte der deutschsprachigen periodischen Presse von den Anfängen bis 1815. Kommentierte Bibliographie der Zeitungen, Zeitschriften, Intelligenzblätter, Kalender und Almanache sowie biographische Hinweise zu Herausgebern, Verlegern und Druckern periodischer Schriften, Bd. 1.1: Hamburg (zus.gest. v. Holger Böning u. Emmy Moepps), Stuttgart-Bad Cannstatt 1997, Sp. $10 f$. 
liert werden, die möglichst wenig Schaden im Sinne der politischen Macht anrichten konnte ${ }^{145}$.

\subsubsection{Die weitere Entwicklung der Zeitungen}

Während der Frühen Neuzeit änderte sich das Erscheinungsbild der Zeitungen kaum: Jürgen Wilke führt dies darauf zurück, dass keine größeren technischen Neuerungen bei der Zeitungsherstellung zwischen 1605 und der napoleonischen Zeit stattfanden. Im 19. Jahrhundert dagegen entwickelte sich eine größere Differenziertheit, die vor allem auf die technischen Innovationen (Erfindung von Schnellpresse und Rotationsdruckverfahren) zurückzuführen $\operatorname{sind}^{146}$.

Die frühen Zeitungen sahen ihre Aufgabe in der Berichterstattung von Tatsachen (nuda veritas) - was auch immer darunter verstanden wurde - und nicht in der politischen Meinungs- und Willensbildung ${ }^{147}$. Systemtheoretisch gesehen nahmen die frühmodernen Zeitungsredakteure damit für sich dieselbe Leitdifferenz wahr/unwahr in Anspruch, die eigentlich dem Wissenschaftssystem zugeordnet war. Vermutlich ist es falsch, die frühen Zeitungen nach dem aufklärerischen Paradigma der kritischen Distanz zur Macht zu sehen: Drucker und Verleger dachten hingegen vorrangig in ökonomischen Kategorien, was ihre Arrangements mit der Macht sehr erleichterte ${ }^{148}$. Alle Zeitungen in Europa waren nur zu betreiben, wenn vor Aufnahme des Erscheinens ein Konsens mit der zuständigen Obrigkeit hergestellt worden war. Dies bedeutete die grundlegende Einbeziehung ins herrschende Rechtssystem, das von der Obrigkeit garantiert wurde. Auch garantierte die Obrigkeit normalerweise per Privileg, dass die Zahl der Zeitungen pro Stadt oder Territorium beschränkt blieb und damit hinlänglicher Monopolgewinn erlangt werden konnte, von dem dann oft ein Teil als Privilegiengebühren an die Herrschaft zurückfloss. Die meist vorgeschriebene Zensuraufsicht wurde anschließend virtuell wahrgenommen, d.h. Redakteure, Drucker und Ver-

145 Reskript des Kurfürsten Karl Ludwig von der Pfalz vom 22. Mai 1672: BlüHm/Engelsing, Die Zeitung, S. 43.

146 WiLKe, Die Zeitung, S. 391.

147 Zum Wahrheitspostulat: Jörg Jochen BERNS, Der nackte Monarch und die nackte Wahrheit. Auskünfte der deutschen Zeitungs- und Zeremoniellschriften des späten 17. und frühen 18. Jahrhunderts zum Verhältnis von Hof und Öffentlichkeit, in: Daphnis 11 (1982), S. 315-350, hier S. 330. - Zum Verzicht auf Wertungen: Stieler, Zeitungs Lust und Nutz (1695/1969), S. 27.

148 Es lässt sich an vielen Beispielen belegen, dass frühmoderne Medienproduzenten unter dem Primat des Ökonomischen standen: Sie besaßen in der Regel eine politische und religiöse Meinung, doch gedruckt haben sie das, was sie am Markt verkaufen konnten: Vgl. dazu die Überlegungen bei WILKE, Grundzüge der Medien- und Kommunikationsgeschichte, S. 38. 
leger wussten selbst, mit welchen Worten sie Konflikte heraufbeschwören konnten. Dass wirklich ein städtischer Bediensteter regelmäßig alle Zeitungen im Andruck las, ist nur selten der Fall gewesen.

Zufällige Meinungsäußerungen konnten stets im Text enthalten sein, vor allem in der Vorlage. Im weiteren Verlauf des Fertigungsprozesses geboten es allerdings die geforderte Schnelligkeit und der knappe Platz sowie der Mangel an weitergehenden Hintergrundinformationen, dass das Überlieferte unverändert weiterverarbeitet wurde. Die Autonomie des Textes, gar zurechenbar als Leistung des Autors, spielt im Zeitungswesen eine eher untergeordnete Rolle gegenüber dem Nachrichtenwert des Berichts. Falls es zu obrigkeitlicher Kritik kam, entschuldigte sich der Drucker in der Regel damit, er habe nur die Vorlage wortgetreu abgedruckt. Zum anderen konnte eine gezielte Einzelmeinung eines Überzeugungstäters (politischer oder religiöser Ausrichtung) eingeflochten werden. Trotz spektakulärer Konfliktfälle stellte die bewusste Beeinflussung der Textgestaltung durch Drucker oder Verleger eher die Ausnahme dar.

In der äußeren Aufmachung verzichteten die Zeitungen auf eine prunkvolle Ausgestaltung. Vorangestellt wurde eine werbewirksame Titelseite, zumeist nur aus Text bestehend, selten mit einem Bild verziert. Der Titeltext konnte teilweise in Rotdruck erscheinen (sog. »Rothe Zeitungen«), eine Methode, die Zeitung für die Nichtakademiker optisch attraktiver zu machen. Auf den Innenseiten folgten die Nachrichten vielfach unter Ortsund Datumsangabe nach der Reihung der Korrespondenzorte am Postweg. Redaktionelle Schwerpunktsetzungen waren selten, und Schlagzeilen entwickelten sich erst nach $1800^{149}$.

Trotz der genannten Forschungsansätze ist die Erforschung der Zeitungen eher vernachlässigt worden. Die Zeitung ist die unscheinbare Schwester der Zeitschrift gewesen, in der die Autoren unter eigenem Namen schrieben und daher das Interesse der Literaturwissenschaftler wecken konnten. Wenn Zeitungen ins Blickfeld der Forschung rückten, dann aus der regionalgeschichtlichen Perspektive der Verleger und Drucker in einschlägigen Orten, so z.B. in Köln, Frankfurt a.M. und Leipzig für das 17. Jahrhundert, bevor für das 18. Jahrhundert eine größere Zahl von Druckorten ins Blickfeld gerieten ${ }^{150}$.

Zur Problematik der frühen Zeitungen liegen einige Studien von Elger Blühm vor ${ }^{151}$. Er beklagt, dass die Zeitungen nicht nur von den Geschichts-

149 WiLKe, Die Zeitung, S. 392f.

150 Ebd., S. 389.

151 Elger BцÜнm, Zeitung und literarisches Leben im 17. Jahrhundert, in: Albrecht ScHÖNE (Hg.), Stadt - Schule - Universität. Buchwesen und die deutsche Literatur, München 1976, S. 470491; Elger BLÜHM, Deutsches Zeitungswesen im 17. Jahrhundert, in: Paul RAABE (Hg.), Bücher und Bibliotheken im 17. Jahrhundert in Deutschland, Hamburg 1980, S. 126-134; BLÜHM, Die deutschen Fürstenhöfe des 17. Jahrhunderts und die Presse, hier S. 596; ders., Die erste Zei- 
forschern, sondern auch von den Bibliothekaren recht stiefmütterlich behandelt worden sind, so dass beträchtliche Verluste zu beklagen sind. Es ist wichtig zu betonen, dass sich die Zeitungen thematisch mitnichten auf Sensationsberichterstattung beschränkten, sondern zu einem erheblichen Anteil politische Berichte lieferten ${ }^{152}$.

Die Produktion einer absatzstarken Zeitung war für jeden Druckwerkeproduzenten die sicherste vorstellbare Einkommensquelle ${ }^{153}$. Verkauft wurde die Zeitung vorwiegend im Abonnement, wobei ein Verkauf über mehrere Stationen möglich war (Kauf durch Zwischenhändler bis zum Endkunden). Daneben spielten der Einzelverkauf und die Vermietung eine geringere Rolle ${ }^{154}$. Verleger und Drucker (beide zunächst noch schwer zu unterscheiden) sowie Postmeister waren diejenigen, die systematisch Nachrichten sammelten, um sie dann in Auswahl in neue Druckwerke einzuarbeiten. Dieses System hatte sich bereits im 16. Jahrhundert etabliert, ein Beispiel dafür war das schon erwähnte Verlagshaus Bernard Jobin in Straßburg. Es darf davon ausgegangen werden, dass diese Methoden sich in den beiden folgenden Jahrhunderten zwar verfeinert, aber nicht grundlegend geändert haben. Darauf verweist auch Else Bogel am Beispiel der Züricher Bodmer-Zeitung. Dieses Periodikum, das die Familie Bodmer seit 1628 herausbrachte, war das bedeutendste Schweizer Blatt des 17. Jahrhunderts. Die Redaktion dieser Zeitung war ebenfalls über andere Zeitungswerke bestens informiert. In Züricher Sammelbänden des 17. Jahrhunderts finden sich zweimal je drei Zeitungen zusammengebunden: Neben der Bodmer-Zeitung waren dies die Straßburger Relation und die Frankfurter Postzeitung. Die Exemplare der Straßburger und Frankfurter Zeitungen waren mit handschriftlichen Notizen versehen, die sich bei näherem Hinsehen als Druckanweisungen herausstellten. Tatsächlich sind in der Bodmer-Zeitung der jeweils nächsten Folge die redigierten Texte aus den beiden anderen Periodika eingerückt auffindbar. Dabei war diese Form der medialen Sekundärverwertung weder anrüchig noch verboten. Die Ausgaben der Bodmer-Zeitung von 1633 und 1634 trugen den Hinweis in ihren Titeln: »[...] auß allerhand glaubwürdigen anderstwo getruckten Zeitungen/vnd gewissen Sendbriefen ${ }^{155}$.

tungen Deutschlands und der Schweiz und der Beginn der europäischen Pressegeschichte, in: Martin Bircher u.a. (Hg.), Schweizerisch-deutsche Beziehungen im konfessionellen Zeitalter, Wiesbaden 1984, S. 101-117; BlÜhm/GeBhardt, Presse und Geschichte, 2 Bd., pas.

152 Für den Jg. 1668 ist dies für den »Nordischen Merkur« ausgewertet worden: Hier betrug der Anteil politischer Inhalte 57\%: BLüHM, Deutsches Zeitungswesen, S. 130f.

153 Vgl. die Beispiele bei FIscher, Die ältesten Zeitungen, S. 27f.

$154 \mathrm{Zu}$ den drei Arten des Pressevertriebs: Dorn/Vogel, Geschichte des Pressevertriebs, S. 7. Dort auch der Hinweis auf den schlechten Forschungsstand zum Vertrieb.

155 Dies gilt besonders für die Bände Q 478 und Q 481 in der Zentralbibliothek Zürich: BogeL, Schweizer Zeitungen des 17. Jahrhunderts, S. 16. 


\subsection{Die Entstehung der politisch-historischen Zeitschriften}

Unter der Aufklärungsperspektive ist der spannendste Differenzierungsprozess die Herausbildung von Zeitschriften, insbesondere mit politisch-historischen Inhalten. Im Gegensatz zum Begriff »Zeitung«, der schon vor Herausbildung des gleichnamigen Periodikums geläufig war, wurde der Begriff »Zeitschrift« erst 1751 von Peter von Hohenthal erstmals verwendet ${ }^{156}$. Die Zeitgenossen des ausgehenden 17. Jahrhunderts sahen zwar, dass etwas Neues entstand, doch fehlten ihnen die Begriffe, es sprachlich präzise zu fas$\operatorname{sen}^{157}$. Auch heute noch fehlt eine konsensfähige Definition, die alle Zeitschriften erfassen könnte. Rudolf Stöber schreibt, die Gattung Zeitschrift habe sich »allen Definitionsversuchen erfolgreich widersetzt $\ll^{158}$. Einstweilen müssen daher für die Frühmoderne formale Begriffsbildungen genügen. So definierte das Wörterbuch Joachim Heinrich Campes eine Zeitschrift als eine Schrift, "welche zu gewissen bestimmten Zeiten herauskömmt« und »in auf einander folgenden Stücken ausgegeben wird «159. Ganz ähnlich ist die Zeitschrift für Susanne Friedrich »ein auf längere Dauer angelegtes, in mehr oder weniger regelmäßigen Abständen erscheinendes, drucktechnisch vervielfältigtes Medium $\aleph^{160}$. Der Unterschied zur Zeitung wird darin nicht deutlich.

Den Prozess der Ausdifferenzierung von der Zeitung zur Zeitschrift hat Johannes Weber auf die Formel $»$ politische Zeitschrift $=$ (monatlicher) Zeitungsextrakt + Räsonnement « gebrach ${ }^{161}$. Darüber hinaus hat Weber betont, dass die moderne periodische Presse zwar ein wichtiges »Konstitutivum des modernen demokratischen Funktionsgefüges« darstellt, dass sie aber ihre

156 Hansjürgen Koschwitz, Der früheste Beleg für das Wort »Zeitschrift«, in: Publizistik. Vierteljahreshefte für Kommunikationsforschung 13 (1968), S. 41-43, hier S. 41.

157 So beobachtete Kaspar Stieler »eine sonderbare Art der Zeitungen/die man Reflexionen oder Rück-gedanken nennet/welche die vormals ausgegangene Novellen auf Wochen/Monate/halbe Jahre etc. vor sich nehmen/examiniren und prüfen/auch darüber ihre politische Meinungen eröffnen«: STIELER, Zeitungs Lust und Nutz (1695/1969), S. 54.

158 StÖвеR, Deutsche Pressegeschichte, S. 81. - Zur Klassifikation der bisherigen Definitionsversuche: Susanne Friedrich, Die Anfänge der historisch-politischen Zeitschrift am Beispiel des »Monatlichen Staats-Spiegels«, in: Wolfgang E.J. WeBER (Hg.), Wissenswelten. Perspektiven der neuzeitlichen Informationskultur, Augsburg 2003, S. 295-311, hier S. 295f.

159 Joachim Heinrich CAMPE (Hg.), Wörterbuch der deutschen Sprache, 5 Bd. u. Supplementbd., Braunschweig 1807-1813 (ND Hildesheim 1970), hier Bd. 5, S. 836, zit. nach BöNING/MoEPPS, Deutsche Presse, Bd. 1.1 (Hamburg), S. IXf.

160 Definition von Susanne Friedrich, Drehscheibe Regensburg, S. 61.

161 Johannes WeBer, Götter-Both Mercurius. Die Urgeschichte der politischen Zeitschrift in Deutschland, Bremen 1994, S. 109, zit. nach Rudolf STÖBER, Historische Zeitschriftenforschung heute, in: Andreas Vogel/Christina Holtz-Bacha (Hg.), Zeitschriften und Zeitschriftenforschung, Wiesbaden 2002, S. 42-59, hier S. 47. 
Entstehung vordemokratischen Ursprüngen verdankt ${ }^{162}$. Weber fährt fort, dass dadurch das barocke Theater der Herrschaftspräsentation konterkariert worden sei: Das Lesepublikum bekam den politisch-militärischen Alltag vor Augen geführt, in dem es nicht nur hoheitlichen Pomp und Prunk wahrzunehmen galt, sondern das gewöhnliche politische Nullsummenspiel mit samt der Erklärungsbedürftigkeit von Niederlagen. Dieser Prozess sei gleichzeitig mit der Diskreditierung religiöser Deutungsmuster als Gründe für Kriege im Zuge der Abwicklung des Dreißigjährigen Krieges eingetreten ${ }^{163}$.

Dieser Gewinn an politischem Einblick setzte sich nicht sofort in die Entstehung eines neuen Mediums um. Es bedurfte einer Übergangszeit von ca. 50 Jahren, bis zögernde Versuche in verschiedenen Ländern, insbesondere in Frankreich, zur Herausformung einer neuen Form der Medienberichterstattung über politische Inhalte führten ${ }^{164}$. Dabei finden sich in Zeitungen immer wieder Ansätze, räsonnierende Elemente zu übermitteln, z.B. in der Gestalt des sog. »gelehrten Artikels«. Nachdem bislang der Holsteinische Unparteyische Avisen-Correspondente von 1712 als erstes Trägermedium angesehen worden war, hat Johannes Weber nachgewiesen, dass schon 1700 in der Leipziger Postamtszeitung ein sog. »Extract« ausgegeben wurde, der sonntags die Begebenheiten der vergangenen Woche kurz kommentieren sollte ${ }^{165}$. Inzwischen hat Esther-Beate Körber weitere Periodika aufgefunden, die sich als Funktionszusammenhang »Zeitungsextrakt« beschreiben lassen ${ }^{166}$. Sie stellten ebenfalls ein Ausdifferenzierungsprodukt der politischen Druckmedienpublizistik dar, waren aber kein einfaches Zwischenglied zwischen Zeitung und Zeitschrift, vielmehr galt:

Die meisten Zeitungsextrakte erschienen nicht vor den Zeitschriften, sondern zugleich mit ihnen. Sie bereiteten das Raisonnement also nicht vor, sondern begleiteten es als,

162 Johannes Weber, Zum 350. Geburtstag der Tageszeitung am 1. Juli 1650, in: Ders./Arnulf Kutsch (Hg.), 350 Jahre Tageszeitung. Forschungen und Dokumente, Berlin 2002, S. 9-22, Zitat S. 21.

163 WeBer, Zum 350. Geburtstag der Tageszeitung am 1. Juli 1650, S. 22.

164 Zum Diskurs der französischen Medienmacher über diesen Prozess: Christiane BerkvensStevelinck/Jeroom Vercruysse (Hg.), Le metier de journaliste au dix-huitième siècle: correspondance entre Prosper Marchand, Jean Rousset de Missy et Lambert Ignace Douxfils, Oxford 1993.

165 Johannes WeBer, Galerie der Zeitungspresse im 17. Jahrhundert mit dem Schwerpunkt: Geschichte der frühen Leipziger Zeitungen, in: Ders./KuTsch, 350 Jahre Tageszeitung, S. 23-136, hier S. 131.

166 Projekt »Zeitungsextrakte«: Esther-Beate KöRBER, Zeitungsextrakte. Überraschungen bei der Erforschung publizistischer Formen der Frühen Neuzeit, in: Blome/BönIng, Presse und Geschichte, S. 125-140; Esther-Beate KöRBER, Entstehung und Funktion der Zeitungsextrakte in der Medienlandschaft der Frühen Neuzeit, in: BAuER/BönInG, Die Entstehung des Zeitungswesens im 17. Jahrhundert, S. 211-234. - Kommentierter Katalog der identifizierten Exemplare: Esther-Beate KöRBER, Zeitungsextrakte. Aufgaben und Geschichte einer funktionellen Gruppe frühneuzeitlicher Publizistik, Bremen 2009. 
wenn man so will, publizistische Akkordstimmen zwischen dem Basso continuo der Zeitungen und den konzertanten Melodiestimmen des publizistischen Räsonnements $^{167}$.

Die Nachfrage nach verbindenden Informationen wuchs offenbar und wurde von den Herausgebern der Periodika in zweierlei Weise aufgegriffen. Erst nach 1770 verlor der Zeitungsextrakt an Bedeutung, um schließlich zu verschwinden ${ }^{168}$.

Für die Zeitschrift war es unumgänglich, sich nicht am Schnelligkeitsparadigma messen zu lassen, wie bei der Zeitung immer mehr gebräuchlich. Die Zeitschrift bedurfte einer größeren zeitlichen Distanz, um Prozesse hinsichtlich ihrer Wirkung und ihrer Messbarkeit am Kriterium Erfolg/Misserfolg zu beobachten. Daher setzte sich schließlich die monatliche Erscheinungsweise als sachlich angemessen durch. Ziel war es, auf der Berichterstattung in den Zeitungen aufzubauen, Sachverhalte zusammenzufassen und gleichzeitig Interpretationen des Geschehenen zu liefern. Im Gegensatz zur Zeitung, die Texte mit geringen Variationen reproduzierte, zeigte die Zeitschrift das Charakteristikum der Originalität, so dass ein gebildeter Redakteur erforderlich war. War bei Zeitungen der unterschwellige Kommentar verpönt - und zwar aus Sicht der Obrigkeit und aus der des Lesers! - leistete die Zeitschrift genau dieses: Deutung des Zeitgeschehens, unvermeidlicherweise mit der jeweiligen Perspektivität des Herausgebers bzw. der Autoren versehen, gern auch etwas satirisch gefasst, da dies den Stoff anschaulicher und unterhaltsamer gestaltete. Zielgruppe war das nachdenkliche Lesepublikum, nicht allein der Adel und das Bildungsbürgertum, sondern potenziell auch weitere Gruppen, denn die Ansprechbarkeit neuer Leserschichten wurde auch hier stets mitgedacht ${ }^{169}$.

In diesen Zeitschriften fand die bürgerliche Aufklärung in Deutschland ihren wichtigsten Niederschlag. Johannes Schwitalla misst der Zeitschrift sogar den Charakter eines »Leitmediums der Aufklärung« $\mathrm{zu}^{170}$. Die Anzahl der neugegründeten Zeitschriften nahm im Laufe des 18. Jahrhunderts von

167 Zitat: ebd., S. 15.

168 KöRBER, Entstehung und Funktion der Zeitungsextrakte, S. 230-232.

169 Da die Auflagensumme erheblich kleiner und der Preis höher war als bei den Zeitungen, dürfte auch das Publikum viel länger auf Adel und höheres Bürgertum beschränkt geblieben sein. Vgl. dazu die Überlegungen bei FrIEDRICH, Die Anfänge der historisch-politischen Zeitschrift, S. 300 mit Nachweisen.

170 Schwitalla, Flugschrift, S. 76. Zentral zum Themenkomplex der frühmodernen Zeitschriften: Kirchner, Das deutsche Zeitschriftenwesen, 2 Bd., pas.; HaAcke, Die politische Zeitschrift 1665-1965, 2 Bd., pas.; Otto DANN, Das historische Interesse in der deutschen Gesellschaft des 18. Jahrhunderts. Geschichte und historische Forschung in den zeitgenössischen Zeitschriften, in: Karl Hammer/Jürgen Voss (Hg.), Historische Forschung im 18. Jahrhundert. Organisation - Zielsetzung - Ergebnisse, Bonn 1976, S. 386-415. - Ein früherer Annäherungsversuch bereits während der NS-Zeit mit zeittypischem Einschlag: Hubert Max, Wesen 
Jahrzehnt zu Jahrzehnt deutlich zu, zusammen hat Joachim Kirchner fast 4.000 Zeitschriften namhaft gemacht - und nach gegenwärtigem Forschungsstand noch nicht einmal alle gefunden. Diese Zahl schließt auch die ephemeren Gründungen mit ein, die sich aus unterschiedlichen Gründen nur eine oder wenige Ausgaben lang halten konnten ${ }^{171}$. Für die Anfangsphase des 18. Jahrhundert, die in diesem Kontext interessiert, war die Zahl der Zeitschriften noch gering: bis 1700 sind 21 Periodika dieser Art überliefert, zwischen 1700 und 1710 sind es 23 und zwischen 1710 und 1720 nicht mehr als 30, die kurzlebigen eingeschlossen ${ }^{172}$. Martin Welke hingegen stellt die Zeitschriften zusammen, die über einen Zeitraum von mehreren Jahren erschienen. Er kam dabei für 1730 auf 14 Zeitschriften im Heiligen Römischen Reich, für 1750 auf 17, für 1770 auf 34 und für 1795 auf 72. Die Auflagen betrugen für 1730 zusammen ca. 10.000 Exemplare, für $1750 \mathrm{ca}$. 12.000, für $1770 \mathrm{ca}$. 31.000 und für 1795 ca. 50.000. Alle Auflagenzahlen sind hochgerechnet: Welke nahm eine Mindestauflage von 500 und eine durchschnittliche Auflage von 600 bis 700 Exemplaren an ${ }^{173}$.

Im Gegensatz zu den Zeitungen, die mit 4 bis 16 Seiten pro Ausgabe auskamen, hatten die Zeitschriften einen größeren Umfang (zumeist zwischen 40 und 200 Seiten), erschienen in längerem Zeitturnus (in der Regel Monatsschriften) und wandten sich in thematischer Aufmachung, im sprachlichen Niveau und im Preis von Anfang an an das Bildungsbürgertum im engeren Sinne. Ebenso wie alle anderen Druckmedien mussten die Zeitschriften von der Obrigkeit genehmigt werden. So jedenfalls war die Norm, doch meistens entschieden die Herausgeber oder Verleger vor Ort, ob sie sich daran hielten oder nicht.

Zeitschrift im Singular - das wirft gleich Probleme auf. Nicht nur die Entstehung der Zeitschrift ist in diesem Zusammenhang von Belang, sondern der weitere Verlauf macht die Zeitschrift zum Medium der Ausdifferenzierung: Während wissenschaftliche Zeitschriften den Anfang machten, kamen historisch-politische, literarische und moralische wenig später nach. Da bald jedes wissenschaftliche Fach eine oder mehrere Zeitschriften ausbildete, zudem zu allen denkbaren weltanschaulichen Lehrsystemen ebenfalls Zeitschriften

und Gestalt der politischen Zeitschrift. Ein Beispiel zur Geschichte des politischen Erziehungsprozesses des deutschen Volkes bis zu den Karlsbader Beschlüssen, Essen 1942.

$171 \mathrm{Vgl}$. die Zusammenstellung bei Joachim Kirchner (Hg.), Grundlagen des deutschen Zeitschriftenwesens. Mit einer Gesamtbibliographie der deutschen Zeitschriften bis zum Jahre 1790, 2 Bd., Leipzig 1928-1932; ders., Das deutsche Zeitschriftenwesen, 2 Bd., pas.; ders., Bibliographie der Zeitschriften des deutschen Sprachgebietes bis 1900, 4 Bd., pas.

172 KirChNER, Grundlagen des deutschen Zeitschriftenwesens, Bd. 2, S. 340.

173 Martin Welke, Zeitung und Öffentlichkeit im 18. Jahrhundert, in: BlÜhm/Gebhardt, Presse und Geschichte, Bd. 1, S. 71-99, hier S. 73f. - Susanne Friedrich nimmt eine Normalauflage von ca. 1000 Stück an: FrIEDRICH, Drehscheibe Regensburg, S. 448f. 
aufgelegt wurden, lässt sich ermessen, wie weitgespannt der Kosmos dieses Mediums reichen konnte. Nicht nur die Gruppenbildungen der Produzenten und Herausgeber sind beachtenswert, sondern bald auch die Gruppierungen der Leserschaft. Schon im 18. Jahrhundert gab man Zeitschriften für Frauen oder für Jugendliche heraus. Jürgen Wilke umschrieb diesen Prozess mit den Worten: »Die Zeitschrift erwies sich als genuines Medium, das der fortschreitenden sozialen Differenzierung und Arbeitsteilung Ausdruck verlieh, sie zugleich aber öffentlich sichtbar machte und weiter vorantrieb « ${ }^{174}$.

Heute hat jede noch so kleine Organisation ihr Periodikum, und keine Kleinst- oder Randgruppe in der Gesellschaft und insbesondere in der Konsumentenschaft bleibt davor verschont, dass sich eine Zeitschrift ihrer jeweiligen Situation annimmt. So gehört die Zeitschrift weiterhin zu den Begriffen, die sich nicht allgemeingültig definieren lassen: Der Prozess der Ausdifferenzierung schreitet über alle sprachlich möglichen Formen hinweg ${ }^{175}$.

Während das Postwesen, die Messrelationen und die Zeitungen ihren Anfang in Deutschland genommen hatten, verhielt es sich mit der Zeitschrift anders: Ihre Wiege stand in Frankreich. Das große Vorbild späterer Zeitschriften war das Journal des Sçavants, das 1665 gegründet worden war. Die Zeitschrift konzentrierte sich auf die Wissenschaften unter Einschluss der Naturwissenschaften. Anzeigen und Rezensionen von Büchern wurden ebenfalls aufgenommen, wie auch Nachrichten von Akademien und anderen gelehrten Gesellschaften. Das Journal erschien nur zu Beginn wöchentlich, später im 14-Tagesabstand mit manchmal längeren Intervallen ${ }^{176}$. Im selben Jahr erfolgte die englische Antwort: Die Philosophical Transactions griffen die Wissenschaften in großer Breite auf. Drei Jahre später erschien in Italien das Giornale de' Letterati ${ }^{177}$.

Für Deutschland sind zunächst tastende Versuche zu konstatieren, initiiert durch Zeitungsunternehmen. 1674 brachte Eberhard Felsecker in Nürnberg

174 Wilke, Grundzüge der Medien- und Kommunikationsgeschichte, S. 93.

175 Statt einer Definition ein Überblick über die Forschungsentwicklung: Hans Bohrmann, Die Erforschung von Zeitung und Zeitschrift in Deutschland, in: Arnold/DitTrich/Zehler, Die Erforschung der Buch- und Bibliotheksgeschichte in Deutschland, S. 346-358; Hans BoнRMANN, Theorien der Zeitung und Zeitschrift, in: LeONHARD u.a., Medienwissenschaft, Bd. 1, S. 143-148; Hans Bohrmann, Forschungsgeschichte der Zeitschrift, in: Leonhard, Medienwissenschaft, Bd. 1, S. 892-895; VogeL/HoLtZ-BACHA, Zeitschriften und Zeitschriftenforschung, pas.

176 Karl Schottenloher, Flugblatt und Zeitung. Ein Wegweiser durch das gedruckte Tagesschrifttum, 2 Bd., München 1922, hier Bd. 1: Von den Anfängen bis zum Jahre 1848, S. 303. Vgl. zu den Folgen dieser Neugründung Otto DanN, Vom Journal des Scavants zur wissenschaftlichen Zeitschrift, in: Bernhard FABIAN/Paul RAABE (Hg.), Gelehrte Bücher vom Humanismus bis zur Gegenwart, Wiesbaden 1983, S. 63-80.

177 Schottenloher, Flugblatt und Zeitung, S. 303. Vgl. zu den drei Wissenschaftsjournalen auch: KirChNer, Das deutsche Zeitschriftenwesen, Bd. 1, S. 16f. 
seinen Götter-Both Mercurius heraus ${ }^{178}$, zwei Jahre später legte Eberhard Werner Happel seine Erbauliche Ruh-Stunden dem Hamburger RelationsCourier bei. Die Relationes Curiosae wurden ab 1681 vom selben Redakteur besorgt ${ }^{179}$. Im Folgejahr erschienen die Acta Eruditorum als selbstständiges Periodikum, nicht als Annex an eine Zeitung. Die gelehrte Zeitschrift richtete sich in lateinischer Sprache an die gesamte europäische Leseöffentlichkeit, wobei auch hier die naturwissenschaftlichen Themen die gesellschaftswissenschaftlichen stark überwogen. Herausgeber Otto Mencke begründete mit dieser Zeitschrift die Tradition Leipziger Journale, die im 18. Jahrhundert in Deutschland dominieren sollten ${ }^{180}$.

Sieben Jahre später unternahm der Philosoph Christian Thomasius den Versuch, ein deutschsprachiges Journal auf dem Markt zu plazieren. Er hatte 1688 als erster eine deutschsprachige Vorlesung angekündigt, eine bemerkenswerte Tat so lange nach der Durchsetzung der deutschsprachigen Predigt durch Luther und seine Anhänger. Schon der Titel des ersten Heftes - mit Namen Schertz= und Ernsthaffter/Vernünfftiger und Einfältiger Gedancken/über allerhand Lustige und nützliche Bücher und Fragen - lässt die Absicht des Herausgebers erkennen, auf hohem Niveau zu unterhalten und gleichzeitig zu bilden (sowohl den Geist als auch den Geschmack). Thomasius nahm für sich in Anspruch, ein eigenes Urteil in wissenschaftlichen wie in politisch-gesellschaftlichen Fragen zu haben, ein Recht auf Kritik zu besitzen. Schmeichelei, wie sonst in Druckschriften häufig zu finden, lehnte er ab. Um nicht in die Schusslinie politischer Machthaber zu geraten, verbarg Thomasius seine eigene Meinung durch die Darstellung eines platonischen Gesprächs von vier fiktiven Reisenden während des Weges von Frankfurt zur Buchmesse nach Leipzig ${ }^{181}$. Seine Zeitschrift beinhaltete daher einige recht scharfe oder gar satirische Rezensionen, worauf die Kritisierten mit

178 Johannes WeBer, Götter-Both Mercurius. Die Urgeschichte der politischen Zeitschrift in Deutschland, Bremen 1994.

179 Uta Egenhoff, Berufsschriftstellertum und Journalismus in der Frühen Neuzeit. Eberhard Werner Happels »Relationes Curiosae« im Medienverbund des 17. Jahrhunderts, Bremen 2008; Flemming Sсноск, Die Text-Kunstkammer. Populäre Wissenssammlungen des Barock am Beispiel der »Relationes Curiosae« von E.W. Happel, Köln/Weimar/Wien 2011; ders., Wissen im neuen Takt. Die Zeitung und ihre Bedeutung für die Entstehung erster populärer »Zeitschriften«, in: BAUER/BöNING, Die Entstehung des Zeitungswesens im 17. Jahrhundert, S. 281-302.

180 Ulrich Hensing, Acta Eruditorum (1682-1782), in: Heinz-Dietrich Fischer (Hg.), Deutsche Zeitschriften des 17. bis 20. Jahrhunderts, Pullach b. München 1973, S. 29-47; Augustinus Hubertus LaEven, The »Acta Eruditorum« under the Editorship of Otto Mencke (1644-1707). The History of an International Learned Journal between 1682 and 1707, Amsterdam 1990 (ndl. 1986).

181 Kirchner, Das deutsche Zeitschriftenwesen, Bd. 1, S. 23-25; Wilke, Grundzüge der Medienund Kommunikationsgeschichte, S. 75f. Zum gesellschaftswissenschaftlichen Denken Thomasius': Martin KüHnel, Das politische Denken von Christian Thomasius. Staat, Gesellschaft, Bürger, Berlin 2001. 
scharfem Widerspruch reagierten. Thomasius konnte zwar das erste Jahr seiner Zeitschrift mit einem Sammelband aller zwölf Hefte abschließen, doch das zweite Jahr überstand das Journal nicht ${ }^{182}$.

Johannes Weber findet in der Nürnberger Zeitschrift Des Teutschen Mercurii, die 1692 erstmals herauskam, alle Argumente für das Vorhandensein eines kritischen Publikums in Deutschland. Weber formuliert: »Festzuhalten ist, dass präzise jener öffentliche Bedarf an politischem Räsonnement benannt wird, der sich über die Schranken des obrigkeitlichen Staats-Arkanums hinwegsetzt und dem neuen Medium zu Leben verhilft« «183. Das Nürnberger Periodikum gehörte zu der Gattung der »historisch-politischen Zeitschriften «, die für die Wende vom 17. zum 18. Jahrhundert die wichtigste Zeitschriftenart mit ca. $40 \%$ des gesamten Druckvolumens ausmachte ${ }^{184}$. Interessant ist auch die weitere Geschichte des jungen Periodikums: Des Teutschen Mercurii wurde zwar bereits im Juni 1692, nach drei Monaten, wieder verboten, weil einige Regensburger Reichstagsgesandte sich beim Nürnberger Magistrat beschwert hatten. Da der Verleger Hoffmann allerdings Beziehungen zum Wiener Reichshofrat besa $\beta$, ließ er sich ein kaiserliches Privileg ausstellen, nach dessen Vorlage in Nürnberg das Druckverbot aufgehoben wurde $^{185}$. Zensur war in der ständischen Gesellschaft keine absolute Größe, sondern ein System, das sich einfügte in die Welt von Rechts- und Klientelbeziehungen, wobei letztere häufig dazu verwendet werden konnten, um formales Recht zu umgehen.

Nach diesen eher kurzlebigen historisch-politischen Periodika stellte der Monatliche Staats-Spiegel das erste Serienwerk von mittlerer zeitlicher Dauer dar, getragen von der ersten Vermittlungsform, dem sachlichen Kommentar. 1698 beantragten die beiden Augsburger Verleger Andreas Maschenbauer und Jacob Koppmeyer ein kaiserliches Privileg für den Staats-Spiegel ${ }^{186}$.

182 [Christian Thomasius], Schertz= und Ernsthaffter/Vernünfftiger und Einfältiger Gedancken/über allerhand Lustige und nützliche Bücher und Fragen. Erster Monath oder Januarius, in einem Gespräch vorgestellet von derer Gesellschaft der Müßigen, Frankfurt a.M./Leipzig 1688. Sammelband der ersten zwölf Hefte: [Christian Thомаsıus], Freymüthige, Lustige und Ernsthaffte iedoch Vernunft $=$ und Gesetz=Mässige Gedancken oder Monaths $=$ Gespräche $/$ über allerhand/ fürnehmlich aber Neue Bücher Durch alle zwölf Monate des 1688. und 1689. Jahrs [...], [4] Bd., Halle a.d. Saale 1690.

183 WeBer, Götter-Both Mercurius, S. 142.

184 Zur »historisch-politischen Zeitschrift«: WILKE, Grundzüge der Medien- und Kommunikationsgeschichte, S. 100f. - Joachim Kirchner ging für den Zeitraum von 1670 bis 1720 von 74 derartigen Zeitschriften aus, einem Anteil von $31 \%$ am gesamten Zeitschriftenaufkommen; er grenzte davon allerdings eine Gruppe von 20 sog. »historischen Fachjournalen« ab, die in anderen Betrachtungen zusammengerechnet wurden: KIRCHNER, Das deutsche Zeitschriftenwesen, Bd. 1, S. 29.

185 Felseckers Wiener Vertrauter war sein früherer Autor Jakob Bernhard Mulz, der inzwischen Mitglied des Reichshofrats geworden war: WeBER, Götter-Both Mercurius, S. 144f.

$186 \mathrm{Zu}$ den Umständen des Antrags: Lindemann, Deutsche Presse bis 1815, S. 196f. - Vgl. zum 
Beide verfügten bereits über Zeitungserfahrung durch die WochentlichOrdinari-Post-Zeitung und damit über ein Korrespondentennetz von europäischer Ausdehnung. Sie gingen offenbar davon aus, dass sich für das neue Blatt ein hinreichender Absatz finden lassen würde. Die Ausdifferenzierung zeigt sich hier im selben Verlagskontext. Der Staats-Spiegel wurde von Stanislaus Reinhard Acxtelmeier (* um 1649; $\uparrow$ um 1715) redaktionell betreut ${ }^{187}$.

Schon im Vorwort zum ersten Heft betont der Herausgeber die Verbundenheit seines neuen Periodikums mit dem niederländischen Mercure historique et politique ${ }^{188}$. Dabei übernahm er nicht nur das Konzept und die Gliederung nach Ländern, sondern wertete auch die Hefte des Vorbildes regelmäßig aus. Die Marktlücke für seine Zeitschrift sah er zum einen in der deutschen Sprache für die einheimische Leserschaft, zum anderen in der zu knappen Berichterstattung über das Alte Reich im Mercure historique ${ }^{189}$. Eine weitere Zeitschrift, auf die Bezug genommen wurde, waren die Lettres historiques, die von Jacques Bernard und Jean Dumont in Den Haag und später in Amsterdam herausgegeben wurden ${ }^{190}$. Im Wortlaut hieß es: $\gg \mathrm{Da}$ diese [gemeint sind die Zeitschriften Mercure und Lettres] auch in Teutsch-

Periodikum auch die Bemerkungen bei Kirchner, Das deutsche Zeitschriftenwesen, Bd. 1, S. 32f.

187 [Stanislaus Reinhard Acxtelmeier (Hg.)], Monatlicher Staats-Spiegel; Worinnen der Kern aller Avisen; Ein Begriff der vornehmsten im H. Röm. Reich vorfallenden Affairen mit vilen Curiosen Beylagen, samt einigen Politischen Reflexionen sich repraesentirt und vorstellet, Augsburg 1698-1709. - Zu Acxtelmeiers Lebensdaten: Michael Holzmann/Hanns BohatTA (Hg.), Deutsches Anonymenlexikon 1501-1850, 7 Bd., Weimar 1902-1926 (ND Hildesheim 1961), hier Bd. 4 (1907), S. 2, zit. nach Friedrich, Drehscheibe Regensburg, S. 450, Anm. 3579; Marco Jänicke, Art. »Acxtelmeier, Stanislaus Reinhard«, in: Gudrun Gersmann/Katrin Moeller/Jürgen-Michael Schmidt (Hg.), Lexikon zur Geschichte der Hexenverfolgung, publiziert in: historicum.net, URL: <http://www.historicum.net/themen/hexenforschung/ lexikon/alphabethisch/a-g/art/Acxtelmeier_St/html/artikel/5824/ca/fef802438148ae234cc46934e7f72cd8/> (11.08.2012).

188 [Gatien DES COURTILZ DE SANDRAS (Gründungsred.)] »Mercure historique et politique, contenant l'état présent de l'Europe, ce qui se passe toutes les cours, l'intérêt des princes, leurs brigeurs, et généralement tout ce qu'il y a de curieux, le tout accompagné de réflexions politiques sur chaque État«, 192 Bd., Den Haag 1686-1782. - Hintergrundinformationen: Jean Lombard, Art. »Mercure historique et politique 1«, in: Jean SGard (Hg.), Dictionnaire des journaux (1600-1789), Bd. 2, Paris 1991, S. 870-878; Jean Lombard, Courtilz de Sandras ou l'aventure sous le regne de Louis XIV, Diss. Paris 1978; ders., Courtilz de Sandras et la crise du roman à la fin du Grand Siècle, Paris 1980; ders., Les rédacteurs du Mercure historique et politique de La Haye (La Haye, novembre 1686 - avril 1782), in: Roger LAthuillère (Hg.), Langue, Littérature du XVIIe et du XVIIIe siècle. Mélanges offerts à Frédéric Deloffre, Paris 1990, S. 295-307. - Ältere Bewertung: Hermann RungE, Courtilz de Sandras und die Anfänge des »Mercure historique et politique«. Ein Beitrag zur Geschichte der periodischen Presse im 17. Jahrhundert, Berlin 1887.

189 Monatlicher Staats-Spiegel, Mai-Heft 1698, Vorwort.

190 [Jacques Bernard/Jean Dumont], Lettres historiques, contenant ce qui se passe de plus important en Europe, et les réflexions nécessaires sur ce sujet, 73 Bd., Den Haag/Amsterdam 16921728. - Hintergrundinformationen: Philip StewarT, Art. »Lettres historique«, in: Jean SGARD (Hg.), Dictionnaire des journaux (1600-1789), Bd. 2, Paris 1991, S. $744 f$. 
land angenommen und debitirt werden/darinnen aber von Reichs $=$ und Teutschen Staats=Sachen wenig enthalten/sie auch der fremden Sprach halber von vilen nicht gelesen werden können«, habe man sich, so die Herausgeber, entschlossen, einen »Monatlichen Staats=Spiegel « zu offerieren, »worinnenn erstens das vornehmste aus allen Avisen, zweytens/die vorfallende Affaires samt denen darzu gehörigen und neuesten Beylagen untermenget/und Drittens über einige der vornehmsten Sachen ein kurtz Raisonnement angefügt wird $\aleph^{191}$. Da der Adel und die bürgerlichen Gelehrten Französisch beherrschten, konnte als intendierter Leser nur der "gemeine Mann« gemeint sein, dem Latein und Französisch nicht geläufig war. Dieses Ziel wurde allerdings konterkariert, indem zahlreiche lateinische und französische Begriffe unerklärt gebraucht wurden. Auch erschienen französische Quellen in der Originalsprache ohne Übersetzung oder Zusammenfassung ${ }^{192}$.

Die Zeitschrift setzte sich aus drei Bestandteilen zusammen: 1. »Das vornehmste aus allen Avisen«; 2. dazugehörige »Beylagen« als Quellenstücke; 3. »In kurtz Raisonnement«, d.h. der bewusste Kommentar des Herausgebers über das Zeitgeschehen ${ }^{193}$. Eigentlich wollte Acxtelmeier an jedes Heft einen Zyklus von politischen »Reflexiones« anhängen. Dazu kam es jedoch später nur bei einer kleinen Zahl von Heften. Die Einteilung der Hefte folgte den niederländischen Vorbildern und richtete sich nach den europäischen Staaten mit leichten Variationen ${ }^{194}$. Diesem Duktus folgte Acxtelmeier auch in den folgenden Jahren. Die Hefte umfassten ca. 70-100 Seiten; erst 1703/04 wurden dickere Hefte aufgelegt, weil mehrfach zwei Monate in einem Heft (mit bis zu 220 Seiten) abgehandelt wurden. 1706 und 1707/I umfassten die Hefte zwischen ca. 90 und ca. 150 Seiten.

Als deutschsprachiger Vorreiter einen neuen Mediengattung wurde der Monatliche Staats-Spiegel von der Zensur besonders beobachtet. Verleger Maschenbauer beklagte sich 1698 anlässlich eines Zensurfalles, er müsse seinen Verlag schließen, wenn ihm der Betrieb der Zeitschrift verboten würde, denn er habe außergewöhnlich hohe Kosten für die auswärtigen Korrespondenzen ${ }^{195}$. Nach der bayerischen Besetzung 1703/04 erschien das Periodi-

191 Monatlicher Staats-Spiegel, Mai-Heft 1698, Vorwort, zit. nach WeBER, Götter-Both Mercurius, S. 121.

192 Ein Beispiel dafür war das Beglaubigungsschreiben des französischen Königs für seinen Botschafter Rousseau de Chamoy in Regensburg vom 19. März 1698: Monatlicher Staats-Spiegel, Mai-Heft 1698, S. 15f.

193 Ebd., Vorwort.

194 Ebd.: 1. »Teutschland/Turckey und Ungarn«, 2. »Spanien/Portugal und Spanische Niederlande «, 3. »Franckreich«, 4. »Engel= und Holland «, 5. »Dänemarck und Schweden «, 6. »Polen und Moscau«, 7. »Italien«, 8. »Schweitz«. - Demgegenüber gliederte sich das April-Heft 1701 wie folgt: 1. »Teutschland «, 2. »Spanien«, 3. »Franckreich«, 4. »Engell- und Holland «, 5. »Dennemarck/Schweden/Pohlen und Moscau«, 6. »Italien«, 7. »Schweitz«.

195 Wolfgang Wüst, Censur und Censurkollegien im frühmodernen Konfessionsstaat, in: Helmut Gier/Johannes Janota (Hg.), Augsburger Buchdruck und Verlagswesen. Von den Anfängen 
kum weiter, wurde allerdings wohl nicht mehr in Augsburg gedruckt. 1706 äußerte sich erneut Unwille im Regensburger Reichstag über die Zeitschrift, weil sie eine missverständliche Passage über die Rechte des Städtekollegiums abgedruckt hatte. $\mathrm{Zu}$ dieser Zeit hatten sich die Gesandten und ihre entsendenden Fürsten und Magistrate noch nicht an die kommentierenden Worte in diesem Medium gewöhnt ${ }^{196}$.

Viele Details für die folgenden Jahre sind ungeklärt, auch die Herausgeberschaft nach Acxtelmeier ab 1708. Über sonstige Mitarbeiter und auswärtige Korrespondenten ist ebenfalls fast nichts bekannt, bis auf einen Kanzlisten in der Cellischen Gesandtschaft in Regensburg, der für die Reichstagsberichterstattung zuständig war. Die Reichstagsberichterstattung nahm denn auch einen beträchtlichen Teil des Druckvolumens ein, zum Missvergnügen mancher Gesandter, so dass es mehrfach Proteste gab. Besonders bezogen sie sich auf ganze Dokumente, die im Wortlaut abgedruckt wurden, Indiz für die direkte Zuleitung aus dem engeren Umfeld der Gesandtschaften. Die Redaktion verteidigte sich mit dem Argument, die fraglichen Texte seien auch schon anderenorts käuflich zu erwerben gewesen, und wies das Argument des Geheimnisverrats zurück. Insbesondere verwiesen die Betreiber auf die öffentlichen Akteneditionen der Zeit (bes. Kaspar Melchior Goldast von Haiminsfeld, Michael Lundorp, Diarium Europaeum und Theatrum Europaeum), in denen vergleichbare Texte völlig ohne Beanstandung erschienen seien ${ }^{197}$.

Von zeitgenössischen Kritikern wurde der Monatliche Staats-Spiegel mit sehr lobenden Worten bedacht. Marcus Paul Huhold schrieb:

Der Monathliche Staats=Spiegel, welcher ietzo rar zu werden anfängt, ist ohnstreitig eine von denen ersten und allerbesten Schrifften von dieser Gattung in Teutschland gewesen, und findet man an diesem Werk nichts auszusetzen, als dass es sehr vitiös gedruckt ist ${ }^{198}$.

bis zur Gegenwart, Wiesbaden 1997, S. 569-586, hier S. 584; vgl. auch FrIEdRICH, Die Anfänge der historisch-politischen Zeitschrift, S. 304f. zur Informationsbeschaffung Maschenbauers aus geschriebenen und gedruckten Zeitungen aus dem In- und Ausland.

196 Darauf verweist Friedrich, Die Anfänge der historisch-politischen Zeitschrift, S. 303f. (mit Quellennachweisen).

197 Bes. in Monatlicher Staats-Spiegel, Januar-Heft 1705, S. 3-5. - Zu den Verlegern und zum Periodikum: FriedRICH, Drehscheibe Regensburg, S. 450-452 mit weiteren Nachweisen; dies., Die Anfänge der historisch-politischen Zeitschrift, S. $306 f$.

198 [Marcus Paul Huhold], Curieuse Nachrichten Von denen Heute zu Tage grand mode gewordenen Journal-, Quartal- und Annual-Schrifften, Darinnen Die einige Jahr her in Teutscher/Lateinischer/Frantzösischer/Italiänischer und Holländischer Sprache häuffig geschriebenen Journale erzehlet/Und bey denen meisten gemeldet/wenn sie angefangen/aufgehöret/oder ob sie noch bis itzo continuiret werden, Nebst beygefügten unpartheyischen Urtheilen und andern curiosen Observantionibus, Itzo von neuem übersehen und vermehrter herausgegeben, Jena $[=» \text { Freyburg } \ll]^{2} 1716$, s.p. 
Auch Johann Peter von Ludewig, Christian Juncker und Christian Gottfried Hoffmann schlossen sich diesem positiven Urteil an ${ }^{199}$.

Die wohl bedeutendste historisch-politische Zeitschrift in deutscher Sprache war die Europäische Fama. Sie erschien in 8 bis 12 Heften pro Jahr und räsonnierte in frühaufklärerischer Manier über politische Entwicklungsprozesse im In- und Ausland ${ }^{200}$. Begründer war Philipp Balthasar Sinold von Schütz (1657-1742), der Spross einer alten, aber nicht mehr sehr einflussreichen Familie aus Hessen. Sinold von Schütz gelang es nach seinem Jurastudium in Jena nicht, in ein attraktives Dienstverhältnis einzutreten. Die ungerade Karriere dürfte dazu beigetragen haben, dass er schon in den 1690er Jahren einige kurzzeitige kulturgeschichtliche Zeitschriften herausgab, bevor ihm 1702 mit der Europäischen Fama der Durchbruch auf dem Medienmarkt gelang ${ }^{201}$.

Die weitere Herausgeberschaft der Zeitschrift ist nicht völlig geklärt. Nach älteren Angaben von Georg Witkowski gab Sinold von Schütz die Europäische Fama von Erscheinungsbeginn bis 1711 heraus ${ }^{202}$. Anschließend übernahm Christian Gottfried Hoffmann, ein Leipziger Jurist, diese Aufgabe für 13 Jahre. Hoffmann schrieb auch das 24-teilige Periodikum Aufrichtige und unpartheiische Gedancken über die Journale, eine Rezensionenzeitschrift über Zeitschriften seiner Zeit von 1714 bis $1717^{203}$. Von 1724 bis 1732 wurde die Europäische Fama von Justus Gotthard Rabener (1688-1731) besorgt. Rabener stammte aus Leipzig, hatte dort Theologie studiert, wurde 1706 als Dr. theol. und 1714 als Dr. phil. promoviert. Später wurde er Professor der Theologie in Leipzig und übte daneben eine Predigerstelle an der Thomaskir-

199 Vgl. Friedrich, Die Anfänge der historisch-politischen Zeitschrift, S. 303 mit Nachweisen.

200 Europäische Fama; Forts.: »Die neue europäische Fama, welche den gegenwärtigen Zustand der vornehmsten Höfe entdecket«, hg. v. Gottlieb Schumann, 16 Bd. (192 T1.), Leipzig 17351756.

201 Ephemere Zeitschriftengründungen: [Philipp Balthasar Sinold von SchÜTZ], Des Träumenden Pasquinii Kluger Staatsphantasien Über den ietzigen verwirreten Zustand der Welt. Erste Erscheinung Allen Curieusen und Staatsverständigen Gemuethern zu fernerem Nachdencken zugeeignet und übergeben, Freyburg [= Leipzig] 1697; [ders.], Das courieuse CafféHaus zu Venedig [...], 3 Bd., Freyburg [= Leipzig] 1698ff.; [ders.], Der Fliehende Passagier Durch Europa/Welcher die remarquablesten Staats= und Privat=Händel/nebst einigen darüber geführten Raisonnements [...] mittheilet, 12 H. (Promenaden), Freystadt [= Leipzig] 16981702 .

202 Georg Witkowski, Geschichte des literarischen Lebens in Leipzig, Leipzig/Berlin 1909, S. 192-195.

203 [Christian Gottfried Hoffmann (Hg.)], Aufrichtige und Unpartheyische Gedancken Über die Journale, Extracte und Monats=Schrifften/Worinnen Dieselben extrahiret/wann es nützlich suppliret und wo es nötig emendiret werden, 24 Stücke in 2 Bd., Freyburg [= Leipzig] 17141717. - Zu Rezensionszeitschriften: Thomas HaBEL, Gelehrte Journale und Zeitungen der Aufklärung. Zur Entstehung, Entwicklung und Erschließung deutschsprachiger Rezensionszeitschriften des 18. Jahrhunderts, Bremen 2007. 
che aus ${ }^{204}$. Nach jüngeren Recherchen durch Astrid Blome stellt sich die Herausgeberschaft viel komplizierter dar ${ }^{205}$. Sowohl die Zeitschrift als auch ihr Begründer verdienten eine monographische Behandlung.

Sinold von Schütz betonte, er wolle nicht der Ungeduld des Lesers Vorschub leisten, indem jede Kleinigkeit sofort gedruckt erscheine. Im Gegenteil stellte er den Unterschied zwischen den Mediengattungen klar heraus, indem er formulierte

daß gegenwärtige Blätter vor keine Nouvellen oder Avisen, sondern vor eine umständlichere Erzählung desjenigen zu achten/was vorher entweder nicht so ausführlich/oder doch nicht mit solcher Gewißheit in den Zeitungen referiret worden ${ }^{206}$.

Dem Leser sollte zart angedeutet werden, dass es kein Verlust sei, in der Europäischen Fama nicht stets die neuesten Nachrichtenhäppchen präsentiert zu bekommen, sondern dass sich viele Zusammenhänge erst aus der Nachschau von einigen Wochen erschließen: Dann sei eine gute Zeitschrift in der Lage, den Vorgang in sachlicher Form aufzubereiten.

Der Herausgeber vertiefte die Differenz zur Zeitung weiter, indem er andeutete, er schreibe nicht, um die Gedanken großer Herren zu erraten oder um vornehme Staatsminister durch »niederträchtige Schreib=Art« zu erbauen, sondern um diejenigen zu informieren, die nicht die Zeit dazu hätten, alle Einzelinformationen aus »den vielfältigen, in allerhand Sprachen und Format in die Lufft fliegenden/Zeitungen zusammen zu klauben « ${ }^{207}$. Der

204 Zu Rabener: DBA Serie I, Fiche 992, S. 366-369.

205 Blome schreibt: „Widersprüchliche Angaben lassen die Autoren der Europäischen Fama teilweise nicht mehr nachvollziehen. Nachdem Philipp Balthasar Sinold, gen. von Schütz, (16571742), die Fama 1702 begründet hatte, wurde 1710 oder 1711 der Leipziger Hofrat und Ratsherr Gottfried Lange (1672-1748) Mitarbeiter der Zeitschrift. In der Fama selbst wurde angezeigt, mit dem 122. Theil 1711 habe $>$ der vorige Herr Autor wieder continuiret火. (123. Theil 1711, S. 262). Aus dem Schriftwechsel des Verlegers Gleditsch mit dem Leipziger Oberkonsistorium (Grund war eine Beschwerde des kaiserlichen Hofes über Berichte im 134. Theil der Fama) geht hervor, dass im Jahr 1713 mindestens drei namentlich nicht genannte Autoren die Beiträge lieferten (HStA Dresden, Oberkonsistorium, Loc. 10753, vol. II, Bl. 60, Bl. 65f.; ich danke Frank Andert und Michael Nagel für diese Angaben). Einer von ihnen dürfte Christian Stieff (1675-1751) gewesen sein (Doerries, Rußlands Eindringen in Europa, S. 182, nach Angaben von Witkowski, Geschichte des literarischen Lebens, S. 195), Verfasser der $>$ Relation von 1706, der seit 1712 bis zum 198. Theil 1717 verantwortlich zeichnete. Stieff wurde von Christian Gottfried Hoffmann (1692-1735) abgelöst, dieser wiederum mit dem 252. Theil 1721 von Justus Gottfried Rabener (1702-1732), einem der bekanntesten Peter-Biographen des 18. Jahrhunderts. Rabener verfasste die Artikel der Europäischen Fama bis zu seinem Tode (338. Theil 1732). Wer seine Arbeit bis zum 360. und letzten Theil fortführte, ist anscheinend bisher nicht bekannt«: Astrid Blome, Das deutsche Rußlandbild im frühen 18. Jahrhundert. Untersuchungen zur zeitgenössischen Presseberichterstattung über Rußland unter Peter I., Wiesbaden 2000, S. 22, Anm. 71.

206 Europäische Fama 49 (1706), S. 3.

207 Ebd. 
normale Leser, gleich ob adligen oder bürgerlichen Standes, der aus verschiedenen Gründen nicht Zeit genug habe, um sich stets einen repräsentativen aktuellen Überblick über den wachsenden Medienmarkt zu verschaffen, würde hier bedient, denn die Auswertung der unterschiedlichen Nachrichten aus ganz Europa nahm ihm nun die Redaktion dieses Periodikums ab.

Sinold von Schütz gliederte seine Zeitschrift Europäische Fama in unterschiedliche Länderabschnitte. Stets begann er mit Italien, was normalerweise zu zahlreichen satirischen Bemerkungen über die weltliche und kirchliche Politik der päpstlichen Kurie genutzt wurde. Die Absicht ist erkennbar, den protestantischen Bildungsbürger Norddeutschlands für sich einzunehmen. Eine Zensur, die die Belange des Papstes als eines Staatsoberhaupts oder seine Stellung als Kirchenführer geschützt hätte, ist nicht zu erkennen: Die sächsische Zensur schien offenbar nichts dagegen gehabt zu haben, wenn sich die Medienproduzenten über die römischen Verhältnisse lustig machten. Ulrich Rosseaux verweist darauf, dass der lutherische Superintendent und Leiter des Geistlichen Ministeriums in Dresden, Valentin Ernst Löscher (1673-1749), selbst scharf gegen die katholische Präsenz im Land argumentierte, sowohl im Wort als auch in der Schrift ${ }^{208}$. Im Windschatten derart mächtiger Protektion ließ es sich gut anzügliche Bemerkungen machen. So schilderte Sinold von Schütz 1707 den päpstlichen Bann über die Schwestern von St. Mariae Verkündigung in Rom und konnte sich dabei den Kommentar nicht verkneifen, dass es dem Hl. Vater leicht falle, scharf mit einem Nonnenkonvent ins Gericht zu gehen. Mächtigere Sünder allerdings, so schrieb er, pflegten in der Regel weit milder behandelt zu werden ${ }^{209}$.

Im zweiten Abschnitt jedes Heftes folgt die Reichspolitik, danach Frankreich. Die restlichen Länder (in der Reihenfolge Spanien, Portugal, England, Niederlande, Polen und $»$ Moskau «) sind teilweise einzeln behandelt, in anderen Heften zu mehreren zusammengefasst (besonders Spanien und Portugal einerseits sowie England und die Niederlande andererseits). Je nach Nachrichtenlage können auch einzelne Länder ganz entfallen, um dann im nächsten Heft wieder aufzutauchen. Angesichts des Türkenkrieges erscheint mehrfach der Abschnitt»Ungarn und Deutschland «.

Als Vorbilder gab Sinold von Schütz die französischsprachigen Zeitschriften Mercure historique et politique, Mercure Galant, Esprits des Cours d'Europe und Novelles des Cours an ${ }^{210}$. So sehr sich Sinold von Schütz als Mitglied der »Fruchtbringenden Gesellschaft« von der kulturellen Hegemo-

208 Vgl. dazu den Beitrag von Ulrich Rosseaux, Das bedrohte Zion. Lutheraner und Katholiken in Dresden nach der Konversion Augusts des Starken (1697-1751), in: Ute Lotz-Heumann/ JanFriedrich Missfelder/Matthias Pohlig (Hg.), Konversion und Konfession in der Frühen Neuzeit, Gütersloh 2007, S. 212-235, bes. S. 217-223.

209 Europäische Fama 65 (1707), S. 313-315.

210 Ebd. 1 (1702), Vorwort zu Bd. 1, S. 1. 
nie Frankreichs in Europa distanzierte, so gern übernahm er das Zeitschriftenkonzept, weil es in Deutschland vielversprechend erschien. Wirklich stellte sich schnell heraus, dass die Europäische Fama ihren Markt fand: Die Hefte erlangten eine kostendeckende Nachfrage und erfuhren teilweise mehrere Nachdrucke, die auch auf dem Titelblatt vermerkt wurden.

$\mathrm{Zu}$ den Quellen für die Zeitschriftenerstellung dürften auch in diesem Fall, wie beim Monatlichen Staats-Spiegel, die regelmäßige internationale Zeitungsauswertung sowie zusätzliche Korrespondentenberichte gehört haben. Die Zeitschrift beachtete eine reichspatriotische Gesinnung. So wurden die Siege über Frankreich und die Ächtung der wittelsbachischen Kurfürsten Josef Clemens von Köln und Max Emanuel von Bayern mit Wohlgefallen kommentiert, worauf noch einzugehen ist. Der britisch-kaiserliche Sieg in der Schlacht bei Höchstädt im August 1704 gegen Franzosen und Bayern wurden denn auch zu einer großen Marketing-Aktion genutzt: Der Verlag druckte das Heft für August 1704 in einer stark vergrößerten Auflage und ließ es im Leipziger Umfeld umsonst an die Interessenten abgeben ${ }^{211}$.

Betreuender Verleger war Johann Friedrich Gleditsch in Leipzig. Obwohl das Deckblatt der monatlichen Hefte weder den Verfasser noch den Verlag nennt, wird der Zusammenhang dem Leser auch ohne Fremdinformationen offenbar, denn der Verleger nutzte das Periodikum als Werbeträger: Anlässlich der halbjährlichen Messen in Leipzig wurde das jeweils aktuelle Buchprogramm des Verlags eingerückt. Der Verfasser schrieb dazu 1709 im 87. Heft, in früheren Bänden sei der Bücher-Katalog bloß angehängt worden. Da aber einige »Mißgönstige« diesen Anhang vor dem Verkauf abgeschnitten hätten, so würde er nun mitten dazwischengesetzt. Gleditsch bot durch eine kurze Notiz an, er würde auf Bestellung auch ältere Bücher beschaffen ${ }^{212}$.

Selbst eine so renommierte Zeitschrift wie die Europäische Fama blieb von politischen Verwicklungen nicht verschont. Am 21. Januar 1713 musste Verleger Gleditsch wegen »ärgerlicher, dem kayserlichen Hofe missfälliger Passagen« 100 Goldgulden Strafe zahlen und künftig alles dem Geheimen Rat vorlegen. In diesem Fall wurde zusätzlich der Zensor - interessanterweise der Leipziger Verleger Johann Burchard Menck - zu 50 Goldgulden Strafe verurteilt, weil er die fragliche Passage nicht moniert hatte ${ }^{213}$. Von den Autoren wurde offenbar niemand belangt. Die Zeitschrift erschien anschließend ungestört weiter.

211 Salomon, Geschichte des deutschen Zeitungswesens, hier Bd. 1, S. 175f.

212 Das Bücherverzeichnis befindet sich auf 33 unpaginierten Seiten zwischen S. 196 u. 197 in Europäische Fama 87 (1709).

213 Witkowski, Geschichte des literarischen Lebens in Leipzig, S. 195. 
Ebenfalls wenig humorvoll reagierte der Preußenkönig Friedrich Wilhelm I. Anfang Januar 1715, als der Briefschreiber zu Papier brachte, die Europäische Fama habe den König im 163. Teil erneut angegriffen und darauf verwiesen, dass der König die Studien nicht schätze, sondern »starckleibige« Soldaten vorziehe. Auch habe sich die Fama zur Frage der englischen Sukzession in einer für Preußen wenig schmeichelhaften Weise geäußert. Der König habe in Erfahrung gebracht, dass der Herausgeber in Leipzig wohne und betreibe nun dessen Bestrafung ${ }^{214}$.

Gerade die kriegerischen Konflikte im Zuge des Spanischen Erbfolgekrieges belebten den Medienmarkt und lösten eine Gründungswelle von politisch-historischen Zeitschriften aus. In der Europäischen Fama hatte seit 1702 zunächst die Kriegs- und Hofgeschichte dominiert, doch zum Zeitpunkt der Übergabe an Rabener 1724 herrschte Frieden. Der neue Herausgeber schrieb:

Es prophezeyhten uns auch daher ihrer viele, weil sie davor hielten, daß es uns bey Friedens=Zeiten an Materie zu schreiben nothwendig gebrechen müßte, einen schädlichen Mißwachs, und wir wollten wohl wünschen, daß diese ihre Prophezeyungen zum theil eingetroffen, und wir nicht anstatt des befürchteten Mangels, so gar großen Überfluß gefunden hätten ${ }^{215}$.

Kriegsberichtserstattung - so der Herausgeber - sei nicht sehr kompliziert: »Das letzte erfodert keine weitläuffige Bemühung, und man hat etwa mit dem Brieff eines Officiers so dem Handel [ = der Schlacht] beygewohnt, und mit dem Belagerungs=Diario die Sache bald gerichtet ${ }^{216}$. Dagegen sei die Meinungsbildung bei Hofe und in den Räten viel schwieriger zu reportieren. Vieles ändere sich schnell, und man brauche mehr Platz, davon zu schreiben. Ab 1735 erschien die Zeitschrift als Die neue europäische Fama bis Anfang 1756 , und brach dann plötzlich $\mathrm{ab}^{217}$. Ob ein Zusammenhang mit dem heraufziehenden Siebenjährigen Krieg bestand, ist unklar. Ein Wiederbelebungsversuch datiert aus dem Jahre 1760 unter dem Titel Die neueste europäische Fama; das Experiment endete 1765.

214 Friedlaender, Berliner geschriebene Zeitungen, S. 248.

215 Europäische Fama 313 (1728), S. 7.

216 Ebd., S. 8.

217 Neue Europäische Fama. 
Im ähnlichen Stil, allerdings bei kürzerer Lebensdauer, erschien 1709 ein $N e u=$ eröffneter Welt $=$ und Staats $=$ Spiegel unter dem Druckort $» H a a g ~ «{ }^{218}$. In Wirklichkeit wurde das Periodikum in Leipzig hergestellt und von Johann Ehrenfried Zschackwitz (1669-1744) redigiert ${ }^{219}$. Zschackwitz wies in der Einleitung zum ersten Band darauf hin, dass er den Augsburger Monatlichen Welt $=$ und Staats $=$ Spiegel auf eigene Faust fortführen wollte, weil dort mehr als ein Jahr lang kein Heft mehr erschienen $\operatorname{se}^{i 20}$. Auf den vorigen Herausgeber Acxtelmeier ging er namentlich nicht ein. Auch qualifizierte er ihn nicht bzw. gab kein Votum dazu ab, dessen Redaktionsmaßstäbe fortsetzen zu wollen. Es bleibt offen, ob er den früheren Herausgeber kannte. Wie der Augsburger Staats-Spiegel erschien auch sein Leipziger Nachfolger anonym. Zschackwitz lüftete allerdings das Geheimnis um die Herkunft des Periodikums, indem er in der Einleitung zum zweiten Band seine Leser aufforderte, interessante Quellenstücke (»curieuse piecen«) an den Verleger Johann Friedrich Braun[en] nach Leipzig einzusenden. Dieser war offenbar der wirtschaftliche Garant des Journals ${ }^{221}$.

Der Neu=eröffnete Welt= und Staats=Spiegel erschien in zwölf Heften pro Jahr zu je ca. 72-144 Seiten Umfang. Die Hefte eines Jahres wurden fortlaufend paginiert und am Ende des Jahres mit einem Register versehen. Manchmal kamen Kurositäten in der Zählung vor, so in Bd. 5, wo man von 1099 auf 2000 sprang (und dadurch 900 Ziffern ausließ). Inhaltlich legte Zschackwitz den Schwerpunkt auf das Heilige Römische Reich und seine äußere wie innere Politik. Daneben kamen europäische Ereignisse zum Abdruck ${ }^{222}$. Dabei ließ er sich von dem Humanistenmotto »ad fontes « leiten: Er druckte vorzugsweise Quellentexte in voller Länge ab und füllte so die Seiten. Die einleitenden oder abschließenden Kommentare waren hingegen zumeist sehr kurz.

Zschackwitz hatte offenbar mit Neidern und Konkurrenten zu tun, die sich nicht auf verbale Attacken beschränkten. Im Vorwort zum dritten Band verwies der Herausgeber darauf, dass Gerüchte über das baldige Erlöschen seines Periodikums die Runde machten, die jedoch aus der Luft gegriffen seien. Auch seien ihm bereits Korrespondenzen »weggekapert« worden - was immer das im Einzelnen bedeutete ${ }^{223}$.

218 [Johann Ehrenfried ZschaCKWITZ (Hg.)], Neu=eröffneter Welt= und Staats=Spiegel $/$ Worinnen die in Europa/wie auch denen andern Theilen der Welt/vornehmlich in Teutschland vorfallende merckwürdigen Begebenheiten kürtzlich vorgestellet [...] wird, 8 Bd. (Tl. 1-100), Haag [= Leipzig] 1709-1716.

219 Zur Biographie Zschackwitz' vgl. unten Hauptteil I, Kap. 3, S. 154-157.

$220 \mathrm{Neu}=$ eröffneter Welt $=$ und Staats=Spiegel, Bd. 1, 1709, H. 1, Vorwort.

221 Ebd., Bd. 2, 1710, H. 13, S. 6.

222 Zur Begründung des Vorgehens: Ebd., Bd. 1, 1709, H. 1, Vorwort S. 3-20.

$223 \mathrm{Neu}=$ eröffneter Welt $=$ und Staats=Spiegel, Bd. 3, 1711, H. 25, Vorwort. 
Die Kritiken über Zschackwitz waren nicht sehr positiv. Christian Gottfried Hoffmann schrieb über Zschackwitz' Zeitschrift, sie sei nicht sehr gelungen. Der Augsburger Vorläufer sei bedeutend besser gewesen ${ }^{224}$. Hoffmann gab Den Haag als Druckort an. Dass das Werk in seiner eigenen Wirkungsstätte Leipzig hergestellt wurde, war ihm offenbar nicht bewusst. Der Text sei sehr satirisch geschrieben, das missfalle ihm - eine Bemerkung, die aus der Feder eines Frühaufklärers erstaunt ${ }^{225}$. Auch hielt er es für unnötig, so viele Quellen einzurücken. Zwar habe man bis vor Kurzem Schwierigkeiten gehabt, staatsrechtliche Quellen zu bekommen, doch habe sich das inzwischen geändert, und nun könne man sie überall lesen. Eine gedruckte Quellenedition sei genug, etwa die Fabersche Staats-Cantzley ${ }^{226}$. Auch Marcus Paul Huhold kam zu einem kritischen Urteil, nachdem er den Augsburger Staats-Spiegel gelobt hatte: »Der [Neu eröffnete] Welt- und Staats-Spiegel aber ist gar vielen Fehlern unterworffen, welche einem jeden, der selbigen mit Verstande lieset, klar und deutlich in die Augen fallen werden ${ }^{227}$.

Als zweite Vermittlungsform für politische Zeitschriften war die Briefform gebräuchlich. Als Beispiel für diese Form kann Der neu=bestellte Agent von Haus aus gelten, eine Zeitschrift, die der Leipziger Theologe und Privatgelehrte Andreas Stübel zwischen 1704 und 1708 erscheinen ließ $\beta^{228}$. Der Agent ist dabei eine Kunstfigur für eine Person in fremdem Auftrag, der Briefe - bei Stübel nach diplomatischen Gepflogenheiten »depeches« genannt - befördert. Als Themenhorizont gibt er »alle vorfallende sonderbare Kirchen $=$ Universitäts $=$ Staats $=$ und Kriegs=Affairen $\ll$ an, über die er anhand gewechselter Briefe berichten will. Es bleibt im Einzelfall unklar, ob die Briefe Quellenwert haben oder »fiktive Briefe« als Erzählform darstellen; der zweite Fall dürfte allerdings die Regel sein. Die Zeitschrift erschien nicht regelmäßig monatlich, so dass drei Bände (»fonctions«) mit jeweils 12 Heften (»depeches«) überliefert sind, von denen jedes Heft 15-20 Briefe

\footnotetext{
224 Aufrichtige und Unpartheyische Gedancken, Bd. 1, 1714, 1. Stück, S. 105-108.

225 Ebd., S. 107.

226 Ebd., S. 106.

227 [Marcus Paul Hunold], Curieuse Nachrichten Von denen Heute zu Tage grand mode gewordenen Journal-, Quartal- und Annual-Schrifften, Darinnen Die einige Jahr her in Teutscher/Lateinischer/Frantzösischer/Italiänischer und Holländischer Sprache häuffig geschriebenen Journale erzehlet/Und bey denen meisten gemeldet/wenn sie angefangen/aufgehöret/oder ob sie noch bis itzo continuiret werden, Nebst beygefügten unpartheyischen Urtheilen und andern curiosen Observantionibus, Itzo von neuem übersehen und vermehrter herausgegeben, Jena $\left[=»\right.$ Freyburg $\lll{ }^{2} 1716$, s.p.

228 [Andreas StüBeL], Der neu=bestellte Agent von Haus aus/mit allerhand curieusen Missiven, Brieffen/Memoralien, Staffeten, Correspondencen, und Commissionen, nach Erforderung der heutigen Staats- und gelehrten Welt [...], 3 Bd., Freyburg [= Leipzig] 1704-1708. Zu Andreas Stübel (1653-1725): KIRCHNER, Das deutsche Zeitschriftenwesen, Bd. 1, S. 32; DBA, Serie I, Fiche 1244, S. 315f.
} 
beinhaltet, zusammen 494 Schreiben. Zu Beginn jedes Hefts ist ein Kupferstich abgebildet.

Stübel hatte zuvor bereits 1699/1700 unter dem Titel Aufgefangene Briefe einen kurzlebigen Periodikaversuch unternommen ${ }^{229}$. Nach dem Ende des neu=bestellten Agenten ließ er von 1710 bis 1721 die Zeitschrift Der mit allerhand Staats $=$, Friedens $=$, Kriegs-, Hof $=$, Literatur $=$ und Religions $=$ wie auch Privat=Affairen beschäftige Secretarius folgen ${ }^{230}$. Nun hießen die Bände Bände, und auch die »Depeschen « wurden in »Expeditionen« umbenannt. Während des zwölf Jahre dauernden Erscheinens des Periodikums wurden in ungleichmäßigen Abständen zusammen 48 Hefte herausgebracht und in vier Bänden mit fortlaufender Paginierung eingebunden sowie mit einem Register versehen. Die Themenschwerpunkte Politik, Hofbegebenheiten und Kriege setzen sich durch alle drei Zeitschriften fort. Stübel schrieb im Vorwort zum ersten Heft, er wolle seinen bisherigen $» B r i e f=S c h a t z$ der geheimen und raresten Correspondentzen « durch das neue Periodikum weiter publizieren. Wie im Theater sei es auch in der Presse nötig, stets »Veränderung und Abwechselung « zu produzieren, um »fernere Liebe/Begierde und recommendation der einhertretenden curiositäten « zu bewirken ${ }^{231}$. Über den üblichen Themenkontext hinaus reichten einzelne Beschreibungen von Münzprägungen sowie weiterer kunsthistorischer Fragen, offenbar persönliche Steckenpferde des Herausgebers. Chronostichen und zahlreiche Rezensionen rundeten das Programm ab. Stübel schrieb seine Texte überwiegend selbst und rückte in geringerem Umfang als die meisten anderen Zeitschriften komplette Quellentexte ein. Das Urteil der Kritik über den Agenten war zurückhaltend. Marcus Paul Huhold schreibt dazu: »Es kommen in diesem Journal viel curieuse und gelehrte Sachen vor, doch sind auch hier, wie insgemein in dergleichen Schrifften, viel unnütze Sachen, und die von schlechter Consideration, häufig anzutreffen $\aleph^{232}$. Auf welche Weise die journalistische Tätigkeit Stübels 1721 abbrach, ist bislang noch nicht geklärt.

229 [Andreas StüBel/Gottfried ZENnER], Aufgefangene Briefe, welche zwischen etzlichen curiose Personen ueber den jetzigen Zustand des Staats und gelehrten Welt gewechselt, 2 Bd., Wahrenberg [= Leipzig] 1699-1700.

230 [Andreas STÜBEL], Der mit allerhand Staats=, Friedens $=$, Krieges $=$, Hof $=$, Literatur $=$ und Religions $=$ wie auch Privat=Affairen beschäftigte Secretarius [...], 4 Bd. (= 48 Expeditionen), Freyburg [= Leipzig] 1710-1721.

231 StüBel, Secretarius, Bd. 1, S. 3 (unpaginiert).

232 [Marcus Paul Huhold], Curieuse Nachrichten von denen heute zu Tage grand mode gewordenen Journal-, Quartal- und Annual-Schrifften, darinnen die einige Jahre her in Teutscher, Lateinischer, Frantzösischer, Italiänischer und Holländischer Sprache häufig geschriebenen Journale erzehlet und bey denen meisten gemeldet, wenn solche entweder angefangen, aufgehöret oder noch bis jetzo continuiret werden [...], Jena [=»Freyburg«] 1715, hier S. 4f. 
Die Zeitschrift Gespräche im Reich derer Todten erfüllt nur die formalen Vorgaben dieser Medien-Gattung: Ab 1718 erschien etwa monatlich ein sog. »Totengespräch «, herausgegeben durch den Leipziger Privatgelehrten David Fassmann (1683-1744) ${ }^{233}$. Er studierte Jura in Altdorf/Nürnberg, amtierte im Spanischen Erbfolgekrieg zeitweise als Schreiber bei der Kriegs- und Landpflegstube in Nürnberg. 1709 bis 1711 war er im kursächsischen Hofdienst, reiste mit dem Kronprinzen nach Frankfurt a.M. zur Kaiserwahl Karls VI. Von 1711 bis 1715 befand er sich in der Reisebegleitung eines adligen Engländers, in dessen Gefolge er am Utrechter Friedenskongress teilnahm. 1716 arbeitete er bei August Hermann Francke in Halle a.d. Saale als Schreiber. Ein Jahr später ließ er sich in Leipzig nieder, wo er als freier Autor und als Sprachlehrer in Französisch und Englisch sein Geld verdiente. Er verfügte durchaus über ein gutes bürgerliches Einkommen, pflegte allerdings einen kostspieligen Lebensstil und führte eine große und aufwändige Bibliothek, so dass er fortwährend unter Finanzschwierigkeiten litt. Ab 1725 stand er im preußischen Hofdienst unter König Friedrich Wilhelm I., den er 1731 fluchtartig verließ, als ihm der intellektuellenfeindliche König die Rolle des Hofnarren übertragen wollte ${ }^{234}$.

Bei den Totengesprächen handelte es sich um die dritte Vermittlungsform für Zeitschriften, nämlich um den Dialog ${ }^{235}$. Diese Form, bekannt aus antiken philosophischen Dialogen, ist bereits bei einigen Flugschriften des konfessionellen Zeitalters gebräuchlich gewesen, entweder als Diskurs mehrerer Personen - z.B. in der Flugschrift Schuyt-praetgens, Op de Vaert naer Amsterdam aus dem Jahre 1608, die auch in deutscher Sprache herausgebracht wurde ${ }^{236}$. Die Thematik wurde hier vermittelt durch vier Niederländer, die sich über Vor- und Nachteile der Friedensverhandlungen zwischen ihrer Republik und Spanien unterhielten - oder als didaktischen Dialog, bei dem eine jüngere Person als Stichwortgeberin für den weisen älteren Haupterzähler dient. Ein weiteres Beispiel für letztere Form war der Dialog in der

233 David Fassmann, Gespräche im Reiche der Todten, 16 Bd., Leipzig 1718-1739 (1744).

234 Zur Biographie Fassmanns: DBA, Fiche 308, S. 161-166. Vgl. auch die biographischen Angaben bei Wilhelm Damberg, Die politische Aussage in den Totengesprächen David Fassmanns. Gespräche in dem Reich der Todten 1718-1740. Ein Beitrag zur Frühgeschichte der politischen Zeitschrift, Diss. Münster 1952.

235 Zur Erzählform des Dialogs am Beispiel der Totengespräche: KIRCHNER, Das deutsche Zeitschriftenwesen, Bd. 1, S. 30-32; dort finden sich auch Hinweise auf das antike Vorbild Lukians sowie andere Totengesprächsprojekte in der Frühmoderne. Vgl. auch STÖBER, Historische Zeitschriftenforschung heute, bes. S. 49.

236 »Schuyt-Praetgens, Op de Vaert naer Amsterdam, tusschen een Lantman, een Hovelinck, een Borger, ende Schipper«, o.O. 1608 (Knuttel, Nr. 1450). Deutsche Ausgabe: »Ein Dialogus oder Gespräch/die noch wehrende Niderländische Friedenstractation betreffendt/Zwischen einem Holländischen Bawern/Hoffdienern/Burgern und Schiffmann«, o.O. 1608 (Knuttel, Nr. 1453). Vgl. auch die ausführliche Interpretation bei Craig E. HARLINE, Pamphlets, Printing and Political Culture in the Early Dutch Republic, Dordrecht 1987, S. 199-208. 
Flugschrift Holländisch Apokalypsis von Petrus Scribani zwischen dem fragenden 24jährigen Jüngling Pelagius und dem erklärenden 80jährigen Greis Bonaventura, der die Geheimnisse des spanisch-niederländischen Krieges aus katholischer Perspektive verdeutlichte ${ }^{237}$.

In den Dialogen Fassmanns trafen jeweils zwei bereits verstorbene Herrscherpersönlichkeiten zusammen, deren Schatten wie in der antiken Mythologie Diskurse pflegten, wobei es unerheblich war, ob sie in ihrem Leben Zeitgenossen gewesen waren. Die Totengespräche summierten sich bis 1739 zu 240 Heften, in denen jeweils eine Begegnung (»Entrevue«) dargestellt wurde. Normalerweise füllte ein Zusammentreffen auch nur ein Heft, doch in einigen Fällen waren es mehrere (bis zu fünf). Am Ende jedes Zusammentreffens erschien ein Secretarius, der den Diskutanden Neuigkeiten aus der Gegenwart übermittelte und sie zu Stellungsnahmen dazu anregte. Die einzelnen Hefte haben durchschnittlich ca. 70-80 Seiten Umfang. 1725 verkaufte der Berliner Verleger J.A. Rüdiger die Hefte zum Preis von drei Groschen. Die Hefte, die zu einem Band gehören (zus. 15 Bände), sind fortlaufend paginiert ${ }^{238}$.

Später hat Fassmann noch einen dreiteiligen 16. Band herausgebracht, ganz im Sinne historiographischer Interessenten, um das übrige Werk benutzbar zu machen. In Teil 1 (1024 S.) schrieb er die Historie nach denen Monarchen, Reichen und Staaten, in Teil 2 (776 S.) Summarien oder kurtzer Inhalt der 240 Entrevuen, d.h. das wichtige Nachschlagewerk über die Anordnung der Biographien und gleichzeitig die Zusammenfassung der wichtigsten Aussagen. Die Historie ist eine Überblicksgeschichte, nach Nationen sortiert. Im Reich sind die Kaiser separiert, die Kurfürsten, die weltlichen Reichsfürsten und die geistlichen Reichsfürsten folgen. Prälaten, Grafen und Städte fehlen. Der Papst wird unter »Italien« abgehandelt. In den Summarien sind die Biographien auf jeweils 2 Seiten zusammengefasst. Teil 3 ist schließlich das unpaginierte Generalregister ${ }^{239}$.

237 Pambo Verimundus (= Charles Scribani), Holländisch Apocalypsis, Oder Offenbarung, Das ist: Was die gesambten Staden von Anno 1577 biß dato in der gantzen Welt für gefährliche Practicken geführt/insonderheit wider Spanien und das Haus Oesterreich hin und wider Feindlichs verübt haben/außgelegt und in Truck verfertigt [...], Newe Newenstat $1626 . \mathrm{Zu}$ Scribani: Lodewijk Brouwers (Hg.), Carolus Scribani, Brüssel 1977, S. 295-332.

238 Zur Forschung über Fassmann und seine Zeitschrift: Käthe Kaschmieder, David Fassmanns Gespräche im Reiche der Toten (1718-1740). Ein Beitrag zur deutschen Geistes- und Kulturgeschichte des 18. Jahrhundert, Diss. Breslau 1934; LindenberG, Leben und Schriften David Fassmanns, pas.; DAMBERG, Die politische Aussage in den Totengesprächen David Fassmanns, pas.; Ulrich Schmid, Gespräche im Reiche derer Todten (1738-1739), in: FIscher, Deutsche Zeitschriften des 17. bis 20. Jahrhunderts, S. 49-59.

239 Das Register ist schwierig zu benutzen, man muss alle Dynastie- und Vornamen einzeln prüfen, bevor man sicher sein kann, dass man wirklich alle relevanten Einträge berücksichtigt hat. 
Fassmann hatte die Form rezipiert aus französischen Editionen durch Fontenelles Nouveaux dialogues des Morts (1683) und durch Fénelons Dialogues des Morts von 1710. Antikes Vorbild war der griechische Schriftsteller Lukian ${ }^{240}$. Ebenso wie für die Europäische Fama gehören die Grundkonzepte Fassmanns damit in den französischen Kulturraum, woraus für Deutschland eine Adaption vorgenommen wird. Allerdings erscheint es wenig angemessen, wenn Literaturhistoriker den Zeitschriftenredakteuren dies vorwerfen - letztere hätten es bestimmt nicht so ausgiebig getan, wenn sie nicht dafür den Beifall des Publikums in klingender Münze bekommen hätten. In seiner Valet-Rede in Band 15 gibt Fassmann freimütig zu, dass für ihn der wirtschaftliche Erfolg Fontenelles Ansporn zur Nachahmung gewesen $\operatorname{sei}^{241}$.

Inhaltlich handelte es sich bei den Gesprächen im Reich derer Todten zunächst nicht um ein Periodikum, das das Zeitgeschehen kommentierte, sondern eher um eine Historienschrift. Gegenstand war die Geschichte als ganze, denn Fassmann präsentierte auch Persönlichkeiten aus dem Mittelalter (z.B. König Ludwig IX., den Heiligen, von Frankreich, der Dialogpartner von Kurfürst Josef Clemens von Köln war). Seine Erzählabsicht stellt der Herausgeber am Anfang der 145. Entrevue (Bd. 10) dar. Obwohl die einzelnen Hefte in der Form einer Zeitschrift erschienen (ca. 12 Hefte pro Jahr), beschreibt Fassmann selbst sie mit dem Satz: »Denn es ist und wird ein Historisches Werk $\ll^{242}$. Fassmann verweist in diesem Zusammenhang auf die Quellen, die er ausgewertet hat: Für die schon lange toten Protagonisten las er frühere historische Darstellungen, für die erst kürzlich verstorbenen die Zeitungen und die Journale. Da selbst jeder Interessent an der Zeitgeschichte nur ein bis zwei Zeitungen oder Journale lesen könne, nahm Fassmann für sich in Anspruch, für jeden Leser etwas Neues zu bieten, zumal er auch über Informationen verfügte, die ihm »aus vornehmen Häusern, und von respectablen Händen, communiciret worden sind ${ }^{2243}$. Fassmann hatte einen großen Rechtfertigungsbedarf, da er mit einigen Äußerungen Herrschaftspersonen vor den Kopf stieß (besonders die russische Zarin). Im Laufe der Jahre wurden allerdings mehr und mehr Personen einbezogen, die erst vor Kurzem verstorben waren, was die zeithistorische Dimension verstärkte.

Im Vorwort zum ersten Teil von Band 16 nahm Fassmann für sich in Anspruch, sich nach der Wahrheit und Unparteilichkeit gerichtet zu haben.

240 Fassmann selbst weist auf die Vorbilder im Vorwort zu Bd. 12 hin: FAssmann, Gespräche im Reiche der Todten, Bd. 12, Vorwort. - Vgl. dazu auch Kaschmieder, David Fassmanns Gespräche im Reiche der Toten, S. 10.

241 Kaschmieder, David Fassmanns Gespräche im Reiche der Toten, S. 11.

242 Fassmann, Gespräche im Reiche der Todten, Bd. 10, S. 11.

243 Ebd. 
Dazu habe auch gedient, nicht öffentlich seinen Namen zu nennen. »Unparteilichkeit« sei - so Fassmann - nicht ungefährlich:

[...] eben deswegen hätte er etliche mal keine geringe Ungelegenheit, seiner Arbeit wegen, haben können, weil es geschienen, als ob er die Wahrheit allzutrocken und klar an den Tag lege, welches dann, von Schmeichlern und Fuchsschwäntzern, an Hohen Orten, gar ungleich angebracht, und auf eine verhaste Art, als etwas ungeziemendes und vermessenes, vorgestellet worden ${ }^{244}$.

Das Arcanum wurde hier im frühaufklärerischen Sinn schon als etwas eigentlich nicht mehr Zeitgemäßes verworfen. Außerdem unterstellte man seinen Verfechtern, sie seien vom Neid gegen den Autor getrieben und verfolgten ihn deswegen.

Sicherlich lässt sich Fassmanns Werk als »Magazin der damaligen Volksbildung« oder als »eine Art Enzyklopädie« bezeichnen. Der Hauptzweck dürfte wohl in der lehrreichen (und damit sinnvollen) Unterhaltung gelegen haben. Die nicht wenigen Frauendarstellungen stellen zudem eine Verbindung her zur weiblichen Leserschaft, zumindest als ein medialer »Türöffner«, da sich wohl kaum ein Leser nur für Personen seines eigenen Geschlechts interessiert haben dürfte ${ }^{245}$. Doch auch die Satire kam nicht zur kurz, wie sich an einem Seitenhieb auf den höfischen Alkoholgenuss ablesen lässt: »Ach würde doch mancher Hofmann dem Mond gleichen und nur alle vier Wochen einmal voll werden; allein, bei vielen bleibt es eben ein frommer Wunsch $\aleph^{246}$.

3.000 Exemplare monatlich brachten David Fassmann und seinem Verleger Wolfgang Deer einen schönen Ertrag ein und lösten unter seinen Berufskollegen Neidgefühle aus ${ }^{247}$. Illegale Nachdrucker traten in Erscheinung und veranlassten Fassmann zu aggressiven Kommentaren. Johann Goldfriedrich erwähnt eine große Ausgabe von 1.500 Exemplaren eines Totengespräche-Heftes aus dem Jahr 1721 durch den Leipziger Verleger Moritz Georg Weidmann. Hierbei handelte es sich um die 34. Entrevue, für die Weidmann in Schweden eine große Nachfrage festgestellt hatte. Der Konkurrent hatte vergeblich versucht, vom Verlag Wolfgang Deer 400 Exemplare mit gutem Rabatt zu erlangen; nach dem Scheitern der Verhandlungen druckte er den Band illegal nach ${ }^{248}$. Schon früher waren die 3. und die 13. Entrevue nach-

244 Ebd., Bd. 16, T1. 1, Vorwort, s.p.

245 Kaschmieder, David Fassmanns Gespräche im Reiche der Toten, S. 20.

246 Fassmann, Gespräche im Reiche der Todten, Bd. 6, S. 78; vgl. auch den Hinweis bei KaschmieDER, David Fassmanns Gespräche im Reiche der Toten, S. 36.

247 Agatha Ковисн, Zensur und Aufklärung in Kursachsen. Ideologische Strömungen und politische Meinungen zur Zeit der sächsisch-polnischen Union (1697-1763), Weimar 1988, S. 166f.; vgl. auch HaACKe, Die Zeitschrift - eine Schrift der Zeit, S. 44.

248 Johann GoldFriedrich, Geschichte des deutschen Buchhandels vom Westfälischen Frieden bis zum Beginn der klassischen Literaturperiode (1648-1740), Bd. 2, Leipzig 1908, S. 205, zit. 
gedruckt worden ${ }^{249}$. Die Zeitschrift als Gattung erfüllte - ungeachtet ihrer zunehmenden Ausdifferenzierung - eine komplementäre Funktion neben der kommentarlos berichtenden Zeitung, den »chronikalisch verdichtenden Messrelationen « und den größeren politisch ausgerichteten Sammelwerken bzw. Historienwerken. Dabei darf man sich die Trenngrenze zwischen Zeitung und Zeitschrift nicht allzu scharf vorstellen. Bevor die beiden Genres fest etabliert waren, erschienen zahlreiche Publikationen, die in ihrer Art eine Mischung aus beiden darstellten und gleichzeitig noch den Anspruch erhoben, eine Chronik darzustellen. Der Zodiacus Mercurialis, zwischen 1667 und 1669 von Johannes Praetorius herausgegeben, kann als eines dieser Zwischenprodukte gelten ${ }^{250}$. Drei Hefte zu jeweils ca. 170 Seiten kamen in drei aufeinander folgenden Jahren heraus. In ihrer inneren Organisation hatten sie Elemente von Messrelationen: Sie stellten Tagesereignisse vor, gingen allerdings auch auf Hexen- und Wundergeschichte $\operatorname{ein}^{251}$. Auf die Zeitschriften weist schon die Gliederung nach europäischen Staaten hin, eine Ordnung, die später im Mercure historique et politique ebenso wie in der Europäischen Fama zu finden sein sollte.

In wieweit die historisch-politischen Zeitschriften in ihrem Informationsgehalt über das kumulative Zeitungswissen hinausreichten, dazu gibt es unterschiedliche Aussagen. Während Hans Bots, der diese Frage anhand des Mercure historique et politique untersucht hat, den Wissenszuwachs vor allem auf das Räsonnement beschränkt, kommt Susanne Friedrich zu dem Schluss, dass die von ihr untersuchten Zeitschriften, besonders der Monatliche Staats-Spiegel und die Europäische Fama, ein deutliches Mehr an Wissen brachten und Bereiche abdeckte, die von den Zeitungen nicht abgehandelt worden waren ${ }^{252}$.

nach Dorn/Vogel, Geschichte des Pressevertriebs in Deutschland, S. 30.

$249 \mathrm{Zu}$ Fassmann als Erfolgsautor und Herausforderung für den Nachdruck: Wittmann, Der gerechtfertigte Nachdrucker, bes. S. 295.

250 Johannes Praetorius, MDCLXVI Zodiacus Mercurialis. Das ist: Jährige Europäische Welt=Chronick $/$ So in einem wohl=verfasseten kurtzem Begriff/alle merckwürdigsten Begebenheiten vorbildet/welche sich im [...] 1666ten Wunder=Jahre [...] zugetragen haben [...], o.O. 1667 (und Folgehefte bis 1669). Den Hinweis auf diese Zeitschrift gab mir Gerhild Scholz Williams, der ich dafür und für mehrere anregende Diskussionen in Wolfenbüttel über literarische Gelehrsamkeit und marktorientierte Publizistik im Barockzeitalter danke. - Zum weiteren Hintergrund: Gerhild Scholz Williams/Stephan Schindler (Hg.), Knowledge, Science, and Literature in Early Modern Germany, Chapel Hill/London 1996.

251 Die öffentliche Hinrichtung eines »Hexenmeisters« in München 1666 stellt Praetorius mit großer Zustimmung zum Tatvorwurf und zum Verfahren dar: Praetorius, Zodiacus Mercurialis (1667), S. 47f.

252 Hans Bots, Quelques gazettes de Hollande en langue française et le Mercure historique et politique. Une analyse comparative, in: Duranton/RÉTAT, Gazette et information politique sous l'Ancien Régime, S. 159-168; FrIEDRICH, Drehscheibe Regensburg, S. 459. 
Das Zeitschriftenwesen vollzog sich im frühen 18. Jahrhundert unter den Umständen eines starken quantitativen Wachstums: Auf der Grundlage der Untersuchungen von Joachim Kirchner stellte Erich Lorenz eine Liste zusammen, nach der 58 deutschsprachige Zeitschriften um 1700 publiziert wurden. Ihre Zahl stieg in den folgenden Jahren bis 1750 auf 260, bis 1790 auf 1.225, um erst während der napoleonischen Kriege wieder zurückzugehen $^{253}$. Zahlreiche Einzelangaben zur Entwicklung der Zeitschriften finden sich auch in der zweibändigen Monographie von Wilmont Haacke sowie in der Medien- und Kommunikationsgeschichte von Jürgen Wilke ${ }^{254}$. Die Lektüre von Zeitungen und Zeitschriften bildete das Fundament für eine Säkularisierung des Politischen vor den Augen eines wachsenden Publikums und damit erst die Voraussetzung für die Bewusstseinsprozesse der Aufklärung in Deutschland.

\subsection{Historienschriften und Reichspublizistik}

Die Historienschriften und staatsrechtliche Studien sind zwar älter als die Zeitungen und Zeitschriften und daher kein direktes Ausdifferenzierungsprodukt ihrer Entwicklung, erfuhren aber im Zuge der Ausdifferenzierung des politischen Mediensystems einen enormen Impuls. Frühere Historienschriftsteller waren darauf angewiesen gewesen, alte Schriften des Genres auszuwerten und daraus neue Texte zu erstellen. $\mathrm{Zu}$ vielen Themen gab es nur eine verfügbare Darstellung, die mangels abweichender Dokumente von späteren Betrachtern weder verifiziert noch falsifiziert werden konnte, sondern geglaubt werden musste. Seit dem 17. Jahrhundert stand nun die Gesamtheit der periodischen Presse als Material zur Verfügung. Die tagesaktuellen Informationen wandelten sich durch inzwischen eingetretene Bekanntheit in Nichtinformationen: Als »geronnene« Berichte wurden sie verfügbar für geschichtlich-kulturelle Weltdeutungen der Geschichtsschreiber ebenso wie als Präjudiz-Quellen der Juristen. Informationen gab es fortan im Überfluss, so dass konkurrierende Interpretationen möglich wurden, weil die Quellen Argumente für unterschiedliche Schlüsse lieferten. Geschichte war dadurch nicht mehr nur die Beschreibung längst vergangener Herrschaftsverhältnisse und gestorbener Potentaten, sondern rückte bis ganz nah an die Gegenwart

253 Zusammenstellung der deutschen Zeitschriften: KirchNER, Grundlagen des deutschen Zeitschriftenwesens, hier Bd. 2, S. 323. Auswertung der Zahlen pro Jg.: $1710=64,1720=119$, 1730=133, 1740=176: Erich Lorenz, Die Entwicklung des deutschen Zeitschriftenwesens. Eine statistische Untersuchung, Diss. Berlin-Charlottenburg 1937, S. 28. Dabei existierten die meisten Zeitschriften nur für einige Jahre.

254 HaAcKe, Die politische Zeitschrift, 2 Bd., pas.; Wilke, Grundzüge der Medien- und Kommunikationsgeschichte, S. 94-115. 
heran. Diese Geschichte galt es jeweils fortzuschreiben oder sie einer perspektivischen Neuinterpretation zuzuführen ${ }^{255}$.

Dabei reichte die Geltung der Historie, wie seit Langem bekannt und durch Reinhart Koselleck eindrucksvoll analysiert ${ }^{256}$, weit über ein Subsystem der Wissenschaften hinaus: Geschichtliche Erfahrbarkeit bereicherte die stets begrenzte individuelle Erfahrung erheblich, und dies galt umso mehr, wenn es sich um die Erfahrungswelten von Eliten der Macht oder des Geistes handelte. Vormoderne Geschichtsschreibung sollte wahrhaftig sein in einer Weise, die spätere Erkenntnistheoretiker »naiven Realismus« genannt haben $^{257}$. Ein Topos dieser Wahrhaftigkeitsforderung, darauf weist Koselleck hin, war die Spiegel-Metapher, der gemäß Geschichte »in keiner Weise entstellt, verblasst oder verzerrt« vermittelt werden sollte, ein Bild, das schon bei Lukian verwendet wurde und das noch in historiographischen Titeln des 17. Jahrhunderts ungebrochen rezitiert wurde - wohlgemerkt nach allen perspektivischen Streitigkeiten des konfessionellen Zeitalters mit seiner Medienpublizistik. Denselben Zweck verfolgte die Metapher der »nackten Wahrheit« (nuda veritas), die naheliegenderweise die Künstler inspirierte ${ }^{258}$. Eine erkenntnistheoretische Weiterentwicklung entstand erst unter aufklärerischer Perspektive durch Johann Martin Chladenius (1710-1759), der die Standortgebundenheit jedes Historikers entdeckte, wie weit sich dieser auch selbst mit seinen Anschauungen und Werthaltungen zurücknehmen mochte ${ }^{259}$. Bis zur allgemeinenen Durchsetzung dieser Erkenntnis war es allerdings noch ein weiter Weg.

Dieses schöngeistig-moralische Verständnis kollidierte mit den Interessen an einer Nutzanwendung im Rahmen der sozialen Konkurrenz. Nicht nur adlige Dynastien ließen sich eine Abkunft von sagenhaften Helden der Vor-

255 Reflexionen über Mediensystem und Reichspublizistik: Johannes ArndT, Zeitung, Mediensystem und Reichspublizistik, in: BAUER/Böning, Die Entstehung des Zeitungswesens im 17. Jahrhundert, S. 179-200.

256 Reinhart Koselleck, Historia Magistra Vitae. Über die Auflösung des Topos im Horizont neuzeitlich bewegter Geschichte, in: Ders., Vergangene Zukunft. Zur Semantik geschichtlicher Zeiten, Frankfurt a.M. 1989, S. 38-66. Vgl. auch seine weitereren Überlegungen zur Zeit als Fundamentalkategorie der Historiographie: Ders., Zeitschichten. Studien zur Historik, Frankfurt a.M. 2000.

257 Zur »Realismus«-Debatte: WiLLASCHEK, Realismus, pas.

258 Zur Spiegel-Metaphorik: Reinhart Koselleck, Standortbindung und Zeitlichkeit. Ein Beitrag zur historiographischen Erschließung der geschichtlichen Welt, in: Ders., Vergangene Zukunft, S. 176-207, hier S. 179. Koselleck nennt die Formel »speculum vitae humanae« bei Gerhard Johann Vossius, Ars historica (1623), Leiden ${ }^{2} 1653$, Kap. V, S. 27.

259 Johann Martin Chladenius, Allgemeine Geschichtswissenschaft, Leipzig 1752, hier zit. nach Koselleck, Standortbindung und Zeitlichkeit, S. 184f. Die zentralen Überlegungen zum »Sehepunkt« finden sich auszugsweise ediert bei: Wolfgang HardTwig (Hg.), Über das Studium der Geschichte, München 1990, S. 11-17. - Vgl. zur Einordnung in den Entwicklungsgang zur modernen Geschichtswissenschaft auch: Friedrich JAEGER/Jörn RüsEN, Geschichte des Historismus. Eine Einführung, München 1992, S. 17. 
oder Frühzeit zuschreiben, selbst auf Götter oder Aeneas wurde zurückgegriffen. Auch bürgerliche Familien boten bei dem Bemühen mit, den Status des eigenen Hauses aufzuwerten. So ist von dem Kölner Kaufmann Hermann Weinsberg (1518-1597) bekannt, dass er nicht nur die aktuelle Berichterstattung verfolgte, etwa über den spanisch-niederländischen Krieg, der in gefährlicher Nähe zu seinem Wohnsitz stattfand, sondern sich auch für historische Themen interessierte. Sein Interesse lag darin, sich adlige Vorfahren gräflichen Standes zuzuschreiben. Bereits sein Vater und sein Großvater, die noch »van Schwelm« gehießen hatten, hatten auf eine adlige weinsbergische Vorfahrenschaft verwiesen. Hermann von Weinsberg fügte diesem fingierten Stammbaum noch zwölf weitere Ahnen hinzu, die bis in die karolingische Zeit zurückreichten. In besitz- und bildungsbürgerlichen Familien war dies kein ungewöhliches Verfahren. Es kontrastierte allerdings in auffälliger Weise zum sonstigen Selbstverständnis Weinsbergs, in seiner Autobiographie die Geschehnisse seiner Zeit verhältnismäßig objektiv zu beschreiben ${ }^{260}$.

Selbst die Zeitschriftenherausgeber fingierten eine ungebrochene historisch-politische Kontinuität und begründeten damit sowohl die Legitimation der Historie als auch die Nutzanwendung der laufenden publizistischen Berichterstattung. Andreas Stübel fasste diese Überlegungen 1713 in folgende Worte:

Denn da andere Königreiche ihren vorigen Staat entweder geändert oder doch in Ungewissheit gesetzet; so halte hingegen das gemeine Wesen unsers Vaterlands fast in allen und jeden Stücken und Kleinigkeiten noch eben den Stand/den es fast vor 1000 Jahren von 921 an gehabt; dergestalt/daß wenn wir von demselben dann und wann abgewichen/solches mehr aus einem Irrthum und Unwissenheit voriger Zeiten als einem Vorsatz etwas zu ändern geschehen seyn ${ }^{261}$.

Stübel charakterisiert hier bezeichnenderweise noch keinen rechtlichen Anspruch, dass dieses politische Vorgehen so hätte geschehen müssen, sondern eine verbreitete Mentalität seiner Zeitgenossen: Das Reich als göttliche Stiftung war gut und bedurfte nur gelegentlicher Renovierungen - »Reformationen « behielten in diesem Zusammenhang ihren ursprünglichen Wortsinn.

$260 \mathrm{Zu}$ Weinsberg als Zeithistoriker: Wolfgang Herborn, Hermann von Weinsberg (1518-1597), in: Manfred Groten (Hg.), Hermann von Weinsberg (1518-1597). Kölner Bürger und Ratsherr. Studien zu Leben und Werk, Köln 2005, S. 15-33, bes. S. 27-29.

261 STÜвеL, Secretarius, Bd. 2 (1713), »Expedition« 13, Brief 144, S. 25-39, Zitat S. 30. 
Dabei waren bei früheren Medien bereits die Anschlussstellen zwischen Publizistik und Historie geschaffen worden. Ein Zeitungsherausgeber wie Johann Carolus in Straßburg hatte eine doppelte Leserschaft im Auge, der er seine Relation empfahl: Den kurzfristigen Leser, der aktuell informiert werden wollte, und den historisch interessierten Rezipienten, der auch im zeitlichen Abstand auf die Texte zurückgreifen wollte. Anders wäre nicht zu erklären, dass Carolus seine Zeitung so anlegte, dass die einzelnen Blätter zu Jahresbänden zusammengestellt werden konnten. Für den ersten überlieferten Jahresband 1609 verfasste der Herausgeber eine Vorrede ${ }^{262}$. Auch Timotheus Ritzsch, der seit 1642 in Leipzig ein Zeitungsprivileg besaß, schrieb im Vorwort seiner ab 1660 umbenannten Neu-einlauffenden Nachricht von Kriegsund Welt-Händeln, ihm gehe es darum, die Gesamtheit eines Jahrganges so anzulegen und zu Silvester zusammenstellbar zu machen, dass man für die interessierten Wissenschaften ein »Jahr= und Geschichts=Buche« bereitstellen könne. Dazu gehörte ein Jahrestitelblatt, mitunter eine Vorrede des Herausgebers (jedenfalls im ersten Band) sowie ein Schlagwortregister - mit 12 Seiten Umfang nicht nur für den Zeitgenossen, sondern auch für den späteren Historiker von unschätzbarem Wert $^{263}$.

Einer der wichtigen Theoretiker des Zusammenhangs zwischen Zeitungsproduktion und Geschichtsschreibung war Daniel Hartnack. Auf seine bunte Biographie wird unten im Zusammenhang mit der Autorenschaft im Zeitungsgeschäft noch einzugehen sein. 1688 ließ er eine Studie mit Reflexionen über die Erstellung von Historienschriften erscheinen. Hartnack stellte sich zwei Fragen: 1. Was soll ein Schriftsteller leisten, damit er eine gute Historienschrift erstellen kann? 2. Auf welche Weise kommt er zu den Informationen, die er für diese qualitative Historienschrift benötigt? Die Maximen des Historien-Verfassers sollten sein: 1. Glaubwürdigkeit; 2. Kürze; 3. gute Ordnung; 4. Beachtung von Chronologie und Kausalität; 5. Vermeidung von Affekten; 6. Zurückhaltung beim eigenen Urteil264. Dazu dient eine gute Fundiertheit der Studie durch eine breite Quellenlage aus den Periodika und die Beachtung eines gewissen zeitlichen Abstands zum beschriebenen Geschehen, um die Folgen bestimmter politisch-militärischer Handlungen abschätzen zu können. Bemerkenswert ist die Forderung, sich kurz zu fassen, der bestehende Überschuss an Meldungen wurde reflektiert. Durch Knappheit in der sprachlichen Ausgestaltung sei es möglich, das wirklich Wichtige eines

262 Weber, Galerie der Zeitungspresse im 17. Jahrhundert, hier S. 33. Die Vorrede verzichtet allerdings auf weiterführende Programmatik und beschränkt sich auf die Tatsache der Fortsetzung des Periodikums, auf die Vorweg-Entschuldigung für eventuelle Versehen sowie auf beste Wünsche für die Leserschaft: Ebd., S. 36.

263 Ders., Umriß der Zeitungsgeschichte Leipzigs im 17. Jahrhundert, hier S. 144.

264 Hartnack, Erachten von Einrichtung Der alten Teutschen und neuen Europäischen Historien, S. 34-36. Zu Biografie und Wirken Hartnacks siehe in dieser Studie S. 151f. 
Geschehenszusammenhanges plastisch hervortreten zu lassen. Viele historiographische Studien der Vergangenheit hätten sich durch übermäßige Ausführlichkeit im Nebensächlichen verloren, einige von ihnen ihre Existenzgrundlagen dadurch zerstört, dass sie wegen der Masse an Text nicht mehr hätten gedruckt werden können. Bezeichnenderweise prophezeit Hartnack dem Theatrum Europaeum genau dieses Schicksal ${ }^{265}$.

Hinsichtlich der Quellen des Historienschreibers betont Hartnack die Notwendigkeit, die aktuellen Zeitungen zu verfolgen. Dieser Zusammenhang begründet zwar noch nicht die moderne Geschichtswissenschaft, darf aber als Plädoyer für die Zeitgeschichtsschreibung gewertet werden: Geschichte, das ist nicht mehr bloß der Rückblick in längst vergangene Zeitalter, sondern Geschichte bildet sich stets weiter durch die gerade vergangenen Handlungen. Geschichte und Gegenwart berühren sich in diesem Konzept unmittelbar. Die Forderung nach der Wahrhaftigkeit der Berichterstattung lässt sich dadurch doppelt begründen: Zum einen lässt es sich in einem netzwerkartigen Mediensystem nicht verhindern, dass die »richtige« Information sich am Ende durchsetzt, denn viele Staatshandlungen haben Folgen, die sich später nicht mehr übersehen lassen (z.B. gewonnene oder verlorene Schlachten). Zum anderen entspricht die Orientierung von Gazetten und Journalen an der Wahrheit dem Grundpostulat wissenschaftlichen Forschens überhaupt und ist damit auch für geschichtswissenschaftliche Studien maßgeblich ${ }^{266}$.

Ein weiterer Aspekt verbindet Zeitungslektüre und Wissenschaft: die Neugier, bei Hartnack »Curiosität« genannt. Neugier wurde von den Zeitgenossen als anthropologische Konstante betrachtet, kam sie doch schon in der Bibel vor, allerdings mit negativer Konnotation ${ }^{267}$. Lorraine Daston ${ }^{268}$ betont, dass der Paradigmenwechsel zur positiven Bewertung in die Zeit von Francis Bacon (1561-1626) zu datieren ist, doch hielten sich die konkurrierenden Wahrnehmungen auch in der Folgezeit die Waage ${ }^{269}$.

265 Bemerkenswerterweise gelingt es Hartnack, seinen eigenen Maßstäben zu entsprechen: Er kommt bei seiner Studie mit 110 Seiten aus.

266 GiESELER, Vom Nutzen und richtigen Gebrauch der frühen Zeitungen, hier S. 261.

$267 »$ Die Athener alle waren gerichtet auff nichts anders/denn etwas neues zu sagen oder zu hören« (Apostelgeschichte 17, 21), hier zit. bei Samuel Fridericus Hagen, Disputatio Juridica de Jure Novellarum [= Von Neuen Zeitungen], Leipzig 1697, S. 11.

268 Lorraine DASTON, Neugierde als Empfindung und Epistemologie in der frühneuzeitlichen Wissenschaft, in: Andreas Grote (Hg.), Macrocosmos in Microcosmo. Die Welt in der Stube. Zur Geschichte des Sammelns 1450 bis 1800, Opladen 1994, S. 35-59, bes. S. 35; dies., Die Lust an der Neugier in der frühneuzeitlichen Wissenschaft, in: Klaus KRÜGER (Hg.), Curiositas. Welterfahrung und ästhetische Neugierde in Mittelalter und früher Neuzeit, Göttingen 2002, S. $147-175$, bes. S. 149 f.

269 Vgl. dazu auch die Interpretation von Neil Kenny, der bei seinen untersuchten Institutionen leider nicht auf die periodische Presse als eigenen Bereich eingeht: Neil Kenny, Curiosity in Early Modern Europe. Word Histories, Wiesbaden 1998; ders., The Uses of Curiosity in Early Modern France and Germany, Oxford 2004. 
Während frühere Zeitungstheoretiker wie Ahasver von Fritsch noch die moralische Abwertung der Neugier als Laster betonten, gelangte Hartnack $\mathrm{zu}$ einer positiven Bewertung. Zwar seien »eitele unnöthige«, »unzeitige« und »unersätliche Begierde« abzulehnen, doch die Neugier etwa zum Wissensgewinn für den eigene Beruf sei hingegen förderungswürdig ${ }^{270}$. Joachim Ernst von Beust schloss sich dieser Tendenz an, für ihn erhob der Stimulus curiositatis die Menschen erst zu höheren kulturellen Tätigkeiten:

Ohne selbigen würden wir mehr schlafen, als wachen, Künste und Wissenschaften begraben liegen und der Mensch nicht viel besser, als die Thiere, seyn, welche bloß für ihren Unterhalt und Sicherheit sorgen ${ }^{271}$.

Auch gestand Beust den Nachrichtenkonsum zwei unterschiedlichen qualitativen Gruppen zu:

Die Erste vor diejenigen, welche, blos ihre Neubegierde zu stillen, dergleichen Blätter halten und lesen: die Zweyte aber solche, welche, zur Ergänzung ihrer historischen Erkänntniss, selbige verständlich und mit Nutzen gebrauchen und behalten ${ }^{272}$.

Eine vergleichbare Haltung liegt dem Artikel über »Neugierigkeit« zugrunde, den Johann Heinrich Zedler in seinem Universal-Lexicon zum Abdruck brachte: Es handelt sich zwar um ein Laster, aber in maßvoller Weise ist Neugier eine Triebfeder beispielsweise der Gelehrsamkeit ${ }^{273}$. Auch unter systemtheoretischer Perspektive ist die Neugier interessant: Neugier entstammt nicht dem System, sondern reproduziert sich selbst, indem der Leser eine Weile nach der Lektüre Bedarf an neuer Lektüre verspürt. Durch die sich selbst reproduzierende Neugier wird dem System stets neue Information abgefragt ${ }^{274}$.

270 Zur späteren Einschätzung der Neugier: Gieseler, Vom Nutzen und richtigen Gebrauch der frühen Zeitungen, S. 261; Pompe, Die Neuheit der Neuheit, hier S. 43f.

271 Joachim Ernst von BEust, Der Versuch einer ausführlichen Erklärung des Post-Regals und was deme anhängig, überhaupt und ins besondere in Ansehung des Heiligen Römischen Reichs Teutscher Nation [...] verfasset, 3 Bd., Jena 1747-1748, hier Bd. 3, Abschnitt 4 »Von Zeitungen, derselben Recht und Nutzen«, S. 591.

272 Ebd., Bd. 3, S. 631.

273 Art. »Neugierigkeit«: Johann Heinrich ZedLER (Hg.), Großes vollständiges Universal-Lexicon aller Wissenschaften und Künste [...], 68 Bd., Halle/Leipzig 1732-1754, hier Bd. 24, Sp. $172-174$.

274 Hartnack, Erachten von Einrichtung Der alten Teutschen und neuen Europäischen Historien, S. 59. - Vgl. zur Neugier aus literaturwissenschaftlicher Sicht: Barbara M. BENEDICT, Curiosity. A Cultural History of Modern Inquiry, Chicago/London 2001; Andreas SpeER, Die gefährdete Neugier. Über die Ursprünge unseres Wissenschaftsverständnisses, in: Forschung und Lehre 12 (2004), S. 655-657. - Vgl. zur Neugier auch FrIEDRICH, Drehscheibe Regensburg, S. 528-533. 
Daniel Hartnack assoziierte den Nachrichtendurchlauf mit der Destillation von Alkohol. Dabei waren die Zeitungen (»Novellen«) die erste »Collection und Sammlung der Materien«, die halbjährlichen Relationen die erste Destillation, während das Diarium Europaeum und das Theatrum Europaeum die zweite Destillation darstellten. Weitere Destillationen seien, so Hartnack, denkbar und anzustreben. Eine dritte Destillation hielt Hartnack für wünschenswert, denn gerade das Theatrum Europaeum werde mit zunehmender Dauer sehr weitschweifig, so dass noch knapper und pointierter das Wesentliche des Geschichtsverlaufes herausgearbeitet werden könne ${ }^{275}$. Um eine flächendeckende Informationserhebung zu erhalten, befürwortete Hartnack bei Zeitungen das Regionalprinzip. Historienschriften hingegen müssten auf einen größeren Überblick achten und unterlägen daher nicht der Verankerung in einer Region. Sie sollten ca. alle zehn Jahre erscheinen, um genügend Abstand zu den einzelnen Begebenheiten zu wahren und zu einem Urteil in der Lage zu sein ${ }^{276}$.

Im Sinne Hartnacks sollen auch in der vorliegenden Studie nicht die verschiedenen Medien der Nachrichtenvermittlung auseinandergezogen, sondern in ihrem Zusammenwirken verstanden werden: Erst die Verschiedenheit der Medien machte das Nachrichtensystem aus. Zwischen politischer Korrespondenz und Briefzeitungen bestand ein enger Zusammenhang dergestalt, dass zahlreiche Autoren in beiden Kontexten Berichte verfassten und verschickten. Zeitungen wurden vor allem von professionellen Lesern bezogen, von Akteuren des politischen Lebens (Standespersonen, Verwaltungsbedienstete, Rechtskonsulten), von Multiplikatoren im Bildungsbereich (Professoren, Geistliche, Lehrer) und besonders von Medienproduzenten. Keine Zeitschriftenredaktion und auch kein Verlag, der juristische Texte produzierte, kam ohne Personen aus, die in der aktuellen Presse belesen waren, denn dies war die Voraussetzung für die Texterstellung wie für ein sinnvolles Lektorat. Der Durchlauf an Berichten, rechtlichen Quellentexten und der laufende Strom von Informationen über die Funktionsweise der Herrschaftssysteme schuf die Grundlage für Historien- und Rechtsquellenwerke, die ihrerseits die Grundlage sowohl für das Rechtssystem als auch die Argumentationsbasis für die Fortentwicklung des politischen Systems war, solange politisches Handeln offiziell am Rückgriff auf das »gute Alte« orientiert war ${ }^{277}$. Doch auch das Naturrecht, dessen Siegeszug in Mitteleuropa

275 Daniel Hartnack, Erachten von Einrichtung Der alten Teutschen und neuen Europäischen Historien, Celle 1688, S. 60. Vgl. dazu auch die Würdigung dieses Gedankens bei Jörg Jochen BERns, Zeitung und Historia. Die historiographischen Konzepte der Zeitungstheoretiker des 17. Jahrhunderts, in: Daphnis 12 (1983), H. 1, S. 87-110, hier S. 98.

276 HARTNACK, Erachten von Einrichtung Der alten Teutschen und neuen Europäischen Historien, S. $104 f$.

277 Michael StolLeis, Geschichte des öffentlichen Rechts in Deutschland, Bd. 1: Reichspublizis- 
parallel zur hier beobachteten Entwicklung stattfand, bedurfte historischer Rückgriffe und nutzte die dichte Publikationslage der Reichsrechtswerke als Fundus $^{278}$.

Die ausführlichsten Überlegungen zum Nachrichtendurchlauf stammten von dem Juristen und Zeitschriftenherausgeber Johann Peter von Ludewig. Sein Cursus informationum setzte sich aus folgenden Schritten zusammen:

1. Am Beginn der Informationskette stand die geschriebene Zeitung. Hier wurde ein politisches Ereignis zu Papier gebracht und damit als Text zu einem vermittelbaren Sachverhalt geformt. Dies geschah dezentral an vielen unterschiedlichen Orten. Beispielsweise hatte die Schreibstelle der kurmainzischen Direktorialkanzlei am Regensburger Reichstag (»Dictatur«) einen Durchsatz von zahlreichen Informationen, die bereits kurze Zeit später in Abschrift gegen Geld erhältlich waren.

2. Einen Tag später standen die wichtigsten Berichte in den Zeitungen, der Rest folgte kurz darauf. Viele Informationen aus Regensburg wurden bereits von interessierten Höfen den Universitäten zum Zweck der akademischen Lehre übermittelt.

3. Aus den Deduktionen, die die Parteien in der Mainzer Dictatur eingereicht hatten, fertigten Michael Caspar Lundorp und Anton Faber (= Christian Leonhard Leucht) ihre Editionen, die monatlich bzw. halbjährlich herausgebracht wurden. Andere Editoren folgten diesen Beispielen.

4. Das Endstadium war erreicht, wenn alles in dauerhaften Reichsrechtskompilatorien stand ${ }^{279}$. Anzuschließen wäre hier, dass die Historienschriftsteller als weitere Endverwerter infrage kommen: Aus den Kompilatorien fertigten sie unter ihrer - historischen - Fragestellung weitere Einzeldarstellungen oder neue Serienwerke.

Der Zeitungskritiker Kaspar Stieler ging ebenfalls auf die Beziehung zwischen Zeitung und Geschichtsschreibung ein. In Zustimmung zu Daniel Hartnack erkannte er an, dass die Novellen der Historie erst das Funda-

tik und Policeywissenschaft 1600-1800, München 1988; ders., Staat und Staatsräson in der frühen Neuzeit. Studien zur Geschichte des öffentlichen Rechts, Frankfurt a.M. 1990; Notker Hammerstein (Hg.), Staatslehre der frühen Neuzeit, Frankfurt a.M. 1995; Dieter WyduCKEL, Ius publicum. Grundlagen und Entwicklung des Öffentlichen Rechts und der deutschen Staatsrechtswissenschaft, Berlin 1984.

278 Zum Naturrecht im Reich: Michael Stolleis, Reichspublizistik - Politik - Naturrecht im 17. und 18. Jahrhundert, in: Ders. (Hg.), Staatsdenker im 17. und 18. Jahrhundert, Frankfurt a.M. 1977, S. 7-28.

279 Johann Peter von Ludewig, Vom Gebrauch und Mißbrauch Der Zeitungen/Bey Eröffnung eines Collegii geführet. Anno 1700, Halle a.d. Saale 1705 (Fotoreprint 1964), S. 89f. - Vgl. zu von Ludewig und seiner Zeitungsschrift auch Monika Estermann, Memoria und Diskurs. Der Buchhandel in der Frühaufklärung, in: BöDEKER, Strukturen der deutschen Frühaufklärung, S. $45-70$, hier S. 55-59. 
ment gegeben hätten. Allerdings beklagte er, dass die fragmentarische Nachrichtenvermittlung in den Zeitungen die Erstellung von Historienwerken erschwere: Sequenzialität aufzulösen und historiographische Entwicklungen daraus zu rekonstruieren, das kam ihm einem anstrengenden Puzzlespiel gleich. Allerdings spekulierte er kontrafaktisch, dass weitaus mehr Denkwürdigkeiten aus alten Zeiten überliefert worden wären, wenn die antiken Griechen und Römer bereits Zeitungen gekannt und konserviert hätten ${ }^{280}$.

Ihre wirkliche Brisanz für die vormoderne Staats- und Gesellschaftsordnung im Heiligen Römischen Reich erhielt die Historie allerdings durch ihre Funktion als Grundlagenwissenschaft für juristische Argumente innerhalb der Rechtsordnung der Zeit. Von der Tagespublizistik profitierte nämlich nicht nur die Historienschriftstellerei, sondern auch die Reichsstaatsrechtspublizistik, kurz »Reichspublizistik» genannt. Meldungen, die die aktuelle Tagesberichterstattung durchlaufen hatten, wurden nun als Daten über die Vergangenheit zu Materialien für historisch argumentierende Juristen. Stieler wies auf diesen Zusammenhang hin: »Was wolte der Autor des Diarii Europäi schreiben, wenn er unter andern die Relationes Semestrales nicht hätte/die beyde zu Leipzig und Frankfurt zur Zeit der Messen heraus gegeben werden «? Die aktuellen Periodika beschafften und verteilten die Inhalte, die der »Historie das erste Fundament zu geben pflegten«. Stieler gelangte zu dem Fazit, dass es ohne Messrelationen und Zeitungen künftig keine Geschichtsschreibung mehr geben könne ${ }^{281}$.

Dem stimmte auch Johann Christian Lünig (1662-1740) zu, der im ersten Drittel des 18. Jahrhunderts zahlreiche Werke mit Quellen zum Reichsstaatsrecht herausgab. Lünig schrieb im Vorwort zur Grundveste europäischer Potenzen Gerechtsame, er orientiere sich am Diarium Europaeum, »welches eigentlich mit lauter Zeitungen angefüllet is $\aleph^{282}$. Lünig problematisierte den Begriff Zeitungen in diesem Zusammenhang nicht. Es kann aber davon ausgegangen werden, dass er sowohl die täglichen Periodika als auch die Deduktionen der Herrschaftsinteressenten gemeinsam unter diesen Begriff fassen wollte.

Unter historiographischer Perspektive stellen das Diarium Europaeum und das Theatrum Europaeum zwei Monumente historiographischen Schaffens vor dem methodologischen Hintergrund des Barockzeitalters dar ${ }^{283}$.

280 Stieler, Zeitungs Lust und Nutz (21697), S. 353f.

281 Zitate: Stieler, Zeitungs Lust und Nutz (1695/1969), S. 160.

282 Johann Christian LüNIG, Grundveste europäischer Potenzen Gerechtsame, Worinn Durch auserlesene Deductiones, Informationes, Repraesentationes, und andere merckwürdige Schrifften ausführlich dargethan wird, Wie es um [...] Unterschiedene hohe Jura, Ansprüche und Praecendenz-Streitigkeiten eigentlich beschaffen sey [...], 2 Tl., Leipzig 1716, hier Vorwort zu Bd. 1, s.p. - Zu Lünig: ZedLeR, Universal-Lexicon, hier Bd. 18, Sp. 1001-1003.

283 [Martin Meyer u.a. (Hg.)], Diarium Europaeum, Philemeri Irenici Elisii Diarium Europaeum insertis actis electoriis Oder Kurtze Beschreibung denkwürdigster Sachen/So sich in Frieds= 
Beide Serienwerke sind eingehend untersucht worden ${ }^{284}$. Im Kontext dieser Studie ist zu betonen, dass beide nicht das Ergebnis von Einzelautoren gewesen sind, sondern von den Frankfurter Verlagshäusern Wilhelm Serlin und Matthäus Merian organisiert wurden, die sich Redakteure, Autoren und Drucker mieteten. Nicht der Genius eines Verfassers sollte zum Ausdruck kommen, sondern aus der Fleißarbeit vieler Helfer sollte ein Kompendium zur Zeitgeschichte entstehen. Dem eigenen Selbstverständnis nach wurde das Theatrum »auß vielen treulich mitgetheilten Schrifften, glaubwürdigen Berichten, und briefflichen Urkunden« sowie »auß der Sachen eigentlichem Verlauff" kompiliert ${ }^{285}$. Beim Diarium hieß es, es sei aus »zugekommenen Acta, Schrifften und Discursen [...] ohne einigen Zusatz« erstellt worden, d.h. der Tenor der Aussage war derselbe ${ }^{286}$. Damit spielten die Redakteure eher auf die eingehenden Korrespondenzen an, die erst später die Grundlage der Periodika wurden: Historienschrift und Zeitungen schöpften damit aus demselben Quellenbestand, auch wenn das Theatrum diese Quellen im Stil einer Nachlese auswertete. Kaspar Stieler kennzeichnete Diarium Europaeum und Theatrum Europaeum aufgrund dieses Umstands, »man könte sie [...] mehr vor alte/als neue Zeitungen schätzen « ${ }^{287}$. In nur wenigen Studien verkörpert sich der Umlauf der Nachrichten auch über den Aktualitätshorizont hinaus so sehr wie in diesen beiden Historienwerken.

Allerdings mussten auch sie der Beschleunigung der politischen Berichterstattung ihren Tribut zollen. Susanne Friedrich sieht die Zeit um 1700 als bedrohlich für die großen Historienschriften und Aktenpublikationen, die nicht schnell genug mit der Berichterstattung nachgekommen und von der Gattung der Zeitschriften überholt worden seien ${ }^{288}$. Ein weiterer Aspekt verdient aber auch Beachtung: Die Menge an verfügbarem Wissen wuchs derart

und Kriegs= Geschäfften in Europa [...] vom Jahre 1657 [...] begeben haben, 45 Bd., Frankfurt a.M. 1659-1683; Johann Philipp ABELEIN u.a. (Hg.), Theatrum Europaeum, Oder Außführliche und Warhafftige Beschreibung aller und jeder denckwürdiger Geschichten/so sich hin und wieder in der Welt [...] zugetragen haben, 21 Bd., Frankfurt a.M. 1643-1738.

284 Sonja Schultheiss, Das »Diarium Europaeum« (1659-1683). Verleger und Autoren, Aufbau und Inhalt, in: AGB 48 (1997), S. 315-346; zum Theatrum Europaeum vgl. immer noch die ältere Studie von Hermann Bingel, Das Theatrum Europaeum. Ein Beitrag zur Publizistik des 17. und 18. Jahrhunderts, Lübeck 1922 (ND Wiesbaden 1969). Eine neue bibliographische und kunsthistorische Bestandsaufnahme im Rahmen der Merian-Ausgaben: Lucas Heinrich Wüthrich (Hg.), Das druckgraphische Werk von Matthaeus Merian d. Älteren, Bd. 3: Die großen Buchpublikationen, Hamburg 1993, S. 113-272. - Bezug zur seriellen Nachrichtenberichterstattung: Sonja Schultheiss-Heinz, Zum Verhältnis von serieller Chronik und Zeitungswesen, in: BAuER/Böning, Die Entstehung des Zeitungswesens im 17. Jahrhundert, S. 201-210.

285 Zit. nach Bingel, Das Theatrum Europaeum, S. 113.

286 Diarium Europaeum, Bd. 34, Bl. 2 [b], zit. nach SchultheIss, Das »Diarium Europaeum«, S. 323.

287 Stieler, Zeitungs Lust und Nutz (1695/1969), S. 55.

288 FriEdRICH, Drehscheibe Regensburg, S. 526f. 
an, dass das Theatrum Europaeum immer weniger Jahrgänge in einem Folianten abhandeln konnte. Waren es im 17. Jahrhundert noch sechs oder sieben Jahre, so behandelten die letzten Bände nur noch zwei oder drei Jahre und erreichten dennoch über 1.000 Seiten Umfang. Die Menge an Informationen vermehrte den Arbeitsaufwand und die Kosten, und auch für Dienstbibliotheken, Professoren oder andere gelehrte Kunden waren die Bücheretats nicht unbeschränkt, so dass das wirtschaftliche Konzept der großen Historienreihen an seine Grenzen stieß. Für das Theatrum Europaeum und sein Ende war der Konkurs des Merian-Verlages verantwortlich, doch ist fraglich, ob selbst bei einer rationaleren Betriebsführung ein derartiges Werk hätte mit Gewinn weitergeführt werden können ${ }^{289}$. Eine vergleichbare Entwicklung ist bei Zedlers Universal-Lexicon zu beobachten, bei dem ebenfalls die Artikel immer voluminöser wurden, weil das zugrunde liegende Wissen schnell wuchs und immer besser verfügbar gemacht werden konnte. Das Lexikon ließ sich im Gegensatz zum Theatrum Europaeum fertigstellen, bevor existenziellen Krisen - wie einem vorzeitigen Tod des Begründers oder einem Konkurs des tragenden Verlages - zum Opfer fallen konnte ${ }^{290}$.

Den grundlegenden Zusammenhang zwischen Geschichtsschreibung und Rechtswesen in der Frühmoderne hat Notker Hammerstein unter dem Leittitel Jus und Historie analysiert ${ }^{291}$. Hammerstein zeichnet ein herrschendes Geschichtsbild, das aus dem Humanismus stammte und bis zum Ende des Alten Reiches gültig war. Wesentlich beeinflusst wurde es von Philipp Melanchthon. Zu den Eckpunkten dieses Verständnisses von Vergangenheit gehörten das Quellenprinzip (Humanisten- und Reformatorenmotto ad fontes), der Topos Historia magistra vitae im Sinne seines didaktischen Wertes besonders für junge Adlige und angehende Regierungspersonen, eine kosmisch-universalistische Weltauffassung sowie ein heilsgeschichtliches

289 Vgl. dazu Bingel, Das Theatrum Europaeum, S. 122f.

290 Zu Zedler: Gerd QuedenBaum, Der Verleger und Buchhändler Johann Heinrich Zedler 17061751. Ein Buchunternehmer in den Zwängen seiner Zeit, Hildesheim/New York 1977; Herbert G. GöPfERT, Zedlers »Universal-Lexicon«, in: Ders., Vom Autor zum Leser. Beiträge zur Geschichte des Buchwesens, München/Wien 1977, S. 63-75; Nicola KAminski, Die Musen als Lexikographen. Zedlers Großes Vollständiges Universal-Lexicon im Schnittpunkt von poetischem, wissenschaftlichem, juristischem und ökonomischem Diskurs, in: Daphnis 29 (2000), S. 649-693; Ulrich Johannes SCHNEIDER, Die Konstruktion des allgemeinen Wissens in Zedlers »Universal-Lexicon«, in: Theo Stammen/ Wolfgang WeBer (Hg.), Wissenssicherung, Wissensordnung und Wissensverarbeitung. Das europäische Modell der Enzyklopädien, Berlin 2004, S. 81-101; Ulrich Johannes SchneIDER, Zedlers »Universal-Lexicon« und die Gelehrtenkultur des 18. Jahrhunderts, in: Hanspeter MARTI/Detlef DöRING (Hg.), Die Universität Leipzig und ihr gelehrtes Umfeld 1680-1780, Basel 2004, S. 195-213.

291 Notker Hammerstein, Jus und Historie. Ein Beitrag zur Geschichte des historischen Denkens an deutschen Universitäten des späten 17. und 18. Jahrhunderts, Göttingen 1972; ders., ReichsHistorie, in: Hans Erich BöDEkER (Hg.), Aufklärung und Geschichte. Studien zur deutschen Geschichtswissenschaft, Göttingen 1986, S. 82-104. 
Reichsverständnis im Sinne einer politischen Selbstwahrnehmung als Höhepunkt der Vier-Reiche-Abfolge (oder »vier-Monarchien-Doktrin«), wie sie beispielsweise in der Carionschen Chronik von Philipp Melanchthon verwirklicht war und später auch bei Johann Sleidanus vorkam ${ }^{292}$.

Wenn Hammerstein sich der Reichspublizistik annahm, dann ging es dabei keineswegs um die periodische Presse oder sonstige kommunikationswissenschaftliche Zusammenhänge. An dieser Stelle muss auf die Doppelbedeutung des Wortes »Publizistik« hingewiesen werden: Während der Jurist und der Rechtshistoriker unter dem »Publizisten« einen fachgelehrten Vertreter des Jus publicum versteht, handelt es sich aus historischer und aus kommunikationsgeschichtlicher Sicht um den (professionellen) Verfasser von Texten, die für die Verbreitung in der Öffentlichkeit bestimmt sind ${ }^{293}$. Hammerstein exemplifiziert seine Fragestellung an einigen ausgewählten Autoren des frühen 18. Jahrhunderts sowie an der rechtswissenschaftlichen Forschung an den beiden führenden Universitäten Leipzig und Halle a.d. Saale ${ }^{294}$.

Aus der Perspektive von Hammerstein stellte sich die »Reichs-Historie« als Hilfswissenschaft zur Reichsstaatsrechtslehre dar, insbesondere seit der zweiten Hälfte des 17. Jahrhunderts. Dabei ordnete sich die Geschichte als akademischer Erkenntnisgegenstand der Jurisprudenz unter, wie es auch der formalen Hierarchie der frühmodernen Universität entsprach. Kein geringerer als Christian Thomasius formulierte 1702: »Die Historie ist allen Wissenschaften der halbe Teil der Grund-Lehren, die man bei jeder Wissenschaft zu lernen hat«; für ihn stellte sie sogar das »rechte Auge der Weisheit« dar ${ }^{295}$. Diese Form von Historie sollte moderne Elemente in die Wissenschaften einbringen. Dazu musste sie sich von der hergebrachten Geschichtsschreibung abheben. Humanistisch-moralisierende, reformatorisch oder gegenreformatorisch polemisierende und barock-kaiserliche bzw. fürstlich-dynastische und heroisierende Geschichtsschreibungen sollten dadurch überwunden werden. An deren Stelle trat eine Analyse des Heiligen Römischen Reiches von den Anfängen unter Kaiser Heinrich I. bis in die Zeit des jeweiligen Verfassers. Der Hauptakzent galt der politisch-verfassungsrechtlichen Ordnung im Reich, d.h. das gewachsene Gefüge der kaiserlichen Oberherrschaft, kontrolliert durch das zweifache Ständesystem. Eine Entscheidung über eine etwaige »Souveränität« wurde nicht gefällt, sondern gerade die Balance des Sys-

292 Hammerstein, Jus und Historie, S. 24-27.

293 Vgl. dazu den erklärenden Hinweis bei Roеck, Reichssystem und Reichsherkommen, S. VII, Anm. 3.

$294 \mathrm{Zu}$ den beiden Elite-Universitäten: Hammerstein, Reichs-Historie, bes. S. 82f. Führende Reichsrechtslehrer waren Christian Thomasius, Nicolaus Hieronymus Gundling und Johann Peter von Ludewig. - Vgl. auch die Einleitung in Hammerstein, Jus und Historie, S. 9-16.

295 Christian Thомasius, Erinnerung wegen zweyer Collegiorum über den Andern Theil seiner Grund-Lehren, Halle a.d. Saale 1702, s.p., zit. nach Hammerstein, Reichs-Historie, S. 83. 
tems betont. Als Wächter für die Funktionsfähigkeit des Systems wurden die beiden obersten Reichsgerichte angesehen. Gerichtsbarkeit, Staatsrechtslehre und Reichshistorie verbanden sich dergestalt als Stützen und Wächter der herrschenden Ordnung, die nicht nur als transzendental legitimiert, sondern auch als gerecht und vernünftig angesehen wurde ${ }^{296}$.

Interessanterweise war diese Form der Geschichtsbetrachtung gleichzeitig auch die Legitimation für die Beschäftigung mit Geschichte. Die »Relevanzfrage«, wie man sie später genannt hätte, ergab sich aus dem Nutzen der Historie für die Staatsordnung, so Hammerstein, ein Zusammenhang, der singulär in Europa sei, denn in allen anderen Ländern diene die Historie zur Unterhaltung, nicht zum Staatsnutzen ${ }^{297}$.

Allerdings beschäftigte sich die Reichshistorie nur vordergründig mit dem Staat, daneben wurde auf andere Bereiche des Wissens zugegriffen, auf Sitten und Gebräuche, Klima, Geographie u.a. ${ }^{298}$. Ihr weiteres Ziel war es, die Gesamtheit der Gesellschaft ebenfalls zu erfassen, und der Hebel dazu war die Rechtsfigur des »Herkommens«. Christian Thomasius misst dem »Herkommen« einen hohen Stellenwert bei; bei ihm gibt es ein »Jus decorum«. Recht soll für ihn nicht nur Ruhe und Ordnung gewährleisten, sondern auch Sitte und Decorum. Darüber hinaus konnte das Herkommen für alle bestehenden geographischen, agrarischen Verhältnisse oder zur Deutung von Volkscharakteren angewandt werden ${ }^{299}$. Die wissenschaftlichen Chancen, die in diesem Ansatz lagen, konnten jedoch nicht ausgelotet werden. Die Folge hätte eine Differenzierung der Historie als Wissenschaft bedeutet, und weder gab es die Forscher noch die Finanzmittel, um eine derartige Ausweitung der historischen Wissenschaft voranzutreiben.

Bernd Roeck hat den zeitgenössischen Begriff »Reichsherkommen« als die Formel identifiziert, durch die Geschichte und Rechtssystem im 17. und 18. Jahrhundert miteinander verknüpft wurden. $\gg$ Reichssystem und Reichsherkommen « heißt seine Studie, auch wenn Roeck mit dem Begriff »Reichssystem« kein systemtheoretisches Verständnis verbindet. Sein Systembegriff ist aus den Quellen abgeleitet und gründet sich vor allem auf den griechischen staatstheoretischen Begriff $\sigma \dot{\sigma} \sigma \tau \eta \mu \alpha$, der für Bund oder Staatenbund steht ${ }^{300}$. So nahm auch die Staatsrechtslehre den Systembegriff auf und verwandte ihn in sinnverwandter Bedeutung zu »Verfassung « oder »Staat«. Dies schloss Vorstellungen von Stabilität ebenso ein wie eine fortschreitende Dynamik.

296 Ebd., S. 85-87.

297 Ebd., S. 86.

298 Ebd., S. 85.

299 Ders., Jus und Historie, S. 61; ders., Reichs-Historie, S. 85.

300 Zum zeitgenössischen Sprachgebrauch: RoECK, Reichssystem und Reichsherkommen, S. VIII. Zum System-Begriff: Ebd., S. 30. 
Neben der Nachrichtenzirkulation innerhalb des Mediensystems lässt sich am Beispiel der Historienschriften eine weitere Kreislaufbewegung konstatieren: Während die Informationen, die das Mediensystem aufbereitete und vermarktete, aus dem politischen Sektor - dem internationalen wie dem »reichischen « - stammten, wurden sie über mehrere Stationen zu Propaganda in den Deduktionen, zu Nachrichten in den Zeitungen, zu sprachlich gefasstem Räsonnement in den Journalen und schließlich zu unterhaltsamen und lehrreichen Exempla in den Historienschriften. Die Zirkulation Politik Medien - Historie - Recht - Politik schließt sich, wenn diese Exempla wiederum zu Elementen eines späteren politischen Prozesses werden. Die historischen Abhandlungen bereiteten dann die Vergangenheit als »Herkommen« im juristischen Sinne auf und begründeten Handlungen und Ansprüche. Hieraus konnte die weitere Rechtsentwicklung schöpfen, um die Tagespolitik im Sinne des Reichsverfassungsgefüges zu gestalten. Dieser Kreislauf blieb im Heiligen Römischen Reich bis zu seinem Ende 1806 bestehen, ungeachtet aller aufklärerischen Kritik am »herkömmlichen « Recht ${ }^{301}$.

Der publizistisch-marktwirtschaftliche Nachrichtenkreislauf berührte immer wieder den juristisch/rechtswissenschaftlich-politisch-historischen Kommunikationsraum. Dieser Bereich stellte die Schnittstelle (systemtheoretisch: den Resonanzbereich) dar zwischen dem politischen und dem rechtlichen System, die in der stratifikatorischen Gesellschaftsordnung noch nicht völlig getrennt waren (Kaiser als Oberrichter; sozialer Standesdünkel auf allen Ebenen). Jus speiste sich aus - gefundenem, nicht gemachtem - göttlichen Recht oder Naturrecht. Zu finden war es in der Bibel und in der Geschichte (der antiken wie der zeitgenössischen). Politik wirkte mittels Recht und durch Verwendung symbolischer Formen aus der Geschichte. Historie war vergangene, geronnene Politik in ihrer zivilen wie militärischen Form. Auch ohne eine allgemein anerkannte Konflikttheorie war das Konfliktträchtige geschichtswürdig, während eine »Alltagsgeschichte« absurd gewirkt hätte. In diesem Punkt traf sich die Historie mit der Publizistik, die ebenfalls das Konflikthafte goutierte. Beide unterschieden sich aber darin, dass Historie das Alte, Publizistik dagegen das Neue schätzte. 



\section{Produktion: Autoren, Drucker, Verleger}

\subsection{Autorenschaft und Originalität der Texte}

Die Autorenschaft der frühmodernen politischen Publizistik ist schwierig zu untersuchen, weil von zahlreichen Presseerzeugnissen gar kein Autor namhaft gemacht werden kann. Dies liegt nicht nur am fortgesetzten Verstoß gegen die Impressumspflicht, sondern auch an der Methodologie der Nachrichtenerhebung und Berichtserstellung. Die im Mediensystem umlaufenden Inhalte beruhten nämlich nur teilweise auf Recherchen, zum größeren Teil hingegen handelte es sich um abgegriffene Neuigkeiten, die im internen Kommunikationsystem der Macht, in der »Machtöffentlichkeit«, zirkulierten $^{1}$. Über diesen Umstand wird im übernächsten Kapitel über die Leserschaft noch zu sprechen sein, wenn der Hof als Leser in den Blick genommen wird. Besser fassbar sind die Informationsprozesse, die sich in Regensburg am Immerwährenden Reichstag abspielten ${ }^{2}$. Auch hier gab es die Machtöffentlichkeit der Weisungen und Berichte zwischen den Fürstenhöfen und ihren Gesandten in der Reichstagsstadt, daneben den Schriftverkehr in Gestalt von Deduktionen, der sich auf anhängige Konflikte bezog. Die Mehrzahl der Deduktionen wurde von der interessierten Partei angestoßen: In seltenen Fällen setzte sich ein Fürst selbst an die Arbeit und verfasste einen Text, dies ist etwa von Friedrich dem Großen in mehreren Fällen überliefert ${ }^{3}$. Normalerweise wurde eine Person, zumeist rechtsgelehrt, aufgefordert, eine derartige Schrift zu verfassen. Dies konnte im Rahmen einer Diensttätigkeit oder auf Honorarbasis geschehen. Andere Schriften entstanden durch ambitionierte Jungjuristen, die sich durch die Unterstützung eines herrschaftlichen Anliegens ein Entree in den Fürstendienst erschreiben wollten ${ }^{4}$.

Daneben schrieben allerdings auch zahlreiche Agenten und Novellanten Texte, die teilweise auf Originalschriften aus den Gesandtschaftskanzleien

1 Zur Entwicklung und Ausfüllung des Begriffs: KöRBER, Öffentlichkeiten der Frühen Neuzeit, S. $53-164$.

2 Vgl. über die Formen der Kommunikation in Regensburg die fundamentale Studie von FrIEDRICH, Drehscheibe Regensburg, bes. S. 158-193.

3 Z.B. Friedrichs Memorandum zum Einmarsch in Schlesien »Raisons qui ont déterminé le Roi à faire entrer ses troupes en Silésie«, Dezember 1740, abgedruckt in: Johann Gustav DroYSEN u.a. (Hg.), Preußische Staatsschriften aus der Regierungszeit Friedrichs II., 3 Bd., Berlin 1877-1892, hier Bd. 1, S. 74-78. - Vgl. dazu auch Johannes Kunisch, Friedrich der Große. Der König und seine Zeit, München 2004, S. 185-187.

$4 \mathrm{Zu}$ den Jungjuristen als Traktatautoren schreibt Wolfgang Burgdorf: »Die (Rück-)Wirkungen der Schriften auf die Verfasser konnten verheerend sein und biographische Katastrophen auslösen; oft jedoch bildeten sie, zumal bei jungen Autoren, das Fundament einer Karriere. Ungezählt sind die Publizisten, die durch die Veröffentlichung von Tendenzschriften 
aufbauten, anderenteils auf mündlichen Mitteilungen des Kanzleipersonals beruhten. Sie schufen dadurch einen ständigen Strom der Informationen für eine Rezipientenschaft, die ursprünglich nicht zur Reichsöffentlichkeit gehören sollte. Da besonders der Kurfürstenrat und die Mainzer Direktorialkanzlei vielfach gegen den Informationsabfluss vorzugehen versuchten, lag es nahe, dass niemand, der sich an diesem Transfer beteiligte, namentlich genannt und damit an den Pranger gestellt werden wollte.

Daher setzen Untersuchungen zu den Autoren der politischen Gelegenheitsschriften und Periodika meist einen Abschnitt später ein, bei den Autoren im Umfeld des jeweiligen Produzenten (Druckers oder Verlegers). Der Forschungsstand zu diesen Autoren ist äußerst heterogen. Dies unterscheidet sich stark von der Erforschung literarischer Autoren. Diese standen in den sprachwissenschaftlichen Disziplinen naheliegenderweise im Vordergrund des Forschungsinteresses, ähnlich wie Künstler in der Kunstgeschichte und Komponisten in der Musikwissenschaft ${ }^{5}$. Zeitungs- und Zeitschriftenautoren haben längst nicht dieselbe Aufmerksamkeit errungen. Im Gegenteil - nicht selten wurde an sie der literarische und künstlerische Maßstab der Originalität oder Genialität angelegt, dem sie nicht standhielten. Dies brachte ihnen herabwürdigende Kommentare ein. Kein Geringerer als der italienische Philosoph Benedetto Croce (1866-1952) etikettierte journalistisches Schreiben als unoriginell und flach, es sei allen anderen literarischen Genres unterlegen. Croce hielt Oberflächlichkeit und Improvisation für konstitutiv im journalistischen Gewerbe, die Betreiber mussten seiner Ansicht nach einen Mangel an mentalen Skrupeln und ästhetischer Sensibilität aufweisen, um erfolgreich zu sein ${ }^{6}$. In diesem Zusammenhang geht es aber nicht um literarische Größe, sondern um die Art und Weise, wie die Verfasser publizistischer Texte ihre Rolle und Funktion wahrnahmen. Viele Autoren hatten ihre Gründe, anonym zu bleiben. Rudolf Stöber nennt »die Furcht vor der Zensur, die Furcht renommierter Autoren vor Prestigeverlust, das Bemühen der Autoren, durch das Verschweigen des eigenen Namens die Aussagen als all-

ihre Übernahme in ein festes Dienstverhältnis beförderten. Publizisten, die sich bereits in Diensten befanden, wurden mit Beförderung oder gar mit einem Adelstitel belohnt«: BuRGDORF, Reichskonstitution und Nation, S. 25; vgl. auch Burgdorfs Überlegungen zu den Autoren: Ebd., S. 26-29.

5 Vgl. die Überlegungen von Klaus GArber, Der Autor im 17. Jahrhundert, in: Zeitschrift für Literaturwissenschaft und Linguistik 11 (1981), H. 42, S. 29-45. - Vom Autor zum Schriftsteller: Hans-Jürgen Haferkorn, Der freie Schriftsteller, in: AGB 5 (1962/64), Sp. 523-712. - Zur beklagenswerten Vernachlässigung der Autoren: Wittmann, Geschichte des deutschen Buchhandels, S. 64-68 (Autoren im konfessionellen Zeitalter) u. 96-102 (Autoren im Barockzeitalter).

6 Benedetto Croce, Il giornalismo e la storia della letteratura, in: Ders., Problemi di estetica e contributi alla storia dell'estetica italiana, Bari 1910, S. 128, zit. nach Brendan DooLey, From Literary Criticism to System Theory. Twenty Years of Journalism History, in: Journal of the History of Ideas 51 (1990), S. 461-483, hier S. 461. 
gemeingültig hinzustellen, bzw. die Furcht, die Nennung des eigenen - unbedeutenden - Namens könnte den Vertriebserfolg behindern «? aber nicht, dass sie ihre Motive verborgen hätten. Zum einen stellen Vorworte und Widmungen Einblicke ins Selbstverständnis der Autoren dar. Zum anderen sind durch zahlreiche Studien Einzelinformationen über die Verfasser von Flugschriften im 16. und 17. Jahrhundert zum Vorschein gekommen. Bei diesen Autoren handelte es sich meistens um Bildungsbürger: Im konfessionellen Zeitalter dominierten Theologen (mit und ohne Inhaberschaft einer vollen Pfarrstelle), daneben schrieben Adlige, Juristen und andere Akademiker, in geringem Maße auch Nichtakademiker ${ }^{8}$. Viele der Verfasser wollten, im Gegensatz zu Drucken und Periodika späterer Zeiten, mit ihrem Namen auf dem Druckwerk stehen, sei es aus Geltungsbedürfnis, sei es als Identifikations- und Wiedererkennungsmerkmal. Die Debatte um Autorenschaften nichtliterater Personen kann hier nicht fortgesetzt werden'. Wichtig ist festzustellen, dass die Rezipientenschaft - und sei es bloß die intendierte schon im Reformationsjahrhundert über die akademische Leserschaft hinausreichte.

Außerhalb des Bereichs der rechtserheblichen Deduktionen waren im Segment der politisch-historisch-militärischen Nachrichten die ersten Autoren die Korrespondenten, die gegen Honorar einmalig oder immer wieder Berichte verfassten. Diese Tätigkeit war keine reguläre Berufstätigkeit wie etwa die des Druckers oder Verlegers. Zum Korrespondenten wurde man auch nicht ausgebildet, sondern zumeist erlangte man diese Rolle durch günstige Gelegenheit. Für eine solche Gelegenheit waren zwei Bedingungen erforderlich: Zum einen musste die betreffende Person beruflich an einer Stelle tätig sein, wo interessante Nachrichten anfielen oder durchliefen. Zum anderen musste ein Kontakt zum Mediensystem hergestellt werden, was durch Anbahnung vonseiten eines professionellen Nachrichtenhändlers geschehen konnte oder durch aktive Maßnahmen des Korrespondenten, Personen zu suchen, die ihm seine Berichte abkauften. Dazu gehörte naheliegenderweise das Vorwissen, dass militärische, politische oder höfische Nachrichten in geldwerte Berichte umgewandelt werden konnten, die nur in geeigneter Weise platziert zu werden brauchten.

7 STÖBER, Deutsche Pressegeschichte, S. 49.

8 Martin Arnold verweist auf eine Stichprobe für das Jahr 1524: Damals verteilten sich die ausgewerteten 368 Flugschriften auf 69,2\% Pfarrer und 19,4\% Laien, während der Rest unidentifiziert blieb: Martin ARnOLD, Handwerker als theologische Schriftsteller. Studien zu Flugschriften der frühen Reformation (1523-1525), Göttingen 1990, S. 43f., zit. nach Schwitalla, Flugschrift, S. 15. - Vgl. dazu auch die Überlegungen bei Wittmann, Geschichte des deutschen Buchhandels, S. 36f.

9 Vgl. dazu Schwitalla, Flugschrift, S. 15-18. 
Auch hier war die Übernahme mehrerer Rollen innerhalb des Mediensystems die Regel. Der Satiriker Johann Fischart wurde bereits als Lektor, Korrektor und Korrespondent des Straßburger Verlagshauses Jobin vorgestellt, auch Michael von Eitzing wurde als Verfasser zahlreicher Flugschriften und als Erfinder der Messrelationen ab 1583 eingeführt ${ }^{10}$. Auf letzteren passt eine Beschreibung genau, die sich bei Georg Steinhausen über die Briefzeitungsschreiber des 16. Jahrhunderts findet: »Wir finden solche Leute auch sonst erwähnt. Nach Hurter, Ferdinand II., gab es z.B. in Cöln einen svielwissenden Mann, der, wie 1584 Hans von Kobenzl seinem Erzherzog schrieb, ihm, Kobenzl, für ein Gehalt von 200 Goldgulten alle französischen und niederländische Zeitungen mittheilte « ${ }^{11}$. Eitzings gesamter Werdegang und seine bekannten Aktivitäten lassen ihn wie geschaffen dafür erscheinen, zusätzlich auch als Briefzeitungsschreiber tätig gewesen zu sein. Ein weiteres Beispiel war der Herausgeber der zweiten niederländischen Zeitung, Broer Jansz, der stolz auf seine frühere Korrespondentenzeit verwies. Im Kolophon seiner 1619 erstmals erschienenen Tydinghen uyt verscheide Quartieren rückte er stets »out Courantier int Legher van syn Princelijcke Excellentie« ein - Jansz war offenbar Kriegsberichterstatter in der Armee von Prinz Moritz von Oranien gewesen ${ }^{12}$.

Dieser Personenkreis darf nicht mit den offiziellen Residenten der Mächte verwechselt werden, die entweder diplomatischen Status besaßen oder auf niedrigerer Ebene für einen fremden Fürsten oder eine Stadtrepublik agierten. Während der offizielle Resident für einen fürstlichen Herrn arbeitete und von diesem geschützt wurde, wobei er der Regierung seines Wirkungsbereichs normalerweise angezeigt worden war (Akkreditierung), schrieb der Korrespondent für den Medienmarkt. Der Resident mochte sich an Maßnahmen zur Geheimhaltung beteiligen, die im gemeinsamen Interesse der lokalen Macht und seines Fürsten liegen konnte. Der Korrespondent schrieb ausdrücklich für die Öffentlichkeit, wirkte daher der Geheimhaltung in der Konsequenz entgegen. Das bedeutete nicht, dass er nicht auch Maßnahmen zur Verschleierung seines Wirkens anwandte, doch diente dies in der Regel dazu, den freien Nachrichtenverkehr gegen Zensurmaßnahmen abzuschirmen $^{13}$.

10 Vgl. die Hinweise zu Fischart auf S. 57 in diesem Buch, vgl. zu Eitzing S. 86-88.

11 Zitat: Steinhausen, Die Entstehung der Zeitung aus dem brieflichen Verkehr, S. 353.

12 Vgl. Ingrid Maier, Amsterdam und Haarlemer Zeitungen (Couranten) des 17. Jahrhunderts im Niedersächsischen Staatsarchiv zu Oldenburg, in: GutJb 78 (2003), S. 170-191, hier S. 178. Jansz behielt diese Praxis bis zu seinem Tod 1652 bei.

13 Vgl. dazu auch die Abstufung der frühmodernen Korrespondenten vom Fürsten über den Gesandten, Agenten bis hin zum kommerziell arbeitenden Zeitungsschreiber oder Novellanten: BAUER, Höfische Gesellschaft und höfische Öffentlichkeit, S. 34f. 
Was hier als Funktionen »Resident« und »Korrespondent« leicht zu trennen ist, fiel in der Realität mitunter zusammen: Johannes Weber berichtet davon, dass zahlreiche Korrespondenten entweder im Umkreis der politischen und militärischen Macht verkehrten oder sogar dort beruflich tätig waren, was ihren Berichten normalerweise eine hohe Zuverlässigkeit ver$\operatorname{lieh}^{14}$. Schon Johann Peter von Ludewig äußerte sich 1705 kritisch über das zeitgenössische Korrespondentenwesen. In früheren Zeiten, so Ludewig, hätten die Fürsten Geheimagenten an fremden Höfen unterhalten. Nach dem Westfälischen Frieden sei dann ein ausufernder diplomatischer Verkehr zwischen den europäischen Monarchen entstanden, woran auch zahlreiche Fürsten und Stadtmagistrate beteiligt worden seien, was die Grundlagen für das Umlaufen politischer Berichte gelegt habe. Zur Zeit Ludwigs XIV. sei dann ein akkreditierter Interessenvertreter jeder Macht an jedem der anderen Höfe die Norm in Europa geworden. Viele dieser Residenten hätten die Grenze zwischen dem diplomatischen Verkehr und dem kommerziellen Nachrichtenhandel überschritten: Sie verkauften Informationen, »wie dann zu Wien, Regensburg, Wetzlar und andrer Orten viel hundert Personen sich durch solche geschriebene correspondentzen ihr Brod zu suchen $[\ldots] \ll^{15}$. Der Jurist verwies im Folgenden auf die Nachteile dieser Form der Informationsdistribution: Die meisten der Korrespondenten hätten weder Zeit noch Mut, etwas Wichtiges zu kommunizieren. Sie produzierten nur Massenware, die allenfalls zur »Kurtzweil dienen « könne ${ }^{16}$. Einen Nutzen für die Fürsten selbst oder für anspruchsvolle Leser konnte Ludewig nicht erkennen: Die Fürsten bezögen ihre qualifizierten Informationen von den Kaufleuten innerhalb ihrer Untertanenschaft.

Ähnlich kritisch äußert sich Paul Jacob Marperger über die Korrespondenten. Ohne zu begründen, auf welche Weise denn Informationen anders hätten gewonnen werden können, schreibt Marperger, bei den Korrespondenten und Betreibern von Briefzeitungen handele es sich um $»$ Nahrungs $=$ begierige Leute«, die alles, was sie an einem Ort aufschnappen oder lesen konnten, aufschrieben ${ }^{17}$. Besonders betroffen seien davon regionale Zeitungen, die systematisch ausgeschlachtet würden. Gegen ein Quartal- oder Annualgeld würden die Korrespondenten diese Berichte an jeden verkaufen, der zahlungswillig sei. Dieser Menschenschlag, so Marperger, sei bereits in jeder größeren Stadt zu finden, insbesondere in den Städten, wo Zeitungen produziert würden. Die Qualität der Berichte sei häufig fragwürdig, was sich in Möglichkeitsformeln wie »könnte« oder »dürffte« im Sprachduktus zeige,

14 Weber, Galerie der Zeitungspresse im 17. Jahrhundert, hier S. 33.

15 Johann Peter von Ludewig, Vom Gebrauch und Mißbrauch Der Zeitungen/Bey Eröffnung eines Collegii geführet. Anno 1700, Halle a.d. Saale 1705 (Fotoreprint 1964), S. 88.

16 Von Ludewig, Vom Gebrauch und Mißbrauch Der Zeitungen, S. 88f.

17 Marperger, Anleitung zum rechten Verstand und nutzbarer Lesung, S. 15. 
weil die Meldungen nicht bestätigt worden seien ${ }^{18}$. Schon damals bildete sich die Regel heraus, dass eine Nachricht dann als zuverlässig bewertet wurde, wenn sie von zwei unabhängigen Quellen übereinstimmend berichtet worden war. Bereits Christian Weise hatte diese Form der Intersubjektivität gefordert, denn das Problem der interessengeleiteten Publizistik war bestens bekannt, u.a. aus der Propaganda des ludivizianischen Frankreich ${ }^{19}$. Die Bewertungen durch frühaufklärerische und kommerzialisierungskritische Medienbeobachter sollten nicht überschätzt werden: Die Korrespondenten waren immerhin in der Lage, die Berichte nach den Kriterien des Nachrichtenwerts aufzubereiten und zu versenden. Auch ohne eine Ausbildung oder verbindliche Richtlinien, wie die Daten gestaltet werden sollten, kam der Informationsverkehr in Gang und reproduzierte sich unter stetigem Wachstum.

Zeitungen und Zeitschriften hatten gemeinsam, dass sie in der Regel ohne Namensnennung des Herausgebers und des Autors des jeweiligen Artikels erschienen. So wurde es seit Beginn der Zeitungspresse gehalten, so übernahmen es 70 Jahre später die Zeitschriften. Erst im Laufe des Aufklärungszeitalters wurden Zeitschriftenartikel namentlich gekennzeichnet. Dies war folgerichtig: Zeitungstexte besaßen einen geringeren Grad an Individualität. Die Suche nach dem Autor einer Zeitung greift daher oft ins Leere: Zwar gab es einen Redakteur, doch war dieser nur in begrenztem Umfang der Autor. Viel eher fungierte er als Arrangeur fremder Texte, die als Nachrichten gekauft worden waren.

In der zeitungshistorischen Forschung ist daher normalerweise der Betreiber einer Zeitung besser fassbar als der tatsächliche Autor. Thomas von Wiering (1640-1703), der Begründer des Hamburger Relations-Courier (ab 1674), stammte aus einer Buchdruckerfamilie im niederländischen Deventer. Ab 1670 betrieb er eine Druckerei in Hamburg, vier Jahre später ließ er sich vom Senat ein Privileg für die Herausgabe einer Zeitung verleihen ${ }^{20}$. »Herausgeber « ist daher der treffendere Begriff als »Autor « des Periodikums, selbst wenn einiges dafür spricht, dass Wiering auch Texte selbst verfasste. Wiering hatte ursprünglich die Absicht, seine periodischen Ausgaben für eine spätere Sammlung aufzubereiten, denn die Ausgaben waren jahrweise paginiert und mit besinnlichen Einführungstexten zu Jahresbeginn und Jahresschluss versehen. Primärnutzung als Zeitung und Sekundärnutzung aus der Rückschau als Historienwerk waren bereits im Konzept angelegt.

Auf der kurzfristigen Zeitebene allerdings wurde der Konkurrenzkampf mit anderen Blättern geführt. Wiering errang bald beträchtlichen Vorteil,

18 Ebd., S. 16.

19 Christian WeISE, Curieuse Gedancken von den Nouvellen oder Zeitungen [...] vermehret von Christian JunCKER, Leipzig/Coburg 1706, S. 36f.

20 Vgl. zu Wiering und seiner Hamburger Tätigkeit: BöNING, Welteroberung durch ein neues Publikum, S. 68-74. 
denn bei ihm war zum einen die Nachrichtendichte größer als bei den Konkurrenten: Niemand hatte soviele Neuigkeiten pro Zeiteinheit wie er. Zum anderen druckte er nachweislich auf mehreren Pressen, was ihm ermöglichte, die erforderliche Anzahl der Exemplare in kürzerer Zeit herzustellen. Vielfach wurde am Ende einer Zeitung die Drucktype verkleinert, weil noch eine aktuelle Meldung kurzfristig untergebracht werden musste ${ }^{21}$. Mehr als andere Blätter konzentrierte sich Wiering auf wirtschaftliche Nachrichten, die ihm zum beträchtlichen Teil die Kaufleute in Hamburg selbst vermittelten (teils als eigene Informationen, teils durch ihre auswärtigen Korrespondenten). Keine Autorenschaft konnte Wiering für zahlreiche Flugschriften bzw. Traktate beanspruchen, die er auszugsweise in seine Zeitung einrückte oder separat publizierte, wobei fremdsprachige Texte übersetzt erschienen ${ }^{22}$.

Eine Ausnahme unter den Zeitungsherausgebern war der Dichter Georg Greflinger (1620-1677). Greflinger gehörte zu der Minderzahl derjenigen, die nicht aus dem Drucker- oder Verlegerberuf stammten, sondern aus dem Lager der Gelehrten ${ }^{23}$. Der Dichter, der von seiner literarischen Kunstfertigkeit nicht leben konnte, ließ sich in Hamburg nieder als Notarius publicus, Verleger und Publizist. 1664 gründete er den Nordischen Mercurius, den Holger Böning als »eine der bedeutendsten publizistischen Leistungen des 17. Jahrhunderts « charakterisiert ${ }^{24}$. Dabei konnte Greflinger auf frühere Erfahrungen seiner Frankfurter Zeit zurückgreifen, wo er bereits Messrelationen und Zeitungstexte sowie historisch-politische Werke verfasst hatte. Die Erscheinungsweise der Zeitung ist nicht vollständig geklärt. Vieles spricht dafür, dass es um 1660 bereits einen Gründungsversuch gegeben hatte, der allerdings nach einer Weile scheiterte, bis das Periodikum 1664 erneut erschien. Auch wurde der Nordische Mercurius teilweise als Wochenzeitung, teilweise als Monatszeitung herausgebracht. Weniger das Wollen des Verfassers war dafür entscheidend gewesen, sondern vermutlich ökonomische Probleme ${ }^{25}$. Das literarische Prunkstück dabei war das Vorwort zur Januarausgabe, das dem Autor Gelegenheit bot, im Stile späterer Zeitschriftenherausgeber räsonnierende Gedanken zu Papier zu bringen, die nicht nur

21 Zum Nachweis feiner Unterschiede in denselben Tagesausgaben: Ebd., S. 69f.

22 Werner Kayser weist für 1706 bis 1748 nicht weniger als 433 Flugschriften nach, die im Verlag Wiering hergestellt worden waren: Werner KAYSER, Thomas von Wiering und Erben. Ein bedeutendes Kapitel hamburgischer Druckgeschichte, in: Auskunft. Mitteilungsblatt Hamburger Bibliotheken 10 (1990), H. 4, S. 343-371, zit. nach Böning, Welteroberung durch ein neues Publikum, S. 72.

$23 \mathrm{Zu}$ Greflinger: Günter Berghaus, Georg Greflinger als Journalist und historisch-politischer Schriftsteller. Mit einem Anhang seiner Schriften über die englische Revolution, in: Wolfenbütteler Barock-Nachrichten 12 (1985), H. 1, S. 1-14; BöNING, Welteroberung durch ein neues Publikum, S. 40-52 (dort auch weitere Literaturhinweise).

24 Ebd., S. 40.

25 Ebd., S. 41. 
Appelle an die Leserschaft, sondern auch Besinnung über die Zeitläufte beinhalteten. Eingefügte Quellenstücke wurden erläutert, Verse und Anekdoten lockerten die Berichterstattung auf. Ansonsten war auch der Nordische Mercurius durchpaginiert und damit erkennbar für die zeithistorische Ex-PostPerspektive mitgestaltet ${ }^{26}$. Greflinger wollte nämlich seine Zeitung auch dem didaktischen Gebrauch öffnen, z.B. im Geographieunterricht:

Diesem wird dienstlich beygefüget: Weilen einige verständige Schulmeister/ausserund inner Landes/auch andere vornehme Leuthe/dergleichen Novellen/nebst den Geistlichen Büchern/ihren Kindern zu lesen geben/um der Welt Zustand/wie auch der Länder/Flüsse und Städte Nahmen darauß bekannt zu machen ${ }^{27}$.

Greflinger wies bereits den Weg für die aktive Textgestaltung, die später vom Redakteur bzw. Autor einer Zeitschrift erwartet wurde: Hier verlangte das Publikum Originalität und eine eigene Bewertung der Zeitläufte. Dennoch gab sich die Leserschaft auch in diesem Periodikum lange mit der Anonymität der Autoren zufrieden, selbst wenn manche Verfasser mit ihrer Maskierung kokettierten. Die Gründe dafür sind vielfältig. Nicht selten dürfte Teamwork bei der Erstellung der Periodika eine Rolle gespielt haben. Zum einen beschäftigten Verleger einen abhängigen Autor, so wie der Leipziger Verleger und Kaufmann Johann Jacob Kees, der seine Leipziger Post- und Ordinari-Zeitung vermutlich durch Johannes Job redigieren ließ. Letzterer arbeitete seit den 1690er Jahren in der Stadt als Oberpostsekretär ${ }^{28}$. Zum anderen arbeiteten unterhalb des Redakteurs Honorarkräfte, die die praktische Tätigkeit der Texterstellung und besonders der Korrektur verrichteten. Der Leipziger Zeitungsherausgeber Georg Kormart schrieb 1660 in einer Eingabe an die kursächsische Regierung, dass sich noch acht »arme[n] Studenten« in seinem Dienst durch das Abschreiben von Zeitungen ernährten ${ }^{29}$. Am Schutzbedürfnis gegenüber der Zensur allein hat es kaum gelegen. Die Obrigkeiten, insbesondere die städtischen, fragten bei Zensurkonflikten die Verleger am Ort durch und hatten bei ihrem weitreichenden strafrechtlichen Drohpotenzial schnell den Verursacher identifiziert. Eher ist anzunehmen, dass die nebenamtlichen Autoren selbst nicht in jedem Fall mit einem Periodikum in Verbindung gebracht werden wollten, weil erregter Anstoß ihnen

26 Ebd., S. 43f.

27 Nordischer Mercurius, Jg. 1669, S. 5, zit. nach BöNING, Welteroberung durch ein neues Publikum, S. 50.

28 Wiткошsкi, Geschichte des literarischen Lebens in Leipzig, S. 235.

29 Verleger Georg Kormart an Kurfürst Johann Georg II., 7. April 1660: StadtA Leipzig, 2. Sektion (Feudalismus), K 8b, fol. 2, zit. nach Jürgen Schumper, »Zeitung Drucken ist ein wichtiges werck«. Zu den Wurzeln Leipziger Zeitungen in der ersten Hälfte des 17. Jahrhunderts, in: Stadt LeipZig (Hg.), »Zeitung Drucken ist ein wichtiges werck«. 350 Jahre Tagespresse in Leipzig, Leipzig 2000, S. 9-69, hier S. 38. 
beruflich schaden konnte. Angst vor sozialen und beruflichen Folgen waren möglicherweise wichtiger als Angst vor strafrechtlichen Konsequenzen.

Dieser Zusammenhang verwundert nicht, wenn ein Blick auf die soziale Situation der Autoren von Zeitschriften oder Serienwerken geworfen wird. Im Gegensatz zu einer Zeitung, für die eine verlegerische oder buchdruckerische Ausbildung oder eine Bestallung als Postmeister hinreichend sein konnte, musste ein Zeitschriftenredakteur vor allem eines haben: Bildung. Gebildete allerdings gab es im 18. Jahrhundert im Heiligen Römischen Reich im Übermaß, viel mehr als angemessene Stellen vorhanden waren. Daher suchten zahlreiche junge und nicht mehr ganz junge Männer während und nach ihrem Studium nach einer Beschäftigung, deren Prestige und Einkommen die Grundlage für eine Familiengründung darstellen konnte ${ }^{30}$.

Erschwerend hinzu kamen die beruflichen Rekrutierungsmuster der vormodernen Gesellschaft. Das Leistungsprinzip spielte bei der Erringung einer Stelle - im öffentlichen Dienst ebenso wie bei privaten Arbeitsverhältnissen - selten die ausschlaggebende Rolle. Gemäß der Leitdifferenz der stratifikatorisch organisierten Gesellschaftsordnung »oben/unten« hatten Patronage und Fürsprache einen wesentlich wichtigeren Anteil, um ein attraktives Amt zu erlangen. An Höfen, Verwaltungen und Bildungsstätten bewarben sich zahlreiche Kandidaten bzw. deren Fürsprecher oft schon, bevor die erwartete Vakanz wirklich eingetreten war ${ }^{31}$. Dass Ämter in Herrschaftsnähe oder an der Spitze von Organisationen vorzugsweise an Adlige vergeben wurden, ist selten bestritten worden. Ansonsten bildeten sich allerorten, in kleinen oder großen, in katholischen oder protestantischen Territorien Juristen-, Professoren- oder Pfarrerdynastien, die teilweise über Generationen hinweg die Entscheidungsprozesse im Vorfeld von Personalberufungen bestimmten ${ }^{32}$. Auch die Honoratiorenschaft der Städte im Heiligen Römischen Reich war

30 Zur »Akademikerschwemme« im 18. Jahrhundert: James van HoRn Melton, Absolutism and the Eighteenth-Century Origins of Compulsory Schooling in Prussia and Austria, Cambridge u.a. 1988; Franz Quarthal, Öffentliche Armut, Akademikerschwemme und Massenarbeitslosigkeit im Zeitalter des Barock, in: Volker Press/Eugen ReInHARd/Hansmartin SchwarzMAIER (Hg.), Barock am Oberrhein, Karlsruhe 1985, S. 153-188, zit. nach Anton SchindLing, Bildung und Wissenschaft in der Frühen Neuzeit, 1650-1800, München 1996, S. 62.

31 Wie junge Adlige durch Fürsprache in Ämter am kaiserlichen Hof gelangten, hat Grete Klingenstein am Beispiel der Karrieren im Haus der Kaunitz exemplifiziert: Grete KLINGENSTEIN, Der Aufstieg des Hauses Kaunitz. Studien zur Herkunft und Bildung des Staatskanzlers Wenzel Anton, Göttingen 1975.

32 Beispiele aus den protestantischen Landeskirchen: Luise ScHORn-SchÜtTE, Evangelische Geistlichkeit in der Frühneuzeit, deren Anteil an der Entfaltung frühmoderner Staatlichkeit und Gesellschaft. Dargestellt am Beispiel des Fürstentums Braunschweig-Wolfenbüttel, der Landgrafschaft Hessen-Kassel und der Stadt Braunschweig, Gütersloh 1996. Selbst in kleinen Territorien wie dem Fürstentum Lippe ist eine derartige Dominanz weniger Familien und deren Nachkommen bei der Ämtervergabe beobachtbar: Johannes ARNDT, Das Fürstentum Lippe im Zeitalter der Französischen Revolution 1770-1820, Münster/New York 1992, S. $110-124$. 
durch Familien- und Klientelbeziehungen verbunden, was Rats- und sonstige Ämterwahlen kalkulierbar und Außenseitersiege selten machte.

Der zweite Selektionsfaktor war Geld. Wer sich kein Studium leisten konnte, oder wer durch Schicksalsschläge sein Studium unterbrechen oder abbrechen musste, kam vom geraden Weg des patronagegestützten Aufstiegs $\mathrm{ab}$, was meist später nicht mehr ausgeglichen werden konnte. Durch den vorzeitigen Tod des Vaters traf es den studierenden Sohn doppelt: In diesem Fall fehlte nicht nur das Geld, sondern auch die Beziehungen des Vaters waren oft nicht mehr in vergleichbarem Maße nutzbar, denn alle Chargen waren konkurrenzmäßig umstritten, und die anderen Patrone dachten selten in Kategorien von Fairness.

Der dritte Selektionsfaktor war die »Conduite«, der gute Ruf. Ein Konflikt mit der Polizei, ein Duell entgegen der herrschenden Gesetzeslage, ein herausfordernder Traktat gegen die Universitätsleitung oder den zensierenden Theologieprofessor konnte ein Studium ebenso schnell beenden wie eine folgenreiche Liebschaft. Voreheliche Enthaltsamkeit war nicht nur ein gesellschaftliches Erfordernis innerhalb der Zünfte, die hierin bekanntermaßen strenger waren als die übrigen gesellschaftlichen Schichten, sondern auch für alle Anwärter auf Karriereberufe. Ein ruinierter Ruf ließ die Chancen innerhalb der Ämterkonkurrenz schnell dahinschmelzen, unabhängig davon, ob der Rufschaden tatsächlich durch einen Verstoß begründet war oder seine Entstehung einer geschickten Intrige eines Mitbewerbers verdankte.

Wenn der Fall des erzwungenen Verlassens eines geraden Karriereweges eingetreten war, dann gab es nur noch wenige Chancen: Für den Armeeeintritt, vielfach der letzte Ausweg für den sozial abstiegsbedrohten Kleinbürger, fehlten den Gebildeten Neigung und zumeist auch körperliche Eignung. Für sie eröffnete sich der Journalismus, ein Berufszweig, der klassischerweise keine förmlichen Ausbildungsgänge ausgeprägt hat. So finden sich unter den Redakteuren, Herausgebern oder Autoren im Zeitschriftengewerbe des späten 17. und frühen 18. Jahrhunderts Charaktere, die über »interessante« Biographien verfügten, was naheliegenderweise den späteren Historiker wesentlich mehr entzückt haben dürfte als die Betroffenen selbst ${ }^{33}$.

$33 \mathrm{Zu}$ den ungeraden Karrieren: Johannes ARNDT, Verkrachte Existenzen? Zeitungs- und Zeitschriftenmacher im Barockzeitalter zwischen Nischenexistenz und beruflicher Etablierung, in: AKG 88 (2006), S. 101-115. Es verwundert nicht, dass sich das Phänomen anschließend fortsetzte: Jörg Requate, Gescheiterte Existenzen? Zur Geschichte des Journalistenberufs im 19. Jahrhundert, in: WeLKE/WILKE, 400 Jahre Zeitung, S. 335-354. 


\subsection{Daniel Hartnack und Philipp Balthasar Sinold von Schütz - frühe Zeitungs- und Zeitschriftenherausgeber}

Es ist unbestreitbar, dass die Mediengeschichte einige ihrer schönsten Periodika Personen verdankt, die durch das Nichtgelingen ihrer Karrieren zu Redakteuren wurden. Daniel Hartnack (1642-1708), der sich als Verfasser der Studie Erachten von Einrichtung Der alten Teutschen und neuen Europäischen Historien einen Namen gemacht hatte, gehörte zu diesem Kreis ${ }^{34}$. Johannes Weber hat Hartnack als einen »gelehrten Streithahn« bezeichnet $^{35}$. Hartnack wollte Theologe werden, doch kamen ihm die innerprotestantischen Konflikte zwischen Orthdoxen und Pietisten mehrmals in seinem Leben in die Quere. Auch mit dem Strafrecht geriet er in Konflikt, indem er als Student eine Bekannte schwängerte und später in den Verdacht geriet, eine adlige Dame bestohlen zu haben. So führte seine berufliche Karriere über mehrere befristete Dienstverhältnisse als Lehrer an verschiedenen Orten zwischen Thüringen und Norddeutschland. Erst 1702 erlangte er eine Pfarrstelle, doch als er 1708 starb, gab es bereits neuerliche Untersuchungen wegen Unregelmäßigkeiten.

Hartnack war keineswegs nur Opfer der Verhältnisse, sondern teilte in seinen Traktaten kräftig gegen seine Gegner aus. Da diese zurückschlugen, erklärten sich mehrere berufliche Erfolglosigkeiten aus Repressalien, vollzogen über die jeweilige Dienstherrschaft. Wichtig ist Hartnack auch wegen seiner Tätigkeit als Zeitungsherausgeber. Über dieses Wirken wissen wir nur das, was in Hartnacks Kontroversen mit dem Theologen Johann Melchior Stenger zu Papier gebracht wurde. Der ansonsten unersprießliche Streit eröffnet heute die Quellengrundlage über eine wichtige Persönlichkeit des frühen, uninstitutionalisierten Pressewesens ${ }^{36}$. Stenger nannte Hartnack einen »Avisen-Schreiber« und »Avisen-Trödler« und hängte damit seiner Liste an Schimpf- und Scheltworten weitere Begriffe an. Demnach hat Hartnack zeitweilig die »Relation aus dem Parnasso« betreut, die ab 1687 im Hamburger Verlag Nikolaus Spieringk herauskam. Hinsichtlich der Aufladung seines Konflikts mit Stenger blieb Hartnack kein Wort schuldig, er zeigte im Stil der Zeit bei Ehrenkonflikten Flagge, gerade in einer sozial prekären Situation galt es, in dieser Hinsicht nicht nachzugeben: Wer im Sinne des Sprichworts als »Klügerer« nachgab, schadete damit seiner Ehrbarkeit, das

34 Hartnack, Erachten von Einrichtung Der alten Teutschen und neuen Europäischen Historien, pas.

35 Weber, Daniel Hartnack, S. 140-158. Zur Biographie Hartnacks: DBA Serie I, Fiche 480, Nr. 1-29. Zur mediengeschichtlichen Bedeutung auch ARNDT, Verkrachte Existenzen, S. 103-109.

36 Zur Kontroverse und den in diesem Zusammenhang gewechselten Traktaten: WeBER, Daniel Hartnack, S. $141 f$. 
galt auch für Bildungsbürger ohne Dauerstelle ${ }^{37}$. Hartnack war damit in einer Branche tätig, die sonst von Druckern und Postmeistern dominiert wurde. Leider ist über die Herausgeberschaft vieler Zeitungen immer noch manches unbekannt, so auch das Verhältnis der Berufsrollen an der Gesamtüberlieferung. Von der Hälfte der Zeitungen weiß man weder Druckort und Drucker oder Redakteur ${ }^{38}$. Dies hing auch mit der Nichtbeachtung der Impressumspflicht zusammen, die bei vielen Zeitungen, ebenso wie schon zuvor bei Flugschriften, verbreitet war. Eine Rückführung auf die gebotene Wahrung des Herrschafts-Arkanums, das allen theoretischen Erwägungen zum Trotz im frühen 18. Jahrhundert bereits deutliche Erosionsspuren aufwies, ist allerdings nicht völlig überzeugend ${ }^{39}$.

Wesentlich weniger katastrophenträchtig als im Falle Hartnacks verlief der Werdegang von Philipp Balthasar Sinold von Schütz (1657-1742), dem Herausgeber der Europäischen Fama ${ }^{40}$. Als adliger Abkömmling wurde er zwar an der Eliteschule in Weißenfels unterrichtet und studierte Jura in Jena, erreichte anschließend aber keine Charge in einer großen Territorialbehörde. Stattdessen diente er zeitweilig als Offizier beim Großherzog von Toskana, um anschließend als Privatgelehrter in Leipzig zu wohnen. Nachdem er einige kurzlebige Periodika ediert hatte, begann er 1702 mit der Herausgabe der Europäischen Fama. Die Dauer seiner Herausgebertätigkeit ist nicht völlig geklärt. Später diente er in verschiedenen Stellungen an kleinen Höfen im Reich, so beim Grafen von Reuß zu Köstritz, der verwitweten Herzogin von Sachsen-Merseburg, dem Herzog von Württemberg-Wels in Bernstadt/Schlesien, dem Grafen von Hohenlohe-Pfedelbach und schließlich dem Grafen von Solms-Laubach. Sinold von Schütz gehörte als »Faramond « der »Fruchtbringenden Gesellschaft $\ll \mathrm{an}^{41}$. Neben der periodischen Autorenschaft verfasste er unter dem Pseudonym »Amadeus Creutzberg $\aleph^{42}$ erbauliche Traktate. Frühaufklärerische Zeitschriftenpublizistik und Erbauungsschriftstellerei gemeinsam zu betreiben empfand er nicht als Widerspruch, damit stand er in einer Reihe mit anderen Rechtsgelehrten seiner Zeit, etwa

37 Zum Forschungskontext »Ehre«: Martin Dinges, Die Ehre als Thema der historischen Anthropologie. Bemerkungen zur Wissenschaftsgeschichte und Konzeptualisierung, in: Klaus Schreiner/Gerd Schwerhoff (Hg.), Verletzte Ehre. Ehrkonflikte in Gesellschaften des Mittelalters und der Frühen Neuzeit, Köln/Weimar/Wien 1995, S. 29-62.

38 Weber, Daniel Hartnack, S. 145f.

39 Vgl. zur theoretischen Begründung des Staats-Arkanums: Gestrich, Absolutismus und Öffentlichkeit, S. 34-74.

40 Biographische Nachweise: DBA, Serie I, Fiche 1147, S. 385-392; Herbert Jaumann (Hg.), Handbuch Gelehrtenkultur der frühen Neuzeit. Bio-bibliographisches Repertorium, Bd. 1, Berlin/New York 2004, S. 611f. - Biographischer Überblick bei ARNDT, Verkrachte Existenzen, S. 112-114.

41 Biographischer Hinweis: DBA, Serie I, Fiche 1188, S. 128ff.

42 Biographischer Hinweis: DBA, Serie I, Fiche 208, S. 365-370. 
Ahasver Fritsch, der in pietistischen Kreisen verkehrte und ebenfalls geistliche Traktate verfasste ${ }^{43}$.

Sinold von Schütz und seine Nachfolger in der Herausgeberschaft der Europäischen Fama nutzten mehrfach die Gelegenheit, in Vorworten und eingeschobenen Sätzen in ihren Heften über das Selbstverständnis der Veranstalter zu räsonnieren. Schon im Vorwort zum ersten Band wurde es als die Aufgabe des Redakteurs bezeichnet, locker aufbereitete Berichte zu reproduzieren. Die Kriterien der klassischen Rhetorik wurden dafür als Paten bemüht: Der Leser sollte »ein paar müßige Stunden« erleben ${ }^{44}$.

Auch sollte sich der Autor »mit einem unpaßionirten Urtheil« versehen, wenn auch das Urteil als konstitutiv angesehen wurde - im Gegensatz zur Praxis beim Zeitungsjournalismus. Die gebotene Zurückhaltung bei der Äußerung der eigenen Meinung hatte einen praktischen Grund: Das persönliche Urteil des Herausgebers konnte nur mit einem Teil der Leserschaft zur Deckung gebracht werden. Dieser Teil, so Sinold von Schütz, könne sich daher an der Bestätigung der eigenen Meinung erfreuen. Für die Andersdenkenden, die sich gleichwohl auch als Lesergruppe angesprochen fühlen sollten, hielt der Herausgeber einen rhetorischen Kunstgriff bereit: Es sei ihm ganz recht, wenn der Leser ihn für einfältig hielte. Beide Gruppen sollten dadurch umso mehr angeregt werden, über die »Staats=Begebenheiten desto scharffsinniger nachzudencken $\aleph^{45}$.

Im nächsten Vorwort, zum 49. Heft vier Jahre später, äußerte sich Sinold von Schütz zum Nachrichtenwert als Kriterium für seine Redakteurstätigkeit. Eine sklavische Orientierung an festen Monatsterminen für das Erscheinen seines Periodikums lehnte er ab. Er wolle sich an der »Wichtigkeit der Avanturen« orientieren, d.h. dann ein neues Heft gestalten, wenn eine »sonderbare Staats = Veränderung « eingetreten war. Diese Überlegungen bedeuteten das Eingeständnis, dass Verleger und Herausgeber sich nicht sicher waren, dass stets genug Stoff zu kommentieren war. Dies galt besonders für die Wintermonate, wenn die militärischen Aktionen im wörtlichen Sinne auf Eis lagen, $»$ sich nicht mit falschen Vorurtheilen zu praecipitiren $\aleph^{46}$. Die Möglichkeit des Gegenteils wurde allerdings auch erwähnt: Man könne bei Bedarf mehrere »Famae« hintereinander herauskommen lassen. Auch sollte ein hinreichender Unterschied zur aktuellen Zeitungsberichterstattung erfolgen, das Kriterium der »Aktualität« hatte daher keine herausragende Priori-

43 Zu Fritsch: Bernhard Anemüller, Art. »Ahasver Fritsch«, in: ADB, Bd. 8 (Leipzig 1878), S. 108f.; Susanne Schuster, Aemilie Juliane von Schwarzburg-Rudolstadt und Ahasver Fritsch. Eine Untersuchung zur Jesusfrömmigkeit im späten 17. Jahrhundert, Leipzig 2006, bes. S. 19-77.

44 Europäische Fama 1 (1702), Vorwort.

45 Ebd.

46 Ebd. 49 (1706), Vorwort, S. 2. 
tät: Die Zusammenhänge, um die es der Europäischen Fama vor allem ginge, würden sich erst in der Nachschau von einigen Wochen erschließen. Dann sei die Fama als eine gute Zeitschrift in der Lage, den Vorgang in sachlicher Form aufzubereiten ${ }^{47}$.

\subsection{Weitere Periodika-Editoren: Andreas Stübel und Johann Ehrenfried Zschackwitz}

Während über den Herausgeber des Augsburger Monatlichen Staats-Spiegels zu wenig bekannt ist, um ihn hier zu thematisieren, liegen über zwei weitere frühe Zeitschriftenherausgeber reichere Informationen vor. Andreas Stübel (1653-1725) unterschied sich vom Typus der »verkrachten Existenz«, denn ihm gelang zunächst problemlos der berufliche Einstieg. Er hatte es an der Universität Leipzig zum $»$ Magister Philosophiae und Baccalaureus Theologiae« gebracht und war 1684 auf die Konrektorenstelle an der Leipziger Schule St. Thomae berufen worden. Gleichzeitig unterrichtete er weiter an der Theologischen Fakultät der Universität. Da er in der Folgezeit mit frühpietistischen und chiliastischen Anschauungen auffiel, betrieben seine orthodox-lutherischen Gegner seine Kaltstellung, die 1697 mit der Emeritierung als Lehrer und einem Lehrverbot an der Universität gelang ${ }^{48}$. Stübel bezog fortan ein Ruhegehalt, das ihm die journalistische Tätigkeit ermöglichte. Seine Periodika Aufgefangene Briefe und Der neu=bestellte Agent von Haus aus erinnern schon in der Form an zweierlei: Zum einen an die diplomatische Praxis der Brief- und Berichtskorrespondenz, zum anderen an die geschriebenen Zeitungen, aus denen die politische Berichterstattung einst hervorgegangen war. Die altertümlichen Begrifflichkeiten boten ihm damit Gelegenheit, seine Informationen zu gliedern und gleichzeitig die Erinnerung an die mediengeschichtliche Herkunft der historisch-politischen Zeitschrift zu aktualisieren.

Auch Johann Ehrenfried Zschackwitz (1669-1744) blickte auf eine Ausbildung an der Universität Leipzig zurück, wo er Rechtswissenschaften studiert hatte. 1691 war er Feldkriegs-Secretarius in der kursächsischen Generalkriegskanzlei. Zwischen 1693 und 1697 amtierte er als Auditeur in der Armee des Herzogs von Sachsen-Gotha. Zwischen 1697 und 1705 übte er verschiedene Sekretärs-Stellen in Dresden aus. 1705 wechselte er nach Leipzig über (vermutlich im Zusammenhang mit der sächsischen Niederlage gegen Schweden), wo er sich als Selbstständiger durchschlagen musste. Er begann

47 Ebd., S. 3.

48 Zu Stübels Biographie: Friedrich Koldewey, Art. »Andreas Stübel«, in: ADB 35, S. 702-704; Kirchner, Das deutsche Zeitschriftenwesen, Bd. 1, S. 32; DBA, Serie I, Fiche 1244, S. $315 f$. 
verschiedene Magazine herauszugeben. Zwischen 1711 und 1713 arbeitete er als Archiv-Sekretär in Eisenach. 1713 wurde er als Professor historiarum ans Gymnasium Academicum nach Coburg berufen. Als er wegen der ungnädigen Aufnahme einiger Zeitschriften-Passagen über Kaiser Karl VI. mit Repressalien aus Wien rechnen musste, begab er sich in preußischen Schutz nach Halle a.d. Saale. 1731 wurde er zum Professor extraordinarius für Jura an die Universität Halle berufen. 1738 erfolgte daselbst seine Beförderung ins Ordinariat ${ }^{49}$. Zwei Bewerbungen auf eine Professur an der Universität Leipzig scheiterten 1723 und 1734, wobei es eine Rolle spielte, dass Zschackwitz durch mehrere Äußerungen Zweifel an seiner rechtgläubig lutherischen Haltung im Sinne der kursächsischen Kirchenleitung geweckt hatte ${ }^{50}$. Zur Stützung der Vorhaltungen zensierten die Theologen Zschackwitz' Euvre, z.B. sein Breve et Compendiosum Examen Juris Publici und die Grundlegung zu dem Lehnrechte ${ }^{51}$. Konsequenzen sind nicht dokumentiert.

Zschackwitz gehört zu den Zeitschriftenherausgebern, über dessen Konflikte mit der zeitgenössischen Zensur einige Details überliefert sind. Einer der früheren Gründe, weshalb Zschackwitz Probleme mit der Rezeption seiner Zeitschrift bekommen hatte, lag auch in seiner Neigung, das Papsttum und die katholischen Welt- und Ordensgeistlichen zu diffamieren. Viel ausgeprägter als bei Sinold von Schütz oder Fassmann, die auch aus ihren Vorurteilen gegenüber Katholiken kein Hehl machten, wurden die Anhänger des konkurrierenden Bekenntnisses in den düstersten Farben gemalt. Jeder Konfessionskonflikt geriet so zu einer Abrechnung mit dem »schwarzen« Charakter der Jesuiten und ihrer Anhänger. Das Diffamierungsverbot, das dem Westfälischen Frieden innewohnte, wurde von Zschackwitz in beinahe jedem Heft verletzt. Schon in der Eröffnungsnummer behauptete Zschackwitz, das Heilige Römische Reich hätte seit mehreren Jahrhunderten nur zwei Feinde:

49 Zur Biographie Zschackwitz’: DBA, 1. Serie, Fiche 1419, Nr. 19-37.

50 Vgl. das Bewerbungsschreiben um eine außerordentliche Professur in Leipzig, 26. Juni 1723 (Abschrift): StadtA Leipzig, Ratsstube, Titelakten XLVI, Nr. 171, fol. 4f. Zschackwitz betont darin seine Treue und Loyalität zum Wettinischen Herrscherhaus. Vgl. zum Kontext um die Zensurverfahren gegen Johann Ehrenfried Zschackwitz: Ковuсн, Zensur und Aufklärung in Kursachsen, S. 132.

51 Dies geht aus einer Anforderung beider Werke seitens der Dresdner Regierung an den Leipziger Magistrat vom 24. September 1723 hervor. Die Leipziger sollten die Bücher ans Oberkonsistorium einsenden zur Durchführung eines förmlichen Verfahrens: Dresdner Regierung an den Leipziger Magistrat, 24. September 1723: StadtA Leipzig, Ratsstube, Titelakten XLVI, Nr. 171, fol. 1. Reichsrecht: Johann Ehrenfried ZschackwiTz, Breve et compendiosum Examen Juris Publici Imperii Germanici olim concimatum et luce expositum in usum collegiorum privatorum explicatorio-examinatoriorum [...], Coburg 1716; Lehnsrecht: Johann Ehrenfried Zschackwitz, Grundlegung zu dem Lehn-Rechte des Teutschen Reiches. Worinnen zugleich von einigen wichtigen Materien des Teutschen Staats-Rechts Nachricht ertheilet wird, Leipzig 1714. 
Die Päpste und die französischen Könige ${ }^{52}$. Dieser Satz gab die Marschrichtung vor: Er setzte gleich einen Schwarz-Weiß-Akzent, und er verbog die historische Wahrheit, der gemäß mindestens die Türken für die Zeit seit dem Spätmittelalter und die Spanier für das 16./17. Jahrhundert hätten erwähnt werden müssen.

Laut Agatha Kobuch produzierte Zschackwitz auch mehrere Zusammenstöße mit den kursächsischen Zensurbehörden. Zumeist handelte es sich um die staatsrechtlichen Publikationen des Autors, die gegen politische und lehnsrechtliche Interessen Kursachsens verstießen ${ }^{53}$. Vom Neu eröffneten Welt- und Staats-Spiegel wurde das Heft 53 durch die sächsische Zensur verboten und eingezogen, nachdem die Stadt Hamburg sich Anfang Mai 1713 beschwert hatte ${ }^{54}$. Zschackwitz hatte dem Rat eine zu schwedenfreundliche Politik vorgehalten, die den Interessen der Bürger schade. Der Redakteur hatte in diesem Heft über die Militäraktionen zwischen Schweden und Dänemark im Rahmen des Nordischen Krieges berichtet. Die Stadt Hamburg versuchte, bei diesen Kämpfen nicht zwischen die Fronten zu geraten. Die Dänen hatten einige Zeit zuvor Stade abgebrannt; daraufhin plünderten und verbrannten die Schweden Altona, die dänische Konkurrenzsiedlung an der Elbe westlich von Hamburg. Zschackwitz suggerierte zwischen beiden Begebenheiten einen Zusammenhang - Hamburg habe daran auch Anteil gehabt. Es habe nämlich, so Zschackwitz, Gerüchte gegeben, dass der Hamburger Magistrat den schwedischen General Steinbock zur Zerstörung Altonas aufgefordert habe, um sich ebenfalls an Dänemark zu rächen:

Dieses [= die Abbrennung Altonas] sollte eine Revanche wegen Stade seyn/von vielen aber wollte versichert werden/weil die Hamburger mit Leib/Seele/und Geist allemal gut Schwedisch wären/sie auch vorigen Jahres an Ihro Majestät in Dännemarck ein ansehnliche Summe Geldes bezahlen müssen/so hätten sie bey dem General Steinbock es dahin in geheim gekartet/daß besagte Stadt so jämmerlich verwüstet worden/um dadurch an höchstbesagter Majestät ein ebenfällige/ ob gleich geheime Revanche zu nehmen ${ }^{55}$.

Zur Begründung seines Protests führte der Hamburger Magistrat aus, er müsse zur Wahrung seiner Neutralität gegenüber den beiden kriegführenden Mächten sehr vorsichtig sein und wolle auf keinen Fall in ein schiefes Licht geraten. Selbstverständlich habe man christliches Mitleid mit den Betroffe-

\footnotetext{
$52 \mathrm{Neu}=$ eröffneter Welt $=$ und Staats $=$ Spiegel, 1709, hier Bd. 1, H. 1, S. 21.

53 Koвuch, Zensur und Aufklärung in Kursachsen, S. 126-132.

54 Beschwerde des Rats der Freien Hansestadt Hamburg an den Magistrat von Leipzig, 3. Mai 1713: StadtA Leipzig, Ratsstube, Titelakten XLVI, Nr. 153, fol. 92f. Vgl. auch KoBUcH, Zensur und Aufklärung in Kursachsen, S. 131, Anm. 378.

$55 \mathrm{Neu}=$ eröffneter Welt $=$ und Staats $=$ Spiegel, 1713, Bd. 5, H. 53, S. 449f.
} 
nen in Altona; man habe sogar für die Opfer sammeln lassen! Die Anschuldigung, die im Neu eröffneten Welt- und Staats-Spiegel suggeriert würde, sei allerdings haltlos, und daher müsse der Verfasser bestraft werden ${ }^{56}$.

Verfahrenstechnisch ging der Leipziger Rat daraufhin in bewährter Weise vor: Er vernahm zunächst den Verleger, der offenbar ganz entspannt zum Gespräch erschien. Johann Friedrich Braun verlautbarte, der Verfasser sei Johann Ehrenfried Zschackwitz; die Zeitschrift habe die reguläre Zensur durchlaufen, und er selbst, Braun, »bekümmere sich darum weiter nicht $\ll^{57}$. Auch der Leipziger Rat formalisierte das Verfahren nun: Er teilte dem Hamburger Stadtregiment mit, dass Zschackwitz der Verfasser sei; da dieser nicht in Leipzig wohne, sondern Sekretär beim Herzog von Sachsen-Eisenach sei, könne man weiter nichts unternehmen. Zum Zeichen des abgeschlossenen Verfahrens wurde eine Mitteilung über den Vorgang verfasst und an die Regierung in Dresden zur Information geschickt ${ }^{58}$.

Die Zeitschrift hat hinsichtlich der Reichstagsberichterstattung einen Bruch zwischen dem Herbst 1713 und dem Sommer 1714. Ob dies mit Zensurmaßnahmen zusammenhing, oder ob Zschackwitz keinen Agenten in Augsburg hatte, wo sich die reichsständischen Vertreter in der fraglichen Zeit befanden, bleibt unklar. Jedenfalls wird die Flugschrift Pflicht $=$ mässiger Bericht, die Ende 1713 in Augsburg öffentlich wegen ihres Angriffs auf die laxe Geheimhaltungspraxis verbrannt worden war, in der Zeitschrift nicht erwähnt. Vielleicht hat der sächsische Kurfürst darüber auch nichts lesen wollen, schließlich war sein Gesandter darin beleidigt worden und hatte das Verdikt über das Druckwerk maßgeblich betrieben ${ }^{59}$.

In den Leipziger Zensurakten findet sich eine weitere Anfrage der Dresdner Regierung an die Bücherkommission vom Dezember 1713: Die Regierung wollte wissen, wer für die Zensur des Neu eröffneten Welt- und Staats-Spiegels zuständig sei ${ }^{60}$. Das Verfahren wurde mit großer Behäbigkeit durchgeführt. Erst Ende Januar 1714 bestellte die Leipziger Bücherkommission den Verleger Johann Friedrich Braun ein, um den Zensor zu erfahren. Braun gab vor, erst in seinen Unterlagen prüfen zu müssen, und reichte wenig später den Namen ein: Es handelte sich um Gottlob Friedrich Irnichen, Professor für

56 Beschwerde des Rats der Freien Hansestadt Hamburg an den Magistrat von Leipzig: Ebd., fol. $92 \mathrm{v}$.

57 Vernehmung des Verlegers Johann Friedrich Braun durch die Leipziger Bücherkommission, 15. Mai 1713: Ebd., fol. 95.

58 Antwortschreiben des Leipziger Magistrats an den Hamburger Rat, 9. Juni 1713: StadtA Leipzig, Ratsstube, Titelakten XLVI, Nr. 153, fol. 95. Bericht des Leipziger Magistrats an die Regierung in Dresden, 9. Juni 1713: Ebd., fol. 96f.

59 Zur Auseinandersetzung um diese Flugschrift: ARndT, »Pflicht=mässiger Bericht«, S. 1-31.

60 Anfrage der Dresdner Regierung an den Leipziger Magistrat, 28. Dezember 1713: StadtA Leipzig, Ratsstube, Titelakten XLVI, Nr. 153, fol. 98. 
Moral und Politik ${ }^{61}$. Es ist interessant, zu sehen, dass die städtische Obrigkeit offenbar nicht informiert war: Zensur lief auf der Ebene zwischen den Verlegern und den zuständigen Professoren der Universität ab, und erst wenn das Placet vorlag, wurde das jeweilige Buch dem Magistrat angezeigt (direkt mit der Bescheinigung der Unbedenklichkeit). Der Leipziger Magistrat teilte der Dresdner Regierung das Ergebnis der Recherche mit; das weitere Verfahren ist in den Leipziger Zensurakten nicht überliefert ${ }^{62}$. Der hier vorliegende Vorgang bietet allerdings Einblick in die Kosten des Zensurverfahrens: Prof. Irnichen erhob für seine zensierende Lektüre des Neu eröffneten Welt- und Staats-Spiegels einen Kostensatz von 12 Gr. pro Heft ${ }^{63}$.

Wenn man Georg Witkowski folgt, dann wurde auch der Neu=eröffnete Welt $=$ und Staats =Spiegel 1716 deswegen eingestellt, weil Zschackwitz durch sein Buch Examen juris publici in einen so scharfen Gegensatz zum kaiserlichen Hof geriet. Ein weiteres Wirken auf der politisch-publizistischen Bühne sei nicht mehr möglich gewesen ${ }^{64}$. Dies bestätigt die herrschende Vorstellung über Zensurverfahren im frühen 17. Jahrhundert, die relativ mild und in die korporativen Strukturen der Zeit eingebettet waren, aber dennoch Wirksamkeit entfalteten, wenn ein einzelner Autor oder Herausgeber aus dem geübten Konsens des Maßhaltens heraustrat und mit schärferen Urteilen und Verurteilungen in Erscheinung trat.

\subsection{David Fassmann - Herausgeber der Totengespräche}

Der Begründer und Redakteur der Gespräche im Reiche der Todten, David Fassmann (1683-1744), gehört sicherlich zu den interessantesten Medienproduzenten des 18. Jahrhunderts ${ }^{65}$. Fassmann gelangte infolge des frühen Todes seines Vaters und anschließend seines Großvaters nicht in den Besitz einer abgeschlossenen akademischen Ausbildung. Sein Studium in Altdorf/Nürnberg musste er 1703 vorzeitig beenden, um sich als Schreiber bei der Kriegs- und Landpflegsstube in Nürnberg zu verdingen. Für die fränkische Metropole unternahm er zwischen 1705 und 1709 mehrere diplomatische Missionen an fürstliche Höfe sowie zu Versammlungen des Fränkischen Kreises. Von 1709 bis 1711 stand Fassmann im Dienst des sächsischen

61 Antwort des Verlegers Johann Friedrich Braun; Protokollnotiz der Leipziger Bücherkommission, 29. Januar 1714: StadtA Leipzig, Ratsstube, Titelakten XLVI, Nr. 153, fol. 99.

62 Antwortschreiben des Leipziger Magistrats an die Dresdner Regierung, 9. Februar 1714: StadtA Leipzig, Ratsstube, Titelakten XLVI, Nr. 153, fol. 101.

63 Vgl. Kostenabrechnung Irnichens über die Zensur von sieben Heften vom 24. Dezember 1712 (12 Gr. pro Heft, zusammen 3 Rtl. 12 Gr. für sieben Hefte): StadtA Leipzig, Ratsstube, Titelakten XLVI, Nr. 153, fol. 100.

64 Witkowski, Geschichte des literarischen Lebens in Leipzig, S. 195.

65 Fassmann, Gespräche im Reiche der Todten, pas. 
Kurfürsten August, dessen Sohn er 1711 zur Kaiserwahl nach Frankfurt a.M. begleitete. Von 1711 bis 1715 reiste Fassmann mit einem englischen Adligen über die britischen Inseln sowie durch Frankreich und Italien, um schließlich die Niederlande kennenzulernen und dort dem Utrechter Friedenskongress beizuwohnen. 1716 diente er August Hermann Francke in Halle a.d. Saale als Schreiber. Daneben betätigte er sich als Sprachlehrer in Englisch und Französisch. Ein Jahr später ließ er sich als freier Autor in Leipzig nieder und begann mit der Erstellung seiner Totengespräche und weiterer historisch-politischer Traktate und Serienwerke. Dabei kamen ihm seine Belesenheit und seine Fremdsprachenkenntnisse zugute ${ }^{66}$.

Von zentraler Bedeutung für spätere Bewertungen waren seine Jahre in Berlin. Fassmann hatte am Berliner Hof von 1725 bis 1731 eine Stellung, die sich nicht genau umschreiben lässt. Damberg bezeichnet ihn als "Zeitungsreferenten«. Auch soll Fassmann König Friedrich Wilhelm I. zwischen 1728 und 1731 bei dessen Krankheiten aus historischen Büchern (bzw. Exzerpten) vorgelesen haben ${ }^{67}$. Es ist bekannt, dass der König in seiner Umgebung die Anwesenheit einiger Gelehrter schätzte, über die seine Generäle und er gern grobe und manchmal auch handgreifliche Späße zu machen pflegten. Der König empfand keinerlei Reue dabei, Gelehrte zu Hofnarren zu deklassieren - er mag sich damit gerechtfertigt haben, dass diese dafür gut bezahlt wurden. Der erste und äußerst tragische Fall war der Historiker Paul Jacob Gundling, der zwar zum Geheimen Rat, Freiherrn und Akademiepräsidenten aufstieg, aber durch die fortgesetzten Demütigungen dem Alkoholismus erlag und schließlich in blasphemischer Weise in einem Weinfass beerdigt wurde $^{68}$. Während der König durch Androhung eines Bußgeldes von 5 Rtl. dafür sorgte, dass Gundling einen großen Leichenzug bekam, weigerten sich die Potsdamer Pfarrer aller Konfessionen standhaft, unter diesen Umständen eine reguläre christliche Trauerfeier zu veranstalten und nahmen dafür selbst Einkommenskürzungen in Kauf. Stattdessen hielt David Fassmann die Leichenpredigt ${ }^{69}$. Fassmann hatte übrigens auf das Intensivste an dem Kesseltreiben gegen den früheren Hofnarren teilgenommen, sich selbst mehrfach mit ihm geprügelt und wohl darauf spekuliert, durch diesen makabren Eifer die Gunst des Königs zu gewinnen. Der Journalist verfasste - auf Anstiftung

66 Autobiographische Angaben: Ebd., Bd. 15, S. 9-20. Zu seiner Biographie generell: DBA, Serie I, Fiche 308, S. 161-166. Vgl. auch die biographischen Angaben bei DAMBERG, Die politische Aussage in den Totengesprächen David Fassmanns, S. 31-42.

67 DAmberg, Die politische Aussage in den Totengesprächen, S. 45.

68 Vgl. zu Gundling die Biographie von Martin SABrow, Herr und Hanswurst, pas.

69 Die »Predigt« wurde anschließend als Flugschrift gedruckt und verkauft: [David Fassmann], Parention Wie sie, Auf allergnädigsten Befehl, Bey einer sehr Volckreichen Versammlung gehalten worden, Von Seiner Königl. Majestät Allerdemütigstem Knecht D[aniel] F[assmann] Als man den, am 11. Aprilis 1731. zu Potsdam verstorbenen Freyherrn von Gundling [...] beerdiget, Potsdam 1731. 
des Königs ${ }^{70}$ - auch eine satirische Studie über den »gelehrten Narren«, die eine verschlüsselte Biographie für Gundling darstellen sollte ${ }^{71}$.

Die Berliner Berichte des braunschweigischen Residenten Wilhelm Stratemann weisen mehrfach auf Fassmanns Aufstieg in der Gunst des Königs hin: Bereits 1728 hatte er - nach einem spektakulären Handgemenge mit dem Theologieprofessor Friedrich August Hackemann - vom König ein Haus in der Friedrichstadt und eine Pfründe in Aussicht gestellt bekommen ${ }^{72}$. Doch allein die Registereintragung, die Richard Wolff dem Verfasser der berühmten und wirtschaftlich erfolgreichen Totengespräche angedeihen ließ, weist schon den Weg: »Fassmann, Hofnarr« steht dort zu lesen, und genau diese Rolle hatte Friedrich Wilhelm I. ihm zugedacht - neben Gundling. Da der König das Vergnügen seiner militärischen Umgebung sah, es den »Gelehrten« zu zeigen, schätzte er diese Spezies auch in mehreren Exemplaren gleichzeitig. Fassmann galt als Favorit für die Nachfolge Gundlings. In seinen Berichten für den Herzog von Braunschweig-Wolfenbüttel konnte Stratemann das diesbezügliche Gerücht schon vermelden, als Gundling noch gar nicht tot war: Fassmann sei als Nachfolger auserkoren, und er sollte ebenfalls »baronisiert « werden ${ }^{73}$. Einen Monat später war Fassmann bereits eingeführt: Für ein Gehalt, das Stratemann auf 1.200 bis 1.500 Rtl. schätzte, übernahm der Journalist alle Amtsstellen Gundlings bis auf den Geheimen Rat und das Generaldirektorium. Stratemann schreibt ganz offen, dass Fassmann sich vom König ausbedungen habe, niemand dürfe ihn schikanieren, wes Standes er auch sei. Bei Förster wird ein Brief Fassmanns an den König zitiert, in dem dieser ein bisheriges Jahreseinkommen von 1.000 Rtl. angibt, das er auch in Berlin bekommen möchte ${ }^{74}$.

Mit der praktischen Anerkennung haperte es allerdings schnell. Am 12. Mai bereits schreibt Stratemann, dass Fassmann sich standhaft geweigert habe, ein »Kleid« anzuziehen, das aus verschiedenfarbigen Seidenstoffen gefertigt worden sei und das einem Narrenkleid gleichkam. Der Resident ging jedoch davon aus, dass der König es - notfalls durch Geschenke - noch dahin bringen würde, Fassmann zum Tragen des Kleides zu bewegen ${ }^{75}$. Das

70 Fassmann bestätigt die Anstiftung durch eine Bemerkung in seiner autobiographischen Einführung in den 15. Bd. seiner Totengespräche: Fassmann, Gespräche im Reiche der Todten, hier Bd. 15, S. 19. Vgl. auch Förster, Friedrich Wilhelm I., König von Preußen, hier Bd. 1, S. 272 .

71 David Fassmann, Der Gelehrte Narr, Oder Gantz natürliche Abbildung Solcher Gelehrten, Die da vermeynen alle Gelehrsamkeit und Wissenschafften verschlucket zu haben [...] Nebst einer lustigen Dedication und sonderbaren Vorrede [...], Freyburg [=Leipzig] 1729.

72 Berichte aus $»$ Berlin, den 2. Octobris $1728 \ll, »$ Berlin, den 16. Octobris $1728 \ll$ und $» B e r l i n$, den 30. Octobris 1728«: WolfF, Vom Berliner Hofe, S. 20-27.

73 Bericht aus »Berlin, den 31. Martii 1731«: WoLfF, Vom Berliner Hofe, S. 219-221.

74 David Fassmann an König Friedrich Wilhelm I., 16. April 1731: Förster, Friedrich Wilhelm I., König von Preußen, Bd. 1, S. 281-284, zit. Betrag S. 283.

75 Bericht aus »Berlin, den 12. Mai 1731«: WolfF, Vom Berliner Hofe, S. 228-230. 
Ende von Fassmanns Karriere als preußischer Hofnarr kam schnell. Am 9. Juni berichtete Stratemann von einem Zusammenstoß Fassmanns mit dem Hofjuden Marcus Magnus: Nachdem der Jude ihn geohrfeigt hatte - vermutlich eine geplante Tat, um den Hofnarren zu kompromittieren -, würgte Fassmann seinen Kontrahenten; beide Kombattanten mussten von Offizieren getrennt werden. Fassmann erinnerte den König daraufhin an dessen Zusage zu Dienstbeginn und verließ den Berliner Hof. Auch spätere Gehaltsaufstockungen konnten ihn zu keinem Sinneswechsel mehr bewegen, obwohl Stratemann sicher war, dass der Journalist dem Angebot wohl folgen müsse, da er nicht die Mittel besitze, derart gut ausgestattete Positionen auszuschlagen. Fassmann zog aber eine ungewisse Freiheit in Ehren einem Leben in vergoldeter Lächerlichkeit vor ${ }^{76}$. Welche Meinung Fassmann anschließend von König Friedrich Wilhelm I. hatte, bleibt offen. Es dürften wohl eher Opportunitätsgründe (und Gewinnaussichten am Markt) gewesen sein, die ihn veranlassten, 1735 eine hymnische Biographie auf den Hohenzollern zu verfassen - wenn man das ausufernde Lob nicht als rhetorisches Mittel der Übertreibung bewerten möchte, die ihre Aussage in das Gegenteil verkehren möchte. Das deutete Friedrich Förster an, der auf ein vorübergehendes Druckverbot durch den preußischen König hinweis, der weder die Anspielungen in den übertriebenen Attribuierungen noch die groben Angriffe auf andere Höflinge übersehen hatte ${ }^{77}$.

In seinen späteren Jahren nach 1731 soll Fassmann in Leipzig das bohemienhafte Leben eines freien Journalisten geführt haben. Sein aufwendiger Lebensstil verzehrte allerdings die hohen Einkünfte, die er aus der erfolgreichen Schriftstellerei bezog, so dass er fortwährend unter Finanzschwierigkeiten litt. Sein Verleger richtete ihm einen Hausstand ein, drängte ihn zur Ehe und versorgte ihn mit Büchern, damit er seiner Redakteurstätigkeit weiter nachgehen konnte. Im Vorwort zu Entrevue 161 verwies Fassmann darauf, dass er seine Bibliothek inzwischen mit neuen Drucken und Manuskripten aufgestockt habe, um weitere Totendialoge verfassen zu können ${ }^{78}$. Doch auch Vorschüsse halfen Fassmann nur kurzfristig weiter. In einigen

76 Handgemenge zwischen Fassmann und dem Hofjuden: Bericht aus »Berlin, den 9. Juni 1731«: Ebd., S. 240-242; erhöhte Gehaltszusage des Königs an Fassmann: Bericht aus »Berlin, den 25. Augusti 1731«: Ebd., S. 257. Förster kennt diese Geschichte offenbar nicht; jedenfalls lässt er den Abschied Fassmanns aus Berlin offen: Förster, Friedrich Wilhelm I., Bd. 1, S. 284. Auch Damberg schreibt über den Abschied nur summarisch: DAMBERG, Die politische Aussage in den Totengesprächen, S. 48.

77 David Fassmann, Leben und Thaten des Allerdurchlauchtigsten und Großmächtigsten Koenigs von Preussen Friderici Wilhelmi Biss auf gegenwertige Zeit aufrichtig beschrieben [...], Hamburg/Breslau 1735. Vgl. dazu Förster, Friedrich Wilhelm I., S. 284.

78 Fassmann, Gespräche im Reiche der Todten, Bd. 11, S. 7. 
Weinkellern Leipzigs war er wohlbekannt, weil er dort vor Hoch und Gering die Zeitungen las und gelehrt interpretierte ${ }^{79}$.

In älteren biographischen Skizzen wurde Fassmann negativ beurteilt, was nicht nur moralische, sondern auch fachspezifische Gründe hatte. Georg Wittkowski sieht im Leben des Schriftstellers und Journalisten Fassmann zahlreiche fragwürdige Eigenschaften des Sachsen:

In allen diesen Schriften erweist sich Faßmann als der charakterlose Schriftsteller, dem es nur um Gunst und Gewinn zu tun ist. Er höhnt und lästert, wo es ihm gefahrlos erscheint; er schildert, um seine Leser zu unterhalten, die derbe Männlichkeit Friedrich Wilhelms I. und die sybaritischen Ausschweifungen Augusts des Starken mit derselben, scheinbar in Bewunderung ersterbenden Ausführlichkeit ${ }^{80}$.

Aus literaturgeschichtlicher Sicht unterschied Käthe Kaschmieder zwischen »literarischer Oberschicht « der bedeutenden deutschen Dichter und »literarischer Unterschicht« der Unterhaltungsschriftsteller und Gelegenheitsautoren, zu denen sie Fassmann rechnete ${ }^{81}$. Seine Neigung, kontroverse Ansichten in seinen Dialogen stehenzulassen und nicht aufzulösen, bewertete Kaschmieder als Gewandtheit, aber auch als Charakterlosigkeit. Sie erwartete offenbar Bekenntnisfreudigkeit, d.h. didaktische Lenkung des Lesers in eine moralische Richtung. In der jüngeren Forschung hingegen wurde der politische Schriftsteller mit größerer Sachlichkeit bewertet. Wilmont Haacke hob seine wichtige Rolle für den politischen Modernisierungprozess hervor: Fassmann war für ihn »Vorbereiter der politischen Reformarbeit an den Regierungssystemen der absolutistischen Fürsten $\ll^{82}$.

David Fassmann hatte wenig Neigung, ähnliche Zensurkonflikte in Kauf zu nehmen wie Johann Ehrenfried Zschackwitz. In seiner 83. Entrevue schrieb er im Rahmen seiner Informationen zu Zar Peter dem Großen einige Einzelheiten über Zarin Katharina I. (1683-1728), insbesondere ihre niedere Herkunft und ihr frivoles voreheliches Leben. Daraufhin kam es zur russischen Intervention bei der Dresdner Regierung, die sich in Leipzig nach dem Verfasser erkundigte. Im Stadtarchiv Leipzig ist ein Teil der Zensurakten überliefert. Der dortige Magistrat erfragte schnell den Verleger und den Autor. Am 1. Mai 1725 wurde Fassmann das erste Mal in dieser Angelegenheit vernommen ${ }^{83}$. Der Autor erklärte, er sei sich keiner Schuld bewusst; außerdem habe die inkriminierte Passage bereits in seiner Einleitung zur neu-

79 Damberg, Die politische Aussage in den Totengesprächen, S. 49.

80 Wiткоwsкi, Geschichte des literarischen Lebens in Leipzig, S. 223.

81 Kaschmieder, David Fassmanns Gespräche im Reiche der Toten, S. 5.

82 HAACKE, Die Zeitschrift - Schrift der Zeit, S. 44.

83 Vernehmungsnotiz Fassmanns durch die Leipziger Bücherkommission, 1. Mai 1725: StadtA Leipzig, Ratsstube, Titelakten XLVI, Nr. 174, fol. 7f. 
esten Historie gestanden, ohne dass jemand Anstoß genommen habe. Damit rekurrierte er auf dasselbe Argument, das auch viele Zeitungsherausgeber bei Zensurprobleme anwandten: Es sei ja schon bekannt. Fassmann fuhr fort, Wahrheit sei ihm wichtiger als Respekt vor hohen Persönlichkeiten. Allerdings machte er auch deutlich, dass dies nur für auswärtige Verhältnisse galt: Freimütig betonte er, über den sächsischen Hof und seine Arcana hätte er dergleichen nicht publiziert ${ }^{84}$. Selten findet man die ausdrückliche Anerkennung der Verschwiegenheitspflicht jedes Schriftstellers gegenüber der eigenen Obrigkeit so deutlich in Worte gefasst. Fassmann bat zum Schluss seiner Stellungnahme darum, die Konfiskation seines Heftes aufzuheben. Der größte Teil der Auflage war zu dieser Zeit bereits verkauft - beim Verleger in Leipzig fanden sich nur noch zwei unverkaufte Exemplare -, und der bestehende Zustand führe nur zum Nachdruck durch auswärtige Konkurrenten ${ }^{85}$.

Einen Tag später wandte sich Fassmann mit einer schriftlichen Eingabe (»Memorial«) an die Regierung in Dresden ${ }^{86}$. Bemerkenswerterweise war er zu dieser Zeit offenbar prominent genug, um bei Problemen mit seiner städtischen Obrigkeit direkt an die Landesherrschaft schreiben zu können mit Aussicht auf Gehör. Im Schreiben wies der Schriftsteller auf die gestrige Vernehmung hin und bat um Vermeidung von Ungnade und Bestrafung. Er bot an, den Text für eine nächste Auflage in gewünschter Weise zu überarbeiten. In weitem Bogen wies er darauf hin, dass die Totengespräche bereits im siebten Jahr publiziert würden und bislang Sachsen dadurch kein Schaden entstanden sei. Im Gegenteil - das Werk bringe vielen Menschen Lohn und Brot (»Nahrung«): Fassmann lässt sich dabei als früher Verwender des Arbeitsplatz-Arguments identifizieren.

Die Eingabe blieb jedoch erfolglos. Fassmann wurde wegen der Anfertigung anstößiger Druckwerke mit vier Wochen »leidlichen Gefängnüß« bestraft ${ }^{87}$. Die Akte endet an dieser Stelle. Der Vollstreckung dieses Urteils soll sich Fassmann durch mehrere Ortswechsel (vorübergehende Aufenthalte in Karlsbad und Bayreuth) entzogen haben. Schließlich stellte sich aber heraus, dass es den Russen nicht darauf ankam, durch diplomatischen Druck eine Bestrafung des Urhebers zu erwirken. Wie Fassmann später in seiner Autobiographie schrieb, konnte er in einer Aussprache mit dem russischen Botschafter in Dresden eine Klärung herbeiführen und sich anschließend wieder sicher in Kursachsen und Preußen bewegen ${ }^{88}$.

\footnotetext{
84 Ebd., fol. 8r.

85 Ebd., fol. 8v.

86 Eingabe Fassmanns an die Regierung in Dresden, 2. Mai 1725: StadtA Leipzig, Ratsstube, Titelakten XLVI, Nr. 174, fol. 14.

87 Erwähnung des Urteils: Protokollnotiz des Bücherinspektors Johann Zacharias Trefurth, 3. Mai 1725: StadtA Leipzig, Ratsstube, Titelakten XLVI, Nr. 174, fol. 15.

88 Fassmann, Gespräche im Reiche der Todten, Bd. 15, S. 18.
} 
Der andere Zensurgegner war die kursächsische Geistlichkeit. Fassmann nahm in der 125. Entrevue Stellung zur Mischehe des lutherischen Herzogs Moritz von Sachsen-Zeitz mit der reformierten Prinzessin Maria Amalia von Brandenburg. Da er sich dabei auf Christian Thomasius berief und die Eheschließung positiv kommentierte, zog er sich Pressionen der lutherischen Prediger zu, die in ihrem Hass gegen den Toleranzbefürworter dessen berufliche und bürgerliche Stellung in Leipzig untergruben und ihn zur Flucht nach Brandenburg zwangen ${ }^{89}$. Geistliche Zensur bot die Möglichkeit für unduldsame Zensoren, heterodoxe Konkurrenten per Mobbing auszuschalten und laue Glaubensverfechter mundtot zu machen. Staatlicherseits bot die geistliche Zensur die Möglichkeit, Ruhe in diesem publizistischen Bereich zu wahren. Angesichts der Sprengkraft geistlicher Kontroversen war es tunlich, theologische Themen in Zeitungen zu vermeiden (das tat selbst Fassmann). Damberg berichtet, dass Fassmann infolge seiner Publikationen bei insgesamt vier Zensurzusammenstößen 14 Tage Gefängnis, ansonsten Flucht und dauernde Angst erleiden musste ${ }^{90}$. Dennoch blieb das Schreiben Fassmanns Passion.

Durch diese Erfahrungen war der Herausgeber der Totengespräche hinlänglich gewarnt, sich eine »unangreifbare Darstellungsweise« (Agatha Kobuch) zuzulegen, damit ihn die sächsischen Zensurstellen nicht noch einmal belangen konnten ${ }^{91}$. Erst ein Nachfolgeprodukt, das Fassmann während des ersten Schlesischen Krieges herausbrachte, ein fiktives »Gespräch « zwischen noch lebenden österreichischen und russischen Diplomaten über den Zustand Europas nach dem Tod Karls VI., wurde von der sächsischen Zensur aus Angst vor Preußen verboten ${ }^{92}$.

Es entsprach barocker Geschmeidigkeit, dass Fassmann seinen Landesherren, König/Kurfürst August den Starken, nach dessen Tod 1733 bei den Totengesprächen ausließ. Stattdessen widmete er ihm eine eigene, materialgesättigte Biographie. Dieses Werk - das noch nicht ausgewertet worden ist - soll hagiographische Passagen enthalten. Durch diese Trennung war der Verfasser des Problems enthoben, den Herrscher auf eine Ebene mit seinen viel kritisierten Monarchen zu stellen. So hielt es Fassmann nicht für opportun, etwas zu Augusts vielen Mätressen zu Papier zu bringen, während die

89 Die Szene steht in der 125. Entrevue zwischen Herzog Moritz Wilhelm zu Sachsen-Zeitz und Graf Ernst von Metternich: Fassmann, Gespräche im Reich der Todten, Bd. 8, S. 10671215; die kritikwürdige Stelle befindet sich auf S. 1194f. (n.b.: Im ausgewerteten Exemplar der Staatsbibliothek Berlin ist die fragliche Paginierung doppelt vergeben; die vorausgehende 124. Entrevue ist auf den überschneidenden Seiten 1183-1268 gedruckt!). Zu den Folgen für Fassmann: Kaschmieder, David Fassmanns Gespräche im Reiche der Toten, S. 26.

90 Damberg, Die politische Aussage in den Totengesprächen, S. 44.

91 Ковисн, Zensur und Aufklärung in Kursachsen, S. 167.

92 Ebd., S. 147f. 
Mätressenwirtschaft anderer Potentaten oft erwähnt wird ${ }^{93}$. Auch bei derartig delikaten Bezügen blieb Fassmann in der Dialogform, die die Möglichkeit bot, kontroverse Meinungen nebeneinander stehen zu lassen.

Fassmann lebte je länger je mehr von der tagesaktuellen Berichterstattung, wobei er zunehmend jüngst verstorbene Protagonisten zu Wort kommen ließ. Aber nicht nur Historienwerke und Zeitungen spielten für ihn eine große Rolle, sondern auch eigene Anschauungen vom Geschehen großer Politik. Wilhelm Damberg hat ermittelt, dass in etwa $40 \%$ der Totengespräche mehr oder weniger lange Passagen über den Frieden von Utrecht 1713, seine Entstehung und seine Bedeutung enthalten sind, den Fassmann in den Niederlanden hautnah erleben durfte und über den er zahlreiche Details kannte und nun an allen passenden Stellen zu Papier brachte ${ }^{94}$.

Für Wilhelm Damberg steht Fassmann an der Schwelle zur Aufklärungshistoriographie:

Er [=Fassmann] weiß, dass sein Journal etwas schlechthin Neues ist, und er bringt es unmissverständlich zum Ausdruck, dass es etwas anderes soll und bringen wird als der größte Teil der zeitgenössischen historisch-politischen Publikationen. Berichten diese nur über die Zeitgeschichte und geben sie Kenntnis über Vergangenes, so tun die Totengespräche bewusst den Schritt zur Reflexion und zum Räsonnement über diese Dinge. Sie wählen bereits unter politisch publizistischen Gesichtspunkten aus.

[...] Der Gefahr, in die ihn seine Zeitschrift durch ihren Gegenstand und ihre Art darüber zu räsonnieren bringen kann, ist sich Fassmann durchaus bewusst. Trotzdem aber drängt es ihn unaufhörlich, auf dem Weg über die öffentliche Kritik staatlicher und gesellschaftlicher Zustände helfend einzugreifen ${ }^{95}$.

Sicherlich hat Damberg recht, wenn er die Stellen in Fassmanns Werken betont, an denen dieser sich kritisch über die soziale Ungleichheit auslässt. Auch der Bürger hat seine honnêteté, die ihm der Adel nicht immer zugestehen will. Es ist auch zutreffend, dass Fassmann die zahlreichen Beispiele persönlicher Übergriffe von Standespersonen gegen Privatbedienstete und selbst Amtsvergehen, die unverfolgt bleiben, auflistet. Allerdings darf nicht alles, was im Werk des Journalisten steht, auf die realistische Goldwaage gelegt werden: Wenn Fassmann von machiavellistischem Machtmissbrauch spricht, von Ermordung innenpolitischer Kritiker, von Verboten der Schulen und Versammlungen der Gebildeten, um alle Untertanen dumm zu halten,

93 Auch ohne den heutigen Begriff galt bereits: sex sells: Vgl. KAschmiEDER, David Fassmanns Gespräche im Reiche der Toten, S. 28.

94 Damberg, Die politische Aussage in den Totengesprächen, S. 150.

95 Ebd., S. 176. 
von der herrschaftlichen Stiftung von Unruhen, um die Untertanen besser beherrschen zu können, von der systematischen steuerlichen Ausplünderung der Reichen, um das Volk arm und ohnmächtig zu halten, dann kann Damberg das nicht auf die Praktiken im Alten Reich beziehen: Fassmann dürfte für derartige fürstliche Herrschaft nur sehr wenige Beispiele nennen können - er dürfte es auch fiktiv gemeint haben, als Ultima ratio einer falschen Innenpolitik, vor der er eher warnt, als dass er sie als gegenwärtig annimmt ${ }^{96}$.

\subsection{Die Honorierung des Autors}

Die Dualität des Mediengewerbes zwischen Wirtschaftsbranche und Kulturbereich kommt auch beim Problem der Autorenhonorierung markant zum Tragen. So haben Wirtschaftsgeschichte und Literaturgeschichte diesen Zusammenhang auf höchst unterschiedliche Weise dargestellt, jeweils auf Einzelaussagen gestützt, die die eigene Ansicht untermauerten. Reinhard Wittmann verweist auf die Klage des Hanauer Predigers Aegidius Henning (ca. 1630-1682), der die Abspeisungen der Honorarwünsche der Autoren durch Standard-Gegenargumente der Verleger aufzeichnete ${ }^{97}$. Hier ist die Literaten-Perspektive vorherrschend, die den Verleger als Geizhals charakterisierte. Dieser hingegen argumentierte nämlich ganz ökonomisch in zweierlei Hinsicht, denn erstens war es für ihn sinnvoll, Texte zu möglichst günstigem Preis einzukaufen, zweitens interessierte er sich für Texte, denen er eine Marktgängigkeit zutraute. In der Literaturwissenschaft wird diese ökonomische Haltung in der Regel mit einem marxistisch-moralisierenden Unterton interpretiert, als sei es einem Verleger zuzumuten gewesen, allein um der Hebung des nationalen Kulturerbes willen Vermögensvorleistungen zu erbringen. Henning sprach denn auch von »der betrieglichen Buchführer und Drucker gewöhnliche Außreden und Entschuldigungen« und darf durch diese Moralisierung als Kronzeuge späterer klassenkämpferischer Interpretatoren dienen ${ }^{98}$. In der Tat waren die Rechte des Autors schlecht: Die Rechtsfigur des geistigen Eigentums eines Verfassers an seinem Text war erst im Entstehen begriffen. Der Autor verkaufte seinen Text gegen ein geringes Entgelt an den Verleger, der daran alle Rechte bekam. Reinhard Wittmann karikierte dieses verlegerische Grundverständnis mit den Worten, »der Autor müsse schon dankbar sein, wenn der Verleger sich seines Manuskriptes annehme

96 Ebd., S. 119.

97 Vgl. die längeren kommentierten Quellenzitate bei Wittmann, Geschichte des deutschen Buchhandels, S. 96-98; Quellengrundlage: Aegidius Henning, Gepriesener Büchermacher Oder von Büchern und Bücher machen ein zwar kleines/jedoch lustiges und erbauliches Büchlein, Frankfurt a.M. 1666, bes. S. 112-121. Wittmann, Geschichte des deutschen Buchhandels, S. 96. 
und ihm das Risiko des Selbstverlages erspare «99. Die bekannten Konflikte zwischen Verlegern und Literaten allerdings handelten vor allem davon, dass der belletristische Autor Werke platzieren wollte, die er selbst für literarisch hochstehend hielt oder mit denen er sich viel Mühe gegeben hatte, während der Verleger sich vorwiegend nach den Chancen am Markt richtete. Auch hatte der Verleger sein volles Lager zu bedenken, das das Ergebnis des herrschenden Sortimentssystems war: Er wollte seine Autoren lieber mit Büchern statt mit Honoraren bezahlen, eine Praxis, die bis heute bei Rezensionen wissenschaftlicher Bücher üblich ist. Mancher gelehrte Autor war damit zufrieden, vor allem wenn er über ein unabhängiges Gehalt als Professor oder Lehrer verfügte, wuchs doch auf diese Weise seine heimische Bibliothek schnell $\mathrm{an}^{100}$. Die literarischen Autoren allerdings konnten ihren Lebensunterhalt nicht mit einer wachsenden Büchersammlung belletristischer Titel ihrer Konkurrenten decken. Fürstliche Honorare erhielten nur wenige prestigeträchtige Erfolgsautoren, und auch diese mussten darum kämpfen und ggf. androhen, den Verlag zu wechseln. Die anderen konnten drei Strategien verfolgen: 1. Sie konnten marktgängige Titel verfassen, wenn sie sich vorher mit den Verlegern absprachen, 2. sie konnten durch schmeichlerische Dedikationen an hochgestellte und spendenfreudige Persönlichkeiten Geld- oder andere Geschenke erlangen, 3. sie konnten sich als Auftragsautoren für Gelegenheitstexte (z.B. Gedichte, Huldigungsadressen, Festlieder, Theaterstücke etc.) verdingen. Auch diese frühe Form von Fundraising in eigener Sache war mühsam und mit Demütigungen verbunden. Vor allem hielt die notwendige dauernde Kontaktpflege zu den Verwaltern der Finanzquellen von der dichterischen und schriftstellerischen Tätigkeit $\mathrm{ab}^{101}$.

Ohne die Stellung der Autoren politisch-historischer Publizistik idealisieren zu wollen, kann festgestellt werden, dass diese Autorengruppe eine weniger riskante Stellung innehatte. Im Gegensatz zum Literaten, der sich in seinem Text verwirklichen wollte, um dem Publikum seine literarische Meisterschaft demonstrieren zu können, schrieb der politischen Publizist dasjenige, was seine Leserschaft lesen wollte. Zwar konnte es zwischen Verleger, Redakteur oder Autor zu Meinungsverschiedenheiten kommen, allerdings in der Regel nicht um die Frage, wie man einen authentischen Text herstelle als vielmehr darum, welcher Text für den intendierten Leser der geeignete sei, doch siegte normalerweise der Pragmatismus. Ein Jahresgehalt von 60 bis 70 Reichstaler wurde um 1700 für angemessen gehalten ${ }^{102}$. Das Risiko der Publizisten lag allerdings darin, dass es zahlreiche Konkurrenten gab,

99 Zitat: Ebd., S. 99.

100 Ebd.

101 Ebd., S. 101.

102 Kirchner, Grundlagen des deutschen Zeitschriftenwesens, hier Bd. 1, S. 34; Ernst Herbert Lehmann, Einführung in die Zeitschriftenkunde, Leipzig 1936, S. 124. 
die für Geld ebenfalls Texte zu schreiben bereit waren, so dass die Verleger wegen des Überflusses an Schriftgelehrten für günstige Kosten ihren Bedarf decken konnten. Reinhard Wittmann charakterisiert den sozialen Bodensatz der Textersteller:

Am Ende des 17. Jahrhunderts überschwemmten die verkrachten Studenten, stellungslosen Gelehrten, gestrandeten Hofmeister nicht nur den Buchhandel, sondern entdeckten den Buchmarkt auch als Produzenten, und erwiesen sich damit als Vorgänger und Frühformen des freien Schriftstellers ${ }^{103}$.

Nun ist es bis heute leicht, diese Nicht-Erfolgreichen im Sinne der Konkurrenz um die »Stellen« in der ständischen Gesellschaft und der entstehenden staatlichen Verwaltung und Bildungsbürokratie mit geringschätzigen Kommentaren zu versehen (besonders, wenn der Autor selbst eine Beamtenstelle hat erringen können). Es sollte aber bedacht werden, dass diese Konstellation die Grundlage für die Konkurrenzgesellschaft als Leistungsgesellschaft darstellte: Wer es schaffte, ins soziale System aufzusteigen, dem konnte gratuliert werden, wer es nicht schaffte, musste nach anderen Wegen suchen, sich zu ernähren.

\subsection{Fazit: Frühmoderne Autoren von politischen Periodika}

Der Befund aus dem Zusammenhang mit den »verkrachten Existenzen« bestätigt sich auch auf breiterer Basis ${ }^{104}$. Das frühmoderne Druckmedienwesen beruhte wesentlich darauf, nicht auf die Ausbildung von festen Karrieremustern mit Vollzeitarbeitsplätzen und ständischen Sozialgarantien hinzuwirken, sondern die Vorteile einer Zusammenarbeit mit Personen zu nutzen, die heute mit dem Begriff »Prekariat« bezeichnet würden. Dies waren nur zum Teil Personen, die bereits wegen verschiedener rechtlicher oder sozialer Verstöße aus einer bürgerlichen Laufbahn hinausgestoßen worden waren, sondern eher Personen, die nach ihrer Ausbildung noch gar kein Vollamt erreicht hatten, sich aber dafür qualifizieren wollten. Zum anderen gehörten hierzu auch Personen, die zwischen verschiedenen beruflichen Ausrichtungen standen, d.h. eine Zwischenphase in ihrer Biographie ableisteten.

Dies galt auch für die Historienschriftsteller, etwa für den ersten Redakteur des Theatrum Europaeum, Johann Philipp Abelein. In seinem Fall war es nicht die Wartezeit zwischen Studium und Erreichen einer Planstelle, son-

103 Zitat: Wittmann, Geschichte des deutschen Buchhandels, S. 102.

104 Vgl. die Überlegungen bei ARNDT, Verkrachte Existenzen, S. 114f. 
dern die Entlassung aus dem Schuldienst im Jahre $1630^{105}$. Erst anschließend trat er in den Dienst des Verlegers Matthäus Merian. Auch der letzte Redakteur des Theatrum, Daniel Schneider, musste einen Karriereknick überstehen. Er war Pfarrer in Goldberg gewesen, wo er sich den Neid und die Missgunst der orthodoxen Lutheraner zuzog, die gegen ihn vor allem deshalb agitierten, weil er in Halle a.d. Saale Thomasius gehört hatte. Er musste seine Pfarrei verlassen und trat in den Diest des Grafen Friedrich Ernst zu Solms-Laubach, der als Präsident am Reichskammergericht wirkte und ihn als Hofprediger in Laubach engagierte. In dieser Eigenschaft schrieb er nebenamtlich Historien für den Merian-Verlag. Später trat er in die Dienste eines anderen reichsgräflichen Hauses, der Grafen von Erbach, und wurde Oberpfarrer und Superintendent in Michelstadt ${ }^{106}$. Der Fall des Redakteurs Andreas Stübel zeigte zudem, dass Zeitschriftenschreiben selbst eine Ruhestandsbeschäftigung sein konnte, wenn der Protagonist in eine sozial abgefederte berufliche Untätigkeit entlassen worden war, sich aber zu jung für eine rein kontemplative Existenz fühlte und nach Tätigkeitsfeldern suchte.

Für das Mediensystem ist der große Gewinn an Flexibilität zu konstatieren, den die Freiheit von sozialen Sicherungslasten, aber auch von Verkrustungen in der Mitarbeiterschaft mit sich brachte. Der Betreiber eines Periodikums, meistens der Verleger, wusste in der Regel auch erst hinterher, ob die Ausrichtung seiner Gazette oder seines Journals Absatz finden würde. Auch die Arrangements mit der staatlichen oder kirchlichen Aufsicht bargen stets ein Restrisiko, dass im Extremfall existenzgefährdend sein konnte. Eine absichernde Fürsorgepflicht des Unternehmers für alle Beteiligten hätte vermutlich viele Selbstständigkeitsexperimente gar nicht erst entstehen lassen.

Andererseits war mindestens sprachlicher, oft auch historisch-politischer, d.h. akademischer Sachverstand erforderlich, um ein Periodikum zu betreiben. Der Verleger, in der Regel aus einer kaufmännischen Profession stammend, verfügte nicht darüber, sondern musste die Expertise (möglichst preiswert) einkaufen. Daher war er interessiert, Studenten oder Examinierte zu gewinnen, die noch nicht so hohe Gehaltsforderungen stellen konnten, sondern eine Bewährungschance suchten. Die Autorenschaft war dabei nur eine der gesuchten Tätigkeiten, Lektoren und Korrektoren wurden ebenfalls gebraucht, weil der Verleger auch diese Aufgaben weder übernehmen wollte noch konnte. Die Jugendlichkeit der Mitwirkenden im beruflichen Übergang hatte eine Jugendlichkeit der Produkte zur Folge: Experimentierfreudigkeit war die Regel, die Vielfalt der Formen und die Prozesse der laufenden Ausdifferenzierung wären nicht mit Personen geglückt, die stets vorrangig an der Bewahrung des Guten und Alten interessiert gewesen wären. Das »Neue«

105 Darauf verweist Bingel, Das Theatrum Europaeum, S. 24.

106 Ebd., S. 102f. 
in den periodischen Druckmedien war also in mehrfacher Hinsicht Prinzip. Dem Mediensystem brachte es viele Vorteile und eine fortdauernde Existenz mit kulturgeschichtlichen Folgen, die hier nicht alle darzustellen sind, auch wenn die sozialen Kosten nicht übersehen werden dürfen. 


\section{Distribution: Buchhandel und Postwesen}

Im Prozess der Zirkulation der Nachrichten steht zwischen dem Autor eines Berichts und dem Leser der organisatorische, technische und logistische Fertigungsprozess des Schriftstücks, das am Ende rezipiert und auch archiviert werden kann, so dass es - in vielen Fällen - bis heute zur Verfügung steht. Der Buchdruck stellte dabei ein Element der longue durée dar, denn seine technische Entwicklung war bereits im Laufe des 15. Jahrhunderts in einer Weise verfeinert, dass sein Betrieb in den folgenden mehr als 350 Jahren im Wesentlichen ähnlich verlief ${ }^{1}$. Grundlegende Weiterentwicklungen fanden erst im frühen 19. Jahrhundert statt, so dass das Verfahren an dieser Stelle nicht ausgebreitet zu werden braucht ${ }^{2}$. Dies bedeutete aber keinesfalls das Fehlen von Ausdifferenzierungsprozessen im Druckgewerbe. Im Gegenteil lässt sich bereits für das 16. Jahrhundert eine beträchtliche Vielfalt der druckgewerblichen Berufe feststellen. Im Ständebuch des Jost Amman von 1568, einem kulturhistorisch wichtigen Überblick über die Berufswelt in den großen oberdeutschen Städten, finden sich nicht weniger als acht unterschiedliche Berufe, die im Rahmen der Druckwerkeproduktion mitwirkten: Der Schriftgießer, der Holzschnittzeichner (Reißer), der Formschneider, der Buchdrucker, der Buchmaler (Brieffmaler), der Buchbinder und der Pergamentmacher (»Permennter «) $)^{3}$. Hinzu kam die professionelle Herstellung des bedruckten Materials, wobei das aufwendig zu erstellende und daher teure Pergament weitgehend durch Papier ersetzt wurde - auch der Papiermacher (»Papyrer«) fehlte bei Amman nicht ${ }^{4}$.

1 Claus W. Gerhardt, Warum wurde die Gutenberg-Presse erst nach über 350 Jahren durch ein besseres System abgelöst?, in: Ders., Beiträge zur Technikgeschichte des Buchwesens. Kleine Schriften, 1969-1976, Frankfurt a.M. 1976, S. 77-100; WiLkE, Grundzüge der Medien- und Kommunikationsgeschichte, S. 13.

2 Zu Gutenberg und zum Verfahren: Dobras, Gutenberg - aventur und Kunst, pas.; Füssel, Gutenberg und seine Wirkung, pas.; Hans-Jürgen Wolf, Schwarze Kunst. Eine illustrierte Geschichte der Druckverfahren, Frankfurt a.M. ${ }^{2} 1981$; GIESECKE, Der Buchdruck in der frühen Neuzeit, pas.; Hans Bohrmann (Hg.), Zeitungsdruck. Die Entwicklung der Technik vom 17. zum 20. Jahrhundert. Mit Beiträgen von Martin Welke und Boris Fuchs, München 2000.

3 Jost Amman, Eygentliche Beschreibung Aller Stände auff Erden/Hoher und Nidriger/Geistlicher und Weltlicher/Aller Künsten/Handwercken und Händeln [...], Frankfurt a.M. 1568; ND: ders., Das Ständebuch. Herrscher, Handwerker und Künstler des ausgehenden Mittelalters. 114 Holzschnitte mit Versen von Hans SACHS, Köln 2006.

4 Vgl. den Überblick zur Papierherstellung von Günter BAYER/Karl Pichol, Papier. Produkt aus Lumpen, Holz und Wasser, Reinbek b. Hamburg 1986; Günter BAYERL, Die Papiermühle. Vorindustrielle Papiermacherei auf dem Gebiet des alten deutschen Reiches. Technologie, Arbeitsverhältnisse, Umwelt, 2 Bd., Frankfurt a.M. u.a. 1987. 


\subsection{Messen, Buchführer und Kolporteure}

Der offizielle Buchhandel war im Reformationszeitalter bereits voll etabliert, erfuhr aber wegen der zunehmenden Quantitäten an Büchern eine starke Ausdehnung. Diese Branche bestand aus Kaufleuten, die eine Spezialisierung im Kauf und Verkauf von Büchern hatten ${ }^{5}$. Die Händler waren in ihrer jeweiligen Heimatstadt offiziell als Bürger etabliert, meistens in einer Korporation (Zunft oder Kaufmannsverbindung) organisiert und unterlagen der obrigkeitlichen Aufsicht. Der Verkauf am Wohnort stellte allerdings nur einen Teil ihrer Tätigkeit dar, daneben spielte im Reformationsjahrhundert der Wanderhandel noch eine zentrale Rolle ${ }^{6}$. Der Beruf wird als äußerst kräftezehrend beschrieben:

Diese Strapazen des Reisebuchhandels dürfen nicht unterschätzt werden - während die kleinhandwerklichen Buchbinder ein zwar kümmerliches, doch hohes Armenhäusleralter zu erreichen pflegten, und die gutsituierten Buchdruckerherren - nach den Porträtstichen zu schließen - hauptsächlich von der Fettleibigkeit bedroht waren, starben zahlreiche Buchhändler ausweislich ihrer Leichenpredigten entkräftet und abgearbeitet im besten Mannesalter?

Drucker und Verleger arbeiteten an der Schnittstelle zwischen drei sozialen Großgruppen der Frühmoderne. Während die Drucker dem Handwerk entstammten, rechneten sich die Verleger den kaufmännischen Berufen zu. Die Autoren und auch die Leser ihrer Produkte hingegen entstammten überwiegend den gebildeten Ständen, vor allem dem Adel und dem akademischen Bürgertum. Es lag daher nahe, dass die Fremdwahrnehmung der Druckgewerbetreibenden durch gebildete Autoren eher distanziert war. Ein verbreiteter Topos unterstellte diesem Berufsstand blanken Materialismus und schonungsloses Gewinnstreben. Martin Luther darf als Patron für diese Anschauung gelten, denn er schrieb im Sommer 1521 von der Wartburg an Spalatin: »Was scheint denn ein solcher Drucker zu denken als: Mir genügt es, dass ich Geld mache: die Leser mögen sehen, was sie wie lesen « ${ }^{8}$.

Anders als die Theologie oder andere Wissenschaften war die Buchdruckerei zunächst eine ökonomische Betätigung, die hohe Kapitaleinsätze

5 Michael Giesecke spricht vom »Handelsnetz als Medium der typographischen Kommunikation«: GieseCKe, Der Buchdruck in der frühen Neuzeit, S. 391-399.

6 Zum frühen Buchhandel: Heinrich Grimm, Die Buchführer des deutschen Kulturbereichs und ihre Niederlassungsorte in der Zeitspanne 1490 bis um 1550, in: AGB 7 (1967), Sp. 1153-1772; vgl. dazu auch Wittmann, Geschichte des deutschen Buchhandels, S. 31.

7 Zitat nach Wittmann, Geschichte des deutschen Buchhandels, S. 85.

8 Brief an Spalatin vom 15. August 1521, zit. nach Horst Wenzel, Mediengeschichte vor und nach Gutenberg, Darmstadt 2007, S. 20. 
erforderte. Johannes Burkhardt formulierte diesen Umstand wie folgt: $» D i e$ Druckkunst war trotz allem noch teure Spitzentechnologie mit beschränktem Bedarf «?. Viele gelernte Drucker begannen ihre Selbstständigkeit mit großem Engagement und ebensogroßen Hoffnungen, um wenig später bankrott zu gehen. Insofern sind an die Entwicklung des neuen Mediums auch wirtschaftsgeschichtliche Maßstäbe anzulegen: Wissenstransfer hatte zunächst einen ganz profan finanziellen Unterbau, um durchführbar und später dauerhaft zu werden. Drei Aspekte trafen zusammen und bedurften im Laufe der Medienentwicklung immer wieder der Austarierung: Zum einen die Idee, der Text, den der Autor oder eine interessierte gesellschaftliche Gruppe vervielfältigt sehen wollte, zum anderen die Ökonomie der Medienproduzenten, die jedesmal fragten: Wer bezahlt das alles - der Markt oder doch der Verfasser?, und drittens die Obrigkeiten geistlicher und weltlicher Ausrichtung, die argwöhnten, durch eine neue Idee in gebundener Fassung könne die überkommene Ordnung in Gefahr geraten.

Buchdruck war praktisch nicht ortsgebunden. Das erscheint auf den ersten Blick als paradox, waren die Druckerpressen doch in die tragende Holzstruktur der Gebäude eingefasst, um den notwendigen Anpressdruck erzeugen zu können. Drucklettern und sonstiger Zubehör ließen sich allerdings nicht nur über Land transportieren, sondern auch gegen Geld leihen. Die fertigen Druckprodukte waren ebenfalls transportabel - wenn auch in beiden Fällen wegen der hohen Kosten Beschränkungen bestanden. Zwischen den übrigen Gewerben der frühneuzeitlichen Städte und den Buchdruckern bestand ein Spannungsverhältnis: Da der Buchdruck erst entstanden war, als die übrigen Handwerke bereits auf eine beträchtliche organisatorische Tradition zurückblicken konnten, fiel eine nahtlose Integration schwer. Auch eignete sich das hergestellte Gut, das bedruckte Blatt oder Buch, nicht zum gleichförmigen Gebrauch: Im Gegensatz zu einem Schuh oder einem Brot besaß ein Druckwerk einen höheren Grad von Individualität - die auch durch die Gleichförmigkeit der Drucke einer Auflage nicht zunichte gemacht wurde. Die Kunden dagegen strebten nach dem »Gebrauch « des vorigen Buches den Kauf eines neuen, anderen Buches an. Dadurch unterlag die Buchproduktion von Anfang an einer sehr viel höheren Dynamik als alle anderen Handwerke, in denen zwar auch Veränderungen eintraten, jedoch mit langsamerer Geschwindigkeit. Michael Giesecke stellt ausführliche Überlegungen zur eigentlich unhandwerklichen Struktur der Buchproduktion und -distribution an: Nicht die Sicherung von Subsistenz in Gestalt einer Produktion für einen geschlossenen Markt war das Ziel des Buchdrucks, sondern immer weitere Expansion - ein Ideal, das nicht vom »Gemeinwohl«, sondern vom »Eigen-

9 Vgl. zur ökonomischen Dimension des Buchgewerbes im 16. Jahrhundert: BuRKHARDT, Reformationsjahrhundert, S. 25. 
nutz« geprägt war ${ }^{10}$ ! Winfried Schulze hat für das 16. Jahrhunderts ein starkes Anwachsen des Eigennutz-Gedankens konstatiert. Das bedeutete nicht, dass Eigennutz vorher nicht vorgekommen wäre, aber nun waren auch die Theoretiker willens, dem Eigennutz eine positive Konnotation zuzuschreiben, wo zuvor die christliche Orientierung auf das jenseitige Gottesreich und auf den Nächsten unumstößlich gewesen waren ${ }^{11}$.

Die Dynamik koppelte die Buchherstellung auf diese Weise stärker an die Marktgesetze: Zusätzlich zum Bestreben der Bedarfsdeckung der Nachfrage nach Büchern generell konkurrierten Bücher verschiedenen Inhalts miteinander. Die Gestaltung eines Druckes konnte ihm auch in Fällen, in denen ein Überangebot von Druckwerken auf die Kunden wartete, gute Marktchancen eröffnen. Die zeitliche Entstehung nach der berufsständischen Organisation der zünftigen Handwerke und die damit gelegentlich verbundene Geringschätzung von Seiten der älteren Professionen war mit den bekannten Härten verbunden. Das Problem der »Überbesetzung" trat hier besonders früh und scharf in Erscheinung und wurde noch dadurch gemehrt, dass zahlreiche »Brot- oder Stellungslose « in diese Profession strebten ${ }^{12}$. Dies blieb nicht ohne Auswirkungen auf die Methoden, mit denen die Druckgewerbetreibenden bei ihrer Konkurrenz zu Werke gingen. Klagen und Prozesse um falsche Auflagenzahlen, unfertige oder unkorrekt gearbeitete Bücher, verschleierte Druckorte, Fehler bei der Paginierung, Pseudonyme, unrechtmäßige Nachdrucke und geistiger Diebstahl in breitem Umfang waren so häufig, dass sie keinesfalls als Ausnahmen bezeichnet werden können. »Schleuderer«, »Höckerer«, »Marks-Sänger« oder »Scarteken-Träger« wurden die Abweichler von der Norm genannt, Begriffe, die Adrian Beier 1690 in seiner Beschreibung des zeitgenössischen Buchwesens zur pejorativen Kennzeichnung einer ökonomischen Verwilderung der Verkehrssitten verwandte ${ }^{13}$. Beier sah klar die Doppelfunktion des Buchhändlers, Kaufmann und Gelehrter in einem sein zu müssen, mit allen daraus resultierenden Problemen. Die Studie ist vor allem deshalb heute noch wertvoll, weil Beier nicht in das Gejammer vieler Gelehrter einstimmte, die im Chor das Lied von der ständigen Verachtung und Benachteiligung des eigenen Standes gesungen haben, und dies mit einer Lautstärke, die jeden Protestruf anderer sozial bedrängter Personen oder Gruppen der Zeit mühelos übertönte. Trotz dieser internen Härten bil-

10 Vgl. die zahlreichen Bemerkungen hierzu bei: Giesecke, Der Buchdruck in der frühen Neuzeit, S. 331-333, 393-399 u. 468.

11 Zur Entwicklung des »Eigennutz«-Gedankens im ökonomischen Denken des 16. Jahrhunderts: Winfried Schulze, Vom Gemeinnutz zum Eigennutz. Über den Normenwandel in der ständischen Gesellschaft der Frühen Neuzeit, in: HZ 243 (1986), S. 591-626.

12 Hinweis von Estermann, Memoria und Diskurs, S. 49.

13 Adrian BeIER, Kurtzer Bericht von Der Nützlichen und Fürtrefflich Buch-Handlung und Deroselben Privilegien, Jena 1690, S. 14, zit. nach Estermann, Memoria und Diskurs, S. 48, Anm. 5. 
deten die Buchdrucker nach außen ein besonderes Selbstbewusstsein aus: Sie hielten sich nicht für Handwerker, sondern betrachteten den Buchdruck als eine »freie Kunst«, sich selbst mithin als Künstler.

Bei Reinhard Wittmann werden drei Phasen der Verkehrsformen des Buchhandels unterschieden, wobei er sich auf die klassische Buchhandelsstudie von Friedrich Kapp und Johann Goldfriedrich stützt: 1. Periode des Wanderverkehrs von 1450 bis 1564; 2. Periode des $» M e ß-$ und Tauschhandels«, beginnend mit dem ersten Willerschen Messkatalog 1564; 3. Periode des Konditionssystems, das 1764 durch Philipp Erasmus Reich in Leipzig eingeführt worden ist ${ }^{14}$. Die Übergänge waren, so Wittmann, in Wirklichkeit nicht so scharf, dass fixe Daten angegeben werden könnten. Stets habe es mehrere gültige Handelssysteme gegeben. Der Tauschhandel habe sich zu Beginn des 17. Jahrhunderts als beherrschendes System durchgesetz ${ }^{15}$. Diese Form begann allerdings schon Jahrzehnte vor 1764 nach und nach zu zerfallen $^{16}$.

Reinhard Wittmann zählt vier Gruppen auf, die im 17. und 18. Jahrhundert mit Büchern handelten: 1. Der reguläre Buchhändler (»Verlegersortimenter «), der zu den Messen nach Frankfurt und Leipzig mit seinem Sortiment reiste. Normalerweise tauschte er seine Bücher gegen die anderer Produzenten ein. Ziel war dabei, ein Sortiment nach Hause zu bringen, von dem er sich hinreichende Marktchancen erwartete ${ }^{17}$. 2. Die »Druckerverleger«, von denen ebenfalls viele die Messen besuchten. Oft standen sie in dauerhaften Beziehungen zu öffentlichen Einrichtungen des Staates oder der Kirche, als Hof-, Kanzlei-, Universitäts- oder Ratsbuchdrucker. Ihre Herren hatten sie nicht selten mit einem Monopol in ihrer Heimatstadt ausgestattet. Ihre Druckereien bedienten vor allem den lokalen Markt. Sie druckten mehrheitlich keine wissenschaftliche Literatur, sondern »kurrente Materien«, d.h. Gebet- und Erbauungsbücher, Ratgeberliteratur, Prognostiken, Flugschriften oder Gelegenheitsgedichte sowie Schulreden und obrigkeitliche Verlautbarungen, auch die lokalen Zeitungen ${ }^{18}$. 3. Die Buchbinder stellten mit 1.500 Firmen bereits eine größere Gruppe, von der einige ebenfalls mit Büchern handelten. Ihre Gewerbe waren allerdings klein, normalerweise waren sie in einer Zunft stadtweit oder landesweit organisiert. Die Buchbinder hatten

14 Wittmann, Geschichte des deutschen Buchhandels, S. 75. - Bezug: Friedrich Kapp/Johann GoldFriedrich, Geschichte des deutschen Buchhandels, 4 Bd. u. Registerbd., Leipzig 18861923 (ND Leipzig 1970).

15 Verfahren im Tauschhandel: Wittmann, Geschichte des deutschen Buchhandels, S. 89-91.

16 Reinhard Wittmann hat diesen Prozess am Beispiel der Nachdruckproblematik um die Mitte des 17. Jahrhunderts nachgezeichnet: Wittmann, Der gerechtfertigte Nachdrucker, S. 293-320.

17 Die »Verlegersortimenter« bildeten 1650138 Firmen; 1740 waren es 187: Ders., Geschichte des deutschen Buchhandels, S. 78-81.

18 Die »Druckerverleger« bildeten ca. 330 Firmen: Ebd., S. 81f. 
das Monopol, als einzige mit gebundenen Büchern Handel treiben zu dürfen. Auch ihr Programmschwerpunkt lag auf der intensiven Literatur, auf den Kalendern oder erbaulichen Schriften, aber auch auf kleinen Romanen. Im Laufe des 18. Jahrhunderts gerieten einige von ihnen in Beziehungen zu Verlegern und wurden deren Filialen. Buchbinder traten auch als Wanderhändler in Erscheinung ${ }^{19}$. 4. Die »Auch-Buchhändler«, d.h. Gewerbetreibende, die außer anderen Handelsgütern auch gedruckte Schriften anboten. Daneben kamen Kupferstecher, Geistliche oder Studenten infrage. Auch die große, heterogene Gruppe der Wanderhändler oder Kolporteure führte nicht selten Schriften mit sich ${ }^{20}$.

Daneben gab es die »Buchführer« oder »Umträger«, d.h. fahrende Buchhändler, die mit ihrem Sortiment vor allem leicht transportabler Texte über Land zogen. Heinrich Grimm zählte mehr als 1.000 derartige fliegende Händler für den Zeitraum von 1490 bis $1550^{21}$. Sie verstießen nicht nur gegen die Zensur, sondern auch gegen Gewerbeordnungen, da sie in der Regel nicht regulär an Märkten und anderen Verkaufsgelegenheiten akkreditiert waren. Einige prominente fliegende Buchhändler bezahlten ihre Tätigkeit mit dem Leben. Ein prominentes Beispiel war der Nürnberger Buchführer Hans Hergot. Er reiste 1527 mit Flugblättern und Nachdrucken durch die sächsischen Territorien, um auf Märkten seine Waren anzubieten. In Leipzig wurde er von zwei Studenten denunziert, bei denen die Flugschrift Von der neuen Wandlung eines christlichen Lebens gefunden worden war. Im Rahmen der folgenden Ermittlungen legte man ihm weitere »aufrührerische« Traktate zur Last. Hergot wurde zum Tode verurteilt und mit dem Schwert hingerichtet ${ }^{22}$.

Der illegale »fliegende« Buchhandel hatte etwas Transitorisches: Besonders in Zeiten des Umbruchs, der staatlichen und kulturellen Unordnung blühte diese Form des Vertriebs. Sie profitierte von Schwächen der staatlichen Marktkontrolle, die jeweils nur für eine bestimmte Zeit galt. Anschließend bekamen die Behörden die Verhältnisse wieder »in den Griff«, während die regulären Buchhändler ihren Handelsbereich ebenfalls wieder besser kontrollieren konnten. Der Kolporteur wurde wieder in eine Randrolle zurückgedrängt - bis zur nächsten Umbruchsphase. Wie ein Nachklang aus dem konfessionellen Zeitalter erscheint der $\S 9$ des bayerischen Zensurmandats von 1769 , in dem es hieß, dass $\gg$ die Erfahrung lehret, daß die meisten schädlichen Bücher und Broschüren durch die herumhausirenden Krämer und sogenannten Kräxenträger in Unsere Lande hereinschleichen ${ }^{23}$.

19 Die Buchbinder bildeten ca. 1500 Firmen: Ebd., S. 82f. - Zum Monopol des Handels mit gebundenen Büchern: Ebd., S. 94.

20 Die »Auch-Buchhändler« lassen sich nicht quantifizieren: Ebd., S. 83f.

21 Grimm, Die Buchführer des deutschen Kulturbereichs, Sp. 1153-1772.

22 Schwitalla, Flugschrift, S. 22; Wittmann, Geschichte des deutschen Buchhandels, S. 48.

23 Zit. nach Lindemann, Deutsche Presse bis 1815, S. 36. 
Übrig blieben die meist kleineren Buchhändler, die ihr Sortiment vor allem auf »kurrente Waren« ausrichteten, die regelmäßig an das Publikum in der eigenen Region verkauft werden konnten. Dazu gehörte das erbauliche Schrifttum, soweit es die herrschenden Bekenntnisse betraf. Daneben wurden aber auch Kalender oder Sensationsschriften aller Art regelmäßig verkauft. Die Buchhändler wussten, dass es hierfür unabhängig von medialen Großwetterlagen stets einen Markt gab.

Durch den Dreißigjährigen Krieg wurde der Buchhandel, wie die meisten Handelsbranchen, schwer geschädigt, und zwar sowohl durch die Verarmung der Kundschaft als auch durch die Bedrohungen und Schäden infolge der Unsicherheit der Verkehrswege. Erst um 1720 hatte sich im Allgemeinen der Vorkriegszustand wieder eingestellt. Einige Großtrends allerdings setzten sich fort, vor allem der Rückgang des Lateinischen zugunsten der deutschen Volkssprache und des Französischen als wichtigster Fremdsprache, der Rückgang der theologischen Literatur insbesondere nach 1730 von ca. $40 \%$ auf nur noch $6 \%$ um 1800. Die historischen Themen machten ca. $16 \%$ des Handelsvolumens aus ${ }^{24}$. Dass dieser ökonomische Einbruch das Zeitungswesen ausließ, wurde oben bereits erwähnt.

Die wichtigsten Termine des internationalen Buchhandels in Mitteleuropa waren die Buchmessen in Frankfurt a.M. und Leipzig ${ }^{25}$. Im frühen 16. Jahrhundert trafen sich mehr als 200 Buchhändler aus 70 bis 80 europäischen Städten in Frankfurt a.M. zur Messe, wo sich auch Papierhändler, Typengießer, Buchbinder sowie schreibende und lesende Kundschaft einfanden. Die Frankfurter Ostermesse begann mit dem Sonntag Judica, der interessierte Tross konnte nach Ostern weiter nach Leipzig ziehen, wo ab dem Sonntag Jubilate Bücher gehandelt wurden. Die Herbstmessen folgten in ähnlicher Weise aufeinander: Zuerst wurde ab Mitte September in Frankfurt gehandelt, dann ab dem Sonntag nach Michaelis in Leipzig ${ }^{26}$. Gehandelt wurde offiziell acht Tage lang, die sich durch hektisches Treiben auszeichneten. Alle

24 Wittmann, Geschichte des deutschen Buchhandels, S. 77f.

25 Buchmessen in der Frühmoderne: KoсH, Brücke zwischen den Völkern; Wolfgang BRÜCKNER, Die Gegenreformation im politischen Kampf um die Frankfurter Buchmessen. Die kaiserliche Zensur zwischen 1567 und 1619, in: Archiv für Frankfurts Geschichte und Kunst 48 (1962), S. 67-86; Monika Toeller, Die Buchmesse in Frankfurt am Main vor 1560. Ihre kommunikative Bedeutung in der Frühdruckzeit, Diss. München 1983; Augustinus H. LaEven, The Frankfurt and Leipzig Book Fairs and the History of the Dutch Book Trade, in: Christiane BerKvens-Stevelinck u.a. (Hg.), Le Magazin de l'Univers. The Dutch Republic as the Center of the European Book Trade, Leiden 1992, S. 185-197; Jürgen Schlimper, Nachrichten für die Messestadt aus fernen Ländern. Zum Zusammenhang von Leipziger Presse- und Stadtentwicklung zur Mitte des 17. Jahrhunderts, in: Hartmut Zwahr/Thomas Topfstedt/Günter Bentele (Hg.), Leipzigs Messen 1497-1997. Gestaltwandel, Umbrüche, Neubeginn, Bd. 1, Köln/Wei$\mathrm{mar} /$ Wien 1997, S. 167-179.

$26 \mathrm{Zu}$ den Terminen: Laeven, The Frankfurt and Leipzig Book Fairs, S. 186f. - In Frankfurt wurde der Beginn der Messe 1710/11 auf den Sonntag Quasimodogeniti verschoben und 
Handelspartner hatten schon zuvor Kataloge gefertigt und am besten schon verteilt, so dass die Handelstage den Autopsien der Bücher und den Preisverhandlungen samt Kreditierungen und Tauschvereinbarungen vorbehalten blieben. Mit Einholung der Handelsflagge und Glockenklang am letzten Tag mussten der Handel eingestellt werden, wenigstens offiziell. Zwar beobachteten die Obrigkeiten - der Frankfurter Magistrat, der Bücherkommissar des Erzbischofs von Mainz, später die Kaiserliche Bücherkommission - das Handelstreiben intensiv, doch war bei allen herrschaftlichen Eingriffen nicht beabsichtigt, dass der Buchhandel sich verlagerte.

Erst die Verfestigung der prokatholischen Dominanz in Frankfurt a.M. nach dem Westfälischen Frieden führte allmählich dazu, dass sich das Schwergewicht des Buchhandels nach Leipzig verlagerte, insbesondere das norddeutsch-protestantische Bezugsfeld. Monika Estermann spricht von einem »Auseinanderdriften« der Handelsverhältnisse in einen vorwärtsstrebenden Nordosten mit Zentrum Leipzig und einen zurückbleibenden Südwesten, zu dem auch Frankfurt a.M. gehörte, aber immer weniger dominierte $^{27}$. Dazu trugen die verschiedenen konfessionellen Medienkulturen bei: Während in Frankfurt trotz des lutherischen Bekenntnisses der Bürgerschaft die Dominanz der katholischen kaiserlichen Bücherkommission mit gleichzeitigem starkem päpstlichen Einfluss ungebrochen war, genoss Leipzig als Handelsmetropole des Ostens weitgehende Freiheiten. Die Buchhändler und Verleger der Stadt bildeten eine familiäre und geschäftlich eng vernetzte Gruppe, die im Rang mit den übrigen Kaufleuten konkurrierte und nicht selten vor denselben rangierte. Dieser ökonomische Rang, verbunden mit der sozialen Blockbildung, sicherte den Buchhändlern Einfluss auf das Stadtregiment: Bürgermeister und Rat riskierten ungern Konflikte und schauten bei Zensurproblemen nicht selten durch die Finger ${ }^{28}$.

Hatte Frankfurt mit lateinischer Literatur viel Geld verdient, profitierte Leipzig vom immer größeren Anteil deutschsprachiger Literatur. Auch nutzte die erneut aufblühende Städtekultur in Thüringen und Sachsen dem Leipziger Buchhandel und -gewerbe als primärer Markt: Keine andere Region im Alten Reich war derart hoch verstädtert wie die sächsischen Lande ${ }^{29}$. Vor

überschnitt sich in der letzten Woche mit Leipzig, was der Pleißestadt nützte: WittmanN, Geschichte des deutschen Buchhandels, S. 85f.

27 Estermann, Memoria und Diskurs, hier S. 47.

28 Vgl. dazu die Überlegungen von Hazel Rosenstrauch, Buchhandelsmanufaktur und Aufklärung. Die Reformen des Buchhändlers und Verlegers Ph.E. Reich (1717-1787). Sozialgeschichtliche Studie zur Entwicklung des literarischen Marktes, Frankfurt a.M. 1986, S. 29.

29 Dass Sachsen keineswegs nur aus Leipzig und Dresden bestand, hat Katrin Keller eindrucksvoll dokumentiert: Katrin KeLLer, Kleinstädte in Kursachsen. Wandlungen einer Städtelandschaft zwischen Dreißigjährigem Krieg und Industrialisierung, Köln/Weimar/Wien 2001; vgl. auch dies., Saxony. Rétablissement and Enlightened Absolutism, in: German History 20 (2002), H. 3, S. 309-331. 
allem die drei Verlage Gleditsch, Fritsch und Weidmann bedienten diese Leserschaft, Unternehmen, die längst schon den Einmannbetrieb hatten hinter sich lassen können ${ }^{30}$. Die Häufung von historisch-politischen Zeitschriften mit Verlagsort Leipzig ist daher keineswegs ein Zufall. Das Zeitungswesen Leipzigs stellt neben Hamburg den wichtigsten Großmarkt des 18. Jahrhunderts dar. Ein DFG-Forschungsprojekt, geleitet durch Michael Nagel, untersucht diesen Pressestandort mit dem Ziel, eine ebensolche biobibliographische Grundlagenarbeit zu erstellen, wie bereits von Holger Böning und Emmy Moepps für Hamburg und Umgebung verfügbar gemacht wurde ${ }^{31}$.

Die Frankfurter Buchhändler versuchten, ihre bis dahin gültige Praxis gegen »Neuerungen« aus dem Norden zu schützen und konzipierten 1669 eine Neue Ordnung und Artikel für Buchhändler, Buchdrucker und Buchbinder, um sie beim Reichstag einzureichen und als Reichsgesetz beschließen zu lassen: Nur Buchhändler sollten am Chargehandel teilnehmen, Buchbinder und Buchdrucker aber ausgeschlossen bleiben. Juden sollte der Handel mit Büchern untersagt werden, als Ausbildungserfordernis wurde eine fünfjährige Lehre und eine zusätzliche zweijährige Dienstzeit als Geselle für notwendig gehalten. Bücherprivilegien sollten bekräftigt werden, Nachdruck ohne ausdrückliche Zustimmung des Erstverlegers verboten sein. Ferner sollten während der Messe keine Buchauktionen stattfinden und die Frankfurter Büchertaxe aufgehoben werden ${ }^{32}$. Durchsetzen konnten sie sich damit allerdings nicht, und der Leipziger Aufstieg wurde dadurch nicht beeinträchtigt.

Im Regensburg des Immerwährenden Reichstags wartete nicht nur eine Schar von Novellisten auf reproduzierbare Texte, sondern auch einige Drucker und Verleger auf Aufträge. Die Veröffentlichung von Traktaten in gedruckter Form schloss stets die Möglichkeit mit ein, dass die Drucke nicht nur für eine geschlossene Gruppe von Empfängern gedacht war, sondern in den freien Handel gelangte und ihr Inhalt damit eine unkontrollierbare Verbreitung fand. Bereits Johannes Haller hatte im Zusammenhang mit der antifranzösischen Publizistik vermutet, dass die gesamte Leserschaft im Reich als Zielgruppe gedacht war, nicht allein das engere politische und administrative Spitzenpersonal ${ }^{33}$. Die Regensburger Drucker produzierten nicht allein das, was offiziell von Kaiser und Reich zur Veröffentlichung bestimmt worden war, sondern die Eingaben aller Interessenten, die dazu einen Auftrag

30 Vgl. Estermann, Memoria und Diskurs, S. 48.

31 Michael Nagel, Das DFG-Projekt einer Pressebibliographie für Leipzig. Erfahrungen und Zwischenergebnisse, in: Astrid Blome (Hg.), Zeitung, Zeitschrift, Intelligenzblatt und Kalender. Beiträge zur historischen Presseforschung, Bremen 2001, S. 21-34.

32 Estermann, Memoria und Diskurs, S. 49; Jürgen Gramlich, Rechtsordnungen des Buchgewerbes im Alten Reich. Genossenschaftliche Strukturen, Arbeits- und Wettbewerbsrecht im deutschen Druckerhandwerk, in: AGB 41 (1994), S. 10-23.

33 Haller, Die deutsche Publizistik in den Jahren 1668-1674, S. 10f., zit. nach Friedrich, Drehscheibe Regensburg, S. 517, Anm. 2982. 
erteilten. Im Weiteren kamen selbst Schriften zum Druck, deren Annahme durch die Mainzer Dictatur verweigert worden war. Manchmal reichte schon die Androhung eines Reichsstands oder einer reichsständischen Gruppe, man werde eine Deduktion »in offnen druck bringen und public werden « lassen, um die Akzeptanz selbst gegen Widerstand durchzusetzen, so oder so ${ }^{34}$.

Es wurde gebräuchlich, dass mehr Drucke gefertigt wurden, als zunächst beauftragt waren, weil die Drucker zusätzlichen Absatz erwarteten. Als 1689 das französische Kriegsmanifest in Regensburg zum limitierten Druck gegeben wurde, um die Exemplare nur an die Gesandten gegen Unterschrift und Siegel auszuhändigen, erhielt der Drucker einen Aufschlag auf den Preis, weil er auf sonstigen Gewinn aus dem Weiterverkauf verzichten musste ${ }^{35}$. Ein anderer Drucker erklärte im selben Jahr, als er wegen einer Flugschrift gegen Wilhelm III. von Oranien zur Rede gestellt wurde, ein Geistlicher von St. Jakob habe ihm den Text gegeben »mit der Versicherung, dass es reißend abgehen würde $\ll^{36}$. Bezeichnenderweise war dies ein gängiges Argument zur Entlastung des Druckers und kennzeichnete zudem die herrschende Praxis. Wohlgemerkt vollzogen sich diese Begebenheiten flankiert durch die städtische Zensur in der Reichstagsstadt. Das Risiko durch eine gefährliche Flugschrift war überschaubar: Selbst wenn es zu einem Protest oder sogar zu einem Verbot kam, war es ein weiter Weg, bis wirklich ernsthafte Sanktionen ergriffen wurden. Die herrschende politische Konkurrenz sorgte dafür, dass ein angegriffener Drucker sich an die Seite um Hilfe wenden konnte, die den Text beschafft hatte, und bei Fürsprache ließ sich der Verstoß oft in ein Delikt minderen Ranges herabhandeln. Es kann davon ausgegangen werden, dass die Drucker und Verleger in Regensburg eine präzise Vorstellung davon hatten, was ungefährlich, was möglicherweise kritisch war und was auf gar keinen Fall ging. In der Mittelkategorie kam es daher darauf an, die Auflage so schnell wie möglich zu verkaufen, damit die Offizin bei Einziehung oder Verbot der Schrift nicht auf den Kosten sitzen blieb.

Ein zentraler Buchhandelsstreit betraf zwar nicht die periodische Presse, wohl aber die politisch-historische Wissensvermittlung im ersten Drittel des 18. Jahrhunderts: Der Konflikt um den Vertrieb des Universal-Lexicons von Johann Heinrich Zedler. Mit beteiligt war der Kanzler der Universität Halle, Johann Peter von Ludewig, den Zedler 1730 als Gutachter für sein Medienvorhaben gewann. Das Werk wurde von zahlreichen Gelehrten der Zeit arbeitsteilig erstellt, leider sind die genauen Zuordnungen der Autoren zu den Artikeln verloren gegangen. An dieser Stelle ist allerdings die neue Ver-

34 Vgl. die Episode um einen fürstlichen Protest gegen die Wahlkapitulation für Josef I. von 1690, zit. nach ebd., S. 518f., Anm. 3001.

35 Nachweis: ebd., S. 519, Anm. 3004.

36 Nachweis: ebd., S. 520, Anm. 3008. 
triebsmethode interessant und zukunftweisend: Der »Zedler« sollte nämlich nicht, wie im alten System üblich, Bogen gegen Bogen getauscht werden, sondern wurde zur Subskription ausgeschrieben. Mit den ca. 1.500 Subskribenden, die schließlich zeichneten, konnte das Werk allen zwischenzeitlichen Schwierigkeiten zum Trotz bis 1750 abgeschlossen werden, wobei 60 Bände und in den Folgejahren noch vier Supplementbände herauskamen. Was den Verlegern die nötige Planungsgrundlage verschaffte - auch wenn Zedler zwischendurch einmal bankrott ging - das schloss viele Buchhändler im Westen und Süden des Reiches vom Vertrieb aus: Ihnen fehlte schlicht das freie Kapital, dieses Riesenwerk auf Lager zu nehmen, ohne die Sicherheit zu haben, es auch verkaufen zu können. Selbst wenn Ludewig darauf verwies, dass der einzelne Band nicht mehr als zwei Reichstaler kosten sollte, bedeutete jede Ausgabe 120 bis 130 Reichstaler ${ }^{37}$. Die Umstellung des Bezahlsystems im Buchhandel von der Tausch- zur Geldwirtschaft, in den 1760er Jahren durch den Leipziger Verleger Philipp Erasmus Reich (1717-1787) verwirklicht, warf damit bereits seine Schatten voraus ${ }^{38}$. Die Dominanz wirtschaftlicher über kulturelle Belange, die von vielen Aufklärungsforschern historiographischer wie literaturwissenschaftlicher Provenienz beklagt wurde und wird, ist allerdings kein Produkt des 18. Jahrhunderts, sondern zeigte sich nun erst in Deutlichkeit, als sich die Rollen der Medienproduzenten hinlänglich ausdifferenziert hatten, um im Verleger den Kaufmann erkennen zu können ${ }^{39}$.

\subsection{Die Zeitungs- und Zeitschriftenproduktion}

Die Herstellung von Zeitungen war zunächst kein eigenes Gewerbe, sondern wurde von mehreren Berufsgruppen betrieben. Genannt werden Buchdrucker, Verleger, Postmeister, Kaufleute, etwa Buchhändler, sowie Absolventen einer akademischen Ausbildung, zumeist einer theologischen, juristischen oder geisteswissenschaftlichen ${ }^{40}$. Im biographischen Kontext des

37 Zur Subskription des Zedlerschen »Universal-Lexicons«: Estermann, Memoria und Diskurs, S. $62-65$.

38 Zur Finanzierungsrevolution des Philipp Erasmus Reich und den Folgen: Wittmann, Geschichte des deutschen Buchhandels, S. 111-120. Vgl. zu Reich auch Rosenstrauch, Buchhandelsmanufaktur und Aufklärung, pas.

39 Zum Verhältnis des Mediensystems zur Marktwirtschaft vgl. vor allem KIESEL/MüNCH, Gesellschaft und Literatur im 18. Jahrhundert, pas. Vgl. auch den kommentierenden Forschungsüberblick bei FaULSTich, Die bürgerliche Mediengesellschaft, S. 177-224. Faulstich betont, dass gerade in diesem Bereich die Sachzusammenhänge bis heute zunächst aus einem Berg von Ideologien freigelegt werden müssen.

40 Über die Querbeziehungen zwischen diesen Berufen vor Abschluss ihrer Professionalisierung: Ute SchneIDer, Grundlagen des Mediensystems. Drucker, Verleger, Buchhändler in ihren ökonomischen Beziehungen 1600-1750, in: ARndt/Körber, Das Mediensystem im Alten Reich der Frühen Neuzeit, S. 27-37. 
jeweils zu untersuchenden Zeitungsmachers wird der Werdegang kurz skizziert, ohne klarzustellen, was das bedeutete. Berufliche Zuordnungen, wie wir sie aus unserer Gegenwart kennen, greifen für das Medienwesen zu kurz. Es scheint daher sinnvoll, von »Rollen « zu sprechen. Dieselbe Person konnte mehrere Rollen gleichzeitig oder nacheinander ausüben, diese Rollen konnten mit hauptsächlich ausgeübten Berufen zusammenfallen, mussten aber nicht. Eine dieser Rollen war die Herstellung und der Vertrieb von Zeitungen.

In der Mehrzahl der Fälle im 17. und 18. Jahrhundert war der Zeitungsmacher der Gründer seines Unternehmens. Viele Neugründungen gingen vorzeitig ein oder erloschen mit dem Tod ihrer Begründer. Der größere Teil des Rests ging an den Sohn, Schwiegersohn, die Witwe oder einen anderen Verwandten über. Dieser Umstand ist bemerkenswert, weil es bereits im 16 . Jahrhundert medienproduzierende Großbetriebe gab, vor allem in den Niederlanden. Beispiele dafür waren das Haus Plantin-Moretus ${ }^{41}$ in Antwerpen sowie die Familie Elzevier ${ }^{42}$ in Leiden und Amsterdam. Dieser Prozess der Medienkonzentration trat erst allmählich ein. Der zeitungs- und druckwerkeproduzierende Kleinbetrieb blieb während dieses Zeitraums bestimmend.

Das bedeutet aber nicht, dass der Zeitungsunternehmer allein hätte arbeiten müssen und auch nicht, dass er alles selbst machen konnte. Vielmehr benötigte er zwei Voraussetzungen, um sein Gewerbe mit Erfolgsaussicht starten zu können: Zum einen bedurfte es des Willens zum Unternehmertum auf ungewisser Grundlage, mit anderen Worten: Risikobereitschaft. Medienproduktion war nur teilweise ein Handwerk, anderenteils aber schon ein moderner Beruf in dem Sinn, dass die hier Tätigen den Konsequenzen von wirtschaftlichen Konjunkturen und von kulturellen Moden ausgesetzt waren. Kein Berufsverband, kein herrschaftliches Privileg konnte sie davor schützen. In einem Zeitalter vor Durchsetzung klassischer Wirtschafts- oder Kulturtheorien waren die Zeitungsmacher auf ihren wachen Sinn und auf ihre Lebenserfahrung angewiesen, um sich dem Risiko einer ungewissen Zukunft stellen zu können. Aufstieg zu Wohlstand oder Scheitern ließen sich nicht vorhersehen. Aus der empirischen Rückschau ist nur erkennbar, dass der Misserfolg mit höherer Wahrscheinlichkeit eintrat als der Erfolg.

41 Zum Verlagshaus Plantin: Colin Clair, Christopher Plantin, London 1960; Marcus DE SchePPER/Francine DE NAVE (Hg.), Ex Officiana Plantiniana. Studia in Memoriam Christopheri Plantini (ca. 1520-1589), Antwerpen 1989; Leon VoET, The Golden Compasses. A History and Evaluation of the Printing and Publishing Activities of the Officina Plantiniana at Antwerp, 2 Bd., Amsterdam/London/New York 1969-1972.

42 Zum Verlagshaus Elzevier: Alphonse Willems, Les Elzevier. Histoire et annales typographiques, Brüssel 1880 (ND Nieuwkoop 1962); David W. Davies, The World of the Elseviers 1580-1712, Den Haag 1954 (ND 1960); Samuel Louis Hartz, The Elseviers and their Contemporaries, Amsterdam 1955; Berry P. Dongelmans/Paul G. HoftiJzer/Otto S. Lankhorst $(\mathrm{Hg})$, Boekverkopers van Europa. Het 17de-eeuwse Nederlandse uitgevershuis Elzevier, Zutphen 2000. 
Zum anderen brachte der Zeitungsproduzent die Befähigung ein, einen Teil der Zeitungsherstellung auf der Grundlage seines beruflichen Werdegangs bewältigen zu können - die restlichen Komponenten wurden hinzugekauft.

Zeitungsherstellung teilte sich in drei funktionale Bereiche: 1. Nachrichtenbeschaffung und Texterstellung, 2. Druckproduktion sowie 3. Logistik und Vertrieb. Für den ersten Bereich standen die »Gelehrten«, die entweder im herrschaftlichen Dienst Informationen erhielten und weiterleiteten (mitunter für Geld) oder hinreichend viele Bekannte besaßen, die ihnen Zugang zu Nachrichten verschafften. Sie waren geübt in der Erstellung von Texten, und aus dem Strom des Wissens, der ständig ihre Hände (und ihr Hirn) passierte, konnten sie verschiedene Ergebnisse formen. Der Zeitungstext war häufig nur ein Nebenprodukt ${ }^{43}$. Zum Weiterreichen und -verarbeiten des Berichts war keine hohe Bildung mehr erforderlich, da der Text vielfach über mehrere Etappen nicht substanziell geändert wurde.

Für den zweiten Bereich standen die Buchdrucker und Verleger mit ihren Kernkompetenzen, die bislang vorrangig mit der Erstellung von Zeitungen in Verbindung gebracht worden sind, wohingegen die übrigen Beteiligten nicht selten in den Hintergrund gerieten. Es entsprach ganz der neuen Medienproduktion, dass sie unter ständigem Zeitdruck litt. Daher wurde darüber nachgedacht, wie man mit begrenzten Ressourcen möglichst viele Zeitungsexemplare in möglichst kurzer Zeit produzieren konnte. Martin Welke hat das »raffiniert einfache Setzschema" beschrieben, durch das die Effektivität jeder Druckpresse verdoppelt werden konnte:

Während es gewöhnlich zum Bedrucken der Vor- und Rückseite eines Bogens jeweils eines eigenen Satzes bedurfte, kam man beim Erstellen der Avisen mit einem Satz für beide Bogenseiten aus. Der gesamte Inhalt der Zeitung wurde auf einem Druckstock gesetzt und dabei die einzelnen Seiten mit ihren Köpfen so gegeneinander ausgerichtet, dass nach einem Wenden der bereits gedruckten Vorderseite des Bogens der Druck nur wiederholt zu werden brauchte, um eine richtige Aufeinanderfolge der einzelnen Zeitungsseiten zu ergeben. Nach dem Zerschneiden der Bögen erhielt man zwei in Inhalt und Satzspiegel identische Exemplare eines Nachrichtenblattes ${ }^{44}$.

Jürgen Wilke betont, dass man auf diese Weise in der zweiten Hälfte des 17. Jahrhunderts auf einer Druckerpresse mit gewöhnlich 300 Bögen 600 Zeitungsexemplare herstellen konnte - dies entsprach etwa der üblichen Auflage einer Zeitung. Wer mehr Exemplare benötigte, brauchte entweder einen

43 Ein Beispiel für einen intellektuellen Zeitungsherausgeber war Daniel Hartnack: WeBER, Daniel Hartnack, S. 140-158.

44 Martin Welke, Rußland in der deutschen Publizistik des 17. Jahrhunderts (1613-1689), in: FOEG 23 (1976), S. 105-276, Zitat S. 144. 
zweiten Drucktag oder eine zweite Presse ${ }^{45}$. - Für den dritten Bereich sorgten die Postmeister. Auf ihre Tätigkeit wird unten in einem gesonderten Abschnitt eingegangen.

Ein erfahrener Verleger oder Drucker konnte ebenfalls ein europäisches Informationsnetz aufbauen, um Neuigkeiten aus aller Herren Länder zu Papier zu bringen. In diesem Fall entstanden allerdings die Kosten des Posttransfers, die keineswegs gering waren. Walter Zimmermann listet in seiner Studie über die Offizin Felsecker in Nürnberg eine Kostenberechnung aus dem Jahre 1706 auf, die allerdings das Verlagshaus Endter betrifft (die Schrift entstand im Rahmen eines Privilegierungsprozesses, den die Familie Felsecker gegen die Endter angestellt hatte):

Gründlicher Ueberschlag derjenigen Unkosten und Profit, welcher sich auss dem B.J. Endterischen Zeitungs Truckh ereignet, als folget:

Die gewisse und wissenlich Jährlich ausszulegende Postgelder für die Correspondenzen bestehen hierinnen:

- für die Hamburger Zeitungen: fl. 20.48

- für die Presslauer Zeitungen: fl. 20.48

- für die Leipziger Zeitungen: fl. 10.24

- für die Schweitzer Zeitungen: fl. 31.18

- für die Wiener Zeitungen: fl. 10.24

- für die Franckfurter Zeitungen: fl. 10.24

- für die Augspurger Zeitungen: fl. 10.24

- für die Heilbronner Zeitungen: fl. 8.-

- für die Frantzösische Zeitungen: fl. 8.-

- für die Welsche Zeitungen: fl. 8.-

Thut alsso nur das Porto diesser gedruckten Avisen ohne die geschriebene jährlich [sc. kosten - Zusatz von W. Zimmermann] fl. 138.30

Die Correspondentz an sich selbst auf das geringste: fl. 200.-

Dem Setzer wochentlich für 12 Formb a 30 kr. das gantze Jahr: fl. 312.-

Für Truckerlohn wochentlich fl. 3 kr. 12, das Jahr: fl. 166.24

Dem Correctori wochentlich fl. 3, das Jahr: fl. 156.-

Dem Herrn Censori jährlich: fl. 25.

Für 31 ballen 3 Riess Papier a 4 fl. 30 kr.: fl. 140.24

Summa der Unkosten: fl. 1.138.1846.

45 WiLKe, Grundzüge der Medien- und Kommunikationsgeschichte, S. 46.

46 Walter Zimmermann, Entwicklungsgeschichte des Nürnberger »Friedens- und Kriegskuriers« (»Nürnberger Kurier«) von seinen ersten Anfängen bis zum Übergang an den »Fränkischen Kurier«, 1663-1865. Ein Beitrag zur Geschichte des deutschen Pressewesens, Nürnberg 1930, S. 142. 
Da die Endter-Erben eigene Einkünfte aus dem Zeitungsverkauf in Höhe von fl. 1.299.- aufführten, ergab sich ein jährlicher Gewinn von fl. 160,24. Die Familie berücksichtigte noch Kreditzinsen für früher aufgenommene Gelder, sodass sie sich auf den Standpunkt stellte, mit dem Zeitungsbetrieb sei kein Geld zu verdienen ${ }^{47}$. Auch wenn die Auflistung der verschiedenen Posten interessant ist, so muss das erkenntnisleitende Interesse berücksichtigt werden, dass das Druckhaus seine Bedürftigkeit zur Schau stellen wollte. Generalisieren lässt sich die Bilanz der unternehmerischen Tätigkeit gewiss nicht. Flugschriften- und Zeitungsdrucken galt als potenziell lukrativ, und zahlreiche Beispiele lassen sich anführen, die belegen, wie reich die Betreiber durch ihre Tätigkeit geworden sind ${ }^{48}$. Dies gaben die Drucker in Basel bei einem Schriftwechsel mit ihrem Magistrat 1696 auch offen zu Protokoll und fügten die Mitteilung hinzu, es sei ihnen nicht möglich, von erbaulichen Schriften und wissenschaftlichen Publikationen allein zu überleben ${ }^{49}$.

Das Zeitungswesen begann im frühen 17. Jahrhundert mit wöchentlicher Berichterstattung. Dies entsprach nicht nur diplomatischen Gepflogenheiten, beispielsweise am Reichstag, wo normalerweise einmal pro Woche berichtet wurde. Vielmehr wurde die Post an vielen Orten wöchentlich befördert, sodass eine höhere Frequenz nur per Kurier- oder Botendienst möglich und entsprechend teurer gewesen wäre. Im Laufe des Jahrhunderts vermehrte sich die Frequenz an zahlreichen Orten, und stets waren es Orte, an denen die Postverbindungen besser waren. Daher ist es keine Überraschung, dass die erste bekannte Wochenzeitung 1650 in Leipzig erschien. Nur diese Stadt bot - neben Frankfurt a.M. - so viele Möglichkeiten der Information aus dem In- und Ausland, so viele Kreuzungen von Post- und Botenwegen, dass eine Tageszeitung kurz nach dem Dreißigjährigen Krieg schon betrieben werden konnte. An anderen Orten mit ein oder zwei Posttagen wöchentlich war der Nachrichtenzustrom nicht groß genug, um jeweils vier Seiten pro Tag mit Aktuellem füllen zu können ${ }^{50}$.

47 Ebd., S. 145.

48 Schon der erste Zeitungsdrucker Johann Carolus hatte einen beträchtlichen Teil der Kreditkosten in Höhe von 3.724 fl., die er 1604 für den Kauf der Offizin Jobin in Straßburg zu zahlen hatte, aus den sprudelnden Erträgen seines Periodikums bestreiten können. Binnen zehn Jahren waren die Gelder zurückgezahlt: WeLke, Johann Carolus und der Beginn der periodischen Tagespresse, S. 74-83.

49 Rudolf MEYer, Die Flugschriften der Epoche Ludwigs XIV. Eine Untersuchung der in schweizerischen Bibliotheken enthaltenen Broschüren, Basel 1955, S. 24, Anm. c., bezogen auf Flugschriften; zit. nach FriedRICH, Drehscheibe Regensburg, S. 420.

50 Else Hauff, Die »Einkommenden Zeitungen« von 1650. Ein Beitrag zur Geschichte der Tageszeitung, in: Kutsch/WeBER, 350 Jahre Tageszeitung. Forschungen und Dokumente, S. 151161, hier S. 152. 
Für die Zeitschriftenproduktion waren ähnliche Voraussetzungen erforderlich wie für die Zeitungsproduktion. Im Zentrum stand normalerweise ein Verleger, der einen akademisch gebildeten Redakteur engagierte. Vielfach war im Haus schon früher eine Zeitung betrieben worden oder wurde parallel produziert, so dass die notwendigen aktuellen Informationen ohnehin durchliefen. Der Aufwand, den Text von ca. 100 Seiten pro Monat zu produzieren und dafür die notwendigen Recherchen zu tätigen, oblag fast ausschließlich dem Redakteur. Da die Zeitschriftenhefte aus einem Guss geschrieben waren, dürfte das Ein-Mann-Unternehmen der Texterstellung die Regel gewesen sein. Zuarbeiten und Zusammenarbeiten waren möglich, viele personelle und arbeitstechnische Details sind bis heute unaufgeklärt und infolge der mangelhaften Überlieferung vermutlich unaufklärbar.

Auch für die Zeitschrift galt das Gebot der Wirtschaftlichkeit. In der Historiographie zum Aufklärungsjahrhundert ist das nicht immer gebührend berücksichtigt worden. Aus dieser Perspektive war ein Verleger eine Person, die literarisch hochstehende Texte zur Bildung der Leserschaft produzierte und Geist und Gut darin investierte, die Qualität des Textes möglichst $\mathrm{zu}$ heben. Mit dieser Sicht korrespondierte das zeitgenössische Publikum, das Druckschriften nach dem Bildungsgehalt auswählte. So schrieb Joachim Kirchner in seiner großen Studie zum Zeitschriftenwesen:

Andererseits beweist wiederum das sprunghafte Kommen und Gehen vieler kurzlebiger, unbedeutender Zeitschriften - und diese waren nun mal in der Überzahl -, dass die deutsche Leserschaft sich nicht mit mäßiger literarischer Kost abspeisen lassen wollte. Sie reagierte bei minderwertiger Ware mit dem gesunden Gefühl der Ablehnung; sie wünschte nicht, das Amt des Volkserziehers, als welches sich die Verfasser der Sittenschriften gern hinzustellen suchten, in falsche Hände abgleiten zu sehen. Das Gefühl der Verantwortung fehlte leider vielen, die sich nicht aus innerer Berufung, sondern aus Erwerbstrieb dem Zeitungswesen zuwandten ${ }^{51}$.

Es ist allerdings anachronistisch, aus dem pädagogischen Impetus, der zweifellos zahlreiche Autoren zur Volksbildung angespornt hat, ein allgemeines Erzieheramt der periodischen Presse generell abzuleiten. Inbesondere für die Verleger, die ein Wirtschaftsunternehmen zu leiten hatten, galt es in erster Linie, die ökonomische Existenz zu sichern. Dies aber konnte nur gelingen, wenn es am Markt hinreichenden Absatz für die Druckwerke gab. Daher kam die entscheidende Rolle dem Leser und seiner Zahlungsbereitschaft zu, und der Verleger hatte zu antizipieren, wie er Leser finden konnte und welche Leser er mit seinen Texten ansprechen wollte.

51 Kirchner, Das deutsche Zeitschriftenwesen, hier Bd. 1, S. 105. 
Gerade bei Zeitschriften konnte im Aufklärungszeitalter der Fall eintreten, dass das Wünschbare des Redakteurs und das Machbare des Verlegers nicht zur Deckung gebracht werden konnten. Daniel Hartnack nutzte das Widmungsschreiben seines Buches zur Historienschriftstellerei, um diesen Aspekt zur Sprache zu bringen. Bewidmet wurden die Buchhändler Wolf Moritz und Johann Andreas Endter in Nürnberg sowie Johann David Zunnern und Balthasar Christoph Wüsten in Frankfurt a.M. Die Buchhändler erscheinen als die »werten Gönner[n]«. Hartnack führt aus, dass die Autoren oft ihre Bücher nicht so ausführlich und gründlich schreiben könnten, wie sie wollten, weil sie von den Verlegern in eine Richtung gedrängt würden. Andererseits könnten die Verleger auch nicht alles drucken, was ihnen an Manuskripten eingeht, weil das ihren Ruin bedeuten würde. Hartnack wörtlich:

[...] daß daher ihnen [= den Verlegern] nicht unbillig das Urtheil überlassen wird/womit sie am besten fahren/was auff der Meß am besten abgehen/und von den Käuffern am meisten gesuchet werden möchte/auff welches letztere das gantze Wesen zu beruhen scheinet $^{52}$.

Hartnack forderte damit vom Autor Respekt vor den vorrangigen Interessen des Verlages: Nicht das Belieben des Autors - das moralische, das philosophische, das religiöse oder das aufklärerische - entschied über das Zustandekommen eines Druckes, sondern die geschätzten Marktchancen des Druckwerks. Für Werke mit geringen oder gar keinen Marktchancen musste der Autor selbst Geld mitbringen, wenn er sein Buch publiziert sehen wollte. Auch an anderer Stelle im selben Werk schrieb Hartnack:

Nunmehr aber stehen die Sachen mehrentheils bey den Buchhändlern/welche theils für sich aestimiren wobey der meiste Profit zu haben/und weniges denen Gelehrten überlassen/was zu schreiben nützlich seyn möchte. Aber was soll man auch von ihnen sagen? sie müsten sich nach den Käuffern richten/es neiget sich alles nach und nach zum Saeculo ignorantiae, und die Welt verlanget auch nunmehr was bessers nicht [...].

Damit erkannte er den »Primat des Ökonomischen « $a^{53}{ }^{53}$. In dieselbe Richtung zielte eine Aussage von Kaspar Stieler. Er betonte pragmatisch, dass die Zeitungsproduktion eine Wirtschaftsbranche sei:

52 Hartnack, Erachten von Einrichtung Der alten Teutschen und neuen Europäischen Historien, Widmungsblatt, s.p.

53 Ebd., S. 110. 
Im übrigen ist bekant/daß der Zeitungs-Verfasser/Verkaufer und Drucker Zweck ist/etwas daran zugewinnen/und ihre Narung davon zuhaben/welches ihnen auch gern zu gönnen/indem niemand des heiligen Grabes umsonst hütet/woferne nur dieser Erwerb nicht gar zugemein würde ${ }^{54}$.

\subsection{Frühe Zeitungsproduktion in Hamburg}

Auf das Hamburger Medienwesen lohnt es sich, näher einzugehen. Kürzlich erschienen aus der Feder von Holger Böning zwei Bücher, die sich mit dem Pressewesen der Elbmetropole vom 17. bis zum frühen 19. Jahrhundert beschäftigten. Der Verfasser, Leiter der Zentralen Wissenschaftlichen Einrichtung »Deutsche Presseforschung« an der Universität Bremen, hat schon zuvor durch ein bio-bibliographisches Verzeichnis aller Periodika derselben Zeit in Hamburg und den umgebenden Medienstandorten sowie durch zahlreiche Publikationen zur Volksaufklärung in der zweiten Hälfte des 18. Jahrhunderts auf sich aufmerksam gemacht ${ }^{55}$.

Drei Umstände machten aus Hamburg ein Medienzentrum ersten Ranges mit internationaler Ausstrahlung. Zum einen gelang es der Elbmetropole, während des Dreißigjährigen Krieges zu einem internationalen Handelszentrum aufzusteigen. Während andere Städte die Hälfte ihrer Bevölkerung einbüßten, wohnten in Hamburg 1669 nicht weniger als 60.000 Menschen, wodurch die Stadt die bis dahin bevölkerungsreichsten Städte Köln, Augsburg und Nürnberg weit hinter sich ließ und nur noch Wien vor sich sah ${ }^{56}$. Damit war auch das ökonomische Wachstumspotenzial gegeben, das für stetig steigende Nachfrage nach Neuigkeiten sorgte. Ehrgeizige Zeitungsunternehmer verfügten so über ein innovationsfreudiges Umfeld, um ihre eigenen Experimente am Markt machen zu können.

Zum anderen handelt es sich bei Hamburg um eine kommunikationsgeschichtliche Doppelstadt: Nicht nur in der Hansestadt wurde gedruckt, sondern auch im benachbarten Altona, das viel kleiner war, aber dem König von

54 Stieler, Zeitungs Lust und Nutz (1695/1969), S. 45f.

55 Studien zu Hamburg: BöNIng, Welteroberung durch ein neues Publikum, pas.; ders., Periodische Presse, Kommunikation und Aufklärung, pas. - Biobibliographie: Böning, Deutsche Presse. Biobibliographische Handbücher zur Geschichte der deutschsprachigen periodischen Presse, 2 Bd., pas. - Volksaufklärung: Holger BöNING (Hg.), Französische Revolution und deutsche Öffentlichkeit. Wandlungen in Presse und Alltagskultur am Ende des 18. Jahrhunderts, München 1992; ders., Aufklärung auch für das Volk? Buchhandel, Verleger und Autoren des 18. Jahrhunderts entdecken den gemeinen Leser, Oldenburg 1998; Holger BönING/Reinhart Siegert (Hg.), Volksaufklärung. Biobibliographisches Handbuch zur Popularisierung aufklärerischen Denkens im deutschen Sprachraum von den Anfängen bis 1850, 2 Bd., Stuttgart-Bad Cannstatt 1990-2001.

56 Vgl. Behringer, Im Zeichen des Merkur, S. 419. 
Dänemark unterstand und gezielt als Konkurrenz aufgebaut werden sollte. Zeitungsmacher, die sich in der einen Stadt unbeliebt gemacht hatten, wechselten nun in die Nachbarschaft, um dort ihr Gewerbe fortzusetzen. Berichte, die in der einen Stadt inopportun waren, erschienen dafür in der Presse der anderen. Die Konkurrenz belebte den Zeitungsmarkt zusätzlich. Im späten 17. Jahrhundert gab es in Hamburg sechs Zeitungen, in Altona zwei ${ }^{57}$. Weder die Leser in Hamburg noch die in Altona konnten davon abgehalten werden, die Presse der jeweils anderen Stadt zu lesen. Politische Konkurrenz hatte hier nicht Angstdenken und völlige Abschottung zur Folge, sondern unternehmerische Freiheit. Die Obrigkeiten, die dänische Krone und der Hamburger Magistrat, beschränkten sich auf gelegentliche Machtdemonstrationen, ließen die Medienproduktion aber ansonsten nach ihrer Eigendynamik verlaufen ${ }^{58}$.

Zum dritten gab es in Hamburg sechs Postämter, mehr als in jeder anderen deutschen Stadt. Naheliegenderweise bestand ein städtischer Botendienst und die Niederlassung der Reichspost. Daneben unterhielten auch die Könige von Dänemark und Schweden Poststationen, ebenso die Kurfürsten von Brandenburg und Hannover ${ }^{59}$. Der Magistrat hatte sich durch die kluge Entscheidung, alle möglichen Postämter zuzulassen, nicht nur in keine einseitige Abhängigkeit begeben, sondern zugleich seinen eigene Botendienst gerettet, der mit den übrigen Diensten konkurrieren konnte. Gleichzeitig bildete die Stellung als Kommunikationszentrum ein Argument gegen Versuche der benachbarten Könige und Fürsten, die Stadt aus den eigenen Außenwirtschaftsbeziehungen auszuschließen. Hamburg wurde durch den Territorialisierungsprozess nicht zurückgeworfen, wie viele andere Städte im Reich, sondern gewann gerade dadurch, dass die Hamburger Märkte von allen Wirtschaftspartnern gebraucht wurden, eben auch der Nachrichtenmarkt.

Mehrere Zeitungen, die in Hamburg gegründet wurden, hingen eng mit den verschiedenen Postdiensten zusammen. Zwei frühe Zeitungen von Johann Meyer und Hans Jacob Kleinhans hießen beide - mindestens zeitweilig - »Post-Zeitung «, was allerdings auch als Camouflage dienen konnte, damit die Kundschaft den Unterschied nicht so deutlich merkte. Privilegienstreitigkeiten zwischen beiden Herausgebern waren dafür ursächlich. Nur Kleinhans handelte dabei in Abstimmung mit der Taxis-Post bzw. ihrer deutschen Direktorin, Alexandrine Gräfin von Taxis, Meyer hingegen hatte

57 Ebd., S. 424. Zur Rolle Altonas: Carsten Prange, Die Zeitungen und Zeitschriften des 17. Jahrhunderts in Hamburg und Altona. Ein Beitrag zur Publizistik der Frühaufklärung, Hamburg 1978, S. 32f.

58 Zu Altona: Böning, Welteroberung durch ein neues Publikum, S. 53-55 u. 169-171.

59 Behringer, Im Zeichen des Merkur, S. 419. 
den Titel usurpiert ${ }^{60}$. Die prominenteste Hamburger Zeitung der Frühzeit, Georg Greflingers Nordischer Mercurius (ca. 1660-1717), erschien zunächst im Botenhaus der Nürnberger Boten, überdauerte deren Präsenz in Hamburg allerdings lange ${ }^{61} .1673$ begann Thomas von Wiering, seinen Relations-Courier herauszugeben. Dazu erlangte er ein städtisches Privileg, das ihm allerdings untersagte, die Altonaer Zeitungen »auszuschreiben«: Er sollte sich insbesondere der Verbreitung von Berichten enthalten, die der Hamburger Senat als anstößig betrachten konnte. Das Argument, er habe »nur« etwas nachgedruckt, sollte nicht verfangen, der Senat kannte diesen apologetischen Begründungszusammenhang bereits zur Genüge ${ }^{62}$.

Die Anwesenheit einer niveauvollen Zeitung zwang alle anderen, nicht zu stark abzufallen. Johann Peter von Ludewig schrieb über die Elbmetropole: »Und zwar sind die Hamburger Gazetten wohl die vollkommensten gewesen/welches auch in einer so florirenten HandelsStadt/die jhre Schiffe in alle Ecken der Welt gehen läßt/am leichtesten seyn können « ${ }^{63}$. Der dänische Pressehistoriker Paul Ries hat die Herkunftsorte der Nachrichten in den Hamburger Zeitungen des Jahrgangs 1669 ausgewertet. In den insgesamt 713 Meldungen der Hamburger Reichspostzeitung dominierten erstaunlicherweise Venedig (102 Meldungen=14,3\%) und Rom $(99=13,8 \%$ ), während die Hauptstädte der europäischen Monarchien erst danach folgten: Paris $(67=9,3 \%)$, Wien $(66=9,2 \%)$, Madrid $(47=6,5 \%)$, Konstantinopel $(42=5,8 \%)$, Berlin $(39=5,4 \%)$, Brüssel $(34=4,7 \%)$, London $(29=4 \%)$, Warschau $(15=2,1 \%)$ und Lissabon $(13=1,8 \%)^{64}$.

Die Hamburger Medienvormacht zeigte sich auch in der Abhängigkeit der Berichterstattung in benachbarten Presseorganen. Paul Ries musste eingestehen, dass die Kopenhagener Wochentliche Zeitung auch als Hamburger Allgemeine hätte durchgehen können, da die Mehrzahl ihrer Berichte drei Tage zuvor in einem der Hamburger Blätter gestanden habe ${ }^{65}$. Abhängigkeiten dieser Art sind auch bei deutschen Periodika die Regel. Es war einfach billiger, eine andere Zeitung zu kopieren, als selbst ein teures Netzwerk an Informanten zu unterhalten.

60 Prange, Die Zeitungen und Zeitschriften des 17. Jahrhunderts in Hamburg und Altona, S. 85-89.

61 Behringer, Im Zeichen des Merkur, S. 423. Zu Greflinger: Prange, Die Zeitungen und Zeitschriften des 17. Jahrhunderts in Hamburg und Altona, S. 125-177; Berghaus, Georg Greflinger als Journalist und historisch-politischer Schriftsteller, S. 1-14.

62 Prange, Die Zeitungen und Zeitschriften des 17. Jahrhunderts in Hamburg und Altona, S. $177 f$.

63 Von Ludewig, Vom Gebrauch und Mißbrauch Der Zeitungen, S. 102, zit. nach BeHringer, Im Zeichen des Merkur, S. 424.

64 Auflistung nach Paul Ries, The Anatomy of Seventeenth-Century Newpapers, in: Daphnis 6 (1977), S. 171-232, hier S. 189, zit. nach BeHRinger, Im Zeichen des Merkur, S. 424.

65 Ries, The Anatomy of Seventeenth-Century Newpapers, S. 201-229, zit. nach BeHringer, Im Zeichen des Merkur, S. 425. 


\subsection{Post und Zeitungswesen}

Während der Buchhandel der Barockzeit - wie gezeigt - im Wander- und Tauschhandel getätigt wurde, entwickelte sich für das Zeitungs- und Zeitschriftenwesen zusätzlich ein anderer Vertriebsweg, der der Geschwindigkeit der neuen Medien entsprach: Der Vertrieb über das Netzwerk der Thurn und Taxis-Post. Für den normalen Endkunden, gleich ob adligen oder bildungsbürgerlichen Standes, wurde das Abonnement der Bezugs- und Bezahlweg, der Ansprechpartner für Interessenten war der jeweilige Postmeister vor Ort.

1695 schrieb Kaspar Stieler: »Vor allen andern aber kommet [...] Der Zeitungen Ursprung aus denen Postheusern her ${ }^{66}$. Das ist etwas übertrieben, aber nicht sehr. Das Postwesen hat in der Tat in maßgeblicher Weise den Zeitungsverkehr gefördert und durch die Regelmäßigkeit seines Austausches erst in der beobachtbaren Dichte ermöglicht. So stellt sich der Zusammenhang bei Jürgen Wilke wie folgt dar:

Die Entstehung von Zeitungen ist in Deutschland durch diese - privatwirtschaftlich und konkurrenzbedingt - dichte Vernetzung des Reichsgebiets mit Postlinien entscheidend gefördert worden. Dabei fungierte die Post nicht nur als Hilfsgewerbe bei der Beschaffung und dem Transport von Nachrichten, sondern wurde seit dem frühen 17. Jahrhundert auch zum wichtigsten Instrument für den Zeitungsvertrieb (Dallmeier 1987). Die enge Symbiose zwischen Kommunikationsmedien und der (staatlichen) Post, die sich in der frühen Neuzeit herausbildete, sollte über Jahrhunderte hinweg bestehen bleiben und ist erst durch die Deregulierung am Ende des 20. Jahrhunderts letztlich (bis auf Rudimente) beseitigt worden ${ }^{67}$.

Liest man die hier zitierte Passage bei Kaspar Stieler weiter, so wird deutlich, dass Stieler den Begründungszusammenhang als Legitimationszusammenhang konstruieren wollte: Postmeister, die Kaiser und Reich mit Eid verbunden waren, stellten für ihn vertrauenswürdige Personen dar, die für einen geregelten Nachrichtenverkehr sorgten und ihn aufrechterhielten. Demgegenüber kritisierte er, dass jeder »Buchdrucker/Binder oder verdorbener Schulmeister« sich als Zeitungsredakteur betätigen könne und etwas »unwahres/gefärliches und verfängliches« herausgeben könne, was aus unsicheren oder gar unruhigen Quellen stammte ${ }^{68}$. Als erfahrenem Hofmann - und Schwiegersohn eines Erfurter Postmeisters - stand Stieler ein geordnetes Nachrichten- und Kommunikationssystem vor Augen, das staatlich kon-

66 Stieler, Zeitungs Lust und Nutz (1695/ 1969), S. 17.

67 WILKE, Grundzüge der Medien- und Kommunikationsgeschichte, S. 49. Der Nachweis »Dallmeier 1987« bezieht sich auf DALLMEIER, Die kaiserliche Reichspost zwischen Zeitungsvertrieb und Zensur, S. 233-258.

68 Zitate: STIELER, Zeitungs Lust und Nutz (1695/1969), S. 18. 
trolliert am besten seine Aufgaben erfüllen konnte, wobei staatliche Kontrolle eine kaiserliche Kontrolle sein sollte.

Eine grundlegende Studie zum frühmodernen Postwesen unter aufklärerischer Perspektive verfasste der Kulmbacher Geheime Regierungsrat Joachim Ernst von Beust $(\dagger 1756)^{69}$. Im dritten Band seines Werkes, das den Schwerpunkt auf der reichspublizistischen Dimension des Postwesens hat, ging Beust auch auf die Postzeitungen ein ${ }^{70}$. Allerdings standen für Beust zahlreiche Aspekte im Vordergrund, die sich mit den Ansichten der Zeitungskritiker generell auseinandersetzten, vor allem mit Kaspar Stieler, Johann Peter von Ludewig, Ahasver von Fritsch, Christian Weise und Daniel Hartnack $^{71}$. So rechnete er zu den erforderlichen Requisiten für eine gute Zeitung die »mündlichen« Kriterien 1. »Wahrheit in der Erfahrung«, 2. richtige Erzählung, 3. nötige Behutsamkeit; ferner die »schriftlichen « Kriterien 1. »Wahrheit in den Nachrichten«, 2. Geschwindigkeit in der Erzählung, 3. Wahl und gute Ordnung in den Berichten, 4. gehörige Schreib-Art. Fehler beim Zeitungsmachen waren für ihn 1. Leichtgläubigkeit, 2. Parteilichkeit, 3. Tätigkeit und Gewinnsucht des Verfassers - dies alles waren keine Besonderheiten der Gazetten, die aus Posthäusern stammten. Demgegenüber wurden die spezifischen Unterschiede der Postzeitungen gegenüber anderen Periodika eher am Rande angeführt.

Staatsgewalt und Zeitungswesen verbanden sich für Beust nicht allein durch die fürstliche Landeshoheit (Superioritas Territorialis), sondern auch durch das Postregal, das er als Rechtsgrund betrachtete, durch das Regierungen regulierend ins Pressewesen eingreifen konnten. Es gab dem Fürsten die Möglichkeit, darauf gestützt Zeitungen einzuschränken. In gravierenden Fällen konnte er sie auch verbieten, wobei die Zensuredikte des Reiches derartige Maßnahmen positivrechtlich absicherten ${ }^{72}$.

Maßgeblich wurde dieser Zusammenhang zwischen Post- und Zeitungswesen durch Wolfgang Behringer in seiner Habilitationsschrift sowie in zahlreichen weiteren Beiträgen erhellt ${ }^{73}$. Er weist darauf hin, dass die Bedeutung der Kommunikationsveränderungen in der Frühmoderne durchaus erkannt wor-

69 Von Beust, Der Versuch einer ausführlichen Erklärung des Post-Regals. - Zur Biographie: DBA I, Fiche 96, Nr. 232-239. - Zur Bewertung: BeHringer, Im Zeichen des Merkur, S. 283.

70 Von Beust, Der Versuch einer ausführlichen Erklärung des Post-Regals, Bd. 3, Abschnitt 4: Von Zeitungen, derselben Recht und Nutzen, S. 589-663.

71 Ebd., S. 593-602.

72 Ebd., S. 642.

73 Behringer, Thurn und Taxis, pas.; ders., Im Zeichen des Merkur, pas.; zur Bedeutung für die frühmodernen Kommunikationsprozesse u.a.: ders., Bausteine zu einer Geschichte der Kommunikation, in: ZHF 21 (1994), S. 92-112; ders., Veränderung der Raum-Zeit-Relation. Zur Bedeutung des Zeitungs- und Nachrichtenwesens während der Zeit des Dreißigjährigen Krieges, in: Benigna von Krusenstjern/Hans Medick (Hg.), Zwischen Alltag und Katastrophe. Der Dreißigjährige Krieg aus der Nähe, Göttingen 1999, S. 39-81. 
den sei. Francis Bacon beispielsweise erklärte neben Kolumbus die Erfinder des Buchdrucks, des Schießpulvers und der Magnetnadel zu den Heroen der Moderne $^{74}$. Johann Jacob Moser fokussierte diesen Modernisierungsprozess noch eindeutiger auf den »Erfinder des Postwesens«. Gern bringt Behringer in diesem Zusammenhang das wichtige Moser-Zitat, das während des Entstehungsprozesses seiner Habilitation lange als Leitmotiv über der Arbeit gestanden hatte, um erst kurz vor Drucklegung durch die Merkur-Metapher verdrängt zu werden: »Das förmliche Postwesen«, so Moser, sei eine »Erfindung, welche gantz erstaunliche Folgen nach sich gezogen, und die Welt in manchen Sachen fast in einen anderen Model gegossen hat $\ll^{75}$.

Erst im 19. Jahrhundert hat dieser Zusammenhang dann eine immer geringere Rolle im Denken gespielt. Archivare konnten mit Briefzeitungsfunden nichts mehr anfangen, die Postgeschichtsschreibung und die Zeitungsforschung entwickelten sich unabhängig voneinander und nahmen sich gegenseitig kaum wahr. Erst 1909 erstellte Max Weber ein Programm zu einer Soziologie des Zeitungswesens, wobei er Postwesen, Zeitungswesen und die dazugehörigen Vorgeschichten für dringend erforschenswert hielt angesichts der wachsenden Bedeutung der Massenmedien und Massenkommunikation in der wilhelminischen Gesellschaft ${ }^{76}$. In der Folge wurde Leipzig zum Zentrum der Zeitungsforschung, und fundamentale Werke entstanden zu beiden Wissensbereichen, etwa von Otto Groth über die Zeitung ${ }^{77}$ oder von Ludwig Kalmus über die Weltgeschichte der Post ${ }^{78}$, ein Werk, das nach der Emigration des Verfassers unverdienterweise der Vergessenheit anheim fiel. Einige Forscher und Institute entwickelten zu dieser Zeit eine beträchtliche Nähe zu den nationalsozialistischen Machthabern, was zu Abwicklungen nach 1945 führte und beiden Teildisziplinen in ihrer weiteren Entwicklung schadete ${ }^{79}$.

Insbesondere waren die alten Paradigmata der Zwischenkriegs-Postund Zeitungshistorie den aufstrebenden Wissenschaften der Soziologie und

74 Behringer, Im Zeichen des Merkur, S. 18.

75 Johann Jacob Moser, Teutsches Staatsrecht, 5. Theil, Worinnen sonderlich die Materie von dem Postwesen, so dann von denen Rechten und Freyheiten, welche der Kayser denen ReichsStänden und deren Unmittelbaren in Ansehung ihrer Lande und Unterthanen mitzutheilen befugt, nicht weniger denen Pflichten, dazu er wegen eben solcher Unterthanen verbunden ist [...] enthalten seynd, Leipzig 1742 ( $\left.{ }^{2} 1752\right)$, zit. nach BeHringer, Im Zeichen des Merkur, S. 19, Anm. 70.

76 Webers Projekt blieb damals unrealisiert, das Programm wurde von Wilhelm Hennis 1995/2003 publiziert: Wilhelm Hennis, Max Webers »Vorbericht für eine Erhebung zur Soziologie des Zeitungswesens«. Einführung und Text, in: Ders., Max Weber und Thukydides. Nachträge zu einer Biographie des Werks, Tübingen 2003, S. 130-149.

77 Groth, Die Zeitung, 4 Bd., pas.; erweiterte Fassung: Otto Groth, Die unerkannte Kulturmacht. Grundlegung der Zeitungswissenschaft (Periodik), 7 Bd., Berlin 1960.

78 Ludwig Kalmus, Weltgeschichte der Post mit besonderer Berücksichtigung des deutschen Sprachgebietes, Wien 1937.

79 Vgl. die Aufzählung bei Behringer, Im Zeichen des Merkur, S. 33f. 
Kommunikationswissenschaft suspekt, die sich seit den 1960er Jahren als Emanzipationswissenschaften einen zentralen Platz in der akademischen Landschaft sicherten. Dabei standen eher funktionale Aspekte im Vordergrund, etwa die Bedeutung der Kommunikation in der Diktatur oder in der modernen kapitalistischen Gesellschaft. Der historische Rückgriff auf die Zeit vor dem Wilhelminismus hingegen spielte eine Nebenrolle. Wolfgang Behringer bescheinigt denn auch insbesondere der soziologischen $»$ Frankfurter Schule«, ihre pessimistische Medientheorie »erscheint in hohem Maße zeitgebunden und methodisch fragwürdig. Bis hin zu Habermas siedelte sie im historischen Nirgendwo einer Geschichtsteleologie, die man eher als idealistisch, denn als marxistisch bezeichnen möchte ${ }^{80}$.

Bestand hingegen hat die wirtschaftsgeschichtliche Einschätzung der Bedeutung des frühmodernen Postwesens durch Werner Sombart. Sombart führt sechs Punkte an, die er als konstitutiv für die Entwicklung dieses Prozesses ansah:

1. Der Übergang zur Allgemeinzugänglichkeit. Im Gegensatz zu Frankreich konnte im Alten Reich schnell jedermann seine Sendungen expedieren, die Nutzung war gerade nicht etatistisch beschränkt, sondern ständeübergreifend und nur von der Zahlungsbereitschaft abhängig.

2. Die Einrichtung regelmäßiger Postkurse mit festen Abgangs- und Ankunftsterminen. Die Strecken wurden zunächst ausgemessen, dann personell besetzt und an alle Interessenten bekannt gegeben. Letzteres geschah auch mit den Speditionsterminen.

3. Die Herstellung eines Netzes an ineinandergreifenden Botenkursen. Dabei war die Offenheit des Systems Prinzip: Andere Dienste, gleich ob staatlicher oder kommerzieller Art, konnten sich ans Postsystem anknüpfen.

4. Die sukzessive Vermehrung dieser Kurse und damit die Intensivierung der Verbindungen in Raum und Zeit.

5. Die Vervollkommung der Kollektion und der Distribution des Postgutes.

6. Die Tarifierung der Leistungen: Aufstellung und Einhaltung von Taxen und Tarifen für bestimmte definierte Leistungen ${ }^{81}$.

Behringer gelangt zu drei Thesen: 1. Die Frühe Neuzeit war eine abgeschlossene Periode der Kommunikationsgeschichte, in deren Zentrum die neue Infrastruktur des Postwesens gestanden hat. 2. Spätere Medien wie die Eisenbahn, das Autobahnsystem, das Flugverkehrsnetz einerseits, das Telefon, das

80 Ebd., S. 35.

81 Werner Sombart, Der moderne Kapitalismus. Historisch-systematische Darstellung des gesamteuropäischen Wirtschaftslebens von seinen Anfängen bis zur Gegenwart, 3 Bd., München/Leipzig 1916-1927 (ND 1987), hier Bd. 2/1, S. 370f., zit. nach BeHRINGER, Im Zeichen des Merkur, S. 65. 
Kabelnetz und das Internet andererseits bauten strukturell und bis in organisatorische Details hinein auf den Medien der Frühen Neuzeit auf, deren Entwicklung damit paradigmatische Bedeutung zukommt. 3. Das »immaterielle Erbe« des frühneuzeitlichen Kommunikationswesens hat die westliche Zeit- und Raumauffassung wesentlich geprägt und in so entscheidender Weise zur Modernisierung der europäischen Kultur beigetragen, dass gerade diese Innovation im Zuge der Globalisierung von allen Zivilisationen übernommen werden musste. Daraus resultiert die metaphorische Generalthese, »daß die Kommunikationsrevolution der Frühneuzeit die `Mutter aller Kom-

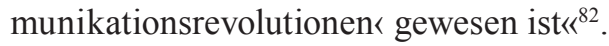

Schon in der Frühmoderne teilten sich die Kommunikationen in technische Infrastruktur, Informationen und Transportwege. Dies weist eine interessante Übereinstimmung aus mit der Beschreibung des Internet-Systems durch Manuel Castells. Dieser sprach für das Internet vom ersten Element der »technological infrastructure of information systems, telecommunications, and transportation lines«, vom zweiten Element der Knotenpunkte (»nodes and hubs «), die den Austausch der Informationen regulierten, und drittens von den »habitats of the social actors who operate the networks $\aleph^{83}$. Behringer kommt zu dem erstaunlichen Resultat, dass die frühmoderne Post aus genau denselben Funktionselementen bestand. Spätere Archäologen beispielsweise würden vom Postnetz nichts finden als nur die »Portale«: Genauso wie beim Internet die Rechner übrigblieben, als Hardware-Schrott, während die Verbindungen verschwänden, so sahen spätere Generationen beim Postverkehr die Posthäuser und die Briefe, nicht aber die Verbindungen. Der Flugverkehr weise dieselben Eigenschaften auf, denn auch hier blieben nur die Flughäfen und die Wracks der Flugzeuge, während die Strecken nur virtuell vorhanden seien ${ }^{84}$.

Das frühmoderne Postwesen war den Botendiensten der Kaufmannsunternehmungen entsprungen ${ }^{85}$. Die Familie Taxis, mit der mehr als drei Jahrhunderte lang das Postwesen verknüpft war, betrieb im 15. Jahrhundert einen Botendienst in Bergamo ${ }^{86}$. Der Begriff »Post « stammte aus dem Lateinischen und bezeichnete als Posita statio einen festen Aufenthaltsort an einer Ver-

82 Teilweise wörtlich so in ebd., S. 42.

83 Manuel Castells, Grassrooting the Space of Flows, in: James O. Wheeler/Yuko AoyAMA/Barney WARF (Hg.), Cities in the Telecommunications Age. The Fracturing of Geography, New York 2000, S. 18-30, Zitat S. 19.

84 Behringer, Im Zeichen des Merkur, S. 24. Zur Geschichte des Fliegens, an deren Erforschung sich Behringer ebenfalls beteiligt hat: Wolfgang BeHRInGer/Constance OTT-KoptschaLiJsKi, Der Traum vom Fliegen. Zwischen Mythos und Technik, Frankfurt a.M. 1991.

$85 \mathrm{Zu}$ den Botendiensten: Klaus Gerteis, Reisen, Boten, Posten. Korrespondenz in Mittelalter und früher Neuzeit, in: Hans PoHL (Hg.), Die Bedeutung der Kommunikation für Wirtschaft und Gesellschaft, Stuttgart 1989, S. 19-36.

86 Zu den Taxis: BeHringer, Im Zeichen des Merkur, S. 58-64. 
kehrsroute, wo Pferde und Reiter bereitgehalten wurden. Hier wurden Nachrichtensendungen übernommen und weiterbefördert. Auf italienisch hieß das Posta und kam schon in Marco Polos Reisebeschreibungen über China aus dem frühen 14. Jahrhundert vor ${ }^{87}$. Italien hatte im 16. Jahrhundert bereits ein dichtes Kommunikationsnetz, ohne dass die Familie Taxis in Gänze dafür zuständig gewesen wäre. Auch in Frankreich entwickelte sich ein staatliches Postsystem, allerdings sehr viel stärker auf die Krone und ihre Bedürfnisse zugeschnitten als im Reich ${ }^{88}$.

Das wichtigste Verdienst der Taxis-Post im 16. Jahrhundert war der Geschwindigkeitsgewinn beim Transport der Briefe zwischen den Zentren des Habsburger Imperiums. Im Spätmittelalter schaffte ein Transportwagen pro Tag ca. $35 \mathrm{~km}$, ein Pferd ca. $60 \mathrm{~km}$. Binnen weniger Jahrzehnte benötigte man im Stafettenverfahren nur noch einen Bruchteil der Zeit, die Tagesleistung konnte für die überbrachte Botschaft auf bis zu $150 \mathrm{~km}$ gesteigert werden. Aus den Entfernungsangaben wurden später Berechnungseinheiten: Eine deutsche Meile dauerte im Postverkehr normalerweise eine Stunde, zwei deutsche Meilen zwei Stunden. Diese Doppelstunde wurde als »eine Post« bezeichnet. Diese Entfernungseinheit entsprach im Alten Reich einem Honorierungsanspruch von einem Gulden ${ }^{89}$. Behringer spricht von $»$ Raumportionierung «, wenn er die Errichtung eines lückenlosen Systems an Posthäusern und -stationen beschreibt, an denen ein galoppierender Reiter ankam, um das »Felleisen « mit den Briefen an den Kollegen weiterzureichen, der mit einem frischen Pferd direkt zur nächsten Etappe aufbrach ${ }^{90}$. Auf »Stundenzetteln « wurde der tatsächliche Verlauf des Transports dokumentiert, gleichzeitig ließ und lässt sich durch diese Evaluation der schrittweise Geschwindigkeitszuwachs nachweisen.

Hatten unter Kaiser Maximilian I. noch die bilateralen Beziehungen zwischen dem Kaiser und der Betreiberfamilie Taxis im Vordergrund gestanden und war die Post unter Karl V. eher zu einer niederländischen Post geworden, so entwickelte sich die Reichspost in ihrer weitreichenden Privilegierung besonders unter Kaiser Rudolf II. Der Prozess ist in seiner Komplexität hier nicht nachzuzeichnen ${ }^{91}$. Wichtig sind die Auswirkungen auf das Zeitungswesen. Das Postsystem bot zudem Gelegenheit, zusätzliche Informationen zu übermitteln. Die Postmeister erfuhren durch ständigen Kontakt mit reisenden Boten allerlei Neuigkeiten, die sie ihrerseits an andere Boten und Reisende weitervermittelten. Warum sollte das nicht systematisiert werden, so dachten sich die Betreiber. Zunächst betrieben sie Handel mit geschriebenen

87 Behringer, Thurn und Taxis, S. 14f.; Behringer, Im Zeichen des Merkur, S. 56.

88 Zu Europa: Behringer, Im Zeichen des Merkur, S. 94-97.

89 Ebd., S. 117-126.

90 Zum Konzept der »Raumportionierung«: ebd., S. 21.

91 Vgl. dazu die ausführliche, quellengesättigte Darstellung in ebd., S. 127-216. 
Zeitungen. In den 1590er Jahren verbreitete beispielsweise das Taxis-Posthaus in Prag briefliche Zusammenstellungen mit politischen und militärischen Berichten. Abschriften davon finden sich heute in den kursächsischen Archiven ebenso wie in den Zeitungen der Familie Fugger. Wolfgang Behringer weist darauf hin, dass diese Informationen bereits öffentlich waren: Nicht Stand oder ökonomisches Interesse war Voraussetzung, um in den Nachrichtendienst einbezogen zu werden, sondern nur die Bereitschaft, dem Postmeister jährlich 15 Rtl. zu bezahlen ${ }^{92}$.

Seit dem 16. Jahrhundert wurden nicht nur Briefe, sondern auch gedruckte Texte wie »Neue Zeitungen« bzw. Flugschriften oder Flugblätter per Post vertrieben. Es blieb den Postmeistern nicht verborgen, wie viele Informationen Zusammenstellungen darstellten, die aus früheren Medien kompiliert worden waren. Das konnten sie auch, davon waren sie überzeugt. Aus diesem Gedanken heraus entstanden erste sog. »Postzeitungen«. Einer der frühesten Herausgeber einer »Postzeitung« war der Frankfurter Postmeister Johannes von den Birghden, der sein Blatt 1617 begründete und während des Dreißigjährigen Krieges zu den streitbarsten Medienunternehmern gehörte. Zwischenzeitlich betrieb er auch ein schwedisches Postwesen im Reich. Birghden versuchte zwar, vom Kaiser ein überregionales Zeitungsmonopol in Analogie zum Postmonopol zu erlangen, doch konnte er diese Zentralisierung des Nachrichtenwesens nicht durchsetzen ${ }^{93}$. Auch ohne dass eine Theorie vom Nutzen ökonomischer Konkurrenz vorgelegen hätte, bestand der Reichshofrat nur auf der Einlieferung von 18 Exemplaren der Frankfurter Postzeitung als Anerkennung seiner Eigenschaft als oberste Zensurbehörde, auch wenn diese Funktion nicht wirklich ausgeübt wurde. Die Zeitungen erfreuten vielmehr die Hofgesellschaft und die Spitzenbürokratie in Wien ${ }^{94}$. Nach dem Vorbild der Frankfurter Postzeitung entstanden zahlreiche weitere Periodika, die den Namensbestandteil »Post « aufwiesen ${ }^{95}$. Manche Zeitungen tragen heute noch in ihrem Namen den Verweis auf die Beziehung ihrer Gründer zum Postsystem, etwa die Rheinische Post oder die Washington Post.

Auch in Hamburg versuchte das Haus Taxis in den 1630er Jahren, ein Reichsmonopol auf seiner Postzeitung zu erlangen, auch hier erließ Kaiser Ferdinand II. zunächst ein Mandat an den Magistrat, den kaiserlichen Post-

92 Ebd., S. 324.

$93 \mathrm{Zu}$ von den Birghden: ebd., S. 382-397. Vgl. auch Karl Heinz Kremer, Johann von den Birghden (1582-1645). Kaiserlicher und königlich-schwedischer Postmeister zu Frankfurt am Main, Bremen 2005.

94 Behringer, Im Zeichen des Merkur, S. 428. Selbstverständlich genoss auch der Reichshofrat Portobefreiung, so dass das Gericht nicht nur die Zeitung umsonst bekam, sondern auch den Transport nicht zu bezahlen brauchte.

95 Vgl. die Auflistung in ebd., S. 408. 
meister Hans Jacob Kleinhans als einzigen legitimen Herausgeber einer Zeitung anzuerkennen. Der Magistrat weigerte sich, seine Privilegierung des Johann Meyer für seine Wöchentliche Zeitung zu widerrufen, sondern plädierte für Vielfalt und die Berechtigung für beide Interessenten, aktuelle Berichte zu drucken. Ein Jahr später wurde ein dahingehender Vergleich zwischen allen Beteiligten anerkannt ${ }^{96}$. Für Leipzig ist für 1652 ein Streit zwischen dem städtisch privilegierten Zeitungsverleger Timotheus Ritzsch und dem Postmeister Christoph Mühlbach überliefert, auch hier konnte sich die lokale Zeitungskultur erfolgreich gegen ein Reichs-Zeitungs-Monopol wehren, der Magistrat erwirkte den Zusammenschluss zu einer »AvisenSocietät $\ll^{97}$.

$\mathrm{Zu}$ dieser Zeit hatten sich in Norddeutschland bereits konkurrierende Postsysteme der großen Landesherren gebildet. Der temporäre Machtverlust der Habsburgerkaiser durch den Dreißigjährigen Krieg trug dazu bei. Brandenburg-Preußen verband 1649 seine Gebiete durch eine Postlinie von Kleve bis nach Königsberg. Kursachsen, Braunschweig-Hannover und HessenKassel folgten bzw. schlossen sich mit den vorhandenen Systemen der protestantischen Standesgenossen zusammen ${ }^{98}$. Dass die Thurn und Taxis-Post zu nachrichtendienstlichen Zwecken tätig wurde, ist bekannt. Doch auch in den norddeutschen Postsystemen fand Vergleichbares statt. Um 1700 waren im Kurfürstentum Hannover die beiden Poststellen in Gifhorn und Nienburg für die Durchsicht wichtiger fremder Post zuständig. Dabei wurde auch diplomatische Post systematisch ausgewertet, indem alle entsprechenden Schreiben geöffnet und später nach dem Abschreiben mit gefälschten neuen Siegeln weitergeschickt wurden. Kurhannover verfügte über international anerkannte Experten in Kryptographie, unter denen Ludwig Ernst v. Neubourg $(\uparrow 1713)$ der bedeutendste war. Nach seinem Tod hatte Johann Philipp Schlemm (1672-1733) das Dechiffrierbüro unter sich ${ }^{99}$.

Als eigene Aktiva brachten die Postmeister ihre Verbindungen zu allen anderen Poststellen ins Medienwesen ein sowie die Möglichkeit, in ihrem Netzwerk kostenfrei expedieren zu können ${ }^{100}$. Bei vorhandenen Nachrichten war es in der Frühmoderne kein großes Problem, einen Lohndrucker zu finden, der die Texte gegen Honorar in gewünschter Zahl zu Papier brachte. Der Postmeister las daher fremde Nachrichten, sowohl handschriftliche als auch

96 Böning, Welteroberung durch ein neues Publikum, S. 28-34.

97 Weber, Galerie der Zeitungspresse im 17. Jahrhundert, hier S. 106.

98 Behringer, Thurn und Taxis, S. 95-98.

99 Georg Schnath, Geschichte Hannovers im Zeitalter der neunten Kur und der englischen Sukzession, 1674-1714, 4 Bd., Hildesheim/Leipzig 1938-1982, hier Bd. 2, S. 60f. - Vgl. zur sonstigen Geheimdiensttätigkeit im Auftrag Kurhannovers: Ebd., Bd. 2, S. 351f.

100 Auf diesen Umstand weist Wolfgang Behringer hin, kennzeichnet die entsprechende Aussage aber als Vermutung: BeHRinger, Im Zeichen des Merkur, S. 428. 
auswärtige Zeitungen, wählte diejenigen aus, die er für die wichtigsten (und politisch unverfänglichsten) hielt, und rückte sie - zumeist im selben Wortlaut - in seine eigene Zeitung ein. Ausländische Texte wurden in der Regel übersetzt (soweit die Sprachkenntnisse des Postmeisters reichten; nicht selten wurde auch für die Übersetzung auswärtiger Sachverstand gegen Honorar eingeworben).

Ein erfahrener Verleger oder Drucker konnte ebenfalls ein europäisches Informationsnetz aufbauen, um Neuigkeiten aus aller Herren Länder zu Papier zu bringen. Fremdzeitungen wurden durch die Post mit Aufschlägen vertrieben. Hinzu kam die Verbindung zur Reichspost, indem die Postmeister auch den sog. »Zeitungsdebit« einzogen: Der Zeitungsabnehmer musste dem lokalen Postmeister einen erhöhten Gesamt-Abonnementpreis zahlen, dessen Höhe von der Transportentfernung abhängig war. Die Aufschläge boten dem Postmeister einen Anreiz, selbst Werbung für fremde Zeitungen zu machen. Die Einkünfte aus diesem Vertriebsgeschäft, die sog. »ZeitungsEmolumente«, waren erheblich und galten als legitimer Nebenerwerb für die Postmeister, die die Zentrale der Reichspost ihnen gern gönnte ${ }^{101}$. Interessanterweise machte die Reichspost von ihrem Anspruch, auch ein Zeitungsmonopol zu besitzen, nicht in der Weise Gebrauch, dass sie die Zeitungsversendung behinderte, sondern das genaue Gegenteil war der Fall ${ }^{102}$.

Die Mehrzahl der Postmeister und Verleger, die sich zur Zeitungsherausgabe entschlossen, war gebildet und hatte daher auch ein intellektuelles Interesse an dieser Art von Erwerb. Vor allem in diesen beiden Berufsgruppen gab es eine hinreichende Zahl von Personen, die über das nötige Kapital verfügte, um mit einem Periodikum an die Öffentlichkeit treten zu können ${ }^{103}$. Verkauft wurde die Zeitung vorwiegend im Abonnement, wobei ein Verkauf über mehrere Stationen möglich war (Kauf durch Zwischenhändler bis zum Endkunden). Daneben spielten der Einzelverkauf und die Vermietung eine geringere Rolle ${ }^{104}$.

Der genannte Prozess gestaltete sich in mehrfacher Hinsicht konfliktreich. Zum einen konkurrierten die Postmeister jahrzehntelang mit städtischen Botendiensten, die auf ihre eigenen Privilegien des Magistrats verweisen konnten, während die Postmeister auf die kaiserlichen Patente zurückgrif-

101 Dorn/Vogel, Geschichte des Pressevertriebs, S. 24; vgl. auch Schwarz, Der Postzeitungsvertrieb in der deutschen Postgeschichte, S. 48. Die Aufschläge konnten zwischen $1 / 2$ und 4 Gulden pro Jahresabonnement liegen: DALLMEIER, Die kaiserliche Reichspost zwischen Zeitungsvertrieb und Zensur, hier S. 238; BeHringer, Im Zeichen des Merkur, S. 429.

102 Feststellung von Behringer: ebd., S. 428.

$103 \mathrm{Ob}$ eine Zeitung wirklich eine sichere Einkommensquelle war, wie Fischer schreibt, muss angesichts der zahlreichen Pleiten fraglich bleiben. Vgl. die Beispiele für den Erfolg bei FISCHER, Die ältesten Zeitungen und ihre Verleger, S. 27f.

$104 \mathrm{Zu}$ den drei Arten des Pressevertriebs: Dorn/Vogel, Geschichte des Pressevertriebs, S. 7. Dort auch der Hinweis auf den schlechten Forschungsstand zum Vertrieb. 
fen $^{105}$. Zum anderen konkurrierten städtisch privilegierte Zeitungsherausgeber mit Postmeistern, die sich für ihr Periodikum wiederum eine Lizenz ihrer vorgesetzten Stellen verschafften, ohne dass dies mit dem jeweiligen Magistrat abgestimmt worden war. Für zahlreiche Zeitungsunternehmungen bedeuteten die Konflikte existenzielle Herausforderungen und Gefährdungen, sie füllten die Akten der Gerichte - stehen dafür oft aber heute noch zur Erforschung der Mikrostrukturen des frühmodernen Kommunikationssystems zur Verfügung.

Hinsichtlich der Öffentlichkeitswirksamkeit lohnte sich das Etikett »Postzeitung«, denn viele Betreiber häuften ein derartiges symbolisches Kapital an, dass die Leserschaft gern auf diese Periodika zurückgriff. Das hatten auch illegale Nachahmer wahrgenommen wie ein Drucker im dänischen Altona, der im 18. Jahrhundert jahrzehntelang einen Reichs-Post-Reuter herausgab, ohne dazu berechtigt zu sein, und dadurch die Hamburger Reichspostzeitung vom Markt verdrängte ${ }^{106}$.

105 Vgl. beispielsweise die Auseinandersetzungen um die Postlizenzen in der Reichsstadt Köln: Wolfgang Behringer, Köln als Kommunikationszentrum um 1600. Die Anfänge des Kölner Post- und Zeitungswesens im Rahmen der frühneuzeitlichen Medienrevolution, in: Georg MöLICH/Gerd Schwerhoff (Hg.), Köln als Kommunikationszentrum. Studien zur frühneuzeitlichen Stadtgeschichte, Köln 2000, S. 183-210.

106 BeHringer, Im Zeichen des Merkur, S. 408f. mit Nachweis. 


\section{Leserschaft}

\subsection{Zur Forschungsentwicklung}

Für die Hochaufklärung stellt der Buchwissenschaftler Reinhard Wittmann fest:

Der Buchmarkt hatte es nun mit einem zumindest tendenziell unbegrenzten, heterogenen und anonymen Publikum zu tun, dessen Lesegeschmack und Bedürfnisse sich immer mehr ausdifferenzierten, dem gleichzeitig an Fachbüchern zum beruflichen Aufstieg und an politischer Information, an blutrünstigen Schauerromanen und an geistlicher Stärkung gelegen war $^{1}$.

Allerdings hat es den Anschein, als reiche dieser Befund weiter in die Vergangenheit zurück, als bislang bekannt. Die Ausrichtung auf den anonymen Markt war seit jeher Proprium der frühmodernen Medienwelt: Die festen Abnehmer in Kirche und Staat stellten immer nur einen Teil der Kundschaft dar, der spannendere Teil hinsichtlich der dynamischen Entwicklungsperspektiven und der plötzlichen Ertragschancen war stets der »freie« Markt. Ausdifferenzierung lässt sich seit der Reformationszeit mühelos nachweisen, spätestens seit dem ausgehenden 17. Jahrhundert dringt die Medienproduktion auf breiter Front in die nichtadligen und nichtakademischen Kreise ein.

Hinsichtlich der Leserschaft kann trotz zahlreicher Forschungsanstrengungen in den letzten Jahrzehnten immer noch gesagt werden, dass erst wenig bekannt ist und vermutlich zahlreiche Überraschungen noch auftauchen werden. Der Prozess der »Alphabetisierung« und »Literalisierung« war ein langer und langsamer, bei dem jede Form der Ungleichzeitigkeit zu beobachten ist. Schon die Begrifflichkeit wirft Probleme auf, wie Hans Erich Bödeker und Ernst Hinrichs in mehreren Sammelbänden und Studien aufgezeigt haben ${ }^{2}$. Auch der Zeitraum, innerhalb dessen der Prozess sich abspielte,

1 Reinhard Wittmann, Gibt es eine Leserevolution am Ende des 18. Jahrhunderts?, in: Roger Chartier/Guglielmo Cavallo (Hg.), Die Welt des Lesens. Von der Schriftrolle zum Bildschirm, Frankfurt a.M. 1999 (ital. 1995), S. 419-454, hier S. 442.

2 Hans Erich BöDEKER / Ernst HinRICHS (Hg.), Alphabetisierung und Literalisierung in Deutschland in der Frühen Neuzeit, Tübingen 1999; Ernst Hinrichs, Zur Erforschung der Alphabetisierung in Nordwestdeutschland in der Frühen Neuzeit, in: Anne ConRad u.a. (Hg.), Das Volk im Visier der Aufklärung. Studien zur Popularisierung der Aufklärung im späten 18. Jahrhundert, Hamburg 1998, S. 35-56; Ernst HinRichs, Alphabetisierung. Lesen und Schreiben, in: Richard van Dülmen/Sina Rauschenbach (Hg.), Macht des Wissens. Die Entstehung der modernen Wissensgesellschaft, Köln/ Weimar/Wien 2004, S. 539-561. - Zu den angelsächsischen Vorbildern: Jack Goody (Hg.), Literacy in Traditional Societies, Cambridge 1968. 
sprengt herkömmliche Forschungsportionierungen. Harvey J. Graff hat die Geschichte der literacy in mehrere Abschnitte geteilt, die durch folgende Schlüsselereignisse charakterisiert sind:

1. Die »Erfindung« der Schrift in Mesopotamien um 3100 v. Chr.

2. Die »Erfindung« des Alphabets im vorklassischen Griechenland um 650 bis $550 \mathrm{v}$. Chr.

3. Der Beginn des Prozesses der Alphabetisierung in den Schulen der griechischen Stadtstaaten um 500 bis 400 v. Chr.

4. Herausbildung öffentlicher Schulen im Römischen Reich 200 v. Chr. bis 200 n. Chr.

5. Entstehung der »karolingischen Sprache« zwischen 800 und $900 \mathrm{n}$. Chr.

6. Vollentwicklung des europäischen Städtewesens im 13. Jahrhundert mit wachsender Nachfrage nach schriftlichen Dokumenten in den Verwaltungen.

7. Entwicklung des Buchdrucks mit separaten Lettern und des Letterngusses um 1450.

8. Dauerhafte Partnerschaft und Trägerschaft des Schulwesens im Alphabetisierungsprozess während des Reformationsjahrhunderts.

9. Europäische Alphabetisierungs-Moderne mit der Durchsetzung der Aufklärung und des Pflichtschulwesens im 18. und frühen 19. Jahrhundert ${ }^{3}$.

Eine weitere Einteilung wurde von Hans-Martin Gauger vorgelegt, der sechs chronologisch aufeinander folgende Leseepochen unterscheidet:

1. Vorhellenistische Lesekultur (bis $400 \mathrm{v}$. Chr.).

2. Hellenistisch-römische Lesekultur (400 v. Chr. bis $500 \mathrm{n}$. Chr.).

3. Frühmittelalterliche Lesekultur (800 bis 1150).

4. Hoch- und spätmittelalterliche Lesekultur (1150 bis 1300).

5. Frühneuzeitliche Lesekultur (1300 bis 1800).

6. Moderne Lesekultur (18. Jahrhundert bis heute) ${ }^{4}$.

3 Harvey J. Graff, The Legacies of Literacy. Continuities and Contradictions in Western Culture and Society, Bloomington 1987, zit. nach HinRichs, Alphabetisierung. Lesen und Schreiben, S. $540 \mathrm{f}$.

4 Martin Gauger, Die sechs Kulturen in der Geschichte des Lesens, in: Paul Goetsch (Hg.), Lesen und Schreiben im 17. und 18. Jahrhundert. Studien zu ihrer Bewertung in Deutschland, England, Frankreich, Tübingen 1994, S. 27-47. 
Weniger weit zurück reicht der Wahrnehmungsfokus in der Geschichte des Lesens von Erich Schön im Rahmen des Handbuch Lesen, wo der Ausgangspunkt die klassische griechische Antike ist ${ }^{5}$. Schön gliedert im Folgenden nach der Zeitalterunterscheidung Mittelalter, Frühe Neuzeit (unter besonderer Betonung der Leseförderung in der Folge der Reformation), Aufklärung, 19. und 20. Jahrhundert. Die Sozialgeschichte des Lesens steht dabei im Vordergrund, nicht nur die intentionale Bildungsgeschichte anhand der Entwicklung der Bildungsinstitutionen.

Für das Zeitalter, das in dieser Studie im Mittelpunkt steht, bedeutet das gesteigerte Bildungsbemühungen während des gesamten Konfessionellen Zeitalters. Die pädagogischen Vorhaben des Aufklärungsjahrhunderts bauten auf diesen Fundamenten auf. Vor allem der Unterschied zwischen Stadt und Land ist in dieser Hinsicht prägend ${ }^{6}$. Fast überall waren die Städte mit ihren Bildungsanstrengungen den ländlichen Gegenden voraus. Ernst Hinrichs führt das auf ein anderes kollektives Bewusstsein zurück, das Kulturtechniken wie Lesen, Schreiben und Rechnen eine höhere Bedeutung beimaß, als das im landwirtschaftlichen Kontext der Fall war'. Positive Ausnahmen im ländlichen Bereich waren die norddeutschen Marschgegenden, die während der Frühen Neuzeit prosperierten, über günstige Besitzrechte verfügten und zudem vom Dreißigjährigen Krieg nur am Rande betroffen waren. Hier legte die bäuerliche Bevölkerung selbst Wert auf gute schulische Ausbildung ihrer Söhne ${ }^{8}$.

Erst dahinter rangierte die Konfessionsdifferenz. Die Schulverhältnisse in deutschen Territorien des 16. bis 18. Jahrhunderts werden gegenwärtig verstärkt untersucht, da sie als ein zentraler Indikator für die Auswirkungen des Konfessionalisierungs- und Sozialdisziplinierungsprozesses angesehen werden können ${ }^{9}$. Die größere Dynamik in protestantischen Territorien und Städten gegenüber vergleichbaren katholischen politischen Einheiten wird dabei immer wieder bestätigt, mag das konfessionspolitisch korrekt sein oder nicht ${ }^{10}$. Eine weitere Differenz schlägt überall durch, regionen- und konfes-

5 Erich Schön, Geschichte des Lesens, in: Bodo Franzmann/Klaus Hasemann/Dietrich LöFfLER/Erich SchÖN (Hg.), Handbuch Lesen, München 1999, S. 1-85.

6 Vgl. Wittmann, Geschichte des deutschen Buchhandels, S. $174 \mathrm{f}$.

7 Hinrichs, Alphabetisierung. Lesen und Schreiben, S. 544.

8 Studien zu den Marschregionen, besonders Butjadingen: Wilhelm NordEN, Die Alphabetisierung der oldenburgischen Küstenmarschen im 17. und 18. Jahrhundert, in: Ernst HiNRichs / Wilhelm Norden (Hg.), Regionalgeschichte. Probleme und Beispiele, Hildesheim 1980, S. 103-164.

9 Vgl. dazu die Sammelbände von Heinz Schilling/Marie-Antoinette Gross (Hg.), Im Spannungsfeld von Staat und Kirche. »Minderheiten« und »Erziehung« im deutsch-französischen Gesellschaftsvergleich 16. bis 18. Jahrhundert, Berlin 2003; Heinz Schilling/Stefan EhrenPREIS (Hg.), Erziehung und Schulwesen zwischen Konfessionalisierung und Säkularisierung. Forschungsperspektiven, europäische Fallbeispiele und Hilfsmittel, Münster u.a. 2003.

10 Bewertung bei Hinrichs, Alphabetisierung. Lesen und Schreiben, S. 544f. 
sionsübergreifend: Die unterschiedlichen Bildungsniveaus von Männern und Frauen. Dieser Befund in der Unterschreibpraxis korreliert mit den verfügbaren Bildungsstätten für die beiden Geschlechter. Generell wird inzwischen vor einer Überschätzung des Merkmals »Signierfähigkeit« gewarnt. Viele Indizien sprechen dafür, dass ein beträchtlicher Teil der Frauen lesefähig war, aber nicht signieren konnte. Gerade für das 18. Jahrhundert überwiegt der vorhandene Lesestoff mit weiblicher Zielgruppe ganz eindeutig und mit Verlauf des Jahrhunderts zunehmend den bildungsbürgerlichen Anteil der Frauen an der Bevölkerung ${ }^{11}$.

Ein eindeutiges Nord-Süd- oder West-Ost-Gefälle hingegen lässt sich für das frühmoderne Deutschland nicht ausmachen. Regionale Vielfalt bestimmt das Bild. Heute zeichnet sich ab, dass Kursachsen und das benachbarte Thüringen die Bildungshochburgen darstellten ${ }^{12}$. Schlusslichter sind, ohne dass das bislang ernsthaft empirisch erhärtet worden wäre, vermutlich Kurbayern und die österreichischen Erzherzogtümer ${ }^{13}$. Konkrete Auswertungen von mehreren Regionen liegen zwar inzwischen vor, angesichts der Differenzen der Bildungslandschaften im polykratischen Reich erscheinen Interpolationen immer noch gewagt ${ }^{14}$.

Nachdem sich während des Reformationsjahrhunderts die Lesefähigkeit, gestärkt durch die obrigkeitlichen Bildungsanstrengungen, verbessert hatte, verursachte der Dreißigjährige Krieg offenbar einen Rückgang dieser Kulturtechnik. Als Gründe dafür sind zum einen die Probleme zu nennen, ein reguläres Bildungswesen unter Kriegsbedingungen aufrechtzuerhalten: Viele Schulen und Hochschulen waren geschlossen worden (teilweise infolge von erzwungenen Konfessionsveränderungen). Zum anderen war der Problemfokus breiter Bevölkerungsschichten spürbar auf Überlebenssicherung ausgerichtet, nicht auf Kulturerwerb und -weitergabe. Zum dritten wurden Stätten der Druckproduktion durch den Krieg in Mitleidenschaft gezogen. Selbst in Städten wie Nürnberg, das verhältnismäßig wenig kriegsbetroffen war, litt das buchherstellende Handwerk ${ }^{15}$.

11 Ebd., S. 546.

$12 \mathrm{Zu}$ Kursachsen: Anne-Kristin KUPKE, Elementarschulunterricht in Kursachsen um 1670, in: BÖDEKER/HINRICHS, Alphabetisierung und Literalisierung in Deutschland in der Frühen Neuzeit, S. 225-252; Wolfgang Schmale, Der Januskopf der Alphabetisierung. Kursachsen in der frühen Neuzeit, in: Ebd., S. 349-366; zu Thüringen: Andreas KlingER, Der Gothaer Fürstenstaat. Herrschaft, Konfession und Dynastie unter Herzog Ernst dem Frommen, Husum 2002.

13 Vgl. Reinhart Siegert, Zur Alphabetisierung in den deutschen Regionen am Ende des 18. Jahrhunderts, in: BöDEKER/HinRICHS, Alphabetisierung und Literalisierung in Deutschland in der Frühen Neuzeit, S. 283-307, hier S. 296 u. $301 f$.

14 Reinhart Siegert verweist auf 14 Studien mit gut aufbereitetem statistischen Material, hinzu kommen die Beiträge in dem Sammelband, in dem Siegerts Beitrag steht: Ebd., S. 287f.

15 Vgl. Sporhan-Krempel, Nürnberg als Nachrichtenzentrum zwischen 1400 und 1700, pas.; dies., Buchdruck und Buchhandel in Nürnberg im 17. Jahrhundert, in: RAABE, Bücher und Bibliotheken im 17. Jahrhundert in Deutschland, S. 25-37. 
Allerdings betraf der Rückgang im Lesebereich nicht alle Sektoren gleichermaßen: Das Zeitungswesen beispielsweise setzte seinen Aufschwung während des Krieges und darüber hinaus fort. Else Bogel und Elger Blühm stellten diesbezüglich fest: »Auch nach dem Westfälischen Frieden nahm die Zahl der deutschsprachigen Zeitungen nicht $a b{ }^{16}{ }^{16}$. Wo in der Forschungsintensität ein mediales »Loch« zwischen den publizistischen Hochphasen der Reformation und des Dreißigjährigen Krieges einerseits und der Hochaufklärung andererseits zu sein scheint, lässt sich hinsichtlich der Zeitungen eher Kontinuität als Unterbrechung feststellen. Für das gesamte 17. Jahrhundert sind für das Gebiet des Heiligen Römischen Reiches ca. 200 Zeitungsunternehmen nachgewiesen. Die Gesamtzahl der Zeitungsexemplare, die erhalten sind, beträgt nach gegenwärtigem Forschungsstand über 60.000 Nummern ${ }^{17}$. Gegen Ende des Jahrhunderts waren gleichzeitig zwischen 50 und 60 Zeitungsverlage tätig. Die Zahl der Leser und sonstigen Rezipienten, die durch ihre Ausgaben erreicht wurden, dürfte zwischen 240.000 und 300.000 Lesern gelegen haben ${ }^{18}$.

Besonders beim illustrierten Flugblatt hat die Forschung lange angenommen, dass diese Mediengattung im 16. und 17. Jahrhundert wie keine andere auf breite Volksschichten gewirkt habe. Kürzlich hat Alfred Messerli diesen Zusammenhang erneut untersucht und dabei den aktuellen Forschungstand seit Beginn der großen Flugblatt-Editionen durch Wolfgang Harms, John Roger Paas u.a. eingearbeitet ${ }^{19}$. Messerli bezweifelt, dass die Flugblätter vorrangig dem »gemeinen Mann« gegolten haben und folgt dabei Überlegungen, die bereits von Rudolf Schenda angestellt worden $\operatorname{sind}^{20}$. Aufgrund der komplexen Bildlichkeit und Sprache dürften die Drucke in ihrer ganzen Vielfalt ohnehin nur geschulten Augen verständlich geworden sein.

16 Bogel/Blühm, Die deutschen Zeitungen, Bd. 1, S. VIII.

17 Vgl. Faulstich, Medien zwischen Herrschaft und Revolte, S. 230, und bei Wilke, Grundzüge der Medien- und Kommunikationsgeschichte, S. 52.

18 Vgl. die unterschiedlichen Berechnungen: Wilke, Die Zeitung, S. 388; Dorn/Vogel, Geschichte des Pressevertriebs, S. 16f.

19 Alfred Messerli, War das illustrierte Flugblatt ein Massenlesestoff? Überlegungen zu einem Paradigmawechsel in der Erforschung seiner Rezeption, in: HARMS/MessERLI, Wahrnehmungsgeschichte und Wissensdiskurs im illustrierten Flugblatt der Frühen Neuzeit, S. 23-31. - Vgl. besonders die wichtigen Editionen von Wolfgang Harms/Michael Schilling (Hg.), Deutsche illustrierte Flugblätter des 16. und 17. Jahrhunderts, Bd. 1-4 u. 7, München, Tübingen 1980-1997, und John Roger PAAs (Hg.), The German Political Broadsheet 1600-1682, (bisher) 10 Bd., Wiesbaden 1985-2010.

20 Schenda hatte zwei Argumente angeführt: 1. Die soziale Verteilung der Bildmedien machte es wenig wahrscheinlich, dass Illiterate sie hätten beziehen können. 2. Die Kompetenz zur Decodierung vielschichtiger Bildflugschriften habe gefehlt: Rudolf ScHENDA, Bilder vom Lesen. Lesen von Bildern, in: IASL 12 (1987), S. 82-106; ders., Bilder im Kopf. Kindheitserinnerungen, in: Carola Lipp (Hg.), Medien popularer Kultur. Erzählung, Bild und Objekt in der volkskundlichen Forschung, Frankfurt a.M./New York 1995, S. 303-316, vgl. dazu auch MesserLI, War das illustrierte Flugblatt ein Massenlesestoff?, S. 25. 
Dem ist zuzustimmen, wenn auch die klare Unterscheidung Lesen Nichtlesen hier, wie an vielen anderen Stellen, fragwürdig geworden ist. Immer noch stellt man sich die ständische Gesellschaft viel statischer vor, als sie tatsächlich war. Um der Einheitlichkeit der interpretatorischen Modellbildung willen werden dabei zahlreiche Berührungspunkte übersehen. So ist bekannt, dass Nachrichteninhalte beispielsweise an Orten der städtischen oder ländlichen Kommunikation ausgetauscht worden sind, auf Märkten, Rathausvorplätzen, in Wirtshäusern, vor oder nach den Gottesdiensten. Diese »öffentlichen Räume« waren nicht nur Räume des Aufenthaltes, sondern auch des Gesprächs ${ }^{21}$. Dies geschah teilweise durch professionelle Nachrichtenhändler, anderenteils durch Weitererzählen. Die Vermittlungsvorgänge konnten auf der Ebene von Gleichrangigen stattfinden, sie konnten aber auch als didaktische Vermittlungsprozesse erfolgen. Der Zeitungsvorleser ist bereits vorgestellt worden, d.h. eine Person, die zwar keine offizielle Funktion innehatte, die aber infolge ihrer erfahrenen Ausbildung zur Interpretation von Berichten in der Lage war und bei Nachfragen plausible Erklärungen bereitstellen konnte.

Daher sollte auch hinsichtlich der Bildflugschriften die Option offengehalten werden, dass interessierte Personen, z.B. Pfarrer oder Lehrer, den Gemeindemitgliedern oder Schülern bebilderte Texte als Unterrichtshilfsmittel vorgestellt und ausgelegt haben. Dieser Zusammenhang ist, soweit ich sehe, bislang erst von Bob Scribner für die Reformation angedacht wor$\operatorname{den}^{22}$. Weitere Überlegungen zur Leserschaft der Flugschriften und der Bildflugblättern sollten folgen, da dieser Rezeptionsweg angesichts der kommunikativen Zusammenhänge über Standesgrenzen hinweg naheliegt. Ein anderer Aspekt ist ökonomischer Natur. Es dürfte den Herstellern von Bildflugschriften angenehm gewesen sein, und zwar aus ökonomischen wie aus ideologischen Gründen, wenn breitere Interessentenschichten angesprochen werden konnten - unabhängig davon, wieviel sie von den Texten und der komplizierten Bildlichkeit wirklich verstanden haben.

Für den Verlauf der Frühen Neuzeit geht die Forschung davon aus, dass ein langsamer Wandel von der intensiven, repetitiven Lektüre zum extensiven, einmaligen Genuss von Lesetexten stattgefunden hat. Konnten um 1500 nur ca. 1 bis $2 \%$ der Bevölkerung zu den Lesefähigen im weitesten Sinne

21 Vgl. dazu die Beiträge im Sammelband von Susanne Rau/Gerd Schwerhoff (Hg.), Zwischen Gotteshaus und Taverne. Öffentliche Räume in Spätmittelalter und Früher Neuzeit, Köln/Weimar/Wien 2004.

22 Robert W. ScRIBNER, Flugblatt und Analphabetentum. Wie kam der gemeine Mann zu reformatorischen Ideen?, in: KöHLER, Flugschriften als Massenmedien der Reformationszeit, S. 65-76. 
gezählt werden ${ }^{23}$, so kann davon ausgegangen werden, dass deren Zahl unter den Erwachsenen im Heiligen Römischen Reich von $10 \%$ zu Beginn des 18. Jahrhunderts bis 1770 auf $15 \%$ stieg, um bis 1800 ca. $25 \%$ zu erreichen ${ }^{24}$. Intensive Lektüre besonders geistlicher Texte zur stetigen Erbauung, daneben zur moralischen und auch zur konfessionellen Festigung in der jeweiligen Denomination, war schon von den Reformatoren gefordert worden. Martin Luthers Schrift An die Ratsherren aller Städte deutsches Landes, daß sie christliche Schulen aufrichten und halten sollen von 1524 setzte ein deutliches dahingehendes Signal ${ }^{25}$. Philipp Melanchthon stellte die Förderung des Primarschulwesens genauso in den Vordergrund seines Wirkens: In Kindheit und Jugend sollten die Grundlagen der Frömmigkeit in jeden Untertanen gleich welchen Geschlechts eingepflanzt werden, damit spätere Predigt und Katechese darauf aufbauen konnten. Die Bibellektüre, das Studium der Katechismen - Luthers Kleiner Katechismus sprach ganz ausdrücklich die Laien an - und die Erbauungsliteratur sollten diesen Prozess ergänzen und $a^{a b s i c h e r n}{ }^{26} .1562$ forderte der Marburger Theologieprofessor Andreas Hyperius alle Gläubigen zu stetiger Bibellektüre auf, wobei er die Druckkunst lobte, die eine hinreichende Verbreitung für alle Haushalte erst ermöglicht hatte $^{27}$. Auch die lutherischen Gesangbücher eigneten sich gut dafür, den

23 Wittmann, Geschichte des deutschen Buchhandels, S. 38f. - Wittmann hält es für höchst problematisch, aus der Existenz populärer Lesestoffe für diese Zeit eine breitere Lesefähigkeit der Mittel- und Unterschichten herzuleiten.

24 Immer noch grundlegend: Rudolf SchENDA, Volk ohne Buch. Studien zur Sozialgeschichte der populären Lesestoffe 1770-1910, Frankfurt a.M. 1970 (ND München 1977); ders., Alphabetisierung und Literarisierungsprozesse in Westeuropa im 18. und 19. Jahrhundert, in: Ernst HinRichs / Günther Wiegelmann (Hg.), Sozialer und kultureller Wandel in der ländlichen Welt des 18. Jahrhunderts, Wolfenbüttel 1982, S. 1-20; Rudolf SchendA, Orale und literarische Kommunikationsformen im Bereich von Analphabeten und Gebildeten im 17. Jahrhundert, in: Wolfgang Brückner/Peter Blickle/Dieter Breuer (Hg.), Literatur und Volk im 17. Jahrhundert. Probleme populärer Kultur in Deutschland, Bd. 2, Wiesbaden 1985, S. 447-464. Rolf Engelsing, Die periodische Presse und ihr Publikum. Zeitungslektüre in Bremen von den Anfängen bis zur Franzosenzeit, in: AGB 4 (1963), Sp. 1481-1531; ders., Analphabetentum und Lektüre. Zur Sozialgeschichte des Lesens in Deutschland zwischen feudaler und industrieller Gesellschaft, Stuttgart 1973; ders., Der Bürger als Leser, pas.; ders., Die Perioden der Lesergeschichte in der Neuzeit, Sp. 945-1002.

25 Edition: Martin Luther, D. Martin Luthers Werke. Kritische Gesamtausgabe, 101 Bd. in 4 Reihen (WA = Weimarer Ausgabe), Weimar 1883-1970, hier Bd. 15, S. 27-53. - Vgl. zur Forschungslage: Marcus Wriedt, Art. »Prägungen: Bildung«, in: Beutel, Luther Handbuch, S. 213-236.

26 Zur Bildungsvorstellung Melanchthons: Nicole KuropKA, Melanchthon, Tübingen 2010, S. 56-71; Martin Greschat, Philipp Melanchthon. Theologe, Pädagoge und Humanist, Gütersloh 2011, bes. Kap. 4: Der Pädagoge, S. 71-89. - Zum Zusammenwirken: Marcus Wriedt, Die theologische Begründung der Bildungsreform bei Luther und Melanchthon, in: Michael Beyer/Günther Wartenberg (Hg.), Humanismus und Wittenberger Reformation, Leipzig 1996, S. 155-184.

27 Andreas Hyperius, Ein treuer und christlicher Rath, wie man die Heilige Schrifft teglich lesen soll/allen Stenden der Christen menschen sehr notwendig/Zwey Bücher, Mühlhausen 1562. 
Glauben und die schriftgemäße Lebenspraxis in gereimter und melodischer Weise aufzunehmen und lebenslang verfügbar zu halten ${ }^{28}$.

Durch die Erforschung der Lesepraktiken kann, wie Helmut Zedelmaier nachwies, eine weitgehende Umsetzung der häuslichen Rezeption geistlicher Texte im gesamten protestantischen Europa angenommen werden ${ }^{29}$. Von zahlreichen frühneuzeitlichen Zeitgenossen ist überliefert, wie intensiv die Lektüre betrieben wurde, sodass es nicht verwunderte, wenn sich der eine oder andere Protestant damit brüstete, den ganzen Psalter auswendig zu können. In der Leichenpredigt für einen württembergischen Hofarzt im 17. Jahrhundert wurde festgestellt, der Verstorbene habe besonders seit dem Tod seiner Frau nach eigenen Angaben das Alte Testament siebzehnmal, das Neue Testament einunddreißigmal, Johann Arndts Wahres Christentum neunundzwanzigmal, dessen Paradiesgärtlein über hundertmal, Kubachs großes Gebetbuch neunundzwanzigmal und das rigisch-livländische Gesangbuch achtmal »durchgelesen, gebetet und gesungen $«{ }^{30}$. Weitere Nachweise dieser Art, per Selbstzuschreibung oder Fremdzuschreibung in einer Leichenpredigt, lassen sich unschwer beibringen. Durch ständige Wiederholung wurde der gesamte biblische Wissenskanon vielfach aktualisiert, selbst in anderen, lebensweltlichen Kontexten konnten von den meisten illiteraten Zeitgenossen bei jeder Gelegenheit biblische Exempla zitiert werden ${ }^{31}$. Wenn daher in den Wissenschaften, etwa bei Johannes Althusius und seiner Staatslehre, ständig biblische Begebenheiten als Argumente herhielten, so entsprach dies keineswegs fleißiger Recherche des Forschers, sondern Ausbreitung des allgemeinen Wissensschatzes zur Bekräftigung von Topoi vor einer Leserschaft, die sich vor allem auf die Bedeutung des Arguments im jeweiligen Kontext konzentrierte ${ }^{32}$.

28 Patrice VeIt, Private Frömmigkeit. Lektüre und Gesang im protestantischen Deutschland der frühen Neuzeit. Das Modell der Leichenpredigten, in: Rudolf Vierhaus (Hg.), Frühe Neuzeit - frühe Moderne? Forschungen zur Vielschichtigkeit von Übergangsprozessen, Göttingen 1992, S. 271-295; Patrice VeIt, Das Gesangbuch in der Praxis Pietatis der Lutheraner, in: Hans-Christoph Rublack (Hg.), Die lutherische Konfessionalisierung in Deutschland. Wissenschaftliches Kolloquium des Vereins für Reformationsgeschichte 1988, Gütersloh 1992, S. 435-454.

29 Zedelmaier, Lesetechniken. Die Praktiken der Lektüre in der Neuzeit, hier bes. S. 15-19.

30 Zit. bei Ulinka Rublack, Erzählungen vom Geblüt und Herzen. Zu einer Historischen Anthropologie des frühneuzeitlichen Körpers, in: Historische Anthropologie 9 (2001), H. 2, S. 214 232, hier S. 229, auch zit. in dies., Die Reformation in Europa, Frankfurt a.M. 2003, S. 215.

31 Zur internalisierten christlichen Wissenspraxis: ENGELsInG, Die Perioden der Lesergeschichte in der Neuzeit, Sp. 958-966.

32 Hauptwerk: Johannes Althusius, Politica methodice digesta atque exemplis sacris et profanis illustrata [...], Herborn ${ }^{3} 1614$ (ND Aalen 1981); Karl-Wilhelm DAHM/Werner KrawiEtz/Dieter Wyduckel (Hg.), Politische Theorie des Johannes Althusius, Berlin 1988; Peter Nitschke, Religion und Politik in der Föderaltheologie des Johannes Althusius, in: Manfred Walther (Hg.), Religion und Politik. Zu Theorie und Praxis des theologisch-politischen Komplexes, Baden-Baden 2004, S. 141-149. 
Bei Erich Schön wird zurecht auf den Umbruch (oder die beschleunigte Entwicklung) im Leseverhalten um 1700 hingewiesen. Wirtschafts- und Bildungsbürgertum bildeten sich aus, nicht mit einem Schlag, sondern über einen langen Zeitraum hinweg. Sie hatten aber um 1700 eine Zahl erreicht, die eine Ausweitung der Medienproduktion und eine Ausdifferenzierung von der Zeitung zur räsonnierenden Zeitschrift ermöglichte ${ }^{33}$. Wenn Schön jedoch schreibt:

Der Absolutismus bedeutete die faktische Entmachtung des niederen Adels durch die Zusammenarbeit des Souveräns mit wirtschaftlich aktiven Bürgern auf der Basis paralleler ökonomischer Interessen, aber auch dadurch, dass die zahlreichen Territorialherren und die Reichsstädte Bürgerliche als Verwaltungs-, Finanz- und Wirtschaftsfachleute in ihren Dienst nahmen ${ }^{34}$,

dann repräsentiert das nicht mehr den aktuellen Stand der Forschung. Inzwischen wird angenommen, dass die Renaissance des Adels den früher angenommenen soziologischen Wandel kompensiert hat. Der Adel dominierte politisch (eher in der leitenden Beamtenschaft als in den Landständen), sozial (Fortdauer der Rechtsungleichheit) und kulturell (Vorbildfunktion in Geschmack und Konsum; Attraktivität der Nobilitierung für alle Karrieristen in sämtlichen gesellschaftlichen Bereichen) weiterhin. Maßstab aller Dinge war nicht der bürgerliche Markt, sondern der fürstliche Hof $^{35}$.

Quantitativ geht Erich Schön von folgenden Zahlen aus: Die Lesebevölkerung bestand um 1700 aus dem Adel (ca. 1\% der Gesamtbevölkerung), den Geistlichen (gut 0,5\%), den Bildungsbürgern (ca. 2,5\%), den alten und neuen Wirtschaftsbürgern (ca. 2\%) und den »Kleinbürgern« in den Städten (ca. 7,5\%): »Nur diese Gruppen kamen als Leser in Frage « ${ }^{36}$. Dabei muss immer berücksichtigt werden, dass selbst in diesen sozialen Schichten die Lesefähigkeit unterschiedlich war: »Die unterschiedlichen Schätzungen der Lesefähigkeit haben ihren Grund darin, daß der Begriff `Lesefähigkeit` nicht

33 SchöN, Geschichte des Lesens, S. 24f.

34 Zitat: Ebd.

35 An der Spitze stand der Kaiserhof: Andreas PEČAR, Die Ökonomie der Ehre. Der höfische Adel am Kaiserhof Karls VI. (1711-1740), Darmstadt 2003; Mark Hengerer, Kaiserhof und Adel in der Mitte des 17. Jahrhunderts. Eine Kommunikationsgeschichte, Konstanz 2004. - Zu den Einzelheiten der territorialen Hofkultur: Volker BAUER, Die höfische Gesellschaft in Deutschland von der Mitte des 17. bis zum Ausgang des 18. Jahrhunderts. Versuch einer Typologie, Tübingen 1993; Volker BAUER, Die Hofökonomie. Der Diskurs über den Fürstenhof in Zeremonialwissenschaft, Hausväterliteratur und Kameralismus, Weimar/Köln/Wien 1997.

36 Zitat: Schön, Geschichte des Lesens, S. 25. 
ein \Entweder-Oder meint, sondern ein sehr breites Spektrum abgestufter Qualifikationen umfaßt« «7. Im Folgenden sollen diese Annahmen geprüft werden.

\subsection{Adel und Hof}

Lange Zeit ist angenommen worden, politische Publizistik sei eine herrschaftsinduzierte Berichterstattung gewesen, von Fürsten angeregt und bezahlt, von ihren Erfüllungsgehilfen ausgeführt, um vor allem den Personen an der Staatsspitze zu dienen. Das gilt für einen Teil der Druckwerke, soweit sie zum »intergouvernementalen Diskurs« im Sinne von Wolfgang Burgdorf gehörten ${ }^{38}$. Diese Studie will - wie schon erwähnt - gerade auf den anderen Teil hinweisen. Es kann nicht bestritten werden, dass Flugschriften, Messrelationen, Zeitungen, Zeitschriften und Historienschriften zur Lektüre von Fürsten und Hofleuten jeden Ranges gehörten. Aus diesem Grund dominierten in der frühen periodischen Presse die Berichte über Hof-, Staats- und Militäraktionen. Die schon erwähnte Europäische Fama hieß im Untertitel »welche den gegenwärtigen Zustand der vornehmsten Höfe entdecket [...] « und thematisierte auf diese Weise gleichermaßen den Hof als Betrachtungsgegenstand und als Lesepublikum ${ }^{39}$. Zwar konnte jeder, der die Elitenkultur Europas im Barockzeitalter kannte, sicher sein, dass die Fürsten über wichtige Begebenheiten informiert wurden. Ob das allerdings wirklich umfassend geschah, hing von der moralischen Qualität der fürstlichen Entourage ab, wie Kaspar Stieler bereits vermerkte: »Denn/ob gleich Fürsten und Herren viel Augen und Ohren um sich haben; so sind sie doch nicht allgegenwärtig/noch allwissend/werden auch wol von ihren Referenten betrogen/welche ihnen nur gute Zeitungen vortragen/die bösen aber verschweigen $\aleph^{40}$. Das Bauen von »potemkinschen Dörfern« war damit bereits vor dem Zeitalter Katharinas der Großen bekannt und wurde als Problem monarchischer Herrschaft bezeichnet. Die Zeitungen, so Stieler, wirkten dem Problem entgegen, sie beschafften verlässliche Berichte für Regierende und Regierte gleichermaßen ${ }^{41}$.

37 Zitat: ebd., S. 27.

38 Burgdorf, Reichskonstitution und Nation, bes. S. 24 (Hofgesellschaft und Regierungen als Leser) u. 26 (Phänomenologie des intergouvernementalen Diskurses).

39 Europäische Fama, pas. Vgl. zur Charakterisierung dieses Periodikums S. 113-117.

40 Stieler, Zeitungs Lust und Nutz (1695/1969), S. 20. - Zur Bedeutung der Zeitung für die höfische Gesellschaft generell: Ebd., S. 73-79.

41 Ebd. 
Neben dem Informationszugang zum Fürsten war auch dessen Weitergabe von Nachrichten an die Höflinge keineswegs stets vollständig und zeitnah gewährleistet. Zum Herrschaftsarkanum gehörte das Prinzip, sich nicht zu sehr in die Karten schauen zu lassen und stets noch einen Trumpf aufzubewahren. Die mediale Berichterstattung sorgte damit für zusätzliche Berichte, die dem Höfling den Eindruck vermitteln konnten, etwas mehr zu wissen als zuvor und oft auch etwas mehr als der lesefaule höfische Konkurrent.

Adel und Hofwesen stehen seit Langem im Fokus des akademischen und des populärwissenschaftlichen Interesses. Wer Freude an der Lektüre von Klatschgeschichten hatte, las Eduard Vehse ${ }^{42}$, wer aber den Hof als Disziplinierungsraum oder die Elite als leisure class wahrnehmen wollte, las Norbert Elias ${ }^{43}$ oder Thorstein Veblen ${ }^{44}$. Die moderne Verfassungs- und Sozialgeschichte seit den 1970er Jahren hat der Adels- und Hofforschung weiteren Auftrieb verliehen, die aktuelle Debatte um die Kulturgeschichte des Politischen wird das Hofleben als Ort für alle denkbaren Formen der symbolischen Kommunikation weiterhin im Zentrum historiographischer Überlegungen belassen ${ }^{45}$.

Zur Dimension der höfischen Öffentlichkeit und des Medienkonsums liegen einige Studien von Volker Bauer vor ${ }^{46}$. Bauer betont, dass das alte Paradigma von der Domestikation des Hofadels durch den absolutistischen Fürsten (Norbert Elias) und der repräsentativen Öffentlichkeit (Jürgen Habermas) längst überwunden ist, vor allem durch die fundamentale Studie von Aloys Winterling über das Hofsystem der Kurfürsten von Köln. Demnach repräsentierte der Hof nicht die Allmacht des Fürsten, sondern er kompensierte vielmehr auf symbolische Weise dessen Ohnmacht ${ }^{47}$. Während früher die Vorbildfunktion des Hofes als Ort der Repräsentation der Macht vor den

42 Eduard VeHSE, Geschichte der deutschen Höfe seit der Reformation, 48 Bd., Hamburg 18511860 .

43 Norbert Elias, Über den Prozeß der Zivilisation. Soziogenetische und psychogenetische Untersuchungen (1949), 2 Bd., Frankfurt a.M. ${ }^{8} 1981$; ders., Die höfische Gesellschaft. Untersuchungen zur Soziologie des Königtums und der höfischen Aristokratie mit einer Einleitung. Soziologie und Geschichtswissenschaft, Frankfurt a.M. 1983.

44 Thorstein Veblen, Theorie der feinen Leute. Eine ökonomische Untersuchung der Institutionen, München 1981 (engl. 1899).

45 Zur neueren Forschungsentwicklung: Rudolf Endres, Adel in der frühen Neuzeit, München 1993, und Ronald G. Asch, Europäischer Adel in der Frühen Neuzeit. Eine Einführung, Köln/Weimar/Wien 2008. - Zur Kulturgeschichte des Politischen: StOLlBERG-Rilinger, Des Kaisers alte Kleider, pas.; dies., Was heißt Kulturgeschichte des Politischen?, pas.

46 Vor allem Volker BAuER, Jetztherrschend, jetztregierend, jetztlebend. Genealogie und Zeitungswesen im Alten Reich des ausgehenden 17. Jahrhundert, in: Daphnis 37 (2008), S. 271300; ders., Höfische Gesellschaft und höfische Öffentlichkeit im Alten Reich, S. 29-68; ders., Nachrichtenmedien und höfische Gesellschaft. Zum Verhältnis von Mediensystem und höfischer Öffentlichkeit im Alten Reich, in: ARndT/KöRBER, Das Mediensystem im Alten Reich der Frühen Neuzeit, S. 173-193.

47 Winterling, Der Hof der Kurfürsten von Köln, pas. 
eigenen Untertanen im Vordergrund des Interesses stand, betonte Winterling den kompetitiven Charakter des Hoflebens: Für die deutschen Territorialherren, insbesondere die geistlichen, führte der Mangel an Geld und an bewaffneter Gewalt (»schimmernde Wehr«) dazu, dass die Pracht des Hofes in Konkurrenz zu anderen Höfen treten musste. Adressaten dessen, was am Hof veranstaltet wurde und von dem »man « sprechen sollte, waren die konkurrierenden Höfe der anderen Reichsfürsten ${ }^{48}$. Dem dienten nicht allein die baulichen und alltagsorganisatorischen Ausgestaltungen des Hofes, sondern auch die kulturellen Sonderprogramme wie die Festkultur ${ }^{49}$, das Hoftheater $^{50}$ als Bauwerk und Programmatik, die fürstlichen Bücher- und Raritätensammlungen $^{51}$ sowie der Hofgarten ${ }^{52}$ in seiner jeweils zeittypischen Grundanlage.

Das Hofleben stand vor dem Problem, so hebt Volker Bauer hervor, dass es wesentlich auf dem Einsatz theatraler Präsenzmedien beruhte, die sich in Gänze nur den Anwesenden erschlossen ${ }^{53}$. Um diese Feste, Musik- und Theateraufführungen, Galadiners, Feuerwerke etc. in einem zweiten Schritt an Außenstehende zu vermitteln, bedurfte es einer medialen Transformation. Texte bzw. Libretti, Speisefolgen, Auflistungen der Teilnehmenden, Kupferstiche und vor allem beschreibende Texte sollten dies leisten. Hier findet sich dieselbe Übersetzungsleistung, die schon den periodischen Medien zugrunde lag: Geschulte Künstler und Autoren rekonstruierten die Begebenheit in vorgegebene bildgebende und sprachliche Formen, um sie anschlieBend als Bilddrucke (selten Gemälde) und Beschreibungen zu verbreiten.

48 Ute DanIEL, Überlegungen zum höfischen Fest der Barockzeit, in: NJbLG 72 (2000), S. 45-66, bes. S. 49.

49 Zum Hoffest: Vera Jung, Körperlust und Disziplin. Studien zur Fest- und Tanzkultur im 16. und 17. Jahrhundert, Köln/Weimar/Wien 2001. - Zum Feuerwerk: Arthur Lotz, Das Feuerwerk. Seine Geschichte und Bibliographie, Zürich 1982. - Zur Verschriftlichung der Festkultur: Helen WatanaBe-O'Kelly, Festival Books in Europe from Renaissance to Rococo, in: The Seventeenth Century 3 (1988), S. 181-201.

50 Zum Hoftheater: Ute DANIEL, Hoftheater. Zur Geschichte des Theaters und der Höfe im 18. und 19. Jahrhundert, Stuttgart 1995.

51 Zur Illustration seien hier nur die Bücher- und Kunstsammlungen der Herzöge von Braunschweig-Wolfenbüttel genannt: Helmar Härtel, Herzog August als Büchersammler. Zum Aufbau seiner Bibliothek, in: Paul RaABE (Hg.), Herzog August zu Braunschweig und Lüneburg (1579-1666). Sammler, Fürst, Gelehrter, Braunschweig 1979, S. 215-319; Jill BepLER (Hg.), Barocke Sammellust. Die Bibliothek und Kunstkammer des Herzogs Ferdinand Albrecht zu Braunschweig-Lüneburg (1636-1687). Ausstellung im Zeughaus der HAB Wolfenbüttel, Weinheim 1988.

52 Grundlegend zur Gartenbaugeschichte: Eva-Maria Stolberg (Hg.), Auf der Suche nach Eden. Eine Kulturgeschichte des Gartens, Frankfurt a.M. u.a. 2008.

53 BAUER, Höfische Gesellschaft und höfische Öffentlichkeit, S. 30. - Vgl. dazu das Paradigma »Kommunikation unter Anwesenden« in der Soziologie und seine Adaption für die Frühneuzeitforschung: André KieserLing, Kommunikation unter Anwesenden. Studien über Interaktionssysteme, Frankfurt a.M. 1999; SCHLÖGL, Kommunikation und Vergesellschaftung unter Anwesenden, S. 155-224. 
Dies wirkte naheliegenderweise zurück auf das Rezeptionsverhalten des Hofes: Wenn der eigene Hof sich stets unter Schaufensterbedingungen inszenierte, so wollten die Höflinge gern wissen, was an anderen Höfen geschah, womit man sich zu messen hatte. Diese Informationen gerieten damit zumindest teilweise - ins Feld der Berichterstattung der Druckmedien, um im Idealfall allen deutschsprachigen Höfen verfügbar gemacht zu werden. Wir haben es hier mit einer spezifischen Form von Neugier zu tun: Die Wissbegierde über andere Hofgeschehnisse geschah nicht aus der Befriedigung eines Sensationsbedürfnisses oder aus wissenschaftlichem Entdeckertrieb, sondern aus der Konkurrenzsituation: Wer stets erfuhr, was die Konkurrenten veranstalteten, konnte auf angemessene Weise antworten, um die Konkurrenz als Prinzip in Gang zu halten.

Zunächst las der Hof die in wachsendem Umfang eingehende briefliche Korrespondenz mit den anderen Höfen. Hierbei handelte es sich um offizielle Staats- und Familienkorrespondenz der regierenden Dynastien. Hatte bis zum Dreißigjährigen Krieg die höfische Korrespondenz mit der wirtschaftlichen und der akademischen Schritt gehalten, so lässt sich ab der zweiten Hälfte des 17. Jahrhundert ein starkes Anwachsen dieses Briefwechsels konstatieren, woraus eine professionelle Organisation der zuständigen Kanzleien (Sekretäre, Schreiber, Postmeister, Boten, Gesandte, Agenten, Spione, Chiffreure und Dechiffreure etc.) resultierte ${ }^{54}$. Der Nachlass dieser Korrespondenz weist noch heute in Staatsarchiven der großen Reichsterritorien einen derartigen Umfang auf, dass er für die Frühmoderne nicht in einer einzelnen Forschungsarbeit ausgewertet werden kann. Ein großer Teil davon war ritualisierte Post: Glückwünsche zu Geburts- oder Namenstagen, zu hohen Kirchenfesten, zum Jahreswechsel, Ankündigungen von Geburten, Verlöbnissen und sonstigen Familienbegebenheiten, Todesanzeigen und Kondolenzschreiben etc. Die freudigen und die trauervollen Familienangelegenheiten waren öffentlichkeitsrelevant und wurden, abhängig von der Ranghöhe der Betroffenen, in den Druckmedien publiziert. Die peinlichen Familienangelegenheiten (Scheidungen, Generationskonflikte, Prozesse um Erbschaften oder Apanagen) gehörten hingegen unter normalen Umständen nicht in die Zeitung, außer die Redaktion erfuhr davon über die zuständigen Gerichte. Der andere Teil betraf konkrete politische Vorhaben in Gestalt von Kooperationen mit befreundeten Höfen bzw. Forderungen und Auseinandersetzungen bezüglich gegnerischer Parteien. Der Inhalt dieser Korrespondenz war normalerweise geheim und nicht für die Transformation in den Nachrichtenverkehr gedacht.

54 Die Aufzählung steht bei BAuER, Höfische Gesellschaft und höfische Öffentlichkeit, S. 31. Für den Unterhalt einer Kanzlei galt es, sowohl aus Gründen der Zeremoniellerfordernisse, aber auch aus Staatsklugheit, die herrschenden Regeln zu kennen und einzuhalten, wozu zeitgenössische Ratgeber Unterstützung anboten: Kaspar STIELER, Teutsche Sekretariat=Kunst: was sie sey, wovon sie handele [...], 2 Bd. in 4 Tlen., Nürnberg 1673/74. 
Hier galt das Herrschaftarkanum ${ }^{55}$, das von staatstheoretischen Denkern wie Niccolò Machiavelli, Giovanni Botero und Justus Lipsius ausgearbeitet worden $w{ }^{56}$. Die mit der Verarbeitung dieser Informationen betrauten Personen, die Sekretäre, trugen das Geheimnis (secretum) bereits in ihrer Amtsbezeichnung ${ }^{57}$. Volker Bauer spricht von einem »Hofnachrichtendienst«, der durch eine Vielzahl von Beteiligten aufrechterhalten wurde, und verortet ihn »in einer Grauzone zwischen Presse und Geheimdienst«, d.h. zwischen Öffentlichkeit und Arkanum. Vier unterschiedliche Zonen dieser Korrespondenzen lassen sich unterscheiden: 1. Fürstenkorrespondenz, 2. Gesandtenkorrespondenz, 3. Agentenkorrespondenz und 4. Novellantenkorrespondenz. Dadurch, dass nur etwa die Hälfte der umlaufenden Berichte Originale waren, die übrigen aber (kommentierte) Abschriften oder Kompilationen, dehnte sich nicht nur das Volumen der Texte aus, sondern es entstand eine Netzwerkstruktur, die dafür sorgte, dass jede wichtige Nachricht mehrfach empfangen wurde und damit an Realitätsgehalt zu gewinnen schien ${ }^{58}$.

Der in früheren Studien manchmal holzschnittartig scharf erscheinende Bruch zwischen den beiden Kommunikationsarten des Geheimen und des nicht Geheimen bestand in Wirklichkeit nicht in dieser Deutlichkeit. Natürlich erfuhren viele Redaktionen, besonders in den Residenzstädten, von Einzelheiten, die nicht für die direkte Verbreitung geeignet waren. Schon im ausgehenden 17. Jahrhundert schrieb Christian Weise, dass die Geheimnisse der Höfe von den Medienproduzenten respektiert werden sollten, und zwar nicht aus Zwang, sondern aus Einsicht in die Notwendigkeiten in einem politischen Konkurrenzsystem. Wenn aber die Folgen offen zutage lägen, so fuhr Weise fort, dann seien die Zeitungen auch berechtigt, darüber zu berichten ${ }^{59}$.

55 Unter dem Stichwort »Arcana Imperii« ist dieser Zusammenhang unter rechtsgeschichtlicher Perspektive von Michael Stolleis untersucht worden, unter historischer von Andreas Gestrich: Stolleis, Arcana Imperii und Ratio Status, pas.; Gestrich, Absolutismus und Öffentlichkeit, S. 34-74.

56 Niccolò Machiavelli, Il Principe/Der Fürst. Italienisch/deutsch. Übers. u. hg. v. P. RiPPEL, Stuttgart 1986; Herfried MünKLER, Machiavelli. Die Begründung des politischen Denkens der Neuzeit aus der Krise der Republik Florenz, Frankfurt a.M. 1982. - Giovanni Botero, Della Ragione di Stato libri dieci, Venedig 1589; zu Botero: Luigi Firpo, Art. »Botero, Giovanni«, in: Alberto M. Ghisalberti, Dizionario biografico degli Italiani, (bisher) 42 Bd., Rom 1960ff. (bis 1993), hier Bd. 13, S. 352-362; A. Enzo BALDini (Hg.), Botero e la ragion di stato, Florenz 1992. - Justus Lipsius, Von der Bestendigkeit. De Constantia (1584). Faksimiledruck der deutschen Übersetzung des Andreas Viritius ( $\left.{ }^{2} 1601\right)$, hg. v. L. Forster, Stuttgart 1965; Gerhard Oestreich, Antiker Geist und moderner Staat bei Justus Lipsius (1547-1606). Der Neustoizismus als politische Bewegung, hg. u. eingeleitet v. Nicolette Mout, Göttingen 1989.

57 Vgl. zum Wortzusammenhang im Lateinischen und im Deutschen: Horst Wenzel, Sekretäre - »heimlîchaere«. Der Schauraum öffentlicher Repräsentation und die Verwaltung des Geheimen, in: Ders., Mediengeschichte vor und nach Gutenberg, Darmstadt 2007, S. 104-121.

58 BAuER, Höfische Gesellschaft und höfische Öffentlichkeit, S. 31-33.

59 Christian Weise, Schediasma curiosa de lectione Novellarum, Weißenfels 1676; deutsche Ausgabe: Ders., Curieuse Gedancken von den Nouvellen oder Zeitungen. Gekürzte Edition: 
Diese Einschätzung zeigt sehr deutlich, dass die Medienmacher im Barockzeitalter noch keineswegs eine publizistische Gegenöffentlichkeit, eine Konfrontation mit den Fürsten, dem Adel und den Hofleuten heraufbeschwören wollten. Es muss daher einmal mehr betont werden, dass sie sich als Teil einer politisch-gesellschaftlichen Gesamtordnung sahen, nicht als Herausforderer und als Unterminierer des ständischen Systems. Hier liegt ein wichtiger Unterschied zur späteren Hochaufklärungszeit, als diese Tendenz tatsächlich beobachtbar wurde.

Der Hof als Leserschaft ist vielfach bezeugt ${ }^{60}$. Ernst Friedlaender beschreibt in seiner Studie über Berliner Briefzeitungen, wie der Berliner Hof und insbesondere Friedrich Wilhelm I. auf die Berichterstattung in der Europäischen Fama reagierte. Eine Humoreske notierte der Brief, der aus »Berlin, den 2 . Juni 1714 « verschickt wurde:

Der 157. theil der Europaeischen Fama so kürtzlich herauskommen beschreibet gar anzüglich hiesige neue Einrichtunge des Hoffes [=nach dem Tod König Friedrichs I. J.A.] und saget, daß durch das retranchiren der Besoldungen und Pensionen, die Leute sich eines mäßigen und nüchtern lebens zu befleißigen genöthiget würden, wär also der König ein guter Doctor. Man will sagen, die Gräffin von Dohna habe solches dem Könige vorgelesen, darauf Er geantwortet: »Es wäre ihm lieb daß er ein so trefflicher Doctor worden, Er wolte dahin bemühet seyn, noch beßere Curen auszuüben ${ }^{61}$.

Die Europäische Fama war keineswegs das einzige Blatt, das am Berliner Hof verfügbar war. David Fassmann schreibt in seiner Biographie über Friedrich Wilhelm I. wörtlich:

Derer Zeitungen halten Ihro Majestät der König gar vielerley Gattungen. Alle Holländische, in Nieder $=$ Teutscher oder Frantzösischer Sprache, also die Amsterdammer, Leidner, Harlemer, Utrechter etc. Ferner: Die Pariser, die von Franckfurth am Mayn, die Hamburger, Leipziger, Berliner, Breslauer und Wiener. Denn obwohl Ihro Majestät der König Dero Gesandten, Residenten und Agenten an denen vornehmsten Höfen und Orten in gantz Europa haben, mithin schon alles weit besser wissen, als es in denen Zeitungen stehet, ja solche Nachrichten erhalten, welche Geheimnisse sind, und nimmermehr in die Zeitungen kommen, so wollen Sie dennoch auch gerne hören, was die Welt raisonniret, redet und schreibet. Derohalben wird eine besondere Person darzu gehalten, die das Beste aus denen Zeitungen nehmen, und es dem König, theils bey

Christian WeISE, Interessanter Abriß über das Lesen von Zeitungen [...] (gestützt auf Ausgabe Frankfurt a.M./Leipzig 1685), in: KuRTH, Die ältesten Schriften für und wider die Zeitung, S. 45-85. - Bezug: Ausgabe 1706, S. 45.

60 Darauf verwies bereits Elger BцÜнм, Deutscher Fürstenstaat und Presse im 17. Jahrhundert, in: Daphnis 11 (1982), S. 287-313, bes. S. 293-297.

61 FriedLaender, Berliner geschriebene Zeitungen, S. 133. 
der Mittags $=$ Tafel, theils in der Abend $=$ Gesellschaft, erzehlen muss; welches dann, wie sonst schon gedacht, zu gar vielerley Discursen und Reflexionen Anlass giebet, da bald diese bald jene hohe und vornehme Person ihre Meynung und Gedancken entdecket $^{62}$.

Dies dokumentiert, dass nicht nur der König oder seine unmittelbar Beauftragten die Zeitungen durcharbeiteten, sondern dass Periodika offen auslagen und die Höflinge einzelne Berichte in die mündliche Kommunikation einbrachten. Bemerkenswerterweise geschah das selbst dann, wenn der König dabei nicht so glanzvoll dargestellt wurde. Jedenfalls war Friedrich Wilhelm genötigt, mit einem humorvollen Spruch darauf zu reagieren anstatt gekränkt zu erscheinen.

Sein Sohn, Friedrich der Große, abonnierte ebenfalls mehrere Zeitungen. Fremde Briefzeitungen ließ er sich dagegen gern zuleiten, mitunter auch auf verdeckte Weise. Überliefert ist, dass er sich auch die Gazette de Cologne, die der Verleger Roderique produzierte, über den Postmeister in Wesel liefern ließ. Von der Gazette de Cologne ist auch der Preis bekannt, den der König resp. der Postmeister dafür bezahlte: 12 Reichstaler kostete das Jahresabonnement ${ }^{63}$.

Während an großen Höfen die gedruckten Periodika die offizielle Hofkorrespondenz ergänzten und die Informationsmöglichkeiten für viele verbreiterten, spielte für die vielen kleinen Höfe im Reich - in geistlichen Territorien, kleinen Fürstentümern oder Grafschaften - Kostenfaktoren eine wichtige Rolle. Diese Höfe, die stets knapp an Barmitteln und oft verschuldet waren, hatten nicht die Möglichkeit, sich ein teures Korrespondentennetz zu leisten. Sie gehörten zu den frühesten und dauerhaftesten Zeitungsabonnenten ${ }^{64}$. Johann Peter von Ludewig formulierte diesen Umstand mit folgenden Worten:

So ist es auch über das an dem; daß manches Land welches keine Gelegenheit hat/correspondentze zu halten/sich mit den gedruckten Zeitungen/als dem leichtesten Mittel/behelffen muß. Und erinnere ich mich hierbey/daß ehmahls ein bekandter Minister an dem Würtenberg. Hoff geschertzet/daß der Kayser etliche Monat todt seyn könte/biß bey Ihnen eben Zeitungen davon aus Wien einlauffen möchten/wann sie

62 Fassmann, Leben und Thaten des Allerdurchlauchtigsten und Großmächtigsten Königs von Preußen Friedrici Wilhelmi, S. 960. - Friedrich Förster schreibt dazu allerdings, dass die Berliner Zeitung nicht gehalten würde, da sie aus Sicht des Königs nur das wiedergebe, was schon in anderen Zeitungen früher zu lesen gewesen sei: Förster, Friedrich Wilhelm I., Bd. 1, S. 249.

63 Salomon, Geschichte des deutschen Zeitungswesens, Bd. 1, S. 173.

64 Bauer, Höfische Gesellschaft und höfische Öffentlichkeit, S. 40; STÖBER, Deutsche Pressegeschichte, S. 66. 
nicht das Franckfurter Blätgen hätten. Und obgleich andere Höffe hierinnen sorgfältiger seyn; So sollte es doch einem Herrn allein fast allzuschwer fallen/fast in einem jeden Winckel von Europa einen correspondenten zubesolden; da im Gegenteil die Zeitungen von allen orten in Europa in den gedruckten Gazetten zusammen lauffen. Dahero auch die grösten minister die Zeit nicht reuet/ solche / nach den eingenommnen geschriebenen relationibus, nicht weniger durch zugehen ${ }^{65}$.

Für die verantwortlichen Politiker bedeutete das zwar doppelte Arbeit, die geschriebenen Relationen und die gedruckten Zeitungen zu sichten, aber geringere Kosten bei gleichbleibendem Ertrag.

Wenn die Zeitungen nicht auslagen, wie in Berlin, dann las ein Hofbediensteter sie zu den Mahlzeiten öffentlich vor. Diese Aufgabe des höfischen Zeitungsvorlesers übte Kaspar Stieler selbst aus, als er in den 1660er Jahren für einige Zeit Kammersekretär am Hofe des Grafen Albert Anton von Schwarzburg-Rudolstadt war ${ }^{66}$. Dass Stieler diese Aufgabe keineswegs widerwillig ausübte, demonstrierte er später in seiner Sekretariats-Kunst, in der er die Zeitungsvorlesung beim Mahl ausdrücklich empfahl ${ }^{67}$. Diese Form der Begleitung der Mittagsmahlzeit wurde so gebräuchlich, dass das Teutsche Hofrecht, ein Standardwerk zur Verwaltungswissenschaft hinsichtlich der Hofhaltung, sie als akzeptierte Alternative zur Tafelmusik bezeichnete ${ }^{68}$. Auch hier ist der Unterschied zwischen Arkanum und Hoföffentlichkeit greifbar: Was geheimgehalten werden sollte, fand in der Abgeschlossenheit der Ratssitzungen oder des Kabinetts statt, was alle Höflinge wissen und hören durften, wurde beim Essen verlesen.

Nicht nur die adligen Höflinge lasen, sondern auch das niedere Dienstpersonal des Hofes. Während die Kanzleibediensteten die Informationen weiterverwerteten, las der Rest der subalternen Hofgesellschaft, die »Lakeyen/Stallknechte/Kalfacter/Gärtner und Torhüter« nicht nur zur eigenen Ergötzung. Kaspar Stieler wies darauf hin, dass sie sich einen Informationsvorteil und einen distinktiven Gewinn gegenüber ihrem sonstigen, außerhöfischen Umfeld erwarben, durch den sie »oft stölzer/als der Bürgermeister der Stadt seyn/weil sie sich weit mehr/als er/in Statsachen zu wissen und erfaren zuhaben einbilden/zumal/wenn lüsterne Leute um sie herum treten/sie befragen und ihnen einen Trunk zu spendiren versprechen ${ }^{69}$. Dies

65 Von Ludewig, Vom Gebrauch und Mißbrauch Der Zeitungen, pas., hier zit. aus BLÜHM/EnGELSING, Die Zeitung, S. 76.

66 StIeLer, Zeitungs Lust und Nutz (1695/ 1969), S. VIIIf.

67 Ders., Teutsche Sekretariat=Kunst, Bd. 2, Tl. 4, S. 176.

68 Friedrich Carl Moser, Teutsches Hofrecht, in zwölf Büchern, 2 Bd., Frankfurt a.M./Leipzig $1754 / 55$, hier Bd. 2, S. 539, zit. nach BAUER, Höfische Gesellschaft und höfische Öffentlichkeit, S. 41.

69 Zitate von Stieler, Zeitungs Lust und Nutz (1695/1969), S. 79. 
zeigt auf die Statuskonkurrenz auch der unteren Stände bei Hofe, wie sie sich nicht nur im Besitz symbolträchtiger Güter manifestierte, sondern auch im privilegierten Zugang zu Informationen, was in späteren kommunikativen Situationen prestigefördernd zur Geltung gebracht werden konnte. Auch über den Münchener Hof der 1680er und 1690er Jahre ist überliefert, dass die Dienerschaft der Kurfürstin Maria Antonie verbotene Traktate und Bücher las, selbst wenn der Hofmeister versuchte, dagegen einzuschreiten ${ }^{70}$.

Darüber hinaus entwickelten sich für die symbolische Kommunikation an den frühmodernen Höfen gesonderte Druckmedien, die nur für den internen Gebrauch auf gleicher Standesebene gedacht waren. Hierbei dominierten die Adress-, Hof- und Staatskalender, die von Volker Bauer untersucht worden $\operatorname{sind}^{71}$. Diese Druckmedien dienten nicht vorrangig den jeweiligen Angehörigen des Hofes, dessen Rangordnung abgebildet wurde, sondern konkurrierenden Höfen sowie auswärtigen Botschaftern, Gesandten und Residenten, um sich auf dem jeweils aktuellen Stand zu orientieren. Die strengen Gepflogenheiten des höfischen Zeremoniells geboten es allen Kommunikationsbeteiligten - den anwesenden für die Präzedenz, den abwesenden für die richtige Titulatur in der Korrespondenz -, stets der richtigen Person die richtige Behandlung zuteil werden zu lassen. Miloš Vec ${ }^{72}$ und Barbara StollbergRilinger ${ }^{73}$ haben in unterschiedlichen Studien verdeutlicht, auf welche Weise sich das Alte Reich gerade in der Zelebration von Rang und Rangunterschieden konstituierte und dass Rang eben nicht nur ein beliebiges Attribut, sondern ein einklagbares Recht bedeutete. So gehörten Hofordnungen, in denen durch Herkommen und fürstliche Entscheidung Ämter und Ränge festgesetzt wurden, zusammen mit Titulaturbüchern ${ }^{74}$, in denen jeder Kommunikant die

70 Ludwig Hüttl, Max Emanuel. Der Blaue Kurfürst (1679-1726). Eine politische Biographie, München 1976, S. 141.

71 Volker BAUER, Repertorium territorialer Amtskalender und Amtshandbücher im Alten Reich. Adreß-, Hof-, Staatskalender und Staatshandbücher des 18. Jahrhunderts, 4 Bd. (I: Nord- und Mitteldeutschland; II: heutiges Bayern, Österreich und Liechtenstein; III: Der Westen und Südwesten; IV: Ostdeutschland), Frankfurt a.M. 1997-2005; Bedeutung: Ders., Territoriale Amtskalender und Amtshandbücher im Alten Reich. Bilanz eines Forschungsprojekts, in: Rechtsgeschichte. Zeitschrift des Max-Planck-Instituts für Europäische Rechtsgeschichte 1 (2002), S. 71-89.

72 Miloš VeC, Zeremoniellwissenschaft im Fürstenstaat. Studien zur juristischen und politischen Theorie absolutistischer Herrschaftsrepräsentation, Frankfurt a.M. 1998.

73 Barbara Stollberg-Rilinger, Die Wissenschaft der feinen Unterschiede. Das Präzedenzrecht und die europäischen Monarchien vom 16. bis zum 18. Jahrhundert, in: Majestas 10 (2002), S. 125-150; dies., Die zeremonielle Inszenierung des Reiches, S. 233-246.

74 Titulaturbücher wurden in jeder Kanzlei geführt. Hilfreiche Hinweise für die Anlage und Pflege derartiger Instrumente lieferte beispielsweise Georg Philipp Harsdörffer, Der Teutsche Secretarius: Das ist: Allen Cantzleyen, Studir- und Schreibstuben nützliches, fast nohtwendiges, und zum drittenmal vermehrtes Titular- und Formularbuch [...], 2 Bd., Nürnberg 1656-1659 (ND Hildesheim/New York 1971). Zur erweiterten Bedeutung: Andreas Herz, »Die Ursach nicht der Wahn«. Georg Philipp Harsdörffers »Teutscher Sekretarius« und die 
formale Ordnung nachschlagen konnte, während die aktuellen Informationen in Adress-, Hof- und Staatskalendern manifestiert wurden.

Viel später als die Zeitungen und Zeitschriften wurden die Hof- und Staatskalender auch der Lektüre durch eine erweiterte Leserschaft unterzogen, besonders durch die wissenschaftlich Interessierten, die hieraus vergleichende Informationen über die europäischen Staaten und deutschen Territorien gewannen ${ }^{75}$. Die Nutzung als Kalender durch nichtakademische Bevölkerungsschichten ist - laut Bauer - ebenfalls erwiesen, doch ohne dass sich dadurch eine signifikante Nachfragesteigerung hätte ergeben können. Die Gattung blieb herrschaftsinduziert, nicht marktinduziert, sie konnte und sollte sich aus diesem Zusammenhang nicht lösen. Der Volkskalender seit den 1760er Jahren war eher ein Hybrid aus einem Amtskalender und einem herkömmlichen Almanach als die logische Fortentwicklung der Hof- und Staatskalender in eine marktwirtschaftliche Positionierung hinein ${ }^{76}$

Dieselben Praktiken der Informationsbeschaffung und -weitergabe galten auch für die Gesandten am Regensburger Reichstag. Höfische Fertigkeiten und exzellente reichsrechtliche Kenntnisse verbanden sich mit dem Streben, auf mündlichem oder schriftlichem Weg stets die neuesten Informationen zu beschaffen. Dazu gehörten neben den offiziellen Korrespondenzen mit dem eigenen Hof die Einziehungen von Nachrichten durch auswärtige Korrespondenten, aber auch durch die Deduktionen der Parteien, die in der Donaustadt ausgegeben wurden. Die Zeitungslektüre ergänzte das Pflichtprogramm. Die herrschende politische Konkurrenz in vertikaler und horizontaler Form bedingte hier eine informationelle Durchlässigkeit, durch die die meisten Geheimhaltungsvorhaben in Kürze konterkariert wurden ${ }^{77}$.

Der höfische und adlige Zeitungs- und Zeitschriftenkonsum blieb ein dauerhaftes Phänomen. Daran änderte sich nichts, als beide Mediengattungen im Laufe des 18. Jahrhunderts ihre Leserschaft aus ständischer Sicht immer mehr verbreiterten. Während die allgemeinen Periodika darauf abzielten, die politische Welt zu erklären, war das Anliegen der höfischen Repräsentation viel eingeschränkter, wurde aber dafür stetig wiederholt: Hervorhebung des Ranges des Fürsten, Betonung des Alters und der Ehrwürdigkeit der Dynastie, ggf. Demonstration der herrscherlichen Frömmigkeit in der jeweiligen Denomination, Lob der vorhandenen moralischen und damit politischen Qualitäten des Landesherren, aber auch Formulierung des Anspruchs auf Aner-

damalige deutsche Sprachdebatte, in: Wolfenbütteler Barock-Nachrichten 36 (2009), H. 1/2, S. 55-63.

75 BaUER, Territoriale Amtskalender, S. 87f.

76 Vgl. dazu ebd., S. 88.

77 Zur Methodologie der Informationsbeschaffung in Regensburg: FrIEDRICH, Drehscheibe Regensburg, S. 194-251; zum Postulat der Geheimhaltung und dessen Durchlöcherung: Ebd., S. 504-515. 
kennung und, falls möglich, Ausdehnung der eigenen politischen Macht. Die Dualität der höfischen Öffentlichkeit in Gestalt der publiken, periodischen, aktuellen und universalen Zeitungen gegenüber den exklusiven, singulären, okkasionellen Hofmedien, die nur hinsichtlich der Mittel ihrer Berichte universell waren, festigte sich und hatte auf lange Sicht eine Entmythologisierung und Delegitimierung des Hofes zur Folge ${ }^{78}$.

\subsection{Das gebildete Bürgertum und die Verwaltung}

Das Bildungsbürgertum gilt als Spezifikum der deutschen Geschichte. Gebildete Staatsdiener, Professoren, Pfarrer und Lehrer, Ärzte und Apotheker gab es auch in allen anderen europäischen Staaten, doch nirgendwo kultivierte der Gelehrtenstand sich in einer derartig auffälligen Weise wie im Heiligen Römischen Reich. Die Glaubensspaltung und mehr noch, die Mehrkonfessionalität als Dauerzustand über die Religionskriege hinaus führten zu gesteigerten Bildungsanstrengungen der höheren Stände, was sich in einer großen Dichte an Bildungsstätten, besonders Universitäten, niederschlug. Im alten Reich gab es ca. 40 Universitäten, die sich hälftig auf die staatskirchenrechtlichen Gruppierungen verteilten ${ }^{79}$. Das dortige Lehrpersonal gehörte genauso selbstverständlich zum Bildungsbürgertum wie die Zöglinge, die dort ausgebildet wurden, um ihrerseits die Denkweisen und Haltungen ihres Standes fortzuführen ${ }^{80}$.

Ein weiterer wichtiger Grund für die Herausbildung des Bildungsbürgertums als Stand war die Verwendung zahlreicher Gebildeter seit dem 16. Jahrhundert im Fürsten- und Staatsdienst. Hans-Ulrich Wehler spricht davon, dieser Stand sei »als verstaatlichte Intelligenz « zu betrachten ${ }^{81}$. Insbesondere Pfarrer (für die konfessionelle Ausrichtung der eigenen Untertanen im jeweils »richtigen « Sinne) und Juristen (für den sich ausbauenden frühmodernen Territorialstaat mit seinen Behörden) waren in wachsendem Maße erforderlich. Der gelehrte Stand seinerseits konkurrierte mit dem Adel um Rang und

78 Vgl. zu den Begrifflichkeiten in ihrer dualistischen Gegenüberstellung die Überlegungen von BAUER, Höfische Gesellschaft und höfische Öffentlichkeit, S. 52-54. - Zur Entmythologisierung des Hofes: Ebd., S. 55f.

79 Anton Schindling, Die protestantischen Universitäten im Heiligen Römischen Reich deutscher Nation im Zeitalter der Aufklärung, in: Notker Hammerstein (Hg.), Universitäten und Aufklärung, Göttingen 1995, S. 9-18; Harald DicKerHoF, Die katholischen Universitäten im Heiligen Römischen Reich deutscher Nation im Zeitalter der Aufklärung, in: Ebd., S. 21-47.

80 Zur Institutionen- und Sozialgeschichte der Universitäten im europäischen Maßstab: Wolfgang E.J. WeBER, Geschichte der europäischen Universität, Stuttgart 2002. - Zur symbolischen Kommunikation an deutschen Hochschulen: Marian Füssel, Gelehrtenkultur als symbolische Praxis. Rang, Ritual und Konflikt an der Universität der Frühen Neuzeit, Darmstadt 2006.

81 Wehler, Deutsche Gesellschaftsgeschichte, Bd. 1, Kap. III, Tl. 6, S. 210-217. 
Prestige im herrschenden Sozialgefüge: Ein Doktortitel wurde - jedenfalls von den Bildungsbürgern - als Verdienstadel anerkannt. Das Selbstbewusstsein der Akademiker wuchs, die Neigung vieler Fürsten, Adelszöglinge und bürgerliche Beamte gegeneinander auszuspielen und beide $\mathrm{zu}$ vermehrten Bildungs- und Weiterbildungsanstrengungen anzuspornen, ebenfalls.

Bildungsbürger unterschieden sich vom Geburtsadel dadurch, dass sie ihre Bildung, ihr Wissen, zunächst durch jahrelange Lernprozesse erwerben und anschließend stets vervollkommnen und aktualisieren mussten. An dieser Stelle hatte »extensives Lesen« seinen anerkannten Platz: An die Seite der Repetitio trat die Durcharbeitung jeweils neuen »Stoffes«, was die Lektüre von immer anderen Werken erforderlich machte ${ }^{82}$. Helmut Zedelmaier hat den didaktischen Teil dieses Prozesses »gelehrtes Lesen« genannt und ihm einen eigenen Platz in der voraufklärerischen Zeit zugewiesen ${ }^{83}$. Ungeachtet aller späteren Veränderungen dürfte diese Form der Wissensvermittlung allerdings weiterbestanden haben, während die neuen Formen des Umgangs mit Wissen an ihre Seite getreten sind.

Als Kronzeugen für das »gelehrte Lesen« nennt Zedelmaier den Herborner Professor Johann Heinrich Alsted, der 1630 seine Encyclopaedia herausbrachte ${ }^{84}$. Darin stellte Alsted eine Verbindung zwischen guter Ordnung des Lernens und Wissens und guter Ordnung im geistlichen und weltlichen Regiment her, wobei er einen »methodischen« Aufbau (ordo methodicus) seines siebenbändigen Werkes im Sinne des französischen Humanisten und Philosophen Petrus Ramus (1515-1572) zugrunde legte. Seine Ordnung, so schrieb Alsted, sei nur das Skelett des Wissens, dem Leser bleibe die Aufgabe, durch anreicherndes Lernen den gesamten Wissenskörper erstehen zu lassen. Der Verfasser betonte, dass Wissen stets ein Anreicherungsprozess sein musste: Wo keine Vorkenntnisse vorhanden waren, konnte nicht verstanden und gespeichert werden. Die Schaffung von Grundkenntnissen und gleichzeitig die Vermittlung der Ordnung von Wissen seien daher die zentralen Voraussetzungen für alles weitere, was der Proband in seinem Leben noch lernen und erfahren solle. Vier Vermittlungsarten wurden dabei unterschieden: 1. dem Lehrer zuhören, 2. Bücher lesen, 3. Nützliches aufschreiben und 4. das bereits Gelernte zu wiederholen (memorieren). Die Bedeutung von Texten wurde dabei besonders betont, denn diese standen dauerhaft zur Verfügung - auch halfen sie, wenn die Lehrer nicht so gut waren, wie sie

82 Zum extensiven Lesen: Engelsing, Die Perioden der Lesergeschichte in der Neuzeit, Sp. 973997, wobei Engelsing zwischen der Phase der Vorbereitung (ca. vor 1770) und der anschließenden Phase der Verallgemeinerung unterscheidet.

83 Zedelmaier, Lesetechniken, S. 19-25.

84 Johann Heinrich Alsted, Encyclopaedia Septem tomis distincta, 7 Bd., Herborn 1630 (ND Stuttgart 1988-90). 
sein sollten ${ }^{85}$. Zu den Texten zählten auch die Mitschriften, die Exzerpte, die sowohl das enthielten, was der Lehrer vorgetragen hatte, als auch das, was während der Lektüre dazugeschrieben worden war. Das Exzerpieren wurde zu einer eigenen Lernform aufgebaut, Bücher wie die Aurifodina von Jeremias Drexel führten den Adepten darein ein ${ }^{86}$.

Schon im vorgelagerten Ausbildungsabschnitt, an Lateinschulen oder Universitäten, trafen Studierende auf Zeitungen als Medien des Unterrichts. Bereits im Musterlehrplan von Johann Amos Comenius 1654 für eine ungarische Schule tauchte das Zeitunglesen auf ${ }^{87}$. Ein halbes Jahrhundert später erschien in Nürnberg eine Bilderchronik Europa, bezogen auf die Jahre 1701 bis 1720. Für jedes Jahr stellte der Verfasser Johann David Köhler einen Bilderbogen aus 10 bis 13 Kupferstichen voraus, die er in kurzen Absätzen kommentierte $^{88}$. Im Mittelpunkt standen europäische Militär- und Friedensereignisse. Auch fürstliche Familienbegebenheiten wurden erwähnt, etwa der Tod des Kurfürsten Johann Wilhelm von Pfalz-Neuburg 1716. Köhler nennt ausdrücklich als Rezipientengruppe »junge Knaben«, die beizeiten bebildert und auf chronikalische Weise an die Historie herangeführt werden sollten ${ }^{89}$. Es gab aber auch eine Bildungsuntergrenze für den Zeitungskonsum, hierauf verwies Johann Hunold: Er schloss den Schulanfänger, der »noch den Nepotem lieset«, vom Zeitungskonsum aus, weil es ihm an historischen, geographischen und philosophischen Grundkenntnissen fehlte. Damit würde er nur $»$ die edle Zeit verderben $\aleph^{90}$.

Das universitäre Zeitungskolleg wurde bereits 1673 von Otto Menke, dem Begründer der Acta Eruditorum, in Leipzig angeboten. 1700 beschrieb auch Johann Peter von Ludewig diese Lehrform als äußerst nützlich für die stu-

85 Vgl. zur Argumentation: Zedelmaier, Lesetechniken, S. 19f. - Zedelmaier hat sich selbst mit Ordnungen des Wissens in seiner Dissertationsschrift beschäftigt: Helmut Zedelmaier, Bibliotheca universalis und bibliotheca selecta. Das Problem der Ordnung des gelehrten Wissens in der frühen Neuzeit, Köln/Weimar/Wien 1992.

86 Zum Exzerpieren: Helmut Zedelmaier, De Ratione Excerpendi. Daniel Georg Morhof und das Exzerpieren, in: Françoise Waquet (Hg.), Mapping the World of Learning. The Polyhistor Daniel Georg Morhof, Wiesbaden 2000, S. 75-92; vgl. auch Florian Neumann, Jeremias Drexels Aurifodina und die Ars excerpendi bei den Jesuiten, in: Zedelmaier/Mulsow, Die Praktiken der Gelehrsamkeit in der frühen Neuzeit, S. 51-61.

87 Vgl. Blühm/Engelsing, Die Zeitung, S. 41. Auch Georg Greflinger pries Zeitungen als Lehrmittel für den Unterricht an: Ebd., S. 42.

88 Johann David KÖHLER, Gedenckwürdigkeiten des jetzt lauffenden achtzehenden Jahr-Hunderts nach Christi Geburt: als eine Fortsetzung der Welt in einer Nuß in Gedächtnis-hülflichen Bilder-Tafeln. Mit einer historischen Einleitung, 20 Bilder, Nürnberg 1701-1739. - Zu Köhler: Thomas NickLAs, Johann David Köhler (1684-1755), Historiker, in: Fränkische Lebensbilder 16 (1996), S. 79-93.

89 KöHLER, Gedenckwürdigkeiten des jetzt lauffenden achtzehenden Jahr-Hunderts, Vorrede.

90 [Johann Hunold], »Kurtze und gründliche Anleitung/Wie man die Journal-, Quartal- und Annual-Schrifften Ohne Versäumung seiner Studiorum zu bequemer Zeit und mit grossen Nutzen lesen kann [...] von J.H.«, o.O. 1716, Zitate S. 4. 
dierende Jugend ${ }^{91}$. Auch Kaspar Stieler widmete der Nützlichkeit der Periodika für die Hochschulen ein eigenes Kapitel. Der Reihe der Fakultäten nach erwähnte Stieler Berichte aus Zeitungen, für die Theologen Bücherangebote auf Messen oder den Verkauf von Bibliotheken, für Juristen die Translation des Reichskammergerichtsarchivs von Speyer nach Wetzlar, für Mediziner die Aderlässe und sonstige Behandlungen von Königen und anderen hochgestellten Persönlichkeiten, und für die Artisten neueste Erkenntnisse und Errungenschaften aus Mathematik und mechanischen Wissenschaften ${ }^{92}$. Insbesondere für die Studierenden, die sich mit politischen Angelegenheiten befassen, sei die Zeitung ein unerschöpflicher Quell des Wissens ${ }^{93}$. Allerdings stelle sich der Nutzen durch Lektüre allein nicht ein, sondern es sei auch die Gesprächsmöglichkeit mit einem politisch erfahrenen Mentor erforderlich:

Gut wäre es / wann junge Anfänger jederzeit einen guten Statsgelehrten zu ihrem Anfürer und Erklärer bey sich hätten/oder schon so verständig und verschlagen wären/daß sie sich selbst darein finden und mit andern ihres gleichen daraus Unterredungen halten könten. Und hieher gehöret wolermelter Herrn Weisens Wunsch/da er spricht: Wollte GOtt! daß die/so Zeitungen lesen/vornemlich unter denen der Stats-weisheit beflissenen Gesellen suchten/die darüber Gespräche führen könten: und dann würden sie erst erkennen/was vor eine Erfahrungs-Kraft daraus gefasset werden könte ${ }^{94}$.

Generell wird im Sinne der Historia magistra vitae argumentiert: Je mehr Exempla der Politikstudent in seinem Leben in den Zeitungen (und auch den Historienschriften) kennengelernt hat, desto eher wird er später richtige Entscheidungen treffen, weil er zweckdienliche Prognosen über die Chancen und Risiken politischer Vorhaben abgeben kann ${ }^{95}$.

Für bereits ausgebildete Personen, insbesondere wenn sie staatliche Ämter innehatten oder sogar bei Hofe verkehrten, entwickelte sich die Kunst des "politischen « Lesens ${ }^{96}$. Dabei galten die Kriterien der Öffentlichkeit der Bildung, wie sie dem Schul- und Universitätsystem innewohnte, nicht mehr. Im Gegenteil traten die Arkan-Elemente der höfischen Sphäre in den Blick, die darauf abzielten, sich bei allem, was man dachte, plante, sagte und tat, nicht in die Karten schauen zu lassen. Es handelte sich dabei nicht in erster Linie

\footnotetext{
91 Zum Zeitungskolleg: BuÜHm/Engelsing, Die Zeitung, S. 74-78.

92 Kap.: Von der Zeitungen Notwendig- und Nutzbarkeit auf hohen Schulen: StiELER, Zeitungs Lust und Nutz (1695/1969), S. 93-96.

93 Kap.: Von der Zeitungen Notwendig- und Nutzbarkeit bey der Statskunde Beflissenen insonderheit: ebd., S. 117-121.

94 Ebd., S. 119.

95 Vgl. zu diesem historiographischen Topos: Koselleck, Historia Magistra Vitae, S. 38-66.

96 Vgl. zum Begriff und zum Zusammenhang: Zedelmaier, Lesetechniken, S. 24.
} 
um eine Bildungstechnik, sondern um eine höfische Fertigkeit. Im kalten Luftzug der höfischen Konkurrenz war jeder Höfling zur Selbsterhaltung aufgefordert, Verstellung, "Simulation und Dissimulation «, waren wichtiger als freier Informationsaustausch. Gerade für Personen bürgerlichen Standes waren diese Techniken erst zu erlernen, während Adlige bereits von ihrer kleinkindlichen Sozialisation her in dieser Hinsicht zur Parkettsicherheit erzogen wurden. Daher sollte Lektüre verborgen betrieben werden, der eigene Wohn- und Arbeitsbereich sollte jeweils mit mehreren Büchern ausgestattet werden, und selbst die Seiten, auf denen gerade gelesen wurde, sollten einer plötzlich eintretenden Person gegenüber verschleiert bleiben ${ }^{97}$. Überhaupt sollten bürgerliche Personen mit Hof- oder Adelskontakt nicht als übermäßig gelehrt auftreten: Begriffe wie »Schulfuchs« oder »Bücher-Narren« kennzeichneten Akademiker als zu sehr theoriebelastet, als dass sie im höfischen Kontext erträglich gewesen wären - heute würde man den Begriff des »Oberlehrers« mit einer sehr ähnlichen Konnotation verwenden. Höfische Konversation, Leichtigkeit der Kommunikation und zielgerichtetes Einsetzen von Wissen im Einzelfall stellten das Verhaltensideal dar.

Dazu diente auch die Zeitungslektüre, die Kaspar Stieler bürgerlichen Personen mit Aussicht auf eine Karriere im herrschaftlichen Dienst als Weiterbildung empfahl. Antritte neuer Regierungen, Reise eines Hofmannes in ein Heilbad, Ernennung von Generälen, Anwerbung und Verkauf von Truppenkörpern, Durchzüge, Bündnisse, Neutralitätserklärungen und plötzliche Rüstungsunternehmungen mussten gelesen und behalten werden, damit der Kandidat stets auf dem aktuellen Stand des Wissens war. Dies galt besonders für Personen, die ein Amt bei Hofe oder in Hofnähe innehatten und antworten können mussten, wenn sie um eine Expertise gefragt wurden: »Da sie dann mit Grund reden und ausfürliche Antwort geben müssen/wo sie anders vor erfarne Leute gehalten seyn wollen ${ }^{98}{ }^{8}$. In dieselbe Richtung zielten die Ratschläge von Johann Georg Neukirch in seinem Grundlagenwerk zur höfischen Konversation:

Ließ mit Bedacht die gelehrten Zeitungen u. die heraus kommenden Bibliothequen, weil darinnen von neuen Büchern raisonnieret und eine kluge Censur angestellet wird [...], liß mit Bedacht die Zeitungen, die Journale, die heraus gegebenen Manifeste, Declarationes, Pacta, Vergleiche, Friedens $=$ Schlüsse und ander Tractaten Gesalbter und Durchlauchtiger Häupter, die Welt $=$ und Staats $=$ Theatra, die Einleitungen zur neuesten Historie der Welt [...]. Mit einem Worte: Lege dich auf die Historie, Geographie, Genealogie $[. . .]^{99}$.

97 Vgl. den Verweis auf eine höfische Klugheitslehre aus dem Jahre 1707: Ebd.

98 Stieler, Zeitungs Lust und Nutz (1695/1969), S. 77.

99 Johann Georg Neukirch, Politisch=Moralische Maximen in der Conversation mit hohen und 
Zwanglose Kommunikation blieb für die Zusammenkünfte von Adel und Bildungsbürgertum wichtiger als Zurschaustellung von Gelehrsamkeit. Johann Bernhard von Rohr fasste das richtige Verhalten in folgenden Worte:

Ein vernünfftiger Mensch [...] redet mehr von solchen Materien, die sich vor alle schicken, als von gelehrten Sachen, und so es ja die Gelegenheit mit sich bringen sollte, iemand mit gelehrten Sachen zu unterhalten, so bemühet er sich solche so zierlich und so leicht vorzubringen, dass der Verstand in Nachsinnen, und die Gedult in Zuhören nicht verdrießlich werden. Compagnien sind keine Auditoria, wo einer an statt eines Professoris die Weißheit allein besitzen und lehren soll [...] ${ }^{100}$.

Die Einzeldaten, die aus den Druckmedien entnommen und in Konversationen eingeflochten wurden, durften stets nur Mittel, nie Zweck sein.

Über den beruflichen Nutzen hinaus konnte Lektüre auch in der Frühmoderne der Erholung dienen. Der Frage, ob geistliche Erbauung mit ihrer Eigenschaft des Innehaltens in der Geschäftigkeit des Alltags nicht auch eine Erholung sein konnte, verdankt das christliche Abendland der Religion bis heute den arbeitsfreien Sonntag, so sehr er seit einiger Zeit unter dem Paradigma der »Nützlichkeit« auf dem Prüfstand steht ${ }^{101}$. Sicher ist, dass Zeitungslektüre für Frauen nicht zum weiblichen Bildungskanon gehörte und auch nicht zu einer »beruflichen « Kenntnisvermittlung diente. Dennoch ist von mehreren Frauen im Bildungsbürgertum bekannt, dass sie Zeitungen mit ähnlich großem Interesse gelesen haben wie ihre Männer. Zu nennen wäre hier beispielsweise Meta Klopstock $(1728-1758)^{102}$. Sie dürfte schon zu ihrer Zeit kaum die einzige gebildete Frau gewesen sein, viele folgten ihr in dieser Neigung ${ }^{103}$.

niedrigen Personen beyderley Geschlechtes auf Universitäten, auf Reisen, bey Hofe, im Vaterland [...], der Studirenden Jugend zum besten entworffen, Braunschweig 1726, S. 70, zit. nach Zedelmaier, Lesetechniken, S. 25, Anm. 55.

100 Johann Bernhard vON RoHR, Einleitung zur Ceremoniel-Wissenschafft Der Privat-Personen/Welche Die allgemeinen Regeln/die bey der Mode, den Titulaturen/dem Range/den Complimens, den Geberden, und bey Höfen überhaupt, als auch bei den geistl. Handlungen, in der Conversation, bey der Correspondenz, bey Visiten, Assembleen, Spielen, Umgang mit Dames, Gastereyen, Divertissements, Ausmeublirung der Zimmer, Kleidung, Equipage u.s.w. insonderheit dem Wohlstand nach von einem jungen teutschen Cavalier in Obacht zu nehmen/vorträgt, Einige Fehler entdecket und verbessert, und sie hin und wieder mit einigen moralischen und historischen Anmerckungen begleitet, hg. v. Gotthardt FrüHSORgE, Berlin 1728 (ND Weinheim 1990), S. 297.

101 Zur Kulturgeschichte des Sonntags: Michael Maurer, Der Sonntag in der frühen Neuzeit, in: AKG 88 (2006), S. 75-100.

102 Dokumentiert ist dies in einem Brief vom 16. Oktober 1756 an ihre Schwester, abgedruckt bei BLÜhm/Engelsing, Die Zeitung, S. 110f.

103 Martin Welke nennt weitere Frauennamen, für die Zeitungslektüre zur Gewohnheit gehörte: Welke, Das Publikum der frühen periodischen Tagespresse in Deutschland, hier S. 23. 


\subsection{Der gemeine Mann in der Stadt}

Gelegentlich wird beklagt, dass noch im frühen 18. Jahrhundert kaum mehr als $5 \%$ der Deutschen regelmäßig lasen und damit die periodische Berichterstattung wahrnehmen konnten. Allerdings wird dabei übersehen, dass im Heiligen Römischen Reich keineswegs die nivellierte Mittelstandsgesellschaft vorherrschte, für die eine Alphabetisierungsquote von $5 \%$ tatsächlich niedrig wäre. Vielmehr gab es eine scharfe Sozialgrenze zwischen Stadtbewohnerschaft und Landbevölkerung. Während die bäuerlichen und unterbäuerlichen Schichten bis ca. 1750 in der Tat noch nicht Zielgruppe der Medienproduktion waren, sieht man von der Gattung des Kalenders ${ }^{104}$ ab, galt dies sehr wohl für die städtische Bevölkerung, und zwar in ihrer Gesamtheit. In Deutschland lebten ca. 20\% der Einwohner in Städten, wobei »Stadt« als Rechtsraum, nicht topographisch als Siedlung mit einer bestimmten Mindesteinwohnerschaft verstanden wird ${ }^{105}$. Dabei waren nach dem Westfälischen Frieden 25 Städte »Großstädte« mit mehr als 10.000 Einwohnern, ihre Zahl vermehrte sich bis 1750 auf ca. 40 . Weitere $5 \%$ der Städte hatten zwischen 2.000 und 10.000 Einwohner, die restlichen der über 3.000 Städte waren überschaubare kommunale Einheiten von unter 2.000 Personen, in denen sich die Eliten ebenso wie die Nichteliten wechselseitig genauso gut kannten wie die Bewohnerschaft in den Dörfern ${ }^{106}$. Nachbarschaften bildeten daher stets Kommunikationsgemeinschaften, das spielte auch für den Medienkonsum eine nicht unerhebliche Rolle.

Für die städtische Sozialordnung ist eine erhebliche soziale Ungleichheit anzunehmen, Hans-Ulrich Wehler hat diesen Umstand in seiner Deutschen Gesellschaftsgeschichte betont und vergleichend dargestellt ${ }^{107}$. Demnach machten die Oberschichten, die als Grundrenten empfangende Immobilienbesitzer, Bankiers oder Fernhandelskaufleute von den Erträgen ihres investierten Vermögens lebten, zwischen 1 und $10 \%$ der Stadtbewohnerschaft aus $^{108}$. Diese Schicht galt als komplett literalisiert, verfügte nicht nur aus

104 Zum gedruckten Kalender: Susanne GreiLIch / York-Gothart Mix (Hg.), Populäre Kalender im vorindustriellen Europa. Der »hinkende bote«/»Messager boiteux«. Kulturwissenschaftliche Analysen und bibliographisches Repertorium. Ein Handbuch, Berlin 2006; Jan KNoPf, Kalender, in: Fischer/Haefs/Mix, Von Almanach bis Zeitung, S. 121-136; Klaus-Dieter HerbST, Das Neueste im Jahresrhythmus. Zur Professionalisierung des Kalenderwesens im 17. Jahrhundert, in: Blome/BönING, Presse und Geschichte, S. 97-124.

105 Überblickswerke zur Struktur der frühneuzeitlichen Städte: Klaus GerTeis, Die deutschen Städte in der frühen Neuzeit. Zur Vorgeschichte der »bürgerlichen Welt«, Darmstadt 1986; Heinz Schilling, Die Stadt in der Frühen Neuzeit, München 1993; Ulrich RossEaux, Städte in der frühen Neuzeit, Darmstadt 2006.

106 Vgl. zur Quantifizierung: Schilling, Die Stadt in der Frühen Neuzeit, S. 4-17.

107 WehLer, Deutsche Gesellschaftsgeschichte, Bd. 1, S. 177-202.

108 Wehler nennt Mainz mit 17\% Oberschicht als Ausnahme: WeHLER, Deutsche Gesellschaftsgeschichte, Bd. 1, Tab. S. 188; soziale Eigenschaften S. 184-189. 
Gründen des demonstrativen Konsums und der bürgerlichen Reputation über Bücherbesitz (oder sogar Bibliotheken), sondern las regelmäßig Periodika, teils aus beruflichen Gründen zur Überwachung der Märkte, anderenteils zur Aus- und Weiterbildung, drittens zur Unterhaltung. Die Mittelschichten machten in zwölf ausgewählten und genauer untersuchten Städten zwischen 10 und $35 \%$ der Einwohnerschaft aus ${ }^{109}$. Hierzu gehörten Kaufleute, die nicht Oberschichtsangehörige waren, sowie die Mehrzahl der Handwerksmeister und sonstigen Selbstständigen in den Städten, höhere kommunale Bedienstete sowie alle Gebildeten, soweit sie ein besoldetes Hauptamt innehatten, samt ihren Familien. Auch diese Schicht war komplett literalisiert. Auch in der selbstständigen Handwerkerschaft darf von einer großen Affinität zum periodischen Schrifttum ausgegangen werden.

Holger Böning bestätigt diese soziale Rahmensituation für die von ihm untersuchte Reichs- und Hansestadt Hamburg. Auch in dieser Kommune waren die städtischen Sozialstratifikationen im 17. und 18. Jahrhundert sehr spitz: Während die Hamburger Oberschicht ca. 5\% der Bevölkerung umfasste, kamen auf die obere Mittelschicht 10-15\%. Die untere Mittelschicht umfasste etwa ein Drittel der Einwohnerschaft, der Rest gehörte den Unterschichten an. Wenn Hamburg um diese Zeit ca. 5.000 Zeitungsleser besaß, dann war praktisch jedes männliche Mitglied der beiden oberen Sozialgruppen dabei. Für jedes Oberschichtenmitglied, das nicht las, ist ein Mitglied der unteren Mittelschicht bzw. der Unterschichten zu veranschlagen. Da die Zahl der Zeitungsleser stetig wuchs, während die Zahl der Oberschichtenangehörigen nur langsam stieg, muss demnach die Erschließung des Lesermarktes in den unteren Bevölkerungsschichten erfolgreich gewesen sein, und die Anfänge dieses Erfolges dürften bereits vor der aufklärerischen Bildungsinitiative gelegen haben ${ }^{110}$.

Rechnet man diese Angaben als Durchschnittswerte für das gesamte Reich hoch, dann kommt man auf ca. 7\% Oberschichten- und ca. 33\% Mittelschichtsangehörige in den Städten. Diese $40 \%$ Besitz-, Gewerbe- und Bildungsbürger machten - bei $20 \%$ Verstädterungsgrad - ca. $8 \%$ der Bewohnerschaft des Alten Reiches aus. Dieses knappe Zwölftel der Deutschen stellt daher den Maßstab dar für die Reichweite periodischer Presse, vor allem hinsichtlich ihrer Produktions- und Verkaufszahlen.

Setzt man diese Zahlen in ein Verhältnis zur Entwicklung der Produktion von politischen Berichtsmedien, fällt eine Diskrepanz auf: Während der Bevölkerungsanteil der Gebildeten sowie der Ober- und Mittelschichten in den Städten nicht signifikant anstieg, schnellte die Zeitungsproduktion wäh-

109 Ebd., Bd. 1, Tab. S. 189; soziale Eigenschaften S. 189-193.

110 Vgl. die diesbezüglichen Überlegungen bei BöNING, Welteroberung durch ein neues Publikum, S. $128 \mathrm{f}$. 
rend des gesamten 17. und 18. Jahrhunderts in die Höhe. Dies bedeutete, dass es nicht um eine Marktsättigung im Bildungsbürgertum ging, sondern um eine Erschließung von Kundenschichten, die zuvor keine Zeitungsrezipienten waren. Martin Welke vergleicht die Verbreitung der Zeitungen mit der der Bibel und der Erbauungsschriften ${ }^{111}$. Von 50 bis 60 politischen Blättern um 1700 wuchs ihre Zahl auf über 200 um 1800, wobei eine Beschleunigung in den letzten dreißig Jahren des 18. Jahrhunderts zu konstatieren ist. Dieselben Zahlen tauchen wieder auf, wenn man nach der Verteilung der Druckorte fragt: Von ca. 50 Druckorten im letzten Drittel des 17. Jahrhunderts stieg ihre Zahl auf über 200 um 1800. Eine Zeitung wurde nicht allein von ihrem Käufer gelesen, sondern ihr Inhalt durch Weitergabe, Vorlesen oder Erzählen anderen Personen zugänglich gemacht (Multiplikationseffekt). Demnach konnten Ende des 18. Jahrhundert bereits ca. 3 Millionen Deutsche durch Zeitungen erreicht werden ${ }^{112}$. Diese Zahlen überstiegen die Summe der Adligen, Geistlichen, Akademiker, Studenten, Kaufleute und Handwerker deutlich. Schon um 1700 kann von einer Reichweite von ca. 20\% der Bevölkerung ausgegangen werden ${ }^{113}$, für die Mitte des 18. Jahrhunderts sind es demnach mehr als $25 \%$ der damaligen Öffentlichkeit gewesen ${ }^{114}$.

Damit ist anzunehmen, dass im 18. Jahrhundert die deutschen Städte und ihre Einwohnerschaft, gleich welchen Standes, flächenmäßig von politischen Periodika erreicht wurde. »Flächenmäßig erreicht« bedeutet nicht, dass jeder Stadtbürger oder jede Stadtbürgerin täglich eine Zeitung gelesen hat - das ist nicht einmal heute der Fall, - sondern will vielmehr zum Ausdruck bringen, dass jeder Einwohner, der eine Zeitung haben wollte, sich ohne besondere Mühe eine beschaffen konnte ${ }^{115}$. Das Abonnement über den Postmeister war dabei die teuerste und verpflichtendste Form, dennoch eine erfolgreiche ${ }^{116}$. Kaspar Stieler schilderte den Zulauf des Pressepublikums mit den Worten:

111 Vgl. Welke, Zeitung und Öffentlichkeit im 18. Jahrhundert, hier S. 79.

112 Wilke, Die Zeitung, S. 393f. u. 397.

113 Ukena, Tagesschrifttum und Öffentlichkeit im 16. und 17. Jahrhundert, hier S. 45; Johannes WeBER, »Die Novellen sind eine Eröffnung des Buchs der ganzen Welt«. Entstehung und Entwicklung der Zeitung des 17. Jahrhunderts, in: Klaus Beyrer/Martin Dallmeier (Hg.), Als die Post noch Zeitung machte. Eine Pressegeschichte, Gießen 1994, S. 15-31, hier S. 20, zit. nach Faulstich, Medien zwischen Herrschaft und Revolte, S. 232.

114 Dorn/Vogel, Geschichte des Pressevertriebs in Deutschland, S. 17.

115 Holger Böning weist dies für die Hamburger Ober- und Mittelschicht im 17. Jahrhundert nach: Holger BöNING, Die Nachbarstadt Hamburg wird zur deutschen Zeitungsmetropole, in: Astrid Blome/Holger Böning (Hg.), Täglich neu! 400 Jahre Zeitungen in Bremen und Nordwestdeutschland, Bremen 2005, S. 110-119.

116 Michael North verweist zurecht darauf, dass auch eine starke Kostenreduktion der politischen Informationsbeschaffung im Zuge der drucktechnischen Aufbereitung immer noch Restkosten verursachte, die dem gemeinen Mann in seiner Mangelsituation zu hoch sein konnten: Michael North, Kommunikation, Handel, Geld und Banken in der Frühen Neuzeit, München 2000 , S. 51. 
»Siehet man doch nur sein Wunder in allen Städten/was vor ein Geleufe nach dem Post Hause in den Zeitungs-Tagen ist; ärger/als wenn man Spende austeilete etc. ${ }^{117}$. Wer nicht abonnierte, für den reichte es, einen Ort zu wissen, wo Zeitungen vorgehalten wurden, wo sogar vorgelesen und kommentiert wurde. Bekannte konnten gelesene Exemplare weiterreichen, das galt nicht nur für sozial symmetrische Freundschaften, sondern auch für asymmetrische Sozialbeziehungen wie Klientelen oder Arbeitsverhältnisse, wo Druckwerke kursierten oder einfach nach der Lektüre im Betrieb herumlagen und daher vom Personal wahrgenommen wurden. Auch die Form des Lesezirkels oder der Lesegesellschaft mit gemeinschaftlicher Übernahme der Beschaffungskosten sowie dem Umlaufprinzip der erstandenen Druckwerke darf im Zeitungswesen angenommen werden, auch wenn bislang vor allem BuchLesegesellschaften untersucht worden $\operatorname{sind}^{118}$.

Der nichtakademische Leser wurde im 17. Jahrhundert durchaus schon entdeckt. So schrieb Christian Thomasius dem Nichtakademiker eine weitreichende Alltagsklugheit zu: »Der unstudierte Mann, er möge nun ein Soldat, Kaufmann, Hauswirt, ja sogar ein Handwerker oder ein Bauer oder eine Weibsperson sein«, könne seinen Verstand unbeschwerter als ein Studierter gebrauchen, der »wegen der allzu langen Gewohnheit, sich von dem Abwege der Autorität und der leidigen Büchersucht nicht losreißen kann «119. Selbst Kaspar Stieler, der sich von der Nützlichkeit der Lektüre in ständischer Differenzierung leiten ließ, erkannte an, dass die »Landleute« durchaus aus den Zeitungen lernen könnten, dass sie ihre Gebäude vor Kriminellen sichern und den Brandschutz beachten sollten. Selbst das Vertreiben eines »TeufelsGespenste« auf seinem Getreidetransporter durch das Absingen von Ein feste Burg ist unser Gott empfahl Stieler dem zeitungsklugen Bauern ${ }^{120}$.

Schon für die frühere Zeit darf man den »gemeinen Mann« und sein weibliches Pendant als Leser bzw. Leserinnen periodischer Presse annehmen, nicht in der gesamten gesellschaftlichen Breite, aber in größerem Ausmaß als nur im Einzelfall ${ }^{121}$. Er gehörte zu den Lieblingen nicht nur der marxistischen Geschichtsforschung, sondern auch der Sozialgeschichtsschreibung der

117 Stieler, Zeitungs Lust und Nutz (1695/1969), S. 79.

118 Marlies PrüsEnER, Lesegesellschaften im 18. Jahrhundert. Ein Beitrag zur Lesergeschichte, Frankfurt a.M. 1971; Otto DANN (Hg.), Lesegesellschaften und bürgerliche Emanzipation. Ein europäischer Vergleich, München 1981.

119 Zit. bei Walter GöTZE, Die Begründung der Volksbildung in der Aufklärungbewegung, Langensalza/Berlin/Leipzig 1932, S. 19, neuerlich zit. bei DAMBERG, Die politische Aussage in den Totengesprächen David Fassmanns, S. 13.

120 Stieler, Zeitungs Lust und Nutz (1695/1969), S. 102.

121 Die »gemeine Frau « ist hierbei stets mitgedacht. Bezeichnenderweise ist es der feministischen Geschichtsforschung noch nicht gelungen, eine geschlechtsneutrale Metapher für Selbstbewusstsein und Eigensinn der Unterschichten in historischer Zeit zu kreieren, um ihr erfolgreiches Beharren gegenüber systematischen Manipulationen ihrer Obrigkeiten sinnfällig zu machen. 
1960er und 1970er sowie der Alltagsgeschichtsschreibung der 1980er Jahre. Ihm wird etwas Authentisches zugeschrieben, etwas, was sich die »guten" Wurzeln im Sinne Rousseaus bewahrt hatte und stets im Widerspruch zum alles Vereinnahmenden der politischen und kulturellen Eliten und ihrer sozialen Großsysteme stand. Dieses Widerspenstige besaß der »gemeine Mann « wirklich. Bislang fehlten zumeist methodische Zugriffe, um dieses Phänomen längsschnittartig fassbar zu machen. Es artikuliert sich vor allem in Anekdoten $^{122}$.

Die oberste Gruppe der Nichtadligen und Nichtakademiker stellten die Kaufleute dar. Kaspar Stieler widmete ihrem Zeitungskonsum ein ganzes Kapitel: Zum einen sei das Zeitungswesen in geschriebener Form im Fernhandel schon vor Erscheinen der Druckfassungen gebräuchlich gewesen. Zum anderen bestünden Wirtschaftskontakte eben aus Informationen: Jede Stadt und jeder Wirtschaftsraum habe sein wirtschaftliches Profil, per Handel erhalte jeder das, was ihm fehle, indem er die Dinge anbiete, die er im Überfluss besitze oder beschaffen könne. Auch verbreite die Presse Berichte über »Fruchtbarkeit und Miswachs«, d.h. über unterschiedliche Grade an Knappheit von Gütern, aber auch von Kredit. Unterschiedliche Orte des Handels in Teilmärkten wurden bekannt gegeben, ebenso wurden Wirtschaftspartner über eingetretene Bankrotte in Kenntnis gesetzt. Letztlich vermittelten die Zeitungen Informationen darüber, welche Handels- und Produktionshemmnisse durch staatliche Anordnungen im In- oder Ausland eingetreten seien oder eintreten würden ${ }^{123}$.

Ein konkretes Beispiel an der sozialen Schnittstelle zwischen Besitz- und Bildungsbürgertum war sicherlich der Kölner Kaufmann und Autobiograph Hermann Weinsberg (1518-1597). Weinsberg hatte - wenn auch ohne Leidenschaft - an der Kölner Universität in allen Fakultäten studiert und war zum Magister Artium und zum Lizentiaten der Rechte promoviert worden ${ }^{124}$. Später hielt er sich durch intensive Lektüre der Flugschriften seiner Zeit über die aktuellen politischen Veränderungen auf dem Laufenden ${ }^{125}$. Von zahlreichen ähnlichen Leserkarrieren im kaufmännischen Berufsstand darf ausgegangen

122 Als Klassiker des Kampfes der konkurrierenden Kulturkonzepte des »Volkes« und der »Eliten« gilt die Studie von Robert Muchembled, Kultur des Volks. Kultur der Eliten, Stuttgart 1982 (franz. 1978). - Für die ökonomische und kulturelle Widerspenstigkeit des arbeitenden Subjekts im Kapitalismus: Oskar Negt/Alexander Kluge, Geschichte und Eigensinn. Geschichtliche Organisation der Arbeitsvermögen. Deutschland als Produktionsöffentlichkeit. Gewalt des Zusammenhangs, Frankfurt a.M. 1981.

123 Stieler, Zeitungs Lust und Nutz (1695/1969), S. 68-72.

124 Biographischer Überblick: Herborn, Hermann von Weinsberg (1518-1597), S. 15-33.

125 Vgl. zu Weinsbergs Bemerkungen zum spanisch-niederländischen Krieg und seinen Auswirkungen auf das Mietpreisniveau in Köln: Hermann von WeInsBerg, Das Buch Weinsberg. Kölner Denkwürdigkeiten aus dem 16. Jahrhundert, hg. v. Konstantin Höнlвaum, Friedrich Lau u. Josef Stein, 5 Bd., Leipzig/Bonn 1886-1926, hier Bd. 5, S. 159. 
werden. 1623 verbot der Nürnberger Magistrat die politischen Debatten der »Kaufleute« am Markt im Zusammenhang mit dem Vorlesen der Zeitungen, gemeint war offenbar nicht der Berufsstand, sondern alle Handeltreibenden, die zusammenkamen. 1631 verbot ein Ratsdekret in Regensburg das öffentliche Ablesen von Zeitungen im dortigen Reichspostamt ${ }^{126}$. Die Verordnungen dürften wohl kaum durchschlagenden Erfolg gehabt haben, signalisierten jedenfalls, dass das Räsonnieren zur täglichen Praxis gehörte ${ }^{127}$.

Für die bislang am besten erforschte Zeitungsstadt Deutschlands, die Hansestadt Hamburg, ist nicht nur der Abonnementsbezug der Periodika gut dokumentiert, sondern auch die öffentliche Auslage der Periodika nicht nur in Poststationen, sondern auch in sog. »Avisenbuden«, in Gasthäusern und den modernen Kaffeehäusern ${ }^{128}$. In Danzig wurde 1707 die Auslage von gedruckten Zeitungen in den Kaffeehäusern geduldet, nur die geschriebenen Zeitungen sollten dort künftig nicht mehr öffentlich zugänglich gemacht wer$\operatorname{den}^{129}$. Die an die Lektüre anschließenden Räsonnements waren zwar nicht ausdrücklich erlaubt, aber zumeist geduldet, solange sich daraus keine handfesten Folgen entwickelten. Selbst politisch-historische Zeitschriften sollten, zumindest aus der Sicht der Betreiber, dem gewerblichen Publikum nicht verborgen bleiben. David Fassmann verwies im Vorwort zum 16. Band seiner Totengespräche darauf hin, seine Kritiker hätten sich darüber geärgert, dass er für »Schuster oder Schneider« schreibe. Fassmann bestritt gar nicht, dass er auch diese Lesergruppe gern ansprechen wollte ${ }^{130}$.

126 Regensburger Ratsdekret vom 10. Oktober 1631: Rudolf FreYTAG, Post und Zeitung, in: APB 4 (1928), S. 24-50, hier S. 42, zit. nach BeHringer, Im Zeichen des Merkur, S. 391.

127 Nachweis: Sporhan-Krempel, Nürnberg als Nachrichtenzentrum zwischen 1400 und 1700, S. 69; Abdruck der Quellenpassage auch bei: BönInG, Welteroberung durch ein neues Publikum, S. 19.

128 Auf die Bedeutung der »Avisenbuden« hatte bereits Paul Jacob Marperger 1726 hingewiesen: Paul Jacob Marperger, Anleitung zum rechten Verstand und nutzbarer Lesung Allerhand sowohl gedruckter als geschriebener [...] Ordentlicher und Außerordentlicher Zeitungen oder Avisen, o.O. 1726, hier S. 21. - Zum Kaffeehaus als Ort der bürgerlichen Geselligkeit, der Zeitungslektüre und des Räsonnements: Franklin KopITzsch, Zeitungen - »Das Idol von Hamburg«. Zeugnisse zur Zeitungslektüre der Hamburger im 18. Jahrhundert, in: Jahrbuch für Regionalgeschichte 24 (2006), S. 101-114, bes. S. 108, zudem mit weiterführenden Literaturhinweisen.

129 Ratsbeschluss Danzig, 1. Dezember 1707: BLÜHm/Engelsing, Die Zeitung, S. 83f.

130 Fassmann, Gespräche im Reiche der Todten, Bd. 16, s.p.; vgl. auch DamBERG, Die politische Aussage in den Totengesprächen David Fassmanns, S. 23, Anm. 43. 
Ob sich daraus eine Adaption der Theorie des »gesunkenen Kulturgut« im Sinne von Hans Naumann ${ }^{131}$ entwickeln lässt, muss die weitere Erforschung noch im Detail erweisen. Roger Chartier hat den romanischen Sprachraum nach Beispielen durchsucht und ist immer wieder fündig geworden. So liegen für die spanische Diözese Cuenca Inquisitionsberichte aus der Zeit von 1560 bis 1610 vor, aus denen die Unterschichtenlektüre klar ersichtlich ist. Bauern, Handwerker und Kaufleute lasen nicht nur Andachtsbücher und Heiligenviten, sondern auch die modischen Ritterromane ${ }^{132}$. Die berühmte literarische Stelle in Miguel de Cervantes' Don Quijote, in der sich spanische Erntearbeiter in der Schenke Passagen aus Ritterromanen vorlesen ließen, ist damit keineswegs einfach in den Bereich der Fiktion zu verweisen, sondern nimmt kulturelle Transferpraktiken auf, die durchaus zeitgemäß waren. Auch die Rahmenhandlung, in der der spanische Pfarrer die Romane eigentlich zur Verbrennung einziehen möchte, davon aber durch die Wirtshausgesellschaft abgebracht wird und sie stattdessen öffentlich vorlesen muss, könnte durchaus ihre Entsprechung in der Wirklichkeit gehabt haben ${ }^{133}$.

Lasen auch die städtischen Unterschichten? Ca. 60\% der städtischen Einwohnerschaften lassen sich den Unterschichten zurechnen, bei jeweils starken quantitativen Unterschieden und bei beträchtlicher sozialer Differenzierung ${ }^{134}$. Unterschichten hatten normalerweise kein Bürgerrecht, sondern zum einen Teil den Status von Einwohnern mit gemindertem, aber dauerhaftem Aufenthaltsrecht ohne politische Mitwirkungen und Grundbesitzberechtigung. Zum anderen Teil waren sie bloß geduldet, weil die ökonomische Bedarfslage oder die christliche Barmherzigkeit es geboten. Bei gegebenem Anlass konnten sie allerdings ausgewiesen werden.

Beim Bildungsstand der städtischen Unterschichten gab es starke lokale Unterschiede. Seit dem Reformationszeitalter waren diese Gruppen verstärkten Bildungsbemühungen ausgesetzt, die besonders in protestantischen Gebieten immerhin die Rezeptionsfähigkeit für biblische und erbauliche Texte anstrebten und auch oft erreichten. Andreas Hyperius hatte die Lesetätigkeit nicht auf den Hausvater beschränkt, sondern alle Hausgenos-

131 Naumann entwickelte diese Theorie aus Befunden der Kleidermode der Oberschichten in der Frühen Neuzeit, die kurz darauf in Einzelelementen auch die Mode breiterer Schichten erreichte: Hans NaumanN, Grundzüge der deutschen Volkskunde, Leipzig 1922, S. 7-18, zit. nach Bernd Rовск, Lebenswelt und Kultur des Bürgertums in der Frühen Neuzeit, München 1991, S. 95.

132 Roger Chartier, »Populärer" Lesestoff und »volkstümliche« Leser in Renaissance und Barock, in: Chartier/Cavallo, Die Welt des Lesens, S. 397-418, hier S. 401.

133 Miguel de Cervantes, Der sinnreiche Junker Don Quijote von der Mancha (1605). In der Übertragung v. Ludwig Braunfels, durchgesehen v. Adolf Spemann, München 1979; Wirtshausszene: Erstes Buch, Kap. 32, S. 317-324.

134 Wehler, Deutsche Gesellschaftsgeschichte, Bd. 1, Tab. S. 193; soziale Eigenschaften S. 193-198. 
sen aufgefordert, sich an der geistlichen Lektüre zu beteiligen ${ }^{135}$. Wenn Hans Medick für den württembergischen Flecken Laichingen im 18. und 19. Jahrhundert einen Bücherbesitz in fast $70 \%$ der Haushalte nachweist, dokumentiert dies den eingetretenen Erfolg dieser obrigkeitlichen Mühen ${ }^{136}$. Medick verweist zudem auf den subventionierten Verkauf der sog. »Armenbibeln« in Württemberg, die bereits für 32 Kreuzer zu erwerben waren. Da Pfarrer vor einer Eheeinsegnung nach dem Besitz einer solchen Ausgabe fragten, nahmen die Untertanen das Angebot $a^{137}$. Dieser Umstand deckt sich mit Erkenntnissen, die Martin Welke aus seinen eigenen Quellenauswertungen gewann:

Die Lesefähigkeit war - so ist der wissenschaftliche Befund - bereits im 17. Jahrhundert in den meisten deutschen Staaten so verbreitet, dass die Alphabetisierungsfrage in Hinsicht auf die Benutzung der Zeitung eine zu vernachlässigende Frage darstellt. Stets gab es unter denen, die sich zu der damals üblichen gemeinschaftlichen Lektüre der neuesten Nachrichten aus aller Welt zusammenfanden, hinlänglich viele Lesekundige, die als Vorleser fungieren konnten ${ }^{138}$.

Angesichts der ständeübergreifenden Kommunikation kann davon ausgegegangen werden, dass politische Informationen auch den Unterschichten zu Ohren und Augen gelangten. Der Bildungskanon war im Primärschulbereich derart auf christliche Inhalte ausgerichtet, dass viele Zöglinge erst aus den Zeitungen grundlegende Informationen über die räumliche und zeitliche Strukturierung der Welt, über Geographie und Geschichte erhielten. Die Zeitung wurde so, ohne dass ihre kommerziellen Betreiber das zu Beginn im Auge gehabt hätten, zu einem zentralen Element der Erwachsenenbildung ${ }^{139}$. Mündliche Vermittler, plakative Aushänge und Bildflugblätter konnten dazu beitragen, Zeitunglesen war Gemeinschaftsangelegenheit $^{140}$. Der höfische Vorleser fand sein Pendant im Vorleser im Wirtshaus, der die dort Anwesenden nicht nur durch seine Zeitungstexte, sondern auch durch seine Kommentare zu eigenen Überlegungen unterhielt. Eine bemerkenswerte Wirtshausepisode spielte in Frankfurt im Jahr 1656 während des schwedisch-polnischen Krieges. Einige Bedienstete eines katholischen Gesandten diskutierten mit mehreren Schmiedeknechten über den Krieg im

135 Hyperius, Ein trewer und christlicher Rath, Bd. 1, fol. IVf., zit. nach Zedelmaier, Lesetechniken, S. $16 \mathrm{f}$.

136 Hans Medick, Weben und Überleben in Laichingen, 1650-1900, Göttingen 1992, Kap.: Erbauliche Lektüre und lutherischer Pietismus. Buchbesitz und Religiosität am Ende der Frühen Neuzeit, 1748-1820, S. 447-560; zum Vergleich mit anderen Städten: S. 460, Anm. 37.

137 Ebd., S. 490, Anm. 95.

138 Zitat: Welke, Das Publikum der frühen periodischen Tagespresse in Deutschland, S. 14f.

139 Dies betont Welke: ebd., S. $15 f$.

140 Ebd., S. 18. 
Osten. Beide Seiten zeigten sich gegenseitig Zeitungsexemplare, in denen unterschiedliche Berichte über die Geschehnisse zu lesen waren. Nachdem man zunächst auf die Gesundheit König Johann Casimirs von Polen getrunken hatte, wollten die katholischen Bediensteten nicht auch auf die Gesundheit König Karls X. Gustav trinken, worauf es zu einer Schlägerei kam. Die Episode ist in einer geschriebenen Zeitung überliefert, denn sie wurde aus Frankfurt unter dem 6. Mai 1656 an den Stockholmer Hof geschickt ${ }^{141}$. Drei Folgerungen lassen sich daraus ziehen:

1. Schmiedeknechte lasen entweder selbst Zeitung oder hatten sich unterrichten lassen, jedenfalls besaßen sie (mindestens) ein Zeitungsexemplar.

2. Was immer dem Einzelnen an Informationen fehlte, das besorgte er sich in der Diskussion mit seinen Zeitgenossen. Damit waren die Berichte anknüpfungsfähig hinsichtlich des alltäglichen Diskurses, sie verschafften jedem Zeitgenossen Informationsversatzstücke, die er bei nächster Gelegenheit in seine alltägliche Kommunikation einfließen lassen konnte ${ }^{142}$.

3. Diskurse zwischen herrschaftlichen Bediensteten und gewöhnlichen Handwerksgesellen waren offenbar nicht ungewöhnlich. Das ständeübergreifende Kommunikationsverhalten ist durch die Forschung bislang gering geachtet worden. Es scheint, als sei das Wissen darüber immer noch von der Vorstellung der »repräsentativen Öffentlichkeit« geprägt, die es wohl gegeben haben mag, doch bestimmte sie nicht die gesamte Kommunikation in der Vormoderne.

1705 fand der Bürgermeister der württembergischen Landstadt Bietigheim in einem Gasthaus seiner Stadt ein Flugblatt mit Vorwürfen gegen die Reichsgeneralität. Das Blatt wurde der Stuttgarter Regierung eingereicht, der Herzog selbst erfuhr davon und fühlte sich beleidigt, doch es gelang nicht, die Produzenten ausfindig zu machen ${ }^{143}$.

Nach dem Tod Kaiser Karls VI. 1740 musste der Regensburger Magistrat Dispute des gemeinen Mannes über die politische Großwetterlage verbieten lassen. Die Neue Europäische Fama kommentierte dies zustimmend: Es stehe den gewöhnlichen Leuten nicht zu, in alkoholisiertem Zustand über Staats-Angelegenheiten und Unternehmungen großer Herren zu debattieren,

141 Abdruck des Textes: BLÜHm/Engelsing, Die Zeitung, S. 36f.

142 Frank Bösch spricht in diesem Zusammenhang von Neuigkeiten als »Währung sozialer Beziehungen«: Bösch, Mediengeschichte, S. 81.

143 Andreas Gestrich, Krieg und Öffentlichkeit in der zweiten Hälfte des 17. Jahrhunderts, in: Angela Giebmeyer/Helga Schnabel-Schüle (Hg.), »Das Wichtigste ist der Mensch«. Fs. für Klaus Gerteis zum 60. Geburtstag, Mainz 2000, S. 21-36, hier S. 32, Anm. 34 (mit Archivnachweis). 
denn dies übersteige ihre Begriffe ${ }^{144}$. Damit rekapitulierte der Redakteur genau die Meinung seiner adligen und bildungsbürgerlichen Leserschaft: Der gemeine Mann war zwar als Rezipient politischer Informationen willkommen, aber nicht als jemand, der sich derart artikulierte, dass politische Forderungen von unten zu befürchten waren.

Innerhalb der Haushalte konnte der vorhandene Lesestoff den Dienstboten nicht verborgen bleiben, allein weil Botengänge von und zum Buchbinder sowie das wiederkehrende Staubwischen anfielen ${ }^{145}$. Rolf Engelsing berichtet zudem, dass viele Dienstboten als Vorleser eingesetzt wurden. Anreize, lesen zu lernen, waren daher reichlich gegeben, selbst im autodidaktischen Verfahren ${ }^{146}$. Das Dienstpersonal konnte in den Städten zwischen 10 und 20\% der Einwohnerschaft ausmachen. Vieles spricht dafür, dass die Dienstbotengruppe die Brücke darstellte, über die das Mediensystem das Kleinbürgertum erreichte $^{147}$. Die Nähe zu bürgerlichen Kulturformen führte zu Neigungen, selbst eine kleinbürgerliche Existenz anzustreben und sich dafür zu qualifizieren, u.a. durch Lektüre ${ }^{148}$. Ähnliche Beobachtungen machte Etienne François bei Studien über die lutherische Reichsstadt Speyer, wo im Laufe des 18. Jahrhunderts ebenfalls ein großer Bevölkerungsanteil literat wurde ${ }^{149}$. Auch hierzu fehlen bislang Studien, die die Zeit vor der »Lesesucht«-Debatte unter die Lupe nehmen.

In den normativen Schriften zum Zeitungswesen, besonders bei Ahasver Fritsch und Johann Ludwig Hartmann, dominierte in den späten 1670er Jahren noch die Vorstellung, der öffentliche Gebrauch dieses Mediums ließe sich völlig verbieten. Fritsch warnte aus der Position eines Regierungsrates vor einer Bedrohung der weltlichen Ordnung, wenn die Untertanen über politische Angelegenheiten räsonnierten ${ }^{150}$. Hartmann schrieb aus Sicht eines pie-

144 Neue Europäische Fama 6 (1740), H. 68, S. 642.

$145 \mathrm{Zu}$ den Dienstboten rechnet Hans-Ulrich Wehler folgende Gruppen: »Verwalter, Schreiber, Kammerdiener, Köche, Konditoren, Tafeldecker, Haiducken, Läufer, Portiers, Gärtner, Kutscher, Lakaien, Jäger, Kellner, Wirtschaftsvögte, Haus-, Wagen- und Reitknechte«: WEHLER, Deutsche Gesellschaftsgeschichte, Bd. 1, S. 194.

146 Rolf Engelsing, Zur Sozialgeschichte deutscher Mittel- und Unterschichten, Göttingen 1973, S. $213 f$.

147 Vgl. die Überlegungen bei KIESEL/MünCH, Gesellschaft und Literatur im 18. Jahrhundert, S. 166. Die spätere aufgeklärte »Dienstbotenlektüre« besaß einen Grad an didaktischer Penetranz und an Hochmut der (gebildeten) Autoren gegenüber den Dienstboten, dass sie möglicherweise nur zum Verschenktwerden geeignet war. Forschungen zu diesem Gedanken stehen noch aus.

148 Vgl. dazu die Ausführungen bei Wittmann, Geschichte des deutschen Buchhandels, S. 179.

149 Etienne François, Buch, Konfession und städtische Gesellschaft im 18. Jahrhundert. Das Beispiel Speyers, in: Rudolf Vierhaus, Mentalitäten und Lebensverhältnisse. Beispiele aus der Sozialgeschichte der Neuzeit. Fs. zum 60. Geburtstag, hg. v. Mitarbeitern u. Schülern, Göttingen 1982, S. 34-54.

150 Ahasver Fritsch, Discursus de Novellarum, quae vocant Neue Zeitunge/hodierno usu et abusu, o.O. 1676 . 
tistischen Pfarrers über »Unzeitige Neue-Zeitungs-Sucht« und reihte diese Praxis ein in eine Kette von Lastern, denen er im Predigtstil mit biblischen Argumenten entgegenzog. Introspektion auf Besserung der Lebensführung und Ausrichtung aller Hoffnungen auf jenseitige Freuden standen für ihn im Vordergrund ${ }^{151}$.

Später wurde bei Kaspar Stieler hinsichtlich der intendierten Leserschaft unterschieden zwischen Kaufleuten und Handwerkern, selbst Bauern, die Zeitungen lesen durften, soweit sie für ihre »Hantierung « notwendig seien. Knechte und Mägde hingegen, d.h. die gesamte unterbürgerliche und unterbäuerliche Bevölkerung, sollte von den Zeitungen ferngehalten werden und stattdessen lieber geistliche, erbauliche Texte lesen ${ }^{152}$. Auch Köhler, Bergleute oder Soldaten gehörten nicht zur Zielgruppe ${ }^{153}$. Johann Peter von Ludewig sah die Verbreitung des Zeitungslesens über den Stand der Gebildeten hinaus ebenfalls mit Skepsis.

Wann man nur die sogenannten Zeitungen, wie solche jetzo an den meisten Orten eingerichtet, in Erwegung ziehet; so wird sich dieses finden, dass unter tausend Lesern kaum einige wenige seyn; welche daraus einen anderen Gebrauch weder suchen noch zu machen wissen, als dass sie davon in Gesellschaften sprechen und die Zeit vertreiben können ${ }^{154}$.

Diese Beobachtung sah schon 1729 den Sinn der Zeitungslektüre in der Bereitstellung von kommunikativer Masse, die in die folgenden Gespräche mit den eigenen Zeitgenossen eingebracht werden konnte. Ludewig erkannte darin keinen Nutzen für den gemeinen Mann, der sich lieber auf sein Tagewerk und auf Gott besinnen solle. Das andere Argument Ludewigs richtete sich dagegen, was heute $»$ Kommerzialisierung« genannt wird:

Man wollte dann sagen: daß dadurch die Buchdrucker und Papiermacher etwas zu thun bekämen; auch das Post-Geld davon nicht wenig abwürfe. Welches aber nur zufälliger Weise geschiehet und den Schaden nicht heilet, der durch das übermäßige Zeitungslesen, unter dem gemeinen Mann, verursachet zu werden pfleget ${ }^{155}$.

151 Johann Ludwig Hartmann, Unzeitige Neue=Zeitungs $=$ Sucht $/$ und Vorwitziger Kriegs $=$ Dis coursen Flucht/[...], Rothenburg 1679.

152 Stieler, Zeitungs Lust und Nutz (1695/1969), S. 40f.

153 Ebd., S. 65.

154 Johann Peter von Ludewig, Unterricht Von denen wöchentlichen Anzeigen, Die Auf Königl. Majest. in Preussen allergnädigsten Special-Befehl/in Dero Reich, Provintzien und Landen, durch die so genannte Intelligenz-Zettel/angeordnet. Absonderlich zum Behuf den Universitäten und Stadt Halle, in folgenden Artickeln entworfen [...], Halle a.d. Saale 1729, S. 2.

155 Ebd., S. 3. 
Das Periodikum, das nach Ludewigs Ansicht für den gemeinen Mann geeignet sei, hieß bei ihm Wöchentliche Anzeigen, die begriffliche Umschreibung der Zeitungsform, die heute als »Intelligenzblätter« bezeichnet wird. Die Kritik am Zeitunglesen breiterer Volksschichten ist damit älter als die »Lesesucht«-Debatte der Hochaufklärung, die sich vor allem gegen den Konsum von Belletristik durch Bevölkerungskreise richtete, die von den Aufklärern eigentlich als illiterat betrachtet wurden.

Die bäuerliche Bevölkerung gehörte ebenfalls nicht zur primären Zielgruppe für die politische Berichterstattung. Glaubt man vielen Darstellungen, so tappte die zahlenstärkste Bevölkerungsschicht vor dem Einsetzen der Bildungsbestrebungen der Volksaufklärung in finsterer Unwissenheit ${ }^{156}$. Reinhard Wittmann geht so weit, Landesherren und adligen Grundherren zu unterstellen, ihnen sei an der Erhaltung der beklagenswerten Zustände im Landschulwesen gelegen gewesen. Dafür führt er ein längeres Zitat Friedrichs des Großen an ${ }^{157}$. Dem muss entgegengehalten werden, dass es schon vor 1750 zahlreiche ernsthafte Bildungsbemühungen gegeben hat, an denen sich auch Landesherren beteiligt haben, man denke nur an Herzog Ernst von Sachsen-Gotha, der seit der Schlussphase des Dreißigjährigen Krieges sein Territorium in ein Bildungsmusterland zu verwandeln versuchte ${ }^{158}$. Für das Oldenburger Land ist immerhin für die zweite Hälfte des 18. Jahrhundert eine breite Lesefähigkeit des Gesindes nachgewiesen worden. Dabei handelte es sich offenbar um bereits länger verbreitete Kulturtechnik, nicht um Früherfolge der Volkspädagogik ${ }^{159}$. Richtig ist an Wittmanns Schilderung allerdings, dass die Vorhaben und die praktischen Erfolge oft weit auseinanderlagen.

Bäuerliche Flugschriften-, Zeitungs- oder Zeitschriftenlektüre ist bislang noch nicht in größerem Stil nachgewiesen worden. Bis zum Erweis des Gegenteils dürften sie daher als Rezipienten aus zweiter Hand, auf Märkten und in Wirtshäusern, betrachtet werden. Allerdings betont Reinhart Siegert zu Recht, dass die Anwesenheit von gebildeten Personen auf dem Lande wie Pfarrer, Schulmeister, akademisch geschulte Amtsleute dennoch Lesestoffe und insbesondere Zeitungen in diese Gegenden gebracht hat ${ }^{160}$. Im Laufe des

156 Einführend zur Volksaufklärung: BöNING/SIEGERT, Volksaufklärung. Biobibliographisches Handbuch zur Popularisierung aufklärerischen Denkens im deutschen Sprachraum, 2 Bd., pas.

157 Wittmann, Geschichte des deutschen Buchhandels, S. 176.

$158 \mathrm{Zu}$ Herzog Ernst: Roswitha Jacobson/Hans-Jörg Ruge (Hg.), Ernst der Fromme (1601-1675). Staatsmann und Reformer. Wissenschaftliche Beiträge und Katalog zur Ausstellung Gotha, 16. Dezember 2001 bis 7. April 2002, Bucha 2002; KLIngER, Der Gothaer Fürstenstaat, pas.

159 Ernst HinRichs, Zur Erforschung der Alphabetisierung in Nordwestdeutschland in der Frühen Neuzeit, S. 35-56; ders., Alphabetisierung. Lesen und Schreiben, S. 539-561.

160 Siegert, Zur Alphabetisierung in den deutschen Regionen am Ende des 18. Jahrhunderts, hier S. 292. 
18. Jahrhunderts stieg die ländliche Lesefähigkeit, für Regionen wie Kursachsen wird gegen Ende des 18. Jahrhunderts bereits mit kompletter Lesefähigkeit der erwachsenen männlichen Bevölkerung gerechnet. Selbst die Lesefähigkeit von Frauen stieg steil an, wenn auch mit deutlichem Abstand zu der der Männer. Martin Welke betont das Prozesshafte dieser Entwicklung: »Die Stabilität der schon im 17. Jahrhundert ausgebildeten kollektiven Rezeptionsformen und die Stetigkeit, mit der sich die Gesamtauflage der Tagespresse vermehrte, kennzeichnen die Ausweitung des Zeitungslesens in Deutschland als einen im Wesentlichen kontinuierlichen Vorgang « ${ }^{161}$. Nach allem Gesagten ist anzunehmen, dass die Zahl der Lesekundigen schon um 1700 größer gewesen sein könnte, als von Erich Schön am Anfang dieses Kapitels angenommen.

161 Zitat: Welke, Gemeinsame Lektüre, S. $42 \mathrm{f}$. 
HauptTeil II:

Das Reichssystem und die Fallstudien 



\section{Reichssystem und Öffentlichkeit}

Das Heilige Römische Reich deutscher Nation erfreut sich seit den späten 1960er Jahren anhaltender Aufmerksamkeit in der Historiographie. Kürzlich formulierte Heinrich August Winkler in deutlicher Anlehnung an den Beginn des Johannesevangeliums: »Im Anfang war das Reich: Was die deutsche Geschichte von der Geschichte der großen westeuropäischen Nationen unterscheidet, hat hier seinen Ursprung « ${ }^{1}$. Die Wertschätzung des Reiches unterlag jedoch langfristigen Schwankungen, so hatten die geschichtsschreibenden Zeitgenossen im 18. Jahrhundert das Reich positiv konnotiert, im 19. Jahrhundert folgte nach einer kurzen Nostalgie-Epoche in den 1820er Jahren eine distanzierte Haltung, bei der das Reich eher als negative Hintergrundfolie für den aufstrebenden preußischen Staat und später für das Wilhelminische Kaisertum dienen musste. Nach dem Zerfall der kleindeutschen Träume im Dritten Reich und dem von ihm verursachten Zweiten Weltkrieg begann die Rückbesinnung auf die positiven Tendenzen der deutschen Verfassungsgeschichte ${ }^{2}$.

Die meisten Studien, die sich mit dem Alten Reich befassen, heben das Kaisertum als Personifizierung der Herrschaftsausübung in diesem Gemeinwesen hervor, meistens beginnen sie auch damit. Das Kaisertum konnte sich damit auf eine doppelte Geschichte stützen, auf eine historiographisch fassbare und in Dokumenten überlieferte einerseits und auf eine mythologischgeistliche andererseits, die durch Deutung entstanden war. Gleichermaßen konnte auf die Ottonen und auf die Reihe der antiken römischen Kaiser seit Augustus zurückgegriffen werden ${ }^{3}$. Der zeremonielle Glanz und die schiedsrichterliche Rolle des Kaisers spielten allerdings im Laufe der Frühen Neu-

1 Heinrich August Winkler, Der lange Weg nach Westen. Deutsche Geschichte vom Ende des Alten Reiches bis zum Untergang der Weimarer Republik, Bd. 1, München 2000, S. 5.

2 Überblicke zur Forschungsentwicklung: Neuhaus, Das Reich in der frühen Neuzeit, bes. S. 57-101; SchindLing, Kaiser, Reich und Reichsverfassung 1648-1806, S. 25-54.

3 Nicht wenige Geschichtsentwürfe der Frühmoderne beginnen bei Adam und Eva, vollziehen die vorchristliche Epoche anhand der biblischen Genealogien, um zur Lebenszeit Jesu zu Kaiser Augustus überzugehen. An diesen schließen die Kaiser der goldenen und silbernen Latinität, die Soldatenkaiser und die Herrscher der Dominatszeit an, um dann die fränkischen, karolingischen und ottonischen Kaiser folgen zu lassen und in die weitere mittelalterliche und frühneuzeitliche Reichsgeschichte überzuleiten. Verbindungsbrücke war die Annahme der Kontinuität von römisch-antikem und mittelalterlichem Kaisertum im Sinne der »Translatio Imperii : Vgl. beispielsweise den Geschichtsentwurf bei ALsted, Encyclopaedia Septem tomis distincta, Tom. VII, Liber XXXII (Historiae capitula I-XXIV: Begründung der Geschichtsdeutung, S. 1979-2067) bzw. Liber XXXIII (Chronologiae capitula I-VIII: Tabellenwerke von AD 3947 v. Chr. bis 1629 n. Chr., S. 2068-2191). 
zeit eine wichtigere Rolle als die manifeste Macht des Reichsoberhaupts, wie sie in einer schlagkräftigen Militärmacht oder in einer umsetzungsstarken Reichsjustiz zum Ausdruck gekommen wäre. Die Versuche Kaiser Karls V. 1547/48 und Ferdinands II. 1620-1630, im Zuge von kriegerischen Auseinandersetzungen im Reich die eigene Stellung hin zu einer machtvollen Monarchie im westeuropäischen Sinne auszubauen, waren nicht geglückt. So standen am Schluss dieser Bemühungen die Westfälischen Friedensverträge, in denen eine eingeschränkte kaiserliche Zentralgewalt festgeschrieben worden war, was die Aufsicht über mehrere Reichsinstitutionen (Reichsgerichte und Reichshofkanzlei), das Vetorecht gegenüber Beschlüssen des Reichstags sowie die Notwendigkeit der Ratifizierung von Reichsbeschlüssen umfasste ${ }^{4}$. Wenige sonstige Reservatrechte blieben dem Kaiser außer$\mathrm{dem}^{5}$. Die Verfassungswirklichkeit nach 1648 stellte sich so dar, dass der Kaiser ohne Zustimmung der Reichstagsmehrheit kaum rechtlich bindende Handlungen durchführen konnte. Der Reichstag vermochte dies allerdings ohne und gegen den Kaiser auch nicht, was die Fortdauer des monarchischen Erbes des Systems verdeutlichte. Die Habsburgerkaiser akzeptierten diesen Verfassungskompromiss von 1648 und erreichten - unter dem doppelten Bedrohungsdruck durch das Osmanische Reich und das Frankreich Ludwigs XIV. - eine »Renaissance« der kaiserlichen Stellung ${ }^{6}$. Erst nach 1740 trat infolge des deutschen Dualismus zwischen Österreich und Preußen sowie durch antikaiserliche englisch-hannoveranische Politik eine Paralysierung der kaiserlichen Reichspolitik ein.

Das herrschaftsbegrenzende Moment für das Kaisertum war die Gesamtheit der Reichsstände, das Konfliktverhältnis wurde mit dem Begriff »institutionalisierter Dualismus « umschrieben?. Unterschwellig waren damit negative Deutungen verbunden: Ein Königtum, das sich der Hilfe der Großen bedienen und dafür Zugeständnisse machen musste (und daher gerade nicht als »souverän« bezeichnet werden konnte), und eine Ständegemeinschaft, die unter sich »zerstritten« war. Hier soll hingegen eine andere begriffliche Erfassung vorgeschlagen werden mit dem Konzept der »dop-

4 Zur Entwicklung der kaiserlichen Stellung im Reich bis 1648: Johannes ARndT, Der Kaiser und das Reich 1600-1648, in: Bussmann/Schilling, 1648 - Krieg und Frieden in Europa, Textbd. 1, S. 69-76. Zur kaiserlichen Politik während des Westfälischen Friedenskongresses: Leopold AuER, Die Ziele der kaiserlichen Politik bei den Westfälischen Friedensverhandlungen und ihre Umsetzung, in: Heinz DuchHARdt (Hg.), Der Westfälische Friede. Diplomatie politische Zäsur - kulturelles Umfeld - Rezeptionsgeschichte, München 1998, S. 143-173.

5 Jürgen Pratje, Die kaiserlichen Reservatrechte, Diss. Erlangen 1957 (Mschr.); vgl. auch Rudolf HoKe, Art. »Iura reservata«, in: HRG 2, Berlin 1978, Sp. 476-481.

6 Volker Press, Die kaiserliche Stellung im Reich zwischen 1648 und 1740. Versuch einer Neubewertung, in: Georg SснміDт (Hg.), Stände und Gesellschaft im Alten Reich, Stuttgart 1989, S. $51-80$.

7 Begriffsinhalt: Peter Moraw, Von offener Verfassung zu gestalteter Verdichtung. Das Reich im späten Mittelalter 1250-1490, Frankfurt a.M. u.a. 1989, S. 416-421. 
pelten Konkurrenz $\ll^{8}$. In einem Mächtesystem ging es für jeden Verfahrensbeteiligten darum, die eigene Macht zu bewahren und wenn möglich auszudehnen. Dieses Bestreben stieß mit den Interessen der anderen Machthaber zusammen. In einem asymmetrischen politischen System wie dem Heiligen Römischen Reich bedeutete dies, dass zum einen die Kaiser resp. Könige mit der Gesamtheit der Reichsstände konkurrierten: diesen Umstand möchte ich »vertikale Konkurrenz« nennen. Zum anderen, und dieser Aspekt ist seltener reflektiert worden, konkurrierten die Reichsstände untereinander um Gebiete, materielle und immaterielle Rechte, Ämter und politische Chancen im Allgemeinen: Für diese Form des politischen Wettstreits möchte ich den Begriff der »horizontalen Konkurrenz« vorschlagen. Beide Konkurrenzen fanden gleichzeitig und nebeneinander statt: Jeder Verfahrensbeteiligte verfügte über mehrere Optionen, entweder mit dem Kaiser gegen gleichrangige Konkurrenten zuammenzuarbeiten oder mit den Standesgenossen gegen den Kaiser oder mit Fürsten gegen andere Fürsten.

Zwar waren Konflikte im Reich der Frühen Neuzeit durch den Zwang zum friedlichen Prozessieren vor einem Schieds- oder Reichsgericht eingehegt, und die Stände, besonders die kleinen, profitierten vom allgemeinen Bestands- und Rechtsschutz durch das Gesamtsystem. Dies hielt aber niemanden davon ab, seinem Standesgenossen nicht das Geringste zu gönnen, was man selbst nicht auch bekommen konnte. Da die materielle Verfügungsmasse begrenzt war - die Zahl der Territorien und Güter konnte nicht beliebig vermehrt werden -, dienten die Bereiche der höfischen Ehrenämter, der immateriellen Rechte und Privilegien, insbesondere im sichtbar zur Schau gestellten Bereich des Zeremoniells, der Titulatur und nicht zuletzt der kulturellen Lebensart als Orte intensiver Konkurrenz. Seit den Studien von Aloys Winterling über die Herrschaftsrepräsentanz der kurkölnischen Erzbischöfe wird dieser Aspekt auch in der frühmodernen Höfe- und Residenzenforschung betont: Adressat herrscherlicher Repräsentation war demnach nicht mehr vorrangig die höfische Untertanenschaft eines Fürsten, sondern die fürstlichen Konkurrenten an anderen Höfen, die gar nicht anwesend

8 Der Begriff $»$ Konkurrenz« ist fester Bestandteil des allgemeinen Sprachgebrauchs, als wissenschaftliche Kategorie aber eher in den Wirtschaftswissenschaften gebräuchlich. Die Selbstverständlichkeit von »Konkurrenz« lässt sich bis hinein in die Soziobiologie verfolgen; so schreibt der Wiener Soziobiologe Franz Wuketits: »Konkurrenz war stets ein wichtiger Faktor in unserer sozialen Evolution«: Franz Wuketits, Was ist Soziobiologie?, München 2002, S. 87. - Neuerdings wird der Aspekt der Konkurrenz auch bei den Schul- und Bildungssystemen der Frühmoderne im Zuge der Konfessionalisierung erkannt: Stefan EHRENPREIS, Erziehung und Schulwesen zwischen Konfessionalisierung und Säkularisierung. Forschungsprobleme und methodische Innovationen, in: Schilling/EHrenPrEIs, Erziehung und Schulwesen zwischen Konfessionalisierung und Säkularisierung, S. 19-33, hier S. 31f.; Gerhard MEnK, Das Bildungswesen in den deutschen protestantischen Territorien der Frühen Neuzeit, in: Ebd., S. 55-99, hier S. 98. 
waren, sich aber - medial vermittelt - stets auf dem Laufenden halten ließen 9 . Aus der »doppelten Konkurrenz« im Reich resultierte eine funktionierende Gewaltenteilung, und dies lange bevor dieser Begriff offiziell in den politikwissenschaftlichen Sprachgebrauch übernommen wurde. Es bedurfte nicht der bekannten Trias von Legislative, Exekutive und Judikative, um den Zweck der Beschränkung monarchischer Allgewalt zu erreichen ${ }^{10}$, ebensowenig eines Systems aus konkurrierenden politischen Parteien ${ }^{11}$.

Beide Konkurrenzen waren miteinander verbunden. Ein beträchtlicher Teil des kaiserlichen Einflusses beruhte darauf, die horizontale Konkurrenz der Reichsstände zu nutzen. Der Kaiser war in dieser Hinsicht Moderator der Konflikte anderer. Jede Regulierung von Konflikten, sowohl die gerichtlichen als auch die außergerichtlichen, bot Gelegenheiten, diese kaiserliche Rolle zu aktualisieren. Viele Kaiser waren geschickt darin, aus der Moderation kleine Gewinne für sich selbst abzuzweigen. Durch das Prinzip der Vermittlung statt einer höchstrichterlichen Entscheidung waren viele Stände mit den Ergebnissen zufrieden, was Anreize bot, weitere Konflikte der kaiserlichen Vermittlung zu übertragen. Selbst Konfliktparteien, die dies nicht wollten, mussten trotzdem mit einer kaiserlichen Intervention rechnen, denn das Reichsoberhaupt fühlte sich berufen, in jeden Konflikt schlichtend einzugreifen. Bemerkenswerterweise fehlte eine praktische Konflikttheorie, um dieses System in Gültigkeit zu halten, vielmehr funktionierte es trotz der vorherrschenden Harmonievorstellungen, die politisch wie religiös fundiert waren. Als Ausdruck kaiserlichen Geschicks darf es gelten, dass meistens die Ausübung manifester Gewalt verhindert werden konnte ${ }^{12}$.

9 Konkurrenz an den Höfen: WinTERLING, Der Hof der Kurfürsten von Köln, pas. - Zur Adressatenschaft der höfischen Repräsentation auch DANIEL, Überlegungen zum höfischen Fest der Barockzeit, S. 45-66. Verknüpfung mit der Kategorie der »Öffentlichkeit«: BAUER, Höfische Gesellschaft und höfische Öffentlichkeit im Alten Reich, S. 29-68.

10 Der Aspekt der Konkurrenz im Reich wird zwar in vielen Studien beiläufig erwähnt, aber nicht ausdrücklich problematisiert. In kulturgeschichtlicher Hinsicht weist etwa Ernst Hinrichs auf die Konkurrenz der Residenzausstattungen der deutschen Fürstentümer hin, die bis heute prachtvolle Hinterlassenschaften gezeitigt hat; die tieferliegenden Gründe für diese Konkurrenz spielen jedoch auch bei ihm keine Rolle: HinRichs, Fürsten und Mächte, hier S. $140 \mathrm{f}$.

11 Der Begriff der Parteien, wie er sich in Quellen aus dem Reichstagsumfeld findet, entspricht eher dem lateinischen Begriff der »factiones« und hat einen negativen Beiklang: FriEDRICH, Drehscheibe Regensburg, S. 254-262. - In Zedlers Universal-Lexicon findet sich ein dahingehender Eintrag unter »Faktion«: ZedLer, Universal-Lexicon, Bd. 9, Sp. 64.

12 Werner Troßbach hat die praktische Konfliktkultur im Reich am Beispiel der Untertanenprozesse vor den Reichsgerichten untersucht und konfliktsoziologisch eingeordnet: Werner Trossbach, Soziale Bewegung und politische Erfahrung. Bäuerlicher Protest in hessischen Territorien 1648-1806, Weingarten 1987, bes. S. 39-67. 
Klassischerweise wird mit Georg Simmel das Geheimnis als »[...] eine der größten Errungenschaften der Menschheit« gepriesen ${ }^{13}$. Seit zoologische und soziobiologische Forschungen allerdings nachgewiesen haben, dass Primaten ${ }^{14}$ und selbst Krähenvögel ${ }^{15}$ ihre Artgenossen täuschen können, darf ein vorkultureller Kern dieser Techniken angenommen werden. Herkömmlicherweise wird der politische Herrschaftsbereich des 17. Jahrhunderts unter dem Blickwinkel des Arcanum betrachtet: Im Verborgenen befinden Fürsten und »Geheime« Räte über das Gemeinwesen, und mitgedacht wird dabei seit der Herrschaftskritik der Aufklärungszeit bis in die jüngste Historiographie -, dass Maßstab allen politischen Handeln nicht das Wohl aller (bonum commune) war, sondern die Staatsräson (ratio status). Demnach erschien es legitim, zugunsten des Abstraktums »Staat« von den Untertanen materielle und immaterielle Opfer in beliebigem Umfang bis hin zu Leib und Leben zu verlangen. Die Verstellung des Monarchen gegenüber seinen Herrschaftsunterworfenen war nicht nur erlaubt, sondern geradezu geboten, und vor allem musste verborgen werden, dass es überhaupt eine geheime Regierungstechnik gab. Andreas Gestrich hat das Spannungsverhältnis zwischen »Geheimnis« und »Öffentlichkeit« in einen Zusammenhang mit politischer »Legitimität« gestellt und darauf hingewiesen, dass das Geheimnis im Barockzeitalter eine Art »Leitfossil« der politischen Kultur gewesen sei ${ }^{16}$.

Für die Befürworter der Geheimhaltungspraxis, die ihre Theorien im Spätmittelalter und der beginnenden Frühen Neuzeit zu Papier brachten, stellte sich der Herrscher als Beauftragter Gottes in der Welt dar: Ebenso wie Gott die Zukunft vor den Menschen geheimhielt, so war es damit auch dem Herrscher gestattet, seine künftigen Vorhaben im Verborgenen vorzubereiten ${ }^{17}$. Allerdings im Gegensatz zu Gott, der einige seiner Geheimnisse, etwa die Artillerie, die Druckerpresse, die Westindischen Inseln, den Menschen nach und nach preisgegeben hatte, um ihnen - so Giovanni Botero -

13 Hier zit. nach Aleida Assmann/Jan Assmann (Hg.), Schleier und Schwelle, Bd. 1: Geheimnis und Öffentlichkeit, München 1997, S. 7.

14 Populärwissenschaftlicher Zugang: Volker ArzT/Immanuel Birmelin, Haben Tiere ein Bewußtsein? Wenn Affen lügen, wenn Katzen denken und Elefanten traurig sind, München ${ }^{2} 1993$.

15 Zur »Intelligenz« von Krähenvögeln: Josef H. Rегснноцf, Rabenschwarze Intelligenz. Was wir von Krähen lernen können, München ${ }^{3}$ 2009. - Zum Zusammenhang zwischen Kultur und Natur in Sozialsystemen: Franz WuKETITs, Soziobiologie. Die Macht der Gene und die Evolution sozialen Verhaltens, Heidelberg/Berlin/Oxford 1997; ders., Warum uns das Böse fasziniert. Die Natur des Bösen und die Illusionen der Moral, Stuttgart, Leipzig 2000.

16 Zur theologischen, staatstheoretischen und historischen Herleitung des Arcanums: GesTRICH, Absolutismus und Öffentlichkeit, S. 34-74; Begriff »Leitfossil«: S. 34. Zur Staatsräson aus systemtheoretischer Sicht: Niklas Luhmann, Staat und Staatsräson im Übergang von traditionaler Herrschaft zu moderner Politik, S. 65-148.

17 Gestrich verweist diesbezüglich auf den »Deus absconditus« bei Nikolaus von Kues: Gestrich, Absolutismus und Öffentlichkeit, S. 41. 
Bewunderung abzunötigen ${ }^{18}$, wurde dem Fürsten das Geheimnis nach und nach abgerungen. Auf die Ausbreitung der Arcana imperii zunächst durch Machiavelli, dann durch Luther reagierte der frühmoderne Staat durch eine "Verbürokratisierung« des Geheimnisses, nachdem dieses bis dahin das persönliche Geheimnis des Fürsten gewesen war ${ }^{19}$. Eine Möglichkeit, so der italienische Staatstheoretiker Virgilio Malvezzi, war das Panoptikum im Sitzungssaal des Geheimen Rates: Durch ein Fensterchen könne der Fürst stets hineinschauen, am besten auf eine Weise, dass er dabei nicht gesehen werden konnte $^{20}$. Durch die Unsichtbarkeit schützte sich der Fürst gegen ein Gesehenwerden und wurde so selbst in der Wahrnehmung seiner Räte zum virtuellen Beobachter. So wie Gott nicht mehr an die Gesetzmäßigkeiten der Schöpfung gebunden gedacht wurde, weil dies seine Allmacht beeinträchtigt hätte, so war der Herrscher - bei Jean Bodin oder im Reich bei Christoph Besold - auch nicht mehr ans positive Recht gebunden: Verborgenheit Gottes, Souveränitätslehre, Staatsräson und Arkanpraxis der Herrschaft gehörten daher argumentativ zusammen ${ }^{21}$.

Oft wird die Aufklärung als Zeitströmung angesehen, während derer das Arcanum grundlegend infrage gestellt und schließlich zerstört wurde ${ }^{22}$. Dies ist in zweifacher Hinsicht nicht richtig: In Wirklichkeit setzte die Erosion des Herrschaftsgeheimnisses bereits viel früher ein. Zum anderen hielten sich Bestandteile des geheimen Regierungshandelns bis in die Gegenwart, der Gegensatz zwischen schnödem Machiavellismus und der Produktion schönen Scheins für die (fernsehende) Öffentlichkeit wurde noch kürzlich - meisterhaft personifiziert durch Robert de Niro und Dustin Hoffman - in dem amerikanischen Film Wag the Dog (USA 1997, Regie: Barry Levinson) in Szene gesetzt $\mathrm{t}^{23}$.

In diesem Zusammenhang geht es um die Vorphase der Aufklärung. Herrschaft auf oberster Ebene im Alten Reich fand vor allem auf dem Reichstag statt. Im Mittelalter war die Hierarchie steiler gewesen, die Kaiser konn-

18 Giovanni Botero, Della Ragione di Stato libri dieci, Venedig 1589, S. 81, zit. nach Niklas LuHmann, Geheimnis, Zeit und Ewigkeit, in: Ders. / Peter Fuchs, Reden und Schweigen, Frankfurt a.M. 1989, S. 101-137, hier S. 115f.

19 Luhmann, Geheimnis, Zeit und Ewigkeit, S. 118.

20 Bezug auf: Virgilio MaLvezzi, Ritratto del Privato politico christiano, in: Opere del Marchese Malvezzi, Mediolanum/Mailand 1635, S. 142, zit. nach Luhmann, Geheimnis, Zeit und Ewigkeit, S. 135.

21 Jean Bodin, Über den Staat. Übers. u. hg. v. Gottfried Niedhart, Stuttgart 1976; Christoph BEsold, De Arcanis Rerum Publicarum, Straßburg [Argentorati] 1614.

22 Die Überschneidungsphase von der einen zur anderen Auffassung lag, so deutet Gestrich die Quellenbefunde, im frühen 18. Jahrhundert: Gestrich, Absolutismus und Öffentlichkeit, S. 36 .

23 Rezension dazu von Andreas KiLB, Totentanz der Wirklichkeit. Kino: »Wag the Dog«, eine Filmsatire von David Mamet und Barry Levinson, in: DIE ZEIT, Ausgabe 14 vom 26. März 1998. 
ten selbst darüber befinden, wen sie zu ihren Hoftagen einladen wollten. Im Zuge der Reichsreform ${ }^{24}$ in der Zeit zwischen ca. 1480 und ca. 1555 verfestigte sich das Reichstagssystem so weit, dass eine bestimmte Gruppe von Kurfürsten, Fürsten, geistlichen Würdenträgern, Grafen und Städten eo ipso das Recht der Teilnahme gewann. Wie fast alles am Reichstag war das Teilnahmerecht nicht einfach dem Herrscher abgetrotzt, sondern von diesem ausdrücklich gewollt: Teilnehmende wurden zwar durch das Sessionsrecht aufgewertet, aber auch in die Pflicht genommen, Reichssteuern bewilligen und leisten zu müssen ${ }^{25}$.

Die Zahl der Teilnahmeberechtigten war nicht eben klein: Sieben Kurfürsten, ca. hundert geistliche und weltliche Fürsten, mehr als hundert Prälaten und Grafen sowie um die fünfzig Städte wurden geladen. Der Reichstag war hierarchisch geschichtet: Dass der Kaiser den Vorrang besaß, verstand sich von selbst, ihm folgten der Reihe nach die Kurfürsten, die geistlichen Reichsfürsten vor den weltlichen, die Prälaten vor den Reichsgrafen, am Ende kamen die Städte. Die Reichsritter - auch sie Lehnsträger des Kaisers wie die meisten der anderen - blieben vom Reichstag ausgeschlossen, sie führten eine reichsrechtliche Sonderexistenz im direkten bilateralen Verhältnis zum Reichsoberhaupt ${ }^{26}$. Das Reich manifestierte sich, so hat es die jüngere Kulturgeschichte des Politischen herausgearbeitet, überhaupt erst über den kommunikativen Zusammenhang des Reichstagssystems. Dieser Zusammenhang bestand zum einen in der Kommunikation des Wortes, zum anderen in der Kommunikation der Symbole und Rituale, die Gemeinschaft und Teilhabe gerade dort stifteten, wo nicht jeder Einzelne um seine Zustimmung gebeten werden sollte ${ }^{27}$.

Den Anstoß für eine Befassung des Reichstags bildete normalerweise die Beobachtung eines politischen Missstandes, der nach Ansicht des Antragstellers ein Eingreifen von Kaiser und Reich erforderte. Dies konnte eine äußere oder innere Sicherheitsbedrohung oder ein Rechtsverstoß sein. Durch die Einbringung und noch mehr durch die Zulassung zur Diskussion wurde die Eingabe oder Supplik (wenn sie von Untertanen stammte) zur Verhandlungsmaterie. Eine zentrale Rolle kam der Kanzlei des Kurfürsten von Mainz auf dem Reichstag zu. Die Schreibstelle der kurfürstlichen Direktorialkanzlei, die Dictatur, brachte die neue Materie allen Sessionsberechtigten offiziell zur Kenntnis. Dies geschah normalerweise durch die Verlesung vor den

24 Vgl. dazu Heinz AngermeIER, Die Reichsreform 1410-1555. Die Staatsproblematik in Deutschland zwischen Mittelalter und Gegenwart, München 1984.

25 Funktionszusammenhang: Neuhaus, Das Reich in der Frühen Neuzeit, S. 39-43 u. 64-77.

26 Vgl. vor allem Volker Press, Kaiser Karl V., König Ferdinand und die Entstehung der Reichsritterschaft, Wiesbaden ${ }^{2} 1980$.

27 Monographische Ausarbeitung dieses lange vernachlässigten, aber eminent wichtigen Zusammenhanges: Stollberg-Rilinger, Des Kaisers alte Kleider, pas. 
Kanzlisten der Gesandtschaften ${ }^{28}$. Im frühen 18. Jahrhundert wurde festgelegt, dass den Kanzlisten nicht zuzumuten sei, mehr als drei Druckbögen mitschreiben zu müssen. Längere Schriftsätze mussten fortan in gedruckter Form ausgefertigt und allen Reichsständen angeboten werden ${ }^{29}$. Zu den Formerfordernissen gehörte zudem, dass Schriftstücke in den zugelassenen Verkehrssprachen - in Deutsch oder Latein - eingeliefert wurden. Auch mussten sie formal und titulaturmäßig korrekt formuliert sein und durften keine groben Beleidigungen enthalten. Mangelhafte Schriftstücke konnten von der Mainzer Direktoralgesandtschaft abgelehnt werden ${ }^{30}$.

Durch diesen Einführungsakt einer neuen Verhandlungsmaterie wurde dieselbe »reichskündig«, d.h. offiziell bekannt für die Verfahrensbeteiligten. Das Reichstagssystem konnte und sollte nicht arkan stattfinden, sondern der Ort des politischen Miteinanders, aber auch der Austragsplatz der beiden Konkurrenzen sein. Öffentlichkeit im engeren Sinne war hier Machtöffentlichkeit, wie sie von Esther-Beate Körber am Beispiel des Herzogtums Preußen im Reformationsjahrhundert herausgearbeitet worden ist ${ }^{31}$. Das folgende Verfahren war offen: $\mathrm{Ob}$ ein Beschluss von Reichs wegen zugunsten der einen oder anderen Seite am Ende erfolgte, war ungewiss. Manche Entscheidungen gelangen schnell, andere erst nach vielen Jahren. Manchmal konnte auch der Konsens dahin gehen, dass die Angelegenheit in der Schwebe gehalten und nicht entschieden wurde. Auch die Nicht-Entscheidung konnte somit eine Entscheidung sein.

Der idealtypische Fall war zwar für das Prozessieren in den Reichsgremien damit erledigt, konnte allerdings auf der Beobachterebene ein Weiterleben erfahren, indem er im Reichsstaatsrecht und in der Reichshistoriographie aufgegriffen wurde. Auch dort konnte ihm in jeder möglichen Entscheidungsvariante eine Bedeutung als Präjudiz für vergleichbare Anträge in der Zukunft zugewiesen werden. Formal wie inhaltlich bot sich die Möglichkeit der Anschlusskommunikation, indem etwa ein neuer Antrag mit ähnlicher Zielrichtung eingebracht wurde oder fehlende Informationen nachgeliefert wurden etc. Der wichtigste Zweck des Reichssystems war in jedem Fall erfüllt: Das System hatte sich durch das Behandeln des Falls prozesshaft aktualisiert, seine Funktionsweise bestätigt und damit seine formale Leistungsbereitschaft dokumentiert.

28 Zur Mainzer Dictatur: Karl HÄRTER, Das kurmainzische Reichstagsdirektorium. Eine zentrale reichspolitische Schaltstelle des Reichserzkanzlers im Reichssystem, in: Peter Claus HarTManN (Hg.), Der Mainzer Kurfürst als Reichserzkanzler. Funktionen, Aktivitäten, Ansprüche und Bedeutung des zweiten Mannes im alten Reich, Stuttgart 1997, S. 171-203.

29 Georg Melchior von Ludolf, Compendieuse Beschreibung Eines Reichs-Tags, Wie er Im Heil. Römischen Reich gehalten wird [...], Halle a.d. Saale 1720, hier S. 40.

30 Zum Einfluss der Mainzer Gesandten auf das Diktierverfahren: FrIEDRICH, Drehscheibe Regensburg, S. 130-132.

31 KörBER, Öffentlichkeiten der Frühen Neuzeit, S. 53-164. 
Im Reichssystem hatte sich, wie in jeder Machtordnung, hinter der Diskurskultur und dem Zeremoniellprozessieren auch eine Droh- und Exekutionskulisse aufgebaut, die für den Fall bereitgehalten wurde, dass Reichsmitglieder oder Nichtreichsmitglieder sich obrigkeitlichen Entscheidungen widersetzten. Vordergründig waren derartige Fälle vor den Reichsgerichten, dem Reichskammergericht in Speyer bzw. ab 1693 in Wetzlar und dem Reichshofrat in Wien, abhandelbar; hintergründig gab es das Instrument der bewaffneten Intervention von Reichs wegen in Gestalt einer Reichsexekution. Letztere konnte auch von einem oder mehreren Reichskreisen ausgeführt werden und hieß dann Kreisexekution ${ }^{32}$. Die mildere Form der Intervention war die Einsetzung einer kaiserlichen Kommission, die entweder eine widerspenstige Landesregierung überprüfte, mit Gehorsamsanspruch beriet oder im Extremfall selbst die Landesherrschaft übernahm ${ }^{33}$. Der jeweils betroffene Landesherr konnte entweder von der Herrschaft suspendiert oder im schlimmsten Fall mit der Reichsacht überzogen und damit aus der politischen und rechtlichen Gemeinschaft ausgeschlossen werden ${ }^{34}$. Normalerweise ließ es ein Reichsstand nicht auf das Äußerste ankommen. Innerhalb der Reichstagskommunikation und der sie begleitenden Korrespondenz war die Drohkulisse eine Fiktion, im systemtheoretischen Sinne eine »nicht realisierte zweite Realität « ${ }^{35}$. Die in den folgenden Fallbeispielen abgehandelten Berichte über fünf innerreichische Konflikte demonstrierten die Realisierung dieses Drohszenarios auf unterschiedliche Weise und trugen damit zu seiner Aktualisierung vor aller Augen bei.

32 Zur Reichsexekution: Raimund J. WeBER, Reichspolitik und reichsgerichtliche Exekution. Vom Markgrafenkrieg (1552-1554) bis zum Lütticher Fall (1789/90), Wetzlar 2000. Da einige Fallstudien folgen, in denen diese Mittel zur Anwendung kamen, wird auf die dort vermerkte weiterführende Forschungsliteratur verwiesen.

33 Zum Instrument der kaiserlichen Kommissionen: Sabine Ullmann, Geschichte auf der langen Bank. Die Kommissionen des Reichshofrats unter Kaiser Maximilian II. (1564-1576), Mainz 2006; Eva Ortlieb, Im Auftrag des Kaisers. Die kaiserlichen Kommissionen des Reichshofrats und die Regelung von Konflikten im Alten Reich (1637-1657), Köln/Wien/Weimar 2001.

34 Zur Reichsacht: Christoph Kampmann, Reichsrebellion und kaiserliche Acht. Politische Strafjustiz im Dreißigjährigen Krieg und das Verfahren gegen Wallenstein, Münster 1992; ders., »Der Leib des Römischen Reichs ist der Stände Eigentum und nicht des Kaisers«. Zur Entstehung der Konkurrenz zwischen Kaiserhof und Reichstag beim Achtverfahren, in: Wolfgang Sellert (Hg.), Reichshofrat und Reichskammergericht. Ein Konkurrenzverhältnis, Köln/Weimar/Wien 1999, S. 169-198; Matthias Weber, Zur Bedeutung der Reichsacht in der Frühen Neuzeit, in: Johannes KunIsch (Hg.), Neue Studien zur frühneuzeitlichen Reichsgeschichte, Berlin 1997, S. 55-90.

35 Niklas Luhmann verweist auf die Wirksamkeit von Drohszenarien, die nicht eingesetzt zu werden brauchen, weil alle Verfahrensbeteiligten wissen, dass es sie gibt. Umgekehrt ist die machthabende Seite gehalten, sie nicht einzusetzen. Auf das hier verhandelte Szenario bedeutete dies: Die Ächtung eines Fürsten erreichte gerade nicht den Gehorsam, der durch die Androhung erzwungen werden sollte. Mit Luhmanns Worten: »Negative Sanktionen sind also negativ auch insofern, als das Medium, das auf ihnen aufbaut, auf ihre Nichtbenutzung angewiesen ist«: Luhmann, Die Politik der Gesellschaft, S. 46f. 
Im Idealfall sollten die anstehenden Materien den Kreis der Sitz- und Stimmberechtigten nicht verlassen. In der Praxis war das nicht durchzuhalten. Als erste wurden auswärtige europäische Mächte von den Verhandlungen informiert, denn diese standen vielfach zum Kaiser im Dissens und zu Reichsständen im Bündnisverhältnis. Als zweite Gruppe wurden die juristischen Mitarbeiter der Reichsstände informiert, weil ohne ihr Mitwirken seit dem 16. Jahrhundert keine erfolgreiche Politik mehr getätigt werden konnte. Politik und Recht gingen ein intensives Wechselverhältnis ein, und Recht wurde mehr und mehr Römisches Recht in seiner akademischen Adaption an die frühneuzeitlichen Verhältnisse ${ }^{36}$.

Was im 16. Jahrhundert als Abfolge von Reichsversammlungen in Abständen von jeweils mehreren Jahren stattfand, verfestigte sich zu einem ständigen Gesandtenkongress nach 1663, dem »Immerwährenden Reichstag«. Versuche, ihn auf gewohnte Weise mit einem Schlussdokument zu beenden, scheiterten mehrfach, schließlich arrangierten sich die Berechtigten mit der Dauerhaftigkeit der Versammlung ${ }^{37}$. Die Fürsten selbst waren schon lange nur noch ausnahmsweise anwesend, auch die Kaiser ließen sich künftig vertreten.

Das Reichstagsprozedere ist nicht zu verstehen ohne das dahinterstehende Teilsystem der politischen Reichsstaatsrechtslehre bzw. der Reichshistoriographie. Das Reichsstaatsrechtswesen gehörte eigentlich in die Bereiche der Universitäten und der Gerichte. Rechtskundige Hochschullehrer sollten den juristischen Nachwuchs ausbilden und Forschungsprobleme in Studien abhandeln. Hinzu kam von alters her die Inanspruchnahme durch die politischen Gewalten, Gutachten für politisch-rechtliche Spezialfragen zu verfassen ${ }^{38}$. Positiv lässt sich das deuten als juristische Beratung für einen nicht rechtsgelehrten Fürsten, negativ als Auftrag zur Produktion von argumentati-

36 Rezeption des Römischen Rechts als europäischer Vorgang: STEIN, Römisches Recht und Europa, pas.

37 Zur Rolle des Reichstags nach 1648: Anton SchinduInG, Die Anfänge des Immerwährenden Reichstags zu Regensburg. Ständevertretung und Staatskunst nach dem Westfälischen Frieden, Mainz 1991; Johannes BURKHARDT, Verfassungsprofil und Leistungsbilanz des Immerwährenden Reichstags. Zur Evaluierung einer frühmodernen Institution, in: Heinz DucHHARDT / Matthias SCHNETTGER (Hg.), Reichsständische Libertät und Habsburgisches Kaisertum, Mainz 1999, S. 151-183.

38 Hermann Conring als Reichsstaatsrechtslehrer und Gottfried Wilhelm Leibniz als Hof historiograph waren nur zwei prominente Gelehrte, die ihren braunschweigischen Territorialherren und Arbeitgebern als Verfasser von Deduktionen zur Verfügung standen - und gelegentlich an befreundete Fürsten »ausgeliehen« wurden: Günter ScHEEL, Hermann Conring als historisch-politischer Ratgeber der Herzöge von Braunschweig und Lüneburg, in: Michael Stolleis (Hg.), Hermann Conring (1606-1681). Beiträge zu Leben und Werk, Berlin 1983, S. 271-301; Günter SCHEel, Leibniz als politischer Ratgeber des Welfenhauses, in: Herbert Breger / Friedrich NiewÖHNER (Hg.), Leibniz und Niedersachsen. Tagung in Wolfenbüttel anläßlich des 350. Geburtstags von G.W. Leibniz (1996), Stuttgart 1999, S. 35-52; Friedrich Beiderbeck, Leibniz als politischer Berater des Welfenhauses am Beispiel der Neunten Kur, in: Hans Poser (Hg.), 
ver Munition für Auseinandersetzungen zwischen fürstlichen Machtkonkurrenten. Rechtsgelehrte haben sich vielfach zu dieser Aufgabe bereiterklärt, sei es, dass es ihrer Eitelkeit schmeichelte, von (manchmal auch auswärtigen) Fürsten um Hilfe ersucht zu werden, sei es, dass es zu ihren Dienstpflichten gehörte, sei es, dass sie sich als frisch examinierte Nachwuchswissenschaftler eine Stellung im Öffentlichen Dienst versprachen oder schlicht deswegen, dass sie vom fraglichen Anliegen, welches sie zu vertreten hatten, selbst überzeugt waren. Hinzu kam die Gutachtertätigkeit vieler juristischer Fakultäten für Prozesse, deren Entscheidungen von den Kammern dem Expertengremium übertragen worden waren ${ }^{39}$.

Die Beobachtung des politischen Systems durch die Rechtsgelehrten war in ihrer Wirkung keineswegs auf die akademischen Hörsäle beschränkt. Weil politisches Handeln sich im Reich auf altes Herkommen und die Vorstellung einer immerwährenden Ordnung stützte, stellte ein Rechtsgutachten eine Waffe gegen jeden Politiker dar, der eine gegenteilige Vorstellung vertrat. Auf diese Weise wirkte die Reichsrechtswissenschaft als institutionalisiertes »Gedächtnis« stets wieder ins tagespolitische Geschehen zurück und verstärkte bzw. widerlegte die kollektive Erinnerung der handelnden Personen am Reichstag, an den Höfen und in den Regierungen. Das wirkungsvollste Gegenmittel gegen ein unliebsames Gutachten war ein Gegengutachten von einem anderen Experten, der einen vergleichbaren Rang besaß. Bei einem beträchtlichen Teil der Deduktionen der folgenden Fallstudien handelt es sich um Rechtsgutachten in diesem Sinne.

Der Übergang zwischen Reichsstaatsrechtslehre und Reichshistoriographie war fließend. Zahlreiche Werke, die heute als historiographische Studien gewertet würden, stammten aus der Feder von Juristen. Unterscheidbar sind beide Gattungen vor allem an ihren Intentionen: Beschränkte sich die Staatsrechtslehre darauf, eng am juristischen Problem zu bleiben und - vielfach - einen Auftrag abzuarbeiten, so neigte die Historiographie zur schönen Erzählung, zum Rekurs auf Zeitungen, auf frühere Historienwerke und auf andere Quellen, die nicht vorrangig juristischen Charakter besessen haben mussten. Da sowohl Historiographie als auch Reichsstaatsrechtslehre im Gegensatz zur mündlichen Kommunikation der Reichstagsverhandlungen bis heute greifbar sind (die Protokolle geben nur einen Teil dessen wieder, was insgesamt kommuniziert worden ist), bietet sich ein breites Hintergrundpanorama, das man empirisch fassen und zu jeder Untersuchung konkreter

Nihil Sine Ratione. VII. Internationaler Leibniz-Kongreß, Berlin 10. bis 14. September 2001, Nachtragsband, Hannover 2002, S. 142-149.

39 Vgl. zur Gutachtertätigkeit beispielsweise der Helmstädter Juristenfakultät: Peter-Michael HAHN, Die Gerichtspraxis der altständischen Gesellschaft im Zeitalter des »Absolutismus«. Die Gutachtertätigkeit der Helmstädter Juristenfakultät für die brandenburgisch-preußischen Territorien 1675-1710, Berlin 1989. 
Reichstagsverhandlungen heranziehen und auswerten kann. Auch für die symbolische Seite des Politikprozessierens gab es die entsprechende Wissenschaftsrichtung, die die Rolle einer professionellen Beobachterin übernahm: die Zeremoniellwissenschaft ${ }^{40}$.

Die Reichsstaatsrechtslehre diente nicht nur der Politik, sondern sie öffnete durch ihr beobachtendes Prozessieren auch politische Inhalte dem neugierigen Blick von Personen, für die sie eigentlich verschlossen bleiben sollten. So profitierten mehrere Herausgeber von Staatsdokumenten der habsburgischen Kaiserdynastie wie der Fürstenhäuser davon, dass sich ein Interesse an großen Quellenpublikationen einstellte. Die Quellenwerke wurden in dicken Folianten in privatwirtschaftlichen Verlagen und Druckereien hergestellt, wo zumindest die dort Beschäftigten Einblicke ins System der Herrschaftsprinzipien und Herrschaftsgeheimnisse gewannen. Kaspar Melchior Goldast von Haiminsfeld ${ }^{41}$, Michael Lundorp ${ }^{42}$, Johann Christian Lünig ${ }^{43}$ oder Johann Joseph Pachner von Eggenstorff ${ }^{44}$ waren nur einige, die sich durch ihre Ausgaben von Urkunden, Reichstagsakten und sonstigen Quellen einen Namen machten. Auch die verschiedenen Herausgeber des Diarium Europaeum ${ }^{45}$ und des Theatrum Europaeum ${ }^{46}$ schöpften aus Quellensammlungen zur

40 Wichtige Quellenzusammenstellungen und Abhandlungen wurden von Johann Christian Lünig und Julius Bernhard von Rohr verfasst: Johann Christian LüNIG, Theatrum ceremoniale historico $=$ politicum oder Historisch $=$ und politischer Schau $=$ Platz aller Ceremonien [...], 3 Bd., Leipzig 1719-1720; Julius Bernhard von RoHr, Einleitung zur Ceremoniel-Wissenschafft Der Privat-Personen [...], hg. v. Gotthardt FrüHSORGE, Berlin 1728 (ND Weinheim 1990); ders., Einleitung zur Ceremoniel-Wissenschafft Der grossen Herren, die in vier besondern Theilen Die meisten Ceremoniel-Handlungen [...] aus den alten und neuen Geschichten erläutert, hg. v. Monika Schlechte, Berlin 1733 (ND Weinheim 1990). Monographisch untersucht wurde der Themenzusammenhang durch VEC, Zeremoniellwissenschaft im Fürstenstaat, pas.

41 Melchior Goldast von Haiminsfeld, Politische Reichshändel. Das ist/Allerhand gemeine Acten/Regimentssachen/und Weltliche Discursen: Das gantze heilige Römische Reich/die Keyserliche und Königliche Majestäten betreffendt, Frankfurt a.M. 1614.

42 Michael Caspar Lundorp, Der Römischen Keyserlichen [...] Mayestat [...] und deß heiligen Römischen Reichs/Geistlicher und Weltlicher Chur und Fürsten und anderer Reichsständ Acta Publica [...], 10 Bücher in 4 Bd., Frankfurt a.M. 1621-1624 (nebst zahlreichen späteren Auflagen).

43 Hauptedition: Johann Christian LÜNIG (Hg.), Das Teutsche Reichs-Archiv [...], 24 Bd., Leipzig $1710-1722$.

44 Johann Joseph Pachner von EgGenstorfF, Vollständige Sammlung aller von Anfang des noch fürwährenden Teutschen Reichs-Tags de Anno 1663 bis anhero abgefaßten Reichs-Schlüsse, 4 Bd., Regensburg 1740-1777.

45 Schultheiss, Das »Diarium Europaeum«, S. 315-346.

46 Johann Philipp Abelein (u.a.), Theatrum Europaeum, Oder Außführliche und Warhafftige Beschreibung aller und jeder denckwürdiger Geschichten/so sich hin und wieder in der Welt [...] zugetragen haben, 22 Bd., Frankfurt a.M. 1643-1737. Viele Bände wurden in mehreren Auflagen gedruckt und erfreuten sich herrschaftlicher Privilegien. Vgl. dazu Bingel, Das Theatrum Europaeum (1909/1969), pas.; Lucas Heinrich WüTHRICH (Hg.), Das druckgraphische Werk von Matthaeus Merian d. Älteren, Bd. 3: Die großen Buchpublikationen, Hamburg 1993, S. 113-272; Gerd Dethlefs, Schauplatz Europa. Das Theatrum Europaeum des Mat- 
Reichsgeschichte (neben der Auswertung von Flugschriften und Zeitungen). Später konnte Johann Jacob Moser, der produktivste Reichsrechts- und Historienschriftsteller des 18. Jahrhunderts, nicht nur direkt auf Archivalien, sondern auch auf die zahlreichen vorliegenden Editionen zurückgreifen, um seine Studien zu beinahe allen Problemen der Reichs- und Territorialgeschichte anzufertigen ${ }^{47}$. Weitere Projekte wurden vorbereitet, so eine große Quellenedition, initiiert durch den Leipziger Verleger Moritz Georg Weidmann im Jahre 1720, wobei die Zeit Ferdinands III. im Mittelpunkt stehen sollte. Obwohl der Medienproduzent bereits von Kaiser Karl VI. in Privataudienz empfangen und sein Anliegen positiv beschieden worden war, gelang das vielbändige und mit zahlreichen Stichen geplante Werk nicht, wohl aus wirtschaftlichen Gründen ${ }^{48}$.

Das Herrschafts-Arkanum wurde dadurch wirkungsvoll durchlöchert: Obwohl die Quelleneditionen privatwirtschaftlich begannen - die Editionskarriere Lünigs ist dafür beispielhaft -, wurde schnell der Punkt erreicht, an dem sich alle fürstlichen Regierungen beteiligen mussten. Statt konsequenter Abstinenz und Wahrung der Staatsgeheimnisse galt fortan: Wer sich verweigerte und seine Archive verschlossen hielt, machte sich verdächtig, er habe etwas zu verbergen ${ }^{49}$. Vielmehr galt es, Sorge zu tragen, um seine urkundlichen Rechte und Ansprüche in ein vorteilhaftes Licht zu stellen, und an dieser Fähigkeit arbeiteten die Kanzleien in den folgenden Jahrzehnten. An die Stelle früherer Geheimhaltung trat die bewusste Selbstdarstellung der herrscherlichen Politik vor der Öffentlichkeit.

Die Rekursion der Beobachtung war auch insofern gewährleistet, als die politisch handelnden Personen im Reich die Reichsstaatsrechtslehre genau verfolgten, nicht nur um geeignete Juristen für den höheren Staatsdienst (oder

thäus Merian als Medium kritischer Öffentlichkeit, in: Klaus Bussmann/Elke Anna WerneR (Hg.), Europa im 17. Jahrhundert. Ein Mythos und seine Bilder, Stuttgart 2004, S. 149-179.

47 Ein Werkeverzeichnis würde den Rahmen einer Fußnote sprengen; daher sei hier nur auf die beiden wichtigsten Reihen Mosers hingewiesen: Johann Jacob Moser, Teutsches Staatsrecht, 50 Bd., Nürnberg 1737ff. (ND Osnabrück 1967); ders., Neues Teutsches Staatsrecht, 20 Bd., Frankfurt a.M. 1766-1782 (ND Osnabrück 1967/68). Moser hatte seine publizistische Tätigkeit als Zeitschriftenherausgeber begonnen: [Johann Jacob Moser (Hg.)], »Reichs=Fama, Welche das Merckwürdigste von demjenigen, so sich gantz kürtzlich auf dem Reichs-Convent [...] zugetragen [...]«, 23 Bd., Frankfurt a.M./Leipzig 1727-1738.

48 Vgl. zu den Einzelheiten des Projekts: Stefan Benz, Zwischen Tradition und Kritik. Katholische Geschichtsschreibung im barocken Heiligen Römischen Reich, Husum 2003, S. 442f.

49 Zur Biographie von Johann Christian Lünig: ZedLer, Universal-Lexicon, Bd. 18, Sp. 11011103. Zur zeitgenössischen Kritik an dem Leipziger Editor: Carl Renatus Hausen, Einige Anecdoten zu dem Leben des berühmten Sammlers Johann Christian Lünig, in: Ders., Vermischte Schriften, Halle a.d. Saale 1766, S. 28-31. Zur Entstehungsgeschichte und komplizierten Gliederung des »Teutschen Reichs-Archivs«: Konrad REPGEN, Über Lünigs »Teutsches Reichs-Archiv« (1710-1722). Aufbau und Zitierungs-Möglichkeiten, in: Ders. (Hg.), Forschungen und Quellen zur Geschichte des Dreißigjährigen Krieges, Münster 1981, S. 240285. 
für Richterämter) zu rekrutieren, sondern auch, um an Debatten über eine Fortentwicklung bzw. Reform des Reiches teilzunehmen. Wolfgang Burgdorf hat kürzlich in einer umfänglichen Studie darauf hingewiesen, wie vielfältig und lebendig dieser Reflexionsprozess über die Fortentwicklung des politischen Gemeinwesens geführt worden ist: Es war allgemein üblich, theoretische Gedanken aus der zweiten Beobachterebene wieder in die Debatte in den Reichsversammlungen zurückzuführen ${ }^{50}$. Bei aller Kritik an der vormodernen Struktur des politischen Apparats im Reich, so berechtigt sie im Vergleich zu anderen großen Nationen in Europa gewesen sein mag, darf nicht übersehen werden, dass das Ende 1806 alles andere als zwangsläufig eintrat.

Die Etablierung des Immerwährenden Reichstags fiel zeitlich zusammen mit dem Aufblühen des europäischen Pressewesens. Es gab schon im Laufe des 17. Jahrhundert immer mehr Informationen, sie kamen immer schneller, sie waren von relativ hoher Zuverlässigkeit. Die Tatsache, dass alle Materien ständig im Schriftverkehr zwischen den Gesandten und ihren Prinzipalen daheim kommuniziert werden mussten, bot jede Gelegenheit, Berichte abzuzweigen und sie Personen zukommen zu lassen, für die sie nicht bestimmt waren. $\mathrm{Zu}$ den auswärtigen Mächten und den Juristen, die schon früher mit Neuigkeiten versorgt worden waren, traten nun - wie schon gezeigt - die Novellanten der Medienproduzenten. Dieses Phänomen war am Reichstag besonders ausgeprägt.

Die staatlichen Gewalten hatten den Prozess der »Medienrevolution« (Michael Giesecke) mit Misstrauen, aber nicht mit Entschlossenheit verfolgt $t^{51}$. Die obrigkeitlichen Bemühungen einer rechtlichen Regulierung des Medienmarktes werden unter dem Begriff der »Zensur« gefasst, ein Wissensbereich, über den sich eine differenzierte Forschungssituation herausgebildet hat ${ }^{52}$. Die föderale Grundordnung des Reiches galt auch für das Medienwesen: Der Kaiser war nur für die zentrale Buchaufsicht und für die rechtlichen Rahmenvorgaben zuständig, alles weitere war Angelegenheit der Reichsstände. Edoardo Tortarolo unterscheidet drei Zensurebenen: 1. die

50 BURGDORF, Reichkonstitution und Nation, pas.

51 Vgl. zu Begriff und Phänomen der »Medienrevolution«: GIeSECKE, Der Buchdruck in der frühen Neuzeit, pas.

52 Klassische Studie zur reichsrechtlichen Situation: Ulrich EISENHARDT, Die kaiserliche Aufsicht über Buchdruck, Buchhandel und Presse im Heiligen Römischen Reich (1496-1806). Ein Beitrag zur Geschichte der Bücher- und Pressezensur, Karlsruhe 1970. - Literaturhistorische Perspektive: Breuer, Geschichte der literarischen Zensur in Deutschland, pas. - Zur Forschungsentwicklung: Erdmann Weyrauch, Zensur-Forschung, in: ArNold/DitTrich/ZeHLER, Die Erforschung der Buch- und Bibliotheksgeschichte in Deutschland, S. 475-488; Dieter BReuer, Stand und Aufgaben der Zensurforschung, in: Herbert G. GöPfERT/Erdmann WeYRAUCH (Hg.), »Unmoralisch an sich ...«. Zensur im 18. und 19. Jahrhundert, Wiesbaden 1988, S. $37-60$. 
Zensur der kaiserlichen Bücherkommission in Frankfurt a.M., 2. die Zensurpolitik und die zentralen Zensurbehörden in den Territorien und 3. die daneben bestehenden unteren Zensurbehörden in den Territorien (universitäre, städtische Zensoren etc. $)^{53}$.

In gesellschaftlichen Teilsektoren gab es eigene Zensursysteme, insbesondere bezüglich der Religion. In der katholischen Kirche war die Zensur institutionalisiert, um die Einheitlichkeit der Lehre zu gewährleisten. Dies war schon vor Beginn der Reformation so gewesen und wurde anschließend durch die Gründung der Congregatio Romanae et universalis Inquisitionis 1542 und der Indexkongregation 1572 verwaltungsrechtlich fixiert ${ }^{54}$. Hubert Wolf nennt ein diesbezügliches Buchkapitel denn auch konsequent »Buchzensur als Heilige Pflicht«, denn als solche fasste die kirchliche Obrigkeit sie auf ${ }^{55}$. Die protestantischen Kirchen kontrollierten das geistliche Schrifttum ebenfalls, nur gab es dort in der Regel keine Zentralinstitutionen, sondern eigens berufene Theologieprofessoren wurden als Zensoren bestallt ${ }^{56}$. Zensierende Professoren waren auch im katholischen Kontext wirksam, gern wurden Ordensgeistliche engagiert. Nur gravierende Fälle oder erst nach der Publikation angezeigte Bücher wurden von den römischen Institutionen verhandelt.

In der Mehrzahl der Spezialstudien wird die Strenge der Territorialzensur betont oder beklagt ${ }^{57}$. Über die lokalen Zensuren ist am wenigsten bekannt,

53 Edoardo Tortarolo, Zensur, öffentliche Meinung und Politik in der Berliner Spätaufklärung. Eine Problemskizze, in: Comparativ 1 (1991), H. 3, S. 80-90, hier S. 81.

54 Diesen Zusammenhang der Kontrolle allen katholischen Schrifttums untersucht insbesondere Hubert Wolf zusammen mit seinen Schülerinnen und Schülern: Hubert WoLf, Index. Der Vatikan und die verbotenen Bücher, München 2006; ders. (Hg.), Inquisition, Index, Zensur. Wissenskulturen der Neuzeit im Widerstreit, Paderborn 2001; ders. (Hg.), Verbotene Bücher. Zur Geschichte des Index im 18. und 19. Jahrhundert, Paderborn u.a. 2006.

55 Wolf, Index. Der Vatikan und die verbotenen Bücher, S. 21-45.

56 Mitunter nutzten diese Zensoren ihr Amt zur eigenen Selbstdarstellung, vgl. die Beispiele bei Albrecht KirchHOFF, Lesefrüchte aus den Acten der kurfürstlich sächsischen Bücher-Commission zu Leipzig, in: Archiv für Geschichte des deutschen Buchhandels 8 (1883), S. 62-122, bes. S. 101-103 (Zensurschwerpunkt: pietistisches Schrifttum).

57 Zur älteren Zensurforschung für die Territorien: Hans W. BIEBER, Die Befugnisse und Konzessionierungen der Münchner Druckereien und Buchhandlungen von 1485-1871. Unter besonderer Berücksichtigung der bayerischen Gesetzgebung des 19. Jahrhunderts, in: Börsenblatt für den deutschen Buchhandel 14 (1958), Sp. 1750-1776; Volker BüCHLER, Die Zensur im frühneuzeitlichen Augsburg 1515-1806, in: ZHVS 84 (1991), S. 69-128; BRÜCKNER, Die Gegenreformation im politischen Kampf um die Frankfurter Buchmessen, S. 67-86; Heinz-Dietrich Fischer (Hg.), Deutsche Kommunikationskontrolle des 15. bis 20. Jahrhunderts, München 1982; Gunter Franz, Bücherzensur und Irenik. Die theologische Zensur im Herzogtum Württemberg in der Konkurrenz von Universität und Regierung, in: Martin BRECHT (Hg.), Theologen und Theologie an der Universität Tübingen, Tübingen 1977, S. 123-194; Hilger Freund, Die Bücher- und Pressezensur im Kurfürstentum Mainz von 1486-1797, Karlsruhe 1971; Grete Klingenstein, Staatsverwaltung und kirchliche Autorität im 18. Jahrhundert. Das Problem der Zensur in der theresianischen Reform, München 1970; Kовuch, Zensur und Aufklärung in Kursachsen, pas.; Victor Muckel, Die Entwicklung der Zensur in Köln, Diss. Köln 
allenfalls der Topos, dass in großen Städten wie Leipzig ${ }^{58}$ oder Augsburg ${ }^{59}$ die ansässigen Verleger sich selbst zensurierten und der Magistrat auf das wirtschaftliche Wohl dieser Gruppe ebensoviel Rücksicht nahm wie auf Empfindlichkeiten auswärtiger Potentaten. Es entsprach dem allgemeinen Selbstverständnis der geistlichen wie der weltlichen Obrigkeiten, dass Zensur ein normaler Bestandteil der rechtlichen Ordnung gesellschaftlicher Verhältnisse sein musste. Dies gehörte zur Verlängerung der »guten Policey«, der umfassenden Daseinsvorsorge durch die Obrigkeiten ${ }^{60}$. Mit zunehmender staatlicher Verdichtung musste sich dieser Anspruch ebenfalls verdichten. Die heutige Fixierung auf angeblich zensurfreie Verhältnisse, wie sie im Grundgesetz angedeutet zu sein scheinen, führt zur verbreiteten Verwunderung über die Selbstverständlichkeit obrigkeitlicher Textkontrollrechte in weitester Hinsicht. Dies kann als Grund dafür gelten, dass Zensuredikte und überlieferte Zensurprozesse lange so interpretiert wurden, als ob die frühmodernen Staatsorgane allgegenwärtig und der Autor, Drucker oder Verleger stets an der kurzen Leine der Machthaber gelaufen sei.

Die Realität sah anders aus. Die Haltung der Fürsten und Regierungen gestaltete sich ambivalent, wollten sie doch vor Indiskretionen bezüglich der eigenen Interessen geschützt sein, schädliche Meldungen zu Lasten der Konkurrenten aber durchaus wissen und verbreitet sehen. Die doppelte Konkurrenz der Fürsten sorgte auf diese Weise für eine Föderalisierung der Medienkontrolle und damit zur Einschränkung ihrer Wirksamkeit. Im Übrigen ist der angenommene Dualismus, Fürsten seien alle strikte Zensurbefürworter gewesen, Medienproduzenten hingegen seien für »Pressefreiheit« eingetreten, für den Beobachtungszeitraum unzutreffend: Es gab vielmehr in der frühmodernen Gesellschaft einen Konsens darüber, dass 1. die Ehre und Autorität der Herrschaftspersonen nicht angegriffen werden sollte, 2. konfessionelle Streitigkeiten und religiöse Diffamierungen nicht in die Zeitun-

1932; Arnd MüLLER, Zensurpolitik der Reichsstadt Nürnberg, in: Mitteilungen des Vereins für Geschichte der Stadt Nürnberg 49 (1959), S. 66-169; Helmut Neumann, Staatliche Bücherzensur und -aufsicht in Bayern von der Reformation bis zum Ausgang des 17. Jahrhunderts, Heidelberg/Karlsruhe 1977; Annette Schreiner-Eickhoff, Die Bücher- und Pressezensur im Herzogtum Württemberg (1495-1803), Diss. Hagen 1981; Thomas SiRges/Ingeborg MüLLER, Zensur in Marburg 1538-1832. Eine lokalgeschichtliche Studie zum Bücher- und Pressewesen, Marburg 1984; Georg Sommer, Die Zensurgeschichte des Königreichs Hannover, Münster 1930; Heinrich TiedEmann, Die Zensur in Bremen von ihren Anfängen bis zu den Karlsbader Beschlüssen 1819, in: BrJ 30 (1926), S. 311-394.

58 Vgl. dazu die marxistisch inspirierte Studie von Frank STAder, Die deutsche Presse von den Anfängen bis 1789. Chronologischer Leitfaden, Leipzig 1989, bes. S. 47 zu Leipzig.

59 Zur Augsburger Selbstzensur: Büchler, Die Zensur im frühneuzeitlichen Augsburg, S. 86 u. 121.

60 Bei Josef von Sonnenfels steht folgerichtig als Fazit der Zuordnung: »Die Büchercensur ist daher als eine der nothwendigeren Polizeyanstalten anzusehen«: von Sonnenfels, Grundsätze der Policey-, Handlung- und Finanzwissenschaft, Bd. 1, S. 82. 
gen gehörten und 3. die allgemeinen »guten Sitten« zu beachten waren ${ }^{61}$. Wer sich hieran orientierte, konnte jahrzehntelang ein Periodikum betreiben, ohne mit Gesetz und Recht in Konflikt zu geraten ${ }^{62}$.

Ein Beispiel für die ambivalenten Verhältnisse war die Unmöglichkeit, die Impressumspflicht durchzusetzen. Im Abschied des Reichstags von Augsburg 1530 war im $\S 58$ Folgendes über den Buchdruck im Reich bestimmt worden:

Und nachdem durch die unordentliche Truckerey biß anhero viel Ubels entstanden: Setzen, ordnen und wollen Wir, daß ein jeder Churfürst, Fürst und Stand des Reichs, geistlich oder weltlich, mittler Zeit des künfftigen Concilii in allen Truckereyen, auch bey allen Buchführern, mit ernstem Fleiß Versehung thun, daß hinfurter nichts Neues, und sonderlich Schmähschrifft, Gemählets, oder dergleichen, weder öffentlich oder heimlich gedicht, getruckt oder feil gehabt werden, es sey dann zuvor durch dieselb geistlich oder weltlich Obrigkeit darzu verordnete verständige Personen besichtigt, des Trucker Nahmen und Zunahmen, auch die Stadt, darinn solches getrucket, mit nähmlichen Worten darinn gesetzt.

Es folgte die Strafandrohung bei Zuwiderhandlung. Selbst säumige Obrigkeiten, die die Buchaufsicht nicht mit dem nötigen Ernst betrieben, sollten durch den Fiskal des Reichskammergerichts zur Rechenschaft gezogen wer$\operatorname{den}^{63}$. Diese Impressumsbestimmung, die die Verantwortlichkeit für verbrei-

61 Zeitgenossen zur Zensur: Johann Jacob Moser fasste den rechtlichen Rahmen 1772 wie folgt zusammen: »Die Zensur ist zu dem Ende eingeführt, damit nichts gedruckt werde, so wider die Reichsgesetze, die Religion, gute Sitten oder den Staat, das ist, das gemeine Beste wäre«: Johann Jacob Moser, Von der Reichsverfassungsmäßigen Freyheit von Teutschen Staats $=$ Sachen zu schreiben, Göttingen/Gotha 1772, S. 93 u. 104. - Schon ein dreiviertel Jahrhundert früher schrieb Kaspar Stieler zur Zeitungsetikette und zum Zeitungsrecht: STIELER, Zeitungs Lust und Nutz (1695/1969), Kap. 5 (Von dem Stoff/und der so genanten Materie der Zeitungen: S. 29-38, bes. S. 32-38) und Kap. 9 (Von dem Zeitungs-Recht/und falscher Zeitungen Bestrafung: S. 164-172).

62 Die faktisch begrenzte Reichweite des Arkanum ist schon im 19. Jahrhundert festgestellt worden. Georg Mentz schrieb 1897 zu diesem Aspekt: »Es giebt kaum ein wichtiges Ereignis jener Zeit, wo nicht der ganze offizielle Schriftwechsel schon den Zeitgenossen bekannt gewesen wäre«: Georg Mentz, Die deutsche Publizistik im 17. Jahrhundert, Hamburg 1897, S. 9. Die jüngere Forschung zur frühneuzeitlichen Zensur hat den Befund sowohl für das 16. als auch für das 18. Jahrhundert bestätigt: Fitos, Zensur als Mißerfolg, pas.; Edoardo TorTARoLo, Zensur als Institution und Praxis im Europa der Frühen Neuzeit, S. 277-294; HaEfs / Mix, Zensur im Jahrhundert der Aufklärung, pas.

63 Quellenabdruck: RTA Augsburg, den 19. November 1530, §58 zur »Truckerey«: [Johann Jakob Schmauss/Heinrich Christian Senckenberg (Hg.)], Neue und vollständigere Sammlung der Reichs $=$ Abschiede, welche von den Zeiten Kayser Conrads II. bis jetzo, auf den Teutschen Reichs $=$ Tägen abgefasset worden [...], 4 Tl. in 2 Bd., Frankfurt a.M. 1747 (ND Osnabrück 1967), hier Bd. 2, S. 314. - Bekräftigung durch die Reichspolizeiordnung 1577, Tit. 35, § 2: Gustav Klemens Schmelzeisen (Hg.), Polizei- und Landesordnungen. Erster Halbbd.: Reich und Territorien, Köln/Graz 1968, S. 57-93, hier S. 77f. - Vgl. auch die Erläuterungen zu 
tete Meinungen nachweisen sollte, wurde immer wieder bekräftigt - nur hielt sich kaum jemand daran. Nicht nur das Flugschriftenwesen verstieß in eklatanter Weise gegen die Impressumspflicht, sondern auch die späteren Periodika, so dass sich der heutige Leser fragt, ob die Obrigkeiten es eigentlich wirklich ernst mit dieser Bestimmung meinten ${ }^{64}$.

Auch die oft dekretierte Vorzensur ließ sich umgehen, indem Druckwerke gar nicht bei den Zensoren eingereicht oder von diesen einfach »durchgewunken« wurden. Es kennzeichnet die Verhältnisse, dass selbst die Produzenten von Periodika vielfach die Vorzensur ignorierten, selbst wenn sie in ihrer Lizenz darauf verpflichtet worden waren ${ }^{65}$. Es blieb die Nachzensur, die bei einem vorhandenen, öffentlich zugänglichen Druckwerk auch noch in größerem zeitlichen Abstand zu seiner Entstehung realisierbar war.

Niklas Luhmann hält diesen Misserfolg der Zensur für unvermeidlich angesichts der Vielzahl der Druckzentren in verschiedenen Staaten und vor allem angesichts der zunehmenden Komplexität dessen, was gedruckt kommuniziert wurde. Daraus resultierte der Zwang für die politische Macht, sich mit der »prinzipiell heterarchisch kommunizierenden Gesellschaft« zu arrangieren $^{66}$. Es standen sich daher nicht eine arkane Herrschaftssphäre und eine unwissende Bevölkerung gegenüber, wie manche Quellen suggerieren, obwohl schon die Zeitgenossen es besser hätten wissen können, sondern eher sind dezentralisierte, laufende Berichte über alle Arten von politischen und militärischen Handlungen beobachtbar, während die Herrschaftszentren darüber nachdachten, wie bestimmte Informationen überhaupt noch zurückgehalten werden konnten. Die besondere Betonung des Arkanums, die verzweifelte Einschwörung von Staatsbediensteten auf die Amtsverschwiegenheit durch Eidesleistungen, die offene Resignation der Reichstagsgesandten über den Verkauf von Informationen durch subalterne Reichstagsbediens-

den Rechtsquellen von EISEnhardt, Die kaiserliche Aufsicht, S. 24-34. - Zudem schrieb die Reichspolizeiordnung von 1548 vor, dass jeder Drucker bzw. Verleger auf Anfrage den Autor einer Schrift preiszugeben hatte: FISCHER, Die ältesten Zeitungen, S. 15.

64 Zur begrenzten Reichweite der Zensur und der Eigendynamik des Mediensystems: ToRTAROLO, Zensur, öffentliche Meinung und Politik in der Berliner Spätaufklärung, S. 80-90; ders., Censorship and the Conception of the Public in Late Eighteenth-Century Germany. Or, are Censorship and Public Opinion Mutually Exclusive?, in: Dario CAStiglione/Lesley Sharpe (Hg.), Shifting the Boundaries. Transformation of Languages of Public and Private in the Eighteenth Century, Exeter 1995, S. 131-150; TorTARolo, Zensur als Institution und Praxis im Europa der Frühen Neuzeit, S. 277-294. - Zensurprobleme bei den frühen Zeitungen: Johannes WeBer, Kontrollmechanismen im deutschen Zeitungswesen des 17. Jahrhunderts. Ein kleiner Beitrag zur Geschichte der Zensur, in: Jahrbuch für Kommunikationsgeschichte 6 (2004), S. 56-73; Wilke, Pressezensur im Alten Reich, S. 27-44.

65 Zum Zusammenhang: BöNIG/MoEPPS, Deutsche Presse, hier Bd. 2, Einleitung S. XXXIII.

66 Luhmann, Die Gesellschaft der Gesellschaft, Bd. 1, S. 312. Zur Bedeutung des Buchdrucks für die Kommunikationsentwicklung aus systemtheoretischer Sicht: Ebd., S. 291-302. 
tete an die Presse ${ }^{67}$, die verschleiernden Umschreibungen der Käuflichkeit von Reichshofratsmitgliedern und subalternen Beamten der Wiener Reichsbürokratie ${ }^{68}$ dürften eher Zeichen eines Rückzugsgefechts gewesen sein als die strahlende Repräsentanz barocker Herrscher-Herrlichkeit. Vieles spricht dafür, dass nicht nur der höfische Rivale die Verstellung von Meinung und Mimik durchschaute, sondern das zur Schau gestellte Gepränge auch von der breiten Bevölkerung als Theater verstanden wurde ${ }^{69}$. Interessanterweise trat diese unfreiwillige Öffnung der Informationen an den Höfen der großen Territorialherren nicht ein. Offenbar wurde mit zweierlei Maß gemessen, die Gründe für die Durchlässigkeit in Regensburg und die recht erfolgreiche Abschottung der Territorialpolitik gegenüber dem Mediensystem bedürfen noch einer vergleichenden Untersuchung.

67 Vgl. dazu die Situation am Reichstag 1713: ARNDT, »Pflicht=mässiger Bericht«, S. 1-31.

68 Vgl. die Schilderung der Käuflichkeit von Personen und Entscheidungen am Reichshofrat: Michael Hughes, Law and Politics in Eighteenth Century Germany. The Imperial Aulic Council in the Reign of Charles VI, Woodbridge u.a. 1988, S. 50-52.

69 Das Feld der literarischen Kritik bestimmter Herrschaftsmethoden schon im 17. Jahrhundert ist weit. Als Beispiel darf hier der »Bäuerische Machiavellus« erwähnt werden, ein Lustspiel, das der Zittauer Schulrektor Christian Weise 1679 aufführte und in dem die zugrunde liegende antimachiavellistische Herrschafts- und Hofkritik nicht nur dem gebildeten Publikum diskret zugänglich gemacht wurde, sondern im öffentlichen Schultheater aufgeführt wurde: Christian WeISE, »Bäuerischer Machiavellus« (1679). Lust-Spiel. Text und Materialien zur Interpretation besorgt von Werner Schubert, Berlin 1966. Zum literarischen Werk von Weise, der auch an der zeitgenössischen Debatte über Sinn und Reichweite von Zeitungen teilnahm, vgl. den Jubiläums-Sammelband von Peter BehnKe/Hans-Gert Roloff (Hg.), Christian Weise. Dichter, Gelehrter, Pädagoge. Beiträge zum ersten Christian-Weise-Symposium aus Anlaß des 350 . Geburtstages, Bern u.a. 1994. 



\section{Reichsvikariatsstreit zwischen Kurbayern und Kurpfalz}

\subsection{Historischer Hintergrund des Vikariatsstreits}

Eine jüngere historische Studie zur Problematik des Reichsvikariats aus historiographischer Perspektive unter Einschluss der jüngeren Reichsverfassungsgeschichte ist ein Desiderat. Vielleicht ist diese verfassungsgeschichtliche Institution innerhalb der Geschichte des Alten Reiches nicht spektakulär genug, da sie im Laufe der Frühen Neuzeit zu selten zu einer Wirksamkeit gelangt ist. Zwischen dem Westfälischen Frieden und dem Ende des Reiches 1806 gab es nur sechs Reichsvikariate: Nach dem Tod Ferdinands III. 1657/58, nach dem Tod Josefs I. 1711, nach dem Tod Karls VI. 1740-1742, nach dem Tod Karls VII. 1745, nach dem Tod Josefs II. 1790 und nach dem Tod Leopolds II. 1792. Abgesehen von 1740-1745 und 1790-1792, als zweimal zwei Vikariate binnen weniger Jahren aufeinander folgten, lagen sonst wenigstens 39 Jahre, längstens 53 Jahre zwischen den Vikariaten. Für einen persönlichen Erfahrungstransfer war dies zu lang. Nur einer der betroffenen Wittelsbacher Kurfürsten aus der bayerischen und der pfälzischen Linie, die eines der Vikariate innehatten, hat sein Amt zweimal ausgeübt: Kurfürst Karl Theodor 1790 und 1792.

So geht jede Erforschung der Vikariatsgeschichte von der juristischen Dissertation aus, die Wolfgang Hermkes 1968 über die verfassungsrechtliche Bedeutung des Reichsvikariats veröffentlicht hat ${ }^{1}$. Das kaiserliche Wahlamt im Reich war von seiner politischen Grundkonstruktion her mit dem Umstand der Vakanz konfrontiert: Da in der dynastisch geprägten Adelswelt des Mittelalters die Neigung bestand, Ämter in der Familie des jeweiligen Amtsinhabers »erblich« werden zu lassen, waren die Königswähler in ihrer Wahlentscheidung erst frei, wenn der frühere Amtsinhaber gestorben war. Nur dann glich das Königtum dem Papsttum, bei dem vorzeitige Nachfolgeregelungen ausgeschlossen waren und sind.

Für den Zeitraum zwischen dem Ableben des früheren Königs bzw. Kaisers und der Krönung des Nachfolgers (bzw. der Beschwörung der Wahlkapitulation) gingen einige Rechte des Reichsoberhaupts an die Reichsvikare über. Für die gesamte Frühmoderne waren die Amtsbefugnisse der Vikare

1 Wolfgang Hermkes, Das Reichsvikariat in Deutschland. Reichsvikare nach dem Tode des Kaisers von der Goldenen Bulle bis zum Ende des Reiches, Karlsruhe 1968. Die folgenden Überlegungen stützen sich auf die Studie von Hermkes; jüngere alternative Sichtweisen werden eingeflochten 
durch die »Goldene Bulle« Kaiser Karls IV. geregelt. Fünf Abschnitte werden unterschieden: 1. Die beiden Träger des Reichsvikariats, 2. die räumliche Trennung ihrer Amtsbezirke, 3. ihre Befugnisse, 4. die spätere Approbation aller Vikariatsentscheidungen durch den neugewählten König/Kaiser und 5. die Beschränkung der Vikariatsrechte².

Die Ausübung der Vikariatsrechte durch Kurpfalz und Kursachsen reicht bis vor die Goldene Bulle zurück. Bis zum 17. Jahrhundert hatte sich die Ausübung der pfälzischen Kur durch die Heidelberger Linie des Hauses Wittelsbach (Rudolfinische Linie) sowie die der sächsischen Kur durch die Albertinische Linie des Hauses Wettin (seit der Kurtranslation von 1547) verfestigt. Die Kurtranslation, die Kaiser Ferdinand II. 1623 / 1628 nach der Verhängung der Reichsacht gegen Kurfürst Friedrich V. von der Pfalz zugunsten von Herzog Maximilian I. von Bayern vollzog, ließ das Problem offen, ob das Vikariatsrecht mit übertragen worden sei. Zwar besaß Maximilian I. eine dahingehende Zusage in seiner Belehnungsurkunde, dieser Passus fehlte allerdings sowohl im Westfälischen Frieden als auch bei der Belehnung von Kurfürst Ferdinand Maria von Bayern am 5. Oktober $1652^{3}$. Die Probleme, die sich aus dieser Überlieferungslage ergaben, werden bei der Vorstellung der diesbezüglichen Deduktionen im Vikariatsstreit noch zu erörtern sein.

Die Grenze zwischen den beiden Vikariatsbezirken verlief quer durch das Reich, so dass die nordöstlichen Gebiete »sächsischen Rechts« zu Kursachsen gehörten, die südwestlichen »rheinischen, fränkischen und schwäbischen Rechts« zu Kurpfalz. Jeweils ganze Territorien gehörten einem der Rechtsbezirke an. Alle Gebiete des Reiches wurden erfasst, mit Ausnahme von Böhmen und den Österreichischen Erblanden ${ }^{4}$.

Die Aufgaben des Vikariatsamts lagen nach dem Westfälischen Frieden vor allem darin, durch eigene Gerichtsbarkeit (Vikariatshofgericht) für den Fortgang der Justiz zu sorgen, denn der Reichshofrat galt als persönliches Gericht des Kaisers und erlosch mit dessen Tod $^{5}$. Die Gerichte tagten in den Residenzorten beider Vikare. Besetzt und besoldet wurden sie

2 Die Regelungen zum Reichsvikariat in Kap. V der »Goldenen Bulle«: Karl Zeumer (Hg.), Quellensammlung zur Geschichte der Deutschen Reichsverfassung vom Mittelalter zur Neuzeit, Tübingen 1913, Nr. 148, S. 199, zit. u. systematisiert nach HermKEs, Reichsvikariat, S. $5 f$. - Zum Kontext der Entstehungsgeschichte der »Goldenen Bulle«: Bernd-Ulrich HergemöLLER, Der Nürnberger Reichstag von 1355/56 und die Goldene Bulle, Diss. Münster 1978.

3 Hermkes, Reichsvikariat, S. 55.

4 Kursachsen beanspruchte das Vikariatsrecht auch über Böhmen, wo sächsische Patente 1619 und 1740 angeschlagen worden waren. Eine durchgängige Kontinuität lag allerdings nicht vor. $\mathrm{Zu}$ diesen Exemtionen und weiteren Exemtionsbestrebungen: Ebd., S. 12-17.

5 Älterer Forschungsstand zum Reichshofrat: Oswald vON Gschliesser, Der Reichshofrat. Bedeutung und Verfassung, Schicksal und Besetzung einer obersten Reichsbehörde von 15591806, Wien 1942 (ND Nendeln 1970). Jüngere Interpretationen: Michael HugHEs, Law and Politics in Eighteenth Century Germany. The Imperial Aulic Council in the Reign of Charles VI, Woodbridge u.a. 1988, OrtLieb, Im Auftrag des Kaisers, pas.; Stefan EhrenPreis, Kaiser- 
durch die Vikare selbst. Zumeist ernannten sie hohe Regierungs- und Justizbeamte bzw. Rechtsprofessoren zu Richtern. Eine paritätische Besetzung der Richterstellen nach Konfessionsproporz war nicht vorgesehen. Nach Ende der Vakanz waren alle Akten an den neuen Kaiser einzusenden und alle Entscheidungen zu approbieren. Das Reichskammergericht als anderes oberstes Reichsgericht erlosch nicht während einer Vakanz ${ }^{6}$. Hier ergingen die Entscheidungen nur im Namen der Vikare, die jeweils ein eigenes Siegel auf dem Weg über den Mainzer Kurfürsten nach Speyer bzw. später nach Wetzlar einsandten.

Das zweite wichtige Recht war das der Belehnung aller kleinerer Lehen von Prälaten, Grafen, Reichsstädten und anderen Reichslehnsträgern. Ausgenommen waren die großen Fürstenlehen, die sog. »Fahnenlehen «. Mit dem Belehnungsrecht war vielfach das Recht verbunden, Lehnsstreitigkeiten zu entscheiden. Auch konnten Herrschaftssuspendierungen aufgehoben und kaiserliche Kommissionen abgelöst werden.

Das dritte Recht, die Befugnis der Präsentation zu geistlichen Pfründen (»Recht der ersten Bitte «), war strittig 7 . Auch die Einziehung von Reichssteuern - z.B. die Städtesteuern, die jeweils am 11. November fällig wurden - ließ sich nicht konfliktfrei realisieren. Die Ausübung des Reichsvikariats dürfte daher in der Regel ein Zuschussgeschäft gewesen sein. Einkünfte nennenswerter Art resultierten vor allem aus den Taxgebühren der Vikariatshofgerichte sowie aus Standeserhöhungen, die ebenfalls mit hohen Gebühren belastet waren ${ }^{8}$. Die Reichsvikare vergaben dabei Würden vom einfachen Adel bis hinauf zum Reichsgrafenstand. Fürstenhüte wurden nicht verliehen. Ob dafür das Verbot der Fürstenbelehnungen ausschlaggebend war, wie Hermkes annimmt, oder ob die Kur- und Reichsfürsten derartige Titel nicht anerkannten, ist unklar'. Legitimationen aller Art (Universitätsprivilegierungen, Volljährigkeitserklärungen, Moratorien) sowie Privilegienerteilungen, -verlängerungen und -bestätigungen waren jedoch die Regel.

In den Untersuchungszeitraum dieser Studie fällt zunächst das Reichsvikariat von 1657/58. Kaiser Ferdinand III. hatte zwar 1653 seinen ältesten Sohn Ferdinand (IV.) zum Römischen König erheben lassen, doch war dieser ein Jahr später gestorben. Eine Königswahl des zweitgeborenen Erzherzogs Leopold hatte noch nicht stattgefunden, als der Kaiser am 2. April

liche Gerichtsbarkeit und Konfessionskonflikt. Der Reichshofrat unter Rudolf II. 1576-1612, Göttingen 2006.

6 Vgl. zum Reichskammergericht im europäischen Vergleich: Ingrid Scheurmann (Hg.), Frieden durch Recht. Das Reichskammergericht von 1495 bis 1806, Mainz 1994; DiestelKamp, Oberste Gerichtsbarkeit und Zentrale Gewalt im Europa der Frühen Neuzeit, pas.

7 Zum Recht der »ersten Bitte«: Anna Hedwig Benna, Preces Primariae und Reichshofrat (1559-1806), in: MÖSTA 5 (1952), S. 87-102.

8 Zu den Rechten der Vikare: Hermkes, Reichsvikariat, S. 18-21.

9 Zur Standeserhöhung: ebd., S. 24f. 
1657 starb $^{10}$. Kursachsen übte sein Reichsvikariat ungestört aus. Zwischen Kurbayern und Kurpfalz entwickelte sich ein Konflikt, in dessen Verlauf beide Wittelsbacherkurfürsten ihre Patente öffentlich anschlugen (und versuchten, die der Gegenseite abzureißen), jeweils ein Vikariatshofgericht einsetzten und Entscheidungen des anderen Gerichts für ungültig erklärten ${ }^{11}$. Da das Vikariat die Einjahresfrist überschritt, gerieten alle Inhaber kleinerer Reichslehen in Rechtsungewissheit, bei welchem Gericht sie um ihre Belehnung nachsuchen sollten. Das Risiko war umso größer, als beide Kontrahenten eine militärische Durchsetzung der eigenen Ansprüche erwogen. So lag es nahe, dass die betroffenen Reichsstände, besonders die Mindermächtigen, die Patente beider Seiten nebeneinander anschlugen. Größeren Spielraum besaßen die Reichsfürsten und die kurfürstlichen Kollegen. Hier stellte sich eine klare Mehrheit für Kurfürst Ferdinand Maria von Bayern heraus, der nicht nur die geistlichen Kurfürsten und alle geistlichen Stände gewann, sondern auch Kursachsen ${ }^{12}$. Nach einigem Schwanken entschied sich das Reichskammergericht, die Siegel der Reichsvikare Kurbayern und Kursachsen anzunehmen, woran kurpfälzischer Protest nichts änderte ${ }^{13}$. Einige protestantische Fürsten hielten es jedoch mit Kurpfalz. Eine einvernehmliche Lösung des gesamten Reiches konnte nicht hergestellt werden. Auf die Argumentationsfiguren beider Seiten wird im Rahmen der folgenden Analyse der Deduktionen eingegangen.

Der Vikariatskonflikt fand sein vorläufiges Ende, als Kaiser Leopold I. im Juli 1658 gewählt worden war. Der neue Kaiser hatte sich zuvor als König von Böhmen ebenfalls für Kurfürst Ferdinand Maria entschieden und erkannte die kurbayerischen Vikariatsentscheidungen an. Doch auch denjenigen, die sich in Lehnsangelegenheiten an das kurpfälzische Vikariatshofgericht gewandt hatten, entstand kein Schaden: Niemand verlor Lehnsrechte oder Privilegien, weil er während der Vakanz falsch optiert hatte.

Versuche der beiden konkurrierenden Wittelsbacher Linien in den 1670er Jahren, eine einvernehmliche Lösung des Vikariatsstreits herzustellen, scheiterten. Da Kaiser Josef I. 1690 zum Römischen König gewählt worden war, trat die nächste Vakanz erst 1711 ein. Zu dieser Zeit war der bayerische Kurfürst Max Emanuel in der Reichsacht und hatte sich ins französisch besetzte Belgien zurückgezogen, so dass Kurfürst Johann Wilhelm von

10 Zum Interregnum und der Wahl Kaiser Leopolds I.: Aretin, Das Alte Reich, Bd. 1, S. 190-195.

11 Zum Verlauf des Vikariats 1657/58: Hermkes, Reichsvikariat, S. 54-69; Aretin, Das Alte Reich, Bd. 1, S. 193.

12 Vgl. zur Unterstützung durch die Reichsfürsten: Hermkes, Reichsvikariat, S. 57f.

13 Zum Reichskammergericht: ebd., S. 60. 
der Pfalz »sein « Vikariat ungestört ausüben konnte ${ }^{14}$. Versuche der Reichsvikare, ihre Rechte im Stil des Kaisers auch gegenüber dem Immerwährenden Reichstag auszuüben, scheiterten. Der Reichstag musste seine Tätigkeit zwischen Juli und Oktober 1711 einstellen. Mit der Kaiserwahl Karls VI. am 12. Oktober 1711 wurde der Streit gegenstandslos ${ }^{15}$.

Nach der Restitution Max Emanuels von Bayern 1714 trat der alte Streit wieder in Erscheinung. Immerhin hatte sich bei den verschiedenen Wittelsbacher Fürsten inzwischen die Einsicht durchgesetzt, dass der Reichsöffentlichkeit nicht dauerhaft das Bild familiärer Uneinigkeit demonstriert werden sollte $^{16}$. Zwei Umstände begünstigten die Verhandlungen: Zum einen war mit der Erbfolge der Linie Pfalz-Neuburg der innerfamiliäre Konfessionsdissens aufgehoben, denn die Neuburger waren seit 1613 katholisch (und gehörten zu den vehementesten Verfechtern einer »Ecclesia militans«, was eigene Probleme aufwarf). Kurfürst Karl Philipp setzte in dieser Hinsicht nach seinem Regierungsantritt 1716 die Politik seines Vorgängers Johann Wilhelm bruchlos fort. Zum anderen verfügten die Wittelsbacher außer über die beiden weltlichen auch über zwei geistliche Stimmen im Kurfürstenrat: Kurfürst Josef Clemens (reg. 1688-1706 und 1714-1719) und anschließend Kurfürst Clemens August (reg. 1719-1761) regierten in Köln; Kurfürst Franz Ludwig aus der neuburgischen Linie hingegen hatte sich zunächst zum Trierer Oberhirten wählen lassen (reg. 1716-1729), um anschließend bis zu seinem Tod 1732 Mainzer Erzbischof zu sein. Am 15. Mai 1724 schlossen alle vier Kurfürsten die »Wittelsbacher Hausunion«, durch die ein gemeinschaftliches Vikariatshofgericht zwischen Kurbayern und Kurpfalz vereinbart wurde ${ }^{17}$. Beide Kurfürsten sollten Räte entsenden, während das Gericht - mit Sitz in Augsburg - in beider Namen Recht zu sprechen hatte.

Der Wert der Wittelsbachischen Hausunion und der darin eingeschlossenen einvernehmlichen Vikariatsregelung musste sich 1740 erweisen, als Kaiser Karl VI. starb, ohne dass zuvor ein Römischer König gewählt worden

14 Zum Interregnum nach dem Tod Kaiser Josefs I. 1711: Aretin, Das Alte Reich, Bd. 2, S. 221229. Zu diesem Reichsvikariat: Hermkes, Reichsvikariat, S. 69-77. Kurfürst Johann Wilhelm war zuvor wieder förmlich in die fünfte Kurwürde eingesetzt worden (Belehnung vom 23. Juni 1708): Ebd., S. 70.

15 Die Tätigkeit des Vikariats endete mit der Beschwörung der Wahlkapitulation durch Kaiser Karl VI. am 19. Dezember 1711: ebd., S. 77.

16 Statt Verweisen auf die Spezialliteratur zu den Wittelsbachern: Hans Rall/Marga Rall, Die Wittelsbacher in Lebensbildern, Graz u.a. 1986; zu Kurpfalz: Meinrad SchAAB, Geschichte der Kurpfalz, Bd. 2: Neuzeit, Stuttgart 1992; zu den bayerischen Landesherren: Alois Schmid/Katharina Weigand (Hg.), Die Herrscher Bayerns. 25 historische Portraits von Tassilo III. bis Ludwig III., München 2001.

17 Zum Verhältnis zwischen den wittelsbachischen Linien und zur Entstehung der Hausunion: Gerhard ImmLer, Der innerwittelsbachische Konflikt. Bayern gegen Pfalz, in: Johannes Erichsen/Katharina Heinemann (Hg.), Die Schlacht von Höchstädt. The Battle of Blenheim. Brennpunkt Europas 1704, Sigmaringen 2004, S. 26-37, bes. S. 33-36. 
war. Es stellte sich schnell heraus, dass die Wittelsbacher sich getäuscht hatten, als sie glaubten, durch ihre Hausunion auch das Vikariatsproblem für alle Zukunft gelöst zu haben. Sie hätten das Reichsherkommen gut genug kennen können, um zu wissen, dass ein derartig weitreichender Vertrag nur dann problemlos akzeptiert werden würde, wenn Kaiser und Reichstag ihn zuvor approbiert hätten. Zwar hatte es einen kurpfälzischen Versuch gegeben, eine kaiserliche Anerkennung zu erlangen, allerdings erfolgte die Approbation nicht. Möglicherweise hing dieses Hinhalten der Wiener Regierung auch mit dem Unwillen der Wittelsbacher zusammen, die »Pragmatische Sanktion « anerkennen zu wollen. Nach Eintritt der Vakanz von 1740 war es zu spät. Sofort meldeten sich Skeptiker unter den Reichsfürsten zu Wort, die die Eigenmacht der Wittelsbacher und die fehlende reichsständische Approbation kritisierten. Sie seien in allen wichtigen Reichsangelegenheiten mitbestimmungsberechtigt, betonten die Kritiker. Wenn dies schon gegenüber dem Kaiser gelte, dann erst recht gegenüber den Reichsvikaren. Mit veränderten Rollen wurde das Reichsvikariat erneut zu einem Medienthema.

Ein Kompromiss ließ sich nicht erzielen. Selbst die Anerkennung für dieses eine Mal ohne Präjudizwirkung für die Zukunft wurde von den Reichsständen nicht erteilt. Das gemeinschaftliche Vikariatshofgericht wurde trotz des Widerspruchs in Augsburg eingerichtet, wo es eine rege Rechtssprechungstätigkeit ausübte ${ }^{18}$. Bemühungen der Opponenten, die Auflösung des Gerichts zu erreichen, blieben ergebnislos. Die Beschäftigung aller Regierungen durch die Kriegsauseinandersetzungen und die Vorbereitungen der Kaiserwahl des bayerischen Kurfürsten führten dazu, dass der Konflikt nicht bis zum äußersten ausgetragen wurde. Kaiser Karl VII. bestätigte nach seiner Wahl die Entscheidung der beiden Vikariatshofgerichte. Den Wittelsbacher Hausvertrag von 1724 legte er dem Reichstag zur Entscheidung vor, um damit das formelle Verfahren einzuhalten. Erneut kam eine Entscheidung nicht zustande ${ }^{19}$.

Das kurze und turbulente Kaisertum Karls VII. endete im Januar 1745 mit dem plötzlichen Tod des Protagonisten. Da der Vikariatsstreit immer noch nicht rechtswirksam vom Reichstag gelöst worden war, kamen Kurbayern und Kurpfalz überein, eine Alternation in ihrem Reichsvikariat eintreten zu lassen. Demnach sollte diesmal Kurbayern das Vikariat allein führen, und bei der folgenden Vakanz sollte Kurpfalz allein amtieren ${ }^{20}$. Der Reichs-

18 Zum Interregnum nach dem Tod Kaiser Karls VI. 1740: Aretin, Das Alte Reich, Bd. 2, S. 409-439. Zum Reichsvikariat von Oktober 1740 bis Januar 1742: Hermkes, Reichsvikariat, S. 77-95.

19 Kaiserliches Kommissionsdekret vom 4. Oktober 1742: ebd., S. 94f.

20 Zum Interregnum nach dem Tod Kaiser Karls VII. 1745: Aretin, Das Alte Reich, Bd. 3, S. 19-28. Zum Reichsvikariat: Hermkes, Reichsvikariat, S. 95-101; zum Vergleich über die Alternation im März 1745: Ebd., S. 95. 
tag blieb formell zusammen, beschloss allerdings »Comitialferien«, nachdem seine Kuriensitzungen von den Reichsvikaren nicht anerkannt wurden, solange sie nicht selbst die Fortsetzung verfügt hatten. Das Reichskammergericht fuhr mit seiner Jurisdiktion fort, da es beide Reichsvikare anerkannte. Ein gemeinschaftliches Vikariatssiegel kam nicht zustande, so dass die Ausfertigung von Gerichtsentscheiden provisorisch unter der Unterschrift des Kanzleiverwalters und eines Protonotars erfolgte ${ }^{21}$. Bei den folgenden Verhandlungen um die Wahlkapitulation erreichte Kurbayern, dass der künftige Kaiser den wittelsbachischen Vikariatsvergleich und auch alle Entscheidungen der Vikariatshofgerichte anerkannte ${ }^{22}$. Der Reichstag beschloss 1752, der wittelsbachischen Alternation zuzustimmen und sie zur künftigen Ordnung des rheinischen Vikariats zu erheben.

\subsection{Der Vikariatsstreit in den Deduktionen}

Das Schwergewicht der medialen Vermittlung des Streits um das süddeutsche Reichsvikariat lag auf den juristischen Deduktionen. Der Begriff Deduktion ist erklärungsbedürftig, weil er etwa in der Philosophie oder Mathematik etwas anderes bedeutet als in der Historiographie oder Rechtsgeschichte ${ }^{23}$. Nach Konrad Repgen handelt es sich um eine Teilgattung der Flugschriften, soweit in ihnen »reichs-, territorial- und dynastierechtliche Ansprüche politisch und rechtlich begründet oder bestritten wurden $\ll^{24}$. Angesichts des historisch fundierten Rechtssystems der Zeit beinhalteten die Deduktionen in aller Regel eine ausführliche Hintergrundgeschichte des jeweiligen Anspruchszusammenhangs, natürlich stets aus dem Blickwinkel des Betreibers der jeweiligen Schrift. In Reichsgremien und vor allem vor Gerichten waren Deduktionen Beweismittel, ähnlich wie heute ein reguläres Expertengutachten ${ }^{25}$.

Beide Seiten hatten ihre Schreiber in Position gebracht: 1657 und 1658 erschien eine beträchtliche Zahl von Drucken zu dieser Frage, eine Erhebung in den Altbestandssammlungen in München, Göttingen und Wolfenbüttel erbrachte allein 19 unterschiedliche Fassungen in deutscher, lateinischer und französischer Sprache. Nun stellt sich die Frage, ob Deduktionen

21 Ebd., S. 97f.

22 Aretin, Das Alte Reich, Bd. 3, S. 24.

23 Vgl. die philosophische Definition bei Lorenz, Art. »Deduktion«, S. $27 \mathrm{f}$.

24 Zitat: REPGEN, Der Westfälische Friede und die zeitgenössische Öffentlichkeit, S. 52.

25 Repgen grenzt die »Deduktion« ab gegenüber dem »Manifest«, das er vor allem bei staatlichen Verlautbarungen über Krieg und Frieden verwendet, und gegenüber der »Streitschrift«, in der aus politischen oder konfessionellen Gründen scharf akzentuierte Angriffe auf eine gegenteilige, als illegitim bezeichnete Konkurrenzposition vorgetragen wurden: ebd., S. 52-57. 
als Parteienschriften denn überhaupt unter dem Kriterium der Öffentlichkeit wahrgenommen werden sollten. Konrad Repgen hat diese Frage anhand der Druckschriften zum Westfälischen Friedenskongress untersucht und positiv beantwortet: In seinen Augen haben sich die zahlreichen Drucke zwar hauptsächlich an die jeweiligen Bündnispartner und die Verhandlungsgegner gerichtet, darüber hinaus aber auch eine weitergehende Öffentlichkeit angesprochen ${ }^{26}$. Nun waren die Jahre 1655 bis 1660 in der Presse bestimmt durch die kriegerischen Auseinandersetzungen im Ostseeraum zwischen Schweden und Polen, doch eine kaiserliche Sedisvakanz stellte dennoch ein Politikum ersten Ranges dar, über das zu berichten war.

Zuerst ließen beide Seiten in den Tagen nach dem Tod Ferdinands III. ihre Notifikationspatente zur Einrichtung des jeweiligen Vikariatshofgerichts ergehen $^{27}$. In der Doppelung der Patente lag allerdings bereits der Konflikt, denn reichsrechtsmäßig konnte es nur ein Gericht geben. Vieles spricht dafür, dass die kurpfälzische Regierung die Initiative ergriff: Ein Kurtzer und Summarischer Bericht erschien unter dem Datum des 1. Mai 1657, mit kurpfälzischem Siegel versehen ${ }^{28}$. Der sprachliche Duktus verdeutlicht die Probleme des Verfassers mit der intendierten Leserschaft: Während der Text in sprachlich leichter Form beginnt, wird er gegen Ende zu einer reinen juristischen Deduktion mit zahlreichen lateinischen Fachausdrücken. Damit stammt er aus der Feder eines Rechtsgelehrten - professionelle Medienreferenten hatte die Heidelberger Regierung damals noch nicht. Die Schrift beginnt mit dem Verweis auf die öffentliche Meinung: »Es ist Reichs= Ja weltkündig auch auß bewehrten Historien/und Historienschreibern/auß der guldenen Bull Kayser Carlen deß Vierdten/auß vielen Kayserlichen und Königl. Privilegien [...] «, dass den Kurfürsten von der Pfalz das Reichsvikariat zustehe ${ }^{29}$. Der alte Begriff $»$ reichs $=$ kündig « umreißt Tatsachen, die im ganzen Reich bekannt waren. Interessanterweise werden erst die Historienschriften und ihre Verfasser genannt, erst dann die Goldene Bulle als Reichsgrundgesetz. Die normative Kraft des historischen Herkommens in der historiographischen Fassung wird damit betont. Die Argumentationslinie der pfälzischen

26 Überlegungen zum Käuferkreis: ebd., S. 66.

27 »Churfuerstl. Pfältzisches Notifications-Patent Uff der Röm. Kays. Majest. [...] Ableiben dero zustehendes Reichsvicariati«, o.O. 1657 (Abdruck des öffentlichen Patents der kurfürstlichpfälzischen Regierung vom 6. April 1657, ohne weiteren Kommentar in irgendeiner Hinsicht); „Churfürstlich Bayrisches Notifications-Patent. Uff der Röm. Keys. Mayest. höchstseeligsten Ableiben dero zustehenden Reichs=Vicariats«, o.O. 1657 (Abdruck des öffentlichen Patents der kurfürstlich-bayerischen Regierung vom 12. April 1657, ohne weiteren Kommentar).

28 »Kurtzer und Summarischer Bericht, Dass das Vicariat in Landen des Rheins/Schwaben und Fränckischen Rechtens/deß Herrn Pfaltzgraffen und Vicarii Carl Ludwigen Churfürstl. Durchl. von Rechtswegen zustehen und gebühren thut [...]«, o.O. 1657.

29 Zusammenfassung des sehr langen Anfangssatzes: »Kurtzer und Summarischer Bericht«, S. 3. 
Deduktion lässt sich wie folgt umreißen: Das Vikariatsrecht hafte am Territorium Rheinpfalz und sei damit 1623/1648 nicht mit der Kurwürde den Münchener Vettern zugeschlagen worden ${ }^{30}$.

Die bayerische Seite reagierte ebenfalls mit einer offiziellen Schrift: Ein Wohlgegründter Gegen = Bericht spielte schon in der Formulierung auf die pfälzische Deduktion $a^{31}$. Die kurpfälzischen Argumente wurden aufgegriffen und widerlegt: Das Vikariat hafte, so der Verfasser, an der Erztruchsessenwürde, und die sei 1623/48 ganz rechtmäßig an die bayerischen Wittelsbacher übergegangen ${ }^{32}$. Er zog eine Parallele zum Kurübergang im Hause Wettin: Als dort die albertinische Linie 1547 die Kurwürde von Kaiser Karl V. übertragen bekam, wurden die neuen Kurfürsten auch Reichsvikare und übten dieses Recht seither ungestört aus. Mediengeschichtlich interessant ist ein Begründungssatz für die Druckpublikation der Deduktion: »[...] damit [...] sonderlich unerfahrne Leuthe darmit [nicht] irr gemacht und verlaittet werden « - wegen dieser Gruppe der nicht fremdsprachenerfahrenen Reichsuntertanen hatte man den Druck in deutscher Sprache auf den Weg gebracht ${ }^{33}$. Der Gegen=Bericht erschien, an die polyglotten Adligen und Gelehrten, das internationale Publikum sowie die europäische Presse gerichtet, auch in einer lateinischen und einer französischen Fassung ${ }^{34}$. In der Münchener Akte liegt sowohl das handschriftliche Konzept der französischen Ausgabe für den Drucker Jean Jacklin (= Johann Jäcklin) als auch ein Exemplar des Drucks. Das Konzept beinhaltet noch kleinere handschriftliche Korrekturen sowie Anweisungen an den Drucker. Kennzeichnend für den offiziellen Charakter der Deduktion ist auch die Angabe des vollen Impressums ${ }^{35}$.

Die Replik aus Heidelberg ließ nicht lange auf sich warten. »Auf kurfürstl. Special-Befelch« erschien unter dem offiziellen Datum 27. Juni 1657 die Ableinung Deß [...] Gegenberichts ${ }^{36}$. Die pfälzische Position wurde nun wortreicher dargelegt: War der Summarische Bericht noch mit 8 Seiten aus-

30 Ebd., S. 4.

31 »Wohlgegründter Gegen=Bericht/Wider Einen unlängsten in Truck außgangnen/also genanten Kurtz = und Summarischen Bericht/wegen deß H. Rom. Reichs Vicariats in Landen deß Rheins/Schwaben/und Fränckischen Rechtens [...]«, München 1657.

32 Ebd., S. 5.

33 Ebd., S. 2.

$34 »$ Refutatio solida informationis cuiusdam Palatinae, quae ostenditur S.R.I. Vicariatum [...] pertinere ad Ferdinandum Mariam etc.«, München 1657; »Refutation du Manifeste Palatin Contestante les preuves evidentes du droit que le Serenissime Prince Ferdinand Marie [...] a au Vicariat du S. Empire [...] «, München 1657; zum Inhalt: Albrecht von ArnswaLdT, De Vicariatus controversia. Beiträge Hermann Conrings in der Diskussion um die Reichsverfassung des 17. Jahrhunderts, Berlin 2004, S. 112f.

35 Andruck der »Refutation« mit Korrekturen: HStA München: Kasten Schwarz, Nr. 3424.

36 »Ableinung Deß ohnlängst von Chur=Bayrischer Seiten in Druck außgesprengten Gegenberichts / etc. Betreffend die Vicariats $=$ Gerechtigkeit in Landen des Rheins $/$ Schwaben $/$ und Fränckischen Rechtens [...] ${ }^{\prime}$, Heidelberg 1657. 
gekommen, wogegen der bayerische Gegenbericht schon 24 Seiten umfasst hatte, benötigte der kurpfälzische Verfasser nun 42 Seiten Umfang. Das Vikariat wurde als ein Akzidenz der Rheinpfalz, nicht der Kurwürde bezeichnet. Außerdem habe Bayern 1648 nur die Rechte übertragen bekommen, die im Westfälischen Friedensinstrument ausdrücklich genannt seien. Alles andere sei der Kurpfalz geblieben. Ein Vergleich mit den Wettinern wird zurückgewiesen, weil die ernestinische Linie nie restituiert worden sei. Auch sprächen die alten Lehnsbriefe für die Heidelberger Position.

Nun war wieder die Münchener Regierung am Zuge. Eine Fernere wohlgegründte Anzeig warf dem Autor der Ableinung auf 43 Seiten vor, er habe keine wirklichen Argumente bringen können ${ }^{37}$. Bayern konnte inzwischen schon auf die Unterstützung durch die anderen Kurfürsten sowie durch das Reichskammergericht verweisen. Hinsichtlich der historischen Argumentation der Pfälzer betonte der Verfasser, Kurfürst Ruprecht von der Pfalz sei 1394 »seines Churfürstenthumbs und Würdigkeit wegen/ein Vicarius und Fürseher des Reichs« geworden, d.h. nicht seiner Inhaberschaft der Rheinpfalz wegen ${ }^{38}$.

1658 setzte sich das Wechselspiel der Deduktionen fort. Zunächst erschien eine Wohlgegründete Abfertigung im kurpfälzischen Auftrag, in der die bekannten Argumente wiederholt und den bayerischen Traktaten beleidigende Formulierungen angelastet wurden. Das kurpfälzische NotifikationsPatent zum Vikariatsantritt wurde angehängt, eine Belehnungsaufforderung an alle Reichsvasallen ebenfalls. Ein Novum war hingegen die Anweisung an alle Buchdrucker und Kupferstecher im eigenen Machtbereich, keine kurbayerischen Vikariatspatente mehr herzustellen ${ }^{39}$. Wieder reagierte die Münchener Regierung: Eine Endtliche abgenötigte Ablainung führte nun die Positionen beider Seiten auf und entschied sich in der Conclusio für die kurbayerische Seite. Die vorige kurpfälzische Schrift bezeichnete der Verfasser als »schäbigen Gugauchs=Gedicht « und bestätigte damit den gegnerischen Kalumnien-Vorwurf ${ }^{40}$. Der »gemeine Mann « wurde ausdrücklich als Zielgruppe angeführt, der durch eine überzeugende Argumentation

37 »Fernere wohlgegründte Anzeig wegen deß Ihr Churfürstl. Durchl. in Bayrn zustehenden Reichs-Vicariats etc.«, München 1657. - Lateinische Fassung oder Vorlage: »Informatio qua ostenditur vacante post obitum Ferdinandi III glorissimae memoriae Imperio provisionem eius sive Vicariatum in partibus Rheni, Sueviae et in jure Franconico Ser.mo Electori Bavariae competere et nullatenus ad Electorem Palatinum pertinere« (Konzept), o.O. 1657. Ebd., S. 22.

39 »Wohlgegründete Abfertigung einer Chur=Bayerischen Theils ohnlängst in Truck gegebenen also genanten Ferneren Anzeig/Wegen des am Rhein, Schwaben und Fränckischen Rechtens Reichs-Vicariats [...]«, Heidelberg 1658.

40 »Endtliche abgenötigte Ablainung Einer ChurPfältzischen unlängstens in Truck gegebnen/also genanten Abfertigung das Vicariat in Landen des Rheins/Schwaben/und Fränckischen Rechtens betreffend [...]«, München 1658, Zitat S. 1. 
von der Richtigkeit der bayerischen Position überzeugt werden müsse, um nicht »irr gemacht« zu werden durch die Heidelberger Ansprüche ${ }^{41}$. Die Kurpfalz behielt beim Deduktionenwechsel das letzte Wort: 1662 erschien eine Schließliche Beantwortung, die allerdings keine neuen Argumente vorbringen konnte ${ }^{42}$.

Während die genannten Schriften offenbar großteils von eigenen Regierungsbediensteten der Parteien erstellt wurden, bezog die Heidelberger Regierung auch auswärtigen Sachverstand mit ein. Zur Information der europäischen Öffentlichkeit wurde Ezechiel Spanheim mit der Erstellung eines Historienbuches über die Entwicklung von Vikariaten in französischer Sprache betraut ${ }^{43}$. Spanheim äußerte sich auf über 300 Seiten, wobei er Vikare in allen Zeitaltern fand, bei den Juden, Persern, Griechen und Römern, im Orient wie im Okzident, besonders aber in der katholischen Kirche. Auch das Reichsvikariat für Italien durch den Herzog von Savoyen wird ausgeführt, von dessen Konstruktion sich allerdings keine Präzedenzwirkung für die Parteien ableiten lie $\beta^{44}$. Schließlich bekräftigte Spanheim die pfälzischen Rechte und wies die bayerischen Ansprüche zurück ${ }^{45}$.

Schon vor Beginn der Vakanz im kaiserlichen Amt hatte der Helmstedter Staatsrechtslehrer Hermann Conring (1606-1681) Texte zur Frage des Reichsvikariats verfasst, auch wenn er nicht öffentlich als Experte für dieses Problem in Erscheinung getreten $w^{4}{ }^{46}$. Auch in anderen die Kurfürsten betreffenden Fragen war Conring tätig geworden, so zugunsten von Kurmainz im Krönungsstreit mit dem Kurfürsten von Köln 1655/56 ${ }^{47}$. Wohl auf Empfehlung des Reichsritters Weyprecht von Gemmingen war der Heidelberger Hof auf Conring aufmerksam geworden ${ }^{48}$. Am 8. Mai 1657, knapp fünf Wochen nach dem Tod Kaiser Ferdinands III., wandte sich Kurfürst

\footnotetext{
41 Ebd., S. 4.

42 „Schließliche Beantwortung Der von Chur Bayrischen Seiten in Truck gegebenen, als genannten Endtlichen abgenötigten Ableinung des Reichs-Vicariats [...] betreffendt«, Heidelberg 1662.

43 [Ezechiel Spanheim (zugeschrieben)] »Discours sur les affaires d'Allemagne et sur le vicariat de l'empire«, o.O. 1657. - Zu Ezechiel Spanheim (1629-1710): DBA I, Fiche 1199, S. 112-122.

44 Zu Savoyen: ebd., S. 121-123.

45 Bekräftigung der kurpfälzischen Rechte: Ebd., S. 169-175; Auflistung der bayerischen Ansprüche: S. 176-194; Zurückweisung der bayerischen Ansprüche: S. 195-205.

46 Vgl. zu Hermann Conring den Sammelband anlässlich seines 300. Todestages: Michael SToLLEIS (Hg.), Hermann Conring (1606-1681). Beiträge zu Leben und Werk, Berlin 1983. Zu Conrings Beratertätigkeit, inbesondere für Herzog August d.J. von Braunschweig-Wolfenbüttel, vgl. den Beitrag von Günter Scheel, Hermann Conring als historisch-politischer Ratgeber der Herzöge von Braunschweig und Lüneburg, S. 271-301.

47 Darauf verweisen Patricia Herberger/Michael Stolleis (Hg.), Hermann Conring, 1606-1681. Ein Gelehrter der Universität Helmstedt. Ausstellung der Herzog August Bibliothek Wolfenbüttel im Juleum Helmstedt, Wolfenbüttel 1981, S. 60.

48 Gemmingen hatte Ende April 1657 einen Empfehlungsbrief für Conring nach Heidelberg geschickt: ARnSwaLdT, De Vicariatus controversia, S. 40f.
} 
Karl Ludwig von der Pfalz brieflich an Conring ${ }^{49}$. Es werde dem Professor schon bekannt sein, so beginnt der Brief, dass der bayerische Kurfürst Ferdinand Maria inzwischen das kurpfälzische Reichsvikariat für sich beanspruche, indem er stipuliere, durch die Kurübertragung von 1623/1648 sei auch das Vikariat an seine Linie des Hauses Wittelsbach übergegangen. Demgegenüber sei der Pfälzer Kurfürst anderer Auffassung: Er beanspruche das Vikariat kraft alten Herkommens, der Bestimmungen der Goldenen Bulle und der innegehabten Privilegien weiterhin für sich. Der Westfälische Friede habe, so schreibt Karl Ludwig, das kurpfälzische Territorium am Rhein völlig restituiert, und so stehe ihm auch das Vikariat wieder zu als ein Teil der rheinpfälzischen Privilegien. Das Recht der kaiserlichen Stellvertretung sei nämlich kein Bestandteil der Kurwürde, die allein an Bayern übergegangen sei. Der Wissenschaftler sollte nun gewonnen werden, ein Rechtsgutachten zugunsten der Pfalz zu verfassen: Wenn ihm noch etwas einfalle, was die Argumentation der Heidelberger Seite stärken würde, dann möge er es bitte schriftlich übermitteln. Der Kurfürst versicherte den Gelehrten schon vorab seiner Dankbarkeit ${ }^{50}$.

Conrings Engagement war keineswegs unumstritten: Der kurmainzische Regierungsrat Johann Christian von Boineburg (1622-1672) ermahnte ihn mehrfach, sich eher auf die kurbayerische als die kurpfälzische Seite zu schlagen. Kurfürst Johann Philipp von Schönborn hatte sich längst auf die bayerische Seite festgelegt. Es sei wegen der konfessionellen Parität im Reich wichtig, so v. Boineburg, dass die beiden Reichsvikare unterschiedlichen Bekenntnissen angehörten. Conring lie $\beta$ sich davon allerdings nicht beeindrucken und blieb bei der einmal begonnenen Verpflichtung. Mit höflichen Worten brachte er zum Ausdruck, dass er sich nicht für die bayerische Perspektive vereinnahmen lasse ${ }^{51}$.

Conrings direkter Antwortbrief nach Heidelberg ist nicht überliefert, ebensowenig wie ein weiteres Schreiben des Kurfürsten. Dagegen liegt Conrings Brief vom 30. Juli/9. August 1657 vor $^{52}$. Conring bedankte sich beim Kurfürsten und bot ihm seine sachkundige Unterstützung an. Schon früher habe er pro defensione iuris Palatini 16 Bögen verfasst, die aber offenbar nicht publiziert worden waren. Dieser »Tractatus« müsse nur noch einmal überarbeitet und aktualisiert werden, wobei besonders auf bayerische Gegen-

49 Zum Brief, der wegen der Kalenderverschiedenheiten Ende April 1657 in München einging: ebd., S. 41.

50 Kurfürst Karl Ludwig von der Pfalz an Prof. Hermann Conring, 28. April/8. Mai 1657 (Konzept): HStA München, Kasten blau, Nr. 100/2, s.p.

51 Zur Korrespondenz zwischen Conring und v. Boineburg: Arnswaldt, De Vicariatus controversia, S. 32-70.

52 Hermann Conring an Kurfürst Karl Ludwig von der Pfalz, 30. Juli/9. August 1657: HStA München, Kasten blau, Nr. 100/2, s.p. 
argumente (obiectionibus) einzugehen sei. Allerdings würde dies seine Zeit benötigen. Conring müsse demnächst im Auftrag seines Landesherrn nach Ostfriesland reisen. Dies werde einige Wochen in Anspruch nehmen. So könne der »Tractatus « erst anschließend überarbeitet werden; das sollte nach der Rückkehr schnell geschehen. Auch auf seine eigene Sicherheit ist Conring bedacht: Er bat den Kurfürsten, über den Frankfurter Reichsdeputationstag $^{53}$ diplomatischen Kontakt zum Herzog von Braunschweig-Wolfenbüttel aufzunehmen, um der Zusammenarbeit eine offizielle Grundlage zu geben. Im Reich des 17. Jahrhunderts war es keineswegs üblich für einen Fürsten, einen Beamten eines anderen Territoriums für sich arbeiten zu lassen. Wenn dessen Landesherr einverstanden war, waren alle Beteiligten auf der sicheren Seite.

$\mathrm{Zu}$ den Sicherheitsmaßnahmen gehörte offenbar auch ein Kurzgutachten, das Conring für den Braunschweig-Wolfenbütteler Kanzler Johann Schwartzkopf (1595-1659) verfasste ${ }^{54}$. Darin führte Conring sieben Argumente für die kurpfälzische und sechs für die kurbayerische Position auf. Er stand in seinem Votum Kurpfalz deutlich näher, weil die Vikariatsrechte bereits vor 1356 von den Pfalzgrafen geführt worden seien, als das Herzogtum Bayern noch gar kein erbliches Reichslehen war. Das Schlussvotum überließ er jedoch höheren Richtern ${ }^{55}$.

Die Korrespondenz zwischen Kurpfalz und Braunschweig-Wolfenbüttel in dieser Angelegenheit ist in der fraglichen Akte im Hauptstaatsarchiv München nicht erwähnt. Auch die weiteren Kontakte zwischen dem Kurfürsten und Conring lassen sich nicht vollständig erhellen. Erst unter dem Datum des 1. Juni 1658 wird ein weiterer Brief der kurpfälzischen Regierung an Conring überliefert ${ }^{56}$. Inzwischen war offenbar der fertige Traktat in Heidelberg eingegangen. Kurfürst Karl Ludwig ließ dem Gelehrten mitteilen, dass ihm der Text unter dem Pseudonym »Andreae Nordenij« [bzw. »Andreas Nordenius $\left.\ll^{57}\right]$ so gut gefallen habe, dass er ihn in Frankfurt drucken lassen wolle. Conring, der gerüchteweise schon als Autor in Reichskreisen gehandelt wurde, möge dazu sein Einverständnis geben. Der Kurfürst rechnete damit,

53 Der Reichsdeputationstag war 1655 zusammengetreten, um die »Negotia remissa« des Jüngsten Reichstags abzuarbeiten. Vgl. zum Verfassungsorgan und seiner wechselvollen Geschichte zwischen 1655 und 1663: Matthias Schnettger, Der Reichsdeputationstag 1655-1663. Kaiser und Stände zwischen Westfälischem Frieden und Immerwährendem Reichstag, Münster 1996.

54 ARnswaldt, De Vicariatus controversia, S. 29.

55 Hermann Conring, Was es mit den Reichs-Vicariaten vor eine Beschaffenheit habe, und wem dieselbige an den Römischen Reich zukommen?, o.O. 1657, abgedruckt in der Ausgabe von Hermann Conring, Opera, hg. v. Johann Wilhelm Goebel, 7 Bd., Braunschweig 1730, hier Bd. 2, S. 463-466. - Auswertung bei: Arnswaldt, De Vicariatus controversia, S. 25-28.

56 Kurfürstliche Regierung Heidelberg an Prof. Hermann Conring, 28. April 1657 (Konzept): HStA München, Kasten blau, Nr. 100/2, s.p.

57 ARnswaldt, De Vicariatus controversia, S. 75. 
dass es Conring "nit zuwider sein werde, das solcher tractat das licht, wie es wol meritiret, durch offen truck sehen möge«. Die Entscheidung darüber war wohl intern schon gefallen, denn Conring wurde aufgefordert, eventuelle Korrekturen oder Zusätze bald einzusenden. Damit war selbstverständlich, dass der Kurfürst die Druckkosten übernahm. Angesichts der Bedeutung des Streitfalls mit Bayern kam es auch auf den Umfang nicht an, und Conring konnte sich gründlich äußern. Die kurpfälzische Regierung sicherte, soweit sie das noch konnte, Diskretion zu: Der Traktat werde unter »Nordenij« publiziert ${ }^{58}$. In dem Schreiben wurde ausdrücklich erwähnt, dass 1652 zwischen Kaiser Leopold I. und Kurfürst Karl Ludwig Kontakte bestanden hatten über die Formulierungen der kurbayerischen Lehnsurkunde. Dabei konnte Kurpfalz verhindern, dass die Vikariatsfrage durch Erwähnung abschließend geregelt wurde. Durch das Fehlen der Passage, die Kurfürst Maximilian I. in seinen Lehnsurkunden von 1628 und 1638 stehen hatte, blieb die Vikariatsfrage in der Schwebe.

»Andreas Nordenius« war übrigens kein Phantasiename: Conring stammte aus Norden in Ostfriesland, und der Apostel Andreas war der dortige Stadtpatron, seine Helmstädter Kollegen und die Wolfenbütteler Regierungsräte entschlüsselten das Pseudonym schnell. Die Schrift Vicariatus imperii Palatinus defensus kam Ende August 1658 gedruckt heraus, nun anonym ${ }^{59}$. Sie umfasste 83 Seiten im Quartformat, sieben Kapitel und einen Quellenanhang. In den ersten beiden Kapiteln stellte Conring die Ausgangslage der Kontroverse dar und skizzierte die konkurrierenden Ansprüche aus den Begründungen in den Vikariatspatenten. Im dritten und vierten Kapitel präsentierte er die Argumente hinsichtlich der Verknüpfung zwischen Kurwürde und Reichsvikariat und widerlegte sie anschließend. Im fünften und sechsten Kapitel erhärtete er den Zusammenhang zwischen Vikariat und Pfalzgrafschaft: Seit Kaiser Friedrich II. dem Staufer habe kein Fürst mehr das rheinische Vikariat innegehabt, der nicht gleichzeitig Pfalzgraf gewesen sei. Daher gebühre Kurfürst Karl Ludwig das Reichsvikariat, auch wenn Conring eine gütliche Vergleichung beider Anwärter unter Beteiligung des Reichstags empfahl ${ }^{60}$.

Die Publikation ging Conring allerdings zu schnell. Mitte Juni 1657 schrieb er an die kurpfälzische Regierung, er sei verwundert, dass der Traktat, den er nur ausgewählten Personen zum Lesen gegeben habe und dessen

[Hermann ConRING], »Vicariatus Imperii Palatinus defensus auctore Andreae Nordenio«, o.O. 1657. Das handschriftliche Konzept für den Text findet sich im HStA München: Kasten Schwarz, Nr. 3421.

59 Arnswald, De Vicariatus controversia, S. 76.

60 [Hermann Conring], Vicariatus imperii Palatinus defensus autore Andreae Nordenio, o.O. 1658, abgedruckt in der Ausgabe von ConRING, Opera, hier Bd. 1, S. 811-836. - Auch das Konzept, 28 Blatt stark, ist im HStA München überliefert: Kasten Schwarz, Nr. 3421. 
Original verschlossen und versiegelt in Helmstedt liege, dennoch schriftlich kursiere und nach Heidelberg gelangt sei - und dazu noch mit Verfasserangabe $^{61}$. Dringend bat er um Wahrung der Diskretion, damit er selbst keine Nachteile durch das Schriftstück erleiden müsse. Conring teilte mit, dass er zur Zeit den Text nicht mit dem Original vergleichen könne, weil er noch vier Wochen in Aurich zu tun habe. Gegen die Publikation erhob er weiterhin keinen Einspruch. Der Name »Nordenij« könne auch entfallen, um gar nicht erst öffentliche Spekulationen über den Verfasser aufkommen zu lassen.

Das weitere Druckverfahren wurde dann nicht mehr im Einzelnen erläutert. Conring erhielt für seinen Dienst zwar kein Geld, aber der Kurfürst erwies sich auf seine Weise erkenntlich: Er ließ den Kammermeister Christian Schlöer einen Pokal im Wert von 40 Rtl. kaufen ${ }^{62}$. Noch ehe der Pokal bei Conring einging, schrieb der Wissenschaftler an die Heidelberger Regierung, dass zwischen dem inzwischen fertigen Druck und der Originalvorlage einige fehlerhafte Unterschiede bestünden. Offenbar hatte die Heidelberger Regierung trotz der Einwände die Erstfassung direkt zum Verleger gebracht. Conring bot an, die Fehler zu verbessern und die richtigen Anhänge beizufügen $^{63}$. Da keine weiteren Briefe in der diesbezüglichen Akte vorliegen, war der Druck damit erledigt. Conring dürfte die Verbundenheit zum Kurfürsten nicht durch weiteres Protestieren strapaziert haben. Dies schien sich insofern gelohnt zu haben, als der Traktat mehr als ein halbes Jahrhundert später, im Vorlauf zu den wittelsbachischen Hausverhandlungen der 1720er Jahre, in einer Neuauflage wiederum zum Vorschein kam: Nun stand der 1681 gestorbene Hermann Conring, völlig befreit von der Drohung durch eventuelle Repressalien, als Autor offen auf dem Druck ${ }^{64}$. Selbst wenn sich Kurpfalz mit seiner Anschauung und Conrings Hilfe in diesem langfristigen Streit nicht durchgesetzt hatte - immerhin hatte das Insistieren auf der eigenen Position den Weg für einen Kompromiss mit Bayern freigemacht, der 1724 vollzogen wurde.

Der Hinweis auf die Fernwirkung von Conrings Publikation dokumentiert, dass in der Zwischenzeit keine Auseinandersetzungen um das Reichsvikariat ausgetragen zu werden brauchten. Die Römische Königswahl Josefs I. von 1690 sowie die Ächtung der bayerischen Wittelsbacherkurfürsten zwischen

61 Hermann Conring an die kurpfälzische Regierung, 14. Juni 1658: HStA München, Kasten blau, Nr. $100 / 2$, s.p.

62 Konzept der dienstlichen Anweisung an SCHLÖER vom 26. August 1658, mit Handzeichen des Kurfürsten »+« beglaubigt: HStA München, Kasten blau, Nr. 100/2, s.p. - Der Pokal wurde Conring allem Anschein nach im Jahr 1660 überbracht: ARNSWALDT, De Vicariatus controversia, S. 100 .

63 Hermann ConRING an die kurpfälzische Regierung, 30. August 1658: HStA München, Kasten blau, Nr. 100/2, s.p.

64 Hermann Conring, Vicariatus Imperii Palatinus defensus, o.O. 1721. 
1706 und 1714 sorgten für Verfahrensklarheit. Insofern stellte die Publikation Gründliche Historische Nachricht von Johann Deckherr (1672-1694) aus dem Jahre 1690, neu aufgelegt 1711, keine Kontroversschrift dar, sondern eine historisch-rechtliche Erläuterung des damaligen Rechtszustands ${ }^{65}$. Deckherr stellt zunächst auf 36 Seiten die früheren Reichsvikariate seit dem 13. Jahrhundert dar. Es folgen 29 Beilagen, die weitere 40 Seiten belegen. Unter diesen Beilagen sind auch mehrere Quellen, die sich auf die Sedisvakanz von 1657/ 58 beziehen, so die Anerkennung des bayerischen Vikariats sowie die Konfirmation der Vikariatshandlungen des bayerischen Kurfürsten Ferdinand Maria durch Kaiser Leopold I ${ }^{66}$.

Auch ohne dass es zu einer Kontroverse gekommen wäre, hatte der pfälzische Kurfürst Johann Wilhelm 1711 eine offizielle Deduktion über sein Reichsvikariatsrecht hinausgehen lassen. Die Kurtze Vorstellung betonte auf 28 Seiten, dass das Vikariat über das Rheinland, Franken und Schwaben bis 1638 unstrittig kurpfälzisch gewesen sei. Anschließend sei aber eine Konfliktsituation entstanden, die durch die Ächtung des Bayernkurfürsten Max Emanuel 1706 wieder zur vorherigen Situation geführt habe. Seitdem sei die Kurpfalz wieder im Besitz von Kurrecht, Erztruchsessenamt und Reichsvikariat ${ }^{67}$. Einmal mehr wurde die kurpfälzische Anschauung wiederholt, das Vikariat hänge von der Rheinpfalz ab, nicht von der Kurwürde ${ }^{68}$. Im Anhang stehen die Notifikations-Patente von 1657 sowie das pfälzische Patent von $1711^{69}$.

Ebenfalls mit historiographischem Interesse legt die Druckschrift Historische Nachricht, die dem Historiker und Bibliothekar Burkhard Gotthelf Struve (1672-1738) zugeschrieben wird, die Problematik des Reichsvikariats

65 [Johann DECKHERR], »Gründliche Historische Nachricht von den von Zeiten Friedrichs II. bis auff den Kays. Leopoldi vorgewesenen Interregnis und in denenselben hergebrachten Vicariaten, deren Verrichtungen und Zufällen«, o.O. 1690; [Johann DECKHERR], »Gründliche Historische Nachricht von denen Interregnis und Vicariaten Teutschen Reiches, deren Verrichtungen und Zufällen, absonderlich soviel die Verwaltung höchster Justiz betrifft«, o.O. 1711. - Zu Johann Deckherr: DBA I, Fiche 224, S. 451-453.

66 Reichskammergericht an Kurfürst Ferdinand Maria von Bayern, 10./20. April 1657: ebd., S. 66f. Das RKG erkennt Ferdinand Maria als den rechtmäßigen Reichsvikar neben dem Kurfürsten von Sachsen an. - Konfirmation Leopolds I. für die kurbayerischen Handlungen als Reichsvikar während der Zeit der Thronvakanz 1657/58, 14. Januar 1659: Ebd., S. 71f.

67 »Kurtze Vorstellung Des Heiligen Römischen Reichs Vicariat, seinem Ursprung binnen währenden Interregno, Und wann ein Römischer König und Kayser mit Tode abgehet oder abwesend und ausser dem Reich sich befindet. Wobey Eine Nachricht von der ehemalig=vorgewesten Strittigkeit zwischen Chur=Pfaltz und Chur=Bayern eben dieses Vicariats halber [...] $\ll$, o.O. 1711, hier S. 4.

68 Ebd., S. 11.

69 Bayerisches Notifikations-Patent, 12. April 1657: »Kurtze Vorstellung«, S. 19-21; Pfälzisches Notifikations-Patent, 6./16. April 1657: Ebd., S. 21-24; Pfälzisches Notifikations-Patent, 22. April 1711: Ebd., S. 26-28. 
auf 49 Seiten $d_{a r}{ }^{70}$. Auch Struve begann in seiner Darstellung mit dem Spätmittelalter. Den Hauptgrund für die jüngeren Probleme sah er darin, dass die Vikariatsfrage im Westfälischen Friedensvertrag nicht ausdrücklich festgesetzt worden war. Den Herleitungsstreit des Vikariats von der Pfalzgrafenschaft (Kurpfalz) oder von der Kurwürde (Kurbayern) stellte er richtig $\operatorname{dar}^{71}$. Beide Seiten hätten ihren Vikariatsantritt öffentlich patentieren lassen, wobei von kurpfälzischer Seite mehrfach bayerische Patente abgerissen worden seien, was Turbulenzen im Kurfürstenrat ausgelöst habe. Der Vikariatsstreit 1657 / 58 wurde faktisch zu Bayerns Gunsten gehandhabt, ein Umstand, der sich auch in der nachträglichen Anerkennung aller Vikariats-Acta von Kurfürst Ferdinand Maria durch Kaiser Leopold I. im Jahre 1659 bekräftigte. Ein rechtlicher Entscheid im Grundsatz aber blieb aus, und so behauptete Kurpfalz seinen Anspruch auch über diese Vakanz hinaus. Anschließend bemühte sich der Straßburger Bischof Wilhelm Egon von Fürstenberg um eine Vermittlung. 1670 setzte er einen Unions-Entwurf auf, nach dem beide Seiten das Vikariat gemeinsam führen sollten ${ }^{72}$. Doch konnte man sich dazu ebensowenig durchringen wie zu einer Alternation des Vikariats. Zeitgleich wurde auch die Frage nach dem italienischen Vikariat diskutiert, was die Situation noch verkomplizierte. Der Verfasser schloss mit dem Hinweis darauf, dass Kurpfalz durch die bayerische Ächtung von 1706 sein altes Recht zurückerlangt habe: »So ist auch dadurch aller Streit völlig gehoben $\aleph^{73}$. An eine mögliche Restitution des Bayernherrschers dachte der Verfasser als Jurist ganz an den Status quo gebunden - dabei nicht mehr, obwohl der Spanische Erbfolgekrieg noch andauerte und sein Ausgang unabsehbar war ${ }^{74}$.

Eine eher didaktisch aufbereitete Abhandlung zur Vikariatsfrage legte Johann Christian Wächtler 1711 vor. In Kurtze Fragen von denen ReichsVicariis gestaltete er 49 Fragen und Antworten zu diesem juristischen Problem $^{75}$. Offenbar ist der kurze, nur acht Blätter umfassende Druck für Studenten im unteren Studienabschnitt bzw. für nichtakademische Interessenten konzipiert gewesen. Er sticht damit stark von juristischen Lehrbüchern ab. Die Interpretation ist pro-pfälzisch: In Frage 10 heißt es: »Woher kommt es

70 [Burkhard Gotthelf STRUVE (zugeschrieben)], »Historische Nachricht von denen Vicariaten des H. Röm. Reiches, wie sie nach Unterschied des Röm., Teutschen und Ital. Reiches unterschieden«, o.O. 1711. - Zu Struve: August Ritter von EISEnHarT, Art. »Burkhard Gotthelf Struve«, in: ADB, Bd. 36, S. 671-676.

$71 »$ Historische Nachricht«, S. 15.

72 Ebd., S. 16.

73 Ebd.

74 Im Anhang sind etliche Quellendokumente aufgeführt: Abdruck des kurpfälzischen Vikariats-Ergreifungspatents vom 23. April 1711: ebd., S. 17-21; Abdruck des kursächsischen Vikariats-Ergreifungspatents vom 22. April 1711: ebd., S. 21-25.

75 [Johann Christian WÄChtLER], »D.J.C.W. Kurtze Fragen von denen Reichs-Vicariis«, Zerbst 1711. 
[=das Vikariat] aber dem Churfürsten von Pfaltz mit besserem Rechte zu?« In Antwort 2 wird dann betont, dass das rheinische Reichsvikariat an der Pfalzgrafschaft hafte, nicht an der Kurwürde.

Mit Eintritt der Vakanz 1740 wurden zunächst die bewährten Klassiker erneut auf den Markt gebracht, allen voran die Gründliche Nachricht von den Reichs-Vicariaten, die Burkhard Gotthelf Struve bereits 1711 geschrieben hatte. Offenbar hatten die Betreiber der Publikation unter Zeitdruck gestanden, denn der Text endete auch mit 1711, ohne dass ein anderer Autor die inzwischen eingetretenen wittelsbachischen Hausvereinbarungen und deren Umstrittenheit nachgetragen hätte ${ }^{76}$.

Eine eigenständige Rechtsgegründete Untersuchung über die Reichsvikariate publizierte Hermann von Wahrenberg $1741^{77}$. Die kurpfälzischen und kurbayerischen Positionen legte Wahrenberg neutral dar: Bayern habe 1657 das Vikariat prätendiert mit dem Argument der Kurtranslation. Darin sei Kurfürst Ferdinand Maria durch Kurmainz, Kursachsen und später auch durch Kaiser Leopold I. anerkannt worden. 1711 sei Kurpfalz unumstritten gewesen. Anschließend stellt Wahrenberg die Wittelsbacher Hausunion in ihren Wirkungen auf das Vikariat vor. Einer breiten Öffentlichkeit wurde nun die Familienvereinigung erstmals bekannt gemacht. Schließlich erwähnt Wahrenberg den Vorschlag eines »Ungenannten«, zugunsten von Bayern eine dritte Vikariatsprovinz im Reich einzurichten ${ }^{78}$. Im Anhang werden die beiden Vikariatspatente von 1740 angeführt.

Der größere Teil des Schrifttums bestand erneut aus offiziellen Verlautbarungen der Regierungen. So wurde die feierliche Eröffnung des gemeinsamen Vikariatshofgerichts in Augsburg durch mehrere Flugschriften kundgetan. Dies hatte eine doppelte Funktion: Zum einen wurden klagewillige Parteien aufmerksam gemacht, an welche Institution sie sich zu wenden hatten. Zum anderen wurden die widerstrebenden Reichsstände durch die Demonstration von der Geschäftigkeit der neuen Einrichtung in Kenntnis gesetzt, d.h. die Kraft des Faktischen schuf sich ihre Normativität ${ }^{79}$. Die Drucke enthielten

76 [Burkhard Gotthelf StRUve], »Gründliche Nachricht von den Reichs-Vicariaten [...]«, Frankfurt a.M./Leipzig 1741; weitere Ausgabe: ders., »Historische Nachricht Von denen Vicariaten des Heil. Röm. Reichs/Wie Sie Nach Unterschied des Römischen/Teutschen und Italiänischen Reiches unterschieden [...]. Von Zeiten Kayser Friedrich des zweyten bis auf Anno 1711 [...] , Frankfurt a.M. 1740.

77 Hermann von WahrenberG, Rechtsgegründete Untersuchung von den Vicariis imperii oder Reichs $=$ Verwesern [...], Regensburg 1741.

78 Vgl. von WaHRENBERG, Rechtsgegründete Untersuchung, §§ 13-16, S. 15-20.

79 »Publication Der Eröffnung des Reichs-Vicariats-Hof=Gerichts in Augsburg, von beyden [...] Churfürsten in Bayern und Pfaltz gemeinsam niedergesetzt«, o.O. 1741; »Publication der Eröffnung deß in der Kaiserl. freyen Reichs-Stadt Augspurg von beyden Durchläuchtigsten Churfürsten in Bayern und Pfaltz niedergesetztes gemeinsamen Reichs = Vicariats-Hof=Gerichts«, Augsburg 1741; »Augspurger Diarium de dato 31. Januarii und 1. Februarii Anno 1741«, Augsburg 1741 . 
jeweils einen Kupferstich. Zudem waren die gemeinschaftlichen Eröffnungspatente angehängt. Alle Personen, die am Vikariatshofgericht eine Funktion ausübten, waren mit ihren richtigen Titulaturen angeführt, um den Schriftverkehr in den Formen der Zeit zu ermöglichen.

Nach der Eröffnung wurde die Verfahrensordnung des Gerichts durch den bayerischen Hofgerichtsagenten Franz Christoph Ludwig von Lang ausführlich in einem Traktat erörtert ${ }^{80}$. Lang ließ zudem den Eid der Richter, den Sessionsplan, den Eid der Agenten, den Wiederabdruck der Reichshofratstaxe von 1659 (die auch den Augsburger Gerichtskosten zugrundeliegen sollte), den Codex titularis der Gerichtsbediensteten sowie einen Nachbericht und eine Errataliste folgen. Die Titulaturen wurden zusätzlich in einer gesonderten Druckschrift publiziert, damit die interessierten Gerichtsparteien sie zum Titulaturbuch in ihrer eigenen Kanzlei hinzufügen konnten ${ }^{81}$. In der Folgezeit waren die das Gericht tragenden Kurfürsten bemüht, die ausufernde Tätigkeit dieses Organs der Rechtspflege in allen Details darzulegen. Mehrere Publikationen mit zusammen mehr als 1.000 Seiten Umfang rückten jeden noch so kleinen Entscheid in Druckform ein, um ihn den kritischen Zeitgenossen zu demonstrieren und gleichzeitig für die Nachwelt zu konservieren $^{82}$.

Flankierend zur Publikationstätigkeit der Gerichtsherren erschienen einige juristische Abhandlungen über die Rechte und Pflichten der Reichsvikare in lateinischer Sprache, insbesondere von Michael Heinrich Gribner $(1682-1734)^{83}$ und Matthias Benjamin Zimmermann (*1706, $\uparrow$ unbek. $)^{84}$. Aus historischer Perspektive ist allerdings eher die Studie von Johann C. König

80 Franz Christoph Ludwig vON LANG, Instruktion und Ordnung des von den [...] Churfürsten in Bayern und Pfalz in [...] Augsburg gemeinschaftlich errichtete [...] Reichs-Vicariat Hof=Gericht, Augsburg 1741. - Zu v. Lang: DBA I, Fiche 734, S. 184-187.

81 »Titulaturen, Tit. Tit. Herren, Herren/Präsidenten=Cantzler/Excellentz, Excellentz/Räthe, Secretarien/und Cantzley $=$ Verwandte Bey dem Reichs $=$ Vicariats-Hof $=$ Gerichts in Augspurg «, o.O. 1741.

82 Anfangsbericht: $»$ Rubra, deren bey dem höchst $=$ preyßlichen Reichs $=$ Vicariats- Hof $=$ Gericht in Augspurg resolvirten Sachen, Febr.-Martium; Continuatio VI per M. Sept. 1741«, Augsburg 1741 (7 S. Umfang über den Zeitraum 3. Februar bis 28. März 1741); »Sammlung einiger merkwürdiger Conclusorum, Welche von einem [...] Reichs $=$ Vicariats-Hof $=$ Gericht zu Augsburg [...] abgefasset worden«, Augsburg 1741 (184 S. Umfang bis zum 16. Oktober 1741); Abschlussbericht: »Conclusa Welche Von einem gemeinsamen Höchst=preyßlichen Reichs=VicariatsHof=Gericht zu Augspurg / Seit Höchst= desselben Eröffnung abgefasset worden [...]«, 2 Bd., Augsburg 1742 (zus. 1360 S.+ Reg.; Druckausgabe der Entscheidungen, die dem neuen Kaiser Karl VII. zur Approbation vorgelegt werden mussten).

83 Michael Heinrich GribnER, Commentario de iuribus vicariorum Imperii, illis in primis, quae perperam a nonnullis in dubium vocantur [...], Leipzig 1743. - Zu Gribner: Zedlers UniversalLexicon, Bd. 11, Sp. 886-889.

84 Matthias Benjamin Zimmermann, Historico-iuridica commentario de vicariatu Sacri Germanico-Romani Imperii ex archi-officiis tradita, Leipzig 1744. - Zu Zimmermann: DBA I, Fiche 141, S. 297. 
über das Reichsvikariat von 1741 interessant, zumal König sein Werk 17431753 erneut in einer Langfassung erscheinen lie $\beta^{85}$. König wollte die reichsrechtliche mit der historischen Perspektive verbinden. Nach einem langen Rückgriff auf das Mittelalter schilderte er den Streit von 1657/58 in abgewogener Weise. In den folgenden Jahrzehnten wurden mindestens fünf Versuche zur Schlichtung der konkurrierenden Ansprüche unternommen, die König alle vorstellte. Auch die Wittelsbacher Hausunion wird im Volltext abgedruckt ${ }^{86}$. Im zweiten Band der dreibändigen Lang-Ausgabe geht König auf die Reaktionen der Reichsstände nach Bekanntwerden der Wittelsbacher Hausunion ein. Dabei erläutert König erst die einzelnen Positionen, um dann eigene Darstellungen der Opponenten abzudrucken ${ }^{87}$.

König weist darauf hin, dass die opponierenden Reichsfürsten unter dem 10. April 1741 ein Promemoria an Kurmainz eingesandt hatten, mit dem sie einen Passus für die neue Wahlkapitulation vorschlugen, durch die der künftige Kaiser zu Reichstagsverhandlungen über den Vikariatsvergleich verpflichtet werden sollte ${ }^{88}$. Auch hier ist die Wittelsbacher Hausunion von 1724 abgedruckt, gefolgt von dem gescheiterten Antrag der Kurpfalz an Kaiser Karl VI. vom 1. Dezember 1724, die Hausunion zu konfirmieren ${ }^{89}$.

Im dritten Teil leitete König bereits zum Interregnum von 1745 über. Um die Schwierigkeiten der vorigen Vikariatszeit nicht zu wiederholen, hatten sich Kurbayern und Kurpfalz 1745 darauf verständigt, diesmal kein gemeinsames Vikariatshofgericht einzusetzen, sondern eine Alternation vorzunehmen. Bayern sollte in diesem Fall beginnen; für die nächste Vakanz war ein Vikariatshofgericht durch Kurpfalz vorgesehen. Johann C. König stellte den Vikariatsvergleich von 1745 vor und schilderte die feierliche Eröffnung des Vikariatshofgerichts in München ${ }^{90}$. Der neuen Regelung haftete dasselbe Problem an wie der alten: Wieder fehlte der eigenmächtigen Vereinbarung der Wittelsbacher die förmliche Zustimmung des Kaisers und der Reichs-

85 Johann C. KöNIG, Gründliche Abhandlung von denen hohen Reichs=Vicariats Gerechtsamen [...], Frankfurt a.M. u.a. 1741 (204 S.+Reg.); ders., Abhandlung derer hohen Reichs-VicariatsGerechtsamen, 3 Tl. in einem Bd., Marburg 1743-1753 (zus. 620 S.).

86 Schlichtungsversuche 1671ff.: KöNIG, Gründliche Abhandlung, §§93-97, S. 152-167. »Wittelsbacher Hausunion« vom 15. Mai 1724: Ebd., §98, S. 168-181.

87 KöNIG, Abhandlung derer hohen Reichs-Vicariats-Gerechtsamen, Bd. 2, S. 34ff. Dabei werden die Positionen von Kurmainz (Bd. 2, S. 34f.), Kurhannover (Bd. 2, S. 35f.), Bamberg und Würzburg (Bd. 2, S. 36-39), Bischof von Augsburg (Bd. 2, S. 39f.), Bischof von Eichstätt (Bd. 2, S. 40f.) sowie dem Herzog von Württemberg (Bd. 2, S. 42f.) verdeutlicht.

88 Ebd., Bd. 2, S. 45f.

89 Text der »Wittelsbacher Hausunion« vom 15. Mai 1724: König, Abhandlung derer hohen Reichs-Vicariats-Gerechtsamen, Bd. 2, § 29, S. 49-64. Kaiserliche Verweigerung der Konfirmation: Ebd., Bd. 2, § 30, S. 64-68.

90 Vikariatsvergleich zwischen Kurbayern und Kurpfalz vom 26. März 1745: KöNIG, Abhandlung derer hohen Reichs-Vicariats-Gerechtsamen, Bd. 3, § 18, S. 13f.; Eröffnungszeremonie des Vikariatshofgerichts in München vom 5. Mai 1745: Ebd., Bd. 3, § 20, S. 17-20. 
stände. Wieder mussten sich die Stände zunächst schicken, um allerdings in der Wahlkapitulation für Kaiser Franz I. den Passus anzubringen, dass eine förmliche Regelung auf dem Reichstag zügig nachgeholt werden sollte ${ }^{91}$. König hatte mit Bedacht lange gewartet, um diese Publikation auf den Markt zu bringen. Es dauerte bis zum August 1752, bevor der Reichstag der Alternation zwischen Kurbayern und Kurpfalz im rheinischen Reichsvikariat seine Zustimmung erteilte. Wenig später erging das kaiserliche Ratifikationsdekret $^{92}$. Anschließend druckte König alle relevanten Aktenstücke ab, die er im Verlauf des dritten Teiles erwähnt hatte. Ein Kommentar ist dazu nicht vermerkt; die juristische Dimension des Druckwerks stand ganz im Vordergrund, nicht die journalistische.

\subsection{Berichte in den Zeitungen}

Für die Zeitungen muss berücksichtigt werden, dass nur ein kleiner Prozentsatz der tatsächlich erstellten Exemplare überliefert ist ${ }^{93}$. Die folgenden Aussagen stützen sich auf diese Überlieferung, wobei aus dem Fehlen von Angaben zu dieser Thematik nicht geschlossen werden kann, dass ein wichtiger Umstand übersehen oder unterdrückt worden wäre.

Der früheste aufgefundene Hinweis auf die Vikariatsdebatte in Zeitungen liest sich in den Ordentlichen Wochentlichen Postzeitungen (= später Frankfurter Postzeitung) des Johann von den Birghden im Jahre 1657 wie folgt:

Auß Heidelberg/vom 20. April. / Nachdem allhier die traurige Zeitung von dem tödtlichen Hintritt der Römisch Keyserl. Maytt. höchstlöbseligster Gedächtnis eingelanget/und aber in der Guldenen Bull Tit. 5 De jure Comitis Palatini, dem Pfaltzgraffen bey Rhein/Ratione Principatus Comitatus Palatini, in den Ländern des Rheins, Schwabens und Fränckischen Rechtens/das Ampt eines Vicarii und Vorwesers im heiligen Reich außtrücklich zugeeignet wird/ solches auch im Münsterischen und Oßnabrüggischen Frieden $=$ Schluß (krafft dessen die Pfaltzgraffschafft bey Rhein/mit allen Geist und Weltlichen Rechten/wie solche Ihr Churfürstl. Durchl. löbliche Vorfahren Christmiltester Gedächtnis vor dem Krieg gehabe/ihro wieder eingeraumt worden/) confirmirt und bestetiget/als seynd höchstermeldt Ihr Churfürstl. Durchl. entschlossen/sich

91 Zur Wahlkapitulation von 1745, Art. III, $\S 18$ u. 19: ebd., Bd. 3, § 24, S. 25.

92 Reichsgutachten, dict. 11. August 1752: ebd., Bd. 3, § 27, S. 28f. Kaiserliches Ratifikationsdekret, 21. August 1752, und Inskribierung desselben in der Dictatur am Regensburger Reichstag, 23. Oktober 1752: Ebd., Bd. 3, § 29, S. $29 f$.

93 Der überlieferte Anteil der Zeitungen für das 17. und 18. Jahrhundert wird auf ca. 10 bis $15 \%$ geschätzt. Vgl. zur Erschließung der Zeitungen in deutscher Sprache: Bogel/BlÜHM, Die deutschen Zeitungen des 17. Jahrhunderts, 3 Bd., pas. Nachträge: Johannes WeBER, Neue Funde aus der Frühgeschichte des deutschen Zeitungswesens, in: AGB 39 (1993), S. 312-360. 
solchen Vicariat-Ampts würcklich zu unterziehen/und selbiges solange zu führen/biß ein ander Häupt im Reich wird geordnet seyn/massen sie zu solchem Ende/dem Herkommen gemäß die gewöhnliche Patent allbereits drucken und so wol allhier/als sonsten im ganzen Land offentlich anschlagen lassen ${ }^{94}$.

Die ganze sprachliche Gestaltung klingt so stark nach einem juristischen Text, dass es sich wohl um den Text des Proklamationspatents oder eine angelehnte Fassung gehandelt haben dürfte, die - naheliegenderweise - die kurpfälzische Rechtsposition beinhaltet. Offenbar lag zu diesem Zeitpunkt die Münchener Sicht der Dinge noch nicht vor. Die Zeitung hätte sonst sicher beide Standpunkte hintereinander eingerückt und damit ihre formale Unabhängigkeit gewahrt.

Die in München erscheinende Mercurii Relation vermeldet unter dem 19. Juli 1658 die Wahl Leopolds I. zum Römischen Kaiser. Zwei Ausgaben später, am 2. August 1658, wird von der Krönungsfeier berichtet, und die verschiedenen Zeremonien werden geschildert. Über das Reichsvikariat vermerkt das Blatt:

So seynd die Strittigkeiten wegen deß Vicariats zwischen Chur Bayrn und Pfaltz verglichen/doch also/daß es bey Chur Bayrn bleiben soll/unnd ist nach der Crönung/welche Chur Cölln verrichtet/vorm Kayserl. Quartier rother und weißer Wein gesprungen/auch guld: und silberne Müntzen außgeworffen worden ${ }^{95}$.

Das Wiener Diarium, erst 1703 gegründet, bekam 1711 erstmals Gelegenheit, zur Frage des Reichsvikariats zu schreiben. Nach Berichten über Krankheit, Tod und Beisetzung Kaiser Josefs I. wurde am 19. Mai 1711 vermeldet, dass Kurfürst Johann Wilhelm seine Vikariatsantrittspatente öffentlich angeschlagen habe ${ }^{96}$. Über die Tätigkeit des Gerichts im Einzelnen sind keine Hinweise aufgefunden worden. Über Wahl und Krönung Karls VI. gibt es hingegen Berichte ${ }^{97}$. Ausführlicher ging die Wöchentliche Relation auf den Vikariatsbeginn 1711 durch Kurfürst Johann Wilhelm von der Pfalz ein und nannte auch gleich einen Fall, der verhandelt wurde. Der Kurfürst ließ seinen Amtsantritt besonders im Hochstift Lüttich verkünden, wo eine kaiserliche Kommissionsregierung die Geschäfte des abgesetzten Wittelsbacher-

94 Frankfurter Postzeitung [Frankfurter Ober-Post-Amts-Zeitung], hg. v. Johann vON DEN BIRGHDEN, Frankfurt a.M. 1615-1866, hier 27. April 1657.

95 Kaiserwahl: »Mercurii Relation, oder wochentliche Reichs Ordinari Zeitungen, von underschidlichen Orthen«, München ca. 1650 - nach 1750, hier Ausgabe 30, 19. Juli 1658; Krönungsfeier: »Mercurii Relation«, Ausgabe 32, 2. August 1658.

96 »Wiener Diarium« (hg. v. GHelen u. Erben), Wien 1703-1779, hier Nr. 813 vom 19. Mai 1711.

97 Kaiserwahl: ebd., Nr. 858 vom 23. Oktober 1711; Kaiserkrönung: ebd., Nr. 876 vom 25. Dezember 1711. 
bischofs Josef Clemens wahrnahm. Nun solle die Kommission ihre Arbeit im Auftrag von Johann Wilhelm fortsetzen. Die Zeitung wies darauf hin, dass das Domkapitel einen Deputierten zum Pfälzer Kurfürsten geschickt habe mit der Bitte, die Regierungsgeschäfte dieser Korporation zu übertragen. Die Wöchentliche Relation stellte nicht die Parallele zur domkapitularischen Administration in Kurköln her, schloss aber eine lange Fußnote zur Lütticher Stiftsgeschichte $\mathrm{an}^{98}$.

Es entsprach der allgemeinen Entwicklung des Zeitungswesens, dass bei Eintritt des nächsten Reichsvikariats 1740 sowohl eine größere Anzahl an Zeitungen vorhanden war als auch eine höhere Intensität der Berichterstattung zu vermerken ist. Der Tod Kaiser Karls VI. wurde im Hamburgischen Avisen-Correspondente, eine der besten Zeitungen des 18. Jahrhunderts, am 1. November 1740 publiziert ${ }^{99}$. Drei Tage später stellte sich die Frage nach dem Reichsvikariat:

Wie man höret, so hat der Churfürst von der Pfalz, so bald er erfahren, daß Ihro Römisch=Kayserl. Majestät mit Tode abgegangen, sofort das Vicariat in den Rheinisch und Schwäbischen Landen, und wo das Fränckische Recht gilt, übernommen; man weiß aber nicht, was der Churfürst von Bayern hierzu sagen wird ${ }^{100}$.

Die Formulierung verdeutlicht, dass der Herausgeber in Hamburg zu dieser Zeit noch keine Kenntnis vom Wittelsbacher Hausvertrag von 1724 besaß.

Viel näher am Ort des Geschehens war naheliegenderweise die Münchener Mercurii Relation mit ihrem Sonderbeilageblatt Extra-Ordinari-Zeitungen. Hier wurde die Öffentlichkeit unterrichtet, dass es 1724 einen Vergleich zwischen Kurbayern und Kurpfalz wegen des Reichsvikariats gegeben hatte $^{101}$. Eine Woche später wurde kundgetan, dass die Patente inzwischen eingetroffen seien. Sie könnten, so die Zeitung, durch die Reichstagsdruckerei in Regensburg bezogen werden. In Bayern und der Pfalz, so der Korrespondent, seien sie allerdings noch nicht ausgehängt ${ }^{102}$.

Inzwischen hatte auch der Hamburgische Avisen-Correspondente diese Neuigkeit erfahren und schrieb dazu: »Die Churfürsten von Bayern und Pfalz sind wegen des Reichs $=$ Vicariats einig geworden, und Bayern hat sei-

98 »Ẅ̈chentliche Relationen« (»Hallische Wöchentliche Relation«, die Einzelhefte heißen 1709/1711 auch: »Wöchentliche Relationen«), Halle a.d. Saale 1709ff.; hier Nr. 21 vom 23. Mai 1711.

99 »Avisen-Correspondente« (auch »Hamburgischer Correspondent« oder mit Langtitel »Aviso. Der Hollsteinische unpartheyische Correspondente. Durch Europa und andere Teile der Welt [...] , Schiffbek, Hamburg 1712-1840, hier Nr. 175 vom 1. November 1740.

100 Ebd., Nr. 177 vom 4. November 1740.

101 Der Vergleich ist mit »19. Mai 1724« allerdings vier Tage zu spät datiert: »Extra-Ordinari-Zeitungen«, o.Nr. vom 26. November 1740.

102 Ebd., o.Nr. vom 3. Dezember 1740. 
nen Gesandten von Regensburg zurückberufen $[. ..] \ll^{103}$. Eine Woche später hieß es, dass das Hofgericht in Augsburg errichtet werden solle; die kurpfälzischen Räte dazu seien bereits ernannt ${ }^{104}$. Die Journalisten hakten nach, als sich herausstellte, dass es für diesen Fall bereits eine länger zurückliegende Vereinbarung zwischen den Wittelsbacher Linien im Reich gab. Am Reichstag drang die Wahrheit durch, auch wenn das den Beteiligten unangenehm war:

Man siehet hier eine Abschrift von dem vereinigten Bündnisse zwischen den beiden letztgemeldeten Churfürsten [=Kurbayern und Kurpfalz], welches, wie es heißt, hat sollen verschwiegen bleiben. Ein Churfürst verspricht dem andern mit 6.000 Mann zu Fuß und 2.000 Reuter, im Fall es nöthig ist, beyzustehen. Trier, Cölln und der Bischof von Freising befinden sich auch in diesem Vertrage, und versprechen, nach Beschaffenheit ihrer Länder, eine gewisse Anzahl Völker [=Soldaten $]^{105}$.

Das Datum der Hausunion von 1724 fehlte noch; der Inhalt könnte aus einer der zahlreichen Flugschriften stammen, die nun umliefen, aber möglicherweise auch durch eine Indiskretion eines Regensburger Sekretärs bekannt geworden sein.

Dass diese Überraschung durch die Wittelsbacher Kurfürsten nicht ohne Echo von Seiten der düpierten Reichsstände passieren würde, konnte sich jeder Kenner der Reichsverfassung vorstellen. Schnell regte sich Widerspruch gegen die neue Wittelsbacher Form des Reichsvikariats. Der AvisenCorrespondente berichtete:

Die Churfürsten von Bayern und Pfalz haben ihre Vicariats=Patente den Ständen in Schwaben, Franken und am Rheinstrom einreichen lassen, aber man zweifelt, ob sie überall angenommen werden durfften, weil die goldene Bulle nicht 3 Vicarios im Reich niedersetzt $[\ldots]^{106}$.

Auch im Jahr 1741 berichtete der Avisen-Correspondente über verschiedene Einzelheiten der Tätigkeit des Augsburger Vikariats-Hofgerichts.

Weniger deutlich schilderten die Berliner Zeitungen den Problemhintergrund der Vikariatsregelung. Die Berlinischen Nachrichten wiesen zwar auf einen Vergleich zwischen Kurbayern und Kurpfalz hin, sahen aber dessen Vereinbarkeit mit der Goldenen Bulle als fraglich $a^{107}$. Die Eröffnung des

$103 »$ Avisen-Correspondente«, Nr. 180 vom 9. November 1740.

104 Ebd., Nr. 184 vom 16. November 1740.

105 Ebd., Nr. 192 vom 30. November 1740.

106 Ebd., Nr. 194 vom 3. Dezember 1740.

107 »Berlinische Nachrichten von Staats- und gelehrten Sachen« [=Spenersche Zeitung], Berlin 1740-1872, hier Nr. 70 vom 8. Dezember 1740. 
Vikariatshofgerichts in Augsburg war ebenfalls eine Meldung wert, wenige Tage später flankiert durch den Abdruck einer gemeinsamen Proklamation der wittelsbachischen Vikare mit stark apologetischem Charakter ${ }^{108}$. Auch die Berlinische privilegierte Zeitung beschrieb die Eröffnung des Vikariatshofgerichts in Augsburg ausführlich, doch deutete der Herausgeber die Regelungen des Doppelvikariats nur zart an. Besonders die Genese des Konflikts und die schließliche Lösung finden sich in den überlieferten Exemplaren der Zeitung nicht näher behandelt ${ }^{109}$.

Dass auch eine klare Darstellung der Hausvereinbarung möglich war, zeigte die Leipziger Zeitung Extract derer [...] eingelauffenen Nouvellen ${ }^{110}$. Am 19. November wurde die zentrale Mitteilung zum Reichsvikariat publiziert:

Die Nachrichten aus dem Reich bekräftigen, daß die Sorge, als ob es wegen des Reichs $=$ Vicariats zwischen Chur $=$ Bayern und Chur $=$ Pfalz einige Mißhelligkeiten setzen würde, völlig verschwunden sey, da man vielmehr gewisse Nachricht habe, daß diese Sache schon im Jahre 1724 zwischen beyden Churfürstlichen Höfen dahin verglichen worden, daß sie einen Vicariats $=$ Rath errichten wollten, der aus einer gleichen Anzahl Räthen bestehen, zu Augspurg zusammen kommen, und die Geschäfte des Reichs $=$ Vicariats in den Landen am Rhein, Schwaben und Fränckischem Rechts und Enden besorgen sollten ${ }^{111}$.

Die Hauptbestimmungen aus dem Hausvertrag von 1724 bezüglich des Vikariats wurden dadurch der Leserschaft in Kurzfassung präsentiert, wenn schon nicht die Patente im Wortlaut eingerückt werden konnten.

Andere Zeitungen, wie das Frankfurter Journal oder die in Hanau erscheinende Europäische Zeitung, brachten die Vikariatsregelung erst mit dem Bericht zur Gerichtseröffnung am 2. Februar $1741^{112}$. Eine ausführliche Schilderung des Prozedere in Augsburg findet sich erneut in der Münchener Sonderausgabe Extra-Ordinari-Zeitungen ${ }^{113}$. Auf den Abschluss der Wirksamkeit des Gerichts durch die erfolgte Kaiserkrönung am 12. Februar 1742 gehen die Zeitungen allerdings nicht (erkennbar) ein.

108 Bericht von der Eröffnung: ebd., Nr. 12 vom 28. Januar 1741; Proklamation der Kurfürsten von Bayern und der Pfalz: Ebd., Nr. 25 vom 28. Februar 1741.

109 »Berlinische privilegierte Zeitung«, begr. durch Johann Andreas RüDIGER, später hg. v. Gotthold Ephraim Lessing [...], Berlin 1721-1778, hier Nr. 20 vom 16. Februar 1741.

$110 »$ Extract derer [...] eingelauffenen Nouvellen«, Leipzig ab 1700.

111 Ebd., Nr. 46 vom 19. November 1740.

$112 »$ Frankfurter Journal« [=»Journal«, auch andere Namen], Frankfurt a.M. ab 1706, hier Nr. 12 vom 10. Februar 1741; »Europäische Zeitung« [=»Hanauischer Mercurius«], hg. v. Justus BöFf, Hanau ab 1701, hier Nr. 14 vom 17. Februar 1741.

113 »Extra-Ordinari-Zeitungen«, o. Nr. vom 18. Februar 1741. 
Nach dem plötzlichen Ableben Kaiser Karls VII. 1745 folgte das nächste Reichsvikariat, und wieder war es offen, wie die Regelung zwischen beiden wittelsbachischen Linien angesichts der schweren Herrschaftskrise in München diesmal ausfallen würde. Wie 1740 drückte die Presse die Unsicherheit direkt aus, etwa die Münchener Zeitungen, die zur Gruppe der Mercurii Relation gehörten. Am 9. Februar 1745 wurde in derselben Zeitung über die Vikariatsfrage Folgendes berichtet:

Bey Hof ist man in Angelegenheiten des Reichs=Vicariats mercklich beschäfftiget; jedoch stehet noch nichts zu vernehmen/wie solches vor diesesmahl werde eingerichtet werden, unerachtet verschiedene Zeitungen bereits allerhand ungegründete Nachrichten davon ertheilen/und unter andern wissen wollen/als ob solches nach Franckfurth zu verlegen resolviret worden, woran man doch wohl am wenigsten gedacht; zugeschweigen, daß wegen Bestellung des Praesidenten und Cantzlers in gewissen Zeitungen eine Nachricht eingelauffen/welche dem bekandten Vicariats=Vergleich schnurstarcks zuwieder ist. Eben so ungegründet ist es/was ein bekandter unvorsichtiger Zeitungs $=$ Schreiber/nebst andern unverantwortlichen Remarquen, auch von der Reise eines vornehmen Ministers nach einem sichern Hofe zu schreiben die Keckheit gehabt. Man tractiret hiesigen Orts die Staats=Angelegenheiten mit dergestaltiger Klugheit und Verschwiegenheit/daß man sich vergebens bemühen würde die Geheimnisse derer Conferentzien zu erfahren. Gleichwohl ist unter der Hand dieser Tage eine dergestaltige Schrifft/deren Absicht leicht zu errathen stehet/unter dem Titul les derniers soupirs de l'Empereur ausgestreuet worden/von welcher jeder Vernünfftiger bey dem ersten Anblick gewahr werden muß/ daß solche zwar von einem sehr niederträchtigen aber desto boßhaffterern Gemüthe entworffen worden/welches sich nicht entblödet hierdurch den unsterblichen Ruhm des Glorwürdigsten Monarchens von der Welt zu verdüstern; Grosse Potentaten unverschämter Weise anzugreiffen/und zwischen denenselben Mißtrauen $\mathrm{zu}$ erregen; höchst $=$ meritirten Ministren aber straffbarer Weise, die ärgsten Schand=Flecke auf eine verleumderische Art anzudichten; durch welches alles der Verfertiger doch in der That nichts anders gethan/als seine Unwissenheit in Staats $=$ Sachen und schlechte Gedenkens $=$ Art; hauptsächlich aber sein vor aller honetten Welt straffbares Genie verrathen zu haben ${ }^{114}$.

Der Gewinn an Umfang bei den Einzelinformationen in den Zeitungen ist klar erkennbar. Auch das Bemühen der Zeitung, Spekulationen in anderen Blättern als unbegründet zurückzuweisen, dürfte sowohl von der Redaktion getragen worden sein als auch von der Münchener Regierung.

Auch der Hamburgische Avisen-Correspondente musste ausweichend berichten. Nach der Mitteilung vom Tod Kaiser Karls VII. ${ }^{115}$ erfährt der

114 »Münchener Zeitungen«, Nr. 12 vom 9. Februar 1745.

$115 »$ Avisen-Correspondente«, Nr. 19 vom 2. Februar 1745. 
Leser 17 Tage später, dass der Münchener Hof »sehr beschäftigt« sei wegen des Reichsvikariats; was er allerdings disponierte, blieb unklar. Man hat den Eindruck, dass der Münchener Korrespondent auf die Vikariatsvariante wartet, die diesmal angewandt werden soll: $»[. .$.$] jedoch ist bis dato nichts gewis-$ ses $\mathrm{zu}$ vernehmen, wie solches diesesmal möchte eingerichtet werden $\aleph^{116}$. Meinungslenkung war das gerade nicht, was die Zeitung vermittelte. Es handelte es sich eher um eine Anspielung, die Nachfragen provozieren sollte: Der unwissende Leser bekam hier Gelegenheit, einzuhaken und sich zu erkundigen, was denn »diesesmal« in diesem Zusammenhang bedeuten sollte. Schon war ein Ansatz zum gemeinschaftlichen Räsonnement der Leserschaft gegeben - und der Zensor konnte gar nichts machen, denn er fand keine anstößige Information im Text, die er hätte streichen lassen können.

Ähnlich anspielungsreich liest sich die nächste Erwähnung des Reichsvikariats. Am 24. Februar stand die sibyllinische Formulierung im AvisenCorrespondente: "Gleichwie das vertrauliche Vernehmen zwischen denen hohen Churfürstl. Häusern, Bayern und Pfaltz, unveränderlich bekannt, eben also ist die Vicariats $=$ Angelegenheit in Richtigkeit gesetzet worden $[\ldots] \ll^{117}$. Nach dieser Lektüre war der Leser, der keine sonstigen Informationen bekam, gewiss nicht schlauer als zuvor. Er wurde es aus dem AvisenCorrespondente auch in den folgenden Wochen nicht, denn das Blatt schwieg zum weiteren Verlauf des Reichsvikariats.

Dabei standen die Berichte für die Presse schnell bereit, wie die interimistische Gerichtsbarkeit denn diesmal ausgeübt werden sollte. Die Münchener Zeitungen vermeldeten am 16. Februar, dass das Modell des gemeinschaftlichen Reichsvikariatshofgerichts, das 1740-42 praktiziert worden ist, auf Widerstand gestoßen sei und diesmal nicht aktualisiert würde. Beide Linien des Hauses Wittelsbach hätten sich, so die Zeitung, auf eine Alternation geeinigt, und Kurbayern übernähme für dieses Mal die Aufgabe. Das Gericht tagte folgerichtigerweise auch in München. Ein diesbezügliches Mandat wurde für bald in Aussicht gestellt ${ }^{118}$. Auch die Berlinische Zeitung bot nach der dreiteiligen Berichterstattung über den Tod Karls VII. ${ }^{119}$ die richtige Interpretation der künftigen Vikariatsgerichtsbarkeit. Am 27. Februar schrieb die Zeitung, bezugnehmend auf einen Korrespondentenbericht aus München:

116 Ebd., Nr. 29 vom 19. Februar 1745.

117 Ebd., Nr. 32 vom 24. Februar 1745.

$118 »$ Münchener Zeitungen«, Nr. 14 vom 16. Februar 1745.

119 Der Tod Kaiser Karls VII. ist der Zeitung allein drei Berichte wert, wobei zunächst die Tatsache, dann die letzten Dispositionen des Kaisers und in der dritten Meldung schließlich der medizinische Krankheitsverlauf vermittelt werden: »Berlinische Zeitung«, Nr. 13, 15, 16 vom 30. Januar, 4. und 6. Februar 1745. 
Endlich ist die Vicariats = Angelegenheit glücklich zu Stande gebracht worden, da sich die beyden Chur=Häuser, Bayern und Pfaltz, dergestalt miteinander verglichen haben, daß sie in Zukunft das Vicariat wechselweise führen wollen. Unser Durchl. Landes $=$ Fürst $[=$ der Kurfürst von Bayern $]$ macht für dieses mal den Anfang, es allein $\mathrm{zu}$ führen. Es werden daher die Vicariats $=$ Patente mit ehestem publiciret, und die Sessiones dieses hohen Gerichts in hiesiger Residenz eröfnet werden ${ }^{120}$.

In Berlin wurden auch Details zum Gericht bekanntgegeben. Die Berlinische Zeitung schrieb: »Es verlautet, daß die meisten Glieder des anzustellenden Vicariats $=$ Gerichts aus dem vorigen Reichs $=$ Hofraths $=$ Collegio genommen werden sollen, dessen mehreste Glieder sich anjetzo zu Augsburg aufhalten ${ }^{121}$. Eine Ausgabe später wird der 19. März als Eröffnungstag für das Vikariatshofgericht annonciert. Unter dem Vorsitz des Präsidenten Graf Truchseß von Waldburg, der schon das vorige Augsburger Vikariatshofgericht geleitet hatte, sollten acht Assessoren amtieren ${ }^{122}$. Dann dauerte alles doch noch länger, als vorgesehen. Am 22. Mai kam die Zeitung auf das Thema »Reichsvikariat« zurück und schilderte, dass die Eröffnung des Vikariatshofgerichts erst am 3. Mai 1745 in München stattgefunden habe. Der zeremonielle Ablauf wurde dargestellt, und dabei wurde nicht vergessen, aus der öffentlichen Proklamation auf den Passus zu verweisen, dass Kurbayern und Kurpfalz für dieses Mal und für die Zukunft vereinbart hätten, im Vikariat für das schwäbische Rechtsgebiet im Reich zu alternieren ${ }^{123}$.

$\mathrm{Zu}$ einer der ersten Amtshandlungen des Vikariats-Hofgerichts gehörte das Verbot einer Schmähschrift. Die Münchnerische Ordinari Post=Zeitungen schrieb darüber:

Nachdemjüngsthin bey hiesigen höchsten Reichs $=$ Vicariats $=$ Hof $=$ Gericht ein Impres sum unter dem Titul »Austria prodita « zum Vorschein gekommen; als ist dise ganz unbesonnene und ärgerliche zumahl wider den hohen Häuptern und Staats=Ministris schuldigen Respect sehr gröblich anstossende/ und dem Authori, als einer Privat=Persohn zu desto grösserer Verantwortung gereichende Schmach=Schrifft Authoritate Supremi Vicariatus per Conclu[su]m d.d. 26. huius nicht nur confiscirt/sondern auch dessen weitere Druck und Divulgation bey Straff fünff Marck löthigen Golds verbotten/sohin diese Verordnung zu Jedermanns Wissen und Wahrnung in die offentliche Zeitungs $=$ Blätter zu setzen gnädigst anbefohlen worden ${ }^{124}$.

120 Ebd., Nr. 25 vom 27. Februar 1745.

121 Ebd., Nr. 32 vom 16. März 1745.

122 Ebd., Nr. 33 vom 18. März 1745.

123 Ebd., Nr. 61 vom 22. Mai 1745.

$124 »$ Münchnerische Ordinari Post=Zeitungen«, Nr. 4 vom 27. Januar 1745. 
Die weitere Tätigkeit des Vikariatsgerichts verlief ohne die Produktion von Schlagzeilen. Nur im Avisen-Correspondente wurde das Thema Reichsvikariat noch einmal kurz nach der Kaiserwahl Franz Stefans von Habsburg-Lothringen angeschnitten. Der Redakteur verwies darauf, dass Kurpfalz gegen die Wahl protestiert habe, das eigene Vikariat aufrechterhalten wolle (obwohl Bayern vereinbarungsgemäß diesmal »dran« gewesen sei), und sogar der Aachener Deputation, die die Reichskleinodien nach Frankfurt transportieren wollte, die militärische Bedeckung durch Jülicher Gebiet verweigert habe ${ }^{125}$.

Nach den erbitterten Fehden um das kurbayerische und kurpfälzische Recht am Vikariat stellte sich auf dem Medienmarkt zu dieser Frage gewohnheitsmäßige Geschäftigkeit ein: Zwar gab es, so wurde dem Leser vor Augen gestellt, im Hintergrund immer wieder Reibungen um Beteiligung und korrekte Ausführung der Gerichtsbarkeit, doch wurde jeweils durch faktische Einsetzung einer Kammer die Handlungsfähigkeit in jedem Fall demonstriert. Durch die Presseberichterstattung konnten Klageinteressenten schnell und präzise in Erfahrung bringen, an welcher Stelle sie ihr Recht zu suchen hatten.

\subsection{Berichte in den Zeitschriften}

Da es während der Thronvakanz 1657/58 noch keine historisch-politischen Zeitschriften in Deutschland gab, ist dieser Zusammenhang allenfalls aus der historischen Rückschau dokumentiert worden. Mit dem Vikariat 1711 befasste sich Andreas Stübel in seinem Staats $=$ Sekretarius $^{126}$. Er vermittelte seiner Leserschaft, dass die Tatsache der Ächtung von Josef Clemens von Köln und Max Emanuel von Bayern eine Entspannung im Vikariatsstreit zur Folge habe. Kurfürst Johann Wilhelm von der Pfalz hatte sich zuvor wieder mit der alten, fünften Kur belehnen lassen, das Reichserztruchsessenamt angetreten und übte nun ganz selbstverständlich die Rechte seiner Vorfahren als Reichsvikar aus. Stübel hatte seine Zeitschrift in Gestalt einer Briefsammlung organisiert und in jedem »Brief« einen zeitgenössischen politischen Sachverhalt untersucht. In Expedition 6, Brief 64, brachte er einige Wiederholungen über die Geschichte des Reichsvikariats, erläuterte die Funktion und ging besonders auf die früheren Streitigkeiten in der Interpretation zwischen den Wittelsbacherlinien ein ${ }^{127}$. Dabei ließ Stübel auch dramatisierende

$125 »$ Avisen-Correspondente«, Nr. 154 vom 25. September 1745.

126 [STÜBEL], »Der mit allerhand Staats=, Friedens $=$, Kriegs $=$, Hof =, Literatur $=$ und Religions $=$ wie auch Privat $=$ Affairen beschäftigte Secretarius $[\ldots] \ll$.

127 Ders., »Staats-Secretarius«, Bd. 1, Expedition 6, Brief 64, S. 524-536. 
Wendungen nicht aus. Bei einer der Verhandlungen um das strittige Reichsvikariat nach 1648 sei der Pfälzer Kurfürst Karl Ludwig mit einem kurbayerischen Gesandten verbal so hart zusammengestoßen, dass der Kurfürst voller Zorn dem Bayern ein Tintenfass an den Kopf geworfen haben soll, weil dieser auf dem Standpunkt seines Herrn bestanden habe ${ }^{128}$. Da die Zeitschrift erst ein Jahr alt war, nutzte Stübel die Gelegenheit, seinen Lesern den formalen Ablauf einer Kaiservakanz zu erläutern ${ }^{129}$.

Ausführlicher und auch im historischen Längsschnitt konnten die Europäische Fama und später die Neue Europäische Fama die Entwicklung der Reichsvikariate 1711, 1740/41 und 1745 beobachten ${ }^{130}$. Das 1702 gegründete Periodikum näherte sich der Thematik fast beiläufig und ohne Aufgeregtheit, für die es auch 1711 gar keinen Anlass gegeben hätte. Zunächst bezeichnet es - in ganz barocker Manier - den frühen Tod Kaiser Josefs I. als göttlichen Fingerzeig: »[...] wir können diesen grossen Verlust [ $=$ den Tod des Kaisers] nicht anders, als unsern überhäuften Sünden zuschreiben, wodurch wir augenblicklich zu einem krancken Leibe ohne Haupt geworden seynd $\aleph^{131}$. Dann erwähnt der Redakteur einen Versuch des Reichshofrats, durch die Vikare Kursachsen und Kurpfalz als Vikariatshofgericht beauftragt zu werden - die Akten seien doch ohnehin in Wien, so dass Kontinuität praktischer sei als Neubeginn. Die beiden Vikariatshöfe wiesen den Vorschlag umgehend zurück. Eine derartige Regelung hätte auch kaum die Zustimmung des Reichstags gefunden ${ }^{132}$. Ebenso wie die Hallische Wöchentliche Relation erwähnte die Europäische Fama, dass das Lütticher Domkapitel einen Antrag auf Zulassung der eigenen Stiftsregierung gestellt habe, um die kaiserliche Sequestrationskommission abzulösen, die nach der Flucht von Kurfürst Josef Clemens ins französische Exil eingerichtet worden war. Kurfürst Johann Wilhelm von der Pfalz verbot umgehend die Regierungsergreifung des Domkapitels und kündigte seine eigene Administration als Reichsvikar $\mathrm{an}^{133}$. In den weiteren Heften des Jahrgangs 1711 spielte das Reichsvikariat keine Rolle mehr, während die Wahl und die Krönung Kaiser Karls VI. als höfische Zentralereignisse des Barock detailliert geschildert wurden ${ }^{134}$.

128 Ebd., S. 528f. - Stübel bezieht sich dabei auf die Verhandlungen zur Wahlvorbereitung für Leopold I., die Episode fand in Frankfurt a.M. statt: Vgl. Matthias Schnettger, Der Wahltag aus der Perspektive des Frankfurter Rats. Das Beispiel 1657/58, in: Evelyn BrockHOFF / Michael MatthäUs (Hg.), Die Kaisermacher. Frankfurt am Main und die Goldene Bulle, Frankfurt a.M. 2006, S. 252-261, hier S. 253.

129 STÜBEL, »Staats-Secretarius«, Bd. 1, Expedition 6, Brief 64, S. 532f.

130 Europäische Fama; Neue Europäische Fama.

131 Europäische Fama 10 (1711), H. 115, S. 509.

132 Ebd. 10 (1711), H. 116, S. 592.

133 Ebd. 10 (1711), H. 117, S. 685.

134 Kaiserwahl Karls VI. am 12. Oktober 1711: ebd. 11 (1711), H. 122, S. 92-108; Krönung Karls VI., 22. Dezember 1711: ebd. 11 (1711), H. 125, S. 363-392. 
Ausführlicher, weil strittig zwischen den Reichsständen, wurde das süddeutsche Vikariat 1740/42 behandelt. Offenbar unter Zeitdruck erhielt der Herausgeber der Neuen Europäischen Fama die Mitteilung vom Tod Kaiser Karls VI. und damit vom Eintritt der Sedisvakanz im kaiserlichen Amt. Er wies darauf hin, dass die Patente für die Einrichtung des Vikariats-Hofgerichts bereits unter dem 30. Oktober 1740 ausgestellt worden seien. Die Texte wurden für das nächste Heft in Aussicht gestellt und dort auch tatsächlich im Wortlaut publiziert ${ }^{135}$. Wichtiger aber war für die Leser, dass der Inhalt der Wittelsbacher Hausunion von 1724 bekanntgemacht wurde. Wer in den Zeitungen die wichtigsten Bestimmungen schon erwähnt gefunden hatte, konnte in der Neuen Europäischen Fama nun den gesamten Wortlaut auf 10 Druckseiten (im Engdruck) nachlesen ${ }^{136}$. In der Einführung zu diesem Quellentext wurden auch die Bedenken erwähnt, die einige fürstliche Reichsstände, allen voran Württemberg, gegen die eigenmächtige Neuerung vorbrachten. Nicht nur, weil der schwäbische Herzog im Einzugsbereich des Hofgerichts lag, sondern auch aus standespolitischen Gründen forderte seine Regierung die Befassung des Reichstags mit dieser Frage ${ }^{137}$. Der Verfasser der Passagen in der Zeitschrift ließ ganz deutlich werden, dass die beiden Wittelsbacherhöfe sich in der Defensive befanden: Sie beriefen sich auf eine Anregung Leopolds I. und beteuerten, sich die kaiserliche Bestätigung demnächst erteilen $\mathrm{zu}$ lassen ${ }^{138}$. Auf weitere fürstliche Bedenken wurde auch später noch einmal verwiesen, allerdings ohne die protestierenden Fürsten beim Namen zu nennen. Ob dabei politische Rücksichtnahmen eine Rolle spielten, blieb dahingestellt. Neben der neuen Dreizahl der Vikare gab es auch Proteste gegen die konfessionelle Zusammensetzung des wittelsbachischen Vikariatshofgerichts $^{139}$.

Anfang 1741 schilderte die Neue Europäische Fama die feierliche Eröffnung des Vikariats-Hofgerichts in Augsburg ausführlich ${ }^{140}$. Interessanter ist, dass die Zeitung bereits informiert war über die künftigen Pläne der Wit-

135 Ankündigung: Neue Europäische Fama 6 (1740), H. 65, S. 405; kursächsisches Patent über die Einrichtung des Vikariats-Hofgerichts vom 24. Oktober 1740: ebd. 6 (1740), H. 66, S. 455459; kurbayerisch-kurpfälzisches Patent über die Einrichtung des Vikariats-Hofgerichts vom 30. Oktober 1740: Ebd., S. 459-463.

136 Ebd. 6 (1740), H. 66, S. 466-475.

137 Ebd. 6 (1740), H. 66, S. 463-466. - Württemberg gehörte zu den Ständen, die die »kurfürstliche Präeminenz« abzuschleifen versuchten oder selbst zu Kurfürsten aufsteigen wollten: Axel Gotthard, Säulen des Reiches. Die Kurfürsten im frühneuzeitlichen Reichsverband, 2 Bd., Husum 1999, bes. Bd. 2, S. 750-840. Zu den Kurfürstenambitionen Württembergs: Ludolf Pelizaeus, Der Aufstieg Württembergs und Hessens zur Kurwürde 1692-1803, Frankfurt a.M. u.a. 2000.

138 Abdruck des Zirkularschreibens der beiden Regierungen in München und Heidelberg: Neue Europäische Fama 6 (1740), H. 69, S. $727 f$.

139 Ebd. 6 (1740), H. 69, S. 728-731.

140 Ebd. 6 (1741), H. 68, S. 643-650. 
telsbacher, bei anhaltendem Widerstand einiger Reichsfürsten das VikariatsHofgericht zwischen beiden Linien alternieren zu lassen. Allerdings gehe es augenblicklich erst einmal um die Anerkennung für dieses Mal. Einige Altfürsten opponierten allerdings weiterhin. Auch gab es Widerspruch gegen das doppelte Vikariatssiegel ${ }^{141}$. Über die weitere Gerichtsarbeit findet sich in der Neuen Europäischen Fama kein Hinweis, nur die kurze Erwähnung, dass das Gericht durch die Ernennung eines neuen Reichshofrats durch Kaiser Karl VII. abgedankt wurde ${ }^{142}$.

So konnte die Zeitschrift ihre Leser zwar im Januar 1745 mit dem plötzlichen Tod Kaiser Karls VII. überraschen, nicht aber mit dem Hinweis auf den neuen Modus des süddeutschen Reichsvikariats ${ }^{143}$. Die beiden Patente Kursachsens und Kurbayerns über die Errichtung der Vikariatshofgerichte wurden komplett eingerückt ${ }^{144}$. Erneut war die Eröffnung des Münchener Vikariatshofgerichts am 30. April 1745 eine Notiz wert, während sich die weitere Tätigkeit des Gerichts bis September desselben Jahres im Stillen vollzog ${ }^{145}$. Dieselben Berichtselemente (Alternationsmodus, Antrittspatente und Eröffnungsfeier) finden sich auch im Leipziger Europäischen Staats-Secretarius, ohne dass dieses Periodikum sich durch weiterführende Informationen oder Kommentare hervorgetan hätte ${ }^{146}$.

\subsection{Berichte in den Historienwerken und juristischen Textsammlungen}

Der Konflikt um das Reichsvikariat 1657/58 fand in den Historienschriften der Folgezeit ausführliche Erörterung. Die Verfasser konnten sich dabei vor allem auf die publizierten Deduktionen der Parteien, die Traktate anderer Autoren sowie die Zeitungserwähnungen stützen. Auf letztere wurde allerdings kaum zurückgegriffen, da sie nur kurz waren und wirklich brisante Zusammenhänge aus Gründen des geringen zeitlichen Abstands vom Geschehen noch kaum erkennen konnten. Im ersten Band des Diarium Europaeum ist davon die Rede, ein »sehr gefährlicher Streit« zwischen beiden

141 Zu den Plänen einer Alternation: ebd. 7 (1741), H. 75, S. 185f. - Zum Widerspruch gegen das doppelte Vikariats-Siegel: ebd. 7 (1741), H. 76, S. 272-274.

142 Ebd. 7 (1741), H. 82, S. 839f.

143 Hinweis auf den Tod Karls VII.: ebd. 10 (1745), H. 117, S. 766. - Über den Alternationsmodus und den Beginn durch Kurbayern: ebd. 10 (1745), H. 117, S. 766.

144 Kursächsisches Patent vom 26. Januar 1745: ebd. 10 (1745), H. 117, S. 766-771; kurbayerisches Patent vom 16. März 1745: Ebd., S. 1009-1013.

145 Ebd. 10 (1745), H. 117, S. 1006.

$146 »$ Europäischer Staats-Secretarius, welcher die neuesten Begebenheiten unpartheyisch erzehlet und vernuenftig beurtheilet [...]«, 144 H. in 12 Bd., Leipzig 1734-1748, hier Bd. 9, H. 105, S. 779-787. 
Linien des Hauses Wittelsbach sei ausgebrochen. Nicht nur rissen beide Seiten die Vikariatsplakate der jeweils anderen ab, sondern es war sogar die Rede von Rüstungen ${ }^{147}$. Im Folgenden wurden die Antrittspatente eingerückt, ebenso die Widerspruchspatente vom 12. Mai und 12. Juni 1657 sowie weitere offizielle Verlautbarungen ${ }^{148}$.

Im achten Band des Theatrum Europaeum wurde das 1657 eingetretene Reichsvikariat kurz abgehandelt, indem die Redaktion die Stiftung der achten Kurwürde 1648 und die Unbestimmtheit der Frage des früheren pfälzischen Vikariats erwähnte. Das Theatrum führt die Argumente der Flugschrift Kurtzer und Summarischer Bericht zugunsten der Kurpfalz auf ${ }^{149}$. Es folgte ein Schreiben des sächsischen Kurfürsten an seinen Heidelberger Amtskollegen, indem der Wettiner mitteilte, den bayerischen Anspruch anzuerkennen ${ }^{150}$. Kursachsen habe, so die Argumentation, ein Interesse an einer pro-bayerischen Auslegung des Streits, denn 1547 sei die sächsische Kurwürde ebenfalls mitsamt dem Vikariatsrecht von der ernestinischen an die albertinische Linie des Hauses Wettin übergegangen ${ }^{151}$.

Im zeitlichen Abstand von über dreißig Jahren erschien 1688 der Deutsche Herold, ein Historienwerk in der Herausgeberschaft von Friedrich Leuthoff von Franckenberg - hinter dem Namen verbarg sich der Jurist Bernhard von Zech ${ }^{152}$. Der Verfasser erinnert an den Vikariatsstreit vor dem DreiBigjährigen Krieg, als Herzog Maximilian von Bayern seinen Regierungssekretär und Archivar Christoph Gewold (1556-1621) eine Deduktion über das bayerische Recht an der Kurwürde schreiben ließ. Die Ansprüche wurden von dem kurpfälzischen Rat Marquard Freher (1565-1614) widerlegt ${ }^{153}$. Die Abwicklung des Konflikts 1657/58 wurde nur kurz gestreift, wobei der

147 Diarium Europaeum, Bd. 1 [hg. v. Martin Meuren], »Philemeri Irenici Elisii Diarium Europaeum insertis actis electoriis Oder Kurtze Beschreibung denkwürdigster Sachen/So sich in Fried $=$ und Kriegs $=$ Geschäfften in Europa [...] vom Jahre 1657 [...] begeben haben«, [5 Bd.], Frankfurt a.M. 1659ff.(-1661), hier Bd. 1, S. 73.

148 Öffentliches Patent der Kurpfalz vom 6. April 1657: ebd., Bd. 1, S. 69-71; Hinweis auf das öffentliche Patent Kurbayerns: Ebd., S. 71; öffentliches Patent der Kurpfalz gegen das - angemaßte - bayerische Vikariat vom 12. Mai 1657: Ebd., S. 87f.; öffentliches Patent Bayerns gegen das - angemaßte - kurpfälzische Vikariat vom 12. Juni 1657: Ebd., S. 310-312.

149 Theatrum Europaeum, Bd. 8 [hg. v. Martin Meyer], Irenico-Polemographiae Continuatio I. Das ist/Der Historisch fortgeführten Friedens $=$ und Kriegs $=$ Beschreibung Zweyter= Oder/deß Theatri Europaei Achter Theil [...], Frankfurt a.M. 1667, S. 6-8.

150 Brief Kursachsen an Kurpfalz, 7. Mai 1657: ebd., Bd. 8, S. 8f.

151 Das »Theatrum Europaeum« verweist auf eine diesbezügliche Deduktion: ebd., Bd. 8, S. 43.

152 Friedrich Leuthoff von Franckenberg [=Bernhard von ZeCH], Der europäische Herold, Oder Zuverläßige Beschreibung Derer Europäisch-Christlichen Kayserthums, Königreiche, freier Staaten und Fürstenthümer [...], Nürnberg 1688.

153 Ebd., S. 91; [Christoph Gewold], Commentarius de Sacri Romani Imperii Septemviratu, München 1616; vgl. dazu Andreas Kraus, Maximilian I. Bayerns großer Kurfürst, Graz u.a. 1990, S. 69 u. 117f. - Zu Gewold: DBA I, Fiche 389, S. 147-154; DBA II, Fiche 445, S. 293-295. - Zu Freher: Rudolf HoKe, Art. »Marquard Freher (1565-1614)«, in: HRG² 1, Sp. $1714 \mathrm{f}$. 
Ausgang ungewiss blieb. Zech schrieb nur, der Streitpunkt sei in suspensum gesetzt worden ${ }^{154} .1705$ erschien der Europäische Herold in einer stark vermehrten Ausgabe und füllte zwei Folianten. Wieder wurde kurz auf den Streit 1657/ 58 rekurriert. Diesmal fanden sich sowohl die kurpfälzischen als auch die bayerischen Begründungen. Auch folgte der Hinweis, dass Kaiser Leopold I. 1662 die kurbayerischen Acta als rechtmäßig anerkannte ${ }^{155}$. Der konkrete Anlass für die Neuauflage dürfte mit dem Tod Kaiser Leopolds I. zusammenhängen. Die Passage zum Reichsvikariat hatte dabei nur eine Erinnerungsfunktion, denn wegen der 1690 erfolgten Wahl Erzherzog Josefs zum Römischen König trat keine Vakanz und auch kein Vikariat ein.

Ohne Kommentare finden sich einige Deduktionen aus den Jahren 1657 / 58 auch in dem Quellenband, den Johann Christian Lünig 1716 unter dem Titel Grundveste europäischer Potenzen Gerechtsame herausgab ${ }^{156}$. Ausführlich kommentiert wurde die Vikariatsfrage hingegen in Johann Ehrenfried Zschackwitz' Einleitung zu denen vornehmsten Rechts $=$ Ansprüchen, eine rechtshistorische Abhandlung in drei Bänden über politisch-dynastische Ansprüche der europäischen Könige und großen Souveräne. Der historische Hergang der Kurübertragung wurde korrekt wiedergegeben, es folgten die Anspruchsbegründungen von Kurbayern und Kurpfalz ${ }^{157}$. In seinen Kommentaren dazu neigte Zschackwitz zur kurpfälzischen Ansicht, dass das Vikariat zum Pfalzgrafenamt und nicht zur Kurwürde gehöre. Zschackwitz führte auch den Ulmer Konvent von 1670 auf, als beide Wittelsbacher Kontrahenten unterschiedliche Kompromissvorschläge diskutierten:

1. Teilung des Vikariats zwischen Bayern und Pfalz.

2. Alternation des Vikariats zwischen beiden Anwärtern.

3. Wahrnehmung des Vikariats in beider Namen.

4. Einrichtung eines gemeinschaftlichen Vikariats-Kollegiums, das die Rechtsprechung durchführen sollte.

Zschackwitz kommentierte: »Allein bey jedem Punkte fanden sich allerley Schwierigkeiten, so dass endlich die gantze conferenz fruchtlos ablieffe,

154 Franckenberg, Der europäische Herold (1688), S. 91.

155 Friedrich Leuthoff von Franckenberg [=Bernhard von ZeiL], Europäischer Herold, Oder Zuverläßige Beschreibung Derer Europäisch-Christlichen Kayserthums, Königreiche, freier Staaten und Fürstenthümer [...], 2 Bd., Leipzig ${ }^{2} 1705$, hier Bd. 1, S. 161f.

156 LÜNIG, Grundveste europäischer Potenzen Gerechtsame, 2 Tl., Leipzig 1716. Im Einzelnen handelte es sich um »Summarischer Bericht« (1657), »Chur=Bayerischer Gegen=Bericht" (1657), »Churpfältzische Ableinung« (1657), »Chur=Bayerische fernere Anzeigung« (1657) und »Churpfältzische Abfertigung der Chur=Bayerischen ferneren Anzeigung « (1658).

157 Johann Ehrenfried Zschаскwiтz, Einleitung zu denen vornehmsten Rechts=Ansprüchen, Derer Gecrönten Hohen Häupter und anderer Souverainen in Europa [...], 3 Bd., Frankfurt a.M. u.a. 1733-1735, hier Bd. 1, S. 497-501. 
wobey es auch also verblieben ${ }^{158}$. Trotz der intensiven Befassung mit dieser und anderen Materien zum Reichsrecht taucht der Wittelsbacher Hausvertrag von 1724 nicht auf, ein Zeichen dafür, dass er offenbar wirkungsvoll geheimgehalten werden konnte.

\subsection{Zusammenfassung}

Auf den ersten Blick könnte es scheinen, die Frage des Reichsvikariats sei eine innere Angelegenheit der hohen Reichsverwaltung gewesen, die allenfalls etwas mit den Kurfürsten und den betroffenen Reichsinstitutionen zu tun gehabt hätte. Die Staatstheoretiker mochten sich den Kopf darüber zerbrechen, ob das Reich in Zeiten der kaiserlichen Vakanz noch eine Monarchie gewesen sei oder eine andere Staatsform darstellte ${ }^{159}$. Für die Reichsuntertanen waren derartige Debatten ohne Belang. Die öffentliche Dimension ergab sich hingegen aus der inzwischen eingetretenen Entwicklung der Obersten Rechtssprechung im Reich, die sich bereits im Laufe des 16. Jahrhunderts als Appellationsinstanz für alle Reichsuntertanen herausgebildet hatte, deren Landesherren über keine Befreiung von der Reichsgerichtsbarkeit verfügten (Privilegia de non appellando) ${ }^{160}$. Diese Mehrheit der Reichsuntertanen musste im Falle der Vakanz im kaiserlichen Amt unterrichtet werden, an wen sie sich bei Rechtsstreitigkeit zu wenden hatte. Daher erfolgte eine öffentliche Patentierung durch die beiden Reichsvikare, und daher waren Konflikte um die Zuständigkeit öffentliche Angelegenheiten ersten Ranges: Nur das »richtige« Vikariatsgericht konnte rechtswirksame Urteile fällen, daher benötigten die Betroffenen Klarheit.

Das Reichsvikariat konnte wegen seines nur sporadischen Eintretens keine Kontinuität in der Berichterstattung erfahren. Der Schwerpunkt der überlieferten Texte lag auf den Deduktionen der Parteien: Ihre juristischen Verfasser machten sich mit der Entwicklungsgeschichte vertraut und verfochten die jeweilige Interpretation ihrer Landesherren. An mehreren Stellen wurden bereits öffentlich bekannte politisch-juristische Sachverhalte als »reichs = kündig « bezeichnet, die Formel für die bereits eingetretene Durchbrechung des Arkanums. Eine andere Formel betraf »unerfahrne Leuthe«, die nicht »irr gemacht« werden durften, daher war die Druckpublikation der jeweiligen Deduktion nicht nur erlaubt, sondern sogar geboten. Der Dis-

158 Ebd., Bd. 1, S. 501.

159 Wolfgang Hermkes zeichnet diese Debatte nach: Hermkes, Reichsvikariat, S. 125-131.

$160 \mathrm{Zu}$ den Appellationsprivilegien zwecks Befreiung von der Reichsjurisdiktion: Ulrich EISENHARDT, Die kaiserlichen Privilegia de non appellando, hg. in Zusammenarbeit mit Elsbeth MARKert, Köln/Wien 1980. 
kurs wurde durch diese Formel gerade nicht auf die engere Reichsöffentlichkeit der Regierungen, Adligen und Gelehrten beschränkt, sondern darüber hinaus ausgedehnt.

In den Zeitungen wurde in der Regel der Beginn des sächsischen und des wittelsbachischen Reichsvikariats sowie der öffentliche Anschlag der Patente bekanntgegeben. Die weitere Tätigkeit blieb unkommentiert, auch das Ende des Reichsvikariats nach der Krönung des neuen Kaisers und dessen Anerkennung der geschehenen Urteile war keine Wortmeldung wert. Im Fall der Münchener Zeitungen 1745 wurde das Vorpreschen anderer Gazetten in der Vikariatsfrage kritisiert, es darf dabei von einer regierungsamtlichen Anweisung ausgegangen werden, das Arkanum zu respektieren, und dies zu einer Zeit, als es schon merklich durchlöchert war. Da die meisten hier ausgewerteten Zeitschriften erst nach 1700 entstanden, wurde das Vikariat von 1711 nur beiläufig erwähnt, während die Vikariate 1740-42 und 1745 die gebührende Erwähnung fanden. Die Historienschriften bedienten sich der Deduktionen, und dieser Literaturgattung oblag es inbesondere, die langfristigen Zusammenhänge zu verdeutlichen und damit ihrerseits Erklärungshintergründe für Gazettiers und Journalisten späterer Generationen zu schaffen.

Die brisanteste mediengeschichtliche Entdeckung im Zusammenhang mit dem Vikariatsstreit war das Bekanntwerden der Wittelsbacher Hausunion von 1724, denn dieser Familienvertrag war bis dahin geheimgehalten worden. Der Vikariatsstreit von 1740 brachte diese Vereinbarung ans Tageslicht, und es dürfte nur Tage gedauert haben zwischen der Realisierung der reichsständischen Vertreter in Regensburg und der Publikation in der Presse. Während sich die Zeitungen auf den Umstand beschränken mussten, verschafften sich Zeitschriften wie die Neue Europäische Fama gleich den kompletten Vertragstext und verbreiteten ihn. Die Publizität dieses Ereignisses geschah damit nicht zeitnah, sondern problemorientiert mit 16 Jahren Verzug. 


\section{Neunte Kurwürde für den Herzog von Braunschweig-Lüneburg}

\subsection{Historischer Hintergrund}

Nachdem das Haus Bayern während des Dreißigjährigen Krieges mit seinen Ambitionen auf eine Kurwürde erfolgreich gewesen war, strebte später mit den Welfen eine andere der prominentesten Fürstenfamilien denselben Rang an. Sicherlich lag es im Interesse jedes Adligen und jeder Adelsfamilie, für erwiesene oder auch fingierte Verdienste belohnt und gegenüber den Standesgenossen herausgehoben zu werden. Die ständische Gesellschaft war - trotz der Dominanz des geburtsständischen Prinzips - eben auch eine Meritokratie. Verdienste waren gegenüber dem Gnadengeber im vorteilhaften Licht darzustellen: Das gelang am besten durch die Präsenz in der Nähe des Kaisers. Aus den verdienstbedingten Standeserhöhungen des Mittelalters war allerdings im Laufe der Frühen Neuzeit ein allgemeiner Trend geworden. Die Habsburger Kaiser hatten spätestens seit dem Dreißigjährigen Krieg eine Praxis im Reich errichtet, nach der Standeserhöhungen für interessierte Adlige stark erleichtert worden waren. Diese Praxis führte zu einer Dynamisierung der Adelswelt im Reich: Waren früher nur einzelne Aufsteiger beobachtbar, die sich ihren Platz in der höheren Ranggruppe mühsam erkämpfen und erdienen mussten, so zogen nun Kohorten von Aufsteigern in jede Adelsgruppe, auch in den Reichsfürstenstand, ein ${ }^{1}$. Die ranghöchsten Dynastien im Reich mussten beobachten, dass der Rangunterschied zu den unter ihnen stehenden Familien immer kleiner wurde: Frühere Ritter waren zu Freiherren aufgestiegen, alte Freiherren zu Grafen, ehemalige Grafen zogen in den Fürstenstand und den Regensburger Reichsfürstenrat ein. Selbst das Kurkollegium hatte 1648 eine Erweiterung erfahren um die Achte Kur für Pfalzgraf Karl Ludwig.

1 Das Phänomen der adligen Standesdynamisierung ist bislang noch nicht in seiner Gesamtheit (Bedeutung für die Unterminierung der ständischen Gesellschaft; Bedeutung der zu zahlenden Taxgebühren für die Verwaltungskostenzusammensetzung der kaiserlichen Reichsadministration etc.) untersucht worden. Zwei Vorstudien, die vor allem die Mindermächtigen und Kleinpotentaten zum Gegenstand haben: Johannes ARndT, Zwischen kollegialer Solidarität und persönlichem Aufstiegsstreben. Die Reichsgrafen im 17. und 18. Jahrhundert, in: Ronald G. Asch (Hg.), Der europäische Adel im Ancien Régime. Von der Krise der ständischen Monarchien bis zur Revolution (ca. 1600-1789), Köln/Weimar/Wien 2001, S. 105-128; ders., Monarch oder der »bloße Edelmann«? Der deutsche Kleinpotentat im 18. Jahrhundert, in: Ronald G. Asch u.a. (Hg.), Die frühneuzeitliche Monarchie und ihr Erbe. Fs. für Heinz Duchhardt zum 60. Geburtstag, Münster u.a. 2003, S. 59-90. 
Anschließend liefen Bestrebungen der kurfürstlichen Familien an, in den Besitz einer Königswürde zu gelangen. Erfolgreich in dieser Hinsicht waren die albertinischen Wettiner, als Kurfürst August der Starke 1697 zum König von Polen gewählt wurde, die Hohenzollern mit der Königserhebung Kurfürst Friedrichs III. in Königsberg 1701 sowie die Herzöge von Savoyen, als Herzog Viktor Amadeus II. den Titel eines Königs von Sardinien annehmen konnte und dafür auf dem Utrechter Friedenskongress die europäische Anerkennung erhielt ${ }^{2}$. Für die Hannoveraner Herzöge kam diese Bewegung zu früh. Neben ihren Kurbemühungen war ein eigenes Königtum nicht erreichbar, wohl half ihnen aber das dynastische Erbrecht zur Nachfolge auf dem englischen Thron nach dem Tod der letzten Stuartkönigin Anna 1714. Der spätere Landgraf Friedrich I. von Hessen-Kassel wurde durch seine Ehe mit Erbprinzessin Ulrike Eleonore von Schweden Herrscher im skandinavischen Königreich, ohne dass seine Dynastie dadurch mehr als vorübergehenden Vorteil erlangte 4 . Teilweise wurden in diesem Zusammenhang ganz abstruse Ideen verfolgt, etwa die zeitweilige Kooperation von Kurfürst Johann Wilhelm von der Pfalz mit einem Projektemacher, der ihm die Krone von Armenien verschaffen wollte ${ }^{5}$.

Bislang ist nicht bekannt, ob dieser Prozess, der dank der neueren Sozialgeschichtsforschung präzise überblickbar ist, den damaligen Zeitgenossen in seiner strukturellen Bedeutung vollkommen vor Augen stand. Auch von den Welfen ist nicht bezeugt, dass sie aus dem Fürstenstand »flohen«,

2 Zu August dem Starken und seiner Reichspolitik: Karl CzoK, August der Starke und Kursachsen, München 1988; Jochen Vöтsch, Kursachsen, das Reich und der mitteldeutsche Raum zu Beginn des 18. Jahrhunderts, Frankfurt a.M. 2003. - Zu Kurfürst Friedrich III. von Brandenburg und seiner Königserhebung 1701: Wolfgang Neugebauer, Friedrich III./I. (16881713), in: Frank-Lothar Kroll (Hg.), Preußens Herrscher. Von den ersten Hohenzollern bis Wilhelm II., München 2000, S. 113-133; Heide BARmeYer (Hg.), Die preußische Rangerhöhung und Königskrönung 1701 in deutscher und europäischer Sicht, Frankfurt a.M. u.a. 2002; Johannes KunISCH (Hg.), Dreihundert Jahre Preußische Königskrönung. Eine Tagungsdokumentation, Berlin 2002; Franziska WindT, Preußen 1701. Eine europäische Geschichte. Ausstellung des Deutschen Historischen Museums Berlin in der Orangerie des Schlosses Charlottenburg, 6. Mai bis 5. August 2001, 2 Bd., Berlin 2001. - Zu Savoyen, das Heinz Duchhardt als europäische »Schwellenmacht« bezeichnet: Duchнardt, Balance of Power und Pentarchie, S. 194-197.

3 Vgl. zur Politik der Hannoveraner die mehrbändige Studie von Georg Schnath, Geschichte Hannovers im Zeitalter der neunten Kur und der englischen Sukzession, 1674-1714, 4 Bd., Hildesheim/Leipzig 1938-1982. Zu Königin Anna vgl. die Kurzbiographie von Ulrike JoRDAn, Anna (1702-1714), in: Peter Wende (Hg.), Englische Könige und Königinnen. Von Heinrich VII. bis Elisabeth II., München 1998, S. 176-187.

4 Eckhart G. Franz, Das Haus Hessen. Eine europäische Familie, Stuttgart 2005, S. 97f.; DuchHARDT, Balance of Power und Pentarchie, S. 214f.

5 Karl Theodor von Heigel, Über den Plan des Kurfürsten Johann Wilhelm von der Pfalz, die armenische Königskrone zu gewinnen (1698-1705). Sitzungsberichte der philosophisch-philologischen und historischen Classe der Königlich Bayerischen Akademie der Wissenschaften zu München (1893), München 1894, Bd. 2, S. 273-319. 
weil es inzwischen zahlreiche Neufürsten gab, die außer mit ihrem formalen Rang in keiner anderen Hinsicht mit dem bedeutendsten Fürstengeschlecht Nordwestdeutschlands konkurrieren konnten. Jedenfalls wurde der Gedanke an den Erwerb der Kurwürde bereits 1672 durch die Diplomaten Herzog Johann Friedrichs von Braunschweig-Lüneburg in Verhandlungen mit Ludwig XIV. zur Sprache gebracht. Der Franzosenkönig antwortete, eine derartige Gnade läge außerhalb seines Zuständigkeitsbereichs. Die folgenden politischen Vorgänge stehen im Mittelpunkt der vierbändigen Untersuchung von Georg Schnath, deren Argumentation ich im Wesentlichen folge ${ }^{6}$. Schon in der Zwischenkriegszeit hat Frieda Freiin von Esebeck eine Dissertation über die Begründung der hannoverschen Kurwürde verfasst ${ }^{7}$. Zur Bedeutung des Projekts und zur Vollendung der Kurerhebung für die Reichspolitik des Hauses Braunschweig-Hannover sind zwei kürzere Studien von Volker Press und Christof Römer unverzichtbar ${ }^{8}$.

Nach der Episode von 1672 wurde das Kurprojekt zurückgestellt, aber nicht vergessen. Die verschiedenen welfischen Linien in Wolfenbüttel, Celle und Calenberg betrieben ihre Ranggleichheit mit den Kurfürsten, konnten aber eine Durchsetzung im kaiserlichen oder reichstäglichen Zeremoniell nicht erreichen'. Im Tractat Caesarini Fuerstenerii de jure suprematus ac legationis principum Germaniae tractatus formulierte Gottfried Wilhelm Leibniz in seiner Eigenschaft als Haushistoriograph ein Gutachten für die annähernde Ranggleichheit zwischen Kurfürsten und Reichsfürsten ${ }^{10}$. Mit der Regierungsübernahme Herzog Ernst Augusts, des Osnabrücker Bischofs, im Herzogtum Calenberg wurde der Ehrgeiz wieder auf die Kurwürde fokus-

6 Schnath, Geschichte Hannovers im Zeitalter der neunten Kur, hier Bd. 1, S. 472.

7 Frieda Freiin von EsEBECK, Die Begründung der hannoverschen Kurwürde, Hildesheim 1935.

8 Volker Press, Kurhannover im System des Alten Reiches 1692-1803, in: Adolf M. Birke/Kurt KLuXen (Hg.), England und Hannover. England and Hanover, München 1986, S. 53-79; Christof RöMER, Der Kaiser und die welfischen Staaten 1679-1755. Abriss der Konstellationen und der Bedingungsfelder, in: Harm Klueting / Wolfgang Schmale (Hg.), Das Reich und seine Territorialstaaten in der Frühen Neuzeit. Aspekte des Mit-, Neben- und Gegeneinanders, Münster u.a. 2004, S. 43-66.

9 Vgl. zur Gliederung des welfischen Gesamtbesitzes in mehrere Linien und die Konkurrenzen zwischen den Familienmitgliedern: Gerd van DEN Heuvel, Niedersachsen im 17. Jahrhundert (1618-1714), in: Christine van den Heuvel/Manfred Boetticher (Hg.), Geschichte Niedersachsens, Bd. 3, T1. 1: Politik, Wirtschaft und Gesellschaft von der Reformation bis zum Beginn des 19. Jahrhunderts, Hannover 1998, S. 119-218. - Beispiele für die Bestrebungen: VON EsEBECK, Die Begründung der hannoverschen Kurwürde, S. 7-9.

10 [Gottfried Wilhelm Leibniz], Caesarini Fuerstenerii De Jure Suprematus Ac Legationis Principum Germaniae Tractatus, Amsterdam 1678 (Erstausgabe 1677). Vgl. zur Bedeutung der Schrift im Rahmen der Rangdiskussionen der Zeit zwischen den Kurfürsten und denen, die es werden wollten, auch Burgdorf, Reichkonstitution und Nation, S. 88-95, und GotTHARD, Säulen des Reiches, hier Bd. 2, S. 803-806. 
siert. Der Herzog erließ eine Primogeniturordnung, eine wichtige Voraussetzung für einen künftigen Kurfürsten ${ }^{11}$. Leibniz schrieb 1684/85 eine weitere Denkschrift unter dem Titel De la grandeur de la Serenissime maison de Bronswick-Luneburg, in der die Verdienste des Hauses als so bedeutend dargestellt wurden, dass ihm eigentlich der kurfürstliche Rang dafür gebühre ${ }^{12}$. Es ist bekannt, dass Leibniz darüber hinaus zahlreiche politische Traktate verfasste und einige diplomatische Vermittlungen unternahm. Die LeibnizForschung hat die Aktivitäten des Gelehrten in dieser Hinsicht gewürdigt, durchaus mit kritischem Unterton, da der Politiker Leibniz weitaus weniger bedeutend war als der Wissenschaftler ${ }^{13}$.

Kaiser Leopold I. war an einem Macht- und Reputationsgewinn des Welfenhauses oder einer anderen großen fürstlichen Dynastie nicht interessiert, weil dies das komplizierte Rangsystem im Reich in Unordnung gebracht hätte. So sehr die Habsburger bei den unteren Adelsrängen Standeserhöhungen vornahmen, um vom Diensteifer und der Steuerbereitschaft der begünstigten Familien zu profitieren, so zurückhaltend waren sie auf der obersten Reichsebene. Die Vermehrung der Kurwürden oder gar die Kreierung von neuen Königen hatte nicht nur eine reichsrechtliche Dimension: Die Rangerhöhten würden, so war sicher anzunehmen, auch auf der europäischen Ebene eine Rolle spielen wollen, und das hätte neue Militär- und Subsidienkonstellationen zur Folge gehabt, wahrscheinlich mit nachteiligen Konsequenzen für die Wiener Politik ${ }^{14}$.

Der Herzog hatte sich in diesem Anliegen nicht nur mit dem Kaiser, den Kurfürsten und seinen Standesgenossen im Reichsfürstenrat auseinanderzusetzen, sondern vor allem mit den beiden anderen Linien seines Hauses. Besonders in letzter Hinsicht stellte er sich als eindeutiger Sieger heraus, ungeachtet der Heftigkeit der Kontroversen während seiner Regierungszeit. Zunächst verständigte sich Ernst August 1682 mit Kurbrandenburg, das

11 Annette von Stieglitz, Der teuerste Hut des Reiches. Hannovers Ringen um die Kurwürde, in: Sabine Meschkat-Peters, Ehrgeiz, Luxus und Fortune. Hannovers Weg zu Englands Krone. Ausstellung des Historischen Museums am Hohen Ufer Hannover, Hannover 2001, S. 68-83, hier S. 73.

12 Zum Gutachten im Rahmen von Leibniz' Tätigkeit als Politikberater: ScHEEL, Leibniz als politischer Ratgeber des Welfenhauses, hier S. 38. Vgl. dazu auch BEIDERBECK, Leibniz als politischer Berater des Welfenhauses am Beispiel der Neunten Kur, S. 142-149. Auf die Ironie im Wirken Leibniz' als jeweils aktualisierter Argumentelieferant weist Bernd Roeck hin: RoEck, Reichssystem und Reichsherkommen, S. 133. Vgl. zur historischen Argumentation im Rahmen des Aufstiegs der Welfen um die Wende zum 18. Jahrhundert: Armin ReEse, Die Rolle der Historie beim Aufstieg des Welfenhauses, 1680-1714, Hildesheim 1967.

13 Vgl. zur Stand dieser Diskussion: Scheel, Leibniz als politischer Ratgeber des Welfenhauses, S. 35.

14 Diese Problemverknüpfung zwischen der europäischen und der Reichsebene betont Karl Otmar Freiherr von Aretin, Das Alte Reich, Bd. 2, S. 54-58. 
ihm Wohlwollen signalisierte ${ }^{15}$. Bevor er mit anderen Kurfürsten handelseinig wurde, kamen ihm die Kriege zugute: Nach dem Beginn des Türkenkriegs 1683 und besonders nach dem Krieg um die Kurpfalz 1689 wurde seine braunschweig-lüneburgische Infanterie von mehr als 20.000 Mann für Frankreich interessant und besonders für den Kaiser überlebenswichtig in seinem Zweifrontenkrieg. Dass Ernst August der familieninterne Machthaber des Welfenhauses und damit der Verfügungsberechtigte über die Soldaten war, demonstrierte er in der souveränen Niederschlagung eines Aufbegehrens innerhalb der eigenen Familie: Sein Sohn Maximilian Wilhelm hatte umstürzlerische Pläne unter Beteiligung ausländischer und auswärtiger Mächte in Angriff genommen, besonders angespornt durch die Verwandten in Wolfenbüttel. Ernst August wurde jedoch früh informiert und ließ die Verursacher inhaftieren. Sein Oberjägermeister Otto Friedrich v. Moltke wurde enthauptet, zwei weitere Verschworene für immer aus dem Herzogtum Hannover verwiesen ${ }^{16}$.

Während der Untersuchungen zur »Prinzenverschwörung« liefen die Verhandlungen mit dem Kaiserhof zur Kurerhebung. Vielleicht gewährleistete gerade diese außergewöhnliche innenpolitische Situation, dass von der großen Diplomatie nichts bekannt wurde. Nachdem sich Ernst August im Januar 1692 mit seinem Vetter Georg Wilhelm in Celle verständigt und ausgeglichen hatte, konnte unter dem Datum des 22. März 1692 der Kurtraktat samt einigen weiteren Vereinbarungen mit dem Kaiserhof geschlossen werden. Die wirkliche Entscheidung fiel allerdings erst am 15. April (als in Hannover die revidierte Fassung des Traktats unterzeichnet wurde) sowie am 30. April (als der Kaiser seine Zustimmung nach Hannover übermittelte). Die Einzelheiten dieses politischen Geschäfts sind oft beschrieben worden: Der Kurfürst erhielt die Kurwürde zugesagt für die Leistung von 6.000 kampffertigen Soldaten für den Türkenkrieg samt 500.000 Rtl. außerordentlicher Türkenhilfe. Ernst August sagte ferner zu, seine künftige Kurstimme bei Kaiser- oder Königswahlen stets dem Hause Habsburg zuzuwenden ${ }^{17}$. Dass Kaiser Leopold I. neben der Bindung Hannovers an seine Politik noch ein anderes Ziel verfolgte, blieb damals allgemein verborgen und offenbarte sich erst bei den anschließenden Gesprächen über die Einführung Hannovers in das Kurkolle-

15 Einige frühere Meinungsverschiedenheiten wurden im Zuge dieser Verhandlungen reguliert: SchnAth, Geschichte Hannovers im Zeitalter der neunten Kur, Bd. 1, S. 475; vON EsEBECK, Die Begründung der hannoverschen Kurwürde, S. 8f.; BEIDERBECK, Leibniz als politischer Berater des Welfenhauses, S. 142f. - Kurbrandenburg brachte 1689 offiziell beim Kurfürstentag in Augsburg den Antrag ein, Hannover mit der neunten Kurwürde zu begaben: von Aretin, Das Alte Reich, Bd. 2, S. 58.

16 Zur sog. »Prinzenverschwörung«: SchnAth, Geschichte Hannovers im Zeitalter der neunten Kur, Bd. 1, S. 575-586.

17 Ebd., Bd. 1, S. 592-611; vON EsEBECK, Die Begründung der hannoverschen Kurwürde, S. 19-24. 
gium: Der Kaiser wollte die böhmische Stimme, die seit dem frühen 16. Jahrhundert - außer bei Wahlhandlungen - ruhte, vollberechtigt bei allen Fragen des Kurfürstenrates zur Geltung bringen. Da es sich nach habsburgischer Ansicht um die Wiederherstellung eines früheren Zustandes handelte, wurde dieser Punkt in den folgenden 16 Jahren unter dem Terminus »Kurböhmische Readmission « verhandelt ${ }^{18}$.

Mit dem Austausch der Urkunden über den Kurtraktat samt seinen Nebenverträgen am 17. Mai 1692 im Hause des Grafen Königsegg in Hannover war aber erst ein Geschäft zwischen dem Kaiser und einem prominenten Vasallen getätigt worden, das noch seine Anerkennung im Reich finden musste. Leicht würde das nicht werden, weder im Kurfürstenrat noch im Reichsfürstenrat. Georg Schnath formuliert die Haltung der bisherigen Standesgenossen Ernst Augusts mit folgenden Worten: »Daß die Fürsten ihrem bisher mächtigsten Standesgenossen diese Beförderung nicht gönnen würden, stand von vornherein fest $\aleph^{19}$. Die Vettern in Wolfenbüttel, die gemeinschaftlich regierenden Herzöge Rudolf August und Anton Ulrich, erfuhren schon im April durch den Versprecher eines Hannoveraner Diplomaten, Graf Breuner, vom Fortschritt des Vorhabens ${ }^{20}$. Der Kaiser wie der Welfenherzog kontaktierten daraufhin die Kurfürsten einzeln, der Kaiser durch Schreiben, der Hannoveraner durch Sondergesandte. Auch wenn sich der Widerstand bereits während des Jahres 1692 organisierte, so gelang es, bis Oktober die Kurfürstenmehrheit zu gewinnen: Am 17. Oktober 1692 stimmten mit Kurmainz, Kurbayern, Kursachsen und Kurbrandenburg vier Fürsten für die Aufnahme des Welfen, während die drei anderen sich der Opposition anschlossen ${ }^{21}$. Damit war die zweite Hürde genommen. Zwei Monate später schritten der Kaiser und der neue Kurfürst zum Vollzug: Am 19. Dezember fand sich der Hannoveraner Minister von Grote in der Wiener Hofburg ein, um für seinen Herrn die

18 Zur »Kurböhmischen Readmission«: Ulrich KüHnE, Geschichte der böhmischen Kur in den Jahrhunderten nach der Goldenen Bulle, in: AUF 10 (1928), S. 1-110, bes. S. 58-76; vON ArETIN, Das Alte Reich, Bd. 2, S. 60; vgl. dazu auch die neueren Interpretationen der böhmischen Rolle im Reich von Volker Press, Böhmen und das Reich in der Frühen Neuzeit, in: Bohemia 35 (1994), S. 63-74; Alexander BEGERT, Böhmen, die böhmische Kur und das Reich vom Hochmittelalter bis zum Ende des Alten Reiches. Studien zur Kurwürde und zur staatsrechtlichen Stellung Böhmens, Husum 2004.

19 Schnath, Geschichte Hannovers im Zeitalter der neunten Kur, Bd. 1, S. 612.

20 Zur Wolfenbütteler Politik und der Rivalität zwischen den welfischen Linien in Wolfenbüttel und Hannover: Christof Römer, Zeitalter des Hochabsolutismus, in: Horst-Rüdiger JARCK/Gerhard Schildt (Hg.), Die Braunschweigische Landesgeschichte. Jahrtausendrückblick einer Region, Braunschweig 2000, S. 535-574.

21 Schnath, Geschichte Hannovers im Zeitalter der neunten Kur, Bd. 1, S. 647; von Aretin, Das Alte Reich 1648-1806, Bd. 2, S. 61; von EsEBECK, Die Begründung der hannoverschen Kurwürde, S. 24-29. 
Belehnung mit der Kur entgegenzunehmen ${ }^{22}$. Damit waren vollendete Tatsachen geschaffen worden. Nur die Einführung mit Sitz und Stimme in den Kurfürstenrat musste noch folgen. Es war zu diesem Zeitpunkt noch nicht absehbar, dass dieser letzte Schritt 16 Jahre auf sich warten lassen würde, und dass der Initiator des Verfahrens, Ernst August, ihn gar nicht mehr erleben sollte. In der niedersächsischen Landesgeschichte wird der Hannoveraner Kurhut gern »der teuerste Hut der Weltgeschichte« genannt: Insgesamt soll Ernst August dafür - allein bis 1694 - Aufwendung von ca. 2 Millionen Reichstalern gehabt haben ${ }^{23}$. In seiner Wertschätzung war ihm das kein zu hoher Preis. Das ist lange in der Forschung übersehen worden. Erst unter neuerer kulturalistischer Perspektive ist ins allgemeine Bewusstsein gerückt, dass der reichsständische Rang nicht eine Nebenangelegenheit der frühmodernen Politik war, sondern zur Substanz gehörte: Der Rang, seine Verteidigung oder seine Verbesserung präfigurierte unmittelbare Macht ${ }^{24}$.

Inzwischen war es in dieser Frage zu einer »tiefen Spaltung des Reiches« gekommen, wie Karl Otmar Freiherr von Aretin formulierte ${ }^{25}$. Die Opponenten setzten sich mit allen politisch-juristischen und publizistischen Mitteln gegen das Kurprojekt ein. Drei Gruppen lassen sich dabei unterscheiden: Unter den Kurfürsten waren weiterhin Kurköln, Kurtrier und Kurpfalz gegen die Erhebung ${ }^{26}$, im Reichsfürstenrat eine zahlenstarke Gruppe mit Salzburg und Münster auf geistlicher sowie Braunschweig-Wolfenbüttel, Sachsen-Gotha, Baden-Baden und Hessen-Kassel auf weltlicher Seite an der Spitze ${ }^{27}$. Die dritte Gruppe bildeten die ausländischen Opponenten: der Papst, Frankreich und Dänemark ${ }^{28}$. Dänemark verband sich sogar mit Münster und Braunschweig-Wolfenbüttel zu einem Hilfsbündnis, falls einer der Reichsstände wegen seiner Haltung zur Neunten Kurwürde von kaiserlicher Seite angegriffen würde ${ }^{29}$. Bis zum Tod Ernst Augusts 1698 änderte sich an

22 Von Aretin, Das Alte Reich 1648-1806, Bd. 2, S. 62; von EsebecK, Die Begründung der hannoverschen Kurwürde, S. 30f.

23 Zu den Kosten: Schnath, Geschichte Hannovers im Zeitalter der neunten Kur, Bd. 1, S. 650.

24 Zur Erforschung der symbolischen Kommunikation im Alten Reich vgl. S. 32 in diesem Buch.

25 Von Aretin, Das Alte Reich, Bd. 2, S. 61.

26 Kurfürstliche Opponenten: Ebd., S. 61. Kurmainz, zunächst auch gegen Hannover eingestellt, war bald aus pragmatischen Gründen auf die kaiserliche Seite umgeschwenkt: Alfred ScHRÖCKER, Die neunte Kur aus der Sicht des Mainzer Kurfürsten Lothar Franz von Schönborn, in: JbWLG 5 (1979), S. 155-163.

27 Die Opponenten umfassten schließlich 17 der 91 stimmberechtigten Mitglieder des Reichsfürstenrats: Vgl. die Aufzählung bei SснNAтH, Geschichte Hannovers im Zeitalter der neunten Kur, Bd. 2, S. 20, sowie die Politik Hannovers gegenüber dieser Gruppe: Ebd., S. 102-120. Vgl. auch Stieglitz, Der teuerste Hut des Reiches, S. 80f. - Die Fürstenopposition blockierte den Reichsfürstenrat zwei Jahre lang: Friedrich, Drehscheibe Regensburg, S. 265f. - Zur Klage mehrerer Reichsfürsten vor dem Reichshofrat: von ArEtin, Das Alte Reich, Bd. 2, S. 62.

28 Zur Opposition: Sснnатн, Geschichte Hannovers im Zeitalter der neunten Kur, Bd. 2, S. 12-34; von EseBeck, Die Begründung der hannoverschen Kurwürde, S. 33f.

29 Von Aretin, Das Alte Reich, Bd. 2, S. 62. 
der Konstellation nichts Grundlegendes. Erst anschließend konnte Kurhannover nach und nach die Anerkennungen gewinnen: Den Anfang machten die drei oppositionellen Kurfürsten, die 1699 - zunächst »extrakollegial« ihre Zustimmung zur Neunten Kur erklärten, so dass das Kurkollegium im November erstmals seit sieben Jahren wieder tagen konnte ${ }^{30}$. Unterdessen hatten die Reichsfürsten eine geschickte Debatte initiiert, in der es nicht nur um die Neunte, sondern auch um eine noch nicht personell bestimmte Zehnte Kur ging, die der katholischen Seite zufallen sollte, falls entweder die bayerische Wittelbacherlinie aussterben oder die pfälzische Kurwürde auf dem Erbwege in die Hand eines protestantischen Pfalzgrafen geraten sollte ${ }^{31}$. Das wichtigste Argument zielte darauf ab, dass eine für das Wohl des Reiches so erhebliche Angelegenheit wie eine Kurerhebung unbedingt von allen Kurien des Reichstags approbiert werden müsse, bevor eine rechtmäßige Belehnung stattfinden könne ${ }^{32}$.

Politisch wichtig war, dass für die Oppositionellen infolge anhaltender Erfolglosigkeit eine immer größere Abhängigkeit von Frankreich entstand, das allein noch Hoffnung bieten konnte. Die Kooperation mit dem »Reichsfeind « barg allerdings erhebliche Risiken in sich, besonders wenn die Gespräche die Bereithaltung von Streitkräften und die Zahlung von Subsidien beinhalteten. Herzog Anton Ulrich als wichtigster Betreiber einer engen bewaffneten Zusammenarbeit mit Dänemark und Frankreich unterschätzte dieses Problem. Gleichzeitig dachte die Hannoveraner Gegenseite an eine Militäraktion, die als kaiserlicher Feldzug gegen den reichsverräterischen Fürstenverein initiiert werden sollte. Das Vorhaben scheiterte 1693 an englischem Widerspruch ${ }^{33}$. Die Bemühungen Braunschweig-Wolfenbüttels erlitten im August 1693 einen schweren Rückschlag, als Frankreich die Subsidien strich $^{34}$. Doch ließ sich Herzog Anton Ulrich von seinem Widerstand gegen Hannover nicht abbringen, auch nicht durch ein Umschwenken Dänemarks von Frankreich zu den Seemächten im Dezember $1696^{35}$. Der Wolfenbütteler Herzog fühlte sich immer noch stark genug, auch Vermittlungsangeboten durch den schwedischen Reichskanzler Bengt Oxenstierna (März 1694), Kurfürst Friedrich III. von Brandenburg (November 1694), den englischen Gesandten James Cresset (Februar 1695) und den niederländischen

30 Sitzung am 18. November 1699: ebd., Bd. 2, S. 65.

31 Vgl. zur weiteren Klärung der Frage der 10. Kur: SснNAтH, Geschichte Hannovers im Zeitalter der neunten Kur, Bd. 2, S. 82f.

32 Vgl. zu den Argumenten der Gegner Kurhannovers: BeIDERBECK, Leibniz als politischer Berater des Welfenhauses, S. 147; von EseBecK, Die Begründung der hannoverschen Kurwürde, S. $38 \mathrm{f}$.

33 Sснnath, Geschichte Hannovers im Zeitalter der neunten Kur, Bd. 2, S. 21.

34 Ebd., Bd. 2, S. 103f.

35 Ebd., Bd. 2, S. 109f. 
Botschafter in Wien Konrad van Heemskerk (Winter 1695/96) keine Chance zu geben ${ }^{36}$.

Nach dem Tod des Kurfürsten Ernst August 1698, zeigte sich die Unabgeschlossenheit seiner Standeserhöhung deutlich im Zeremoniell: Sein Sohn und Nachfolger Georg Ludwig konnte zwar den Potentaten in Europa und Ständen im Reich die Sterbenachrichten offiziell mitteilen, die die Kurerhebung bereits anerkannt hatten, den anderen aber nicht, weil diese Herrscher seine Schreiben unter kurfürstlichen Kurialien nicht anzunehmen bereit waren, Georg Ludwig aber auch nicht auf diese Formeln verzichten konnte. So wurden diese Fürsten durch den Celler Onkel, Herzog Georg Wilhelm, angeschrieben, und dieser empfing auch die Kondolenzschreiben ${ }^{37}$. In den folgenden Jahren versuchte der neue Kurfürst in Hannover, die Zustimmung zu seiner Introduktion durch bilaterale Verhandlungen zu erreichen. Dabei schwankte Kurmainz, während die Frontstellung ansonsten wie zuvor blieb: Kurbayern, Kursachsen und Kurbrandenburg wollten seiner Session zustimmen, während die übrigen drei bei ihrem Nein blieben. Kurbayern verursachte nur dadurch Schwierigkeiten, weil Max Emanuel der böhmischen Readmission ablehnend gegenüberstand - bei seiner dynastischen Eifersucht gegenüber den Habsburgern eine naheliegende Haltung, die auch durch intensive diplomatische Bearbeitung durch Hannoveraner Gesandte nicht verändert werden konnte. Der Kaiser blieb hingegen bei seiner Position: erst die böhmische Stimmübertragung, dann die Zulassung der Neunten Kur. Mehrere Monate lang dauerten die Gespräche, wobei sowohl die Geschenke des Hannoveraner Kurfürsten als auch die Sorge aller Seiten über die schon sieben Jahre anhaltende Inaktivität des Kurfürstenrats schließlich zu einer Annäherung führte. Durch die Anerkennung der Kur »extrakollegial « war der Weg frei, dass der Kurfürstenrat am 18. November 1699 wieder zusammentreten konnte ${ }^{38}$. Über die erste feierliche Teilnahme der Hannoveraner war damit aber noch nichts entschieden.

Mit den opponierenden Reichsfürsten hingegen hielt Hannover direkte Verhandlungen für unnötig. Allerdings ergab sich gegen den Hauptgegner Braunschweig-Wolfenbüttel bald eine Gelegenheit zur politischen Bereinigung. Unter der treibenden Kraft von Herzog Anton Ulrich hatte sich die ältere welfische Linie so sehr in ihre Bestrebungen auf Wahrung des innerfamiliären Vorrangs verstrickt, dass auch militärische Maßnahmen in die

36 Ebd., Bd. 2, S. 111.

37 Ebd., Bd. 3, S. 3.

38 Zu den Einzelheiten: Ebd., S. 162-168; von EsEBECK, Die Begründung der hannoverschen Kurwürde, S. 70. 
Überlegungen einbezogen wurden. Aus Paris wurde finanzielle und politische Hilfe angefordert. Dabei merkte man in Wolfenbüttel offenbar nicht, dass Hannover einen fast vollständigen Einblick in die Korrespondenz der östlichen Verwandten mit Frankreich besaß. In den Poststellen in Gifhorn und Nienburg wurden alle durchlaufenden diplomatischen Schreiben der Franzosen geöffnet, bei Bedarf kopiert und dann mit gefälschten Siegeln wieder verschlossen und weitergeleitet. Die Hannoveraner verfügten zudem über Experten für Kryptographie von europäischem Rang, so dass auch verschlüsselte Briefe ausgewertet werden konnten ${ }^{39}$.

1698 und 1701 schloss Herzog Anton Ulrich zwei Allianzen mit Frankreich, die ihm neuerliche Subsidien einbrachten ${ }^{40}$. Der Herzog wurde zudem auch wieder von der dänischen Krone unterstützt, mit der er am 26. Januar 1700 eine Wiederaufnahme der früheren Allianz vereinbarte ${ }^{41}$. Ziel seiner Wünsche war hier, im Rahmen eines bewaffneten Zusammenstoßes in Norddeutschland das Fürstentum Celle zu erobern und seiner Linie zuzuwenden. Auf mehreren Fürstenkonventen gelang es dem umtriebigen Wolfenbütteler nicht, seine Standesgenossen zu einem gemeinsamen Vorgehen zu bewegen. Die Nürnberger Tagung vom April 1700 erbrachte zwar Einigkeit über drei gemeinsame Forderungen:

1. Eine Declaratio de non praejudicando wegen ihrer Übergehung bei der Errichtung der Neunten Kur.

2. Die Zusage, dass die Kurangelegenheit nicht ohne Zustimmung aller Reichstagskurien reguliert werden sollte.

3. Eine Sanctio pragmatica, dass künftige Veränderungen im Kurkollegium stets als Angelegenheit betrachtet werden würden, die den gesamten Reichstag etwas anging ${ }^{42}$.

Die kaiserliche Resolution, die die Reichsfürsten erwirkten, stellte ihre Forderungen allerdings nicht zufrieden, sondern sicherte nur das allgemeine Wohlwollen des Reichsoberhaupts zu und verwies sie hinsichtlich der Einzelheiten an den Kurfürsten von Mainz. Daraufhin riefen die Fürsten Frankreich in seiner Eigenschaft als Garanten des Westfälischen Friedens um Hilfe an. Ludwig XIV. nahm das Anliegen der Fürsten zwar mit großem Interesse auf, stellte aber fest, dass die Unterzeichner des Antrags überwiegend nur kleine Kontingente zur Reichsarmee stellten. Für seine Zwecke war hingegen die Schaffung einer militärischen Gegenmacht gegen den Kaiser im Reich

39 Schnath, Geschichte Hannovers im Zeitalter der neunten Kur, Bd. 3, S. 60.

40 Allianzen vom 9. September 1698 und 4. März 1701: ebd., Bd. 3, S. 180 u. $197 f$.

41 Ebd., Bd. 3, S. $187 f$.

42 Ebd., Bd. 3, S. 194; Römer, Der Kaiser und die welfischen Staaten, S. 47. 
von Belang, und zwar umso mehr, als König Karl II. von Spanien Anfang November 1700 starb und damit die spanische Erbschaft eröffnet wurde.

Kurhannover sicherte seine finanzielle Handlungsfähigkeit durch einen Subsidienvertrag mit England, für den das Kurfürstentum 10.000 Söldner stellte. England zahlte dafür 200.000 Rtl. an Werbegeldern und 43.000 Rtl. an monatlichem Sold. Da Kurhannover als englischer Erbanwärter ohnehin aus Eigennutz die englischen Interessen vertreten musste, konnte die kurfürstliche Regierung in London geringere Finanzleistungen erreichen als für die Soldaten aus Dänemark, Kurbrandenburg oder Hessen-Kassel, auch wenn das Kurfürst Georg Ludwig nicht gefiel ${ }^{43}$. Immerhin bot die Konstellation der Hannoveraner Regierung endlich die Gelegenheit, mit dem Unruhefaktor im nahen Wolfenbüttel abzurechnen und Herzog Anton Ulrich für die nächste Zeit als militärischen Widerpart auszuschalten. Die Gelegenheit war insofern günstig, als der militärische Einsatz nicht - wie unter anderen Umständen - als Bruch des Landfriedens bewertet werden würde, sondern als eine vom Kaiser und dem Reichstag zu begrüßende Aktion gegen französische Stützpunkte im Reich. Der überall beobachtbare Aufmarsch von Truppen ließ in Hannover und Celle die Einsicht reifen, dass ein schnelles Vorgehen sinnvoller sei, als ein Warten darauf, bis Anton Ulrich seine 12.000 Mann in ersten Einsätzen schlachtentauglich gemacht hätte. Das strategische Ziel war, die über das Wolfenbütteler Land verstreute Kavallerie zu entwaffnen, während die Fußtruppen in Braunschweig und Wolfenbüttel eingeschlossen und solange belagert werden sollten, bis die beiden Herzöge in Verhandlungen einwilligen würden. Diese seien dann zu zwingen, ihren reichsrechtswidrigen Verbindungen zu Frankreich und seinen Verbündeten zu entsagen ${ }^{44}$. Gleichzeitig liefen diplomatische Bemühungen an, weitere deutsche Fürsten von Interventionen in den innerwelfischen Streit abzuhalten, besonders Preußen. Beinahe hätte der Geheime Justizrat Gottfried Wilhelm Leibniz genau dies herbeigeführt, als er auf Anfrage der preußischen Königin Sophie Charlotte Vermittlungsgespräche mit Kurhannover aufnahm, um dem Frieden zu dienen. Georg Schnath spricht despektierlich von einem »Ausrutscher auf dem Gebiet der hohen Politik«. Leibniz war nämlich von keinem der beiden Kurfürsten beauftragt oder nur willkommen als Vermittler. Die hannoversche Regierung konnte seine Initiative abbremsen, nicht ohne ihn zu rügen und ihm aufzuerlegen, sich weiterer Verhandlungen auf eigene Faust in dieser delikaten Angelegenheit zu enthalten ${ }^{45}$.

43 Schnath, Geschichte Hannovers im Zeitalter der neunten Kur, Bd. 3, S. 362f.; Gert Brauer, Die hannoversch-englischen Subsidienverträge 1702-1748, Diss. Frankfurt a.M. 1961, S. 21.

44 Schnath, Geschichte Hannovers im Zeitalter der neunten Kur, Bd. 3, S. 366.

45 Ebd., Bd. 3, S. 368-370. 
Die Durchführung der Militäraktion zeigte, dass die Hannoveraner Regierung sehr präzise über die militärischen und politischen Verhältnisse in Wolfenbüttel informiert war, während dies für die Gegenseite nicht galt. Am 19./20. März 1702 besetzten die Reitertruppen Georg Ludwigs (zus. ca. 4.000 Mann) strategisch wichtige Punkte im benachbarten Herzogtum, während man dort völlig überrascht war. Wichtigstes Ziel war, wie ursprünglich geplant, die Wolfenbütteler Reitereinheiten (ca. 2.500 Mann) zu zersprengen und ihnen erst gar keine Chance zum Zusammenrotten zu lassen. Dafür verfügten die Hannoveraner über genaue Karten und Pläne über die Aufenthaltsorte der Soldaten. Zunächst verhaftete man die Offiziere und besetzte die Kirchtürme, damit kein Sturmläuten fernere Orte vorzeitig warnte. Dann erst wurden Unteroffiziere und Mannschaften gefangen. Blutvergießen sollte nach Möglichkeit vermieden werden. Zur strategischen Absicherung besetzte man auch die Reichsstadt Goslar und die hildesheimische Landesfestung Peine. Zwar war das Territorium am Abend des 20. März in der Hand der Hannoveraner - von den beiden Festungsstädten abgesehen -, doch man hatte nur 500 Reiter verhaftet. Der Rest war entkommen oder desertiert. Dass die Kontrolle nicht vollkommen war, demonstrierte Herzog Anton Ulrich am 22. März, als es ihm gelang, mit 600 Reitern von Wolfenbüttel nach Braunschweig zu gelangen, um seinen Bruder zu unterstützen bzw. ihn von ungünstigen Entscheidungen abzuhalten ${ }^{46}$. Direkt begannen diplomatische Bemühungen, um nicht doch noch ein Ausbrechen der Wolfenbütteler und damit einen regulären Krieg in Norddeutschland entstehen zu lassen. Dazu hatten die Hannoveraner beizeiten ein kaiserliches Mandat erwirkt, das Herzog Anton Ulrich absetzte und Herzog Rudolf August zum alleinigen Landesherrn ernannte. Gestützt auf dieses Mandat setzte sich der ältere Bruder erstmals gegen seinen agilen Mitregenten durch. Anton Ulrich verließ Wolfenbüttel, wo die Verhandlungen stattgefunden hatten, mit unbekanntem Ziel. Die Hannoveraner Unterhändler hatten nun leichtes Spiel, Rudolf August am 19. April 1702 im »Braunschweiger Vergleich« zur Abtretung von 800 Reitern und 2.400 Fußsoldaten zugunsten des Kaisers zu überreden. Der Herzog erhielt dafür eine »Vergütung« zugesichert. Wichtiger war aber die in Aussicht gestellte prompte Räumung des Landes, die auch nach Leistung der Unterschrift zügig erfolgte. Herzog Anton Ulrich wurde angeboten, dem Vertrag binnen zwei Monaten beizutreten und von allen künftigen Verträgen mit Frankreich Abstand zu nehmen. Falls er die Frist versäumen sollte, so würde er auf die Landesherrschaft dauerhaft verzichten

46 Zur Besetzung: ebd., Bd. 3, S. 372f.; vgl. auch die detaillierte Behandlung durch Georg Schnath in einem gesonderten Beitrag: Ders., Die Überwältigung Braunschweig-Wolfenbüttels durch Hannover und Celle zu Beginn des Spanischen Erbfolgekrieges, März 1702, in: Braunschweigisches Jahrbuch für Landesgeschichte 56 (1975), S. 27-100. 
müssen, auch auf die Nachfolge nach dem Tod seines Bruders. Diese Androhung wirkte: Anton Ulrich erschien innerhalb der Frist und trat dem Vertrag am 26. Mai bei, woraufhin der Kaiser seinen Herrschaftsausschluss am 3. Juli aufhob ${ }^{47}$. Ungelöst blieb die Kurfrage: Kurfürst Georg Ludwig hatte sie nicht zur Bedingung für das Abrücken der Hannoveraner gemacht, weil man mit langwierigem Widerstand und möglicherweise mit einer auswärtigen Militärintervention rechnete. Auch gegenüber der Öffentlichen Meinung im Reich sollte das Unternehmen als reichspatriotische Tat gegen einen französischen Verbündeten gewertet werden, nicht als gewaltsamer Austrag eines Familienkonflikts. Gestützt auf den militärischen Erfolg war man in Hannover sicher, dass man auch auf diplomatischem Wege ans Ziel kommen würde, wenn man den Vettern in Braunschweig erst einmal die Zähne gezeigt hätte.

Bis dahin benötigte man allerdings vier weitere Jahre, während deren Herzog Rudolf August von Braunschweig-Wolfenbüttel (Januar 1704) und Herzog Georg Wilhelm von Braunschweig-Celle (August 1705) starben. Der zwischenzeitig vereinbarte Vergleich von Celle 1703 fand nie die Zustimmung Herzog Anton Ulrichs und wurde daher schnell hinfällig. Für die verschiedenen Opponenten hatte sich der Konflikt inzwischen erschöpft: Die Militäraktion von 1702 und die Erbfälle, die ohne Komplikationen verlaufen waren, zeigten deutlich, dass es nur eine Frage der Zeit war, bis Hannover sich durchsetzen würde. Frankreich hatte durch den ungünstigen Verlauf des spanischen Erbfolgekriegs auch keine große Neigung mehr, sich in Norddeutschland zu engagieren. Zudem waren mit den beiden exilierten Wittelsbachern zwei wichtige Gegner der Sessionsveränderung im Kurfürstenrat ausgeschaltet worden. Herzog Anton Ulrich war des Widerstrebens nach 14 erfolglosen Jahren ebenfalls müde. Nun ging es nur noch um die Konzessionen, die Georg Ludwig zu machen bereit war. Am 17. Januar 1706 unterschrieben die Verhandlungsführer beider Seiten in Braunschweig den »Reunions- oder Haupttraktat« sowie den »Permutationsrezess«. Der erste Vertrag regelte die Anerkennung der Neunten Kur sowie die Präzedenz, der zweite die Abtretung aller Wolfenbütteler Ansprüche auf Lauenburg. Herzog Anton Ulrich konnte immerhin seinen Vorrang im Reichsfürstenrat sowie auf dem Niedersächsischen Kreistag wahren. In Personalibus dagegen beanspruchte der Kurfürst stets seinen Vorrang, wobei er gegenüber dem Kaiser damit argumentierte, es gehe um die Wahrung der Rechte aller Kurfürsten, und er könne hier keine Einzelabweichungen entstehen lassen. Wolfenbüttel erhielt ferner das Amt Campen sowie einige Orte innerhalb des Amtes Gifhorn als Entschädigung für seine aufgegebenen Lauenburger Ansprüche. Anton Ulrich musste schließlich auf fast alles verzichten, wofür er jahrzehn-

47 Ders., Geschichte Hannovers im Zeitalter der neunten Kur, Bd. 3, S. $373 f$. 
telang gekämpft hatte. Immerhin erhielt er die Zusage auf Mitbelehnung mit der Kur, die allerdings praktisch erst seinem Nachfolger 1726 zuteil wurde ${ }^{48}$.

Während derselben Zeit war der übrige Widerstand gegen die Neunte Kur fast völlig zum Erliegen gekommen. Der Krieg um die spanische Erbfolge führte zum erwarteten Schulterschluss der Reichsstände mit dem Kaiser, insbesondere, wenn ihre Territorien im Westen oder im Süden lagen und daher von Kampfhandlungen bedroht wurden. Kaiser und Welfenkurfürst konnten nach der Exilierung der Wittelsbacher 1706 Anspielungen fallen lassen, dass Opponenten der Neunten Kur wohl auch mit Frankreich sympathisieren würden, ein durchaus gefährliches Argument. Dänemark erkannte Georg Ludwig im August 1706 an, Markgraf Ludwig Wilhelm von Baden im November desselben Jahres. Nachdem der Herzog von Sachsen-Meiningen und der Herzog von Savoyen im Frühjahr 1707 diesen Schritten gefolgt waren, fehlten nur noch die Zustimmungen aus Frankreich und Rom. Ludwig XIV. hat Kurhannover im Art. 14 des Rastatter Friedens anerkannt, nur der Heilige Stuhl blieb eine positive Erklärung stets schuldig ${ }^{49}$.

Erst im Jahr 1708 gelang die Einführung in den Kurfürstenrat mit vollem Sitz- und Stimmrecht. Wie schon Kaiser Leopold I. es gewünscht hatte, so wurde es jetzt unter seinem Sohn Josef I. vollzogen. Nachdem der Reichstag am 30. Juni 1708 das zustimmende Reichsgutachten ${ }^{50}$ verabschiedet hatte, erfolgte das kaiserliche Ratifikationsdekret am 6. September 1708. Einen Tag später fanden die Zeremonien statt: Zunächst wurde die Readmission Böhmens durchgeführt, wobei das Königreich-Kurfürstentum durch den Grafen Franz Ferdinand von Kinsky vertreten wurde, bevor Freiherr Johann Christoph von Limbach für die Welfen deren Sitz einnehmen konnte ${ }^{51}$. Kurfürst Georg Ludwig profitierte dabei in doppelter Hinsicht von der Abwesenheit der Wittelsbacher: Zum einen gehörten Josef Clemens und Max Emanuel zu den entschiedensten Gegnern der Neunten Kur - in enger Abstimmung mit Frankreich -, zum anderen bekam Kurhannover das Erzschatzmeisteramt, das durch die kurpfälzische Bekleidung des Erztruchsessenamts wieder freigeworden war $^{52}$. Durch die bayerische Restitution 1714 konnte das hannover-

$48 \mathrm{Zu}$ den Verhandlungen und ihren Ergebnissen: ebd., Bd. 3, S. 394-396. - Herzog Anton Ulrich musste ferner zurückschwenken zur prokaiserlichen Politik, die Kontakte zu Frankreich schwächten sich ab: RöMER, Der Kaiser und die welfischen Staaten, S. 48f.

49 SсhnAth, Geschichte Hannovers im Zeitalter der neunten Kur, Bd. 3, S. 409f.

50 Abdruck des Reichsgutachtens vom 30. Juni 1708: Hanns Hubert Hofmann (Hg.), Quellen zum Verfassungsorganismus des Heiligen Römischen Reiches Deutscher Nation 1495-1815, Darmstadt 1976, S. 279-281.

51 Vgl. die Schilderung des zeremoniellen Ablaufs bei Schnath, Geschichte Hannovers im Zeitalter der neunten Kur, Bd. 3, S. 420-422.

52 Georg Melchior von Ludolf, Electa Juris Publici. Worinnen Die Vornehmsten Staats-Affairen in Europa/Besonders in Teutsch=Land/aus bewährtesten Actis publicis [...] recensiret werden, 21 Bd., München 1709-1725, hier Bd. 7, S. 460-463. 
sche Stimmrecht nicht mehr rückgängig gemacht werden, doch musste man das Erzschatzmeisteramt wieder an die Pfalz rückübertragen. Die Welfen protestierten dagegen, wenn auch ohne Erfolg. Das ihnen zugedachte $»$ Erzbannerträgeramt« warf hingegen neue Probleme auf, sowohl mit Kursachsen als auch mit dem Herzog von Württemberg, der sein Amt als Träger der Reichssturmfahne beeinträchtigt sah. Der Austrag dieser Streitigkeiten soll allerdings nicht an dieser Stelle verhandelt werden, selbst wenn sich Gottfried Wilhelm Leibniz schon 1694 mit einer umfangreichen Deduktion zu diesem Thema geäußert und dabei eine württembergische Schrift widerlegt hatte ${ }^{53}$.

\subsection{Deduktionen und Flugschriften zum Reichsrechtsstreit}

Im Gegensatz zur Öffentlichkeit im Reich konnte die kurfürstliche Regierung in Hannover und den zugehörigen Territorien die Medienverhältnisse kontrollieren. Missliebige Informationen konnten nicht in Umlauf gesetzt werden, geheime Handlungen bei Hofe blieben geheim. Sebastian Küster spricht für die folgende Epoche von zwei »Teilöffentlichkeiten«, eine »Volksöffentlichkeit« und eine der staatstragenden Obrigkeit ${ }^{54}$. Politische Traktate, die umliefen, stammten vorwiegend aus dem Umfeld von Hof und Regierung sowie von Personen, die von diesem Machtzentrum beauftragt worden waren oder ihm zuarbeiteten. Ob der Kurfürst anwesend war oder später - nach 1714 - in London regierte, änderte an der Macht der Hannoveraner Räte wenig. Die »Volksöffentlichkeit« wird bei Sebastian Küster allerdings so konstruiert wie die »repräsentative Öffentlichkeit« bei Jürgen Habermas: Die Herrschaft zelebrierte sich in Pracht, und das Volk applaudierte. Wenn der Herrscher abwesend war, dann fand Öffentlichkeit nicht statt - außer in kirchlich vermittelter Form (Analogie der Unsichtbarkeit Gottes und des Landesherrn). Auf dieser Basis konnte sich in Hannover kein breites Druckgewerbe entwi-

53 Württembergische Position: »Deduction Daß dem Hoch=Fürstl. Haus Würtemberg/das Reichs $=$ Panner oder Reichs $=$ Fendrichs $=$ Amt $/$ Praedicat und Insigne, schon von etlichen Seculis her/rechtmässig zustehe/und dahero ohne Kränckung desselben althergebrachter Praerogativen, keinem andern Chur $=$ oder Fürsten erst neuerlich verliehen werden könne [...]«, o.O. 1694. Widerlegung durch Leibniz: [Gottfried Wilhelm LeIBNIz], »Wechsel= Schrifften vom Reichs $=$ Bannier, In sich haltend einen Beweiß Vom Unterscheid zwischen demselben und der Würtembergischen Sturm=Fahne, Dann ferner die Hoch=Fürstl. Würtembergische Deduction samt deren Beantwortung [...]«, Hannover 1694. Vgl. dazu: Schnath, Geschichte Hannovers im Zeitalter der neunten Kur, Bd. 3, S. 424-432; vON EsEBECK, Die Begründung der hannoverschen Kurwürde, S. 104-111; BEIDERBECK, Leibniz als politischer Berater des Welfenhauses, S. 147f. Vgl. zum Streit zwischen Kurhannover und Württemberg auch die Studie von Ludolf Pelizaeus, Der Aufstieg Württembergs und Hessens zur Kurwürde, pas.

54 Sebastian Küster, Vier Monarchien - Vier Öffentlichkeiten. Kommunikation um die Schlacht bei Dettingen, Münster 2004, S. $216 \mathrm{f}$. 
ckeln, es fehlten die Medienproduzenten, anders als in den Hauptstädten der europäischen Mächte und in den großen Druckgewerbestädten im Reich. Mit dem fehlenden Angebot korrelierte die Nachfrage: Auch fremdsprachige Zeitungen sind nicht nachgewiesen, jedenfalls nicht in nennenswerter Zahl ${ }^{55}$.

Dafür entwickelte sich außerhalb der welfischen Lande eine ausgiebige Publizistik um das Für und Wider der Neunten Kur, die vor allem auf der Basis von Traktaten ausgetragen wurde. Eröffnet wurde die Debatte durch die Schrift Caesarini Fuerstenerii De Jure Suprematus Ac Legationis Principum Germaniae Tractatus, die Gottfried Wilhelm Leibniz 1677 herausbrachte ${ }^{56}$. Er hatte den Traktat im Auftrag der Hannoveraner Regierung verfasst, für die er die Gleichrangigkeit Braunschweig-Lüneburgs mit den Kurfürsten des Reiches nachweisen sollte. Leibniz stellte in diesem Zusammenhang die "Suprematstheorie« auf, eine Ausdehnung der Landesherrschaft in die völkerrechtliche Dimension unter völliger Ausschöpfung aller Zugeständnisse, die die Reichsfürsten im Westfälischen Frieden hatten durchsetzen können. Friedrich Beiderbeck betont, dass diese Theorie den frühneuzeitlichen territorialen Verdichtungsprozess zum Ausdruck brachte, wenn auch weiterhin unter Anerkennung der Bindungen an den supraterritorialen Verbund des Alten Reiches. Bezogen auf den Kurfürstenstatus schreibt Beiderbeck:

Zwar sollte nicht übersehen werden, daß im »Caesarinus« teilweise sehr polemische Äußerungen über das Kurkollegium zu finden sind, wie beispielsweise der Vorwurf, der Kurfürstenstand betreibe die Errichtung einer Oligarchie. Trotzdem würdigte Leibniz schon 1677 den funktionellen Spielraum, den das Kurkolleg im Verfassungsleben des Reiches einnahm und der es im Vergleich zum Fürstenkollegium aufgrund seiner geringen Stimmenzahl zu einem leicht zu einigenden, flexiblen und daher mächtigen Verfassungsorgan machte; für einen ambitionierten Reichsfürsten wie Ernst August eine verlockende Perspektive, die zahlreichen Hürden im Willensbildungsprozeß des Fürstenkollegiums hinter sich zu lassen, um Reichspolitik an zentraler Stelle mitzugestalten ${ }^{57}$.

Wichtig war für Leibniz nicht mehr nur die formalrechtliche Betrachtungsweise, der gemäß ein förmlicher Rang zur völkerrechtlichen Anerkennung führte. Er ließ sich eher von der pragmatisch-politischen Sicht leiten: Danach war nur ein Fürst »souverän«, der über hinreichende finanzielle und militärische Mittel verfügte, um innerhalb der europäischen Konflikte eine handelnde Rolle spielen zu können. Aus dieser Sicht schloss der Hannovera-

55 Ebd., S. 217f. u. 468f.

56 Im Folgenden wird zurückgegriffen auf die Ausgabe von 1678: [Gottfried Wilhelm LeIBNIZ], "Caesarini Fuerstenerii De Jure Suprematus Ac Legationis Principum Germaniae Tractatus«, Amsterdam 1678.

57 BeIDERBECK, Leibniz als politischer Berater des Welfenhauses, S. 144. 
ner Gelehrte, dass im Reich auch die Fürsten im Kurkolleg sitzen sollten, die diese Handlungsfähigkeit unter Beweis gestellt hatten ${ }^{58}$. BraunschweigLüneburg konnte aufgrund der militärischen Hilfen zum Türkenkrieg einen derartigen Rang für sich in Anspruch nehmen und drang schließlich damit durch.

Der Streit wurde zunächst nicht öffentlich aufgegriffen, weil er abgeschirmt zwischen dem Wiener und dem Hannoveraner Hof ausgehandelt wurde. Die erste publizierte Schilderung betraf daher die feierliche Belehnungszeremonie vom 19. Dezember 1692, über die ein gesonderter Bericht herausgebracht wurde ${ }^{59}$. Auch wenn der Text in der äußeren Form einer Flugschrift erschien, so folgte er doch der Textgestaltung einer Reportage. Der Bericht ist, seiner eigenen Orts- und Datumszeile folgend, einen Tag nach dem Actus verfasst worden ${ }^{60}$. Dabei kokettiert der Schreiber damit, dass er in einen Bereich der Hofburg vordringen konnte, der sonst hohen Standespersonen vorbehalten sei. Er selbst habe sich »Fuß für Fuß« vorgearbeitet, bis er kaum sechs Fuß weit von der kaiserlichen Bühne entfernt war und das Geschehen gut verfolgen konnte. Es folgt die Ablaufschilderung: Auffahrt der Hannoveraner Gesandten, der Freiherren von Grote und von Limbach, Aufstellung in der Hofburg (Platzierung der Funktionsträger und des adligen Publikums), Auftritt des Kaisers, der aus der Geheimen Ratsstube in den Rittersaal hineinschritt, das Schwert voraustragen ließ und auf dem Thron unter dem Baldachin (roter Damast mit »güldenen Frangen«) Platz nahm. Die Gesandten wurden vom Oberkämmerer hineingebeten, machten drei »Reverenzen«, d.h. Verbeugungen mit Kniefall, und nahmen schließlich vor dem Thron eine kniende Stellung ein. Der Kaiser erwiderte den Gruß durch einmaliges Ziehen seines Hutes (mit blauer Feder). Dort sprach der Freiherr von Grote eine »zierliche wolgesetzte Rede« wegen der Investitur Hannovers ${ }^{61}$. Gleichzeitig entschuldigte er seinen Herrn wegen dessen Verhinderung, beim Actus selbst zugegen zu sein.

Anschließend trat der Graf Waldstein als Senior des Reichshofrats vor, kniete vor dem Kaiser und bekam von diesem mit leiser Stimme gesagt, was er antworten sollte. Daraufhin erklärte Waldstein, der Kaiser lasse die Entschuldigung des Herzogs Ernst August wegen dessen Abwesenheit gelten. Die Kurwürde komme demselben zu wegen der treuen Dienste, die er

58 Vgl. die zusammenfassenden Bemerkungen zum »Caesarinus«: Ebd., S. 144

59 »Wahrer außführlicher Bericht von Wien/Was bey jüngster Investitur Des neunten Electorats De dato den 9./19. Decembr. 1692 Vorgangen«, Hamburg 1692.

60 Die Überschrift erscheint auf dieselbe Weise, wie ausführliche Beilagen in zeitgenössischen Zeitungen angekündigt wurden: »Extract Schreibens aus Wien vom 10. Decembr. styl. vet. $1692 \ll$.

61 An der Erstellung der Rede hatte Gottfried Wilhelm Leibniz mitgewirkt: BEIDERBECK, Leibniz als politischer Berater des Welfenhauses, S. 148f. 
dem ganzen Reich geleistet habe. Zum Schluss betonte Waldstein, der Kaiser bleibe dem Herzog von Braunschweig-Lüneburg mit Freundschaft und kaiserlicher Huld zugetan und auch den Hannoveraner Gesandten mit kaiserlicher Gnade gewogen. Nun standen die Gesandten auf, traten näher zur Bühne und knieten nach abermaliger Reverenz direkt vor dem Kaiser nieder. Der Reichshofrat Graf Waldstein las ihnen die Huldigungsformel vor, die sie, mit dem Finger auf dem Evangelienbuch, nachsprachen. Der Kaiser, der das Evangelienbuch auf dem Schoß liegen hatte, hatte während des Sprechens der Huldigungsformel seinen Hut abgesetzt.

Er nahm das Reichsschwert, das der Fürst Schwarzenberg als Obersthofmeister der Kaiserin (in Stellvertretung des Obersthofmarschalls) trug, in beide Hände und bot den Gesandten den Schwertknopf zum Kuss dar. Die Gesandten standen daraufhin auf, machten eine weitere Kniebeuge und gingen rückwärts zu ihrer vorigen Stelle »unter der Bühne«, wo sie wieder knieten. Hier sprach der Freiherr von Limbach eine »wohlgesetzte Dancksagung «. Dann standen beide auf und machten eine weitere Reverenz. Der Kaiser winkte dem Grafen Waldstein, der daraufhin den bereitliegenden Kurhut (Silber, vergoldet, mit blauem Samt) an den Freiherrn von Grote übergab, der ihn mitsamt Kissen annahm, indem er eine weitere tiefe Reverenz machte. Beim Rückweg zur Tür zur zweiten Antichambre entboten beide Gesandte zwei weitere Reverenzen, eine in der Mitte des Raumes und die andere zwei Schritte vor der Tür, um dann in der Antichambre zu verschwinden.

Der Autor des Berichts kam nicht umhin, darauf hinzuweisen, dass der Herr Kammerpräsident (gemeint war der Freiherr von Grote) einen spanisch gekleideten Kavalier neben sich hatte, der ihm bei den Kniebeugen behilflich war, da er bereits betagt war und ihm der Schweiß die Wangen hinunterlief. Anschließend fanden in der ganzen Stadt Wien Feierlichkeiten statt, bei denen nach Mitteilung des Berichterstatters wohl tausendmal auf die Gesundheit des Kurfürsten von Braunschweig-Lüneburg getrunken worden sei.

In der Folgezeit waren die originellen Deduktionen, die eigene Rechtsstandpunkte herleiteten, in der Minderzahl gegenüber einer großen Zahl von Drucken aus den Jahren 1692 und 1693, die mit oder ohne Vorwort eine Anzahl von Quellenstücken zu Papier brachten. Diese Quellenstücke stammten aus den Kanzleien der Betroffenen und waren mehrheitlich dazu gedacht, eigene Standpunkte der Gegenseite zunächst brieflich vor Augen zu stellen. Ihre Veröffentlichung war dann eine Spätfolge. In der Schrift Acta Publica wurden 19 Quellenstücke zugunsten der Hannoveraner Position abgedruckt, die Schrift Receß bestand aus vier Quellenabdrucken ${ }^{62}$. Auch unter der fik-

62 »Acta Publica Den Neunden Electorat betreffende«, o.O. 1692; »Receß zwischen Ihro 
tiven Verfasserangabe »Hyppolito à Lapide« erschien eine Edition von 25 Quellenstücken, die Deutungen beider konkurrierenden Lager enthielt ${ }^{63}$.

Dabei dominierten detaillierte Deduktionen gegen die Neunte Kurwürde: Die Hannoveraner Regierung hatte vollendete Tatsachen geschaffen, den Opponenten blieb nach der Überraschung nur der wortreiche Protest. Die Herzöge Rudolf August und Anton Ulrich von Braunschweig-Wolfenbüttel hatten unter dem Datum 11./21. August 1692 offiziellen Protest (»Protestation, Declaration und Reservation «) gegen die Erhebung des Hannoveraner Vetters in den Kurfürstenstand eingelegt. Die beiden Herzöge stellten sich als Betroffene der Entscheidung dar, die ohne ihr Vorwissen vom Kaiser getroffen worden sei. Die Linie Braunschweig-Wolfenbüttel als die ältere welfische Linie verliere ihren angestammten Vorrang, wenn die Hannoveraner künftig einen höheren Stand innehätten. Die beiden Fürsten gingen davon aus, dass sie zu einer so folgenreichen Entscheidung vorher hätten gehört werden müssen. Da das nicht erfolgt sei, beanspruchten sie innerhalb des Niedersächsischen Kreises und im welfischen Familienrecht weiterhin ihre angestammte Position ${ }^{64}$.

In der Druckschrift Miscellanea juris publici curiosa de Novemviratu meint der anonyme Verfasser unter dem Titel Unmaßgebliche Gedanken, vier interessierte Hauptparteien müssten gegen die Kurerhebung eintreten: 1. die kaiserliche Familie, denn künftig würde die Kaiserwahl bei mehr Wählern schwieriger; 2. Das Kurfürstenkollegium, dessen »Präeminenz« mit jedem weiteren Kurfürsten sinke; 3. die übrigen Reichsfürsten, die mitbestimmen wollten, weil ihre Rangordnung durch die Verfassungsänderung berührt sei; 4. die Könige von Frankreich und Schweden, die einen schweren Eingriff in die Bestimmungen des Westfälischen Friedens zu konstatieren hätten ${ }^{65}$. Drei Fragen sollten sich die Kurfürsten stellen: 1. Ob ein neunter Kurfürst eingeführt werden sollte? 2. Mit wessen Zustimmung er sein Recht erhalten könne? 3. Ob es ratsam sei, durch die anderen Kurfürsten eingeführt zu werden? An Antworten gab der Verfasser: $\mathrm{Zu}$ 1. nach der Goldenen Bulle dürfe keine neue Kur geschaffen werden; zu 2. die Investitur sei kaiserliches Recht;

Römisch=Kayserlichen Majest. und dem Hoch=Fürstl. Hauss Braunschweig=Lüneburg, Die Chur=Würde betreffend «, o.O. 1692.

63 Hyppolito À LAPIDE, »Allerhand Curiose Raisonnements von der IX. Chur=Würde Deß Durchleucht. Fürsten und Herrn/Herrn Ernst Augusti Hertzogen zu Braunschweig und Lüneburg als nunmehro des Heil. Röm. Reichs Ertzpanner und Chur=Fürsten/zusammen getragen «, o.O. 1693.

$64 »$ Verwahrungs=Schrifft/Des Fürstlichen Hauses Braunschweig Lüneburg=Braunschweig/ betreffendt Die Von dem Fürstl. Hause Braunschweig Lüneburg=Hannover verlangende Chur=Würde. Wie dieselbe Beym Kayserlichen Hofe den Actis publicis insinuiret worden«, o.O. 1692 .

65 »Miscellanea juris publici curiosa de Novemviratu. Bestehend in nachfolgenden Fragen: $\mathrm{Ob}$ nemlich der Neunte Electorat eingeführet werden könne? [...]«, o.O. 1692, hier S. 4-9. 
in der Goldenen Bulle stehe das, was der Kaiser allein oder mit Zustimmung der Kurfürsten tun dürfe; zu 3. für die Einführung einer neunten Kur bestehe keine reichsrechtliche Notwendigkeit, daher sei die Frage bedeutungslos ${ }^{66}$. In ähnlicher Weise argumentierten die Schriften Remarques über einen im Römischen Reiche sine die \& consule ausgestreueten Vorschlag/die Neundte Chur $=$ Sache betreffend und Vorstellung Des Hohen Reichs $=$ Rechtens ${ }^{67}$. Überall wurde die Integrität des Reiches für verletzt gehalten, wenn die Kurfürstenzahl erhöht würde: Zuständig sei der gesamte Reichstag.

Auf die letzte dieser Schriften replizierte die prohannoveranische Deduktion Anmerckungen oder Refutation der Vorstellung deß hohen Reichs $=$ Rechtens. Der unbekannte Verfasser erklärt die Siebenzahl der Kurfürsten nicht für zwingend geboten, schließlich sei schon 1648 davon abgewichen worden $^{68}$. In zwei weiteren Deduktionen in den folgenden beiden Jahren bekräftigte Gottfried Wilhelm Leibniz den Anspruch der Hannoveraner Herzöge auf die Kurfürstenwürde ${ }^{69}$. Leibniz rekurrierte dabei auf die Vorstellung der Kurfürsten als »Säulen des Reiches«, wobei er erwähnte, dass ein Haus auf acht oder neun Säulen besser ruhe als bloß auf sieben ${ }^{70}$. 1694 legte Leibniz eine ausführliche Deduktion vor, die den Zweck verfolgte, zu beweisen, das von Kaiser Leopold I. für Kurhannover gestiftete Amt des »Erzbannerträgers« sei nicht dasselbe wie die württembergische Gerechtigkeit der ReichsSturmfahne. Dieses Ergebnis stand schon als These im Vorwort, und alle folgenden Argumente dienten dazu, dies zu bestätigen ${ }^{71}$. Leibniz ging dabei auf eine Deduktion des württembergischen Oberrats Johann Georg von Kulpis ein und rückte dessen kompletten Text ein ${ }^{72}$. Das Haus Württemberg versi-

66 Ebd., S. 9-11. Auch hier folgten im Anhang einige Quellenstücke.

67 »Remarques über einen im Römischen Reiche sine die \& consule ausgestreueten Vorschlag/die Neundte Chur=Sache betreffend«, o.O. 1692; »Vorstellung Des Hohen Reichs=Rechtens/Vermöge Dessen An den Grund Gesetzen des Heil. Römischen Reichs und der darinnen von dem gesambten Reich bestättigten Zahl der Chur=Fürsten ohne vorher in allen dreyen Reichs $=$ Collegiis geschehene Berathschlagung $/[$ [..] Nichts zu verendern [...] «, o.O. 1692.

68 »Anmerckungen oder Refutation der Vorstellung de $\beta$ hohen Reichs=Rechtens, da $\beta$ ohne ein allgemeines Reichs $=$ Gutachten an der Zahl der Chur=Fürsten nicht zu ändern sey [...]«, o.O. 1693; vgl. vor allem die 16 Seiten umfassende Einführung, bevor auch in dieser Schrift 27 Quellen angehängt werden.

69 [Gottfried Wilhelm Leibniz], »Unvorgreifliches Sentiment Uber die Neue Hannoverische Chur=Würde/Darinnen die dabey vorkommende vornehmste Quaestiones unpartheyisch ausgeführet/und die gröste dubia removiret worden«, o.O. 1693.

70 Ebd., S. 7.

71 [Gottfried Wilhelm LeIBnIZ], »Wechsel = Schrifften vom Reichs=Bannier, In sich haltend einen Beweiß Vom Unterscheid zwischen demselben und der Würtembergischen Sturm=Fahne, Dann ferner die Hoch=Fürstl. Würtembergische Deduction samt deren Beantwortung [...]«, Hannover 1694.

72 Johann Georg voN KulpIs, »Deduction Daß dem Hoch=Fürstl. Haus Württemberg/das Reichs $=$ Panner $=$ oder Reichs $=$ Fendrich $=$ Amt $/$ Praedicat und Insigne, schon von etlichen Seculis her/rechtmässig zustehe [...]«, o.O. 1693. 
cherte sich anschließend der gutachterlichen Dienste von Christian Leonhard Leucht, dem bekannten Herausgeber der Europäischen Staats-Cantzley, die üblicherweise unter Leuchts Pseudonym »Anton Faber« firmierte ${ }^{73}$.

Bei den antihannoveranischen Schriften wurde sogar die Gefahr, dass noch weitere Kurwürden, eine zehnte oder elfte Kur, entstünden, an die Wand gemalt. In der Druckschrift Gründlicher Unterricht Vom Ursprung derer 7. Chur $=$ Fürsten lehnte der anonyme Verfasser derartige Tendenzen scharf ab. Die Vergrößerung des Kurfürstenrates sei reichsrechtlich verboten, weil sie 1. gegen die Goldene Bulle verstoße, 2. der darauf gegründeten Observanz widerspreche und 3. nicht mit den Dispositionen des Westfälischen Friedens im Einklang stehe ${ }^{74}$. Die Fenster-Wirkung war dabei fest einkalkuliert, so etwa bei der Declaratio nullitatis, die am 25. Januar 1693 zwischen den Regensburger Vertretern von Dänemark, Münster, Sachsen-Gotha, Braunschweig-Wolfenbüttel und Hessen-Kassel vereinbart wurde: Die Unterzeichner lehnten die Neunte Kur als einen Verstoß gegen die Reichsordnungen ab und erklärten sie für unwirksam, null und nichtig ${ }^{75}$. Die Veröffentlichung war in diesem Fall allerdings von Anfang an beabsichtigt, und so spricht alles dafür, dass der Druck bereits in Regensburg aufgelegt wurde. Der Kaiser verbot den obersten Reichsbehörden, die »Declaratio« anzunehmen ${ }^{76}$.

Bei anderen Schriften wurde nicht nur juristischer Scharfsinn, sondern auch literarischer Ehrgeiz aufgewendet, um die eigene Position zu vermitteln. Im Schreiben An Einen Gesandten zu Regensburg, einem fingierten Brief, stand ein Gespräch zwischen einem kurfürstlichen und einem fürstlichen Minister im Mittelpunkt, den der Verfasser vorgab, gehört zu haben ${ }^{77}$. In diesem Dialog ging es um die Verfahrensweise, wie von Seiten des Kaisers und der Kurfürstenmehrheit der Herzog von Braunschweig-Lüneburg zum Neunten Kurfürsten erhoben worden sei. Aus dramaturgischen Grün-

73 [Christian Leonhard Leucht (Pseud.: Cassander Thucelius)], Electa Juris Publici Curiosa. Vorstellend das Alte Fürsten $=$ Recht $/$ samt den Novem $=$ Viratum Vornehmlich aber Des Fürstlichen Haußes Würtemberg Jura Wegen des Reichs = Pannerer und Fendrich Ambts / [...], Frankfurt a.M./Leipzig 1694. - Leucht bekräftigte später seine Positionen in seiner mehrbändigen Edition von staatsrechtlichen Quellen: Christian Leonhard LEUCHT, Des Heillgen Römischen Reichs-Staats Acta von itzigen 18. seculo sich anfahend, in welchen nicht allein, die bey annoch währenden Reichs-Tag eingereichte Staats-Schrifften [...] enthalten [...] In gute Ordnung gebracht [...] von Cassandro Thucelio, 5 Bd., Frankfurt a.M. u.a. 1715-1722.

74 »Gründlicher Unterricht Vom Ursprung derer 7. Chur=Fürsten mit Vorstellung der Motiven und Ursachen [...] ob selbige itziger Zeit mit den Neundten/Zehnden/Eilfften etc. derer Fürsten und Stände des Reichs [...] könne vermehret werden«, o.O. 1693. - Im Anhang sind einige Dokumente zu den Friedensverhandlungen von Münster und Osnabrück angeführt sowie ein Schreiben von Kurpfalz an Brandenburg-Preußen.

75 Schnath, Geschichte Hannovers im Zeitalter der neunten Kur, Bd. 2, S. 20.

76 Ebd., Bd. 2, S. 26.

77 »Schreiben An Einen Gesandten zu Regensburg vom 8. October 1692 Den Neundten Electorat betreffent«, o.O. ${ }^{2} 1693$. - Zur Stilform des »fingierten Briefes«: Helmuth RogGe, Fingierte Briefe als Mittel politischer Satire, München 1966. 
den wurde der Bericht auf dem 8. Oktober 1692 rückdatiert, also auf einen Zeitpunkt, als die Entscheidung des Kurfürstenrats über die Kurerhebung noch nicht gefallen war (sie fand erst am 17. Oktober 1692 statt). Die Debatten in diesem Dialog verliefen sehr höflich, im diplomatischen Stil der Zeit. Als Fazit lässt sich ausmachen, dass beide Disputanten nichts dagegen hätten, wenn die Angelegenheit im Plenum des Reichstags verhandelt werden würde. Dies ist auch die Stoßrichtung der Argumentation: Hinter der Flugschrift verbirgt sich die Meinung der Reichsfürsten, die Kurerhebungen für eine Reichstags-Angelegenheit in genere erachten und künftige Entscheidungen dieser Tragweite dem Kurfürstenrat entziehen wollen. Die Flugschrift ist ein schönes Beispiel, wie eine schwierige politische Entscheidung auf ihre reichsrechtlichen Grundlagen abgeklopft werden konnte, ohne dass die Debatte mit Latinismen überlastet worden wäre. Zielgruppe dürfte hier eine Öffentlichkeit gewesen sein, die über die Juristen hinausging ${ }^{78}$. Dabei ist davon auszugehen, dass der Verfasser in rechtlichen Fragen bewandert war. Allerdings kleidete er rhetorisch geschickt die Thematik in einen Dialog ein, eine seit der Antike erprobte Form, diskursiv schwierige Sachverhalte zu erläutern und gegensätzliche Auffassungen zum Austrag zu bringen.

Noch um 1700 erschienen Schriften, die den reichsfürstlichen Standpunkt gegen die Neunte Kur unterstrichen. Während der Traktat Die untadelige Conduite noch einmal die Unvereinbarkeit der Kurfürstenpromotion mit dem Westfälischen Frieden betonte ${ }^{79}$, argumentierte die französischsprachige Schrift Lettre ecrite auf der Grundlage des europäischen Mächtesystems: Durch den dauerhaften Machtanstieg des Kurfürsten Georg Ludwig von Braunschweig-Lüneburg, in seinem Besitz vermehrt um die unmittelbar bevorstehende Vereinigung der hannoveranischen und cellischen Besitzanteile, wären alle Nachbarn bedroht. Diese wurden aufgefordert, sich mit Herzog Anton Ulrich von Braunschweig-Wolfenbüttel zu verbünden, um mit ihm gemeinsame Gegenmaßnahmen zu ergreifen. Das nächste Argument wandte sich direkt gegen den Kaiser: Wenn nun keine Abhilfe geschaffen würde, dann drohe eine kaiserliche Herrschaftsweise über das Reich, durch die die Reichsstände nur noch gewöhnliche Untertanen (sujets simples) des Kaisers seien. Frankreich hingegen würde jedem Opponenten gegen diese Entwicklung seine hilfreiche Hand anbieten ${ }^{80}$. Georg Schnath schreibt dazu:

78 Dafür spricht auch, dass diese Flugschrift mehrfach nachgedruckt wurde: FRIEDRICH, Drehscheibe Regensburg, S. 423 (mit Quellennachweisen).

79 »Die Untadeliche Conduite derer Correspondierenden Reichs-Fürsten/Welche Sie Bey Anruffung derer Hohen Garants Deß Westphäl. Friedens Uber die IX. Chur-Sache erwiesen«, o.O. 1700 .

80 »Lettre écrite par un gentilhomme à un de ses amis sur un bruit qui court touchant la jonction du duché d'Hanover avec celui de Zell«, o.O. [=Amsterdam] 1700. 
Das alles läßt vermuten, daß der Urheber, mindestens aber der Auftraggeber dieser Flugschrift in Wolfenbüttel zu suchen ist, wenn auch das übermäßig gehäufte Lob Anton Ulrichs dessen persönliche Verfasserschaft unwahrscheinlich macht. Die von Hannover sofort eingeleiteten Nachforschungen ergaben, daß der Drucker den Auftrag von einem französischen Kaufmann Amiot in Amsterdam bekommen hatte und daß diesem das Manuskript tatsächlich aus Wolfenbüttel zugeleitet worden war. Amiot und Pain wurden von der Obrigkeit in Strafe genommen, die Drucklegung einer zweiten Flugschrift ähnlichen Inhalts mit dem Datum Bremen, 10. April 1700, ward verhindert. Weitere Ermittlungen, mit denen die Hauskonferenz vom 24. April 1700 den Rittmeister v. Eltz beauftragte, hatten das unerwartete Ergebnis, daß Anton Ulrich das Pamphlet nicht veranlaßt, sondern im Gegenteil den Franzosen Delorme, einen Konfidenten des Prinzen Ludwig Rudolf, davongejagt habe, als dieser ihm den Text vorlegte. Delorme bezeichnete, von Eltz in Halberstadt aufgespürt, als Verfasser des Pasquills niemanden anders als J.A. Ducros, der deren noch mehrere unter der Feder habe. Auch scheint der Gesandte Du Héron im Hintergrund der Affäre zu stehen, die sich dann aber im Sande verlief ${ }^{81}$.

Die militärische Zuspitzung zwischen Kurhannover und Braunschweig-Wolfenbüttel 1701 und Anfang 1702 war Gegenstand zahlreicher Druckschriften. Die meisten von ihnen erschienen allerdings erst, als der Hannoveraner Angriff auf die östlichen Vettern schon vollendet war. Direkt nach dem Ereignis erschien ein »Bericht« im Stile einer Neuen Zeitung des 16. Jahrhunderts: Der Leser erfuhr hier von den Einzelheiten des Hannoveraner Truppeneinmarschs ins Herzogtum Braunschweig-Wolfenbüttel, ohne dass eine Tendenz für die eine oder andere Seite erkennbar wurde. Auch wurde nicht über die Kriegsursachen räsoniert, sondern allein auf die militärischen Ereignisse Bezug genommen ${ }^{82}$. Am Beginn der folgenden Flugschriftendebatte stand die Schrift Uhrsachen ${ }^{83}$. Sie repräsentierte die Ansicht der Regierung in Hannover und demaskierte die Wolfenbütteler Bemühungen als reichsverräterische Kriegsrüstungen, die ganz Norddeutschland mit der Furie der Gewalt überzogen hätten, wenn nicht rechtzeitig eingeschritten worden wäre. Die hannoversche Aktion konnte vor diesem Hintergrund als Waffeneinsatz für den Frieden etikettiert werden. Das abgedruckte Dokument war zwar nicht - wie sonst vielfach gebräuchlich - mit Herkunftsort und Datumsangabe versehen, stellte aber dennoch ein Kriegsmanifest im Sinne der Klas-

81 Schnath, Geschichte Hannovers im Zeitalter der neunten Kur, Bd. 3, S. 186f.

82 »Bericht von der Fürstl. Zellisch= und Hannöverischen Trouppen Einfall In Die Fürstliche Braunschweig = Wolffenbüttelsche Lande [...]«, o.O. 1702.

83 »Uhrsachen Warumb das Haus Braunschweig-Lüneburg, Zellischer Linie, gegen die vom Hause Braunschweig-Lüneburg, Wolfenbüttelische Linie, vorgenommene ungemeine Armatur [...] seine Sicherheit zu beobachten [...] gemüssiget worden«, o.O. 1702. 
sifizierung von Konrad Repgen dar ${ }^{84}$. Im Text wurden Passagen zitiert, die aus dem Wolfenbütteler Memorandum zum Bündnis der Fürsten stammten. Vermutlich sind die Informationen der Regierung in Hannover auf nachrichtendienstlichem Wege verfügbar gemacht worden. Gegenüber Herzog Anton Ulrich erhob der anonyme Verfasser den Vorwurf, er habe einen Teil des Celler Erbes an sich bringen wollen ${ }^{85}$.

Die Wolfenbütteler Seite brachte ihre Verbitterung über die Entwicklung in der Schrift Umbständlicher Bericht zum Ausdruck. Die Tendenz erschließt sich schon im ersten Satz, als der anonyme Verfasser der Hannoveraner Regierung die Schuld für den Konflikt vom März 1702 zuwies:

Welcher Gestalt die in denen Fürstl. Braunschw. Lüneb. Häusern eine Zeithero obgeschwebte Mißhelligkeiten im Monat Martio dieses 1702. Jahres/durch der Fürstl. Zell = und Hannöverischen Trouppen feindlichen Einfall in die Fürstlich Wolfenbüttelschen Lande öffentliche Thätigkeiten ausgebrochen/solches wird zweifels ohne bey vielen annoch im frischen Andencken beruhen $[\ldots]^{86}$.

Die Argumente der gegnerischen Seite wurden als "Schein-Uhrsachen « bezeichnet, die im Druck überall ausgestreut worden seien. Die »Conduite«, d.h. das rechtliche und moralische Verhalten des Herzogs Anton Ulrich wurde dagegen als »untadelhafft« bezeichnet.

Der »Truppeneinfall«, wie die Regierung in Wolfenbüttel ihn empfand, war nur der eine Diskussionspunkt. Viel gravierender unter langfristiger Perspektive war die Zurücksetzung der Wolfenbütteler durch die Verleihung der Neunten Kurwürde an den Herzog von Braunschweig-Lüneburg. Dabei warf der Verfasser den Hannoveranern vor, sie hätten das Kurprojekt von langer Hand vorbereitet und sich dazu mit der Celler Linie abgestimmt und diese einbezogen. Die Wolfenbütteler Verwandten seien hingegen über das Procedere völlig in Unkenntnis gelassen worden ${ }^{87}$. Nun habe man sich mit Dänemark und Frankreich verbündet, allerdings nur mit defensiver Absicht, um sicher im eigenen Territorium die Landesherrschaft ausüben zu können. Der anonyme Verfasser betonte, dass Herzog Anton Ulrich keinerlei Absicht habe, sich hinter dem Rücken der Hannoveraner Linie in den Besitz von Teilen des Herzogtums Celle zu bringen (angesichts des bevorstehenden Aus-

84 Zu Kriegsmanifesten: Repgen, Kriegslegitimationen in Alteuropa, hier S. 39-47.

85 »Uhrsachen«, S. 11 u. 13.

86 »Umbständlicher Bericht von denen In den Fürstlich Braunschweig. Lüneburgischen Häusern/Zell- und Wolffenbüttelscher Linie, bishero vorgekommenen Differentien«, o.O. 1702, hier S. 1. - In den Beilagen sind Briefe abgedruckt, die die Harmlosigkeit der Wolfenbütteler Absichten kundtun sollen.

87 Ebd., S. 20. 
sterbens des letzten Herzogs dort). Die Nachfolge solle, wie in guten Familien gebräuchlich, einvernehmlich geregelt werden ${ }^{88}$.

Zum Schluss kam es noch zum direkten Schlagabtausch. Die Wolfenbütteler Seite ließ eine Wiederlegung der Uhrsachen-Schrift erscheinen, in der längere Passagen des kritisierten Textes eingerückt und kommentiert wurden. Vor allem wurde jede unterstellte illegitime kriegerische Absicht zurückgeweisen. Statt dessen rückte man mehrere Vorwürfe gegen die Hannoveraner ein, um sie beim unvoreingenommenen Publikum in Misskredit zu bringen ${ }^{89}$. Nun reagierte auch die Regierung in Hannover noch einmal und publizierte ihre »Anmerckungen« zu der »Wiederlegung« der Wolfenbütteler. In neun Kapiteln wies man die erhobenen Vorwürfe zurück. Wichtigstes Argument war die Höhe der Wolfenbütteler Subsidien, die für eine Neutralität viel zu hoch gewesen seien. Wolfenbüttel sei für die Pariser Regierung nicht bedeutend genug gewesen, um derart ausgestattet zu werden. Daher seien die Rüstungen offensiver Natur gewesen, um auf dem norddeutschen Kriegsschauplatz eine Diversion zugunsten Frankreichs zu inszenieren. Ziel sei naheliegenderweise Hannover gewesen, weil dies angesichts der künftigen Verbindung englische Kräfte absorbiert hätte und Frankreich gegenüber seinem Hauptfeind entlastet worden wäre ${ }^{90}$. Die Introduktion Kurhannovers in den Kurfürstenrat 1708 war hingegen keiner ausführlichen Deduktionen mehr wert, nachdem die Opponenten nacheinander ihren Widerstand aufgegeben hatten.

\subsection{Berichte in den Zeitungen}

In den Zeitungen des Jahres 1692 spielte die Einrichtung der neunten Kurwürde keine prominente Rolle. Die Präliminarien blieben den Lesern als Staats-Arkana verborgen. Erst die Belehnung des Herzogs von Braunschweig-Lüneburg als Kurfürst am 19. Dezember 1692 wurde thematisiert. Die Leipziger Post und Ordinari-Zeitung weist in der Ausgabe vom 19./29. Dezember 1692 auf einen Bericht aus Wien vom 20. Dezember hin, der vom Belehnungsakt handelt:

88 Ebd., S. 19.

89 »Fürstlich braunschweigische wolffenbüttelsche Wiederlegung der Ursachen, welche das Fürstliche Haus Braunschweig- Zellischer Linie zu Colorirung des in die wolffenbüttelischen Lande vorgenommenen feindlichen Einfalls publicirt«, o.O. 1702.

90 »Anmerckungen Bey der Fürstlichen Wolffenbüttelschen Wiederlegung der Uhrsachen/Warum die Zellische Linie gegen der Wolffenbüttelschen ungemeine Werbungen Ihre Sicherheit zu beobachten sich gemüßiget befunden [...]«, Köln 1702; Hauptargument S. 6. 
Ingleichen hat der Herr von Groot/Hertzoglicher Hannoveris. Estats=Minister und Cammer $=$ Präsident $/$ mit einer ansehnlichen Suite von Cavalliers $/$ neben dem Herrn von Limbach/auch Hannoveris. geheimer Rath/gestern das Lehen über das Churfürstenthum von Ihr. Kayserl. Maj. würcklich erhalten/wie denn im herunter gehen von empfangenem Kayserl. Lehen/ein Cavallier den Chur=Hut auf einem rothen sammeten Polster liegend/zum Wagen getragen: Dass also nun der neundte Churfürst constituiret ${ }^{91}$.

Auch die Münchener Zeitung Extract-Schreiben erwähnt das Ereignis in Wien in der Ausgabe vom 27. Dezember 1692: „So hat auch der Hannoverische Gesandte göstert den Chur $=$ Huet und das Reichs $=$ Lehen $/$ als der Neundte Chur $=$ Fürst vor seinen Principalen erhalten ${ }^{92}{ }^{92}$. Interessant ist, dass die vollständig überlieferte Eingelauffene Ordinari Post-Zeitung aus Braunschweig den gesamten Dezember 1692 und Januar 1693 über den Vorgang schweigt. Ob seitens der Braunschweiger Regierung aktiv auf eine Unterdrückung der Nachricht hingewirkt wurde, ist unklar; eine Selbstzensur der Redaktion ist ebenso gut möglich.

Eine wichtige Ausnahme stellt allerdings die Münchener Zeitung Mercurii Relation dar, die offenbar doch schon im Laufe des Jahres 1692 feststellte, dass etwas Besonderes zwischen dem Kaiser und dem Herzog von Braunschweig-Lüneburg in Vorbereitung war ${ }^{93}$. Die Zeitung fällt durch eine scharfsinnige Beobachtung der welfischen Politik der frühen 1690er Jahre auf, die den Lesern detailliert mitgeteilt wird. Vorbehaltlich der Berichterstattung in den parallelen Medien darf festgehalten werden, dass die Zeitung intensiv die Beteiligung der Hannoveraner an den militärischen Aktionen der Zeit auf kaiserlicher Seite - gegen die Türken und gegen Frankreich - beobachtete. So konstatierte die Ausgabe vom 12. April 1692 die Nachricht aus Hannover (sub dato 18. März), der Herzog von Braunschweig-Celle sei nach Den Haag zum niederländischen Verbündeten gereist. Aus Wien wurde das Eintreffen eines Kuriers erwartet. Wenige Wochen später, am 26. April, konnte die Mercurii Relation berichten, dass der Hannoveraner Korrespondent (sub dato 8. April a.st.) vom Eintreffen des Kuriers erfahren habe: Letzterer sei mitten in der Nacht in die ansonsten verschlossene Stadt eingelassen worden. Über Herkunft und Auftrag des Kuriers konnte nur spekuliert werden, ein Antrag

91 »Leipziger Post und Ordinari-Zeitung«, 19./29. Dezember 1692, Jahrgangszählung S. 1201. Die gesamte Zeremonie wurde unter dem 24. Dezember a.st. noch einmal detailliert erläutert: Ebd., S. 1222f.

$92 »$ Extract-Schreiben« (gehört zu »Wochentliche Ordinari-Zeitung«), 27. Dezember 1692.

93 »Mercurii Relation, oder wochentliche Reichs Ordinari Zeitungen, von underschidlichen Orthen«, München 1680-1701. Die seit 1680 in München herausgebrachte Zeitung »Mercurii Relation, oder wochentliche Reichs Ordinari Zeitungen« erschien zweimal wöchentlich unter zwei verschiedenen Namen, besaß aber - nach gegenwärtigem Kenntnisstand - eine gemeinsame Redaktion. 
der Republik Venedig auf 1.000 Soldaten wurde für wahrscheinlich gehalten. Im Übrigen seien die Truppen in Bewegung gesetzt worden.

Im Juni gingen die Überlegungen schon weiter. Inzwischen galt als klar, dass Hannover dem Kaiser weit über die Verpflichtung zur Reichshilfe hinaus militärischen Beistand leistete, und die Mercurii Relation ging daher in der Ausgabe vom 7. Juni davon aus, dass der Kaiser dafür irgendeine Kompensation zu leisten habe. Es passte in die katholische Sicht einer Münchener Zeitung, dass man eine Gratifikation auf Kosten der Reichskirche befürchtete: »Nunmehro wird nichts mehr gezweifelt an deme/daß das Bischoffthumb Oßnabrück bey diesem Hause bleiben/und ein Printz von demselben allda sonder Changierung der Religion residiren solk $\aleph^{94}$. Der Verursacher der Meldung rechnete daher - aufgrund guter Kenntnis der Reichsgeschichte - damit, dass der Kaiser Kompensationen auf Kosten Dritter vergebe, um Unterstützer seiner Politik zufriedenzustellen.

An dieser Stelle muss nochmals daran erinnert werden, dass die Kurerhebung zunächst ein Arcanum gegenüber dem Reich gewesen war, das nicht über die Regensburger Gremien verlief. Wann dort die Wahrheit durchsickerte, ist einstweilen unbekannt. Die kaiserliche Regierung teilte die Nachricht vom Erlass des Kurtraktats vom 22. März den Kurfürsten am 30. Juni 1692 offiziell mit. Die Information dürfte nicht auf dem Wege über die Reichstagsdictatur verlaufen sein, sondern im bilateralen Verkehr der Höfe, sonst hätte es in der öffentlichen Aufregung wohl kaum bis zum 3. Oktober 1692 gedauert, bis die Kurfürsten von Mainz, Köln, Trier und Pfalz ihren Protest zu Papier gebracht hätten.

Die Öffentlichkeit im Reich erfuhr von der Neunten Kur scheibchenweise. Die erste Mitteilung, die bislang gefunden werden konnte, datiert aus der Mercurii Relation vom 9. August 1692. Darin steht, versteckt unter dem Herkunftsnachweis:

Auß dem Mecklenburgischen/vom 23. dito [gemeint war der Juli]: Ihro Hoch=Fürstl. Durchl. der Hertzog von Zell befindet sich anjetzo in Ratzeburg/selbige Vestung zu besehen/und ein oder ander Anstalten zu machen. Nun stehet es darauff/daß die Sache wegen de $\beta$ Chur $=$ Hut zwischen den dreyen Häusern zur völligen Richtigkeit gebracht werden wird/wie dann der Titul die Herren Chur=Fürsten von Braunschweig=Lüneburg/so wol zu Zell/und Wolffenbüttel/als zu Hannover gebraucht wird.

Der Verfasser der Zeilen hatte offenbar die Nachricht erhalten, dass das Welfenhaus als Ganzes in den kurfürstlichen Rang erhoben würde, damit kein innerfamiliärer Zwist ausbräche.

94 Meldung »Auß dem Lüneburgischen, 16. Mai 1692«: »Mercurii Relation«, 7. Juni 1692. 
Das Thema wurde in den folgenden Ausgaben nicht weiter vertieft. Erst von der erfolgten Belehnung am 19. Dezember in Wien wurde der Leser der Mercurii Relation in Kenntnis gesetzt. Der Münchener Rezipient musste darauf bis zum 3. Januar warten, als der Bericht aus Wien (sub dato 24. Dezember) eingetroffen und weiterverarbeitet war: »Der Hertzog zu Hannover ist zum Chur =Fürsten würcklich erwöhlt worden [...] . Als Grund wurde sachlich zutreffend die große Truppenstellung von 6.000 Mann für den Türkenkrieg genannt.

In der Mercurii Relation erfolgte noch in der Ausgabe vom 7. März 1693 eine Mitteilung über die Rückkehr des Hannoveraner Gesandten von Grote, der für seinen Herrn per procurationem die Belehnung entgegengenommen hatte. Der Bericht aus Hannover (sub dato 17. Februar) verwies auf das öffentliche Feuerwerk, das der Kurfürst zu Ehren des ihn besuchenden Kurfürsten von Brandenburg gab. Dabei trugen vier Wassernymphen einen großen Kurhut, der bläulich brannte. In den folgenden Jahren wurde Hannover zum festen Berichtsort in der Zeitung: Ein kurfürstlicher Hof war viel gewichtiger als ein gewöhnlicher fürstlicher. Die Einbeziehung ins Postsystem der Zeit dürfte sich in ähnlicher Weise zugunsten der neuen Metropole ersten Ranges in Norddeutschland entwickelt haben.

Nicht nur die Verleihung des Kurhutes an den Welfenherrscher war ein Pressethema, sondern auch die feierliche Introduktion in den Kurfürstenrat 1708. Das Wiener Diarium hatte seinen Schwerpunkt auf Hofgeschehnisse in Wien und berichtete über die Regensburger Begebenheiten nur knapp. Die Introduktion Hannovers in den Kurfürstenrat am 7. September 1708 wurde hinter dem Hinweis auf den Antritt einer Bäderreise des kaiserlichen Prinzipalkommissars, Kardinal Lamberg, in einem Nebensatz versteckt. Vor dessen Abreise, so teilte das Blatt am 21. September 1708 mit, habe die »kurböhmische Readmission« und die »kurhannoversche Introduktion« in den Kurfürstenrat planmäßig stattgefunden. Die Gesandten für Böhmen und Hannover, Graf Kinsky und Baron Limbach, hätten ihre Legitimationen bei der kurmainzischen Direktorialkanzlei abgegeben und seien zur Zeremonie sechsspännig vorgefahren. Nach der Platzeinnahme habe es die üblichen Glückwunsch-Komplimente im Re- und Correlationssaal gegeben ${ }^{95}$. Spuren davon, dass der dieser Meldung zugrundeliegende »Plan« in irgendeiner Weise Gegenstand der früheren Berichterstattung gewesen war, konnten nicht gefunden werden.

Zuvor waren der Leserschaft des Hildesheimer Relations-Couriers berichtet worden, dass die fürstlichen Opponenten der Hannoveraner Kurwürde inzwischen ihren Widerstand eingestellt hätten. Die Zeitung druckte zu

95 Mitteilung aus Regensburg vom 19. September 1708: »Wiener Diarium«, Nr. 536 vom 21. September 1708 . 
Beginn des Jahres 1707 eine Regensburger Nachricht von der Zustimmung Badens zur Neunten Kur:

Se. Hoch =Fürstl. Durchl. der Marggraf von Baden=Baden hat nunmehro Hannover auch vor Chur=Fürst erkannt/und weil kein Fürst mehr übrig ist/der solches nicht getan hat/mögte diese Chur=Affaire wohl so viel ehender angefangen und die Introduction ins Werck gestellet werden ${ }^{96}$.

Einstweilen ist wegen der bruchstückhaften Überlieferungslage unklar, wie weitgehend die Berichterstattung über die Neunte Kur vorher in der Tagespresse war. Aus den zitierten Sätzen allerdings geht klar hervor, dass der frühere Widerstand Stück für Stück abgebröckelt ist, dass Baden der letzte Widerständige war und dass verfassungsrechtlich nun noch die formelle Einführung in den Kurfürstenrat erfolgen musste. Der Leser im Reich, der die Presse fortlaufend verfolgte, durfte nun in Erwartung des Berichts von der Introduktion verbleiben.

In aller Ausführlichkeit wurde die kurhannoversche Introduktion im Hamburger Relations-Courier geschildert. Die Zeitung vermerkte dazu am 13. September 1708: »Regensburg, 6. Sept. - Gestern arrivirte allhier der Herr Graff Kinsky als Chur=Böhmischer Gesandter/worauff hiesige Chur $=$ Braunschweigige Gesandtschafft gewartet/in Hoffnung/es werde nun die Chur $=$ Braunschweigische Introduction ins Churfürstl. Collegium ehester Tagen ihren Effect erreichen $\aleph^{97}$. Die Einführungsmeldung allerdings fehlte in der Zeitung, was mit nicht überlieferten Ausgaben zu tun haben könnte. Erst elf Tage danach wurde erwähnt, dass die inzwischen eingeführten Gesandten beider neuen Kurfürstenratsmitglieder Böhmen und Hannover, Graf Kinsky und Baron Limbach, vom Regensburger Magistrat mit jeweils 40 Kannen Wein und 40 Pfund Fisch beschenkt worden waren ${ }^{98}$.

Im Hildesheimer Relations-Courier wurde die Leserschaft einige Tage später informiert, dass noch Verzögerungen bei der Readmission Böhmens und Kurhannovers zu beobachten seien, denn das jüngste kaiserliche Kommissionsdekret sei noch nicht öffentlich verlesen worden. Die kurfürstlichen Gesandten hätten sich im kurmainzischen Quartier getroffen, um über die Lage zu verhandeln (ohne die »Neulinge«). Viele Informanten seien überzeugt, dass morgen alle »Obstacula« aus dem Weg geräumt seien ${ }^{99}$. In derselben Ausgabe steht etwas weiter unten eine weitere Nachricht aus »Frankfurt/vom 18. Septembr.«, demnach die böhmische Readmission und die

\footnotetext{
$96 »$ Hildesheimer Relations-Courier«, Nr. 4, 12. Januar 1707.

97 »Hamburger Relations-Courier«, Nr. 145, 13. September 1708.

98 Ebd., Nr. 151, 24. September 1708.

99 »Hildesheimer Relations-Courier«, Nr. 24, 22. September 1708.
} 
kurhannoversche Introduktion erfolgreich stattgefunden hätten. Für Böhmen sei der böhmische Vizekanzler Graf Kinsky als kurböhmischer Reichstagsgesandter eingeführt worden.

\subsection{Raisonnement in den Zeitschriften}

Als das Problem der Hannoveraner Kurwürde auf der reichsrechtlichen Tagesordnung stand, hatte sich das Zeitschriftenwesen noch nicht so weit ausgebreitet, dass eine zusammenhängende Berichterstattung vorliegt. Dafür wurde die Introduktion des braunschweig-lüneburgischen Gesandten in den Kurfürstenrat 1708 zu einem Thema in den Periodika, die seit dem ausgehenden 17. Jahrhundert gegründet worden waren. Am weitesten zurück reichte dabei der Monatliche Staats-Spiegel von Stanislaus Reinhard Acxtelmeier ${ }^{100}$. Die Zeitschrift stieg mitten in die Auseinandersetzungen des Jahres 1699 ein, indem ein Schreiben des Königs von Dänemark an den Reichstag in lateinischer Sprache abgedruckt wurde, durch das Frankreich und Schweden zum Eingreifen gegen »Kurhannover« aufgefordert wurden ${ }^{101}$. Acxtelmeier wies darauf hin, der Text solle demnächst auch in einem niederländischen Periodikum erscheinen. Der Herausgeber ließ keinen Zweifel daran, dass er selbst auf Seiten des Kaisers stand: Er hoffe, dass das Reichsoberhaupt bei seiner Haltung bliebe. Es dürfe nicht sein, - so Acxtelmeier - dass »fremde Puissancen « sich in Reichsinterna einmischten. Außerdem sei nicht zu dulden, dass diese sich von Reichsständen »wegen dabey habenden Privat-Interesse« auffordern ließen, im Reich zu intervenieren ${ }^{102}$.

Nachdem bis dahin Detailprobleme in der Sache der Neunten Kurwürde verhandelt worden waren, nahm Acxtelmeier im April-Heft 1701 die Schrift Epistola ad amicum des niederländischen Verfassers Gibellini de Lindenfels zum Anlass, um die kontroversen Positionen zur Frage der Neunten Kur vorzutragen und zu bewerten. Dabei, so schrieb er, seien drei Fragen strittig:

1. Ob eine oder die andere Verordnung des westfälischen Friedens=Instruments, der Aureae Bullae oder andere Reichs $=$ Constitutiones auf dem Reichs $=$ Tage durch mehrere Stimmen könne geändert werden?

100 [Stanislaus Reinhard Acxtelmeier (Hg.)], »Monatlicher Staats-Spiegel; Worinnen der Kern aller Avisen; Ein Begriff der vornehmsten im H. Röm. Reich vorfallenden Affairen mit vilen Curiosen Beylagen, samt einigen Politischen Reflexionen sich repraesentirt und vorstellet, Augsburg 1698-1709.

101 Ebd. Februar-Heft (1699), S. 24-26 (einführender Kommentar); S. 26-30 (Abdruck des dänischen Schreibens).

102 Ebd. Februar-Heft (1699), S. 30. 
2. Ob die Errichtung einer Neunten Chur in dem Instrumento Pacis Osnabrugensis, oder in der güldenen Bull mit klaren deutlichen Worten verboten?

3. Ob die Einrichtung der Neunten Kur allein durch Kaiser und Kurfürsten beschlossen werden könne oder ob es der Zustimmung des gesamten Reichstags bedürfe ${ }^{103}$ ?

In der Diskussion der ersten Frage stellte Acxtelmeier fest, dass die Reichsgremien sich stets für berechtigt gehalten hätten, frühere Beschlüsse zu ändern. Dies gelte auch für Modifikationen an den Reichsgrundgesetzen. Zudem verwies er auf die Kraft der Rechtsgewohnheit (Consuetudo), die im Laufe der Zeit Veränderungen herbeiführe, die schließlich eigene rechtliche Kraft entfalteten ${ }^{104}$. In der Diskussion der zweiten Frage verwies Acxtelmeier auf einige Rechtsgelehrte, die unter Rückgriff auf den Westfälischen Frieden eine Vermehrung des Kurkollegs für unstatthaft gehalten hätten - dies waren naheliegenderweise die Juristen der »Correspondierenden Fürsten«. Demgegenüber hätten andere betont, die Entscheidung von 1648 enthalte keine Bindewirkung für 1701. Die Heimfallregel für die zweite wittelsbachische Kur beziehe sich nicht auf die Siebenzahl, sondern nur auf das Problem, dass ein Fürstenhaus zwei erbliche Kuren besitze und damit einen überdurchschnittlichen Einfluss erlange ${ }^{105}$. In der Diskussion zur dritten Frage referierte Acxtelmeier ebenfalls zunächst die Position der »Correspondierenden Fürsten«: Es läge nicht im Wohl des Reiches - so hatten deren Vertreter argumentiert -, dass die Neunte Kur geschaffen würde, sondern diese diene nur dem Privatinteresse des Hauses Hannover. Dem Reichsfürstenrat geschehe Schaden, wenn mit Hannover eine wichtige fürstliche Stimme nicht mehr mitwirke. Dadurch sei zudem die Streitsache von erheblicher Bedeutung, und der Reichsfürstenrat müsse zustimmen. Eine vertröstende Erklärung für die Zukunft, dass die Rechte der Fürsten nicht präjudiziert werden sollten, sei zu wenig. Die kaisernahe fürstliche Gruppierung sah sich dagegen nicht beschwert durch die Neunte Kur, zumal Hannover sie infolge seiner Verdienste um das Reich zurecht erhalte. Stattdessen klagten diese Fürsten über den starken Druck, den die Opponenten ihrerseits aufgebaut hätten, um eine geschlossene Front gegen Kaiser und Kurfürsten entstehen zu lassen. Die Befürworter der Kurerhebung verwiesen darauf, dass dem Reich kein Schaden entstehe: Wenn der Kurfürst von Hannover dem Gemeinwohl ebenso diene wie bisher, sei das Ergebnis dasselbe. Auch würde der Reichsfürsten-

103 Ebd. April-Heft (1701), S. 3.

104 Ebd., S. 3-9.

105 Zusammen mit der Kölner Erzbischofswürde waren es sogar drei Wittelsbacher Stimmen im Kurkollegium, worauf auch verwiesen wurde: Ebd., S. 9-11. 
rat nicht schwächer, weil sein Einfluss auf die politische Willensbildung im Reichstag im bisherigen Umfang bestehen bliebe. Auch nach dem Wechsel Kurhannovers bliebe der Verfahrensgang im Reichstag gleich: Beide fürstlichen Kurien müssten sich zu einem Reichsschluss genauso vergleichen wie bisher; die kurfürstliche Kurie erhielte durch den Zuzug in dieser Hinsicht kein Übergewicht ${ }^{106}$.

Im Februar-Heft 1702 druckte Acxtelmeier einen Brief der Herzöge Rudolf August und Anton Ulrich von Braunschweig-Wolfenbüttel an die »Correspondierenden Fürsten« in der Neunten Kurfrage ab. Die Herzöge hatten unter dem 5. Dezember 1701 notifiziert, dass sie ihr Reichstags-Votum wieder aufnehmen wollten, nachdem die Gesandtschaft eine Zeitlang unbesetzt geblieben war ${ }^{107}$. Die anschließende Besetzung des Herzogtums Braunschweig-Wolfenbüttel durch Hannoveraner Truppen fehlte allerdings in der Berichterstattung. Erst im Februar 1706 erfolgte eine abschließende Mitteilung über die Beilegung des Familienzwistes im Welfenhause. Folgende Bestimmungen wurden angeführt: 1. Braunschweig-Wolfenbüttel erkannte die Präzedenz Kurhannovers auf allen Reichsversammlungen an. 2. Herzog Anton Ulrich führte weiterhin das Kondirektorium im Niedersächsischen Kreis, wie vordem. Damit ging er als Direktor ex officio im Kreisaufruf den Hannoveranern voran. 3. Im Reichsfürstenrat stimmte Braunschweig-Wolfenbüttel weiterhin vor Braunschweig-Calenberg und Braunschweig-Grubenhagen $a b^{108}$.

In der 1702 gegründeten Europäischen Fama konnte nur noch der Abschluss der braunschweigischen Familienstreitigkeiten vermeldet werden $^{109}$. Herausgeber Philipp Balthasar Sinold von Schütz ging im ersten Jahrgang seines Periodikums auf den Einmarsch ins Braunschweigische ein. Der Militäraktion ging zunächst der Schlagabtausch am Regensburger Reichstag voraus. Dort, so berichtete die Zeitschrift, habe der Regensburger Gesandte für Braunschweig-Lüneburg und Celle am Reichstag eröffnet, 1. welch schädliche Consilia die Wolfenbütteler Regierung gegen Hannover hege, 2. dass Pläne bestünden, 20.000 Soldaten mit Geld ausländischer Potentaten auszurüsten zu diesem Zweck, 3. dass ein »Neutralitäts«-Traktat zwischen Braunschweig-Wolfenbüttel und Frankreich abgeschlossen worden sei, um die französische Erbfolge in Spanien durch Militärmanöver in Norddeutschland zu unterstützen ${ }^{110}$.

106 Ebd., S. 11-24.

107 Ebd. Februar-Heft (1702), S. 47-49.

108 Ebd. Februar-Heft (1706), S. 27.

109 Europäische Fama.

110 Ebd. 4 (1702), S. 362-365, hier S. 362f. 
Daraufhin habe der Braunschweig-Wolfenbütteler Gesandte erwidert, dass 1. für die Besatzung auf den beiden Landesfestungen mehr als 12.000 Mann benötigt würden, die man bislang beschäftige, 2. die Soldaten seiner Regierung nur der eigenen Sicherheit dienten, 3. seine Regierung sich am »Spanischen Sukzessions $=$ Streit $«$ erst nach einem Reichsbeschluss beteiligen werde, 4. der Pakt mit Frankreich nur der eigenen Verteidigung diene, 5. die Herzöge von Braunschweig-Wolfenbüttel berechtigt seien, sich gegen die Neunte Kurwürde zu versichern, 6. Herzog Anton Ulrich von BraunschweigWolfenbüttel vor Gott bezeugen könne, er habe keine Nebenartikel wegen einer »Diversion« im Reich zu Frankreichs Gunsten abgeschlossen, 7. erst recht kein Offensivbündnis mit der Regierung in Paris bestehe ${ }^{111}$.

Herausgeber Sinold von Schütz verwies anschließend darauf, dass Kaiser Leopold I. als Folge dieser Eröffnungen - und dem Bekanntwerden der Wolfenbütteler Bündnislage nach dem Einmarsch - den Herzog Anton Ulrich von Braunschweig-Wolfenbüttel seiner Mitregierung enthoben und die Landesherrschaft allein dem Herzog Rudolf August übertragen habe. Wenig später sei ein Vergleich zwischen beiden welfischen Linien geschlossen worden, wonach die Hannoveraner Truppen das Land wieder verlassen hätten, während die Wolfenbütteler Soldaten zur Reichsarmee an die Oberrheinfront abkommandiert worden seien ${ }^{112}$.

Im folgenden Heft rückte die Redaktion der Europäischen Fama den Vertragstext des Vergleichs zwischen beiden Braunschweiger Linien im Wortlaut $\operatorname{ein}^{113}$. Dabei konnte Sinold von Schütz nicht unterlassen, einen antifranzösischen Kommentar einzuflechten:

Es ist leichtlich $\mathrm{zu}$ erachten/daß diese Zeitung [=vom welfischen Vergleich; J.A.] an dem Frantzösischen Hofe nicht so angenehm gewesen/als der Tod des Königs in England/und es hat sonsten auch das Ansehen/ob sey überall in Deutschland vor die Frantzösischen Ohrenbläser und Spionen keine gute Zeit/weil man fast überall die Ohren vor ihren Schmeicheleyen verstopfet. Ich wollte wünschen/daß das Wörtlein »fast« allhier hätte ausgelassen werden können: Jedoch wird der geneigte Leser/welchem der Zustand von Europa bekannt ist/satsam erkennen/wie nöthig es gewesen/dasselbe mit einzuflicken; Wiewohl wir allerseits die Hoffnung haben/es werde bald wieder eine Zeit kommen/da man ohne Abbruch der Wahrheit einen grossen Strich dadurch machen kann ${ }^{114}$.

111 Ebd. 4 (1702), S. 364f.

112 Ebd. 4 (1702), S. 365.

113 Ebd. 5 (1702), S. 439-441.

114 Ebd. 5 (1702), S. $441 f$. 
Damit war das braunschweigisch-wolfenbüttelsche Militärabenteuer beendet, und Sinold von Schütz kam erst im Jahre 1708 wieder auf die Hannoveraner Kurfrage zu sprechen. Die Aufnahme des kurhannoverschen Gesandten in den Kurfürstenrat kommentierte er mit folgenden Worten:

Bey der Reichs $=$ Versammlung zu Regensburg hat nunmehro die seit verschiedenen Jahren streitig gewesene Hanoverische Chur $=$ Sache ihre Endschafft erreichet, indem dieselbe vermittelst eines Schlusses von allen 3 Reichs $=$ Collegiis verglichen, auch mit selbigem der Legations-Secretarius Reck an Se. Churfürstl. Durchlauchtigkeit zu Braunschweig und Lüneburg nach dem Oberrhein in Dero Haupt $=$ Quartier abgeschicket worden. Dieser Reichs $=$ Schluß wird sodann Sr. Kayserlichen Majestät zur Ratifikation übersendet werden, und die würckliche Introduction darauf erfolgen ${ }^{115}$.

Der Verfasser nutzt die Gelegenheit, zusätzlich zum Sachstandsbericht noch das folgende formale Verfahren vorzustellen. Dem Leser blieb wenig vom Reichsverfassungs-Prozedere verborgen.

Zwei Hefte später schilderte Sinold von Schütz den schon bekannten Actus der ersten Teilnahme Kurhannovers an einer Sitzung des Kurfürstenrates. Die Sitzung wurde durch Kurmainz am 7. September 1708 angekündigt. Daraufhin versammelten sich die Reichstagskurien bereits vormittags um 9.00 Uhr, um einige formelle Regularien zu klären (Versicherungsakt wegen der Fortdauer des kurmainzischen Direktoriums trotz kurböhmischer Readmission; Steuerveranlagung der neuen Kurfürstenratsmitglieder für Reichssteuer und Kammerzieler nach allgemeinem Kurfürstenanschlag). Auch mussten die Vollmachten der beiden Gesandten durch Kurmainz geprüft werden. Um 19.00 Uhr sei die Auffahrt des kurböhmischen Gesandten Graf Kinsky und sein Eintritt in den Kurfürstenrat nebst Einnahme des regulären Platzes an vierter Stelle, den Kurböhmen seit alter Zeit innehatte, erfolgt. Eine Stunde später sei auch der kurhannoversche Gesandte Freiherr von Limbach erschienen und habe seinen neugeschaffenen neunten Platzes am Ende in der Rangfolge der Gesandten eingenommen ${ }^{116}$. In einem späteren Heft 1710 wies die Redaktion der Europäischen Fama darauf hin, dass Kurhannover aus der Verfügungsmasse durch die wittelsbachische Ächtung von 1706 die Würde des Erzschatzmeisters des Reiches erhalten habe, da Kurpfalz inzwischen wieder das Truchsessenamt eingenommen habe ${ }^{117}$.

In den anderen Zeitschriften wurde das Hannoveraner Einrücken in den Kurfürstenrat mit weniger Worten abgehandelt. Andreas Stübel ging auf

115 Ebd. 79 (1708), S. 522 f.

116 Ebd. 81 (1708), S. 678-680.

117 Ebd. 100 (1708), S. 289. - Die Veränderung musste 1714 im Zuge der bayerischen Restitution wieder rückgängig gemacht werden. 
zwei Termine ein: Zunächst wies er seine Leser darauf hin, dass das kaiserliche Kommissions-Dekret zur Introduktion der Neunten Kur am 21. Juli 1706 in der Regensburger Dictatur verlesen worden sei. Die katholische Seite habe zur konfessionellen Kompensation - für den Fall einer protestantischen Nachfolge in Kurpfalz und des Aussterbens Kurbayerns - ein Votum supernumerarium zugesagt bekommen ${ }^{118}$. Im folgenden Heft, Depeche 6, schilderte Stübel die Prozedur der Readmission Kurböhmens und der Introduktion Kurhannovers vom 7. September 1708. Über den Hannoveraner Gesandten Freiherrn von Limbach wurde vermittelt, dieser sei durch den kurmainzischen Direktorialgesandten sieben oder acht Schritte vor der Tür des Kurfürstenzimmers empfangen und in den Raum geleitet worden, wo Komplimente ausgetauscht worden seien. Nach dieser Introduktion seien alle Beteiligten in den Re- und Correlationssaal aller Reichsstände gegangen und hätten sich im Plenum mit allen anwesenden Gesandten komplimentiert ${ }^{119}$.

Der anonyme Autor der Zeitschrift Der Welt Urtheile erwähnt 1708 ebenfalls die Hannoveraner Introduktion in den Kurfürstenrat, nachdem die Standeserhöhung bereits 1690 (sic!) erfolgt sei. Das besondere Verdienst der Welfenherzöge habe dabei in der bedeutenden Militärhilfe gegen die Türken an den Kaiser gelegen ${ }^{120}$. Im Folgenden wurden einmal mehr die Argumente der opponierenden Fürsten aufgeführt und auch einige eigene machttheoretische Gedanken des Verfassers zu Papier gebracht: 1. Sei damit endgültig die Siebenzahl aufgegeben worden, »in welcher ein sonderbahres Geheimniß enthalten sey«, nachdem schon 1648 zugunsten der Kurpfalz eine achte Kur gestiftet worden sei (allerdings mit Vereinigungsvorbehalt im Falle des Aussterbens einer Wittelsbacher Linie). 2. Die Mehrheitsfindung für den Kaiser im Kurfürstenrat werde schwerer. 3. Dem Reichskammergericht entgehe viel an Zuständigkeit und Einkommen dadurch, dass die welfischen Lande ein Privilegium de non appellando bekommen hätten. 4. Die Kurfürsten würden durch ihre Zahl schwieriger kompromissfähig. Auch drohten weitere Kurerhebungen durch Österreich. 5. Diejenigen, die bislang im Rang vor den Welfen gewesen seien, wollten denen nun nicht nachgesetzt werden. Auch

$118 »$ Von dem endlichen Reichs $=$ Concluso zu Regensburg wegen der Braunschweig $=$ Lüneburgischen Chur/samt dessen gantzen Inhalt«: [Andreas StüBeL (Hg.)], Der neu=bestellte Agent von Haus aus/mit allerhand curieusen Missiven, Brieffen/Memoralien, Staffeten, Correspondencen, und Commissionen, nach Erforderung der heutigen Staats- und gelehrten Welt [...], 3 Bd., Freyburg [= Leipzig] 1704-1708, hier Bd. 3, Depeche 5, S. 417 f.

$119 »$ Von Readmittierung des Königl. und Chur=Böhmischen/wie auch Introducierung des Chur $=$ Hannoverischen Gesandten in das Churfürstl. Collegium auf den Reichs $=$ Tag $z u$ Regensburg [...]«: »Der neu=bestellte Agent«, Bd. 3, Depeche 6, S. 514-519. - Im Anschluss an die Zeremonialschilderung wies Stübel auf Medaillen und Kupferstiche hin, die im Zuge der Feierlichkeiten gefertigt wurden: Ebd., S. 517-519.

$120 »$ Der Welt Urtheile von den gegenwärtigen Staats-, Kriegs-, gelehrten und gemeinen Sachen schertz- und ernsthafft ausgeführet«, 2 Bd. (20 H.), Leipzig 1706-1711; hier Bd. 1, 9. Pensée, S. 740 . 
würde der Reichsfürstenrat herabgewürdigt durch den sukzessiven Auszug der großen Dynastien. 6. Der Konsens der Garantiemächte des Westfälischen Friedens fehle. 7. Die katholischen Fürsten würden beim Papst und anderen katholischen Mächten über ihre Rang- und Einflussminderung klagen. 8. Auch die Erzamtsfrage sei für Kurhannover noch nicht abschließend geregelt ${ }^{121}$.

Die Zeitschrift Neu=eröffneter Welt $=$ und Staats = Spiegel, herausgegeben von Johann Ehrenfried Zschackwitz, setzte erst ein, als das Kurhannover-Kapitel bereits abgeschlossen war ${ }^{122}$. Im Rahmen seiner antikatholischen Berichterstattung kam der Herausgeber 1713 auf die Lage der Katholiken in Hannover zu sprechen. Dabei wies er auf Gerüchte aus London hin, die besagten, der englische König Georg I. wolle zum Katholizismus konvertieren. Allerdings beruhigte Zschackwitz seine Leser: Der katholische Kirchenbau in Hannover sei kein bedrohliches Indiz, denn der Kurfürst erfülle nur eine Pflicht, die sein Vater 1692 eingegangen sei, als er dem Kaiser das freie Religionsexerzitium für die Katholiken in seinen Residenzstädten versprach. Nach der Introduktion Georgs in den Kurfürstenrat 1708 sei die Kirche dann gebaut und »vor zwei Jahren « fertiggestellt worden. Ein Kirchenbau in Celle sei hingegen verboten worden, weil dort keine Residenz mehr sei. In Kurhannover gebe es nur sehr wenige Katholiken, die von drei Priestern in Hannover und zwei in Celle betreut würden. Alle Priester müssten Deutsche sein. Den Jesuiten sei der Aufenthalt im Kurfürstentum verboten ${ }^{123}$.

Schon aus der Rückschau einer historiographischen Perspektive präsentierte Johann Jakob Schmauss im Jahre 1711 die Hannoveraner Kurpromotion in seiner Zeitschrift Curieuses Bücher-Cabinet ${ }^{124}$. Die Erhebung des Herzogs Ernst August von Braunschweig-Lüneburg sei allein vom Kaiser vorgenommen worden. Zahlreiche Reichsstände hätten dagegen protestiert, als sie vom Geschehenen erfuhren. In ihren Augen sei für die Erhebung die Zustimmung des gesamten Reichstags, nicht nur das Benehmen mit den Kurfürsten, erforderlich gewesen. Es seien sogar die Garantiemächte von 1648 angerufen worden, doch die laufenden Kriege hätten »Weitläuffigkeiten« verhindert. Der heftigste Widerstand sei durch die Herzöge von Braunschweig-Wolfenbüttel, d.h. durch die ältere welfische Linie erfolgt, die sich nicht damit abfinden wollten, im Rang hinter den Vettern in Hannover

$121 »$ Der Welt Urtheile«, Bd. 1, 9. Pensée, S. 741-745.

122 [Johann Ehrenfried ZschackwITZ (Hg.)], Neu=eröffneter Welt $=$ und Staats $=$ Spiegel $/$ Worinnen die in Europa/wie auch denen andern Theilen der Welt/vornehmlich in Teutschland vorfallende merckwürdigen Begebenheiten kürtzlich vorgestellet [...] wird, 8 Bd. (Tl. 1-100), Haag [= Leipzig] 1709-1716.

123 Ebd., 1713, Bd. 5, H. 49, S. 80f.

124 Antonio Paullini [d.i. Johann Jakob Schmauss], Curieuses Bücher-Cabinet oder Nachricht von Historischen Staats- und galanten Sachen, 8 Bd., Frankfurt a.M., Köln 1711-1722. 
zurückstehen zu müssen. 1706 habe Kaiser Josef I. zugesagt, künftige Kurerhebungen nur noch mit dem Konsens des (gesamten) Reichstags vorzunehmen. Anschließend schilderte Schmauss die zeitgleiche »Readmission« der böhmischen Kurstimme und die »Introduktion« Kurhannovers am 7. September 1708. Es schließt sich das komplizierte Verfahren an, durch das eine Ausgleichsstimme der katholischen Seite vereinbart wurde, die für den Fall eines Erlöschens der pfalz-neuburgischen Linie des Hauses Wittelsbach die katholische Mehrheit im Kurfürstenrat sicherstellen sollte ${ }^{125}$.

Im Jahre 1724, mit weitem zeitlichen Abstand, kam die Europäische Fama noch einmal auf die Hannoveraner Kurwürde zurück. Die Erfahrungen mit der umstrittenen Prozedur wurden in einen Zusammenhang gerückt mit den Gerüchten, der Herzog von Lothringen und der Landgraf von Hessen-Kassel betrieben ebenfalls ihre Erhebung in den Kurfürstenstand. Kurwürden - so der Verfasser - seien sehr schwer zu kreieren, weil die Widerstände unter den Reichsständen schon bei der Neunten Kur deutlich zutage getreten seien. Frankreich habe zudem versucht, den Konflikt für sich auszunutzen. Es bestehe daher nicht nur die Gefahr inneren Dissenses über eine solche Frage, sondern auch die der Intervention ausländischer Mächte. Mit ironischem Unterton fügte Justus Gottfried Rabener, der die Zeitschrift damals herausgab, hinzu, auch die Publizisten würden neuerlich klagen, dass KurPromotionen die schöne Siebenzahl der Goldenen Bulle zerstört hätten ${ }^{126}$.

Auch David Fassmann fand im Rahmen seiner Zeitschriftenreihe Gespräche im Reiche der Todten Gelegenheit, den Konflikt um die Erhebung des Herzogs von Braunschweig-Lüneburg zum Neunten Kurfürsten abzuhandeln ${ }^{127}$. In der 123. Entrevue, in der sich König Georg I. von England und König Karl IX. von Schweden über die Geschichte ihrer Zeit unterhielten, resümierte der Welfe den Aufstieg seines Vaters in die erste Reihe der Fürsten im Reich mit folgenden Worten:

Wegen so vieler, dem Kayser und dem Römischen Reiche, von unserm Hause geleisteten, auch sonst die allgemeine Wohlfahrt von Europa befördernden Dienste erhielte mein Vater Anno 1692 von dem glorwürdigsten Kayser Leopoldo die neundte Chur. Ob nun aber wohl diese, unserm Hause so grosse Ehre, und schöne Vortheile bringende Sache von Seiten des Kayserlichen Hofes, biß auf das Ertz=Amt, welches noch nicht ausgefunden gewesen, seine Richtigkeit erlanget hatte, so machten dennoch fast alle Chur $=$ und Fürsten des Reichs ein sehr scheeles und mißvergnügtes Gesichte

125 Ebd., Bd. 2, 1711, S. 368-377.

126 Europäische Fama 277 (1724), S. 9-15.

127 [David Fassmann], Gespräche im Reiche der Todten, 15 Bd. (Entrevue 1-240); dreiteiliger Schlussband 16, Leipzig 1718-1741. 
darzu, setzten unserm Hause unendlich viele Obstacula dargegen in den Weg, und die Protestationes lieffen von allen Seiten $\operatorname{ein}^{128}$.

Auch auf den Streit um das Reichsbanneramt und auf die Introduktion Kurhannovers in den Kurfürstenrat 1708 ging Fassmann im Folgenden ein, ohne allerdings die Konflikthaftigkeit der Situation weiter auszuführen ${ }^{129}$.

\subsection{Behandlung in den Reichsrechtssammlungen und Historienschriften}

Bei den Reichsrechtssammlungen und Historienschriften der ersten Hälfte des 18. Jahrhunderts lässt sich gut erkennen, wie sehr inzwischen die Deduktionen, Zeitungen und Zeitschriften den Historikern vorarbeiteten und Materialien bereitstellten, die diese dann nur noch gestalterisch anzupassen hatten für ihren jeweiligen Interessenschwerpunkt. Nicht selten wurden diese Schriften zu einer kommentierten Aneinanderreihung von Dokumenten. Beim Theatrum Europaeum ist dies in der Hannoveraner Kurfrage der Fall. In einem kurzen historischen Vorspann wurde darauf hingewiesen, dass mehrere altfürstliche Häuser seit 1648 nach der eigenen Kurpromotion gestrebt hätten, vor allem die Welfen und die Hessen. Die Hannoveraner Linie des Hauses Braunschweig sei 1692 als erste ans Ziel gelangt: Für ein festes Bündnis, die künftige Wahlstimme zugunsten der Habsburger sowie eine besondere Militärhilfe gegen die Türken stellte Kaiser Leopold das Erhebungsdiplom aus. Es folgen fünfzehn Quellenabdrucke bzw. -auszüge auf 21 Druckseiten $^{130}$. Die Fortsetzung der $» k u r b r a u n s c h w e i g i-$

128 Ebd., Bd. 8, 1728, Entrevue 123, S. 1112f.

129 Reichbanneramt: »Gespräche im Reiche der Todten«, Bd. 8, Entrevue 123, S. 1132f.; Introduktion in den Kurfürstenrat: Ebd., S. 1153f.

130 [Matthäus Merians Erben (Hg.)], Theatri Europaei Continuati Vierzehender Theil/Das ist: Abermalige Außführliche Fortsetzung Denck= und Merckwürdigster Geschichten [...], Frankfurt a.M. 1702. - Quellen: 1. Wiener Rezeß, 22. März 1692 (S. 313-315); 2. Unions-Pactum Kaiser - Welfen, 22. März 1692 (S. 315-317); 3. Artikel wegen katholischer Religionsausübung, 22. März 1692 (S. 317-318); 4. Herzog von Braunschweig-Lüneburg an die Landstände, 4. Juni 1692 (S. 318f.); 5. Kurfürstliches Conclusum, 17. Oktober 1692 (S. $320 f$.); 6. Protestation von Kurtrier, Kurköln und Kurpfalz, o.D. (S. 321f.); 7. Remonstration der reichsfürstlichen Opponenten, 16. Juli 1692 (S. 322f.); 8. Remonstrationsschreiben an den Kaiser, 23. Juli 1692 (S. 324); 9. Conclusum des Reichsfürstenrates, 27. August 1692 (S. 325-326); 10. Reichsfürstenratsschreiben an den Kaiser, 4. September 1692 (S. 326-327); 11. Reichsfürstenratsschreiben an Kurmainz, 29. August 1692 (S. 327-328); 12. Protestation BraunschweigWolfenbüttel, 21. August 1692 (S. 328-329); 13. Geistliche Fürsten an die katholischen Kurfürsten, 11. August 1692 (S. 329-330); 14. Geistliche Fürsten an den Papst, 10. November 1692 (S. 330-332); 15. Kaiserlicher Vortrag an die dissentierenden Kurfürsten und Reichsfürsten, 17. Dezember 1692 (S. 332f.). 
schen Geschichte« bis 1695 erfolgte später im selben Band ${ }^{131}$. In Band 15 wurden weitere Dokumente zum Abdruck gebracht, die vor allem den fürstlichen Widerstand gegen den Aufstieg der Hannoveraner zum Gegenstand hatten. Die Fürstentage von Goslar und Nürnberg 1700 fanden Erwähnung, daneben wurden fünf weitere Quellenstücke eingerück $t^{132}$. Der Verfasser von Band 16, zuständig für den Zeitraum 1700-1703, hielt das Thema offenbar für erschöpfend behandelt. Er erwähnte nur noch, dass Kaiser Leopold I. auf die Aktionen der Fürstenopposition ungnädig reagiert habe, woraufhin die Fürsten mit einer umfänglichen Deduktion geantwortet hätten, in der sie die reichsrechtliche Legitimität ihres Standpunktes verdeutlicht hätten ${ }^{133}$.

Im Europäischen Herold, einer zweibändigen Zusammenstellung zu den Staatenbeziehungen, druckte Bernhard von Zech (1649-1720) unter dem Pseudonym »Friedrich Leuthoff von Franckenberg « mehrere Dokumente aus den Jahren 1692 und $1693 a^{134}$. Er begann mit dem Kurtraktat vom 22. März 1692 und ließ dann das Gründungsdokument des oppositionellen Fürstenvereins vom 16./26. Januar 1693 folgen. Darin wurden acht Gründe gegen die Errichtung der Neunten Kurwürde aufgelistet: 1. Verstoß gegen die mystische Siebenzahl der Kurfürsten; 2. keine Notwendigkeit für das Reich, stattdessen Erschwerung der Meinungsbildung im Kurfürstenrat; 3. Zustimmung der Garantiemächte Frankreich und Schweden fehlte; 4. die katholische Seite verlöre die Mehrheit im Kurfürstenrat, wenn die bayerische Kurwürde fortfallen sollte und Kurpfalz protestantisch würde; 5. mit Braunschweig-Lüneburg würde dem Reichsfürstenrat eines der mächtigsten Mitglieder entzogen, was das Gewicht des Gremiums im Reich empfindlich schwächen würde; 6 . auch anderen Interessenten sei die Kurerhebung abgeschlagen worden, z.B. Österreich und Siebenbürgen; 7. der Kaiser hätte den Konsens des

131 Ebd., S. 507-509.

132 [Carl Gustav Merians Erben (Hg.)], Theatri Europaei Continuati Fünffzehender Theil/Das ist: Abermalige Außführliche Fortsetzung Denck= und Merckwürdigster Geschichten [...], Frankfurt a.M. 1707: Fürstentag in Goslar 18. Januar - 15. Februar 1700 nebst Abdruck des Rezesses (S. 699-702); Fürstenverein von Nürnberg, 19. Juli 1700, unter Beteiligung von Würzburg, Münster, Sachsen-Gotha, Brandenburg-Kulmbach, Brandenburg-Ansbach, Hessen-Darmstadt, Dänemark als Herzog von Holstein, Braunschweig-Wolfenbüttel, BadenBaden und Baden-Durlach) (S. 707-709); Schreiben des Kaisers an Kurmainz, 25. März 1700 (S. 702); Fürstliches Memorial mit Gravamina, Ende Mai 1700 (S. 703-706); Kaiserliche Resolution an die Fürsten-Opposition, 3. August 1700 (S. 709f.); Neues fürstliches Memorial an den Kaiser, 30. August 1700 (S. 710f.).

133 Deduktion »Die untadelige Conduite derer correspondierenden Reichsfürsten ...« (1702), in: [Carl Gustav Merians Erben (Hg.)], Theatri Europaei Continuati Sechszehender Theil. Oder Außführlich fortgeführte Friedens- und Kriegsbeschreibung [...], 2 Teilbd., Frankfurt a.M. 1717, Teilbd. 16/I, S. 4.

134 Friedrich Leuthoff von Franckenberg [d.i. Bernhard von Zech], Europäischer Herold, Oder Zuverläßige Beschreibung Derer Europäisch-Christlichen Kayserthums, Königreiche, freier Staaten und Fürstenthümer [...], 2 Bd., Leipzig ${ }^{2} 1705$. 
Reichstags und nicht nur des Kurfürstenrates in dieser Frage suchen müssen; 8. nicht nur Hannover, sondern auch andere Stände hätten sich im Türkenkrieg hervorgetan (besonders Ungarn), dennoch könnten nicht alle dafür in den Kurfürstenrat aufgenommen werden ${ }^{135}$. Acht Gegenargumente der Hannoveraner Seite wurden diesen Anschauungen gegenübergestellt. Den Abschluss machte der Abdruck der Declaratio nullitatis der Opponenten vom Februar $1693^{136}$.

Zacharias Zwantzig ging in seinem Theatrum Praecedentiae nicht auf den Kurerhebungskonflikt im Ganzen ein, sondern nur auf den Einzelaspekt der geänderten Rangfolge zwischen den beiden welfischen Linien Braunschweig-Wolfenbüttel (ältere Linie) und Braunschweig-Lüneburg (jüngere Linie). Die Schilderung ist sachlich zutreffend und frei von Polemik und Parteinahme für die eine oder andere Seite ${ }^{137}$.

Ein Spezialproblem stand auch im Mittelpunkt der Electa Juris Publici von Georg Melchior von Ludolf. Über die Rahmenumstände der Kurerhebung wurde nichts gesagt, auch nicht über die politischen Pflichten, die der neue Kurfürst Ernst August eingegangen war. Behandelt wurde vorzugsweise das Kompensationsproblem für die Katholiken, die 1708 nicht nur eine neue, böhmische Kur für sich verbuchten, sondern auch die Anwartschaft auf eine weitere katholische Kur festschreiben ließen für den Fall, dass bei Aussterben einer Wittelsbacher Linie die Achte Kur erübrigt würde. Er schloss diese Passage mit einer kurzen Schilderung der Zulassung von Kurböhmen und Kurhannover zur Session am 7. September $1708^{138}$.

Johann Christian Lünig, der wohl bekannteste Reichsrechtskompilator des frühen 18. Jahrhunderts, stellte in seiner Bibliotheca deductionum S.[ancti] R.[omani] I.[mperii] keine vollständige Sammlung aller Druckschriften zum Streit um die Neunte Kur vor, sondern beschränkte sich darauf, einige Schriften aus den Jahren 1692 und 1693 zu nennen, die jeweils besonders viele Quellen enthielten. Insbesondere handelte es sich dabei um »Acta publica den IX. Electorat betr." (19 bzw. 24 Quellen), Miscellanea juris publici curiosa de novem viratu (18 Quellen), Hippolythus a Lapide, Allerhand curiöse

135 Ebd., Bd. 1, S. 313-316.

136 Gegenargumente Kurhannovers: ebd., Bd. 1, S. 316-318; »Declaration nullitatis«, 4./ 14. Februar 1693: ebd., Bd. 1, S. 318f.

137 Zacharias Zwantzig [Pseud.: Ehrenhart Zweyburg], Theatrum Praecedentiae oder Eines Theils Illustrer Rang=Streit, Andern Theils Illustre Rang-Ordnung, Wie nemlich Die considerablen Potenzen und Grandes in der Welt [...] Nach Qualität ihres Standes, Namens, Dignität und Characters samt und sonders, In der Präcedentz, in dem Rang und Tractamente streitig seynd und competieren [...], 2 Tl. in 1 Bd., Berlin/Frankfurt a.M. 1706, hier Tl. 2, S. $147 f$.

138 Ludolf druckte im Folgenden 12 Dokumente zu 1708 ab: Georg Melchior von Ludolf, Electa Juris Publici. Worinnen Die Vornehmsten Staats-Affairen in Europa/Besonders in Teutsch=Land/aus bewährtesten Actis publicis [...] recensiret werden, 21 Bd., München 1709-1725, hier Bd. 1, S. 1-28. 
Raisonnements (25 Quellen) sowie um den Discursus de Novemviratu, den Lünig als eine listige Buchhändler-Erfindung beschrieb, weil es sich dabei um einen Neuabdruck einer früheren Schrift handelte ${ }^{139}$.

Zum Abschluss soll eine bebilderte Publikation zur Reichshistorie im 18. Jahrhundert kurz erwähnt werden: Johann David Köhlers Gedenkwürdigkeiten, eine Bilderchronik aus 20 Kupferstichen zu historischen Begebenheiten des frühen 18. Jahrhunderts. Bei Köhler wird unter dem Jahr 1708 die Beendigung des Kurstreits vermeldet. Das Bild trifft die Verneigung der anwesenden kurfürstlichen Gesandten beim Eintritt von Kurböhmen und Kurhannover zur ersten gemeinsamen Session. Sieben kurfürstliche Gesandte waren anwesend, die Vertreter von Kurköln und Kurbayern fehlten wegen der 1706 durchgeführten Ächtung ihrer Prinzipalen. In der anschließenden Bilderklärung wird die Kurerhebung von 1692 erwähnt und die Doppelzeremonie vom 7. September 1708 vorgestellt ${ }^{140}$. Auch im Jahr 1709 wird nochmals an Kurhannover erinnert: Auf dem Bild wird eine Medaille mit der Reichskrone gezeigt und in der Erklärung die Verleihung des Erzschatzmeisteramtes an Kurhannover erläutert ${ }^{141}$.

\subsection{Zusammenfassung}

Der Streit um die Kurerhebung Hannovers war weniger auf Öffentlichkeit angelegt als der Vikariatskonflikt. So fehlten öffentliche Patente, allerdings dominierten einmal mehr die Deduktionen ab dem Bekanntwerden des kaiserlichen Vorhabens im Laufe des Sommers 1692. Die meisten derartigen Schriften entstammten dem näheren Umfeld der interessierten Parteien. $\mathrm{Ob}$ der Franzose J.A. Ducros einen Auftrag seiner Regierung zur Erstellung der Flugschrift Lettre ecrite hatte, ist unklar. Erster Berichtshöhepunkt war die Belehnung im Dezember 1692. In den folgenden Jahren ebbte die Publizistik zu diesem Thema langsam ab, weil immer mehr kritische Parteien sich ins Unvermeidliche schicken mussten. Die tatsächliche Introduktion des kurhannoveranischen Gesandten in den Kurfürstenrat 1708 fand in den Druckmedien als Zeremoniellereignis statt. Dazwischen wurde auch die Publizistik zur Militäraktion von 1702 in Braunschweig-Wolfenbüttel einbezogen.

139 Johann Christian LüNIG (Hg.), Bibliotheca deductionum S.R.I, anietzo in eine geschicktere Ordnung gebracht, durchaus verbessert, und ansehnlich vermehret von Gottlob August JENICHEN, 4 Tl., Leipzig 1745, hier Tl. 1, S. 161-167.

140 Johann David KöHLER, Gedenckwürdigkeiten des jetzt lauffenden achtzehenden Jahr-Hunderts nach Christ Geburt: als eine Fortsetzung der Welt in einer Nuß in Gedächtnis-hülflichen Bilder-Tafeln. Mit einer historischen Einleitung, 20 Bilder, Nürnberg 1701-1739, hier S. 90f. (Bild) u. 98f. (Erklärung).

141 Ebd., S. 116f. (Bild) u. 119f. (Erklärung). 
Die Zeitungen warteten ein offizielles Ereignis ab, bevor sie mit der Berichterstattung begannen. Ausnahme war die Mercurii Relation aus München, die schon seit dem Frühjahr 1692 argwöhnte, es gebe eine besondere militärische Zusammenarbeit zwischen Kaiser und Welfenherzog, woraus sich ein Kompensationsanspruch des letzteren ergeben könne. Die Umstände dieser Frühform des investigativen Journalismus liegen allerdings leider im Dunkeln.

Da die Zeitschriften erst im letzten Jahrzehnt des 17. und ersten Jahrzehnt des 18. Jahrhunderts entstanden, fehlt eine breite Berichterstattung über den ganzen Kurstreit. Nur der weitere Verlauf wurde vor allem im Staats $=$ Spiegel von Acxtelmeier und in der Europäischen Fama abgehandelt. Beide Periodika waren äußerst reichspatriotisch, was eine klare Parteinahme für das kaiserlich-hannoversche Geschäft und eine klare Gegnerschaft zu den Ambitionen Herzog Anton Ulrichs - im Zusammenwirken mit Frankreich - zur Folge hatte. Ebenso wie in den Historienschriften wurde die Konfliktlage souverän und sachlich zutreffend erläutert, die Kernprobleme, nämlich die Frage nach der Zuständigkeit des Reichsfürstenrates und die immanente Problematik des welfischen Hauskonflikts, stehen jeweils im Mittelpunkt. - Markante Interventionen durch Zensurinstanzen in die Berichterstattung sind nicht bekanntgeworden. 


\section{4. Ächtung Kurfürst Max Emanuels von Bayern}

\subsection{Dimensionen des Konflikts}

Möglicherweise wird es überraschen, in einer Studie über innenpolitische Konflikte im Reich die Person Max Emanuels von Bayern anzutreffen. Der Kurfürst wird gemeinhin assoziiert mit einer europaweit ausgreifenden Politik, mit einer politischen Sprengkraft versehen, die ihn weit über Bayern und das Reich hinaushob. Ein kriegerisches Zeitalter bot ihm Gelegenheit, sowohl auf dem Balkan gegen die Türken als auch im westeuropäischen Ausland gegen verschiedene Gegner zu kämpfen. Wo soll da die Innenpolitik sein, gerade bei einem Herrscher, der fast ein Jahrzehnt lang sein Stammland gar nicht betreten konnte, mithin zu einer Innenpolitik gar nicht in der Lage war?

Die historiographische Perspektive soll hier auf die innenpolitische Dimension des kurfürstlichen Wirkens gerichtet werden, d.h. nicht auf die bayerisch-innenpolitische, sondern auf die reichsinnenpolitische. Letztlich wurde der Wittelsbacher deswegen zu seinem langen Exil gezwungen, weil er mit den Normen innenpolitischen Handelns und Regierens im Reich in Kollision geriet und dadurch die Widerstände auslöste, die seine Vertreibung und Absetzung zur Folge hatten.

Dabei hatte Kurfürst Max Emanuel von Bayern (*1662, reg. 1679-1706 und 1714-1726) seine politische Laufbahn in traditioneller Weise begonnen ${ }^{1}$. Er erhielt eine Ausbildung, wie sie einem Prinzen aus prominentem reichsfürstlichen Hause zustand. Vor allem wurden ihm die hochadligen Wertvorstellungen eingepflanzt, die später immer wieder zur Leitschnur seines Handelns werden sollten. In den 1680er Jahren kämpfte er für längere Zeit auf dem Balkan im kaiserlichen Dienst gegen die Türken². An politisch-militärische Geländegewinne innerhalb des Reiches dachte er zu dieser Zeit noch nicht; jedenfalls gibt es dafür keine Spuren. In den Bereich der dynastischen Politik fielen allerdings die Bemühungen, Mitglieder seines Hauses

1 Grundlegend zum Werdegang Max Emanuels ist immer noch die aus den Archivalien geschöpfte Biographie von Ludwig HütTL, Max Emanuel. Der Blaue Kurfürst (1679-1726), München 1976. Dies gilt ungeachtet der penetranten 1968er Diktion, innerhalb derer Hüttl den Kurfürsten und das bayerische »Volk« gemeinsam porträtieren möchte: Ebd., S. 11. Aus seiner Sicht ist ein Barockfürst zwar ein absolutistischer Despot, doch erliegt Hüttl erfreulicherweise dem Charme des Wittelsbacher Herrschers über weite Strecken, was das Buch lesenswert erhält.

2 Zur Militärgeschichte des Kurfürsten: Marcus Junkelmann, Kurfürst Max Emanuel von Bayern als Feldherr, München 2000. 
auf Bischofsstühle im Reich zu bringen, eine Politik, die er von seinen Vorfahren übernommen hatte und erfolgreich fortsetzte ${ }^{3}$.

Während dieser Zeit entschied sich der Kurfürst auch, sich durch die Eheschließung mit einer Habsburgerin mit der dominierenden Dynastie Europas zu verbinden. Kaiser Leopold I. bot ihm die Hand seiner Tochter Maria Antonie an. Die Heirat fand 1685 statt. Nachdem die Kurfürstin 1692 früh im Kindbett gestorben war, fand der Witwer mit Therese Kunigunde, Tochter des Königs Johann III. Sobieski von Polen, eine zweite Frau von königlichem Rang. Die Heiratsverbindungen führen in die dynastische Denkwelt des Kurfürsten ein: Max Emanuel war inzwischen durchdrungen von dem Ehrgeiz, seinem Haus Wittelsbach einen bedeutenden Zuwachs materieller oder immaterieller Art zu hinterlassen. Entweder wollte er vorteilhaften Territorialgewinn verbuchen, oder ihm stand der Sinn nach einer europäischen Königskrone, gleich ob es eine schon vorhandene oder eine noch zu schaffende sein würde. Als Türkensieger und damit Beschützer des Abendlandes fühlte er sich nicht nur dynastisch, sondern auch persönlich aufgrund seiner Leistungen berechtigt, weitgehende Forderungen zu stellen, besonders an den Kaiser, den er durch sein Handeln vielfach unterstützt hatte. In zahlreichen Studien über die 1690er Jahre und den Spanischen Erbfolgekrieg äußern viele Historiographen bis in die Gegenwart Unverständnis über die wechselvollen Koalitionsverhandlungen und Vertragsabschlüsse, an denen der Kurfürst beteiligt war ${ }^{4}$. Der größte Teil dieser Bestrebungen lässt sich erklären, wenn man in Max Emanuel einen Fürsten sieht, der sich bewusst war, nicht zur allerersten Garnitur der europäischen Mächte zu gehören, aber in diesen erlauchten Kreis aufsteigen wollte. Daher durchlebte er dasselbe barocke »Wechselfieber«, das auch vom Großen Kurfürsten Friedrich Wilhelm von Brandenburg bekannt ist ${ }^{5}$.

3 Manfred Weittlauff, Die Reichskirchenpolitik des Hauses Bayern unter Kurfürst Max Emanuel (1679-1726). Vom Regierungsantritt Max Emanuels bis zum Beginn des Spanischen Erbfolgekrieges, St. Ottilien 1985. Überblick über die dynastische Politik der Wittelsbacher: Jörg Engelbrecht, Krone und Exil. Das Haus Wittelsbach in der deutschen und europäischen Politik (1679-1761), in: Frank Günter Zehnder (Hg.), Im Wechselspiel der Kräfte. Politische Entwicklungen des 17. und 18. Jahrhunderts in Kurköln, Köln 1999, S. 9-22.

4 Zur internationalen Politik: Karl Otmar Freiherr von Aretin, Die Politik des Kurfürsten Max Emanuel und die europäischen Mächte, in: Hubert Glaser (Hg.), Kurfürst Max Emanuel. Bayern und Europa um 1700, Bd. 1, München 1976, S. 35-50. Zur Geschichtsschreibung: Hans Schmidt, Max Emanuels Bild in der Geschichtsschreibung, in: Glaser, Kurfürst Max Emanuel, Bd. 1, S. 459-474.

5 Zur Biographie des Großen Kurfürsten: Ernst Opgenoorth, Friedrich Wilhelm, der Große Kurfürst von Brandenburg. Eine politische Biographie, 2 Bd., Göttingen u.a. 1971-1978. Zur internationalen Mächtepolitik: Johannes Kunisch, Kurfürst Friedrich Wilhelm und die großen Mächte, in: Gerd HeinRich (Hg.), »Ein sonderbares Licht in Teutschland«. Beiträge zur Geschichte des Großen Kurfürsten von Brandenburg (1640-1688), Berlin 1990, S. 9-32. 
Das Konkurrenzparadigma ist auf den Wittelsbacher sehr gut anwendbar: Max Emanuel erstrebte nicht nur Ruhm und Glanz in der Weise, wie Adlige es schon immer gehalten hatten, sondern er lebte in einer Zeit sich zuspitzender hochadliger Konkurrenz. In diesen Denkzusammenhang fallen seine Bemühungen, eine Königskrone zu erlangen. Ein bayerisches Königtum schied aus, wie sich schnell herausstellte. An Bayern hing er nicht so sehr, als dass er sein Stammterritorium nicht im Tausch gegen etwas Besseres aufgegeben hätte ${ }^{6} .1692$ wurde Max Emanuel im Auftrag der Madrider Regierung Generalstatthalter der Spanischen Niederlande. In den folgenden Jahren tauchten immer wieder Pläne auf, Bayern gegen die flämischen Provinzen zu tauschen, was der Wittelsbacher akzeptiert haben dürfte, falls damit auch sein Wunsch nach einer neuen Königskrone in Erfüllung ginge. Gleichzeitig erhoffte er für seinen Sohn Joseph Ferdinand den Erwerb des spanischen Erbes, das nach dem bevorstehenden Tod des kinderlosen Karls II. disponibel werden würde, aber aus Gründen des europäischen Mächtegleichgewichts weder den Habsburgern noch den Bourbonen zufallen sollte. Max Emanuel erreichte die testamentarische Zustimmung der spanischen Krone zur wittelsbachischen Sukzession, und selbst die europäischen Mächte gewöhnten sich an diese geplante Lösung. Der Tod des Wittelsbacherprinzen 1699 im Alter von sechs Jahren machte die Hoffnungen zunichte?

Es war nicht nur dieser dynastische Rückschlag, der den Kurfürsten in seinen Ambitionen behinderte. Weit weniger als die anderen Königskandidaten lebte Max Emanuel eigenen stringenten Planungen nach, sondern eher war er ein Getriebener, Verführter und manchmal auch Verfolgter von den Diplomaten der Mächte und den Vertretern der Kurie, die ihm Handlungsvorgaben zu suggerieren versuchten. Selbst Ludwig Hüttl stellte dem Kurfürsten kein schmeichelhaftes Urteil aus, wenn er ihn anlässlich seiner Wienreise 1687 wie folgt charakterisierte:

6 Insofern verwundert die hymnische Verehrung dieses Fürsten in Bayern bis heute. Selbst in der großen Ausstellung 1976 wurde von einer siebenundvierzigjährigen Regierungszeit geschrieben (ohne Abzug der Jahre, in denen Max Emanuel gar kein Kurfürst war). Im Einleitungsessay von Hubert Glaser zur Phase der Vertreibung und Ächtung des Kurfürsten scheinen die laufenden Reichsrechtsverstöße und Gewalttaten, die die Absetzung bedingt hatten, in konstruktivistischer Weise als bloße Diskurse abgetan zu werden, denen kein Augenmerk zu widmen sei, weil der Kurfürst seine Absetzung auch nicht anerkannt habe und weiterhin die kurfürstlichen Kurialien geführt habe. Die machtpolitisch durchgesetzte Restitution 1714 lässt sich vor diesem Hintergrund als Legitimation für eine derartige Interpretation bewerten: Glaser, Kurfürst Max Emanuel, hier Bd. 2, S. 146f.

7 Zur spanischen Sukzession und den dynastischen Ambitionen Max Emanuels: Reginald DE SCHRYver, Max II. Emanuel von Bayern und das spanische Erbe. Die europäischen Ambitionen des Hauses Wittelsbach, Mainz 1996. 
Ein Mann von 25 Jahren, der sich bei Wien, Gran und Ofen [als Türkensieger - J.A.] ausgezeichnet hatte, ehrgeizig und stolz, voller unausgereifter Pläne und Hoffnungen, den Vergnügungen des Augenblicks völlig ergeben und im Gegensatz zu seinen Vorfahren Maximilian I. und Ferdinand Maria kaum fähig, seine Vergnügungen mit seinen Pflichten als Regent in Einklang zu bringen ${ }^{8}$.

Als Karl II. Ende 1700 starb, konkurrierten Herzog Philipp von Anjou für das Haus Bourbon und Erzherzog Karl für die Habsburger um den Thron in Madrid. Max Emanuel stand vor der Entscheidung: Er akzeptierte das letzte Testament Karls II. und blieb in seiner Brüsseler Statthalterschaft, nun allerdings im Dienst Philipps V., des ersten bourbonischen Königs von Spanien? Auch wenn der Kurfürst in den folgenden beiden Jahren Verhandlungen mit Kaiser Leopold über einen vorteilhaften Bündniswechsel führte, legte er sich schließlich auf ein französisches Bündnis mit Ludwig XIV. fest. Während der Kaiser ihm nur die Garantie seines aktuellen Besitzes und ungewisse Aussichten auf noch zu erringende Zugewinne machte, kam der Franzosenkönig den Wünschen des Wittelsbachers weiter entgegen ${ }^{10}$.

Ohnehin erschien der prachtvolle Hof in Versailles dem bayerischen Kurfürsten wesentlich attraktiver als die noch im spanischen Hofzeremoniell einherschreitende Wiener Hofgesellschaft. In der Imitation in München und Umgebung, sowohl was das tägliche Hofleben mit seinen Feiern, künstlerischen und musischen Gestaltungen sowie vor allem seinen Baumaßnahmen anging, war der französische Einfluss omnipräsent. Die noch heute sichtbaren Hinterlassenschaften des bayerischen Hochbarocks wurden 1976 von Hubert Glaser in einer großen Ausstellung in München präsentiert ${ }^{11}$. Dabei konnte demonstriert werden, dass der höfisch-kulturelle Abstand Max Emanuels zu den europäischen Monarchen wesentlich kleiner war als der machtpolitische Unterschied ${ }^{12}$. In einem Zeitalter, in dem die Zurschaustellung von Rang, Ruhm und Ehre zwar immens teuer, aber immer noch preiswer-

8 HüttL, Max Emanuel, S. 164.

9 Ludwig Hüttl betont, dass Max Emanuel zwar von Frankreich zuvor umworben worden war, doch dass es seine Entscheidung war, 1701 seinen Gesandten Ferdinand Solar Graf Monasterol nach Paris zu schicken und den Bourbonen seine Dienste anzubieten, und dies in dem Wissen, dass ein Scheitern der militärischen Kooperation ihn seine bayerischen Stammlande kosten konnte: HüTtL, Max Emanuel, S. 295.

10 Versuchte bayerische Großmachtpolitik: Karl Otmar Freiherr von Aretin, Die Politik des Kurfürsten Max Emanuel von Bayern und die europäischen Mächte, in: Ders., Das Reich. Friedensgarantie und europäisches Gleichgewicht 1648-1806, Stuttgart 1992, S. 209-240.

11 Zur Dokumentation der Ausstellung der Katalog von Glaser, Kurfürst Max Emanuel. Bayern und Europa um 1700, 2 Bd., pas.

12 Vgl. zur Selbstrepräsentation Max Emanuels in allen künstlerischen Medien: Rudolf FELBINGER, Maximilian II. Emanuel von Bayern (1662-1726). Anspruch und Inszenierung des »Blauen Kurfürsten«, München 1999 (Mschr.). Felbinger ging methodisch von Peter Burkes Untersuchung zur höfischen Repräsentation Ludwigs XIV. aus und stieß dabei auf zahlreiche 
ter war als ein durchschlagender militärischer Sieg, bedeutete der Aufwand einen wichtigen Schritt auf dem Weg zu den Zielen, die sich der Kurfürst gesteckt hatte. Eine Alternative gab es auch für Max Emanuel nicht, denn für eine selbstständige militärische Rolle fehlten dem Wittelsbacher die nötigen finanziellen Mittel, wie Peter Claus Hartmann in verschiedenen Studien nachweisen konnte: Ohne die gewaltigen Summen, die Frankreich und das Spanien Philipps V. sich die bayerische Unterstützung kosten ließen, wäre Max Emanuels militärisches Engagement gar nicht erst zur Entfaltung gekommen. Über den Zeitraum zwischen 1701 und 1715 flossen ca. 27 Millionen Gulden aus Frankreich und ca. 6 Millionen Gulden aus Spanien an Max Emanuel, obwohl er den größten Teil der Zeit im niederländischen Exil weilte und der strategische Nutzen einer Kontrolle Oberdeutschlands nach 1704 nicht mehr erreichbar war ${ }^{13}$.

Der Konflikt des Kurfürsten mit dem Reichssystem nahm nicht seinen Ausgang aus der niederländischen Statthalterschaft, sondern begann nach der Rückkehr Max Emanuels nach München 1701. Nachdem der kriegerische Austrag um das spanische Erbe unabwendbar geworden war, glaubte der Wittelsbacher in Überschätzung seiner Situation, er habe die freie Wahl zwischen beiden Konfliktparteien und könne sich mit der Seite verbinden, die ihm für seine Mitwirkung die vorteilhaftesten Konditionen in Aussicht stellte. Für Konflikte außerhalb des Reichsgebiets oder für begrenzte Waffengänge in Mitteleuropa hätte diese Option möglicherweise bestanden, doch nicht für einen großen europäischen Krieg. Der Kurfürst war Lehnsmann des Reiches, und als solcher war er rechtlich verpflichtet, seine internationalen Bündnisse im Interesse des Reichswohls zu disponieren. Reichsrechtlich bestand daher keine freie Wahl: Die Pflicht zur Verteidigung des Reiches an der Seite des Kaisers war seit alters hergebracht und hatte im Westfälischen Frieden eine zusätzliche Bekräftigung erfahren: In Artikel VIII, § 2 war festgelegt worden, dass die Reichsstände zum Abschluss von Verträgen mit Partnern innerhalb und außerhalb des Reiches berechtigt waren. Allerdings waren im Friedensinstrument zwei Einschränkungen niedergelegt: 1. Die Bündnisse sollten der Erhaltung bzw. der Sicherheit der Betroffenen

Parallelen: Peter Burke, Ludwig XIV. Die Inszenierung des Sonnenkönigs, Frankfurt a.M. 1995 (engl. 1992).

13 Vgl. zur Finanzpolitik des Kurfürsten, die schließlich in die Überschuldung führte und noch die politische Handlungsfähigkeit seiner Nachfolger beeinträchtigte: Peter Claus HarTmanN, Die Subsidien- und Finanzpolitik Kurfürst Max Emanuels von Bayern im Spanischen Erbfolgekrieg, in: ZBLG 32 (1969), S. 238-289; zu den Zahlen: Ebd., S. 288. Hartmann untersuchte anschließend die weitere bayerische Finanzpolitik: Ders., Geld als Instrument europäischer Machtpolitik im Zeitalter des Merkantilismus. Studien zu den finanziellen und politischen Beziehungen der Wittelsbacher Territorien Kurbayern, Kurpfalz und Kurköln mit Frankreich und dem Kaiser von 1715 bis 1740, München 1978. 
dienen. 2. Abkommen mit Zielrichtung gegen Kaiser und Reich, gegen den Landfrieden und gegen den Westfälischen Vertrag waren verboten ${ }^{14}$.

Max Emanuel ließ sich von diesen reichsrechtlichen Vorgaben nicht beeindrucken. Während der Verhandlungen mit Frankreich stand er unter dem Einfluss des französischen Gesandten Louis Gaspard de Ricous, der die Schwächen und Eitelkeiten des Wittelsbachers geschickt ausnutzte und ihn schließlich zum Bündnisvertrag vom 9. März 1701 bewegen konnte. Max Emanuel sah in klaren Momenten die Risiken ein, die ihm und seinem Land im Falle einer Niederlage drohten. Er eignete sich allerdings die französische Sicht an, dass der mögliche Lohn einer herausgehobenen europäischen Stellung das Wagnis wert sei ${ }^{15}$. Dieses Abkommen sollte der bayerischen Expansion den Weg bahnen und richtete sich zwangsläufig gegen den Kaiser. Das Bündnis war im Übrigen geheim und wurde auch nicht in der europäischen Presse bekannt, bevor die militärischen Aktionen den politischen Zusammenhang offenlegten ${ }^{16}$. Damit richtete er sich auch gegen das Reich, was mit dem Paukenschlag gegen die Reichsstadt Ulm im September 1702 offensichtlich wurde: Per Handstreich setzte sich der Kurfürst in den Besitz der Stadt und ließ dort ein Truppenkontingent stationieren ${ }^{17}$.

Die Aktion löste Entsetzen unter den kleineren und mittleren Reichsständen aus. Besonders die Mitstände im Schwäbischen und Fränkischen Reichskreis, die in den vorangegangenen Jahrzehnten mit Bayern und dem Kaiser gegen Frankreich zusammengearbeitet hatten, sahen sich nicht nur verlassen, sondern in ihrer Existenz bedroht. In den folgenden 16 Monaten nahmen die bayerischen Truppen Memmingen, Dillingen, Lauingen (alle im Oktober 1702), Neuburg/Donau (Februar 1703), Regensburg (April 1703), Augsburg (Dezember 1703) und Passau (Januar 1704) ein. Ein Versuch, den Kaiser durch die Annexion Tirols direkt in seinen Erblanden zu treffen, scheiterte im Sommer 1703 durch einen großen Volksaufstand der Bergbewohnerschaft ${ }^{18}$. Niemand im Reich glaubte Max Emanuel seine Beteuerungen, nur durch seinen militärischen Schutz könnten die genannten süddeutschen Städte in Sicherheit leben. Zu deutlich war die Absicht, dass der Fürst sich

14 Westfälischer Friede, Osnabrücker Friedensinstrument vom 24. Oktober 1648, Art. VIII § 2: Arno Buschmann (Hg.), Kaiser und Reich. Klassische Texte und Dokumente zur Verfassungsgeschichte des H1. Römischen Reiches Deutscher Nation vom Beginn des 12. Jahrhunderts bis zum Jahre 1806, München 1984, S. 339.

15 Zum Schwanken des Kurfürsten während der Gespräche und zum Einfluss Ricous: HütTL, Max Emanuel, S. 328f.

16 Vgl. zu den Bündnisverhandlungen, die zum zweiten Abkommen vom 17. Juni 1702 führten, sowie zu den militärischen Aktionen des Jahres 1702: Max Braubach, Die Politik des Kurfürsten Max Emanuel von Bayern im Jahre 1702, in: HJb 43 (1923), S. 53-92.

$17 \mathrm{Zu}$ den diplomatischen Hintergründen der Offensive: DE SchrYver, Max II. Emanuel von Bayern und das spanische Erbe, S. 138-142.

$18 \mathrm{Zu}$ den übrigen Städteeroberungen Hüttl, Max Emanuel, S. 336-363; vgl. auch Felbinger, Maximilian II. Emanuel von Bayern, S. 73. 
mit französischer Hilfe nun in Süddeutschland eine Territorialbasis schaffen wollte, die seinem Ehrgeiz Genüge leistete und möglicherweise Grundlage für ein Königreich werden könnte. Auch ohne dass der reichsfreie Status der Städte formell beseitigt worden wäre, mussten sie der kurfürstlichen Finanzknappheit dadurch dienen, dass sie von der bayerischen Soldateska und anschließend von den Fremdverwaltungsbehörden ausgeplündert wurden ${ }^{19}$. Besonders der Anschlag auf Regensburg, wo ein großer Teil der Reichstagsgesandten vor Erscheinen der Bayern flüchtete, galt als Signal des Angriffs auf das Reichssystem als Ganzes. Dass die Aktionen des Kurfürsten zwischen 1702 und 1704 als schwerer Landfriedensbruch zu gelten hatten, war außerhalb Bayerns im Reich unumstritten. Hier war diese Perspektive entscheidend, auch wenn Bernd Wunder zurecht betont, dass unter dem strategischen Blickwinkel der europäischen Mächte von einer französisch-bayerischen »Diversion« gesprochen werden konnte ${ }^{20}$.

Ebenso schnell, wie die bayerische Hegemonie entstanden war, verschwand sie auch wieder im Sommer 1704. Nachdem die Front der Kaiserlichen und der Kreistruppen am Oberrhein zunächst zusammengebrochen war, rückten die intakten Armeen des Prinzen Eugen und des Herzogs von Marlborough aus den Niederlanden nach Süddeutschland vor und schlugen die bayerisch-französische Armee am 13. August 1704 bei Höchstädt nahe Augsburg ${ }^{21}$. Mit der Niederlage, der anschließenden Auflösung seiner Truppen sowie der feindlichen Besetzung der bayerischen Kernlande zerplatzte der Traum des bayerischen Kurfürsten von seiner Geltung als europäische Macht nach 1699 ein zweites Mal. Um nicht in die Hände des Kaisers zu geraten und sich einem persönlichen Strafgericht auszusetzen, floh Max Emanuel nach Brüssel, später nach Mons, Compiègne und Paris, wo er in den folgenden Jahren als französischer Statthalter und anschließend als prominenter Höfling wirkte ${ }^{22}$.

19 Vgl. beispielsweise die Ausplünderung Augsburgs im Dezember 1703: HüTtL, Max Emanuel, S. 362.

20 Bernd Wunder, Die bayerische $»$ Diversion« Ludwigs XIV. in den Jahren 1700-1704. Kurbayern, Schwaben und Franken zwischen Habsburg und Bourbon zu Beginn des Spanischen Erbfolgekrieges, in: ZBLG 32 (1969), S. 228-289.

21 Schlacht bei Höchstädt: Hüttr, Max Emanuel, S. 371-374; Junkelmann, Kurfürst Max Emanuel von Bayern als Feldherr, S. 241-265. Vgl. auch den Ausst.-Kat. von ERichSEN/HeineMANN, Die Schlacht von Höchstädt, pas. - Karl Otmar Freiherr von Aretin kommentierte die Bedeutung der Schlacht für das Reich mit folgenden Worten: »Prinz Eugen und Marlborough retteten an diesem Tag das Reich für hundert Jahre«: von Aretin, Die Politik des Kurfürsten Max Emanuel und die europäischen Mächte, S. 45. Vgl. auch zur Kriegführung des Kaisers und der oberdeutschen Stände gegen Frankreich und zeitweise gegen Bayern: Max PlassMANn, Krieg und Defension am Oberrhein. Die Vorderen Reichskreise und Markgraf Ludwig Wilhelm von Baden (1693-1706), Berlin 2000.

22 Die Verlagerung der Residenz Max Emanuels nach Mons erfolgte nach der Niederlage von Ramillies am 23. Mai 1706: HütTL, Max Emanuel, S. 401. - Aufgabe von Mons nach der 
Das Strafgericht richtete sich stattdessen gegen die hinterlassenen Beamten des geflohenen Kurfürsten, gegen seine Frau und Kinder sowie im weiteren Sinne gegen die Gesamtheit der bayerischen Untertanen. Kaiserliche Truppen rückten in Bayern ein, exilierten die Kurfürstin nach Venedig, verbrachten die Prinzen nach Klagenfurt, setzten eine österreichische Spitzenadministration ein und nutzten das Land fiskalisch in einer Weise, die zu einem großen Bauernaufstand führte ${ }^{23}$.

Inzwischen hatte sich der Reichstag wieder im befreiten Regensburg versammelt. Der kurbayerische Gesandte Kaspar Marquardt Baron von Zindt war allerdings nicht mehr dabei, nachdem ihn Kaiser Josef I. als Geschäftsträger eines Reichsverräters von allen Sitzungen ausgeschlossen und aus dem Reich verwiesen hatte ${ }^{24} .1706$ erfolgte nach vorausgegangenen umfänglichen Konsultationen des Kaisers mit den Kurfürsten die Ächtung Max Emanuels, zusammen mit seinem Bruder, dem Kölner Erzbischof Josef Clemens, der als geistlicher Fürst zwar nicht formell geächtet, aber »privatisiert« werden konnte. Das Absetzungsverfahren war - wenn man der Dissertation von Julius Froboese aus dem Jahre 1874 folgen darf - vor allem vom Römischen König Josef und vom Pfälzer Kurfürsten Johann Wilhelm gefördert worden $^{25}$. Kaiser Leopold I. - unterstützt von seinen probayerischen Beichtvätern - hatte lange mit Mahnungen und einer Geheimdiplomatie versucht, Max Emanuel vom französischen Bündnis wieder abzubringen. Die eigensüchtigen Gründe des Pfälzer Kurfürsten waren mit Händen greifbar. Er wollte wieder den angestammten Vorrang vor den Bayern einnehmen, den die Pfalz 1621 / 1648 verloren hatte, sowie die Oberpfalz zurückgewinnen ${ }^{26}$.

Schlacht von Malplaquet am 11. September 1709: Ebd., S. 409. Aufenthalt in Compiègne: Ebd., S. 491-499.

23 Christian Proвst, Lieber bayrisch sterben. Der bayerische Volksaufstand der Jahre 1705 und 1706, München 1978; Henric L. Wuermeling, Die Sendlinger Mordweihnacht. 1705 - die erste europäische Revolution, München u.a. 1985. Quellenausgabe hierzu: Adolf Rотн (Hg.), Lieber bayrisch sterben. Der oberländische Bauernaufstand von 1705. Zeitgenössische Berichte, München 1955.

24 Zu Kaspar Marquard Zindt (auch: Zündt), Baron von Kenzingen (ca. 1636-1715): Walter FürNROHR, Kurbaierns Gesandte auf dem Immerwährenden Reichstag. Zur baierischen Außenpolitik 1663-1806, Göttingen 1971, S. 69-73. Fürnrohr vertritt eine apologetische Interpretation der Tätigkeit des Gesandten. - Baron Zindt war erst 1701 nach Regensburg gesandt worden, galt als frankophil und konnte unter den beunruhigten Gesandtenkollegen kaum Kontakte aufbauen. Nach der Ausweisungsankündigung vom 11. September 1704 gelang es ihm, das wichtige bayerische Gesandtschaftsarchiv verpacken und aus Regensburg auf bayerisches Gebiet schaffen zu lassen, bevor er selbst aus dem Reich abreiste: FrIEDRICH, Drehscheibe Regensburg, S. 225 u. 358-370.

25 Julius Froboese, Die Achterklärung der Kurfürsten von Baiern und Köln 1706 und ihre reichsrechtliche Bedeutung, Mühlhausen 1874, S. 1.

26 Dazu vor allem: Franz FeldmeIER, Die Ächtung des Kurfürsten Max Emanuel von Bayern und die Übertragung der Oberpfalz und der fünften Chur an Churpfalz, in: OBA 58 (1914), S. 145 269. Vgl. dazu auch Georg Wilhelm SANTE, Die kurpfälzische Politik des Kurfürsten Johann Wilhelm vornehmlich im Spanischen Erbfolgekrieg 1690-1716, in: HJb 44 (1924), S. 19-64. 
Das Ächtungsverfahren wurde noch durch Leopold eingeleitet, um dann durch seinen Sohn Josef I. im April 1706 durchgeführt und abgeschlossen zu werden ${ }^{27}$. Vergeblich hofften die Wittelsbacher in Belgien darauf, dass sich einige Reichsstände dem Verfahren in den Weg stellen würden. Niemand, am wenigsten die von den Militäraktionen der vergangenen Jahre betroffenen Süddeutschen, rührte eine Hand für die hochadligen Exulanten ${ }^{28}$. In einem Schreiben an König Karl XII. von Schweden, ebenfalls ein Wittelsbacher, hob Max Emanuel hervor, »welche Übel und welche Schande« aus der Ächtung für das Gesamthaus hervorgehen würde. Der Schwedenkönig beließ es jedoch bei einem papiernen Protest, statt zum erhofften Angriff auf den Kaiser überzugehen ${ }^{29}$.

Natürlich erkannte auch König Ludwig XIV. im Frühjahr 1706 das Reichsachtverfahren nicht an. Dabei stützte er sich auf die Position, dass nur die Kurfürsten, nicht aber der gesamte Reichstag diesem Schritt zugestimmt hätten. Der König gab den Wittelsbachern folglich auch weiterhin die kurfürstlichen Kurialien ${ }^{30}$. Im Reich allerdings mussten beide Wittelsbacher bis zum Ende des Spanischen Erbfolgekrieges warten, ehe sie ihre früheren Würden zurückerhielten und in ihre Territorien zurückkehren konnten. Nachdem durch den frühen Tod Josefs I. 1711 ein erneutes habsburgisches Großreich - zudem noch unter dem Namensvetter Karls V. - drohte, betrieben die Seemächte nicht nur die spanische Erbteilung, sondern auch die Wiederherstellung des Status quo ante im Reich. Beide Exkurfürsten unternahmen auf französisches Anraten zunächst den Versuch, die Zulassung zur Kaiserwahl zu erreichen, bekamen aber von den übrigen Kurfürsten die kalte Schulter gezeigt. Selbst französische Drohungen an die Königswähler änderten an der Lage nichts ${ }^{31}$.

Die Friedensverträge von Rastatt (zwischen dem Kaiser und Frankreich) und von Baden (zwischen Frankreich und dem Reich) führten dazu, dass die Wittelsbacherherrscher von Köln und Bayern wieder in ihre früheren Rechte

Zur aktuellen Bewertung der Rivalität der wittelsbachischen Linien: IMMLER, Der innerwittelsbachische Konflikt, S. 26-37, bes. S. 28-31.

27 Froboese kommt zu dem Schluss, dass das Ächtungsverfahren gegen Max Emanuel bzw. das »Privations«-Verfahren gegen Josef Clemens (der nur seine weltlichen Herrschaftsrechts verlor, nicht aber seine geistlichen Würden) im Einklang mit dem Reichsrecht durchgeführt wurden: Froboese, Die Achterklärung, S. 77f.

28 Zur Reaktion der Wittelsbacher auf das Absetzungsverfahren: HürtL, Max Emanuel, S. $474-478$.

29 Brief Max Emanuels von Bayern an König Karl XII. von Schweden, 19. Mai 1706, zit. nach Hans Rall, Kurfürst Max Emanuel und das Haus Wittelsbach im 17. und 18. Jahrhundert, in: Glaser, Kurfürst Max Emanuel, Bd. 1, S. 51-66, Zitat S. 58.

30 HütTl, Max Emanuel, S. 476.

31 Vgl. die Bemühungen der Wittelsbacher in enger Abstimmung mit Frankreich: August RosenLEHNER, Die Stellung der Kurfürsten Max Emanuel von Bayern und Joseph Clemens von Köln zur Kaiserwahl Karls VI., München 1900. 
eingesetzt wurden. Alle abgetrennten Gebiete und Rechte mussten gemäß den Bestimmungen des Friedens restituiert werden. Kurfürst Max Emanuel regierte noch mehr als ein Jahrzehnt in seinen bayerischen Landen. Die internationale Lage sowie seine Schuldenlast hinderten ihn an weiteren kriegerischen Unternehmungen, hemmten aber seine prachtvolle Hofhaltung und seine Baumaßnahmen nicht ${ }^{32}$.

\subsection{Darstellung des Konflikts in den Deduktionen und Zeitungen}

Max Emanuel war der Öffentlichkeit im Reich keineswegs ein Unbekannter, als er 1702 seinen Feldzug gegen die Reichsstadt Ulm begann. Als Türkensieger kam er in zahlreichen Medienberichten vor, ebenso wurde seine Tätigkeit als Statthalter in Brüssel erwähnt. Der mediale Zuspruch beruhte zum einen auf dem Nachrichtenwert der Kriegsleistungen, zum anderen auf der aktiven Unterstützung durch organisierte Meinungsbildner in Bayern. So schreibt Rudolf Felbinger, die Münchener Hofbeamtenschaft habe maßgeblich an der öffentlichen Darstellung in Bild, Gedicht und Wort mitgewirkt. Zudem festigten die bayerischen Jesuiten und Theatiner - obwohl in Konkurrenz zueinander stehend - die Verehrung des Kurfürsten durch seine eigenen Untertanen. Dies gelang auch über seine Exilszeit hinweg ${ }^{33}$.

Es entsprach der herrschenden Praxis, dass über die komplizierten diplomatischen Verhandlungen, die der Kurfürst zwischen 1700 und 1702 führte, keine Presseberichterstattung stattfand. Alles lief - im Sinne der üblichen Arkanpolitik - unter strenger Geheimhaltung ab, und wenn auch die Tatsache bekannt wurde, dass Gespräche geführt wurden, so blieben doch die Ergebnisse nebulös. Es ist allerdings fraglich, ob eine bewusste Beeinflussung der Presse im Sinne der Geheimhaltung stattgefunden hat. Eher war der Nachrichtenwert dieser Thematik noch zu gering, weil zunächst nur Informationsbruchstücke vorlagen, die nicht auf ihren Wahrheitsgehalt zu überprüfen waren und in sich widersprüchlich gewesen sein dürften.

Dies änderte sich in dem Moment, in dem die Feindseligkeiten einsetzten. Der Handstreich gegen Ulm stellte nicht nur einen Angriff auf einen Reichsstand dar, sondern galt dem ganzen Reichssystem als Missachtung der Friedensordnung. Die Regensburger Reichstagsgesandten, die nun unmittelbar bedroht waren, setzten schnell zum Gegenschlag an. Noch ehe sich die Zei-

32 Zur Kulturförderung: HüTtL, Max Emanuel, S. 549-559.

33 Felbinger, Maximilian II. Emanuel von Bayern, S. 102. Felbinger verweist auch in dieser Hinsicht auf das französische Vorbild der fürstlichen Darstellung, auch wenn die bayerischen Maßnahmen nicht so gut organisiert abliefen wie ihre französischen Vorbilder. - Vgl. auch die probayerische Interpretation bei Gerald Neumann, Die Rolle Kurbayerns im Spanischen Erbfolgekrieg im Blick der öffentlichen Meinung, in: JFL 60 (2000), S. 333-347. 
tungen ein umfassendes Bild von der neuen Lage machen konnten, gelangte ein beträchtlicher Teil des Briefwechsels zwischen der Pariser Regierung und dem französischen Gesandten Ricous in die Hände der Kaiserlichen. Der Inhalt wurde umgehend in Regensburg gedruckt und allen Interessenten angeboten ${ }^{34}$.

Die Tagespresse, die sich des Konflikts sofort annahm, ging auf jede militärische Aktion von Belang ein, allerdings ohne die Frage der reichsrechtlichen Bedeutung in den Mittelpunkt zu stellen ${ }^{35}$. Was vielfach später als Mangel an Courage der Zeitungsmacher oder als Wirkung einer allgegenwärtigen Zensur gedeutet wurde, lässt sich auch anders erklären: Da Postmeister und Zeitungsverleger zumeist kaum Zeit hatten, den Inhalt einer Meldung zu prüfen, waren sie erst recht nicht in der Lage, im Schnellverfahren eine reichsrechtliche Bewertung vorzunehmen. Weder hatten sie fachkundige Kommentatoren zur Hand, noch war übersehbar, wie sich die Lage weiter entwickeln würde. Jedes Wissen war fragmentarisch, und spätere Informationen konnten einen Sachverhalt in einem ganz anderen Licht erscheinen lassen. So erwies es sich nicht als ein Zeichen von Angst, sondern von Klugheit, konträre Positionen - hier die folgenden Selbstrechtfertigungen der Kriegsparteien - hintereinander in den Gazetten abzudrucken. Militärische Ereignisse allerdings galten als ungefährlich: Zum einen erwies es sich sehr schnell, dass die Verbreitung der Nachricht ohnehin nicht zu verhindern war; zum anderen ließ sich auch der Wahrheitsgehalt des Schlachtenergebnisses nicht vertuschen. Die militärischen Ereignisse konnten in ihrer Darstellung in einer Zeitung gleichzeitig als Gelegenheit genutzt werden, andere kriegsrelevante Informationen zu übermitteln. Bereits wenige Tage nach der Übergabe Passaus erschien die Flugschrift Species Facti betreffend Die [...] Besetzung der Stadt Passau, die auf einem brieflichen Bericht vom 15. Januar 1704 aus der eingenommenen Stadt beruhte. Wo der Text gedruckt worden ist, bleibt unklar. Die detaillierten Angaben des 6 Blatt starken Schriftstücks machen allerdings die persönliche Augenzeugenschaft des Verfassers glaubhaft. Im Mittelpunkt stehen die Vorgeschichte, die Einnahme und die unmittelbaren Folgen. Klare Wertungen sind im Text nicht enthalten ${ }^{36}$.

Anders war dies bei einer Hamburger Zeitungsmeldung zum selben Ereignis. Der Hamburger Relations-Courier schrieb am 1. Februar 1704 nicht nur, dass Max Emanuels Truppen Passau erobert hatten, sondern auch, dass die Bayern in Oberösterreich 600.000 Gulden Brandschatzung ausgeschrieben

34 HüTtl, Max Emanuel, S. 340.

35 In der Altonaer »Europäischen Relation« wird der Konflikt in Oberdeutschland detailliert erwähnt. Militärische Nachrichten stehen ohne weitergehende Erörterungen: »Europäische Relation «, Jgg. 1702-1704, pas.

36 »Species facti Betreffend Die von Churfürstl. Durchl. zu Bayern geschehene Besetzung der Stadt Passau [...]«, o.O. 1704. 
hatten. Die Orientierung der Hamburger Zeitung am Gemeinwohl des Reiches wurde diesmal angedeutet, denn der Redakteur schreibt angesichts der angelaufenen Gegenmaßnahmen der Kaiserlichen, er hoffe, dass die feindlichen Pläne ohne Erfolg blieben ${ }^{37}$.

Zur selben Zeit setzte die Flut der Parteienschriften ein. Ob Max Emanuel sich wirklich durch die Traktate gegen ihn bedroht fühlte, ist nicht überliefert. Er hatte schon während seiner Brüsseler Statthalterschaft 1699 gegnerische Traktate erdulden müssen, die ihn lächerlich machten und ihm heimliche Absprachen mit der niederländischen Republik unterstellten. Damals wurden die Schriften innerhalb seines Machtbereichs produziert, so dass er öffentliche Verbrennungen anordnete und die Hersteller mit Tod oder Verbannung bedrohte ${ }^{38}$. In diesem Fall waren die Urheber der Schriften unbekannt, und die Mehrzahl von ihnen dürfte außerhalb Bayerns geschrieben und gedruckt worden sein, wodurch dem Wittelsbacher jeder Zugriff versagt blieb.

Mit Blick auf die europäische Öffentlichkeit entschied sich der Kurfürst, sein Vorgehen gegen Ulm durch ein ausführliches Kriegsmanifest zu rechtfertigen. Als ob er nichts zu verbergen hätte, wurde die Einnahme der Stadt in allen Einzelheiten geschildert, um dann den Sicherungscharakter dieser Maßnahme zu rechtfertigen. Im Stil eines souveränen Herrschers suggerierte Max Emanuel, er verfüge über das Recht zu Krieg und Frieden und könne sich über diesen Konflikt wie ein König äußern und entsprechend handeln. Das »Sendschreiben«, das Max Emanuel anschließend an die Stände des Schwäbischen und Fränkischen Kreises schickte, ist im Anhang abgedruckt. Im nämlichen Sendschreiben zielte Max Emanuel darauf, die süddeutschen Reichsstände zur Duldung des Geschehenen zu bewegen. Das Schreiben sollte zum einen aktuellem Widerspruch und aktiven Gegenmaßnahmen legitimatorisch entgegenwirken, zum anderen verfahrenstechnisch auf spätere Verhandlungen mit dem Kaiser und den Kreisen verweisen, um auf diese Weise Zeit zu gewinnen, die neue Machtverteilung in Schwaben zu etablieren ${ }^{39}$.

37 Zitat: »[...] also daß zu hoffen/ daß des Feindes habendes absehen Fruchtloß abgehen dörffte«: »Hamburgischer Relations-Courier«, Nr. 19 vom 1. Februar 1704.

38 HütTl, Max Emanuel, S. 273.

39 »Relation über den Hergang Der Von Ih. Churfl. Durchl. In Bayern/ etc. besetzten Stadt Ulm«, o.O. 1702. Das Sendschreiben, das in diesem Druck im Anhang steht, wurde auch separat als unkommentierte Schrift publiziert: »Sr. Chur=Fürstl. Durchl. zu Bayern Send=Schreiben An die hohe Directores der Fränckischen und Schwäbischen Creysse/die Einnehmung der Kayserl. Freyen Reichs $=$ Stadt Ulm/und andere deroselben Kriegs $=$ Verfassungen betreffend Zusamt Einer ausführlichen Relation wie und welcher Gestalt die Stadt Ulm ist erobert worden«, o.O. 1702 . 
Leider ist nicht mehr rekonstruierbar, ob die probayerischen Traktate in Altbayern oder in den besetzten Städten entstanden. Nur wenige diesbezügliche Einzelkonflikte sind überliefert. Der Ulmer Drucker Balthasar Kühn versuchte während der bayerischen Besetzung, den Auftrag zu umgehen, eine antikaiserliche Schrift produzieren zu müssen, indem er vorschob, die städtische Zensur verbiete ihm dies. Das für die Ulmer Zensur zuständige Pfarrkirchenbaupflegeamt wies seine Argumentation jedoch zurück: Ihm wurde bedeutet, er solle sich in einer so brisanten Frage nicht auf frühere städtische Praktiken berufen, um den Magistrat nicht in größere Schwierigkeiten zu bringen, als ohnehin bestünden ${ }^{40}$. Um welche Schrift es sich handelt, wird leider nicht mitgeteilt.

Der bayerische Kurfürst hatte diese mediale Strategie jedoch selbst konterkariert, indem er noch 1702 weitere süddeutsche Städte besetzen ließ. Nun erschienen sowohl Kriegsflugschriften alten Typs, wie sie seit der Reformationszeit üblich waren, neben den kurbayerischen Deduktionen, die sich aus verharmlosenden Formeln über die Militäraktionen und deren langfristiger Zielsetzung und aus Klagen gegen vermeintliche kaiserliche Ungerechtigkeiten gegenüber Bayern zusammensetzten. Die gewonnenen Schlachten und sonstigen vermeintlichen Erfolge, z.B. bei Neuburg im November 1703 wurden propagandistisch gefeiert, obwohl die bayerische Armee Neuburg im ersten Anlauf nicht hatte einnehmen können ${ }^{41}$. Als apologetisches Beispiel kann der Druck einer kurbayerischen Eingabe am Reichstag vom Januar 1703 gewertet werden ${ }^{42}$.

Der kaiserlich-reichsständische Widerstand organisierte sich und artikulierte sich in dem kaiserlichen Mandat, das im Februar 1703 am Reichstag publiziert und anschließend als 16seitige Flugschrift für die Öffentlichkeit gedruckt erschien. Der Kaiser wies darin den apologetischen Schriftsatz zurück, den der kurbayerische Gesandte von Zindt am 15. Februar vorgelegt hatte. Die Argumentation des Kaisers zielte auf Landfriedensbruch durch Kurbayern: Die umgehende Wiederherstellung des früheren Zustands wurde verlangt ${ }^{43}$. Schon zuvor war eine Zusammenstellung kaiserlicher Kommissionsdekrete gegen den König von Frankreich, den Herzog von Anjou und

40 Auf diese leider undatierte Episode weisen Elmar Schmitt und Bernhard Appenzeller im Zusammenhang mit ihrer Geschichte des Verlags Kühn hin: Elmar SchmitT/Bernhard AppeNZELLER, Balthasar Kühn. Buchdruckerei und Verlag Kühn, Ulm, 1637-1736. Bibliographie mit einer Geschichte des Ulmer Buchdrucks von 1571 bis 1781 und einer Darstellung der reichsstädtischen Bücher- und Zeitungszensur, Weissenhorn 1992, S. 77.

41 »Relation Von den Belägerung der Chur=Pfälzischen Stadt Neuburg an der Donau«, o.O. 1703.

42 »Vorstellung/Welche Ihre Churfürstl. Durchl. in Bayern/ etc. den Reichs=Convent in Regenspurg/durch Dero Gesandtschaft allda thun lassen/den 15. Jenner/Anno 1703«, o.O. 1703.

43 »Vorstell = und Ahndung Wider den Chur=Fürsten von Bayern/Und Dessen Gesandten zu Regenspurg«, o.O. 1703. 
deren Bündnispartner im Reich publiziert worden ${ }^{44}$. Ein $» C h u r=$ Bayrisches Gegen =Manifest $«$ vom Juni 1703 sollte die schwerwiegenden Vorwürfe der kaiserlichen Seite ausräumen. Da diese in der Hauptsache nicht abzustreiten waren, betonte das Schreiben Plünderungen der Gegenseite, die Schuld des Hauses Habsburg am Konflikt und klagte über den Undank des Kaiserhauses gegenüber einem Kurfürsten, der seit Jahrzehnten zum Ruhme eben dieses Hauses gedient habe, ohne dafür hinreichend belohnt worden zu sein. Dieser Aspekt trifft in der Tat ins Zentrum des bayerischen Selbstverständnisses, denn Max Emanuel hatte an zahlreichen Stellen die kaiserliche Unterstützung für seine ehrgeizigen dynastischen Ambitionen eingefordert, ohne sie zu erhalten. Die weiteren Argumente waren formaler Art. So beteuerte die Schrift die französische Treue zum Rijswijker Frieden und die Absicht des Kurfürsten, durch die Besetzung einiger Städte Süddeutschland besser gegen Kriegsgefahr und politische Bedrohung der Reichsfreiheit (sic!) schützen zu können. Daher, so schloss die Schrift, handele es sich bei den bayerischen Militäraktionen um eine legitime Selbstverteidigung. Man vertraue, so der anonyme Autor, auf die göttliche Hilfe ${ }^{45}$.

Zwischendurch wuchs die Ungewissheit. Im August 1703 meldete das Wiener Diarium, es halte sich in Bayern hartnäckig das Gerücht, Max Emanuel sei bei einem seiner Feldzüge gefallen. Verstärkt werde diese Flüsterpropaganda dadurch, dass von einer amtlichen Anweisung die Rede sei, niemand dürfe über Leben oder Tod des Kurfürsten in Bayern mehr öffentlich berichten. Allerdings, so wägt die Wiener Zeitung ab, hätten »Münchener Briefe« eines eigenen Korrespondenten übermittelt, Max Emanuel sei bereits vor einer Woche in Begleitung einiger Adliger in seine Residenz eingeritten und halte sich dort auf ${ }^{46}$. Die öffentliche Bestätigung folgte prompt, denn der Kurfürst ließ noch Ende August 1703 ein Dekret herausgehen, das den bayerischen Klerus mit einer Sondersteuer belegte, weil diese Vermögensgruppe als eine der wenigen nach fast einem Vierteljahrhundert fiskalischer Selbstüberschätzung überhaupt noch zahlungskräftig war ${ }^{47}$.

44 »Commissions $=$ Decreta, Kayserliche Commissions $=$ Decreta und Reichs $=$ Schlüsse $/$ Wider den König in Franckreich/Hertzog von Anjou/, Chur=Cölln und Chur=Bayern/[...]«, o.O. 1703.

45 »Chur=Bayerisches Gegen=Manifest, Auff Die wiederholter=ergangene Kayserliche Avocatoria, und die darin enthaltene [...] Kriegs=Declaration [...]«, o.O. 1703 (datiert auf den 1. Juni 1703). Wenig später erschien auch eine lateinische Ausgabe: »Manifestum seu Responsum Electorale Bavaricum Ad Iterato vulgatas Litteras Avocatoriales Caesareas \& contentum in illis, ipsaque iam actuali invasione hostili confirmatam belli declarationem«, o.O. [München] 1703.

46 »Regensburger Briefe vom 26. dto.«: »Wiener Diarium«, Nr. 7 vom 29. August 1703.

$47 »$ Decretum Serenissimi Domini Ducis Electoralis«, o.O. [München] 1703. Durch das Dekret vom 29. August 1703 wurden den geistlichen Einrichtungen Getreidelieferungen abverlangt und weitere Geldforderungen angekündigt. 
Auch die betroffenen Reichskreise meldeten sich mit einer langen Schrift zu Wort. 1704 erschien ein über 300 Seiten langer Druck, der die bayerischen Aktionen in Süddeutschland zwischen 1702 und 1704 detailliert auflistete und zahreiche Dokumente wiedergab, z.B. das Manifest Max Emanuels an die Stadt Ulm nach der Besetzung oder die Ausweisung des kurbayerischen Reichstagsgesandten v. Zindt aus Regensburg durch kaiserliche Anweisung ${ }^{48}$. An Argumenten mangelte es den Bayerngegnern nicht, waren doch im Laufe der Kriegshandlungen zahlreiche Dokumente in die Hände der Sieger gelangt, die die Geheimverabredungen des Wittelsbachers eindeutig erwiesen und alle öffentlichen Apologien zur Makulatur werden ließen ${ }^{49}$. In gewissen Stilelementen deutete der Text auf eine Ähnlichkeit mit den späteren Zeitschriften von David Fassmann hin. Fassmann stand in der Tat zur selben Zeit als Kreisregimentsschreiber im Dienst des Fränkischen Kreises ${ }^{50}$. Der Form nach ist die Schrift auch eher ein Historienbericht als eine wirkliche Deduktion. Sehr wahrscheinlich erschien sie erst im Druck, als der bayerische Kurfürst bereits geschlagen worden war.

1704 erschien zudem das Manifeste de l'Electeur de Bavière, das Franz Feldmeier als eine französische Tendenzschrift zugunsten der französischbayerischen Kriegführung bezeichnete, die ohne Wissen Max Emanuels herausgebracht worden $\mathrm{sei}^{51}$. Die 44 Seiten umfangreiche Schrift richtete sich an das französischsprachige Europa, besonders den Adel und die Gelehrten. Dieser Leserschaft wollte der Wittelsbacher als intendierter Verfasser vermitteln, dass er stets die Reichsverfassung habe wahren wollen. Die kaiserlichen Vorwürfe wurden darauf reduziert, der Bayer dürfe den König von Spanien nicht unterstützen und solle Waffenhilfe leisten. Letzteres verstieße - so der Verfasser - gegen den Rijswijker Frieden. Stets habe er, ebenso wie seine Vorfahren, den Habsburgern gedient, ohne von ihnen jemals eine angemessene Anerkennung erhalten zu haben ${ }^{52}$.

Auf die mediale Berichterstattung zur Schlacht von Höchstädt am 13. August 1704 kann an dieser Stelle nur knapp eingegangen werden. Der Hamburger Relations-Courier erhielt die Information über Höchstädt offenbar

48 Manifest Max Emanuels an die Stadt Ulm nach der Besetzung vom 10. September 1702 oder die Ausweisung des kurbayerischen Reichstagsgesandten v. Zindt aus Regensburg durch kaiserliche Anweisung vom 28. August 1704: »Unter chur-, bayer- und franzoesischer Gewalt hart gedrueckte, aber nicht untergedrueckte Schwaben. Oder ausfuehrlicher Bericht des zweijährigen im Schwabenlande geführten Krieges«, Freiburg i.Br. 1704.

49 Besonders peinlich war der Verlust der Equipage des französischen Gesandten in Bayern, Louis Gaspard de Ricous, im Juni 1704 an die Engländer unter Marlborough. Alle Verschlüsselungscodes wurden dadurch geöffnet, und die Engländer und Kaiserlichen konnten sämtliche früheren Geheimbotschaften zur Kenntnis nehmen: Hütru, Max Emanuel, S. 365.

50 Vgl. die autobiographischen Angaben bei David Fassmann, Gespräche im Reiche der Todten, Bd. 15, Vorwort.

51 FeldmeIER, Die Ächtung des Kurfürsten Max Emanuel, S. 147.

52 »Manifeste de l'Electeur de Bavière« (verfasst von J.F. Dubos), o.O. 1704. 
erst kurz vor Redaktionsschluss, denn in der Ausgabe 131 vom 19. August 1704 erschien sie erst auf der vorletzten Seite. Möglicherweise wartete man auch die Bestätigung durch unterschiedliche Kuriere ab; in diesem Fall sollen es drei gewesen sein. Neben dem Schlachtenerfolg des Prinzen Eugen wurden die herausragenden Verdienste des Erbprinzen von Hessen-Kassel betont, der u.a. den französischen Marschall Tallard festgenommen habe. Die Schlacht selbst habe von 14.00 bis 17.00 Uhr gedauert. Beim Feind seien 10.000 Mann gefallen, auf 4.000-5.000 Tote belaufe sich der Verlust beim Sieger. Die Information, dass Kurfürst Max Emanuel gefallen sei, wurde als Gerücht gekennzeichnet, weil offenbar diesbezüglich nicht alle Kuriere übereinstimmten. Weitere Berichte wurden erwartet ${ }^{53}$. Drei Tage später zeigte der Hamburgische Relations-Courier eine Mitteilung aus Berlin an, die den Sieg der Alliierten bei Höchstädt bestätigte. Die Zahl der gefallenen »Feinde«, d.h. der Franzosen und Bayern, hatte sich inzwischen auf 18.000 Mann erhöht, die Toten der Engländer und Kaiserlichen wurden dagegen nicht angegeben ${ }^{54}$.

Das Wiener Diarium rückte den Schlachtenbericht über Höchstädt gar nicht in die reguläre Berichterstattung ein. Die üblichen acht Seiten boten zu wenig Raum, denn der zur Verfügung stehende Text umfasste 10 Seiten. Dafür brachte die Zeitung eine Sonderausgabe unter dem Titel Continuatio Diarii heraus, die undatiert ist. Darin wurde das österreichische Kriegstagebuch vom 31. Juli bis zum 15. August übermittelt. Die Freude über den Sieg der eigenen Seite war unverkennbar. Detailliert rekonstruierte der Korrespondent den Schlachtenablauf, ohne dass man die Leser durch Gräuelinformationen über den Umfang des Blutbads verschreckte ${ }^{55}$.

Durch Max Emanuels Rückzug vom deutschen Kriegsschauplatz reduzierte sich das Interesse an seiner Person vorübergehend. Mittelbar tauchte er in den Folgen seines Handelns auf. So berichteten die Historischen Remarques von der Restitution der Reichsunmittelbarkeit der Stadt Donauwörth im Sommer 1705. Die Zeitschrift fügte der Nachricht eine lange Geschichtserzählung bei, in der frühere bayerische Einnahmen der Stadt in den Jahren 1266, 1398 und 1458 erläutert wurden ${ }^{56}$. Ein persönlicher Bericht über Max Emanuel und seinen Bruder Josef Clemens wurde eingeordnet in das System der Unfreiheit unter Ludwig XIV. von Frankreich. Peter Ambros Lehmann schrieb in seinen Remarques historiques über die fehlende Freizügigkeit der Wittelsbacher in ihrem Exil innerhalb des französischen Machtbereichs:

53 »Hamburgischer Relations-Courier«, Nr. 131 vom 19. August 1704.

54 Ebd., Nr. 133 vom 22. August 1704.

55 Sonderausgabe »Continuatio Diarii« zum »Wiener Diarium«, Ende August 1704.

56 Vgl. Historische Remarques der neuesten Sachen in Europa des [...] Jahres« (hg. v. Peter Ambros LehmanN), Hamburg 1699-1707, hier Jg. 7/ 1705, vom 30. Juni 1705, S. 204. 
Lüttich: Der Chur=Fürst von Cöln hat Permission bekommen $/$ dem Chur=Fürsten von Bayern eine Visite zu geben. Die bayden Herren Gebrüdere/Chur=Fürsten von Cöln und Bayern/stellen der Welt ein höchstmerckwürdiges Exempel einer mit Franckreich unglücklich getroffenen Alliantz vor/indem sie durch selbige beyde dahin gebracht worden/daß sie nun ihre Länder mit dem Rücken ansehen müssen. Und auch in diesem Zustande/wie es dieser Relation zufolge scheinet/bey ihrem Alliirten nicht so viel Freyheit haben/daß sie einander nach Belieben zusprechen dürffen/ob sie gleich nunmehro in einem Lande sich befinden. Zugleich aber siehet man auch hieraus/wie gut es Franckreich mit seinen Alliirten meinet ${ }^{57}$.

Das nächste zentrale Ereignis mit Max Emanuel von Bayern als Hauptdarsteller war die Zeremonie der Ächtung und der Aberkennung der Lehen am 29. April 1706. Inzwischen hatte der Wechsel im Kaisertum stattgefunden, und der junge Kaiser Josef I. nutzte die Gelegenheit, sich selbst als Hüter und Durchsetzer des Reichsrechts öffentlich zu präsentieren. Die Wiener Regierung wählte die spektakulärste Möglichkeit einer feierlichen Zeremonie nicht zuletzt deshalb, um den Medien Gelegenheit zur ausgiebigen Berichterstattung über das Ereignis zu geben. So finden sich in allen einschlägigen Zeitungen Berichte über die Geschehnisse des Tages in Wien. Drei Seiten war diese Zeremonie einer Sonderausgabe des Wiener Diarium wert, dessen Redakteur einen besonders detaillierten, weil ortsnahen Beobachter darstellte ${ }^{58}$ :

Nachdeme der Donnerstag/welcher war der 29. April dieses lauffenden 1706. Jahrs/von Ihrer jetzo glorwürdigst regierenden Kayserl. Majestät benennet worden/die Achts=Erklärung wider die beede Gebrüder und Churfürsten/von Cölln und Bayern/publiciren zu lassen; Also wurde zu dem Ende umb Mittagszeit der kayserl. Reichs $=$ Vice $=$ Cantzler $($ Titl.) Herr Friedrich Carl $/$ Graf von Schönborn $/$ etc. zuforderist vom 6. Kayserl. Hartschieren zu Pferd auß seiner Wohnung abgeholet/und biß in die Kayserl. Burg begleitet.

Gleich darauff verfügten sich Ihre Kayserl. Majestät/mit Vorhertrettung deren zweyen Reichs $=$ Herolden und deren hohen Herren Ministern $/$ in Ihrer gewöhnlich $=$ schwartzen Hof $=$ Mantel $=$ Kleydung $/$ auß Dero Retirada $=$ Zimmer in die so genannte $/$ wegen

57 Ebd., Jg. 7/1705, vom 17. März 1705, S. 85f.

58 Der Bericht war bereits in der Ausgabe des »Wiener Diarium«, Nr. 286 vom 30. April 1706 angekündigt worden und erschien ohne gesonderte Datierung einige Tage später unter dem Titel: »Beschreibung Der Achts=Erklärung So Ihro Röm. Kayserl. Majest. Wider die beede Gebrüder und gewesene Chur=Fürsten Von Cölln und Bayrn/Joseph Clemens und Maximilian Emmanuel/Allhier In Wien und zu Regenspurg offentlich vollziehen lassen«, o.O. [Wien] 1706 (eingerückt im »Wiener Diarium« zwischen den Ausgaben Nr. 291 und 292 vom 18. resp. 21. Mai 1706). 
der noch fürwährenden hohen Trauer durchauß mit schwartzem Tuch außspallierte und ringsum mit 30 Hartschiren auch 30 Trabanten besetzte Ritterstuben/allwo die Kayserl. Herren geheime Räthe und Reichs $=$ Hof $=$ Räthe $/$ wie auch eine überau grosse Menge vieler anderen hohen und nidrigen Stands=Persohnen bereits zugegen gewesen.

So bald nun Ihro Kays. Majestät auff Dero Thron/bey welchem rechter Hand der Obrist $=$ Hof $=$ Marschall $/$ (Tit.) Herr Carl Ernst Graf zu Waldstein/etc. mit dem blossen Schwerd: und nächst ihme der Kayserl. Obrist $=$ Hof $=$ Meister $/$ Ihro Durchl. Herr Carl Theodor Otto Fürst von Salm/etc. samt dem Kayserl. Hartschieren=Hauptmann (Tit.) Herrn Maximilian Guidobald Graf von Martinitz etc. sodann zur lincken Seiten der Kayserliche Obrist $=$ Cämmerer $/$ (Tit.) Herr Leopold Johann Donat Trautsohn Graf zu Falckenstein/etc. nebens dem Anfangs ermeldeten Herrn Reichs=Vice $=$ Cantzlern/so alle nechst dem erhobenen Thron: und der Kays. Reichs $=$ Hof $=$ Rath und geheime Referendarius, (Tit.) Herr Caspar Florentz von Consbruch/etc. auf der ersten Staffel: die zwey Reichs $=$ Herolden aber in ihrer gebräuchlichen Tracht mit schwartzen Hüten bedecket und Stäblein in denen Händen beederseits auff ebenem Boden gestanden/niedergesetzet; nahete sich zu Deroselben der Herr Reichs $=$ Vice $=$ Cantzler mit gebogenen Knyen/und empfienge den allergnädigsten Befelch $/$ die Achts=Erklärung wider die beede Gebrüder Joseph Clemens/gewesenen Churfürsten von Cölln/und Maximilian Emmanuel/gewesenen Churfürsten von Bayern/zu verkünden.

Diesem zu Folg thate der Herr Reichs=Vice $=$ Cantzler einen nachdrücklichen $/$ zierlich= und wohl verfassten Vortrag: Mithin behändigte derselbe dem Herrn geheimen Referendario von Consbruch beede respective Privations $=$ und Achts $=$ Erklärungs $=$ Sententzen $/$ welche derselbe dann auch sogleich offentlich ablase.

Nach diesem tratte der Herr Reichs Vice Cantzler wieder hervor/und machte einen kurtzen/aber nachdrücklichen Schluß: überreichte darauff Ihro Kayserlichen Majestät die Lehens $=$ Brieffe aller von Weyland vorbesagten zweyen Churfürsten inngehabten Chur $=$ und Fürstlichen auch anderen Reichs = Lehen/von welchen allerhöchstgedachte kayserliche Majestät einen nach dem andern mit Dero Handen zerrissen/und auff den Boden warffen; die zwey Reichs=Herolden hebten selbige $/$ mit bedecktem Haubt/auff beeden Knyen bey Ihro Kays. Majest. Füssen auff/zerrissen solche ferners in mehrere Stücke/giengen damit an das erste nechst dem Thron gegen die Pastey hinaußgehende Fenster/woselbsten Sie es noch in kleinere Stückl zerrissen/und endlich zum Fenster hinauß geworffen.

Da dieses nun vollbracht/ begaben Sich Ihr Röm. Kayserl. Majest. wieder in Dero Retirada unter Begleitung derer Herren Ministern und Cavallieren; Die Reichs=Herolden aber (nachdeme sie beede Sentenzen/oder Achts=Erklärungen auß denen Handen vorgedachten Herrn Geheimben Referendarii empfangen/mit dem Befehl/sol- 
che auff den gewöhnlichen Plätzen dieser Kayserlichen Residentz Statt sowohl/als auch nachgehends in denen von beeden gewesten Chur=Fürsten besessenen Ländern kund zu machen) setzten sich/außer der neuern Burg/da die Schweitzer die Wacht halten/zu Pferdt/und ritten sogleich in die Mitte des Burgg=Platzes/allwo/nebst der daselbst gewöhnlichen Wacht von der Kayserl. Stadt=Gardt/so bey Aufsitzung das Gewehr praesentirte/nachmahls aber selbiges vor den Fuß stellete/12. Kayserliche Trompeter/1. Paucker und 6. Hartschiers/sambt 4. Kayserlichen Reut=Knechten/alle zu Pferdt/benebens einer unbeschreiblichen Menge Volcks warteten/und bey der Ankunfft gedachter 2. Reichs=Herolden mit ihren Trompeten und Paucken sich vernehmen liessen; darauff einer von mehr besagten zweyen Reichs $=$ Herolden die Sentenz oder Achts Erklärungen unter erhebtem Gewehr deren Hartschieren ablase/und als solches geschehen/die Trompeter mit dem Paucker auch nach jedesmahliger Ablesung eines Sentenz sich hören lassen/ritten sie sambtlich/als erstlichen 6. Trompeter vorauß/nach denen der Paucker/darauff wieder 6. Trompeter/sodann die zwey Reichs $=$ Herolden/ und hinter ihnen die Hartschierer/denen die 4. Kayserl. Reut $=$ Knechte folgeten/von dem Burgg $=$ Platz hinweg/auff den Graben/allwo sie erstlich bey der Säulen: und hernacher auff dem Neuen Marckt/unweit dem Brunnen/auff eben die Manier/wie im Burg=Platz/die Ablesung verrichteten.

Welchem allen nach Sie sambtlich in obiger Ordnung zurück in die Kayserliche Burg gekehret / daselbst die beede Reichs = Herolden ferneren Kayserlichen Befehl erhalten: Daß ein jeder in Begleitung zweyer Kayserlichen Hartschieren und eines Reut Knechts zu Pferdt/in vorbenante Länder sich verfügen/ und alldort vorgedachte respective Privation- und Achts=Erklärung publiciren solle; worauff sich dann alles Reyßfertig machte/ und langte folgends der eine Kays. Reichs=Herold/Adrian von Pecquerau, mit seinen zweyen Kayserl. Hartschieren den 9. May zu Regenspurg an/liefferte auch sogleich von Ihro Kays. Maj. dasigem Magistrat ein Schreiben/worinnen Allerhöchst besagte Kayserl. Majest. demselben kund thaten/wie sie erwehnten Reichs $=$ Herold dahin geschicket/ihre wider die bißherige Chur=Fürsten von Cölln und Bayrn erlassene gerechteste Erklär = und Verordnungen in dasiger Stadt offentlich zu verkündigen und zu publiciren; derohalben Sie an dem Magistrat begehret/ihn/Herold/hierunter zu gebührlicher Vollbringung seines obhabenden Befehls willfährig an Hand zugehen; wie Sie dann denselben übrigens an Ihro Hochfürstl. Eminenz, den Herrn Princial =Commissarium, verwisen / als welche hierunter die Nothdurfft verordnen würde; weßwegen auch allda den 10. Dito das Kayserl. Commissions $=$ Decret offentlich dictiret: den 11. dieses aber/die Publication der Kayserl. Verordnung folgender Gestalt vollzogen wurde:

Nach 8. Uhr marschirte dasiger Stadt=Adjutant mit ohngefehr 40. biß 50. Mann von der Stadt $=$ Garnison hinauff/in Ihro Hochfürstl. Eminenz Quartier/und kamen von dar in folgender Ordnung: erstlichen die Helffte von obgedachter Garnison, dann 4. Trompeter von Ihro Hochfürstlichen Eminenz, (so zu 2. und 2. abgewechslet bliessen) 
folgends der Reichs =Herold in der Mitte/in dem gewöhnlichen Herolds=Habit, worauff vorn und hinten der Kayserl. Adler gestickt/auff dem Hut gelb= und schwartze Federn / in der rechten Hand einen dinnen Herolds =Staab / und auff jeder Seithe einen Kayserl. Hartschiern habend/(der Herold/die 4. Trompeter und 2. Hartschierers waren zu Pferd) und letztlich der Rest gedachter Garnison, durch den Bach nach dem Rath =Hauß; woselbst die von der Stadt=Garnison, umb dem Herold $/ 2$ Hartschirer und 4. Trompeters/ einen Creyß machten/und gedachte 4. Trompeters zugleich bliessen/umb die Leuthe herbey kommen zu machen; alsdann verlaß der Herold erstl. den Sentenz gegen Weyland Chur=Cölln/ und dann den gegen Weyl. Chur=Bayrn; so offt einer verlesen/stosten die Trompeter in ihre Trompeten; Wie solches geschehen/gieng der Marsch weiter den Bischoffs = Hoff vorbey / nach der neue Pfarr/wo abermahls die Patenta von dem Herold abgelesen: und von da die lange Gasse hinauff/die neue Kirche vorbey/nach dem Jacobs=Platze/wo es zum dritten mahl verlesen: und dabey eben das observirt ward/wie beym Rath=Hauß; von dar begleiteten obige von hiesiger Stadt $=$ Garnison den Reichs $=$ Herold widerumb in Ih. Hochfürstl. Eminenz Quartier; Gedachter Herold aber ware selbigen Nachmittag weiter auff Cölln und Lüttig gangen/umb allda dergleichen zuverrichten.

Die öffentliche Darstellung konnte aber auch viel knapper ausfallen. Der Hamburger Relations-Courier schrieb in seiner Ausgabe Nr. 74 vom 11. Mai 1706:

Vorgestern seynd endlich beyde gewesene Chur Fürsten von Cölln und Bayern/gleich nach 12 Uhren/durch einen solennen Actum in der Kayserl. Ritter=Stube in die Reichs $=$ Acht und Bann declariret worden: Ihro Kayserl. Majestät sassen unter einem Baldachin/so offt nun eine von denen Cöllnischen und Bayrischen Investituren verlesen waren/wurden solche aller höchstgedachter Ih. Kays. Majest. vorgezeiget/die einen Riß daraine gethan/sodann thate auch der Reichs=Herold mit seinem stabe einen Stoß hinein/zerrisse es / und wurff es zum Fenster hinauß auff den Burg=Platz/allwo 2 Chöre/jeder von 6 Trompetern/stunde/so wechselsweise dazu geblasen/welches auch durch die gantze stadt/auff denen vornehmsten Plätzen geschehen. Es werden auch bem. Reichs = Herolden nach dem Reich und an die Städte/allwo diese Publication durch Affigirung der Patenta nothwendig geschehen muß/abgefertiget werden ${ }^{59}$.

Bemerkenswert ist der Begriff »endlich« im ersten Satz, der signalisierte, dass der Verfasser bereits seit geraumer Zeit auf die Ächtung gewartet hatte. Die Formel, die Reichsherolde seien »nach dem Reich« abgeschickt worden, wies auf eine ähnliche Zeremonie in Regensburg hin, die am 13. Mai 1706

$59 »$ Hamburger Relations-Courier [...]«, hier Nr. 74 vom 11. Mai 1706. 
durchgeführt wurde. Der Hamburger Relations-Courier schrieb auch über diesen öffentlichen Akt:

Verwichenen Dienstag gegen 10 Uhr Vormittags/wurden die Achts-Patenta durch einen expresse anhero abgeschickten Kayserl. und des Reichs $=$ Herolden $/$ nahmentlich Herrn Adrian Bergberau/folgender massen publiciret: Gedachter Herold/nachdem er seinen Habit/welcher in einem langen schwartzen Thalar, und in Form eines Meßgewandts darüber gehengten Stück gelben Sammets/auf welchen hinten und fornen ein grosser Kayserl. Adler gestickt war/bestanden/zu St. Emmeran angelegt/empfing von Ihro Hochfürstl. Eminenz die Patenta/satzte sich darauf zu Pferd/und ritte von dem Hoch=fürstlichen Quartier unter einer kleinen Escorte von hiesiger Stadt $=$ Guarnison $/ 4$ Hoch $=$ Fürstl. Trompeter vor sich habend $/$ zwischen 2 Kayserl. Carabiniers durch die Stadt nach dem Rath $=\mathrm{Hau} ß \mathrm{zu} /$ woselbst er zuerst/hernach bey der Haupt $=$ Wacht $/$ und dann auff dem Jacober $=$ Platz besagte Patenta öffentlich ablase/nachdeme vorhero die Trompeter darzu geblasen hatten. Die Thore/ausser das an der Steiernen Brücke/wurden während dem Actu gesperret/und die Verlesung von einer großen Menge Volkes angehöret. Mehrgemeldter Herold hatte in der Hand einen silbernen Scepter/auff dessen Spitze ein doppelter Adler stunde/dessen Huth aber war mit einer schwartzen und gelben Feder gezieret. Mittags darauf speißte der Herold bey Sr. Hoch Fürstl. Eminentz/gegen Abend aber gienge er per Pasta nacher Nürnberg/von dar er nach Franckfurth/und so weiter nach Cölln gehen wird [... Es folgen Informationen zum Verbleib der Prinzen und zu Militärbewegungen in Bayern - J.A.]. $\mathrm{Zu}$ München ist die Publication des Banns/vermög eingelauffener Nachrichten auch geschehen $^{60}$.

Die Methode der Zeitungsproduzenten, einlaufende Nachrichten schnellstmöglich abzuschreiben und dann auch im eigenen Periodikum zu publizieren, führte mitunter zu Effekten des unfreiwilligen Humors. Dem Autor des Frankfurter Journals unterlief dabei die Formulierung »Ihr. Kayserliche Majestät sassen auf einem Baldagin [...]«. Da ein Baldachin ethymologisch eine »prunkvolle Überdachung« darstellt, kann der Kaiser vernünftigerweise nur unter demselben gesessen haben. Gerade ein derartiger Lapsus eröffnet Möglichkeiten, Kommunikationswege zu erkennen; in diesem Fall findet sich die Formulierung vier Tage später im Hildesheimer RelationsCourier erneut ${ }^{61}$.

In der Folgezeit kamen die Zeitungen immer wieder einmal in Wortnot hinsichtlich der titulaturmäßigen Bezeichnung der Wittelsbacher. Im lau-

60 Ebd., Nr. 81 vom 25. Mai 1706 (Bezug auf Bericht aus Regensburg vom 13. Mai). Schon etwas früher, nämlich am 19. Mai 1706, war die Mitteilung desselben Inhalts im »Hildesheimer Relations-Courier«, Nr. 40 erschienen.

61 Meldung aus »Wien, den 1. Mai«: »Frankfurter Journal«, Nr. 38 vom 11. Mai 1706; auch ebenso zu lesen im »Hildesheimer Relations-Courier«, hier Nr. 39 vom 15. Mai 1706. Zum 
fenden Text schafften es die Redakteure zumeist, die beiden hohen Exulanten mit »die gewesenen Kurfürsten « zu bezeichnen und damit der offiziellen Sprachregelung zu folgen. Problematischer wurde es beim Abdruck von Dokumenten, in denen noch die vormaligen Prädikate standen. Im Anhang an die Ausgabe vom 8.-10. Dezember 1706 finden sich zwei Briefwechsel zwischen Max Emanuel und dem Herzog von Marlborough. Beide reagieren auf Vorschläge zu Friedensverhandlungen, die der Wittelsbacher im Namen seines französischen Protektors gemacht hatte. Es hat den Anschein, dass der Brite seinem Briefpartner beide Male die Titulatur »Ew. Churfürstliche Durchlaucht « gab. Im Wiener Diarium dagegen steht nur »Euer $=====\ll$, eine Formulierung der vorauseilenden Selbstzensur, die den widerstreitenden Prinzipien der korrekten Reichsrechtsbezeichnung und der kompletten Textwiedergabe kompromisshalber versuchte, gerecht zu werden ${ }^{62}$.

Die Absetzungszeremonie wurde nicht nur in den Zeitungen traktiert, sondern führte auch zu separaten Flugschriften. Die genaue Abfolge der Ereignisse wurde in der Flugschrift Curieuser Bericht auf acht Seiten wiedergegeben. Eine Kommentierung des Berichts erfolgte nicht. Bemerkenswerterweise wurde der Druckort Wien offen ausgewiesen. Dies entsprach genau den üblichen Rechtsvorschriften, unterschied sich aber von der herrschenden Praxis, nach der Flugschriften nur das Druckjahr, nicht aber nähere Angaben zum Autor oder zum Druckort nebst Drucker auf dem Titelblatt führten. Der Druck Curieuser Bericht dürfte daher mit Einverständnis oder sogar auf Anweisung staatlicher Stellen herausgebracht worden $\operatorname{sein}^{63}$. Ob dies auch für einen Bericht in den Mitteilungen der Ordentlichen Wochentlichen Kayserlichen Reichs $=$ Post $=$ Zeitungen, Frankfurt, gilt, erscheint fraglich. Ihr Korrespondent in Wien hatte sich viel dezidierter geäußert, und so erfuhr der Leser der Gazette vier präzise bestimmte Gründe für die Absetzung des Bayernkurfürsten: 1. Übergabe der Spanischen Niederlande an Frankreich; 2. Verführung seines Kölner Bruders Josef Clemens zur Aufnahme französischer Soldaten in seine Territorien; 3. Einnahme mehrerer süddeutscher Städte mit bewaffneter Hand; 4. diplomatische Interventionen in Ungarn zugunsten des Osmanischen Reiches ${ }^{64}$.

Weniger um mediale Spektakularität als vielmehr um die Postulierung eigener Rechtsansprüche ging es in der Quellenpublikation zum Ächtungsverfahren, die Kurfürst Johann Wilhelm von der Pfalz im Mai und Juli 1706

Baldachin: KLuge, Etymologisches Wörterbuch der deutschen Sprache (221989), S. 56.

$62 »$ Wiener Diarium«, 8.-10. Dezember 1706.

63 »Curieuser Bericht/Mit was vor Solennitäten Ihr. Röm. Kayser. Majest. Josephus I. Die beyden Gebrüdere und bißherigen ChurFürsten von Cölln und Bayern/in [...] Wien den 29. Aprilis Anno 1706. In die [...] Acht und Ober=Acht öffentlich erklären lassen«, Wien 1706.

64 »Noch ein anderes von Wien den 12. Dito«: »Ordentliche Wochentliche Kayserliche Reichs = Post=Zeitungen $\ll[$ [=Frankfurter Postzeitung], Nr. 41 vom 21. Mai 1706. 
herausgab. Der Kurfürst ließ unter dem Datum des 17. Mai 1706 ein offizielles Mandat an alle seine Staatsbediensteten herausgehen. Das Mandat war vierteilig aufgebaut: Zunächst erfolgte nach der Titulatur des Kurfürsten der Hinweis auf das abgeschlossene Ächtungsverfahren des Kaisers gegen die früheren Mitkurfürsten aus Köln und Bayern wegen fortgesetzten Landfriedensbruchs und anderer schwerer Verbrechen gegen das Reich und seine Mitglieder. Dann folgten die kompletten Texte der beiden Privations- bzw. Ächtungsurteile des Kaisers vom 29. April 1706. In der Schlusssequenz forderte der Kurfürst seine Staatsdiener und Untertanen bei Strafandrohung auf, sich strikt an die kaiserlichen Vorschriften zu halten (d.h. keinem der Ex-Kurfürsten bzw. ihren Erfüllungsgehilfen in irgendeiner Weise behilflich zu sein) ${ }^{65}$.

Die Ächtungszeremonie war nicht nur in ihrer Anlage auf Öffentlichkeit in Wien ausgerichtet, sondern auch an anderen Orten wurden feierliche Aktionen durchgeführt, um die Prozedur vom 29. April allgemein bekannt zu machen. Die Information der Öffentlichkeit war ein Aspekt, aber besonders musste das Geschehene in den Territorien der Geächteten offiziell verkündet werden, weil damit der Bindungsabbruch zwischen den geflohenen früheren Herrschern und ihren vormaligen Untertanen sinnfällig und rechtswirksam wurde. Kaiser Josef I. informierte zunächst offiziell den Reichstag ${ }^{66}$. Die Historischen Remarques schilderten die öffentliche Verkündigung der Ächtung in Regensburg. Zusätzlich zur Schilderung der Verkündigungszeremonie durch den kaiserlichen Herold schließt Peter Ambros Lehmann den Hinweis an, dass das Regensburger Domkapitel sich geweigert habe, zwei Trompeter für diesen feierlichen Akt zu schicken. Auch ließen die geistlichen Herren es nicht zu, dass die Ächtungspatente in der Stiftsimmunität öffentlich angeschlagen wurden. Dieser zivile Ungehorsam erklärte sich daraus, dass Josef Clemens zusätzlich zu seinen zahlreichen Ämtern auch Bischof von Regensburg war, so dass sich seine früheren Untergebenen im Loyalitätskonflikt glaubten ${ }^{67}$. An verschiedenen Stellen war bereits angekündigt worden, dass der Herold nach Regensburg auch die übrigen Kathedral- und Residenzstädte des früheren Kurfürsten von Köln aufsuchen sollte.

$65 \mathrm{Ob}$ das Mandat bereits in der Urfassung in Düsseldorf vom 17. Mai 1706 erschien, ist unklar; jedenfalls wurde am 15. Juli 1706 eine Druckfassung in Heidelberg herausgebracht und in Umlauf gesetzt: $\gg$ Respective Privation Auch Acht $=$ und Ober $=$ Achts $=$ Erklärung Gegen Die gewesene Churfürsten zu Cölln und in Bayrn/Joseph Clemens Und Maximilian Emanuel etc.«, Heidelberg (15. Juli) 1706.

66 Vgl. den Wortlaut der kaiserlichen Deklaration der Ächtung, abgedruckt unter der Herkunftsangabe »Ein anderes aus Wien vom 8. Dito«: »Ordentliche Wochentliche Kayserliche Reichs $=$ Post $=$ Zeitungen $\ll[=$ Frankfurter Postzeitung], Nr. 40 vom 18. Mai 1706. Der Text war, in einer gekürzten Fassung, auch durch einen Wiener Korrespondenten zur Redaktion des »Frankfurter Journals« übermittelt worden: »Frankfurter Journal«, Nr. 41 vom 22. Mai 1706.

67 »Historische Remarques«, Jg. 8/1706, vom 11. Mai 1706, S. 151. 
Dies geschah am 19. Mai in Köln. Eine Ausgabe der Extraordinari-Kayserl. Reichs $=$ Post $=$ Zeitung schrieb einen Tag später:

Gestern ist alhier vor dem Chur $=$ Cöllnischen und auf dem alten Marckt vorm Rath $=\mathrm{Hau} ß /$ die Achts $=$ Erklärung gegen Cölln und Bayern $/$ durch einen kayserlichen Herold publicirt worden/derselbe wird nun ferners nach Lüttich und in andere Städte gehen/umb allda ein gleiches zu thun ${ }^{68}$.

Ausführlicher wurde die Publikation im Frankfurter Journal geschildert:

Die Publicirung der Kayserl. Achts=Erklärung gegen Cölln und Bayern/ist mit folgenden Ceremonien geschehen. Es ritte der Kayserl. Herold mit seinem Stab und 2 Kayserl. Hatschiers aus dem Hof Ihro Hochfürstl. Durchl. von Sachsen-Zeitz/mit 4 Trompetern/blasend/erstlich nach dem Churfürstl. Hof in der Tranckgaß/und lasen beyder Verbrechen öffentlich ab/und risse darauf die Patenta von beyden Churfürsten entzwey/und gieng auf gleiche Weiß auf den alten Marckt an das Kauffhauß/solche auch hernechst zu affigiren/selbigen accompagnirte der Stadt=Adjutant zu Pferd mit $30 \mathrm{Stadt}=$ Genadirern sampt ihrem Capitain; Morgen gehet er nach Bonn/ein gleiches zu thun/und hernach auf Lüttich ${ }^{69}$.

Zwei Tage später erschien der Herold auch in Bonn. Ebenso wie in Regensburg reagierte die Bevölkerung mit einer Missfallenskundgebung:

Vorgestern [ $=21$. Mai] hat der Kayserl. Herold die Bayer. Achts $=$ Erklärung in der Chur $=$ Cöllnischen Residentz zu Bonn publiciret/bey welchem Actu sich wenige Leut auff der Strassen gefunden/sondern ihre Häuser und Thüren zugehalten [sic!]. Morgen wird vorgedachter Herold unter Convoy auff Lüttig gehen/in selbigem Fürstenthum ebenmässige Proclamation vorzunehmen ${ }^{70}$.

Bemerkenswert ist hier nicht der passive Widerspruch der kurkölnischen Untertanen, sondern die Tatsache, dass die Presse diese Passagen aus Regensburg und Bonn ungehindert verbreiten konnte. Beim Leser wurde ein Restzweifel an der Rechtmäßigkeit der Aktion gesät oder ggf. sogar bestätigt.

Für den Zeitabschnitt zwischen 1706 und 1711 ist die umfängliche Deduktion Anzeige Der Justiz und Legalitet Der Kayserl. Achts = Erklärung bedeutsam, die zwar ohne Verfasser, aber mit Speyer als Druckortsangabe herausgebracht wurde. Sie richtete sich mit ihren 72 Seiten und 105 Paragraphen

68 Mitteilung aus »Cölln/den 20. May«: »Extraordinari-Kayserl. Reichs $=$ Post=Zeitung «, ohne Nr. vom 22. Mai 1706.

69 Mitteilung aus »Cölln/den 20. May«: »Frankfurter Journal«, Nr. 42 vom 25. Mai 1706.

70 Mitteilung aus »Cölln/den 23. May«: »Extraordinari-Kayserl. Reichs $=$ Post $=$ Zeitung $«$, ohne Nr. vom 25. Mai 1706. 
nicht nur gegen das bayerische Selbstverständnis, sondern auch gegen eine starke Strömung unter den Mitgliedern des Reichsfürstenrats, die eine Achterklärung für eine Angelegenheit hielten, die der Zustimmung des gesamten Reichstags bedurfte, nicht nur die der Kurfürsten ${ }^{71}$.

Im selben Jahr erschien die Schrift Des bedrängten Bayerlands wehmüthiges Gespräch, ein fingierter Dialog der Personifikation Bayerns mit dem exilierten Kurfürsten. Auf sechs Seiten wird ein gereimter Dialog vorgelegt, in der Max Emanuel zwar als »Churfürst« tituliert wird, aber dennoch scharfe Kritik seines Landes ertragen muss. So mahnt die Bavaria ihn vor dem Konflikt mit Kaiser Leopold I. (was ggf. auf einen früheren Entstehungstermin verweist?), stellt ihm das Schicksal Absaloms vor Augen, der auch gegen den rechtmäßigen Herrscher rebelliert und sein Leben verloren habe, weist auf die Vielzahl und Übermacht der Feinde hin, warnt vor Frankreich und dessen Unzuverlässigkeit, bittet um kluge Fürsorge für die kurfürstliche Familie und beschwört zuletzt allgemein das nahende Unheil.

Der Wittelsbacher aber entgegnet in seinen Versen, er wolle zum Königtum gelangen und habe ein Recht dazu. Durch List gelange er zum Sieg, seine Verbündeten werden ihm helfen (besonders die Geistlichen), auch könne er die Ketzer schlagen und sei überhaupt »Herr im eigenen Hause«. Die Bavaria kann er allerdings nicht überzeugen. Der Schlussvers der Bayern-Personifikation lautet:

Gebt dem Kayser/was Kaysers ist

So bleibt der Hahn auf seinem Mist ${ }^{72}$.

Die Kaiserwahl 1711 gab den Anlass zu einer verstärkten Auseinandersetzung in den Druckschriften. Die exilierten Wittelsbacher verstanden, zusammen mit ihrem französischen Protektor, dieses verfassungsrechtliche Ereignis als Chance, ihr früheres Wahlrecht zu reklamieren und auf dem Wege der Zulassung zum Frankfurter Wahlakt wieder in den Besitz aller alten Rechte zu gelangen.

Diese »Briefe« waren sofort als offene Briefe konzipiert worden, nicht nur für die Reichsstände, an die sie unmittelbar adressiert waren, sondern für die ganze europäische Öffentlichkeit. Die Hallenser Zeitung Wöchentliche Relationen vermeldete am 22. August 1711, dass in der Dictatur des Regensburger Reichstags »Pakete« mit gedruckten Protestschreiben der früheren Kurfürs-

71 "Anzeige Der Justiz und Legalitet Der Kayserl. Achts = Erklaerung Derer gewesenen Churfürsten von Cölln und Bayern, Mit [...] Bericht Was Nach: [...] S.P. Westphal. Wegen der Achts $=$ Erklärung Eines Reichs $=$ Standes $[\ldots]$ Zwischen denen Chur $=$ und Fürstlichen Collegien [...] gehandelt worden«, Speyer 1709.

72 »Des bedrängten Bayerlands wehmüthiges Gespräch mit Ihrem Churfürsten von einem Bayrischen Patrioten entworffen«, o.O. 1709. 
ten von Köln und Bayern eingegangen seien. Offizielle Adressaten seien die kurfürstlichen Legations-Sekretäre gewesen, die Druckwerke sollten aber an alle Interessenten verteilt werden. Für die europäische Leserschaft hatten sich beide Wittelsbacher abgesprochen, die Texte in unterschiedlichen Sprachen zu publizieren: Josef Clemens ließ seine Protestation gegen die Kaiserwahl ohne seine Beteiligung am 4. Juli 1711 in Französisch erscheinen, während Max Emanuel seine Publikation drei Tage später datierte und die deutsche Sprache wählte ${ }^{73}$.

Das Schreiben Max Emanuels wurde auch in weiteren Editionen im Reich publiziert. Die vier Seiten umfassende Schrift Vergeblich und zernichtete Protestation, die noch 1711 erschien, stellte der deutschen Leserschaft eine deutschsprachige Übersetzung bereit. Das Originalschreiben ist allerdings paraphrasiert. Der Kurfürst wurde in der dritten Person beschrieben, versehen mit der Titulatur »der Durchläuchtige Chur-Fürst von Bayrn«, was die Schrift zu einer probayerischen macht. Der Verfasser wies auf den »Hass« im Reich gegenüber dem Wittelsbacher hin. Nur dadurch sei der Ausschluss von der Kaiserwahl zustande gekommen, der jeder rechtlichen Grundlage entbehre. Einmal mehr wurde das wittelsbachische Argument betont, die Reichsacht sei erst wirksam, wenn alle Kurien des Reichstags zugestimmt hätten ${ }^{74}$.

Hinsichtlich der Titulatur ist auch beim Hildesheimer Relations-Courier zu beobachten, dass Max Emanuel der Titel »Churfürst von Bayern« gegeben wird, möglicherweise ein Zugeständnis an Kurfürst Josef Clemens von Köln. Die Zeitung informierte, dass unter dem 29. Juni 1711 die Nachricht aus Paris eingetroffen sei, Max Emanuel halte sich in der französischen Hauptstadt zwecks Übertragung der südniederländischen Souveränität auf ${ }^{75}$.

Während die Kurfürsten sich still verhielten und Josef Clemens und Max Emanuel keiner Antwort würdigten, formulierten gelehrte Reichsrechtsexperten die Argumente für die Unbegründetheit des Antrags. Einer von ihnen war Gottfried Ruehlmann. Er legte eine 67 Seiten starke Historische und Staats $=$ mäßige Untersuchung vor, in der er seine fortlaufende Argumentation mit eingerückten Rechtsdokumenten untermauerte. Die beiden Schreiben Josef Clemens' wurden dabei nicht nur inhaltlich, sondern auch formal untersucht, und Ruehlmann stellte dabei fest, dass der gewesene Kurfürst zwar traditionell seine früheren Standesgenossen mit »Euer Liebden« anredete, aber in der »Wir«-Form schrieb, was im Verkehr unter Standesgleichen nicht gebräuchlich sei. Der Autor fühlte sich dadurch an die Schreibweise des

73 »Wöchentliche Relationen«, Nr. 34 vom 22. August 1711.

$74 »$ Vergeblich und zernichtete Protestation Prinz Emanuels, geweßten Chur=Fürsten von Bayrn. Belangende die unbefugt $=$ gesuchte Admission zu der Kayserl. Wahl. Aus dem Lateinischen Original translatiert«, o.O. 1711.

$75 »$ Hildesheimer Relations-Courier«, Nr. 4 vom 11. Juli 1711. 
französischen Königs an die Reichsstände erinnert und konnte sich den ironischen Seitenhieb nicht verkneifen, demnächst werde Josef Clemens vielleicht als »König von Köln« in seiner Korrespondenz in Erscheinung treten ${ }^{76}$.

In der Hauptsache hielt der Verfasser ein Wiederaufleben des Wahlrechts für unmöglich, solange die Reichsacht nicht aufgehoben sei. Dies könne aber nach geltendem Reichsrecht nur durch Zusammenwirken von Kaiser und Kurfürsten geschehen. Da es keinen Kaiser gebe, sei über die Aufhebung der Ächtung von 1706 erst nach der Kaiserwahl rechtmäßig zu befinden. Kurmainz könne daher dem Antrag nicht zustimmen. Die Reichsacht sei über den früheren Kölner Kurfürsten und seinen Bruder zu Recht verhängt worden, weil diese sich des fortgesetzten schweren Landfriedensbruches, der militärischen Zusammenarbeit mit dem französischen Reichsfeind und der Schmähung der kaiserlichen Majestät schuldig gemacht hätten. Auch am Papst übte der Verfasser Kritik: Zwar habe die römische Kurie signalisiert, die geächteten Kurfürsten mit dem Reich aussöhnen zu wollen, doch hätte der Papst den Kölner Rechtsbrecher besser direkt abgesetzt und einen neuen Kurfürsten wählen lassen - wozu er auch fünf Jahre nach der Ächtung noch keine Anstalten gemacht habe ${ }^{77}$. In einer weiteren Flugschrift, die ebenfalls Ruehlmann zugeschrieben wurde, stand zusätzlich der Vorwurf zu lesen, der bayerische Potentat habe sogar mit den ungarischen Aufständischen gegen den Kaiser kollaboriert ${ }^{78}$.

Im weiteren Fortgang griff die Flugschrift auf mittelalterliche Beispiele zurück, wie damals mit geächteten Fürsten im Falle einer Unterwerfung nebst anschließendem politischen Ausgleich verfahren worden sei. Als frühneuzeitliche Beispiele wurden die Absetzungen der Kölner Kurfürsten Hermann von Wied und Gebhardt Truchseß von Waldburg genannt, ebenso wie die Ächtung des Pfälzer Kurfürsten Friedrich V. zu Beginn des Dreißigjährigen Krieges ${ }^{79}$.

Nach den historischen Beispielen kam Ruehlmann zu seiner Conclusio. Seiner Ansicht nach wogen die Vergehen der Wittelsbacher schwerer als die der anderen genannten Geächteten früherer Zeiten. Beide Kurfürsten hätten sich zuletzt nicht der kaiserlichen Gnade unterworfen, sondern seien außer

76 Gottfried Ruehlmann, Historische und Staatsmäßige Untersuchung/obs dem H. Röm. Reiche Deutscher Nation zuträglich und rühmlich sey/die beyden gewesenen Chur-Fürsten von Cöln und Bayern/Ihren Verlangen nach/zur instehenden Wahl eines neuen Römischen Kaysers ordentlich zu beruffen [...], o.O. 1711, S. $6 f$.

77 Ebd., S. 16.

78 »Des gewesenen Chur=Fürstens von Bayern Protestation Wider die jetzt bevorstehende Römische Kayser=Wahl Nebst kurz abgefasten Histor $=$ und Politischen Anmerckungen Woraus derselben Protestation Nichtigkeit und Ohnmacht zu ersehen« (Gottfried RuEHLMANN zugeschrieben), o.O. 1711, S. 13.

79 Ebd., S. $72 f$. 
Landes geflohen ${ }^{80}$. Ziehe man die Maßstäbe heran, die bei vergleichbaren Fällen angewandt worden seien, dürfe Josef Clemens nur eines seiner Fürstentümer als Stiftsherr zurückbekommen. Der Papst könne ihn ja - so fügte Ruehlmann polemisch hinzu - zum Kardinal erheben, nachdem er sich »so sehr bekümmert « gezeigt habe ${ }^{81}$. Ruehlmann stand damit für das Prinzip »Strafe muss sein« ein:

Sollten aber die Ächter [= die geächteten früheren Kurfürsten - J.A.] so gnädig und ihrer Würden und Länder unverlohren davon kommen/so ist zu befürchten/wie leider! eben aus vorigen Exempeln geschehen/daß da kein währender Unglücks=Spiegel vorhanden/es noch mehr ins künfftige geben werde/welche wider Kayserl. Majestät rebellieren/und das H. Reich in merckliche Unruhe und Schaden setzen ${ }^{82}$.

Die übrigen Kurfürsten seien - so Ruehlmann - gegen die Restitution der Wittelsbacher eingestellt ${ }^{83}$. In wessen Auftrag Ruehlmann schrieb, bleibt unklar. Franz Feldmeier ist der Ansicht, Ruehlmann habe sich aus eigener Initiative zu Wort gemeldet. Für den bayerischen Apologeten war der Thüringer Historiograph ein Autor, der mit einem gehässigen Ton und einem »beschränkten Untertanenverstand« geschrieben habe ${ }^{84}$.

Über diese komplizierten Positionsbestimmungen in den Deduktionen wurde der Zeitungsleser nicht informiert. Max Emanuel kam im Hamburgischen Relations-Courier während der Wahlverhandlungen nur erneut als Militär vor: Laut eines Berichts aus Köln vom 2. Oktober 1711 sollte er Anweisung durch Ludwig XIV. erhalten haben, sich nach Luxemburg zu begeben $^{85}$. Die Stadt war als starke Festung bekannt, so dass es nahe lag, der Wittelsbacher werde dort militärische Aktionen vorbereiten oder starten. Auf derartige Gedanken ließ sich die Hamburger Gazette allerdings gar nicht ein. Auch die Kaiserwahl erschien in der Ausgabe vom 19. Oktober 1711 in nüchterner Form, wobei das übliche Zeremoniell erneut geschildert wurde. Ein beträchtlicher Teil der Leserschaft dürfte sich noch an die Römische Königswahl Josefs I. 1690 erinnert haben, die nach demselben Zeremoniell veranstaltet worden war $^{86}$. An keiner der überprüften Stellen wurde explizit darauf hingewiesen, dass die beiden Wittelsbacher an der Wahl nicht hatten teilnehmen dürfen und dass es zuvor zu dieser Frage Debatten gegeben hatte.

80 Ebd., S. 64-66.

81 Ebd., S. 68f.

82 Ebd., S. 73.

83 Ebd., S. 75f

84 Feldmeier, Die Ächtung des Kurfürsten Max Emanuel, S. 231f.

85 »Hamburgischer Relations-Courier«, Nr. 156 vom 5. Oktober 1711.

86 Ebd., Nr.164 vom 19. Oktober 1711. 
Die Restitution der Wittelsbacher im Zuge des Friedens von Rastatt und Baden war ein weit weniger spektakuläres Ereignis als die militärische Niederlage nebst späterer Ächtung. Kaiser Karl VI. hatte - wohl im Zuge der letzten militärischen Kampagne im Winter 1713/14 - nochmals eine Quellenzusammenstellung früherer Mandate gegen Frankreich und seine Verbündeten und vor allem die Verbote an Reichsuntertanen, in den französischen Streitkräften zu kämpfen, in Umlauf gesetzt ${ }^{87}$. Neue Argumente lassen sich in dieser Schrift nicht mehr finden.

Der Rastatter Friede selbst war ein erstrangiges Medienereignis, doch erfuhr die Leserschaft im Reich vor allem zuverlässig und schnell, wann und wo die Übereinkunft erreicht worden war. Der Hamburgische RelationsCourier vermeldete den Frieden am 15. März 1714 und griff dabei auf eine Meldung aus »Heydelberg/vom 6. Martii« zurück, in der geschrieben wurde, »heute Mittag« sei der Frieden unterzeichnet worden. Über die Bedingungen erfuhren die Leser zunächst nichts. Der Redakteur setzte als allgemeine Hoffnung dazu: »Der Herr gebe seinen Segen darzu/daß solcher Friede künfftig lang dauren möge«. Vier Tage jünger war im selben Blatt eine Mitteilung aus Frankfurt a.M., die den Friedensschluss bestätigte und immerhin die inhaltliche Tendenz übermittelte, die Bedingungen seien besser ausgefallen als zunächst vermutet - was immer das bedeuten mochte ${ }^{88}$.

Am 19. März wusste der Hamburgische Relations-Courier bereits mehr, indem er sich auf ein Schreiben vom Oberrhein vom 6. März berief. Darin stand, dass die Friedensbedingungen offiziell noch geheim gehalten würden, solange die Kuriere nicht an den Höfen angekommen seien. Die Herrscher sollten die Friedensergebnisse nicht aus der Zeitung erfahren. Inoffiziell wusste die Zeitung allerdings schon sehr viele Einzelheiten: Bayern und Kurköln fielen wieder an die Wittelsbacher, ihre früheren Herrscher, die völlig restituiert würden. Für Kurpfalz sei eine Entschädigung vorgesehen, im Gespräch sei Landau, dazu möglicherweise Teile von Luxemburg oder Limburg. Max Emanuel würde von Frankreich für sein langes Exil entschädigt. Allerdings standen auch Spekulationen in der Mitteilung, so der Hinweis eines »hohen Herrn«, der französische König sei am Schlagfluss gestorben ${ }^{89}$.

Vom Badener Frieden im September 1714 ist dieselbe schnelle Information zu konstatieren. Nachdem im Hamburgischen Relations-Courier vom 14. September 1714 zunächst mitgeteilt wurde, dass am 4. September der

87 »Erneut $=$ und geschärffte Kayserliche Abruffung $=$ Gehei $\beta=$ Gebott $=$ und Verbotts $=$ Brieffe/Wider alle [...] Welche In der Cron Franckreich/deß Duc de Anjou/und der beyden respective entsetzten und geächteten Gebrüderen Joseph Clemens/und Maximilian Emanuels / geweßter Chur=Fürsten zu Cölln/und Bayern/etc. [...] Diensten sich befinden und verharren [...] « o.O. 1713.

88 »Hamburgischer Relations-Courier«, Nr. 43 vom 15. März 1714.

89 Ebd., Nr. 45 vom 19. März 1714. 
Verhandlungsdurchbruch erzielt worden sei, konnte die Zeitung sechs Tage später den 7. September als Unterzeichnungstag verbuchen: Um 13.00 Uhr seien die entscheidenden Unterschriften durch die Delegationsleiter, Prinz Eugen und Marschall Villars, geleistet worden. Hinsichtlich der Restitution der Wittelsbacher schrieb die Zeitung ganz offen, dass deren Rückkehr in den Kreis der zivilisierten Herrscher damit offiziell abgeschlossen sei. Bekräftigt wurde diese Einschätzung durch die Tatsache, dass die kurkölnischen und kurbayerischen Minister, die am Verhandlungsort weilten, nach der Vertragsunterzeichnung zu einem offiziellen Essen eingeladen worden seien ${ }^{90}$.

Im Wiener Diarium erfuhr der Leser nichts über die Rückkehr Max Emanuels und dessen Gründe. Nun liegt es nahe, dass eine diplomatische Niederlage, die der Kaiser in diesem Fall erlitt, nicht auch noch durch seine privilegierte Gazette vor dem Publikum der Hauptstadt detailliert ausgebreitet werden sollte. Dass jedoch die Friedensschlüsse insgesamt fehlten - zumindest ließen sie sich im Bestand der überlieferten Exemplare in der Sammlung der »Deutschen Presseforschung « in Bremen nicht ausfindig machen stimmt merkwürdig.

\subsection{Darstellung des Konflikts in den Zeitschriften}

Eine frühe Zeitschriftenbehandlung der Wittelsbacher Kurfürsten findet sich in den Geheimen Briefen, die 1701 bis 1702 anonym herausgebracht wurden. Da »Freystadt« als Druckort angeben wurde, könnte es sich um Leipzig handeln, das mehrfach unter »Freystadt« oder »Wahrmund « fingierte. In der stilistischen und inhaltlichen Ausrichtung besteht eine Ähnlichkeit zu Periodika von Sinold von Schütz, was auch das Erlöschen der Zeitschrift mit dem Jahrgang 1702 erklären würde. Inzwischen hat sich der thüringische Jurist Gottfried Zenner als Verfasser und Herausgeber dieser Briefsammlungen herausgestellt ${ }^{91}$. Hinsichtlich Kurkölns und Kurbayerns kritisiert der Verfasser die französischen Bündnisse, die sich gegen die kaiserlichen Interessen richteten und daher reichsrechtswidrig seien. Der Beginn militärischer Aktionen gegen oberdeutsche Reichsstädte - im Einzelnen ist hier Ulm gemeint - dient dem fingierten Briefschreiber als Anlass zur Bestürzung. Das Bestreben laufe auf einen verabscheuungswürdigen Bürgerkrieg hinaus (unter inhaltli-

90 Ebd., Nr. 146 vom 14. September 1714; ebd., Nr. 149 vom 20. September 1714.

91 Vgl. fiktive Briefsammlung "Geheime Briefe, so zwischen curiosen Personen [...] gewechselt wurden «, 2 Bd., Freystadt [=Leipzig?] 1701-1702. Die Briefe wurden später nochmals herausgegeben: »Curieuse Schatz=Kammer/bestehend in 237 Geheimen Briefen/so zwischen curiosen Personen über notable Sachen der Staats $=$ und gelehrten Welt gewechselt wurden $/[. ..] \ll$, 3 Bd., Leipzig 1701/1704-1705. Zu Gottfried Zenner (1656-1721): DBA, 1. Serie, Fiche 1409, Nr. 13-15. 
cher Bezugnahme auf Ciceros Mahnungen vor dem drohenden Bürgerkrieg seiner Zeit). Als Grund für das Verhalten des Bayern nennt der Autor dessen Ambitionen auf die Königswürde: Es bestehe eine »Jalousie« auf die Wettiner und Hohenzollern, die aus rangniedrigeren Geschlechtern stammten und dennoch zum Königtum gelangt seien. Frankreich habe diese Ambitionen unterstützt und Max Emanuel eine Königswürde in Aussicht gestellt, wenn der Kurfürst sich politisch mit Ludwig XIV. verbinden würde ${ }^{92}$.

Die einzelnen Hefte dieser fingierten Briefe wurden 1704/05 in drei Jahresbänden herausgebracht - insgesamt fast 600 Briefe mit Räsonnements über aktuelle politische Ereignisse. Hinsichtlich der Bewertung Bayerns spricht der Verfasser davon, dass der kaiserliche Hof dem Kurfürsten Max Emanuel gegenüber mit großer Zurückhaltung aufgetreten sei, obwohl der Wittelsbacher den Kaiser seit Jahren provoziert habe. Der Verfasser hält diese maßvolle Strategie in der Vergangenheit für richtig. Allerdings seien zuletzt schärfere Aktionen gefolgt. Das bayerische Votum am Reichstag sei suspendiert worden, und auch die Verweisung des bayerischen Gesandten aus Regensburg werde folgen ${ }^{93}$. Zwar sei Max Emanuel nicht geächtet und seine Untertanen noch nicht von ihren Treueeiden entbunden worden, doch sei der Kurfürst durch die ergangenen Avocatoria bereits stillschweigend pro hoste imperii erklärt worden. Daher hätten die Untertanen nicht mehr die Pflicht, den Kurfürsten bei seinen kriegerischen Handlungen zu unterstützen. Die »weltliche Obligation« (=positive Gesetzestreue) spreche zwar für die Bindung an Max Emanuel, aber die »natürliche Obligation« (= göttliches oder Naturrecht) spreche für die Pflicht zur Achtung des Reichsrechts ${ }^{94}$. Der Zeitschriftenverfasser nimmt die Gelegenheit der Abrechnung mit Bayern wahr, über die »lügenhafften Zeitungen« zu räsonnieren. Diese Verfasser der Falschmeldungen, so nimmt er an, seien entweder Verräter oder Narren. In Deutschland könnten viele von französischen oder bayerischen Spionen stammen, »welche allerhand Dinge erdichten $\aleph^{95}$. Beispiele über den Aufmarsch Marlboroughs und des Prinzen Eugen gegen Bayern im Sommer 1704 werden erwähnt. Der Leser möge sich daher auf seine Klugheit besinnen und nicht alles glauben, was gedruckt erscheint. Besser sei es, mit Tacitus der Zeit Gelegenheit zu geben, die Wahrheit zu erweisen: »Vera visu \& mora, falsa festinatione invalescunt « - »wahre Dinge erkennt man durch Verzug/Lügen aber durch plötzliches Geschrei « ${ }^{96}$.

92 412. Sendschreiben vom 6. Dezember 1702: »Geheime Briefe«, Bd. 2, 1702, S. 917-923.

93 408. Sendschreiben vom 21. November 1702: ebd., Bd. 2, 1702, S. 879-882.

94 Rekurs auf das Bibelwort »Man muß Gott mehr gehorchen als den Menschen« (Apg. 5,29): 428. Sendschreiben vom 14. Januar 1703: ebd., Bd. 3, 1705, S. 27-29.

95 567. Sendschreiben vom 16. Juni 1704: ebd., Bd. 3, 1705, S. 812-816.

96 Ebd., S. 816. 
In einem anderen fingierten Brief wird die offizielle Verlautbarung Max Emanuels gegenüber der Stadt Ulm - gemeint ist vermutlich die Deklaration »Sr. Chur=Fürstl. Durchl. zu Bayern Send=Schreiben An die hohe Directores der Fränckischen und Schwäbischen Creysse« - als »bloße Gleißnerey« bezeichnet: Von Freiheit für Ulm könne in Wirklichkeit keinerlei Rede sein. Der Verfasser fordert, dass gegen Max Emanuel die Reichsacht verhängt werden sollte ${ }^{97}$. Die Forderung ist sehr bemerkenswert: Aller sonstigen Rücksichtnahme gegen regierende Fürsten zum Trotz wird hier in einem Periodikum eine Bestrafung eines Herrschers gefordert! Hier fühlte sich nicht nur der Autor und Verleger sehr sicher vor einer bayerischen Intervention, sondern offenbar auch vor der eigenen Obrigkeit, von der aus wohl keine Schritte erwartet wurden. Auch dem Kölner Kurfürsten Josef Clemens wirft der Verfasser »Heucheley« vor, wenn er stets von seiner Treue zum Reiche spreche und schreibe, aber gleichzeitig französische Truppen ins Land aufnehme. Niemand solle ihm glauben, so der Autor der Geheimen Briefe, und Frankreichs vollmundig versprochene Hilfe werde ihm im Ernstfall nicht nützen, sondern die französischen Truppen würden schnell wieder in ihre Heimat zurückkehren $^{98}$.

Eine sehr dichte Beschreibung der Militäraktionen Max Emanuels liegt durch den Monatlichen Staats-Spiegel des Stanislaus Reinhard Acxtelmeier vor. Acxtelmeier hatte nicht nur seinen Berichtsschwerpunkt auf der ersten Dekade des 18. Jahrhunderts, sondern verlegte sein Periodikum auch in der Reichstadt Augsburg. Damit stand er während der beiden kritischen Jahre mitten im Geschehen, was ihm detaillierte Informationen verschaffte, aber auch das Risiko in sich barg, in die Kriegshandlungen einbezogen oder das Opfer von gewalttätigen bayerischen Gegenmaßnahmen gegen seine Berichte zu werden ${ }^{99}$. Der Einmarsch der Bayern in Ulm im September 1702 wird zwar beschrieben, aber hinsichtlich seiner reichsrechtlichen Bedeutung nicht kommentiert. Der Herausgeber verwendet hier die bekannte Strategie, brisante Sachverhalte nicht durch eigene Festlegungen, sondern durch die Gegenüberstellung der Positionspapiere der Konfliktparteien zu verdeutlichen. Durch die acht Dokumente, die Acxtelmeier abdruckt, erschließt sich dem Leser ein umfassendes Bild über den Ablauf des Geschehens sowie die Begründungen, die beide Seiten diesem Sachverhalt unterlegen wollen ${ }^{100}$. Die kom-

97 416. Sendschreiben vom 14. Dezember 1702: ebd., Bd. 2, 1702, S. 933-936.

98 289. Sendschreiben vom 31. März 1702: ebd., Bd. 2, 1702, S. 237f.

99 [Stanislaus Reinhard Acxtelmeier (Hg.)], »Monatlicher Staats-Spiegel; Worinnen der Kern aller Avisen; Ein Begriff der vornehmsten im H. Röm. Reich vorfallenden Affairen mit vilen Curiosen Beylagen, samt einigen Politischen Reflexionen sich repraesentirt und vorstellet«, Augsburg 1698-1709.

100 Dokumente: Rechtfertigung Max Emanuels gegenüber dem Kaiser, 8. September 1702: S. 33-35; Relation über den militärischen Hergang der Besetzung, 8. September 1702: S. 35-43; Brief Max Emanuels an den Ulmer Magistrat, 7. September 1702: S. 43-47; Recht- 
promisslose Haltung Kaiser Leopold I. zur bayerischen Umtriebigkeit wurde dem Leser deutlich, als er im November 1702 erfuhr, der ständige kurbayerische Resident in Wien sei außer Landes verwiesen worden. Der Reichstagsgesandte Max Emanuels sei allerdings noch vor Ort - ein Zeichen dafür, dass Acxtelmeier auch mit dessen Entfernung aus Regensburg rechnete ${ }^{101}$.

Im Weiteren beschränkte sich die Zeitschrift nicht nur auf die Gegenüberstellung Bayern - Kaiser und reichsständische Gegner, sondern auch die bayerischen Untertanen kamen zu Wort. So fand eine Eingabe der bayerischen Stände ebenfalls ihren Weg in das Periodikum. Unter dem 22. November 1702 hatte die Landschaft in Ober- und Niederbayern nämlich ihren Landesherrn um Maßnahmen zu Sicherung von Ruhe und Ordnung gebeten: Das Territorium könne nach den hohen Abgaben der vergangenen beiden Jahrzehnte nun keinen Krieg gebrauchen. Das Papier ist von großer Deutlichkeit, wenn sogar formuliert wird, dass ein Großteil der Steuern außer Landes ausgegeben worden sei (und damit nicht dem Landeswohl zugute gekommen sei, zu dessen Erhaltung der Kurfürst doch eigentlich verantwortlich wäre) ${ }^{102}$.

Die nächste längere Passage im Monatlichen Staats-Spiegel steht im Zusammenhang mit dem bayerischen Vorgehen gegen Regensburg. Dort hatte der Baron von Zindt als kurbayerischer Gesandter zunächst die Friedenschalmeien erklingen lassen. Er warb um Verständnis für Max Emanuel und forderte Verhandlungen statt kaiserlicher Verbotsmandate ${ }^{103}$. Im AprilHeft der Zeitschrift schilderte Acxtelmeier ausführlich den bayerischen Militäraufmarsch im Regensburger Umland sowie die Besetzung der Donaubrücke. Der Kaiser weigerte sich fortan, Reichstagsbeschlüsse zu ratifizieren, weil er nicht erkennen konnte, ob diese den freien Willen der Reichstagsgesandten (bzw. deren Prinzipalen) oder den repressiven Willen der Münchener Regierung ausdrückten. Die Gesandten fuhren fort, dem bayerischen Kurfürsten diplomatische Brücken bauen zu wollen ${ }^{104}$. Max Emanuel ging einstweilen darauf ein und publizierte eine Deduktion Rationes invincibiles victae, das ist $/$ Gegen $=$ Bewei $\beta /$ da $\beta$ der Reichs $=$ Convent dermalen in der Stadt Regensburg gar wohl bleiben kann ${ }^{105}$. Die Deduktion, die Acxtel-

fertigung Max Emanuels an die Reichskreise Schwabens und Frankens, 10. September 1702: S. 48-54; Kaiserliches Promemoria an Max Emanuel, 12. September 1702: S. 55f.; Reichstags-Conclusum gegen Bayern, 13. September 1702: S. 57f.; Dank des Ulmer Magistrats an die Reichstagskurien, 20. September 1702: S. 59f.; Promemoria des Reichstags vom 14. September 1702, in dem die Besetzung undiplomatisch eine »gewaltthätige Occupation« genannt wird: S. 61f.

$101 »$ Monatlicher Staats-Spiegel«, 1702, November-Heft, S. 46.

102 Eingabe der Stände in Ober- und Niederbayern an Kurfürst Max Emanuel, 22. November 1702: ebd., 1703, Januar-Heft, S. 19-31.

103 Vorstellung des bayerischen Reichstagsgesandten an alle drei Kurien, 15. Januar 1703: ebd., 1703, Januar-Heft, S. 33-40.

104 Vgl. die Schilderung, versehen mit vielen Dokumenten: ebd., 1703, April-Heft, S. 6-36.

105 Textabdruck der bayerischen Deduktion: ebd., 1703, Mai-Heft, S. 14-18. 
meier im Wortlaut abdruckte, war insofern bemerkenswert, als sie Aussagen zur Reichstagskommunikation beinhaltete: So wandte sich der Verfasser gegen den Verdacht, dass Frankreich durch die kurbayerische Gesandtschaft mit Geheiminformationen aus Regensburg versorgt werden könnte. Die Gesprächssituation am Reichstag sei generell so offen, dass es ohnehin unmöglich sei, den Fluss der Informationen nach Frankreich wirkungsvoll zu verhindern ${ }^{106}$.

Die folgenden Kampfhandlungen in Oberdeutschland werden im Monatlichen Staats-Spiegel ausführlicher behandelt als etwa in der Europäischen Fama, auf die im Folgenden noch näher eingegangen wird. Von den durchschnittlich 100-120 Seiten Heftumfang werden 60 für die Auseinandersetzungen mit Max Emanuel in Anspruch genommen. Acxtelmeier hält sich mit Bewertungen weiterhin zurück, um Max Emanuel nicht zu reizen. Immerhin kommentiert er die militärische Machtübernahme der Bayern in Regensburg am 28. August 1703 und die Entwaffnung der städtischen Milizen und Torwachen mit einem »leider ${ }^{107}$.

Kaum hatten die bayerischen Truppen Süddeutschland nach der Schlacht von Höchstädt im August 1704 geräumt, wurde Acxtelmeier mutiger. So bezweifelte er, dass die Übertragung der bayerischen Landesherrschaft an die Kurfürstin praktikabel sei. Der Kaiser - so Acxtelmeier - werde die Submission verlangen und kaum mit einer Regierung zusammenarbeiten, die im Namen des in hostico sich aufhaltenden Kurfürsten wirken wolle ${ }^{108}$. Damit war die Sonderstellung des Monatlichen Staats-Spiegels beendet, dessen Berichterstattung in der Folgezeit wieder auf der Basis eines offenen Medienverkehrs im Reich durchgeführt werden konnte.

Erst anlässlich der Ächtung bzw. »Privation« der Wittelsbacherbrüder geht Acxtelmeier erneut auf diese Thematik ein. Seine Sympathie mit der kaiserlichen Position dokumentiert er einmal mehr, indem er betont, Kaiser Josef I. habe erst »nach so langem Zuwarten/und so vielen vergeblich geschehenen Ermahn = und Anerbietungen « die Acht-Erklärung ausgesprochen. In der Folge wird ein kompletter Bericht über die Absetzungszeremonie als Quelle eingerückt. Allem Anschein nach greift der Herausgeber dabei auf einen Text zurück, den er in einem gesonderten Medium (Briefbericht, Flugschrift oder Zeitungstext) vorgefunden hat ${ }^{109}$. Drei Monate später folgt der Abdruck des Conclusums des Kurfürstenrats vom Oktober 1705, das dem Kaiser erst die

\footnotetext{
106 Ebd., S. 16.

107 Darstellung der Regensburger Desarmierung: ebd., 1703, September-Heft, S. 1.

108 Kommentar Acxtelmeiers in: ebd., 1704, September-Heft, S. $16 f$.

109 Bericht über die Zeremonie in Wien vom 29. April 1706 (Volltexte der Absetzungsurkunden machen dabei den Hauptteil des Textes aus) samt Acxtelmeiers Hinweisen auf die öffentlichen Verkündigungen in München, Regensburg und Kurköln sowie Lüttich: ebd., 1706, Mai-Heft, S. $9-40$.
} 
Handhabe für die Absetzung lieferte. Acxtelmeier entschuldigt sich damit, er habe diesen Text erst neulich in einem separaten Druck bekommen ${ }^{110}$. Dabei ist unklar, ob die Publikation auf eigenes Risiko unterblieb oder ob Acxtelmeier dahingehende Anweisungen erhalten hatte, den Text erst erscheinen zu lassen, nachdem die Folgen ohnehin allgemein bekannt waren.

Da der Monatliche Staats $=$ Spiegel nur bis 1709 erschien, konnte er die Restitution der Wittelsbacher nicht mehr kommentieren. 1707 wurde allerdings noch darauf hingewiesen, dass die Reichsstadt Donauwörth ihre Reichsfreiheit zurückerhielt, die sie 1608 nach einer bayerischen Exekution verloren hatte. Acxtelmeier druckt die Eingabe des Donauwörther Magistrats an den Reichstag ab, durch die die Stadt offenbar erfolgreich war. Die Ratsmitglieder geben darin ihrer Hoffnung Ausdruck, dass der neu errungene Status auch in den nächsten Friedensschlüssen bestätigt wird. Wertende Kommentare des Herausgebers fehlen ${ }^{111}$.

Die umfassendste und differenzierteste Darstellung der Ächtung der Wittelsbacher und deren Ursache findet sich in der Zeitschrift Die Europäische Fama des Philipp Balthasar Sinold von Schütz ${ }^{12}$. Das Erscheinen des Periodikums 1702 fällt mit dem Beginn der bayerischen Aggressionen in Süddeutschland zeitlich zusammen. Bei Sinold von Schütz wird dem Zeitgenossen der Zusammenhang zwischen den beiden Brüdern Max Emanuel und Josef Clemens aus dem Hause Wittelsbach in ihrer Frankreichpolitik verdeutlicht. Der Verfasser erinnert dabei an einen anderen rheinischen Kurfürsten, der ebenfalls in einer Kriegssituation eng mit Frankreich gegen den Kaiser zusammengearbeitet hatte: Philipp Christoph von Sötern, den früheren Trierer Erzbischof. Sötern hatte sich während des Dreißigjährigen Krieges auf die französische Seite geschlagen gegen die Bedrohung seines Herrschaftsgebiets durch die spanische Administration in Brüssel ${ }^{113}$. Sinold von Schütz verband mit dieser Parallelisierung eine moralisch-didaktische Assoziation: Sötern hatte sich ebenfalls unter Nichtbeachtung seiner reichsrechtlichen Pflichten mit dem Reichsfeind verbündet und mit ihm zusammen gekämpft. Dafür war der Trierer Kurfürst von den Habsburgern für mehr als 10 Jahre gefangengehalten worden. Zusätzlich spart der Autor nicht mit kritischen Kommentaren über die französische Bündnistreue: »Von den Frantzo-

110 Conclusum des Kurfürstenrats vom 27. November 1705: ebd., 1706, August-Heft, S. 17-20. Im Conclusum wird der 29. Januar als Datum der offiziellen Anfrage des Kaisers an den Kurfürstenrat in dieser Sache genannt; die Debatte über den Ächtungspunkt sei am 18. Februar 1705 und damit noch zu Leopolds Lebzeiten eröffnet worden. Der Kurfürstenrat sei dem kaiserlichen Vorschlag in Gänze gefolgt.

111 Rat Donauwörth an den Reichstag vom 30. Juli 1707 (zur Dictatur eingebracht am 2. September 1707): ebd., 1707, September-Heft, S. 12-15.

112 Vgl. Europäische Fama.

113 Vgl. ebd. 1 (1702), H. 3, S. 265f. - Zur Philipp Christoph von Sötern: Karlies AbmeIER, Der Trierer Kurfürst Philipp Christoph von Sötern und der Westfälische Friede, Münster 1986. 
sen selbsten aber werden Se. Churfürstl. Durchl. sonder Zweiffel im Hertzen ausgelachet/welchen die Deutsche Leichtgläubigkeit jederzeit zum Gespötte dienen müssen $\aleph^{114}$.

Neben allgemeiner Ausrichtung der Politik an Frankreich hatte Erzbischof Josef Clemens zwar keine aktive Expansionspolitik betrieben, aber immerhin im Jahre 170215.000 französische Soldaten auf seine Festungen am Niederrhein aufgenommen. Angesichts der strategischen Scharnierfunktion des Niederrheins, der schon im 17. Jahrhundert mehrfach den Spaniern und Franzosen als Aufmarschgebiet in die Republik der Niederlande gedient hatte, wirkte die französische Stationierung der Strategie der Reichsverteidigung und damit den kaiserlichen Interessen sehr entgegen. Wie ein Hohn auf das Reichsrecht empfand es daher Sinold von Schütz, dass Josef Clemens die Truppen »Burgundische Kriegsvölker« nannte, als ob sie auf Veranlassung und zum Schutz des Burgundischen Reichskreises gedacht gewesen seien ${ }^{115}$. Kaiserlicherseits ergingen mehrere scharfe Resolutionen an den Kölner Kurfürsten, von denen eine in der Europäischen Fama abgedruckt wurde $^{116}$.

Den bayerischen Militäraufmarsch in Schwaben schilderte Sinold von Schütz in breiter Ausführlichkeit, wobei er zahlreiche Deduktionen der Kriegsparteien einrückte, z.B. das bayerische Kriegsmanifest, das die Ulmer Besetzung begleitete, sowie das bayerische Schreiben an die Kreise Schwabens und Frankens ${ }^{117}$. Der Herausgeber der Europäischen Fama machte kein Hehl daraus, dass der Wittelsbacher letzteres Schreiben »zur Beschönigung seines Unternehmens« drucken ließ, eine Formulierung, die keinen Zweifel an der publizistischen Kritik ließ. Da der Verfasser hier offenbar bei noch währender Regierungszeit Max Emanuels nicht direkt als politischer Richter in Erscheinung treten wollte, schrieb er in den verbindenden Text eine gespielte Meinungsenthaltung, um dann bruchlos das scharf formulierte kaiserliche Handschreiben an Max Emanuel vom 18. September 1702 abzudrucken, dessen Form und Inhalt an Deutlichkeit nicht zu überbieten war. Der Kaiser forderte den bayerischen Kurfürsten zur umgehenden Räumung Ulms auf und verlangte ein Ende aller militärischen Aktionen, die dieser in Verbindung mit Bayern begonnen hatte. Dabei verwies er auf die Pflichten, die der Kurfürst gegenüber Kaiser und Reich habe ${ }^{118}$. Sinold von Schütz brauchte

114 Vgl. Europäische Fama 1 (1702), H. 3, S. 266.

115 Vgl. die Kritik in ebd. 1 (1702), H. 1, S. 37-45.

116 Vgl. ebd. 1 (1702), H. 2, S. 126-130.

117 Handstreich gegen Ulm, 8. September 1702, mit Kriegsmanifest: Europäische Fama 8 (1702), S. 741-744. Bayerisches Schreiben an die benachbarten Reichskreise, Herbst 1702: Europäische Fama 9 (1709), S. 795-802.

118 Kaiserliches Handschreiben vom 18. September 1702: Europäische Fama 9 (1702), S. 802 805 . 
hier ebenfalls keinen Kommentar anzuschließen, sondern setzte hinter das kaiserliche Schreiben die unaufrichtige Replik des Kurfürsten vom 30. September $1702^{119}$. Erst anschließend äußerte der Verfasser milde Kritik an Bayern.

In den folgenden Militärberichten über Süddeutschland herrscht Sachlichkeit vor. Sinold von Schütz schildert die Besetzung Regensburgs im April 1703 ohne weitergehende Bewertung, wenn man von der Polemik gegenüber Max Emanuels Kriegslegitimation absieht. Der Kurfürst hatte auf die kaiserlichen Mandate mit der Schrift Chur=Bayerisches Gegen= Manifest auf die Wiederhold ergangene kayserliche Avocatoria [...] geantwortet, er sei nicht der Aggressor, wie der Kaiser fälschlich behaupte, sondern der Angegriffene, dem ein Notwehrrecht gebühre. Auch betreibe der Kaiser ein Ächtungsverfahren gegen die Wittelsbacherbrüder ${ }^{120}$. Schon früher hatte Sinold von Schütz die bayerischen Selbstrechtfertigungen wie folgt kommentiert: »Denn man muß sich keineswegs die Einbildung machen/daß jemahls ein krieg = führender Fürste etwas vornehmen sollte/davon er nicht vor der ehrbaren Welt Rechenschafft geben/und sein Beginnen vertheidigen könnte « ${ }^{121}$. Das genannte Kriegsmanifest bewertete der Redakteur mit folgendem Kommentar: »Es ist bekannt, daß die weitläuffigen Schrifften nicht allemahl die besten seynd/ und halte ich vor unnöthig/ über dieses Manifest einige Anmerckungen zu machen; indem sich dasselbe gleichsam selbst wiederleget $\aleph^{122}$.

Auch der weitere Fortgang der bayerischen Gewalt wird erläutert, wenn auch nicht mit der Intensität wie der Handstreich gegen Ulm. In den Heften 20 und 21 weist Philipp Balthasar Sinold von Schütz auf die Eroberungen von Kempten (Anfang Dezember 1703), Augsburg (14. Dezember 1703) und Passau (8. Januar 1704) hin, ohne dass jeweils ein Kommentar abgeben worden wäre. Zu Passau wird nur erwähnt, dass die Stadt »milde« behandelt worden sei - was immer das unter den gegebenen Bedingungen bedeuten mochte $^{123}$. Der Herausgeber bleibt bei seiner Überzeugung, dass das unrechtmäßige Handeln des Wittelsbacherkurfürsten bereits hinreichend zur Vermittlung gelangt ist. Es wird daher nur weiteres Material präsentiert, das schon früher gewonnene Überzeugungen bestätigt.

Unverhohlene Genugtuung ist dem Herausgeber der Europäischen Fama anzumerken, als er den Sommerfeldzug der Alliierten 1704 und die Siege gegen die französisch-bayerische Allianz beschreibt. Sowohl die Schlacht bei

119 Bayerische Replik auf das kaiserliche Handschreiben, 30. September 1702: Europäische Fama 9 (1702), S. 805-811.

120 Hinweis auf das Manifest: Europäische Fama 16 (1703), S. 309f.

121 Zu Regensburg: Europäische Fama 14 (1703), S. 126.

122 Europäische Fama 16 (1703), S. 316.

123 Zu Kempten: Europäische Fama 20 (1703), S. 651f.; zu Augsburg: Ebd., S. 652; zu Passau: Europäische Fama 21 (1703), S. 734f. 
Donauwörth als auch das entscheidende Treffen bei Höchstädt erschloss sich dem Journalisten erst bruchstückhaft, was aber seiner anhaltenden Freude keinen Eintrag tun konnte. Mitunter schoss er dabei über das Ziel hinaus, wenn er etwa das Hausen der siegreichen Truppen in Bayern mit einem positiven, verständnisvollen Grundton vermittelt. Das Anliegen ist ein politischpädagogisches:

Mit diesem Lichte [ $=$ d.h. mit dem Licht der brennenden bayerischen Häuser $]$ muste man diejenigen erleuchten/die es bisher noch nicht hatten gläuben wollen/daß es eine unverantwortliche Sache sey/das Reich nur darum zu beunruhigen/damit der allerchristlichste König sein Werck desto besser ausführen/und sich zu seiner allgemeinen Monarchie alle Tage mehr Hoffnung machen könne ${ }^{124}$.

Hinter der »allgemeinen Monarchie« offenbart sich der zeitgenössische Sprachgebrauch dessen, was auch als »Universalmonarchie« in der staatstheoretischen Diskussion eine Rolle spielen sollte ${ }^{125}$. Nach der Schlacht von Höchstädt hieß es dann pathetisch: »Die Europäische Fama hätte sich/wenn es möglich wäre/gerne ein Dutzend Trompeten zugeleget « ${ }^{126}$.

Die Bewertung der Niederlage und Vertreibung der Wittelsbacher Kurfürsten erfolgte auch sonst mit moralisierender Wertung, bei deren Formulierung die Volksweisheit »Hochmut kommt vor dem Fall« Pate gestanden haben mochte. So schrieb der anonyme Verfasser der Zeitschrift Der Welt Urtheile als Fazit des militärischen Wirkens Max Emanuels:

Ehe ich aufhöre, von den verdorbenen Anschlägen der Cron Frankreich zu reden, wirst du mein Leser erlauben/noch mit wenigen an den Churfürsten von Bayern/und an die Rebellen in Hungarn zu gedencken. Es sahe schlimm genug aus, wie dieser ehrgeitzige Herr/nicht geringer als die übrigen zwey Churfürsten sein wollten/die sich mit ihren grossen Verdiensten Cron und Scepter zu wege gebracht haben/und da er durch Frantzösischen Beystand das Fränckische Königreich wiederum aufzurichten vermeynte ${ }^{127}$.

Für die Anschläge gegen Ulm und weitere süddeutsche Städte, aus Sicht des Verfassers die schwersten Schläge, die ein Reichsfürst in der gegebenen Situ-

124 Kommentar zur Schlacht bei Donauwörth, 2. Juli 1704: Europäische Fama 25 (1704), S. $40 f$.

125 Vgl. zu dieser Diskussion, die das 16. und 17. Jahrhundert durchzog: Franz BosBach, Monarchia Universalis. Ein politischer Leitbegriff der frühen Neuzeit, Göttingen 1988.

126 Schilderung der Schlacht bei Höchstädt, 13. August 1704: Europäische Fama 26 (1704), S. 78-105; Zitat S. 78.

127 »Der Welt Urtheile von den gegenwärtigen Staats-, Kriegs-, gelehrten und gemeinen Sachen schertz- und ernsthafft ausgeführet«, 2 Bd. (20 H.), Leipzig 1706-1711, hier Bd. 1, S. 50f., 1. Pensée. 
ation gegen Kaiser und Reich führen konnte, sei ihm der verdiente Lohn erteilt worden:

Aber wie hat es GOttes Allmacht doch so wunderlich gefüget/daß in zwey Bataillen seine Macht ist gedämpffet/und er selbst nicht allein von Land und Leuten verjaget/sondern auch in einen so elenden Stand versetzet worden/daß man ihn vor nichts anders als einen Frantzösischen General, seine Gemahlin vor eine armselige Exulantin, und seine Kinder vor arme Waysen halten muß/die sich dem Glücke höchst verbunden werden erkennen müssen/wenn man ihnen den Titel und die Revenuen vergönnet/welche vor mehr als fünffhundert Jahren ihre Ahnherren die Grafen von Wittelsbach gehabt haben ${ }^{128}$.

Auch auf die vorerst letzte große öffentliche Verlautbarung im Namen Max Emanuels, das Manifeste von 1704, geht Sinold von Schütz ein. Der Text wird komplett übersetzt und in die Europäische Fama eingerückt. Der Leser erfährt von der Abwälzung aller Schuld auf die Habsburger und die Zurückweisung jeglicher Vorwürfe, gegen Reichsgesetze verstoßen zu haben. Der Herausgeber verurteilt die Argumentation des Bayern. Im Übrigen hält er das Exil der Brüder in Brüssel für ein stillschweigendes Schuldeingeständnis, würden sie doch sonst in ihren Territorien residieren ${ }^{129}$.

Die detaillierte Schilderung des Ächtungsverfahrens gegen die Wittelsbacher-Kurfürsten nahm einen prominenten Platz in der ZeitschriftenBerichterstattung des Jahres 1706 ein. In der Europäischen Fama füllte der Bericht von der Absetzungszeremonie ihrer Bedeutung gemäß den gesamten Deutschland-Abschnitt des 49. Teils von 1706 aus. Sinold von Schütz leitete seine Bemerkungen mit dem Satz ein, dass etwas derartiges seit 80 Jahren nicht mehr geschehen $\operatorname{sei}^{130}$. Zunächst steht, wie in den Zeitungen, der memorable actus vom 29. April 1706 im Vordergrund. Die beiden Ächtungspatente werden im vollen Wortlaut eingerückt ${ }^{131}$. Dem Leser wird anschließend erklärt, was Acht und Oberacht reichsrechtlich bedeuten. Dazu nennt der Verfasser mehrere Beispiele von Ächtungen im Laufe der Frühen Neuzeit. Er verweist darauf, dass seit der Wahlkapitulation Karls V. ein förmliches Verfahren zur Ächtung vor dem Kurfürstenrat notwendig ist.

Im folgenden Teil berichtet die Europäische Fama über die feierliche Ächtungsbekanntmachtung in Regensburg am 11. Mai 1706. Auch verweist der

128 Ebd., S. 51.

129 Abdruck des »Manifeste«: Europäische Fama 30 (1705), S. 388-425. Kommentar Sinold von Schütz dazu: S. 423-425.

130 Zur Darstellung der Kurfürstenächtungen: Europäische Fama 49 (1706), S. 11-49.

131 Ächtungspatent gegen den früheren Kurfürsten von Köln, 29. April 1706: Europäische Fama 49 (1706), S. 16-24; Ächtungspatent gegen den früheren Kurfürsten von Bayern, 29. April 1706: Ebd., S. 24-32. 
Verfasser darauf, dass die Patente den Reichstruppen am Oberrhein unter allgemeinem Trommelschlag - vermutlich im Stile, der einer Hinrichtungszeremonie nicht unähnlich gewesen sein dürfte - bekanntgegeben worden sind ${ }^{132}$. Inzwischen wurde der Zeitschriftenredaktion auch das Conclusum des Kurfürstenrats vom 27. November 1705 bekannt, das erst die Grundlage für eine rechtlich einwandfreie Lehnsentsetzung bildete: Der Text wird daher an dieser Stelle angehängt, in Abweichung von der Chronologie, aber im inhaltlichen Kontext sinnvoll plaziert ${ }^{133}$.

Nicht alle Verfasser begnügten sich mit der Schilderung der zeremoniellen Handlung und deren politischer Interpretation. Andreas Stübel verzierte seinen Bericht in Der neubestellt Agent von Haus aus mit der Schilderung von zwei Himmelsereignissen, die in einen legitimatorischen Zusammenhang zur Ächtung der beiden prominenten Reichsmitglieder gerückt wurde. Stübel verweist zunächst auf das schwere Gewitter über Wien in der Nacht vom 30. April zum 1. Mai 1706, bei dem der Turm des Stephansdoms von einem Blitz getroffen wurde. Metaphorisch war es vom Blitzschlag zum Bannstrahl des Kaisers gegen die Wittelsbacher Kurfürsten nur ein kurzer Weg ${ }^{134}$. Auch die Mondfinsternis der Nacht vom 27. zum 28. April und besonders die totale Sonnenfinstenis vom 12. Mai 1706 über Süddeutschland verband Stübel astronomisch und politisch wie folgt miteinander: »[...] daß Zwey grosse Lichter des Reiches und stellae primae magnitudinis vom Himmel gefallen und ihren Schein verlohren $\aleph^{135}$.

Mit der Ächtung wurde das Thema Kurköln und Kurbayern zunächst ad acta gelegt. Der gewesene Kurfürst Max Emanuel tauchte fortan vor allem im Kontext der Kriegsberichterstattung über die französischen Streitkräfte auf, nicht aber mehr im Reich. Sinold von Schütz informiert noch im Jahr 1706 seine Leser darüber, dass die Söhne Max Emanuels nur mehr den Titel »Grafen von Wittelsbach« führen dürfen. Anschließend folgt die moralisierende Wendung, dass der frühere Kurfürst sicher an einen derartigen Ausgang nicht gedacht hätte, als er die Franzosen ins Land geholt und die reichsfreien Gebiete zwischen Ulm und Passau militärisch besetzen ließ ${ }^{136}$. Schon etwas früher hatte er die symbolische Damnatio memoriae am früheren Bayernherrscher vollzogen, indem er darauf verwies, dass in den kaiserlichen Räumen in Wien alle Bilder der beiden exilierten Exkurfürsten entfernt wor-

132 Bekanntgabe der Ächtungspatente: Europäische Fama 50 (1706), S. 110-112.

133 Conclusum des Kurfürstenrats vom 27. Nov. 1705: Europäische Fama 50 (1706), S. 113-115.

134 Andreas StÜBel, Der neubestellt Agent von Haus aus, mit allerhand curieusen Missiven, Brieffen, Memoralien, Staffeten, Correspondencen, und Commissionen, nach Erforderung der heutigen Staats- und gelehrten Welt, Freyburg [=Leipzig] 1704-1707, hier H. 6, 1706, S. 410-435.

135 Ebd., S. 412.

136 Über die »Grafen von Wittelsbach«: Europäische Fama 54 (1706), S. $425 f$. 
den seien. Sein Kommentar, gleichzeitig gegen Frankreich und gegen die Betroffenen gerichtet:

Das [...] ist eine Revange, die von dem Triebe der Menschlichen Natur entspringet, alldieweil niemand gerne das Bild desjenigen lieben oder in seinem Zimmer leiden wird, der uns alles gebrannte Hertzeleid angethan, und biß dato nicht unterlässet, uns den äussersten Verdruß allenthalben zu verursachen, und unsern gäntzlichen Ruin zu suchen $^{137}$.

Auch nach der militärischen Entscheidung von Höchstädt war der symbolisch-kulturelle Konflikt um Max Emanuel nicht zu Ende. Sinold von Schütz berichtet, dass es 1707 eine Kontroverse zwischen den Regierungen in Den Haag und London einerseits und Wien andererseits gegeben habe. Der Grund dafür war, dass die Seemächte die abgesetzten Kurfürsten weiterhin mit »Se. Churfürstl. Durchlauchtigkeit« titulierten, während der Kaiser auf sein höchstrichterliches Recht zur Fürstenabsetzung nach rechtsförmigem Verfahren bestand und dieses auch durch andere europäische Monarchen anerkannt sehen wollte. Die Wiener Regierung verwies darauf, dass die englische wie die niederländische Regierung im Jahr zuvor auf diesen Umstand aufmerksam gemacht worden seien ${ }^{138}$.

Der andere betroffene Wittelsbacher, Josef Clemens, hatte die Zeit im südniederländischen Exil dazu genutzt, um seine Kontakte zur römischen Kurie zu aktivieren. Ein geistlicher Kurfürst konnte nicht nur vom Kaiser, sondern auch vom Papst abgesetzt werden. Ihm war völlig bewusst, auf welche Weise er die Gunst zumindest der einen Seite bewahren konnte: Indem er sich gemäß den Bestimmungen des Konzils von Trient tatsächlich zum Priester und zum Bischof weihen ließ, was die deutschen Reichsbischöfe in der Praxis der Zeit fast ausnahmslos unterließen ${ }^{139}$. Sinold von Schütz berichtet über diese Begebenheit des Jahres 1707 mit folgenden Worten, die er an die Schilderung eines römischen Konsistoriums anschließt:

In eben demselben Consistorio beschloß der Papst, dem gewesenen Churfürsten zu Cölln das bekannte Pallium, nachdem er nunmehro den Priester=Orden angenommen, zu übersenden, weil Se. Päpstliche Heiligkeit wohl wissen, daß dieser unglückliche Fürst eines guten Mantels niemahls so sehr benöthiget gewesen, als anjetzo, um

137 Abhängung der Bilder der abgesetzten Kurfürsten: Europäische Fama 50 (1706), S. 116.

138 Zeremonielle Meinungsverschiedenheiten: Europäische Fama 61 (1706), S. 23.

139 Subdiakonatsweihe 15. August 1706 in Lille, Diakonatsweihe und Priesterweihe 16. August 1706 ebendort: HütTL, Max Emanuel, S. 478. Josef Clemens wollte eigentlich die geistliche Würde niederlegen, ließ sich aber von seinem Bruder und den französischen Beratern zur Weihe überreden, da er nur so materiell abgesichert bleiben konnte: Ebd., S. 477f. Die Weihe zum Bischof erfolgte im Mai 1707 in Mons: Ebd., S. 478. 
diejenigen Fehler zu bedecken, welche er gegen das Römische Reich begangen, und welche ihn aus demselben verbannet haben ${ }^{140}$.

Philipp Balthasar Sinold von Schütz hält sich an die im Reich übliche Terminologie und umschreibt die Wittelsbacher während des folgenden Zeitabschnitts mit »der gewesene Churfürst von Köln« und »der gewesene Churfürst von Bayern«. Von letzterem wird berichet, dass es ihm 1708 misslang, 100 Briefe mit konspirativem Inhalt nach Bayern befördern zu lassen ${ }^{141}$. Mit vergleichbar ironischem Unterton berichtet Johann Ehrenfried von Zschackwitz über den Bayern, als er auf dessen Verurteilung zur Tatenlosigkeit in Paris verweist. Max Emanuel müsse nun der Madame de Maintenon Komplimente machen oder mit dem französischen Dauphin ins Theater gehen.

Jedoch durffte ihn [= Max Emanuel - J.A.] weit mehr soulagiret haben/wann ihm die operisten mit einer opera von wieder einsetzung in das verlorne land/in effectu hätten auffwarten können. Denn/allem ansehen nach/wird es mit diesem Herrn balde dahin kommen/daß er in dessen geschichten den nahmen/Emanuel sine terra, oder ohne land/führet/gleich wie es ehemahls einen König in Engeland gab/der Johannes sine terra hieß/indem er auch über nichts zu befehlen hatte ${ }^{142}$.

Das wichtigste mediale Ereignis im Reich, bei dem die geächteten Wittelsbacher in Erscheinung traten, war die Kaiserwahl Karls VI. im Jahre 1711. In der Europäischen Fama wurde darauf aufmerksam gemacht, dass der frühere Kurfürst Josef Clemens durch mehrere Schreiben an den Kurfürsten von Mainz und an die früheren kurfürstlichen Kollegen um die formgerechte Einladung zur Kaiserwahl gebeten hatte. Sinold von Schütz druckt die Briefe - allerdings ohne genaue Datumsangabe - ab und kommentiert: »Es ist leichtlich zu erachten, dass diese Schreiben von keiner Würckung gewesen ${ }^{143}$. Auch den folgenden Protest Josef Clemens' gegen den Wahlakt kommentiert der Herausgeber der Europäischen Fama als wirkungslos ${ }^{144}$. Dieselbe Konnotation findet sich auch in anderen Zeitschriften, z.B. in Das Neueste von Historisch = und Politischen Sachen. Hier sind auch die beiden Schreiben der Wittelsbacher an die Kurfürsten abgedruckt. Der Verfasser betont die falschen Kurialien: Kurfürsten verwandten im Briefverkehr

140 Zum Priestertum Josef Clemens’ 1707: Europäische Fama 66 (1707), S. 434.

141 Zur Konspiration: Europäische Fama 79 (1708), S. 526f.

$142 \mathrm{Neu}=$ eröffneter Welt $=$ und Staats $=$ Spiegel, hier Bd. 1, S. 682.

143 Bitte Josef Clemens' um Einladung zur Kaiserwahl 1711: Europäische Fama 119 (1711), S. $839 f$.

144 Kommentar zum Protest Josef Clemens': ebd. 120 (1711), S. 928. Der Text des Protests, den der Herausgeber wohl zum Zeitpunkt der Kenntnisnahme des Inhalts noch nicht in Händen hatte, wurde - wie schon erwähnt - im darauffolgenden Heft eingerückt: Ebd. 121 (1711), S. 23-33. 
miteinander die $» I c h \ll-F o r m$, nicht die »Wir«-Form, wie im Schreiben von Josef Clemens. Dies wird in der Zeitschrift als königsmäßige Anmaßung interpretiert, die dem französischen Stil entspreche, der die Wittelsbacher bei ihrem Aufenthalt in Belgien ausgesetzt seien ${ }^{145}$. Der Kurfürst von Mainz würdigte das Schreiben keiner Antwort, sondern schickte es an den Absender zurück ${ }^{146}$. Dieselbe Zeitschrift widerlegte anschließend die Argumente im Schreiben Max Emanuels an die Kurfürsten vom Juli 1711 und bekräftigte die Rechtmäßigkeit der Reichsacht und des Wahlausschlusses des früheren bayerischen Kurfürsten ${ }^{147}$. Dieser Argumentation schließt sich Andreas Stübel an, indem er einen fiktiven Brief zur Frage publiziert, ob die gewesenen Kurfürsten von Köln und Bayern wieder mit dem Reich ausgesöhnt werden könnten und dabei zu einem negativen Ergebnis kommt ${ }^{148}$. Schon vier Hefte (»Expeditionen«) zuvor hatte Stübel die beiden Schreiben der Wittelsbacher vom Sommer 1711 erläutert ${ }^{149}$.

Auch über die Schlussphase des Spanischen Erbfolgekrieges und die währenddessen geschehenen Verhandlungen in Utrecht wurde der Leser der Europäischen Fama umfassend informiert, wobei sich die Informationen auf die betroffenen Nationenabschnitte »Reich«, »Frankreich«, »Spanien«, »England und Niederlande« verteilten. So interpretiert der neue Herausgeber Christian Gottfried Hoffmann die förmliche Abtretung der südlichen Niederlande an Max Emanuel durch Philipp V. von Spanien als französisches Druckmittel, um den Kaiser zu zwingen, die wittelsbachische Herrschaft in Bayern zu restituieren, wollte er nicht auf seine niederländischen Ansprüche verzichten $^{150}$.

In der Kommentierung der Utrechter Friedensverhandlungen tritt die reichspatriotische Gesinnung des neuen Herausgebers der Europäischen Fama deutlich zutage. Hoffmann ereifert sich im Heft 145 über die französischen Zumutungen, wie er sie empfindet. Ein habsburgischer Verzicht auf das spanische Erbe erscheint ihm ebenso unerträglich wie die vorgesehene Restitutio in internum der Wittelsbacher. Wenn diese ihre Länder und Wür-

$145 \gg$ Das Neueste von Historisch $=$ und Politischen Sachen/bestehend In unterschiedenen Urtheilen über die jetzigen Staats $=$, Kriegs $=$ und andere Affairen / [...] 2 , Bd. (H. 1-24), Frankfurt a.M. 1711-1714: Abdruck des Schreibens Josef Clemens' an Kurmainz, 7. Mai 1711: Bd. 1, H. 2, S. 147f.; Schreiben an alle Kurfürsten, 7. Mai 1711: S. 148f.

146 Ebd., Bd. 1, H. 2, S. 150.

147 Ebd., Bd. 1, H. 3, S. 208-213.

148 Andreas StüBEL, Der mit allerhand Staats=, Friedens $=$, Kriegs $=$, Hof $=$, Literatur $=$ und Religions $=$ wie auch Privat $=$ Affairen beschäftigte Secretarius [...], hier Bd. 1, Expedition 11, Brief 120, S. 985-989.

149 Ebd., Bd. 1, Expedition 7, Brief 89, S. 620-627.

150 Abtretungsdekret Philipp V. hinsichtlich der südlichen Niederlande an Max Emanuel, 2. Jan. 1712: Europäische Fama 136 (1711), S. 347-350. Verschiedene Zusatzkonditionen wegen der katholischen Konfession, der Achtung der Landesprivilegien sowie der Übernahme spanischer Schulden und Pensionen stehen in Europäische Fama 137 (1712), S. 419-423. 
den ungeschmälert zurückerhielten und sogar noch auf eine Entschädigung hoffen könnten, so der Kommentar, dann würde künftig kein Reichsfürst mehr vor Verrat und Gewalt zurückschrecken. Von einer kaiserlichen Autorität könne unter derartigen Umständen kaum noch die Rede sein ${ }^{151}$.

Ein Jahr später musste Hoffmann seinen Lesern dennoch mitteilen, dass es auf die befürchtete frankreichfreundliche Umsetzung der bayerischen Restitution hinauslief. Zwar war die künftige Zugehörigkeit der Oberpfalz und die Reihenfolge der beiden Kurwürden Bayerns und der Pfalz noch unklar, doch konnte der Herausgeber der Europäischen Fama immerhin von einer vielversprechenden kaiserlichen Gegenstrategie berichten: Am Wiener Hof hatte man eine Liste zusammengestellt, die alle Schäden beinhaltete, die die Bayern zwischen 1702 und 1704 in Süddeutschland angerichtet hatten. Diese Summen wollte man offenbar mit den bayerischen Entschädigungsansprüchen verrechnen ${ }^{152}$. Im Detail sollte sich die Restitution noch schwieriger erweisen, als zunächst beschrieben. Die österreichische Administration in Bayern hatte in den vorangangenen 10 Jahren zahlreiche Veränderungen im bayerischen Grenz- und Privilegienzustand vorgenommen, die nun alle wieder rückabgewickelt werden mussten: Nachbarn mussten Gebietsabschnitte abtreten, eingesessene Adlige auf die ihnen übertragenen Rechte verzichten, und die Reichsstadt Donauwörth verlor ihre Reichsfreiheit ein weiteres Mal ${ }^{153}$. Eine bruchlose Restitution ging den reichsständischen Gesandten in Regensburg denn doch zu weit: Christian Gottfried Hoffmann berichtet davon, dass der frühere bayerische Gesandte Baron von Zindt Sitz und Stimme für seinen Herrn im Kurfürstenrat wieder in Besitz nehmen wollte mit der alten Vollmacht von vor 1704. Die anderen kurfürstlichen Gesandten bedeuteten ihm, er solle sich eine neue Vollmacht ausstellen lassen ${ }^{154}$.

Ein einziges Mal nötigt die französische Hartnäckigkeit zugunsten der Wittelsbacher dem Herausgeber der Europäischen Fama auch einen positiven Kommentar ab: »Inzwischen gereichet es Franckreich zu grosser Ehre, dass es diese zwey Herren, die ihm so getreulich wider den Kayser und das Reich angehangen, so völlig restituiren hielft [...] $\ll^{155}$.

Die tatsächliche Besitzergreifung Münchens durch Bevollmächtigte Max Emanuels am 18. Januar 1715 wird im Neu=eröffneten Welt $=$ und Staats $=$ Spiegel des Johann Ehrenfried Zschackwitz erwähnt, eine Zeit-

151 Kommentar Hoffmanns zu den Utrechter Verhandlungen: Europäische Fama 145 (1713), S. $77-83$.

152 Der Bericht repräsentierte den Verhandlungsstand vom 15. Juni 1714: Europäische Fama 160 (1714), S. 305f.

153 Vgl. die lange Liste mit Einzelpunkten: Europäische Fama 167 (1715), S. 936-945.

154 Ungeachtet aller Kritik an den Wittelsbacherkurfürsten bringt Hoffmann für Zindt Verständnis auf: Der Gesandte wird als Opfer der früheren »Fataliteten des Chur-Hauses Bayern« angesehen: Europäische Fama 173 (1715), S. 399f.

155 Europäische Fama 167 (1715), S. 941. 
schrift, die erst 1709 einsetzt, als die Thematik Max Emanuel gerade nicht sehr aktuell ist. Da Zschackwitz die Aktenpublikationen in den Vordergrund rückt, besteht für ihn keine besondere Veranlassung, sich dem gewesenen Kurfürsten von Bayern oder seinem Kölner Bruder zuzuwenden, die zu dieser Zeit nicht in der Lage waren, reichsrechtlich erhebliche Quellen zu produzieren. Erst die Rückkehr der Wittelsbacher hätte zum Thema werden können, wenn die Zeitschrift über das Jahr 1716 hinausgeführt worden wäre. So wurde nur der Zusammenhang betont, dass Frankreich die Übergabe von München (Kaiser an Bayern) zeitgleich mit der von Freiburg (Frankreich an den Kaiser) durchführen lassen wollte. Ähnliche Junktims wurden auch zwischen Ingolstadt und Altbreisach sowie zwischen der Oberpfalz und Kehl geschlossen. Größere Bedeutung haben die Übergaben in Zschackwitz' Zeitschrift aber nicht ${ }^{156}$. Erkennbar größere Vorsicht in der Bewertung der wittelsbachischen Restitutionen ist auch bei Andreas Stübel zu erkennen. Nach seiner früheren Kritik an den beiden Kurfürsten und der Befürwortung von deren Ächtung 1706 äußert sich der Herausgeber des Staats $=$ Secretarius nur knapp und sachlich zum Faktum der erfolgten Restitution durch die Friedensschlüsse von Rastatt und Baden unter Vermeidung jeglicher Wertungen ${ }^{157}$.

Bereits etwas früher als sein bayerischer Bruder war Kurfürst Josef Clemens wieder in seine Lande zurückgekehrt. Aus den Niederlanden kommend, betrat er zunächst bei Lüttich heimischen Boden und wurde in seiner Kathedralstadt mit einem prachtvollen Introitus empfangen, dessen Kosten Hoffmann auf mehr als 100.000 Rtl. schätzt. Berichtet wird von personellen Veränderungen in der Administration, wo der neue und alte Landesherr eigene Vertraute einsetzte. Von einem Strafgericht war allerdings keine Rede ${ }^{158}$. Wenig später zeigten sich die beiden Wittelsbacher Brüder der gesamten Reichsöffentlichkeit in München, als Josef Clemens seinen Bruder besuchte. Die Feierlichkeiten im Herbst 1715 sollten europaweite Ausstrahlung entfalten, und hinsichtlich des Medieninteresses dürfte der Plan aufgegangen sein. Der restituierte Kölner Kurfürst sorgte für höchste Anerkennung dadurch, dass er persönlich eine Messe zelebrierte und eine eigene Predigt hielt. In der Europäischen Fama wird darauf verwiesen und betont, es seien »wohl ganze Secula hingegangen «, in denen kein Reichsfürst persönlich gepredigt habe eine protestantische Kritik daran, dass der Episkopat im Reich noch immer die Regularien des Konzils von Trient hinsichtlich der Amtsanforderungen an Bischöfe ignorierte ${ }^{159}$.

156 [Zschackwitz], Neu=eröffneter Welt $=$ und Staats $=$ Spiegel, hier Bd. 7, 1715, H. 78, S. 549f.

157 STÜвEL, »Staats=Secretarius«, Bd. 3, Expedition 25, Brief 292, S. 59-63.

158 Zu Lüttich: Europäische Fama 165 (1715), S. 797f.

159 Josef Clemens in München, September 1715: ebd., 1715, H. 177, S. 669-671. 
Nach ihrer Restitution waren beide Kurfürsten allerdings wieder voll in die politische Berichterstattung integriert, als wäre nichts geschehen. Politische Publizistik war ihrem Selbstverständnis nach keine moralische Veranstaltung, sondern eine aktualitätsbezogene Informations- und Unterhaltungsangelegenheit. So fehlte bei der Darstellung der Belehnung von Josef Clemens und Max Emanuel durch Kaiser Karl VI. im April resp. Mai 1717 im Historischen Mercurius jeglicher Hinweis darauf, dass dieser zeremonielle Akt die beiden Wittelsbacher erst im vollen reichsrechtlichen Sinne wieder zu regierenden Kurfürsten machte. Die Kurzmitteilung unterscheidet sich nicht von vergleichbaren Zeremonialmitteilungen, wie sie zu hunderten in den Zeitschriften zu finden sind. Der »Actus« fand wieder in der kaiserlichen Burg in Wien statt - vermutlich erneut in der Ritterstube - wobei die kaiserlichen Minister und die Gesandten der Mächte und der Reichsstände zugegen waren. Auch schreibt der Berichterstatter von »einer ungemeinen Menge Volcks«, die sich vor der Burg sammelte ${ }^{160}$. Wichtiger als Spekulationen darüber, wieviele von den Anwesenden 11 Jahre zuvor auch der Ächtungszeremonie beigewohnt hatten, war der Zeitschrift der Hinweis darauf, dass Max Emanuel ausdrücklich mit dem Reichserztruchsessenamt belehnt worden war. Wer reichsrechtlich bewandert war, konnte dies als Andeutung verstehen, dass die Frage nach dem Reichsvikariat und seiner Ableitung künftig wieder eine Rolle spielen würde, denn die Friedensschlüsse von Rastatt und Baden hatten dazu genauso wenig geregelt wie der Westfälische Friede zuvor.

David Fassmann nahm sich der Geschichte der Wittelsbacher Dynastie ebenfalls an, allerdings mit zeitlichem Abstand innerhalb seiner Gespräche im Reiche der Todten ${ }^{161}$. Die Darstellung war ebensogut ein Historienwerk wie eine Zeitschrift; hier wird sie aus formalen Gründen dem Zeitschriftenkapitel zugewiesen. Fassmann geht auf die Ächtungsepisode der Wittelsbacher dreimal ein, in seinen Darstellungen über Kaiser Josef I. ${ }^{162}$, über Kurfürst Josef Clemens ${ }^{163}$ und über Kurfürst Max Emanuel ${ }^{164}$. Zwar war das Thema für alle Beteiligten immer noch brisant, aber die Protagonisten waren inzwischen gestorben und daher unmittelbare Repressalien von hoher

$160 »$ Historischer Mercurius worinnen das Wichtigste, was zu disen Zeiten in ganz Europa vorgehet, [...] zusammengetragen und entworffen wird«, 84 Tl. in 7 Bd., Augsburg 1712-1718, hier Jg. $1717 / 1$, S. 426 f.

161 [Fassmann], Gespräche im Reiche der Todten, 15 Bd. (Entrevue 1-240); dreiteiliger Schlussband 16, Leipzig 1718-1741.

162 Gespräch zwischen Papst Innozenz XI. und Kaiser Josef I.: ebd., Bd. 4, 1722, Entrevue 49, S. $3-80$.

163 Gespräch zwischen König Ludwig IX. dem Heiligen und Kurfürst Josef Clemens von Köln: ebd., Bd. 5, 1724, Entrevue 71, S. 467-542.

164 Gespräche zwischen Herzog Karl dem Kühnen von Burgund und Kurfürst Max Emanuel von Bayern: ebd., Bd. 7, 1727, Entrevuen 105-107, S. 661-719, 725-808 u. 813-912. 
Seite nicht mehr akut zu befürchten. Jedenfalls musste sich Fassmann an eine ehrerbietige Berichterstattung halten: Die Wittelsbacher hatten durch ihre Restitution auch ihre Ehre wiedererlangt und durften nun nicht mehr als Reichsfeinde dargestellt werden, wie dies in der Europäischen Fama während ihrer Ächtung möglich gewesen war. In der 49. Entrevue zwischen Kaiser Josef I. und Papst Innozenz XI. schildert Fassmann daher zwar ausführlich die Goldene Bulle von 1356 als wichtigste Verfassungsgrundlage des Reiches und auch den detaillierten Ablauf des kaiserlichen Krönungszeremoniells $^{165}$, doch die Ächtungszeremonie der Wittelsbacher Kurfüsten kommt nicht vor. Damit dem Leser aber das Zeremoniell einer Kurfürstenabsetzung nicht verborgen bleibt, wird das Beispiel des Herzogs von Mantua gewählt. Der Herzog hatte 1708 sein Amt verloren, und die Prozedur, die in Wien in Abwesenheit des Delinquenten vonstatten ging, dürfte nach dem Vorbild der Absetzung der Wittelsbacher am 29. April 1706 ausgerichtet worden $\operatorname{sein}^{166}$. Das vorige oder weitere Verhältnis Josefs I. zu den Wittelsbachern spielt bei Fassmann keine herausragende Rolle. Der Schwerpunkt der Zeitschrift lag auf der europäischen Dimension, so dass sich trotz des kurzen Lebens genug Stoff für die autobiographischen Schilderungen des Kaisers ergab. Auch stellte sein Gesprächspartner keine Fragen nach Bayern, sondern seine Gedanken drehten sich um politisch-religiöse Fragen, die in höheren Sphären angesiedelt waren.

Dass Fassmann den Kölner Erzbischof Josef Clemens ausgerechnet mit einem mittelalterlichen französischen König disputieren lässt, überrascht: Der Rangunterschied scheint auf den ersten Blick als zu groß. Nach der Lebensschilderung des Königs bekommt auch der Kölner Erzbischof Gelegenheit, auf seine Biographie einzugehen ${ }^{167}$. Im Mittelpunkt steht dabei die enge Kooperation mit Frankreich, mit einem Amtsnachfolger Ludwigs IX., der sich dafür natürlich sehr interessierte. Fassmann nutzt die Gelegenheit, Josef Clemens seine anhaltende Renitenz gegen die kaiserlichen Proteste wegen seiner Frankophilie schildern zu lassen. Der Kaiser hatte bereits unmittelbar nach dem Eintritt des spanischen Erbfalls den Grafen Schlick nach Bonn geschickt, um den Kurfürsten von militärischen Unternehmungen abzuhalten. Josef Clemens hingegen agitierte gegen das Ächtungsverfahren gegen den Herzog von Mantua. Er stellte 2.000 Reiter und 4.000 Fußsoldaten auf, die auf die Festungen Bonn, Kaiserswerth, Rheinberg und Lüttich verteilt wurden. Wegen der nötigen Kontributionsleistungen entstand ein heftiger Konflikt zwischen dem Kurfürsten und dem Kölner Domkapitel. Die Aufnahme französischer Soldaten sollte helfen, auch diesen Kon-

165 Ebd., Bd. 4, 1722, Entrevue 49: Goldene Bulle S. 16-31; Krönungszeremoniell S. 38-55.

166 Ebd., Bd. 4, 1722, Entrevue 49: Kaiserliche Ächtungszeremonie S. 84-86.

167 Ebd., Bd. 5, 1724, Entrevue 71: Biographie Josef Clemens' S. 531-542. 
flikt zu meistern. Ein kaiserlicher Befehl, die Truppen wieder außer Landes zu schaffen, wurde vom Kurfürsten ignoriert. Im Winter 1702/03 eroberten englische und niederländische Truppen das Kurfürstentum. Josef Clemens floh in die südlichen Niederlande, die französisch besetzt waren. Dort vernahm er seine Absetzung als Kurfürst, die er nicht anerkannte, zu deren Details er sich im Fassmann'schen Dialog auch nicht äußern wollte. Wichtiger war für ihn seine Priesterweihe, die Weihnachten 1706 vollzogen wurde, um sich der fortdauernden Unterstützung der Kurie zu versichern ${ }^{168}$. Hier bot sich ein weiterer Anknüpfungspunkt zu Ludwig dem Heiligen: Das Verhältnis von Religiosität zu politischer Opportunität. Für Josef Clemens ging die Rechnung auf: Er wurde nicht als Erzbischof abgesetzt, sondern das Domkapitel vertrat ihn nur, statt einen neuen Oberhirten zu wählen. In den folgenden Jahren hielt sich Josef Clemens in Rijssel und Valenciennes auf.

Die in diesem Zusammenhang interessanteste Darstellung Fassmanns betraf Kurfürst Max Emanuel von Bayern. Dem Wittelsbacher wurden für sein abwechslungsreiches Leben nicht nur drei Entrevuen gewidmet, sondern mit Karl dem Kühnen auch ein erstklassiger, militärisch schlagkräftiger Gesprächspartner zugewiesen. Für beide Herrscher galt, dass sie trotz allen äußeren Glanzes, den sie in ihrer Gegenwart und in der Historie ausstrahlten, dennoch auf eine sehr wechselvolle militärische Bilanz zurückblicken mussten. Immerhin traute sich Fassmann bereits 1727, ein Jahr nach dem Tod des Kurfürsten, über ihn zu schreiben. Heldentum und Militaria stehen naheliegenderweise im Dialog im Vordergrund. In den Entrevuen 106 und 107 bekommt Max Emanuel Gelegenheit, von seinen Erfahrungen aus der Zeit des Spanischen Erbfolgekrieges zu berichten. Er interpretiert die ausgetragenen Konflikte nicht aus der Sicht des Reichsrechts, sondern aus der Dynastieperspektive: »Zwischen denen Häusern Oesterreich und Bayern hat, von undencklichen Jahren her, eine ziemliche Jalousie geherrschet «169. Der dynastische Zweikampf mit dem jeweiligen Haupt des Habsburgerhauses - der allem Anschein nach das Selbstverständnis des Kurfürsten sehr treffend wiedergibt - lässt ihn vor den Augen der Nachwelt besser dastehen, z.B. beim Handstreich auf Ulm im September $1702^{170}$. Schon 1703 geriet Bayern in die Defensive, als Reichs- und Kaisertruppen nach Bayern einmarschierten, auch wenn der Schlachtenverlauf unentschieden blieb. Max Emanuel nahm in der zweiten Jahreshälfte Augsburg und Passau ein und belagerte den Reichstag in Regensburg. Das Jahr 1704 mit der Niederlage bei Höchstädt sowie die Ächtung 1706 will der Kurfürst im Dialog nur streifen -

168 Ebd., Bd. 5, 1724, Entrevue 71: Priesterweihe Josef Clemens' S. 535.

169 Ebd., Bd. 7, 1727, Entrevue 106: Rivalität zwischen den Dynastien Wittelsbach und Habsburg S. 807.

170 Ebd., Bd. 7, 1727, Entrevue 107: Einnahme Ulms S. 891. 
es handele sich um »lauter verhaßte Dinge«, die keiner ausführlicheren Erörterung mehr bedürften ${ }^{171}$. Die weitere Biographie handelt daher nicht mehr von den Begebenheiten, die Max Emanuel in der Zeit bis zu seiner Restitution erleben musste. Die große Geste, der Krieg in den südlichen Niederlanden, war wesentlich spannender - und für seinen Gesprächspartner natürlich viel naheliegender, handelte es sich doch um dessen frühere Herrschaftsgebiete. So bleibt auch das glückliche Ende des Exils Max Emanuels ohne ausführliche Würdigung. Kein politischer Triumph wird angedeutet, der auch nur auf Fürsprache eines Franzosenkönigs zustandekam.

\subsection{Darstellung des Konflikts in den Historienschriften}

Von Kurfürst Max Emanuel ist bekannt, dass er sich in künstlerischer Hinsicht Denkmäler hat setzen lassen. In historiographischer Hinsicht hat er das immerhin vorgehabt ${ }^{172}$. Schon in den 1670er Jahren stand der savoyische Hofhistoriograph Thomas Blanc auch im Dienst des Wittelsbachers, für den er 1680 eine Histoire de Bavière in vier Bändchen herausbrachte. Blanc erhielt dafür aus bayerischen Kassen mindestens 1.200 fl., verteilt auf zwei Tranchen $^{173}$. Über längere Zeit beschrieb Johann Franz Diani die Feldzüge des Kurfürsten. Diani wurde seit 1671 mit jährlich 300 fl. für diesen Teil seiner Arbeiten entlohnt. Später stieg er auf der militärischen Karriereleiter bis zum Obristen auf. Der Feldhistoriograph dürfte neben der Fertigung eigener Schriftsätze auch als Ansprechpartner für die europäische Presse gedient haben, die über die bayerischen Militäraktionen stets gut unterrichtet war. Selbst während der österreichischen Besatzungszeit forschte Diani in München. Sein Gehalt betrug nun $700 \mathrm{fl}$. jährlich. Allerdings blieb es bei Projekten. Bislang ist keine einzige gedruckte Zeile historiographischen Textes ihm direkt zugeordnet worden ${ }^{174}$. Ob er an den bayerischen Kriegsmanifesten und Selbstrechtfertigungen mitgewirkt hat, ist zu vermuten, aber nicht erwiesen.

Die zeitgenössische historiographische Wahrnehmung des Kurfürsten teilte sich in bayerische Patrioten, die ihn in Schutz nahmen, und Reichspatrioten, die ihn als Verräter brandmarkten. Das bedeutendste Werk der Anhänger Max Emanuels, die Kollektivbiographie der bayerischen Kurfürsten durch den Historiographen Christian Nikolaus Naumann, geriet gera-

171 Ebd., Bd. 7, 1727, Entrevue 107: Höchstädt und die Folgen S. 910.

172 Vgl. dazu Benz, Zwischen Tradition und Kritik, S. 505-514.

173 Thomas Blanc, Histoire de Bavière, 4 Bd., Paris 1680. Benz verweist auf eine anzunehmende Vermittlung durch Kurfürstin Henriette Adelaide hin, der Mutter des Kurfürsten, die aus Savoyen stammte: Benz, Zwischen Tradition und Kritik, S. 505.

174 Ebd., S. 506f. Benz verweist auf Exzerpte im Kriegsarchiv; besonders weit können demnach die Arbeiten nicht gediehen sein. 
dezu zur Apologie. Das Werk wurde aber nur als Manuskript überliefert und blieb ungedruckt, stand daher der zeitgenössischen Öffentlichkeit nicht zur Verfügung, allerdings wohl späteren Historikern ${ }^{175}$. Maßvoll kritisch hingegen urteilte der anonyme Verfasser der Druckschrift Des Großen Feld-Herrens Eugenii Hertzog von Savoyen und kayserlichen General-Lieutenants Helden-Thaten, indem er die Verstöße des Wittelsbachers gegen Kaiser und Reich seinem Feldherrengenie gegenüberstellte ${ }^{176}$. Max Emanuel erschien als Opfer französischer Verführungskunst. Schärfer fiel das Verdikt bei Gottlieb Eustachius Rinck aus, der 1713 eine Biographie über Kaiser Leopold I. herausbrachte. Darin wurde zwar auch Max Emanuels kriegerische Leidenschaft und Kunstfertigkeit behandelt, doch neben dem Reichsverrat wurden ihm auch organisatorische Sorglosigkeit, Vergnügungssucht insbesondere mit Mätressen sowie seine Schwäche im Umgang mit Geld zur Last gelegt ${ }^{177}$.

Das Theatrum Europaeum griff die bayerischen Militäraktionen detailliert auf, wobei es sich auf die inzwischen hoch entwickelte aktuelle Berichterstattung in Zeitungen und Zeitschriften stützen konnte. In den beiden Teilen des 16. Bandes wurden die kurkölnischen Einquartierungen französischer Truppen sowie die Besetzungen der oberdeutschen Reichsstädte von 1702 bis 1704 nachgezeichnet ${ }^{178}$. Auch die Auseinandersetzungen zwischen Bayern und dem Reichstag wurden dargestellt, wobei das Theatrum verhältnismäßig sachlich blieb, ohne aber vom reichspatriotischen Standpunkt abzurücken ${ }^{179}$. Im 17. Band war die Schlacht bei Höchstädt der Redaktion eine vierseitige Darstellung wert. Die Ächtungszeremonie der Wittelsbacher Kurfürsten im April 1706 wurde ebenso präsentiert wie der schon zuvor mitgeteilte Ausschluss der Gesandten beider Delinquenten vom Reichstagsgeschehen ${ }^{180}$.

Die zeitnächste Historiendarstellung geschah durch Anton Fabers Europäische Staats-Cantzley. In Band 7, der 1703 herauskam, wurden bereits 23

175 Christian Nikolaus Naumann, Leben und Werk der Kurfürsten von Bayern, Manuskript Leipzig 1730 (Bayerische Staatsbibliothek München, Cgm 2832), zit. nach SснмidT, Max Emanuels Bild in der Geschichtsschreibung, hier S. 461.

$176 »$ Des Großen Feld-Herrens Eugenii Hertzog von Savoyen und kayserlichen General-Lieutenants Helden-Thaten«, o.O. 1710, zit. nach SснміDт, Max Emanuels Bild in der Geschichtsschreibung, S. 459.

177 Gottlieb Eustachius RincK, Leopolds des Großen Röm. Kaysers wunderwürdiges Leben und Thaten aus geheimen Nachrichten eröffnet, Cölln 1713, vor allem S. 251f., zit. nach SснміDT, Max Emanuels Bild in der Geschichtsschreibung, S. 460.

178 [Carl Gustav Merians Erben (Hg.)], Theatri Europaei Continuati Sechszehender Theil. Oder Außführlich fortgeführte Friedens- und Kriegsbeschreibung [...].

179 Susanne Friedrich konstatiert eine scharfe Wendung des Theatrum Europaeum im 16. Band gegen Bayern wegen der Bündnissituation mit Frankreich: FRIEDRICH, Drehscheibe Regensburg, S. 486.

180 [Daniel Schneider (Hg.)], Theatri Europaei Siebenzehender Theil Oder Außführlich fortgeführte Friedens $=$ und Kriegs=Beschreibung [...] von dem 1704ten Jahr, biß Ausgangs 1706ten [...], 3 Teilbd., Frankfurt a.M. 1718. - Schlacht bei Höchstädt: Bd. 17/I, S. 93-97; Reichsacht gegen die Wittelsbacher: Bd. 17/I, S. 16-18. 
Dokumente zu bayerischen Kriegsaktionen in Oberdeutschland sowie 55 Dokumente zu Reichsmaßnahmen gegen Frankreich, Bayern und Kurköln abgedruckt ${ }^{181}$. Zur Kommentierung reichte dabei die Zeit nicht, auch war das Format der Edition nicht darauf abgestellt. Bemerkenswert ist dennoch, dass der gesamte Konflikt im Reich bereits vor der Entscheidungsschlacht von Höchstädt komplett verbreitet worden war, nicht nur in Gestalt kurzer Zeitungsnotizen, sondern in dokumentierter Form aus den betroffenen Kanzleien. Die Unbotmäßigkeit des Bayern-Kurfürsten war damit allgemein bekannt, bei Fürsten, Reichsgerichten, allen Kanzleien, an den Juristischen Fakultäten, durch die Zeitschriften bei allen Gebildeten und durch die Zeitungen beim Rest der lesefähigen und politisch interessierten Bevölkerung.

In Band 8 setzte sich die Berichterstattung in breiter Form fort: Auf mehr als 380 Seiten wurden Dokumente zu den bayerischen Gewalttaten präsentiert, der Krieg von 1703 in Oberdeutschland und Tirol war damit nicht nur das beherrschende Thema der Publizistik, sondern auch der Staatsrechtswissenschaft. In Band 9 druckte Faber 29 Dokumente ab, die sich mit der Frage der Regensburger Neutralität angesichts der bayerischen Militärbesetzung befassten. 1704 nach der Besetzung der Stadt hatte sich die kurmainzische Reichstagsdirektion unter kaiserlicher Beteiligung mit Bayern über eine hinreichende Sicherheit des Reichstagsbetriebs verständigen wollen. Kurfürst Max Emanuel ließ die Verhandlungen allerdings durch viele Forderungen immer weiter in die Länge ziehen. Die Gespräche waren selbst im Juli 1704, einen Monat vor der Schlacht bei Höchstädt, noch zu keinem Ergebnis gelang $\mathrm{t}^{182}$. Die Ächtung der Wittelsbacher wurde in Band 11 abgehandelt, wobei Faber das Conclusum des Kurfürstenrats vom November 1705, die Ächtungspatente und einige weitere Dokumente veröffentlichte ${ }^{183}$.

Im Historischen Kern, einer kurzlebigen Historienschrift von 1705 bis 1710, blickte der Redakteur Eberhard Werner Happel aus der Distanz von

181 Anton Faber [= Christian Leonhard Leucht], Europäische Staats-Cantzley, darinnen zum Behuff der neuesten politischen-, Kirchen- und Reichshistorie [...] abgehandelt worden und zum Vorschein gekommen ist, 115 Bd., Frankfurt a.M.,/Leipzig/Nürnberg 1697-1760, hier Bd. 7 (1703), S. 551-633: 23 Dokumente zu bayerischen Kriegsaktionen in Oberdeutschland 1700-1703; ebd., S. 634-854: 55 Dokumente mit Reichsschlüssen gegen Frankreich, Bayern und Kurköln 1702.

182 Ebd., Bd. 9, S. 383-489.

183 Ebd., Bd. 11, S. 608-644. Im Einzelnen: 1. Conclusum des Kurfürstenrats wegen des Banns/der Privation gegen Josef Clemens von Köln und Max Emanuel von Bayern, 27. November 1705: S. 608-611. 2. Relation über »Actus Declarationis« zum Bann gegen die Wittelsbacher, 29. April 1706: S. 611-616. 3. Ächtungspatent gegen Kurfürst Josef Clemens von Köln, 29. April 1706: S. 616-627. 4. Ächtungspatent gegen Kurfürst Max Emanuel von Bayern, 29. April 1706: S. 627-638. 5. Kaiserliches Publikationsreskript an den Magistrat von Regensburg, 30. April 1706: S. 639. 6. Extractus Protokolli des Reichshofrats über die Publikation einer Reichs-Achts-Erklärung, 4. Mai 1706: S. 640-641. 7. Kaiserliches Kommissionsdekret Kaiser Josefs I. über die Ächtung der Wittelsbacher, 10. Mai 1706: S. 641-644. 
vier bis acht Jahren auf die Geschehnisse um den gewesenen Bayernkurfürsten zurück ${ }^{184}$. Das Werk entstand im Hamburger Verlag Thomas von Wiering und profitierte daher vom Informationsfluss der Hamburger Zeitungsproduktion. Im Band von 1706 wurde die Ächtung der Wittelsbacher Kurfürsten unter dem Monat April vermeldet ${ }^{185}$. Im einleitenden Kommentar verurteilt Happel die Politik der beiden gewesenen Herrscher - Max Emanuel und Josef Clemens von Köln -, indem er ihnen »unverantwortliche[n] Proceduren « zur Last legt. Anschließend druckt er den bekannten Bericht aus Wien ab, der auf dem Wiener Diarium beruht.

Johann Ehrenfried Zschackwitz arbeitete den Konflikt zwischen dem Reich und Max Emanuel von Bayern in seine Biographie über Kaiser Josef I. ein $^{186}$. Dabei fehlte nicht der Hinweis auf die Stationierung von 15.000 französischen Soldaten im Kurfürstentum Köln, eine Maßnahme, die Kurfürst Josef Clemens angelastet wurde und die dem bayerischen Militärengagement zugunsten Frankreichs vorausging. Im Reich sei dagegen ein so großer Widerstand entstanden, dass schon 1702 der kurkölnische Gesandte Baron Zeller genötigt worden sei, sein Stimmrecht im Kurfürstenrat ruhen zu las$\operatorname{sen}^{187}$. Zschackwitz druckte dazu zahlreiche Dokumente.

Die kurbayerischen Militäraktionen von 1702 bis 1704 schilderte Zschackwitz ebenso wie die schriftlichen Rechtfertigungen Max Emanuels unter Abdruck der Deduktionen ${ }^{188}$. Nach der Erwähnung des Ausschlusses des Barons von Zindt vom Regensburger Reichstag vom 28. August 1704 geht Zschackwitz ausführlich auf die Ächtung Max Emanuels und der »Privation« seines Bruders am 29. April 1706 ein. Hier wurden sowohl die Zeremonie detailliert geschildert als auch die Absetzungspatente abgedruckt ${ }^{189}$. Zschackwitz weist darauf hin, dass die öffentliche Verkündung durch die Herolde zunächst auf dem Äußeren Burgplatz stattfand, anschließend auf dem Graben und auf dem Neumarkt.

In den Heillgen Römischen Reichs-Staats Acta des Christian Leonhard Leucht sind sowohl die Auseinandersetzungen von Kurfürst Josef Clemens von Köln als auch seines Bruders Max Emanuel mit dem Reich durch zahl-

184 [Eberhard Werner HAPPEL], »Des Historischen Kerns oder so genannten kurtzen Chronica Vierdter Theil Zweytes Stück Fürstellend Die merckwürdigste Welt= und Wunder=Geschichte/So sich in und ausser Europa durch die Welt hin und wieder von Ao. 1705 biß 1709 [...] begeben haben [...] beschrieben von Everhardo Guerno Happelio«, Hamburg 1710.

185 Ebd., Jg. 1706, S. 65-68.

186 Johann Ehrenfried Zschackwitz, Leben und Thaten Josephi I. Römischen Kaysers, samt der unter seiner Majestät glorwürdigsten Regierung vorgefallenen Reichs-Historie. Alles mit behörigen Documenten bekräfftiget [...], Leipzig 1712.

187 Ebd., S. 47-70.

188 Ebd., S. 84-102.

189 Ebd., S. 119-138. 
reiche Dokumente abgebildet ${ }^{190}$. In Band 3 stehen die militärischen Zusammenstöße in Oberdeutschland im Vordergrund, während in Band 4 die politischen Auseinandersetzungen auf dem Reichstag dominieren. Eine Unterscheidung zwischen denjenigen Dokumenten, die in den offiziellen Sitzungen verhandelt worden sind und denen, die auch auf dem offenen Druckwerkemarkt vertrieben wurden, kann nicht hergestellt werden ${ }^{191}$. In Band 5 nehmen die Schlacht bei Höchstädt und die dazugehörigen Dokumente 150 Seiten ein. Dabei greift der Redakteur zurück auf das französischsprachige Manifeste Max Emanuels vom 19. Februar 1702, in dem der Wittelsbacher seine Berechtigung zum gewaltsamen Konfliktaustrag dargelegt hatte. Auch die französischsprachige Response vom 19. März 1702, ein Dokument eines unbekannten Verfassers, in dem alle Argumente einzeln widerlegt werden, wird gedruckt ${ }^{192}$.

Eine ausgiebige Kommentierung der Geschehnisse des frühen 18. Jahrhunderts aus reichsrechtlicher Sicht stellen die Electa Juris Publici dar, die Georg Melchior von Ludolf zwischen 1709 und 1725 herausbrachte ${ }^{193}$. Im Vordergrund stehen hier nicht die militärischen Auseinandersetzungen, sondern die Verhängung der Reichsacht gegen die Wittelsbacher. Ludolf schließt sich dabei denjenigen an, die von einem Mitwirkungsrecht aller Reichsstände ausgehen ${ }^{194}$. Ludolf stellt sich damit nicht nur auf den kurbayerischen Standpunkt, sondern verficht eine Anschauung, die im Rahmen der Verhandlungen zur »ständigen Wahlkapitulation« (Perpetua) 1711 zur Rechtsnorm für das Reich werden sollte.

Im siebten Band kommt Ludolf ein weiteres Mal auf die Lage Bayerns zu sprechen. Er behandelt die Restitution Bayerns und die damit verbundenen Komplikationen. Dabei resümiert er die Geschichte der Kur-Translation an Bayern 1623/48. Diese Regelung, die den Pfälzer Kurfürsten als Preis für ihre unvollkommene Restitution 1648 abgepresst worden sei, wurde durch die Ächtung Max Emanuels 1706 revidiert. Die Fünfte Kur fiel an Kurfürst Johann Wilhelm zurück, die Achte Kur erlosch als zweite wittelsbachische Kur, wofür Kurfürst Georg Ludwig von Hannover von der neunten an die achte Stelle im Kurfürstenkolleg vorrückte. Damit bekam er das Erzschatz-

190 Leucht [Pseud. Cassander Thucelius], Des Heillgen Römischen Reichs-Staats Acta von itzigen 18. Seculo sich anfahend, in welchen nicht allein, die bey annoch währenden Reichs-Tag eingereichte Staats-Schrifften [...] enthalten [...] In gute Ordnung gebracht [...] von Cassandro Thucelio. Kurkölnische Dokumente: Bd. 2, S. 531-621; kurbayerische Dokumente: Bd. 2, S. 613-642.

191 Militäraktionen: ebd., Bd. 3, S. 371-670; Reichstagsdiskussionen: ebd., S. 29-156.

192 »Manifeste«: ebd., Bd. 5, S. 25-63; »Response«: ebd., S. 81-166.

193 Von Ludolf, Electa Juris Publici. Worinnen Die Vornehmsten Staats-Affairen in Europa/Besonders in Teutsch=Land/aus bewährtesten Actis publicis [...] recensiret werden. 194 Ebd., Bd. 1 (1709), S. 591-600. 
meisteramt, das durch das Revirement verwaist war ${ }^{195}$. Nach den Friedensschlüssen von Rastatt und Baden mussten 1714 die gefundenen Regelungen wieder geändert werden, weil Ludwig XIV. für seine beiden wittelsbachischen Verbündeten die vollkommene Restitution hatte durchsetzen können. Die Kurpfalz ging mit leeren Händen aus dieser Regulierung hervor und musste sich mit dem begnügen, was bereits vor 1706 im eigenen Besitz war. Zwar sicherte der Kaiser dem Pfälzer Kurfürsten einen territorialen Ausgleich zu, doch war keiner zu finden, und so blieb die Angelegenheit unerledigt ${ }^{196}$.

\subsection{Zusammenfassung}

Kurfürst Max Emanuel von Bayern verwickelte sich ab 1701 in ein komplexes Konfliktszenario, das sich in mindestens vier Aspekte einteilen lässt: 1. Er beteiligte sich am europäischen Krieg zwischen dem Kaiser und Frankreich um das spanische Erbe. 2. Er nutzte die Gelegenheit, den alten dynastischen Konflikt zwischen den Habsburgern und den Wittelsbachern einmal mehr offen auszutragen. 3. Der Kurfürst forderte durch seine Angriffe auf freie Reichsstände das System des Landfriedens heraus und isolierte sich dadurch von allen anderen Fürsten und Städten im Reich. 4. Der Kurfürst brauchte riesige Finanzmittel, die er vor allem seiner eigenen Bevölkerung abpresste. In den Druckmedien kam vor allem der erste und der dritte Konflikt zur Berichterstattung: Internationales interessierte die Leserschaft am meisten, zudem konnte über fremde und gar reichsfeindliche Machthandlungen frei berichtet werden, besonders Ludwig XIV. von Frankreich war seit Jahrzehnten die Personifikation des Bösen auf der politischen Ebene. Landfriedensbrüche im Reich waren allerdings ebenfalls Berichtsmaterien, dafür sorgte schon die Verteilung von Informationen am Regensburger Reichstag. Der dynastische Aspekt hingegen und erst recht das Verhältnis des Kurfürsten zu seinen Untertanen blieben demgegenüber im Windschatten der Wahrnehmung und wurden selten oder gar nicht angesprochen.

Auslöser der Berichterstattung gegen Kurfürst Max Emanuel war die Besetzung der Reichsstadt Ulm im September 1702. Binnen weniger Wochen entstand das Bild vom wittelsbachischen Reichsfeind, das die beiden kurfürstlichen Brüder Josef Clemens und Max Emanuel umfasste, nachdem die Aktionen des Kölner Erzbischofs bis dahin durch Deduktionen, aber kaum durch Zeitungen behandelt worden waren. Während die Deduktionen von allen interessierten Seiten produziert wurden, kamen die Materialien, aus

195 Ebd., Bd. 7 (1715), S. 397-399.

196 Ebd., Bd. 7 (1715), S. 400. - Dokumente: S. 402-414. 
denen die Zeitungen und Zeitschriften schöpften, sowohl aus dem Umfeld des Regensburger Reichstags, vom Wiener Hof und von den Kreistagen der süddeutschen Kreise. Ein weiterer Teil entstammte der erbeuteten Korrespondenz zwischen Max Emanuel und seinen Pariser Verbündeten, die der französische Gesandte Ricous 1702 verloren hatte. Probayerische Schriften waren während des gesamten Betrachtungszeitraums klar in den Minderheit, mitunter zielten sie in französischer Sprache in erster Linie auf eine europaweite Öffentlichkeit. Ein dritter Teil der Quellen betraf sehr präzise Korrespondentenberichte vom Ort des Geschehens, etwa von Schlachtfeldern (Höchstädt) oder aus Wien resp. Regensburg (Ächtungszeremonien).

In den Zeitschriften wurde ebenfalls der Reichspatriotismus kultiviert und gegen den hochadligen Rechtsbrecher argumentiert. Hier wurde auch der dynastische Kern des Streits zwischen dem Kaiser und dem Münchener Königsanwärter aufgezeigt. Der Redakteur der Geheimen Briefe, Gottfried Zenner, thematisierte zudem den Loyalitätskonflikt der Untertanen zwischen Gefolgschaft gegenüber dem rechtsbrecherischen Landesherrn und dem Gehorsam gegenüber dem kaiserlichen Gebot. Während Stanislaus Reinhard Acxtelmeier in Augsburg während der wittelsbachischen Militärexpansion noch vorsichtig redigieren musste, brauchte die Europäische Fama in Leipzig kein Blatt vor den Mund zu nehmen: Da in Regensburg so bereitwillig Informationen ausgegeben wurden, berührte der Konflikt kein Herrschaftsarkanum mehr. Diese Zeitschrift konnte auch Kriegsmanifeste konstruktivisch deuten und als verbale Untermauerung jeglicher Kriegsabsichten entlarven.

Nach den unmittelbaren Kampfhandlungen relativierten sich die kriegerischen Unternehmungen des bayerischen Kurfürsten. Schon David Fassmann stellte die Selbstwahrnehmung Max Emanuels in den Vordergrund, und spätere Historiographen werteten die heroischen Leistungen in den Türkenkriegen deutlich stärker als die Kollaboration mit Frankreich. Dieser Umstand zieht sich durch bis in die Historiographie unserer Tage, etwa wenn Max Emanuels Regierungszeit von 1679 bis 1726 als durchgängig bezeichnet wird und die ächtungsbedingte Unterbrechung fehlt. Die zeitgenössische Zeitungspresse »rehabilitierte« den Wittelsbacher auch unmittelbar nach seiner Restitution 1714: Fortan war er wieder der »Kurfürst von Bayern« und »Kurfürstliche Durchlaucht«, als wäre nichts geschehen - Zeitungen repräsentieren eben stets ihre Gegenwart ${ }^{197}$.

197 Zur historiographischen Wahrnehmung Max Emanuels: Johannes ARndT, Max Emanuel, Kurfürst von Bayern oder Graf von Wittelsbach? Das Gedenken an Exil und Ächtung eines Barockfürsten in der bayerischen Historiographie, in: Martin WredE/Horst CARL (Hg.), Zwischen Schande und Ehre. Erinnerungsbrüche und die Kontinuität des Hauses. Legitimationsmuster und Traditionsverständnis des frühneuzeitlichen Adels in Umbruch und Krise, Mainz 2007, S. 65-80. 



\section{Siegener Konfessionsstreit}

\subsection{Dimensionen des Konflikts}

Fürst Wilhelm Hyazinth von Nassau-Siegen (1667-1743) gehört nicht zu den herausragenden Herrscherpersönlichkeiten der Frühen Neuzeit. Einen Biographen hat der Fürst bislang noch nicht gefunden. Wer Einzelheiten über sein Leben und seine Regierungsweise sucht, ist nach wie vor auf die ältere Studie von Ernst Friedrich Keller ${ }^{1}$ aus dem Jahre 1868 sowie die 1894 erschienene Siegener Stadtgeschichte von Heinrich von Achenbach ${ }^{2}$ angewiesen. Die ältere reichsrechtliche Behandlung des Falles Nassau-Siegen durch Johann Jacob Moser ist sehr fragmentarisch und hat einen Schwerpunkt auf den 1730er Jahren und den damals ausgetragenen Auseinandersetzungen um die verschiedenen Kommissionen, die an Stelle des Fürsten in Siegen wirkten ${ }^{3}$.

Auch unter den neuen Paradigmata der Geschichtsschreibung nach dem Zweiten Weltkrieg sind vor allem Spezialaspekte der Historie dieses Fürsten erhellt worden. Carlo de Clercq hat ihn 1962 unter dynastiegeschichtlicher Perspektive in einem Aufsatz über die katholischen Nassauer-Siegener Fürsten kurz abgehandelt ${ }^{4}$. Werner Troßbach verhandelte 1986 die Causa Wilhelmi Hyazinthi im Rahmen seiner vergleichenden Untersuchung zu Fürstenabsetzungen im Alten Reich ${ }^{5}$. Hans-Joachim Behr wertete 1991 die Archivalien des Niederrheinisch-Westfälischen Reichskreises hinsichtlich der Aussagen über Fürst Wilhelm Hyazinth aus ${ }^{6}$. Andreas Kalipke entfaltete den Fall Nassau-Siegen im Rahmen seines Beitrags über die Behandlung von Konfessionskonflikten im Regensburger Corpus Evangelicorum?

1 Ernst Friedrich Keller, Fürst Wilhelm Hyazinth von Nassau-Siegen. Prätendent der oranischen Erbschaft, seine Regierung und Zeitgenossen, in: AVNA 9 (1868), S. 49-122.

2 Heinrich von Achenbach, Geschichte der Stadt Siegen, Bd. 2, Siegen 1894 (ND Kreuztal 1980).

3 Johann Jacob Moser, Teutsches Staatsrecht, Bd. 24, Darinn der Rest der Materie von dem Herkommen in denen Häusern derer weltlichen Reichs-Stände in Ansehung ihrer Schulden [...] anzutreffen seynd, Leipzig 1746 (ND Osnabrück 1968), hier S. 242-264.

4 Carlo de ClercQ, Die katholischen Fürsten von Nassau-Siegen, in: NasA 73 (1962), S. 129 152. De Clercq geht auf die Siegener Verhältnisse nicht gesondert ein.

5 Werner Trossbach, Fürstenabsetzungen im 18. Jahrhundert, in: ZHF 13 (1986), S. 425-454, zu Wilhelm Hyazinth: bes. S. 430-441.

6 Hans-Joachim BeHR, »Zur Rettung derer hart getruckten Nassaw-Siegischen Unterthanen«. Der Niederrheinisch-Westfälische Kreis und Siegen im 18. Jahrhundert, in: JWKG 85 (1991), S. $159-184$.

7 Andreas KaLIPKE, »Weitläuffigkeiten« und »Bedencklichkeiten«. Die Behandlung konfessioneller Konflikte am Corpus Evangelicorum, in: ZHF 35 (2008), S. 405-447. 
Christian Brachthäuser hat kürzlich eine knappe biographische Skizze über Wilhelm Hyazinth vorgelegt und dabei zahlreiche Irrtümer in der bisherigen Forschung korrigiert ${ }^{8}$. Zur Entwicklung der konfessionellen Konflikte in Nassau-Siegen ist weiterhin die ältere Festschrift von Heinrich Schlosser und Wilhelm Neuser hilfreich ${ }^{9}$, da eine jüngere Aufarbeitung von Paul Münch ${ }^{10}$ in einem Reihenkontext erschien, der mit dem Jahr 1648 endete.

Für Keller gehörte Wilhelm Hyazinth zu der Gruppe der Standesgenossen, die sich an den engen Grenzen ihrer überschaubaren Landesherrschaft sowie an den eingeschränkten Befugnissen der herrschenden Politik- und Regierungslehre rieben. Keller schrieb über den Fürsten, er war »ein so stolzer, eingebildeter und hoch fahrender Mann, dass er sich in seinem kleinen Fürstenthume keinem Herkommen, Gesetz und Ordnung unterwerfen wollte und selbst mit der größten Heftigkeit gegen den Kaiser auftrat, wenn derselbe nicht in seine Pläne eingehen wollte oder wegen seiner Gewaltthätigkeit ernste Massregeln gegen ihn ergreifen müßte « ${ }^{11}$. Wenig später charakterisiert Keller ihn als »jesuitisch-spanisch-aristokratischen Zögling « ${ }^{12}$. Achenbach brach gleich zu Beginn des Kapitels über seine Regierungszeit den Stab über den Fürsten: »Obwohl mit bedeutenden geistigen Gaben ausgerüstet, sollte es ihm [ $=$ Wilhelm Hyazinth $]$ wegen seiner verfehlten Erziehung und den üblen Seiten seines Charakters fast niemals gelingen, etwas wirklich Nützliches zu vollbringen«. Dann charakterisiert Achenbach den Siegener Landesherrn mit den Substantiven »Selbstüberschätzung«, »Eitelkeit«, »Stolz«, »Hochmut«, »Hartnäckigkeit« hinsichtlich seiner vermeintlichen Würde, »Wankelmütigkeit«, »Zugänglichkeit für Schmeicheleien« und $»$ Verschwendungssucht $\ll^{13}$. Wilhelm Hyazinth war daher nicht nur wegen seiner ausgebliebenen politischen Erfolge wenig biographiewürdig, sondern auch, weil sein eigener Anteil an seiner Regierungstätigkeit infolge des starken Einflusses seiner gegenreformatorisch gesinnten Berater nur undeutlich bestimmt werden konnte.

Das fürstliche Haus der Nassauer war in zahlreiche Linien gespalten. Während des Dreißigjährigen Krieges waren zwei Linien, eine in Hadamar

8 Christian BrachthäUser, Le Prince Regent d'Orange. Wilhelm Hyazinth Fürst zu Oranien und Nassau-Siegen (1667-1743), Groß-Gerau 2010. Brachthäuser korrigiert u.a. das Geburtsdatum des Fürsten auf den 3. April 1667: S. 14.

9 Heinrich Schlosser/Wilhelm Neuser, Die Evangelische Kirche in Nassau-Oranien, 1530 1930. Fs. zum Gedächtnis der Einführung der Reformation und des Heidelberger Katechismus in den Grafschaften Nassau-Dillenburg und Nassau-Siegen, 2 Bd., Siegen 1931-1933.

10 Paul Münch, Nassau, ottonische Linien, in: Anton Schindling / Walter Ziegler (Hg.), Die Territorien des Reichs im Zeitalter der Reformation und Konfessionalisierung, Bd. 4, Münster 1992, S. 234-252.

11 Keller, Fürst Wilhelm Hyazinth, S. 51.

12 Ebd., S. 51.

13 Von Achenbach, Geschichte der Stadt Siegen, Bd. 2, T1. 10/1, S. 16. 
und eine in Siegen, zum Katholizismus übergetreten und hatten ihre Länder rekatholisiert. Ihre Hoffnung, alle reformierten Vettern ächten zu lassen und als einzige besitzende Linien fortzubestehen, erfüllte sich nur zeitwei$\operatorname{lig}^{14}$. In Nassau-Siegen etablierten sich je eine reformierte und eine katholische Linie, die das Land nach Ämtern aufteilten. Selbst in den katholischen Ämtern, nach dem Stifter der katholischen Linie »Johannsland « genannt, zu denen die Gebiete Netphen, Wilnsdorf, Eiserfeld, Kaan und Weidenau gehörten, gab es weiterhin protestantische Untertanen. Die gemischtkonfessionelle Hauptstadt Siegen wurde von beiden Seiten regiert. Ein gemeinsames Appellationsgericht mit Räten beider Konfessionen stellte die Spitze der NassauSiegener Jurisdiktion dar ${ }^{15}$.

Die katholischen Grafen und späteren Fürsten entwickelten dabei die größere Dynamik, siedelten die Jesuiten in Siegen an und arbeiteten auch nach dem Westfälischen Frieden daran, das gesamte Territorium schrittweise zu katholisieren. Unterstützt wurden sie dabei von den katholischen Vormächten der Umgebung, insbesonders dem Erzbischof von Köln und der Düsseldorfer Regierung der Pfalzgrafen von Neuburg, die seit 1685 auch Kurfürsten von der Pfalz geworden waren.

Keller beschreibt im Folgenden die chronologischen Ereignisse, die sich in den vier Jahrzehnten der Regierungszeit des Fürsten ereignet haben. Wilhelm Hyazinth trat die Nachfolge in Nassau-Siegen katholischen Anteils Ende 1699 an, um dort gut zwei Jahre später das Aussterben der niederländischen Linie Oranien-Nassau zu erleben. Er selbst hielt sich infolge seiner Abstammung von Graf Wilhelm dem Reichen von Nassau (1487-1559), dem Vater Wilhelms I. von Oranien, für erbberechtigt im souveränen Fürstentum Oranien sowie in der Statthalterschaft in den Niederlanden und strebte daher mit Macht die Durchsetzung dieser Rechte an ${ }^{16}$. Der folgende Erbstreit wurde schnell und endgültig zugunsten einer anderen Linie des Hauses Nassau sowie zugunsten Preußens entschieden. Die preußische Konkurrenz führte auch zur ersten schwereren Gewalttat, die dem Fürsten angelastet wurde: Im Jahr 1702 ließ er seinen früheren Kanzler Hermann Jung verhaften und sogar

14 Vgl. zur Programmatik das Restitutionsedikt des Grafen Johann VIII. von Nassau-Siegen vom 6. Juni 1626: Albrecht P. Luttenberger (Hg.), Katholische Reform und Konfessionalisierung, Darmstadt 2006, S. 373-377. Zur Einordnung des Edikts in die Kirchenpolitik dieses Fürsten: Gerhard Sреснт, Johann VIII. von Nassau-Siegen und die katholische Restauration in der Grafschaft Siegen, Paderborn 1964; Karl Demand, Das Siegerland im Widerstreit von Glauben, Recht und Politik 1607-1651, in: HJLG 32 (1982), S. 175-206. - Zu den Konfessionsverhältnissen in Nassau-Hadamar: Matthias T. KLOFT, Staat und Kirche in Nassau-Hadamar, in: AMRhKG 38 (1986), S. 47-106; Bd. 39 (1987), S. 107-156.

15 Trossbach, Fürstenabsetzungen im 18. Jahrhundert, S. 431.

16 Christian Brachthäuser legt ein Schwergewicht seiner Überlegungen auf den Aspekt der Erbberechtigung: BrachthäUser, Le Prince Regent d'Orange, S. 41-54. 
foltern, weil er ihn verdächtigte, er habe mit der preußischen Regierung konspiriert. Später wurde Jung freigelassen, allerdings 1704 erneut verhaftet ${ }^{17}$.

Was zunächst wie ein persönlicher Konflikt eines aggressiven Landesherrn mit seiner nächsten Umgebung aussah, entwickelte sich bald zu einer Strukturkrise eines Kleinterritoriums. Fürst Wilhelm Hyazinth hatte nämlich seit dem oranien-nassauischen Erbfall seine Souveränitätsansprüche international formuliert und sich gleich den Titel »Hoheit« beigelegt - dies teilte er allen europäischen Höfen mit ${ }^{18}$. Obwohl die Einkünfte aus seinem Teilterritorium nicht einmal die bisherigen Kosten abgedeckt hatten, erhöhte er den Hofhaltungsaufwand sprunghaft, um den neuen Rang auch zeichenhaft zu verdeutlichen: Höflinge und Dienstleute geistlichen und weltlichen Standes, bevorzugt aus Spanien und Italien, gingen im Siegener Schloss ein und aus, während die fiskalischen Einkünfte in keiner Weise mit der neuen Großzügigkeit der Staatsleitung Schritt halten konnten. So half nur eine weitgesteckte Steuererhöhung gegenüber den Untertanen. Hans-Joachim Behr beziffert die Summe der eingehobenen Abgaben während der Jahre 1700 bis 1707 auf fast 150.000 Rtl., ohne dass der Herrscher davon wenigstens seine Steuerpflichten gegenüber dem Reich und dem Reichskammergericht erfüllt hätte ${ }^{19}$.

Komplizierte Verhandlungen wie in anderen Territorien der Zeit entfielen, denn Nassau-Siegen hatte keine Landstände: Während die wenigen Adelsfamilien im 15. und 16. Jahrhundert versuchten, sich zur Rheinischen Reichsritterschaft zu schlagen, mussten verschuldete Geschlechter unter ihnen ihre Besitzungen an die Landesherrschaft oder an bürgerliche Käufer veräußern ${ }^{20}$. Dennoch stieß die Finanzverwaltung schnell auf den Widerstand der Bürger und Bauern des Territoriums. Die Strafjustiz gegenüber den Opponenten führte zu fiskalisch motivierten hohen Geldstrafen, die sich in einigen Fällen kaum noch von Vermögenskonfiskationen unterschieden, was eine wachsende Militanz der betroffenen Untertanen auslöste. Die Organe der Inneren Sicherheit rüsteten ebenfalls auf: Der Fürst ließ die Stadt durch eine Mauer in Ober- und Unterstadt teilen. Tor und Schildwache trennten fortan die Konfessionsgruppen, und nahe dem Oberen Schloss wurde ein Kanonenturm errichtet, mit dem man nicht nur auf die Bürger, sondern auch auf die reformierten Vettern im Unteren Schloss schießen konnte ${ }^{21}$.

17 Keller, Fürst Wilhelm Hyazinth, S. 60-63; Brachthäuser, Le Prince Regent d'Orange, S. 59.

18 KelLer, Fürst Wilhelm Hyazinth, S. 57f.

19 Zusätzlich verpfändete der Fürst die Ämter Wilnsdorf und Wilgersdorf an ein Frankfurter Bankhaus, um über die regulären Einkünfte hinaus noch Kredite zu erhalten: BeHR, »Zur Rettung derer hart getruckten Nassaw-Siegischen Unterthanen «, S. 160.

20 Nur der Adelsbesitz der von Holdighausen blieb bis zum Ende des Alten Reiches in adliger Hand: Ludwig BALD, Das Fürstentum Nassau-Siegen. Territorialgeschichte des Siegerlandes. Mit einem Atlas von 10 Kartenblättern, Marburg 1939, S. 160-162.

21 Keller, Fürst Wilhelm Hyazinth, S. 65f. 
Zur selben Zeit wuchsen die Übergriffe gegen die protestantischen Untertanen. Diese wurden nicht nur in besonderem Maße vom Steuerdruck betroffen, sondern auch in ihrer Religionsausübung mehr und mehr eingeschränkt ${ }^{22}$. Die Regierung dekretierte sogar die Pflicht, an katholischen Kulthandlungen teilnehmen zu müssen und bei öffentlichen Prozessionen vor dem Venerabile die Knie zu beugen ${ }^{23}$.

Da sich der reformierte Vetter im anderen Siegener Schloss bedroht fühlte, rückte im Januar 1705 preußisches Militär im Auftrag des NiederrheinischWestfälischen Reichskreises in die Stadt ein ${ }^{24}$. Die jubelnde Bevölkerung stürmte den Zwingturm, stürzte die Kanonen hinunter und trug das Gebäude $\mathrm{ab}^{25}$. Der Fürst versuchte, in Regensburg dagegen zu protestieren, doch ohne Erfolg, da sein Renommee dort bereits schweren Schaden gelitten hatte ${ }^{26}$. Im folgenden Sommer wurde jedenfalls eine neuerliche Intervention erforderlich, nachdem der Reichshofrat auf zahlreiche Klagen hin eine kurpfälzische Kommission nach Siegen entsandte, die am 15. Juli 1706 mit 50 pfälzischen Soldaten und 500 Mann bergischen Milizionären (»bergischer Ausschuss«) in die Stadt einzog. Fürst Wilhelm Hyazinth wurde gezwungen, die Schreiben des Reichshofrats und des Niederrheinisch-Westfälischen Kreises anzunehmen. Anschließend begannen die Kommissionsmitglieder mit Untersuchungen und Befragungen, denen sich der Fürst noch am selben Nachmittag durch Flucht nach Hadamar entzog ${ }^{27}$. Die Kommission verfuhr nach einer gebräuchlichen Praxis, indem sie nicht den abwesenden Landesherrn verurteilte, sondern den Sieur de Colomba, den späteren Grafen Jonquiers. Er hatte sich im Jesuitenkolleg versteckt, wurde verraten und in der Festung Jülich interniert. Das anschließende Gerichtsverfahren gegen ihn endete am 20. Dezember 1710 mit der Verweisung aus dem Reich auf ewige Zeiten ${ }^{28}$.

Sobald es wieder ruhiger war, kehrte der Landesherr nach Siegen zurück und nahm die Verfolgung der Verantwortlichen auf. Er ließ eine »Protestation « verfassen und drucken, die unter dem Datum vom 1. September 1706 herauskam und dem Reichstag als »Memoriale« vorgelegt wurde. Darin sprach der Fürst dem Kaiser das Recht ab, in seinem Territorium zu interve-

22 Zum wachsenden Steuerdruck: Trossbach, Fürstenabsetzungen im 18. Jahrhundert, S. $432 \mathrm{f}$.

23 Keller, Fürst Wilhelm Hyazinth, S. 70.

24 Trossbach, Fürstenabsetzungen im 18. Jahrhundert, S. 433f.; Brachthäuser, Le Prince Regent d'Orange, S. 61f. - Vgl. zur Politik des Niederrheinisch-Westfälischen Reichskreises, dem verfassungsrechtlich die Aufrechterhaltung von Ruhe und Frieden aufgegeben war: BEHR, »Zur Rettung derer hart getruckten Nassaw-Siegischen Unterthanen«, pas.

25 Keller, Fürst Wilhelm Hyazinth, S. 69.

26 Trossbach, Fürstenabsetzungen im 18. Jahrhundert, S. 434.

27 Keller, Fürst Wilhelm Hyazinth, S. 72.

28 Ebd., S. 73; BrachthäUser, Le Prince Regent d'Orange, S. 65. 
nieren, weil dies seiner Ansicht nach gegen die Reichsgrundgesetze und die Wahlkapitulationen verstieße ${ }^{29}$.

Im Dezember 1706 eskalierte der Steuerkonflikt erneut gewaltsam, als die Regierung den Weidenauer Gemeindevorsteher Johann Thomas Flender gefangennehmen ließ. Die Untertanen zogen mit mehr als 600 Mann in die Residenzstadt und wurden von der Schlosswache durch Schüsse zerstreut, wobei ein Demonstrant zu Tode kam, mehrere weitere verletzt wurden ${ }^{30}$. Geführt durch den früheren Kanzler Hermann Jung reichten einige Untertanen Klage gegen den Fürsten am Reichshofrat ein. Eine weitere Klage wurde von Fürst Friedrich Wilhelm Adolf von Nassau (1680-1722) erhoben, dem reformierten Cousin des Beklagten, der den reformierten Landesteil Siegens regierte. Das Wiener Gericht forderte in Siegen einen Bericht binnen zwei Monaten an und verfügte die Freilassung der Gefangenen ${ }^{31}$. Mitte März kehrte Fürst Wilhelm Hyazinth aus Aachen zurück und befahl, die Weidenauer Hammergewerke und Kaufleute Jakob und Friedrich Flender sowie deren Schwager Johann Eberhard Schutte festzunehmen und als »Rädelsführer« abzuurteilen. Die Beschuldigten wurden gewarnt und flohen, nur Friedrich Flender $\left({ }^{*} 1674\right)$ wurde gefasst. Der Fürst ließ ihn ohne vorherigen regulären Prozess am 29. März 1707 hinrichten ${ }^{32}$. Flender wurde durch die Bluttat im kollektiven Gedächtnis der Siegerländer Protestanten zum Märtyrer und nimmt diese Stellung bis heute ein ${ }^{33}$.

Der Justizmord machte aus Sicht der Reichsgerichte das Maß voll. Die aktuelle Tat, zusammen mit dem schlechten Ruf, den der Fürst inzwischen im Reich genoss, führten zu einem Reichshofratsspruch, der Wilhelm Hyazinth seiner Landesherrschaft entsetzte und stattdessen das Kölner Domkapitel mit der Ausübung der Regierungsgeschäfte beauftragte. Ein Kreiskontingent von 1.000 Mann rückte in Siegen ein; die Administration nahm ihre Tätigkeit am 20. April 1707 auf $^{34}$. Die entscheidenden Personen in Siegen waren fortan die Kurkölnischen Räte A.J. Solemacher und J.J. Maes. Fürst Wilhelm Hyazinth verließ einmal mehr sein Territorium und begab sich nach

29 Keller, Fürst Wilhelm Hyazinth, S. 73.

30 Ebd., S. 75; BRAchthäUSER, Le Prince Regent d'Orange, S. 66.

31 BeHR, »Zur Rettung derer hart getruckten Nassaw-Siegischen Unterthanen«, S. 161.

32 Keller, Fürst Wilhelm Hyazinth, S. 77; TROssbach, Fürstenabsetzungen im 18. Jahrhundert, S. 435. Vgl. zu den Umständen der Hinrichtung und der anschließenden Beerdigung: BeHR, »Zur Rettung derer hart getruckten Nassaw-Siegischen Unterthanen«, S. 161; BRACHTHÄUSER, Le Prince Regent d'Orange, S. 67f.

33 Vgl. Schlosser/Neuser, Die evangelische Kirche in Nassau-Oranien, Bd. 1, S. 36.

34 Von Achenbach, Geschichte der Stadt Siegen, Bd. 2, Tl. 10/1, S. 55. Hans-Joachim Behr betont die konfessionspolitische Bedeutung der Kommissionsübertragung; Kaiser Josef I. wollte weder einen reformierten Nassauer Fürsten noch den König von Preußen beauftragen, da beiden zugetraut wurde, den seit Langem schwelenden Siegener Konfessionsstreit im reformierten Sinne zu regulieren. Vgl. BEHR, »Zur Rettung derer hart getruckten Nassaw-Siegischen Unterthanen«, S. 159. 
Limburg, um dort mit seinen katholischen Verwandten aus Hadamar über die Lage zu beraten ${ }^{35}$. Später reiste der Fürst nach Regensburg, um dort persönlich auf die Reichstagsgesandten einzuwirken. Sein fast zweijähriger Aufenthalt bewirkte allerdings keine Lockerung der Bestimmungen ${ }^{36}$. Das Regensburger Corpus Evangelicorum hatte als Interesseninstanz der Minderheit der protestantischen Reichsstände den Fall Nassau-Siegen aufgegriffen, konnte sich jedoch in mehreren Behandlungen nur zu papiernen Protesten bei den Administrationsregierungen, den Direktoren des Niederrheinische-Westfälischen Kreises und dem Kaiser durchringen. Auch wenn König Friedrich I. von Preußen und später Friedrich Wilhelm I. Repressionen gegen die katholischen Schutzmächte der Konfessionsübergriffe erwogen, rangen sie sich letztlich nicht zu Aktionen durch ${ }^{37}$. Die protestantische Korrespondenz folgte der »Gradus-Lehre«, die das Corpus Evangelicorum üblicherweise verfolgte, um diplomatische Maßnahmen in aufsteigender Intensität anstelle direkter Militäraktionen anzuwenden. Die deeskalierende Strategie verpuffte jedoch in diesem Fall an der völlig fehlenden Neigung des Kaisers und der katholischen Stände, die Konfessionsbedrückung der Siegerländer Protestanten in irgendeiner Weise für anstößig zu halten ${ }^{38}$.

Während der folgenden drei Jahre stellte sich heraus, dass die kaiserliche Kommission sich nur beauftragt sah, die Verschwendung und Gewalttaten des Landesherrn abzustellen, nicht aber den Bemühungen der Siegener Regierung zur Rekatholisierung des Territoriums entgegenzuwirken. Die Subdelegierten des Kölner Domkapitels weilten jeweils nur für einige Tage in Siegen, um während der restlichen Zeit ihre Amtsgeschäft nach Aktenlage von Köln aus zu führen ${ }^{39}$. Die kaiserliche Kommission machte zunächst einige gegenreformatorische Maßnahmen des früheren Fürsten Johann Franz Desideratus rückgängig, um dann 1708 - auf der Grundlage einer Bestandsgarantie des Reichshofrates für die kirchlichen Zustände zu Beginn der Administration - die katholischen Schulmeister in Weidenau, Eiserfeld und Kaan wieder einzusetzen ${ }^{40}$. Falls die betroffenen Untertanen passiven Widerstand leiste-

35 Keller, Fürst Wilhelm Hyazinth, S. 77; TRossbach, Fürstenabsetzungen im 18. Jahrhundert, S. 436.

36 Keller, Fürst Wilhelm Hyazinth, S. 80.

37 Andreas Kalipke arbeitet vier Phasen der Behandlung des Falles im Corpus Evangelicorum heraus: KALIPKE, »Weitläuffigkeiten« und »Bedencklichkeiten«, S. 412f. (1. Phase nach dem Justizmord an Friedrich Flender 1707), 415 (2. Phase nach der blutigen Fronleichnamsprozession 1712), 416 (3. Phase nach dem Gewaltakt gegenüber den Weidenauer Hammerschmieden 1716) u. 416 (4. Phase nach der zwangsweisen Einsetzung katholischer Schulmeister in den Weidenauer Schulen durch die kurkölnische Administrationsregierung 1717).

38 Zur Gradus-Lehre: KALIPKE, »Weitläuffigkeiten« und »Bedencklichkeiten«, S. 418 u. 428.

39 Zur Amtsführung der Kommissäre: BeHR, »Zur Rettung derer hart getruckten Nassaw-Siegischen Unterthanen «, S. 163.

40 Zur strittigen Politik der kaiserlichen Kommission 1707-1710: BeHR, »Zur Rettung derer hart getruckten Nassaw-Siegischen Unterthanen«, S. 168; BRAChthäUSER, Le Prince Regent 
ten, wirkten die Kreistruppen unter dem Befehl kurpfälzischer und münsterischer Kommandeure auf das Engste mit der Regierung zusammen ${ }^{41}$. Der reformierte Fürst Friedrich Wilhelm Adolf war nicht in der Lage, wirkungsvolle Gegenmaßnahmen unterhalb der Schwelle der Gewalt vorzunehmen, um dieser kirchenpolitischen Expansion entgegenzuwirken. Er beschränkte sich, wie die Untertanen ihrerseits, auf papierne Proteste beim Corpus Evangelicorum des Reichstags wie beim Niederrheinisch-Westfälischen Reichskreis und auf Klagen am Reichshofrat.

Da das Kölner Domkapitel signalisierte, kein Interesse an der Administrationsregierung mehr zu haben, die zunehmend als Bürde empfunden wurde, und die Proteste der verschiedenen Seiten am Reichstag immer schriller wurden, entschieden die drei Reichstagskurien am 19. Juni 1709, den Kaiser um die Einsetzung einer neuen Kommission in Siegen zu bitten. Die Beschwerden sollten abgeschafft und die Weichen für eine geordnete Rückkehr des Fürsten in sein Land gestellt werden ${ }^{42}$. Der Reichshofrat entließ die kurkölnische Administration aus ihrer Aufgabe, die Wiederherstellung der fürstlichen Alleinherrschaft unterblieb jedoch, stattdessen beaufsichtigte fortan ein Vorstandskommissar des Niederrheinisch-Westfälischen Kreisdirektoriums die Tätigkeit der Siegener Regierung, der in Finanz- und Jurisdiktionsangelegenheiten das ausschlaggebende Wort führte ${ }^{43}$.

Fürst Wilhelm Hyazinth war in der Zwischenzeit nur jeweils kurzzeitig in seinem Land gewesen. Die Kommission hatte ihm eine Jahresrente von 3.000 Rtl. zugestanden, die vom Reichshofrat auf 4.000 Rtl. heraufgesetzt wurde ${ }^{44}$. Nach dem Tod Kaiser Josefs I. im April 1711 bestätigte Kurfürst Johann Wilhelm von der Pfalz als Reichsvikar zunächst die Kölner domkapitularische Kommission, setzte im Juni die drei Kreisdirektoren zu neuen Kommissaren ein, um im Oktober desselben Jahres Fürst Wilhelm Hyazinth als Landesherrn zu restituieren ${ }^{45}$.

d'Orange, S. 71-74.

41 In beiden Territorien regierten entschiedene Anhänger einer späten Gegenreformation: Kurfürst Johann Wilhelm von der Pfalz wird zwar in Düsseldorf bis heute als Kunst- und Kulturförderer verehrt, initiierte aber im Zusammenhang mit der sog. »Rijswijker Klausel« schwere Konfessionskonflikte in der Rheinpfalz, die ebenfalls den Reichstag und das Corpus Evangelicorum beschäftigten: Meinrad Sснан, Die Wiederherstellung des Katholizismus in der Kurpfalz im 17. und 18. Jahrhundert, in: ZGO 114 (1966), S. 147-205. - Paderborner Bischof war seit 1705 Franz Arnold von Wolff-Metternich, dem ebenfalls sehr an der Ausbreitung der katholischen Religion in seinem Einflussbereich gelegen war: BEHR, »Zur Rettung derer hart getruckten Nassaw-Siegischen Unterthanen«, S. 166f.

42 Ebd., S. 169f.

43 BRachthäuser, Le Prince Regent d'Orange, S. 73f.

44 BeHR, »Zur Rettung derer hart getruckten Nassaw-Siegischen Unterthanen«, S. $165 \mathrm{f}$.

45 Kommissionsbestätigung vom 4. Mai 1711; Restitution des Fürsten am 24. Oktober 1711: voN AсHENBACH, Geschichte der Stadt Siegen, Bd. 2, T1. 10/1, S. 76; BeHR, »Zur Rettung derer hart getruckten Nassaw-Siegischen Unterthanen«, S. 170. 
Faktisch entstand zunächst eine Doppelherrschaft des Fürsten und des Niederrheinisch-Westfälischen Kreisdirektoriums. Der Reichshofrat lehnte wenig später (1713) die Bestätigung des kurpfälzischen Restitutionsspruches ab. Damit war Fürst Wilhelm Hyazinth wieder von den Regierungsgeschäften ausgeschlossen. Seine Regierungsräte amtierten unter der Aufsicht durch das Kreisdirektorium weiter. Ihre Herrschaft führte zwar dazu, dass die Steuerbedrückungen gemildert wurden, nicht aber die systematische Benachteiligung des protestantischen Bevölkerungsteils ${ }^{46}$. Die Siegener Jesuiten arbeiteten mit der Regierung und den katholischen Kreisdirektoren intensiv daran, die protestantische Kultausübung schrittweise zu erschweren, einzuschränken und schließlich aus Nassau-Siegen ein geschlossenes katholisches Territorium werden zu lassen. Die Klagen der betroffenen Untertanen häuften sich erneut beim Corpus Evangelicorum ${ }^{47}$.

Am 26. Mai 1712 kam es zur Konfrontation anlässlich der Fronleichnamsprozession. Um den Verlauf des Prozessionsweges hatte es schon in den vorausgegangen Jahren Auseinandersetzungen gegeben. Auch diesmal hatten sich beide Seiten auf eine Konfrontation vorbereitet und bewaffnete Kräfte bereitgestellt. Aus einer unübersichtlichen Situation heraus fielen Schüsse, wobei es auf Seiten der reformierten Garde drei Tote und mehrere Verletzte gab, von denen zwei weitere später starben. Beide Seiten schoben sich gegenseitig die Schuld am Zusammensto $ß \mathrm{zu}^{48}$. Die Kreiskommission ließ die Fronleichnamsgewalt unbeanstandet und setzte ihre Förderung der gegenreformatorischen Politik fort. Die katholische Regierung verbot den protestantischen Gottesdienst und Schulunterricht in Siegen ${ }^{49}$.

Weitere Vorstöße des Corpus Evangelicorum beim Kaiser und am Reichstag in der Siegener Angelegenheit blieben ohne Ergebnis. Dadurch konnte sich die katholische Siegener Regierung bestärkt sehen, das begonnene Werk im Einverständnis mit den katholischen Kreisdirektoren fortzusetzen. Zwar sahen hellsichtige Katholiken wie der Münsteraner Vizekanzler von Cochenheim ein, dass nur eine Restitution des calvinistischen Gottesdienstes und insbesondere des Schulwesens eine Beruhigung der Lage im katholischen Teil Nassau-Siegens bewirken würde, doch sein Bischof Franz Arnold von Wolff-Metternich setzte durch, dass alles im vorigen Stand blieb ${ }^{50}$.

46 Keller, Fürst Wilhelm Hyazinth, S. 83.

47 Ebd., S. 87.

48 Ebd., S. 83; von Achenbach, Geschichte der Stadt Siegen, Bd. 2, Tl. 10/1, S. 91-99; Behr, »Zur Rettung derer hart getruckten Nassaw-Siegischen Unterthanen«, S. 175.

49 Keller, Fürst Wilhelm Hyazinth, S. 90. - Auch eine kaiserliche Kommission durch Kurtrier und Hessen-Darmstadt konnte keine einheitliche Bewertung zustande bringen: BRACHTHÄUSER, Le Prince Regent d'Orange, S. 84.

50 StA Münster, Fürstbistum Münster Landesarchiv, Nr. 468, 467a, Bl. 553-560; zit. nach BeHR, »Zur Rettung derer hart getruckten Nassaw-Siegischen Unterthanen«, S. 177, Anm. 47. 
Die reformierten Gemeinden griffen inzwischen zur Selbsthilfe und setzten sich - wenn die Kreissoldaten abgezogen waren - wieder in den Besitz ihrer Schulen und Kapellen. Die Regierung drohte an, jeden als Rebellen zu behandeln, der sich an diesen eigenmächtigen Restitutionen oder an sonstigen Zusammenrottungen beteiligte. Am 27. Februar 1716 kam es daraufhin $\mathrm{zu}$ einem weiteren bewaffneten Zusammenstoß, als eine Menge Weidenauer Bürger verhindern wollten, dass einige Hammerschmiede ins Siegener Gefängnis geführt werden sollten. Die Kreissoldaten und ihre katholischen Unterstützer nutzten die Gelegenheit, Häuser reformierter Untertanen zu plündern. Als daraufhin die Bevölkerung zusammenlief, eröffnete das Kreiskontingent das Feuer auf die Bevölkerung; abermals gab es mehrere Tote ${ }^{51}$. Erneut folgten diplomatische Auseinandersetzungen, in deren Verlauf der Münsteraner Bischof besonders in die Schusslinie geriet. Die Satisfaktionsforderung durch den Preußenkönig Friedrich Wilhelm blieb jedoch ohne Folgen. Die katholischen Reichsstände glaubten hingegen den offiziellen katholischen Berichten, die den Weidenauer »Rebellen $«$ die Schuld zuwiesen ${ }^{52}$.

In den folgenden Jahren traten die preußischen Kreistruppen, die ebenfalls im Territorium stationiert wurden, in einigen Fällen für die reformierten Landesuntertanen der katholischen Linie des Hauses Nassau ein. Kleinere Gewalttätigkeiten - Besetzung von Kapellen bei reformiertem Gottesdienst 1717, zwangsweise Einsetzung eines katholischen Lehrers in die früher reformierten Schulen in Affolderbach und Eschenbach 1722 - blieben nicht aus, und 1719 prügelten sich selbst die verschiedenkonfessionellen Soldaten des Kreiskontingents. Insgesamt ebbte die Gewalt aber schon dadurch ab, dass die konfessionsverschiedenen Kreisdirektoren ein Auge auf die Lage im Siegerländer Kleinstaat warfen und ihre Exekutionsorgane eine Art militärisches Gleichgewicht herausbildeten ${ }^{53}$.

Der eingespielte Modus wurde allerdings plötzlich dadurch gestört, dass Kaiser Karl VI. 1723 den Kreisdirektoren - ohne Begründung und Anhörung - das Kommissionsmandat entzog und den Kölner Kurfürsten Clemens August allein mit der Leitung der Kommission beauftragte. Der Kur-

51 Keller, Fürst Wilhelm Hyazinth, S. 92; von Achenbach, Geschichte der Stadt Siegen, Bd. 2, T1. 10/1, S. 99-103; BrachthäUSER, Le Prince Regent d'Orange, S. 85. - Hans-Joachim Behr berichtet von neun toten Weidenauern, während von den verletzten acht Personen später noch zwei starben: BeHR, »Zur Rettung derer hart getruckten Nassaw-Siegischen Unterthanen«, S. 177. - Werner Troßbach zählt alle Opfer beider Seiten zusammen und kommt dabei auf 15 Tote: Trossbach, Fürstenabsetzungen im 18. Jahrhundert, S. 438f.

52 Zu Preußen: Vgl. Schlosser/Neuser, Die evangelische Kirche in Nassau-Oranien, Bd. 1, S. 36; zu den katholischen Ständen: BeHR, »Zur Rettung derer hart getruckten Nassaw-Siegischen Unterthanen«, S. 177.

53 Auch Hans-Joachim Behr bescheinigt den Verantwortlichen: »Ungeachtet aller auch internen konfessionellen Streitigkeiten und Probleme hat sich die Kommission des Kreises bemüht, ihren Aufgaben so gut wie möglich nachzukommen«; in diesem Kontext muss das als ein Minimalerfolg gewertet werden: ebd., S. 179. 
fürst war auch Bischof von Münster, doch war das nicht der Grund für den Wechsel. Der Kaiser hatte von Fürst Wilhelm Hyazinth verlangt, einen neuen Revers zu unterzeichnen, der die Befugnisse seiner Regierung in Siegen regeln sollte. Da der Fürst das verweigerte, wurden auch seine Regierungsräte ihrer Ämter enthoben und durch kurkölnische Räte ersetzt ${ }^{54}$. Die neue Regierung setzte dort an, wo die katholischen Kommissare 1716 haltmachen mussten: Katholische Soldaten vertrieben erneut die calvinistischen Pfarrer aus Weidenau, Eiserfeld und Kaan ${ }^{55}$. Bereits vier Jahre später erfolgte die nächste Änderung: Karl VI. beauftragte nun Prinz Emanuel Ignatius von Nassau-Siegen, einen Halbbruder des abgesetzten Fürsten, mit der Landesregierung. Die Befugnisse waren gering, denn die praktischen Regierungsgeschäfte führten weiterhin die kurkölnischen Regierungsräte in Siegen. Prinz Emanuel Ignatius trat zwar sein Amt am 6. Oktober 1727 an, begab sich aber bald wieder nach Brüssel, ohne sich um das ihm anvertraute Territorium weiter zu kümmern ${ }^{56}$. Werner Troßbach kommentiert die Lage zutreffend: »Das Karussel der `Ordnungsmächte` war ins Rotieren gekommen: Die von der einen >Ordnungsmacht geschaffene Unordnung wurde durch die Unordnung der folgenden 〉Ordnungsmacht abgelöst $\iota^{57}$. Als Quintessenz lässt sich konstatieren, dass die verschiedenen Administrationen daran scheiterten, dass die Administratoren konfessionell parteiisch und am Bestand des Landes desinteressiert waren ${ }^{58}$. Zudem verschärfte sich die Schuldenkrise des Territoriums ${ }^{59}$.

Eine zusätzliche Dramatik entstand dadurch, dass in kurzer Folge alle Mitglieder der katholischen nassauischen Linien Siegen und Hadamar starben. Verschiedene Varianten der Erbfolge wurden unter Einflussnahme des Kaisers, der Niederlande und einiger interessierter Reichsstände diskutiert, doch waren sie nach wenigen Jahren wieder überholt ${ }^{60}$. Fürst Wilhelm Hyazinth bot sich vorübergehend die Perspektive auf eine Vereinigung der gesamten

54 Von Achenbach, Geschichte der Stadt Siegen, Bd. 2, T1. 10/1, S. 104; Behr, »Zur Rettung derer hart getruckten Nassaw-Siegischen Unterthanen«, S. 181.

55 Trossbach, Fürstenabsetzungen im 18. Jahrhundert, S. 439.

56 BEHR, »Zur Rettung derer hart getruckten Nassaw-Siegischen Unterthanen«, S. 181f.

57 Trossbach, Fürstenabsetzungen im 18. Jahrhundert, S. 440.

58 Ebd., S. 441.

59 Die Wiener Reichshofkanzlei bezifferte 1737 den Schuldenstand Nassau-Siegens auf mehr als 1,5 Millionen Gulden. Vgl. den Vorschlag der Reichshofkanzlei an Kaiser Karl VI. wegen des Nassauischen Schuldenwesens, März 1737: HHStA Wien, Reichshofkanzlei, Kleinere Reichsstände, Bd. 367, fol. 229-233.

60 Zur verwickelten dynastischen Entwickung: BEHR, »Zur Rettung derer hart getruckten Nassaw-Siegischen Unterthanen«, S. 182f. - Kaiser Karl VI. erließ 1731 sogar ein Bitt-Zirkular an die katholischen Reichsstände, um den jüngsten Stiefbruder Wilhelm Hyazinths, Fürst Franz Hugo Ferdinand Gereon von Nassau-Siegen, finanziell zu unterstützen, damit dieser als standesgemäßer Nachfolger im katholischen Teil Nassaus aufgebaut werden könne, allerdings ohne spürbare Resonanz: BrachthäUser, Le Prince Regent d'Orange, S. 100. 
Siegener und Westerwälder Besitzungen seines Hauses, doch war sein Alter fortgeschritten, und einen legitimen Sohn besaß er nicht. Der Fürst hatte sich nach dem Scheitern seiner Pläne 1723 immer mehr zurückgezogen. Zu diesem Zeitpunkt war selbst sein Verhältnis zu Kaiser Karl VI. gespannt ${ }^{61} .1725$ verlegte er seinen Wohnsitz nach Madrid, von wo er erst 1739 nach Brüssel und 1740 nach Köln umzog. Ein Jahr später kehrte er nach Hadamar zurück, wo er die Nachfolge seines Vetters antrat. Zwar erteilte ihm Kaiser Karl VI. am 26. Juli 1740 das Dekret zur Wiedereinsetzung in seine Siegener Besitzungen, doch gehorchte die Siegener Regierung des reformierten Prinzen Wilhelm Karl von Oranien-Nassau (1711-1751) dieser Anweisung nicht ${ }^{62}$. Ohne seine Autorität in Siegen wiederhergestellt zu haben, starb Wilhelm Hyazinth am 18. Februar 1743 in Hadamar ${ }^{63}$. Ob Wilhelm Hyazinth symptomatisch für »die potentiell selbstzerstörerische Labilität deutscher Duodezfürstentümer« war, wie Werner Troßbach annimmt, bedarf noch weitergehender Reflexionen ${ }^{64}$. Zu erinnern ist, dass selbst große Dynastien - beispielsweise die spanischen Habsburger 1700 oder ihre österreichischen Vettern 1740 vor dem Aussterben nicht geschützt waren, und selbst bahnbrechende politische und ökonomische Reformen, falls sie ihnen gelungen wären, hätten an diesem Schicksal nichts geändert.

Allen Einschränkungen des protestantischen Gottesdienstes zum Trotz hatte der reformierte Bevölkerungsteil an seinem Glauben festgehalten. Er begrüßte 1742 die Restitution seines Bekenntnisses mit großem Jubel. Am 17. und 20. Februar nahm Statthalter Prinz Wilhelm Karl von Oranien-Nassau nach seinem Vergleich mit dem katholischen Onkel Fürst Wilhelm Hyazinth die Huldigung in Siegen und Umgebung entgegen und beschloss damit eine 120 Jahre dauernde Phase der katholischen Landesherrschaft ${ }^{65}$.

\subsection{Deduktionen und Zeitungsberichte}

Der Streit zwischen den Konfessionsparteien innerhalb des Hauses Nassau sowie zwischen unterschiedlichen Konfessionsgruppen in Nassau-Siegen hat in der Tagespresse keine großen Wellen geschlagen. Mehrere Gründe sind dafür verantwortlich:

61 Von Achenbach, Geschichte der Stadt Siegen, Bd. 2, T1. 10/1, S. 104.

62 Zur letzten Verwirrung um Fürst Wilhelm Hyazinth: BEHR, »Zur Rettung derer hart getruckten Nassaw-Siegischen Unterthanen«, S. 183f.

63 Von Achenbach, Geschichte der Stadt Siegen, Bd. 2, T1. 10/1, S. 17.

64 Trossbach, Fürstenabsetzungen im 18. Jahrhundert, S. 441.

65 Keller, Fürst Wilhelm Hyazinth, S. 115; von Achenbach, Geschichte der Stadt Siegen, Bd. 2, T1. 10/1, S. 17; BEHR, »Zur Rettung derer hart getruckten Nassaw-Siegischen Unterthanen«, S. 184. 
1. Nassau gehörte zu den kleinen und jüngeren Fürstentümern, galt damit als politisch zweitklassig und hinsichtlich der voraussetzbaren landeskundlichen Kenntnisse bei der Leserschaft als unentwickelt.

2. Eine eigene Zeitung in Siegen ist für diese Zeit nicht überliefert.

3. Konfessionskonflikte als Zeitungsthemen bargen viele Risiken in sich. Sie waren schwer überschaubar, zogen vielfach politisch motivierte Interventionen nach sich, stellten sich in widersprüchlichen Schriftsätzen dar, die der Redakteur nicht überprüfen konnte. Schließlich drohte jeder Konfessionskonflikt, eine Parteinahme der Leserschaft auszulösen, die von den Obrigkeiten als gefährlich eingestuft wurde (»Gährung « unter der Bevölkerung). All diese Probleme galten auch für diesen Konflikt, der zudem noch durch den größeren, reichsweit bekannten Konfessionskonflikt um die kurpfälzischen Protestanten ${ }^{66}$ überschattet wurde.

4. Die Anzahl der Schriftsätze, die zum Druck gelangten, dürften auch aus diesen Gründen eher gering gewesen sein.

5. Die Archivalienüberlieferung ist infolge der Territorialteilung zwischen dem größten Teil Nassaus, der 1815 zum Großherzogtum wurde, und dem Siegerland, das zur preußischen Provinz Westfalen geschlagen wurde, getrennt worden.

Dennoch lassen sich zahlreiche Informationen zusammentragen, die den aufmerksamen Leser im Reich über das kleine Territorium zwischen Sauerland und Westerwald erreichen konnten. 1702 informierte Fürst Wilhelm Hyazinth die politische Öffentlichkeit durch eine 12 Seiten starke Deduktion mit 23 Seiten Beilagen in lateinischer Sprache über seine Erbansprüche auf die oranische Erbschaft, die seit dem Tod König Wilhelms III. von England-Oranien vakant geworden war ${ }^{67}$. Dabei störte sich der Fürst nicht daran, dass der Oranierkönig seine Hinterlassenschaften in Gänze seinem Neffen Johann Wilhelm Friso von Nassau-Diez hinterlassen hatte. Wilhelm Hyazinth beschränkte seine Verlautbarung nicht auf das Reich, sondern die lateinische Fassung sollte die gesamte europäische Öffentlichkeit erreichen. Zusätzlich wurden Notariatspatente über die formelle Besitzergreifung im Fürstentum Orange am Unterlauf der Rhône ausgefertigt. Der Fürst stellte sich in den folgenden Jahren als souveräner Prinz von Oranien und Nassau

66 Hans von Hymmen, Der erste preußische König und die Gegenreformation in der Pfalz, Bielefeld 1904; Christoph Flegel, Die Rijswijker Klausel und die lutherische Kirche in der Kurpfalz, in: Heinz Duchnardt (Hg.), Der Friede von Rijswijk 1697, Mainz 1998, S. 271-279.

67 »Facti Species Qua ex Pactis diversis \& Fideicommissariis Dispositionibus Illustriss. Comitum Nassoviae \& Baronum Bredae \& nec non Testamento Sereniss. Principis Auriaci \& Comitis Nassov. Philippi Wilhelmi dicucide demonstrantur [...] Domino Wilhelmo Hyazinto [...] successionem in supremum Principatum Aurasionensem [...] indubitanter competere«, o.O. 1702. 
dar und verlangte, dass ihm die entsprechenden Kurialien gegeben wurden. Die hochadligen Dynastien in Europa erkannten diesen Anspruch allerdings nicht an.

Der innere Konflikt in Nassau-Siegen hingegen wurde erst spät deutlich. Das mehrfache Erscheinen der Kreiskontingente in Siegen lässt sich in der Tagespresse bislang nicht nachweisen, wozu allerdings die selektive Überlieferungslage beigetragen haben könnte. Selbst die Hinrichtung von Friedrich Flender 1707 konnte von der überregionalen Presse nicht eingeschätzt werden und wurde offenbar als ganz normaler Fall der Ausübung der Blutgerichtsbarkeit betrachtet, nicht als Justizskandal.

1709 errichtete die kurkölnische Administrationsregierung in Siegen die erste Position, indem sie eine 24 Seiten starke Wahrhaffte Vorstellung herausgab $^{68}$. Die Administration verwies auf ihre kaiserliche Einsetzung und informierte alle Korrespondenten im Reich, dass sie künftige Ansprechstation in Hinblick auf dieses Territorium sei. In konfessionspolitischer Hinsicht machte sich die Regierung die Standpunkte zu eigen, die die jesuitischen Beamten des Fürsten schon früher ausgearbeitet hatten. Nassau-Siegen wurde nachträglich zu einem schon 1624 rechtmäßig katholischen Territorium rückverwandelt. Die Rechte, die die Reformierten dort bis dahin besaßen und weiterhin reklamierten, ließen sich durch diesen Kunstgriff als vorübergehende Gewährung der Landesherrschaft deklarieren, womit die praktizierte Rekatholisierung legitimiert werden sollte ${ }^{69}$. Nicht die Reformierten, wie in deren Druckschriften beklagt, sondern die Katholiken seien seit Langem in Nassau-Siegen unterdrückt worden. Als Beispiel wurde erwähnt, dass katholische Einwohner des Territoriums früher ihre Kinder keine auswärtigen Schulen besuchen lassen durften. In den Beilagen wurden Dokumente gebracht, die die katholischen Besitzstände manifestierten, etwa der Mediationsrezess vom 15. Mai 1651, durch den die konfessionelle Mischverfassung verankert worden war, der an dieser Stelle aber vor allem wegen der offiziellen Zulassung der Jesuiten im Lande gedruckt wurde ${ }^{70}$.

Die protestantische Seite, vertreten durch den reformierten Fürsten Friedrich Wilhelm Adolf von Nassau, antwortete auf diese Schrift im Folgejahr mit der Schrift Gründliche Widerlegung ${ }^{71}$. Diese Schrift hatte 322 Seiten Umfang und richtete sich im engeren Sinn an die Reichstagsgesandten, vor

68 »Wahrhaffte Vorstellung von Seitten der Fürstlich=Siegischen Administrations=Cantzley, den Punctum religionis betreffend«, o.O. 1709.

69 Ebd., S. 3.

70 Ebd., S. 5, Quellenabdruck S. 11-13.

71 »An Sämbtlicher Churfürsten, Fürsten und Ständen des Heil. Römischen Reichs [...] Gründliche Widerlegung und reiterirte Vorstellung Gegen die Von [...] Kaiserl. AdministrationsCantzley, in puncto der Nassau-Siegischen Successions Sach [...] übergebene [...] GegenRemonstration [...]«, o.O. 1710 . 
allem an die Mitglieder des Corpus Evangelicorum. Sie dürfte auch für die folgende nationale und internationale Presseberichterstattung eine zentrale Grundlage dargestellt haben. Die Ansprüche aus der Wahrhafften Vorstellung wurden zurückgewiesen, der Charakter Nassau-Siegens als altprotestantisches Territorium bekräftigt, das erst nach dem Westfälischen Frieden katholische Ämter erhalten habe. Im Vordergrund steht die Verteilung dieser Ämter und die rechtlich gebotenen Formen der Herrschaftsausübung in ihnen. Auf einen seit 1680 anhängigen Streit vor dem Reichskammergericht wird verwiesen.

Die katholische Administrationsregierung ruhte daraufhin nicht und ließ noch im selben Jahr die Deduktion Beständige Rechtliche Ablehnung erscheinen $^{72}$. Auf 73 Seiten im Folio-Format bekräftigte die Administration ihre Haltung und legte dar, dass bereits 1623/24 in der Siegener St. Johannis-Kirche das katholische Bekenntnis gegolten habe. Daher sei Nassau-Siegen nach der Normaljahresregelung des Westfälischen Friedens als katholisches Territorium zu betrachten. Die Reformierten hätten bei der Huldigung an Graf Johann VIII. von Nassau-Siegen nur ein Exercitium ad tempus zugesagt erhalten, das 1626 widerrufen worden $\mathrm{se}^{\mathrm{i}}$. In weiteren Einzelnachweisen wird der Eindruck erweckt, als ob die Reformierten in Siegen sich nicht zu beklagen hätten, weil ihnen kein Unrecht geschehen sei.

Auf dieser Deduktionengrundlage konnten nun auch die Wochenzeitungen die Lage in Siegen einschätzen. Der früheste Bericht in einer Zeitung geschah 1711 im Rahmen einer dynastisch-landesgeschichtlichen Darstellung. In den Wöchentlichen Relationen aus Halle wurde am 13. Juni ohne konkreten Bezug zum Konfessionskonflikt auf die Dynastie Nassau eingegangen. In einer langen Fußnote erläuterte der Redakteur die fünf Zweige des Astes Nassau-ottonisch und die drei Zweige des Astes Nassau-walramisch. Dabei schreibt er zu Nassau-Siegen:

Das Haus Nassau-Siegen ist wiederum in zwei Linien/nemlich in die Catholische und Reformirte getheilet. Die Catholische ruhet auf den Fürsten Wilhelm Hyacinth. In dessen Regierung ist solche Unordnung eingerissen/daß ihm seine eigene Unterthanen den Gehorsam aufgekündiget haben: auch hat der Kayserl. Reichs=Hof=Rath die Controvers also decidiret/ daß der Fürst sein Land nunmehro mit dem Rücken ansehen müssen. Und ist dem Dom=Capitul zu Cölln die Execution aufgetragen worden/welches das land anietzo regiret. Der Fürst hat sich inzwischen nach dem Reichs=Tage zu Regensburg gewendet/allwo er mit seiner Printzessin Tochter im Elende lebet. Wie

72 »An Sämbtlicher Churfürsten Fürsten und Ständen des Heil. Römischen Reichs [...] Beständige Rechtliche Ablehnung und Refutation Nahmens Der zum Hochfürstlichen Nassau=Siegen= Catholischen Land bestellter kaiserlicher Administrations-Cantzley [...] , o.O. 1710.

73 Ebd., S. 5. 
denn vor noch nicht gar langer Zeit gemeldet wurde/daß sein Gast=Wirth allbereits $11.480 \mathrm{fl}$. Tisch=Gelder zu prätendiren hätte/und deswegen vor seine Tafel nicht weiter sorgen wollte ${ }^{74}$.

Der gewaltsame Zusammenstoß während der Siegener Fronleichnamsprozession 1712 wurde im Hamburger Relations-Courier mit folgenden Worten reportiert:

[...] Zu Siegen ist zwischen den Catholischen und Reformirten wegen Haltung einer Procession/ein Disput entstanden, und weiln die letzere die erstere durch ein Strasse nichts passiren lassen wollen/und einige Soldaten mit Gewehr allda gestanden/hat ein Catholischer Lieutenant mit bey sich habenden Soldaten/so vor der Procession gangen/auff sie Feuer geben lassen/deren 3 erschossen und 10 blessirt/ohn daß die Reformirte dargegen Feuer geben/und hat der Reformirte Fürst dieses Nahmens/solches Factum nach dem Kayserl. Hoff berichtet ${ }^{75}$.

Einige Tage später teilte dieselbe Zeitung mit, dass der Fall Siegen zum Verhandlungsgegenstand innerhalb des Corpus Evangelicorum geworden sei. Aus Regensburg hatte die Zeitung unter dem 18. Juli erfahren: »[...] Als nun darauff das jüngstberichtete Nassau-Siegische Gravamen vorkahme/wurde beliebt/das deshalb vertröstete Memorial von dem Reformirten Fürsten noch vorhero zu erwarten $[\ldots] \ll^{76}$.

Die protestantische Siegener Regierung publizierte tatsächlich im September 1712 zwei Zeugenbefragungen, die in ihrem Sinne von den gewalttätigen Vorkommnissen am 26. Mai 1712 berichteten ${ }^{77}$. Vier Zeugen seien am 27. Mai 1712 auf der Siegener Kanzlei befragt worden; zur Beglaubigung unterzeichnete der Notar Heinrich Lipsius. Die übrigen Zeugen waren am 15. und 19. September 1712 in Siegen vernommen worden. Mehrheitlich sagten die Zeugen aus, soweit sie die Szenerie in der Siegener Innenstadt hatten überblicken können: 1. Zunächst hätten die Katholiken Steine auf die reformierte Garde geworfen; 2. Schüsse seien von den katholischen Kreistruppen auf die Garde abgeben worden; 3. einer oder wenige Schüsse seien von der Garde erwidert worden, bevor sich die Gardisten zurückgezogen hätten.

74 »Wöchentliche Relationen« (»Hallische Wöchentliche Relation«, die Einzelhefte heißen 1709/1711 auch: »Wöchentliche Relationen«), Halle a.d. Saale 1709ff;; hier Nr. 24 vom 13. Juni 1711.

75 Hamburger $»$ Relations-Courier«, Nr. 92 vom 13. Juni 1712.

76 Ebd., Nr. 116 vom 25. Juli 1712.

77 »Species facti, welcher Gestalt die Catholische in die Stadt Siegen am Frohnleichnamstag dises 1712 Jahrs armata manu eine Procession gehalten haben«, o.O. 1712; $2^{\circ}, 4$ Bll. 
Bis 1716 hatte vor allem die katholische Seite ihre Öffentlichkeitsarbeit verbessert. Heinrich von Achenbach weist darauf hin, dass nach dem Massaker an den protestantischen Weidenauern vom 27. Februar 1716 von den Parteien konträre Berichte verfasst und in Umlauf gesetzt wurden. Die katholische Administrationsregierung plazierte ihre Variante des Geschehens in der Kölnischen Zeitung, der Haarlemer Gazette und an anderen Orten ${ }^{78}$. Erst anschließend ließ die reformierte Regierung des Fürsten Friedrich Wilhelm Adolf eine Species facti erstellen und übersandte sie an Frankfurter, Hamburger und Nürnberger Zeitungen sowie an französische und niederländische Gazetten $^{79}$.

Diese zeitliche Abfolge führte dazu, dass auch die protestantischen Presseorgane zunächst die prokatholische Sicht vervielfältigten. Die Hallenser Wöchentliche Relationen berichtet am 28. März 1716 von dem Zusammenstoß in Weidenau:

In dem Nassau-Siegischen ist zwischen denen Catholischen und Reformirten ein neuer Krieg entstanden/indem die Bauren zu Weidenau dergestalt aufeinander gerathen $/ \mathrm{da} ß$ verschiedene ums Leben gekommen/und die übrigen durch Crey $\beta=$ Trouppen auseinander gejaget werden müssen ${ }^{80}$.

Der Bericht war offen tendenziös: Was in Wirklichkeit ein vermischter Herrschafts- und Konfessionskonflikt war, wurde in der Nachricht zu einer Massenschlägerei zwischen fanatisierten Untertanengruppen uminterpretiert. Die Kreistruppen erschienen als neutrale Schlichter des Streits zwischen dem gewalttätigen Pöbel - ihre Rolle als Exekutionsorgan der katholischen Administration blieb hingegen verborgen. Die deutlichste Form einer derartigen Interpretation findet sich im Wiener Diarium vom 17. März 1716: »Daß die Bauren der Gemeinde Weydenau/im Nassau-Siegischen/schon wieder rebelliert hätten; aber auch wieder auseinander verjaget worden wären « ${ }^{81}$.

Weitere Informationen zu diesem Fall erhielt der Wiener Leser nicht mehr; die folgenden Wochen bleibt die Zeitung zum Siegener Streit stumm. Anders die Wöchentliche Relationen. Sie revidierte ihren Bericht wenig später, als ihr präzisere Informationen (vermutlich durch die genannte Species facti über das Corpus Evangelicorum) zugegangen waren:

78 Von Achenbach, Geschichte der Stadt Siegen, Bd. 2, Tl. 10/1, S. 101.

79 Ebd., Bd. 2, Tl. 10/1, S. 101. - Die Berichte konnten allerdings bislang nicht aufgefunden werden.

80 »Wöchentliche Relationen«, Nr. 13 vom 28. März 1716.

81 »Von dem Maynstrom/vom 10. März«: »Wiener Diarium«, Nr. 1317 vom 17. März 1716. 
Von Cleve wird unterm 28. Mart. berichtet/daß der neulich zu Weidenau entstandene Tumult daher gerühret/daß/da man denen dasigen Reformirten Einwohnern angedeutet/daß ihnen ihre Kirche genommen werden sollte/die Catholicken so muthwillig gewesen/daß sie diese auf allerley Weyse insultiret/und so gar ihre Häuser zu plündern angefangen. Da nun die Reformirten sich widersetzet/und in der Confusion einen Notarium von ungefehr auf den Arm geschlagen/wäre ein Detachement von Chur=Pfältzisch= und Münsterischen Trouppen dazu gekommen/welches nicht nur die besten Reformirten Einwohner gefangen genommen/sondern auch an denen/die sie retten wollen/grosse Grausamkeit ausgeübet hat ${ }^{82}$.

Der Hamburger Relations-Courier verfügte bereits am 16. März über die korrekten Informationen zum Massaker in Siegen. Die Zeitung schrieb unter Berufung auf einen Düsseldorfer Korrespondenten:

An hiesigem Hofe ist von Siegen ein Expresser angelangt/welcher den völligen Verlauff des zwischen denen auff dasigem Schloß liegenden Münsterischen und Chur=Pfältzischen Cray $\beta=$ Trouppen / und denen Protestanten in selbigem Fürstenthum vorgangen/überbracht/und seynd von Seiten besagter Trouppen nebst den Todten 4 blessirt worden; an Seiten der Bauren aber 15 so wohl Manns= als Weibs=Personen todt blieben ${ }^{83}$.

Zum juristischen Nachspiel des Massakers vom Februar 1716 vor dem Corpus Evangelicorum schreibt die Wöchentliche Relationen aus Halle:

Die Fürst. Nassau=Siegische Regierung Reformirten Theils ist neulich wieder bey dem Evangelischen Corpore zu Regensburg wegen die Catholische Regierung mit einem gedruckten weitläuftigen Memorial eingekommen/wegen der am 27. Februar dieses Jahrs bey der Gemeine zu Weidenau Catholischer Seits vorgenommenen blutigen Action/dabey Mord und Todtschlag auch eine entsetzliche Religions=Turbation vorgegangen. Es ist in dem gedachten Memorial gebeten/eine solche Resolution in dieser Sache zu nehmen/damit die deshalb bereits abgefasste Reichs=Constitutions mäßige Conclusa würcklich vollzogen/und die bedrengeten Glaubens=Genossen ohne ferneren Anstand von ihrem Elend errettet werden möchte ${ }^{84}$.

82 »Wöchentliche Relationen«, Nr. 15 vom 11. April 1716.

83 »Düsseldorf/vom 9. Martii«: Hamburger »Relations-Courier«, Nr. 43 vom 16. März 1716.

84 »Wöchentliche Relationen«, Nr. 40 vom 3. Oktober 1716. 
Angefügt ist eine lange Fußnote, in der die früheren Religions-Bedrückungen vorgestellt werden, denen die Protestanten in Nassau-Siegen seit fast einem Jahrhundert ausgesetzt waren.

Die weiteren Auseinandersetzungen im Siegerland vollzogen sich ohne ständige Pressebegleitung. Niedergehende Staatswirtschaft, Selbstsucht auswärtiger Administrationsregierungen, konsequente kulturelle und religiöse Untergrundarbeit der geistlichen Orden sowie die Beharrungskraft der protestantischen Untertanenschaft waren keine Themen, mit denen die Zeitungen ihre damaligen Leser unterhalten konnten. Erst im Vorfeld des Herrschaftsübergangs an eine reformierte Landesherrschaft wurden wieder Druckwerke an die Öffentlichkeit gebracht. 1740 fertigte die reformierte Pfarrerschaft in Nassau-Siegen eine 40 Seiten starke Deduktion unter dem Titel Wahre Beschaffenheit ${ }^{85}$. Darin bekräftigten die Geistlichen ihren Standpunkt, dass die protestantischen Untertanen der katholischen Linie des Hauses NassauSiegen rechtmäßig im Besitz ihrer konfessionellen Rechte seien und darin nicht gestört werden dürften. Im Druck wurde darauf hingewiesen, dass der Text bereits zuvor dem künftigen Landesherren, Prinz Wilhelm Karl von Oranien-Nassau, übergeben worden sei. Der friesische Statthalter sei gebeten worden, nach seinem Regierungsantritt nicht nur die freie Ausübung des calvinistischen Bekenntnisses in allen Ausprägungen zu gewährleisten, sondern auch alle Entfremdungen von reformiertem Kirchengut durch die Katholiken seit 1700 rückgängig zu machen.

An entlegener Stelle kam Fürst Wilhelm Hyazinth von Nassau-Siegen 1742 noch einmal vor. Nachdem er bereits durch das Reichsvikariat von 1711 vorübergehend in seine Landesherrschaft wieder eingesetzt worden war, versuchte er dies beim Reichsvikariat von 1740-42 noch einmal. Eine Zusammenfassung der Conclusa des Vikariatshofgerichts, das Kurbayern und Kurpfalz gemeinschaftlich in Augsburg eingerichtet hatten, weist im zweiten Band acht Registereinträge zu Prozesshandlungen in dieser Sache aus. Die Rechnung ging jedoch offenbar nicht auf. Kennzeichnend ist die Entscheidung des Gerichts am 28. März 1741 zu einer Eingabe des Fürsten, die diesen als Querulanten erscheinen ließ: ponatur ad acta ${ }^{86}$.

Im Februar desselben Jahres berichtete die Berliner Zeitung über den nahe bevorstehenden Herrschaftswechsel in Siegen zugunsten des Prinzen von Oranien:

85 »Wahre Beschaffenheit Des Contra Instrumentum Pacis Westphalicae theils höchst turbirt, destituirt, und bedrängten/ theils aber anjetzo in weiterer und grösserer Gefahr situirten Evangelisch-Reformirten Status Ecclesiastici in dessen Fürstenthümern Nassau-Siegen, den 8. September 1740 angestellet«, o.O. 1740.

86 »Conclusa Welche Von einem gemeinsamen Höchst=preyßlichen Reichs=VicariatsHof $=$ Gericht $\mathrm{zu}$ Augspurg / Seit Höchst= desselben Eröffnung abgefasset worden [...]«, 2 Bd., Augsburg 1742, hier Bd. 2, S. 1350. 
Die bisherigen Streitigkeiten zwischen dem Printzen von Oranien, und dem Fürsten Wilhelm Hyacinth von Nassau=Siegen, sind nunmehro den 10ten dieses durch einen getroffenen Vergleich endlich gehoben worden. Krafft gemeldeten Vergleichs kömmt der Printz zum Besitz des Fürstenthumbs Siegen, und bezahlt dagegen dem Fürsten jährlich eine sehr beträchtliche Summe Geldes. Den 12ten. ist ein Expresser von hier nach Cassel abgegangen, um der Printzessin von Oranien die erfreuliche Zeitung von dem Vergleich zu überbringen; der Printz selbst aber wird innerhalb wenig Tagen nach Siegen reisen, und allda die Huldigung von Seinen neuen Unterthanen annehmen ${ }^{87}$.

Der 1743 erfolgte Tod des Fürsten Wilhelm Hyazinth hingegen war der Presse keiner gesonderten Notiz und keines Rückblicks wert. Todesnachrichten wurden nur von Päpsten, Kaisern, Königen und Kurfürsten sowie wenigen bedeutenden Reichsfürsten eingerückt. Hätten alle anthropologischen Übergangsereignisse adliger Personen in der Presse abgebildet werden sollen, wäre deren Umfang leicht verdoppelt worden, woran weder den Herausgebern noch der Leserschaft lag.

\subsection{Darstellung in den Zeitschriften}

Der konfessionell-politische Konflikt im Fürstentum Nassau-Siegen wurde für die Zeitschriften bereits im Jahre 1706 wahrgenommen. Eine sehr detaillierte Schilderung des Konflikts zwischen dem Fürsten Wilhelm Hyazinth und seinen Untertanen sowie zwischen den beiden katholischen und calvinistischen Regierungen in Siegen lieferte der Monatliche Staats-Spiegel, der von Stanislaus Reinhard Acxtelmeier im ersten Jahrzehnt des 18. Jahrhunderts in Augsburg herausgebracht wurde ${ }^{88}$. Gerade in der paritätischen schwäbischen Reichsstadt am Lech war die Sensibilität für die komplizierten Konkurrenz- und Kooperationsformen zwischen den Bekenntnissen besonders hoch ${ }^{89}$. Im August-Heft 1698 stellt Acxtelmeier den Konflikt zunächst in seiner Unübersichtlichkeit dar: Fürst Wilhelm Hyazinth beschwert sich vor dem Reichstag darüber, dass kurpfälzische Reiter sein Schloss besetzt und seinen Kanzler Graf von Jonquiers entführt hätten. Er vermutet, dies

87 »Franckfurt am Mayn, vom 16 Februar«: »Berlinische Nachrichten«, Nr. 24 vom 24. Februar 1742.

88 [AcXtelmeier], Monatlicher Staats-Spiegel; Worinnen der Kern aller Avisen; Ein Begriff der vornehmsten im H. Röm. Reich vorfallenden Affairen mit vilen Curiosen Beylagen, samt einigen Politischen Reflexionen sich repraesentirt und vorstellet.

$89 \mathrm{Zu}$ den Konfessionsverhältnissen in Augsburg nach dem Westfälischen Frieden: Etienne FrançoIs, Die unsichtbare Grenze. Protestanten und Katholiken in Augsburg 1648-1806, Sigmaringen 1991. 
sei auf kaiserliche Anordnung hin geschehen ${ }^{90}$. Der Fürst ließ daraufhin drei Traktate anfertigen und an viele Reichsstände schicken. Ob diese Traktate gedruckt erschienen, ist einstweilen unklar, keines von ihnen ist bislang aufgefunden worden ${ }^{91}$.

Im Folgenden dominierten bei Acxtelmeier die Religionsbeschwerden aus dem Fürstentum Nassau-Siegen. Am 15. Februar 1707 legten die reformierten Untertanen des Fürstentums Nassau-Siegen eine Religionsbeschwerde am Reichstag vor. Der Hinweis im Quellenabdruck, dass das Schriftstück in der kursächsischen Kanzlei diktiert worden ist, deutet auf eine Eingabe (oder Weiterleitung) an das Corpus Evangelicorum hin. Die Nassauer Untertanen beschwerten sich über die Behinderung des reformierten Kults, die Wegnahme der Kirchen, die Einsetzung katholischer Lehrer und die Errichtung eines katholischen Schulzwangs für reformierte Kinder, das Verbot des reformierten Presbyteriums, das Verbot des Heidelberger Katechismus und anderer reformierter Bücher. Es hat den Anschein, dass für die Supplik soweit sie abgedruckt ist - keine konkrete Regierungsmaßnahme verantwortlich war, sondern dass es sich um eine summarische Klage über die religiösen Bedrückungen der vergangenen 50 Jahre handelte, denn die Klagepunkte erscheinen sehr unspezifisch ${ }^{92}$.

Johann Jakob Schmauss weist in seiner Zeitschrift Curieuses BücherCabinet darauf hin, dass mit dem Jahr 1706 die öffentliche Berichterstattung über den Siegener Konflikt ihren Anfang genommen habe. Der Einmarsch der kurpfälzischen, kurkölnischen und kurbrandenburgischen Kommissionstruppen habe nicht nur die Abreise des Fürsten zunächst nach Aachen, dann nach Regensburg zur Folge gehabt, sondern auch das Erscheinen zahlreicher Protestflugschriften und Deduktionen am Reichstag ${ }^{93}$.

In der Europäischen Fama taucht der Siegener Konflikt in Heft 66 im Jahre 1707 erstmals auf. Herausgeber Philipp Balthasar Sinold von Schütz kommentiert die Herrschaftsentsetzung Wilhelm Hyazinths mit folgenden Worten:

90 Staats-Spiegel, August-Heft 1706, S. 65-76. - Diese Vermutung wird auch in der Zeitschrift »Der Welt Urtheile« aufgegriffen: »Der Welt Urtheile von den gegenwärtigen Staats-, Kriegs-, gelehrten und gemeinen Sachen schertz- und ernsthafft ausgeführet«, 2 Bd. (20 H.), Leipzig 1706-1711, hier Bd. 1, 4. Pensée, S. 328-335.

91 1. Traktat: »Kurtzer Bericht von der Chur=Pfältzischen Dragonern geschehener Invasion und gewaltsamen Occupirung deß Residentz=Schlosses zu Siegen [...]«: Staats-Spiegel, AugustHeft 1706, S. 66-69; 2. Traktat: »An den Höchst=preißlichen Reichs=Hof=Rath/praemissis praemittendis remonstrandum« (ebd., S. 70-72); 3. Traktat: »Lettre Circulaire aux Princes \& Estats de l'Empire«, herausgebracht in Den Haag am 12. August 1706 (ebd., S. 73-76).

92 Ebd., Februar-Heft 1707, S. 62-65.

93 Antonio Paullini [d.i. Johann Jakob Schmauss], Curieuses Bücher-Cabinet oder Nachricht von Historischen Staats- und galanten Sachen, 8 Bd., Frankfurt a.M./Köln 1711-1722, hier Bd. 1, 1711, S. 906-908. 
Der Römisch-Catholische Fürst von Nassau=Siegen hat sich aus seinem Lande retiriret, nachdem zu Stillung der bißherigen Unruhe einige Königl. Preußische, Chur=Pfältzische und Ertz=Stifft $=$ Cöllnische Trouppen hinein marschiret. So hat er auch seinen grossen Staat/als angemaßter Printz von Oranien abgeschaffet sintemal er nicht allein 12. Hofcavaliers, eben so viel Pagen und 24. Laquayen, sondern auch 30. Musicanten und Comüdianten, wie ingleichen so viele Trabanten, 12. Trompeter, nebst 24. Jägern gehalten, und soll dieser Hof=staat meistentheils aus Frantzosen und Italiänern bestanden seyen also daß dieses kleine Fürstenthum den Unterhalt einer so grossen Anzahl Bedienten nicht verschaffen können, die Fürstl. Anverwandten sich der bedrängten Unterthanen haben annehmen, und um Abstellung der verwirrten Haußhaltung gehöriger Orten klagen müssen ${ }^{94}$.

Dieser Kommentar ordnete den Streit in den größeren Zusammenhang ein und traf damit genau das Zentrum des Problems in Nassau-Siegen: Fürst Wilhelm Hyazinth hatte sich in den Kopf gesetzt, im Stile der Zeit seinen persönlichen Rang zu heben. Da ihm praktische Ansatzpunkte für territoriale Zugewinne oder das Erlangen attraktiver Ämter auf europäischer Ebene fehlten, blieb ihm nur die symbolische Politik: Als souveräner Fürst von Oranien stellte er sich nach dem Tod von Wilhelm III. von Oranien dar, ungeachtet der unklaren Erblage. Diesem angestrebten Rang zuliebe wurde der Hofstaat im zitierten Umfang ausgebaut. Dabei spielte wohl eine Rolle, dass der Fürst die Aufmerksamkeit des französischen Königs erregen wollte, um von diesem gefördert zu werden - die Dominanz französischer Höflinge weist darauf hin. Außerdem ist nicht auszuschließen, dass das Vorbild des bayerischen Kurfürsten Max Emanuel, mit französischer Hilfe seine Macht zu erweitern, in Siegen Schule machte - auch wenn man klug genug war, einer Konfrontation mit dem Kaiser aus dem Wege zu gehen. Die Regierungsdetails in Siegen blieben allerdings verborgen, sowohl der Justizmord an Friedrich Flender als auch die kaiserlichen Entscheidungen gegen Wilhelm Hyazinth.

Im August-Heft 1707 konkretisierte sich die Berichterstattung im Monatlichen Staats-Spiegel, wobei Acxtelmeier sich auf ein nassauisches Memoriale der calvinistischen Seite in Siegen stützen konnte, das der Staatsrechtler Julius Wilhelm Zinkgraf im Vormonat beim Corpus Evangelicorum in Regensburg eingereicht hatte. Der Jurist führte darin aus, es sei »Reich kundig«, dass in Nassau-Siegen seit dem 16. Jahrhundert das protestantische Bekenntnis gelte, auch 1624, zum Normaljahrsstichtag. Die Rekatholisierung habe erst 1626 eingesetzt, sei aber dessen ungeachtet nach 1648 fortgesetzt worden. Es folgt eine weit ausholende Aufstellung der Gegenrefor-

94 Europäische Fama, hier 66 (1707), S. 434. 
mationsmaßnahmen in Siegen und Umgebung mit mehreren Beilagen ${ }^{95}$. Ein weiteres Memoriale Zinkgrafs im Namen der protestantischen Fürsten von Nassau wurde im April 1709 in Regensburg eingereicht. Darin führte der Jurist jüngere Konfessionsverstöße der kaiserlichen Kommissionsregierung des Kölner Domkapitels auf ${ }^{96}$. Die Kommissionsregierung konterte mit einer Beschwerde an den Reichstag, die sich gegen den Ungehorsam der Siegener Untertanen richtete. Auf die vorausgegangenen Konfessionsbeschwerden wurde mit keinem Wort eingegangen ${ }^{97}$. In den folgenden Monaten gingen weitere Beschwerden beider Seiten in Regensburg ein, wobei die Argumentationsmuster Konfessionsbeschwernis vs. Ungehorsam gleich blieben.

Mit dem Jahr 1710 setzt die Berichterstattung im Welt= und Staats=Spiegel von Johann Ehrenfried Zschackwitz ein ${ }^{98}$. Radikaler als in den anderen Zeitschriften wird hier der protestantische Standpunkt vertreten, wobei die Urheber »unruhige Geistliche« der katholischen Seite seien ${ }^{99}$. Zschackwitz druckt Memoranden der katholischen Siegener Exil-Regierung in Hadamar sowie der kaiserlichen Kommission in Siegen ab und stellt eine Eingabe der reformierten Siegener Regierung an das Corpus Evangelicorum dagegen ${ }^{100}$. Die katholischen Eingaben beim Reichstag bezeichnet Zschackwitz als »mit lauter ungründigen Dingen angefüllet«.

Im Appendix von Heft 36 des Jahrgangs 1711 druckt Zschackwitz das Restitutionsmandat des kurpfälzischen Vikariatshofgerichts vom 24. Oktober $1711 \mathrm{ab}$, durch das Fürst Wilhelm Hyazinth von Nassau-Siegen wieder in den vorigen Besitz seiner Lande eingesetzt wurde ${ }^{101}$. Kurfürst Johann Wilhelm von der Pfalz interpretierte dabei das Reichsgutachten vom 19. Juli 1709 als Zustimmung zur Position von Wilhelm Hyazinth. Im Folgenden finden sich weitere Hinweise darauf, dass Kurpfalz auch seine Rechte als Ausschreiben-

95 Staats-Spiegel, August-Heft 1707, S. 10-20.

96 Das Memoriale wurde in Regensburg am 27. April 1709 diktiert: ebd., April-Heft 1709, S. 14-21.

97 Die Beschwerde wurde in Regensburg am 30. April 1709 diktiert: ebd., Mai-Heft 1709, S. 13-16.

98 [Johann Ehrenfried Zschackwitz (Hg.)], Neu=eröffneter Welt= und Staats=Spiegel $/$ Worinnen die in Europa/wie auch denen andern Theilen der Welt/vornehmlich in Teutschland vorfallende merckwürdigen Begebenheiten kürtzlich vorgestellet [...] wird, 8 Bd. (T1. 1-100), Haag [=Leipzig] 1709-1716.

99 Ebd., Jg. 1710, Bd. 1, H. 9, S. 834.

100 Memorial der Siegener Administrations-Regierung (kath.) gegen Fürst von Nassau-Siegen (ref.) wegen Religionsstreit an die Reichstagsgesandten, dictat. Regensburg, 3. Januar 1710: Welt $=$ und Staats=Spiegel, Jg. 1710, Bd. 1, H. 9, S. 834-839; Memorial der Siegener Regierungsräte (kath., in Hadamar) gegen Fürst von Nassau-Siegen (ref.) wegen Religionsstreit an die Reichstagsgesandten, dictat. Regensburg, 25. Januar 1710: Ebd., S. 884-886; Memorial der Siegener Regierung (ref.) gegen die Eingabe der katholischen Siegener Regierung, dictat. am Corpus Evangelicorum, Regensburg, 12. Februar 1710: Ebd., S. 950-952.

101 Welt $=$ und Staats=Spiegel, Jg. 1711, Bd. 3, H. 36, S. 1108f.; Wiederabdruck: Jg. 1711, Bd. 4, H. 37, S. $87 f$. 
der Fürst des Niederrheinisch-Westfälischen Reichskreises zugunsten der Siegener Katholiken instrumentalisierte.

Johann Jakob Schmauss mochte in seinem Bücher-Cabinet die einseitige Verantwortlichkeit der Katholiken für die problematische Lage nicht so stehen lassen, obwohl er kein katholischer Sachwalter war. Er kritisierte vor allem die grobe Wortwahl, mit der auf protestantisch-nassauischer Seite argumentiert werde:

Der Streit wird bis dato noch hefftiger fortgesetzt/die gewechselten Schrifften aber/vornehmlich auf Reformirter Seite/sind mit solchen anzüglichen personalibus und injuriösen Redens $=$ Arten angefüllet $/ \mathrm{da} ß$ ein gewisser verständiger Mann urtheilet/es werde nicht leicht ein scriptum publicum in controversiis illustribus vorkommen/da $\beta$ es ärger gemacht worden/als in diesen Fürstl. Nassauischen Streitschriff$\operatorname{ten}^{102}$.

Grund dafür - so Schmauss - sei der Konzipist der reformierten Nassauer, der Theologe Caspar Eberhardi. Obwohl es auch in den katholischen Drucken an sarcasmis nicht gemangelt habe, so sei in den reformierten Schriften doch der Respekt vor Reichsfürsten und dem ganzen Reichskonvent missachtet worden ${ }^{103}$.

Auf diese differenzierten Expositionen des Siegener Konfessionskonflikts konnte die Berichterstattung 1712 aufbauen. Dabei bestätigte Zschackwitz seine Grundhaltung, als er zum Zusammenstoß vom Fronleichnamstag am 26. Mai 1712 in Siegen schrieb:

In Siegen stiftete die Römische Clerisey abermahls ein ziemlich Blut=Bad und Unruhe. Denn als solche zu Anfang des Monates Junii [sic!] ihren Umgang halten/und vor dem Fürstl. Schlosse vorbey gehen wollte, warnete die deswegen dahin gestellte Wache sei zwar wegen dieses Begehrens, weil sie darzu nicht berechtiget wären, doch jene, deren Art insgemein ist, nach Rechte nicht viel zu fragen, drunge mit Gewalt durch, so daß die Wacht sich genöthiget sahe, der auflauffenden Menge zu weichen. Indessen geschah von ohngefähr, daß ein Soldat, der sein Bajonet auf die Flinte gestoßen, hinter sich einen der Römisch=Catholischen verwundete/welches wenig vergossene Blut aber bey diesen rasenden Leuten ein rechter Zunder zu mehrerer Tollheit ware, indem da sich den Aufruhr ungemein vergrösserten, und die darbey seyenden Münsterischen Soldaten dahin bewegeten, auf ermeldte Wache Feuer zu geben/wodurch zwei Gemeine und ein Lieutenant todt geschossen ward. indem nun die Garde sich weiter wehrete, wurden die Papisten vollends gar so kühn, daß sie das Schloß mit Canonen beschossen. Diese von großer Wichtigkeit seyende Sache, berichtete der dasige Hof

102 Bücher-Cabinet, Bd. 1, 1711, S. 905.

103 Ebd., Bd. 1, 1711, S. 906. 
[= der reformierte Hof des Fürsten Friedrich Wilhelm Adolf von Nassau] so gleich an Ihr. Königl. Majestät in Preussen, die sothane Unfug schwerlich mit einem blossen Achsel=Zucken anschauen durfften ${ }^{104}$.

Die Wertungen, nach denen der katholischen »Clerisey« (nicht den Soldaten) die Gewalttat zugeschrieben wurde, die Anerkennung des Reichsrechts bezweifelt, die Attribute »toll« und »kühn« vergeben und zuletzt noch das fehlende Vertrauen der reformierten Regierung in die kaiserliche Unparteilichkeit formuliert wurden, waren eindeutig.

So blieben auch Hinweise auf allerhöchste Proteste gegen die Gewalttat nicht aus. Das Protestschreiben Kurfürst Georg Augusts von Hannover an den Kaiser vom 11. Juni 1712 wurde mit einem Hinweis auf den Blutdurst der »Papisten« und »Jesuiten« anmoderiert, am Ende folgt das Fazit des Redakteurs:

Allerdings weiset die Erfahrung/wie die Durchl. Feder meldet/daß die Papisten mit nichts anders/als der Protestanten Untergang umgehen. Allein da jene an keine Reichs $=$ Constitutiones sich binden/warum thun diese solches nicht auch/und gebrauchen die in allen Rechten erlaubte Gegenwehr/weil doch die täglichen querelen besagen $/ \mathrm{da} ß$ die Papisten über alle Reichs=Satzungen sich nur zu moquiren pflegen ${ }^{105}$.

Dass der Herausgeber des Welt $=$ und Staats=Spiegel hiermit einen verklausulierte Aufruf zum gewaltsamen Widerstand gegen katholische Machinationen publizierte und sich damit in einen Widerspruch zum Religionsfrieden von 1648 und seinem Lästerverbot setzte, nahm er offenbar in Kauf. Einige Seiten später brachte Zschackwitz eine weitere Eingabe der reformierten Nassau-Siegener Regierung an das Corpus Evangelicorum ${ }^{106}$.

Der Austrag der Kontroverse vor den Reichsgremien wurde der Leserschaft deutlich, als Zschackwitz einen Brief des Kurfürsten Johann Wilhelm von Pfalz-Neuburg an das Corpus Evangelicorum abdruckte ${ }^{107}$. Darin stellte der Kurfürst den Siegener Sachverhalt völlig anders dar und ließ die reformierte Seite als die schuldige erkennen. Münster und Kurpfalz - als Entsender des Kreiskontingents - hätten Satisfaktion zu verlangen. Der Kurfürst überließ die Angelegenheit im Weiteren dem Kaiser.

104 Welt= und Staats=Spiegel, Jg. 1712, Bd. 4, H. 45, S. 765f.

105 Zum Schreiben des Kurfürsten und der Einbettung durch Zschackwitz: ebd., Jg. 1713, Bd. 5, H. 54, S. 457-459.

106 Protest, im Corpus Evangelicorum präsentiert am 30. Juli 1713: ebd., Jg. 1713, Bd. 5, H. 54, S. 470-478.

107 Brief von Kurfürst Johann Wilhelm von Pfalz-Neuburg an das Corpus Evangelicorum vom 11. Januar 1713: ebd., Jg. 1714, Bd. 6, H. 67, S. 538-540. 
Später weist Zschackwitz seine Leser darauf hin, dass der Religionsstreit zwischen dem Fürsten Wilhelm Hyazinth von Nassau-Siegen und seinen protestantischen Untertanen inzwischen »viele Volumina« an Akten ausmache. Strategisch wolle der Fürst den Streit an den Reichshofrat übertragen, da er den Kaiser auf seiner Seite vermutete. Die reformierte Siegener Regierung hingegen wende sich weiterhin an das Corpus Evangelicorum ${ }^{108}$. Die Vermutungen der Regierung und des Redakteurs erfüllten sich, als der Reichshofrat 1713 den Kurfürsten von Trier und den Landgrafen von Hessen-Darmstadt als kaiserliche Kommissare zur Klärung der Siegener Angelegenheiten einsetzte, ohne dass diese eine Änderung bewirken konnten ${ }^{109}$.

Der zweite blutige Zusammenstoß im Siegerland am 27. Februar 1716 wurde vor allem in der Europäischen Fama kommentiert. Sie war von der prokatholischen Interpretation des Geschehens betroffen, als sie in Heft 184 berichtete, dass die unruhigen Weidenauer Untertanen im Fürstentum Nassau-Siegen sich mit Gewehren zusammengerottet hätten, um zu rebellieren. Davor waren sie schon von der Obrigkeit zu ruhigem Verhalten gemahnt worden. Sie hätten aber den Amtsschultheißen und den Notar verprügelt, auch auf Zeugen geschossen. Daraufhin habe am 27. Februar 1716 das Niederrheinisch-Westfälische Kreiskommando 50 Mann schicken müssen, um die Ordnung wiederherzustellen. Bei Herannahen des Kommandos seien 200 bis 300 Bauern zusammengelaufen und hätten Schüsse auf die Kreissoldaten abgegeben. Der Leutnant Brischar sei dabei durch den Kopf geschossen worden. Erst anschließend hätten die Kreissoldaten zurückgeschossen, wobei 7 bis 8 Weidenauer ums Leben gekommen und 4 weitere verwundet worden seien ${ }^{110}$.

Vier Hefte später musste der Herausgeber eingestehen, sich geirrt zu haben. Es sei unzutreffend gewesen, die Untertanen in Weidenau der Rebellion zu beschuldigen. Die Europäische Fama schrieb wörtlich:

Es wird der geneigte Leser in vorigem Theile etwas davon finden, so eine Catholische Feder aus dem Westerwalde in die Welt geschrieben, und worinnen die guten Weidenauer Unterthanen einer Rebellion beschuldiget werden. Es befindet sich aber die Sache gantz anders, weder man sie daselbst abgemahlet; und die Liebe zur Wahrheit befiehlet uns, da man seit der Zeit bessere Information eingezogen, selbige dem Publico und der Ehrbahren Vernünfftigen Welt nicht zu verschweigen ${ }^{111}$.

108 Zschackwitz bringt in diesem Zusammenhang eine weitere Eingabe der reformierten Nassau-Siegener Regierung an das Corpus Evangelicorum, praes. Regensburg 4. Juli 1713: ebd., Jg. 1715, Bd. 8, H. 78, S. 489-491 zzgl. Anlagen.

109 Reichshofrats-Conclusum vom 23. Mai 1713: ebd., Jg. 1715, Bd. 8, H. 78, S. 492.

110 Europäische Fama 184 (1716), S. 290-292.

111 Ebd. 188 (1716), S. 647-651, bes. S. 648. 
Inzwischen seien verbesserte Informationen aus dem Umfeld des Corpus Evangelicorum eingegangen. Demnach ging es um die reformierte Kapelle und Schule in Weidenau, deren Kircheneinkünfte von katholischer Seite eingezogen worden seien. Auch sei ein katholischer Schulmeister installiert worden. Wegen des protestantischen Widerspruchs sei den Beteiligten eine hohe Strafsteuer auferlegt worden. Deren künftige Versammlungen seien bei schweren Strafandrohungen verboten worden ${ }^{112}$. Auf insgesamt vier Druckseiten fasste der Redakteur die Gewalttaten der katholischen Kommissionsregierung und ihrer Soldaten (bzw. des kurpfälzischen Kreiskontingents) zusammen. Vor allem das Handgemenge vom 27. Februar 1716 und die anschließenden Auseinandersetzungen zwischen den reformierten Hammerschmieden und den pfälzischen Kreissoldaten, bei denen durch Granatenwurf neun Weidenauer getötet wurden, wurden unter mitfühlenden Worten für die Protestanten geschildert. Auf Seiten der Pfälzer sei ein Leutnant und ein Gemeiner ums Leben gekommen. Etliche Weidenauer seien auf das Schloss Siegen in Gewahrsam geführt worden, wo ihnen ein »schlimmes Urtheil« drohe - nur der Kaiser könne helfen ${ }^{113}$. In Heft 191 wurde noch angeführt, dass die Weidenauer Untertanen das Corpus Evangelicorum angeschrieben hätten, sich für ihre Rettung beim Kaiser zu verwenden ${ }^{114}$.

Noch einmal tauchte die Siegener Konfessionsproblematik in der Europäischen Fama auf: Im Jahr 1720 griff der Redakteur Christian Gottfried Hoffmann eine Deduktion der Religionsbeschwerden auf, die das Corpus Evangelicorum kurz zuvor im Druck hatte herausgehen lassen. Leider wird der Titel der Schrift nicht genannt. Sie enthielt einen Abriss der Siegener Katholisierungsgeschichte seit 1623, die Restitution der Calvinisten nach 1648 sowie die neuerlichen Katholisierungsbestrebungen unter Fürst Wilhelm Hyazinth und den folgenden Kommissionsregierungen. An dieser Stelle wurden auch die beiden bewaffneten Zusammenstöße in Siegen 1712 und Weidenau 1716 noch einmal in Kurzfassungen präsentiert ${ }^{115}$. Ausführlichere Wertungen fehlten allerdings, auch wurden die Einzelheiten des weiteren Konfliktsverlaufs nicht aufgeführt.

Erst 1740 geht die inzwischen laufende Neue Europäische Fama, herausgegeben von Christian Schumann, auf die Lage in Nassau-Siegen ein ${ }^{116}$. Nun ging es um den bevorstehenden Wechsel in der Landesherrschaft, da Fürst Wilhelm Hyazinth keinen legitimen und sukzessionsfähigen männlichen Erben hatte. Schon versuche der Prinz von Nassau-Oranien, so schrieb

\footnotetext{
112 Mandat der Kommissionsregierung vom 22. Februar 1716: ebd. 188 (1716), S. 649.

113 Ebd. 188 (1716), S. 650f.

114 Ebd. 191 (1716), S. 891. - Ansonsten findet sich ein kurzer Hinweis auf den Weidenauer Zwischenfall im »Historische[n] Mercurius«, Jg. 1716, H. 1, S. 341.

115 Europäische Fama 235 (1720), S. 589-593.

116 Neue Europäische Fama.
} 
die Zeitung, den exilierten Siegener Fürsten zum Verzicht auf seine Ansprüche in Siegen und Dillenburg zu bewegen. Der Fürst habe dies jedoch abgelehnt und hoffe, auf der Grundlage eines Reichshofratsentschlusses wieder als Landesherr nach Siegen zurückkehren zu können ${ }^{117}$. Im selben Jahr weist die Zeitschrift auf die Flugschrift Wahre Beschaffenheit des contra Instrum. [entum] P.[acis] W.[estphalicae] [...] Evangel. Reformirten Status Ecclesiastici, worin die Forderung der Protestanten erhoben worden war, dass für Siegen ein religionsrechtliches Konservatorium errichtet werde, falls der Fürst doch noch seine früheren Herrschaftsrechte zurückerlangen sollte ${ }^{118}$. Die Gefahr erschien dem Herausgeber allerdings nicht sehr groß:

Die Zeitungs=Schreiber haben bisher mit diesem Fürsten, von welchem wir bei gegenwärtigen Gelegenheiten etwas beybringen können, wunderliche Comödien gespielet, bald soll er es nicht selbst, sondern eine vermumte Person seyen, bald soll er sich wieder aus dem Reiche entfernet haben; den neuesten Nachrichten zu Folge aber ist er mit besonderer distinction zu Cölln empfangen worden ${ }^{119}$.

Fürst Wilhelm Hyazinth erscheint hier als Chimäre, die von der Presse überall und nirgends gesichtet wird.

Drei Jahre später wurde das Ableben des Fürsten auf ganz unspektakuläre Weise vermittelt: »Der alte Fürst Wilhelm Hyazinth von Nassau-Siegen ist nunmehro auch zu Hadamar im 77 Jahr seines Alters verschieden, davon man die Nachricht sogleich an den Printzen von Oranien überbracht hat $\aleph^{120}$. Das Thema der Konfessionskonflikte in Nassau ist damit überholt, es geht aus den Händen der Gazettiers und Journalisten in die der Historiographen über. Der beträchtliche Jubel der Siegener, soweit sie protestantischen Bekenntnisses waren, eignete sich nicht für eine gesonderte Erwähnung. Jubel besaß noch keinen eigenen Medienwert als authentische Gefühlsäußerung, sondern wurde nur erwähnt, falls er im Rahmen von Inszenierungen erwartet und erwünscht war. Menschenmassen erschienen ansonsten nur als Mediensubjekte, sobald sie begannen, Gewalt und Zerstörung zu verüben. Den Abschluss machte der kurze Hinweis auf den Nachfolger, Prinz Wilhelm Karl von Oranien-Nassau: »Der Prinz von Oranien hat ohnlängst die Belehnung über seine Nassauische Lande am Kayserl. Hof erhalten, wofür $12.000 \mathrm{Fl}$. an die Reichs $=$ Cantzley bezahlt worden $\ll^{121}$.

\footnotetext{
117 Ebd. 6 (1740), H. 59, S. $934 f$.

118 Ebd. 6 (1740), H. 68, S. 640-642.

119 Ebd. 6 (1740), H. 68, S. 640f.

120 Ebd. 8 (1743), H. 93, S. 753.

121 Ebd. 9 (1744), H. 108, S. 1008.
} 


\subsection{Historienschriften und Reichsrechtskompilatorien}

Aufgrund der zurückhaltenden Medienberichterstattung wurde der Siegener Konfessionsstreit auch in den Historienschriften eher am Rande behandelt. Das Theatrum Europaeum greift das Thema erst 1709 erstmals auf, ohne jedoch substanzielle Details zu nennen ${ }^{122}$. In Band 19 werden zwei Dokumente präsentiert. Zunächst erfährt der Leser, dass die kaiserliche Administrations-Kommission in Siegen ein Memorial an das Reichstagsdirektorium gesandt hat: Darin weist die Kommission alle Schuld am herrschenden Disput auf den evangelisch-nassauischen Kanzleidirektor, der eine unzulässige Klage vor dem Corpus Evangelicorum zur Folge gehabt habe. Die Grundlage für die konfessionelle Parität in Siegen sei der Vertrag von $1651^{123}$. Im selben Band druckt der Redakteur das Vikariatsdekret des Kurfürsten Johann Wilhelm von der Pfalz vom 24. Oktober 1711 ab. Darin setzt der Kurfürst den suspendierten Fürsten Wilhelm Hyazinth von Nassau-Siegen wieder in seine Herrschaft ein. Alle Siegener Beamten, die dem Fürsten zuvor unterstanden hatten, wurden wieder zum Gehorsam ihm gegenüber verpflichtet ${ }^{124}$ Der 20. Band führt nur die Belehnung der beiden Halbbrüder des Fürsten Wilhelm Hyazinth von Nassau im Jahre 1713 auf ${ }^{125}$. Auf den gewaltsamen Zusammenstoß von 1712 geht das Theatrum Europaeum nicht ein.

Johann Christian Lünig handelt ebenfalls mehrere Deduktionen über den Nassauer Konflikt ab, ohne ihm jedoch einen besonderen Stellenwert einzuräumen. In der Bibliotheca deductionum S.[acri] R.[omani] I.[mperii] werden acht Religionsdrucke, zwölf Sukzessionsdrucke und zwei Sequesterdrucke auf insgesamt elf Seiten präsentiert ${ }^{126}$. Auch in Lünigs Teutscher Reichs-Cantzley ist das Thema Nassau-Siegen im Wesentlichen durch sechs Deduktionen vertreten $^{127}$.

122 [Carl Gustav Merians Erben (Hg.)], Theatri Europaei Achtzehender Theil Oder Außführlich fortgeführte Friedens- und Kriegs-Beschreibung [...], Frankfurt a.M. 1720, 3 T1. mit separater Paginierung, hier T1. 3, S. 173-179.

123 [Carl Gustav Merians Erben (Hg.)], Theatri Europaei Neunzehender Theil. Oder Außführlich fortgeführte Friedens- und Kriegs-Beschreibung [...], Frankfurt a.M. 1723, 2 T1. mit separater Paginierung, hier T1. 1, S. 166f.

124 Theatrum Europaeum, Bd. 19, T1. 1, S. 641.

125 [Daniel SchneIDER], Theatri Europaei Zwantzigster Theil. Oder/Ausführlich fortgeführte Friedens $=$ und Kriegs $=$ Beschreibung. Und was mehr Von denck $=$ und merckwürdigsten Geschichten in Europa [...] vom 1713. biß zu Ausgang des 1715ten Jahres vorgegangen und sich begeben haben. [...], Frankfurt a.M. 1734, 3 Tl. mit separater Paginierung, hier T1. 1, S. 341.

126 Johann Christian LüNIG (Hg.), Bibliotheca deductionum S.R.I, anietzo in eine geschicktere Ordnung gebracht, durchaus verbessert, und ansehnlich vermehret von Gottlob August Jenichen, 4 Tl., Leipzig 1745, hier T1. 2, S. 144-154.

127 Johann Christian LüNIG, Die Teutsche Reichs-Cantzley, worinnen zu finden auserlesene Briefe, welche von Kaysern, Königen, Chur- und Fürsten, Praelaten, Grafen und Herren, auch Rittern, Edlen und Unedlen, ingleichen freyen Republicken, Reichs- Crayß- und Land-Stän- 
Dokumentarische Pflichten führten zum Abdruck von 19 Dokumenten zum Siegener Streit in Eberhard Christian Wilhelm von Schauroths großer Edition der Quellen des Corpus Evangelicorum ${ }^{128}$. Allerdings findet keine Bewertung der einzelnen Schriften durch den Herausgeber statt. Als beste Zusammenstellung über den geschichtlichen Hergang des Konflikts eignet sich das kurze Promemoria des Corpus Evangelicorum an Kurfürst Clemens August von Köln vom November $1724^{129}$.

Etwas umfangreicher ist die Berichterstattung in Anton Fabers Europäische Staats-Cantzley ${ }^{130}$. Die erste Erwähnung ist aus dem Jahr 1707 überliefert, als die Quellensammlung in Band 12 zwei protestantische Schriftsätze gegen die katholischen Konfessionsübergriffe abdruckt. Begleitet werden die Texte von zwei rückgreifenden Dokumenten, zum einen das Katholisierungsmandat Graf Johanns VIII. von Nassau aus dem Jahre 1626 und zum anderen ein Extrakt aus der Kaiserlichen Kommissions-Sentenz zur Frage der Nutzung der Siegener Nikolai-Kirche durch die Konfessionsgruppen von $1650^{131}$. In Band 15 erscheint ein Mandat Kaiser Josefs I. an Fürst Friedrich Wilhelm Adolf von Nassau-Siegen vom Dezember 1708 mit der Aufforderung, alle religiösen Neuerungen zugunsten der Protestanten rückgängig zu machen ${ }^{132}$. Damit korrespondiert die Deduktion Wahrhaffte Vorstellung von Seitten der Fürstlich=Siegischen Administrations=Cantzley, den Punctum religionis betreffend von 1709, die alle reformierten Vorwürfe zurückweist ${ }^{133}$. Ausführlich wird die protestantische Sicht des Konflikts im Memorandum des Kanzleidirektors Julius Wilhelm Zinkgraf vom April 1709

den [...] de A. 1648 [...] bis auf [...] dieses 1714. Jahr [...] in teutscher Sprache abgelassen worden, 24 Bd., Leipzig 1710-1722, hier Bd. 6 (1714) und Bd. 7 (1715).

128 Eberhard Christian Wilhelm von Sснаuroth (Hg.), Vollständige Sammlung aller Conclusorum, Schreiben und anderer übrigen Verhandlungen des hochpreislichen Corporis Evangelicorum (1663-1752) ... nach Ordnung der Materien zusammen getragen, 3 Bd., Regensburg 1751-1752, bes. Bd. 2, S. 208-242.

129 Ebd., Bd. 2, S. 235-237.

130 FABER [ $=$ Christian Leonhard Leucht], Europäische Staats-Cantzley, darinnen zum Behuff der neuesten politischen-, Kirchen- und Reichshistorie [...] abgehandelt worden und zum Vorschein gekommen ist.

$131 »$ Deductio Gravaminum« vom 21. Mai 1707: ebd., Bd. 12, S. 141-157; Memoriale der fürstlichen Linien Nassau gegen Nassau-Siegen (kath.) wegen verschiedener gegenreformatorischer Maßnahmen, dictat. Regensburg 30. Juli 1707: Ebd., Bd. 12, S. 118-128; Katholisierungsmandat des Grafen Johann VIII. von Nassau-Katzenelnbogen (Siegen kath.), 6. Juni 1626: Ebd., Bd. 12, S. 129-140; Extrakt aus der Kaiserlichen Kommissions-Sentenz zur Frage der Nutzung der Siegener Nikolai-Kirche durch die Konfessionsgruppen, 4./14. November 1650: Ebd., Bd. 12, S. 140.

132 Das Mandat vom 10. Dezember 1708 bezieht sich auf eine Beschwerde des Kölner Domkapitels als Kommissionsregierung: ebd., Bd. 15, S. 16f.

133 Ebd., Bd. 15, S. 41-62. 
deutlich, das bereits im Staats-Spiegel von Stanislaus Reinhard Acxtelmeier publiziert worden war ${ }^{134}$.

In Band 17 der Staats-Cantzley wird deutlich, dass der Siegener Konfessionskonflikt bereits vollständig in die Debatten auf den Reichsversammlungen integriert war. Kurbrandenburg und Kurhannover, die Protektoren der Protestanten in der Kurpfalz und im Herzogtum Berg, hatten sich auch der diplomatischen Vertretung der Siegerländer Glaubensbrüder angenommen. Auf der anderen Seite operierten der Kaiser, der Reichshofrat, die Kurpfalz und das Kurkölner Domkapitel zusammen, um unter Koordination der Siegener Jesuiten die Rekatholisierung Nassaus zu fördern. Mehrere Quellen aus dem Jahr 1711 dokumentieren diese Bemühungen der beiden Lager ${ }^{135}$. Am Ende wurde, wie andernorts, die Restitution Wilhelm Hyazinths durch den kurpfälzischen Reichsvikar 1711 angeführt ${ }^{136}$.

Weitere Einträge zu Nassau-Siegen finden sich in Band 21 der StaatsCantzley von 1712, und sie betreffen die Gewaltaktion am Fronleichnamstag 1712 in Siegen. Auf fünf Seiten wird der Bericht des Fürsten Friedrich Wilhelm Adolf von Nassau-Siegen an Landgraf Karl von Hessen-Kassel wiedergegeben, wobei auf frühere katholische Übergriffe sowie auf die Inszenierung der Prozession als Militärparade mit der pfälzisch-münsterischen Kreistruppe sowie mit dem katholischen Landesaufgebot hingewiesen wird. Der Nassauer Fürst fahre mit der gewaltsamen Eskalation fort, zunächst mit Gewehrschüssen auf die reformierte Schlosswache und anschließend mit der Kanone vom Oberen Schloss über das Untere Schloss hinweg, das er selbst mit seiner Familie bewohnte ${ }^{137}$. Etwas weiter unten rückt die Redaktion die Deduktion Species facti ein, die bereits oben als separate Druckschrift behandelt worden ist ${ }^{138}$.

134 Das Memoriale wurde in Regensburg am 27. April 1709 diktiert: ebd., Bd. 15, S. 1-9.

135 Schreiben der kaiserlichen Administrationskommission für Siegen an den Reichstag, 27. Februar 1711 mit der Zurückweisung aller Vorwürfe, sie würde den konfessionellen Status quo stören: ebd., Bd. 17, S. 29-31. - Schreiben der Vertreter Preußens, Kurhannovers und HessenKassels anlässlich des Kölner Kreistags an die Kurkölner Administrationsregierung, 23. März 1711 mit der Forderung, die Religionsveränderungen rückgängig zu machen: Ebd., Bd. 17, S. 32-36. - Protest der kurpfälzischen und Münsteraner Räte beim Niederrheinisch-Westfälischen Reichskreis gegen den Protestantischen Rekurs an den Reichstag und Forderung der Verhandlung auf dem Kreistag, 13. April 1711: Ebd., Bd. 17, S. 37f. - Protest der Vertreter Preußens, Kurhannovers und Hessen-Kassels gegen das Schreiben der Direktorialräte aus Kurpfalz und Münster, 29. April 1711, gegen den katholischen Protest: Ebd., Bd. 17, S. 38-41.

136 Restitution des Fürsten von Nassau vom 24. Oktober 1711: ebd., Bd. 21, S. 1f.

137 Undatierter Bericht: ebd., Bd. 21, S. 5-10.

138 »Species facti, welcher Gestalt die Catholische in die Stadt Siegen am Frohnleichnamstag dises 1712 Jahrs armata manu eine Procession gehalten haben«, o.O. 1712, nachgedruckt bei Anton FABER, Europäische Staats-Cantzley, Bd. 21, S. 36-56. 
Ausführlich kommentierte auch Burkhard Gotthelf Struve seine Publikationen über die Konfessionskonflikte im Allgemeinen und den Nassau-Siegener Streit im Besonderen. In seiner Ausführlichen Historie der Religions=Beschwerden von 1722 stellt Struve auf elf Seiten einen Kurzabriss der Konfessionsgeschichte Siegens und des Siegerlandes seit dem frühen 17. Jahrhundert vor ${ }^{139}$. Die protestantische Diktion wird sogleich sichtbar, indem Struve erklärt, Siegen sei bis 1626 reformiert gewesen - erst dann habe die Rekatholisierung begonnen. Angesichts des Normaljahres 1624, wie es 1648 festgesetzt werden sollte, entfiele dann der spätere katholische Anspruch, Siegen sei bereits ab 1623 rekatholisiert worden. Der Umschlag wird bei Struve auch konkretisiert: 1626 sei durch Graf Johann VIII. von Nassau-Siegen ein »ärgerliches Religionsedikt» erschienen. Es folgt eine Auflistung der katholischen Religionsübergriffe. Ab 1695 wurden katholische Schulmeister in Netphen, Wilnsdorf und Rödgen eingesetzt. Den betroffenen protestantischen Eltern wurde verboten, ihre Kinder an andere Schulen zu schicken. In vielfältiger Weise strebten die Katholiken an, Protestanten durch symbolische Handlungen zu stören oder zwangsweise in die eigenen Rituale einzubeziehen: So erfolgten ausgiebige Prozessionen der katholischen Seite, mit fliegenden Fahnen, Pfeifen und Trommeln, nahe der St. Nikolai-Kirche in Siegen, wo die sonntägliche Gottesdienstzeit für die öffentlichen katholischen Zeremonien gewählt wurden, damit man »den Reformirten Pfarrherren auf der Cantzel nicht einmal hören können«. Zudem mussten die Reformierten helfen, den »Himmel« (= den Baldachin) zu tragen sowie bei Passierung und Elevation des Venerabile niederzuknien ${ }^{140}$. An todkranken Protestanten wurden Zwangsbekehrungen durch die Jesuiten vorgenommen. Ferner verbot die Regierung den reformierten Presbyterien, ihre Tagungen durchzuführen. Detailliert schildert Struve die folgenden Klagen der Siegener Protestanten beim Kaiser, beim Reichstag und dem Corpus Evangelicorum sowie bei verschiedenen großen protestantischen Reichsständen zwischen 1707 und 1712. Im Anschluss berichtet er von den beiden gewaltsamen Zusammenstößen von 1712 und 1716, wobei deutlich wird, dass er mehrere der früheren Deduktionen der protestantischen Seite oder deren Verarbeitung in anderen Druckmedien, z.B. Zeitschriften, kannte ${ }^{141}$. Auch in Struves Corpus Actorum et Gravaminorum Religionis aus dem Jahre 1727 werden die Auseinandersetzungen in Siegen aufgeführt, wenn auch in sehr viel

139 Burkhard Gotthelf Struve (Hg.), Ausführliche Historie der Religions=Beschwerden Zwischen denen Römisch-Catholischen und Evangelischen im Teutschen Reich [...], 2 Tl. in 1 Bd., Leipzig 1722, hier T1. 2, S. 333-343.

140 Ebd., Bd. 2, S. 337.

141 Ebd., Bd. 2, S. 341-343. 
knapperer Form ${ }^{142}$. Interessanterweise ist für die katholische Position keine Kirchengeschichte überliefert, die detaillierter auf die Siegener Verhältnisse eingeht.

\subsection{Zusammenfassung}

Es wurde bereits darauf verwiesen, dass das Fürstentum Nassau-Siegen zu den mindermächtigen Reichsständen gehörte und dass mangels eigener Drucktätigkeit oder Zeitschriftenherausgabe nur eine mittelbare öffentliche Wahrnehmung möglich war. Der Streit in den Deduktionen erreichte 1709/10 einen ersten Höhepunkt, als je eine umfangreiche Druckschrift jeder Seite publiziert und am Regensburger Reichstag verteilt wurde. Alle anderen Medien konnten hierauf aufbauend ihre Meinung bilden und ihre Berichterstattung gestalten. Die früheren Konfessionszusammenstöße wurden nun zur Vorgeschichte der folgenden Begebenheiten. Die Zeitungen ließen sich normalerweise von ihren Korrespondenten in Köln oder Düsseldorf unterrichten, dies waren gleichzeitig diejenigen, die über die Höfe der Kölner und Pfälzer Kurfürsten informierten.

In den Zeitschriften erschienen schon seit 1706 einzelne Mitteilungen über den Siegener Konfessionskonflikt. Normalerweise war die Kommentierung der protestantischen Seite zugetan, die reformierten Untertanen im Siegerland genossen breite Sympathien, während die Herrschaftsausübung des Fürsten und der folgenden Kommissionen skeptisch bewertet wurde. Kritische Töne gegenüber der protestantischen Seite erhob vor allem Johann Jakob Schmauss, der in seinem Curieusen Bücher-Cabinet die scharfe Wortwahl in einigen protestantischen Deduktionen verurteilte, ohne dass er deren Inhalt widerlegt hätte. Die lancierte katholische Pressemeldung über eine »Rebellion« der Weidenauer Bauern 1716 entlarvte vor allem die Europäische Fama.

In den Historienschriften spielte der Siegener Konflikt, wie nicht anders zu erwarten, ebenfalls eine Nebenrolle. Im Theatrum Europaeum und in Fabers Staats-Cantzley konnten die Gewalttaten von 1712 und 1716 nicht gefunden werden. Einzelmitteilungen stehen oft zusammenhangslos und ermöglichen kein geschlossenes Bild über den Gang der Ereignisse und erst recht nicht über die komplizierten Zusammenhänge. In Schauroths Edition der Dokumente des Corpus Evangelicorum sind eher magere Hinweise zu finden.

142 Streit zwischen Fürst Wilhelm Hyazinth von Nassau-Siegen bzw. der kaiserlichen Kommissionregierung mit seinen protestantischen Untertanen 1707-1712: Burkhard Gotthelf STRUVE (Hg.), Corpus Actorum et Gravaminorum Religionis, 3 Tl. in einem Band, Frankfurt a.M. 1727, T1. 1, S. 72-83. Gewaltanwendungen am Fronleichnam 1712 in Siegen und im Februar 1716 in Weidenau: Ebd., S. 73. 
Ein guter Überblick findet sich vor allem in Struves Kirchengeschichte von 1720, wo die gesamte Konfliktkonstellation auf knappem Raum zutreffend erläutert wird. Der zeitgenössische Interessent am Siegener Konflikt hatte es damit viel schwerer als bei den vier anderen Konflikten dieser Studie, sich über Ursachen, Anlässe und Formen der Auseinandersetzungen zu informieren. Vier Gründe mögen den Medienproduzenten erschwert haben, den Siegener Konflikt in detaillierterer Weise darzustellen:

1. Die Grundkonstellation des Konflikts auf der Ebene der Beteiligten war sehr komplex. Statt rivalisierender Landesherren gab es hier nicht nur den Fürsten und den Kaiser, sondern auch zwei beteiligte Korporationen, den Niederrheinisch-Westfälischen Reichskreis und das Domkapitel von Köln. Beide Körperschaften entzogen sich einer klaren Interessenzuordnung, auch ließen sich ihnen weder politische Fehler noch Laster zuschreiben.

2. Der Siegener Streit war ein Konfessionskonflikt. Alle Medienmacher waren sich einig darin, dass religiös motivierte Streitigkeiten ein unkalkulierbares Unruhepotenzial in sich bargen, das sich in aufgebrachten Reaktionen von Machthabern, aber auch von Gelehrten und gewöhnlichen Bürgern oder deren Zusammenschlüssen artikulieren konnte. Um dem Verbot aus dem Westfälischen Frieden, religiöse Ressentiments zu schüren, zu entsprechen, hielten sich die meisten Organe bei konfessionellen Themen wesentlich mehr zurück als etwa bei militärischen Konflikten.

3. Die Rolle Preußens war kaum einzuschätzen. Zwar nahm die preußische Krone für sich eine Beschützerrolle für rheinische und westfälische Protestanten in Diasporasituationen in Anspruch, vor allem für die Herzogtümer Jülich und Berg, doch in der Siegener Frage operierte die Berliner Regierung eher zurückhaltend, ohne dass dafür Gründe erkennbar waren.

4. In Siegen saß neben dem reichsnotorischen Fürsten Wilhelm Hyazinth noch ein calvinistischer Fürst desselben Hauses, Fürst Friedrich Wilhelm Adolf. Diesem gelang es nicht, den gegenreformatorischen Maßnahmen seines Vetters erfolgreich entgegenzuwirken. Aus Sicht von Zeitungsund Zeitschriftenredakteuren wäre er sicher prominenter in die Berichterstattung gelangt, wenn er etwas rühriger für seine Glaubensgenossen eingetreten wäre. Ihm fehlte allerdings der Sinn für die Nützlichkeit größeren Medienengagements, was angesichts der hohen propagandistischen Kompetenz der Nassau-Oranier erstaunlich bleibt.

So blieb Siegen ein Randthema. Wesentliche Zusammenhänge, zum einen die konfessionspolitisch bedingte Unterstützung der katholischen Siegener Funktionsträger durch Kurpfalz und das Kölner Domkapitel sowie die in dieselbe Richtung weisende Wiener Politik wurden in den Medien nicht thema- 
tisiert. Selbst die Flugschriften, die zugunsten der reformierten Untertanen argumentierten, wagten den Angriff auf das katholische Kartell nicht, und auch das Corpus Evangelicorum nutzte den Konflikt nicht zu einer generellen Abrechnung mit der ungenügenden Wahrnehmung der konfessionspolitischen Neutralität durch Kaiser und Reichshofrat. 



\section{Suspendierung Herzog Karl Leopolds von Mecklenburg-Schwerin}

\subsection{Historischer Hintergrund}

Das Herzogtum Mecklenburg ist von der Forschung wenig beachtet worden, obwohl das Land mit Rostock eine im Spätmittelalter gegründete Landesuniversität aufwies. Die DDR mit ihrer Geringschätzung der früheren sozialen Feudalordnung und der historisch gewachsenen geographischen Gliederung ihres Herrschaftsgebietes hat naheliegenderweise daran nichts geändert. Auch für die vormoderne öffentliche Meinung in Gestalt von Deduktionen, Zeitungen und Zeitschriften erwartet der Forscher daher kaum einen Überfluss an Informationen, wenn er beginnt, sich für die mecklenburgische Verfassungssituation im frühen 18. Jahrhundert zu interessieren. Umso überraschender erscheint dann eine Bemerkung in der rechtshistorischen Dissertation von Matthias Carl aus dem Jahr 1885. Carl schreibt:

Die Zeitungen und Flugschriften, die mehr oder weniger offiziellen Publicationen jener Jahre, sind angefüllt mit Betrachtungen und Deductionen, in denen die Ansichten privater und höfischer Kreise über diese Angelegenheit und ihre Verknüpfung mit den übrigen Fragen der Politik jener Zeit zum Ausdruck gelangen ${ }^{1}$.

»Diese Angelegenheit« bezog sich dabei auf den Mecklenburger Verfassungsstreit, so wie er sich zwischen Herzog Karl Leopold und seinen Landständen entwickelte. Eine solche Bemerkung weckt Erwartungen, dass eine im Reich sehr häufig vorgekommene Konfliktlage offenbar gegen jede Erwartung breit und detailliert vor den Augen und Ohren aller Interessenten in ganz Europa ausgebreitet worden ist - und genau dies war der Fall.

Das Herzogtum Mecklenburg gilt als eines der rückständigsten Territorien innerhalb der neueren deutschen Geschichte. Die als »ostelbisch« beschriebenen sozial-ökonomischen Verhältnisse, die schon der politischen Entwicklung innerhalb Brandenburg-Preußens als Grundlage zugeschrieben wurden, traten in Mecklenburg in noch schärferer Form auf: Ländliche Raumordnung mit wenigen bedeutenden Städten (die Hansestadt Rostock stellte die Ausnahme dar, Wismar war seit 1648 schwedisch und damit aus Mecklenburg ausgegliedert), mit vielen Adligen, die als mächtig beschrieben wurden, mit demgegenüber zahlreichen Landbewohnern, deren Rechtsstatus kaum als

1 Carl Matthias, Die Mecklenburger Frage in der ersten Hälfte des 18. Jahrhunderts und das Dekret Kaiser Karls VI. vom 11. Mai 1728, Diss. Halle 1885, S. 1. 
der von Bauern zu bezeichnen war ${ }^{2}$. Über allem befand sich ein Landesherr, dem seine Landstände schon früher jegliche Gestaltungsmöglichkeit auf die Landesentwicklung genommen hatten und der sich nur noch durch symbolische Aktionen und Baumaßnahmen in Erinnerung bringen konnte.

Der hier zu untersuchende Konflikt zeigt eine etwas andere Verteilung: Herzog Karl Leopold von Mecklenburg-Schwerin (1678-1747) war gerade kein schwacher Herrscher, der sich mit seiner Ohnmacht abgefunden hatte, und der Adel dominierte nicht, sondern prozessierte. Ständekonflikte waren in der Mecklenburger Geschichte häufig vorgekommen: Sigrid Jahns, die die maßgebliche neuere Untersuchung zu diesem Konflikt verfasst hat, beginnt mit dem Jahr 1658, dem Regierungsantritt Christian I. Louis' von Mecklenburg, und entwickelt dabei die langfristigen Strukturen der Auseinandersetzung zwischen herzoglicher Landesherrschaft und dem politischen Selbstbehauptungswillen der landständischen Korporationen der Ritterschaft und der Landstädte ${ }^{3}$. Politische Konflikte zwischen den sich herausbildenden frühmodernen Territorialstaaten und ihren Landständen gehörten zum politischen Szenario in ganz Europa; nur die Konflikthäufigkeit und -intensität variierten in zeitlicher Hinsicht. Einige dieser Konflikte eskalierten zu einem jahrzehnte- oder gar jahrhundertelangen, teilweise gewalttätigen Ringen um die Machtverteilung. Diese »exzeptionellen Ständekonflikte« betrafen im Reich ansonsten vor allem die Territorien Württemberg ${ }^{4}$ und Ostfriesland $^{5}$. Am Ende dieser Entwicklung - auch das ist einer der Gründe für das

2 Zur politischen sozialen Lage im Territorium vgl. die ältere Studie von Otto VitenSE, Geschichte von Mecklenburg, Gotha 1920. Wegen der intensiven Quellenauswertung ist weiterhin die Studie von Peter Wick wichtig, obwohl sie infolge ihrer marxistischen Deutung und ihrer Unkenntnis des Reichssystems zu einigen theoretischen wie inhaltlichen Fehlinterpretationen gelangt: Peter WICK, Versuche zur Errichtung des Absolutismus in Mecklenburg in der erste Hälfte des 18. Jahrhunderts, Berlin(-Ost) 1964. Zu den Verhältnissen im späteren 18. Jahrhundert: Gerhard HeItz, Herzog, Stände und Bauern in Mecklenburg-Schwerin in den Jahren von 1756-1785, in: Günter Vogler (Hg.), Europäische Herrscher. Ihre Rolle bei der Gestaltung von Politik und Gesellschaft vom 16. bis zum 18. Jahrhundert, Weimar 1988, S. $262-274$.

3 Sigrid JAHNS, »Mecklenburgisches Wesen« oder absolutistisches Regiment? Mecklenburgischer Ständekonflikt und neue kaiserliche Reichspolitik (1658-1755), in: Paul-Joachim HeINIG u.a. (Hg.), Reich, Regionen und Europa in Mittelalter und Neuzeit. Fs. für Peter Moraw, Berlin 2000, S. 323-351.

4 Einen systematisierenden Überblick über Ständekonflikte im Reich bietet ein Einführungskapitel der Dissertation von Gabriele Haug-Moritz. In dieser Studie wird anschließend schwerpunktmäßig der exzeptionelle Ständekonflikt im Herzogtum Württemberg untersucht, der seinen zeitlichen Schwerpunkt später erreichte als der mecklenburgische Streit: Gabriele HaUG-Moritz, Württembergischer Ständekonflikt und deutscher Dualismus. Ein Beitrag zur Geschichte des Reichsverbands in der Mitte des 18. Jahrhunderts, Stuttgart 1992, S. 5-42.

$5 \mathrm{Zu}$ Ostfriesland, wo der Konflikt zwischen der Dynastie der Cirksena und den Landständen schon in der Entstehungsgeschichte der Landesherrschaft im 15. Jahrhundert angelegt war und die gesamte Frühe Neuzeit bis 1744 durchzog: Heinz Schiluing, Die Emder Revolution als europäisches Ereignis, in: Hajo von Lengen (Hg.), Die Emder Revolution von 1595, Aurich 
starke Interesse der Forschung - stand jeweils eine Ständerepublik auf adliger Basis (Mecklenburg), auf bürgerlicher (Württemberg) oder auf bürgerlich-städtischer Basis (Ostfriesland/Emden).

Der innerreichische Konflikt in Mecklenburg-Schwerin im Sinne der Fragestellung setzte mit dem Herrschaftsantritt des Herzogs Karl Leopold im Jahre 1713 ein. Die Grunddisposition des politischen Gegensatzes griff er von seinen Vorgängern auf: Der gewünschte ungehinderte Zugriff auf die Steuerkraft der Untertanen und die angestrebte Sprengung der mecklenburgischen Landesverfassung, die zwei herrschende Linien an eine gemeinsame Ständeversammlung band ${ }^{6}$. Ritterschaft und Städte hatten dabei wenig Mühe, die Differenzen zwischen den herrschenden Linien in Schwerin und Güstrow (bis 1695) bzw. in Schwerin und Strelitz (von 1705 bis 1918) zwecks Erhalts ihrer Stellung auszunutzen ${ }^{7}$.

Während die Stände sich auf papierne Proteste stützen mussten, weil ihnen die Ausübung manifester Gewalt verboten war, stellte in Wirklichkeit der Kaiser als Schützer des Reichsrechts den machtpolitischen Gegenpol zu einem gewalttätigen Territorialfürsten dar. Der Kaiser konnte zwar keinen Fürsten nur deshalb disziplinieren, weil der mächtig war und mächtiger werden wollte - dies gehörte zu den allgemeinen Herrschaftsprinzipien der Vormoderne, denen jeder Kaiser in seinen Hausmachtsgebieten ebenfalls nacheiferte. Wohl konnte er aber einen Reichsstand wegen fortgesetzter Unhöflichkeit in der Korrespondenz maßregeln, denn beleidigen lassen musste sich das Reichsoberhaupt nicht. Die zeremoniellen Formen waren einklagbare Rechte, so hatte jeder Stand ein Interesse daran, dass sie gewahrt blieben. Ein Herrscher, der es an der nötigen Sensibilität mangeln ließ, verlor die Solidarität seiner Standesgenossen. Auch boten anhängige Prozesse vor den Reichsgerichten dem Kaiser stets eine Handhabe, in einen Konflikt-

1995, S. 113-136; Bernd KAPPELHOFF, Absolutistisches Regiment oder Ständeherrschaft? Landesherr und Landstände in Ostfriesland im ersten Drittel des 18. Jahrhunderts, Hildesheim 1982; ders., Politische Partizipation und frühmoderner Staat. Ostfriesland von 16. bis zum 19. Jahrhundert, in: Hajo von LENGEN (Hg.), Collectanea Frisica. Beiträge zur historischen Landeskunde Ostfrieslands, Aurich 1995, S. 267-290, mit Hinweisen auf Forschungsstand und Forschungsentwicklung.

6 Die Stände von Ritterschaft und Städten hatten sich in Mecklenburg 1523 zu einer landesweiten Union zusammengeschlossen, die auch bei späteren Landesteilungen fortgesetzt wurde: Gründungsdokument der Mecklenburger Ständeunion vom 1. August 1523: Hugo SACHSSE (Hg.), Mecklenburgische Urkunden und Daten. Quellen vornehmlich für Staatsgeschichte und Staatsrecht Mecklenburgs, Rostock 1900, S. 214-216.

7 Zur Ständestruktur und zum Machtgleichgewicht im Territorium: JAHNS, »Mecklenburgisches Wesen«, S. 328-332. Vgl. auch die kurze ständegeschichtliche Überblicksdarstellung bei Uwe Heck, Geschichte des Landtags in Mecklenburg. Ein Abriß, Rostock 1997, sowie die Einführung in die Archivalienüberlieferung der Stände: Peter-Joachim RAKow u.a. (Hg.), Die Bestände des Landeshauptarchiv Schwerin, Bd. 1: Urkunden- und Aktenbestände 1158-1945, Schwerin 1999, S. 229-232. 
fall einzugreifen. Das diesbezügliche Instrumentarium war groß und reichte von einer brieflichen Anfrage über eine Kommissionseinsetzung bis hin zur Reichsexekution.

Bereits in der zweiten Hälfte des 17. Jahrhunderts hatten die mecklenburgischen Stände die kaiserliche Unterstützung in Anspruch genommen: Die Entscheidungen des Reichshofrats fielen dabei fast völlig zugunsten der Stände aus ${ }^{8}$. Für das Verständnis des Fortgangs ist wichtig, dass aus Sicht der mecklenburgischen Landesherrschaft der Kaiser und seine Rechtsprechung keineswegs als neutrale schiedsrichterliche Gewalt betrachtet wurde, sondern als der Protektor der Gegenseite gegen jegliche Veränderung. Die Konflikte bis 1713 zeichneten sich jedoch durch zwei Eigenschaften aus, die sie von der Folgezeit unterschieden: Zum einen waren auswärtige Mächte weitgehend unbeteiligt, besaßen jedenfalls noch keinen erheblichen Einfluss auf die innermecklenburgischen Angelegenheiten, zum anderen wurden von Seiten der Landesherrschaft bis auf die militärisch vollzogenen Steuereintreibungen keine weitergehenden Gewaltmaßnahmen durchgeführt, insbesondere nicht gegen widerstrebende Adlige.

All dies änderte sich 1713, als Herzog Karl Leopold seine Herrschaft antrat. Dieser Fürst, von dem Sigrid Jahns schreibt, er sei »eine problematische Persönlichkeit mit pathologischen Zügen gewesen «", verfolgte dieselben Ziele wie seine Vorgänger, nämlich Stärkung der eigenen Herrschaftsmacht im Innern und Reduzierung der Landstände auf eine im Wesentlichen dekorative Stellung. Daneben erstrebte er die Errichtung einer respektablen Militärmacht, die vor dem Hintergrund der traumatischen Erfahrungen der Mecklenburger in den Kriegen des vorangegangenen Jahrhunderts Sicherheit und wenn möglich machtpolitisches Gewicht verleihen sollte. Allerdings neigte Karl Leopold von Anfang an zu exzessiver Gewalttätigkeit. Vor Regierungsantritt hatte er einige Zeit im schwedischen Armeelager in Polen verbracht, wo er König Karl XII. von Schweden zu seinem Vorbild erwählte, dessen Verständnis von Heldentum nach innen wie außen er nachahmen wollte ${ }^{10}$. Einer seiner Gegner, Prinz Eugen von Savoyen, bezeichnete den Mecklenburger denn auch als »Affen Karls XII.«11.

8 Auf diese Einseitigkeit verweist JAHNS, »Mecklenburgisch Wesen«, S. 336.

9 Ebd., S. 338.

10 Zur Persönlichkeit Karl Leopolds: Gerhard Heitz, Herzog Carl Leopold von MecklenburgSchwerin (1679-1747), in: Rolf Straubel/Ulman Weiss (Hg.), Kaiser, König, Kardinal. Deutsche Fürsten 1500-1800, Leipzig/Jena/Berlin 1991, S. 303-310. Zu Karl XII. als Vorbild: Ebd., S. 303; Matthias, Die Mecklenburger Frage in der ersten Hälfte des 18. Jahrhunderts, S. 11; JAHNS, »Mecklenburgisch Wesen«, S. 338.

11 Zitat: Walter Mediger, Mecklenburg, Rußland und England-Hannover 1706-1721. Ein Beitrag zur Geschichte des Nordischen Krieges, 2 Bd., Hildesheim 1967, Bd. 1, S. 367. 
Karl Leopold betrachtete diese Imitation allerdings nicht nur als höfische Attitüde, sondern als Chance zu mehr Macht. An vielen Stellen ist später nicht nur eine hohe Meinung von landesherrlicher Autorität feststellbar, die zu einer Marginalisierung von ständischer Herrschaftsmitwirkung führte, sondern auch eine Vorstellung, Politik vollziehe sich wie Kriegführung nach dem Prinzip von Befehl und Gehorsam. Bedenkenträgerei wurde unter derartigen Vorzeichen schnell zur Rebellion, so nahm es jedenfalls der Herzog wahr ${ }^{12}$. Einstweilen wirkte die landesherrliche Administration, deren Spitzenstellungen vorwiegend mit bürgerlichen Juristen besetzt war, mit. Mecklenburg verfügte über die übliche Dreiteilung von Regierung, Rentkammer und Justizkollegien. Herrschaftsarkana wurden im Geheimen Rat verhandelt, der sich personell mit der Regierung überschnitt ${ }^{13}$.

Der Herzog begann den Kampf gegen die intermediären Gewalten mit der Unterminierung der Stellung Rostocks. Die zuvor weitgehend autonome Hanse- und Hafenstadt wurde bis 1715 soweit drangsaliert, bis der Magistrat einen Unterwerfungsvertrag unterzeichnete. Zu diesem Zweck mussten einige opponierende Stadtratsmitglieder längere Inhaftierungen unter erschwerten Bedingungen ertragen, zunächst im Rathaus, dann an anderen Orten. Herzog Karl Leopold ließ sich von seinem Tun nicht dadurch abhalten, dass mehrere Mandate des Reichshofrats ergingen, Rostock in allen Rechten zu restituieren ${ }^{14}$.

Eine zentrale Frage für den Ausgang eines Ständekonflikts war die nach der Abgeschlossenheit des Territoriums gegenüber äußeren Potentaten. Sigrid Jahns betont, dass die interventionsfreie Durchführung eines derartigen Konflikts über längere Zeit im Reich die Ausnahme darstellte, z.B. in Brandenburg-Preußen in der Mitte des 17. Jahrhunderts ${ }^{15}$. Dem fürstlichen Betreiber einer fundamentalen Auseinandersetzung mit seinen Ständen drohte Gefahr aus drei Richtungen: Von mächtigen fürstlichen Nachbarn, von Seiten der kaiserlichen Politikinteressen und von Seiten des Reichsrechts, das feste formale Vorgaben für ideale Herrschaftsverhältnisse und auch für die geregelte

12 Vgl. zum Selbstverständnis Karl Leopolds die Überlegungen von Andreas PeČAR, Am Rande des Alten Reiches? Mecklenburgs Stellung im Alten Reich am Beispiel landständischer Repräsentationen und kaiserlichen Einflusses, in: Matthias Manke/Ernst Münch (Hg.), Verfassung und Lebenswirklichkeit. Der Landesgrundgesetzliche Erbvergleich von 1755 in seiner Zeit, Lübeck 2006, S. 201-223.

13 Zur Verwaltungsgeschichte der mecklenburgischen Spitzenadministration: Gabriele BAUMGARTNER, Die Entwicklung der obersten Landesverwaltung Mecklenburg-Schwerins vom Ende des 16. bis zur Mitte des 18. Jahrhunderts, Diss. Rostock 1991.

14 Stephan Mauelshagen, »Die Freiheiten zernichtet«. Die Stadt Rostock im Kampf mit Herzog Karl Leopold von Mecklenburg-Schwerin (1714-1716), in: Sylvia Schraut/Bernhard Stier (Hg.), Stadt und Land. Bilder, Inszenierungen und Visionen in Geschichte und Gegenwart. Fs. für Wolfgang von Hippel zum 65. Geburtstag, Stuttgart 2001, S. 75-87; vgl. auch Wick, Versuche zur Errichtung des Absolutismus in Mecklenburg, S. 57-73.

15 Vgl. hierzu die Überlegungen von JAHNS, »Mecklenburgisches Wesen«, S. 327. 
Durchführung von Meinungsverschiedenheiten bereithielt. Als vierte Gefahr konnte die Beteiligung internationaler Mächte hinzutreten. Zumeist verbanden sich mehrere dieser Einflussrichtungen, so auch im Falle Mecklenburg. Fürstliche Interessenten waren die Linien des Hauses Braunschweig-Lüneburg $^{16}$ sowie die brandenburgischen Hohenzollern ${ }^{17}$. Kaiser Karl VI. entwickelte schnell ein Interesse am Konflikt, das zunächst als Kette von Reichshofratsprozessen begann, um dann zu einer Frage der kaiserlichen Ehre und deren Behandlung durch den nicht nur gewalttätigen, sondern auch undiplomatischen Herzog zu werden ${ }^{18}$. Der Kaiser hatte nach dem Ende des Spanischen Erbfolgekrieges eine Machtstellung in Europa erreicht, die das Haus Habsburg seit der Zeit Karls V. nicht mehr besessen hatte. Auch wenn ihm der Abschied von der Herrschaft über das spanische Weltreich schwerfiel, so besa $\beta$ er die niederländischen und italienischen Hinterlassenschaften der spanischen Verwandten und dazu das sich ausdehnende Balkanimperium, das seit 1683 dem Osmanischen Reich entwunden worden war ${ }^{19}$. Karl VI. war nicht der Herrscher, der diese Möglichkeiten gegen die Reichsstände ins Feld führen wollte, aber er war darauf bedacht, dass seinen Rechten und seiner Autorität als Reichsoberhaupt kein Abbruch geschah. So wie der Reichstag das Forum war, auf dem politische Gestaltung stattfand, so bedeutete der Reichshofrat das Gremium, das die kaiserlichen Rechte, die der Reichsstände, aber auch die der Landstände wahrte und damit die überkommene Distinktion innerhalb des Reiches fortschrieb ${ }^{20}$.

16 Zur Machtpolitik der Welfen innerhalb des Reichssystems: PrEss, Kurhannover im System des Alten Reiches, S. 53-79; Kerstin RAHN, »Die Weide des weissen Rosses von Braunschweig bis an die Ostsee erweitern ...«? Kurhannover und Mecklenburg in der ersten Hälfte des 18. Jahrhunderts, in: Manke/Münch, Verfassung und Lebenswirklichkeit, S. 335-349.

17 Zur kurbrandenburgischen Reichspolitik: Ernst Opgenoorth, Der Große Kurfürst, das Reich und die europäischen Mächte, in: Oswald Hauser (Hg.), Preußen, Europa und das Reich, Köln 1987, S. 19-31; Anton SchindLing, Kurbrandenburg im System des Reichs während der zweiten Hälfte des 17. Jahrhunderts. Eine Problemskizze, in: Hauser, Preußen, Europa und das Reich, S. 33-46; Anton Schindling, Der Große Kurfürst und das Reich, in: Heinrich, »Ein sonderbares Licht in Teutschland«, S. 59-74; Axel GotтhaRD, Der »Große Kurfürst« und das Kurkolleg, in: FBPG N.F. 6 (1996), S. 1-54.

18 Der erste Prozess der Ritterschaft am Reichshofrat betraf die gewaltsame Eintreibung der Kontribution von Rittergütern mittels Einquartierungen im Winter 1713/14; Kaiser Karl VI. erließ am 28. Juni 1714 ein Mahnschreiben an den Herzog: WICK, Versuche zur Errichtung des Absolutismus in Mecklenburg, S. 44. - Zur Reichspolitik unter Kaiser Karl VI.: von ARETIN, Das Alte Reich, Bd. 2, S. 255-262.

19 Vgl. zu Persönlichkeit Karls VI. und zur habsburgischen Großmacht im frühen 18. Jahrhundert: Bernd RiLl, Karl VI. Habsburg als barocke Großmacht, Graz/Wien/Köln 1992; Oswald REDLICH, Das Werden einer Großmacht. Österreich von 1700 bis 1740, Brünn/München/Wien 1942.

20 Die Reichshofratspolitik zur Zeit Karls VI. wurde eingehend untersucht von Michael HugHES, Law and Politics in Eighteenth Century Germany, pas. 
Auf internationaler Ebene, auf der die Ostseekonflikte zwischen Dänemark, Schweden und Russland unter Beteiligung der englischen und niederländischen Interessenten ausgetragen wurden, spielte Mecklenburg nur eine untergeordnete Rolle ${ }^{21}$. Russland schaute allerdings dem innermecklenburgischen Konflikt nicht nur zu: Zar Peter der Große (1672-1725) war mit Herzog Karl Leopold verbunden, da er der Onkel von dessen zweiter Frau Catharina Iwanowna war ${ }^{22}$. Der Kampf gegen die mecklenburgische Ritterschaft wurde dadurch begünstigt, dass im Zuge des Nordischen Krieges russische Truppen im Land bzw. in der Nähe stationiert wurden. Karl Leopold nutzte 1716 seine Militärkooperation mit Russland ${ }^{23}$ dazu, widerstrebende Adlige mit Truppeneinquartierungen soweit unter Druck zu setzen, bis diese entweder seine Forderungen erfüllten oder das Land verließen. Güter von Exulanten wurden unter Sequester gestellt und zum Nutzen der Rentkammer verwaltet. Dabei nahm der Herzog auf natürliches wie positives Recht keinerlei Rücksicht und stellte sich außerhalb der herrschenden Reichsrechtsordnung und auch der überkommenen politiktheoretisch akzeptablen Formen monarchischer Herrschaft in Europa.

Die Ritterschaft nahm den Konflikt in seiner grundsätzlichen Form an. Wann der Beschluss fiel, den Herzog für seinen Machtmissbrauch vor den Reichsgerichten zur Rechenschaft zu ziehen und dazu systematisch die Beweismittel zu sammeln, ist nicht mehr rekonstruierbar. Jedenfalls forderte der »Engere Ausschuss « des Landtags im Sommer 1717 den passiven Widerstand: Kein Adliger sollte die Zwangsabgaben leisten oder irgendwelche erzwungenen Ergebenheitsdokumente unterzeichnen, sondern über alle rechtswidrigen Maßnahmen des Herzogs Protokolle anlegen und nach Ratzeburg, dem Zentrum des Widerstands, einsenden ${ }^{24}$. Die Dokumentensammlung der exilierten Ritterschaft dürfte schnell an Umfang gewonnen haben, und aus ihr ließen sich auch die Argumente gewinnen, die man für Prozessschriftsätze und Flugschriften benötigte. Im Zentrum des ritterschaftlichen Widerstands stand Andreas Gottlieb von Bernsdorff (1649-1726), ein Adliger, der sowohl in Mecklenburg als auch in den welfischen Landen begütert

21 Für Schweden war Mecklenburg verhältnismäßig unbedeutend, und auch das englische Interesse reichte nicht weiter als das welfische Hausmachtinteresse König Georgs I. - Zu den Ostseekonflikten des 16. und 17. Jahrhunderts: Klaus ZERnACK, Das Zeitalter der nordischen Kriege von 1558 bis 1809 als frühneuzeitliche Geschichtsepoche, in: ZHF 1 (1974), S. 55-79; ders., Schweden als europäische Großmacht in der frühen Neuzeit, in: HZ 232 (1981), S. 327357.

22 Zur Eheschließung und ihrer Bedeutung: Wick, Versuche zur Errichtung des Absolutismus in Mecklenburg, S. 81-83.

23 Bündnispolitik mit Russland: Wick, Versuche zur Errichtung des Absolutismus in Mecklenburg, S. 83-108. Vgl. zur internationalen Einordnung der Kooperation: Mediger, Mecklenburg, Rußland und England-Hannover, 2 Bd., pas.

24 Peter Wick sieht Andreas Gottlieb von Bernsdorff als Initiator dieser Formen der Prozessvorbereitungen: WICK, Versuche zur Errichtung des Absolutismus in Mecklenburg, S. 110. 
war. In den 1670er Jahren war er die zentrale Figur im Widerstand gegen Herzog Christian I. Louis von Mecklenburg gewesen. Bernsdorff hatte lange als Kanzler im Herzogtum Braunschweig-Celle amtiert, ehe er zu den wichtigsten Beratern König Georgs I. von England aufstieg und die deutsche Kanzlei in London übernahm ${ }^{25}$. Schon 1715 hatte er im Interesse Englands in St. Petersburg verbreiten lassen, der Mecklenburger Herzog wolle zum Katholizismus konvertieren, um sein Eheprojekt mit der Zarenprinzessin zu hintertreiben $^{26}$. Nun vermochte er auch seinen Herrn zur Unterstützung der mecklenburgischen Ritterschaft zu gewinnen. Unter seiner Führung gelangte die Ritterschaft von passiver Resignation der Exulanten zu strategischem Widerstand mit dem Ziel, den Herzog als Machtfaktor auszuschließen und das überkommene Ständeregiment im Territorium zu restituieren ${ }^{27}$.

Als die russischen Soldaten 1717 größtenteils wieder aus Mecklenburg abzogen, hatte der Herzog seine Herrschaft soweit konsolidiert, dass die Adligen nicht wagten, zurückzukehren, da sie um ihre Freiheit und nicht wenige auch um ihr Leben bangten. Karl Leopold verheimlichte in keiner Weise, dass mit den adligen Privilegien auch die gesamte landständische Verfassung fortfallen sollte. Politisch war Mecklenburg in zwei Teile auseinandergetreten: Im Territorium herrschte der Herzog und seine Administration vermeintlich absolutistisch, während der exilierte Adel zwar keine laufenden Einkünfte bezog ${ }^{28}$, aber dennoch politisch-publizistisch tätig war und die öffentliche Meinung im gesamten Reich beeinflusste ${ }^{29}$.

Bis zum Jahr 1717 hatte sich der Meinungsbildungsprozess am Reichshofrat und in der kaiserlichen Administration insgesamt so verfestigt, dass Her-

$25 \mathrm{Zu}$ Bernsdorff: Hans-Joachim Ballschmieter, Andreas Gottlieb von Bernsdorff und der mecklenburgische Ständekampf (1680-1720), Köln/Graz 1962; Hartwig vON BernstorfF, Andreas Gottlieb von Bernstorff 1649-1726. Staatsmann, Junker, Patriarch zwischen deutschem Partikularismus und europäischer Politik, Bochum 1999; JAHNS, »Mecklenburgisches Wesen«, S. 333f.; RAHN, »Die Weide des weissen Rosses von Braunschweig bis an die Ostsee erweitern ...«, S. 337-339.

26 Mediger, Mecklenburg, Rußland und England-Hannover, Bd. 1, S. $178 \mathrm{f}$.

$27 \mathrm{Zu}$ Bernsdorff als Organisator der Wiener Prozesse der Ritterschaft: Hughes, Law and Politics, S. 96-99.

28 In ihrer Finanznot waren viele Adlige bereit, ihre Güter zu verpfänden, was die Landesregierung allerdings verbot: Hans Henrich KLÜVER, Beschreibung des Herzogtums Mecklenburg, 6 Bd., Hamburg 1728-1740, hier Bd. 4, S. 531-533. Kaiser Karl VI. erließ am 3. September 1717 ein fünf Jahr geltendes Moratorium: LHA Schwerin, Acta diff., Bd. 1 (Anno 1717 bis März 1718), zit. nach Wick, Versuche zur Errichtung des Absolutismus in Mecklenburg, S. 112.

29 Der »Höchst=gemüßigte Bericht« von 1719 mit seinen beinahe 900 Dokumenten macht den Umfang des belastenden Materials gegen den Herzog erkennbar: [Johann Schevius (Hg.)], »Höchst=gemüßigter Historischer= Acten-mäßiger Bericht von dem, was von Anfange der, im Monath Augusto 1713. angetretenen Regierung Herrn Carl Leopold, Hertzogen zu Mecklenburg, biß zu der, im Monat Martio und April 1719. ergangenen Kayserl. Execution von dem Fürstl. Mecklenburgischen Ministerio wider die Mecklenburgische Ritterschafft und Stadt Rostock vorgenommen worden (mit Beylagen von Num. 1-885)«, o.O. 1719. 
zog Karl Leopold nicht nur immer wieder vermahnt werden müsse, sondern dass eventuell militärische Maßnahmen gegen ihn durchzuführen seien. Da der Kaiser inzwischen - aufgrund des Art. 20 in seiner Wahlkapitulation - eine Reichsacht nicht mehr ohne eine komplizierte Mehrheitsbildung auf dem Reichstag durchführen konnte, stand zunächst nur eine Kommissionseinsetzung samt der Exekution durch einen Reichskreis zur Debatte. Der mecklenburgische Adel betrieb den Erlass eines »Konservatoriums«, d.h. eine strafbewehrte Wiederherstellungsanordnung des politischen Zustands, der vor Ausbruch des Konflikts bestanden hatte. Nach Erörterung im Geheimen Rat in Wien im März 1716 erging ein entsprechender Beschluss durch den Reichshofrat Anfang Oktober $1717^{30}$.

Der Kaiser hatte zwei Optionen, an wen die Durchsetzung der reichsrechtlichen Intervention in Mecklenburg übertragen werden konnte: An Kurhannover oder an Kurbrandenburg. Kurhannover hatte den gesamten Ständekonflikt als beteiligte Macht begleitet und betrieb eine adelsfreundliche Politik. Für Karl VI. war die Beauftragung Kurhannovers (und damit Englands) die günstigste Lösung: Bei dieser Macht würden ihr Eigeninteresse an der Wahrung ihrer Einflusssphäre in Norddeutschland und die Wiederherstellung des Reichsrechts zusammenfallen. Niemand rechnete damit, dass die Hannoveraner sich in Mecklenburg festsetzen oder Territorialteile abtrennen würden. Risikoreicher war hingegen eine Einbeziehung Kurbrandenburgs. Der Preußenkönig Friedrich Wilhelm I. hatte bereits signalisiert, dass er der Politik Karl Leopolds weitaus weniger kritisch gegenüberstand. Zudem hegte Brandenburg Erbhoffnungen auf Mecklenburg und stützte sich dabei auf den Erbvertrag von Wittstock aus dem Jahre $1442^{31}$. Von einer Beteiligung des Hohenzollern an der Exekution wollte der Kaiserhof Abstand nehmen, um die Angelegenheit nicht zu verkomplizieren.

30 Beschluss des Geheimen Rats vom 12. März 1716; Votum des Reichshofrats am 2. Oktober 1717: Hughes, Law and Politics, S. 105-107. Sigrid Jahns umschreibt den Begriff: »Ein Konservatorium war ein reichsgerichtlicher Befehl an eine Macht A, um eine Partei B vor einer Partei C zu schützen«: JAHNS, »Mecklenburgisches Wesen«, S. 340. - Peter Wick schreibt als Bewertung der Ausgangslage vor der Reichsexekution: »Der Herzog Carl Leopold war zweifellos rein verfassungsmäßig bei seinem Vorgehen gegen den Adel im Recht. Er verlangte im Grunde ja nur das, was in der Mehrzahl der anderen deutschen Länder eine Selbstverständlichkeit war«. Dies war eben gerade nicht der Fall: Das Reich des 18. Jahrhunderts war insofern ein Rechtsstaat, als die Landherrschaft zwar die Untertanen besteuern durfte. Deren Ausplünderung, die Vertreibung des Adels außer Landes und die Inhaftierung aller Oppositionellen war hingegen nicht erlaubt. Der Herzog hatte sich aus der Rechtsordnung des Reiches verabschiedet. Vgl. die Verständnisschwierigkeiten bei Wick mangels reichsgeschichtlicher Kenntnisse: Wick, Versuche zur Errichtung des Absolutismus in Mecklenburg, S. 126f.

31 Wittstocker Vertrag zwischen Mecklenburg und Brandenburg-Preußen vom 12. April 1442: SAChSse, Mecklenburgische Urkunden und Daten, S. 161-166; vgl. dazu auch Heck, Geschichte des Landtags in Mecklenburg, S. 13f. - Erneuerung der Vereinbarungen am 12. Juli 1693: SACHSSE, Mecklenburgische Urkunden und Daten, S. 399-403. 
Nach langwierigen Abstimmungen zwischen Wien, London, Dresden und Braunschweig - auch Herzog August Wilhelm von Braunschweig-Wolfenbüttel wurde noch an der Exekution beteiligt, während Kursachsen-Polen als Verbündeter gegenüber einer eventuellen russischen Intervention gewonnen wurde ${ }^{32}$ - konnte das Militärkommando von ca. 12.000 Mann ab dem 25. Februar 1719 nach Mecklenburg einrücken. Nach einem kurzen Scharmützel nahe dem Ort Walsmühlen gelang die Besetzung des größten Teils des Landes unter Einschluss der Residenzstadt Schwerin. Da Herzog Karl Leopold in den vorangegangenen Monaten sowohl den Zaren als auch den Preußenkönig brüskiert hatte, erhielt er keinerlei militärische Unterstützung und musste nach Danzig fliehen ${ }^{33}$. Eine kaiserliche Kommission übernahm mit dem 22. Juni 1719 die Regierungsgeschäfte; in ihr waren vier Hannoveraner und Wolfenbütteler Räte tätig. Ihr Auftrag bestand aus vier Punkten: 1. Wiederherstellung der ständischen Privilegien; 2. Konsolidierung der Landesfinanzen; 3. Wiederherstellung einer geregelten Justiz; 4. Führung der laufenden Regierungsgeschäfte ${ }^{34}$. Bald kehrten auch die exilierten Adligen nach Mecklenburg zurück.

Was aus reichsrechtlicher Sicht als ein Erfolg über die Despotie erscheinen konnte, wurde am kaiserlichen Hof schnell als Fehlschlag betrachtet. Die Hoffnung, dass der gewalttätige Herzog sich unterwerfen und jetzt endlich die kaiserlichen Befehle erfüllen würde, woraufhin der Kaiser ihn großmütig wieder in seine vorigen Rechte einsetzen konnte, erfüllte sich nicht. Karl Leopold gab zwar Verlautbarungen seiner Demut gegenüber dem Reichsoberhaupt zu Papier, richtete sich aber in seinem Handeln in keiner Weise danach. Sein pathologischer Charakter wird deutlich, wenn man die schikanöse Behandlung seiner nächsten Umgebung betrachtet. Schon mit heraufziehender Kreisexekution hatte zunächst sein Wiener Resident, Freiherr Johann Dietrich von Eichholtz, Kritik an der Halsstarrigkeit geübt und sofortige Unterwerfung unter des Kaisers Willen gefordert, um eine Katastrophe $\mathrm{zu}$ vermeiden. Eichholtz berief sich auf die Worte des Reichsvizekanzlers Friedrich Karl Graf Schönborn, um sich im Verlauf des Schreibens immer mehr mit den Forderungen zu identifizieren. Er stellte Karl Leopold seinen politischen Ruin vor Augen, wenn er nicht im letzten Moment nachgäbe: In schonungsloser Deutlichkeit formulierte Eichholtz, es ginge nicht um eine

32 Abkommen vom 5. Januar 1719 in Wien zwischen dem Kaiser, Kurhannover und KursachsenPolen: Wick, Versuche zur Errichtung des Absolutismus in Mecklenburg, S. 132; von ARETin, Das Alte Reich, Bd. 2, S. 260.

33 Vgl. die sehr quellennahe Darstellung der Besetzung Mecklenburgs bei Wick, Versuche zur Errichtung des Absolutismus in Mecklenburg, S. 125-146.

34 Mitglieder waren der Geheimrat von Spörke, der Oberappellationsrat von Alvensleben (beide aus Hannover), der Hofrichter und Oberhauptmann von Heimbuch sowie der Kammerjunker und Hofrat von Steinberg (beide aus Wolfenbüttel). Zur kaiserlichen Kommission: BAUMGARTNER, Die Entwicklung der obersten Landesverwaltung Mecklenburg-Schwerins, S. 61-63. 
temporäre Einschränkung, sondern die Exekutionstruppen würden im Lande bleiben, bis die völlige Bezahlung der Unkosten erfolgt wäre ${ }^{35}$. Zudem sei damit zu rechnen, dass die Ritterschaft sich alle zuviel bezahlten Steuern zurückerstatten lassen würde ${ }^{36}$. Widerstand gegen die Exekutionstruppen würde dem Herzog die Reichsacht einbringen. Weitere Folgen seien die politische Restitution des Adels sowie die Befriedigung von Schadensersatzansprüchen der geschiedenen Herzogin; deren Mutter sei in Wien schon vorstellig geworden. Ein weiterer wichtiger Punkt wurde ebenfalls klar formuliert: Eichholtz schrieb, dem Kaiser gehe es vor allem um den Angriff auf seine Ehre, seitdem Karl Leopold die Zuständigkeit der Reichsgerichtsbarkeit für Mecklenburg infrage gestellt hatte. Karl VI. habe diesen Angriff viel schwerer empfunden als das Schicksal der Adligen an der Ostsee. Hier müsse eine schnelle und eindeutige Klarstellung erfolgen. Zum Schluss folgte noch ein Hinweis in eigener Sache: Bei den kaiserlichen Ministern werde er, sobald er mit mecklenburgischen Themen erscheine, »kkurtz abgefertiget « und habe keinerlei Möglichkeit mehr, irgendetwas zu bewirken. Der Herzog möge ihm einen Adjunkten zur Unterstützung schicken ${ }^{37}$.

Wenig später übten auch seine vier Regierungsräte Edzard Adolf von Petkum, Hermann Christian von Wolffradt, Johann Joachim Schöpfer und Johann Ernst Schaper in einem Brief vom 17. März 1719 Kritik am militärisch-politischen Zusammenbruch Mecklenburgs bei Einmarsch der Exekutionstruppen. Der Landesherr, so die Unterzeichner, möge nicht außer Landes gehen, weil er dadurch seine Untertanen und seine Räte verlassen würde. Auch solle der Herzog die Landmiliz nicht nach Polen führen, sondern nur soweit verkleinern, dass mit dem Rest wenigstens die reguläre Verwaltung und die Steuererhebung gesichert werden könnten. Drittens möge der Landesherr von Gewaltaktionen gegen die Exekutionsmächte absehen und lieber »heylsame Consilia und Vorstellung« fördern. Die unterzeichneten Räte wollen dazu nach Kräften beitragen. Der erboste Landesherr entließ daraufhin die Räte Wolffradt, Schaper und Schöpfer. Petkum behielt er; dieser war wohl unentbehrlich. Wolffradt unterwarf sich dem Landesherrn, distan-

35 Die Kommission setzte die Exekutionskosten auf 600.000 Reichstaler an, zu denen noch 200.000 Reichstaler hinzukamen, die die Kommissare der Ritterschaft als Darlehen gewährt hatten: RAHN, "Die Weide des weissen Rosses von Braunschweig bis an die Ostsee erweitern ...«, S. 343, mit archivalischen Nachweisen.

36 Eine dahin gerichtete Spezifikation der Zwangsabgaben, Schäden und Einkommensausfälle der Ritterschaft aus dem Jahre 1720 summierte sich auf mehr als 5,4 Millionen Reichstaler es war klar, dass die Mecklenburger Kammergüter mehr als 100 Jahre daran würden abbezahlen müssen, wenn die ganze Summe eingehoben worden wäre. Der Reichshofrat bewilligte allerdings nur eine Gesamtsumme von 350.000 Reichstalern: ebd., S. 344.

37 Freiherr von Eichholtz an Herzog Karl Leopold von Mecklenburg, 3. Januar 1719: LHA Schwerin 2.11-1/2 Auswärtige Beziehungen, Nr. 1606, fol. 4-9. 
zierte sich vom Brief und erlangte seine Wiedereinstellung ${ }^{38}$. Es ist unklar, ob die kritischen Töne aus seiner engsten Umgebung den Herzog vier Jahre später zu despotischen Kriminalprozessen gegen Geheimrat von Wolffradt, Geheimsekretär Scharff sowie den Bürgermeister Brasch aus Dömitz veranlasste, die mit der Hinrichtung von Wolffradts und dem Tod Scharffs und Braschs im Gefängnis endeten ${ }^{39}$. Alle diese Episoden wurden umgehend im Reich bekannt.

Karl Leopold ließ sich von seinem schlechten Ruf überhaupt nicht beeindrucken. Er bereiste Preußen und Polen und erschien auch in Wien, um seine Restitution gegen den Kaiser zu betreiben ${ }^{40}$. Als das scheiterte, errichtete er in der Festungsstadt Dömitz eine Kleinregierung, durch die er seine despotische Regierungsweise fortsetzte. Gegen alle Anordnungen der Kommission protestierte er schriftlich und bedrohte seine Landsassen für den Fall, dass sie an Landtagen teilnähmen, die nicht von ihm selbst einberufen worden wären. Die Kommissionsregierung hingegen wurde zu einer Dauereinrichtung, sowohl wegen der ungeklärten Stellung des Herzogs und der Rückfallgefahr in den vorigen despotischen Regierungszustand als auch wegen des Eigeninteresses der braunschweig-lüneburgischen Machtpolitik. Diese Interessen bestimmten die Entscheidungen der Kommissare, die Anweisungen aus Wien nur dann befolgten, wenn sich keine Widersprüche zu den Wünschen aus London resp. Hannover ergaben ${ }^{41}$.

Dem Reichsrecht mochte auf diese Weise Genugtuung geschehen sein, doch am Wohl des Landes orientierte sich die kaiserliche Herrschaftssuspendierung nicht. Faktisch entstand eine Doppelherrschaft, in der die kaiserliche Kommission die Außen-, Sicherheits- und Finanzpolitik kontrollierte. Der Herzog hingegen administrierte seinen Einflussbereich und behielt darüber hinaus die Personalpolitik und die Justiz in seinen Händen ${ }^{42}$. Konkurrierende Anweisungen stürzten die Landesbediensteten von einem Loyalitätskonflikt

38 Vgl. die Schilderung der Begebenheit bei Wick, Versuche zur Errichtung des Absolutismus in Mecklenburg, S. 139; BaumgarTner, Die Entwicklung der obersten Landesverwaltung Mecklenburg-Schwerins, S. 61.

39 Vgl. zu den Umständen der Prozesse: Wick, Versuche zur Errichtung des Absolutismus in Mecklenburg, S. $157 f$.

40 Vgl. den Bericht über die Wienreise in ebd. 1720, H. 234, S. 542f. Karl Leopold wurde zwar am 9. Juni 1720 beim Kaiser vorgelassen, erreichte allerdings nichts und musste nach einem halben Jahr unverrichteter Dinge Wien wieder verlassen: Bericht über den weiteren Verlauf der Reise in der »Europäischen Fama« 239 (1720), S. 1006. Reichsvizekanzler Graf Schönborn und Hofkanzler Philipp Ludwig Graf Sinzendorff sollen Wien verlassen haben, um nicht mit dem Herzog zusammentreffen zu müssen: Hughes, Law and Politics, S. 157.

41 Zur Transformation der Kommission von einer kaiserlichen in eine englische: JAHNS, »Mecklenburgisches Wesen«, S. 341.

42 Sigrid Jahns betont, dass diese Herrschaftskonstruktion in jedem Fall chaotische Verhältnisse zur Folge haben musste: ebd., S. 341f.; BaUmgarTnER, Die Entwicklung der obersten Landesverwaltung Mecklenburg-Schwerins, S. 65-67. 
in den nächsten und sorgten für ständige Rechtsunsicherheit. Während die Kommission die Adelsreaktion unterstützte und die mecklenburgische Ritterschaft die Gelegenheit nicht verstreichen ließ, den ökonomischen Ausbau der Gutsherrschaft auf Kosten der Landbevölkerung und der kleinen Landstädte voranzutreiben, war der Herzog besorgt, in seinem Einflussbereich die Steuermittel zu erlangen, die er für die Fortsetzung seiner fürstenmäßigen Herrschaftsrepräsentation benötigte.

Da Karl Leopold trotz seiner politisch sehr beengten Lage nicht aufgab, suspendierte ihn Kaiser Karl VI. mit Resolution vom 11. Mai 1728 von seiner Landesherrschaft ${ }^{43}$. Aus kaiserlicher Sicht war dies eine geschickte Idee: Zum einen benötigte der Wiener Hof dafür, anders als bei einer Reichsacht ${ }^{44}$, keine Zustimmung des Reichstags, zum anderen hebelte er den Einfluss der Kommissionsmächte aus ${ }^{45}$. An die Stelle des Herzogs trat sein Bruder Christian Ludwig als kaiserlicher Kommissar, faktisch als Landesadministrator. Wohlgemerkt war Karl Leopold nicht dauerhaft suspendiert, sondern nur bis zur Leistung völliger »Parition und Submission«, d.h. bis zur Erfüllung aller kaiserlichen Forderungen nicht nur verbal, sondern auch in der Tat. Damit war Herzog Christian Ludwig auch nur interimistischer Landesherr, der sich somit ebenfalls an die kaiserlichen Weisungen zu halten hatte, wollte er seinen neuen Status nicht später wieder einbüßen - und wieder unter die Regierung seines gewalttätigen Bruders fallen. Karl VI. glaubte, so die mecklenburgischen Verhältnisse endgültig unter Kontrolle gebracht zu haben. Auch die Wirkung im Reich war nicht unerheblich: Der Kaiser hatte das Reichsrecht zwar etwas gedehnt, aber nicht gebrochen, und gleichzeitig allen mindermächtigen Reichsständen demonstriert, dass es weiterhin angeraten war, sich kaiserlichen Anweisungen zu fügen und Beschlüssen der Reichsgerichte Folge zu leisten.

In Wirklichkeit war die Lage des Kaisers allerdings weit weniger beneidenswert. Die beiden Kreisexekutoren, die die Kommission in Schwerin per-

43 Abdruck: Johann Jacob Moser, Teutsches Staatsrecht, Bd. 24, Leipzig 1748 (ND Osnabrück), S. $265-275$.

44 Nach den Erfahrungen mit der Ächtung des Kurfürsten Friedrich V. von der Pfalz 1620/21 sowie weiterer Reichsstände während des Dreißigjährigen Krieges hatten die Reichsstände im Westfälischen Friedenskongress unter Assistenz der Garantiemächte verabredet, künftige Ächtungen und Fürstenabsetzungen der kaiserlichen Verfügungsgewalt zu entziehen und unter die Kontrolle des Reichstags zu stellen. Die diesbezügliche Regelung sollte in die ständige kaiserliche Wahlkapitulation aufgenommen werden. Vgl. zur Problematik der Reichsacht: Weber, Zur Bedeutung der Reichsacht in der Frühen Neuzeit, S. 55-90; Kampmann, »Der Leib des Römischen Reichs ist der Stände Eigentum und nicht des Kaisers«, S. 169-198.

45 Da die Kommission im Verständnis der Zeit personalisiert auf die Landesherren von Kurhannover und Braunschweig-Wolfenbüttel bezogen war, hatte sie de iure ohnehin mit dem Tod König Georgs I. von England 1727 aufgehört; praktisch wirkten die Räte allerdings weiter. Vgl. WICK, Versuche zur Errichtung des Absolutismus in Mecklenburg, S. 172; BAUMgarTnER, Die Entwicklung der obersten Landesverwaltung Mecklenburg-Schwerins, S. 62. 
sonell gestellt hatten, wurden weiterhin benötigt für den Fall einer neuerlichen militärischen Auseinandersetzung mit dem Herzog. In diesem Fall sollten sie dem Administrator Christian Ludwig Hilfe leisten. Zudem wurde Preußen als dritte »Konservationsmacht« berufen, damit der Einfluss Kurhannovers eingedämmt wurde. Das Verhältnis zwischen Kaiser und englischem König hatte sich nämlich in den 1720er Jahren abgekühlt, und 1727 hatte die englische Regierung von Karl VI. die Aufgabe seiner Ostindienkompanie in Ostende verlangt, eine Forderung, die der Kaiser wegen der ungeklärten Erbsituation in seinem eigenen Hause schließlich zugestehen musste $^{46}$. Der Tod König Georgs I. am 22. Juni 1727 bot dem Wiener Hof die Gelegenheit, die Administrationskommission neu zu besetzen ${ }^{47}$.

Ein Wechsel der Verhältnisse in Mecklenburg trat faktisch nicht ein, weil die beiden Exekutoren von 1719 den politischen Hebel einsetzten, ihre Kommissionstätigkeit und ihre Truppenpräsenz erst beenden zu wollen, wenn ihnen die Exekutionskosten erstattet worden $\operatorname{seien}^{48}$. Zudem setzten die welfischen Fürsten durch, dass die Suspendierung des Mecklenburger Herzogs als Thema am Reichstag behandelt wurde, ohne dass sich an den Fakten im Herzogtum an der Ostsee dadurch etwas änderte ${ }^{49}$. Dieser Dissens fiel zeitlich mit dem Zusammenbruch der kaiserlichen Reichspolitik zusammen. Sigrid Jahns verweist darauf, dass der Abtritt des Reichsvizekanzlers Graf Schönborn in Wien von Amt und Einfluss 1729 das Ergebnis seiner Resignation über die Wende von der aktiven Reichspolitik zur Hausmachtpolitik der Zugeständnisse an die internationalen Mächte darstellte ${ }^{50}$.

Die inneren Verhältnisse in Mecklenburg änderten sich nur insofern, als nun auch die preußischen Interessen in der Kommissionsarbeit berücksichtigt werden mussten, was praktisch zu einer Lähmung der Geschäfte in vielen Fragen führte. Unterdessen dominierte der Adel und die See- und Hansestadt Rostock weiter, während es in den Landstädten und unter der Bauernschaft zu sozialen Konflikten kam $^{51}$. Herzog Karl Leopold, der seine Entmachtung immer noch nicht akzeptierte, hielt durch sein Verhalten auch

46 Zur kurzen Geschichte der Ostende-Kompanie und ihrer internationalen Bedeutung: DuchHARDT, Balance of Power und Pentarchie, S. 270-273 u. 279. Zur internationalen Lage und der kaiserlichen Position: Hughes, Law and Politics, S. $206 \mathrm{f}$.

47 Zur internationalen Dimension: von Aretin, Das Alte Reich, Bd. 2, S. 323.

48 Dieses Mittel war im Reich erprobt, seit Herzog Maximilian I. 1607 auf diese Weise die Reichsstadt Donauwörth nach einem Exekutionsauftrag des Reichshofrats erst zur reichsrechtlichen Parition zwang, um die Stadt anschließend in dauerhafte Pfandschaft zu übernehmen und zu rekatholisieren: Maximilian Lanzinner, Donauwörth. Der bayerische Griff nach der Reichsstadt 1607/1608, in: Alois Schmid/Katharina Weigand (Hg.), Schauplätze der Geschichte in Bayern, München 2003, S. 216-230.

49 Wick, Versuche zur Errichtung des Absolutismus in Mecklenburg, S. 179.

50 JAHNS, »Mecklenburgisches Wesen«, S. 343.

51 Zu den Auseinandersetzungen: Wick, Versuche zur Errichtung des Absolutismus in Mecklenburg, S. 183-190. 
die Handlungsunfähigkeit der mecklenburgischen Bürokratie und Justiz aufrecht. 1732 wurde Herzog Christian Ludwig zwar erneut vom Kaiser zum Kommissar ernannt, doch blieb seine faktische Stellung schwach. Besonders litt der Herzog darunter, dass ihm keine Einkünfte des Landes zuflossen, weil die welfischen und preußischen Kommissare (und in seinen Gebieten Herzog Karl Leopold) die Kontrolle über die Steuern ausübten ${ }^{52}$. Die früheren Kommissare sollten das Entschädigungsgeschäft abschließen und ihre Räte zurückziehen, forderte er. Dies geschah aber erst 1733.

Im selben Jahr machte Herzog Karl Leopold einmal mehr auf sich aufmerksam. Für einen außenstehenden Beobachter war schwer verständlich, weshalb dieser Herzog bei der Geistlichkeit und den Untertanen in den Landstädten und Dörfern immer noch erheblichen Rückhalt besaß. Dieser Umstand ist bezeichnend für den Mangel an Vertrauen, den die Mecklenburger gegenüber ihrem Adel hegten ${ }^{53}$. Karl Leopold berief ein Landesaufgebot zusammen in der Hoffnung, bis zu 60.000 Mann zu mobilisieren und damit die Exekutionsmächte zu vertreiben und seine unumschränkte Herrschaft wiederherzustellen. Das Bauernaufgebot erreichte kaum mehr als ein Zehntel der gewünschten Stärke. Zwar versammelten sich die Bauern an einigen Orten, um durch den Aufstand die Herrschaft Karl Leopolds über das gesamte Territorium wiederherzustellen, wie sie meinten, doch ging von ihnen keine wirkliche militärische Wirkung aus. Die Hannoveraner und Braunschweiger Truppen wurden verstärkt und stellten Ruhe und Ordnung bald wieder her ${ }^{54}$. Preußen nutzte die günstige Gelegenheit, um eigene Truppen ins Territorium einrücken zu lassen. Kaiserliche Anordnungen, dass die Soldaten der Kommissionsmächte das Territorium verlassen sollten, wurden erst 1735 befolgt, nachdem ein Drittel der herzoglichen Domänengüter den drei interessierten Fürsten als Schadensersatz für ihre Exekutionskosten verpfändet worden war. Herzog Christian Ludwig baute sich zu seinem Schutz eine Kerntruppe auf, bestehend aus zwei Regimentern des Herzogs von Hol-

52 Ernennung Christian Ludwigs von Mecklenburg-Schwerin zum kaiserlichen Kommissar, 28. April 1732: Baumgartner, Die Entwicklung der obersten Landesverwaltung Mecklenburg-Schwerins, S. 63. Zur Finanzschwäche Christian Ludwigs: Wick, Versuche zur Errichtung des Absolutismus in Mecklenburg, S. 181 u. 208f.

53 Zum Verhältnis Karl Leopolds zur Pfarrerschaft und den bürgerlichen und bäuerlichen Untertanen: Baumgartner, Die Entwicklung der obersten Landesverwaltung Mecklenburg-Schwerins, S. 63. Peter Wick weist auf zahlreiche Konflikte zwischen Pfarrern und Adligen hin, wobei letztere die Neigung zeigten, die Geistlichen ihren Gutsherrschaften zu unterstellen: Wick, Versuche zur Errichung des Absolutismus in Mecklenburg, S. 24.

54 Zur Vorbereitung und zum Scheitern des Aufstandsprojekts: ebd., S. 193-237; vgl. auch JAHNS, »Mecklenburgisches Wesen«, S. 344 und RAHN, »Die Weide des weissen Rosses von Braunschweig bis an die Ostsee erweitern ...«, S. 344. 
stein-Gottorp und des Fürsten von Schwarzburg-Rudolstadt sowie 200 Reitern, die ihm der Bischof von Bamberg zur Verfügung gestellt hatte ${ }^{55}$.

Der einheimische Adel mochte das machtpolitische Patt zwischen dem Kaiser und den drei in der Administrationskommission vertretenen Fürsten als Quelle ihrer Privilegien und Freiheiten betrachten, dem Land insgesamt schadete der Zustand sehr. Von einer geregelten Verfassungsordnung konnte keine Rede sein. Diese musste in einem zwanzigjährigen innenpolitischen Ringen neu bestimmt werden. Sie wurde es 1755 - erwartungsgemäß als Festschreibung der weitreichenden Adelsvorrechte, als Bekräftigung der gemeinschaftlichen landständischen Verfassung unter Beteiligung beider Linien des Mecklenburger Hauses. Zu dieser Zeit regierte Herzog Christian Ludwig bereits seit 1747 nach dem Tod seines Bruders kraft eigenen Rechts. Seine Versuche, in Absprache mit dem Strelitzer Vetter die Landstände für die beiden Teilterritorien zu teilen, scheiterten an deren Widerstand. Erneut klagten Ritterschaft und Städte vor dem Reichshofrat, die folgende kaiserliche Kommission schaffte die Trennung der Stände nicht. Nach zähen Verhandlungen musste der Herzog zwar die Gesamtständeverfassung bestehen lassen, aber immerhin gelang ihm am 18. April 1755 der Abschluss des »Landesgrundgesetzlichen Erbvergleichs ${ }^{56}{ }^{56}$. Die Landesherrschaft blieb auf ihre eigenen Einkünfte aus Domänen und Regalien verwiesen, um davon die reguläre Administration und Rechtsprechung zu bezahlen. Die Steuerbewilligung der Stände für weitergehende Gemeinschaftsaufgaben wurde restituiert, auch wenn einige Abgaben zu Dauerpflichten wurden, allerdings streng limitiert und ständisch kontrolliert. Die Kontribution wurde zu je einem Drittel aus den Adelsgütern, den Städten und dem Domanium geleistet. Die steuerliche Privilegierung der ständetragenden Gesellschaftsgruppen blieb bestehen. Der Adel beispielsweise genoss weiterhin Steuerfreiheit für seine alten Hufen und musste nur für die später erworbenen Bauernländereien Abgaben leisten. Die bäuerliche Leibeigenschaft fand ihre endgültige Festschreibung, und auch die adligen Herrschafts-, Gerichts- und Patronatsrechte wurden bestätigt. Neben diesen ökonomischen Folgen handelten die Stände das Recht heraus, an allen politisch bedeutsamen Fragen per Landtag beteiligt zu werden. Von absoluten Regierungsrechten der Herzöge blieb kaum mehr übrig als die Verfügungsgewalt über das Domanium ${ }^{57}$. Bemerkenswert ist die

55 Wick, Versuche zur Errichtung des Absolutismus in Mecklenburg, S. 250; Baumgartner, Die Entwicklung der obersten Landesverwaltung Mecklenburg-Schwerins, S. 63f.

56 »Landesgrundgesetzlicher Erbvergleich« vom 18. April 1755: SACHSSE, Mecklenburgische Urkunden und Daten, S. 466-534. Zusammenfassung und Bewertung: Wick, Versuche zur Errichtung des Absolutismus in Mecklenburg, S. 257f.; Heck, Geschichte des Landtags in Mecklenburg, S. 29.

57 Vgl. die Umschreibung und Bewertung des Erbvergleichs bei JAHNS, »Mecklenburgisches Wesen«, S. 346f. 
zeitliche Reichweite dieses Herrschaftsvertrags: Er galt, allen historischen Umbrüchen zum Trotz, bis zum Ende des Ersten Weltkriegs.

Für das hier zu behandelnde Zeitalter bleibt eine größere, aus den Akten erarbeitete Studie ein Desiderat. Der Zugang zur Thematik wird zudem erheblich dadurch erschwert, dass alle handelnden Parteien gleichermaßen unsympatisch erscheinen. Ein ordentlicher »Plot«, eine nachfühlbare Erzählgeschichte, fehlt und ist auch mit Kunstgriffen nicht herstellbar: Herzog Karl Leopold war eine Klagegestalt nach außen und oben, ein Despot hingegen gegenüber seinen Untertanen und insbesondere gegenüber seinen Höflingen - je intensiver der Forscher sich mit seiner Geschichte befasst, desto mehr gelangt er zu der Überzeugung, dass der Herzog sein Schicksal verdiente. Nicht einmal zum großen Bösewicht reichte es: Nach der Suspendierung folgte ein jahrzehntelanger politischer Niedergang und ein unspektakulärer natürlicher Tod. Seine Räte waren unselbstständige Wortklempner und Begriffsdrechsler, die die herzogliche Politik mit trugen. Obwohl die Mecklenburger Despotie nicht durch Mauer und Stacheldraht abgeschirmt war, bleiben selbst Räte beim Herzog, als dieser sich bereits durch Gewalttaten disqualifiziert hatte. Der mecklenburgische Adel bildete eine eigensüchtige Clique mit ausschließlichen Lobby-Interessen, die das Land als den Vorläufer eines Supermarkts betrachtete, in dem man sich nach Belieben bedienen konnte und auf diese Sichtweise noch einen Rechtsanspruch forderte. Keines dieser drei Lager leistete wirklich etwas für das Land, das weder mächtiger noch sicherer, weder weniger verschuldet noch ökonomisch besser strukturiert und schon gar nicht sozial gerechter wurde. Bleiben noch der Kaiser und die auswärtigen Mächte: Karl VI. wollte die Rolle des kaiserlichen Rechtsschützers spielen, schaffte das aber nur zum Teil. Es konnte der Wiener Administration nicht verborgen geblieben sein, dass die Mecklenburger Polykratie nach 1719 zwar unter Gleichgewichtsaspekten als zweckmäßig gesehen werden konnte, aber für die kaiserliche Klientel der Mindermächtigen im Reich dennoch ein Schreckbild gewesen sein musste. Zur Inhaftierung des Herzogs, wofür es spätestens nach den Justizmorden in den frühen 1720er Jahren Gründe genug gab, fehlte dem Kaiser der Mut und die Kraft. Stattdessen lieferte er Mecklenburg seinen großen fürstlichen Nachbarn aus. Von ihnen hatte niemand uneigennützige Motive, wobei man diese bei England-Hannover und Brandenburg-Preußen vielleicht auch am wenigsten erwartet hätte. 


\subsection{Deduktionen und Flugschriften}

\subsubsection{Prolog: Drucksachen zum Ehekonflikt Herzog Karl Leopolds}

Angesichts der Dimensionen des Konflikts ist die Hinterlassenschaft an Druckschriften überbordend. Herzog Karl Leopold von Mecklenburg-Schwerin geriet nicht durch seinen Dissens mit den Landständen in die Öffentlichkeit im Reich, sondern zunächst 1716 wegen der Trennung von seiner ersten Gemahlin, Herzogin Sophia Hedwig aus dem Hause Nassau-Dietz (16901734). Die Ehe ging 1710 unter großer öffentlicher Anteilnahme auseinander, weil die Herzogin auf grobe und unehrenhafte Weise behandelt worden war und ihre Übersiedlung nach Hamburg eher einer Flucht entsprach. Später folgten jahrelange Auseinandersetzungen über den Unterhalt. Die Ehe zur linken Hand mit Christine Dorothea von Lepel (1692-1728) von 1710 stellte nur ein Interim dar ${ }^{58}$. Im Jahr 1716 ging der Herzog eine zweite reguläre Ehe mit Prinzessin Catharina Iwanowna (1692-1733) ein, einer Nichte des Zaren Peter des Großen ${ }^{59}$.

Ebenfalls 1716 erschien die anonyme Flugschrift Kurtzer und deutlicher Beweis, die das Eheleben im Mecklenburger Herzogshaus in den Blick nahm ${ }^{60}$. Auf acht Seiten wurde ausgeführt, dass der Herzog zu seiner neuen Ehe berechtigt sei und dadurch kein Verstoss gegen das Bigamieverbot aus der Constitutio Criminalis Carolina vorlag ${ }^{61}$. Im Einzelnen wurden folgende Thesen aufgestellt:

1. These: Die Ehe ist im Protestantismus ein auflösbarer Vertrag (contractus).

2. These: Der Ehezweck ist die Erzeugung legitimer Nachkommen; daher sind beide Parteien zum Beischlaf verpflichtet (Verweigerung $=$ Scheidungsgrund).

3. These: Die Herzogin hat durch eigene eheliche Verweigerung den Anlass zur Trennung gegeben (Verschuldensprinzip).

58 Matthias, Die Mecklenburger Frage in der ersten Hälfte des 18. Jahrhunderts, S. 11. - Zu den Eheverwicklungen: von ARETIN, Das Alte Reich, Bd. 2, S. 256.

59 Zur Eheschließung und ihrer Bedeutung vgl. die ausführliche, quellengesättigte ältere Studie von Wilhelm Paul GrafF, Die zweite Ehe des Herzogs Karl Leopold. Ein Kulturbild aus Mecklenburg im ersten Viertel des 18. Jahrhunderts, in: Verein für Mecklenburgischer Geschichte und Altertumskunde 60 (1895), S. 199-308. Kurzfassung: WICK, Versuche zur Errichtung des Absolutismus in Mecklenburg, S. 81-83.

60 »Kurtzer und deutlicher Beweis, dass Ihro Regierende Hoch=Fürstl. Durchlaucht zu Mecklenburg/etc. Mit gutem Fug Rechtens Zu Einer Neuen Vermählung schreiten«, o.O. 1716.

61 »Constitutio Criminalis Carolina« vom 31. Juli 1532, § 121: Gustav Radbruch (Hg.), Die Peinliche Gerichtsordnung Kaiser Karls V. von 1532, Stuttgart ${ }^{4} 1978$, S. 80. 
4. These: Der protestantische Landesherr ist »Episcopus« in seinem Territorium und kann daher auch seine eigene Ehe auflösen.

5. These: Gegebenenfalls darf er sogar in Polygamie leben.

6. These: Als ranghohe Persönlichkeit darf er auch im Konkubinat leben.

7. These: Alles zuvor in Mecklenburg Geschehene ist legitim, weil es der Erzeugung eines Nachfolgers dienen sollte; staatliche Unordnung ist schlimmer als eheliche Ausnahmesituationen.

$\mathrm{Zu}$ dem Zeitpunkt, als die Flugschrift erschien, war Karl Leopold, wie Michael Hughes schreibt, inzwischen auch morganatisch mit einer Hofdame verheiratet. Der Reichshofrat sah die Ehescheidung allerdings als nichtig an, was eine Debatte der protestantischen Reichsstände über die Zuständigkeit des Wiener Gerichts für fürstliche Eheangelegenheiten auslöste ${ }^{62}$. In Wien wurde die Flugschrift auf Anordnung des Reichshofrats öffentlich verbrannt ${ }^{63}$.

Der mediengeschichtliche Clou der Flugschrift liegt darin, dass sie offenbar gar nicht aus der Umgebung Karl Leopolds stammte und nicht zur Rechtfertigung seiner Heiratspolitik diente. Der Autor darf im Lager der adligen Opposition des Herzogs vermutet werden, und geschrieben wurde sie, um denselben am Kaiserhof und in den Augen der Öffentlichkeit im Reich zu diskreditieren. Die Hamburger Zeitung Curieuser Extract Derer Neuesten Zeitungen Nr. 20 vom 8. März 1717 schreibt dazu:

Rostock/vom 6. Martii. Obgleich im Junio negst verwichenen Jahres ein gewisses fameuses, die vormahlige gerechteste Ehe=Scheidung Sr. Hoch=Fürstl. Durchl. unsers gnädigsten Landes=Fürsten/zwar dem Ansehen nach vertheidigendes / in der That aber höchst blamirendes/und im vorigen Jahre ohne Benennung des Orthes gedrucktes Scriptum betitelt: Kurtzer und deutlicher Beweiß, daß Ihro Regirende Hoch=Fürstl. Durchlaucht zu Mecklenburg/mit gutem Fug Rechtens zu einer neuen Vermählung geschritten/Alhie zu Rostock/wie auch zu Parchim/Güstrow und Schwerin durch den Scharffrichter öffentlich verbrandt worden; Dessen ungeachtet aber ein abermahliger Calumniante sich neulich gefunden/und mit gleicher Boßheit obberührte Ehe=Scheidungs Sache auff die allergehäßigste Manier vorzustellen/und durch die Hechel zuziehen/unterfangen/solches auch durch ein gedrucktes Scriptum dessen Rubrique ist: Kurtz und deutliche von einem Freundt an dem anderen geschriebene Anmerckungen über einen so genandten Kurtz= und deutlichen Beweiß/daß Ihr. Durchl. der Regierende Hertzog zu Mecklenburg mit gutem Fug Rechtens zu einer neuen Vermählung geschritten A. 1716 auch ohne Benennung Zeit und Orthes bekandt gemachet hat; So ist auff desfals anhero ergangenen Hohen Befehl solche scandaleuse

62 Hughes, Law and Politics in Eighteenth Century Germany, S. 103.

63 Europäische Fama 187 (1716), S. 597f. 
Schrift alhie zu Rostock auf öffentlichen Marckt durch den Scharfrichter verbrandt worden/ und dieser Tagen in mehr andern Städten dieser Lande als Parchim/Güstrow und Schwerin ein gleiches geschehen ${ }^{64}$.

Die Verbrennung der Schrift im Herzogtum Mecklenburg stellte die öffentliche Distanzierung des Herzogs von dem Machwerk heraus. Bezeichnend war allerdings, dass man dem Herzog im Reich durchaus zutraute, derartige Schritte gutzuheißen und in Schriftform gießen zu lassen. So blieben Gegenschriften nicht aus, wie die Deduktion Zufällige Gedanken ${ }^{65}$. Hier wurde ausgeführt, dass die Ehe nicht, wie in der Schrift Kurtzer und deutlicher Beweis fingiert, ein bloßer Vertrag sei, den man nach Belieben lösen könne - dies gelte auch für Protestanten im Reich. Zahlreiche Rechtsautoritäten wurden dafür angeführt. Die wenigen Befürworter der Polygamie, etwa der Danziger Jurist Samuel Friedrich Willenberg (1663-1748) oder der frühere schwedische Rat Johann Lyser (1631-1684), hätten die Verbrennung ihrer Schriften durch den Henker erlitten. Sie seien zudem anschließend des Landes verwiesen worden.

\subsubsection{Deduktionen über den Ständekonflikt bis 1719}

Der Ständekonflikt des Herzogs setzte nicht erst im Jahre 1716 ein, sondern entwickelte sich schon direkt im Anschluss an den Herrschaftsantritt Karl Leopolds 1713. Für die Wahrnehmung in den zeitgenössischen Druckmedien benötigte die Auseinandersetzung allerdings erst einige Zeit, ehe sie breit ausgetragen werden konnte. Der Durchbruch der Mecklenburg-Angelegenheit $\mathrm{zu}$ einem allgemeinen Thema in der Berichterstattung erfolgte im Laufe des Jahres 1716. Den Anfang machten Quellenpublikationen wie der Druck des kaiserlichen Dehortatorium vom Oktober 1716: Darin wurde Karl Leopold ernstlich gewarnt, dass die Fortsetzung der autokratischen und gewalttätigen Politik gegen die intermediären Kräfte in seinem Territorium schwerwiegende rechtliche Folgen nach sich ziehen würde. Im Schreiben wurde er darauf hingewiesen, dass die rechtswidrigen Handlungen bereits »reichs=kündig « und damit öffentlich seien ${ }^{66}$.

64 »Curieuser Extract Derer Neuesten Zeitungen«(Rostock), Nr. 20 vom 8. März 1716; die Ausgabe liegt der Korrespondenz des Jahres 1716 zwischen Mecklenburg und dem Wiener Residenten von Eichholtz bei: LHA Schwerin, 2.11-2/1 Auswärtige Beziehungen, Nr. 2501, fol. 669 .

65 »J.H.R. zufällige Gedancken Über den sogenannten kurtzen und deutlichen Doch übel abgefasten Beweis [...] ${ }^{\circ}$, o.O. 1716, $4^{\circ}, 8 \mathrm{~S}$.

66 »Copia Kayserl. Dehortatorii an des Hn. Hertzogs zu Mecklenburg Fürstl. Durchl., vom 20. October. 1716«, o.O. 1716, 4 S. 
Die große Mehrzahl der Deduktionen über den Ständekonflikt erschien in den Jahren 1718 und 1719, als überall im Reich die Exekution des Niedersächsischen Kreises erwartet wurde und Ende Februar 1719 endlich stattfand, gefolgt von der Errichtung der neuen Ordnung im Herzogtum. Mehrere hundert dieser Deduktionen wurden in zwei großen Quelleneditionen publiziert, in den vierbändigen, anonym herausgegebenen Collectanea Mecklenburgica sowie im Acten $=m \ddot{3} \beta$ igen Bericht von Johann Schevius ${ }^{67}$. Waren die Collectanea eine bloße Sammlung von Deduktionen, kaiserlichen und herzoglichen Mandaten sowie weiteren Rechtsschriften, so stellte Schevius eine ausführliche Abhandlung voran, die die politische Entwicklung in MecklenburgSchwerin vom Amtsantritt Karl Leopolds bis zu seiner Herrschaftsablösung durch die welfischen Exekutionstruppen schilderte. Die Quellensammlung von 885 Dokumenten ist als Anhang gekennzeichnet, umfasst aber den größten Teil der über 1.100 Seiten starken Publikation. Die meisten Schriftstücke, die bis dahin den Konflikt bestimmt hatten, finden sich in einer der beiden Editionen wieder. Schevius verweist darauf, dass sein Sammelwerk angestoßen worden sei durch die Eingabe der Rechtfertigungsschrift Herzog Karl Leopolds vom 17. Dezember 1717 beim Reichstag. Der Fürst versuchte, die sich abzeichnende Exekution gegen sein Land abzuwenden, indem er sie als unrechtmäßig bezeichnete, da er als Landesherr souverän sei ${ }^{68}$.

Es wird klar zum Ausdruck gebracht, dass die in Ratzeburg versammelte oppositionelle und exilierte mecklenburgische Ritterschaft Initiator und Finanzier der Quellensammlung war. Die Herrschaft Karl Leopolds, so der Tenor der Abhandlung, habe jedes rechtlich erträgliche Maß gesprengt. Ein Formelkompromiss sei daher nicht mehr ausreichend für eine Einigung. Nur eine gründliche Sicherung aller ständischen Rechte könne erwirken, dass die Adligen ohne Furcht um Leib und Leben wieder ins Herzogtum zurückkehrten. Bezugsgröße war die Deduktion Gegründete Wiederlegung, die die Ritterschaft 1718 gegen den herzoglichen Vorwurf der Rebellion erstellt hatte ${ }^{69}$. Diese Rechtfertigungsschrift, die auch als Flugschrift erschien, wurde an dieser Stelle aufgegriffen, und es ging dabei um fünf Gedanken:

67 [ANONYM], »Collectanea Mecklenburgica«, Bd. 1-4, o.O. [= Flensburg] 1718; [Schevius], »Höchst=gemüßigter Historischer= Acten=mäßiger Bericht.

68 »Höchst=gemüßigte Anzeige an eine Hoch=löbl. Reichs= Versammlung/von Seiner Hochfürstlichen Durchl. dem regierenden Hertzoge zu Mecklenburg/Schwerin und Gustrow/das [...] ungehorsame Betragen einiger dero Vasallen und Unterthanen [...]«, o.O. 1718. - Vgl. zur Interpretation auch PEČAR, Am Rande des Alten Reiches, S. 201-205.

69 »Gegründete Wiederlegung/Eines sub Rubro Einer Höchst= gemüßigten Anzeige An eine Hochlöbl. Reichs=Versammlung von Fürstl. Mecklenburgis. Seiten publicirten Schreibens $[\ldots .$. «, o.O. 1718. Die Deduktion ist auch im ganzen abgedruckt bei Georg Melchior von LudoLf, Electa Juris Publici. Worinnen Die Vornehmsten Staats-Affairen in Europa/Besonders in Teutsch=Land/aus bewährtesten Actis publicis [...] recensiret werden, 21 Bd., München 17091725, hier Bd. 12, S. 511-573 u. 646-680. - Vgl. zur Interpretation auch PEČAR, Am Rande des Alten Reiches, S. 205-207. 
1. Ist die fürstliche Bewaffnung des Landes nötig, nützlich und tragbar?

2. Darf das auswärtige Bündnis mit Russland dazu führen, dass die Parition gegenüber dem Kaiser unterbleibt?

3. Rechtfertigt die Landesdefension so hohe Steuern?

4. Schützen die Privilegien die Stände vor den Belastungen?

5. Können Kaiser und Reichsgerichte in dieser Sache etwas verordnen ${ }^{70}$ ?

In der Gegründeten Wiederlegung ebenso wie in der einführenden Abhandlung bei Schevius wird die Gerechtigkeit der kaiserlichen Mandate an den Herzog von Mecklenburg betont. Selbst im Kommissionsdekret sei zu lesen, so der Verfasser, dass Zweifel an der Notwendigkeit der mecklenburgischen Armierung im tatsächlichen Umfang bestünden und der Verdacht nicht ausgeräumt worden sei, die Truppen dienten einer »arbitrarischen Unterwürffigkeit« der Stände unter die landesherrliche Gewalt. In Wirklichkeit sei eine militärische Defension sinnlos. Gegen die mächtigen Nachbarn Dänemark, England-Hannover und Preußen könne man sich nicht wehren, selbst wenn alles Vermögen der Mecklenburger dafür aufgewendet würde. Andere Feinde in vergleichbarer Größenordnung aber habe man nicht zu befürchten, da diese viel zu weit entfernt wohnten ${ }^{71}$.

Es sollte ganz die Gefühlslage des von Reichsfürsten dominierten Reichstags treffen, wenn die Mecklenburger Adligen in der Schlusswendung der einführenden Abhandlung - an monarchomachische Tradition anknüpfend den Beratertopos beschworen, demnach ein König oder Fürst nicht irrt, sondern nur schlecht beraten sein konnte:

Dabey wir aber feierlich contestiren/daß/gleichwie für Sr. Fürstl. Durchl. Unsers gnädigsten Landes $=$ und Lehns=Herrn Hohe Persohn/Wir je und in alle wege alle Veneration und Pflicht=mäßigen Respect hegen und vorbehalten/auch in unverruckter Treue/Gehorsahm und Devotion gegen Dieselbe/bis an unser Ende beständig zu beharren gedencken; Also auch alles/was hierin zu nothdringlicher Rettung Unser Unschuld und Bescheinigung derer vielfältig erlittenen Bedrückungen/von denen unjustificirlichen Factis unumbgänglich hat referiret und gesaget werden müssen/gar nicht auf Sr. Fürstl. Durchl./ sondern vielmehr nur allein auf solcher Unternehmungen erste Uhrheber und Rathgeber gemeynet seyn solle ${ }^{72}$.

70 Ebd., zit. nach dem ND in von Ludolf, Electa Juris Publici, Bd. 12, S. $645 f$.

71 Die Schrift wurde - ungewöhnlich genug - nicht am Reichstag eingereicht, sondern den Reichsständen in gedruckter Form in particulari zugesandt: ebd., Bd. 12, S. 912.

72 [Schevius], »Höchst=gemüßigter Historischer= Acten=mäßiger Bericht «, S. 2. 
In 11 Kapiteln und auf 392 Druckseiten wurden anschließend die zahllosen Konflikte und das gewalttätige Verhalten der herzoglichen Regierung dargestellt. Auch wenn vermieden wurde, den Herzog direkt anzugreifen, so ist doch unverkennbar, dass weder dieser selbst noch irgendein Beamter sagen konnte, er habe von alle dem nichts gewusst und es sei nur ein Missverständnis. Die Stände stellten sich als die Opfer der Entwicklung dar. Die Gegenseite sollte nach Publikation dieser Aktenfundierung nicht mehr behaupten können, ungehorsame oder gar rebellische Untertanen hätten die Probleme verursacht, die das Reich nun bitte im zentralistischen Sinne lösen möge. Auf den folgenden 761 Seiten wurden anschließend die Dokumente ausgebreitet.

Die gesammelten Dokumente umfassten ursprünglich handschriftliche und gedruckte Texte, ohne dass in jedem Fall die ursprüngliche Form angegeben worden wäre. Die ansonsten gedruckten Einzelschriften lassen sich in mehrere Gruppen fassen: 1. Mandate des Herzogs an Adel und sonstige Untertanen, 2. Deduktionen des Herzogs, 3. Deduktionen der Stände, 4. Mandate und sonstige Schreiben des Kaisers, und 5. fingierte Briefe. Ein Beispiel für die erste Gruppe war die Verordnung, strafbares und pflichtwidriges Verhalten von Vasallen und Untertanen betr. von $1718^{73}$. Darin führte Herzog Karl Leopold die strafbaren Handlungen seiner adligen Vasallen auf, besonders die des Engeren Ausschusses der Stände. Auch die Publikation der herrschaftswidrigen Meinung in gedruckter Form wurde den Adligen zum Vorwurf gemacht - für Karl Leopold handelte es sich um die Verführung der Untertanen zur »öffentlichen Rebellion«. Ein Strafprozess gegen die Rechtsbrecher sei die notwendige Folge. Der Herzog forderte die Adligen auf, sich in Rostock bei der Regierung dem Verhör zu stellen: Dort sollten sie ihre Unschuld beweisen. Karl Leopold sicherte den Adligen freies Geleit zu, wobei unklar blieb, ob dies für alle galt oder nur für diejenigen, die sich von den Vorwürfen reinigen konnten.

In der Flugschrift Convocations=Mandat von 1717 verkoppelte der Adel ein landesherrliches Mandat mit einer eigenen Erwiderungsschrift ${ }^{74}$. Die Vorladung Karl Leopolds an den Engeren Ausschuss vom 13. August 1717 stand am Anfang, es folgte die Rechtfertigung der Ausschuss-Mitglieder vom 27. August 1717, durch die sie ihr Kommen entschuldigten, weil sie ihre Sicherheit in Mecklenburg gefährdet sahen. Die Inhaftierung der Rostocker Stadträte wie der ritterschaftlichen Deputierten im vorigen Jahr war ihnen Mah-

73 »Verordnung, strafbares und pflichtwidriges Verhalten von Vasallen und Untertanen betr.» (vom 27. April 1718), o.O. 1718.

74 »Des Durchläuchtigsten Fürsten und Herrn/Carl Leopold, Hertzogen zu Mecklenburg [...] an Landräthe und Deputierte zum Engern Ausschuß der Ritter= und Landschafft derer Fürstenthümer Mecklenburg sub dato den 13. Augusti dieses 1717. Jahres [...] gedruckt insinuirtes Convocations=Mandat [...] Nebst des besagten Engern Ausschusses [...] Entschuldigungs=Memorial $\ll$, o.O. 1717, $2^{\circ}$. 
nung genug. Angefügt war eine umfängliche Auflistung der Gewalttaten und Rechtswidrigkeiten, die der Herzog und seine Regierung gegenüber der Ritterschaft in den vergangenen Jahren begangen hatten. Auch diente zur Legitimation des Adels, dass Kaiser Karl VI. durch ein Reskript vom 14. September 1716 alle Landtagshandlungen in Mecklenburg bis zum »recuperirten Ruhestand « für nichtig erklärt hatte. Aus Gründen der Dramatisierung hatte der Verfasser noch ein Notariatsinstrument vom 24. August 1717 hinzugefügt, das die versuchte Gefangennahme des Ritters Victor August von Viereggen durch russische Soldaten beschrieb ${ }^{75}$.

$\mathrm{Zu}$ den häufigsten Gattungen der Deduktionen gehörte die Eingabe an den Wiener Kaiserhof. Angesichts von mehr als 100 anhängigen Reichshofratsprozessen stapelten sich in Wien die Schilderungen der Gewalttaten des Herzogs, seiner Beamten und seiner Verbündeten, der russischen Soldaten. Die 15 Seiten umfassende Flugschrift Abdruck der [...] Vorstellung von 1717 bringt dies zum Ausdruck ${ }^{76}$. Der Text ist als Schreiben an den Kaiser deklariert, datiert in Ratzeburg am 14. September 1717. Die Ritterschaft informierte zunächst über die fortgesetzte Unterdrückung der Mecklenburger Stände. Zwei Zitationen an die Ritterschaft, sich wieder ins Territorium zu begeben, könnten nicht befolgt werden, weil der Adel nicht die Erfahrung einer sechsmonatigen Haft nach Vorbild des Rostocker Magistrats machen wolle. Auf jüngste Protestnoten an den Landesherren habe Herzog Karl Leopold mit einem harten öffentlichen Patent geantwortet: Die sog. »Fürstliche Declaration« vom 3. September 1717 bedrohe die Stände als Rebellen und legte ihnen zur Last, »seditiöse Schrifften « herausgegeben zu haben ${ }^{77}$. Die Stände ihrerseits warfen dem Herzog vor, »das Land zur Einöde gemachet« zu haben und alle Verfassung umzustürzen. Die Stände widerlegten den Vorwurf, sie dürften nicht am Reichshofrat klagen. Zudem baten sie um kaiserlichen Schutz.

Das Jahr 1718 zeigte die heftigsten publizistischen Auseinandersetzungen zwischen dem Herzog und seiner Ritterschaft. Zahllos sind die Titel, die als selbstständige Schriften oder als eingerückte Zeitungsartikel erschienen. Eine vollständige Auswertung aller Titel ist im Rahmen dieses Projekts nicht zu leisten. Wichtiger ist die Darstellung der politischen Mechanismen, die hinter den Druckwerken standen. Die oppositionelle Ritterschaft war

75 Notariatsinstrument des Notars Johann Gerhard Poppe aus Güstrow vom 24. August 1717, wodurch bestätigt wurde, dass Victor August von Viereggen am 21. und 24. August bei ihm gewesen sei, um zu berichten, wie die russischen Soldaten ihn auf seinem Gut hätten gefangennehmen wollen und wie er mit einem Bediensteten zu Ross geflüchtet sei: ebd., s.p.

76 »Abdruck Der an Ih. Römischen Kayserl. [...] Majestät Geschehenen Allerunterthänigsten Vorstellung/Der länger unerträglichen Noht und Bedrückung des Mecklenburgischen Adels $[\ldots] \ll$, o.O. $1717,15 \mathrm{~S}$.

77 Ebd., S. 12. 
zwar physisch nicht mehr im Territorium präsent, aber im geschriebenen und gedruckten Wort stärker denn je. Der Herzog konnte sich zwar an den Gütern seiner ungetreuen Vasallen vergreifen, auch an deren Verwandten, soweit sie nicht ebenfalls geflohen waren, aber nicht an ihren Personen und am verschriftlichten Wort. Der Mecklenburg-Streit ist daher charakteristisch für die Möglichkeiten des publizistischen Streits, in der Frühform des »asymmetrischen Krieges« ausgetragen zu werden: Selbst ohne nennenswerte finanzielle Mittel konnte durch die Beeinflussung der öffentlichen Meinung Krieg geführt werden. Wie sehr sich der Herzog über die Schriften der Adligen geärgert haben muss, zeigen symbolische Akte der Ohnmacht: Am 25. Juni 1718 ließ Herzog Karl Leopold drei Deduktionen der Ritter in Rostock, Parchim, Schwerin und Sternberg öffentlich verbrennen ${ }^{78}$.

Als sich Anfang 1719 der Einmarsch der Exekutionstruppen abzeichnete, erschien die Druckschrift Conservatorii, die das kaiserliche Konservatorium vom 17. Oktober 1717, verbunden mit drei anderen Dokumenten, in gesondertem Druck bekanntgab. Das Konservatorium war die Rechtsgrundlage der Exekution, durch das der Kaiser den englischen König in seiner Eigenschaft als Kurfürst von Hannover zusammen mit dem Herzog von BraunschweigWolfenbüttel zum Einmarsch ermächtigte ${ }^{79}$. Es folgten das kaiserliche Reskript an die Exekutoren vom 7. Januar 1719, ein Extrakt des Schreibens Karl Leopolds an König Friedrich Wilhelm von Preußen vom 11. Januar 1719 und die Antwort des Preußenkönigs vom 16. Januar 1719. Die Öffentlichkeit wurde bereits im kaiserlichen Konservatorium erwähnt und als Argument verwendet: »Ew. Lbd. Lbd. wird außer allen Zweifel vorhin als Reichs- und Crayßkündig zum Überfluß bekannt seyn [...] « - dann folgte der Vorwurf an Karl Leopold wegen Unterdrückung und gewalttätiger Bedrängung seiner Landstände. Die Bekanntheit des Verstoßes ersparte dem Kaiser eine nochmalige Schilderung des detaillierten Sachverhaltes, der nur noch der subsumierenden Feststellung der Rechtswidrigkeit und Strafbarkeit bedurfte, um dann zur Anweisung an die Exekutionsmächte überzugehen.

78 Peter Wick nennt die drei Drucke: »Protestation gegen den Landtag vom 11. Juni 1718«, o.O. 1718: gedruckt in KLÜVER, Beschreibung des Herzogtums Mecklenburg, Bd. 4, S. 640-648; »Fernerweitige Demonstration [...]«, o.O. 1718: »Collectanea Mecklenburgica«, Fasc. 1-4, o.O. [=Flensburg] 1718, hier Bd. 2, S. 1ff.; »Protestschreiben vom 18. Juni«, o.O. 1718: Ebd., Bd. 2, S. 71-76; alle Titel zit. nach Wick, Versuche zur Errichtung des Absolutismus in Mecklenburg, S. 122, Anm. 49.

79 »Abdruck des von Ihro Römisch. Kayserl. Majest. an Se. Königl. von Groß=Brittannien und des Hrn. Hertzogs von Braunschweig= Wolffenbüttel Durchl. abgelassenen CONSERVATORII, zu Vornehmung der Execution in Mecklenburg [...] , o.O. 1719, 15 S. - Das Konservatorium wurde später auch im Sammelwerk von Johann Schevius publiziert: SchEviUs, $»$ Höchst=gemüßigter Historischer= Acten=mäßiger Bericht $«$, Dok. 868, S. 746-749. 
Das kaiserliche Reskript verschärfte die Aufforderung an die Exekutoren, bald einzuschreiten - nachdem auf das Konservatorium bereits fast 15 Monate verstrichen waren. Bezeichnend ist hier die implizite Verkleinerung der Titulatur des Delinquenten. Die kaiserliche Kanzlei schrieb »dem Hertzogen von Mecklenburg« (ohne den Zusatz »Lbd.«!) und später bloß»dieser Fürst«. Diese Distanzierung war sonst ungebräuchlich ${ }^{80}$. Als Vorwürfe wurden genannt: 1. Unterdrückung der Stände trotz mehrerer kaiserlicher Mahnungen. 2. Widerspruch gegen das Konservatorium: »das gesamte Reich auch ein und andern Stand desselben ins besondere gegen Uns zu animiren«; dieser Passus beinhaltete den Hinweis auf einen ehrenrührigen Angriff auf das kaiserliche Jurisdiktionsrecht, was den Kaiser besonders erbitterte. 3. Armierungen zu unternehmen (= Landfriedensbruch). 4. Schreiben des Herzogs an den Kaiser vom 5. Februar 1718 mit Behauptung der Freiheit von der Reichsjurisdiktion ${ }^{81}$.

Im dritten Dokument der Flugschrift Conservatorii ersuchte Karl Leopold um preußische Hilfe gegen die drohende Exekution ${ }^{82}$. Direkt im Anschluss daran riet Preußenkönig Friedrich Wilhelm I. seinem Mecklenburger Nachbarn eine schnelle Unterwerfung unter den kaiserlichen Willen, die Restitution des Adels auf seinen Gütern, die Fixierung der Kontribution auf eine Weise, die mit dem Ehr- und Selbstverständnis des Adels vereinbar sei, und eine Überlassung seiner Truppen an einen kaiserlichen Kommandanten. Für eine Militäraktion, so der König, seien die Truppen ohnehin ungeeignet. Eine Exekution könnte katastrophale Folgen für Karl Leopold haben, daher sei schnelles Handeln unbedingt erforderlich ${ }^{83}$. Die Botschaft an die herzoglichen Anhänger wie an die Öffentlichkeit im Reich lautete, dass Karl Leopold selbst von seinen sonstigen Unterstützern aufgegeben worden sei und von niemandem mehr Hilfe erwarten könne.

Während des Einmarsches der Exekutionstruppen publizierte Herzog Karl Leopold seine letzte Deklaration als freier Landesherr. Diese Erklärung vom 27. Februar 1719 machte bekannt, dass der Herzog allen Adligen ihre konfiszierten Güter zurückerstatten wolle. Die russischen Truppen, so kündigte er an, würden das Land vollständig verlassen. Bis zum tatsächlichen Abzug müssten sie allerdings noch durch die mecklenburgischen Untertanen versorgt werden. Der Text wurde nicht nur im Quartformat als Flugschrift publiziert, sondern auch als Einblattdruck im Folioformat zum Aushang erstellt ${ }^{84}$.

80 Ebd., S. 9.

81 Ebd., S. 9-11.

82 Extrakt des Schreibens Karl Leopolds an König Friedrich Wilhelm von Preußen vom 11. Januar 1719: ebd. S. 12f.

83 Antwort Friedrich Wilhelms I. an Karl Leopold, 16. Januar 1719: ebd. S. 13-15.

84 »Declaration Ihro Hochfürstl. Durchl. Carl Leopold/Hertzog zu Mecklenburg/etc. etc. Betreffend Die Restitution Derer in Versicherung genommenen Adlichen Gütern«, o.O. 1719, 
Der Truppeneinmarsch durch England-Kurhannover und BraunschweigWolfenbüttel wurde selbst durch Flugschriften beschrieben. Die Flugschrift Schreiben eines Volontairs erschien in der Gestalt eines fingierten Briefes ${ }^{85}$. Der Kriegsfreiwillige, der nicht namentlich genannt wurde, betonte, er sei auf Hannoveraner Seite nur für eine Polizeiaktion, nicht für einen regulären Feldzug, geworben worden. Allerdings sei es dennoch zum Zusammenstoß mit den mecklenburgischen Truppen unter Generalmajor von Schwerin gekommen. Der Verfasser nutzte nicht nur die Gelegenheit, zu schildern, wie die mecklenburgischen Einheiten zurückgetrieben worden waren, sondern brachte auch drei tatsächliche Briefe zwischen den beiden Oberkommandierenden und Herzog Karl Leopold ${ }^{86}$. Ein Zweytes Schreiben eines Volontairs setzte die Flugschrift wenig später fort, um den Rest der Besetzung Mecklenburgs zu schildern, nicht ohne auch den Abzug der restlichen russischen Kontingente auszuführen ${ }^{87}$.

Inzwischen hatte sich auch die exilierte Ritterschaft ein Bild über die veränderte Lage gemacht und brachte den Triumph als Umbständliche Nachricht auf sechs Seiten zu Papier ${ }^{88}$. Der anonyme Autor schilderte die Exekutionsandrohung und den anschließenden Einmarsch unter Einschluss des Scharmützels bei Walsmühlen. Mit Wohlgefallen konnte er vermerken, dass Herzog Karl Leopold sein Territorium am 4. März verlassen habe - und dabei darauf hoffen, dass der Despot nicht zurückkehrte. Nun bestand kaum noch ein Risiko bei einer Titulaturverkleinerung: In der Schrift konnte »des Hertzogen Carl Leopold « geschrieben werden, wobei das »Durchlaucht« fehlte. Beim Kaiser stand natürlich weiterhin korrekterweise »Ihro Kayserl. Majestät«, auch schrieb der Verfasser »Herrn Hertzog zu Wolffenbüttel Durchl.«, wie es im titulaturfesten Barockzeitalter gebräuchlich war. Das falsche Verwenden oder Unterlassen von Formbestandteilen konnte als Beleidigung verstanden werden, und in diesem Fall war es offenbar auch so gemeint. Am

$4^{\circ}$, s.p.; »Des Herrn Hertzog zu Mecklenburg-Schwerin Declarations-Edict, die Restitution derer, eine Zeithero in Versicherung genommene Adlichen Gütern betreffend «, o.O. 1719, 4, s.p.; Einblattdruck: LHA Schwerin, Best. 2.11-2/1 Auswärtige Beziehungen, Nr. 1606, fol. 469.

85 »Schreiben eines Volontairs Bey Denen Kayserl. Executions Crayß=Trouppen im Mecklenburgischen/An Seinen guten Freund in Hamburg«, o.O. 1719, s.p. (16 S.). Der fingierte Brief wird auf den 20. März 1719 datiert. - Zur Literaturgattung der fingierten Briefe: RogGe, Fingierte Briefe als Mittel politischer Satire, pas.

86 Drei Anlagebriefe zur Flugschrift: 1. Generalmajor von Schwerin an Karl Leopold, 6. März 1719; 2. Generalmajor von Schwerin an General von Bülow, 13. März 1719; 3. Antwort von Bülow an von Schwerin, 15. März 1719: ebd., s.p.

87 »Zweytes Schreiben eines Volontairs Bey Denen Kayserl. Executions Crayß=Trouppen im Mecklenburgischen/An Seinen guten Freund in Hamburg«, o.O. 1719, s.p. (16 S.).

88 »Umbständliche Nachricht/alles dessen/was seith dem Einmarsch der von Ihro Kayserl. Majestät angeordneten Crayß=Executions-Trouppen in Mecklenburg [...] vorgefallen [...]«, o.O. 1719, s.p. (6 S.). 
Ende der Schrift wurde informiert, dass die Kommission den Adel zur Rückkehr ins Land aufgefordert habe. Auch hatten die Exekutoren allen mecklenburgischen Beamten geboten, sie sollten Steuern und sonstige Einkünfte nur noch an die neu eingerichtete Kreis-Exekutions-Cassa in Boizenburg einliefern. Für Zuwiderhandlungen, d.h. Geldtransfers an Karl Leopold, wurden schwere Strafen angedroht.

Kurz nach dem Einmarsch kam der triumphierenden Ritterschaft ein Zufall zugute. Die Druckschrift Mecklenburgische Conjuncturen verwies darauf, dass selbst die herzogliche Regierung im Begriff sei, auseinanderzufallen. Der Adel hatte den schon erwähnten Brief vom 17. März 1719 zugespielt erhalten, in dem die vier mecklenburgischen Regierungsräte einen Ausgleich mit den Exekutoren anrieten. Der Bruch in der mecklenburgischen Administration wurde im ganzen Reich offenbar, als dieser Brief der Ritterschaft in die Hände geriet, die das Schreiben sogleich als Flugschrift publizieren lie $\beta^{89}$. Karl Leopold trug in Verkennung seiner Lage selbst dazu aktiv bei, indem er seine vom Kaiser verlangte Rechtfertigungsschrift über die Prozesse in gedruckter Form am Reichstag verteilen lie $\beta^{90}$. Dies festigte das Bild, das ohnehin beinahe jedermann von ihm hatte, der ein unabhängiges Urteil und keine politischen Interessen an dem Fall besaß. Dass der Herzog nach dem Einmarsch in einer »stronger position than for years" gewesen sein soll, wie Michael Hughes annimmt, ist kaum zu glauben - er besaß keinen einzigen mächtigen Freund, sondern nur Fürsten, die ihm freundliche Worte übermittelten, ohne bereit zu sein, sich in irgendeiner substanziellen Weise für ihn zu engagieren ${ }^{91}$.

Über den wenig später erfolgten Beginn der Kommissionsregierung liegt die große Quellenedition Erste Communication mit 155 Dokumenten aus dem Jahre 1719 vor $^{92}$. Die Sammlung beginnt mit dem kaiserlichen Kommissionsdekret vom 23. Juni 1719 sowie mit dem Protokoll der ersten Kommissionssitzung vom 2. Juni 1719. Es folgen das kaiserliche Konservatorium für die Stadt Rostock vom 21. August 1716 und das Konservatorium für die mecklenburgische Ritterschaft vom 22. Oktober 1717, das am 7. Januar 1719

89 »Mecklenburgische Conjuncturen Oder Gegenwärtiger Zustand im Mecklenburgischen/Nebst einem Brief Welchen einige Hoch= Fürstliche Mecklenburgische Räthe An Ihro Hoch=Fürstl. Durchlaucht abgehen lassen«, o.O. 1719.

90 »Abdruck Des, auf Ihro Kayserl. Majestät Allergnädigstes Verlangen, von dem Regierenden Hertzog zu Mecklenburg erstatteten allerunterthänigsten Berichts/wegen des Criminal-Verfahrens wieder den Geheimben Rath Wolffradt, und gewesenen Geheimden Secretair Scharffen«, o.O. 1724.

91 Vgl. die Überlegungen bei Hughes, Law and Politics, S. 156.

92 »Erste Communication Derer Decretorum So von der zur Execution und Untersuchung in Mecklenburg Aller höchst Verordneten Kayserlichen Subdelegations-Commission zu Rostock. Von der Zeit der Commissions-Eröffnung als den 22. Juni 1719 an/biß den 1. Novembris desselben Jahres [...]«, o.O. 1719, $92 \mathrm{~S}$. 
nochmals ausgedehnt worden war ${ }^{93}$. Anschließend werden die Maßnahmen dokumentiert, die der Wiederherstellung der politischen und wirtschaftlichen Ordnung im Herzogtum dienten, vor allem das Dekret zur Restitution der zuvor eingezogenen adligen Güter vom 26. Juni $1719^{94}$.

\subsubsection{Deduktionen über die kaiserliche Kommissionsregierung und die Bemühungen Herzog Karl Leopolds, zur Landesherrschaft zurückzugelangen}

Ähnlich wie im Fall Nassau-Siegen bedeutete auch in Mecklenburg die Herrschaftssuspendierung des früheren Landesherren keineswegs das Ende des Konflikts. Dasselbe galt für die Berichterstattung in den Druckmedien. Die Häufigkeit der Deduktionen nahm zwar ab, doch zu wichtigen Ereignissen wurden weiterhin Schriften aufgelegt. Dabei konnten die Produzenten das Vorwissen der Leserschaft voraussetzen: Herzog Karl Leopold war wirklich eine »reichs-kündige« Persönlichkeit geworden, im medientheoretischen Sinne waren Mitteilungen über den despotischen Exherrscher stets anschlussfähig.

Das nächste Jahr mit einer größeren Dichte an Deduktionen zum Thema war 1724. Der Herzog hatte sich inzwischen seine Zwergherrschaft in Dömitz und zeitweise in Schwerin errichtet und setzte seinen Papierkrieg mit dem Reich fort, nachdem der Adel für ihn unerreichbar geworden war. Seine aggressiven Neigungen hatte er an seinen Regierungsmitgliedern ausgelassen, insbesondere an Regierungsrat Wolffradt, der 1723 nach einem Scheinprozess hingerichtet worden war, was seine Gegner umgehend im gesamten Reich bekanntmachten ${ }^{95}$. Zwei Reichshofrats-Conclusa vom März 1724 forderten dem Herzog einen Bericht über diese Gewaltakte sowie tatsächliche Zeichen von »Parition« gegenüber kaiserlichen und reichsgerichtlichen Geboten $\mathrm{ab}^{96}$. Kaiser Karl VI. hatte im selben Jahr eine Resolution ausgefertigt, die 23 Beschwerdepunkte der mecklenburgischen Ritterschaft regulierte. Damit wurde einer der Sammelprozesse vor dem Reichshofrat im Sinne der adligen Antragsteller abgeschlossen ${ }^{97}$.

93 Ebd., S. 1-18.

94 Ebd., S. 19f. - Die Kommissare unterzeichneten mit der Formel: »Königl. Groß Britannische und Chur=Fürstl. auch Hoch=Fürstl. Braunschweig=Lüneburg. zur Kayserl. Commission Subdelegirte Räthe« (es folgten die fünf Namen).

95 Graff, Die zweite Ehe des Herzogs Karl Leopold, S. 301.

96 Beide Conclusa waren am 21. März 1724 ausgefertigt worden: »Abdruck Zweyer Reichs=Hof=Raths Conclusorum in causa Mecklenburg«, o.O. 1724, 4 S.

97 »Abdruck der Kayserlichen Resolutionum ad Gravamina [...]«, o.O. 1724, 32 S., s.p. 
Der Herzog hingegen publizierte einen Teil seiner Schreiben selbst in Flugschriften, etwa im Abdruck von 1724. In diesem Fall waren es vier Briefe an den Kaiser, die von August 1723 bis Juni 1724 ausgefertigt worden waren, ergänzt durch ein kaiserliches Antwortschreiben vom März 172498. Diese Briefsammlung skizziert das Scheitern der herzoglichen Strategie: Da er weiter die Beschwerden gegen ihn als das Werk von »Übelwollenden und Wiederwärtigen« bezeichnete, gewannen seine Worte wenig Gewicht und Wirkung. Auch die Infragestellung der kaiserlichen Gerichtshoheit stritt er zunächst ab, um dann eine gekünstelte Einräumungsformulierung zu präsentieren, die noch Rücknahmemöglichkeiten bot. Durch die fortdauernde Diskrepanz zwischen Worten und Handeln fehlten alle Voraussetzungen zu Vergebung und Versöhnung mit dem Reichsoberhaupt. Der Wiener Hof bemängelte genau dieses Defizit im eingerückten kaiserlichen Brief; Karl Leopold glaubte, diese Einwände durch sein letztes langes Schreiben zu entkräften.

In Wirklichkeit war schon das Erscheinen der Druckfassung ein Widerspruch zu Karl Leopolds Worten. Der Herzog publizierte die Texte nicht etwa, um einen nahenden Ausgleich mit dem Kaiser zu dokumentieren, sondern um Verbündete für seine Position unter den Reichsfürsten zu gewinnen. Stimmungsmache im Reich statt Kompromissbereitschaft mit dem Kaiser, das war die unausgesprochene Botschaft des Herzogs. Er verstand das frühmoderne Mediensystem überhaupt nicht: Er operierte mit seinen Schriften ganz auf der Ebene der Reichsfürsten, ohne an eine weitere Publizität zu denken. Dabei insistierte er auf überkommene Ansprüche, die er für unverlierbar hielt. Seine Gegner in der Mecklenburgischen Ritterschaft waren ihm darin weit voraus: Sie appellierten an die Reichsöffentlichkeit, an Reichsstände wie an Intellektuelle und an die Leserschaft darüber hinaus. Daher stellten sie Gräuelgeschichten in den Vordergrund - Sensationelles zog schon damals. Der Herzog schädigte zudem aus ihrer Sicht das Gemeinwohl, er war in staatstheoretischer Hinsicht ein »schlechter« Herrscher. Die Seite des Herzogs kam gar nicht auf die Idee, die Mecklenburger Ritterschaft als die eigensüchtigen Zerstörer Mecklenburgs zu charakterisieren - die Idee hätte nahegelegen, denn die übrigen einheimischen Sozialgruppen der Bürger (bes. Pfarrer) und Bauern standen mehrheitlich auf Seiten des Herzogs, trotz aller Kriegslasten. Inwieweit moderne englische Methoden der politisch-publizistischen Auseinandersetzung von den mecklenburgischen Adligen, wenigs-

98 »Abdruck Derer an Ihro Römisch. Kayserl. Majest. von dem Regierenden Hertzog zu Mecklenburg [...] abgelassenen Allerunterthänigsten Schreiben [...] , o.O. 1724, s.p. (22 S.). - Schreiben von Karl Leopold an Kaiser Karl VI. vom 21. August 1723, 30. November 1723, 24. März 1724 und 7. Juni 1724; das kaiserliche Antwortschreiben ist auf den 21. März 1724 datiert. 
tens von Bernsdorff, der England sehr gut kannte, genutzt wurden, muss einstweilen offenbleiben.

Durch die Publikation seiner Rechtfertigungsschrift Abdruck des [...] Berichts gestaltete Herzog Karl Leopold seine Lage hinsichtlich der öffentlichen Meinung im Reich noch ungünstiger ${ }^{99}$. Die Prozesse gegen die Regierungsbeamten Wolffradt und Scharff wurden damit allgemein bekannt und für Justizmorde angesehen. Die Publikation bestätigte nur das verbreitete Bild eines Despoten, der zu Recht von der Landesherrschaft ausgeschlossen worden war.

Demgegenüber verlor die Deduktion »Erzehlung« der kaiserlichen Kommision von 1724 an Bedeutung, da sie sich nur gegen ehrverletzende Angriffe Karl Leopolds in seinen Schreiben zur Wehr setzte ${ }^{100}$. In der Schrift wurde Karl Leopold vorgeworfen, er habe fragwürdige mecklenburgische Beamte animiert, Unwahrheiten über die Amtsführung der Kommission zu deklarieren, um die Kommissare so öffentlich in Misskredit zu bringen. Es folgten zahlreiche weitere Vorwürfe gegen Karl Leopold, besonders die Schaffung einer Machtbasis in Dömitz und Schwerin. Dort hatte der Herzog die gesamten Steuern und Zölle an sich gezogen und ihre Überweisung an die Kommissions-Cassa in Boizenburg dauerhaft blockiert. Gerade diese Einkünfte stellten die Grundlage dar, weshalb der Herzog nach der Kreisexekution noch fast 30 Jahre lang faktisch im Kleinen weiterregieren, dabei aber große diplomatische und publizistische Aktivitäten entfalten konnte.

In den folgenden Jahren dominierten die Publikationen von obrigkeitlichen Anordnungen der kaiserlichen und der herzoglichen Seite. 1725 und 1726 erschienen mehrere Beschlüsse des Reichshofrats zugunsten der mecklenburgischen Ritterschaft im Druck ${ }^{101}$. Auch die kaiserliche Resolution vom 11. Mai 1728, durch die Herzog Karl Leopold von Mecklenburg von seiner Landesherrschaft suspendiert wurde, gründete auf einem Reichshofrats-Conclusum. Bezeichnend für den Grad an Öffentlichkeit des Verfahrens gegen den Herzog war der Anfangssatz der Resolution:

99 »Abdruck Des, auf Ihro Kayserl. Majestät Allergnädigstes Verlangen, von dem Regierenden Hertzog zu Mecklenburg erstatteten allerunterthänigsten Berichts/wegen des Criminal-Verfahrens wieder den Geheimben Rath Wolffradt, und gewesenen Geheimden Secretair Scharffen«, o.O. 1724, 14 B11.

$100 »$ Wahrhaffte Aus Beygedruckten Original-Documentis Erwiesene Erzehlung Dessen was auff Ordre E. Hohen Kayserlichen Commission in Mecklenburg vorgefallen [...] , o.O. 1724, 15 S.

101 »Abdruck Zweyer abermahliger Kayserl. Reichs=Hof=Raths Conclusorum In Sachen Ritterschaft Mecklenburg contra selbigen Herrn Hertzogs Hochfürstlichen Durchl. Executionis etc.«, o.O. 1725, 4 S., s.p.; »Continuierter Zweyter Nachtrag Kayserl. Reichs=Hof=Raths Conclusorum, Vom 23. Januar 1726. Die Mecklenburgischen Executions=Sachen betreffend «, o.O. 1726,4 S., s.p. 
Wird nunmehro von Ihro Kayserlichen Majestät/Krafft obhabenden allerhöchsten Kayserlichen Obrist=Richterlichen Amts/aus Reichs=kündigen Ursachen/die sonsten Herrn Hertzog Carl Leopold zu Mecklenburg gehörige völlige Landes=Regierung sistiret/und selbige Dero Brudern/Herrn Hertzog Christian Ludwig zu Mecklenburg/als Agnato proximo, bis auf weitere Kayserliche Verordnung/und auf folgende Maasse allergnädigst aufgetragen als: daß [...]

- Anschließend folgten die Bedingungen für die Regierung Christian Ludwigs $^{102}$.

Zwei weitere Flugschriften des Jahres 1729 publizierten jeweils mehrere gesammelte kaiserliche Resolutionen auf der Grundlage von Reichshofratsverhandlungen über ritterschaftliche Klagen gegen die herzoglichen Willkürmaßnahmen ${ }^{103}$. Teilweise wurden dabei noch Materien abgetragen, deren Grund in den 1710er Jahren gelegt worden waren. Die Mühlen der Justiz brauchten ihre Zeit, zumal angesichts der dreistelligen Anzahl an ritterschaftlichen Beschwerden in Wien.

Eine weitergehende Stoßrichtung hatte das Kaiserliche Commissionsdekret zum Inhalt, das Karl VI. durch seinen Prinzipalkommissar Fürstenberg am 11. Juni 1729 am Regensburger Reichstag eingeben ließ ${ }^{104}$. Im Prolog wurden die zentralen Vorwürfe des Kaisers gegenüber dem Mecklenburger Herzog nochmals pointiert zusammengefasst:

[...] und sey vorhin Reichs=kündig/welchergestalt des Herrn Carl Leopold zu Mecklenburg Hochfürstl. Durchl. nach Antritt Ihrer Landes=Regierung hierbey einer ohnverantwortlichen Abänderung sich unterzogen/wieder die vorhin mit dessen Vasallen und Unterthanen errichtete/auch in Uebung gebrachte Lands=Receß und Privilegien und zwar via facti vermittelst gantz entsetzlicher Thathandlungen verfahren [...].

Im Weiteren folgten neue Vorwürfe, insbesondere Gewaltmaßnahmen der mecklenburgischen Entourage Karl Leopolds gegen das welfische Exekutionskommando sowie die Folterung und Hinrichtung von Beamten in Dömitz.

$102 \gg$ Abdruck Hochpreißlich=Kayserl. Reichs=Hof=Raths Resolution und Verordnung, Die allerhöchste Provisional-Veränderung Bey Der Hertzoglich=Mecklenburgischen Landes=Regierung/Und Deren gemessene Kayserliche Administration betreffend«, o.O. 1728.

103 »Allergerechteste Kayserliche Resolutiones und Verordnungen in Sachen Mecklenburgis. Ritter= und Landschafft contra Deß Herrn Hertzogs Carl Leopolds zu Mecklenburg Hochfürstl. Durchl. in puncto diversorum Gravaminum [...]«, o.O. 1729, 23 S.; »Gedoppelte Kayserliche Fernerweit Allergerechtest=erlassene, Resolutionibus Vom 11. Mai 1728 und 17ten Jan. a.c. [...] In Sachen Mecklenburgis. Ritter= und Landschafft/Contra Deß Herrn Hertzogs Carl Leopolds zu Mecklenburg Hochfürstl. Durchlaucht [...]«, o.O. 1729, 9 S.

$104 »$ Kaiserliches Commissionsdecret in Sachen Mecklenburg [...]«, o.O. 1729, 6 S. 
Ein weiterer wichtiger Punkt - vermutlich die Ursache für die prominente Platzierung dieses Verfahrens am Reichstag - lag in der fortgesetzten Unehrerbietigkeit des Herzogs gegenüber dem Kaiser und den Reichsorganen. Vor allem hatte der Herzog an mehreren Stellen durchblicken lassen, dass er die kaiserliche Obergewalt und die Gültigkeit von Reichsgerichtsurteilen für Mecklenburg bestritt. Stattdessen betonte er - so warf ihm die kaiserliche Seite vor - sein »unumschränktes Arbitrium«, die zeitgenössische Umschreibung für eine ungesetzmäßige Gewaltherrschaft. Dazu passte, dass Karl Leopold noch nach der Suspendierung am 17. und 27. Dezember 1728 ein gedrucktes Patent an die Gerichtsstube und später an die Kirche in Parchim hatte anschlagen lassen und darin die Kommission und seines Bruders Regiment verunglimpfte, indem er erneut die kaiserlichen Mandate und Gerichtsurteile gegen ihn für rechtswidrig erklärte. Der Kaiser sah es aufgrund all dieser Vorkommnisse als erwiesen an, dass der »habitus renitendi bei dem Hertzog fest eingewurtzelt« sei. Resigniert und verärgert fügte der Kaiser hinzu, eine Subordination Karl Leopolds sei umso weniger zu erwarten, als der Herzog in Dömitz und Schwerin noch eine eigene Miliz unterhalte, zur ständigen Verunsicherung seines Bruders. Das Commissionsdecret erfüllte den Zweck, in der Öffentlichkeit auf die Beleidigung des Kaisers offiziell zu reagieren. In Rechtsstreitigkeiten wie bei Ehrkränkungen galt die Regel: Wer sich nicht gegen einen Angriff wehrte, gab im Verständnis der Zeit sein Recht auf, oder bei Ehrensachen erkannte er ex silentio den Vorwurf als berechtigt an.

Zudem hatte Karl VI. mit Widerspruch aus dem Kreis der Reichsfürsten zu rechnen. Zwar gab es keine offiziellen Sympathien mit Herzog Karl Leopold von Mecklenburg, wohl aber Bedenken hinsichtlich des eingeschlagenen Weges einer »Suspendierung" des Herzogs, weil es sich hier um eine Umgehung des Verbots der kaiserlichen Reichsachtsverhängung handelte, wie sie nach den Erfahrungen mit der Praxis Kaiser Josefs I. in die Wahlkapitulation für Karls VI. von 1711 eingeschrieben worden war. Demnach sollte die Reichsacht nicht mehr, wie gegen die Wittelsbacher Kurfürsten 1706 und einige italienische Fürsten 1708/09, durch Kaiser und Kurfürstenrat verhängt werden, sondern nur noch nach Beschluss des gesamten Reichstags. In den beiden Deduktionen Pro Memoria und Scriptum Pro Memoria aus dem Jahre 1729 lautete der Tenor, dass der Kaiser den Konsens des Reichstags auch für die Übertragung der Landesherrschaft an Herzog Christian Ludwig von Mecklenburg benötigte ${ }^{105}$. Zudem sei die Frage ungelöst geblieben, auf welche Weise die Mecklenburger Stände aus der Treuepflicht Herzog Karl

$105 »$ Pro Memoria oder Information die Mecklenburgische Administrations-Sache betreffend «, o.O. 1729; „Scriptum Pro Memoria In der Mecklenburgischen Administrations-Sache/So im Monath Augusti 1729 heraus gekommen«, o.O. 1729. 
Leopold gegenüber entlassen und in die Lehnspflicht gegenüber dem neuen Landesherrn gestellt werden sollten ${ }^{106}$. Aus reichsrechtlicher Perspektive argumentierte auch Johann Gottfried von Meiern, der 1730 eine eigene Flugschrift unter dem Titel Pro Memoria auf den Markt brachte und ebenfalls die Bindung des Kaisers an die Reichstagsmitwirkung einforderte ${ }^{107}$. Der Kaiser versicherte in einem eigenen Reskript vom 25. August 1730 - das ebenfalls gesondert als Flugschrift erschien - an den Reichstag, dass er keine unlauteren Absichten mit der Suspendierung Karl Leopolds von Mecklenburg verfolge. Alles, so formulierte der Kaiser, solle nur zum Nutzen des Reiches und seines Rechtssystems geschehen, und er habe in keiner Weise die Absicht, den Rechten der Stände zu nahe zu treten ${ }^{108}$. Auf die Bekanntheit der Vorwürfe gegen den hochadligen Rechtsbrecher wies er in der Begründung hin:

Es ist nehmlich Reichs=kündig/was massen Uns breits vor vielen Jahren der Hertzog Carl Leopold von Mecklenburg=Schwerin/durch seine ungerechte Aufführung nach einer gehabten langwührigen Gedult/dahin endlich vermöget hat/die bekannte Executions-Commission, gegen Ihn zu verhängen/und selbe weyl. des verstorbenen Königs von Groß=Brittannien/als Churfürsten zu Hannover und des Hertzogs von Wolfenbüttel Lbdn. Lbdn. aufzutragen.

Der Prinzipalkommissar möge das den Reichsständen übermitteln, damit die Missstimmung einiger Stände, die die Angelegenheit zum Reichstagsthema machen wollten, gedämpft werde.

Herzog Karl Leopold versuchte unterdessen, sein Schreiben an den neuen König Georg II. von England um Unterstützung der europäischen Öffentlichkeit bekannt zu machen, indem er es in lateinischer Sprache publizierte ${ }^{109}$. Der König möge sich dafür einsetzen, dass Karl Leopold wieder in seine angestammten Rechte eingesetzt werde. Georg II. reagierte umgehend und wies den Herzog darauf hin, dass die Restitution nicht in seiner Gewalt liege. Wenn der Herzog allerdings die kaiserlichen Auflagen erfüllen sollte, dann würden alle Streitfragen regulierbar werden.

106 Verweis auf Art. 20 in der Wahlkapitulation für Kaiser Karl VI.: JAHNS, »Mecklenburgisches Wesen«, S. 342, Anm. 30. - In der Wahlkapitulation für Kaiser Karl VII. 1742 wurde auch die kaiserliche Suspendierung oder Ausschließung eines Reichsstandes von der Landesherrschaft oder vom Reichstagsstimmrecht an die vorherige Zustimmung des Reichstags gebunden.

107 [Johann Gottfried von Meiern], »Pro Memoria oder Gegen=Information Die Mecklenburgische Administrations-Sache betreffend «, o.O. 1730, 28 S., s.p.

108 »Kaiserliches Rescriptum An die Höchst=Ansehnliche Kays. Commission in Regenspurg/in der Mecklenburgischen Angelegenheit«, o.O. 1730, 5 Bll.

$109 »$ Epistola Ducis Megapolitani Caroli Leopoldi Ad Regem Magnae Britanniae, de dato Suerini, 27. Junii Anno 1730«, o.O. 1730, 6 S. 
Wie weit der Herzog davon entfernt war, zeigte die im selben Jahr erschienene Dokumentensammlung, die auf Betreiben des früheren mecklenburgischen Oberlanddrosten Joachim Friedrich von der Lühe zusammengestellt worden war ${ }^{110}$. Von der Lühe klagte dagegen, dass er durch ein Memorial der mecklenburgischen Regierung in Dömitz an den Reichshofrat beleidigt worden sei, weil ihm neben anderen Vergehen die Unterschlagung einer groBen Summe Geldes unterstellt worden sei. Allein in diesem einzelnen Fall umfasste die Deduktion 152 Seiten, versehen mit Beilagen auf 292 Seiten. Die Dokumentensammlung lässt sich lesen als ein Baustein zur Auseinandersetzung zwischen Herzog Karl Leopold von Mecklenburg und seiner Ritterschaft. Zahllose weitere Klagen dieser Art, sowohl wegen des ruppigen Umgangs des Herzogs mit seinen Vasallen als auch wegen der »empfindlichsten Expressionibus«, die sich in den offiziellen Schreiben des Herzogs zuhauf finden lassen, waren immer noch in Wien anhängig.

Auch der letzte spektakuläre Auftritt Karl Leopolds von Mecklenburg begann mit einer öffentlichen Verlautbarung. Er publizierte das Mandat vom 21. Dezember 1732, mit dem er alle mecklenburgischen Landesbeamten und Untertanen zum Widerstand gegen die Kommissionsregierung unter Leitung seines Bruders aufforderte ${ }^{111}$. Dazu bot er das Landesaufgebot auf, zusammen sollten 60.000 Mann erscheinen, doch tatsächlich fanden sich »nur« 6.000 Männer ein. Karl Leopold betonte im Mandat seine unumschränkten, durch Gott gegebenen landesherrlichen Rechte, denen gemäß sich die Untertanen zu verhalten hätten. Auf dieser Grundlage seien sie auch verpflichtet, sich am Landesaufgebot (dessen Kampfauftrag noch nicht ausdrücklich umrissen wurde) aktiv zu beteiligen. Die rechtliche Herleitung kann jedem, der die reichsrechtlichen Verhältnisse kennt, nur als abenteuerlich erscheinen: Er griff auf die Goldene Bulle, den Westfälischen Frieden und auf die kaiserliche Wahlkapitulation zurück, um die Unbedingtheit der Landeshoheit zu untermauern, wobei er jegliche auswärtigen Eingriffsrechte einschließlich der kaiserlichen Gewalt und der Reichsgerichtsbarkeit einmal mehr abstritt.

Nachdem das Bewaffnungsprojekt durch schnelles Eingreifen der kurhannoverschen Armee zusammengebrochen war, ließ der wieder wehrlose Herzog erneut die Schalmeien erklingen. Per Brief aus Schwerin vom 29. September 1733, der in verschiedenen Variationen als Flugschrift erschien, appellierte er einmal mehr an die kaiserliche »Gnade, Hulde und Mildigkeit«, um wieder in seine ererbten Rechte eingesetzt zu werden ${ }^{112}$. Er schrieb,

$110 »$ Gemüßigte, gründliche ex actis publicis gezogene und mit nöthigen Documentis bewährte Information $[\ldots] \ll$, o.O. 1730.

111 »Mandatum Karl Leopolds, so im ganzen Lande von allen Canzeln den 21 December 1732 abgelesen worden«, o.O. 1732, $4 \mathrm{~S}$.

112 »Des Durchl. Fürsten Carl Leopold, Hertzogs zu Mecklenburg Schreiben an Ihro Maj. dem Kayser«, o.O. 1733; »Copia Submissions-Schreiben/Von Sr. Durchleucht dem Hertzog Carl 
er könne bei »lauterster Prüfung« nichts finden, womit er die kaiserliche Ungnade verdient habe. Karl Leopold bewies damit nicht nur einmal mehr seine Uneinsichtigkeit, sondern auch ein hohes Maß an Dreistigkeit angesicht einer gerade erlittenen Niederlage. Sein Angebot, die »allerschuldigste Submission und Parition« leisten zu wollen, war ohne Schuldeinsicht nicht mehr als eine Floskel. In einer der beiden Flugschriftenausgaben der Copia waren zwei Mandate Karl Leopolds aus demselben Jahr angehängt, in denen dieser seinen Landesuntertanen den Gehorsam gegenüber dem kaiserlichen Kommissar Christian Ludwig verbot und das unmittelbare Bevorstehen des Aufstands ankündigte. Gerade die letzte dieser beiden Anlagen war im Sinne der gesamten Flugschrift kontraproduktiv, rief sie doch - aus reichsrechtlicher Sicht - zur Selbsthilfe und damit zum Friedensbruch auf. Daher liegt die Vermutung nahe, dass mindestens diese Ausgabe in Wirklichkeit von den Gegnern des Herzogs lanciert worden ist ${ }^{113}$.

Die Reichsstände wurden auch über diesen Fehlschlag der herzoglichen Politik hinaus von Karl Leopold weiterhin mit Schreiben überhäuft. Typisch dafür war die Copia eines [...] Circular-Schreibens, ein Rundschreiben, das Herzog Karl Leopold unter dem 21. April 1736 an einige Reichsfürsten mit der Einforderung fürstlicher Solidarität schickte ${ }^{114}$. Schon im ersten Absatz nannte er die kaiserlichen Maßnahmen der letzten 20 Jahre gegen ihn selbst »Reichs=Gesetzbrüchige Turbationes und Oppressiones «. Ungeachtet der Tatsache, dass er zuvor nicht nur wegen der Pressionen gegen seine Stände und Untertanen abgemahnt worden war, sondern auch wegen mehrerer verbaler Entgleisungen und Beleidigungen des Reichsoberhaupts scharfe Verweise hatte hinnehmen müssen, unterstellte er dem Kaiser einmal mehr rechtsbrüchiges Handeln. Durch die Anschreiben machte er seine Adressaten gleichsam zu Komplizen seiner Weltsicht - sodass schon aus diesem formalen Grund mit einer nennenswerten Zustimmung nicht zu rechnen war. Karl Leopold verwies auf ein früheres Zirkular, das er im März 1729 auf reichsfürstlicher Ebene verschickt hatte - offenbar auch ohne für ihn positive Reaktionen.

Leopold an Se. Kayserl. Majestät/d. d. Schwerin, den 29. September 1733«, o.O. 1733, 10 S.

113 Ebd., s.p.

114 »Copia eines von [...] Carl Leopold zu Mecklenburg an einige uhralte Fürstl. Häuser abgelassenen Circular-Schreibens«, o.O. 1736, 8, 4 B11., 5 S. 


\subsection{Darstellung in den Zeitungen}

Am Beispiel des Mecklenburger Ständestreits lässt sich - nach gegenwärtigem Forschungsstand - zeigen, dass für das Erringen medialer Öffentlichkeit erst eine gewisse »Aktivierungsenergie« aufgewandt werden musste, bevor ein Konflikt zu einem Pressethema werden konnte. Obwohl Herzog Karl Leopold von Mecklenburg-Schwerin bereits von Anfang seiner Regierungszeit an auf Konfrontationskurs zu seinen Untertanen, besonders zu seinen Landständen ging, blieb dies zunächst ein »No-Name-Konflikt «. Interessanterweise findet sich ein früher Zeitungseintrag in der Wöchentlichen Relation aus Halle a.d. Saale, einer Zeitung aus einem preußischen Territorium. Nachdem die Zeitung bis dahin vor allem militärische Begebenheiten aus Mecklenburg übermittelt hatte ${ }^{115}$, erschien am 18. September 1717 ein Hinweis darauf, dass Herzog Karl Leopold von Mecklenburg ein Patent publiziert hatte, das seine Ritterschaft der Rebellion und den Kaiser einer rechtswidrigen Handlung beschuldigt habe. Die kaiserlichen Mandate, so die Zeitung, widersprächen nach Ansicht des Herzogs den Reichskonstitutionen, besonders dem Westfälischen Frieden und der kaiserlichen Wahlkapitulation, und seien daher nichtig. Die Zeitung fuhr fort, der Adel habe bereits eine Gegenschrift angekündigt ${ }^{116}$.

Derartige Beschuldigungen konnten nicht ohne Folgen bleiben. Die Wöchentliche Relation konnte Ende November 1717 davon berichten, dass im Niedersächsischen Kreis Anstalten für eine Exekution gegen Mecklenburg getroffen würden. Allerdings, so der Redakteur, rechne die politische Öffentlichkeit damit, dass der Herzog im letzten Moment nachgebe, damit es nicht zum militärischen Ernstfall, der »Extremität« komme ${ }^{117}$. Eine Woche später schrieb die Zeitung:

Am Kayserl. Hofe soll/in Faveur der Mecklenburgischen Ritterschaft/eine wichtige Resolution gefasset/und der Ritterschaftl. Deputirte/Herr Major von Rathen/mit derselben zu Ihro Groß=Britannischen Maj. Abgereiset seyn. An Hanover und Wolffenbüttel sind auch aufs neue Kayserl. Monitoria ergangen/die Execution wider Se. Durchl. den Hertzog von Mecklenburg ohne Verzug vorzunehmen ${ }^{118}$.

115 So z.B. unter dem 15. und 22. August 1716 sowie unter dem 3. Oktober 1716. Im Jahr 1717 erschienen nach Ausweis des Jahresregisters 37 Betreffe wegen Mecklenburg in der Zeitung, ebenfalls vorwiegend Militaria.

116 Bericht aus »Teutschland«: »Wöchentliche Relation«, Nr. 38 vom 18. September 1717.

117 Bericht aus »Teutschland«: ebd., Nr. 48 vom 27. November 1717.

118 Bericht aus »Teutschland«: ebd., Nr. 49 vom 4. Dezember 1717. Im Folgenden wird das kaiserliche Kommissionsdekret, das in Regensburg am 17. November 1717 öffentlich diktiert worden war, in der »Mecklenburgischen Streit=Sache« auf der Länge einer ganzen Zeitungsseite abgedruckt. 
Damit greift die Zeitung das Exekutions-Motiv auf: Ein militärisches Ereignis, das an sich berichterstattungswürdig wäre, wird hier antizipiert. Die Mitteilung ist auch insofern interessant, als der Preußenkönig Friedrich Wilhelm I. dem Mecklenburger Herzog im Prinzip wohlgesonnen war, was eine kritische Berichterstattung über diesen Fall hätte beeinträchtigen können.

Der Herzog, so informiert die Wöchentliche Relation ihre Leser, versuche seine Position dadurch zu stärken, dass er einige Reichsstände angeschrieben habe, ihn zu unterstützen und die weiteren Reichsgutachten noch einige Zeit warten zu lassen. Der Brief laufe in Regensburg am Reichstag um ${ }^{119}$. Dieselbe Zeitung spekuliert im Juli 1718 neuerlich darüber, ob der Herzog sich den kaiserlichen Anweisungen im letzten Moment beugt oder es auf die »Extremität«, ankommen lassen wird. Dabei erfährt die Leserschaft, dass Herzog Karl Leopold weiterhin adlige Güter konfiszierte. Auf dem letzten Landtag seien nur 20 Adlige erschienen. Die Festung Rostock werde in groBer Eile befestigt. Der Herzog habe zudem am 25. Juni drei gedruckte Schriften des »Engeren Ausschusses« der Ritterschaft öffentlich verbrennen lassen und damit dokumentiert, was er von der politischen Partizipation seiner Stände hielt. In der anschließenden Fußnote druckte die Zeitung ein Schreiben des englischen Königs Georgs I. an Herzog Karl Leopold vom 17. Mai $1718 \mathrm{ab}$, in dem der König seinen Verwandten dringend zum Einlenken aufforderte ${ }^{120}$. Peter Wick hat nachgewiesen, dass es sich bei diesem »Brief« sowie der Antwort des Herzogs wenig später um ausdrückliche Darstellungen der eigenen Positionen vor der Öffentlichkeit im Reich und in Europa handelte ${ }^{121}$.

Sicher ist, dass im Herbst 1718 auch in anderen Zeitungen Berichte auftauchten, die auf eine bevorstehende Reichsexekution gegen den Mecklenburger Herzog hindeuteten. In diese Meldungen mussten an bestimmten Stellen einige erklärende Floskeln eingearbeitet werden, um dem Leser zu verdeutlichen, dass der Herzog bereits über Jahre hinweg die Reichsgesetze missachtet und den Kaiser als Reichsoberhaupt schwer beleidigt hatte. Über den Winter 1718/19 verging in einigen Zeitungen, z.B. im Frankfurter Journal oder in der Hanauer Europäischen Zeitung, kaum ein Tag, an dem nicht über den Mecklenburg-Fall berichtet wurde. Angesichts der langen Zeit bis zur zweiten Februarhälfte 1719, als die Truppen endlich über die Elbe setzten, mussten aus dramaturgischen Gründen mehrfach kaum bedeutsame Handlungen eingerückt werden, um den Erwartungsbogen der Leser nicht zusammenbrechen zu lassen.

119 Bericht aus »Teutschland«: ebd., Nr. 5 vom 29. Januar 1718.

120 Bericht aus »Teutschland«: ebd., Nr. 28 vom 9. Juli 1718.

121 Bericht aus »Teutschland«: ebd. 
Am 17. Dezember 1718 schrieb die Münchener Zeitung Mercurii Relation: $» A u ß$ dem Hannoverischen wird gemeldet/daß die dortige zu der Execution ins Mecklenburgische gewidmete Trouppen zwar marschfertig stünden/allein sie wären noch erstlich auss Engelland zum würcklichen Auffbruch Ordre erwartend « ${ }^{122}$. In den folgenden Ausgaben wird einige Male auf das Erwarten des Einsatzbefehls hingewiesen. Von Herzog Karl Leopold erfährt der Leser, dass der Mecklenburger Landesherr schon rückversichernde Maßnahmen für den Fall der militärischen Konfrontation vorgenommen hat: Er will - so schreibt die Mercurii Relation am 1. Januar 1719, mit Hilfe von 1.000 bereitgestellten schwedischen Söldnern über das Meer nach Polen fliehen ${ }^{123}$. Letzte Vermittlungsversuche zwischen dem Herzog und seinen adligen Ständen werden unternommen, so durch den Baron von Kniphausen. In mehreren Zeitungen kommt die Dramatik der Lage zum Ausdruck: Kniphausen habe »[...] vorzustellen/in was für einen schlechten Zustand der Herzog sich nicht allein selbsten/sondern auch dessen Unterthanen sezen würde/wann die anjetzo fast nicht mehr zu evitiren seyende Execution ihren Fortgang haben würde [...] « $\ll^{124}$. Das Drohszenario bleibt beinahe einen Winter lang aufgebaut. Ende Januar werden sogar die Mannschaftsstärken der Exekutionstruppen publiziert, Mitteilungen, die die Militärführung kaum gerne gelesen haben dürfte ${ }^{125}$. Die Spekulationen setzten sich fort, Herzog Karl Leopold werde es angesichts der allgemein eingeschätzten Kräfteverhältnisse nicht auf den Ernstfall ankommen lassen. Auch wollte der Rostocker Korrespondent des Frankfurter Journal erfahren haben, dass sich die Russen entweder nach Polen oder per Schiff nach Riga zurückziehen würden. Die ritterschaftlichen Untertanen des Herzogs bedachte er mit den Worten: »Inzwischen wartet der Mecklenburgische Adel mit Schmertzen auf den Ausgang ihrer Sache $\ll^{126}$.

122 Bericht aus »Nieder=Elbe/den 3. Dezember«: »Mercurii Relation«, Nr. 50 vom 17. Dezember 1718. In früheren Ausgaben der Zeitung aus 1718 sind keine Berichte bezüglich Mecklenburg gefunden worden; allerdings ist die Überlieferung nicht ganz vollständig.

123 »Aus dem Holsteinischen/den 16. December«: ebd., Nr. 1 vom 1. Januar 1719. Dieselbe Meldung bringt auch die »Extraordinaire Europäische Zeitung« aus Hanau zum Jahreswechsel 1718/19, allerdings mit der Verdoppelung der Zahl: Hier handelt es sich um 2.000 schwedische Söldner: »Extraordinaire Europäische Zeitung«, Nr. 102, o.D., [Dezember 1718].

124 Meldung aus »Nieder=Elbe/vom 28. Dezember«: ebd., Nr. 2 vom 7. Januar 1719; fast wortgleich in »Extraordinaire Europäische Zeitung«, Nr. 104, o.d. [Dez.] 1718. Auch noch einen Monat später ist von laufenden Verhandlungen die Rede, die den Aufmarsch flankierten: »Nieder=Elbe/den 25. Januarii«: »Europäische Zeitung«, Nr. 9 vom 31. Januar 1719; »Nieder=Elbe/den 31. Jan.«: »Frankfurter Journal«, Nr. 9 vom 31. Januar 1719.

125 In der Meldung »Nieder=Elbe/den 18. Januarii« werden 8.000 Mann Infanterie, 4.000 Reiter und 4.000 Mann Reserve angegeben: ebd., Nr. 7 vom 24. Januar 1719.

$126 »$ Rostock/den 25. Januarii«: ebd., Nr. 10 vom 4. Februar 1719. 
Noch am 11. März 1719 konnte die Mercurii Relation keine Vollzugsmeldung übermitteln. Die Hoffnung auf eine Lösung in letzter Minute wurde in der Presse wachgehalten:

Es verlautet zwar auß dem Mecklenburgischen/daß Seine Hochfürstl. Durchl. der Hertzog zween von dessen Räth an die Gräntzen gesandt/welche wann sie seheten/ daß es denen ankommenden Trouppen ein Ernst wäre in Mecklenburg einzudringen/denen Cheffs eine Proposition thun/und einen gütlichen Vergleich vorschlagen solten $^{127}$.

Dabei hatte dieselbe Zeitung bereits eine Woche zuvor die Hoffnungen stark gedämpft, indem sie auf Bemühungen des Herzogs verwies, durch ein neues Bündnis mit »den Moscowitern« neue russische Truppen ins Land kommen $\mathrm{zu}$ lassen ${ }^{128}$.

Dass man in München nicht ganz nahe am Geschehen war, zeigt ein Blick in den Hamburgischen Relations-Courier. Die Hamburger Gazette hatte bereits am 21. Februar 1719 einen ausführlichen Bericht über den Einmarsch der Niedersächsischen Kreisarmee im Rahmen des kaiserlichen Exekutionsauftrags ins Herzogtum Mecklenburg abgedruckt. Sogar die militärische Stärke der Einheiten wurde genannt: 20 Esquadronen Kavallerie und 11 Battaillone Infanterie sollen die beiden Exekutoren, der Kurfürst von Hannover und der Herzog von Braunschweig-Wolfenbüttel, aufgestellt haben. In allen Einzelheiten wurde der Aufmarschplan samt des Antransports von 20-30 Kanonen aus Hannover erörtert ${ }^{129}$. In den folgenden Tagen wurden auch die militärischen Scharmützel zwischen den Kreistruppen und den Soldaten des Herzogs erwähnt, so zunächst das Treffen bei »Waddemühle« (= Walsmühlen) zwischen einem Hannoveraner Regiment und einer Abteilung der Mecklenburgischen Armee Anfang März. Dieselbe Nachricht vom 10. März teilte ebenfalls mit, dass Herzog Karl Leopold sich dem kaiserlichen Willen unterworfen habe und dies in einem Patent zum Ausdruck gebracht habe. Die Adligen könnten nun wieder ins Land zurückkehren ${ }^{130}$. Am 14. März berichtete die Zeitung bereits, dass die Kreisarmee unter Führung von General von Bülow im Begriff sei, das Herzogtum komplett zu besetzen. Herzog Karl Leopold sei aus Rostock mit unbekanntem Ziel abgereist; seine Familie sei zurückgeblieben ${ }^{131}$.

127 Meldung aus »Nieder=Elbe/vom 25. Februarii«: »Mercurii Relation«, Nr. 11 vom 11. März 1719.

128 Meldung aus »Wien, vom 22. Februarii«: ebd., Nr. 10 vom 4. März 1719.

129 Mitteilung »Aus dem Hollsteinischen/vom 20 Februarii«: »Hamburgischer Relations-Courier«, Nr. 30 vom 21. Februar 1719.

130 Ebd., Nr. 40 vom 10. März 1719.

131 Ebd. 
Auch die Zeitungen aus Frankfurt und Hanau bringen detaillierte Berichte über den Einmarsch:

Aus dem Mecklenburgischen wird gemeldet/daß die Mecklenburgische Trouppen alle besetzt gehabte Schantzen und Advenüen/so bald die Kayserl. Trouppen sich gemeldet/und die Advocatoria angeschlagen/verlassen/und sich en bonne Ordre retiriret; die Beamte und Zöllner hätten sich zwar anfänglich geweigert/ihre Bücher und Rollen auffzuweisen und herzugeben/nachdem man aber dieselbe mit einer Wache belegen wollen/hatten sie alles gethan/was man verlange; der Hertzog hätte sich von Rostock aus mit einer kleinen Suite weg begeben/ohne daß jemand wüste/wohin er sich gewendet/doch gienge das Gerüchte/als wann er sich nach einem hohen Potentaten erhoben. Der Herr geheimbde Rath Schöpffer wäre auff seiner Rückkunfft von Petersburg von den Kayserlichen auffgehoben worden/derselbe soll der vornehmste seyn/so zu allen denen Extremitäten gerathen/als möchte es ihme wohl schlecht ergehen. Man hätte zwar aus Rostock die Cantzeley und die Archiven weg gebracht/und vorgegeben/daß man selbige wieder auff der Hertzoglichen Residentz zu Schwerin wollte bewahren/allein es war dahin nichts gekommen/und man urtheilete/daß alles ausserhalb Landes in Verwahrung gebracht worden/deßgleichen die von dem Hertzog bißher gesammlete Baarschafften/so in einer Million Rthl. bestehen solle ${ }^{132}$.

Erst anschließend erfährt das Lesepublikum, dass von Mecklenburger Seite zunächst bewaffneter Widerstand geleistet worden war. Im Frankfurter Journal liest sich das wie folgt:

Mit denen angelangten Brieffen aus Ratzeburg vernimmt man, daß als die Hanöverische Trouppen vergangenen Sonntag Nachts den starcken Paß Walsmühle auff dem Weg nach Schwerin passiren wollen/die allda gestandene Russen/welche den Vor=Posten gehabt/Feuer auf sie gegeben/wodurch dann alle andere Trouppen in Action gerathen wären/und biß des andern Morgens um $9 \mathrm{Uhr}$ gefochten worden/zu welcher Zeit die Hannöverische die Mecklenburger ummarschiret/und selbige besetzet hätten/und damit man sie aus ihrem Vortheil desto besser delogiren könnte/wären die Canonen angeführet worden; die alte Zellische Battaillon von de Breul hätte den ersten Angriff gethan/wovon auch viele blessirt und getödtet worden/des Hertzogen gantze Macht hätte daselbst gestanden/ausser 2 Battaillons/die in Rostock geblieben/die Land=Militz hätte gleich das Gewehr weg geworffen/und die beede Regimenter Vittinghoff und Lilienstätt/so erstlich mit den Pferden beritten gemacht worden/welche man von den Adlichen Gütern genommen/hätten das Reißaus genommen; Der Hertzog von Mecklenburg wäre auff diese unglückliche Rencontre mit dessen beeden geheimden Räthen Schröpffer und Schraper nach Güstrau gangen/um sich von dannen weiter nach Berlin zu begeben. Den 27. wäre überall im Mecklenbur- 
gischen ein Placat angeschlagen worden/worinnen man denen Edelleuten bekandt gemacht/daß sie ihre Güter wieder könten in Possession nehmen/und da Se. Durchl. die Czaarische Trouppen weg marschiren zu lassen resolviret/also ihnen das Nöthige hierzu angeschaffet werden möchte/dieses Placat hätte man so bald nicht nach dem Kayserl. Hoff gesandt/da man schon einigen Edelleuten ihre Güter/worauff sie bißhero noch gesessen auffs neue weg genommen ${ }^{133}$.

Vier Tage später beziffert die Wöchentliche Relation die Verluste der Kreistruppen auf 150 Soldaten ${ }^{134}$.

Die Fluchtvorbereitungen des Herzogs werden auch in der Europäischen Zeitung vom selben Tag bestätigt:

Aus dem Mecklenburgischen hat man/daß der Hertzog zwar Willens gewesen/auch bereits seinen Wagen angespannet gehabt/um von Rostock sich weg zu begeben/es wäre ihm aber solches von dem Commendanten selbiger Statt abgerathen und ein und anders vorgetragen worden/welches ihn veranlasset/vors erste zu bleiben/und abzuwarten was die Executions=Trouppen würden vornehmen/und wann selbige etwa gar suchen sollten/Rostock zu berennen oder einzuschliessen/alsdann es doch noch Zeit genug wär sich zu Wasser von dannen zu retiriren. Derjenige geheimbte Rath/vor welchen man so grosse Sorge gehabt/daß er auffgehoben [= gefangen genommen] worden/hätte sich zu besagtem Rostock eingefunden; deßgleichen der Herr geheimbde Rath Schraper. Zu Schwerin würde man es auff die Extremität nicht ankommen lassen; der Commendant der Vestung Damitz [= Dömitz] aber solle Ordre haben/sich zu defendiren/wiewol doch von einigen gezweifelt werden wollte/daß er es würde darauff ankommen lassen ${ }^{135}$.

Die Münchener Zeitung kommt mit der Geschwindigkeit der Entwicklung nicht mit: Ihre Leser erfahren die Einzelheiten der militärischen Besetzung nicht. Erst als alles schon entschieden ist, kommt Mecklenburg wieder als Thema vor. Nun ist es eine politische Meldung aus London: Dort habe König Georg I. mit den Hannoverschen Ministern unter Ausschluss der englischen Kronberater über die Mecklenburgfrage getagt. Die Mercurii Relation weicht an dieser Stelle einmal von ihrer sonstigen Gepflogenheit der politischen Zurückhaltung ab und erläutert einen möglichen Grund für dieses Verhalten. Begründungsbedarf ist nämlich vorhanden: Die Klausurtagung habe nämlich bei den Engländern »Verdruß causirt«. Die Zeitung im Weiteren: »Diese Affairen solle der König nit wenig intriquiren/insonderheit, da man

133 Meldung »Nieder=Elbe/den 4. Martii«: »Frankfurter Journal«, Nr. 20 vom 10. März 1719.

134 Meldung $»$ Nieder=Elbe/den 8. Martii«: ebd., Nr. 21 vom 14. März 1719.

135 Meldung »Nieder=Elbe/den 8. Martii«: »Europäische Zeitung«, Nr. 21 vom 14. März 1719. 
besorgt/dass sich Preußen darinn meliren möchte $\ll^{136}$. Interessanterweise hat die Meldung den Weg von London über Wien nach München genommen. Eine öffentliche Spekulation über die Machtkonkurrenz zwischen EnglandHannover und Preußen ist schon bemerkenswert; es ist nicht auszuschließen, dass sie durch eine interessierte Seite - entweder am Kaiserhof oder in der bayerischen Regierung - passieren durfte, um etwas Sand ins Räderwerk dieser beiden protestantischen Führungsmächte im Reich zu streuen. Einen Beweis hierfür gibt es allerdings bislang nicht.

Ansonsten ist in der Berichterstattung das Bemühen erkennbar, nicht durch fragwürdige Kommentare in den Konflikt hineingezogen zu werden. Kaum etwas wird über den Ständekonflikt geschrieben. Nur aus der Mitteilung, dass Adlige zurückkehren könnten, kann der Leser erschließen, dass diese zuvor das Land verlassen mussten. Als eine überdurchschnittlich detaillierte Darstellung der innermecklenburgischen Verhältnisse vor der Exekution darf der Bericht im Frankfurter Journal vom 16. Dezember 1718 gelten. Dort wurde zum Ständestreit vermeldet, dass die Ritterschaft eine 22 Druckbogen starke Deduktion verfasst habe, worin sie feststellte, dass alle Mecklenburger Grundgesetze für sie sprächen. Die Meldung kommentiert, dass diese Feststellung in Rostock - wo sich der Herzog zu dieser Zeit befand - wohl schlecht aufgenommen werden würde. Dem Herzog wurde angelastet, er wolle die Güter des in Wien verstorbenen Oberstleutnant von Roden zugunsten der Rentkammer versteigern lassen. Zudem sollten die Untertanen von Adelsgütern, die unter landesherrlichen Administratoren stünden, mit einer Kopfsteuer zusätzlich zu den regulären Abgaben belastet werden ${ }^{137}$. Naheliegenderweise kamen derartige Einzelmitteilungen nicht zu jedermanns Gesicht. Doch waren sie als Informationen ins Mediensystem eingespeist worden, und damit dienten sie den Zeitungsmachern im ganzen Reich, die wechselseitig ihre Gazetten lasen, als Hintergrundinformationen für weitere Mitteilungen, in denen dieser Sachstand vorausgesetzt wurde und der daher für Anspielungen aller Art genutzt werden konnte.

Nach diesen recht ausführlichen Berichten in verschiedenen deutschen Zeitungen ist noch erwähnenswert, dass die Hauszeitung des wichtigsten Gegenpols des Herzogs, des Kaisers, lange über den Fall Mecklenburg schwieg. Erst am 1. November 1718 verlautete im Wiener Diarium, dass die Mecklenburger sich viele Sorgen machten wegen einer Exekution ${ }^{138}$. Erst kurz vor Beginn der laufenden Exekution wurden in der Zeitung weitere Informationen übermittelt: »Vermög Schreiben aus Hannover wäre das Executions=Wesen festgestellet/und sollte nächstens von denen dazu

136 Meldung »Wien, den 29. Martii«: »Mercurii Relation«, Nr. 15 vom 8. April 1719.

137 Meldung »Wien, den 29. Martii«: ebd.

138 »Von dem Elbstrom/vom 24. October«: »Wiener Diarium«, Nr. 1591 vom 1. November 1718. 
bestimmten Chur=Braunschweigisch $=$ Hochfürstlich=Wolfenbüttelischen und andern Truppen dasselbe vorgenommen werden ${ }^{139}$. Eine Woche später wurde der tatsächlich erfolgte Aufbruch gemeldet ${ }^{140}$. Diese Berichterstattung ist ein klares Beispiel dafür, dass militärische Ereignisse auch unter strengen Zensurbedingungen stets gemeldet werden konnten (wenn auch nicht immer notwendigerweise zutreffend in der Interpretation). In den folgenden Tagen erschienen weitere kleine Militärnachrichten aus Norddeutschland. Die politischen Hintergründe blieben allerdings dem Wiener Leser zunächst verborgen, auch die Rolle des Kaisers bzw. des Reichshofrats in diesem Konflikt. Größere Klarheit entstand mit einem Schlag am 31. März 1719. An diesem Tag rückte das Wiener Diarium außerhalb der regulären Blattgestaltung einen zweiseitigen Bericht ein, der den Prozess der Besetzung Mecklenburgs durch die Kreistruppen beschrieb. Im Vorspann dieses Textes wird erwähnt, dass der Herzog sich eine rechtswidrige Herrschaftsweise über sein Territorium angemasst hatte. Die Exekution geschah daher auf Anweisung des Kaisers und diente der Wiederherstellung des Rechts ${ }^{141}$.

Nach der Besetzung wurden Militärbewegungen, die Etablierung der Administrationsregierung sowie die Reisen des Herzogs erwähnt, auch wenn die Hintergründe weitgehend verborgen blieben. Die Wöchentliche Relation wies ihre Leser am 8. April 1719 darauf hin, dass die mecklenburgischen Landesbeamten angewiesen worden seien, künftig alle Landeseinkünfte an eine gesonderte Kasse der kaiserlichen Kommission zu überweisen; widrigenfalls drohten Strafen und Doppeleinziehung der Gelder ${ }^{142}$. Über die Einzelheiten des Ständekonflikts musste sich der Leser aus anderen Medien unterrichten; die Zeitungen vermittelten ihm darüber nur ein holzschnittartiges Bild. Die Stände bzw. ihre Ausschüsse tauchten in der Berichterstattung vor allem dann auf, wenn sie im Zusammenhang mit Verhandlungen der Administrationsregierung genannt wurden ${ }^{143}$. Als Herzog Karl Leopold nach Wien reiste, um dort sein Anliegen dem Kaiser persönlich nahezubringen und die Rücknahme der Kommissionsentscheidung zu betreiben, notierte die Presse Ankunft und Abreise. Die verhandelten Gegenstände in Wien blieben allerdings im Unklaren, wenn auch der Leser ex nihilo erahnen konnte, dass der Herzog seinen Hauptwunsch nicht erfüllt bekam ${ }^{144}$. Einige Monate spä-

$139 »$ Von dem Elbstrom/vom 10. Hornung«: ebd., Nr. 1622 vom 17. Februar 1719.

$140 »$ Von dem Elbstrom/vom 18. Februar«: ebd., Nr. 1624 vom 24. Februar 1719.

141 Abdruck der Flugschrift »Bericht dessen, was seit dem Einmarsch derer von Ihro Kayserlichen Majestät angeordneten Cray $\beta=$ Executions=Trouppen in Mecklenburg/zwischen diesen und den Hertzoglichen Völkeren/auch sonsten vorgangen«, o.O. 1719 (im Anschluss an die Ausgabe Nr. 1634 vom 31. März 1719).

142 Bericht aus »Teutschland«: »Wöchentliche Relation«, Nr. 14 vom 8. April 1719.

$143 »$ Hamburgischer Relations-Courier«, Nr. 43 vom 16. März 1719.

144 Mitteilung über die Ankunft in Wien am 5. Juni 1720: Bericht aus »Teutschland«: »Wöchentliche Relation«, Nr. 26 vom 29. Juni 1720. Notiz über die Abreise aus Wien: Bericht aus 
ter teilte die Wöchentliche Relation mit, dass der mecklenburgische Minister Banquard in Wien am Kaiserhof nicht mehr offiziell vorgelassen werden sollte, sondern ihm beschieden worden sei, sein Herr möge sich an die kaiserliche Kommission in Rostock wenden ${ }^{145}$. So verwunderte sich der Zeitungsleser kaum, als er im Januar 1722 erfuhr, dass in Dömitz eine Konspiration gegen Herzog Karl Leopold aufgedeckt worden sei. Einige Soldaten hätten versucht, den Herzog in seinem Schloss mitsamt Personal und Wache in die Luft zu sprengen. Acht von ihnen seien hingerichtet und gevierteilt worden $^{146}$.

Aus der Abfolge der Nachrichten erschloss sich der anhaltende Misserfolg des Herzogs und damit der anschlussfähige Eindruck, dass es sich bei ihm um einen reichsnotorischen Querulanten handelte, der immer wieder Rundschreiben verschickte und sich weigerte, auf dem Vergleichswege eine Regelung seines gestörten Verhältnisses zum Kaiser zu erreichen. Aus dieser Perspektive berichtete die Augspurgische Ober-Post-Zeitung vom 14. Juni 1723:

Regensburg/den 1. Juni. Wie verlautet/hat der Hertzog von Mecklenburg=Schwerin an die sämtl. Reichs=Stände ein Schreiben abgelassen/darinn über die Proceduren der Kayserl. Commission geklagt/und die Stände um Assistenz ersuchet etc. welche sie aber hierin nicht meliren wollen ${ }^{147}$.

Zweierlei ist bemerkenswert: Erstens wurde dem Herzog der Titel nicht vollständig gegeben, sonst hätte es lauten müssen: »[...] haben des Hertzog von Mecklenburg=Schwerin Hochfürstl. Durchl. [...] ein Schreiben abgelassen [...] «. Zweitens wurde freimütig vorweggenommen, dass die Reichsstände dem Herzog nicht helfen wollten. Die Vorwegnahme des Ergebnisses reichte zur Diskreditierung des Herzogs: Seine routinemäßig wiederholten Bitten waren schon $\mathrm{zu}$ folgenlosen Ritualen geworden.

Vor diesem Hintergrund blieb Herzog Karl Leopold von Mecklenburg eine feste Größe in den Zeitungen. Kennzeichnenderweise wurde nicht zwischen den Herzögen Karl Leopold und Christian Ludwig unterschieden: Wenn »Hertzog von Mecklenburg« in der Zeitung steht, war Karl Leopold gemeint. Sein Bruder ist (noch) keine Mediengröße. In der Berlinischen Zeitung des J.A. Rüdiger sind für 1725 drei Meldungen Mecklenburg betreffend zu finden. Zunächst wurde am 10. März gemeldet, dass Mecklenburger Adlige versucht hätten, sich auf eigene Faust mit dem Herzog auszusöhnen. Kai-

»Teutschland«: ebd., Nr. 48 vom 30. November 1720.

145 Bericht aus »Teutschland«: ebd., Nr. 14 vom 5. April 1721.

146 Bericht aus »Teutschland«: ebd., Nr. 4 vom 24. Januar 1722.

147 »Augspurgische Ordinari-Post-Zeitung [...]«, o.O. 1723-1766; hier Ausgabe vom 14. Juni 1723. 
serlicherseits wurden sie allerdings mit Missfallen bedacht ${ }^{148}$. Fünf Wochen später kam aus Wien die Nachricht, dass Reichsvizekanzler Schönborn dem Mecklenburger Agenten in der Habsburgermetropole signalisiert habe, Karl Leopold könne in sein Land zurückkehren, falls er sich dem Kaiser unterwürfe und sich mit seinem Adel vergleiche und diese Regelung »heiliglich" einhalte ${ }^{149}$. Anfang Oktober wurde der Mecklenburg-Fall auch im Rahmen der diplomatischen Verhandlungen in Hannover thematisiert, die König Georg I. von England anlässlich seines Besuchs im Herkunftsterritorium führte. Gesprächspartner, so meldete die Berlinische Zeitung, war der kaiserliche Gesandte Graf Starhemberg, der einen Tag später auch mit dem Grafen Bernsdorff verhandelte, der die Administrationsregierung in Mecklenburg leitete. Welche Entscheidungen im Einzelnen besprochen wurden, blieb allerdings unerwähnt ${ }^{150}$.

Im Juni 1727 vermeldete der Avisen-Correspondente eine weitere Eingabe des Herzogs in Wien: »Der Hertzog von Mecklenburg beschwert sich noch immer über die grossen Bedruckungen der Executions=Trouppen, mit der Bitte, daß doch der Reichs=Hof=Rath der Sachen einmahl ein Ende machen möchte $\aleph^{151}$. Der Wunsch ging im darauffolgenden Jahr in Erfüllung, aber nicht so, wie der Herzog es gewollt hatte: Zwar wurde die Sequestrationskommission aufgelöst, doch der Landesherr wurde nicht restituiert, sondern abgesetzt und sein Bruder zum Nachfolger erklärt.

Die Suspendierung des Herzogs Karl Leopold im Mai 1728 wurde nicht in allen Zeitungen direkt angesprochen. Hingegen war die Fortdauer des Konflikts zwischen dem Herzog und dem Reich bekannt. Am 24. Februar vermeldet der Avisen-Correspondente, dass der Herzog eine Druckschrift in Regensburg eingereicht habe, in der er seine Rechtspositionen sowie sechs Anlagen zu Papier gebracht habe ${ }^{152}$. Bezeichnend ist, dass die Zeitung kommentiert, Karl Leopold habe teilweise »in sehr harten Terminis« geschrieben. Dies bezog sich vor allem auf seine Worte, die er an den Kaiser und den Reichshofrat richtete und die dort als ehrkränkend aufgefasst worden waren. Damit wird der Leserschaft im Reich verdeutlicht, dass es sich um einen summarischen Konflikt handelte: Der Herzog stand nicht nur gegen seine Stände und Untertanen, sondern er galt auch hinsichtlich seines Umgangs mit den Ehr- und Höflichkeitsgepflogenheiten der hochadligen Welt auf Kriegs-

148 Meldung »Aus dem Mecklenburgischen, den 26. Februar«: »Berlinische Zeitung«, 10. März 1725.

149 Meldung »Wien, den 4. März«: ebd., 17. April 1725.

150 Meldung »Hannover, den 24. September«: ebd., 6. Oktober 1725.

151 Meldung aus Wien: »Avisen-Correspondente«, Nr. 96 vom 7. Juni 1727.

152 Der Titel lautete: »Extractus gnädigsten Rescripti des zu Mecklenburg-Schwerin und Güstrow regierenden Hertzogs Carl Leopold Hoch=Fürstl. Durchl. nach Regensburg de dato Dantzig den 10. Januar 1728«: ebd., Nr. 31 vom 24. Febuar 1728. 
fuß. Sein Appell an die übrigen Reichsstände um Unterstützung konnte vor diesem Hintergrund kaum erfolgreich sein.

Die entscheidende Meldung über den Herrscherwechsel in Mecklenburg steht im Avisen-Correspondente in einem Nebensatz:

Ihro Durchlaucht, der Hertzog von Mecklenburg-Grabau [= Herzog Christian Ludwig], welchem letzthin von Ihro Kaiserl. Majestät durch ein allergnädigst=publicirtes Reichs $=$ Hof $=$ Raths Conclusum die Regierung aufgetragen worden, sind allhier $[=$ in Hamburg] angelanget $[. . .]^{153}$.

Durch diese Bemerkungen zu einem »Staatsbesuch« eröffnete die Zeitung den Lesern, dass in Mecklenburg endlich auch im rechtlichen Sinne gehandelt worden war. Der querulantische Karl Leopold behielt zwar seinen Titel, aber seine Chancen auf Rückkehr in die Regierung waren dahin. Dass der Herzog sich nicht damit zufriedengeben wollte, erfuhr der Leser des AvisenCorrespondente bereits am 9. Juli, als die Zeitung berichtete:

Wie man aus dem Mecklenburgischen vernimmt, so hätten des regierenden Hertzogs zu Mecklenburg an dero Civil $=$ als Militär $=$ Bediente bey Leib $=$ und Lebens $=$ Strafe die Ordre ergehen lassen/denen neuen Kayserl. Regierungs=Verordnungen keine Parition zu leisten; welches in dasigem Land eine große Consternation verursachte ${ }^{154}$.

Weitere Einzelheiten zu diesen Verwaltungsstreitigkeiten werden nicht berichtet. Erst unter dem 20. August wurde vermerkt, dass Herzog Christian Ludwig in seinem bisherigen Domizil, Schloss Neustadt, bleiben wolle, bis die neue Administrationsregierung sich etabliert habe. Auch ein neuer Landtag sei vorgesehen, so die Gazette, doch der Termin stehe noch nicht fest ${ }^{155}$. Über Karl Leopold erfuhr der Leser - jedenfalls in dieser Ausgabe - nichts. Es muss offen bleiben, ob die Mecklenburger Nachbarschaft das Thema zu brisant machte oder ob für die mediale Öffentlichkeit die Mecklenburger Verhältnisse zu unübersichtlich waren.

Weit deutlicher wurde der Leser in der Wöchentlichen Relation vom 19. Juni 1728 unterrichtet, die nicht nur sachlich zutreffend den Wechsel von der Kommission Kurhannovers und Braunschweig-Wolfenbüttels zur neuen kommissarischen Landesadministration durch Herzog Christian Ludwig schilderte, sondern gleich das kaiserliche Mandat zur Regierungsverände-

153 Bericht aus »Hamburg, den 3. Juny«: ebd., Nr. 89 vom 4. Juni 1728.

154 In diesem Zusammenhang wird ferner berichtet, dass der Kaiser mit Kurmainz darüber korrespondiert habe, die mecklenburgische Reichstags-Stimme ebenfalls zu suspendieren: ebd., Nr. 109 vom 9. Juli 1728.

155 Bericht »Aus dem Mecklenburgischen« den 12. August: ebd., Nr. 133 vom 20. August 1728. 
rung einrückte ${ }^{156}$. Bei anderen Zeitungen hat man den Eindruck, dass der Umstand der Herrscherabsetzung verschleiert wurde, selbst wenn dort sonst Mitteilungen über Mecklenburg gebracht wurden. So berichtete die Mercurii Relation über den Transport von Möbeln über See im Auftrag des Herzogs, doch eine klare Reisestrategie wird nicht erkennbar ${ }^{157}$.

Die deutliche und klare Berichterstattung der Wöchentlichen Relation umging auch keine brisanten Zahlen, sofern sie die Mecklenburgischen Kompensationsleistungen an die Kommissionsmächte betrafen. Zum 1. November 1732 schrieb die Zeitung über die Abfindungen in Höhe von einer Million Rtl. an England-Hannover und 300.000 Rtl. an Braunschweig-Wolfenbüttel, die im Laufe von zehn Jahren aus den Landeseinkünften entrichtet werden sollten $^{158}$. Fünf Wochen später wurde die Mitteilung nachgeschoben, dass Herzog Christian Ludwig nun durch Reichshofrats-Conclusum interimistischer Landesherr über Mecklenburg werden würde ${ }^{159}$.

1735 unternahm Herzog Karl Leopold von Dömitz aus einen Versuch, die Stadt Schwerin mit bewaffneter Hand in seine Gewalt zu bringen. Einzelheiten der militärischen Maßnahmen liessen sich bislang noch nicht in der Presse auffinden. In den Leipziger Zeitungen findet sich dafür am 5. Januar 1735 ein Mandat Kaiser Karls VI. gegen Herzog Karl Leopold, durch das der Kaiser den ruhigen Verlauf des Mecklenburgischen Landtags sicherstellen wolle. Der Text sparte dabei nicht mit harten Worten gegen den Herzog, der offen als Rechtsbrecher bezeichnet wurde. Der Kaiser verbot allen Mecklenburgern, Herzog Karl Leopold »in seinem tumultuantischen Vorhaben« in irgendeiner Weise zu unterstützen ${ }^{160}$. Zwei Wochen später berichtete der Leipziger Extract derer [...] einlauffenden Nouvellen davon, dass der Herzog Schwerin habe besetzen wollen:

Aus dem Mecklenburgischen [o.D.] hat man ferner, dass zwar von Seiten des Herzogs Carl Leopold noch einige Truppen aus Dömitz auf das Schloss zu Schwerin gezogen worden, allein man habe das äußerste nicht abwarten wollen, da man denn am 10. dieses zum Accord geschritten, ohne dass ein Schuss geschehen: der Herzog Carl Leopold hätte, nachdem die Stadt erstiegen worden, sich zu Wasser nach Wismar retiriret $^{161}$.

156 Bericht aus »Teutschland«: »Wöchentliche Relation«, Nr. 25 vom 19. Juni 1728.

157 Bericht aus »Dantzig/vom 28. May«: »Mercurii Relation«, Nr. 24 vom 19. Juni 1728.

158 Bericht aus »Teutschland«: »Wöchentliche Relation«, Nr. 44 vom 1. November 1732.

159 Bericht aus »Teutschland«: ebd., Nr. 49 vom 6. Dezember 1732.

160 Mitteilung »Aus dem Mecklenburgischen, den 29. Dez. [1734]«: »Leipziger Zeitungen«, Nr. 3 vom 5. Januar 1735.

$161 »$ Aus dem Mecklenburgischen [o.D.]«: »Extract derer [...] einlauffenden Nouvellen«, Nr. 7 vom 19. Februar 1735. 
Weitere Kampfhandlungen folgten. Erst im April 1735 zog sich Herzog Karl Leopold einmal mehr aus Mecklenburg zurück. Die Berlinische Privilegierte Zeitung berichtete über den Umstand, dass der Herzog vor den Truppen seines Bruders und der Konservations-Mächte England-Hannover, Preußen und Braunschweig-Wolfenbüttel geflohen sei. Seine Beamten hätten allerdings Ordre, fügte der Verfasser feinsinnig hinzu, sich gegen die feindliche Übermacht zu wehren; der Herzog kündigte an, bald zurückzukehren ${ }^{162}$. Immerhin konnte die Administrationsregierung anschließend die Lage beruhigen, auch wenn im Juli gemeldet wurde, dass der Leiter der Administrationsregierung, Herzog Christian Ludwig, sehr knapp bei Kasse sei, was seine politische Handlungsfähigkeit stark einschränke ${ }^{163}$.

\subsection{Darstellung in den Zeitschriften}

Angesichts der Breite der Überlieferung im Bereich der Deduktionen und angesichts der Berichterstattung in den Zeitungen bot sich für die Redakteure der politisch-historischen Zeitschriften eine Menge an Material, das sie ihrer Leserschaft aufbereiten konnten. Am ausführlichsten erschien der mecklenburgische Ständekonflikt in der Europäischen Fama ${ }^{164}$. Hier, wie auch in allen anderen ausgewerteten Zeitschriften, wurde der Konflikt im Jahre 1716 wahrgenommen und in seinen Grundzügen eingeführt. Während der folgenden Jahre konnte darauf aufgebaut werden, und die verschiedenen spektakulären Ereignisse ließen sich dann ohne grundsätzlichen Darstellungsbedarf des Hintergrunds immer weiter anschließen. Es entspricht völlig der Schwerpunktsetzung in den Deduktionen, dass zunächst die Eheschließung des mecklenburgischen Herzogs Karl Leopold mit der russischen Prinzessin Catharina Iwanowna 1716 thematisiert wurde ${ }^{165}$. Dieses Ereignis bot Gelegenheit, auf die strittige Flugschrift über die Legitimation der Bigamie einzugehen. Der Redakteur der Europäischen Fama bezeichnet das Beilager zwischen dem Herzog und der Zarennichte als »Anlaß zu vielerley Discursen«. Er verurteilt die Flugschrift Kurzer und deutlicher Beweis von 1716 mit den Worten:

162 Bericht aus »Nieder=Elbe, den 24. April«: »Berlinische Privilegierte Zeitung«, Nr. 51 vom 28. April 1735.

163 »Aus dem Mecklenburgischen, den 26. Juli«: »Leipziger Zeitungen«, Nr. 1, 31. Woche, vom 1. August 1735.

164 Europäische Fama.

165 Ebd. 183 (1716), S. 229. 
[...] die Argumente, die er [= der Verfasser der Flugschrift] vorbringt, sind auch dergestalt absurd, daß, wenn man sie gelten liesse, endlich ein viehischer Naturalismus, eine willkührliche Vielweiberey, eine freie Verstossung der Gemahlinnen, und eine gar ärgerliche Nachahmung des geringern Adels, wo nicht der gemeinen Leute, zu besorgen stünde.

Der Kaiser habe die Schrift so übel aufgenommen, dass er sie durch den Henker öffentlich habe verbrennen lassen.

Naheliegenderweise ging der Redakteur davon aus, dass die inkriminierte Schrift im Auftrag des Herzogs auf den Markt gebracht worden sei. Er verwandte einen Kunstgriff, um seine Kritik an den Verhältnissen im mecklenburgischen Herzogshaus nicht persönlich werden zu lassen ${ }^{166}$ :

1. Er griff nur den Autor an, nicht den Herzog.

2. Der Inhalt der Schrift wurde völlig abgelehnt.

3. Der Hinweis auf die kaiserliche Verbrennung schützte den Zeitschriftenautor.

4. Zuletzt setzte er noch die Vermutung hinzu, die Schrift stamme gar nicht vom Herzog selbst.

5. Eventuelle Proteste aus Schwerin wären gegen diese Interpretation ins Leere gelaufen, allerdings ist davon in keinem der folgenden Druckmedien die Rede.

Zwei Hefte später rückte der zentrale Ständekonflikt im Herzogtum an der Ostsee ins Blickfeld der Europäischen Fama. Die Rede war nicht nur von der Anwesenheit russischer Truppen im Land, sondern auch von deren Verwendung durch den Herzog zu Repressionen gegen widerspenstige Adlige. Mehrere von ihnen hätten bereits den Kaiser um Hilfe angeschrieben. Kaiser Karl VI. sei sehr unzufrieden über die Entwicklung, habe bereits mehrere Monitoria geschickt, die aber unbeachtet geblieben seien ${ }^{167}$. Der Herzog habe sich nicht einmal gescheut, die Familienangehörigen von Ritterschaftsmitgliedern zu misshandeln, deren Oberhaupt außer Landes geflohen sei. Die Redaktion wies darauf hin, dass Details noch nicht übermittelt werden könnten, solange die Akten der Konfliktparteien nicht im Druck erschienen seien. Dies weist zum einen auf die Bedeutung der Deduktionen als Quellengrundlage hin, zum anderen auf das Sicherheitsbedürfnis der Journalisten,

166 Ebd. 187 (1716), S. 597f.

167 Ebd. 189 (1716), S. 753ff. - Auch im »Historischen Mercurius« werden russische Besatzung und Unterdrückung des Adels 1716 im Zusammenhang abgehandelt: »Historischer Mercurius worinnen das Wichtigste, was zu disen Zeiten in ganz Europa vorgehet, [...] zusammengetragen und entworffen wird«, 84 Tl. in 7 Bd., Augsburg 1712-1718, hier Jg. 1716/2, S. $206 f$. 
die etwas Greifbares in der Hand halten wollten, bevor sie Nachteiliges über einen regierenden Landesherrn schrieben.

In den letzten Monaten des Jahres 1716 wurden die Berichte über Mecklenburg länger. Die Tendenz der Berichterstattung richtete sich dabei eher gegen den Herzog als gegen den Zaren als Kriegsherrn der Soldaten, die in Mecklenburg stationiert waren. Die Redaktion der Europäischen Fama wusste schon zu dieser Zeit, dass es einen kaiserlichen Exekutionsauftrag an den englischen König in seiner Eigenschaft als Kurfürst von Hannover geben werde. Allerdings stünden noch Verhandlungen zwischen England und Russland einem Eingreifen im Weg, die russische Regierung spiele dabei auf Zeit ${ }^{168}$. Ende 1717 ergriff die Zeitschrift die Gelegenheit, mit Erscheinen des kaiserlichen Kommissions-Dekret in Regensburg nochmals die mehr als 100jährige Geschichte des Konflikts zu erörtern ${ }^{169}$. Im Anschluss daran wurde berichtet, dass Karl Leopold sich keineswegs unterwarf, sondern aufrüstete: $\mathrm{Zu}$ den schon anwesenden 3.200 russischen Soldaten kamen nun noch ca. 12.000 Rekruten, die der Herzog im Land geworben hatte. Im August und September scheiterten zwei Versuche, einen Ausschusstag einzuberufen, an der Abwesenheit der meisten adligen Mitglieder ${ }^{170}$.

Das weit gespannte Mediensystem sorgte dafür, dass keinem Interessenten im Reich verborgen blieb, auf welche Weise Herzog Karl Leopold sein Verständnis von Landesherrschaft in Mecklenburg exekutierte. Inzwischen war der Mecklenburger so diskreditiert, dass am Reichstag sogar Bedenken gegen die öffentliche Publikation seiner Gegenvorstellungen zum kaiserlichen Exekutionsmandat laut wurden. Die Ansichten des Herzogs wollten die Gesandten (und die entsendenden Prinzipale) nicht mehr hören und nicht mehr lesen. Um dieser Zensurforderung eine Begründung zu geben, besann man sich auf die Formel, es handele sich dabei um ein schwebendes Reichshofratsverfahren, in das nicht eingegriffen werden solle. Wie sehr dieses Argument vorgeschoben war, zeigte sich wenig später, als die mecklenburgische Ritterschaft eine weitere Supplik an den Reichstag schickte, die umgehend im Druck erschien - offenbar durch keinerlei Bedenken wegen des Reichshofrats-Verfahrens verzögert. Die Europäische Fama zitierte passagenweise die verschiedenen Bedrückungsmaßnahmen aus dieser Supplik und versäumte nicht, darauf hinzuweisen, dass der Herzog selbst diese Eingabe nicht angenommen hätte, solange zahlreiche seiner Lehnsleute außer Landes weilten ${ }^{171}$.

168 Europäische Fama 193 (1716), S. 60-67.

169 Kommissionsdekret vom 17. Oktober 1717: ebd. 206 (1717), S. 136-140. - Der »Historische Mercurius« fügt die Information hinzu, dass 6.000 kaiserliche Soldaten aus Schlesien nach Mecklenburg gesandt werden sollen: Historischer Mercurius, Jg. 1717/2, S. 542.

170 Europäische Fama 206 (1717), S. 165-174.

171 Ebd. 210 (1718), S. 489-491. 
Um den Anschein der Unparteilichkeit zu wahren, druckte die Europäische Fama einen zwei Seiten langen Brief des Mecklenburger Herzogs an Kaiser Karl VI. vom 5. Februar 1718. Der Herzog schrieb darin zwar von Devotion, Respekt und Gehorsam gegenüber der kaiserlichen Majestät, betonte aber sogleich seine landesherrlichen Rechte und ging in der Substanz auf keine der zuvor gestellten kaiserlichen Forderungen ein. Alle Anschuldigungen, so der Herzog, seien bloße Gerüchte der malkontenten Adligen, daher besäßen sie keine rechtserhebliche Substanz ${ }^{172}$.

An diesen Brief konnte angeknüpft werden, als die mecklenburgische Ritterschaft im April 1718 durch den Freiherrn von Bohr eine Widerlegung des Inhalts am Reichstag eingab. Die Unterzeichner betonten den Fortbestand ihrer Mitregierungsrechte im Herzogtum gegenüber den absolutistischen Ansprüchen der Landesregierung ${ }^{173}$. Durch seine wütende Reaktion setzte sich der Herzog aus Sicht der Redaktion noch mehr in den Nachteil: Er stellte die Veröffentlichung als Angriff auf seine Ehre dar und ordnete an, dass alle Adligen einen eidlichen Revers unterzeichnen sollten, sie hätten mit der Schrift nichts zu tun und der Verfasser sei ihnen unbekannt. Bei Ablehnung sollten die Güter konfisziert werden, was auch bei einigen Adligen geschah, die daraufhin aus Mecklenburg flohen ${ }^{174}$. Auch Karl Leopolds gleichzeitige Korrespondenz mit England-Hannover und Braunschweig-Wolfenbüttel war der Zeitschrift erwähnenswert, wobei beide Herrscher den Mecklenburger mahnten, seinen Sinn zu ändern, denn eine längere Opposition gegen kaiserliche Verordnungen seien noch keinem Reichsstand gut bekommen ${ }^{175}$. Herzogliche Bedrückungen der Stände und gleichzeitige dynastische Diplomatie wurden in der Europäischen Fama mit großer Offenheit verhandelt, jedoch ist keinerlei Angst vor einem gewalttätigen Territorialherren erkennbar, dessen Lande nicht sehr weit von Leipzig entfernt lagen.

Die militärische Besetzung Mecklenburgs durch die welfischen Herrscher wurde in der Europäischen Fama umfänglich geschildert, ausgehend von dem kaiserlichen Reskript vom Januar 1719, nun endlich mit dem Einmarsch zu beginnen ${ }^{176}$. Mehrere Quellentexte unterschiedlicher Gattungen (Deduktionen, obrigkeitliche Verfügungen, Zeitzeugenberichte) folgten, und der Redakteur kommentierte am Schluss: »Gantz Deutschland und Europa hat dem Höchsten zu danken Ursache, daß dieses unter der Asche glimmende Feuer so zeitig und glücklich gedämpffet worden $\aleph^{177}$. Auch in Andreas Stübels Staats=Secretarius wurde der Einmarsch ausführlich gewürdigt, hier

172 Ebd., S. 493-495.

173 Quellenabdruck: ebd. 216 (1718), S. 1050-1053.

174 Ebd., S. 1053.

175 Ebd., S. 1061-1064.

176 Ebd. 222 (1719), S. 220-250.

177 Ebd., S. 249. 
im Stil des Periodikums durch einen fingierten Brief vom 30. März 1719, der den damaligen Zustand der soeben vollendeten Besetzung Mecklenburgs sowie die Flucht des Herzogs zum Zielpunkt hatte ${ }^{178}$.

Der langsame und mühevolle Wiederaufbau Mecklenburgs, die Sicherung der Staatsgewalt, die Restitution des Adels und der städtischen Freiheit sowie die Administration der zerrütteten Staatsfinanzen bei gleichzeitigen Kompensationsansprüchen der Exekutionsmächte stellten Zusammenhänge dar, die zu kompliziert für eine Medienberichterstattung waren. Daher wurde die Wien-Reise von Herzog Karl Leopold das wichtigste Mecklenburg-Ereignis des Jahres 1720. Die Zeitschrift teilte mit, der Herzog sei inkognito als Graf von Schwerin in die kaiserliche Hauptstadt gereist, wo er erst nach komplizierten Vorverhandlungen überhaupt zum Kaiser vorgelassen worden sei. In der ersten Kaiseraudienz wurde deutlich, dass auch der persönliche Kontakt zu keiner Annäherung der Standpunkte führen würde. Ebensowenig gelang es Karl Leopold, den Prinzen Eugen von Savoyen, die Kaiserinwitwe Amalie und den Reichshofratspräsident Graf Windischgraetz bei Besuchen zu überzeugen ${ }^{179}$. Zahlreiche Eingaben und Beschwerden beim Reichshofrat bestätigten das Bild, das die Wiener Hofgesellschaft vom Mecklenburger hatte. Der Herzog blieb bis November in Wien, doch das einzige, was er erreichte, war eine Verlängerung der Zahlungstermine für die Kreisexekutionskosten. Diskret am Rande vermerkte die Europäische Fama, dass eine verklausulierte preußische Demarche zugunsten des Herzogs stattfand, die allerdings ebenfalls erfolglos blieb ${ }^{180}$. Im folgenden Jahr trug die Zeitschrift noch zwei Argumente im Zusammenhang mit dem Wienbesuch nach: Nachdem Herzog Karl Leopold sich beim Kaiser darüber beschwert habe, dass dessen Minister offenbar von den Feinden des Mecklenburgers eingenommen seien, konterte Karl VI. damit, dass seine Regierung sehr wohl eine präzise Vorstellung von den Verhältnissen an der Ostsee besitze. Eher habe der Herzog Veranlassung, über seine eigenen Minister zu klagen, die ihm zu so nachteiligen Regierungsmaßnahmen geraten hätten ${ }^{181}$. Einmal mehr setzte die Redaktion der Zeitschrift den Beratertopos als Argument ein: Indem der Kaiser die Bediensteten des Herzogs als schlechte Berater bezeichnete, entlastete er das Gespräch von einem direkten Vorwurf. Genauso entlastete sich Hoffmann von einer zu kritischen Bewertung des Verhaltens des Herzogs, indem er eventuellen Unwillen in Schwerin bei der Lektüre seiner Zeitschrift

178 [Andreas StüBel (Hg.)], Der mit allerhand Staats $=$, Friedens $=$, Krieges $=$, Hof $=$, Literatur $=$ und Religions $=$ wie auch Privat $=$ Affairen beschäftigte Secretarius [...], 4 Bd. (= 48 Expeditionen), Freyburg [= Leipzig] 1710-1721, hier Bd. 4, Expedition 38, Brief 461, S. 185-190.

179 Die erste Kaiseraudienz fand am 9. Juni 1720 statt: Europäische Fama 234 (1720), S. 542f.

180 Ebd. 239 (1720), S. $1006 f$.

181 Ebd. 243 (1721), S. 267f. 
ablenkte. Welche Ansicht Hoffmann wirklich hegte, beweist der Schlusssatz: Bei dem mecklenburgischen Herzog sei durch das fragliche Gespräch keine Wirkung eingetreten.

Der Publizist David Fassmann hat Herzog Karl Leopold in seinen Totengesprächen keinen Dialog widmen können, da der Herzog ihn überlebte. In seinem Reisenden Chineser, einem Periodikum, das den fremden Blick eines fingierten Asiaten auf die politischen Geschehnisse in Europa richtete, führte Fassmann den mecklenburgischen Ständekonflikt am Beispiel des Landtags von 1721 aus. In sachlicher Form, ohne irgendwelche polemischen Untertöne oder Anspielungen auf frühere Geschehnisse, wies er darauf hin, dass der Herzog den Landtag für unrechtmäßig erklärt habe. Die Anhängerschaft des früheren Landesherrn wurde aufgefordert, diese Ladung nicht anzuerkennen. Karl Leopold drohte den Teilnehmern den Ausschluss von jeder Huld und künftigen Ämtern an. Fassmann brauchte die faktische Ohnmacht Leopolds gegenüber der kaiserlichen Kommission gar nicht zu betonen: Es reichte der Schlusssatz, dass der Landtag dennoch in Rostock stattgefunden habe, und zwar unter starker Adelsbeteiligung ${ }^{182}$.

Die Europäische Fama griff den Mecklenburgkonflikt 1722 wieder auf, indem sie von einem gescheiterten Sprengstoffanschlag auf Herzog Karl Leopold berichtete. Die Schlosswache in Dömitz hatte einen verdächtigen Mann durchsucht, der sich als der Kurier eines diesbezüglichen Briefes herausstellte. So kam heraus, dass im Schloss schon Pulver und Lunten gelegt worden waren: An fünf Orten sollte die Sprengung zeitgleich vorgenommen werden. Der Redakteur bewertete den Plan als die Reaktion der Untertanen auf die harte Haltung des Landesherrn. Herzog Karl Leopold verhängte ein scharfes Strafgericht und ließ mehrere Personen hinrichten ${ }^{183}$. Die Berichte in der Zeitschrift aus den Jahren 1722 bis 1727 bestätigten den Starrsinn des Herzogs, mit den immer gleichen Argumenten in seinen Schreiben den Wiener Hof beeindrucken zu wollen. Die Europäische Fama brauchte dies nicht zu kommentieren, der Hinweis genügte, dass der Kaiserhof die Annahme weiterer Schreiben von Karl Leopold verweigert habe ${ }^{184}$.

Die Schreiben des Mecklenburgers wurden allerdings auch wegen ihrer Form gerügt, und auch das thematisierte die Europäische Fama. Konfliktverhalten in der ständischen Gesellschaft war zwar oft ungewohnt, aber nicht grundsätzlich strafwürdig. Voraussetzung war allerdings die Kenntnis und die Wahrung der Formen, in denen die Gegensätze ausgetragen wurden. Dazu gehörte auch die richtige Wortwahl in Schreiben an die Gegen-

182 David Fassmann, Der, Auf Ordre und Kosten seines Kaysers, reisende Chineser, Tl. 1, Stück 1-28, Leipzig 1721-1723, hier 1. Tl., 7. Stück, S. 297.

183 Europäische Fama 257 (1722), S. $423 f$.

184 Vgl. den Hinweis auf eine 16 Seiten starke Eingabe Karl Leopolds in Wien von 1722: ebd. 262 (1722), S. 841-857. 
seite. Nimmt man die scharfen kaiserlichen Reaktionen zum Maßstab, dann beherrschte der Herzog sie nicht. Der Kaiser betrachtete derartige Formulierungen, im Sprachgebrauch der Zeit »irrespectuose Termini« genannt, als Angriffe auf seine Ehre. In der Europäischen Fama stand - mit ironischem Unterton - dazu zu lesen:

Die Schreib=Art, deren sich Ihr. Fürstliche Durchlaucht zu bedienen pflegen, ist überhaupt in dem, was man Invectivas, Schelt- und Schmäh=Schrifften zu nennen pflegt, ungemein ausdrückend, und es kann sich einer aus derselben einen zulänglichen Vorrath von denen dahin gehörigen Redens=Arten sammeln ${ }^{185}$.

Etwas neutraler zum Mecklenburg-Konflikt äußerte sich David Fassmann. Es ist unklar, ob dies eine Vorsichtsmaßnahme angesichts seines Engagements in Preußen war. Fassmanns M.G. Historie war eher eine Chronik als eine räsonnierende Zeitschrift. Die Fortdauer der Auseinandersetzungen zwischen Kaiser Karl VI. und Herzog Karl Leopold wurde 1725 erwähnt: Einmal mehr habe der Kaiser vollkommene Parition und Submission unter die früheren Anordnungen gefordert. In einem weiteren Schreiben befahl der Kaiser dem Herzog, ihm in zwei Monaten Bericht zu erstatten wegen der Hinrichtung des Geheimen Rates Wolffradts und der Tortur, die der Geheime Rat Scharff erleiden musste ${ }^{186}$. Fassmann verwies zudem 1725 darauf, dass Zar Peter der Große den Herzog restituieren wolle und den Abzug der Kreistruppen aus Mecklenburg gefordert habe ${ }^{187}$. Auch stellte Fassmann einen Vergleichsvorschlag vor, der ebenfalls auf die Restitution Karl Leopolds bei gleichzeitiger Beibehaltung aller alten ständischen Mitwirkungsmöglichkeiten hinauslief, ein Projekt, das wohl nur aus der Umgebung des Mecklenburgers stammen konnte, denn auf Seiten des Kaisers und des Reiches stand man weit von einem derartigen Vorhaben entfernt ${ }^{188}$.

In einem anderen Periodikum, den Sonderbahren Nationen-Gesprächen, ging Fassmann auf die Herrschaftssuspendierung Karl Leopolds vom Mai 1728 ein. Schon in früheren Heften hatten die beiden fingierten Gesprächspartner, der »Österreicher« und der »Franke«, einige Male über den Stand der Prozesse am Reichshofrat zwischen dem Herzog und seinen Landständen gesprochen. Fassmann nutzte diese Dialoge, auch die gescheiterte Ehe des

185 Ebd. 286 (1724), S. 862f., hier S. 863.

186 Die Hinrichtung Wolffradts fand am 6. November 1723 statt. Der Leichnam wurde gevierteilt und öffentlich ausgehängt: [David FASSMANN], M.G. Historie des Jahrs 1724 oder zur Kirchen= Politisch= und Gelehrten=Historie dieses Jahrs gehörige Haupt=Anmerkungen, in gewisse zu Coburg Monathlich edirte Zeitungs=Extracte aufs fleissigste gebracht [...], Coburg 1725, S. $180-183$.

$187 »$ Januarius 1725«: ebd., 1726, S. 24.

188 »August 1725«: ebd., 1726, S. 240. 
Herzogs sowie die Proteste gegen die Form seiner respektlosen Schreiben zu erwähnen $^{189}$. Im folgenden Heft druckte Fassmann ohne längeren Kommentar das Reichshofrats-Conclusum vom 11. Mai 1728 ab, durch das Herzog Karl Leopold von seiner Landesherrschaft suspendiert wurde und die Regierungsgewalt auf Herzog Christian Ludwig überging ${ }^{100}$.

Auch die Europäische Fama berichtete von der Suspendierung Karl Leopolds 1728 zeitnah und sah darin den Abschluss eines mehrjährigen Machtmissbrauchs in Tateinheit mit fortgesetzter ehrkränkender Belästigung des Reichsoberhaupts und des Reichshofrats durch formal inakzeptable Schriftsätze $^{191}$. Die näheren Umstände des Herrschaftsübergangs an Herzog Christian Ludwig wurden erst einige Monate publiziert. Offenbar wollte der Redakteur sich erst ein klares Bild darüber verschaffen, wie es nun wirklich in Mecklenburg weiterging, nachdem zu diesem Konflikt schon zahlreiche folgenlose Ankündigungen gemacht worden waren. Erst um die Jahreswende 1728/29 folgte in Heft 322 eine Zusammenfassung des Konflikts. Dabei fehlte nicht der Verweis darauf, dass der frühere Landesherr zwecks seiner Restitution weiterhin rührig sei, etwa durch Versendung eines neuerlichen Rundschreibens an die anderen Reichsstände ${ }^{192}$. Offenbar machte das Zirkular Karl Leopolds wenigstens bei einigen Reichsständen Eindruck, denn Frankreich, Schweden und einige nicht einzeln genannte Fürsten forderten einen Reichstagsbeschluss zu diesem kaiserlichen Rechtsakt. Auch hier wurde klar gesehen, dass der Suspendierungsakt das frühere Ächtungsund Absetzungsrecht des Kaisers gegenüber Reichsfürsten berührte, ein altes verfassungsrechtliches Diskussionsthema auf Reichstagen ${ }^{193}$. Es folgten die Auseinandersetzungen um eine Deduktion, die Kurhannover eigennützige Motive bei der Übernahme der Kaiserlichen Administrationsregierung unterstellte. Dies war eine der wenigen Stellen in der Medienberichterstattung, an der die Interessenkollisionen der Exekutionsmächte einmal thematisiert wurden ${ }^{194}$.

Ein Jahr später griff die Europäische Fama diesen Punkt der Interessen erneut auf. Es blieb auch den publizistisch tätigen Zeitgenossen nicht verborgen, dass die Welfen ihren Einfluss sichern wollten, wenn sie sich mit eigenen Vorschlägen an den Kaiser wandten. Auch Preußen wollte Konzessionen für eigene gute Vermittlungsdienste erlangen. Die Zeitschrift zitiert ein

189 [David Fassmann], Sonderbahre Nationen=Gespräche oder Curieuse Discurse Über die Jetzigen Conjuncturen und wichtigsten Begebenheiten [...], 2 Bd. (32 Entrevuen), Berlin 17271733, hier Bd. 2, 17. Entrevue, S. 31.

190 Ebd., Bd. 2, 18. Entrevue, S. 89-100.

191 Europäische Fama 316 (1728), S. 320-332.

192 Ebd. 322 (1729), S. 841.

193 Ebd., S. 849.

194 Ebd., S. 856-866. 
Schreiben Georgs II. von England an den Preußenkönig Friedrich Wilhelm, in dem dieser die kaiserliche Position für richtig erklärte. In verklausulierter Weise wurde vermittelt, dass sich der englische König auf einen preußischen Schriftsatz bezog, den die Berliner Regierung offenbar per Druck in Regensburg hatte ausgehen lassen ${ }^{195}$. Die Welfen wollten zusätzlich ihre Exekutionskosten für die Militäraktionen von 1719 sowie den Verwaltungsaufwand der letzten zehn Jahre erstattet bekommen ${ }^{196}$.

In den Jahren 1730 bis 1732 konnte die Europäische Fama nur vom Fortgang des Deduktionenstreits aus Mecklenburg berichten, denn substanzielle Veränderungen hatten sich nicht ereignet. Die Leserschaft erfuhr davon, dass der Herzog trotz bestehender Kommissionsregierung in der Festung Dömitz eine Kleinstherrschaft eingerichtet hatte und dort auf die gewohnte gewalttätige Weise weiterregierte, wobei die umliegende Bevölkerung gezwungen wurde, ihm Lebensmittel und andere Güter des täglichen Bedarfs zu liefern ${ }^{197}$. Das Erscheinen einer preußischen Deduktion, die den eigenen Erbanspruch auf Mecklenburg bekräftigte, wurde vom Redakteur der Zeitschrift mit dem ironischen Kommentar bedacht, sie würde dem Mecklenburger Untertanen die Furcht vor seinen Drangsalen nehmen und ihm die Zuversicht auf eine bessere, preußische Regierung geben ${ }^{198} .1731$ fügte die Europäische Fama hinzu, dass Herzog Karl Leopold eine jährliche Apanage in Höhe von 40.000 Reichstalern aus dem Mecklenburger Steueraufkommen erhalte. Die Kosten für die Exekution seien auf dem Verhandlungswege auf eine Million Reichstaler festgesetzt worden. Die Landschaft müsse diese Summe binnen zehn Jahren abtragen ${ }^{199}$.

1734 informiert die Europäische Fama ihre Leser, dass der Herzog sich trotz fortgesetzter Widersetzlichkeit gegen die kaiserlichen Anordnungen die Unterstützung durch die Bevölkerung erhalten habe. Die Geistlichkeit folge dem Herzog und verweigere die öffentliche Vorlesung kaiserlicher Mandate von der Kanzel. In einigen Fällen hätten sogar herzogstreue Beamte öffentlich Mandatsaushänge abgerissen. Der breite Widerwille, den der Herzog sich in der Öffentlichkeit im Reich zugezogen hatte, betraf damit nur den Kaiserhof, die anderen Fürstenhöfe, die Regierungskanzleien, den Reichstag sowie den Mecklenburger Adel ${ }^{200}$.

195 Ebd. 324 (1729), S. 1019-1056.

196 Schreiben beider welfischer Linien an Kaiser Karl VI., Mai 1729: ebd., S. 1045-1049.

197 Ebd. 328 (1730), S. 275-279.

198 Deduktion $»$ Kurtze historische, und aus authenticis Documentis \& Actis fideliter gezogene Information von dem Ursprung und Verfolg des Königl. Preußis. und Marggräfl. Brandenburgischen Eventuel=Successions=Rechts [...]«, o.O. 1730 (ND von 1708). - Kommentar: Europäische Fama 328 (1730), S. 277-279.

199 Ebd. 343 (1731), S. 551f.

200 Ebd. 353 (1734), S. 428-444. 
Im Außenverhältnis nutzte dieser Umstand dem Herzog in keiner Weise. 1734 schrieb Karl Leopold erneut an die Reichsversammlung. Die Europäische Fama kommentierte:

Doch wie man sich zu Regensburg hieran [= an der schriftlichen Eingabe] wenig oder nichts kehrte, so ließ sich auch die Commißion nichts irren, der Herzog mochte immerhin in einem publicirten Patente alle von dem Reichs=Hof=Rath und seinem Herrn Bruder ergangenen Befehle widerlegen, und darinnen erwehntes Aufgebot aus geistlichen, weltlichen und natürlichen Rechten justificiren wollen [...].

Einmal mehr musste ein Kreisaufgebot einmarschieren, um die Ordnung wiederherzustellen und das Mecklenburger Landesaufgebot zu zerstreuen, das der Herzog mobilisiert hatte. Da Preußen an dieser Aktion mit eigenen Soldaten mitgewirkt hatte, war Friedrich Wilhelm I. künftig weiterhin militärisch präsent und damit - aus seiner Sicht: endlich - dritte Pazifikationsmacht neben den beiden welfischen Linien $^{201}$.

Ab 1735 setzte die Neue Europäische Fama die Berichterstattung ihrer Vorgängerin bruchlos fort. Als Herzog Karl Leopold bewaffnete Aktionen gegen einen Landtag ergriff, den sein Bruder als Administrator nach Rostock einberufen hatte, mussten holsteinische und schwarzburgische Truppen im kaiserlichen Auftrag nach Mecklenburg einrücken, um die Ruhe und Ordnung wiederherzustellen und die Ständeversammlung zu sichern ${ }^{202}$. Wenig später berichtete der Europäische Staats=Secretarius über das abenteuerliche Vorhaben Karl Leopolds, er wolle sich sein Schweriner Schloss nicht von den Kommissionstruppen nehmen lassen, eher lasse er den Gebäudekomplex sprengen und fliehe auf dem Wasserweg nach Dömitz. Der Redakteur räsonniert über eine Stimmung der Verzweiflung und des Untergangs beim Herzog ${ }^{203}$. Blieb es hier bei einer folgenlosen Ankündigung, so beging Karl Leopold am 9. September 1735 seine nächste Gewalttat. Im Schweriner Schloss kam es zu einer Auseinandersetzung zwischen dem Herzog und seinem Beamten. Der Oberhofmarschall Balthasar Henning von Wendessen war offenbar Opfer der Intrige eines malkontenten Untergebenen geworden, wobei sich der Herzog den erhobenen Vorwürfen angeschlossen hatte, ohne ihnen auf den Grund zu gehen. Im Verlauf des offenen Konfliktes misshandelten der Herzog selbst und anschließend seine Bediensteten von Wendessen durch Schläge auf Kopf und Körper schwer. Der Herzog soll in die-

201 Ebd., S. 433.

202 Neue Europäische Fama, hier 1735, Bd. 1, H. 8, S. 641-661.

203 »Europäischer Staats-Secretarius, welcher die neuesten Begebenheiten unpartheyisch erzehlet und vernuenftig beurtheilet [...]«, 144 H. in 12 Bd., Leipzig 1734-1748, hier Jg. 1735, H. 12, S. 1048. 
ser Auseinandersetzung bereits den Hirschfänger in der Hand gehabt haben, um von Wendessen zu töten, konnte aber noch davon abgehalten werden. Der gedemütigte Beamte wurde einige Tage in Haft gehalten und musste unter fortdauernder Todesangst eine Unterwerfungserklärung gegenüber seinem Landesherren, den Wunsch auf Wiedereinstellung in den Staatsdienst und seinen Verzicht auf Rache gegen alle Beteiligten unterschreiben. Erst anschließend wurde er freigelassen. Der Verfasser des Berichts meint, dass der Adlige wohl am Reichshofrat gegen die ungeheuerliche Behandlung klagen werde ${ }^{204}$. Von Wendessen reichte tatsächlich Klage am Reichshofrat ein und wurde dort völlig rehabilitiert ${ }^{205}$.

Die kleinen Auseinandersetzungen um Patente und Landtagsberechtigungen setzten sich bis zum Ende Karl Leopolds fort. Als Kaiser Karl VI. 1740 starb, suchten die Mecklenburger Administrationsregierung und die Landstände sogleich um eine Konfirmation für die bisherige Kommission beim kursächsischen Vikariatshofgericht nach: Dies sei zur Wahrung von Sicherheit und Ordnung im Land erforderlich; man kannte Karl Leopold genau ${ }^{206}$. Das sächsische Reichsgericht stellte auch umgehend die erforderliche Beauftragung aus ${ }^{207}$.

1745 zeigte sich, dass die Sicherung durch das Vikariatshofgericht weise gewesen war. Herzog Karl Leopold von Mecklenburg demonstrierte wieder, dass er aus den Erfahrungen seiner fast 30jährigen Ächtung im öffentlichen Ansehen im Reich nichts gelernt hatte. In einer Eingabe an den Reichstag forderte er einmal mehr seine Restitution mit den seit 1716 bekannten Argumenten. Anlass für die Eingabe war die Ablehnung des neugewählten Kaisers Franz I., die Regierungsverhältnisse in Mecklenburg zu revidieren. Der Kaiser hatte die Herrschaft Christian Ludwigs bekräftigt und in Fortsetzung der Politik seiner Amtsvorgänger von Karl Leopold die Submission gefor$\operatorname{dert}^{208}$.

Zwei Jahre später blieb der Neuen Europäischen Fama nur mehr die Aufgabe, einen Nachruf auf den medienträchtigen Selbstherrscher an der Ostsee zu publizieren. Das Ableben des Herzogs am 28. November 1747 wurde auf folgende Weise kommentiert: »Ein Herr, dessen Regierung, wie aus den Geschichten bekannt, voller Unruhe gewesen $\aleph^{209}$. Als die Zeitschrift zwei

204 Ebd., 1735, H. 21, S. 794; vgl. auch Neue Europäische Fama 1 (1735), H. 8, S. 661.

205 Ebd. 2 (1737), H. 23, S. 906.

206 Ebd. 6 (1740), H. 69, S. 69.

207 Ebd., S. 737.

208 Regest des Schreibens von Kaiser Franz I. an Herzog Karl Leopold vom 25. Januar 1745 und die Eingabe des Herzogs an den Reichstag: »Europäischer Staats-Secretarius«, 1747, H. 123, S. 209-215.

209 Neue Europäische Fama 13 (1747), H. 151, S. 617. 
Jahre später noch einmal auf Karl Leopold und den Mecklenburger Ständestreit zu sprechen kam, fasste sie seine Herrschaft mit folgendem Satz zusammen:

Es succedirte [...] 1713 sein Bruder Carl Leopold. Diesem war das Principium beygebracht, da $\beta$ er als ein in seinen Landen souverän regierender Reichs=Fürst, solches willkührlich regieren könnte, und an keine Verträge, Reversalien und Pacten seiner Vorfahren, ob sie gleich von Kaysern confirmiret worden, gebunden wäre ${ }^{210}$.

\subsection{Darstellung in den Reichsrechtssammlungen}

Georg Melchior von Ludolf würdigte den Mecklenburg-Konflikt in seiner periodischen Rechtssammlung Electa Juris Publici ausführlich, brachte das Thema allerdings erst 1718 auf die Tagesordnung ${ }^{211}$. Auslöser waren für ihn nicht die Deduktionen gegen russische Militärübergriffe oder gegen despotische Akte der Zentralverwaltung an Adligen, sondern der kaiserliche Akt der militärischen Exekution gegen Herzog Karl Leopold, wie er durch die Resolution vom Oktober 1717 beschlossen worden war und im Laufe des Jahres 1718 im ganzen Reich bekannt wurde ${ }^{212}$. Nun nannte der Redakteur auch weitere Einzelheiten über Mecklenburg, in sieben der 12 Hefte des Jahres 1718 wurde das Herzogtum an der Ostsee erwähnt. Der Konflikt wurde systematisch entwickelt: Zunächst führte Ludolf die Entstehung des Ständestreits auf die hohen Militärkosten zurück, die der Herzog seinen Untertanen aufbürden wollte. Zusätzlich wurden die Streitkräfte von den Ständen als Bedrohung ihrer Freiheiten betrachtet. Gegenüber Kaiser und Reich argumentierte die Ritterschaft mit der nur begrenzten fiskalischen Leistungsfähigkeit des Landes, das solche Lasten nicht tragen könne. Der Herzog hingegen habe die Abgaben gewaltsam mit Militär eingehoben, dagegen seien zahlreiche Klagen beim Reichshofrat erhoben worden ${ }^{213}$. Als Quelle für die Gegenposition führte Ludolf eine Deduktion der Mecklenburger Regierung vom 17. Dezember 1717 an, in der die Ritterschaft als eine Körperschaft dargestellt wurde, die unter Leitung einiger Wortführer den Landesherrn in übler Weise vor der Öffentlichkeit im Reich diffamiert habe. Zudem weigere

210 Ebd. 14 (1749), H. 178, S. 815.

211 Georg Melchior von Ludolf, Electa Juris Publici. Worinnen Die Vornehmsten Staats-Affairen in Europa/Besonders in Teutsch=Land/aus bewährtesten Actis publicis [...] recensiret werden, 21 Bd., München 1709-1725.

212 Ebd., Bd. 12 (1718), S. 139-141; Abdruck der Resolution vom 17. Oktober 1717: Ebd., S. 141-146.

213 Ebd., Bd. 12 (1718), S. 297-301. 
sich der Adel, Steuern und Gehorsam im verlangten Maße zu leisten ${ }^{214}$. Man kann Ludolf nicht nachsagen, dass das politische Selbstverständnis Karl Leopolds bei ihm unterrepräsentiert gewesen sei. Zwei weitere Deduktionen des Herzogs vom Februar 1718 an den Kaiser und vom März 1718 an die Reichsstände sind ebenfalls in die Electa Juris Publici eingearbeitet worden ${ }^{215}$.

Herzog Karl Leopold hatte schon die Deduktion Höchst-gemüßigte Anzeig direkt an die Reichsstände geschickt, nachdem die Schrift vom kurmainzischen Reichstagsdirektorium mit Hinweis auf die schwebenden Reichsgerichtsverfahren abgelehnt worden war. Bei Ludolf sind allein für den Zeitraum vom 29. November 1717 bis zum 28. April 1718 fünf Zirkularschreiben des Herzogs direkt an die Reichsstände abgedruckt ${ }^{216}$. Auch die mecklenburgischen Stände verschickten, vermutlich aus demselben Grund, ihre Antwort »Gegründete Wiederlegung« an die Reichsstände direkt ${ }^{217}$. Das Verfahren, dass landständische Petenten sich mit Rundschreiben an alle Reichsstände in particulari wandten, war ungewöhnlicher, als wenn regierende Fürsten diesen Weg wählten. Normalerweise verletzte ein solches Vorgehen die Ehre des eigenen Landesherrn, dies in einem viel größeren Maß als bei Eingaben an ein Reichsgericht oder an die Mainzer Reichstagsdictatur, obwohl es dort auch öffentlich geworden wäre.

Die Electa Juris Publici sind nicht streng chronologisch aufgebaut, so finden sich auch in den folgenden Bänden Deduktionen und amtliche Schreiben aus dem Jahre 1718, die hier nicht in allen Einzelheiten wiedergegeben werden können. Ludolf geht nicht auf seine Quellen ein, doch an einer Stelle werden Einblicke ins Verfahren ermöglicht: Im Frühjahr 1718 erhielt der Redakteur ein Schreiben des englischen Königs Georg an Herzog Karl Leopold zugespielt, das auch umgehend im nächsten Heft der Electa erschien. Wenig später erkannte Ludolf, dass dieser Brief nur eine Kurzfassung eines in Wirklichkeit längeren Schreibens war. In der Kurzfassung fehlten näm-

214 Deduktion »Höchst=gemüßigte Anzeige an eine Hoch=löbl. Reichs= Versammlung/von Seiner Hochfürstlichen Durchl. dem regierenden Hertzoge zu Mecklenburg/Schwerin und Gustrow/das [...] ungehorsame Betragen einiger dero Vasallen und Unterthanen [...]«, o.O. 1718; vgl. dazu von Ludolf, Electa Juris Publici, Bd. 12 (1718), S. 327-332.

215 Schreiben Karl Leopolds von Mecklenburg an Kaiser Karl VI., 5. Februar 1718: ebd., Bd. 12 (1718), S. 415-421; Karl Leopold von Mecklenburg an die Reichsstände, 21. März 1718: ebd., S. 421-426. In beiden Schreiben wies der Herzog wortreich alle Vorwürfe gegen seine Landesherrschaft zurück und betonte, er habe nur das gefordert, was jedem Landesherrn im Reich zustehe.

216 Zirkularschreiben vom 29. November 1717, 21. Januar 1718, und 28. April 1718: ebd., Bd. 17 (1719), S. 875-877, 877-880 u. 889-897. Die beiden Zirkularschreiben vom 21. März 1718 und 13. April 1718 finden sich ebd., Bd. 12 (1718), S. 421-426 u. Bd. 13 (1718), S. 260-262.

217 »Gegründete Wiederlegung/Eines sub Rubro Einer Höchst= gemüßigten Anzeige An eine Hochlöbl. Reichs=Versammlung von Fürstl. Mecklenburgis. Seiten publicirten Schreibens [...] , o.O. 1718; Abdruck bei von Ludolf, Electa Juris Publici, Bd. 12 (1718), S. 511-573 u. $646-680$. 
lich die Höflichkeitsfloskeln, die der König seinem hochadligen Briefpartner zuteil werden ließ. Der Text war damit - beinahe im Stil des modernen Journalismus - sprachlich gestrafft und auf seine wesentlichen Kernaussagen reduziert worden. Ob es sich dabei um einen journalistischen Eingriff oder um eine kuriale Verkürzung auf Betreiben der adligen Gegner des Herzogs handelte, lässt sich nicht mehr erkennen. Im Verständnis der Zeit musste der Brief in der Kurzform unhöflich erscheinen ${ }^{218}$.

Auch in einem anderen Fall ging es um die Courtoisie. In der Ausschreibung zum Sternberger Landtag vom 21. Juni 1718 verwandte Herzog Karl Leopold nur in den Schreiben an seine wenigen Parteigänger in der Ritterschaft die Formel »Lieber Getreuer«, vor allem an jene, die den eidlichen Rezess der Lossagung von der Ständeopposition unterzeichnet hatten. Die übrigen Adligen, die nicht unterschrieben hatten, wurden hingegen in forma patenti eingeladen, offenbar durch einen gedruckten Einladungsbrief mit der Klausel »Also haben wir solches dir/gleich andern von unserer Lieben und Getreuen Ritter- und Landschafft [...]« versehen ${ }^{219}$. Daraufhin ließen viele Adlige die Befürchtung verlauten, dass Pressionen gegen die anwesenden Ständemitglieder ausgeübt werden könnten, und sahen sich in ihrem Entschluss zum Fernbleiben bestätigt. Die Ständeopposition protestierte schon vorab gegen den Landtag und seine Beschlüsse, was in den Electa Juris Publici durch mehrere Dokumente belegt wurde.

Im unmittelbaren Vorfeld der Exekution gegen Mecklenburg verfügte der Kaiser noch ein Excitatorium gegen den Herzog und zugunsten der mecklenburgischen Ritterschaft und der Stadt Rostock ${ }^{220}$. In dieser Verfügung erhob der Kaiser folgende Vorwürfe gegen den Herzog:

1. Karl Leopold habe trotz mehrfacher Abmahnungen seine Unterdrückungspolitik gegenüber den Ständen fortgesetzt.

2. Er habe damit fortgefahren, die kaiserlichen Verordnungen »durch vermeintliche und irrige Bewegungs=Ursachen in offenen Druck zu eludiren«. Damit verging er sich in doppelter Weise gegen den Kaiser, zum einen gegen seine Ehre (durch fortgesetzte und offenbare Weigerung) und gegen das Arcanum, weil der Widerspruch auch noch gedruckt veröffentlicht wurde.

218 Brief England-Hannover an Mecklenburg, 6./17. Mai 1718, gekürzte Fassung: von LudolF, Electa Juris Publici, Bd. 13 (1719), S. 262-265; Brief England-Hannover an Mecklenburg, 6./ 17. Mai 1718, komplette Fassung: ebd., S. 458-462.

219 Vorbericht von Ludolfs zu den Dokumenten über den Sternberger Landtag, 21. Juni 1718: ebd., Bd. 15 (1719), S. 869-874.

220 Kaiserliches »Excitatorium« zugunsten der mecklenburgischen Ritterschaft und der Stadt Rostock durch Kurhannover und Braunschweig-Wolfenbüttel vom 7. Januar 1719: Quellenabdruck (ohne Beilagen) ebd., Bd. 18 (1720), S. 970-973. 
3. Er habe das ganze Reich gegen den Kaiser und die reguläre Ausübung der Reichsjustiz aufgehetzt.

4. Er habe Truppen in großer Zahl unterhalten und noch zusätzlich angeworben, ohne dass das Territorium wirklich bedroht gewesen sei.

5. Er habe die Rechtsabhängigkeit Mecklenburgs vom Reich, d.h. die Zuständigkeit der obersten Reichsgerichte, geleugnet, dies stelle einen Angriff auf die Majestät des Kaisers dar. Karl Leopold habe damit den Verfassungskonsens im Reich aufgekündigt mit der Gefahr der Nachahmung durch andere, falls er nicht zur Räson gebracht würde.

In Band 19 der Electa Juris Publici behandelte Ludolf das Einrücken des Exekutionskommandos nach Mecklenburg. Der Redakteur schrieb ganz offen, dass Karl Leopold seinen Adel weiterhin gewaltsam behandele, $\gg$ ja noch ärger als vorhin ${ }^{221}$. Beim Autor wuchs der Mut mit dem Eindruck, dass der Herzog wohl für längere Zeit suspendiert werden würde und daher aus Mecklenburg keine Schritte gegen die freien Worte zu befürchten waren. Es folgten einige Dokumente zu militärischen Einzelheiten. Da die Electa Juris Publici im Laufe des Jahres 1721 ihr Erscheinen einstellten, konnte der weitere Verlauf des Mecklenburg-Konflikts nicht mehr dokumentiert werden.

Johann Jacob Moser konnte den Mecklenburg-Konflikt in seinem vielbändigen juristischen Sammelwerk Reichs=Fama nur noch aus der Rückschau behandeln, da seine editorische Tätigkeit erst 1727 begann $^{222}$. Moser baute das Werk als juristisches Periodikum auf, zunächst als Monatshefte gestaltet. Die Bände drei und vier erschienen als Jahresbände, ab Band fünf wurden Halbjahresbände herausgegeben, später konnten manchmal drei oder mehr Bände pro Jahr erscheinen. Eine generelle Interpretation der Quellen, die das Schwergewicht der Edition ausmachten, war nicht beabsichtigt, allerdings fügte Moser einigen Quellen Erläuterungen bei, die in der Regel am Ende einer Quelle stehen.

Die Mecklenburg-Frage stellte sich in diesem Periodikum erstmals, als der englische König Georg I. 1727 starb und Herzog Karl Leopold versuchte, diesen Umstand zum Abschütteln der kaiserlichen Kommission zu nutzen. Moser publizierte zwei Briefe Karl Leopolds an König Georg II. und an den Herzog von Braunschweig-Wolfenbüttel und ließ die Antworten aus London und Wolfenbüttel folgen ${ }^{223}$. In einem weiteren Brief an den Herzog von

\footnotetext{
221 Ebd., Bd. 19 (1721), S. 160.

222 [MosER], Reichs=Fama, Welche das Merckwürdigste von demjenigen, so sich gantz kürtzlich auf dem Reichs-Convent [...] zugetragen [...].

223 Karl Leopold an König Georg II. von England, 3. September 1727: ebd., Bd. 3, S. 91-101. Karl Leopold an den Herzog von Braunschweig-Wolfenbüttel, 3. Oktober 1727: ebd., S. 101-103. König Georg II. an Karl Leopold, 10. Oktober 1727 (st.n.): ebd., S. 103; Herzog von Braunschweig-Wolfenbüttel an Karl Leopold, 13. November 1727: ebd., S. 104.
} 
Braunschweig-Wolfenbüttel, den Moser undatiert abdruckte, bemängelte Karl Leopold, der Wolfenbütteler Herzog sei auf seine berechtigten Ansprüche im vorigen Brief nicht eingegangen, sondern habe sein eigenes »landfriedensbrüchiges Betragen«, d.h. die Teilnahme an der Exekution, mit dem kaiserlichen Auftrag bemäntelt. Der Herzog von Braunschweig-Wolfenbüttel klagte gegen diesen Vorwurf anschließend vor dem Reichshofrat wegen Beleidigung ${ }^{224}$. Auch wenn Moser eine ausdrückliche Parteinahme vermeidet, so sprachen die Quellen für sich: Schon aus dem beleidigenden Charakter vieler Formulierungen in Karl Leopolds Schreiben konnte der Leser der Publikation auf die Art und Weise des Konflikts und die geringen Chancen des Mecklenburgers schließen. Anschließend druckte Moser die kaiserliche Resolution vom 11. Mai 1728, durch die Herzog Karl Leopold seiner Herrschaft provisorisch enthoben wurde und sein Bruder Christian Ludwig zum kaiserlichen Kommissar bestellt wurde, in Gänze $\mathrm{ab}^{225}$. Moser nutzte die Gelegenheit, im Anhang an dieses Schlüsseldokument eine 25 Seiten starke Zusammenfassung des Konflikts im Ostseeterritorium folgen zu lassen, die von der Kriegslage, der Bedrückung Rostocks über die kaiserlichen Resolutionen bis hin zur Exekution von 1719 reichte $^{226}$.

Die Fortsetzung des Konflikts nach 1719 und die Probleme mit den verschiedenen Kommissionsregierungen schilderte Moser im vierten Band seiner Reichs $=F a m a^{227}$. Im fünften Band ging der Staatsrechtler auch auf die Gewalttätigkeiten des Herzogs gegenüber seiner unmittelbaren Umgebung ein. So erfuhr der Leser, dass nicht nur die früheren Regierungsmitglieder von Wolffradt und Scharff sowie der Oberhofmarschall von Wendessen Opfer des Landesherrn wurden, sondern auch der Dömitzer Bürgermeister Brasch, der an der unmenschlichen Behandlung in der Haft starb. Seine Frau wurde vom Herzog mit öffentlichem Staupenschlag und Landesverweisung bestraft $^{228}$. Im sechsten Band bewertete Moser die chaotischen politischen Zustände und Entwicklungen in Mecklenburg mit folgenden Worten:

In dem Mecklenburgischen bliebe es in der bisherigen Confusion, indeme der kayserl. Administrator, Herr Hertzog Christian Ludwig, diese eine Administration nicht zu Stande bringen, ja nicht einmal seine seit etlichen Jahren rückständige Appenage, weniger das ihme qua Administratori ausgeworffene Appointement aus dasiger Executions $=$ Casse bekommen konnte, die Commission= Subdelegation und Exe-

224 Herzog Karl Leopold an den Herzog von Braunschweig-Wolfenbüttel, o.D.: ebd., Bd. 3, S. 107f. samt Kommentar von Moser.

225 Ebd., Bd. 3, S. 131-150.

226 Ebd., S. 150-175.

227 Ebd., Bd. 4, S. 498-529.

228 Ebd., Bd. 5, S. 540. 
cutions-Trouppen aber noch immer im Lande blieben, und dahero offt niemand wuste, ob er des Hertzogs, oder des Administratoris oder der Commission Befehlen gehorchen sollte 229 .

Damit traf er den Kern der Probleme vollkommener, als die meisten Zeitungs- und Zeitschriftenschreiber.

\subsection{Darstellung in den Historienschriften}

Die wichtigste Historienschrift zum Dreißigjährigen Krieg und zum Barockzeitalter, das Theatrum Europaeum, erfasste die Vorgeschichte und die Zuspitzung des Konflikts in Mecklenburg bis 1718. Da das Periodikum anschließend aufgegeben wurde, fehlt eine Behandlung der Folgezeit. Früher als in anderen Periodika wies das Theatrum auf schwere Herrschaftsprobleme im Territorium hin: Bereits für 1714 ist von Unfrieden zwischen dem Herzog und seinen Ständen die Rede, wobei die chronologische Tiefendimension einstweilen im Ungewissen blieb ${ }^{230}$. Ein wichtiger Punkt, so das Historienwerk, waren die Landesschulden, die der Herzog unter dem Begriff "Vorschuss« den Ständen auf dem Kontributionswege zur Tilgung auferlegen wollte. Da der Herzog Milizionäre in den adligen Dorfschaften einquartiert hatte, um die Steuerleistung zu beschleunigen, wurde er durch ein Conclusum des Reichshofrats abgemahnt, zu herkömmlichen Praktiken der Steuereinziehung zurückzukehren ${ }^{231}$.

Anders als bei den meisten aktualitätsbezogenen Periodika nahm sich das Theatrum Europaeum auch des Konflikts zwischen dem Herzog und der Stadt Rostock an. Im Steuerstreit mit der Stadt hatte Karl Leopold zunächst die Akzise unter seine eigene Administration genommen. Die Hansestadt empfand dies als Abbau der städtischen Selbstverwaltungsrechte, zumal die neue Akzise-Verwaltung auch Verfahren gegen frühere (vermeintliche) Unregelmäßigkeiten bei der Steuer und damit im Finanzwesen der Stadt generell eingeleitet hatte. Rostock erwirkte ein Reichshofrats-Mandat zu seinen Gunsten. Im Anschluss an die Schilderung des Rostocker Akzise-Streits von 1714 gibt Redakteur Schneider bereits einen Ausblick auf den Fortgang des Konflikts:

\footnotetext{
229 Ebd., Bd. 6, S. 446.

230 Daniel Schneider (Hg.), Theatri Europaei Zwantzigster Theil. Oder/Ausführlich fortgeführte Friedens $=$ und Kriegs=Beschreibung. Und was mehr Von denck= und merckwürdigsten Geschichten in Europa [...] vom 1713. biß zu Ausgang des 1715ten Jahres vorgegangen und sich begeben haben. [...], Frankfurt a.M. 1734, 3 Teilbd. für die Jahre 1713 bis 1715.

231 Ebd., Bd. 20, Teilbd. 2, S. 185-187.
} 
[...] was es aber gewürcket [es=das Mandatum sine clausula des Reichshofrats an den Herzog], wird die Folge zeigen, und auf unserm Theatro zu sehen seyn, dass und wie der Lärmen dieser Orten immer ärger und grösser geworden, und die Sache, so zu sagen, hernach gar in das Gantze gerissen sey ${ }^{232}$.

Im folgenden Jahr ließ der Herzog zunächst die Bürgermeister von Rostock in Arrest nehmen, dann den gesamten Stadtrat in einem Raum des Rathauses sechs Tage lang internieren und durch starkes Heizen quälen, wodurch einige Mitglieder ohnmächtig wurden. Jedes gefangene Ratsmitglied wurde zu 100 Pfd. lötigen Goldes Geldbuße verurteilt - Redakteur Schneider rechnete das um in jeweils 9.600 mecklenburgische Reichstaler -, eine Summe, die den gesamten Vermögenswert selbst der Magistratsmitglieder überstieg. Da die Verurteilten nicht bezahlen konnten und wollten, begann die Justiz mit der Versiegelung ihrer Güter. Vier bis fünf Milizionäre wurden pro Haus eingelegt, und es kam zu den entsprechenden Exzessen gegen die Familienmitglieder $^{233}$. Die Ritterschaft und die Freunde der Inhaftierten konnten am 9. März 1715 ein Reichshofratsmandat sine clausula zur Freilassung erwirken ${ }^{234}$. Der Herzog reagierte allerdings erst, als das Reichshofratsmandat Anfang August 1715 veröffentlicht wurde, was ihm eine schwere Ansehenseinbuße eintrug. Am 21. August 1715 schloss er einen Vergleich mit den Inhaftierten und ließ sie anschließend frei ${ }^{235}$.

Im 21. Band des Theatrum Europaeum wurde in den Teilen für die Jahre 1716 bis 1718 immer wieder auf den Mecklenburg-Konflikt eingegangen. Der Zusammenhang zwischen der russischen Militärpräsenz und den gewaltsamen Aktionen des Herzogs wurde immer mehr offenbar. Einige Adlige aus der Opposition wurden von den Russen gefangengenommen und - vorgeblich durch Fürsprache des Herzogs - auf Arrest freigelassen. Die Bedingungen waren so, dass der Herzog sie jederzeit wieder inhaftieren oder - bei Landesflucht - ihre Güter konfiszieren konnte. Die Betreffenden mussten im Oktober 1716 einen diesbezüglichen Revers unterschreiben ${ }^{236}$. Der Redakteur des Bandes brachte in der Anmoderation einer adligen Bittschrift an den Herzog folgende unterstützende Worte zu Papier:

232 Ebd., S. 185-187.

233 Ebd., Bd. 20, Teilbd. 3, S. 135-143.

234 Ebd., S. 153.

235 Ebd., S. 167-173.

236 [Anonym], Jubilaeum Theatri Europaei das ist, Der die Geschichts=Erzehlung von Einhundert Jahren beschließende Ein und zwantzigste Theil Desselbigen [...] Friedens $=$ und Kriegs=Beschreibung [...], Frankfurt a.M. 1738, 3 Teilbd. für die Jahre 1716 bis 1718, hier Teilbd. 1, S. 236. 
Die Ritterschafft vermeynte noch immer, es würde das Hertze ihres Landes=Herrn / des Hertzogs von Mecklenburg-Schwerin/durch de- und wehmüthiges Bitt=Memorial noch zu erweichen seyn/und brachte nachstehendes zu Papier: [... $]^{237}$.

Im dritten Teil zum Jahr 1718 füllte der Konflikt zwischen Herzog und Adel nicht weniger als 54 Seiten. Die Berichtstendenz des Historienwerkes blieb dabei ständefreundlich: »Die angesonnenen Portiones [= Maßeinheiten für Naturallieferungen an die Streitkräfte - J.A.] wurden nach wie vor mit greulicher Härte eingetrieben, darvon alle betrübte und beweißlich erscheinigte Exempel anzuführen, allzulang fallen würde $\ll^{238}$. Der Herzog hingegen wurde als jemand beschrieben, der nur nach außen hin positiv wirken wollte, substanziell aber keine Änderung seines Verhaltens beabsichtigte: »Der Hertzog wollte doch den Schein haben, daß ihm nicht lieb sey, wenn ein= oder der andere zur Ungebühr beschweret würde/ und versprach Erleichterung zu schaffen « ${ }^{239}$. Da das Theatrum Europaeum nicht über 1718 hinaus geführt wurde, konnte auch der dramatische Höhepunkt der Herrschaftsentsetzung Karl Leopolds nicht mehr abgebildet werden.

Dafür kam die mecklenburgische Exekution als eines der europäischen Hauptereignisse in Johann David Köhlers schon erwähnten Gedenckwürdigkeiten vor $^{240}$. Im Bilderreigen zum Jahr 1719 wird die Einnahme Mecklenburgs durch die Niedersächsische Kreisexekution gezeigt. Unter dem Gedenkvers »Das Recht soll an das Licht« erwähnt Köhler auf zwei Seiten die gewalttätigen Übergriffe des Herzogs Karl Leopold von MecklenburgSchwerin gegen seine Landstände. Zunächst habe er Kriegskontributionen im Rahmen des Nordischen Krieges erhoben, meistens unbewilligt. Dann hätten die Stände am Reichshofrat geklagt. Mehrere Vermittlungsversuche des Kaisers seien gescheitert. Der Herzog habe eine russische Armee ins Land gelassen, um die Stände zu unterdrücken. Die meisten Adligen seien daraufhin geflüchtet. Der Herzog sei von der Herrschaft suspendiert worden, und eine kaiserliche Kommission habe die Regierungsgeschäfte übernommen ${ }^{241}$.

Die wichtigste Mecklenburgische Landesgeschichte des frühen 18. Jahrhunderts wurde unter dem Pseudonym »Hans Henrich Klüver« durch Christoph Georg Jargow in sechs Bänden herausgegeben ${ }^{242}$. Jargow war in Ros-

237 Theatrum Europaeum, Bd. 21, Teilbd. 2, S. 219.

238 Ebd., Bd. 21, Teilbd. 3, S. 140-194, Zitat S. 140.

239 Ebd., S. 141.

240 Johann David KöHLER, Gedenckwürdigkeiten des jetzt lauffenden achtzehenden Jahr-Hunderts nach Christ Geburt: als eine Fortsetzung der Welt in einer Nuß in Gedächtnis-hülflichen Bilder-Tafeln. Mit einer historischen Einleitung, 20 Bilder, Nürnberg 1701-1739.

241 Ebd., S. 250-254.

242 Hans Henrich KLÜVER [= Christoph-Georg JARGOW], Beschreibung des Herzogtums Mecklenburg, 6 Bd., Hamburg 1728-1740. 
tock und Helmstedt als Jurist ausgebildet worden, amtierte kurz als Senator in Heiligenhofen, um dann die Stelle eines Hofrats im Dienst des Herzogs von Mecklenburg-Strelitz zu bekleiden ${ }^{243}$. Das Mecklenburger Geschichtswerk erschien sukzessive und begann 1728 mit einer zweibändigen Landesbeschreibung Mecklenburgs. Der dritte Band, in zwei Teilbände getrennt, behandelte die Geschichte Mecklenburgs vom Obotritenkönig Anthyrius bis 1713. Konzeptionell erwies sich dieses Vorgehen als sehr geschickt, konnte sich doch der Verfasser zunächst einen Namen machen, ehe er die kritische Phase der mecklenburgischen Geschichte in Angriff nahm. Dass die Rechnung aufging, zeigte sich daran, dass die ersten Bände bereits 1737 in Neuauflage erschienen.

1739 kam der vierte Band heraus, der die absolutistische Regierungszeit Karl Leopolds bis 1719 beinhaltete. Hier handelte Jargow die Eheabwicklung Karl Leopolds mit Herzogin Sophia Hedwig ab, um anschließend den Ständekonflikt mit der Ritterschaft und der Stadt Rostock zu analysieren. Widerstand oder Widerspruch hat es gegen das Publikationsvorhaben offenbar nicht gegeben. Das Hamburger Verlagshaus Thomas von Wiering Erben, das auch in der Herausgabe von Periodika erfahren war, brachte noch den fünften und sechsten Band der Mecklenburger Geschichte heraus, die die Zeit der kaiserlichen Administrationsregierung behandelten, ohne dass dieses Publikationsprojekt gestoppt worden wäre. 1740 konnte Jargow im Vorwort zum 5. Band sein Verständnis von der Reichweite der »Reichsöffentlichkeit« formulieren:

Wir erkennen aber auch daraus [= aus dem Schicksal des Herzogs - J.A.], daß ein Reichs=Stand nicht nach eigener Willkühr seines Landes Regierungs=Verfassung verändern und die Gerechtsahme seiner Stände ausser Acht lassen könne, mithin Ihro Kayserliche Majestät gnugsahme Befugnisse und Macht habe, die Regierungs=Form in eines Reichs=Fürsten Landen auf den Reichs= und Landes Grundgesetzmäßigen Fuß herzustellen und die Mediat=Unterthanen bey ihren Gerechtsahmen zu schützen $^{244}$.

Im Folgenden arbeitete Jargow heraus, dass im Fall Mecklenburgs nicht nur das Reichsrecht über die autonomen fürstlichen Befugnisse eines Reichsstands gestellt worden war, sondern das ganze Reich diesem Schritt durch tacito Consensu beigepflichtet hatte.

Der Aspekt der Öffentlichkeit kam auch in einzelnen Passagen der Darstellung zum Tragen. Durch das Convocations-Mandat vom 13. August 1717 rief Karl Leopold alle Mitglieder des Ständeausschusses in der Form »öffent-

243 DBA, Fiche 601, S. 301-304.

244 KLÜVER/JARGOw, Beschreibung des Herzogtums Mecklenburg, Bd. 5, Vorwort S. III. 
licher Anschläge« zur Sitzung zusammen, damit sich niemand durch Unwissenheit entschuldigen konnte, insbesondere nicht diejenigen, die schon ins $»$ Ausland « nach Ratzeburg geflohen waren ${ }^{245}$. Die Ausschussmitglieder blieben bekanntlich aus, um den bestehenden und den erwarteten Pressionen zu entgehen. Bei Jargow wird ihr langes »Entschuldigungs-Memorial« vom 27. August 1717 abgedruckt $^{246}$. Als der Herzog dies realisierte, warf er den Ausschuss-Mitgliedern vor, sich auf rechtswidrige Weise außer Landes begeben zu haben und durch »verschiedene überalle im Lande currende Weise herumgesandte seditiöse Schrifften« den gemeinen Mann zum Aufstand anstacheln zu wollen. Dadurch sei ein gerechtes Herrschaftsverfahren gegen Querulanten in »ein verhasstes Ansehen« versetzt worden. Der abwesende Adel verhindere durch seine Traktate einen Ausgleich der Landesregierung mit den Städten. Zudem seien die Untertanen zum Ungehorsam aufgerufen und eine »vorsetzlich misbrauchte Appellation « an den Kaiser betrieben wor$\operatorname{den}^{247}$. Zu einer systematischen Betrachtung des Aspektes von Öffentlichkeit drang Jargow allerdings nicht durch, es fehlte ihm noch jede Theorie über die Rolle von Öffentlichkeit und öffentlicher Meinung für die Legitimität von Herrschaft im Barockzeitalter.

\subsection{Zusammenfassung}

Der Mecklenburg-Konflikt wurde erst relativ spät auf die Bühne der Medienberichterstattung gehoben. In der Wahrnehmung der Redakteure von Zeitungen und Zeitschriften war er zunächst verdeckt durch den Nordischen Krieg: Frühe Gewalttaten konnten der enthemmten Soldateska zugerechnet werden, nicht vorsätzlichen herrscherlichen Maßnahmen. So entwickelte sich eine reguläre Publizistik, die den Schwerpunkt auf das gewaltsame Verhältnis zwischen Herzog Karl Leopold und seinem Adel legte, erst im Jahr 1716. Das kaiserliche Dehortatorium vom Oktober 1716 schaffte allen Publizisten eine Grundlage für ihre Berichterstattung. Der Konflikt um die Abwicklung der ersten Ehe des Herzogs bildete nur den Prolog, die Bigamie-Diskussion wurde nicht als lancierte Aktion erkannt. Vielmehr wurde der Mecklenburger Landesherr schnell als Gewalttäter charakterisiert, vielfach kennzeichnete man die Illegalität seiner Handlungen als »reichs=kündig«. Der Mecklenburger Adel verfolgte eine Doppelstrategie: Auf der Rechtsebene verklagten die Ritter ihren regierenden Autokrator vor dem Reichshofrat in mehr als 100 Verfahren, auf der Medienebene wurden zahlreiche Deduktio-

245 Ebd., Bd. 4, S. 518-520.

246 Ebd., S. 520-528.

247 Deklaration Karl Leopolds, 3. September 1717: ebd., S. 535-540. 
nen produziert, die nur zum Teil an konkrete Herrschaftspersonen oder Institutionen gerichtet waren, zum anderen Teil aber den Zweck hatten, gedruckt $\mathrm{zu}$ werden. Quellensammlungen, natürlich auch vom Adel in Auftrag gegeben, rundeten diese Auseinandersetzung ab. Der Medienkrieg war die asymmetrische Kriegführung im 18. Jahrhundert: Auf der Grundlage vieler tatsächlichen und mancher zugeschriebenen Rechtsbrüche konnte der Herzog zum großen Ungeheuer aufgebaut werden, der einen wehrlosen Adel entrechtete und außer Landes trieb.

Herzog Karl Leopold versuchte, auf der Medienebene dagegenzuhalten. Dabei entfaltete er sein Politikverständnis eines princeps legibus solutus, das er wohl eher bei seinem Vorbild Karl XII. von Schweden abgeschaut als wirklich bei Jean Bodin gelesen hatte. Dass seine Anschauungen und Absichten reichsrechtswidrig waren, erschloss sich ihm zu keinem Zeitpunkt, weder vor noch nach der Exekution und Herrschaftsentsetzung. Karl Leopolds Schriften weisen damit eine ununterbrochene Kette der illusorischen Ansprüche auf, die sich bis zu seinem Tod 1747 durchziehen lässt. Naheliegenderweise trauten ihm Kaiser, Reichsstände und seine eigenen Landsassen zu, dass er im Falle einer Wiedereinsetzung in die Landeshoheit bruchlos mit der gewalttätigen Politik fortfahren würde. Erschwert wurde seine Selbstdarstellung durch die mehrfache Infragestellung der kaiserlichen Gerichtshoheit, was wütende Reaktionen von Kaiser Karl VI. auslöste, der sich sowohl in seinem Amt als auch in seiner persönlichen Ehre angegriffen fühlte. Auch gegenüber anderen Korrespondenten vergriff der Herzog sich im Ton, sodass zusätzliche Klagen vor dem Reichshofrat wegen Beleidigung eingereicht wurden. Konsequenterweise verkleinerten auch die Gegner des Herzogs dessen Kurialien in einigen ihrer Deduktionen und Berichte.

Die Zeitungen griffen den Mecklenburger Ständekonflikt ab dem Jahr 1717 auf, nachdem sie eine hinreichende »Aktivierungsenergie« in Gestalt von Deduktionen erhalten hatten. Die drohende Exekution warf ihre Schatten in den Gazetten voraus, die stets mit dem Beginn der Feindseligkeiten rechneten und selbst marginale Militärbewegungen brachten, um das Thema präsent zu halten. Der Einmarsch und weitere Gewalttaten waren natürliche Zeitungsinhalte. Nachdem der Herzog als Missetäter einmal medial aufgebaut worden war, konnte immer wieder auf ihn zurückgriffen werden, was auch in den folgenden Jahrzehnten geschah, wenn auch mit abnehmender Tendenz.

Die Zeitschriften nahmen den Mecklenburger Herzog bereits 1716 im Rahmen seines Scheidungsstreits und der lancierten Bigamie-Deduktion wahr. Auch räumten die Redakteure an verschiedenen Stellen ein, auf Deduktionen zurückzugreifen, wenn sie nicht Traktate oder Teile derselben direkt einrückten. Der Verfall des öffentlichen Ansehens Karl Leopolds wurde in den Zeitschriften offen thematisiert. Ohne Scheu schrieben die Herausge- 
ber davon, wie des Herzogs Schriftsätze nicht einmal mehr am Reichstag angenommen wurden und in particulari an die Reichsstände versandt werden mussten, während seine Gegner sich weiterhin der kurmainzischen Dictatur in Regensburg als Verbreitungsstelle ihrer Ansichten bedienen durften.

In den Historienschriften und Reichsrechtspublikationen wurde Karl Leopold aus größerer Distanz, dafür aber mit konsequenterer Bewertung behandelt. Der weitere Blick schloss auch die Unterdrückung der Stadt Rostock mit ein, die in den Jahren 1714 und 1715 am Beginn der Gewaltherrschaft des mecklenburgischen Autokrators gestanden hatte. Der Doppelkonflikt zwischen Herzog und Landständen einerseits, zwischen Herzog und Kaiser andererseits wurde im Theatrum Europaeum ebenso wie in von Jargows mecklenburgischer Geschichte sorgfältig herausgearbeitet. Dabei wurden Beispiele für Ehrverletzungen durch den Herzog und seine Erfüllungsgehilfen genannt, aber auch der reichsrechtliche Anspruch des Kaisers auf Gehorsam und ehrerbietigen Umgang bekräftigt, zur Mahnung an alle anderen Reichsstände, die vergleichbare Absichten verfolgen mochten.

Ein wichtiges Element für den Erfolg der Presse lag darin, dass interessierte Parteien dort Informationen lancieren konnten, die den eigenen Gegnern schadeten. Das Verbot eines Presseorgans oder einer einzelnen Ausgabe war viel weniger wichtig als die gezielte Desinformation oder manipulierte Mitteilung. Gerade der Mecklenburg-Konflikt ist ein charakteristisches Beispiel für den Einsatz der Presse als Kampfmittel gegen Herrschaftskonkurrenten. In der dreiteiligen vertikalen Herrschaftskonkurrenz ist ein abgestufter Medieneinsatz erkennbar: Die unterste Ebene, die mecklenburgischen Landstände, setzten die medialen Vermittlungsmöglichkeiten ihrer Anliegen am effektivsten ein. Darüber hinaus mehren sich die Indizien dafür, dass die Stände auch gezielte Indiskretionen (Publikation des Schriftverkehrs Dritter) oder Desinformation (Lancierung fingierter Druckschriften, z.B. über die Scheidungsmodalitäten des Herzogs) anwandten, um den bereits rufgeschädigten Herzog weiter zu diskreditieren. Der Punkt, an dem die Öffentlichkeit im Reich (beinahe) alles zu glauben bereit war, was den Herzog schlecht dastehen ließ, war bereits vor Beginn der Exekution im Februar 1719 überschritten.

Die mittlere Position nahm Herzog Karl Leopold ein. Der Herzog beklagte sich über die Skrupellosigkeit seiner Untertanen in Schrift und Tat. Dies tat er mit großer Ausdauer: Wenn man seiner Öffentlichkeitsarbeit überhaupt etwas Positives zuschreiben möchte, dann seine unglaubliche Ausdauer, mit der Kampagne immer weiter fortzufahren, selbst als Erfolg kaum noch zu erwarten war. Ein wichtiger Grund für das Scheitern lag darin, dass die Medienstrategie des Herzogs äußerst eindimensional und phantasielos war. Karl Leopold betonte - im Grunde bereits seit 1713 - sein Herrscherrecht als Landesherr, wobei sein Verständnis von diesem Recht weit über alles 
hinausging, was das Reichsrecht einem Fürsten zugestand. Auf die naheliegende Idee, die Stände nicht in erster Linie als ungehorsame Untertanen, sondern als gemeinwohlfeindliche Ausplünderer des Landes zu brandmarken und auf diese Weise sich selbst als wirklichen Verfechter eines "guten Regiments « zu positionieren, kam er nicht. Die medienpolitische Hegemonie der Ritterschaft konnte er nicht brechen: Öffentliche Verbrennungen von ritterschaftlichen Druckschriften, wie am 25. Juni 1718 geschehen, können als symbolische Politik und das Eingeständnis argumentativer Armut gewertet werden ${ }^{248}$.

Trotzdem blieben ihm Pfarrerschaft, Bürgertum der Kleinstädte und Bauern treu ergeben - über Jahrzehnte hinweg bis zu seinem Tod, und der Herzog wusste diesen Umstand nicht propagandistisch zu nutzen. Vermutlich hätte er dazu eine Vorstellung von der Bedeutung öffentlicher Meinung und ihrer sozialen Reichweite haben müssen, die er nicht besaß. Die Untertanen spielten für ihn, wie für viele Fürsten seiner Zeit, in der Öffentlichkeitsarbeit eine untergeordnete Rolle: Seinem Selbstverständnis nach hatte er sich niemandem gegenüber zu rechtfertigen, den Untertanen am allerwenigsten. Wenn die Untertanen Ziel von Schreiben Karl Leopolds waren, dann galt dies für Edikte und Mandate, die in gewohnter Weise von den Kanzeln verlesen und daneben in großer Zahl per Plakatdruck produziert und angeschlagen wurden. Nach der Besetzung des Landes durch welfische Truppen ließ der Herzog heimlich im Schweriner Schloss drucken, so z.B. die 3.000 Exemplare für das Aufstandspatent vom Herbst $1732^{249}$.

Der Herzog von Mecklenburg richtete seine Ansprüche stets an den Kaiser, daneben an die Reichsstände (durch zahllose Eingaben am Reichstag und sogar Zirkularschreiben an die einzelnen reichsständischen Regierungen). Selbst in der Spätphase seiner Regierung, nach den gescheiterten Landesaufgeboten der 1730er Jahre, fuhr Karl Leopold mit Schreiben an die Reichsstände fort: Peter Wick nennt Schreiben von 1736, 1738, 1745, 1746 und $1747^{250}$. Propagandistisch blieb Karl Leopold auf diese Weise stets in der Defensive ${ }^{251}$.

248 Wick, Versuche zur Errichtung des Absolutismus in Mecklenburg, S. 122.

249 Ebd., S. 206.

250 Ebd., S. 255.

251 In dieser Haltung erinnerte er merkwürdigerweise an die spanische Monarchie im 16. Jahrhundert, die im niederländische Aufstand ebenfalls keine wirkungsvolle Medienstrategie entwickelte, weil sie offenbar annahm, auf die politische Meinung breiterer nichtadliger Kreise komme es ohnehin nicht an. Der antispanischen Propaganda, der "schwarzen Legende" (»leyenda negra «) stand die spanische Regierung hilflos gegenüber: Judith Pollmann, Eine natürliche Feindschaft. Ursprung und Funktion der schwarzen Legende über Spanien in den Niederlanden, 1560-1581, in: Franz Bosbach (Hg.), Feindbilder. Die Darstellung der Gegner in der politischen Publizistik des Mittelalters und der Neuzeit, Köln/Weimar/Wien 1992, S. 73-93. Zur weiteren antispanischen Publizistik vor allem im Reich: Peer SснміDт, Spani- 
Da seine Gewalttaten allerdings notorisch waren und lautes Klagen den Grundtenor aller seiner Publikationen darstellte, fand er schon vor der Exekution nirgendwo mehr wirkliches Gehör. Kurbrandenburg war darin keine Ausnahme, denn König Friedrich Wilhelm I. hatte dem Mecklenburger schon im Januar 1719 deutlich gemacht, dass nur eine Umkehr vor Beginn der Besetzung seiner Lande ihm weitere Chancen offenhielt ${ }^{252}$. Spätere freundliche Worte von Friedrich Wilhelm an den Herzog von Dömitz sind vor allem aus der Perspektive der Konkurrenz zwischen Brandenburg und England-Hannover sowie mit dem Habsburger Haus hinsichtlich des Einflusses in Nordostdeutschland zu verstehen, nicht als generelle politische Übereinstimmung zwischen Berlin und Schwerin/Dömitz.

Die oberste Position hatte der Kaiser inne. Seine Administration und er nahmen den Mecklenburg-Konflikt als ein reichsrechtliches Problem wahr, nicht als ein mediales. In Wien kontrollierte man die heimische Presse wirkungsvoll, und in dem großen Zentralkomplex waren andere Zeitungen nur unter erheblichen Kosten zu beschaffen, so dass ausländische Berichte vorzugsweise auf Adel, Bildungs- und Besitzbürgertum beschränkt blieben oder zumindest eine Durchmischung der öffentlichen Informationen länger dauerte als anderswo. Wenn kaiserlicherseits überhaupt eine Öffentlichkeit gezielt angesprochen wurde, dann war es die des Reichstags in Regensburg. Die dortige Meinung war für das Reichsoberhaupt wichtig, die der restlichen sozialen Gruppen im Reich kaum. Die Angelegenheit im Falle Mecklenburg war für den Kaiser unproblematisch, da seine Sicht mit der der mecklenburgischen Stände übereinstimmte und entschiedener Widerspruch zugunsten Karl Leopolds sich in Regensburg nicht zeigte.

sche Universalmonarchie oder »teutsche Libertet«. Das spanische Imperium in der Propaganda des Dreißigjährigen Krieges, Stuttgart 2001.

252 Brief Friedrich Wilhelms I. an Karl Leopold, 16. Januar 1719: »Conservatorii«, S. 13-15. 



\section{Abschließende Betrachtungen}

Der Schwerpunkt der politischen Druckpublizistik lag auf der Außen- und Militärpolitik. Das hing damit zusammen, dass die Ergebnisse leicht messbar waren. Schlachten und Verträge schufen Tatsachen mit sichtbaren Folgen, und konkurrierende Deutungen wurden durch die Realität bald entschieden. An zweiter Stelle standen innenpolitische Informationen. Auch hier lag der Schwerpunkt auf Gewalt (Landfriedensbruch) sowie der überzogenen landesherrlichen oder gerichtsherrlichen Machtausübung (Inhaftierung von Stände- oder Behördenmitgliedern). Konflikte oberhalb einer bestimmten Komplexitätsschwelle waren medial nicht vermittelbar und blieben daher außerhalb der Berichterstattung (z.B. komplizierte Gerichtsverfahren, die nicht in mediale Häppchen zerlegbar waren). An dritter Stelle rangierten Religionsfragen ${ }^{1}$. Wegen der Komplexität und der Unzerlegbarkeit sowie der Vieldeutigkeit der Begriffe fand in diesem Konfliktfeld keine laufende Berichterstattung statt. Es dominierten stattdessen die Deduktionen, außer wenn Gewalt angewendet wurde. Entgegen der früheren Vermutung einer Fortdauer des Herrschaftsarkanums ist beobachtbar, dass erstaunlich viele politische Informationen im Umlauf waren. Durch die schiere Menge wurden die Arkana als Herrschaftsmethoden implizit aufgedeckt und abgeschliffen. Jedes Historienwerk zeigte die Ränke und »Anschläge« der Mächtigen an, zudem auch die aktuellen Traktate, z.B. gegen König Ludwig XIV.

Zum Abschluss sollen die beiden Grundfragen der Arbeit nach der Beschaffenheit der Öffentlichkeit und den Möglichkeiten frühmoderner Herrschaftskontrolle durch diese Öffentlichkeit wieder aufgegriffen werden. »Öffentlichkeit« im Sinn dieser Überlegungen soll nicht moralisch belegt oder modernisierungstheoretisch überfrachtet werden. Öffentlichkeit wird vielmehr, ausgehend von systemtheoretischen Vorarbeiten, funktionalisiert als Summe von Kommunikationen mit dem Ziel, Herrschenden und Beherrschten die Verständigung über politische Prozesse zu ermöglichen. Verständigung ist dabei weniger allgemeine Partizipation im aktiven Sinn, sondern zunächst einfach Anspruch und Einlösung von Information und Informiertwerden. Heute wird dieser Zusammenhang gern »Aushandeln« genannt, ein

1 Dazu liegt inzwischen die Dissertation von Peter Brachwitz vor, die allerdings nicht genuin mediengeschichtlich konzipiert ist, sondern von der Leitdifferenz Sichtbarkeit/Unsichtbarkeit ausgeht: Peter Brachwitz, Die Autorität des Sichtbaren. Religionsgravamina im Reich des 18. Jahrhunderts, Berlin/New York 2011. Für den Kontext der Öffentlichkeit bes. S. 15-59. 
Sammelbegriff, der unterschiedliche Prozesse der asymmetrischen Kommunikation über Machtangelegenheiten und Gemeinwohl zusammenfasst ${ }^{2}$.

Es ist deutlich geworden, dass ein derartiges Öffentlichkeitsverständnis viel älter war als die Aufklärung, dass es einen mächtigen Schub nahm mit der Reformation, sich anschließend viele Jahrzehnte über Flugblätter und Flugschriften samt verwandten Druckwerken artikulierte, um seit dem frühen 17. Jahrhundert in periodische Formen überzugehen. Der »Strukturwandel der Öffentlichkeit« fand somit als laufender Prozess statt, aber nicht mit den Eigenschaften, die Jürgen Habermas ihm zugewiesen hat. Viel wichtiger war zum einen die Medienrevolution im Sinne Wolfgang Behringers, nämlich die sukzessive Verkürzung und Verdichtung von Nachrichtenübermittlungsintervallen. Zum anderen führte die Bereitstellung von gedruckten Informationen dazu, dass nicht nur Adlige, Beamte und Gebildete als Leser darauf zurückgriffen, sondern nach und nach weitere Bevölkerungsschichten hinzukamen. Die Periodisierung dieser Ausdehnung der Rezipientenschaft ist vor allem von Martin Welke mit methodisch begründeten Zahlen charakterisiert worden, doch unter dem Vorbehalt, dass der Prozess noch durch zahlreiche Einzeluntersuchungen untermauert werden sollte. Überraschungen sind zu erwarten.

Am Anfang des Mediensystems der politischen Publizistik stand das Entstehen der Informationen-Öffentlichkeit im Sinne von Esther-Beate Körber ${ }^{3}$. Während eine politische Öffentlichkeit schon vorhanden war, seitdem es Politik gab, jedenfalls für die daran beteiligten Personen, beförderte die Informationen-Öffentlichkeit die Verbreitung dieser Informationen an ein darüber hinausreichendes Publikum, das nicht aus Herrschaftspersonen bestand.

Einmal mehr muss betont werden, dass das Druckwesen und dieser Öffentlichkeitsbereich aus eigendynamischen Prozessen entstanden waren. Dies galt, wie gezeigt, sowohl für den Buchdruck als Ganzes als auch für die Entstehung der ephemeren und später periodischen politischen Informationsmedien. Kirche und Fürstenstaat hatten mit einer Mischung aus Nützlichkeitserwägungen und Skepsis reagiert. Der Nutzen wurde für größer gehalten als der mögliche Schaden; so ließen die Obrigkeiten die Dinge laufen. Die flankierende Zensur sollte unliebsame Folgen verhindern, war aber keineswegs in der Lage, die eigendynamischen Prozesse vorherzusehen oder zu steuern $^{4}$. Es blieb auch für die folgenden Jahrhunderte dabei: Unternehme-

2 Vgl. dazu die Überlegungen bei Wolfgang Reinhard, Zusammenfassung. Staatsbildung durch »Aushandeln«?, in: Ronald G. Asch/Dagmar Freist (Hg.), Staatsbildung als kultureller Prozess. Strukturwandel und Legitimation von Herrschaft in der Frühen Neuzeit, Köln/Wei$\mathrm{mar} /$ Wien 2005, S. 429-438.

3 KöRBER, Öffentlichkeiten der Frühen Neuzeit, S. 297-366.

4 Zu Entwicklung und Bewertung vgl. S. 254-259 in diesem Buch. 
rische Persönlichkeiten innerhalb des Medienbereichs sorgten für Innovationen und Ausdifferenzierungen.

Die Janusköpfigkeit der Medienproduzenten gegenüber den Obrigkeiten wurde konstitutiv: Offiziell bekräftigten Drucker, Verleger und Autoren ihren Respekt vor den kirchlichen und staatlichen Stellen, gleichzeitig wirkten sie im Geheimen dem normativen Rahmen allen Seins und Handelns überall dort entgegen, wo dies lukrativ zu sein schien, selbst über konfessionelle Grenzen hinweg ${ }^{5}$. Zwar waren die ab 1605 erscheinenden Zeitungen im Prinzip leichter kontrollierbar, doch blieben die Spielräume der Herausgeber groß, sich am Kundengeschmack zu orientieren ${ }^{6}$. Die Permanenz der Kriege und Konflikte ${ }^{7}$ im frühneuzeitlichen Europa sorgte für »freien« Informationsstoff. Selbst während des Dreißigjährigen Krieges entstanden immer mehr Zeitungen, und sie erschienen in immer kürzeren Abständen bis hin zur ersten Tageszeitung 1650 in Leipzig ${ }^{8}$. Abhängig war das Zeitungswesen, wie Wolfgang Behringer dargestellt hat, vom sich immer dichter verbindenden Postnetz ${ }^{9}$.

Dieses eigendynamische System der Informationen-Öffentlichkeit gewann größeren Einfluss auf das politische Informationssystem als zunächst von den Obrigkeiten erwartet. Die Macht-Öffentlichkeit im Heiligen Römischen Reich teilte sich in die großen Höfe und Residenzen einerseits und in die Reichsinstitutionen andererseits. In den Territorien gab es neben dem dynastischen Briefwechsel die offizielle Staatskorrespondenz, durch die politische Handlungen und insbesondere Verträge angebahnt oder zum Abschluss gebracht wurden. Diese Verständigung über Regierungsangelegenheiten fand

5 Detailstudien zum Untergrundbuchdruck in Köln: Johannes ARNDT, Der spanisch-niederländische Krieg in der deutschsprachigen Publizistik 1566-1648, in: Horst LADEMACHER/Simon Groenveld (Hg.), Krieg und Kultur. Die Rezeption von Krieg und Frieden in der Niederländischen Republik und im Deutschen Reich 1568-1648, Münster u.a. 1998, S. 401-418; Johannes ARndT, Köln und die Medienproduktion zum spanisch-niederländischen Krieg 1566-1648, in: Dieter Geuenich (Hg.), Köln und die Niederrheinlande in ihren historischen Raumbeziehungen (15.-20. Jahrhundert), Pulheim/Mönchengladbach 2000, S. 339-353.

6 Zur Gründung der Zeitungen: WeBER, »Untherthenige Supplication Johann Caroli/Buchtruckers«, S. 257-265. - Die Zeitungen traten übrigens an die Seite und nicht an die Stelle der Flugschriften; vgl. zu den Prozessen des Hinzutretens neuer Medien zu den alten: GieseCKe, Der Buchdruck in der frühen Neuzeit, pas.

7 Zur Kategorie der »Bellizität« im Kontext des frühmodernen Staatsbildungsprozesses: Johannes Burkhardt, Die Friedlosigkeit der frühen Neuzeit. Grundlegung einer Theorie der Bellizität Europas, in: ZHF 24 (1997), S. 509-574.

8 Zur frühen Zeitungsentwicklung: Johannes WeBER, Der große Krieg und die frühe Zeitung. Gestalt und Entwicklung der deutschen Nachrichtenpresse in der ersten Hälfte des 17. Jahrhunderts, in: Jahrbuch für Kommunikationsgeschichte 1 (1999), S. 23-61. - Zur Tageszeitung: Hauff, Die »Einkommenden Zeitungen« von 1650 (1963), S. 227-235. Vgl. dazu auch den Presseartikel von BöNIng/WeBer, Politik für alle, S. 74.

9 Zum frühmodernen Postwesen und der Rolle der Postzeitung als Verbindungsstück zwischen beiden Systemen: Beust, Der Versuch einer ausführlichen Erklärung des Post-Regals, 3 Bd., pas. Zur modernen Post-Forschung bes. Behringer, Im Zeichen des Merkur, pas. 
in einem »arkanen« und einem öffentlichen Zweig statt. Wie das Arkanum praktisch ausgestaltet wurde und ob es überhaupt durchzuhalten war, darauf ist weniger Augenmerk gelegt worden. In der Praxis ließen sich zwar viele Regierungshandlungen geheim halten, aber bei Weitem nicht alle. Christian Weise schrieb dazu, dass die Geheimnisse der Höfe von den Medienproduzenten zwar zu respektieren seien, dass allerdings die Folgen meist schnell zutage träten, und darüber dürften die Zeitungen dann berichten ${ }^{10}$.

Der öffentliche Bereich der territorialen Herrschaft umfasste alle die Maßnahmen, die einer Beteiligung der Untertanen bedurften, d.h. auch das »Öffentliche« Recht ${ }^{11}$. In der Frühmoderne wurden Öffentliches Recht und Privatrecht noch nicht als Gegensätze wahrgenommen. »Öffentlichkeit« war eher eine Prozessmaxime, der Begriff »Publizist« hatte eine doppelte Bedeutung als Jurist mit Schwerpunkt Ius publicum oder als Mitarbeiter eines Journals ${ }^{12}$. $\mathrm{Zu}$ diesem Bereich sind auch öffentliche Verlautbarungen zu zählen, die die Begründung für einen bewaffneten Konflikt enthielten. Von den »Kriegsmanifesten«, die Konrad Repgen untersucht hat, sind viele als Traktate publiziert worden ${ }^{13}$.

Lange ist angenommen worden, die offiziellen Korrespondenzen hätten ausgereicht, um fürstliche Herrscher und ihre Familien hinlänglich mit Nachrichten zu versorgen. Seit dem 16. Jahrhundert wurden aber darüber hinaus gesonderte Informanten in fremden Städten auf Honorarbasis beschäftigt, die öffentlich zugängliche Informationen zusammenstellten und ihren hochadligen Auftraggebern zuleiteten. Die Gattung ihrer Schriften werden heute Briefzeitungen oder geschriebene Zeitungen genannt. Weder hatten die Autoren irgendeinen offiziellen diplomatischen Status, noch waren sie nur für einen Auftraggeber tätig. In der Regel darf angenommen werden, dass sie ihre standardisierten Texte an jeden Zahlungswilligen schickten ${ }^{14}$. Neben den Höfen waren das vor allem Wirtschaftsinteressenten, z.B. inter-

10 Christian Weise, Schediasma curiosa de lectione Novellarum, Weißenfels 1676; deutsche Ausgabe: Christian WeISE, Curieuse Gedancken von den Nouvellen oder Zeitungen [...] vermehret von Christian JunCKer, Leipzig/Coburg 1706. Gekürzte Edition: Christian WeISE, Interessanter Abriß über das Lesen von Zeitungen [...] (gestützt auf Ausgabe 1685), in: KuRTH, Die ältesten Schriften für und wider die Zeitung, S. 45-85. - Bezug: Ausgabe 1706, S. 45.

11 Michael Stolleis, Art. »Öffentliches Recht I (bis 1750)«, in: Adalbert ErLER / Ekkehard KaufMANN (Hg.), Handwörterbuch zur deutschen Rechtsgeschichte, 5 Bd., Berlin 1971-1998, hier Bd. 3 (1984), Sp. 1190-1198.

$12 \mathrm{Zu}$ »Öffentlichkeit« als Prozessmaxime: Gunter Wesener, Art. »Prozeßmaximen«, in: ERLer/Kaufmann, Handwörterbuch zur deutschen Rechtsgeschichte, Bd. 4, Berlin 1990, Sp. 55-62. - Vgl. zur doppelten Bedeutung von »Publizist«: RoEcK, Reichssystem und Reichsherkommen, S. VII, Anm. 3.

13 Repgen, Kriegslegitimationen in Alteuropa, S. 27-49.

14 Forschungsüberblick: BöNING, Handgeschriebene und gedruckte Zeitungen im Spannungsfeld von Abhängigkeit, Koexistenz und Konkurrenz (Ausgaben 2008 u. 2011), pas. - Vgl. die Überlegungen vorn im Hauptteil I, Kap. 1, S. 63-75. 
nationale Handelshäuser wie die Fugger ${ }^{15}$. Während Herzog August d.J. von Braunschweig-Wolfenbüttel im Dreißigjährigen Krieg noch bis zu 1.750 Rtl. jährlich für seine Korrespondenten in europäischen Zentren ausgab, konnten seine Nachfahren die Mittel konzentrierter einsetzen und die Basisinformationen den Zeitungen entnehmen ${ }^{16}$.

Es waren gerade die Eigenheiten des Reiches und seiner Institutionen, die anders als in den europäischen Königtümern für Öffentlichkeit sorgten. Der Föderalismus im Reich führte zu einer erheblichen Partizipationsbreite der politischen Entscheidungsprozesse: Daran nahmen nicht nur der Kaiser und seine Spitzenbeamten und Diplomaten teil, sondern die Reichsfürsten mit ihren Regierungsgremien, deren Diplomaten in Regensburg, die kleinen Reichsstände mit ihren Korporationen (Prälaten-, Grafenkollegien) und die reichsstädtischen Bürgermeister, deren Magistrate und Ratsgremien, jeweils unterstützt durch rechtsgelehrte Berater. Da es einige hundert Reichsstände gab, bedeutete das, dass mehrere tausend Personen schon im Vorfeld von Entscheidungen mitwirkten, und sei es nur als Skribenten ${ }^{17}$. Herrschaftsrelevant waren zudem die landständischen Korporationen, die teilweise über eigene rechtsgelehrte Syndici verfügten. Auch Landstädte stellten im Laufe der Frühmoderne Justitiare ein, um ihre Interessen gegenüber der Landesherrschaft wahren zu können, im äußersten Fall durch Prozesse vor den Reichsgerichten ${ }^{18}$. Gewaltenteilung ist in der deutschen Geschichte nicht erst durch den institutionellen Dreiklang nach Charles de Montesquieu und JeanJacques Rousseau eingeführt worden, sondern bestand bereits seit Jahrhunderten als Föderaldualismus auf der Reichsebene sowie durch Ständedualismus auf der Territorialebene.

Wenn man in Betracht zieht, dass das Reichssystem nicht ein bloßes Rechtssystem war, sondern ein dynamisches politisches System, dann stellt sich die Frage nach der Informiertheit für den genannten Kreis der Beteiligten. Nicht nur die »vertikale Konkurrenz«, der kaiserlich-ständische Dualismus, war zu beachten, sondern auch die »horizontale Konkurrenz«, nämlich die Eifersucht, mit der besonders die größeren Reichsstände um politische und sonstige Chancen wetteiferten. Daneben waren die »mindermächtigen«

15 Klarvill, Fugger-Zeitungen, pas.; Mathilde August Hedwig Fitzler, Die Entstehung der sogenannten Fuggerzeitungen in der Wiener Nationalbibliothek, Baden b. Wien 1937; WeRNER/Henning, Das kaufmännische Nachrichtenwesen im späten Mittelalter und in der frühen Neuzeit, S. 3-51.

16 Vgl. dazu die Ausführungen vorn im Hauptteil I, Kap. 1, S. 66.

17 Zum deutschen Föderalismus und seiner Tradition: Axel GotThard, Einleitung, in: Werner KünZEL/Werner Rellecke (Hg.), Geschichte der deutschen Länder. Entwicklungen und Traditionen vom Mittelalter bis zur Gegenwart, Münster 2005, S. 7-33. - Gotthard nennt für 1500 fast 400 Reichsstände, deren Zahl bis 1800 auf ca. 300 sank: Ebd., S. 15.

$18 \mathrm{Zu}$ den frühmodernen Landständen: Kersten KRÜGER, Die landständische Verfassung, München 2003 . 
Stände bestrebt, korporativ ihren Rang gegenüber Niedrigeren zu bewahren, während sie als Individuen bzw. als Dynastien Rangverbesserungen für sich und ihre Nachkommen zu erlangen trachteten ${ }^{19}$. Daher mussten die Reichstagsgesandten aller Seiten im Reichsrecht und der Reichsgeschichte gebildet sein, schnell und umfassend neue Informationen aufnehmen können und gleichzeitig in höfischen kommunikativen Fertigkeiten erfahren sein ${ }^{20}$.

Für Susanne Friedrich steht fest, dass es mit dem Immerwährenden Reichstag eine »Reichsöffentlichkeit» gegeben hat, die sich immer weiter ausdehnte:

Die Grenze zwischen Geheimnis und öffentlicher Sphäre wurde um 1700 häufig überschritten. Schwerwiegender war jedoch, dass sie sich zu verschieben begann. Das Mediensystem um 1700 entwickelte sich weiter in Richtung einer Verstetigung und Intensivierung politischer Information ${ }^{21}$.

Dies geschah gegen den Willen der politischen Potenzen, die es jedoch nicht aufhalten konnten. Im Umfeld des Reichstagspersonals warteten professionelle Zeitungsschreiber darauf, Informationen und Deduktionen aufzuschnappen und ihren Finanziers zukommen zu lassen. Versuche, die niederen Bediensteten der Gesandten am Nachrichtenverkauf an diese Zeitungsschreiber zu hindern, scheiterten in der Praxis immer wieder ${ }^{22}$.

Der Kreis dieser Öffentlichkeit im Reich wurde noch gemehrt durch die hoch entwickelte Gerichtsbarkeit, insbesondere durch die beiden Obersten Reichsgerichte, das Reichskammergericht und den Reichshofrat. Das politische Reichsgeschehen lag dem Gerichtspersonal in Speyer und später in Wetzlar ebenso offen vor Augen wie den Reichstagsgesandten und den Spitzenbeamten in den territorialen Zentralverwaltungen, und auch die Vertreter der streitenden Parteien hatten sich die nötigen Kenntnisse zu verschaffen und ständig zu aktualisieren, weil angesichts der historischen Fundierung des frühmodernen Rechtssystems jede Herrschaftshandlung ein Exempel für einen rechtlichen Anspruch sein oder werden konnte ${ }^{23}$.

19 Zur adligen Rangkonkurrenz vgl. die Überlegungen von ARndT, Monarch oder der »bloße Edelmann«?, S. 59-90.

20 Karl Otmar Freiherr von Aretin formulierte die Anforderungen summierend: »Hätte ein wichtiger Reichsstand einen unbedeutenden Gesandten nach Regensburg geschickt, so hätte er nicht nur seinen Einfluss am Reichstag, sondern weitgehend auch den im Reich verloren«: voN ArETIN, Heiliges Römisches Reich 1776-1806, hier Bd. 1, S. 55.

21 Friedrich, Drehscheibe Regensburg, S. 534.

22 Zum systematischen Nachrichtenhandel im Reichstagsumfeld: ARNDT, »Pflicht=mässiger Bericht«, S. 1-31; Gestrich, Absolutismus und Öffentlichkeit, S. 96-100.

23 Zur Rechts- und Sozialgeschichte des Reichskammergerichts: Scheurmann, Frieden durch Recht, pas.; Diestelkamp, Oberste Gerichtsbarkeit und Zentrale Gewalt im Europa der Frühen Neuzeit, pas.; Sigrid Jahns, Das Reichskammergericht und seine Richter. Verfassungsund Sozialstruktur eines höchsten Gerichts im Alten Reich, 2 Bd. in 3 Teilbd., Köln/Wei- 
Das Mediensystem erwies sich aus politischer Sicht in seiner Ambivalenz zwischen Nützlichkeit und potenziellem Risiko als unverzichtbar. Die Regierungen hielten die bestehenden Zensureinrichtungen für ausreichend, um weitergehende Kritik durch dauerhafte Kontrolle auszuschließen. Vor der Veröffentlichung von Unliebsamem fürchtete man sich nur in Maßen. Die Zukunft der staatlichen Medienpolitik lag in der Manipulation: Interessengeleitet modifizierte Informationen wurden auf systemfremde Weise ins Mediensystem eingeschleust und dort mit den anderen Informationen vermischt, so dass der Leser keine sichere Kenntnis erhielt, dass es sich um Fremdreferenz handelte.

Vor diesem Hintergrund politischer Öffentlichkeit in ihrer kommunikativen Doppelstruktur - höfisch-politisch wie medientechnisch - konnten politische Konflikte zu Gegenständen der Wahrnehmung werden, indem sie einen ähnlichen idealtypischen Verlauf nahmen wie später politische Skandale in ihrer Medienkarriere ${ }^{24}$. Im Reich gab es einen - noch nicht fest definierten Punkt A in der öffentlichen Konfliktwahrnehmung, bei dessen Überschreiten das Problem zum allgemeinen Diskursgegenstand wurde. Zuerst geschah das normalerweise dadurch, dass die Konfliktparteien Schriftsätze publizierten, die entweder für den Kaiser oder die Reichsgerichte (handschriftlich) oder den Reichstag (handschriftlich oder Drucksatz) oder auch für die breite Öffentlichkeit (Drucksatz) gefertigt worden waren. Nun wurde der Konflikt »reichs=kündig«. Auf den Reichsversammlungen, vor den Reichsgerichten und an den Höfen wurde darüber gesprochen.

Der Punkt B wurde überschritten, wenn die Informationen die Presse erreichten. Zeitungen brauchten normalerweise erst etwas Zeit, um sich mit den Umständen eines Konflikts vertraut zu machen. Hilfreich war vor allem das Erscheinen von Deduktionen, auf deren Inhalt man sich stützen konnte, dies galt hinsichtlich des gesicherten Informationsgehalts ebenso wie hinsichtlich der Zensur. Kontroverse Deduktionen wurden einfach gegenübergestellt. Ein gewaltsamer Zusammenstoss war immer eine Nachricht wert. Dabei konnten die Konfliktparteien, normalerweise aber nur eine Seite, schwer oder vollkommen diskreditiert werden.

mar/Wien 2003. - Gschliesser, Der Reichshofrat, pas. Eine neuere Gesamtdarstellung zum Reichshofrat fehlt bislang. Gegenwärtiger Problemaufriss: Siegrid WestPhal, Der Reichshofrat. Kaiserliches Machtinstrument oder Mediator?, in: Leopold AuER/Werner Ogris/Eva Ortlieb (Hg.), Höchstgerichte in Europa. Bausteine frühneuzeitlicher Rechtsordnungen, Köln/Wien/Weimar 2007, S. 115-137.

24 Zur Erforschung von Skandalen: Frank Bösch, Historische Skandalforschung als Schnittstelle zwischen Medien-, Kommunikations- und Geschichtswissenschaft, in: Fabio Crivellari/Kay Kirchmann/Marcus SAndl/Rudolf Schlögl (Hg.), Die Medien der Geschichte. Historizität und Medialität in interdisziplinärer Perspektive, Konstanz 2004, S. 445-464. 
Wenn dieser Punkt $\mathrm{C}$ erreicht war, konnten die Zeitungen immer offener vom Konflikt berichten und auch Bewertungen zuungunsten des Diskreditierten einfließen lassen. Entgegen früherer Annahmen finden sich in Zeitungen sehr wohl Wertungen, wenn auch knapp, selten und eher implizit. Sonja Schultheiß-Heinz ${ }^{25}$ hat das vergleichend für französische, englische und deutsche Blätter während des europäischen Kriegsgeschehens in den 1670er Jahren detailliert nachgeweisen, und auch Andreas Würgler ${ }^{26}$ weist in seinem Forschungsüberblick darauf hin. In den Fallstudien dieser Arbeit ist ebenfalls eine reichspatriotische Wertung an vielen Stellen nachweisbar, insbesondere in den Druckschriften, die sich gegen den »Reichsfeind« Max Emanuel von Bayern richteten. Dies konnte als politische oder reichsrechtliche Argumentation geschehen, aber auch durch einen symbolischen Angriff. So wurde Herzog Karl Leopold von Mecklenburg-Schwerin gelegentlich in seinen hochadligen Kurialien verletzt, wenn er in der Presse nur noch als »der Herzog« oder »dieser Herzog« bezeichnet wurde und nicht mehr als »Seine Hochfürstliche Durchlaucht«.

War der Konflikt überwunden oder lagen die letzten Kampfhandlungen bereits einige Zeit zurück, wurde Punkt D passiert. Der Streitgegenstand verlor an Aktualität und rückte in die Zuständigkeit der Historienschriftsteller und der Reichspublizisten. Es blieb bis zum Ende des Alten Reiches dabei, dass vergangenes Geschehen nicht nur einen Exempel-Charakter für künftige moralisch geleitete Herrschaftshandlungen besitzen sollte, sondern auch einen Anspruchs-Charakter aller rechtsfähigen Persönlichkeiten, die sich dessen durch neue Deduktionen und die daraus folgenden Prozesse bedienen konnten.

Als dritte Öffentlichkeitsform führte Esther-Beate Körber die BildungsÖffentlichkeit ein, die im Rahmen des hier untersuchten Konfliktszenarios ebenfalls eine wichtige Rolle wahrnahm, insbesondere an den juristischen Fakultäten der über 40 Universitäten im Reich ${ }^{27}$. Im Rahmen des Ius publicum wurden politische Probleme der Vergangenheit und der Gegenwart wissenschaftlich erörtert ${ }^{28}$, und die Öffentlichkeit des Reichssystems war hier Prinzip, denn jedes Thema konnte auf seinen rechtswissenschaftlichen Kern hin ausgerichtet präsentiert werden. Niemand konnte es einem Professor als Verletzung eines Staatsgeheimnisses ankreiden, wenn er einen politisch-

25 Sonja Schultheiss-Heinz, Politik in der europäischen Publizistik. Eine historische Inhaltsanalyse von Zeitungen des 17. Jahrhunderts, Stuttgart 2004, pas.

26 WÜrgLER, Medien in der Frühen Neuzeit, S. 106.

27 Schindling, Die protestantischen Universitäten im Heiligen Römischen Reich deutscher Nation, S. 9-19; Dickerhof, Die katholischen Universitäten im Heiligen Römischen Reich deutscher Nation, S. 21-47. - Vgl. auch den Überblick bei Weber, Geschichte der europäischen Universität, pas.

28 Über den Zusammenhang von Reichsrecht und Reichshistoriographie vorn im Hauptteil II, Kap. 1, S. 248-253. 
rechtlichen Konflikt als Konflikt bezeichnete. Auf einer zweiten Ebene wurden auch die Materialien der politischen Druckmedien in den akademischen Unterricht eingebaut, z.B. in Zeitungskollegs ${ }^{29}$. Schon für die Zeitungskritiker gehörte der studierende Nachwuchs zu einer der wichtigsten Lesergruppen. Johann Hunold verfasste 1716 einen eigenen Traktat, der Studenten zur Lektüre von »Journal-, Quartal- und Annual-Schrifften« anleiten sollte ${ }^{30}$.

Gerade die Staatsrechtskundler wurden noch auf eine andere Weise für die Unterrichtung der Reichsöffentlichkeit in Anspruch genommen: Für die konkurrierenden Interessen besonders der Reichsfürsten verfassten sie Rechtsgutachten, die als Deduktionen im engeren Sinne den Reichsständen und ihren Gesandten in Regensburg zugehen sollten, im Weiteren aber auch auf dem Medienmarkt angeboten wurden. Prominente Beispiele waren der Helmstedter Hochschullehrer Hermann Conring ${ }^{31}$ und der welfische Haushistoriograph und Philosoph Gottfried Wilhelm Leibniz ${ }^{32}$. Auch noch nicht arrivierte Juristen nahmen öffentlich zu Rechtsfragen Stellung, sei es durch Deduktionen, die sie als Empfehlungsschreiben für Reichsfürsten anfertigten, sei es durch Herausgabe einer rechtshistorischen Zeitschrift wie Johann Jacob Mosers Reichs-Fama ${ }^{33}$. Die juristische Autorentätigkeit verselbstständigte sich im Laufe des 18. Jahrhunderts, so dass nicht nur juristische Abhandlungen zu konkreten Konfliktfällen erschienen, sondern zunehmend auch Schriften zu allgemeinen Rechtsproblemen, wie z.B. zu einer grundlegenden Reform der Reichsverfassung ${ }^{34}$.

Im Aufklärungszeitalter entwickelte sich die frühmoderne politische Publizistik zu einer derartigen Dichte, dass an einen Rückbau oder gar Abbau nicht mehr zu denken war. Paradoxerweise wurde gleichzeitig das Herrschafts-Arkanum immer noch kultiviert, als seine Erhaltung bereits Illusion geworden war. Schon neigten die Fürsten dazu, Regierungsakten für große Quelleneditionen im Stil der Werke eines Johann Christian Lünig freizugeben. Daraus bedienten sich nicht nur die Kanzleien der anderen Höfe, sondern auch die Schreiber und Verleger von politischen Periodika, was in sei-

29 Vgl. die Ankündigung des Leipziger Professors Gottlieb Schumann, Abriß eines Collegii über die Politischen Zeitungen [...], Leipzig 1738, S. 3.

30 [HunOLD], »Kurtze und gründliche Anleitung.

31 Für das Haus der Welfen: ScHeEl, Hermann Conring als historisch-politischer Ratgeber der Herzöge von Braunschweig und Lüneburg, S. 271-301. - Für die Kurpfalz: Arnswaldt, De Vicariatus controversia, pas.

32 Scheel, Leibniz als politischer Ratgeber des Welfenhauses, S. 35-52; BeIDERBEck, Leibniz als politischer Berater des Welfenhauses am Beispiel der Neunten Kur, S. 142-149.

33 Die periodische Schrift begann im Stile einer Zeitschrift, wurde aber später mehr und mehr zu einer Rechtsfallsammlung: [Moser], Reichs=Fama.

34 Burgdorf, Reichkonstitution und Nation, pas. Zwar bezog sich der »intergouvernementale Diskurs« eigentlich auf die Staatskanzleien im Reich, doch waren die meisten dieser Schriften im freien Handel erhältlich und sprachen damit die gesamte Reichsöffentlichkeit an. 
ner Fernwirkung auf breitere Bevölkerungskreise nicht wirklich verstanden wurde ${ }^{35}$.

Was bedeutete das für die Möglichkeit einer Kontrolle fürstlicher und administrativer Machtausübung? Das Alte Reich war in seiner theoretischen Konzeption hierarchisch organisiert: Zwar kontrollierten die oberen Ebenen die unteren, aber eine Kontrolle von unten nach oben war nicht vorgesehen. Angesichts der sakralen Herleitung galt die göttliche Aufsicht über das Gemeinwesen als hinreichend. In der Praxis gab es die Kontrolleinrichtungen aber doch, sie folgten nur nicht dem Schema, das später aus dem Gewaltenteilungsmodell der Aufklärung hervorgehen sollte. »Herrschaftskontrolle« fand auf drei Ebenen statt: auf einer normativen, einer juristischen und einer publizistischen Ebene. Die normative Herrschaftskontrolle setzte bei der Ausbildung künftiger Herrschaftsinhaber an. Im dynastischen Fürstenstaat gab es nur wenige potenziell herrschaftsfähige Personen, und diese wurden entsprechend geschult. Fürstenspiegel ${ }^{36}$ für Hochadlige und Adelsspiege $^{37}$ für die sonstigen Nobiles sicherten den Rahmen, innerhalb dessen sich Bildung und Ausbildung der Eliten abspielten. Dieser Kontrollzusammenhang war vorgelagert, er entfaltete sich vor dem Herrschaftsantritt der betreffenden Personen. Die normative Herrschaftskontrolle schloss allerdings auch bürgerliche Personen mit ein: Die Juristenausbildung und auch die vielfältige Ikonographie zur Herrschaftsgerechtigkeit und zum »guten Regiment« insbesondere in Städten zeigten den Zöglingen der regierungsbeteiligten Familien, auf welche Weise die Ämter auszuüben und welche Fehler unbedingt $\mathrm{zu}$ vermeiden waren $^{38}$.

35 Johann Christian Lünig brachte im ersten Viertel des 18. Jahrhunderts zahlreiche Editionen von Reichsquellen heraus, für die er sich die Originale von den Fürsten erbeten hatte. Er wurde später zu einer Institution, an der keine Regierung mehr vorbeikam. Von Lünig sei nur seine Hauptedition erwähnt: Johann Christian LüNIG (Hg.), Das Teutsche Reichs-Archiv [...], 24 Bd., Leipzig 1710-1722. Vgl. zu den Hintergründen: REPgen, Über Lünigs »Teutsches Reichs-Archiv«, S. 240-285.

36 Klassische Vorlage: Erasmus von RotTerdam, Fürstenerziehung. Institutio Principis Christiani. Die Erziehung eines christlichen Fürsten (1525), hg. v. Anton J. GAIL, Paderborn 1968. Untersuchungen: Bruno Singer, Die Fürstenspiegel in Deutschland im Zeitalter des Humanismus und der Reformation, München 1981; Peter TöввICKE, Höfische Erziehung. Grundsätze und Struktur einer pädagogischen Doktrin des Umgangsverhaltens, nach den fürstlichen Erziehungsinstruktionen des 16. bis zum 18. Jahrhundert, Darmstadt 1983; Rainer A. MüLLER, Die deutschen Fürstenspiegel des 17. Jahrhunderts. Regierungslehre und politische Pädagogik, in: HZ 240 (1985), S. 571-597; Hans-Otto Mühleisen/ Theo Stammen (Hg.), Politische Tugendlehre und Regierungskunst. Studien zum Fürstenspiegel der frühen Neuzeit, Tübingen 1990.

37 Klassische Vorlage: Wolf Helmhardt von HoHBERG, Georgica Curiosa, Das ist: Umständlicher Bericht und klarer Unterricht Von dem Adelichen Land= und Feld=Leben [...], 3 Bd., Nürnberg 1682 (ND Wien 1984). - Untersuchung: Otto BRUNNER, Adeliges Landleben und europäischer Geist. Leben und Werk Wolf Helmhards von Hohberg, Salzburg 1949.

38 Vgl. zur Vorstellung vom »guten Regiment« im Rahmen des republikanischen Selbstverständnis frühneuzeitlicher Städte am Beispiels Zürichs: Thomas MAIssen, Die Geburt der Repub- 
Die juristische Herrschaftskontrolle war demgegenüber nachgelagert, sie kam erst zum Tragen, wenn ein Herrscher ungeachtet seiner Erziehung und oft auch der Mahnungen seiner Berater dennoch geltende soziale und rechtliche Normen verletzt hatte. Das Rechtssystem des Reiches, insbesondere die Rechtsprechung der beiden Obergerichte - Reichskammergericht und Reichshofrat - zielte vor allem darauf ab, dass die Personen, die über politische und militärische Machtmittel verfügen konnten, damit keinen größeren Schaden verursachten. Bei den hier analysierten Fallstudien handelt es sich in drei Exempeln um den fragwürdigen Einsatz von Machtmitteln. Im Rechtsgefüge hatten sich Modalitäten der Vermahnung und schließlich der Exekution gegen Herrscher eingespielt, die dennoch nicht von der Gewalt ablassen wollten. Dies konnte bis hin zur Reichsacht und Herrschaftsentsetzung und im Extremfall zum Strafprozess gegen die Kontravenienten reichen.

Die publizistische Herrschaftskontrolle ist bislang zumeist außer Betracht geblieben. Höfe beobachteten sich gegenseitig, auf die Öffentlichkeitsdimension hat Volker Bauer hingeweisen ${ }^{39}$. Sie sahen dabei aber nicht nur die barocke Performanz, sondern auch die Abweichungen von der Norm. Rechtsstreitigkeiten eines Fürsten konnten an anderen Höfen als Schwäche und als Chance für eigene Positionsgewinne wahrgenommen werden. Daher waren Berichte darüber in Briefzeitungen oder - bei schwereren Herrschaftskonflikten - auch in gedruckten Periodika stets ein Politikum ersten Ranges. Es bestand die Gefahr, einen Rufschaden zu erleiden, der bei Reichs- und Kreistagen thematisiert wurde. Das ultimative Risiko bestand in einer Untertanenrevolte. Große Fürsten konnten sich sicherer fühlen, zumal wenn sie Militär besaßen. Für kleine Reichsstände sind nicht wenige Beispiele überliefert, dass Konflikte sich zu städtischen oder bäuerlichen Revolten auswuchsen, zu deren Beendigung entweder auswärtige Hilfe oder demütigende Kompromisse erforderlich wurden ${ }^{40}$.

lik. Staatsverständnis und Repräsentation der frühmodernen Eidgenossenschaft, Göttingen 2006, S. 384. - Zum Ikonographie des »Urteil des Kambyses«, einer von spätmittelalterlichen Gemälden aufgegriffenen Parabel über den ungerechten und bestechlichen Richter Sisamnes, dem zur Strafe bei lebendigem Leib die Haut abgezogen wurde: Hugo van DER Velden, Cambyses for Example. The Origins and Function of an »Exemplum Iustitiae« in Netherlandish Art of the Fifteenth, Sixteenth and Seventeenth Centuries, in: Simiolus. Netherlands Quarterly for the History of Art 23 (1995), S. 5-62.

39 BAUER, Höfische Gesellschaft und höfische Öffentlichkeit im Alten Reich, S. 29-68; ders., Nachrichtenmedien und höfische Gesellschaft, S. 173-193.

40 Zum bäuerlichen Widerstand: Peter Blickle u.a. (Hg.), Aufruhr und Empörung? Studien zum bäuerlichen Widerstand im Alten Reich, München 1980; ders., Unruhen in der ständischen Gesellschaft, pas.; Helmut GaBeL, Widerstand und Kooperation. Studien zur politischen Kultur rheinischer und maasländischer Kleinterritorien (1648-1794), Tübingen 1995; Volker Press, Von den Bauernrevolten des 16. zur konstitutionellen Verfassung des 19. Jahrhunderts. Die Untertanenkonflikte in Hohenzollern-Hechingen und ihre Lösungen, in: Hermann WEBER (Hg.), Politische Ordnungen und soziale Kräfte im Alten Reich, Wiesbaden 1980, S. 85-112; 
Die Frage nach der Herrschaftskontrolle darf nicht dahingehend verstanden werden, dass ein frühmoderner Kaiser oder Fürst Angst vor einem Journalisten gehabe hätte, der ihm eine ungünstige Berichterstattung in Aussicht gestellt hätte, wenn er nicht in dessen Sinn handeln würde. Eine derartige Vorstellung wäre völlig wirklichkeitsfern ${ }^{41}$. Im Heiligen Römischen Reich fehlten formale Überprüfungsmechanismen, wie sie im modernen Verfassungsstaat mit seinem formalisierten Mehrheitsprinzip sowie mit seinen parlamentarischen Kontrollbefugnissen präsent sind. Das Reich ruhte zum einen auf seinen Grundgesetzen, insbesondere auf dem Westfälischen Frieden samt den damit verbundenen Garantierechten Frankreichs und Schwedens. Zum anderen bot die Reichsexekutionsordnung Handhaben gegen einen Machtmissbrauch selbst durch Reichsfürsten. Hinzu trat als subsidiäres Element für jeden Machtinhaber im Reich die Notwendigkeit, den eigenen politischen Ruf durch normenkonformes Handeln, d.h. durch Wahrung der reichsherkömmlichen Grenzen der Machtausübung, zu schützen. Der Ruf musste nicht nur gegenüber dem Kaiser als »Quelle allen Rechts« bewahrt werden, nicht nur gegenüber den Standesgenossen (vermittelt durch die »Reichsöffentlichkeit« der Reichsversammlungen samt zugehöriger Korrespondenz sowie vor dem Hintergrund der Reichsstaatsrechtslehre), sondern in zunehmendem Maße auch als Begründungserfordernis gegenüber einer wachsenden lesekundigen »Öffentlichkeit«.

Zur Interpretation dieses Zusammenhangs greife ich auf das Konzept der »Öffentlichen Meinung « zurück, wie es von der Publizistin und Demoskopin Elisabeth Noelle-Neumann (1916-2010) entwickelt worden ist ${ }^{42}$. Die Grundidee liegt darin, dass Menschen in Gegenwart und Vergangenheit ihre Handlungen nicht nur durch den groben Rahmen von Strafrechtsnormen leiten ließen, sondern vor allem durch soziale Kontrollmechanismen: Nicht Vergehen und Strafe bestimmten demnach das Denken, sondern soziale Ehre und Schande mit den Folgen der Anerkennung, Missbilligung oder Isolierung ${ }^{43}$.

Schulze, Bäuerlicher Widerstand und feudale Herrschaft in der frühen Neuzeit, pas.; ders., Die veränderte Bedeutung sozialer Konflikte im 16. und 17. Jahrhundert, S. 276-308; TROssBach, Soziale Bewegung und politische Erfahrung, pas.

41 Selbst heute würde kein Politiker öffentlich zugeben, er habe seine Position mit Rücksicht auf die Außenwahrnehmung geändert.

42 Sie führte damals ihren Mädchennamen: Elisabeth NoELLE, Öffentliche Meinung und soziale Kontrolle, Tübingen 1966, S. 7f., zit. nach Jürgen WILKE (Hg.), Öffentliche Meinung. Theorie, Methoden, Befunde, Freiburg i.Br. / München 1992, hier S. 10, Anm. 2. - Noelle-Neumann entwickelte später die gesamte Theorie in einer großen, mehrfach neu aufgelegten Studie: Elisabeth Noelle-Neumann, Die Schweigespirale. Öffentliche Meinung - unsere soziale Haut, München/Zürich 1980; aktuelle Neuauflage: dies., Öffentliche Meinung. Die Entdeckung der Schweigespirale, Frankfurt a.M. ${ }^{4} 1996$, nach der im Folgenden zitiert wird. - Definition des Begriffs »Öffentliche Meinung«: S. 343.

43 Noelle-Neumann legte dieses Sozialmodell ihren wissenschaftlichen Überlegungen zum Wahlverhalten der Bevölkerung in modernen Demokratien zugrunde, ließ aber mehrere ihrer 
In unnachahmlicher Weise hatte John Locke (1632-1704) bereits 1690 diesen Wahrnehmungszusammenhang unter dem Begriff $»$ Law of Opinion ${ }^{44}$ zu Papier gebracht, wobei er seine Formulierungen so wählte, dass sie sowohl auf den Privatmann als auch auf den Herrscher anwendbar wurden. Locke schrieb in zwei Passagen:

Was Tugend und was Laster ist, das wird entschieden nach dem Maßstab von Billigung oder Ablehnung, Lob oder Tadel, der durch geheimes und stillschweigendes Einverständnis in den verschiedenen Gesellschaften [...] der Welt gesetzt wird: Nach diesem Maßstab, entsprechend den Ansichten, den Grundsätzen, den Gepflogenheiten am Platze wird das Verhalten gerühmt oder verworfen ${ }^{45}$.

Niemand, der die Sitten und Auffassungen seiner Umwelt verletzt, entrinnt der Strafe ihrer Kritik und ihrer Feindseligkeit. Nicht einer unter zehntausend Menschen ist so unbeugsam und so stumpf, so unempfindlich, dass er sich aufrechthalten könnte, wenn er in seinem Kreis nur auf Anlehnung und Unbeliebtheit stößt. Das muss ein unnatürlicher und abwegiger Charakter sein, der sich damit abfinden kann, in seiner engeren Umgebung überall Mißachtung zu spüren. Viele Menschen haben die Einsamkeit gesucht und sich mit ihr befreundet: aber wer überhaupt ein menschenähnliches Wesen hat, bringt es nicht fertig, in einer Welt zu leben, in der ihm seine Mitmenschen - seine Bekannten und die Leute, mit denen er spricht - ständig abweisend und verächtlich begegnen. Diese Last ist zu schwer, als daß ein Mensch es ertragen könnte ${ }^{46}$.

Als theoretische Abstraktion aus diesem Forschungsbefund formulierte Noelle-Neumann: »Öffentliche Meinung ist eine Meinung in wertbesetzten Bereichen, die ohne Furcht vor Sanktionen ausgesprochen werden und auf der sich öffentliches Handeln gründen kann « ${ }^{47}$.

Übertragen auf das Heilige Römische Reich sind die sozialen Verbindlichkeiten innerhalb der adligen und bürgerlichen Herrschaftseliten gut beobachtbar. Rechtliche, soziale und materielle Besitzstände waren nicht nur in der Erwerbung durch Konkurrenz umstritten, sondern auch stets von Ver-

Schüler nach den historischen Wurzeln dieser Überlegungen forschen. Dabei stieß sie auf einschlägige Zitate bei Cicero (50 v. Chr.), Michel de Montaigne (1588) und Jean Jacques Rousseau (1744), die alle den genannten Zusammenhang klar vor Augen gehabt hatten, wenn sie über ihre eigenen Gesellschaften schrieben. In deutscher Sprache sei der Begriff erstmals 1702 aufgetaucht, als Christian Thomasius ihn in der deutschen Ausgabe einer Schrift über Hexenprozesse verwendet habe: ebd., S. 344f.

44 John Locke, An Essay Concerning Human Understanding, London 1690.

45 Ebd., S. 177

46 Ebd., beide Stellen zit. nach: Elisabeth NoElle, Öffentliche Meinung und soziale Kontrolle, Tübingen 1966, S. 8f. Noelle fügt dort auch die englischen Originalpassagen bei: Ebd., Anm. 17 u. 18.

47 Ebd., S. 343. 
lust bedroht. Daher bestanden während des Westfälischen Friedenskongresses vor allem die kleineren und mittleren Reichsstände auf einem System von Normen, die die politischen Prozesse im Reich bestimmen sollten, statt in die kalte Welt einer »Souveränität« zwischen den europäischen Mächten entlassen zu werden ${ }^{48}$. Für alle regierenden Personen sollte die Respektierung der herrschenden Ordnung des Politikprozessierens verbindlich bleiben. Theoretisch orientierte sich diese Ordnung an den christlichen und antiken Herrschertugenden, vor allem der Gottesfurcht (Pietas), Gerechtigkeit (Iustitia), Staatsklugheit (Prudentia), Beständigkeit/Verlässlichkeit (Constantia), der Stärke (Fortitudo) und der Mäßigung (Temperantia), wobei im 17. und 18. Jahrhundert keine signifikanten konfessionellen Unterschiede nachzuweisen $\operatorname{sind}^{49}$. Praktisch materialisierte sich dieser Vorstellungszusammenhang insbesonders im Respekt vor dem Reichsoberhaupt, vor den Mehrheitsentscheidungen der Reichsversammlungen, vor den rechtlichen Entscheidungen der Reichsgerichte. Gewaltanwendung gegenüber Erbkonkurrenten, reichsständischen Nachbarn, Mindermächtigen und selbst gegenüber den eigenen Untertanen war normalerweise verboten und nur mit Spezialgenehmigungen durch Reichsinstanzen akzeptabel. Wer gegen diese formalen Ordnungsmerkmale verstieß, lief Gefahr, entweder als krank oder geisteskrank zu gelten ${ }^{50}$ oder als deviant mit der Folge reichsrechtlich begründeten Widerspruchs. In einem politischen Konkurrenzsystem fanden sich zumeist Akteure, die diesen Widerspruch auch manifest zum Ausdruck brachten. In Zusammenhang mit dieser Studie lässt sich feststellen, dass Exekutionen von Reichs wegen weiterhin durchführbar waren, auch wenn es fürstliche Bestrebungen gab, so weitgehende Eingriffe in eine Landeshoheit zu unterbinden.

48 Die Reichsstände widerstanden dafür Versuchungen, das Reich in einen lockeren Staatenbund umzuwandeln, was von Seiten Schwedens und Hessen-Kassels betrieben wurde. Zur schwedischen Politik in Osnabrück: Sven Lundkvist, Die schwedischen Friedenskonzeptionen und ihre Umsetzung in Osnabrück, in: Duchнardt, Der Westfälische Friede, S. 349-359; Klaus MaLETTKE, Scheffers Gesandtschaft in Osnabrück: »Stände seyn nicht nur Räthe, die man hören, sondern deren Räthen man auch folgen müsse«, in: Ebd., S. 501-522. - Zur Unzulässigkeit der Behauptung einer reichsständischen »Souveränität« 1648: Johannes BURKHARDT, Der Westfälische Friede und die Legende von der landesherrlichen Souveränität, in: Jörg ENGELBRECHT/Stephan LAUX (Hg.), Landes- und Reichsgeschichte. Fs. für Hansgeorg Molitor zum 65. Geburtstag, Bielefeld 2004, S. 199-220.

49 Zum fehlenden konfessionellen Unterschied: Heinz DuchHARdT, Das protestantische Herrscherbild des 17. Jahrhunderts, in: Konrad Repgen (Hg.), Das Herrscherbild im 17. Jahrhundert, Münster 1991, S. 26-42, hier S. 30.

50 Zum Aspekt der herrscherlichen Krankheit bis hin zur Regierungsunfähigkeit: H.C. Erik MidelforT, Verrückte Hoheit. Wahn und Kummer in deutschen Herrschhäusern, Stuttgart 1996. - Noch in den 1790er Jahren wurden Reichsstände wegen Geisteskrankheit unter Vormundschaft gestellt: Johannes ARNDT, Kabale und Liebe in Detmold. Zur Geschichte einer Hofintrige und einer Fürstenabsetzung in Lippe während des ausgehenden 18. Jahrhunderts, in: Lipp. Mitt. 60 (1991), S. 27-74; Werner TrossBaCh, Der Schatten der Aufklärung. Bauern, Bürger und Illuminaten in der Grafschaft Wied-Neuwied, Fulda 1991. 
Die Reichsrechtstheorie hinkte in dieser Hinsicht übrigens der Realität hinterher: Welche Umstände eine Fürstenabsetzung oder Einschränkung der Landesherrschaft zwingend erforderlich machten, oder auf welche Weise ein Fürst zu normenkonformem Verhalten gebracht werden sollte, das löste die Theorie nicht auf ${ }^{51}$.

Normalerweise sollte schon eine fürstliche Erziehung gewährleisten, dass das spätere Verhalten des Hochadligen im Rahmens der standesspezifischen Normen blieb. Erziehungshandbücher fassten diesen Zusammenhang von Ehre $^{52}$ und Schande ${ }^{53}$ in Worte, und auch die politischen Testamente, sehr viel machiavellistischer auf die Staatsinteressen ausgerichtet, griffen den Normenhorizont an vielen Stellen auf ${ }^{54}$. Im Fall eines Erbprinzen hatte die Sicherstellung der Normenkonformität erhebliche politische Konsequenzen für die hochadlige Familie, die Regierungsbeamten, die Stände, die sonstigen Eliten und für den gesamten Untertanenverband, sodass Heinz Duchhardt das politische Testament als »Verfassungsäquivalent« bezeichnet hat ${ }^{55}$.

Auch geistliche Herrschaftsinhaber unterlagen einer sozialen Verhaltenserwartung. Mit ironischem Unterton hat der Staatsrechtler Friedrich Karl von Moser 1787 die Eigenschaften beschrieben, die einem ehrgeizigen Prälaten den Aufstieg zum Reichsbischof ebnen konnten: Wer ernstlich daran interessiert sei, so Moser, der solle eine wohlbestellte Küche pflegen und einen gut sortierten Weinkeller unterhalten. Durch Feste und Geschenke könne er dann rechtzeitig Freunde im Domkapitel gewinnen und diese bei Laune halten. Wichtig sei es, stets darauf zu verzichten, andere durch demonstrative Tugendhaftigkeit, Geist und Einsicht zu provozieren. Es sei vorteilhaft, fünf gerade sein zu lassen und dabei mit Frauen ebenso gut auszukommen wie mit Männern. Wenn der Anwärter sich dann überall beliebt gemacht habe, vorteilhafte Heiraten vermittelt habe und enge Kontakte zu den wichtigen Höfen im Reich pflege, dann werde ihm schon irgendwann die Mehrheit der Stimm-

51 Vgl. diese Feststellung bei Duchнardt, Das protestantische Fürstenbild, S. 30.

52 Für die internationalen Beziehungen zwischen Herrschern hat Michael Rohrschneider jüngst ergänzende Bemerkungen zum Begriff »Reputation« publiziert: Michael RoHRSCHNEIDER, Reputation als Leitfaktor in den internationalen Beziehungen der Frühen Neuzeit, in: HZ 291 (2010), H. 2, S. 331-352. - Weitere Forschungsüberblicke: Martin DingEs, Die Ehre als Thema der historischen Anthropologie. Bemerkungen zur Wissenschaftsgeschichte und Konzeptualisierung, in: Schreiner/Schwerhoff, Verletzte Ehre, S. 29-62; WeBer, Honor, fama, gloria, S. 70-98. - Zum Transformationsprozess von Ehre von der Antike bis ins 20. Jahrhundert: Winfried Speitkamp, Ohrfeige, Duell und Ehrenmord. Eine Geschichte der Ehre, Stuttgart 2010.

53 Forschungsüberblick zu »Schande«: WREDE/CARL, Zwischen Schande und Ehre, pas.

54 Politische Testamente: Heinz Duchnardt (Hg.), Politische Testamente und andere Quellen zum Fürstenethos der Frühen Neuzeit, Darmstadt 1987; Richard Dietrich (Hg.), Die politischen Testamente der Hohenzollern, Köln/Wien 1986.

55 Heinz Duchhard, Das politische Testament als »Verfassungsäquivalent«, in: Der Staat 25 (1986), S. 600-607. 
berechtigten bei einer Bischofswahl zufallen ${ }^{56}$. Diese Einsicht bezog sich nicht nur auf seine Zeit, sondern charakterisierte die Erwartung an Adlige in der Reichskirche auch während des Betrachtungszeitraums dieser Studie.

Es wird deutlich, dass die öffentliche Meinung eine stille Innenseite besaß: Wer sich konform verhielt, vermied das Gerede der Standesgenossen oder gar den Unmut der Untertanen. Wer dies jedoch nicht wollte oder konnte, lernte die lautstarke Außenseite dieser sozialen Kraft kennen. Entgegen bisherigen Annahmen stand zu Beginn des Widerstands gegen einen fürstlichen Rechtsübertreter nicht die juristische Verurteilung, sondern zunächst zog er sich schwächere Formen der Missbilligung zu. Über wen laufend schlecht berichtet wurde, der konnte ab einem bestimmten Punkt auch durch wohlgesetzte Rechtfertigungsdeduktionen kein Gehör mehr finden. Dauernde Kritik durch Kaiser, Reichsgerichte und Presse untergruben die Ehre eines Fürsten. Als verbindliche Standesnorm im Verkehr unter Ranggleichen war sie ein hohes Gut, das notfalls mit Gewalt zu schützen war. Darüber hinaus musste ein Fürst seinen guten Ruf auch gegenüber seinem Niederadel und gegenüber seinen sonstigen Untertanen wahren, dies erforderte die Beobachtung der öffentlichen Berichterstattung über alle Herrschaftshandlungen nicht nur im deutschen, sondern auch im europäischen Sprachraum ${ }^{57}$.

Nicht zuletzt deshalb reagierte jeder Herrschaftsträger auf kritische Presseberichte empfindlich. Neben den Aspekt der Ehrverminderung trat noch der Einblick der Untertanen in die Arcana der landesherrlichen Administration: Dadurch wurde Herrschaftswissen zu den Untertanen transferiert und Wissensgrundlagen geschaffen, die Ansatzpunkte für weitere Kritik liefern konnten. Öffentlich wurde der Konflikt daher nicht nur aus der Sicht von oben, von den anderen Reichsständen her, sondern auch von unten, aus der Perspektive der Herrschaftsunterworfenen ${ }^{58}$. Else Bogel und Elger Blühm schrieben über diesen Zusammenhang:

So waren die Zeitungen von Anfang an nicht nur »Geschichtsbücher«, wie ihre Schreiber und Verleger meinten, sondern politische Faktoren. Fürsten und Räte erkannten dies rasch. Sie wurden durch die bloße Existenz der Zeitungen gezwungen, auf die Presse - im eigenen Land und außerhalb der Grenzen - zu achten. Oft zögernd und

56 Friedrich Karl von Moser, Über die Regierung der geistlichen Staaten in Deutschland, Frankfurt/Leipzig 1787, S. 107f.

57 Zur Begriffsentwicklung der »Ehre«: Friedrich ZunKel, Art. »Ehre, Reputation«, in: Otto Brunner/Werner Conze/Reinhart Koselleck (Hg.), GG, Bd. 2, Stuttgart 1975, S. 1-63; zur Fürstenehre in Spätmittelalter und Früher Neuzeit: Jean-Marie MoEgLIN, Fürstliche Ehre und verletzte Ehre der Fürsten im spätmittelalterlichen deutschen Reich, in: SchreIner/SchwerHOFF, Verletzte Ehre, S. 77-91; WeBER, Honor, fama, gloria, S. 70-98.

58 Vgl. dazu die Überlegungen zu »Öffentlichkeit und Informationspolitik« von Georg ScнмidT, Die Geschichte des Alten Reiches. Staat und Nation in der Frühen Neuzeit, 1495-1806, München 1999, S. 142-146. 
gegen ihren Willen mussten sie anerkennen, dass von nun an bei allen ihren Handlungen in Krieg und Frieden unwiderruflich mit dem öffentlichen Wirken der Presse zu rechnen war $^{59}$.

Volker Bauer spricht von einem Beitrag zur Säkularisierung des Politischen, was nun nicht auf die Zurückdrängung des Religiösen zurückzuführen war, sondern auf eine verbreitete Einsicht in die Art und Weise des Zustandekommens von Politik ${ }^{60}$. Johannes Weber resümiert diesen Prozess wie folgt:

Die sukzessive, detaillierte Berichterstattung über politisch-militärische Vorgänge legte die Winkelzüge, die Wechselhaftigkeit und die Grenzen von Herrschaftshandeln bloß. Die Aktionen der Mächtigen verloren dadurch allmählich die Aura höherer Lenkung und erschienen schließlich als mühevolles, menschliches Alltagsgeschäft wie jedes andere. Damit rückte Politik in die Reichweite gewöhnlichen Verstandes; sie wurde zu einem Gegenstand, der auch von solchen diskutiert werden konnte, die nicht zur Herrschaft berufen waren. Die regelmäßige politische Zeitungspresse ist also in ihrer langfristigen mentalitätsgeschichtlichen Wirkung [...] kaum zu überschätzen ${ }^{61}$.

Diese Säkularisierung geschah in zwei Schritten: zunächst durch die Zeitungen, darauf aufbauend durch die politischen Journale ${ }^{62}$. Wichtig ist, zu betonen, dass dies noch keine radikalaufklärerische Systemkritik darstellte: Auch wenn Teilkritik an der ständischen Gesellschaft die ganze Barockzeit hindurch beobachtbar war - man denke an Grimmelshausens Kritik am adligen Vorzug bei der Stellenbesetzung in den Offizierskorps ${ }^{63}$ oder an die verbreitete Hofkritik ${ }^{64}$ vieler Gelehrter -, so fehlten Neigungen zur grundlegenden Infragestellung der Erbmonarchie ebenso wie der christlichen Fundierung der politischen und gesellschaftlichen Systeme.

59 Else Bogel/Elger Blühm, Die deutschen Zeitungen des 17. Jahrhunderts. Ein Bestandsverzeichnis mit historischen und bibliographischen Angaben, 3 Bd., Bremen/München 19711985, hier Bd. 1, S. IX.

60 BAUER, Höfische Gesellschaft und höfische Öffentlichkeit im Alten Reich, S. 42.

61 Zitat: WeBer, Deutsche Presse im Zeitalter des Barock, S. 145; zit. auch bei FAulstich, Die bürgerliche Mediengesellschaft, S. 31.

62 »Die Zeitungen schaffen also die Bedingungen der Möglichkeit einer räsonierenden bürgerlichen Öffentlichkeit, nicht aber schon diese selbst. Die räsonierende Öffentlichkeit überregionaler Reichweite nimmt ihren Anfang mit den politischen Journalen«: WeBER, Deutsche Presse im Zeitalter des Barock, S. 149.

63 Johann Jacob Christoffel von Grimmelshausen, Simplicissimus teutsch (1668/1669), hg. v. Dieter Breuer, Frankfurt a.M. 2005, 1. Buch, Kap. 15-17 (S. 58-67).

64 Helmuth KIESEL, »Bei Hof, bei Höll«. Untersuchungen zur literarischen Hofkritik von Sebastian Brant bis Friedrich Schiller, Tübingen 1979. 
Interessanterweise wurde dieser Mechanismus des öffentlichen Rügens nach 1648 vor allem an den »Feinden des Reiches « exemplifiziert: Indem man die genannten Maßstäbe an internationale Herrscher wie den türkischen Sultan oder an Ludwig XIV. von Frankreich anlegte, auch wenn man diese Monarchen nicht disziplinieren konnte, aktualisierte man vor den Augen potenzieller Unterstützer die Normen, auf denen das Erlaubt- oder Verbotensein von Herrschaftsmaßnahmen beruhte ${ }^{65}$. Hinzu trat ein Diskurs über die »deutsche Freiheit«, der die Rechte und Pflichten der Territorialherren sowohl gegenüber ihresgleichen als auch gegenüber ihren Untertanen sprachlich fasste und politisch-moralisch bewertete. Georg Schmidt resümiert diesen Zusammenhang mit den Worten:

Allein der Diskurs über die deutsche Freiheit und das Wissen um bestimmte Normierungen schufen ein Klima, das manchen Grundherrn und manche Obrigkeit vor allzu offensichtlichen Verletzungen dieses Grundkonsenses zurückschrecken ließ ${ }^{66}$.

Als Kurfürst Max Emanuel von Bayern sich 1702 entschloss, mit französischer Rückendeckung benachbarte Territorien, insbesondere Reichsstädte, mit eigenen Garnisonen zu belegen, um sie später einem neuen »Königreich Bayern« einzuverleiben, passierte zweierlei: Zum einen entwickelte sich auf Reichs- und Kreisebene eine rege Korrespondenz über diese gewaltsamen Verstöße, zum anderen wurden zahlreiche Druckschriften mit den Einzelheiten der bayerischen Aktionen aufgelegt, stets mit reichspatriotischem Pathos untermalt, beispielsweise in der Europäischen $\mathrm{Fama}^{67}$. Die wenigen prowittelsbachischen Deduktionen, teilweise in Latein und Französisch, wirkten

65 Zum Denkhorizont des Topos »Feinde des Reiches«: WreDE, Das Reich und seine Feinde, pas. - Zur Propaganda gegen das Osmanische Reich bereits im 16. Jahrhundert und der integrierenden Wirkung auf den Reichsverband: Winfried Schulze, Reich und Türkengefahr. Studien zu den politischen und gesellschaftlichen Auswirkungen einer äußeren Bedrohung, München 1978; István Hiller, Feind im Frieden. Die Rolle des Osmanischen Reiches in der europäischen Politik zur Zeit des Westfälischen Friedens, in: Duchнardt, Der Westfälische Friede, S. 393-404. - Zu Frankreich: Franz BosBaCh, Der französische Erbfeind. Zu einem deutschen Feindbild im Zeitalter Ludwigs XIV., in: Ders., Feindbilder, S. 117-139.

66 Georg SснміDт, Die »deutsche Freiheit« und der Westfälische Friede, in: Ronald G. Asch/Wulf Eckart Voss / Martin Wrede (Hg.), Frieden und Krieg in der Frühen Neuzeit. Die europäische Staatenordnung und die außereuropäische Welt, München 2001, S. 323-347, Zitat S. 346.

671702 gelangte ein beträchtlicher Teil des Briefwechsels zwischen der Pariser Regierung und dem französischen Gesandten Ricous in die Hände der Kaiserlichen. Sie wurden umgehend in Regensburg gedruckt und allen Interessenten angeboten: HürTL, Max Emanuel, S. 340. Vgl. die Berichterstattung in der Altonaer »Europäischen Relation« sowie die militärischen Nachrichten in der »Europäischen Relation«, Jgg. 1702-1704 pas. - Zu den Berichten in der »Europäischen Fama«, wo zugleich der Zusammenhang mit dem »Reichsverrat« des Trierer Erzbischofs Philipp Christoph von Sötern während des Dreißigjährigen Krieges und dessen anschließende zehnjährige Haft in Österreich hervorgehoben wurde: Europäische Fama 3 (1702), S. 265ff. 
wie kleine Inseln im Meer der breiten antibayerischen Presse ${ }^{68}$. Ohne größeren Widerstand stimmte der Kurfürstenrat der Ächtung Max Emanuels bzw. der »Privation« seines Bruders Josef Clemens von Köln zu. Eine Vielzahl von Druckschriften machte 1706 die feierlichen Verkündigungszeremonien in Wien, Regensburg und an anderen Orten überall in Wort und Bild bekannt ${ }^{69}$.

Ein weiteres Beispiel war Herzog Karl Leopold von Mecklenburg-Schwerin. Er unterdrückte seine Landstände, wollte nach 1715 auf vielfache kaiserliche Ermahnungen nicht hören, wurde 1719 mit einer Reichsexekution überzogen und seiner Landesherrschaft entsetzt ${ }^{70}$ - alles vollzog sich unter intensiver Anteilnahme der politischen Druckmedien ${ }^{71}$. Auch Preußenkönig Friedrich Wilhelm I. wollte sich nicht offen auf die Seite des nördlichen Nachbarn schlagen, obwohl ihm die Disziplinierung eines Reichsfürsten und insbesondere die herausgehobene Rolle der Hannoveraner Regierung bei der Exekution sehr unangenehm war ${ }^{72}$.

Es lässt sich sagen, dass Politiksystem und Mediensystem im späten 17. und frühen 18. Jahrhundert insoweit synchron arbeiteten, als sie beide in ihrer Bewertung eine normenkonforme Herrschaftsausübung prämierten. Für das Politiksystem war dies zu erwarten, für das Mediensystem nicht unbedingt. Die Medienproduzenten erfüllten aber durch eine affirmative Haltung zum frühmodernen Reichssystem eine Erwartung ihrer Leserschaft,

68 Vgl. „Chur=Bayerisches Gegen=Manifest, Auff Die wiederholter=ergangene Kayserliche Avocatoria, und die darin enthaltene [...] Kriegs=Declaration [...]«, o.O. 1703 (datiert auf den 1. Juni 1703), das wenig später auch in einer lateinischen Ausgabe erschien: »Manifestum seu Responsum Electorale Bavaricum Ad Iterato vulgatas Litteras Avocatoriales Caesareas \& contentum in illis, ipsaque iam actuali invasione hostili confirmatam belli declarationem «, o.O. [München] 1703. Vgl. »Manifeste de l'Electeur de Bavière« (verfasst von J.F. Dubos), o.O. 1704. - Im Jahr 1711 ließ auch der abgesetzte Kölner Kurfürst Josef Clemens seinen Protest gegen die ohne ihn und seinen Bruder vollzogene Kaiserwahl Karls VI. in französischer Sprache erscheinen: Abgedruckt in »Wöchentliche Relationen«, Nr. 34 vom 22. August 1711.

$69 \mathrm{Zu}$ den Details vgl. vorn im Hauptteil II, Kap. 1, S. 355-363.

$70 \mathrm{Zu}$ den reichsrechtlichen Dimensionen des Konflikts und den gerichtlichen Konsequenzen: JAHNS, »Mecklenburgisches Wesen« oder absolutistisches Regiment?, S. 323-351. - Landesgeschichtliche Perspektive: Wick, Versuche zur Errichtung des Absolutismus in Mecklenburg, pas.

71 Vgl. die Sammlungen von Deduktionen: [ANONym], Collectanea Mecklenburgica, Fasc. 1-4, o.O. [= Flensburg] 1718; [Johann Schevius (Hg.)], »Höchst=gemüßigter Historischer= Actenmäßiger Bericht von dem, was von Anfange der, im Monath Augusto 1713. angetretenen Regierung Herrn Carl Leopold, Hertzogen zu Mecklenburg, biß zu der, im Monat Martio und April 1719. ergangenen Kayserl. Execution von dem Fürstl. Mecklenburgischen Ministerio wider die Mecklenburgische Ritterschafft und Stadt Rostock vorgenommen worden (mit Beylagen von Num. 1-885)«, o.O. 1719.

72 Zudem hegte Brandenburg Erbhoffnungen auf Mecklenburg und stützte sich dabei auf den Erbvertrag von Wittstock aus dem Jahre 1442: Wittstocker Vertrag zwischen Mecklenburg und Brandenburg-Preußen vom 12. April 1442: SAChsse, Mecklenburgische Urkunden und Daten, S. 161-166. 
die "gute Herrschaft« positiv konnotiert und »schlechte«, d.h. normwidrige Politik kritisiert sehen wollte. Darüber, was das eine und was das andere darstellte, darf bis weit ins 18. Jahrhundert hinein ein breiter Konsens angenommen werden. Anders stellte sich die Frage in der Konfessionsspolitik und Religionsberichterstattung, Bereiche, in denen sich bereits ein struktureller Dissens herausgebildet hatte, der im Westfälischen Frieden rechtlich eingehegt worden war und in der Folgezeit sorgfältig beachtet und gepflegt wurde.

Für die Herrschaftskontrolle bedeutete dies, dass eine unmittelbare Kontrolle einer Herrschaftspersönlichkeit weniger wichtig war als eine potenzielle Kontrolle. Sowohl das Reichssystem als auch das Mediensystem waren infolge der Föderalordnung dezentralisiert und auf Konkurrenz ausgerichtet. Jede Herrschaftshandlung konnte irgendwo eine Vertextung nach sich ziehen, daher mussten jeder Fürst und jede Regierung stets mit Publizität rechnen. Die potenzielle Kontrolle durch das Vorhandensein des Mediensystems ließ es ratsam sein, allfällige Konflikte nicht über ein bestimmte Maß hinaus anschwellen zu lassen. Es empfahl sich, von Anfang an eine Strategie bereitzulegen, wie zu argumentieren sei, falls der fragliche Fall zu einem Medienereignis werden würde.

Jeder Reichsfürst hatte daher allen Grund, sein Bild in der Öffentlichkeit zu pflegen, da es nicht folgenlos blieb, wenn er als Rechtsbrecher und Gewalttäter erschien. Zwar drohte kein neuer Bauernkrieg, doch kleinere Formen von Widersetzlichkeiten gegen die Obrigkeit sind aus zahlreichen Reichsterritorien bekannt. Dies umfasste städtische Missfallenskundgebungen $^{73}$ ebenso wie Proteste der Landbevölkerung unter Einschluss prozessualer Verfahren vor den Reichsgerichten ${ }^{74}$, beide sind in den letzten Jahrzehnten vielfältig untersucht worden. Durch die Druckmedien musste die Möglichkeit in Rechnung gestellt werden, dass jede derartige Widerstandsaktion im ganzen Reich bekannt werden konnte. Das Risiko durch Nachahmungen wurde daher mit der zunehmenden Dichte der periodischen Berichterstattung gemehrt.

Der Umstand, dass Herrschaftsträger auch im dynastischen Fürstenstaat - und nicht erst in der parlamentarischen Demokratie - Rücksicht auf die Wahrnehmungen der Herrschaftsunterworfenen nehmen mussten, wurde schon von den Zeitgenossen des ausgehenden 17. Jahrhundert festgestellt: Der Staatsrechtslehrer Johann Peter von Ludewig wies den Gedan-

73 Städtische Proteste: WÜrGLER, Unruhen und Öffentlichkeit, pas.

74 Ländlicher Widerstand: BLICKLE, Unruhen in der ständischen Gesellschaft, pas.; ders./Thomas Adam (Hg.), Bundschuh. Untergrombach 1502, das unruhige Reich und die Revolutionierbarkeit Europas, Stuttgart 2004; GABEL, Widerstand und Kooperation, pas.; Press, Von den Bauernrevolten des 16. zur konstitutionellen Verfassung des 19. Jahrhunderts, S. 85-112; Schulze, Bäuerlicher Widerstand und feudale Herrschaft in der frühen Neuzeit, pas.; Trossbach, Soziale Bewegung und politische Erfahrung, pas. 
ken zurück, das Mediensystem sei durch die Politik gesteuert. Eher sei es so, so schrieb er, dass die Zeitungen einen solchen Druck auf die Herrschenden ausübten, dass diese sich eine offizielle Ausrede - in heutigem Deutsch eine »Sprachregelung « - ausdenken mussten, um überhaupt noch ein Staatsgeheimnis wahren zu können. Als Beispiel nannte er den Kriegsflottenbau der niederländischen Republik 1688 im Vorfeld der Intervention in England. Auf Anfragen der Politik und der Medienmacher hätte die Regierung bekanntgegeben, man bereite sich auf einen bewaffneten Konflikt mit Dänemark vor. Der wirkliche Grund sei durch diese Falschinformation verschleiert worden ${ }^{75}$.

Ein zusätzlicher Aspekt bestand im Nachleben eines Herrschers in der Historiographie. Von vielen Monarchen der europäischen Geschichte ist bekannt, wie sehr die öffentliche Meinung aus ihrer Spätzeit und der frühen Phase nach ihrem Tod prägend geworden ist für die dauerhafte Erinnerung an sie. Viele von ihnen haben selbst durch eigenes Bemühen ihr Bild geschönt - von Kaiser Karl V. und König Gustav Adolf von Schweden ist die intensive Medienarbeit bekannt -, andere wie beispielsweise König Philipp II. von Spanien waren darin wenig erfolgreich. Es konnte aber auch ein diffuses Bild entstehen, das galt nicht nur für Albrecht von Wallenstein, dem Schiller bekanntlich nachrief: »[...] schwankt sein Charakterbild in der Geschichte«, sondern auch für Kurfürst Max Emanuel von Bayern, der bis heute sehr differierende Bewertungen erhält ${ }^{76}$.

75 Der diesbezügliche Vorschlag zur Sprachregelung sei vom Ratspensionär Gaspard Fagel gekommen: Ludewig, Vom Gebrauch und Mißbrauch Der Zeitungen, S. 90.

76 Vgl. ARndt, Max Emanuel, Kurfürst von Bayern oder Graf von Wittelsbach?, pas. 

ANHANG 



\section{Data-Liste der Prüfdaten für die inneren Konflikte im Reich}

\subsection{Liste der Daten (nach Konflikten sortiert)}

\subsubsection{Reichsvikariatsstreit zwischen Kurbayern und Kurpfalz}

1657-04-02 (Vi): Tod Kaiser Ferdinands III.; Beginn der Sedisvakanz

1658-07-18 (Vi): Kaiserwahl Leopolds I.

1658-08-01 (Vi): Kaiserkrönung Leopolds I.

1705-05-05 (Vi): Tod Kaiser Leopolds I.

Josef I. rückt als Römischer König (seit 1690) direkt ins kaiserliche Amt nach, keine Sedisvakanz

1711-04-17 (Vi): Tod Kaiser Josefs I.; Beginn der Sedisvakanz

1711-10-12 (Vi): Kaiserwahl Karls VI.

1711-12-22 (Vi): Kaiserkrönung Karls VI.

1740-10-20 (Vi): Tod Kaiser Karls VI.; Beginn der Sedisvakanz

1742-01-24 (Vi): Kaiserwahl Karls VII.

1742-02-12 (Vi): Kaiserkrönung Karls VII.

1745-01-20 (Vi): Tod Kaiser Karls VII.; Beginn der Sedisvakanz

1745-09-13 (Vi): Kaiserwahl Franz' I.

1745-10-04 (Vi): Kaiserkrönung Franz’ I.

\subsubsection{Neunte Kurwürde für den Herzog von Braunschweig-Lüneburg}

1692-03-07 (NK): Urkundenaustausch zwischen Leopold I. und dem Gesandten von Hannover

1692-03-22 (NK): Kurtraktat zwischen Leopold I. und dem Gesandten von Hannover

1692-06-30 (NK): Information an die Kurfürsten

1692-10-03 (NK): Protest von Kurmainz, Kurköln, Kurtrier und Kurpfalz gegen die Neunte Kur von Hannover

1692-10-17 (NK): Abstimmung im Kurfürstenrat: Kurmainz, Kurbayern,

Kursachsen und Kurbrandenburg stimmen für die Kurpromotion, Kurköln, Kurtrier und Kurpfalz dagegen

1692-12-19 (NK): Investitur des Gesandten von Hannover mit der Kurwürde durch Kaiser Leopold I. 
1705-08-28 (NK): Herzog Georg Wilhelm von Hannover stirbt; es erbt Herzog Georg Ludwig

1708-09-07 (NK): Introduktion Kurhannovers in den Kurfürstenrat; kurz zuvor war die Stimme für Kurböhmen »readmittiert« worden. Kaiser Josef I. führte nun ebenfalls ein Kurvotum.

1714-08-12 (NK): Queen Anne von Großbritannien stirbt; neuer britischer König wird Kurfürst Georg Ludwig von Hannover

\subsection{3 Ächtung Kurfürst Max Emanuels von Bayern}

1701-03-09 (ME): Erstes Militärabkommen zwischen König Ludwig XIV. und Kurfürst Max Emanuel von Bayern

1702-06-17 (ME): Zweites Militärabkommen zwischen König Ludwig XIV. und Kurfürst Max Emanuel von Bayern

1702-09-08 (ME): Beginn der Kampfhandlungen des Kurfürsten Max Emanuel in Süddeutschland durch die Besetzung der Reichsstadt Ulm

1704-08-13 (ME): Schlacht bei Höchstädt: Die vereinigten Armeen des Herzogs von Marlborough und des Prinzen Eugen von Savoyen schlagen die Streitkräfte Frankreichs und Kurbayerns

1704-08-28 (ME): Verweisung der Gesandten Kurkölns und Kurbayerns vom Regensburger Reichstag

1705-11-27 (ME): Conclusum des Kurfürstenrats mit Zustimmung zur Absetzung der beiden Wittelsbacherkurfürsten

1706-04-29 (ME): Öffentliche Zeremonie der Absetzung der beiden Wittelsbacherkurfürsten durch Kaiser Josef I. in Wien

1706-05-11 (ME): Feierliche Publikation der Absetzung der beiden Wittelsbacherkurfürsten durch Kaiser Josef I. am Reichstag in Regensburg 1711-10-12 (ME): Kaiserwahl Karls VI.

1714-03-06 (ME): Friedensschluß von Rastatt zwischen Karl VI. und Ludwig XIV.

1714-09-07 (ME): Friedensschluß von Baden zwischen den Reichsständen und Ludwig XIV.

\subsubsection{Siegener Konfessionsstreit}

1702-xx-xx (WH): Fürst Wilhelm Hyazinth von Nassau-Siegen reklamiert die oranische Erbschaft

1705-01-xx (WH): Preußisches Militär marschiert in Siegen ein

1706-07-15 (WH): Ein kurpfälzisches Kreiskontingent marschiert in Siegen ein 
1707-03-29 (WH): Der Siegener Bürger Friedrich Flender wird als Anführer einer gewaltlosen Widerstandsbewegung ohne regulären Strafprozess zum Tode verurteilt und hingerichtet

1707-04-20 (WH): Machtübernahme durch eine kurkölnische Kreiskommission

1711-10-24 (WH): Das kurpfälzische Vikariatshofgericht restituiert Wilhelm Hyazinth

1712-05-26 (WH): Bei der Siegener Fronleichnamsprozession kommt es zu gewaltsamen Zusammenstößen; fünf Gardesoldaten kommen ums Leben

1716-02-27 (WH): Festnahme mehrerer Hammerschmiede durch die Administrationsregierung; neue Proteste, die gewaltsam niedergeschlagen werden (mehrere Tote)

1716-04-21 (WH): Wilhelm Hyazinth protestiert gegen die katholischen Gewalttaten (sic!)

1723-xx-xx (WH): Übertragung der Landesverwaltung an eine Kommission des Kölner Kurfürsten Clemens August

1727-10-06 (WH): Antritt der Landesverwaltung durch Prinz Emanuel Ignatius (Halbbruder von Wilhelm Hyazinth)

1740-07-26 (WH): Wiedereinsetzung Wilhelm Hyazinths in seine Landesherrschaft durch Kaiser Karl VI.; die oranische Regierung in Siegen folgt aber den Anweisungen des Fürsten nicht

1743-02-18 (WH): Fürst Wilhelm Hyazinth stirbt im Exil in Hadamar

\subsubsection{Suspendierung Herzog Karl Leopolds von Mecklenburg-Schwerin}

1708-1710 (KL): Ehe Herzog Karl Leopolds von Mecklenburg-Schwerin mit Prinzessin Sophia Hedwig von Nassau-Diez; 1710 Scheidung

1714-12-24 (KL): RHR-Urteil gegen Karl Leopold wegen Bedrückung des Adels

1715-07-26 (KL): Kaiserliche Ermahnung an Karl Leopold wegen Bedrückung der Untertanen

1717-10-22 (KL): Kaiserlicher Exekutionsauftrag an den Kurfürsten von Hannover und den Herzog von Braunschweig-Wolfenbüttel

1719-02-25 (KL): Beginn der Exekution gegen Mecklenburg: Das Territorium wird von welfischen Truppen besetzt

1719-06-22 (KL): Regierungsübernahme durch eine kaiserliche Kommission 1720-06-09 (KL): Herzog Karl Leopold erhält Audienz bei Kaiser Karl VI. in Wien

1728-05-11 (KL): Suspendierung Karl Leopolds von der Landesherrschaft durch kaiserliche Resolution 
1732-04-28 (KL): Herzog Christian Ludwig, Bruder Karl Leopolds, wird zum kaiserlichen Kommissar ernannt

1747-11-28 (KL): Herzog Karl Leopold von Mecklenburg-Schwerin stirbt 1755-04-18 (KL): Landesgrundgesetzlicher Erbvergleich (LGGEV): Grundgesetz für Mecklenburg bis 1918

\subsection{Liste der Daten (chronologisch sortiert)}

1657-04-02 (Vi): Tod Kaiser Ferdinands III.; Beginn der Sedisvakanz 1658-07-18 (Vi): Kaiserwahl Leopolds I.

1658-08-01 (Vi): Kaiserkrönung Leopolds I.

1692-03-07 (NK): Urkundenaustausch zwischen Leopold I. und dem Gesandten von Hannover

1692-03-22 (NK): Kurtraktat zwischen Leopold I. und dem Gesandten von Hannover 1692-06-30 (NK): Information an die Kurfürsten

1692-10-03 (NK): Protest von Kurmainz, Kurköln, Kurtrier und Kurpfalz gegen die Neunte Kur von Hannover

1692-10-17 (NK): Abstimmung im Kurfürstenrat: Kurmainz, Kurbayern, Kursachsen und Kurbrandenburg stimmen für die Kurpromotion, Kurköln, Kurtrier und Kurpfalz dagegen

1692-12-19 (NK): Investitur des Gesandten von Hannover mit der Kurwürde durch Kaiser Leopold I.

1701-03-09 (ME): Erstes Militärabkommen zwischen König Ludwig XIV. und Kurfürst Max Emanuel von Bayern

1702-xx-xx (WH): Fürst Wilhelm Hyazinth von Nassau-Siegen reklamiert die oranische Erbschaft

1702-06-17 (ME): Zweites Militärabkommen zwischen König Ludwig XIV. und Kurfürst Max Emanuel von Bayern

1702-09-08 (ME): Beginn der Kampfhandlungen des Kurfürsten Max Emanuel in Süddeutschland durch die Besetzung der Reichsstadt Ulm

1704-08-13 (ME): Schlacht bei Höchstädt: Die vereinigten Armeen des Herzogs von Marlborough und des Prinzen Eugen von Savoyen schlagen die Streitkräfte Frankreichs und Kurbayerns

1704-08-28 (ME): Verweisung der Gesandten Kurkölns und Kurbayerns vom Regensburger Reichstag

1705-05-05 (Vi): Tod Kaiser Leopolds I.; Josef I. rückt als Römischer König (seit 1690) direkt ins kaiserliche Amt nach, keine Sedisvakanz 1705-01-xx (WH): Preußisches Militär marschiert in Siegen ein 1705-08-28 (NK): Herzog Georg Wilhelm von Hannover stirbt; es erbt Herzog Georg Ludwig 
1705-11-27 (ME): Conclusum des Kurfürstenrats mit Zustimmung zur Absetzung der beiden Wittelsbacherkurfürsten

1706-04-29 (ME): Öffentliche Zeremonie der Absetzung der beiden Wittelsbacherkurfürsten durch Kaiser Josef I. in Wien

1706-05-11 (ME): Feierliche Publikation der Absetzung der beiden Wittelsbacherkurfürsten durch Kaiser Josef I. am Reichstag in Regensburg

1706-07-15 (WH): Ein kurpfälzisches Kreiskontingent marschiert in Siegen ein

1707-03-29 (WH): Der Siegener Bürger Friedrich Flender wird als Anführer einer gewaltlosen Widerstandsbewegung ohne regulären Strafprozess zum Tode verurteilt und hingerichtet

1707-04-20 (WH): Machtübernahme durch eine kurkölnische Kreiskommission

1708-09-07 (NK): Introduktion Kurhannovers in den Kurfürstenrat; kurz zuvor war die Stimme für Kurböhmen »readmittiert« worden. Kaiser Josef I. führte nun ebenfalls ein Kurvotum.

1711-04-17 (Vi): Tod Kaiser Josefs I.; Beginn der Sedisvakanz

1711-10-12 (Vi+ME): Kaiserwahl Karls VI.

1711-10-24 (WH): Das kurpfälzische Vikariatshofgericht restituiert Wilhelm Hyazinth

1711-12-22 (Vi): Kaiserkrönung Karls VI.

1712-05-26 (WH): Bei der Siegener Fronleichnamsprozession kommt es zu gewaltsamen Zusammenstößen; fünf Gardesoldaten kommen ums Leben

1714-03-06 (ME): Friedensschluß von Rastatt zwischen Karl VI. und Ludwig XIV.

1714-08-12 (NK): Queen Anne von Großbritannien stirbt; neuer britischer König wird Kurfürst Georg Ludwig von Hannover

1714-09-07 (ME): Friedensschluß von Baden zwischen den Reichsständen und Ludwig XIV.

1714-12-24 (KL): RHR-Urteil gegen Karl Leopold wegen Bedrückung des Adels

1715-07-26 (KL): Kaiserliche Ermahnung an Karl Leopold wegen Bedrückung der Untertanen

1716-02-27 (WH): Festnahme mehrerer Hammerschmiede durch die Administrationsregierung; neue Proteste, die gewaltsam niedergeschlagen werden (mehrere Tote)

1716-04-21 (WH): Wilhelm Hyazinth protestiert gegen die katholischen Gewalttaten (sic!)

1717-10-22 (KL): Kaiserlicher Exekutionsauftrag an den Kurfürsten von Hannover und den Herzog von Braunschweig-Wolfenbüttel

1719-02-25 (KL): Beginn der Exekution gegen Mecklenburg: Das Territorium wird von welfischen Truppen besetzt 
1719-06-22 (KL): Regierungsübernahme durch eine kaiserliche Kommission 1720-06-09 (KL): Herzog Karl Leopold erhält Audienz bei Kaiser Karl VI. in Wien

1723-xx-xx (WH): Übertragung der Landesverwaltung an eine Kommission des Kölner Kurfürsten Clemens August

1727-10-06 (WH): Antritt der Landesverwaltung durch Prinz Emanuel Ignatius (Halbbruder von Wilhelm Hyazinth)

1728-05-11 (KL): Suspendierung Karl Leopolds von der Landesherrschaft durch kaiserliche Resolution

1732-04-28 (KL): Herzog Christian Ludwig, Bruder Karl Leopolds, wird zum kaiserlichen Kommissar ernannt

1740-07-26 (WH): Wiedereinsetzung Wilhelm Hyazinths in seine Landesherrschaft durch Kaiser Karl VI.; die oranische Regierung in Siegen folgt aber den Anweisungen des Fürsten nicht

1740-10-20 (Vi): Tod Kaiser Karls VI.; Beginn der Sedisvakanz

1742-01-24 (Vi): Kaiserwahl Karls VII.

1742-02-12 (Vi): Kaiserkrönung Karls VII.

1743-02-18 (WH): Fürst Wilhelm Hyazinth stirbt im Exil in Hadamar

1745-01-20 (Vi): Tod Kaiser Karls VII.; Beginn der Sedisvakanz

1745-09-13 (Vi): Kaiserwahl Franz’ I.

1745-10-04 (Vi): Kaiserkrönung Franz' I.

1747-11-28 (KL): Herzog Karl Leopold von Mecklenburg-Schwerin stirbt

1755-04-18 (KL): Landesgrundgesetzlicher Erbvergleich (LGGEV): Grundgesetz für Mecklenburg bis 1918 


\section{Abkürzungsverzeichnis ${ }^{1}$}

Abt. Abteilung

AHKBAW Abhandlungen der historischen Classe der Königlich Bayerischen Akademie der Wissenschaften

AHVN Annalen des Historischen Vereins für den

Niederrhein

AKG Archiv für Kulturgeschichte

AMRhKG Archiv für mittelrheinische Kirchengeschichte

APB Archiv für Postgeschichte in Bayern

AUF Archiv für Urkundenforschung

Ausst.-Kat. Ausstellungskatalog

AVNA Annalen des Vereins für nassauische Altertumskunde und Geschichtsforschung

BrJ Bremisches Jahrbuch

d. Ä. der Ältere

d.J. der Jüngere

DBA Bernd Fabian (Hg.), Deutsches Biographisches Archiv. Eine Kumulation aus 254 der wichtigsten biographischen Nachschlagewerke für den deutschen Bereich bis zum Ausgang des 19. Jahrhunderts, Microfiche-Edition, München 1982ff.; Zitierweise: DBA [Serie] I oder II, Fiche $[\mathrm{x}]$, S. [Seitenzahl].

1 Alle weiteren Abkürzungen nach Siegfried M. SchwerTner, IATG 2. Internationales Abkürzungsverzeichnis für Theologie und Grenzgebiete. Zeitschriften, Serien, Lexika, Quellenwerke mit bibliographischen Angaben, Berlin ${ }^{2} 1992$. 
DBI Deutscher Biographischer Index; Gesamtregister zum Deutschen Biographischen Archiv (Microfiche-Sammlung), $10 \mathrm{Bd}$.

engl. $\quad$ englisch (Sprache der Erstausgabe des Buches)

etc. et cetera

FBPG N.F. Forschungen zur brandenburgischen und preußischen Geschichte, Neue Folge

fl.

Gulden

FOEG Forschungen zur osteuropäischen Geschichte

franz. $\quad$ französisch (Sprache der Erstausgabe des Buches)

Fs. $\quad$ Festschrift

GG Otto Brunner/Werner Conze/Reinhart Koselleck (Hg.), Geschichtliche Grundbegriffe. Historisches Lexikon zur politisch-sozialen Sprache in Deutschland, 7. Bd., Stuttgart 1972-1992.

GutJb Gutenberg-Jahrbuch

GWU Geschichte in Wissenschaft und Unterricht

HAB Herzog August Bibliothek (Wolfenbüttel)

Hg. Herausgeber

HHStA Wien Haus-, Hof- und Staatsarchiv Wien

$\mathrm{HJb} \quad$ Historisches Jahrbuch

HJLG Hessisches Jahrbuch für Landesgeschichte

HRG Adalbert ERLER/Ekkehard KaUfmann (Hg.), Handwörterbuch zur deutschen Rechtsgeschichte, 5 Bd., Berlin 19711998. 
HStA Hauptstaatsarchiv

HWP Joachim RitTeR (Hg.), Historisches Wörterbuch der Philosophie, 14 Bd., Darmstadt 1971-2007.

IASL Internationales Archiv für Sozialgeschichte der deutschen Literatur

IPM Westfälischer Friedensschluß 1648, Münsteraner Vertrag (Instrumentum Pacis Monasteriense)

IPO Westfälischer Friedensschluß 1648, Osnabrücker Vertrag (Instrumentum Pacis Osnabrugense)

JbWLG Jahrbuch für westdeutsche Landesgeschichte

JFL Jahrbuch für fränkische Landesforschung

Jg. Jahrgang

JWKG Jahrbuch für westfälische Kirchengeschichte

Knuttel Willem Pieter Cornelius Knuttel (Hg.), Catalogus van de pamfletten-verzameling berustende in de Koninklijke Bibliotheek, 9 Bd., Den Haag 1889-1920 (ND Utrecht 1978).

Konv. Konvolut

lat. lateinisch

LHA Landeshauptarchiv

Lipp. Mitt. Lippische Mitteilungen

ND Neudruck

ndl. niederländisch (Sprache der Erstausgabe des Buches) 
N.F. Neue Folge

NJbLG Niedersächsisches Jahrbuch für Landesgeschichte

o.D. ohne Datumsangabe

o.O. ohne Ortsangabe

praes. vorgelegt (praesentatum)

RBPH Revue Belge de Philologie et d'Histoire

Red. $\quad$ Redakteur

Rep. $\quad$ Repertorium

Rhein. Vjbll. Rheinische Vierteljahrsblätter

RHR Reichshofrat

RKG Reichskammergericht

RTA Reichstagsabschied

Rtl. Reichstaler

RT Reichstag

schwed. schwedisch (Sprache der Erstausgabe des Buches)

s.p. ohne Seitenangabe (sine pagina)

StadtA Stadtarchiv

StA Staatsarchiv

VHVOPf Veröffentlichungen des Historischen Vereins für die Oberpfalz

VSWG Vierteljahrschrift für Sozial- und Wirtschaftsgeschichte 
WA Martin Luther, D. Martin Luthers Werke. Kritische Gesamtausgabe, $101 \mathrm{Bd}$. in 4 Reihen (= Weimarer Ausgabe).

z.B.

zum Beispiel

ZfS Zeitschrift für Soziologie

ZHF

Zeitschrift für historische Forschung

ZHVS

Zeitschrift des Historischen Vereins für Schwaben

ZRG-GA Zeitschrift der Savigny-Stiftung für Rechtsgeschichte (Germanistische Abt.)

ZRG-KA Zeitschrift der Savigny-Stiftung für Rechtsgeschichte (Kanonistische Abt.)

ZRG-RA Zeitschrift der Savigny-Stiftung für Rechtsgeschichte (Romanistische Abt.) 



\section{Quellen- und Literaturverzeichnis}

\subsection{Flugpublizistik und Traktate}

1584 Relatio: »Relatio historica dessen, so sich nach dem Abschied der Coellnischen Zusammen=Kunfft wegen der Niederländischen Pacification gehalten [...] «, Köln 1584.

1608 Schuyt-Praetgens: „Schuyt-Praetgens, Op de Vaert naer Amsterdam, tusschen een Lantman, een Hovelinck, een Borger, ende Schipper«, o.O. 1608 (Knuttel, Nr. 1450).

1608 Dialogus: »Ein Dialogus oder Gespräch/die noch wehrende Niderländische Friedenstractation betreffendt/Zwischen einem Holländischen Bawern/Hoffdienern/Burgern und Schiffmann«, o.O. 1608 (Knuttel, Nr. 1453).

1657 Ableinung: »Ableinung Deß ohnlängst von Chur=Bayrischer Seiten in Druck außgesprengten Gegenberichts / etc. Betreffend die Vicariats $=$ Gerechtigkeit in Landen des Rheins $/$ Schwaben/und Fränckischen Rechtens [...]«, Heidelberg 1657.

1657 Bayrisches Notifications-Patent: »Churfürstlich Bayrisches Notifications-Patent. Uff der Röm. Keys. Mayest. höchstseeligsten Ableiben dero zustehenden Reichs=Vicariats«, o.O. 1657.

1657 Bericht: »Kurtzer und Summarischer Bericht, Dass das Vicariat in Landen des Rheins / Schwaben und Fränckischen Rechtens/deß Herrn Pfaltzgraffen und Vicarii Carl Ludwigen Churfürstl. Durchl. von Rechtswegen zustehen und gebühren thut [...]«, o.O. 1657.

1657 Fernere Anzeige: »Fernere wohlgegründte Anzeig wegen deß Ihr Churfürstl. Durchl. in Bayrn zustehenden Reichs-Vicariats etc.«, München 1657.

1657 Gegen=Bericht: »Wohlgegründter Gegen=Bericht/Wider Einen unlängsten in Truck außgangnen/also genanten Kurtz= und Summarischen Bericht/wegen de $\beta$ H. Rom. Reichs Vicariats in Landen deß Rheins/Schwaben/und Fränckischen Rechtens [...] «, München 1657.

1657 Informatio: »Informatio qua ostenditur vacante post obitum Ferdinandi III glorissimae memoriae Imperio provisionem eius sive Vicariatum in partibus Rheni, Sueviae et in jure Franconico Ser.mo Electori Bavariae competere et nullatenus ad Electorem Palatinum pertinere« (Konzept), o.O. 1657.

1657 Pfältzisches Notifications-Patent: »Churfuerstl. Pfältzisches Notifications-Patent Uff der Röm. Kays. Majest. [...] Ableiben dero zustehendes Reichsvicariati«, o.O. 1657.

1657 Refutatio solida: »Refutatio solida informationis cuiusdam Palatinae, quae ostenditur S.R.I. Vicariatum [...] pertinere ad Ferdinandum Mariam etc.«, München 1657.

1657 Refutation du Manifeste: »Refutation du Manifeste Palatin Contestante les preuves evidentes du droit que le Serenissime Prince Ferdinand Marie [...] a au Vicariat du S. Empire [...]«, München 1657.

1658 Abfertigung: »Wohlgegründete Abfertigung einer Chur=Bayerischen Theils ohnlängst in Truck gegebenen also genanten Ferneren Anzeig/Wegen des am Rhein, Schwaben und Fränckischen Rechtens Reichs-Vicariats [...]«, Heidelberg 1658.

1658 Ablainung: »Endtliche abgenötigte Ablainung Einer ChurPfältzischen unlängstens in Truck gegebnen/also genanten Abfertigung das Vicariat in Landen des Rheins/Schwaben/und Fränckischen Rechtens betreffend [...]«, München 1658.

1662 Beantwortung: „Schließliche Beantwortung Der von Chur Bayrischen Seiten in Truck gegebenen, als genannten Endtlichen abgenötigten Ableinung des Reichs-Vicariats [...] betreffendt«, Heidelberg 1662.

1692 Acta: »Acta Publica Den Neunden Electorat betreffende«, o.O. 1692.

1692 Bericht: „Wahrer außführlicher Bericht von Wien/Was bey jüngster Investitur Des neunten Electorats De dato den 9./19. Decembr. 1692 Vorgangen «, Hamburg 1692.

1692 Extract: »Extract Schreiben/Auß Wien/Ungarn/Pariß/Engeland/Polen/Heydelberg/Berlin und Cöln/etc. Mitbringend: Was weiter Neues in diesen Orthen vorbey gangen«, o.O. 1692.

1692 Miscellanea: »Miscellanea juris publici curiosa de Novemviratu. Bestehend in nachfolgenden Fragen: Ob nemlich der Neunte Electorat eingeführet werden könne? [...]«, o.O. 1692. 
1692 Remarques: »Remarques über einen im Römischen Reiche sine die \& consule ausgestreueten Vorschlag/die Neundte Chur=Sache betreffend«, o.O. 1692.

1692 Rezeß: »Receß zwischen Ihro Römisch=Kayserlichen Majest. und dem Hoch=Fürstl. Hauss Braunschweig=Lüneburg, Die Chur=Würde betreffend«, o.O. 1692.

1692 Verwahrungs=Schrifft: $»$ Verwahrungs=Schrifft $/$ Des Fürstlichen Hauses Braunschweig Lüneburg=Braunschweig/betreffendt Die Von dem Fürstl. Hause Braunschweig Lüneburg= Hannover verlangende Chur=Würde. Wie dieselbe Beym Kayserlichen Hofe den Actis publicis insinuiret worden«, o.O. 1692.

1692 Vorstellung: »Vorstellung Des Hohen Reichs=Rechtens/Vermöge Dessen An den Grund Gesetzen des Heil. Römischen Reichs und der darinnen von dem gesambten Reich bestättigten Zahl der Chur=Fürsten ohne vorher in allen dreyen Reichs=Collegiis geschehene Berathschlagung / [...] Nichts zu verendern [...]«, o.O. 1692.

1693 Anmerckungen:»Anmerckungen oder Refutation der Vorstellung deß hohen Reichs=Rechtens, daß ohne ein allgemeines Reichs=Gutachten an der Zahl der Chur=Fürsten nicht zu ändern sey $[\ldots] \ll$, o.O. 1693 .

1693 Schreiben: „Schreiben An Einen Gesandten zu Regensburg vom 8. October 1692 Den Neundten Electorat betreffent«, o.O. ${ }^{2} 1693$.

1693 Unterrichtung: »Gründlicher Unterricht Vom Ursprung derer 7. Chur=Fürsten mit Vorstellung der Motiven und Ursachen [...] ob selbige itziger Zeit mit den Neundten/Zehnden/Eilfften etc. derer Fürsten und Stände des Reichs [...] könne vermehret werden«, o.O. 1693.

1694 Deduction: »Deduction Daß dem Hoch=Fürstl. Haus Würtemberg/das Reichs=Panner oder Reichs $=$ Fendrichs $=$ Amt $/$ Praedicat und Insigne, schon von etlichen Seculis her/rechtmässig zustehe/und dahero ohne Kränckung desselben althergebrachter Praerogativen, keinem andern Chur= oder Fürsten erst neuerlich verliehen werden könne [...] «, o.O. 1694.

1700 Conduite: »Die Untadeliche Conduite derer Correspondierenden Reichs-Fürsten/Welche Sie Bey Anruffung derer Hohen Garants Deß Westphäl. Friedens Uber die IX. Chur-Sache erwiesen «, o.O. 1700.

1700 Lettre: »Lettre écrite par un gentilhomme à un de ses amis sur un bruit qui court touchant la jonction du duché d'Hanover avec celui de Zell«, o.O. [=Amsterdam] 1700.

1702 Anmerckungen: »Anmerckungen Bey der Fürstlichen Wolffenbüttelschen Wiederlegung der Uhrsachen/Warum die Zellische Linie gegen der Wolffenbüttelschen ungemeine Werbungen Ihre Sicherheit zu beobachten sich gemüßiget befunden [...]«, Köln 1702.

1702 Bericht: »Bericht von der Fürstl. Zellisch= und Hannöverischen Trouppen Einfall In Die Fürstliche Braunschweig= Wolffenbüttelsche Lande [...]«, o.O. 1702.

1702 Facti Species: »Facti Species Qua ex Pactis diversis \& Fideicommissariis Dispositionibus Illustriss. Comitum Nassoviae \& Baronum Bredae \& nec non Testamento Sereniss. Principis Auriaci \& Comitis Nassov. Philippi Wilhelmi dicucide demonstrantur [...] Domino Wilhelmo Hyazinto [...] successionem in supremum Principatum Aurasionensem [...] indubitanter competere«, o.O. 1702 .

1702 Relation: »Relation über den Hergang Der Von Ih. Churfl. Durchl. In Bayern/etc. besetzten Stadt Ulm«, o.O. 1702.

1702 Send=Schreiben: »Sr. Chur=Fürstl. Durchl. zu Bayern Send=Schreiben An die hohe Directores der Fränckischen und Schwäbischen Creysse/die Einnehmung der Kayserl. Freyen Reichs $=$ Stadt Ulm/und andere deroselben Kriegs=Verfassungen betreffend Zusamt Einer ausführlichen Relation wie und welcher Gestalt die Stadt Ulm ist erobert worden«, o.O. 1702.

1702 Wiederlegung: »Fürstlich braunschweigische wolffenbüttelsche Wiederlegung der Ursachen, welche das Fürstliche Haus Braunschweig-Zellischer Linie zu Colorirung des in die wolffenbüttelischen Lande vorgenommenen feindlichen Einfalls publicirt«, o.O. 1702.

1702 Uhrsachen: »Uhrsachen Warumb das Haus Braunschweig-Lüneburg, Zellischer Linie, gegen die vom Hause Braunschweig-Lüneburg, Wolfenbüttelische Linie, vorgenommene ungemeine Armatur [...] seine Sicherheit zu beobachten [...] gemüssiget worden«, o.O. 1702.

1702 Umbständlicher Bericht: »Umbständlicher Bericht von denen In den Fürstlich Braunschweig. Lüneburgischen Häusern/Zell- und Wolffenbüttelscher Linie, bishero vorgekommenen Differentien«, o.O. 1702. 
1703 Commissions=Decreta: »Commissions=Decreta, Kayserliche Commissions=Decreta und Reichs=Schlüsse/Wider den König in Franckreich/Hertzog von Anjou/, Chur=Cölln und Chur=Bayern $/[\ldots] \ll$, o.O. 1703.

1703 Decretum: »Decretum Serenissimi Domini Ducis Electoralis«, o.O. [München] 1703.

1703 Gegen=Manifest: »Chur=Bayerisches Gegen=Manifest, Auff Die wiederholter=ergangene Kayserliche Avocatoria, und die darin enthaltene [...] Kriegs=Declaration [...]«, o.O. 1703.

1703 Manifestum: »Manifestum seu Responsum Electorale Bavaricum Ad Iterato vulgatas Litteras Avocatoriales Caesareas \& contentum in illis, ipsaque iam actuali invasione hostili confirmatam belli declarationem«, o.O. [München] 1703.

1703 Relation: »Relation Von den Belägerung der Chur=Pfälzischen Stadt Neuburg an der Donau«, o.O. 1703.

1703 Vorstellung: »Vorstellung/Welche Ihre Churfürstl. Durchl. in Bayern/etc. den Reichs $=$ Convent in Regenspurg/durch Dero Gesandtschaft allda thun lassen/den 15. Jenner/ Anno $1703 \ll$, o.O. 1703.

1703 Vorstell= und Ahndung: »Vorstell= und Ahndung Wider den Chur=Fürsten von Bayern/Und Dessen Gesandten zu Regenspurg«, o.O. 1703.

1704 Gewalt: »Unter chur-, bayer- und franzoesischer Gewalt hart gedrueckte, aber nicht untergedrueckte Schwaben. Oder ausfuehrlicher Bericht des zweijährigen im Schwabenlande geführten Krieges«, Freiburg i.Br. 1704.

1704 Manifeste: »Manifeste de l'Electeur de Bavière« (verfasst von J.F. Dubos), o.O. 1704.

1706 Bericht: »Curieuser Bericht/Mit was vor Solennitäten Ihr. Röm. Kayser. Majest. Josephus I. Die beyden Gebrüdere und bißherigen ChurFürsten von Cölln und Bayern/in [...] Wien den 29. Aprilis Anno 1706. In die [...] Acht und Ober=Acht öffentlich erklären lassen«, Wien 1706.

1706 Beschreibung: »Beschreibung Der Achts=Erklärung So Ihro Röm. Kayserl. Majest. Wider die beede Gebrüder und gewesene Chur=Fürsten Von Cölln und Bayrn/Joseph Clemens und Maximilian Emmanuel/Allhier In Wien und zu Regenspurg offentlich vollziehen lassen«, o.O. [Wien] 1706.

1706 Privation: »Respective Privation Auch Acht= und Ober=Achts=Erklärung Gegen Die gewesene Churfürsten zu Cölln und in Bayrn/Joseph Clemens Und Maximilian Emanuel etc.«, Heidelberg (15. Juli) 1706.

1709 Anzeige: »Anzeige Der Justiz und Legalitet Der Kayserl. Achts= Erklaerung Derer gewesenen Churfürsten von Cölln und Bayern, Mit [...] Bericht Was Nach: [...] S.P. Westphal. Wegen der Achts $=$ Erklärung Eines Reichs=Standes [...] Zwischen denen Chur= und Fürstlichen Collegien [...] gehandelt worden«, Speyer 1709.

1709 Gespräch: »Des bedrängten Bayerlands wehmüthiges Gespräch mit Ihrem Churfürsten von einem Bayrischen Patrioten entworffen«, o.O. 1709.

1709 Vorstellung: »Wahrhaffte Vorstellung von Seitten der Fürstlich=Siegischen Administrations $=$ Cantzley, den Punctum religionis betreffend «, o.O. 1709.

1710 Ablehnung: »An Sämbtlicher Churfürsten Fürsten und Ständen des Heil. Römischen Reichs [...] Beständige Rechtliche Ablehnung und Refutation Nahmens Der zum Hochfürstlichen $\mathrm{Nassau}=$ Siegen $=$ Catholischen Land bestellter kaiserlicher Administrations-Cantzley [...] $\ll$, o.O. 1710 .

1710 Widerlegung: »An Sämbtlicher Churfürsten, Fürsten und Ständen des Heil. Römischen Reichs [...] Gründliche Widerlegung und reiterirte Vorstellung Gegen die Von [...] Kaiserl. Administrations- Cantzley, in puncto der Nassau-Siegischen Successions Sach [...] übergebene [...] Gegen-Remonstration [...]«, o.O. 1710.

1710 Helden-Thaten: »Des Großen Feld-Herrens Eugenii Hertzog von Savoyen und kayserlichen General-Lieutenants Helden-Thaten«, o.O. 1710.

1711 Protestation: »Vergeblich und zernichtete Protestation Prinz Emanuels, geweßten Chur=Fürsten von Bayrn. Belangende die unbefugt $=$ gesuchte Admission $z u$ der Kayserl. Wahl. Aus dem Lateinischen Original translatiert«, o.O. 1711.

1711 Vorstellung A: »Kurtze Vorstellung Des Heiligen Römischen Reichs Vicariat, seinem Ursprung binnen währenden Interregno, Und wann ein Römischer König und Kayser mit Tode abgehet oder abwesend und ausser dem Reich sich befindet. Wobey Eine Nachricht von der 
ehemalig=vorgewesten Strittigkeit zwischen Chur=Pfaltz und Chur=Bayern eben dieses Vicariats halber [...]«, o.O. 1711.

1711 Vorstellung B: »Kurtze Vorstellung des Heil. Röm. Reichs Vicariats, Seinem Ursprung / Gerechtigkeit/Macht und Gewalt, Binnen währendem Interregno [...]«, o.O. 1711.

1712 Species Facti: »Species facti, welcher Gestalt die Catholische in die Stadt Siegen am Frohnleichnamstag dises 1712 Jahrs armata manu eine Procession gehalten haben«, o.O. 1712.

1713 Verbotts=Brieffe: $»$ Erneut $=$ und geschärffte Kayserliche Abruffung $=$ Gehei $\beta=$ Gebott $=$ und Verbotts=Brieffe/Wider alle [...] Welche In der Cron Franckreich/deß Duc de Anjou/und der beyden respective entsetzten und geächteten Gebrüderen Joseph Clemens/und Maximilian Emanuels/geweßter Chur=Fürsten zu Cölln/und Bayern/etc. [...] Diensten sich befinden und verharren [...]«, o.O. 1713 .

1713 Bericht: »Pflicht=mässiger Bericht Von dem Secreto Comitiali«, o.O. 1713.

1716 Beweis: »Kurtzer und deutlicher Beweis, daß Ihro Regierende Hoch=Fürstl. Durchlaucht zu Mecklenburg/etc. Mit gutem Fug Rechtens Zu Einer Neuen Vermählung schreiten«, o.O. 1716.

1716 Dehortatorii: „Copia Kayserl. Dehortatorii an des Hn. Hertzogs zu Mecklenburg Fürstl. Durchl., vom 20. October. 1716«, o.O. 1716.

1716 Gedancken: »J.H.R. zufällige Gedancken Über den sogenannten kurtzen und deutlichen Doch übel abgefasten Beweis [...]«, o.O. 1716.

1717 Abdruck: »Abdruck Der an Ih. Römischen Kayserl. [...] Majestät Geschehenen Allerunterthänigsten Vorstellung/Der länger unerträglichen Noht und Bedrückung des Mecklenburgischen Adels [...]«, o.O. 1717.

1717 Convocations=Mandat: »Des Durchläuchtigsten Fürsten und Herrn/Carl Leopold, Hertzogen zu Mecklenburg [...] an Landräthe und Deputierte zum Engern Ausschuß der Ritter= und Landschafft derer Fürstenthümer Mecklenburg sub dato den 13. Augusti dieses 1717. Jahres [...] gedruckt insinuirtes Convocations=Mandat [...] Nebst des besagten Engern Ausschusses [...] Entschuldigungs=Memoriak $\ll$ o.O. 1717.

1718 Anzeige: $» H o ̈ c h s t=$ gemüßigte Anzeige an eine Hoch=löbl. Reichs= Versammlung/von Seiner Hochfürstlichen Durchl. dem regierenden Hertzoge zu Mecklenburg/Schwerin und Gustrow/das [...] ungehorsame Betragen einiger dero Vasallen und Unterthanen [...]«, o.O. 1718.

1718 Collectanea: »Collectanea Mecklenburgica«, Bd. 1-4, o.O. [= Flensburg] 1718.

1718 Verordnung: »Verordnung, strafbares und pflichtwidriges Verhalten von Vasallen und Untertanen betr.« (vom 27. April 1718), o.O. 1718.

1718 Wiederlegung: »Gegründete Wiederlegung/Eines sub Rubro Einer Höchst= gemüßigten Anzeige An eine Hochlöbl. Reichs=Versammlung von Fürstl. Mecklenburgis. Seiten publicirten Schreibens [...] «, o.O. 1718.

1719 Abdruck: »Abdruck des von Ihro Römisch. Kayserl. Majest. an Se. Königl. von Groß=Brittannien und des Hrn. Hertzogs von Braunschweig= Wolffenbüttel Durchl. abgelassenen CONSERVATORII, zu Vornehmung der Execution in Mecklenburg [...]«, o.O. 1719.

1719 Conjunkturen: »Mecklenburgische Conjuncturen Oder Gegenwärtiger Zustand im Mecklenburgischen/Nebst einem Brief Welchen einige Hoch= Fürstliche Mecklenburgische Räthe An Ihro Hoch=Fürstl. Durchlaucht abgehen lassen«, o.O. 1719.

1719 Declaration: »Declaration Ihro Hochfürstl. Durchl. Carl Leopold/Hertzog zu Mecklenburg/etc. etc. Betreffend Die Restitution Derer in Versicherung genommenen Adlichen Gütern«, o.O. 1719.

1719 Declarations-Edict: »Des Herrn Hertzog zu Mecklenburg-Schwerin Declarations-Edict, die Restitution derer, eine Zeithero in Versicherung genommene Adlichen Gütern betreffend«, o.O. 1719 .

1719 Erste Communication: »Erste Communication Derer Decretorum So von der zur Execution und Untersuchung in Mecklenburg Aller höchst Verordneten Kayserlichen SubdelegationsCommission zu Rostock. Von der Zeit der Commissions-Eröffnung als den 22. Juni 1719 an/biß den 1. Novembris desselben Jahres [...]«, o.O. 1719.

1719 Nachricht: »Umbständliche Nachricht/alles dessen/was seith dem Einmarsch der von Ihro Kayserl. Majestät angeordneten Crayß=Executions-Trouppen in Mecklenburg [...] vorgefallen $[\ldots] \ll$, o.O. 1719 . 
1719 Schreiben: »Schreiben eines Volontairs Bey Denen Kayserl. Executions Crayß=Trouppen im Mecklenburgischen/An Seinen guten Freund in Hamburg«, o.O. 1719.

1719 Zweytes Schreiben: »Zweytes Schreiben eines Volontairs Bey Denen Kayserl. Executions Cray $\beta=$ Trouppen im Mecklenburgischen/An Seinen guten Freund in Hamburg«, o.O. 1719.

1724 Abdruck Berichts: »Abdruck Des, auf Ihro Kayserl. Majestät Allergnädigstes Verlangen, von dem Regierenden Hertzog zu Mecklenburg erstatteten allerunterthänigsten Berichts/wegen des Criminal-Verfahrens wieder den Geheimben Rath Wolffradt, und gewesenen Geheimden Secretair Scharffen«, o.O. 1724.

1724 Abdruck Schreiben: »Abdruck Derer an Ihro Römisch. Kayserl. Majest. von dem Regierenden Hertzog zu Mecklenburg [...] abgelassenen Allerunterthänigsten Schreiben [...]«, o.O. 1724

1724 Erzehlung: »Wahrhaffte Aus Beygedruckten Original-Documentis Erwiesene Erzehlung Dessen was auff Ordre E. Hohen Kayserlichen Commission in Mecklenburg vorgefallen [...] , o.O. 1724 .

1725 Abdruck: »Abdruck Zweyer abermahliger Kayserl. Reichs=Hof=Raths Conclusorum In Sachen Ritterschaft Mecklenburg contra selbigen Herrn Hertzogs Hochfürstlichen Durchl. Executionis etc.«, o.O. 1725

1726 Zweyter Nachtrag: „Continuierter Zweyter Nachtrag Kayserl. Reichs=Hof=Raths Conclusorum, Vom 23. Januar 1726. Die Mecklenburgischen Executions=Sachen betreffend «, o.O. 1726.

1728 Abdruck: »Abdruck Hochpreißlich=Kayserl. Reichs=Hof=Raths Resolution und Verordnung, Die allerhöchste Provisional-Veränderung Bey Der Hertzoglich=Mecklenburgischen Landes=Regierung/Und Deren gemessene Kayserliche Administration betreffend «, o.O. 1728 .

1729 Resolutiones: »Allergerechteste Kayserliche Resolutiones und Verordnungen in Sachen Mecklenburgis. Ritter= und Landschafft contra Deß Herrn Hertzogs Carl Leopolds zu Mecklenburg Hochfürstl. Durchl. in puncto diversorum Gravaminum [...]«, o.O. 1729.

1729 Resolutionibus: „Gedoppelte Kayserliche Fernerweit Allergerechtest=erlassene, Resolutionibus Vom 11. Mai 1728 und 17ten Jan. a.c. [...] In Sachen Mecklenburgis. Ritter= und Landschafft/Contra Deß Herrn Hertzogs Carl Leopolds zu Mecklenburg Hochfürstl. Durchlaucht $[\ldots] \ll$, o.O. 1729 .

1729 Commissionsdecret: »Kaiserliches Commissionsdecret in Sachen Mecklenburg [...]«, o.O. 1729.

1729 Pro Memoria: »Pro Memoria oder Information die Mecklenburgische Administrations-Sache betreffend «, o.O. 1729.

1729 Scriptum: »Scriptum Pro Memoria In der Mecklenburgischen Administrations-Sache/So im Monath Augusti 1729 heraus gekommen«, o.O. 1729.

1730 Epistola: »Epistola Ducis Megapolitani Caroli Leopoldi Ad Regem Magnae Britanniae, de dato Suerini, 27. Junii Anno 1730«, o.O. 1730.

1730 Information: »Gemüßigte, gründliche ex actis publicis gezogene und mit nöthigen Documentis bewährte Information [...]«, o.O. 1730.

1730 Kurtze historische Information: »Kurtze historische, und aus authenticis Documentis \& Actis fideliter gezogene Information von dem Ursprung und Verfolg des Königl. Preußis. und Marggräfl. Brandenburgischen Eventuel=Successions=Rechts [...]«, o.O. 1730 (ND von 1708).

1730 Rescriptum: »Kaiserliches Rescriptum An die Höchst=Ansehnliche Kays. Commission in Regenspurg/in der Mecklenburgischen Angelegenheit«, o.O. 1730.

1732 Mandatum: »Mandatum Karl Leopolds, so im ganzen Lande von allen Canzeln den 21 December 1732 abgelesen worden«, o.O. 1732.

1733 Copia: „Copia Submissions-Schreiben/Von Sr. Durchleucht dem Hertzog Carl Leopold an Se. Kayserl. Majestät/d. d. Schwerin, den 29. September 1733«, o.O. 1733.

1733 Schreiben: »Des Durchl. Fürsten Carl Leopold, Hertzogs zu Mecklenburg Schreiben an Ihro Maj. dem Kayser«, o.O. 1733.

1736 Copia: „Copia eines von [...] Carl Leopold zu Mecklenburg an einige uhralte Fürstl. Häuser abgelassenen Circular-Schreibens«, o.O. 1736.

1740 Beschaffenheit: »Wahre Beschaffenheit Des Contra Instrumentum Pacis Westphalicae theils höchst turbirt, destituirt, und bedrängten/theils aber anjetzo in weiterer und grösserer Gefahr 
situirten Evangelisch-Reformirten Status Ecclesiastici in dessen Fürstenthümern Nassau-Siegen, den 8. September 1740 angestellet«, o.O. 1740.

1741 Diarium: »Augspurger Diarium de dato 31. Januarii und 1. Februarii Anno 1741«, Augsburg 1741.

1741 Publication A: »Publication Der Eröffnung des Reichs-Vicariats-Hof=Gerichts in Augsburg, von beyden [...] Churfürsten in Bayern und Pfaltz gemeinsam niedergesetzt«, o.O. 1741.

1741 Publication B: »Publication der Eröffnung deß in der Kaiserl. freyen Reichs-Stadt Augspurg von beyden Durchläuchtigsten Churfürsten in Bayern und Pfaltz niedergesetztes gemeinsamen Reichs=Vicariats-Hof $=$ Gerichts $«$, Augsburg 1741.

1741 Rubra: $»$ Rubra, deren bey dem höchst=preyßlichen Reichs=Vicariats- Hof=Gericht in Augspurg resolvirten Sachen, Febr.-Martium; Continuatio VI per M. Sept. 1741«, Augsburg 1741.

1741 Sammlung: »Sammlung einiger merkwürdiger Conclusorum, Welche von einem [...] Reichs=Vicariats-Hof=Gericht zu Augsburg [...] abgefasset worden«, Augsburg 1741.

1741 Titulaturen: »Titulaturen, Tit. Tit. Herren, Herren/Präsidenten=Cantzler/Excellentz, Excellentz/Räthe, Secretarien/und Cantzley $=$ Verwandte Bey dem Reichs=Vicariats-Hof $=$ Gerichts in Augspurg«, o.O. 1741.

1742 Conclusa: »Conclusa Welche Von einem gemeinsamen Höchst=preyßlichen Reichs=VicariatsHof $=$ Gericht zu Augspurg /Seit Höchst= desselben Eröffnung abgefasset worden [...]«, 2 Bd., Augsburg 1742.

\subsection{Zeitungen}

Augspurgische Ordinari-Post-Zeitung, [...], o.O. 1723-1766.

Avisen-Correspondente $=$ Hamburgischer Avisen-Correspondente

Berlinische Nachrichten von Staats- und gelehrten Sachen [= Spenersche Zeitung], Berlin 1740 1872.

Berlinische privilegierte Zeitung, begr. durch Johann Andreas RüDIGER, später hg. v. Gotthold Ephraim Lessing [...], Berlin 1721-1778.

Braunschweigische Zeitung, ab 1645.

Curieuser Extract Derer Neuesten Zeitungen, Rostock, ab 1711.

Danziger Ordinari Freytags Zeitung, Danzig 1669.

Europäische Zeitung [= Hanauischer Mercurius], hg. v. Justus BöfF, Hanau ab 1701.

Extract derer [...] eingelauffenen Nouvellen [vorher: Leipziger Post- und Ordinari-Zeitung; später: Leipziger Zeitungen], Leipzig ab 1700.

Extraordinari-Kayserl. Reichs=Post=Zeitung, vermutl. Frankfurt a.M. ab 1706.

Frankfurter Journal [= Journal, auch andere Namen], Frankfurt a.M. ab 1639.

Frankfurter Postzeitung [ $=$ Reichs=Post=Zeitungen und Frankfurter Ober-Post-Amts-Zeitung], hg. v. Johann von DEN BiRGHDEN, Frankfurt a.M. 1615-1866.

Hamburg[isch]er Relations-Courier [...], Hamburg 1674-1811.

Hamburgischer Avisen-Correspondente [= $\gg$ Hamburgischer Correspondent oder mit Langtitel »Aviso. Der Hollsteinische unpartheyische Correspondente. Durch Europa und andere Teile der Welt [...]«], Schiffbek/Hamburg 1712-1840.

Hildesheimer Relations-Courier, [= Privilegirte Hildesheimische Zeitung], Hildesheim ab 1705.

Leipziger Post und Ordinari-Zeitung[en], ab 1673.

Lippische Intelligenzblätter, Lemgo 1767-1799. 
Mercurii Relation, oder wochentliche Reichs Ordinari Zeitungen, von underschidlichen Orthen, München ca. 1650 - nach 1750 (Vorläufer ab 1628).

Wiener »Ordentlichen Postzeitungen«, Wien (seit 1622).

Wienerischer Mercurio [= Posttäglicher Mercurius], Wien ab 1703.

Wiener[isches] Diarium, Wien 1703-1779.

Wöchentliche Relation[en] (Hallische Wöchentliche Relation, Jahresbände: Wöchentliche Relationen), Halle a.d. Saale ab 1709.

\subsection{Zeitschriften}

Acxtelmeier, Stanislaus Reinhard (Hg.)=Monatlicher Staats-Spiegel.

Aufgefangene Briefe: [StüBEL, Andreas (Hg.)], Aufgefangene Briefe, welche zwischen etzlichen curiose Personen ueber den jetzigen Zustand des Staats und gelehrten Welt gewechselt, 2 Bd., Wahrenberg [= Leipzig] 1699-1700.

Aufrichtige und Unpartheyische Gedancken: [Hoffmann, Christian Gottfried (Hg.)], Aufrichtige und Unpartheyische Gedancken Über die Journale, Extracte und Monats=Schrifften/Worinnen Dieselben extrahiret/wann es nützlich suppliret und wo es nötig emendiret werden, 24 Stücke in 2 Bd., Freyburg [= Leipzig] 1714-1717.

CourtilZ DE SANDRAS, Gatien des (Gründungs-Hg.)=Mercure historique.

Curieuse Nachrichten 1715: [Huhold, Marcus Paul (Hg.)], Curieuse Nachrichten von denen heute zu Tage grand mode gewordenen Journal-, Quartal- und Annual-Schrifften, darinnen die einige Jahre her in Teutscher, Lateinischer, Frantzösischer, Italiänischer und Holländischer Sprache häufig geschriebenen Journale erzehlet und bey denen meisten gemeldet, wenn solche entweder angefangen, aufgehöret oder noch bis jetzo continuiret werden [...] (verfasst v. Marcus Paul HuHOLD), Jena [= „Freyburg« 1715.

Curieuse Nachrichten 1716: [Hunold, Marcus Paul (Hg.)], Curieuse Nachrichten Von denen Heute zu Tage grand mode gewordenen Journal-, Quartal- und Annual-Schrifften, Darinnen Die einige Jahr her in Teutscher/Lateinischer/Frantzösischer/Italiänischer und Holländischer Sprache häuffig geschriebenen Journale erzehlet/Und bey denen meisten gemeldet/wenn sie angefangen/aufgehöret/oder ob sie noch bis itzo continuiret werden, Nebst beygefügten unpartheyischen Urtheilen und andern curiosen Observantionibus, Itzo von neuem übersehen und vermehrter herausgegeben (verfasst von Marcus Paul HuноLD), Jena [ $=»$ Freyburg ${ }^{2}{ }^{2} 1716$.

Europäische Fama: [SINOLd von SchÜTz, Philipp Balthasar u.a. (Hg.)], Die Europäische Fama, welche den gegenwärtigen Zustand der vornehmsten Höfe entdecket [...], 30 Bd. (360 Tl.), Leipzig $1702-1735$.

Europäische Fama, neue: [Schumann, Gottlieb (Hg.)], Die neue europäische Fama, welche den gegenwärtigen Zustand der vornehmsten Höfe entdecket, 16 Bd. (192 Tl.), Leipzig 1735-1756.

Europäischer Staats-Secretarius: [WeIDMAnN, Moritz Georg (Hg.)], Europäischer Staats-Secretarius, welcher die neuesten Begebenheiten unpartheyisch erzehlet und vernuenftig beurtheilet [...], 144 H. in 12 Bd., Leipzig 1734-1748.

[Fassmann, David (Hg.)], Gespräche im Reiche der Todten, 16 Bd., Leipzig 1718-1739 (1740).

[- (Hg.)], Der, Auf Ordre und Kosten seines Kaysers, reisende Chineser, Tl. 1, Stück 1-28, Leipzig 1721-1723.

[- (Hg.)], Sonderbahre Nationen=Gespräche oder Curieuse Discurse Über die Jetzigen Conjuncturen und wichtigsten Begebenheiten [...], 2 Bd. (32 Entrevuen), Berlin 1727-1733.

Götten, Heinrich Ludwig [HLG], Gründliche Nachricht, Von den Frantzösischen, Lateinischen und Deutschen Journalen, Ephemeridibus, Monatlichen Extracten, oder wie sie sonsten Nahmen haben mögen [...], Leipzig/Gardelegen 1718. 
- Continuation der gründlichen Nachricht. Von denen Journalen, Ephemeridibus, Monatlichen Extracten, So in Frantzösischer, Lateinischer und Deutscher Sprache Von Anno 1717. biß 1720. ans Licht kommen [...], Leipzig/Gardelegen 1720.

- Die andere Continuation der Gründlichen Nachricht. Von denen Journalen, Ephemeridibus, Monatlichen Extracten, So in Frantzösischer, Lateinischer und Deutscher Sprache von Anno 1720. biß 1724. ans Licht kommen [...], Leipzig/Gardelegen 1724.

Götter-Both Mercurius: Der Verkleidete Götter-Both Mercurius, welcher durch Europa wandernd, einige wichtige Discursen [...] warhafftig der Welt zum Nachricht entdecket, und verfasset [...], Warburg 1675.

Historischer Kern: [HAPPel, Eberhard Werner (Hg.)], Des Historischen Kerns oder so genannten kurtzen Chronica Vierdter Theil Zweytes Stück Fürstellend Die merckwürdigste Welt= und Wunder $=$ Geschichte $/$ So sich in und ausser Europa durch die Welt hin und wieder von Ao. 1705 biß 1709 [...] begeben haben [...] beschrieben von Everhardo Guerno HAPPELIO, Hamburg 1710.

Historischer Mercurius worinnen das Wichtigste, was zu disen Zeiten in ganz Europa vorgehet, [...] zusammengetragen und entworffen wird, 84 Tl. in 7 Bd., Augsburg 1712-1718.

Hoffmann, Christian Gottfried (Hg.)=Aufrichtige und Unpartheyische Gedancken.

[Lehmann, Peter Ambros (Hg.)], Historische Remarques der neuesten Sachen in Europa des [...] Jahres, Hamburg 1699-1707.

Lettres historiques: [Bernard, Jacques/Dumont, Jean], Lettres historiques, contenant ce qui se passe de plus important en Europe, et les réflexions nécessaires sur ce sujet, 73 Bd., Den Haag/Amsterdam 1692-1728.

Ludolf, Georg Melchior von, Electa Juris Publici. Worinnen Die Vornehmsten Staats-Affairen in Europa/Besonders in Teutsch=Land/aus bewährtesten Actis publicis [...] recensiret werden, 21 Bd., München 1709-1725.

Mercure historique: [Courtilz DE SAndRas, Gatien des (Gründungs-Hg.)], »Mercure historique et politique, contenant l'état présent de l'Europe, ce qui se passe toutes les cours, l'intérêt des princes, leurs brigeurs, et généralement tout ce qu'il y a de curieux, le tout accompagné de réflexions politiques sur chaque État«, 192 Bd., Den Haag 1686-1782.

Monatlicher Staats-Spiegel: [Acxtelmeier, Stanislaus Reinhard (Hg.)], Monatlicher Staats-Spiegel; Worinnen der Kern aller Avisen; Ein Begriff der vornehmsten im H. Röm. Reich vorfallenden Affairen mit vilen Curiosen Beylagen, samt einigen Politischen Reflexionen sich repraesentirt und vorstellet, Augsburg 1698-1709.

[Moser, Johann Jacob (Hg.)]=»Reichs=Fama $\ll$

Neu=eröffneter Welt $=$ und Staats=Spiegel: [Zschackwitz, Johann Ehrenfried (Hg.)], $\mathrm{Neu}=$ eröffneter Welt $=$ und Staats $=$ Spiegel $/$ Worinnen die in Europa $/$ wie auch denen andern Theilen der Welt/vornehmlich in Teutschland vorfallende merckwürdigen Begebenheiten kürtzlich vorgestellet [...] wird, 8 Bd. (T1. 1-100), Haag [= Leipzig] 1709-1716.

Das Neueste von Historisch= und Politischen Sachen/bestehend In unterschiedenen Urtheilen über die jetzigen Staats=, Kriegs= und andere Affairen/[...], 2 Bd. (H. 1-24), Frankfurt a.M. 1711-1714.

Paullini, Antonio [d.i. Schmauss, Johann Jakob], Curieuses Bücher-Cabinet oder Nachricht von Historischen Staats- und galanten Sachen, 8 Bd., Frankfurt a.M., Köln 1711-1722.

Reichs=Fama: [Moser, Johann Jacob (Hg.)], Welche das Merckwürdigste von demjenigen, so sich gantz kürtzlich auf dem Reichs-Convent [...] zugetragen [...], 23 Bd., Frankfurt a.M./Leipzig 1727-1738.

Relationes Curiosae: Relationes Curiosae Oder Denckwürdigkeiten der Welt/Worinnen Allerhand remarquable Seltenheiten/merckwürdige und bißher unbekannte Geschichte/LebensBeschreibungen [...] mit allem Fleiß zusammen getragen [...] worden; Daß also diese Arbeit gar 
füglich E.G. Happelii Continuation seiner hiebevor gedruckten curieusen Relationen genannt werden könne, 3 Bd., Hamburg 1707-1709.

Schumann, Gottlieb (Hg.)=Europäische Fama, neue.

SInOld von Schütz, Philipp Balthasar u.a. (Hg.)=Europäische Fama.

[- (Hg.)], Des Träumenden Pasquinii Kluger Staatsphantasien Über den ietzigen verwirreten Zustand der Welt. Erste Erscheinung Allen Curieusen und Staatsverständigen Gemuethern zu fernerem Nachdencken zugeeignet und übergeben, Freyburg [= Leipzig] 1697.

[- (Hg.)], Das courieuse Caffé-Haus zu Venedig [...], 3 Bd., Freyburg [= Leipzig] 1698-1700.

[- (Hg.)], Der Fliehende Passagier Durch Europa/Welcher die remarquablesten Staats= und Privat=Händel/nebst einigen darüber geführten Raisonnements [...] mittheilet, 12 H. (Promenaden), Freystadt [= Leipzig] 1698-1702.

[SтüвеL, Andreas, Hg.], Der neu=bestellte Agent von Haus aus/mit allerhand curieusen Missiven, Brieffen/Memoralien, Staffeten, Correspondencen, und Commissionen, nach Erforderung der heutigen Staats- und gelehrten Welt [...], 3 Bd., Freyburg [= Leipzig] 1704-1708.

$[-\mathrm{Hg}$.], Der mit allerhand Staats $=$, Friedens $=, \mathrm{Kriegs}=, \mathrm{Hof}=$, Literatur $=$ und Religions $=$ wie auch Privat=Affairen beschäftigte Secretarius [...], 4 Bd. (= 48 Expeditionen), Freyburg [= Leipzig] 1710-1721.

Der Welt Urtheile von den gegenwärtigen Staats-, Kriegs-, gelehrten und gemeinen Sachen schertz- und ernsthafft ausgeführet, 2 Bd. (20 H.), Leipzig 1706-1711.

Thомаsıus, Christian, Schertz= und Ernsthaffter/Vernünfftiger und Einfältiger Gedancken/über allerhand Lustige und nützliche Bücher und Fragen. Erster Monath oder Januarius, in einem Gespräch vorgestellet von derer Gesellschaft der Müßigen, Frankfurt a.M./Leipzig 1688.

- Freymüthige, Lustige und Ernsthaffte iedoch Vernunft= und Gesetz=Mässige Gedancken oder Monaths $=$ Gespräche / über allerhand / fürnehmlich aber Neue Bücher Durch alle zwölf Monate des 1688. und 1689. Jahrs [...], [4] Bd., Halle a.d. Saale 1690.

ZschackwITZ, Johann Ehrenfried $(\mathrm{Hg})=.\mathrm{Neu}=$ eröffneter Welt= und Staats=Spiegel.

\subsection{Sonstige Quellenwerke und -editionen}

Abelein, Johann Philipp u.a. (Hg.) = Theatrum Europaeum

Adelung, Johann Christoph (Hg.), Versuch eines vollständigen grammatisch-kritischen Wörterbuchs der hochdeutschen Mundart, mit beständiger Vergleichung der übrigen Mundarten, besonders aber der oberdeutschen, 5 Bd., Leipzig 1774-1786.

Alsted, Johann Heinrich, Encyclopaedia Septem tomis distincta, 7 Bd., Herborn 1630 (ND Stuttgart 1988-90).

Althusius, Johannes, Politica methodice digesta atque exemplis sacris et profanis illustrata [...], Herborn ${ }^{3} 1614$ (ND Aalen 1981).

Amman, Jost, Eygentliche Beschreibung Aller Stände auff Erden/Hoher und Nidriger/Geistlicher und Weltlicher/Aller Künsten/Handwercken und Händeln [...], Frankfurt a.M. 1568 (ND 2006).

BEIER, Adrian, Kurtzer Bericht von Der Nützlichen und Fürtrefflich Buch-Handlung und Deroselben Privilegien, Jena 1690.

Besold, Christoph, De Arcanis Rerum Publicarum, Straßburg [Argentorati] 1614.

Beust, Joachim Ernst von, Der Versuch einer ausführlichen Erklärung des Post-Regals und was deme anhängig, überhaupt und ins besondere in Ansehung des Heiligen Römischen Reichs Teutscher Nation [...] verfasset, 3 Bd., Jena 1747-1748.

Blanc, Thomas, Histoire de Bavière, 4 Bd., Paris 1680.

Blühm, Elger/Engelsing, Rolf (Hg.), Die Zeitung. Deutsche Urteile und Dokumente von den Anfängen bis zur Gegenwart, Bremen 1967. 
Bodin, Jean, Über den Staat. Übersetzt und herausgegeben durch Gottfried NIEDHART, Stuttgart 1976.

Botero, Giovanni, Della Ragione di Stato libri dieci, Venedig 1589.

BREDNICH, Rolf Wilhelm, Liedpublizistik des 15. bis 17. Jahrhunderts, 2 Bd., Baden-Baden 1974.

Buschmann, Arno (Hg.), Kaiser und Reich. Klassische Texte und Dokumente zur Verfassungsgeschichte des Hl. Römischen Reiches Deutscher Nation vom Beginn des 12. Jahrhunderts bis zum Jahre 1806, München 1984.

Cervantes, Miguel de, Der sinnreiche Junker Don Quijote von der Mancha (1605). In der Übertragung von Ludwig Braunfels, durchgesehen von Adolf Spemann, München 1979.

Chladenius, Johann Martin, Allgemeine Geschichtswissenschaft, Leipzig 1752.

ConRIng, Hermann, Was es mit den Reichs-Vicariaten vor eine Beschaffenheit habe, und wem dieselbige an den Römischen Reich zukommen?, o.O. 1657, abgedruckt in der Ausgabe von Hermann ConRing, Opera, hg. v. Johann Wilhelm Goebel, 7 Bd., Braunschweig 1730, hier Bd. 2, S. $463-466$.

[-] $»$ Vicariatus Imperii Palatinus defensus auctore Andreae Nordenio«, o.O. 1657, abgedruckt in der Ausgabe von Hermann ConRing, Opera, Bd. 1, S. 811-836.

- Vicariatus Imperii Palatinus defensus, o.O. 1721.

Coupe, William A. (Hg.), The German Illustrated Broadsheet in the Seventeenth Century. Historical and Iconographical Studies, 2 Bd., Baden-Baden 1966-1967.

[DECKHERR, Johann], »Gründliche Historische Nachricht von den von Zeiten Friedrichs II. bis auff den Kays. Leopoldi vorgewesenen Interregnis und in denenselben hergebrachten Vicariaten, deren Verrichtungen und Zufällen«, o.O. 1690.

[-] $\gg$ Gründliche Historische Nachricht von denen Interregnis und Vicariaten Teutschen Reiches, deren Verrichtungen und Zufällen, absonderlich soviel die Verwaltung höchster Justiz betrifft«, o.O. 1711.

Dietrich, Richard (Hg.), Die politischen Testamente der Hohenzollern, Köln/Wien 1986.

Diarium Europaeum: [MeYer, Martin u.a. (Hg.)], Philemeri Irenici Elisii Diarium Europaeum insertis actis electoriis Oder Kurtze Beschreibung denkwürdigster Sachen/So sich in Frieds= und Kriegs $=$ Geschäfften in Europa/fürnemlich aber in dem Heil. Röm. Reich/und demselben nahe angrentzenden königreichen/Landen und Herrschafften [...] vom Jahre 1657 biß ins Jahr [1681] begeben haben, 45 Bd., Frankfurt a.M. 1659-1683.

Droysen, Johann Gustav u.a. (Hg.), Preußische Staatsschriften aus der Regierungszeit Friedrichs II., 3 Bd., Berlin 1877-1892.

Duchnardt, Heinz (Hg.), Politische Testamente und andere Quellen zum Fürstenethos der Frühen Neuzeit, Darmstadt 1987 (FSGA - Ausgewählte Quellen zur deutschen Geschichte der Neuzeit, Bd. 18).

Eitzing, Michael von, De Leone Belgico eius Topographia atque historica descriptione liber [...], Köln 1583.

- Niderländische Beschreibung/in Hochteutsch/und Historischer weiß gestellt/auff den Belgischen Löwen/der Sibenzehn Provintzen deß gantzen Niederlandts [...], 2 Bd., Köln 1584.

- Rerum Vaticiniis accomodata Historia: Das ist: Eine Hystorische Beschreibung oder Relation deß so sich nit allain under dem jetzt regier. Khayser Rudolpho II. [...] wegen Hinlegung und Abstellung der Niderländischen [...] Empoerung etc. verloffen, Köln 1584.

- Kurtzer Historischer Begriff und Inhalt/der Haendel/so sich im Niederlandt/und Ertzstifft Cölln die nechsten sechs Monat hero/und etwas darvor/zugetragen/bis auff jetzt ablauffendts Monat Septembris/ Anno 1586, Köln 1586.

- Kurtzer Historischer Begriff und Inhalt/der Hendel/so sich im Niederlandt/und Ertzstifft Cöln die nechsten sechs Monat hero/und etwas davor/zugetragen/biß auff jetz ablauffendts Monat Septembris Anno 1586, o.O. 1587. 
- Belgici Leonis Chorographia Das ist Ein Newe Landt beschreibung des Belgischen Lewen in XVII Prouincien des gantzen Niderlandts außgetheilet, Köln 1587.

[-] M. Eytzeringeri Historicarum Relationum Continuatio. Das ist historische Beschreibung was sich hin und wider durch gantz Europa gedenckwirdigs zugetragen [...], Köln 1599.

Ens, Caspar, Annalium sive Commentariorum de bello Gallico Belgico tomi III [...], Köln 1606.

- Annalium Mercurio Gallobellico succenturiatorum tomus quintus [...], Köln 1606.

- Fama austriaca, Das ist: Eigentliche Verzeichnuß denckwürdiger Geschichten/welche sich in den nechstverflossenen 16 Jahren hero biß auff und in das Jahr 1627 begeben haben [...], Köln 1627.

Erasmus von Rotterdam, Fürstenerziehung. Institutio Principis Christiani. Die Erziehung eines christlichen Fürsten (1525), hg. v. Anton J. GaIL, Paderborn 1968.

FABER, Anton [= Leucht, Christian Leonhard], Europäische Staats-Cantzley, darinnen zum Behuff der neuesten politischen-, Kirchen- und Reichshistorie [...] abgehandelt worden und zum Vorschein gekommen ist, Frankfurt a.M./Leipzig/Nürnberg 1697-1760.

[Fassmann, David], M.G. Historie des Jahrs 1724 oder zur Kirchen= Politisch= und Gelehrten=Historie dieses Jahrs gehörige Haupt=Anmerkungen, in gewisse zu Coburg Monathlich edirte Zeitungs=Extracte aufs fleissigste gebracht [...], Coburg 1725.

[-] Der Gelehrte Narr, Oder Gantz natürliche Abbildung Solcher Gelehrten, Die da vermeynen alle Gelehrsamkeit und Wissenschafften verschlucket zu haben [...] Nebst einer lustigen Dedication und sonderbaren Vorrede [...], Freyburg [= Leipzig] 1729.

[-] Parention Wie sie, Auf allergnädigsten Befehl, Bey einer sehr Volckreichen Versammlung gehalten worden, Von Seiner Königl. Majestät Allerdemütigstem Knecht D[aniel] F[assmann] Als man den, am 11. Aprilis 1731. zu Potsdam verstorbenen Freyherrn von Gundling [...] beerdiget, Potsdam 1731.

- Leben und Thaten des Allerdurchlauchtigsten und Großmächtigsten Koenigs von Preussen Friderici Wilhelmi Biss auf gegenwertige Zeit aufrichtig beschrieben [...], Hamburg/Breslau 1735.

Franckenberg, Friedrich Leuthoff von [ $=$ Zech, Bernhard von], Der europäische Herold, Oder Zuverläßige Beschreibung Derer Europäisch-Christlichen Kayserthums, Königreiche, freier Staaten und Fürstenthümer [...], Nürnberg 1688.

- $[=$ ZесH, Bernhard von], Europäischer Herold, Oder Zuverläßige Beschreibung Derer Europäisch-Christlichen Kayserthums, Königreiche, freier Staaten und Fürstenthümer [...], 2 Bd., Leipzig ${ }^{2} 1705$.

Friedlaender, Ernst (Hg.), Berliner geschriebene Zeitungen: Aus den Jahren 1713 bis 1717 und 1735. Ein Beitrag zur preußischen Geschichte unter König Friedrich Wilhelm I., Berlin 1902.

Fritsch, Ahasver, Discursus de Novellarum, quae vocant Neue Zeitunge/hodierno usu et abusu, o.O. 1676 .

[Gewold, Christoph], Commentarius de Sacri Romani Imperii Septemviratu, München 1616.

Goldast von Haiminsfeld, Melchior, Politische Reichshändel. Das ist/Allerhand gemeine Acten/Regimentssachen/und Weltliche Discursen: Das gantze heilige Römische Reich/die Keyserliche und Königliche Majestäten betreffendt, Frankfurt a.M. 1614.

Gribner, Michael Heinrich, Commentario de iuribus vicariorum Imperii, illis in primis, quae perperam a nonnullis in dubium vocantur [...], Leipzig 1743.

Grimmelshausen, Johann Jacob Christoffel von, Simplicissimus teutsch (1668/1669), hg. v. Dieter BREUER, Frankfurt a.M. 2005.

Hagen, Samuel Fridericus, Disputatio Juridica de Jure Novellarum [= Von Neuen Zeitungen], Leipzig 1697.

[HAPPEL, Eberhard Werner], »Des Historischen Kerns oder so genannten kurtzen Chronica Vierdter Theil Zweytes Stück Fürstellend Die merckwürdigste Welt $=$ und Wunder $=$ Geschichte $/$ So sich in und ausser Europa durch die Welt hin und wieder von Ao. 1705 biß 1709 [...] begeben haben [...] beschrieben von Everhardo Guerno Happelio«, Hamburg 1710. 
Harms, Wolfgang/Schilling, Michael (Hg.), Deutsche illustrierte Flugblätter des 16. und 17. Jahrhunderts, Bd. 1-4, 6/1 u. 6/2, München, Tübingen 1980-1997.

- u.a. (Hg.), Illustrierte Flugblätter des Barock. Eine Auswahl, Tübingen 1983 (Deutsche Neudrucke, Reihe Barock, Bd. 30).

- /Kruse, Joachim (Hg.), Illustrierte Flugblätter aus den Jahrhunderten der Reformation und der Glaubenskämpfe. Ausst.-Kat. der Veste Coburg, Coburg 1983 (Katalog der Kunstsammlungen der Veste Coburg, Bd. 40).

HarsdörfFER, Georg Philipp, Der Teutsche Secretarius: Das ist: Allen Cantzleyen, Studir- und Schreibstuben nützliches, fast nohtwendiges, und zum drittenmal vermehrtes Titular- und Formularbuch [...], 2 Bd., Nürnberg 1656-1659 (ND Hildesheim/New York 1971).

Hartmann, Johann Ludwig, Unzeitige Neue=Zeitungs=Sucht $/$ und Vorwitziger Kriegs=Discoursen Flucht/[...], Rothenburg 1679.

Hartnack, Daniel, Erachten von Einrichtung Der alten Teutschen und neuen Europäischen Historien, Celle 1688.

Hausen, Carl Renatus, Einige Anecdoten zu dem Leben des berühmten Sammlers Johann Christian Lünig, in: Ders., Vermischte Schriften, Halle a.d. Saale 1766, S. 28-31.

Hellwig, Fritz (Hg.), Franz Hogenberg - Abraham Hogenberg. Geschichtsblätter, Nördlingen 1983.

Henning, Aegidius, Gepriesener Büchermacher Oder von Büchern und Bücher machen ein zwar kleines/jedoch lustiges und erbauliches Büchlein, Frankfurt a.M. 1666.

Hoffmann, Hanns Hubert (Hg.), Quellen zum Verfassungsorganismus des Heiligen Römischen Reiches Deutscher Nation 1495-1815, Darmstadt 1976.

HoHBerg, Wolf Helmhardt von, Georgica Curiosa, Das ist: Umständlicher Bericht und klarer Unterricht Von dem Adelichen Land= und Feld=Leben [...], 3 Bd., Nürnberg 1682 (ND Wien 1984).

HüBNER, Johann, Reales Staats $=$ Zeitungs $=$ und Conversations $=$ Lexicon. Darinnen so wohl die Religionen und geistlichen Orden, die Reiche und Staaten [...] deutlich beschrieben werden [...], Leipzig ${ }^{8} 1717$.

[HunoLD, Johann], »Kurtze und gründliche Anleitung/Wie man die Journal-, Quartal- und Annual-Schrifften Ohne Versäumung seiner Studiorum zu bequemer Zeit und mit grossen Nutzen lesen kann [...] von J.H.«, o.O. 1716.

Hyperius, Andreas, Ein treuer und christlicher Rath, wie man die Heilige Schrifft teglich lesen soll/allen Stenden der Christen menschen sehr notwendig/Zwey Bücher, Mühlhausen 1562 .

Jöcher, Christian Gottlieb/Adelung, Johann Christoph (Hg.), Allgemeines Gelehrten-Lexicon, 4 Bd. (Forts. 7 Bd.), Leipzig 1750-1751 (Forts. bis 1897).

Karnehm, Christl/Preysing, Maria Gräfin von (Hg.), Die Korrespondenz Hans Fuggers von 1566 1594. Regesten der Kopierbücher aus dem Fugger-Archiv, 3 Bd., München 2003.

Klarvill, Viktor van (Hg.), Fugger-Zeitungen. Ungedruckte Briefe an das Haus Fugger aus den Jahren 1568-1605, Wien/Leipzig/München 1923.

KLÜVER, Hans Henrich [= JARGOW, Christoph-Georg], Beschreibung des Herzogtums Mecklenburg, 6 Bd., Hamburg 1728-1740.

Knuttel, Willem Pieter Cornelius (Hg.), Catalogus van de pamfletten-verzameling berustende in de Koninklijke Bibliotheek, 9 Bd., Den Haag 1889-1920 (ND Utrecht 1978) (=Knuttel).

KöHLER, Hans-Joachim (Hg.), Flugschriften des frühen 16. Jahrhunderts (1501-1530). MicroficheSerie, Leiden $1989 \mathrm{ff}$.

- Flugschriften des späteren 16. Jahrhunderts (1531-1600). Microfiche-Serie, Leiden 1990ff.

KöHLER, Johann David, Gedenckwürdigkeiten des jetzt lauffenden achtzehenden Jahr-Hunderts nach Christi Geburt: als eine Fortsetzung der Welt in einer Nuß in Gedächtnis-hülflichen Bilder-Tafeln. Mit einer historischen Einleitung, 20 Bilder, Nürnberg 1701-1739.

KöNIG, Johann C., Gründliche Abhandlung von denen hohen Reichs=Vicariats Gerechtsamen [...], Frankfurt a.M. u.a. 1741. 
- Abhandlung derer hohen Reichs-Vicariats-Gerechtsamen, 3 Tl. in einem Bd., Marburg 17431753.

KuLPIS, Johann Georg von, »Deduction Daß dem Hoch=Fürstl. Haus Württemberg/das Reichs= Panner $=$ oder Reichs $=$ Fendrich $=$ Amt $/$ Praedicat und Insigne, schon von etlichen Seculis her/rechtmässig zustehe [...] «, o.O. 1693.

KurTh, Karl (Hg.), Die ältesten Schriften für und wider die Zeitung, Brünn u.a. 1944.

Lang, Franz Christoph Ludwig von, Instruktion und Ordnung des von den [...] Churfürsten in Bayern und Pfalz in [...] Augsburg gemeinschaftlich errichteten [...] Reichs-Vicariat Hof $=$ Gericht, Augsburg 1741.

LAPIDE, Hyppolito à (Pseud.), »Allerhand Curiose Raisonnements von der IX. Chur=Würde Deß Durchleucht. Fürsten und Herrn/Herrn Ernst Augusti Hertzogen zu Braunschweig und Lüneburg als nunmehro des Heil. Röm. Reichs Ertzpanner und Chur=Fürsten/zusammen getragen«, o.O. 1693 .

[LeibNiz, Gottfried Wilhelm], »Caesarini Fuerstenerii De Jure Suprematus Ac Legationis Principum Germaniae Tractatus«, Amsterdam 1678 (Erstausgabe 1677).

[-] »Unvorgreifliches Sentiment Uber die Neue Hannoverische Chur=Würde/ Darinnen die dabey vorkommende vornehmste Quaestiones unpartheyisch ausgeführet/und die gröste dubia removiret worden «, o.O. 1693.

$[-] »$ Wechsel=Schrifften vom Reichs=Bannier, In sich haltend einen Beweiß Vom Unterscheid zwischen demselben und der Würtembergischen Sturm=Fahne, Dann ferner die Hoch=Fürstl. Würtembergische Deduction samt deren Beantwortung [...]«, Hannover 1694.

[Leucht, Christian Leonhard (Pseud.: Thucelius, Cassander)], »Electa Juris Publici Curiosa. Vorstellend das Alte Fürsten=Recht/samt den Novem=Viratum Vornehmlich aber Des Fürstlichen Haußes Würtemberg Jura Wegen des Reichs=Pannerer und Fendrich Ambts /[...]«, Frankfurt a.M./Leipzig 1694.

- Des Heillgen Römischen Reichs-Staats Acta von itzigen 18. seculo sich anfahend, in welchen nicht allein, die bey annoch währenden Reichs-Tag eingereichte Staats-Schrifften [...] enthalten [...] In gute Ordnung gebracht [...] von Cassandro Thucelio, 5 Bd., Frankfurt a.M. u.a. 17151722 .

- =FABER, Anton (Pseud.).

Lipsius, Justus, Von der Bestendigkeit. De Constantia (1584). Faksimiledruck der deutschen Übersetzung des Andreas Viritius ('1601), hg. v. L. Forster, Stuttgart 1965.

Lorchanus, Gaspar [= Ens, Caspar], Mercurii Gallobelgici succenturiati sive rerum in Gallia et Belgio [...] gestarum historicae narrationis continuatae tomus quartus [...], Köln 1603.

LuCINGE, René de, De la naissance, durée et chute des Estats, Paris 1588.

LudewIG, Johann Peter von, Vom Gebrauch und Mißbrauch Der Zeitungen/Bey Eröffnung eines Collegii geführet. Anno 1700, Halle a.d. Saale 1705 (Fotoreprint 1964).

- Unterricht Von denen wöchentlichen Anzeigen, Die Auf Königl. Majest. in Preussen allergnädigsten Special-Befehl/in Dero Reich, Provintzien und Landen, durch die so genannte Intelligenz-Zettel/angeordnet. Absonderlich zum Behuf den Universitäten und Stadt Halle, in folgenden Artickeln entworfen [...], Halle a.d. Saale 1729.

Ludolf, Georg Melchior von, Compendieuse Beschreibung Eines Reichs-Tags, Wie er Im Heil. Römischen Reich gehalten wird [...], Halle a.d. Saale 1720.

LÜNIG, Johann Christian (Hg.), Das Teutsche Reichs-Archiv [...], 24 Bd., Leipzig 1710-1722.

- Grundveste europäischer Potenzen Gerechtsame, Worinn Durch auserlesene Deductiones, Informationes, Repraesentationes, und andere merckwürdige Schrifften ausführlich dargethan wird, Wie es um [...] Unterschiedene hohe Jura, Ansprüche und Praecendenz-Streitigkeiten eigentlich beschaffen sey [...], 2 Tl., Leipzig 1716.

- Theatrum ceremoniale historico=politicum oder Historisch $=$ und politischer Schau=Platz aller Ceremonien [...], 3 Bd., Leipzig 1719-1720.

- (Hg.), Bibliotheca deductionum S.R.I., anietzo in eine geschicktere Ordnung gebracht, durchaus verbessert, und ansehnlich vermehret von Gottlob August Jenichen, 4 Tl., Leipzig 1745. 
LundorP, Michael Caspar, Der Römischen Keyserlichen [...] Mayestat [...] und deß heiligen Römischen Reichs / Geistlicher und Weltlicher Chur und Fürsten und anderer Reichsständ Acta Publica [...], 10 Bücher in 4 Bd., Frankfurt a.M. 1621-1624 (nebst zahlreichen späteren Auflagen).

Luther, Martin, D. Martin Luthers Werke. Kritische Gesamtausgabe, 101 Bd. in 4 Reihen (WA = Weimarer Ausgabe), Weimar 1883-1970.

LutTenBerger, Albrecht P. (Hg.), Katholische Reform und Konfessionalisierung, Darmstadt 2006 (FSGA - Ausgewählte Quellen zur deutschen Geschichte der Neuzeit, Bd. 17).

Machiavelli, Niccolò, Il Principe/Der Fürst. Italienisch/deutsch, übers. u. hg. v. Philipp RIPpel, Stuttgart 1986.

Malvezzi, Virgilio, Ritratto del Privato politico christiano, in: Opere del Marchese Malvezzi, Mediolanum/Mailand 1635.

MarPerger, Paul Jacob, Anleitung zum rechten Verstand und nutzbarer Lesung Allerhand sowohl gedruckter als geschriebener [...] Ordentlicher und Außerordentlicher Zeitungen oder Avisen, o.O. 1726 .

[MeIERN, Johann Gottfried von], »Pro Memoria oder Gegen=Information Die Mecklenburgische Administrations-Sache betreffend«, o.O. 1730.

Meurer, Peter H. (Hg.), Atlantes Colonienses. Die Kölner Schule der Atlaskartographie, Bad Neustadt a.d. Saale 1988.

MeYer, Martin u.a. (Hg.)= Diarium Europaeum.

Moser, Friedrich Carl, Teutsches Hofrecht, in zwölf Büchern, 2 Bd., Frankfurt a.M./Leipzig $1754 / 55$.

Moser, Johann Jacob, Teutsches Staatsrecht, 50 Bd., Nürnberg 1737ff. (ND Osnabrück 1967).

- Neues Teutsches Staatsrecht, 20 Bd., Frankfurt a.M. 1766-1782 (ND Osnabrück 1967/68).

- Von der Reichsverfassungsmäßigen Freyheit von Teutschen Staats=Sachen zu schreiben, Göttingen, Gotha 1772.

Mühleisen, Hans-Otto/Stammen, Theodor/Philipp, Michael (Hg.), Fürstenspiegel der Frühen Neuzeit, Frankfurt a.M. 1997.

Naumann, Christian Nikolaus, Leben und Werk der Kurfürsten von Bayern, Manuskript Leipzig 1730.

NeukiRch, Johann Georg, Politisch=Moralische Maximen in der Conversation mit hohen und niedrigen Personen beyderley Geschlechtes auf Universitäten, auf Reisen, bey Hofe, im Vaterland [...], der Studirenden Jugend zum besten entworffen, Braunschweig 1726.

PaAs, John Roger (Hg.), The German Political Broadsheet 1600-1700 (bisher bis 1682), 10 Bd., Wiesbaden 1985ff. (-2010).

Pachner von Eggenstorff, Johann Joseph, Vollständige Sammlung aller von Anfang des noch fürwährenden Teutschen Reichs-Tags de Anno 1663 bis anhero abgefaßten Reichs-Schlüsse, 4 Bd., Regensburg 1740-1777.

Palazzo, Giovanni Antonio, Discorso del Governo e della Ragion Vera di Stato, Venedig 1606.

Praetorius, Johannes, MDCLXVI Zodiacus Mercurialis. Das ist: Jährige Europäische Welt $=$ Chronick /So in einem wohl=verfasseten kurtzem Begriff/alle merckwürdigsten Begebenheiten vorbildet/welche sich im [...] 1666ten Wunder=Jahre [...] zugetragen haben [...], o.O. 1667 (und Folgehefte bis 1669).

Radbruch, Gustav (Hg.), Die Peinliche Gerichtsordnung Kaiser Karls V. von 1532, Stuttgart ${ }^{4} 1978$.

Riephan, Wilhelmus, Supplementum Epitomes. Das ist/Kurtze Warhaffte/unnd Eigentliche Historische beschreibung/deren glaubwürdigsten Händeln und Geschichten, die welche sich in [...] Hoch unnd Niederteutschland [...] zugetragen [...], Köln 1593.

RонR, Johann Bernhard von, Einleitung zur Ceremoniel-Wissenschafft Der Privat-Personen/Welche Die allgemeinen Regeln/die bey der Mode, den Titulaturen/dem Range/den Complimens, den Geberden, und bey Höfen überhaupt, als auch bei den geistl. Handlungen, in der Conversation, bey der Correspondenz, bey Visiten, Assembleen, Spielen, Umgang mit Dames, Gaste- 
reyen, Divertissements, Ausmeublirung der Zimmer, Kleidung, Equipage u.s.w. insonderheit dem Wohlstand nach von einem jungen teutschen Cavalier in Obacht zu nehmen/vorträgt, Einige Fehler entdecket und verbessert, und sie hin und wieder mit einigen moralischen und historischen Anmerckungen begleitet, hg. v. Gotthardt FrÜHSORgE, Berlin 1728 (ND Weinheim 1990).

- Einleitung zur Ceremoniel-Wissenschafft Der grossen Herren, die in vier besondern Theilen Die meisten Ceremoniel- Handlungen/so die Europäischen Puissancen überhaupt/und die Teutschen Landes=Fürsten insonderheit, so wohl in ihren Häusern, in Ansehung ihrer selbst, ihrer Familie und Bedienten, als auch gegen ihre Mit=Regenten, und gegen ihre Unterthanen bey Krieges $=$ und Friedens=Zeiten zu beobachten pflegen; Nebst den mancherley Arten der Divertissements vorträgt/sie so viel als möglich in allgemeine Regeln und Lehr=Sätze einschlüßt, und hin und wieder mit einigen Historischen Anmerckungen aus dem alten und neuen Geschichten erläutert, (hg. v. Monika Schlechte), Berlin 1733 (ND Weinheim 1990).

Rотн, Adolf (Hg.), Lieber bayrisch sterben. Der oberländische Bauernaufstand von 1705. Zeitgenössische Berichte, München 1955.

Rühlmann, Gottfried, Historische und Staatsmäßige Untersuchung/obs dem H. Röm. Reiche Deutscher Nation zuträglich und rühmlich sey/die beyden gewesenen Chur-Fürsten von Cöln und Bayern/Ihren Verlangen nach/zur instehenden Wahl eines neuen Römischen Kaysers ordentlich zu beruffen [...], o.O. 1711 .

[- (zugeschrieben)], »Des gewesenen Chur=Fürstens von Bayern Protestation Wider die jetzt bevorstehende Römische Kayser=Wahl Nebst kurz abgefasten Histor= und Politischen Anmerckungen Woraus derselben Protestation Nichtigkeit und Ohnmacht zu ersehen«, o.O. 1711.

SACHSSE, Hugo (Hg.), Mecklenburgische Urkunden und Daten. Quellen vornehmlich für Staatsgeschichte und Staatsrecht Mecklenburgs, Rostock 1900.

Sснаuroth, Eberhard Christian Wilhelm von (Hg.), Vollständige Sammlung aller Conclusorum, Schreiben und anderer übrigen Verhandlungen des hochpreislichen Corporis Evangelicorum (1663-1752) ... nach Ordnung der Materien zusammen getragen, 3 Bd., Regensburg 1751-1752.

[Schevius, Johann (Hg.)], Höchst=gemüßigter Historischer= Acten-mäßiger Bericht von dem, was von Anfange der, im Monath Augusto 1713. angetretenen Regierung Herrn Carl Leopold, Hertzogen zu Mecklenburg, biß zu der, im Monat Martio und April 1719. ergangenen Kayserl. Execution von dem Fürstl. Mecklenburgischen Ministerio wider die Mecklenburgische Ritterschafft und Stadt Rostock vorgenommen worden (mit Beylagen von Num. 1-885), o.O. 1719.

[Schmauss, Johann Jakob/Senckenberg, Heinrich Christian (Hg.)], Neue und vollständigere Sammlung der Reichs=Abschiede, welche von den Zeiten Kayser Conrads II. bis jetzo, auf den Teutschen Reichs=Tägen abgefasset worden [...], 4 Tl. in 2 Bd., Frankfurt a.M. 1747 (ND Osnabrück 1967).

Schmelzeisen, Gustav Klemens (Hg.), Polizei- und Landesordnungen. Erster Halbband: Reich und Territorien, Köln/Graz 1968.

Schumann, Gottlieb, Abriß eines Collegii über die Politischen Zeitungen [...], Leipzig 1738.

SchwARzKopf, Joachim von, Über Zeitungen. Ein Beitrag zur Staatswissenschaft, Frankfurt a.M. 1795.

- Über politische und gelehrte Zeitungen, Meßrelationen, Intelligenzblätter und über Flugschriften zu Frankfurt am Mayn, Frankfurt a.M. 1802.

Sonnenfels, Joseph von, Grundsätze der Policey-, Handlung- und Finanzwissenschaft, 3 Bd., Wien 1765-1776.

[SPANHEIM, Ezechiel (zugeschrieben)], »Discours sur les affaires d'Allemagne et sur le vicariat de l'empire«, o.O. 1657.

Steger, Tobias, Unpostreuterische/Das ist/Unpartheyhische Geschicht Schriften/So sich speder der nehesten Herbstmesse/in Spanien/England/Franckreich/Niederland/Böhmen/Polen/Ungern/Und fast in dem mehrer teil Europa zugetragen bis auff jetzigen September [...], Straßburg 1590.

Stieler, Kaspar, Teutsche Sekretariat=Kunst: was sie sey, wovon sie handele [...], 2 Bd. in 4 Tl., Nürnberg $1673 / 74$. 
- Zeitungs Lust und Nutz/Oder: derer so genanten Novellen oder Zeitungen Wirckende Ergetzlichkeiten/Anmuth/Nothwendigkeit und Fromm: Auch/was bey deren Lesung zu lernen/zu Beobachten und zu Bedencken sey [...]. Entworffen von dem Spaten, Hamburg ${ }^{1} 1695,{ }^{2} 1697$.

- Zeitungs Lust und Nutz. Vollständiger ND der Originalausgabe von 1695, hg. v. Gert HageLWEIDE, Bremen 1969.

[Struve, Burkhard Gotthelf (zugeschrieben)], »Historische Nachricht von denen Vicariaten des H. Röm. Reiches, wie sie nach Unterschied des Röm., Teutschen und Ital. Reiches unterschieden «, o.O. 1711.

- (Hg.), Ausführliche Historie der Religions=Beschwerden Zwischen denen Römisch-Catholischen und Evangelischen im Teutschen Reich [...], 2 Tl. in 1 Bd., Leipzig 1722.

- (Hg.), Corpus Actorum et Gravaminorum Religionis, 3 Tl. in einem Bd., Frankfurt a.M. 1727.

[-] »Historische Nachricht Von denen Vicariaten des Heil. Röm. Reichs/Wie Sie Nach Unterschied des Römischen/Teutschen und Italiänischen Reiches unterschieden [...]. Von Zeiten Kayser Friedrich des zweyten bis auf Anno 1711 [...]«, Frankfurt a.M. 1740 .

[-] 》Gründliche Nachricht von den Reichs-Vicariaten [...]«, Frankfurt a.M./Leipzig 1741.

Theatrum Europaeum: [ABeLEIN, Johann Philipp u.a. (Hg.)], Theatrum Europaeum, Oder Außführliche und Warhafftige Beschreibung aller und jeder denckwürdiger Geschichten/so sich hin und wieder in der Welt [...] zugetragen haben, 21 Bd., Frankfurt a.M. 1643-1738.

Tномаsius, Christian, Erinnerung wegen zweyer Collegiorum über den Andern Theil seiner Grund-Lehren, Halle a.d. Saale 1702.

Verimundus, Pambo [= Scribani, Charles], Holländisch Apocalypsis, Oder Offenbarung, Das ist: Was die gesambten Staden von Anno 1577 biß dato in der gantzen Welt für gefährliche Practicken geführt/insonderheit wider Spanien und das Haus Oesterreich hin und wider Feindlichs verübt haben/außgelegt und in Truck verfertigt [...], Newe Newenstat 1626.

Vossius, Gerhard Johann, Ars historica (1623), Leiden ${ }^{2} 1653$.

[WächtLeR, Johann Christian], »D.J.C.W. Kurtze Fragen von denen Reichs-Vicariis«, Zerbst 1711.

WAHRENBERG, Hermann von, Rechtsgegründete Untersuchung von den Vicariis imperii oder Reichs=Verwesern [...], Regensburg 1741.

WeinsBerg, Hermann von, Das Buch Weinsberg. Kölner Denkwürdigkeiten aus dem 16. Jahrhundert., hg. v. Konstantin HöHLbaum / Friedrich Lau/ Josef Stein, 5 Bd., Leipzig/Bonn 1886-1926.

WeIsE, Christian, »Bäuerischer Machiavellus« (1679). Lust-Spiel. Text und Materialien zur Interpretation besorgt von Werner SCHUBERT, Berlin 1966.

- Interessanter Abriß über das Lesen von Zeitungen [...], Frankfurt a.M./Leipzig 1685.

- Schediasma curiosa de lectione Novellarum, Weißenfels 1676.

- Curieuse Gedancken von den Nouvellen oder Zeitungen [...] vermehret von Christian JUNCKER, Leipzig/Coburg 1706.

WolfF, Richard (Hg.), Berliner geschriebene Zeitungen aus dem Jahr 1740. Der Regierungsanfang Friedrich des Großen, Berlin 1912.

- Vom Berliner Hofe zur Zeit Friedrich Wilhelms I. Berichte des Braunschweigischen Gesandten in Berlin, 1728-1733, Berlin 1914.

WütнRich, Lucas Heinrich (Hg.), Das druckgraphische Werk von Matthaeus Merian d. Älteren, Bd. 3: Die großen Buchpublikationen, Hamburg 1993.

ZeDLER, Johann Heinrich (Hg.), Großes vollständiges Universal-Lexicon aller Wissenschaften und Künste [...], 68 Bd., Halle/Leipzig 1732-1754.

Zeil, Bernhard von, Der europäische Herold $=$ FranCKenBerg, Friedrich Leuthoff von.

Zeumer, Karl (Hg.), Quellensammlung zur Geschichte der Deutschen Reichsverfassung vom Mittelalter zur Neuzeit, Tübingen 1913.

Zimmermann, Matthias Benjamin, Historico-iuridica commentario de vicariatu Sacri GermanicoRomani Imperii ex archi-officiis tradita, Leipzig 1744. 
ZschackwITZ, Johann Ehrenfried, Leben und Thaten Josephi I. Römischen Kaysers, samt der unter seiner Majestät glorwürdigsten Regierung vorgefallenen Reichs-Historie. Alles mit behörigen Documenten bekräfftiget [...], Leipzig 1712.

- Grundlegung zu dem Lehn-Rechte des Teutschen Reiches. Worinnen zugleich von einigen wichtigen Materien des Teutschen Staats-Rechts Nachricht ertheilet wird, Leipzig 1714.

- Breve et compendiosum Examen Juris Publici Imperii Germanici olim concimatum et luce expositum in usum collegiorum privatorum explicatorio-examinatoriorum [...], Coburg 1716.

- Einleitung zu denen vornehmsten Rechts=Ansprüchen, Derer Gecrönten Hohen Häupter und anderer Souverainen in Europa [...], 3 Bd., Frankfurt a.M. u.a. 1733-1735.

ZwantZIG, Zacharias [= Zweyburg, Ehrenhart], Theatrum Praecedentiae oder Eines Theils Illustrer Rang=Streit, Andern Theils Illustre Rang-Ordnung, Wie nemlich Die considerablen Potenzen und Grandes in der Welt [...] Nach Qualität ihres Standes, Namens, Dignität und Characters samt und sonders, In der Präcedentz, in dem Rang und Tractamente streitig seynd und competieren [...], 2 Tl. in 1 Bd., Berlin/Frankfurt a.M. 1706.

\subsection{Sekundärliteratur}

Achenbach, Heinrich von, Geschichte der Stadt Siegen, 2 Bd., Siegen 1894 (ND Kreuztal 1980).

ADAm, Wolfgang, Textelemente des Briefes auf illustrierten Flugblättern der Frühen Neuzeit, in: Wolfgang Harms / Alfred Messerli (Hg.), Wahrnehmungsgeschichte und Wissensdiskurs im illustrierten Flugblatt der Frühen Neuzeit (1450-1700), Basel 2002, S. 341-367.

Althoff, Gerd/Siep, Ludwig, Symbolische Kommunikation und gesellschaftliche Wertesysteme vom Mittelalter bis zur Französischen Revolution, in: Jahrbuch für Kommunikationsgeschichte 3 (2001), S. 210-230.

Anderson, Matthew S.[mith], The Rise of Modern Diplomacy 1450-1919, London/New York 1993.

ANGelike, Karin, Louis-François Mettra. Ein französischer Zeitungsverleger in Köln (1770-1800), Köln/Weimar/Wien 2001.

Angerer, Martin (Hg.), 450 Jahre Evangelische Kirche in Regensburg (1542-1992). Ausstellung im Museum der Stadt Regensburg, Regensburg 1992.

Angermeier, Heinz, Die Reichsreform 1410-1555. Die Staatsproblematik in Deutschland zwischen Mittelalter und Gegenwart, München 1984.

Aretin, Karl Otmar Freiherr von, Heiliges Römisches Reich 1776-1806. Reichsverfassung und Staatssouveränität, 2 Bd., Wiesbaden 1967.

- Die Politik des Kurfürsten Max Emanuel und die europäischen Mächte, in: Hubert GLASER (Hg.), Kurfürst Max Emanuel. Bayern und Europa um 1700, Bd. 1, München 1976, S. 35-50.

- Das Reich. Friedensgarantie und europäisches Gleichgewicht 1648-1806, Stuttgart 1986 (ND 1992).

- Die Politik des Kurfürsten Max Emanuel von Bayern und die europäischen Mächte, in: Ders., Das Reich. Friedensgarantie und europäisches Gleichgewicht 1648-1806, Stuttgart 1986 (ND 1992), S. 209-240.

- Das Alte Reich 1648-1806, 3 Bd., Stuttgart 1993-1997.

ARndT, Johannes, Kabale und Liebe in Detmold. Zur Geschichte einer Hofintrige und einer Fürstenabsetzung in Lippe während des ausgehenden 18. Jahrhunderts, in: Lipp. Mitt. 60 (1991), S. 27-74.

- Das Fürstentum Lippe im Zeitalter der Französischen Revolution 1770-1820, Münster/New York 1992.

- Der Kaiser und das Reich 1600-1648, in: Klaus Bussmann/Heinz Schilling (Hg.), 1648 Krieg und Frieden in Europa. Katalog zur 26. Europaratsausstellung Münster/Osnabrück 1998, Textbd. 1, München 1998, S. 69-76.

- Das Heilige Römische Reich und die Niederlande 1566-1648. Politisch-konfessionelle Verflechtung und Publizistik im Achtzigjährigen Krieg, Köln/Wien/Weimar 1998. 
- Köln und die Medienproduktion zum spanisch-niederländischen Krieg 1566-1648, in: Dieter Geuenich (Hg.), Köln und die Niederrheinlande in ihren historischen Raumbeziehungen (15.20. Jahrhundert), Pulheim/Mönchengladbach 2000, S. 339-353.

- Zwischen kollegialer Solidarität und persönlichem Aufstiegsstreben. Die Reichsgrafen im 17. und 18. Jahrhundert, in: Ronald G. Asch (Hg.), Der europäische Adel im Ancien Régime. Von der Krise der ständischen Monarchien bis zur Revolution (ca. 1600-1789), Köln/Weimar/Wien 2001, S. 105-128.

- $» P f l i c h t=$ mässiger Bericht $«$. Ein medialer Angriff auf die Geheimnisse des Reichstags aus dem Jahr 1713, in: Jahrbuch für Kommunikationsgeschichte 4 (2002), S. 1-31.

- Monarch oder der »bloße Edelmann«? Der deutsche Kleinpotentat im 18. Jahrhundert, in: Ronald G. Asch/Johannes ARndt/Matthias Schnettger (Hg.), Die frühneuzeitliche Monarchie und ihr Erbe. Fs. für Heinz Duchhardt zum 60. Geburtstag, Münster/New York 2003, S. 59-90.

- Gab es im frühmodernen Heiligen Römischen Reich ein »Mediensystem der politischen Publizistik«? Einige systemtheoretische Überlegungen, in: Jahrbuch für Kommunikationsgeschichte 6 (2004), S. 74-102.

- Verkrachte Existenzen? Zeitungs- und Zeitschriftenmacher im Barockzeitalter zwischen Nischenexistenz und beruflicher Etablierung, in: AKG 88 (2006), S. 101-115.

- Max Emanuel, Kurfürst von Bayern oder Graf von Wittelsbach? Das Gedenken an Exil und Ächtung eines Barockfürsten in der bayerischen Historiographie, in: Martin WREDE/Horst CARL (Hg.), Zwischen Schande und Ehre. Erinnerungsbrüche und die Kontinuität des Hauses. Legitimationsmuster und Traditionsverständnis des frühneuzeitlichen Adels in Umbruch und Krise, Mainz 2007, S. 65-80.

- /Körber, Esther-Beate (Hg.), Das Mediensystem im Alten Reich der Frühen Neuzeit 1600 1750, Göttingen 2010.

- Zeitung, Mediensystem und Reichspublizistik, in: Volker Bauer/Holger Böning (Hg.), Die Entstehung des Zeitungswesens im 17. Jahrhundert. Ein neues Medium und seine Folgen für das Kommunikationssystem der Frühen Neuzeit, Bremen 2011, S. 179-200.

ARnold, Martin, Handwerker als theologische Schriftsteller. Studien zu Flugschriften der frühen Reformation (1523-1525), Göttingen 1990.

Arnold, Werner/Dittrich, Wolfgang/Zehler, Bernhard (Hg.), Die Erforschung der Buch- und Bibliotheksgeschichte in Deutschland. Fs. für Paul Raabe zum 60. Geburtstag, Wiesbaden 1987.

ARnSwaldT, Albrecht von, De Vicariatus controversia. Beiträge Hermann Conrings in der Diskussion um die Reichsverfassung des 17. Jahrhunderts, Berlin 2004.

Arzt, Volker, Haben Tiere ein Bewußtsein? Wenn Affen lügen, wenn Katzen denken und Elefanten traurig sind, Gütersloh 1994.

Asbach, Olaf/Malettke, Klaus/Externbrink, Sven (Hg.), Altes Reich, Frankreich und Europa. Politische, philosophische und historische Aspekte des französischen Deutschlandbildes im 17. und 18. Jahrhundert, Berlin 2001.

Asch, Ronald G., Europäischer Adel in der Frühen Neuzeit. Eine Einführung, Köln/Weimar/Wien 2008.

- (Hg.), Der europäische Adel im Ancien Régime. Von der Krise der ständischen Monarchien bis zur Revolution, Köln/Weimar/Wien 2001.

- /ARndt, Johannes/Schnettger, Matthias (Hg.), Die frühneuzeitliche Monarchie und ihr Erbe. Fs. für Heinz Duchhardt zum 60. Geburtstag, Münster/New York 2003.

- /Duchiardt, Heinz (Hg.), Der Absolutismus - ein Mythos? Strukturwandel monarchischer Herrschaft, Köln/Weimar/Wien 1996.

- /Freist, Dagmar (Hg.), Staatsbildung als kultureller Prozess. Strukturwandel und Legitimation von Herrschaft in der Frühen Neuzeit, Köln/Weimar/Wien 2005.

- /Voss, Wulf Eckart/Wrede, Martin (Hg.), Frieden und Krieg in der Frühen Neuzeit. Die europäische Staatenordnung und die außereuropäische Welt, München 2001.

Assmann, Aleida/Assmann, Jan (Hg.), Schleier und Schwelle, Bd. 1: Geheimnis und Öffentlichkeit, München 1997. 
Auer, Leopold, Die Ziele der kaiserlichen Politik bei den Westfälischen Friedensverhandlungen und ihre Umsetzung, in: Heinz Duchnardt (Hg.), Der Westfälische Friede. Diplomatie - politische Zäsur - kulturelles Umfeld - Rezeptionsgeschichte, München 1998, S. 143173.

- /OGris, Werner/Ortlieb, Eva (Hg.), Höchstgerichte in Europa. Bausteine frühneuzeitlicher Rechtsordnungen, Köln/Wien/Weimar 2007.

Backmann, Sibylle u.a. (Hg.), Ehrkonzepte in der Frühen Neuzeit. Identitäten und Abgrenzungen, Berlin 1998.

BALD, Ludwig, Das Fürstentum Nassau-Siegen. Territorialgeschichte des Siegerlandes. Mit einem Atlas von 10 Kartenblättern, Marburg 1939.

Baldini, A. Enzo (Hg.), Botero e la ragion di stato. Atti del convegno in memoria di Luigi Firpo, Turin, 8. bis 10. März 1990, Florenz 1992.

BAllschmieter, Hans-Joachim, Andreas Gottlieb von Bernsdorff und der mecklenburgische Ständekampf (1680-1720), Köln/Graz 1962.

BAngerter-Schmid, Eva Maria, Erbauliche illustrierte Flugblätter aus den Jahren 1570-1670, Frankfurt a.M. u.a. 1986.

Barber, Giles/Fabian, Bernhard (Hg.), Buch und Buchhandel in Europa im 18. Jahrhundert, Hamburg 1981.

BARmeYer, Heide (Hg.), Die preußische Rangerhöhung und Königskrönung 1701 in deutscher und europäischer Sicht, Frankfurt a.M. u.a. 2002.

Bauer, Martin, Die »Gemain Sag« im späteren Mittelalter. Studien zu einem Faktor mittelalterlicher Öffentlichkeit und seinem historischen Aussagewert, Diss. Erlangen 1981.

BAuer, Oswald, Zeitungen vor der Zeitung. Die Fuggerzeitungen (1568-1605) und das frühmoderne Nachrichtensystem, Berlin 2011.

Bauer, Volker, Die höfische Gesellschaft in Deutschland von der Mitte des 17. bis zum Ausgang des 18. Jahrhunderts. Versuch einer Typologie, Tübingen 1993.

- Die Hofökonomie. Der Diskurs über den Fürstenhof in Zeremonialwissenschaft, Hausväterliteratur und Kameralismus, Weimar/Köln/Wien 1997.

- Repertorium territorialer Amtskalender und Amtshandbücher im Alten Reich. Adreß-, Hof-, Staatskalender und Staatshandbücher des 18. Jahrhunderts, 4 Bd. (I: Nord- und Mitteldeutschland; II: heutiges Bayern, Österreich und Liechtenstein; III: Der Westen und Südwesten; IV: Ostdeutschland), Frankfurt a.M. 1997-2005.

- Territoriale Amtskalender und Amtshandbücher im Alten Reich. Bilanz eines Forschungsprojekts, in: Rechtsgeschichte. Zeitschrift des Max-Planck-Instituts für Europäische Rechtsgeschichte 1 (2002), S. 71-89.

- Höfische Gesellschaft und höfische Öffentlichkeit im Alten Reich. Überlegungen zur Mediengeschichte des Fürstenhofs im 17. und 18. Jahrhundert, in: Jahrbuch für Kommunikationsgeschichte 5 (2003), S. 29-68.

- Jetztherrschend, jetztregierend, jetztlebend. Genealogie und Zeitungswesen im Alten Reich des ausgehenden 17. Jahrhundert, in: Daphnis 37 (2008), S. 271-300.

- Nachrichtenmedien und höfische Gesellschaft. Zum Verhältnis von Mediensystem und höfischer Öffentlichkeit im Alten Reich, in: Johannes Arndt/Esther-Beate KöRBER (Hg.), Das Mediensystem im Alten Reich der Frühen Neuzeit 1600-1750, Göttingen 2010, S. 173-193.

- /Böning, Holger (Hg.), Die Entstehung des Zeitungswesens im 17. Jahrhundert. Ein neues Medium und seine Folgen für das Kommunikationssystem der Frühen Neuzeit, Bremen 2011.

Baumanns, Markus, Das publizistische Werk des kaiserlichen Diplomaten Franz Paul Freiherr von Lisola (1613-1674). Ein Beitrag zum Verhältnis von Absolutistischem Staat, Öffentlichkeit und Mächtepolitik in der Frühen Neuzeit, Berlin 1994.

Baumgart, Peter, Friedrich Wilhelm I. (1713-1740), in: Frank-Lothar Kroll (Hg.), Preußens Herrscher. Von den ersten Hohenzollern bis Wilhelm II., München 2000, S. 134-159.

- Absolutismus ein Mythos? Aufgeklärter Absolutismus ein Widerspruch? Reflexionen zu einem kontroversen Thema gegenwärtiger Frühneuzeitforschung, in: ZHF 27 (2000), S. 573-589. 
Baumgartner, Gabriele, Die Entwicklung der obersten Landesverwaltung Mecklenburg-Schwerins vom Ende des 16. bis zur Mitte des 18. Jahrhunderts. Eine Studie zur Verwaltungsgeschichte, 2 Teilbd., Diss. Rostock 1991.

Bayerl, Günter, Die Papiermühle. Vorindustrielle Papiermacherei auf dem Gebiet des alten deutschen Reiches. Technologie, Arbeitsverhältnisse, Umwelt, 2 Bd., Frankfurt a.M. u.a. 1987.

- / Pichol, Karl, Papier. Produkt aus Lumpen, Holz und Wasser, Reinbek b. Hamburg 1986.

BeCKER, Frank/Reinhardt-BeCKer, Elke, Systemtheorie. Eine Einführung für die Geschichts- und Kulturwissenschaften, Frankfurt a.M. 2001.

BegERT, Alexander, Böhmen, die böhmische Kur und das Reich vom Hochmittelalter bis zum Ende des Alten Reiches. Studien zur Kurwürde und zur staatsrechtlichen Stellung Böhmens, Husum 2004.

Behnke, Peter/Roloff, Hans-Gert (Hg.), Christian Weise. Dichter, Gelehrter, Pädagoge. Beiträge zum ersten Christian-Weise-Symposium aus Anlaß des 350. Geburtstages, Bern u.a. 1994.

BeHR, Hans-Joachim, »Zur Rettung derer hart getruckten Nassaw-Siegischen Unterthanen«. Der Niederrheinisch-Westfälische Kreis und Siegen im 18. Jahrhundert, in: JWKG 85 (1991), S. $159-184$.

Behringer, Wolfgang, Thurn und Taxis. Die Geschichte ihrer Post und ihrer Unternehmen, München/Zürich 1990.

- Bausteine zu einer Geschichte der Kommunikation, in: ZHF 21 (1994), S. 92-112.

- Postamt und Briefkasten, in: Klaus Beyrer/Hans-Christian TÄubrich (Hg.), Der Brief. Eine Kulturgeschichte der schriftlichen Kommunikation. Ausstellung des Museums für Post und Kommunikation Frankfurt a.M. und Nürnberg (1996/97), Heidelberg 1996, S. 55-63.

- Veränderung der Raum-Zeit-Relation. Zur Bedeutung des Zeitungs- und Nachrichtenwesens während der Zeit des Dreißigjährigen Krieges, in: Benigna von Krusenstuern/Hans Medick (Hg.), Zwischen Alltag und Katastrophe. Der Dreißigjährige Krieg aus der Nähe, Göttingen 1999, S. 39-81.

- Köln als Kommunikationszentrum um 1600. Die Anfänge des Kölner Post- und Zeitungswesens im Rahmen der frühneuzeitlichen Medienrevolution, in: Georg MöLICH/Gerd Schwerhoff (Hg.), Köln als Kommunikationszentrum. Studien zur frühneuzeitlichen Stadtgeschichte, Köln 2000, S. $183-210$.

- Nachrichten sind Geld. Ein Wundermann des Fortschritts: Johann Carolus und die Erfindung der Zeitung, in: Michael Jeismann (Hg.), Das 17. Jahrhundert. Krieg und Frieden, München 2000, S. 43-47.

- $»$ Die Welt in einen andern Model gegossen«. Das frühneuzeitliche Postwesen als Motor der Kommunikationsrevolution, in: GWU 53 (2002), H. 7/8, S. 424-433.

- Im Zeichen des Merkur. Reichspost und Kommunikationsrevolution in der Frühen Neuzeit, Göttingen 2003.

- /Otт-Koptschalisski, Constance, Der Traum vom Fliegen. Zwischen Mythos und Technik, Frankfurt a.M. 1991.

BeIDERBECK, Friedrich, Leibniz als politischer Berater des Welfenhauses am Beispiel der Neunten Kur, in: Hans Poser (Hg.), Nihil Sine Ratione. VII. Internationaler Leibniz-Kongreß, Berlin 10. bis 14. September 2001, Nachtragsbd., Hannover 2002, S. 142-149.

Bellanger, Claude u.a. (Hg.), Histoire générale de la presse française, 5 Bd., Paris 1969-1978.

Bellingradt, Daniel, Flugpublizistik und Öffentlichkeit um 1700. Dynamiken, Akteure und Strukturen im urbanen Raum des Alten Reiches, Stuttgart 2011.

Bender, Klaus, Die Frankfurter Meßrelationen und Michael Kaspar Lundorp. Neue Funde aus den Jahren 1620-1627, in: Wolfenbütteler Notizen zur Buchgeschichte 9 (1984), H. 3, S. 87-109.

- (Hg.), Relationes historicae. Ein Bestandsverzeichnis der deutschen Meßrelationen von 1583 bis 1648, Berlin/New York 1994.

Benedict, Barbara M., Curiosity. A Cultural History of Modern Inquiry, Chicago/London 2001.

Benna, Anna Hedwig, Preces Primariae und Reichshofrat (1559-1806), in: MÖSTA 5 (1952), S. 87-102. 
Benz, Stefan, Zwischen Tradition und Kritik. Katholische Geschichtsschreibung im barocken Heiligen Römischen Reich, Husum 2003.

Bepler, Jill (Hg.), Barocke Sammellust. Die Bibliothek und Kunstkammer des Herzogs Ferdinand Albrecht zu Braunschweig-Lüneburg (1636-1687). Ausstellung im Zeughaus der HAB Wolfenbüttel, Weinheim 1988.

Berghaus, Günter, Georg Greflinger als Journalist und historisch-politischer Schriftsteller. Mit einem Anhang seiner Schriften über die englische Revolution, in: Wolfenbütteler BarockNachrichten 12 (1985), H. 1, S. 1-14.

Berkvens-Stevelinck, Christiane u.a. (Hg.), Le Magazin de l'Univers. The Dutch Republic as the Center of the European Book Trade, Leiden u.a. 1992.

Berns, Jörg Jochen, Der nackte Monarch und die nackte Wahrheit. Auskünfte der deutschen Zeitungs- und Zeremoniellschriften des späten 17. und frühen 18. Jahrhunderts zum Verhältnis von Hof und Öffentlichkeit, in: Daphnis 11 (1982), S. 315-350.

- Zeitung und Historia. Die historiographischen Konzepte der Zeitungstheoretiker des 17. Jahrhunderts, in: Daphnis 12 (1983), H. 1, S. 87-110.

Bernstorff, Hartwig von, Andreas Gottlieb von Bernstorff 1649-1726. Staatsmann, Junker, Patriarch zwischen deutschem Partikularismus und europäischer Politik, Bochum 1999.

Bertaud, Jean-Paul, La presse et le pouvoir de Louis XIV à Napoléon I ${ }^{\text {er }}$, Paris 2000.

Beutel, Albrecht (Hg.), Luther Handbuch, Tübingen 2005.

Beyer, Franz-Heinrich, Eigenart und Wirkung des reformatorisch-polemischen Flugblatts im Zusammenhang der Publizistik der Reformationszeit, Frankfurt a.M. u.a. 1994.

Beyer, Michael/Wartenberg, Günther (Hg.), Humanismus und Wittenberger Reformation. Festgabe anläßlich des 500. Geburtstags des Praeceptor Germaniae Philipp Melanchthon am 16. Februar 1997. Helmar Junghans gewidmet, Leipzig 1996.

Beyrer, Klaus/Dallmeier, Martin (Hg.), Als die Post noch Zeitung machte. Eine Pressegeschichte. Eine Publikation des Deutschen Postmuseums Frankfurt a.M. anläßlich der gleichnamigen Ausstellung vom 9. Juni bis 4. September 1994, Gießen 1994.

- /Täubrich, Hans-Christian (Hg.), Der Brief. Eine Kulturgeschichte der schriftlichen Kommunikation. Ausstellung des Museums für Post und Kommunikation Frankfurt a.M. und Nürnberg (1996/97), Heidelberg 1996.

Bieber, Hans W., Die Befugnisse und Konzessionierungen der Münchner Druckereien und Buchhandlungen von 1485-1871. Unter besonderer Berücksichtigung der bayerischen Gesetzgebung des 19. Jahrhunderts, in: Börsenblatt für den deutschen Buchhandel 14 (1958), S. 1750-1776.

BıLhÖFER, Peter, Nicht gegen Ehre und Gewissen. Friedrich V., Kurfürst von der Pfalz - der »Winterkönig« von Böhmen (1596-1632), Heidelberg 2004.

Bingel, Hermann, Das Theatrum Europaeum. Ein Beitrag zur Publizistik des 17. und 18. Jahrhunderts, Wiesbaden 1969 (ND von 1909).

Bircher, Martin/Sparn, Walter/Weyrauch, Erdmann (Hg.), Schweizerisch-deutsche Beziehungen im konfessionellen Zeitalter. Beiträge zur Kulturgeschichte 1580-1650, Wiesbaden 1984.

Birke, Adolf M./Kluxen, Kurt (Hg.), England und Hannover. England and Hanover, München u.a. 1986.

Blickle, Peter, Landschaften im Alten Reich. Die staatliche Funktion des Gemeinen Mannes in Oberdeutschland, München 1973.

- Auf dem Weg zu einem Modell der bäuerlichen Rebellion. Zusammenfassung, in: Ders. u.a. (Hg.), Aufruhr und Empörung? Studien zum bäuerlichen Widerstand im Alten Reich, München 1980, S. 296-308.

- Unruhen in der ständischen Gesellschaft 1300-1800, München 1988.

- Kommunalismus. Skizzen zu einer gesellschaftliche Organisationsform, Bd. 1: Oberdeutschland, Bd. 2: Europa, München 2000.

- u.a. (Hg.), Aufruhr und Empörung? Studien zum bäuerlichen Widerstand im Alten Reich, München 1980.

- /AdAm, Thomas (Hg.), Bundschuh. Untergrombach 1502, das unruhige Reich und die Revolutionierbarkeit Europas, Stuttgart 2004.

Buindow, Ulrich, Berliner geschriebene Zeitungen des 18. Jahrhunderts, Diss. Berlin 1939. 
Blome, Astrid, Das deutsche Rußlandbild im frühen 18. Jahrhundert. Untersuchungen zur zeitgenössischen Presseberichterstattung über Rußland unter Peter I., Wiesbaden 2000.

- (Hg.), Zeitung, Zeitschrift, Intelligenzblatt und Kalender. Beiträge zur historischen Presseforschung, Bremen 2001.

- /BönING, Holger (Hg.), Täglich neu! 400 Jahre Zeitungen in Bremen und Nordwestdeutschland, Bremen 2005.

- /Böning, Holger (Hg.), Presse und Geschichte. Leistungen und Perspektiven der historischen Presseforschung, Bremen 2008.

BцÜнм, Elger, Zeitung und literarisches Leben im 17. Jahrhundert, in: August ScHÖNE (Hg.), Stadt - Schule - Universität. Buchwesen und die deutsche Literatur im 17. Jahrhundert, München 1976, S. 492-505.

- Deutsches Zeitungswesen im 17. Jahrhundert, in: Paul RaABE (Hg.), Bücher und Bibliotheken im 17. Jahrhundert in Deutschland, Hamburg 1980, S. 126-134.

- Die deutschen Fürstenhöfe des 17. Jahrhunderts und die Presse, in: August Buck u.a. (Hg.), Europäische Hofkultur im 16. und 17. Jahrhundert, Bd. 3, Hamburg 1981, S. 595600 .

- Deutscher Fürstenstaat und Presse im 17. Jahrhundert, in: Daphnis 11 (1982), S. 287-313.

- Über Regensburgs älteste Zeitung (Tl. 1), in: VHVOPf 123 (1983), S. 259-275.

- Die ersten Zeitungen Deutschlands und der Schweiz und der Beginn der europäischen Pressegeschichte, in: Martin BiRCHER (Hg.), Schweizerisch-deutsche Beziehungen im konfessionellen Zeitalter, Wiesbaden 1984, S. 101-117.

- /Gebhardt, Hartwig (Hg.), Presse und Geschichte, 2 Bd., München 1977-1987.

BÖDEKER, Hans Erich, Strukturen der deutschen Frühaufklärung (1680-1720). Thesen, in: Ders. (Hg.), Strukturen der deutschen Frühaufklärung 1680-1720, Göttingen 2008, S. 9-20.

- (Hg.), Aufklärung und Geschichte. Studien zur deutschen Geschichtswissenschaft, Göttingen 1986.

- /HinRichs, Ernst (Hg.), Alphabetisierung und Literalisierung in Deutschland in der Frühen Neuzeit, Tübingen 1999.

BöHN, Andreas/SEIDLER, Andreas, Mediengeschichte. Eine Einführung, Tübingen 2008.

BöNING, Holger, Französische Revolution und deutsche Öffentlichkeit. Wandlungen in Presse und Alltagskultur am Ende des 18. Jahrhunderts, München 1992.

- Aufklärung und Presse im 18. Jahrhundert, in: Hans-Wolf JäGER (Hg.), »Öffentlichkeit« im 18. Jahrhundert, Göttingen 1997, S. 151-163.

- Aufklärung auch für das Volk? Buchhandel, Verleger und Autoren des 18. Jahrhunderts entdecken den gemeinen Leser, Oldenburg 1998.

- Periodische Presse, Kommunikation und Aufklärung. Hamburg und Altona als Beispiel, Bremen 2002.

- Welteroberung durch ein neues Publikum. Die deutsche Presse und der Weg zur Aufklärung. Hamburg und Altona als Beispiel, Bremen 2002.

- Die Nachbarstadt Hamburg wird zur deutschen Zeitungsmetropole, in: Astrid Blome/Holger BöNING (Hg.), Täglich neu! 400 Jahre Zeitungen in Bremen und Nordwestdeutschland, Bremen 2005, S. 110-119.

- »Gewiss ist es/dass alle gedruckten Zeitungen erst geschrieben seyn müssen«. Handgeschriebene und gedruckte Zeitung im Spannungsfeld von Abhängigkeit, Koexistenz und Konkurrenz, in: Daphnis 37 (2008), S. 203-242.

- Handgeschriebene und gedruckte Zeitung im Spannungsfeld von Abhängigkeit, Koexistenz und Konkurrenz, in: Volker BAUER/Holger BöNING (Hg.), Die Entstehung des Zeitungswesens im 17. Jahrhundert. Ein neues Medium und seine Folgen für das Kommunikationssystem der Frühen Neuzeit, Bremen 2011, S. 23-56.

- (Hg.), Deutsche Presse. Biobibliographische Handbücher zur Geschichte der deutschsprachigen periodischen Presse von den Anfängen bis 1815. Kommentierte Bibliographie der Zeitungen, Zeitschriften, Intelligenzblätter, Kalender und Almanache sowie biographische Hinweise zu Herausgebern, Verlegern und Druckern periodischer Schriften, Bd. 1: Hamburg (zusammengestellt v. Holger BöNING/Emmy MoEPPs); Bd. 2: Altona, Bergedorf, Harburg, Schiffbek, 
Wandsbek (zusammengestellt v. Holger BöNING/Emmy MoEPPs), Stuttgart-Bad Cannstatt 1997.

- /Siegert, Reinhart (Hg.), Volksaufklärung. Biobibliographisches Handbuch zur Popularisierung aufklärerischen Denkens im deutschen Sprachraum von den Anfängen bis 1850, 2 Bd., Stuttgart-Bad Cannstatt 1990-2001.

- /Weber, Johannes, Politik für alle. Am 1. Juli 1650 erschien in Leipzig die erste Tageszeitung der Welt. Die Geheimniskrämerei der Mächtigen hatte ein Ende, in: DIE ZEIT Nr. 27, 29. Juni 1997, S. 74.

Bösch, Frank, Historische Skandalforschung als Schnittstelle zwischen Medien-, Kommunikations- und Geschichtswissenschaft, in: Fabio Crivellari/Kay Kirchmann/Marcus SANDL/ Rudolf Schlögl (Hg.), Die Medien der Geschichte. Historizität und Medialität in interdisziplinärer Perspektive, Konstanz 2004, S. 445-464.

- Mediengeschichte. Vom asiatischen Buchdruck zum globalen Fernsehzeitalter, Frankfurt a.M. u.a. 2011.

BöTtCHER, Diethelm, Die schwedische Propaganda im protestantischen Deutschland, 1628-1634, in: ARG 44 (1953), S. 181-203.

Bogel, Else, Schweizer Zeitungen des 17. Jahrhunderts. Beiträge zur frühen Pressegeschichte von Zürich, Basel, Bern, Schaffhausen, St. Gallen und Solothurn, Bremen 1973.

- /BLüнм, Elger, Die deutschen Zeitungen des 17. Jahrhunderts. Ein Bestandsverzeichnis mit historischen und bibliographischen Angaben, 3 Bd., Bremen, München 1971-1985.

Boнatcová, Mirjam, Irrgarten der Schicksale. Einblattdrucke vom Anfang des Dreißigjährigen Krieges, Prag 1966.

Bohrmann, Hans, Die Erforschung von Zeitung und Zeitschrift in Deutschland, in: Werner Arnold/Wolfgang Dittrich/Bernhard Zehler (Hg.), Die Erforschung der Buch- und Bibliotheksgeschichte in Deutschland. Fs. für Paul Raabe zum 60. Geburtstag, Wiesbaden 1987, S. 346-358.

- Theorien der Zeitung und Zeitschrift, in: Joachim-Felix Leonhard u.a. (Hg.), Medienwissenschaft. Ein Handbuch zur Entwicklung der Medien und Kommunikationsformen, Bd. 1, Berlin/New York 1999, S. 143-148.

- Forschungsgeschichte der Zeitschrift, in: Joachim-Felix Leonhard u.a. (Hg.), Medienwissenschaft. Ein Handbuch zur Entwicklung der Medien und Kommunikationsformen, Bd. 1, Berlin/New York 1999, S. 892-895.

- (Hg.), Zeitungsdruck. Die Entwicklung der Technik vom 17. zum 20. Jahrhundert. Mit Beiträgen von Martin Welke und Boris Fuchs, München 2000.

BonACKer, Wilhelm, Le baron Michael van Eitzing (ca. 1530-1598) et la »Belgici Leonis Chorographia«, in: RBPH 37 (1959), S. 950-967.

BonNEy, Richard, The Limits of Absolutism in Ancien Régime France, Aldershot 1995.

BosBach, Franz, Monarchia Universalis. Ein politischer Leitbegriff der frühen Neuzeit, Göttingen 1988.

- Der französische Erbfeind. Zu einem deutschen Feindbild im Zeitalter Ludwigs XIV., in: Ders. (Hg.), Feindbilder. Die Darstellung des Gegners in der politischen Publizistik des Mittelalters und der Neuzeit, Köln/Weimar/Wien 1992, S. 117-139.

- (Hg.), Feindbilder. Die Darstellung der Gegner in der politischen Publizistik des Mittelalters und der Neuzeit, Köln/Wien 1992.

Bots, Hans, Quelques gazettes de Hollande en langue française et le »Mercure historique et politique«: une analyse comparative, in: Henri Duranton/Pierre Retat (Hg.), Gazette et information politique sous l'Ancien Régime, St. Etienne 1999, S. 159-168.

BRachthäuser, Christian, Le Prince Regent d'Orange. Wilhelm Hyazinth Fürst zu Oranien und Nassau-Siegen (1667-1743), Groß-Gerau 2010.

Braubach, Max, Die Politik des Kurfürsten Max Emanuel von Bayern im Jahre 1702, in: HJb 43 (1923), S. 53-92.

Brauer, Gert, Die hannoversch-englischen Subsidienverträge 1702-1748, Diss. Frankfurt a.M. 1961. 
Brednich, Rolf Wilhelm, Art. »Flugblatt, Flugschrift«, in: Kurt RanKe/Rolf Wilhelm Brednich (Hg.), Enzyklopädie des Märchens. Handwörterbuch zur historischen und vergleichenden Erzählforschung, (bislang) 14 Bd., hier Bd. 4, Berlin/New York 1984, Sp. 1339-1358.

BREGER, Herbert/NieWÖHNER, Friedrich (Hg.), Leibniz und Niedersachsen. Tagung in Wolfenbüttel anläßlich des 350. Geburtstags von G.W. Leibniz (1996), Stuttgart 1999.

BreuER, Dieter, Geschichte der literarischen Zensur in Deutschland, Heidelberg 1982.

- Stand und Aufgaben der Zensurforschung, in: Herbert G. GöPfert/Erdmann Weyrauch (Hg.), »Unmoralisch an sich ..... Zensur im 18. und 19. Jahrhundert, Wiesbaden 1988, S. 37-60.

Brockhoғf, Evelyn/Matтhäus, Michael (Hg.), Die Kaisermacher. Frankfurt am Main und die Goldene Bulle, Frankfurt a.M. 2006.

Веонм, Berthold, Große Konkordanz zur Luther-Bibel, Stuttgart ${ }^{3} 1993$.

Brouwers, Lodewijk (Hg.), Carolus Scribani, Brüssel 1977.

BRÜCKNER, Wolfgang, Die Gegenreformation im politischen Kampf um die Frankfurter Buchmessen. Die kaiserliche Zensur zwischen 1567 und 1619, in: Archiv für Frankfurts Geschichte und Kunst 48 (1962), S. 67-86.

- Populäre Druckgraphik Europas. Deutschland vom 15. bis 20. Jahrhundert, München 1969.

- /Blickle, Peter/Breuer, Dieter (Hg.), Literatur und Volk im 17. Jahrhundert. Probleme populärer Kultur in Deutschland, 2 Bd., Wiesbaden 1985.

BRUNET, Roger, Les villes Européennes, Paris 1989.

- Lignes de force de l'espace européen, in: Mappe Monde 66 (2002), H. 2, S. 14-19.

BRUNNER, Otto, Adeliges Landleben und europäischer Geist. Leben und Werk Wolf Helmhards von Hohberg, Salzburg 1949.

- /Conze, Werner/KoselLeck, Reinhart (Hg.), Geschichtliche Grundbegriffe. Historisches Lexikon zur politisch-sozialen Sprache in Deutschland, 7 Bd., Stuttgart 1972-1992 (= GG).

Buck, August u.a. (Hg.), Europäische Hofkultur im 16. und 17. Jahrhundert, 3 Bd., Hamburg 1981.

BüChLER, Volker, Die Zensur im frühneuzeitlichen Augsburg 1515-1806, in: ZHVS 84 (1991), S. $69-128$.

BÜNGEL, Werner, Der Brief. Ein kulturgeschichtliches Dokument, Berlin 1939.

BURGDORF, Wolfgang, Reichkonstitution und Nation. Verfassungsreformprojekte für das Heilige Römische Reich Deutscher Nation in politischen Schriften von 1648 bis 1806, Mainz 1998.

- Der intergouvernementale publizistische Diskurs. Agitation und Emanzipation, politische Gelegenheitsschriften und ihre Bedeutung für die Entstehung politischer Öffentlichkeit im Alten Reich, in: Johannes Arndt/Esther-Beate Körber (Hg.), Das Mediensystem im Alten Reich der Frühen Neuzeit 1600-1750, Göttingen 2010, S. 75-97.

Burkhard, Johannes, Die Friedlosigkeit der frühen Neuzeit. Grundlegung einer Theorie der Bellizität Europas, in: ZHF 24 (1997), S. 509-574.

- Verfassungsprofil und Leistungsbilanz des Immerwährenden Reichstags. Zur Evaluierung einer frühmodernen Institution, in: Heinz Duchhardt/Matthias SChNetTger (Hg.), Reichsständische Libertät und Habsburgisches Kaisertum, Mainz 1999, S. 151-183.

- Das Reformationsjahrhundert. Deutsche Geschichte zwischen Medienrevolution und Institutionenbildung 1517-1617, Stuttgart 2002.

- Der Westfälische Friede und die Legende von der landesherrlichen Souveränität, in: Jörg Engelbrecht /Stephan Laux (Hg.), Landes- und Reichsgeschichte. Fs. für Hansgeorg Molitor zum 65. Geburtstag, Bielefeld 2004, S. 199-220.

- /Werkstetter, Christine (Hg.), Kommunikation und Medien in der Frühen Neuzeit, München 2005.

Bussmann, Klaus/Schilding, Heinz (Hg.), 1648 - Krieg und Frieden in Europa. Katalog zur 26. Europaratsausstellung Münster/Osnabrück 1998, 2 Bd., München 1998.

- /Werner, Elke Anna (Hg.), Europa im 17. Jahrhundert. Ein Mythos und seine Bilder, Stuttgart 2004.

CAmpe, Joachim Heinrich (Hg.), Wörterbuch der deutschen Sprache, 5 Bd. u. Supplementbd., Braunschweig 1807-1813 (ND Hildesheim 1970). 
CASTells, Manuel, Grassrooting the Space of Flows, in: James O. Wheeler/Yuko Aoyama/Barney WARF (Hg.), Cities in the Telecommunications Age. The Fracturing of Geography, New York u.a. 2000 , S. $18-30$.

Castiglione, Dario/Sharpe, Lesley (Hg.), Shifting the Boundaries. Transformation of Languages of Public and Private in the Eighteenth Century, Exeter 1995.

Censer, Jack R., The French Press in the Age of Enlightenment, London/New York 1994.

Chaline, Olivier, Die Schlacht am Weißen Berg (8. November 1620), in: Klaus Bussmann/Heinz Schilding (Hg.), 1648 - Krieg und Frieden in Europa. Katalog zur 26. Europaratsausstellung Münster/Osnabrück 1998, Textbd. 1, München 1998, S. 95-101.

Chartier, Roger, »Populärer« Lesestoff und »volkstümliche « Leser in Renaissance und Barock, in: Roger Chartier/Guglielmo Cavallo (Hg.), Die Welt des Lesens. Von der Schriftrolle zum Bildschirm, Frankfurt a.M. 1999, S. 397-418.

- /CAvallo, Guglielmo (Hg.), Die Welt des Lesens. Von der Schriftrolle zum Bildschirm, Frankfurt a.M. 1999 (ital. 1995).

Chrisman, Miriam Usher, Lay Culture, Learned Culture. Books and Social Change in Strasbourg, 1480-1599, New Haven/London 1982.

Clair, Colin, Christopher Plantin, London 1960.

ClercQ, Carlo de, Die katholischen Fürsten von Nassau-Siegen, in: Nass. Ann. 73 (1962), S. 129 152.

Conrad, Anne/Herzig, Arno/Kopitzsch, Franklin (Hg.), Das Volk im Visier der Aufklärung. Popularisierung der Aufklärung im späten 18. Jahrhundert, Münster 1998.

Consentius, Ernst, Die Berliner Zeitungen bis zur Regierung Friedrichs des Großen, Berlin 1904.

- Ein Zeitungsschreiber im 17. Jahrhundert. Mit Benutzung von Akten des Geh. Staatsarchivs, in: Deutschland. Monatsschrift für die gesamte Kultur 6 (Schiller-Ausgabe) 1905 (Mai), S. 246-251.

Cools, Hans /Keblusek, Marika/Noldus, Badeloch (Hg.), Your Humble Servant. Agents in Early Modern Europe, Hilversum 2006.

Crivellari, Fabio/Schlögl, Rudolf u.a. (Hg.), Die Medien der Geschichte. Historizität und Medialität in interdisziplinärer Perspektive, Konstanz 2004.

Croce, Benedetto, Il giornalismo e la storia della letteratura, in: Ders., Problemi di estetica e contributi alla storia dell'estetica italiana, Bari 1910, S. 128-132.

Сzок, Karl, August der Starke und Kursachsen, München 1988.

Dahlmann, Dittmar (Hg.), Die Kenntnis Rußlands im deutschsprachigen Raum im 18. Jahrhundert. Wissenschaft und Publizistik über das Russische Reich, Göttingen 2006.

Dahm, Karl-Wilhelm/Krawietz, Werner/Wyduckel, Dieter (Hg.), Politische Theorie des Johannes Althusius, Berlin 1988.

DALLMEIER, Martin, Die kaiserliche Reichspost zwischen Zeitungsvertrieb und Zensur im 18. Jahrhundert, in: Elger Blühm/Hartwig Gebhardt (Hg.), Presse und Geschichte. Neue Beiträge zur historischen Kommunikationsforschung, Bd. 2, München 1987, S. 233-258.

- (Hg.), 500 Jahre Post. Thurn und Taxis. Ausstellung anläßlich der 500jährigen Wiederkehr der Anfänge der Post in Mitteleuropa 1490-1990. Fürstliches Marstallmuseum Regensburg, Regensburg 1990.

DAMBERG, Wilhelm, Die politische Aussage in den Totengesprächen David Fassmanns. Gespräche in dem Reich der Todten 1718-1740. Ein Beitrag zur Frühgeschichte der politischen Zeitschrift, Diss. Münster 1952.

Daniel, Ute, Hoftheater. Zur Geschichte des Theaters und der Höfe im 18. und 19. Jahrhundert, Stuttgart 1995.

- Überlegungen zum höfischen Fest der Barockzeit, in: NJbLG 72 (2000), S. 45-66.

DanN, Otto, Das historische Interesse in der deutschen Gesellschaft des 18. Jahrhunderts. Geschichte und historische Forschung in den zeitgenössischen Zeitschriften, in: Karl HAMMER/Jürgen Voss (Hg.), Historische Forschung im 18. Jahrhundert. Organisation - Zielsetzung - Ergebnisse, Bonn 1976, S. 386-415. 
- Vom Journal des Scavants zur wissenschaftlichen Zeitschrift, in: Bernhard FABIAN/Paul RAABE (Hg.), Gelehrte Bücher vom Humanismus bis zur Gegenwart, Wiesbaden 1983, S. $63-$ 80.

- (Hg.), Lesegesellschaften und bürgerliche Emanzipation. Ein europäischer Vergleich, München 1981.

DAston, Lorraine, Neugierde als Empfindung und Epistemologie in der frühneuzeitlichen Wissenschaft, in: Andreas Grote (Hg.), Macrocosmos in Microcosmo. Die Welt in der Stube. Zur Geschichte des Sammelns 1450 bis 1800, Opladen 1994, S. 35-59.

- Die Lust an der Neugier in der frühneuzeitlichen Wissenschaft, in: Klaus KRÜGER (Hg.), Curiositas. Welterfahrung und ästhetische Neugierde in Mittelalter und früher Neuzeit, Göttingen 2002, S. 147-175.

Dauser, Regina, Informationskultur und Beziehungswissen. Das Korrespondentennetz Hans Fuggers (1531-1598), Tübingen 2008.

Davies, David W., The World of the Elseviers 1580-1712, Den Haag 1954 (ND 1960).

Demandt, Karl, Das Siegerland im Widerstreit von Glauben, Recht und Politik 1607-1651, in: HJLG 32 (1982), S. 175-206.

Dethlefs, Gerd, Schauplatz Europa. Das Theatrum Europaeum des Matthäus Merian als Medium kritischer Öffentlichkeit, in: Klaus Bussmann/Elke Anna Werner (Hg.), Europa im 17. Jahrhundert. Ein Mythos und seine Bilder, Stuttgart 2004, S. 149-179.

DickerhoF, Harald, Die katholischen Universitäten im Heiligen Römischen Reich deutscher Nation im Zeitalter der Aufklärung, in: Notker Hammerstein (Hg.), Universitäten und Aufklärung, Göttingen 1995, S. 21-47.

DiestelKamp, Bernhard, Rechtsfälle aus dem Alten Reich. Denkwürdige Prozesse vor dem Reichskammergericht, München 1995.

- (Hg.), Oberste Gerichtsbarkeit und Zentrale Gewalt im Europa der Frühen Neuzeit, Köln/Wien/Weimar 1996.

- /Scheurmann, Ingrid (Hg.), Friedenssicherung und Rechtsgewährung. Sechs Beiträge zur Geschichte des Reichskammergerichts und der obersten Gerichtsbarkeit im alten Europa, Bonn/Wetzlar 1997.

Dietz, Alexander, Frankfurter Handelsgeschichte, 3 Bd., Frankfurt a.M. 1921.

DingEs, Martin, Die Ehre als Thema der Stadtgeschichte. Eine Semantik im Übergang vom Ancien Régime zur Moderne, in: ZHF 16 (1989), S. 409-440.

Dinges, Martin, Die Ehre als Thema der historischen Anthropologie. Bemerkungen zur Wissenschaftsgeschichte und Konzeptualisierung, in: Klaus Schreiner/Gerd Schwerhoff (Hg.), Verletzte Ehre. Ehrkonflikte in Gesellschaften des Mittelalters und der Frühen Neuzeit, Köln/ Weimar/Wien 1995, S. 29-62.

DiPPER, Christof, Deutsche Geschichte 1648-1789, Frankfurt a.M. 1991.

DoBras, Wolfgang (Red.), Gutenberg - aventur und Kunst. Vom Geheimunternehmen zur ersten Medienrevolution. Katalog zur Ausstellung der Stadt Mainz, 14. April bis 3. Oktober 2000, Mainz 2000.

Doering-Manteuffel, Sabine/Mancal, Josef/Wüst, Wolfgang (Hg.), Pressewesen der Aufklärung. Periodische Schriften im Alten Reich, Berlin 2001.

Dongelmans, Berry P. / HoftiJzer, Paul G. / Lankhorst, Otto S. (Hg), Boekverkopers van Europa. Het 17de-eeuwse Nederlandse uitgevershuis Elzevier, Zutphen 2000.

Dooley, Brendan, From Literary Criticism to System Theory. Twenty Years of Journalism History, in: Journal of the History of Ideas 51 (1990), S. 461-483.

Dorn, Margit/Vogel, Andreas, Geschichte des Pressevertriebs in Deutschland. Mit einem Schwerpunkt auf der Entwicklung des Pressehandels, Baden-Baden 2001.

Droste, Heiko, »Einige Wiener briefe wollen noch publiciren«. Die Geschriebene Zeitung als öffentliches Nachrichtenmedium, in: Volker Bauer/Holger Böning (Hg.), Die Entstehung des Zeitungswesens im 17. Jahrhundert. Ein neues Medium und seine Folgen für das Kommunikationssystem der Frühen Neuzeit, Bremen 2011, S. 1-22.

Duchнardt, Heinz, Das politische Testament als »Verfassungsäquivalent«, in: Der Staat 25 (1986), S. 600-607. 
- Das Zeitalter des Absolutismus, München 1989; seit der 4. Aufl.: Barock und Aufklärung, München ${ }^{4} 2007$.

- Altes Reich und europäische Staatenwelt 1648-1806, München 1990.

- Das protestantische Herrscherbild des 17. Jahrhunderts, in: Konrad Repgen (Hg.), Das Herrscherbild im 17. Jahrhundert, Münster 1991, S. 26-42.

- Balance of Power und Pentarchie. Internationale Beziehungen 1700-1785, Paderborn u.a. 1997.

- Die Absolutismusdebatte - eine Antipolemik, in: HZ 275 (2002), S. 323-331.

- Barock und Aufklärung, München ${ }^{4} 2007$.

- (Hg.), Der Westfälische Friede. Diplomatie - politische Zäsur - kulturelles Umfeld - Rezeptionsgeschichte, München 1998.

- (Hg.), Der Friede von Rijswijk 1697, Mainz 1998.

Dülmen, Richard van/Rauschenbach, Sina (Hg.), Macht des Wissens. Die Entstehung der modernen Wissensgesellschaft, Köln/Weimar/Wien 2004.

Duranton, Henri/Rétat, Pierre (Hg.), Gazettes et information politique sous l'Ancien Régime, St. Etienne 1999.

Ebrecht, Angelika u.a. (Hg.), Brieftheorie des 18. Jahrhunderts. Texte, Kommentare, Essays, Stuttgart 1990

ECKHARDT, Nils, Arzt, Medizin und Tod im Spiegel der von David Fassmann (1683-1744) in den Jahren von 1718 bis 1739 herausgegebenen Zeitschrift »Gespräche in dem Reiche derer Todten«, Diss. Düsseldorf 1987.

EgEnHOFF, Uta, Berufsschriftstellertum und Journalismus in der Frühen Neuzeit. Eberhard Werner Happels »Relationes Curiosae« im Medienverbund des 17. Jahrhunderts, Bremen 2008.

EHRENPREIS, Stefan, Erziehung und Schulwesen zwischen Konfessionalisierung und Säkularisierung. Forschungsprobleme und methodische Innovationen, in: Heinz SchiLling/Stefan EhrenPreis (Hg.), Erziehung und Schulwesen zwischen Konfessionalisierung und Säkularisierung. Forschungsperspektiven, europäische Fallbeispiele und Hilfsmittel, Münster u.a. 2003, S. 19-33.

- Kaiserliche Gerichtsbarkeit und Konfessionskonflikt. Der Reichshofrat unter Rudolf II. 15761612, Göttingen 2006.

EisenHARDT, Ulrich, Die kaiserliche Aufsicht über Buchdruck, Buchhandel und Presse im Heiligen Römischen Reich (1496-1806). Ein Beitrag zur Geschichte der Bücher- und Pressezensur, Karlsruhe 1970.

- Die kaiserlichen Privilegia de non appellando (hg. in Zusammenarbeit mit Elsbeth MARKERT), Köln/Wien 1980.

EISERMAnN, Falk, Bevor die Blätter fliegen lernten. Buchdruck, politische Kommunikation und die »Medienrevolution« des 15. Jahrhunderts, in: Karl-Heinz SpIEss (Hg.), Medien der Kommunikation im Mittelalter, Stuttgart 2003, S. 289-313.

Elias, Norbert, Über den Prozeß der Zivilisation. Soziogenetische und psychogenetische Untersuchungen, 2 Bd., Frankfurt a.M. ${ }^{8} 1981$.

- Die höfische Gesellschaft. Untersuchungen zur Soziologie des Königtums und der höfischen Aristokratie mit einer Einleitung. Soziologie und Geschichtswissenschaft, Frankfurt a.M. 1983.

ENDREs, Rudolf, Adel in der frühen Neuzeit, München 1993.

EngelbRecht, Jörg, Krone und Exil. Das Haus Wittelsbach in der deutschen und europäischen Politik (1679-1761), in: Frank Günter ZeHnder (Hg.), Im Wechselspiel der Kräfte. Politische Entwicklungen des 17. und 18. Jahrhunderts in Kurköln, Köln 1999, S. 9-22.

- /Laux, Stephan (Hg.), Landes- und Reichsgeschichte. Fs. für Hansgeorg Molitor zum 65. Geburtstag, Bielefeld 2004.

Engelsing, Rolf, Die periodische Presse und ihr Publikum. Zeitungslektüre in Bremen von den Anfängen bis zur Franzosenzeit, in: AGB 4 (1963), Sp. 1481-1531.

- Die Perioden der Lesergeschichte in der Neuzeit. Das statistische Ausmaß und die soziokulturelle Bedeutung der Lektüre, in: AGB 10 (1970), Sp. 945-1002. 
- Analphabetentum und Lektüre. Zur Sozialgeschichte des Lesens in Deutschland zwischen feudaler und industrieller Gesellschaft, Stuttgart 1973.

- Zur Sozialgeschichte deutscher Mittel- und Unterschichten, Göttingen 1973.

- Der Bürger als Leser. Lesergeschichte in Deutschland 1500-1800, Stuttgart 1974.

Erichsen, Johannes / Heinemann, Katharina (Hg.), Die Schlacht von Höchstädt. The Battle of Blenheim. Brennpunkt Europas 1704, Sigmaringen 2004.

ErLer, Adalbert/Kaufmann, Ekkehard (Hg.), Handwörterbuch zur deutschen Rechtsgeschichte, 5 Bd., Berlin 1971-1998.

Esebeck, Frieda Freiin von, Die Begründung der hannoverschen Kurwürde, Hildesheim 1935.

Estermann, Monika, Memoria und Diskurs. Der Buchhandel in der Frühaufklärung, in: Hans Erich BöDEKER (Hg.), Strukturen der deutschen Frühaufklärung 1680-1720, Göttingen 2008, S. $45-70$.

Fabian, Bernhard/RaAbe, Paul (Hg.), Gelehrte Bücher vom Humanismus bis zur Gegenwart, Wiesbaden 1983.

Faulstich, Werner, Medien zwischen Herrschaft und Revolte. Die Medienkultur der frühen Neuzeit zwischen 1400 und 1700, Göttingen 1998.

- Die bürgerliche Mediengesellschaft (1700-1830), Göttingen 2002.

- /Hickethier, Knut (Hg.), Öffentlichkeit im Wandel. Neue Beiträge zur Begriffsklärung, Bardowick 2000 .

FelBingER, Rudolf, Maximilian II. Emanuel von Bayern (1662-1726). Anspruch und Inszenierung des »Blauen Kurfürsten«, München 1999 (Mschr.).

Feldmeier, Franz, Die Ächtung des Kurfürsten Max Emanuel von Bayern und die Übertragung der Oberpfalz und der fünften Chur an Churpfalz, in: OBA 58 (1914), S. 145269.

Feyel, Gilles, L'annonce et la nouvelle. La presse d'information en France sous l'Ancien Régime (1630-1788), Oxford 2000.

FISCHER, Ernst, »Immer schon die vollständigste Preßfreiheit«? Beobachtungen zum Verhältnis von Zensur und Buchhandel im 18. Jahrhundert, in: Wilhelm HAEFs / York-Gothart Mix (Hg.), Zensur im Jahrhundert der Aufklärung. Geschichte - Theorie - Praxis, Göttingen 2007, S. 61-78.

- /Haefs, Wilhelm/Mix, York-Gothart (Hg.), Von Almanach bis Zeitung. Ein Handbuch der Medien in Deutschland 1700-1800, München 1999.

Fischer, Heinz-Dietrich (Hg.), Deutsche Publizisten des 15. bis 20. Jahrhunderts, München 1971.

- (Hg.), Deutsche Zeitschriften des 17. bis 20. Jahrhundert, Pullach b. München 1973.

- (Hg.), Deutsche Kommunikationskontrolle des 15. bis 20. Jahrhunderts, München 1982.

FISCHER, Helmut, Die ältesten Zeitungen und ihre Verleger, Augsburg 1936.

FIsCHER, Ludwig, Wirkliche Öffentlichkeiten? Reflexionen mit Rücksicht auf Pierre Bourdieus Kultursoziologie, in: Werner Faulstich/Knut Hickethier (Hg.), Öffentlichkeit im Wandel. Neue Beiträge zur Begriffsklärung, Bardowick 2000, S. 63-74.

Fiтos, Stephan, Zensur als Mißerfolg. Die Verbreitung indizierter deutscher Druckschriften in der zweiten Hälfte des 16. Jahrhunderts, Frankfurt a.M. u.a. 2000.

Fitzler, Mathilde August Hedwig, Die Entstehung der sogenannten Fuggerzeitungen in der Wiener Nationalbibliothek, Baden b. Wien 1937.

FLEGEL, Christoph, Die Rijswijker Klausel und die lutherische Kirche in der Kurpfalz, in: Heinz DuchHardt (Hg.), Der Friede von Rijswijk 1697, Mainz 1998, S. 271-279.

Förster, Friedrich, Friedrich Wilhelm I., König von Preußen, 3 Bd., Potsdam 1834-1835.

FrançoIs, Etienne, Buch, Konfession und städtische Gesellschaft im 18. Jahrhundert. Das Beispiel Speyers, in: Rudolf VIERHaus, Mentalitäten und Lebensverhältnisse. Beispiele aus der Sozialgeschichte der Neuzeit. Fs. für Rudolf Vierhaus zum 60. Geburtstag, hg. v. Mitarbeitern und Schülern, Göttingen 1982, S. 34-54.

Franz, Eckhart G., Das Haus Hessen. Eine europäische Familie, Stuttgart 2005. 
Franz, Gunther, Bücherzensur und Irenik. Die theologische Zensur im Herzogtum Württemberg in der Konkurrenz von Universität und Regierung, in: Martin BRECHT (Hg.), Theologen und Theologie an der Universität Tübingen, Tübingen 1977, S. 123-194.

Franzmann, Bodo u.a. (Hg.), Handbuch Lesen, München 1999.

Freist, Dagmar, Absolutismus, Darmstadt 2008.

Freund, Hilger, Die Bücher- und Pressezensur im Kurfürstentum Mainz von 1486-1797, Karlsruhe 1971.

Freytag, Rudolf, Post und Zeitung. Ein Streifzug durch die Geschichte des Post- und Zeitungswesens bis zum Beginn des 19. Jahrhunderts, München $1928\left({ }^{2} 1930\right)$.

- Post und Zeitung, in: APB 4 (1928), S. 24-50.

Friedrich, Susanne, Die Anfänge der historisch-politischen Zeitschrift am Beispiel des »Monatlichen Staats-Spiegels«, in: Wolfgang E.J. Weber (Hg.), Wissenswelten. Perspektiven der neuzeitlichen Informationskultur, Augsburg 2003, S. 295-311.

- Drehscheibe Regensburg. Das Informations- und Kommunikationssystem des Immerwährenden Reichstags um 1700, Berlin 2007.

Fritz, Gerd/Strassner, Erich (Hg.), Die Sprache der ersten deutschen Wochenzeitungen im 17. Jahrhundert, Tübingen 1996.

Froboese, Julius, Die Achterklärung der Kurfürsten von Baiern und Köln 1706 und ihre reichsrechtliche Bedeutung, Mühlhausen 1874.

FÜRnROHR, Walter, Kurbaierns Gesandte auf dem Immerwährenden Reichstag. Zur baierischen Außenpolitik 1663-1806, Göttingen 1971.

FüssEL, Marian, Gelehrtenkultur als symbolische Praxis. Rang, Ritual und Konflikt an der Universität der Frühen Neuzeit, Darmstadt 2006.

FüsSEL, Stephan, Gutenberg und seine Wirkung, Frankfurt a.M. 1999 (22004).

- Johannes Gutenberg, Reinbek b. Hamburg 1999.

- (Hg.), Deutsche Dichter der Frühen Neuzeit. Ihr Leben und Werk (1450-1600), Berlin 1993.

Gabel, Helmut, Widerstand und Kooperation. Studien zur politischen Kultur rheinischer und maasländischer Kleinterritorien (1648-1794), Tübingen 1995.

GAdAmER, Hans-Georg, Wahrheit und Methode. Grundzüge einer philosophischen Hermeneutik, Tübingen 1960.

GARBER, Klaus, Der Autor im 17. Jahrhundert, in: Zeitschrift für Literaturwissenschaft und Linguistik 11 (1981), H. 42, S. 29-45.

Gauger, Martin, Die sechs Kulturen in der Geschichte des Lesens, in: Paul Goetsch (Hg.), Lesen und Schreiben im 17. und 18. Jahrhundert. Studien zu ihrer Bewertung in Deutschland, England, Frankreich, Tübingen 1994, S. 27-47.

Gebele, Marianne, Geschichte des deutschen Kaufmannsbriefes bis zum Ende des 18. Jahrhunderts, Diss. München 1949 (Mschr.).

Gerhardt, Claus W., Warum wurde die Gutenberg-Presse erst nach über 350 Jahren durch ein besseres System abgelöst?, in: Ders., Beiträge zur Technikgeschichte des Buchwesens. Kleine Schriften, 1969-1976, Frankfurt a.M. 1976, S. 77-100.

- Beiträge zur Technikgeschichte des Buchwesens. Kleine Schriften, 1969-1976, Frankfurt a.M. 1976.

Gerteis, Klaus, Die deutschen Städte in der frühen Neuzeit. Zur Vorgeschichte der »bürgerlichen Welt«, Darmstadt 1986.

- Reisen, Boten, Posten. Korrespondenz in Mittelalter und früher Neuzeit, in: Hans PoHL (Hg.), Die Bedeutung der Kommunikation für Wirtschaft und Gesellschaft, Stuttgart 1989, S. 19-36.

Gerth, Hans H., Bürgerliche Intelligenz um 1800. Zur Soziologie des deutschen Frühliberalismus, Göttingen ${ }^{2} 1976$.

Gestrich, Andreas, Absolutismus und Öffentlichkeit. Politische Kommunikation zu Beginn des 18. Jahrhunderts, Göttingen 1994. 
- Krieg und Öffentlichkeit in der zweiten Hälfte des 17. Jahrhunderts, in: Angela GieBMEYer/Helga Schnabel-Schüle (Hg.), »Das Wichtigste ist der Mensch«. Fs. für Klaus Gerteis zum 60. Geburtstag, Mainz 2000, S. 21-36.

Geuenich, Dieter (Hg.), Köln und die Niederrheinlande in ihren historischen Raumbeziehungen (15.-20. Jahrhundert), Pulheim/Mönchengladbach 2000.

Giebmeyer, Angela/Schnabel-SchüLe, Helga (Hg.), »Das Wichtigste ist der Mensch«. Fs. für Klaus Gerteis zum 60. Geburtstag, Mainz 2000.

GieR, Helmut/Janota, Johannes (Hg.), Augsburger Buchdruck und Verlagswesen. Von den Anfängen bis zur Gegenwart, Wiesbaden 1997.

GiESECKE, Michael, Der Buchdruck in der frühen Neuzeit. Eine historische Fallstudie über die Durchsetzung neuer Informations- und Kommunikationstechnologien, Frankfurt a.M. 1991.

Gieseler, Jens, Vom Nutzen und richtigen Gebrauch der frühen Zeitungen. Zur sogenannten Pressedebatte des 17. Jahrhunderts, in: Gerd Fritz/Erich Strassner (Hg.), Die Sprache der ersten deutschen Wochenzeitungen im 17. Jahrhundert, Tübingen 1996, S. 259-285.

Glaser, Hubert (Hg.), Kurfürst Max Emanuel. Bayern und Europa um 1700, 2 Bd., München 1976.

GLÜER, Juliane, Meßrelationen um 1600. Ein neues Medium zwischen aktueller Presse und Geschichtsschreibung. Eine textsortengeschichtliche Untersuchung, Göppingen 2000.

GÖPFERT, Herbert G., Zedlers »Universal-Lexicon«, in: Ders., Vom Autor zum Leser. Beiträge zur Geschichte des Buchwesens, München/Wien 1977, S. 63-75.

- Vom Autor zum Leser. Beiträge zur Geschichte des Buchwesens, München/Wien 1977.

- /Weyrauch, Erdmann (Hg.), »Unmoralisch an sich ...«. Zensur im 18. und 19. Jahrhundert, Wiesbaden 1988.

Goetsch, Paul (Hg.), Lesen und Schreiben im 17. und 18. Jahrhundert. Studien zu ihrer Bewertung in Deutschland, England, Frankreich, Tübingen 1994.

GöтZE, Walter, Die Begründung der Volksbildung in der Aufklärungsbewegung, Langensalza/Berlin/Leipzig 1932.

GolDFRIEDRICH, Johann, Geschichte des deutschen Buchhandels vom Westfälischen Frieden bis zum Beginn der klassischen Literaturperiode (1648-1740), 2 Bd., Leipzig 1908 (ND Aalen 1970).

Goody, Jack (Hg.), Literacy in Traditional Societies, Cambridge 1968.

GotтhaRD, Axel, Der »Große Kurfürst« und das Kurkolleg, in: FBPG N.F. 6 (1996), S. 1-54.

- Säulen des Reiches. Die Kurfürsten im frühneuzeitlichen Reichsverband, 2 Bd., Husum 1999.

- Das Alte Reich, 1495-1806, Darmstadt 2003.

- Einleitung, in: Werner Künzel/Werner Rellecke (Hg.), Geschichte der deutschen Länder. Entwicklungen und Traditionen vom Mittelalter bis zur Gegenwart, Münster 2005, S. 7-33.

GrafF, Harvey J., The Legacies of Literacy. Continuities and Contradictions in Western Culture and Society, Bloomington 1987.

GrafF, Wilhelm Paul, Die zweite Ehe des Herzogs Karl Leopold. Ein Kulturbild aus Mecklenburg im ersten Viertel des 18. Jahrhunderts, in: Verein für Mecklenburgischer Geschichte und Altertumskunde 60 (1895), S. 199-308.

Gramlich, Jürgen, Rechtsordnungen des Buchgewerbes im Alten Reich. Genossenschaftliche Strukturen, Arbeits- und Wettbewerbsrecht im deutschen Druckerhandwerk, Frankfurt a.M. 1994.

GreILICH, Susanne/Mix, York-Gothart (Hg.), Populäre Kalender im vorindustriellen Europa. Der »hinkende bote«/»Messager boiteux«. Kulturwissenschaftliche Analysen und bibliographisches Repertorium. Ein Handbuch, Berlin 2006.

Grenzmann, Ludger/STackmann, Karl (Hg.), Literatur und Laienbildung im Spätmittelalter und in der Reformationszeit. Symposium Wolfenbüttel 1981, Stuttgart 1984.

Greschat, Martin, Philipp Melanchthon. Theologe, Pädagoge und Humanist, Gütersloh 2011.

Grimm, Heinrich, Die Buchführer des deutschen Kulturbereichs und ihre Niederlassungsorte in der Zeitspanne 1490 bis um 1550, in: AGB 7 (1967), Sp. 1153-1772. 
Grote, Andreas (Hg.), Macrocosmos in Microcosmo. Die Welt in der Stube. Zur Geschichte des Sammelns 1450-1800, Opladen 1994.

Groten, Manfred (Hg.), Hermann von Weinsberg (1518-1597). Kölner Bürger und Ratsherr. Studien zu Leben und Werk, Köln 2005.

Groth, Otto, Die Zeitung. Ein System der Zeitungskunde (Journalistik), 4 Bd., Mannheim u.a. 1928-1930.

- Geschichte der deutschen Zeitungswissenschaft. Probleme und Methoden, München 1948.

- Die unerkannte Kulturmacht. Grundlegung der Zeitungswissenschaft (Periodik), 7 Bd., Berlin 1960.

Gschliesser, Oswald von, Der Reichshofrat. Bedeutung und Verfassung, Schicksal und Besetzung einer obersten Reichsbehörde von 1559-1806, Wien 1942 (ND Nendeln 1970).

Gstettner, Hans, Regensburger Reichstags-Korrespondenzen. Ein Stück Pressepolitik des Heiligen Römischen Reiches deutscher Nation, München 1936.

HaAcKe, Wilmont, Die Zeitschrift - Schrift der Zeit, Essen 1961.

- Die politische Zeitschrift 1665-1965, 2 Bd., Stuttgart 1968-1982.

Habel, Thomas, Gelehrte Journale und Zeitungen der Aufklärung. Zur Entstehung, Entwicklung und Erschließung deutschsprachiger Rezensionszeitschriften des 18. Jahrhunderts, Bremen 2007.

Habermas, Jürgen, Strukturwandel der Öffentlichkeit. Untersuchungen zu einer Kategorie der bürgerlichen Gesellschaft, Neuwied 1962 (ND Frankfurt a.M. 1990).

HaEfs, Wilhelm/Mix, York-Gothart (Hg.), Zensur im Jahrhundert der Aufklärung. Geschichte Theorie - Praxis, Göttingen 2007.

HÄNISCH, Ulrike Dorothea, »Confessio Augustana triumphans«. Funktionen der Publizistik zum Confessio Augustana-Jubiläum 1630. Zeitung, Flugblatt, Flugschrift, Frankfurt a.M. u.a. 1993.

Härtel, Helmar, Herzog August als Büchersammler. Zum Aufbau seiner Bibliothek, in: Paul RaABe (Hg.), Herzog August zu Braunschweig und Lüneburg (1579-1666). Sammler, Fürst, Gelehrter, Braunschweig 1979, S. 215-319.

HÄRTER, Karl, Das kurmainzische Reichstagsdirektorium. Eine zentrale reichspolitische Schaltstelle des Reichserzkanzlers im Reichssystem, in: Peter Claus Hartmann (Hg.), Der Mainzer Kurfürst als Reichserzkanzler. Funktionen, Aktivitäten, Ansprüche und Bedeutung des zweiten Mannes im alten Reich, Stuttgart 1997, S. 171-203.

HAFERKoRn, Hans-Jürgen, Der freie Schriftsteller, in: AGB 5 (1962/64), Sp. 523-712.

Haftlmeier-Seiffert, Renate, Bauerndarstellungen auf deutschen illustrierten Flugblättern des 17. Jahrhunderts, Frankfurt a.M. u.a. 1991.

Hahn, Peter Michael, Die Gerichtspraxis der altständischen Gesellschaft im Zeitalter des »Absolutismus«. Die Gutachtertätigkeit der Helmstädter Juristenfakultät für die brandenburgischpreußischen Territorien 1675-1710, Berlin 1989.

Haller, Johannes, Die deutsche Publizistik in den Jahren 1668-1674. Ein Beitrag zur Geschichte der Raubkriege Ludwigs XIV., Diss. Heidelberg 1892.

Hammer, Karl (Hg.), Historische Forschung im 18. Jahrhundert. Organisation, Zielsetzung, Ergebnisse, Bonn 1976.

Hammerstein, Notker, Jus und Historie. Ein Beitrag zur Geschichte des historischen Denkens an deutschen Universitäten des späten 17. und 18. Jahrhunderts, Göttingen 1972.

- Reichs-Historie, in: Hans Erich BöDEKer (Hg.), Aufklärung und Geschichte. Studien zur deutschen Geschichtswissenschaft, Göttingen 1986, S. 82-104.

- Res publica litteraria. Ausgewählte Aufsätze zur frühneuzeitlichen Bildungs-, Wissenschaftsund Universitätsgeschichte, Berlin 2000.

- (Hg.), Staatslehre der frühen Neuzeit, Frankfurt a.M. 1995.

- (Hg.), Universitäten und Aufklärung, Göttingen 1995.

Hardtwig, Wolfgang (Hg.), Über das Studium der Geschichte, München 1990.

Harline, Craig E., Pamphlets, Printing and Political Culture in the Early Dutch Republic, Dordrecht 1987. 
Harms, Wolfgang/Messerli, Alfred (Hg.), Wahrnehmungsgeschichte und Wissensdiskurs im illustrierten Flugblatt der Frühen Neuzeit (1450-1700), Basel 2002.

Hartmann, Anja Victorine, Arcana Imperii und Theatrum Mundi. Überlegungen zur Bedeutung des Geheimnisses in der Frühen Neuzeit, in: GWU 53 (2002), H. 7/8, S. 434-443.

Hartmann, Peter Claus, Die Subsidien- und Finanzpolitik Kurfürst Max Emanuels von Bayern im Spanischen Erbfolgekrieg, in: ZBLG 32 (1969), S. 238-289.

- Geld als Instrument europäischer Machtpolitik im Zeitalter des Merkantilismus. Studien zu den finanziellen und politischen Beziehungen der Wittelsbacher Territorien Kurbayern, Kurpfalz und Kurköln mit Frankreich und dem Kaiser von 1715 bis 1740, München 1978.

Hartmann, Peter Claus (Hg.), Der Mainzer Kurfürst als Reichserzkanzler. Funktionen, Aktivitäten, Ansprüche und Bedeutung des zweiten Mannes im alten Reich, Stuttgart 1997.

Hartmann, Wilhelm, Wolfenbüttel als Druckort des »Aviso« von 1609, der ältesten periodisch gedruckten Zeitung, in: NJbLG 31 (1959), S. 175-189.

HARTZ, Samuel Louis, The Elseviers and their Contemporaries, Amsterdam 1955.

HaufF, Else, Die »Einkommenden Zeitungen« von 1650. Ein Beitrag zur Geschichte der Tageszeitung, in: Gazette. International Journal for Mass Communication Studies 9 (1963), H. 3, S. $227-235$.

- Die »Einkommenden Zeitungen« von 1650. Ein Beitrag zur Geschichte der Tageszeitung, in: Arnulf Kutsch/Johannes WeBER (Hg.), 350 Jahre Tageszeitung. Forschungen und Dokumente, Berlin 2002, S. 151-161.

Hauffen, Adolf, Johannes Fischart. Ein Leitbild aus der Zeit der Gegenreformation, 2 Bd., Berlin/Leipzig 1922.

HAUG-Moritz, Gabriele, Württembergischer Ständekonflikt und deutscher Dualismus. Ein Beitrag zur Geschichte des Reichsverbands in der Mitte des 18. Jahrhunderts, Stuttgart 1992.

Hauser, Oswald (Hg.), Preußen, Europa und das Reich, Köln 1987.

Heck, Uwe, Geschichte des Landtags in Mecklenburg. Ein Abriß, Rostock 1997.

HeIGEL, Karl Theodor von, Über den Plan des Kurfürsten Johann Wilhelm von der Pfalz, die armenische Königskrone zu gewinnen (1698-1705). Sitzungsberichte der philosophisch-philologischen und historischen Classe der Königlich Bayerischen Akademie der Wissenschaften zu München (1893), München 1894, Bd. 2, S. 273-319.

Heimann, Heinz-Dieter/Hlavácek, Ivan (Hg.), Kommunikationspraxis und Korrespondenzwesen im Mittelalter und in der Renaissance, Paderborn u.a. 1997.

HeinIG, Paul-Joachim u.a. (Hg.), Reich, Regionen und Europa in Mittelalter und Neuzeit. Fs. für Peter Moraw, Berlin 2000.

HeINRICH, Gerd, »Ein sonderbares Licht in Teutschland«. Beiträge zur Geschichte des Großen Kurfürsten von Brandenburg (1640-1688), Berlin 1990.

Heırz, Gerhard, Herzog, Stände und Bauern in Mecklenburg-Schwerin in den Jahren von 1756 1785, in: Günter Vogler (Hg.), Europäische Herrscher. Ihre Rolle bei der Gestaltung von Politik und Gesellschaft vom 16. bis zum 18. Jahrhundert, Weimar 1988, S. 262-274.

- Herzog Carl Leopold von Mecklenburg-Schwerin (1679-1747), in: Rolf Straubel/Ulman WeIss (Hg.), Kaiser, König, Kardinal. Deutsche Fürsten 1500-1800, Leipzig/Jena/Berlin 1991, S. 303-310.

Held, Jutta (Hg.), Intellektuelle in der Frühen Neuzeit, München 2002.

Hengerer, Mark, Kaiserhof und Adel in der Mitte des 17. Jahrhunderts. Eine Kommunikationsgeschichte, Konstanz 2004.

HennIs, Wilhelm, Max Webers »Vorbericht für eine Erhebung zur Soziologie des Zeitungswesens«. Einführung und Text, in: Ders., Max Weber und Thukydides. Nachträge zu einer Biographie des Werks, Tübingen 2003, S. 130-149.

Henshall, Nicholas, The Myth of Absolutism. Change and Continuity in Early Modern European Monarchy, London/New York 1992.

Hensing, Ulrich, Acta Eruditorum (1682-1782), in: Heinz-Dietrich FIscher (Hg.), Deutsche Zeitschriften des 17. bis 20. Jahrhunderts, Pullach b. München 1973, S. 29-47. 
Herberger, Patricia/Stolleis, Michael (Hg.), Hermann Conring, 1606-1681. Ein Gelehrter der Universität Helmstedt. Ausstellung der Herzog August Bibliothek Wolfenbüttel im Juleum Helmstedt, Wolfenbüttel 1981.

Herborn, Wolfgang, Hermann von Weinsberg (1518-1597), in: Manfred Groten (Hg.), Hermann von Weinsberg (1518-1597). Kölner Bürger und Ratsherr. Studien zu Leben und Werk, Köln 2005, S. 15-33.

Herbst, Klaus-Dieter, Das Neueste im Jahresrhythmus. Zur Professionalisierung des Kalenderwesens im 17. Jahrhundert, in: Astrid Blome/Holger Böning (Hg.), Presse und Geschichte. Leistungen und Perspektiven der historischen Presseforschung, Bremen 2008, S. 97-124.

Hergemöller, Bernd-Ulrich, Der Nürnberger Reichstag von 1355/56 und die Goldene Bulle, Diss. Münster 1978.

Hermkes, Wolfgang, Das Reichsvikariat in Deutschland. Reichsvikare nach dem Tode des Kaisers von der Goldenen Bulle bis zum Ende des Reiches, Karlsruhe 1968.

Herz, Andreas, »Die Ursach nicht der Wahn«. Georg Philipp Harsdörffers »Teutscher Sekretarius« und die damalige deutsche Sprachdebatte, in: Wolfenbütteler Barock-Nachrichten 36 (2009), H. 1/2, S. 55-63.

Heuvel, Christine van den/Boetticher, Manfred (Hg.), Geschichte Niedersachsens, Bd. 3, T1. 1: Politik, Wirtschaft und Gesellschaft von der Reformation bis zum Beginn des 19. Jahrhunderts, Hannover 1998.

Heuvel, Gerd van den, Niedersachsen im 17. Jahrhundert (1618-1714), in: Christine van den Heuvel/Manfred Boetticher (Hg.), Geschichte Niedersachsens, Bd. 3, Tl. 1: Politik, Wirtschaft und Gesellschaft von der Reformation bis zum Beginn des 19. Jahrhunderts, Hannover 1998, S. 119218.

Hiller, István, Feind im Frieden. Die Rolle des Osmanischen Reiches in der europäischen Politik zur Zeit des Westfälischen Friedens, in: Heinz Duchнardt (Hg.), Der Westfälische Friede. Diplomatie - politische Zäsur - kulturelles Umfeld - Rezeptionsgeschichte, München 1998, S. 393-404.

Hinrichs, Ernst, Zur Erforschung der Alphabetisierung in Nordwestdeutschland in der Frühen Neuzeit, in: Anne Conrad u.a. (Hg.), Das Volk im Visier der Aufklärung. Studien zur Popularisierung der Aufklärung im späten 18. Jahrhundert, Hamburg 1998, S. 35-56.

- Fürsten und Mächte. Zum Problem des europäischen Absolutismus, Göttingen 2000.

- Alphabetisierung. Lesen und Schreiben, in: Richard van Dülmen/Sina Rauschenbach (Hg.), Macht des Wissens. Die Entstehung der modernen Wissensgesellschaft, Köln/Weimar/Wien 2004, S. 539-561.

- /Norden, Wilhelm (Hg.), Regionalgeschichte. Probleme und Beispiele, Hildesheim 1980.

- /Wiegelmann, Günther (Hg.), Sozialer und kultureller Wandel in der ländlichen Welt des 18. Jahrhunderts, Wolfenbüttel 1982.

HöLscher, Lucian, Öffentlichkeit und Geheimnis. Eine begriffsgeschichtliche Untersuchung zur Entstehung der Öffentlichkeit in der frühen Neuzeit, Stuttgart 1979.

- Die Öffentlichkeit begegnet sich selbst. Zur Struktur öffentlichen Redens im 18. Jahrhundert zwischen Diskurs- und Sozialgeschichte, in: Hans-Wolf JäGER (Hg.), »Öffentlichkeit« im 18. Jahrhundert, Göttingen 1997, S. 11-31.

Holzmann, Michael/Bohatta, Hanns (Hg.), Deutsches Anonymenlexikon 1501-1850, 7 Bd., Weimar 1902-1926 (ND Hildesheim 1961).

Honemann, Volker u.a. (Hg.), Einblattdrucke des 15. und frühen 16. Jahrhunderts. Probleme, Perspektiven, Fallstudien, Tübingen 2000.

Horn Melton, James van, Absolutism and the Eighteenth Century Origins of Compulsory Schooling in Prussia and Austria, Cambridge u.a. 1988.

Hughes, Michael, Law and Politics in Eighteenth Century Germany. The Imperial Aulic Council in the Reign of Charles VI, Woodbridge u.a. 1988.

Hütтl, Ludwig, Max Emanuel. Der Blaue Kurfürst (1679-1726). Eine politische Biographie, München 1976.

HunEKE, Friedrich, Die »Lippischen Intelligenzblätter« (Lemgo 1767-1799). Lektüre und gesellschaftliche Erfahrung, Bielefeld 1989. 
Hymmen, Hans von, Der erste preußische König und die Gegenreformation in der Pfalz, Bielefeld 1904.

ImMLER, Gerhard, Der innerwittelsbachische Konflikt. Bayern gegen Pfalz, in: Johannes ERICHSen/Katharina Heinemann (Hg.), Die Schlacht von Höchstädt. The Battle of Blenheim. Brennpunkt Europas 1704, Sigmaringen 2004, S. 26-37.

IsERLOH, Erwin, Luthers Thesenanschlag. Tatsache oder Legende?, Wiesbaden 1962.

IsRael, Jonathan I., Radical Enlightenment. Philosophy and the Making of Modernity, 1650-1750, Oxford/New York 2001.

- Enlightenment Contested. Philosophy, Modernity, and the Emancipation of Man 1670-1752, Oxford/New York 2006.

- A Revolution of the Mind. Radical Enlightenment and the Intellectual Origins of Modern Democracy, Princeton 2010.

JACOBSOn, Roswitha/Ruge, Hans-Jörg (Hg.), Ernst der Fromme (1601-1675). Staatsmann und Reformer. Wissenschaftliche Beiträge und Katalog zur Ausstellung Gotha, 16. Dezember 2001 bis 7. April 2002, Bucha 2002.

JAEGER, Friedrich/Rüsen, Jörn, Geschichte des Historismus. Eine Einführung, München 1992.

JäGER, Hans-Wolf (Hg.), »Öffentlichkeit« im 18. Jahrhundert, Göttingen 1997.

JänICKe, Marco, Art. »Acxtelmeier, Stanislaus Reinhard«, in: Gudrun Gersmann/Katrin MoelLER/Jürgen-Michael SCHмidT (Hg.), Lexikon zur Geschichte der Hexenverfolgung, publiziert in: historicum.net, URL: <http://www.historicum.net/themen/hexenforschung/ lexikon/alphabethisch/a-g/art/Acxtelmeier_St/html/artikel/5824/ca/fef802438148ae234cc46934e7f72cd8/> (11.08.2012).

JAHNS, Sigrid, »Mecklenburgisches Wesen« oder absolutistisches Regiment? Mecklenburgischer Ständekonflikt und neue kaiserliche Reichspolitik (1658-1755), in: Paul-Joachim HeINIG u.a. (Hg.), Reich, Regionen und Europa in Mittelalter und Neuzeit. Fs. für Peter Moraw, Berlin 2000, S. 323-351.

- Das Reichskammergericht und seine Richter. Verfassungs- und Sozialstruktur eines höchsten Gerichts im Alten Reich, 2 Bd. in 3 Teilbd., Köln/Weimar/Wien 2003.

JARCK, Horst-Rüdiger/SCHILDT, Gerhard (Hg.), Die Braunschweigische Landesgeschichte. Jahrtausendrückblick einer Region, Braunschweig 2000.

JaumanN, Herbert (Hg.), Handbuch Gelehrtenkultur der frühen Neuzeit. Bio-bibliographisches Repertorium, Bd. 1, Berlin/New York 2004.

Jeismann, Michael, Das 17. Jahrhundert. Krieg und Frieden, München 2000.

Johannesson, Kurt, The Renaissance of the Goths in Sixteenth-Century Sweden. Johannes and Olaus Magnus as Politicians and Historians, Berkeley 1991 (schwed. 1982).

Jordan, Ulrike, Anna (1702-1714), in: Peter Wende (Hg.), Englische Könige und Königinnen. Von Heinrich VII. bis Elisabeth II., München 1998, S. 176-187.

JunG, Vera, Körperlust und Disziplin. Studien zur Fest- und Tanzkultur im 16. und 17. Jahrhundert, Köln/Weimar/Wien 2001.

Junkelmann, Marcus, Kurfürst Max Emanuel von Bayern als Feldherr, München 2000.

KALIPKE, Andreas, »Weitläuffigkeiten« und »Bedencklichkeiten«. Die Behandlung konfessioneller Konflikte am Corpus Evangelicorum, in: ZHF 35 (2008), S. 405-447.

Kalmus, Ludwig, Weltgeschichte der Post mit besonderer Berücksichtigung des deutschen Sprachgebietes, Wien 1937.

KAMINSKi, Nicola, Die Musen als Lexikographen. Zedlers Großes Vollständiges Universal-Lexicon im Schnittpunkt von poetischem, wissenschaftlichem, juristischem und ökonomischem Diskurs, in: Daphnis 29 (2000), S. 649-693.

Kampmann, Christoph, Reichsrebellion und kaiserliche Acht. Politische Strafjustiz im Dreißigjährigen Krieg und das Verfahren gegen Wallenstein, Münster 1992.

_ »Der Leib des Römischen Reichs ist der Stände Eigentum und nicht des Kaisers«. Zur Entstehung der Konkurrenz zwischen Kaiserhof und Reichstag beim Achtverfahren, in: Wolfgang 
SELlERT (Hg.), Reichshofrat und Reichskammergericht. Ein Konkurrenzverhältnis, Köln/Weimar/Wien 1999, S. 169-198.

Kapp, Friedrich/GoldFriedrich, Johann, Geschichte des deutschen Buchhandels, 4 Bd. u. Registerbd., Leipzig 1886-1923 (ND Leipzig 1970).

Kappelhoff, Bernd, Absolutistisches Regiment oder Ständeherrschaft? Landesherr und Landstände in Ostfriesland im ersten Drittel des 18. Jahrhunderts, Hildesheim 1982.

- Politische Partizipation und frühmoderner Staat. Ostfriesland von 16. bis zum 19. Jahrhundert, in: Hajo von Lengen (Hg.), Collectanea Frisica. Beiträge zur historischen Landeskunde Ostfrieslands, Aurich 1995, S. 267-290.

Karnehm, Christl, Das Korrespondenznetz Hans Fuggers (1531-1598), in: Johannes Burkhardt/Christine Werkstetter (Hg.), Kommunikation und Medien in der Frühen Neuzeit, München 2005, S. 301-311.

Kaschmieder, Käthe, David Fassmanns Gespräche im Reiche der Toten (1718-1740). Ein Beitrag zur deutschen Geistes- und Kulturgeschichte des 18. Jahrhunderts, Diss. Breslau 1934.

Kastner, Ruth, Geistlicher Rauffhandel. Form und Funktion der illustrierten Flugblätter zum Reformationsjubiläum 1617, Frankfurt a.M. u.a. 1982.

Kaufhold, Martin, Öffentlichkeit im politischen Konflikt. Die Publikation der kurialen Prozesse gegen Ludwig den Bayern in Salzburg, in: ZHF 22 (1995), S. 435-454.

Kaufmann, Thomas, Das Ende der Reformation. Magdeburgs »Herrgotts Kanzlei« (1548$1551 / 52)$, Tübingen 2003.

KaYser, Werner, Thomas von Wiering und Erben. Ein bedeutendes Kapitel hamburgischer Druckgeschichte, in: Auskunft. Mitteilungsblatt Hamburger Bibliotheken 10 (1990), H. 4, S. 343-371.

Keller, Ernst Friedrich [Adolf], Fürst Wilhelm Hyazinth von Nassau-Siegen. Prätendent der oranischen Erbschaft, seine Regierung und Zeitgenossen, in: AVNA 9 (1868), S. 49-122.

Keller, Katrin, Kleinstädte in Kursachsen. Wandlungen einer Städtelandschaft zwischen DreiBigjährigem Krieg und Industrialisierung, Köln/Weimar/Wien 2001.

- Saxony. Rétablissement and Enlightened Absolutism, in: German History 20 (2002), H. 3, S. 309-331.

Kenny, Neil, Curiosity in Early Modern Europe. Word Histories, Wiesbaden 1998.

- The Uses of Curiosity in Early Modern France and Germany, Oxford 2004.

KIESEL, Helmuth/MüNCH, Paul, Gesellschaft und Literatur im 18. Jahrhundert. Voraussetzungen und Entstehung des literarischen Markts in Deutschland, München 1977.

Kieserling, André, Kommunikation unter Anwesenden. Studien über Interaktionssysteme, Frankfurt a.M. 1999.

KilB, Andreas, Totentanz der Wirklichkeit. Kino: »Wag the Dog«, eine Filmsatire von David Mamet und Barry Levinson, in: DIE ZEIT Nr. 14, 26. März 1998, S. 64.

KIESEL, Helmuth, »Bei Hof, bei Höll«. Untersuchungen zur literarischen Hofkritik von Sebastian Brant bis Friedrich Schiller, Tübingen 1979.

Kirchноғ, Albrecht, Lesefrüchte aus den Acten der kurfürstlich sächsischen Bücher-Commission zu Leipzig, in: Archiv für Geschichte des deutschen Buchhandels 8 (1883), S. 62-122.

Kirchner, Joachim, Das deutsche Zeitschriftenwesen. Seine Geschichte und seine Probleme, 2 Bd., Wiesbaden 1958.

- (Hg.), Grundlagen des deutschen Zeitschriftenwesens. Mit einer Gesamtbibliographie der deutschen Zeitschriften bis zum Jahre 1790, 2 Bd., Leipzig 1928-1932.

- (Hg.), Bibliographie der Zeitschriften des deutschen Sprachgebietes bis 1900, 4 Bd., Stuttgart 1968-1989.

KleinPaul, Johannes, Das Nachrichtenwesen der deutschen Fürsten im 16. und 17. Jahrhundert. Ein Beitrag zur Geschichte der Geschriebenen Zeitungen, Leipzig 1930.

- Der Nachrichtendienst der Herzöge von Braunschweig im 16. und 17. Jahrhundert, in: Zeitungswissenschaft 5 (1930), S. 82-94.

Klesmann, Bernd, Bellum solemne. Formen und Funktionen europäischer Kriegserklärungen des 17. Jahrhunderts, Mainz 2007.

KLingenstein, Grete, Staatsverwaltung und kirchliche Autorität im 18. Jahrhundert. Das Problem der Zensur in der theresianischen Reform, München 1970. 
- Der Aufstieg des Hauses Kaunitz. Studien zur Herkunft und Bildung des Staatskanzlers Wenzel Anton, Göttingen 1975.

Klinger, Andreas, Der Gothaer Fürstenstaat. Herrschaft, Konfession und Dynastie unter Herzog Ernst dem Frommen, Husum 2002.

Kloft, Matthias T., Staat und Kirche in Nassau-Hadamar, in: AMRhKG 38 (1986), S. 47-106; Jg. 39 (1987), S. 107-156.

Klueting, Harm/Schmale, Wolfgang (Hg.), Das Reich und seine Territorialstaaten in der Frühen Neuzeit. Aspekte des Mit-, Neben- und Gegeneinanders, Münster u.a. 2004.

Kluge, Friedrich (Hg.), Etymologisches Wörterbuch der deutschen Sprache, Berlin/New York ${ }^{22} 1989$.

Knopf, Jan, Kalender, in: Ernst Fischer / Wilhelm Haefs / York-Gothart Mix (Hg.), Von Almanach bis Zeitung. Ein Handbuch der Medien in Deutschland 1700-1800, München 1999, S. 121-136.

Ковисн, Agatha, Zensur und Aufklärung in Kursachsen. Ideologische Strömungen und politische Meinungen zur Zeit der sächsisch-polnischen Union (1697-1763), Weimar 1988.

Косн, Rainer (Hg.), Brücke zwischen den Völkern. Zur Geschichte der Frankfurter Messe, 3 Bd., Frankfurt a.M. 1991.

KöHLER, Hans-Joachim, Die Flugschriften. Versuch einer Präzisierung eines geläufigen Begriffs, in: Horst RABE u.a. (Hg.), Festgabe für Ernst Walter Zeeden zum 60. Geburtstag, Münster 1976, S. 36-61.

- Fragestellungen und Methoden zur Interpretation frühneuzeitlicher Flugschriften, in: Ders. (Hg.), Flugschriften als Massenmedium der Reformationszeit, Stuttgart 1981, S. 1-27.

- Das Tübinger Flugschriftenprojekt. Bibliographie, Inhaltserschließung, Textpublikation der Flugschriften des frühen 16. Jahrhunderts, in: Wolfenbütteler Notizen zur Buchgeschichte 9 (1984), S. 3-22.

- Die Flugschriften der Frühen Neuzeit. Ein Überblick, in: Werner ARnold/Wolfgang DitTRich/Bernhard ZehLer (Hg.), Die Erforschung der Buch- und Bibliotheksgeschichte in Deutschland. Fs. für Paul Raabe zum 60. Geburtstag, Wiesbaden 1987, S. 307-345.

- (Hg.), Flugschriften als Massenmedium der Reformationszeit. Beiträge zum Tübinger Symposion 1980, Stuttgart 1981.

- u.a. (Hg.), Bibliographie der deutschen und lateinischen Flugschriften des frühen 16. Jahrhunderts, Tübingen 1978.

KöRBER, Esther-Beate, Öffentlichkeiten der frühen Neuzeit. Teilnehmer, Formen, Institutionen und Entscheidungen öffentlicher Kommunikation im Herzogtum Preußen von 1525 bis 1618, Berlin/New York 1998.

- Die Zeit der Aufklärung. Eine Geschichte des 18. Jahrhunderts, Stuttgart 2006.

- Zeitungsextrakte. Überraschungen bei der Erforschung publizistischer Formen der Frühen Neuzeit, in: Astrid Blome/Holger Böning (Hg.), Presse und Geschichte. Leistungen und Perspektiven der historischen Presseforschung, Bremen 2008, S. 125-140.

- Zeitungsextrakte. Aufgaben und Geschichte einer funktionellen Gruppe frühneuzeitlicher Publizistik, Bremen 2009.

- Entstehung und Funktion der Zeitungsextrakte in der Medienlandschaft der Frühen Neuzeit, in: Volker BAuER/Holger BönIng (Hg.), Die Entstehung des Zeitungswesens im 17. Jahrhundert. Ein neues Medium und seine Folgen für das Kommunikationssystem der Frühen Neuzeit, Bremen 2011, S. 211-234.

Kopitzsch, Franklin, Zeitungen - »Das Idol von Hamburg«. Zeugnisse zur Zeitungslektüre der Hamburger im 18. Jahrhundert, in: Jahrbuch für Regionalgeschichte 24 (2006), S. 101-114.

Koschwiтz, Hansjürgen, Der früheste Beleg für das Wort »Zeitschrift«, in: Publizistik. Vierteljahreshefte für Kommunikationsforschung 13 (1968), S. 41-43.

Koselleck, Reinhart, Kritik und Krise. Ein Beitrag zur Pathogenese der bürgerlichen Welt, Freiburg i.Br./München 1959 (21969).

- Historia Magistra Vitae. Über die Auflösung des Topos im Horizont neuzeitlich bewegter Geschichte, in: Ders., Vergangene Zukunft. Zur Semantik geschichtlicher Zeiten, Frankfurt a.M. 1989, S. 38-66. 
- Standortbindung und Zeitlichkeit. Ein Beitrag zur historiographischen Erschließung der geschichtlichen Welt, in: Ders., Vergangene Zukunft. Zur Semantik geschichtlicher Zeiten, Frankfurt a.M. 1989, S. 176-207.

- Vergangene Zukunft. Zur Semantik geschichtlicher Zeiten, Frankfurt a.M. 1989.

- Zeitschichten. Studien zur Historik, Frankfurt a.M. 2000.

Koser, Reinhold, Der Kanzleienstreit. Ein Beitrag zur Quellenkunde der Geschichte des Dreißigjährigen Krieges, Halle a.d. Saale 1874.

Kranhold, Karl Heinz, Frühgeschichte der Danziger Presse, Münster 1967.

Kraus, Andreas, Maximilian I. Bayerns großer Kurfürst, Graz u.a. 1990.

Kremer, Karl Heinz, Johann von den Birghden (1582-1645). Kaiserlicher und königlich-schwedischer Postmeister zu Frankfurt am Main, Bremen 2005.

Kroll, Frank-Lothar (Hg.), Preußens Herrscher. Von den ersten Hohenzollern bis Wilhelm II., München 2000.

KRÜGER, Kersten, Die landständische Verfassung, München 2003.

KRÜGER, Klaus (Hg.), Curiositas. Welterfahrung und ästhetische Neugierde in Mittelalter und früher Neuzeit, Göttingen 2002.

Krusenstjern, Benigna von/Medick, Hans (Hg.), Zwischen Alltag und Katastrophe. Der Dreißigjährige Krieg aus der Nähe, Göttingen 1999.

Kühlmann, Wilhelm, Gelehrtenrepublik und Fürstenstaat. Entwicklung und Kritik des deutschen Späthumanismus in der Literatur des Barockzeitalters, Tübingen 1982.

- Johann Fischart, in: Stephan Füssel (Hg.), Deutsche Dichter der Frühen Neuzeit. Ihr Leben und Werk (1450-1600), Berlin 1993, S. 589-612.

KÜHNE, Ulrich, Geschichte der böhmischen Kur in den Jahrhunderten nach der Goldenen Bulle, in: AUF 10 (1928), S. 1-110.

Kühnel, Martin, Das politische Denken von Christian Thomasius. Staat, Gesellschaft, Bürger, Berlin 2001.

Kümmel, Albert/Scholz, Leander/Schumacher, Eckhard (Hg.), Einführung in die Geschichte der Medien, Paderborn 2004.

KünZEL, Werner/Rellecke, Werner (Hg.), Geschichte der deutschen Länder. Entwicklungen und Traditionen vom Mittelalter bis zur Gegenwart, Münster 2005.

Küster, Sebastian, Vier Monarchien - Vier Öffentlichkeiten. Kommunikation um die Schlacht bei Dettingen, Münster 2004.

Kunisch, Johannes, Kurfürst Friedrich Wilhelm und die großen Mächte, in: Gerd HeInRICH (Hg.), »Ein sonderbares Licht in Teutschland«. Beiträge zur Geschichte des Großen Kurfürsten von Brandenburg (1640-1688), Berlin 1990, S. 9-32.

- Absolutismus und Öffentlichkeit, in: Hans-Wolf JäGER (Hg.), »Öffentlichkeit« im 18. Jahrhundert, Göttingen 1997, S. 33-49.

- Absolutismus. Europäische Geschichte vom Westfälischen Frieden bis zur Krise des Ancien Régime, Göttingen ${ }^{2} 1999$.

- Friedrich der Große. Der König und seine Zeit, München 2004.

- (Hg.), Neue Studien zur frühneuzeitlichen Reichsgeschichte, Berlin 1997.

- (Hg.), Dreihundert Jahre Preußische Königskrönung. Eine Tagungsdokumentation, Berlin 2002.

KuPKe, Anne-Kristin, Elementarschulunterricht in Kursachsen um 1670, in: Hans Erich BöDEKER/Ernst HinRichs (Hg.), Alphabetisierung und Literalisierung in Deutschland in der Frühen Neuzeit, Tübingen 1999, S. 225-252.

KuropKa, Nicole, Melanchthon, Tübingen 2010.

Kutsch, Arnulf/Weber, Johannes (Hg.), 350 Jahre Tageszeitung. Forschungen und Dokumente, Berlin 2002.

Laeven, Augustinus H., The Frankfurt and Leipzig Book Fairs and the History of the Dutch Book Trade, in: Christiane Berkvens-Stevelinck u.a. (Hg.), Le Magazin de l'Univers. The Dutch Republic as the Centre of the European Book Trade, Leiden 1992, S. 185-197. 
Laeven, Augustinus H., The »Acta Eruditorum« under the Editorship of Otto Mencke (16441707). The History of an International Learned Journal between 1682 and 1707, Amsterdam 1990 (ndl. 1986).

LAng, Elisabeth Constanze, Friedrich V., Tilly und Gustav Adolf im Flugblatt des Dreißigjährigen Krieges, Diss. Austin 1974.

LANG, Helmut W., Die Neue Zeitung des 15. bis 17. Jahrhunderts. Entwicklungsgeschichte und Typologie, in: Elger Blühm/Hartwig Gebhardt (Hg.), Presse und Geschichte, Bd. 2, München 1987, S. 57-60.

LANZINner, Maximilian, Donauwörth. Der bayerische Griff nach der Reichsstadt 1607/1608, in: Alois Schmid/Katharina Weigand (Hg.), Schauplätze der Geschichte in Bayern, München 2003, S. 216-230.

Lasswell, Harold D./Lerner, Daniel/Speier, Hans (Hg.), Propaganda and Communication in World History, 3 Bd., Honolulu 1979-1980.

Lathuillère, Roger (Hg.), Langue, Littérature du XVIIe et du XVIIIe siècle. Mélanges offerts à Frédéric Deloffre, Paris 1990.

Lehmann, Ernst Herbert, Einführung in die Zeitschriftenkunde, Leipzig 1936.

Lengen, Hajo von (Hg.), Die Emder Revolution von 1595, Aurich 1995.

- Collectanea Frisica. Beiträge zur historischen Landeskunde Ostfrieslands, Aurich 1995.

LeOnhard, Joachim-Felix u.a. (Hg.), Medienwissenschaft. Ein Handbuch zur Entwicklung der Medien und Kommunikationsformen, Bd. 1, Berlin/New York 1999.

Lindemann, Margot, Deutsche Presse bis 1815. Geschichte der deutschen Presse, T1. 1, Berlin 1969.

LindenBerG, Ludwig, Leben und Schriften David Fassmanns (1683-1744) mit besonderer Berücksichtigung seiner Totengespräche, Diss. Berlin 1937.

Lipp, Carola (Hg.), Medien populärer Kultur. Erzählung, Bild und Objekt in der volkskundlichen Forschung. Rolf Wilhelm Brednich zum 60. Geburtstag, Frankfurt a.M./New York 1995.

LoHse, Bernhard, Martin Luther. Eine Einführung in sein Leben und sein Werk, München 1981 ( $\left.{ }^{3} 1997\right)$.

Lombard, Jean, Courtilz de Sandras ou l'aventure sous le regne de Louis XIV, Diss. Paris 1978.

- Courtilz de Sandras et la crise du roman à la fin du Grand Siècle, Paris 1980.

- Les rédacteurs du Mercure historique et politique de La Haye (La Haye, novembre 1686 avril 1782), in: Roger LAthuillère (Hg.), Langue, Littérature du XVIIe et du XVIIIe siècle. Mélanges offerts à Frédéric Deloffre, Paris 1990, S. 295-307.

- Art. »Mercure historique et politique 1«, in: Jean SGARD (Hg.), Dictionnaire des journaux (1600-1789), Bd. 2, Paris 1991, S. 870-878.

Lorenz, Erich, Die Entwicklung des deutschen Zeitschriftenwesens. Eine statistische Untersuchung, Diss. Berlin-Charlottenburg 1937.

Lorenz, Kuno, Art. »Deduktion«, in: Joachim Ritter (Hg.), HWP, 14 Bd., hier Bd. 2, Darmstadt 1972, S. 29f.

Lottes, Günther, Reformation in Regensburg, in: Martin Angerer (Hg.), 450 Jahre Evangelische Kirche in Regensburg (1542-1992). Ausstellung im Museum der Stadt Regensburg, Regensburg 1992, S. 15-28.

Lotz, Arthur, Das Feuerwerk. Seine Geschichte und Bibliographie, Zürich 1982.

Lotz-Heumann, Ute/Missfelder, Jan-Friedrich/Pohlig, Matthias (Hg.), Konversion und Konfession in der Frühen Neuzeit, Gütersloh 2007.

Luhmann, Niklas, Macht, Stuttgart 1975 ( $\left.{ }^{2} 1988\right)$.

- Funktion der Religion, Frankfurt a.M. 1977 (ND 1996).

- Soziale Systeme. Grundriß einer allgemeinen Theorie, Frankfurt a.M. 1984/1987.

- Tautologie und Paradoxie in den Selbstbeschreibungen der modernen Gesellschaft, in: ZfS 16 (1987), S. 161-174.

- Die Wirtschaft der Gesellschaft, Frankfurt a.M. 1988.

- Geheimnis, Zeit und Ewigkeit, in: Ders./Peter Fuchs (Hg.), Reden und Schweigen, Frankfurt a.M. 1989, S. 101-137.

- Staat und Staatsräson im Übergang von traditionaler Herrschaft zu moderner Politik, in: Ders., Gesellschaftsstruktur und Semantik, Bd. 3, Frankfurt a.M. 1989, S. 65-148. 
- Die Wissenschaft der Gesellschaft, Frankfurt a.M. 1990 (21994).

- Die Realität der Massenmedien, Opladen ${ }^{2} 1996$.

- Die Gesellschaft der Gesellschaft, 2 Bd., Frankfurt a.M. 1997.

- Die Politik der Gesellschaft, hg. v. André Kieserling, Frankfurt a.M. 2000.

LundKvist, Sven, Die schwedischen Friedenskonzeptionen und ihre Umsetzung in Osnabrück, in: Heinz Duchinardt (Hg.), Der Westfälische Friede. Diplomatie - politische Zäsur - kulturelles Umfeld - Rezeptionsgeschichte, München 1998, S. 349-359.

MAAr, Elke, Bildung durch Unterhaltung. Die Entdeckung des Infotainment in der Aufklärung. Hallenser und Wiener Moralische Wochenschriften in der Blütezeit des Moraljournalismus, 1748-1782, Pfaffenweiler 1995.

MaIER, Ingrid, Amsterdamer und Haarlemer Zeitungen (Couranten) des 17. Jahrhunderts im Niedersächsischen Staatsarchiv zu Oldenburg, in: GutJb 78 (2003), S. 170-191.

Maissen, Thomas, Die Geburt der Republik. Staatsverständnis und Repräsentation der frühmodernen Eidgenossenschaft, Göttingen 2006.

Manheim, Ernst, Die Träger der Öffentlichen Meinung. Studien zur Soziologie der Öffentlichkeit, Brünn u.a. 1933.

- Aufklärung und öffentliche Meinung. Studien zur Soziologie der Öffentlichkeit im 18. Jahrhundert, Stuttgart-Bad Cannstatt ${ }^{2} 1979$.

Manke, Matthias/Münch, Ernst (Hg.), Verfassung und Lebenswirklichkeit. Der Landesgrundgesetzliche Erbvergleich von 1755 in seiner Zeit, Lübeck 2006.

Marti, Hanspeter/DörIng, Detlef (Hg.), Die Universität Leipzig und ihr gelehrtes Umfeld 16801780, Basel 2004.

Matsch, Erwin, Der Auswärtige Dienst von Österreich(-Ungarn) 1720-1920, Köln/ Wien 1986.

Matthias, Carl, Die Mecklenburger Frage in der ersten Hälfte des 18. Jahrhunderts und das Dekret Kaiser Karls VI. vom 11. Mai 1728, Diss. Halle 1885.

Mauelshagen, Stephan, »Die Freiheiten zernichtet«. Die Stadt Rostock im Kampf mit Herzog Karl Leopold von Mecklenburg-Schwerin (1714-1716), in: Sylvia Schraut/Bernhard Stier (Hg.), Stadt und Land. Bilder, Inszenierungen und Visionen in Geschichte und Gegenwart. Fs. für Wolfgang von Hippel zum 65. Geburtstag, Stuttgart 2001, S. 75-87.

Maurer, Michael, Der Sonntag in der frühen Neuzeit, in: AKG 88 (2006), S. 75-100.

Max, Hubert, Wesen und Gestalt der politischen Zeitschrift. Ein Beispiel zur Geschichte des politischen Erziehungsprozesses des deutschen Volkes bis zu den Karlsbader Beschlüssen, Essen 1942.

Medick, Hans, Weben und Überleben in Laichingen, 1650-1900. Lokalgeschichte als Allgemeine Geschichte, Göttingen 1996.

Mediger, Walther, Mecklenburg, Rußland und England-Hannover 1706-1721. Ein Beitrag zur Geschichte des Nordischen Krieges, 2 Bd., Hildesheim 1967.

MeID, Volker, Die deutsche Literatur im Zeitalter des Barock. Vom Späthumanismus zur Frühaufklärung, München 2009.

Mentz, Georg, Die deutsche Publizistik im 17. Jahrhundert, Hamburg 1897.

Meschkat-Peters, Sabine, Ehrgeiz, Luxus und Fortune. Hannovers Weg zu Englands Krone. Ausstellung des Historischen Museums am Hohen Ufer Hannover, Hannover 2001.

Messerli, Alfred, War das illustrierte Flugblatt ein Massenlesestoff? Überlegungen zu einem Paradigmawechsel in der Erforschung seiner Rezeption, in: Wolfgang Harms / Alfred MEsSERLI (Hg.), Wahrnehmungsgeschichte und Wissensdiskurs im illustrierten Flugblatt der Frühen Neuzeit (1450-1700), Basel 2002, S. 23-31.

Meyer, Rudolf, Die Flugschriften der Epoche Ludwigs XIV. Eine Untersuchung der in schweizerischen Bibliotheken enthaltenen Broschüren, Basel 1955.

Midelfort, H.C. Erik, Verrückte Hoheit. Wahn und Kummer in deutschen Herrscherhäusern, Stuttgart 1996.

Moeglin, Jean-Marie, Fürstliche Ehre und verletzte Ehre der Fürsten im spätmittelalterlichen deutschen Reich, in: Klaus SchreInER/Gerd Schwerhoff (Hg.), Verletzte Ehre. Ehrkonflikte in Gesellschaften des Mittelalters und der Frühen Neuzeit, Köln/Weimar/Wien 1995, S. 77-91. 
MöLıch, Georg / Schwerhoff, Gerd (Hg.), Köln als Kommunikationszentrum. Studien zur frühneuzeitlichen Stadtgeschichte, Köln 2000.

Mörke, Olaf, Pamphlet und Propaganda. Politische Kommunikation und technische Innovation in Westeuropa in der Frühen Neuzeit, in: Michael NoRTH (Hg.), Kommunikationsrevolutionen im 16. und 19. Jahrhundert, Köln/Weimar/Wien 1995, S. 15-32.

Moraw, Peter, Von offener Verfassung zu gestalteter Verdichtung. Das Reich im späten Mittelalter 1250-1490, Frankfurt a.M. 1989.

Muchembled, Robert, Kultur des Volks. Kultur der Eliten, Stuttgart 1982 (franz. 1978).

Muckel, Victor, Die Entwicklung der Zensur in Köln, Diss. Köln 1932.

Mühleisen, Hans-Otto/Stammen, Theo (Hg.), Politische Tugendlehre und Regierungskunst. Studien zum Fürstenspiegel der frühen Neuzeit, Tübingen 1990.

Müller, Arnd, Zensurpolitik der Reichsstadt Nürnberg, in: Mitteilungen des Vereins für Geschichte der Stadt Nürnberg 49 (1959), S. 66-169.

MüLler, Rainer A., Die deutschen Fürstenspiegel des 17. Jahrhunderts. Regierungslehre und politische Pädagogik, in: HZ 240 (1985), S. 571-597.

Münch, Paul, Nassau, ottonische Linien, in: Anton SchinduIng / Walter Ziegler (Hg.), Die Territorien des Reichs im Zeitalter der Reformation und Konfessionalisierung, Bd. 4, Münster 1992, S. 234-252.

MüNKLER, Herfried, Machiavelli. Die Begründung des politischen Denkens der Neuzeit aus der Krise der Republik Florenz, Frankfurt a.M. 1982.

NAGEL, Michael, Das DFG-Projekt einer Pressebibliographie für Leipzig. Erfahrungen und Zwischenergebnisse, in: Astrid Blome (Hg.), Zeitung, Zeitschrift, Intelligenzblatt und Kalender. Beiträge zur historischen Presseforschung, Bremen 2001, S. 21-34.

Naumann, Hans, Grundzüge der deutschen Volkskunde, Leipzig 1922.

Negt, Oskar/Kluge, Alexander, Geschichte und Eigensinn. Geschichtliche Organisation der Arbeitsvermögen. Deutschland als Produktionsöffentlichkeit. Gewalt des Zusammenhangs, Frankfurt a.M. 1981.

Neugebauer, Wolfgang, Friedrich III./I. (1688-1713), in: Frank-Lothar Kroll (Hg.), Preußens Herrscher. Von den ersten Hohenzollern bis Wilhelm II., München 2000, S. 113-133.

Neunaus, Helmut, Das Reich in der frühen Neuzeit, München 1997.

Neumann, Florian, Jeremias Drexels Aurifodina und die Ars excerpendi bei den Jesuiten, in: Helmut Zedelmaier/Martin Mulsow (Hg.), Die Praktiken der Gelehrsamkeit in der frühen Neuzeit, Tübingen 2001, S. 51-61.

Neumann, Gerald, Die Rolle Kurbayerns im Spanischen Erbfolgekrieg im Blick der öffentlichen Meinung, in: JFL 60 (2000), S. 333-347.

Neumann, Helmut, Staatliche Bücherzensur und -aufsicht in Bayern von der Reformation bis zum Ausgang des 17. Jahrhunderts, Heidelberg/Karlsruhe 1977.

NickLAS, Thomas, Johann David Köhler (1684-1755), Historiker, in: Fränkische Lebensbilder 16 (1996), S. 79-93.

Nitschke, Peter, Religion und Politik in der Föderaltheologie des Johannes Althusius, in: Manfred Walther (Hg.), Religion und Politik. Zu Theorie und Praxis des theologisch-politischen Komplexes, Baden-Baden 2004, S. 141-149.

NoelLE, Elisabeth, Öffentliche Meinung und soziale Kontrolle, Tübingen 1966.

Noelle-Neumann, Elisabeth, Die Schweigespirale. Öffentliche Meinung - unsere soziale Haut, München/Zürich 1980.

- Öffentliche Meinung. Die Entdeckung der Schweigespirale, Frankfurt a.M. ${ }^{4} 1996$.

Norden, Wilhelm, Die Alphabetisierung der oldenburgischen Küstenmarschen im 17. und 18. Jahrhundert, in: Ernst Hinrichs/Wilhelm Norden (Hg.), Regionalgeschichte. Probleme und Beispiele, Hildesheim 1980, S. 103-164.

NorTh, Michael (Hg.), Kommunikationsrevolutionen im 16. und 19. Jahrhundert, Köln 1995.

Oelke, Harry, Die Konfessionsbildung des 16. Jahrhunderts im Spiegel illustrierter Flugblätter, Berlin 1992. 
- Konfessionelle Bildpropaganda des späten 16. Jahrhunderts. Die Nas-Fischart-Kontroverse 1568/71, in: ARG 87 (1996), S. 149-200.

Oestreich, Gerhard, Antiker Geist und moderner Staat bei Justus Lipsius (1547-1606). Der Neustoizismus als politische Bewegung, hg. u. eingeleitet v. Nicolette Mout, Göttingen 1989.

OpeL, Julius Otto, Anfänge der deutschen Zeitungspresse 1609-1650, Leipzig 1879.

Opgenoorth, Ernst, Friedrich Wilhelm, der Große Kurfürst von Brandenburg. Eine politische Biographie, 2 Bd., Göttingen u.a. 1971-1978.

- Der Große Kurfürst, das Reich und die europäischen Mächte, in: Oswald Hauser (Hg.), Preußen, Europa und das Reich, Köln 1987, S. 19-31.

- Publicum - privatum - arcanum. Ein Versuch zur Begrifflichkeit frühneuzeitlicher Kommunikationsgeschichte, in: Bernd Sösemann (Hg.), Kommunikation und Medien in Preußen vom 16. bis zum 19. Jahrhundert, Stuttgart 2002, S. 22-44.

Oredsson, Sverker, Geschichtsschreibung und Kult. Gustav Adolf, Schweden und der Dreißigjährige Krieg, Berlin 1994 (schwed. 1992).

OrtLieb, Eva, Im Auftrag des Kaisers. Die kaiserlichen Kommissionen des Reichshofrats und die Regelung von Konflikten im Alten Reich (1637-1657), Köln/Wien/Weimar 2001.

PeČAr, Andreas, Die Ökonomie der Ehre. Der höfische Adel am Kaiserhof Karls VI. (1711-1740), Darmstadt 2003.

- Am Rande des Alten Reiches? Mecklenburgs Stellung im Alten Reich am Beispiel landständischer Repräsentationen und kaiserlichen Einflusses, in: Matthias Manke/Ernst Münch (Hg.), Verfassung und Lebenswirklichkeit. Der Landesgrundgesetzliche Erbvergleich von 1755 in seiner Zeit, Lübeck 2006, S. 201-223.

Pelizaeus, Ludolf, Der Aufstieg Württembergs und Hessens zur Kurwürde 1692-1803, Frankfurt a.M. u.a. 2000.

Pfarr, Kristina, Die neue Zeitung. Empirische Untersuchung eines Informationsmediums der frühen Neuzeit unter besonderer Berücksichtigung von Gewaltdarstellungen, Diss. Mainz 1994.

Plassmann, Max, Krieg und Defension am Oberrhein. Die Vorderen Reichskreise und Markgraf Ludwig Wilhelm von Baden (1693-1706), Berlin 2000.

PoHL, Hans (Hg.), Die Bedeutung der Kommunikation für Wirtschaft und Gesellschaft. Referate der 12. Arbeitstagung der Gesellschaft für Sozial- und Wirtschaftsgeschichte, Stuttgart 1989.

Pollmann, Judith, Eine natürliche Feindschaft. Ursprung und Funktion der schwarzen Legende über Spanien in den Niederlanden, 1560-1581, in: Franz BosBach (Hg.), Feindbilder. Die Darstellung der Gegner in der politischen Publizistik des Mittelalters und der Neuzeit, Köln/Weimar/Wien 1992, S. 73-93.

Pompe, Hedwig, Die Neuheit der Neuheit. Der Zeitungsdiskurs im späten 17. Jahrhundert, in: Albert Kümmel/Leander Scholz/Eckhard Schumacher (Hg.), Einführung in die Geschichte der Medien, Paderborn 2004, S. 35-63.

Poser, Hans (Hg.), Nihil Sine Ratione. VII. Internationaler Leibniz-Kongreß, Berlin 10. bis 14. September 2001, Nachtragsbd., Hannover 2002.

Prange, Carsten, Die Zeitungen und Zeitschriften des 17. Jahrhunderts in Hamburg und Altona. Ein Beitrag zur Publizistik der Frühaufklärung, Hamburg 1978.

PratjE, Jürgen, Die kaiserlichen Reservatrechte, Diss. Erlangen 1957 (Mschr.).

Press, Volker, Kaiser Karl V., König Ferdinand und die Entstehung der Reichsritterschaft, Wiesbaden ${ }^{2} 1980$.

- Von den Bauernrevolten des 16. zur konstitutionellen Verfassung des 19. Jahrhunderts. Die Untertanenkonflikte in Hohenzollern-Hechingen und ihre Lösungen, in: Hermann WeBER (Hg.), Politische Ordnungen und soziale Kräfte im Alten Reich, Wiesbaden 1980, S. 85-112.

- Kurhannover im System des Alten Reiches 1692-1803, in: Adolf M. Birke/Kurt KluXen (Hg.), England und Hannover. England and Hanover, München 1986, S. 53-79.

- Die kaiserliche Stellung im Reich zwischen 1648 und 1740. Versuch einer Neubewertung, in: Georg Schmidt (Hg.), Stände und Gesellschaft im Alten Reich, Stuttgart 1989, S. 51-80.

- Böhmen und das Reich in der Frühen Neuzeit, in: Bohemia 35 (1994), S. 63-74.

- Das Alte Reich. Ausgewählte Aufsätze, hg. v. Johannes Kunisch, Berlin 1997. 
- Adel im Alten Reich. Gesammelte Vorträge und Aufsätze, hg. v. Franz BrendLE / Anton SchindLING, Tübingen 1998.

- /Reinhard, Eugen/Schwarzmaier, Hansmartin (Hg.), Barock am Oberrhein, Karlsruhe 1985.

Probst, Christian, Lieber bayrisch sterben. Der bayerische Volksaufstand der Jahre 1705 und 1706, München 1978.

Prüsener, Marlies, Lesegesellschaften im 18. Jahrhundert. Ein Beitrag zur Lesergeschichte, Frankfurt a.M. 1971.

Prutz, Robert, Geschichte des deutschen Journalismus, Bd. 1 (mehr nicht erschienen), Hannover 1845.

Quedenbaum, Gerd, Der Verleger und Buchhändler Johann Heinrich Zedler 1706-1751. Ein Buchunternehmer in den Zwängen seiner Zeit, Hildesheim/New York 1977.

Quentin, Ernst, Die Leipziger Meßrelationen. Ein Beitrag zur Geschichte des ältesten deutschen Zeitungswesens, Leipzig 1941.

RaAbe, Paul, Pseudonyme und anonyme Schriften im 17. und 18. Jahrhundert, in: Ders. (Hg.), Der Zensur zum Trotz. Das gefesselte Wort und die Freiheit in Europa. Ausst.-Kat., Weinheim 1991, S. 53-58.

- (Hg.), Herzog August zu Braunschweig und Lüneburg (1579-1666). Sammler, Fürst, Gelehrter. Eine Ausstellung des Landes Niedersachsen in der Herzog August Bibliothek Wolfenbüttel, Braunschweig 1979.

- (Hg.), Bücher und Bibliotheken im 17. Jahrhundert in Deutschland, Hamburg 1980.

- (Hg.), Gutenberg. 550 Jahre Buchdruck in Europa. Ausstellung im Zeughaus der Herzog August Bibliothek Wolfenbüttel, Weinheim 1990.

- (Hg.), Der Zensur zum Trotz. Das gefesselte Wort und die Freiheit in Europa, Weinheim 1991.

RAHN, Kerstin, »Die Weide des weissen Rosses von Braunschweig bis an die Ostsee erweitern ...«? Kurhannover und Mecklenburg in der ersten Hälfte des 18. Jahrhunderts, in: Matthias MAnKe/Ernst MüNCH (Hg.), Verfassung und Lebenswirklichkeit. Der Landesgrundgesetzliche Erbvergleich von 1755 in seiner Zeit, Lübeck 2006, S. 335-349.

RAINER, Wolfgang, Johann Fischart 1546-1590, in: Heinz-Dietrich Fischer (Hg.), Deutsche Publizisten des 15. bis 20. Jahrhunderts, München 1971, S. 59-69.

Rakow, Peter-Joachim/Schütt, Christel/Sievenkopp, Christa (Hg.), Die Bestände des Landeshauptarchiv Schwerin, Bd. 1: Urkunden- und Aktenbestände 1158-1945, Schwerin 1999.

Rall, Hans, Kurfürst Max Emanuel und das Haus Wittelsbach im 17. und 18. Jahrhundert, in: Hubert Glaser (Hg.), Kurfürst Max Emanuel. Bayern und Europa um 1700, Bd. 1, München 1976, S. 51-66.

- /Rall, Marga, Die Wittelsbacher in Lebensbildern, Graz u.a. 1986.

RANKe, Kurt/Brednich, Rolf Wilhelm (Hg.), Enzyklopädie des Märchens. Handwörterbuch zur historischen und vergleichenden Erzählforschung, (bislang) 14 Bd., Berlin/New York 19752012.

RaU, Susanne/Schwerhoff, Gerd (Hg.), Zwischen Gotteshaus und Taverne. Öffentliche Räume in Spätmittelalter und Früher Neuzeit, Köln/Weimar/Wien 2004.

RedLich, Oswald, Das Werden einer Großmacht. Österreich von 1700 bis 1740, Brünn/München / Wien 1942.

ReEse, Armin, Die Rolle der Historie beim Aufstieg des Welfenhauses, 1680-1714, Hildesheim 1967.

ReIchнolf, Josef H., Rabenschwarze Intelligenz. Was wir von Krähen lernen können, München ${ }^{3} 2009$.

Reinhard, Wolfgang/Schilding, Heinz (Hg.), Die katholische Konfessionalisierung, Gütersloh 1995.

- Geschichte der Staatsgewalt. Eine vergleichende Verfassungsgeschichte Europas von den Anfängen bis zur Gegenwart, München 1999. 
- Zusammenfassung. Staatsbildung durch »Aushandeln«?, in: Ronald G. Asch/Dagmar FreIST (Hg.), Staatsbildung als kultureller Prozess. Strukturwandel und Legitimation von Herrschaft in der Frühen Neuzeit, Köln/Weimar/Wien 2005, S. 429-438.

RePGEN, Konrad, Über Lünigs »Teutsches Reichs-Archiv« (1710-1722). Aufbau und ZitierungsMöglichkeiten, in: Ders. (Hg.), Forschungen und Quellen zur Geschichte des Dreißigjährigen Krieges, Münster 1981, S. 240-285.

- Kriegslegitimationen in Alteuropa. Entwurf einer historischen Typologie, in: HZ 241 (1985), S. $27-49$.

- Der Westfälische Friede und die zeitgenössische Öffentlichkeit, in: HJb 117/I (1997), S. 38-83.

- Dreißigjähriger Krieg und Westfälischer Friede. Studien und Quellen, hg. v. Franz BosBACH / Christoph Kampmann, Paderborn u.a. 1998.

- (Hg.), Forschungen und Quellen zur Geschichte des Dreißigjährigen Krieges, Münster 1981.

- (Hg.), Das Herrscherbild im 17. Jahrhundert, Münster 1991.

ReQuATE, Jörg, Gescheiterte Existenzen? Zur Geschichte des Journalistenberufs im 19. Jahrhundert, in: Martin Welke/Jürgen Wilke (Hg.), 400 Jahre Zeitung. Die Entwicklung der Tagespresse im internationalen Kontext, Bremen 2008, S. 335-354.

RIEPL, Wolfgang, Das Nachrichtenwesen des Altertums. Mit besonderer Rücksicht auf die Römer, Leipzig 1913 (ND Hildesheim 1972).

RIES, Paul, The Anatomy of Seventeenth-Century Newpapers, in: Daphnis 6 (1977), S. 171-232.

RiLl, Bernd, Karl VI. Habsburg als barocke Großmacht, Graz/Wien/Köln 1992.

Ritter, Joachim (Hg.), Historisches Wörterbuch der Philosophie, 14 Bd., Darmstadt 1971-2007 (= HWP).

Roeck, Bernd, Reichssystem und Reichsherkommen. Die Diskussion über die Staatlichkeit des Reiches in der politischen Publizistik des 17. und 18. Jahrhunderts, Stuttgart 1984.

- Lebenswelt und Kultur des Bürgertums in der Frühen Neuzeit, München 1991.

RöMER, Christof, Das Zeitalter des Hochabsolutismus (1635-1735), in: Horst-Rüdiger JARCK/Gerhard Schildt (Hg.), Die Braunschweigische Landesgeschichte. Jahrtausendrückblick einer Region, Braunschweig 2000, S. 535-574.

- Der Kaiser und die welfischen Staaten 1679-1755. Abriß der Konstellationen und der Bedingungsfelder, in: Harm Klueting/Wolfgang Schmale (Hg.), Das Reich und seine Territorialstaaten in der Frühen Neuzeit. Aspekte des Mit-, Neben- und Gegeneinanders, Münster u.a. 2004, S. 43-66.

Rogge, Helmuth, Fingierte Briefe als Mittel politischer Satire, München 1966.

RohrschneIder, Michael, Reputation als Leitfaktor in den internationalen Beziehungen der Frühen Neuzeit, in: HZ 291 (2010), H. 2, S. 331-352.

Rosenlehner, August, Die Stellung der Kurfürsten Max Emanuel von Bayern und Joseph Clemens von Köln zur Kaiserwahl Karls VI., München 1900.

Rosenstrauch, Hazel, Buchhandelsmanufaktur und Aufklärung. Die Reformen des Buchhändlers und Verlegers Ph.E. Reich (1717-1787). Sozialgeschichtliche Studie zur Entwicklung des literarischen Marktes, Frankfurt a.M. 1986.

Rosseaux, Ulrich, Das Reich und seine Territorien als Kommunikationsraum im frühen 17. Jahrhundert, in: BDLG 137 (2001), S. 73-100.

- Die Leipziger Meßrelationen 1605-1730. Ein Beitrag zur Medien- und Kommunikationsgeschichte der Frühen Neuzeit, in: Leipziger Jahrbuch zur Buchgeschichte 12 (2003), S. 11-32.

- Die Entstehung der Meßrelationen. Zur Entwicklung eines frühneuzeitlichen Nachrichtenmediums aus der Zeitgeschichtsschreibung des 16. Jahrhunderts, in: HJb 124 (2004), S. 97-123.

- Städte in der frühen Neuzeit, Darmstadt 2006.

- Das bedrohte Zion. Lutheraner und Katholiken in Dresden nach der Konversion Augusts des Starken (1697-1751), in: Ute Lotz-Heumann/Jan-Friedrich Missfelder/Matthias Pohlig (Hg.), Konversion und Konfession in der Frühen Neuzeit, Gütersloh 2007, S. 212-235.

Roтн, Paul, Die Neuen Zeitungen in Deutschland im 15. und 16. Jahrhundert, Leipzig 1914.

Rublack, Hans-Christian (Hg.), Die lutherische Konfessionalisierung in Deutschland. Wissenschaftliches Kolloquium des Vereins für Reformationsgeschichte 1988, Gütersloh 1992. 
RuBLACK, Ulinka, Erzählungen vom Geblüt und Herzen. Zu einer Historischen Anthropologie des frühneuzeitlichen Körpers, in: Historische Anthropologie 9 (2001), H. 2, S. 214-232.

- Die Reformation in Europa, Frankfurt a.M. 2003.

Runge, Hermann, Courtilz de Sandras und die Anfänge des »Mercure historique et politique«. Ein Beitrag zur Geschichte der periodischen Presse im 17. Jahrhundert, Berlin 1887.

SaAlfeld, Diedrich, Die ständische Gliederung der Gesellschaft Deutschlands im Zeitalter des Absolutismus. Ein Quantifizierungsversuch, in: VSWG 67 (1980), S. 457-483.

SABrow, Martin, Herr und Hanswurst. Das tragische Schicksal des Hofgelehrten Jacob Paul von Gundling, Stuttgart/München 2001.

SAlomon, Ludwig, Geschichte des deutschen Zeitungswesens von den ersten Anfängen bis zur Wiederaufrichtung des deutschen Reiches, 3 Bd., Oldenburg 1900-1906.

SANTE, Georg Wilhelm, Die kurpfälzische Politik des Kurfürsten Johann Wilhelm vornehmlich im Spanischen Erbfolgekrieg 1690-1716, in: HJb 44 (1924), S. 19-64.

SснаAв, Meinrad, Die Wiederherstellung des Katholizismus in der Kurpfalz im 17. und 18. Jahrhundert, in: ZGO 114 (1966), S. 147-205.

- Geschichte der Kurpfalz, Bd. 2: Neuzeit, Stuttgart 1992.

Scheel, Günter, Hermann Conring als historisch-politischer Ratgeber der Herzöge von Braunschweig und Lüneburg, in: Michael Stolleis (Hg.), Hermann Conring (1606-1681). Beiträge zu Leben und Werk, Berlin 1983, S. 271-301.

- Leibniz als politischer Ratgeber des Welfenhauses, in: Herbert Breger/Friedrich NiEWÖHNER (Hg.), Leibniz und Niedersachsen. Tagung in Wolfenbüttel anläßlich des 350. Geburtstags von G.W. Leibniz (1996), Stuttgart 1999, S. 35-52.

ScHENDA, Rudolf, Volk ohne Buch. Studien zur Sozialgeschichte der populären Lesestoffe 17701910, Frankfurt a.M. 1970 (ND München 1977).

- Alphabetisierung und Literarisierungsprozesse in Westeuropa im 18. und 19. Jahrhundert, in: Ernst HinRichs / Günther Wiegelmann (Hg.), Sozialer und kultureller Wandel in der ländlichen Welt des 18. Jahrhunderts, Wolfenbüttel 1982, S. 1-20.

- Orale und literarische Kommunikationsformen im Bereich von Analphabeten und Gebildeten im 17. Jahrhundert, in: Wolfgang BRÜCKNER/Peter Blickle/Dieter BreuER (Hg.), Literatur und Volk im 17. Jahrhundert. Probleme populärer Kultur in Deutschland, Bd. 2, Wiesbaden 1985, S. 447-464.

- Bilder vom Lesen. Lesen von Bildern, in: IASL 12 (1987), S. 82-106.

- Bilder im Kopf. Kindheitserinnerungen, in: Carola Lipp (Hg.), Medien popularer Kultur. Erzählung, Bild und Objekt in der volkskundlichen Forschung, Frankfurt a.M./New York 1995, S. 303-316.

Schepper, Marcus de/Nave, Francine de (Hg.), Ex Officiana Plantiniana. Studia in Memoriam Christopheri Plantini (ca. 1520-1589), Antwerpen 1989.

Scheurmann, Ingrid (Hg.), Frieden durch Recht. Das Reichskammergericht von 1495 bis 1806, Mainz 1994.

Schiewe, Jürgen, Öffentlichkeit. Entstehung und Wandel in Deutschland, Paderborn u.a. 2004.

Schiluing, Heinz, Die Stadt in der Frühen Neuzeit, München 1993.

- Die Emder Revolution als europäisches Ereignis, in: Hajo von Lengen (Hg.), Die Emder Revolution von 1595, Aurich 1995, S. 113-136.

- (Hg.), Die reformierte Konfessionalisierung in Deutschland. Das Problem der »Zweiten Reformation«, Gütersloh 1986.

- /Ehrenpreis, Stefan (Hg.), Erziehung und Schulwesen zwischen Konfessionalisierung und Säkularisierung. Forschungsperspektiven, europäische Fallbeispiele und Hilfsmittel, Münster u.a. 2003.

- /Ehrenpreis, Stefan (Hg.), Frühneuzeitliche Bildungsgeschichte der Reformierten in konfessionsvergleichender Perspektive. Schulwesen, Lesekultur und Wissenschaft, Berlin 2007. 
- /Gross, Marie-Antoinette (Hg.), Im Spannungsfeld von Staat und Kirche. »Minderheiten« und »Erziehung« im deutsch-französischen Gesellschaftsvergleich 16. bis 18. Jahrhundert, Berlin 2003.

- /Heun, Werner/Götzmann, Jutta (Hg.), Heiliges Römisches Reich Deutscher Nation 962-1806. Altes Reich und neue Staaten 1495-1806. 29. Ausstellung des Europarats im Deutschen Historischen Museum Berlin, Bd. 2: Essays, Dresden 2006.

Schilling, Michael, Bildpublizistik der frühen Neuzeit. Aufgaben und Leistungen des illustrierten Flugblatts in Deutschland bis um 1700, Tübingen 1990.

Schindling, Anton, Kurbrandenburg im System des Reichs während der zweiten Hälfte des 17. Jahrhunderts. Eine Problemskizze, in: Oswald Hauser (Hg.), Preußen, Europa und das Reich, Köln 1987, S. 33-46.

- Der Große Kurfürst und das Reich, in: Gerd HeInRICH (Hg.), »Ein sonderbares Licht in Teutschland«. Beiträge zur Geschichte des Großen Kurfürsten von Brandenburg (1640-1688), Berlin 1990, S. 59-74.

- Die Anfänge des Immerwährenden Reichstags zu Regensburg. Ständevertretung und Staatskunst nach dem Westfälischen Frieden, Mainz 1991.

- Die protestantischen Universitäten im Heiligen Römischen Reich deutscher Nation im Zeitalter der Aufklärung, in: Notker Hammerstein (Hg.), Universitäten und Aufklärung, Göttingen 1995, S. 9-19.

- Kaiser, Reich und Reichsverfassung 1648-1806. Das neue Bild vom Alten Reich, in: Olaf Asbach/Klaus Malettke/Sven Externbrink (Hg.), Altes Reich, Frankreich und Europa. Politische, philosophische und historische Aspekte des französischen Deutschlandbildes im 17. und 18. Jahrhundert, Berlin 2001, S. 25-54.

Schlimper, Jürgen, Nachrichten für die Messestadt aus fernen Ländern. Zum Zusammenhang von Leipziger Presse- und Stadtentwicklung zur Mitte des 17. Jahrhunderts, in: Hartmut Zwahr/Thomas Topfstedt / Günter Bentele (Hg.), Leipzigs Messen 1497-1997. Gestaltwandel, Umbrüche, Neubeginn, Bd. 1, Köln/Weimar/Wien 1997, S. 167-179.

- »Zeitung Drucken ist ein wichtiges werck«. Zu den Wurzeln Leipziger Zeitungen in der ersten Hälfte des 17. Jahrhunderts, in: Stadt LeIPZIG (Hg.), »Zeitung Drucken ist ein wichtiges werck«. 350 Jahre Tagespresse in Leipzig, Leipzig 2000, S. 9-69.

Schlosser, Heinrich/Neuser, Wilhelm, Die Evangelische Kirche in Nassau-Oranien, 1530-1930. Fs. zum Gedächtnis der Einführung der Reformation und des Heidelberger Katechismus in den Grafschaften Nassau-Dillenburg und Nassau-Siegen, 2 Bd., Siegen 1931-1933.

ScHLÖGL, Rudolf, Politik beobachten. Öffentlichkeit und Medien in der Frühen Neuzeit, in: ZHF 35 (2008), S. 581-616.

- Kommunikation und Vergesellschaftung unter Anwesenden. Formen des Sozialen und ihre Transformation in der Frühen Neuzeit, in: GuG 34 (2008), S. 155-224.

Schmale, Wolfgang, The Future of »Absolutism« in Historiography. Recent Tendencies, in: Journal of Early Modern History 2 (1998), S. 192-202.

- Der Januskopf der Alphabetisierung. Kursachsen in der frühen Neuzeit, in: Hans Erich BöDEKER/Ernst Hinrichs (Hg.), Alphabetisierung und Literalisierung in Deutschland in der Frühen Neuzeit, Tübingen 1999, S. 349-366.

Schmid, Alois/Weigand, Katharina (Hg.), Die Herrscher Bayerns. 25 historische Portraits von Tassilo III. bis Ludwig III., München 2001.

- /Weigand, Katharina (Hg.), Schauplätze der Geschichte in Bayern, München 2003.

SCHMID, Ulrich, Gespräche im Reiche derer Todten (1738-1739), in: Heinz-Dietrich FischER (Hg.), Deutsche Zeitschriften des 17. bis 20. Jahrhunderts, Pullach b. München 1973, S. 4959.

Schmidt, Georg, Geschichte des Alten Reiches. Staat und Nation in der Frühen Neuzeit, $1495-$ 1806, München 1999.

- Die »deutsche Freiheit« und der Westfälische Friede, in: Ronald G. Asch/Wulf Eckart Voss / Martin Wrede (Hg.), Frieden und Krieg in der Frühen Neuzeit. Die europäische Staatenordnung und die außereuropäische Welt, München 2001, S. 323-347.

- (Hg.), Stände und Gesellschaft im Alten Reich, Stuttgart 1989. 
Schmidt, Hans, Max Emanuels Bild in der Geschichtsschreibung, in: Hubert Glaser (Hg.), Kurfürst Max Emanuel. Bayern und Europa um 1700, Bd. 1, München 1976, S. 459-474.

SснміDт, Peer, Spanische Universalmonarchie oder »teutsche Libertet«. Das spanische Imperium in der Propaganda des Dreißigjährigen Krieges, Stuttgart 2001.

Schmitt, Elmar/ Appenzeller, Bernhard, Balthasar Kühn. Buchdruckerei und Verlag Kühn, Ulm, 1637-1736. Bibliographie mit einer Geschichte des Ulmer Buchdrucks von 1571 bis 1781 und einer Darstellung der reichsstädtischen Bücher- und Zeitungszensur, Weissenhorn 1992.

Sснмітz, Wolfgang, Gutenberg und die Ausbreitung des Buchdrucks zu seinen Lebzeiten, in: Marginalien 164 (2001), H. 4, S. 18-34.

Schnath, Georg, Geschichte Hannovers im Zeitalter der neunten Kur und der englischen Sukzession, 1674-1714, 4 Bd., Hildesheim/Leipzig 1938-1982.

- Die Überwältigung Braunschweig-Wolfenbüttels durch Hannover und Celle zu Beginn des Spanischen Erbfolgekrieges, März 1702, in: Braunschweigisches Jahrbuch für Landesgeschichte 56 (1975), S. 27-100.

SchNeIDER, Falko, Öffentlichkeit und Diskurs. Studien zu Entstehung und Struktur der Öffentlichkeit im 18. Jahrhundert, Bielefeld 1992.

SCHNeIDER, Ulrich Johannes, Die Konstruktion des allgemeinen Wissens in Zedlers »UniversalLexicon«, in: Theo Stammen / Wolfgang Weber (Hg.), Wissenssicherung, Wissensordnung und Wissensverarbeitung. Das europäische Modell der Enzyklopädien, Berlin 2004, S. 81-101.

- Zedlers »Universal-Lexicon« und die Gelehrtenkultur des 18. Jahrhunderts, in: Hanspeter Marti/Detlef Döring (Hg.), Die Universität Leipzig und ihr gelehrtes Umfeld 1680-1780, Basel 2004, S. 195-213.

SCHNeIDER, Ute, Grundlagen des Mediensystems. Drucker, Verleger, Buchhändler in ihren ökonomischen Beziehungen 1600-1750, in: Johannes ArNdt/Esther-Beate KöRBER (Hg.), Das Mediensystem im Alten Reich der Frühen Neuzeit 1600-1750, Göttingen 2010, S. 27-37.

Schnettger, Matthias, Der Reichsdeputationstag 1655-1663. Kaiser und Stände zwischen Westfälischem Frieden und Immerwährendem Reichstag, Münster 1996.

- Der Wahltag aus der Perspektive des Frankfurter Rats. Das Beispiel 1657/58, in: Evelyn Brockhoff / Michael Matthäus (Hg.), Die Kaisermacher. Frankfurt am Main und die Goldene Bulle, Frankfurt a.M. 2006, S. 252-261.

- (Hg.), Imperium Romanum - Irregulare Corpus - Teutscher Reich-Staat. Das Alte Reich im Verständnis der Zeitgenossen und der Historiographie, Mainz 2002.

Schoeller, Wilfried F., Schubart. Leben und Meinungen eines schwäbischen Rebellen, den die Rache seines Fürsten auf den Asperg brachte. Mit einer Auswahl seiner Schriften, Berlin 1979.

Schön, Erich, Geschichte des Lesens, in: Bodo Franzmann u.a. (Hg.), Handbuch Lesen, München 1999, S. $1-85$.

SCHÖNE, Albrecht (Hg.), Stadt - Schule - Universität - Buchwesen und die deutsche Literatur im 17. Jahrhundert, München 1976.

Sсноск, Flemming, Die Text-Kunstkammer. Populäre Wissenssammlungen des Barock am Beispiel der »Relationes Curiosae« von E.W. Happel, Köln/Weimar/Wien 2011.

- Wissen im neuen Takt. Die Zeitung und ihre Bedeutung für die Entstehung erster populärer »Zeitschriften«, in: Volker Bauer/Holger BöNINg (Hg.), Die Entstehung des Zeitungswesens im 17. Jahrhundert. Ein neues Medium und seine Folgen für das Kommunikationssystem der Frühen Neuzeit, Bremen 2011, S. 281-302.

ScHOLL, Armin (Hg.), Systemtheorie und Konstruktivismus in der Kommunikationswissenschaft, Konstanz 2002.

Scholz Williams, Gerhild/Schindler, Step, Knowledge, Science, and Literature in Early Modern Germany, Chapel Hill/London 1996.

Schorn-Schütte, Luise, Evangelische Geistlichkeit in der Frühneuzeit, deren Anteil an der Entfaltung frühmoderner Staatlichkeit und Gesellschaft. Dargestellt am Beispiel des Fürstentums Braunschweig-Wolfenbüttel, der Landgrafschaft Hessen-Kassel und der Stadt Braunschweig, Gütersloh 1996.

- (Hg.), Intellektuelle in der Frühen Neuzeit, Berlin 2011. 
Schottenloher, Karl, Flugblatt und Zeitung. Ein Wegweiser durch das gedruckte Tagesschrifttum, 2 Bd., München 1922.

Schraut, Sylvia/Stier, Bernhard (Hg.), Stadt und Land. Bilder, Inszenierungen und Visionen in Geschichte und Gegenwart. Fs. für Wolfgang von Hippel zum 65. Geburtstag, Stuttgart 2001.

Schreiner, Klaus, Verletzte Ehre. Ritualisierte Formen sozialer, politische und rechtlicher Entehrung im späteren Mittelalter und in der beginnenden Neuzeit, in: Dietmar WiLlowert (Hg.), Die Entstehung des öffentlichen Strafrechts. Bestandsaufnahme eines europäischen Forschungsproblems, Köln/Weimar/Wien 1999, S. 263-320.

Schreiner-Eickhoff, Annette, Die Bücher- und Pressezensur im Herzogtum Württemberg (14951803), Diss. Hagen 1981.

SCHRöcKER, Alfred, Die neunte Kur aus der Sicht des Mainzer Kurfürsten Lothar Franz von Schönborn, in: JbWLG 5 (1979), S. 155-163.

SChryver, Reginald de, Max II. Emanuel von Bayern und das spanische Erbe. Die europäischen Ambitionen des Hauses Wittelsbach, Mainz 1996.

Schubert, Friedrich Hermann, Die deutschen Reichstage in der Staatslehre der frühen Neuzeit, Göttingen 1966.

Schultheiss, Sonja, Das »Diarium Europaeum« (1659-1683). Verleger und Autoren, Aufbau und Inhalt, in: AGB 48 (1997), S. 315-346.

Schultheiss-Heinz, Sonja, Politik in der europäischen Publizistik. Eine historische Inhaltsanalyse von Zeitungen des 17. Jahrhunderts, Stuttgart 2004.

- Zum Verhältnis von serieller Chronik und Zeitungswesen, in: Volker BAUER/Holger BöNING (Hg.), Die Entstehung des Zeitungswesens im 17. Jahrhundert. Ein neues Medium und seine Folgen für das Kommunikationssystem der Frühen Neuzeit, Bremen 2011, S. 201-210.

Schulze, Winfried, Reich und Türkengefahr. Studien zu den politischen und gesellschaftlichen Auswirkungen einer äußeren Bedrohung, München 1978.

- Bäuerlicher Widerstand und feudale Herrschaft in der frühen Neuzeit, Stuttgart 1980.

- Die veränderte Bedeutung sozialer Konflikte im 16. und 17. Jahrhundert, in: Ders. (Hg.), Europäische Bauernrevolten der frühen Neuzeit, Frankfurt a.M. 1982, S. 276-308.

- Vom Gemeinnutz zum Eigennutz. Über den Normenwandel in der ständischen Gesellschaft der Frühen Neuzeit, in: HZ 243 (1986), S. 591-626.

- (Hg.), Ständische Gesellschaft und soziale Mobilität, München 1988.

- Die ständische Gesellschaft des 16./17. Jahrhunderts und die moderne historische Forschung, in: Hans Erich BöDEKER/Ernst HinRichs (Hg.), Alteuropa - Ancien Régime - Frühe Neuzeit?, Stuttgart 1991, S. 51-77.

- Das Reich und der Gemeine Mann, in: Heinz Schilling / Werner Heun / Jutta Götzmann (Hg.), Heiliges Römisches Reich Deutscher Nation 962-1806. Altes Reich und neue Staaten 14951806. 29. Ausstellung des Europarats im Deutschen Historischen Museum Berlin, Bd. 2: Essays, Dresden 2006, S. 69-79.

Schwarz, Konrad, Der Postzeitungsvertrieb in der deutschen Postgeschichte, Berlin 1936.

Schwitalla, Johannes, Deutsche Flugschriften 1460-1525. Textsortengeschichtliche Studien, Tübingen 1983.

- Flugschrift. Eine Einführung, Tübingen 1999.

SCRIBNER, Robert W., Flugblatt und Analphabetentum. Wie kam der gemeine Mann zu reformatorischen Ideen?, in: Hans-Joachim KöHLER (Hg.), Flugschriften als Massenmedien der Reformationszeit, Stuttgart 1981, S. 65-76.

Selderhuis, Herman J. (Hg.), Calvin Handbuch, Tübingen 2008.

SelLerT, Wolfgang (Hg.), Reichshofrat und Reichskammergericht. Ein Konkurrenzverhältnis, Köln/Weimar/Wien 1999.

SETTEKoRn, Wolfgang, Überlegungen zur Konzeptionalisierung von »Öffentlichkeit«, in: Werner Faulstich/Knut Hickethier (Hg.), Öffentlichkeit im Wandel. Neue Beiträge zur Begriffsklärung, Bardowick 2000, S. 15-33.

SGARD, Jean (Hg.), Dictionnaire des journaux (1600-1789), 2 Bd., Paris 1991. 
Siegert, Reinhart, Zur Alphabetisierung in den deutschen Regionen am Ende des 18. Jahrhunderts, in: Hans Erich BöDEKER/Ernst HinRIchs (Hg.), Alphabetisierung und Literalisierung in Deutschland in der Frühen Neuzeit, Tübingen 1999, S. 283-307.

SiмEсек, Zdenek, Geschriebene Zeitungen in den böhmischen Ländern um 1600 und ihr Entstehungs- und Rezeptionszusammenhang mit den gedruckten Zeitungen, in: Elger BLÜHM/Hartwig Gebhardt (Hg.), Presse und Geschichte, Bd. 2: Neue Beiträge zur historischen Kommunikationsforschung, München 1987, S. 71-82.

Singer, Bruno, Die Fürstenspiegel in Deutschland im Zeitalter des Humanismus und der Reformation, München 1981.

SIRGES, Thomas / MülLER, Ingeborg, Zensur in Marburg 1538-1832. Eine lokalgeschichtliche Studie zum Bücher- und Pressewesen, Marburg 1984.

SKInNER, Quentin, Niccolò Machiavelli, Hamburg ${ }^{4} 2005$.

Sösemann, Bernd (Hg.), Kommunikation und Medien in Preußen vom 16. bis zum 19. Jahrhundert, Stuttgart 2002.

SOMBART, Werner, Der moderne Kapitalismus. Historisch-systematische Darstellung des gesamteuropäischen Wirtschaftslebens von seinen Anfängen bis zur Gegenwart, 3 Bd., München/Leipzig 1916-1927 (ND 1987).

Sommer, Georg, Die Zensurgeschichte des Königreichs Hannover, Münster 1930.

SPEER, Andreas, Die gefährdete Neugier. Über die Ursprünge unseres Wissenschaftsverständnisses, in: Forschung und Lehre 12 (2004), S. 655-657.

SpeitKamp, Winfried, Ohrfeige, Duell und Ehrenmord. Eine Geschichte der Ehre, Stuttgart 2010.

Siess, Karl-Heinz (Hg.), Medien der Kommunikation im Mittelalter, Stuttgart 2003.

Sporhan-Krempel, Lore, Nürnberg als Nachrichtenzentrum zwischen 1400 und 1700, Nürnberg 1968.

- Lore, Buchdruck und Buchhandel in Nürnberg im 17. Jahrhundert, in: Paul RaABe (Hg.), Bücher und Bibliotheken im 17. Jahrhundert in Deutschland, Hamburg 1980, S. 25-37.

STAAB, Joachim Friedrich, Nachrichtenwert-Theorie. Formale Struktur und empirischer Gehalt, Freiburg/München 1990.

STADER, Frank, Die deutsche Presse von den Anfängen bis 1789. Chronologischer Leitfaden, Leipzig 1989.

Stalljohann, Marina, Der Kaufmann im Fokus der Meßrelationen, in: Volker Bauer/Holger Böning (Hg.), Die Entstehung des Zeitungswesens im 17. Jahrhundert. Ein neues Medium und seine Folgen für das Kommunikationssystem der Frühen Neuzeit, Bremen 2011, S. 115-134.

Stammen, Theo/Weber, Wolfgang (Hg), Wissenssicherung, Wissensordnung und Wissensverarbeitung. Das europäische Modell der Enzyklopädien, Berlin 2004.

Stein, Peter G., Römisches Recht und Europa. Die Geschichte einer Rechtskultur. Aus dem Englischen v. Klaus Luig, Frankfurt a.M. 1996.

Steinhausen, Georg, Die Entstehung der Zeitung aus dem brieflichen Verkehr, in: Archiv für Post und Telegraphie 23 (1895), S. 347-357.

Stewart, Philip, Art. »Lettres historique«, in: Jean SGard (Hg.), Dictionnaire des journaux (16001789), Bd. 2, Paris 1991, S. $744 f$.

Stieglitz, Annette von, Der teuerste Hut des Reiches. Hannovers Ringen um die Kurwürde, in: Sabine MeschKat-Peters, Ehrgeiz, Luxus und Fortune. Hannovers Weg zu Englands Krone. Ausstellung des Historischen Museums am Hohen Ufer Hannover, Hannover 2001, S. 68-83.

Stieve, Felix, Über die ältesten halbjährlichen Zeitungen oder Meßrelationen und insbesondere über deren Begründer Freiherr Michael von Aitzing, in: AHKBAW 16 (1883), 1. Abt., S. 177265.

StÖBER, Rudolf, Deutsche Pressegeschichte. Einführung, Systematik, Glossar, Konstanz 2000 (2005).

- Historische Zeitschriftenforschung heute, in: Andreas Vogel/Christina Holtz-Bacha (Hg.), Zeitschriften und Zeitschriftenforschung, Wiesbaden 2002, S. 42-59.

- Mediengeschichte. Die Evolution »neuer« Medien von Gutenberg bis Gates. Eine Einführung, Bd. 1: Presse - Telekommunikation, Wiesbaden 2003. 
Stolberg, Michael, Homo patiens. Krankheits- und Körpererfahrung in der Frühen Neuzeit, Köln/Weimar/Wien 2003.

Stoll, Doris, Die Kölner Presse im 16. Jahrhundert. Nicolaus Schreibers »Neue Zeitungen aus Cöllen«, Wiesbaden 1991.

Stollberg-Rilinger, Barbara, Zeremoniell als politisches Verfahren. Rangordnung und Rangstreit als Strukturmerkmale des frühneuzeitlichen Reichstags, in: Johannes Kunisch (Hg.), Neue Studien zur frühneuzeitlichen Reichsgeschichte, Berlin 1997, S. 91-132.

- Zeremoniell, Ritual, Symbol. Neue Forschungen zur symbolischen Kommunikation in Spätmittelalter und Früher Neuzeit, in: ZHF 27 (2000), S. 388-405.

- Die zeremonielle Inszenierung des Reiches, oder: Was leistet der kulturalistische Ansatz für die Reichsverfassungsgeschichte?, in: Matthias SchnetTGer (Hg.), Imperium Romanum - Irregulare Corpus - Teutscher Reichs-Staat. Das Alte Reich im Verständnis der Zeitgenossen und der Historiographie, Mainz 2002, S. 233-246.

- Die Wissenschaft der feinen Unterschiede. Das Präzedenzrecht und die europäischen Monarchien vom 16. bis zum 18. Jahrhundert, in: Majestas 10 (2002), S. 125-150.

- Des Kaisers alte Kleider. Verfassungsgeschichte und Symbolsprache des Alten Reiches, München 2008.

- (Hg.), Vormoderne politische Verfahren, Berlin 2001.

- (Hg.), Was heißt Kulturgeschichte des Politischen?, Berlin 2005.

Stolleis, Michael, Reichspublizistik - Politik - Naturrecht im 17. und 18. Jahrhundert, in: Ders. (Hg.), Staatsdenker im 17. und 18. Jahrhundert, Frankfurt a.M. 1977, S. 7-28.

- Arcana Imperii und Ratio Status. Bemerkungen zur politischen Theorie des frühen 17. Jahrhunderts, Göttingen 1980.

- Art. »Öffentliches Recht I (bis 1750)«, in: HRG 3 (1984), Sp. 1189-1198.

- Geschichte des öffentlichen Rechts in Deutschland, Bd. 1: Reichspublizistik und Policeywissenschaft 1600-1800, München 1988.

- Staat und Staatsräson in der frühen Neuzeit. Studien zur Geschichte des öffentlichen Rechts, Frankfurt a.M. 1990

- (Hg.), Staatsdenker im 17. und 18. Jahrhundert. Reichspublizistik - Politik - Naturrecht, Frankfurt a.M. 1977.

- (Hg.), Hermann Conring (1606-1681). Beiträge zu Leben und Werk, Berlin 1983.

Straubel, Rolf/Weiss, Ulman (Hg.), Kaiser, König, Kardinal. Deutsche Fürsten 1500-1800, Leipzig/Jena/Berlin 1991.

StudT, Birgit, Neue Zeitungen und politische Propaganda, in: ZGO 143 (1996), S. 145-219.

Süssmann, Johannes/Scholz, Susanne/Engel, Gisela (Hg.), Fallstudien. Theorie, Geschichte, Methoden, Berlin 2007.

TAnis, James/Horst, Daniel (Hg.), Images of Discord. A Graphic Interpretation of the Opening Decades of the Eighty Year's War, Bryn Mawr 1993.

Tiedemann, Heinrich, Die Zensur in Bremen von ihren Anfängen bis zu den Karlsbader Beschlüssen 1819, in: BrJ 30 (1926), S. 311-394.

TöввіскE, Peter, Höfische Erziehung. Grundsätze und Struktur einer pädagogischen Doktrin des Umgangsverhaltens, nach den fürstlichen Erziehungsinstruktionen des 16. bis zum 18. Jahrhundert, Darmstadt 1983.

Toeller, Monika, Die Buchmesse in Frankfurt am Main vor 1560. Ihre kommunikative Bedeutung in der Frühdruckzeit, Diss. München 1983.

Tortarolo, Edoardo, Zensur, öffentliche Meinung und Politik in der Berliner Spätaufklärung. Eine Problemskizze, in: Comparativ 1 (1991), H. 3, S. 80-90.

- Censorship and the Conception of the Public in Late Eighteenth-Century Germany. Or, are Censorship and Public Opinion Mutually Exclusive?, in: Dario Castiglione/Lesley Sharpe (Hg.), Shifting the Boundaries. Transformation of Languages of Public and Private in the Eighteenth Century, Exeter 1995, S. 131-150. 
- Zensur als Institution und Praxis im Europa der Frühen Neuzeit. Ein Überblick, in: Helmut Zedelmaier/Martin Mulsow (Hg.), Die Praktiken der Gelehrsamkeit in der frühen Neuzeit, Tübingen 2001, S. 277-294.

TRossbach, Werner, Fürstenabsetzungen im 18. Jahrhundert, in: ZHF 13 (1986), S. 425-454.

- Soziale Bewegung und politische Erfahrung. Bäuerlicher Protest in hessischen Territorien 1648-1806, Weingarten 1987.

- Der Schatten der Aufklärung. Bauern, Bürger und Illuminaten in der Grafschaft Wied-Neuwied, Fulda 1991.

Tschopp, Silvia Serena, Heilsgeschichtliche Deutungsmuster in der Publizistik des Dreißigjährigen Krieges. Pro- und antischwedische Propaganda in Deutschland 1628 bis 1635, Frankfurt a.M. u.a. 1991.

Ukena, Peter, Tagesschrifttum und Öffentlichkeit im 16. und 17. Jahrhundert, in: Elger Blühm/Hartwig Gebhardt (Hg.), Presse und Geschichte, Bd. 1, München u.a. 1977, S. 35-53.

Ullmann, Sabine, Geschichte auf der langen Bank. Die Kommissionen des Reichshofrats unter Kaiser Maximilian II. (1564-1576), Mainz 2006.

Veblen, Thorstein, Theorie der feinen Leute. Eine ökonomische Untersuchung der Institutionen (1899), München 1981.

VeC, Miloš, Zeremoniellwissenschaft im Fürstenstaat. Studien zur juristischen und politischen Theorie absolutistischer Herrschaftsrepräsentation, Frankfurt a.M. 1998.

VehSE, Eduard, Geschichte der deutschen Höfe seit der Reformation, 48 Bd., Hamburg 1851-1860.

VeIT, Patrice, Private Frömmigkeit. Lektüre und Gesang im protestantischen Deutschland der frühen Neuzeit. Das Modell der Leichenpredigten, in: Rudolf Vierhaus (Hg.), Frühe Neuzeit frühe Moderne? Forschungen zur Vielschichtigkeit von Übergangsprozessen, Göttingen 1992, S. 271-295.

- Das Gesangbuch in der Praxis Pietatis der Lutheraner, in: Hans-Christoph Rublack (Hg.), Die lutherische Konfessionalisierung in Deutschland, Gütersloh 1992, S. 435-454.

Velden, Hugo van der, Cambyses for Example. The Origins and Function of an »Exemplum Iustitiae « in Netherlandish Art of the Fifteenth, Sixteenth and Seventeenth Centuries, in: Simiolus. Netherlands Quarterly for the History of Art 23 (1995), S. 5-62.

Vermaseren, Bernard A., Van nieuwsbericht tot geschiedwerk, in: Het Boek 28 (1944), S. $241-$ 257.

VIERHAus, Rudolf, Mentalitäten und Lebensverhältnisse. Beispiele aus der Sozialgeschichte der Neuzeit. Fs. zum 60. Geburtstag, hg. v. Mitarbeitern und Schülern, Göttingen 1982.

- (Hg.), Frühe Neuzeit - frühe Moderne? Forschungen zur Vielschichtigkeit von Übergangsprozessen, Göttingen 1992.

Vitense, Otto, Geschichte von Mecklenburg, Gotha 1920.

Voet, Leon, The Golden Compasses. A History and Evaluation of the Printing and Publishing Activities of the Officina Plantiniana at Antwerp, 2 Bd., Amsterdam/London/New York 19691972.

Vötsch, Jochen, Kursachsen, das Reich und der mitteldeutsche Raum zu Beginn des 18. Jahrhunderts, Frankfurt a.M. 2003.

Vogel, Andreas, Pressegattungen im Zeitschriftengewand. Warum die Wissenschaft eine Pressesystematik braucht, in: Ders. /Christina Holtz-Bacha (Hg.), Zeitschriften und Zeitschriftenforschung, Wiesbaden 2002, S. 11-27.

- /Holtz-Bacha, Christina (Hg.), Zeitschriften und Zeitschriftenforschung, Wiesbaden 2002.

Vogel, Sabine, Kulturtransfer in der Frühen Neuzeit. Die Vorworte Lyoner Drucker des 16. Jahrhunderts, Tübingen 1999.

Vogler, Günter (Hg.), Europäische Herrscher. Ihre Rolle bei der Gestaltung von Politik und Gesellschaft vom 16. bis zum 18. Jahrhundert, Weimar 1988.

VoLMER, Annett, Presse und Frankophonie im 18. Jahrhundert. Studien zur französischsprachigen Presse in Thüringen, Kursachsen und Rußland, Leipzig 2000. 
WÄschER, Hermann, Das deutsche illustrierte Flugblatt. Von den Anfängen bis zu den Befreiungskriegen, 2 Bd., Dresden 1955-1956.

Walther, Manfred (Hg.), Religion und Politik. Zu Theorie und Praxis des theologisch-politischen Komplexes, Baden-Baden 2004.

Waquet, Françoise (Hg.), Mapping the World of Learning. The Polyhistor Daniel Georg Morhof, Wiesbaden 2000.

Watanabe-O'Kelly, Helen, Festival Books in Europe from Renaissance to Rococo, in: The Seventeenth Century 3 (1988), S. 181-201.

Watzlawick, Paul (Hg.), Die erfundene Wirklichkeit. Wie wissen wir, was wir zu wissen glauben? Beiträge zum Konstruktivismus, München ${ }^{7} 1991$.

Weber, Hermann (Hg.), Politische Ordnungen und soziale Kräfte im Alten Reich, Wiesbaden 1980.

WeBer, Johannes, »Untherthenige Supplication Johann Caroli/Buchtruckers«. Der Beginn gedruckter politischer Wochenzeitungen im Jahre 1605, in: AGB 38 (1992), S. 257-265.

- Neue Funde aus der Frühgeschichte des deutschen Zeitungswesens, in: AGB 39 (1993), S. 312360 .

- Daniel Hartnack. Ein gelehrter Streithahn und Avisenschreiber am Ende des 17. Jahrhunderts. Zum Beginn politisch-kommentierender Zeitungspresse, in: GutJb 68 (1993), S. 140-158.

- $»$ Die Novellen sind eine Eröffnung des Buchs der ganzen Welt «. Entstehung und Entwicklung der Zeitung des 17. Jahrhunderts, in: Klaus Beyrer/Martin Dallmeier (Hg.), Als die Post noch Zeitung machte. Eine Pressegeschichte, Gießen 1994, S. 15-25.

- Götter-Both Mercurius. Die Urgeschichte der politischen Zeitschrift in Deutschland, Bremen 1994.

- Avisen, Relationen, Gazetten. Der Beginn des europäischen Zeitungswesens, Oldenburg 1997.

- Deutsche Presse im Zeitalter des Barock. Zur Vorgeschichte öffentlichen politischen Räsonnements, in:Hans-WolfJäGER(Hg.), Öffentlichkeit«im 18.Jahrhundert, Göttingen 1997, S. 137-149.

- Der große Krieg und die frühe Zeitung. Gestalt und Entwicklung der deutschen Nachrichtenpresse in der ersten Hälfte des 17. Jahrhunderts, in: Jahrbuch für Kommunikationsgeschichte 1 (1999), S. 23-61.

- Zum 350. Geburtstag der Tageszeitung am 1. Juli 1650, in: Arnulf KuTsCh/Johannes WeBeR (Hg.), 350 Jahre Tageszeitung. Forschungen und Dokumente, Berlin 2002, S. 9-22.

- Galerie der Zeitungspresse im 17. Jahrhundert mit dem Schwerpunkt: Geschichte der frühen Leipziger Zeitungen, in: Arnulf Kutsch/Johannes Weber (Hg.), 350 Jahre Tageszeitung. Forschungen und Dokumente, Berlin 2002, S. 23-136.

- Umriß der Zeitungsgeschichte Leipzigs im 17. Jahrhundert, in: Arnulf Kutsch/Johannes WeBer (Hg.), 350 Jahre Tageszeitung. Forschungen und Dokumente, Berlin 2002, S. 137-150.

- Kontrollmechanismen im deutschen Zeitungswesen des 17. Jahrhunderts. Ein kleiner Beitrag zur Geschichte der Zensur, in: Jahrbuch für Kommunikationsgeschichte 6 (2004), S. 56-73.

- Straßburg 1605. Die Geburt der Zeitung, in: Jahrbuch für Kommunikationsgeschichte 7 (2005), S. 3-26.

Weber, Matthias, Zur Bedeutung der Reichsacht in der Frühen Neuzeit, in: Johannes Kunisch (Hg.), Neue Studien zur frühneuzeitlichen Reichsgeschichte, Berlin 1997, S. 55-90.

Weber, Raimund J., Reichspolitik und reichsgerichtliche Exekution. Vom Markgrafenkrieg (15521554) bis zum Lütticher Fall (1789/90), Wetzlar 2000.

WeBER, Wolfgang E.J., Honor, fama, gloria. Wahrnehmungen und Funktionszusammenhänge der Ehre in der Herrschaftslehre des 17. Jahrhunderts, in: Sibylle Backmann u.a. (Hg.), Ehrkonzepte in der Frühen Neuzeit. Identitäten und Abgrenzungen, Berlin 1998, S. 70-98.

- Geschichte der europäischen Universität, Stuttgart 2002.

- (Hg.), Wissenswelten. Perspektiven der neuzeitlichen Informationskultur, Augsburg 2003.

Wehler, Hans-Ulrich, Deutsche Gesellschaftsgeschichte, 5 Bd., München 1987-2009.

Weittlauff, Manfred, Die Reichskirchenpolitik des Hauses Bayern unter Kurfürst Max Emanuel (1679-1726). Vom Regierungsantritt Max Emanuels bis zum Beginn des Spanischen Erbfolgekrieges, St. Ottilien 1985.

WeLke, Martin, Rußland in der deutschen Publizistik des 17. Jahrhunderts (1613-1689), in: FOEG 23 (1976), S. 105-276. 
- Zeitung und Öffentlichkeit im 18. Jahrhundert, in: Elger BlüHm/Hartwig GeBhardt (Hg.), Presse und Geschichte, Bd. 1: Beiträge zur historischen Kommunikationsforschung, München 1977, S. 71-99.

- Die Legende vom »unpolitischen Deutschen«. Zeitungslesen im 18. Jahrhundert als Spiegel des politischen Interesses, in: Jahrbuch der Wittheit zu Bremen 25 (1981), S. 161-188.

- Das Publikum der frühen periodischen Tagespresse in Deutschland, in: Dittmar DahlmanN (Hg.), Die Kenntnis Rußlands im deutschsprachigen Raum im 18. Jahrhundert. Wissenschaft und Publizistik über das russische Reich, Göttingen 2006, S. 11-24.

- Johann Carolus und der Beginn der periodischen Tagespresse. Versuch, einen Irrweg der Forschung zu korrigieren, in: Martin Welke/ Jürgen WiLKe (Hg.), 400 Jahre Zeitung. Die Entwicklung der Tagespresse im internationalen Kontext, Bremen 2008, S. 9-116.

- Vom Elend der pressehistorischen Forschung in Deutschland. Dargestellt am Beispiel des Wolfenbütteler »Aviso«, in: Volker Bauer/Holger BöNING (Hg.), Die Entstehung des Zeitungswesens im 17. Jahrhundert. Ein neues Medium und seine Folgen für das Kommunikationssystem der Frühen Neuzeit, Bremen 2011, S. 135-158.

- /WILKE, Jürgen (Hg.), 400 Jahre Zeitung. Die Entwicklung der Tagespresse im internationalen Kontext, Bremen 2008.

Weller, Emil, Die Lieder des Dreissigjährigen Krieges, Basel 1855.

Wende, Peter (Hg.), Englische Könige und Königinnen. Von Heinrich VII. bis Elisabeth II., München 1998.

Wenzel, Horst, Mediengeschichte vor und nach Gutenberg, Darmstadt 2007.

- Sekretäre-»heimlîchaere«. Der Schauraum öffentlicher Repräsentation und die Verwaltung des Geheimen, in: Ders., Mediengeschichte vor und nach Gutenberg, Darmstadt 2007, S. 104-121.

Werner, Theodor Gustav/Henning, Friedrich-Wilhelm (Hg.), Das kaufmännische Nachrichtenwesen im späten Mittelalter und in der frühen Neuzeit und sein Einfluß auf die Entstehung der handschriftlichen Zeitung, in: Scripta mercaturae 2 (1975), S. 3-51.

Wesener, Gunter, Art. »Prozeßmaximen«, in: HRG 4 (1990), Sp. 55-62.

WestPhal, Siegrid, Der Reichshofrat. Kaiserliches Machtinstrument oder Mediator?, in: Leopold Auer/Werner Ogris/Eva Ortlieb (Hg.), Höchstgerichte in Europa. Bausteine frühneuzeitlicher Rechtsordnungen, Köln/Wien/Weimar 2007, S. 115-137.

WeYrauch, Erdmann, Zensur-Forschung, in: Werner ARnold/Wolfgang DitTrich/Bernhard ZehLER (Hg.), Die Erforschung der Buch- und Bibliotheksgeschichte in Deutschland. Fs. für Paul Raabe zum 60. Geburtstag, Wiesbaden 1987, S. 475-488.

Wheeler, James O./Aoyama, Yuko/Warf, Barney (Hg.), Cities in the Telecommunications Age. The Fracturing of Geography, New York u.a. 2000.

White, David Manning, The »Gate-Keeper«. A Case Study in the Selection of News, in: Journalism Quarterly 27 (1950), S. 383-390.

Wick, Peter, Versuche zur Errichtung des Absolutismus in Mecklenburg in der erste Hälfte des 18. Jahrhunderts. Ein Beitrag zur Geschichte des deutschen Territorialabsolutismus, Berlin(-Ost) 1964.

WILKE, Jürgen, Nachrichtenauswahl und Medienrealität in vier Jahrhunderten. Eine Modellstudie zur Verbindung von historischer und empirischer Publizistikwissenschaft, Berlin/New York 1984.

- Die Zeitung, in: Ernst Fischer/Wilhelm HaEfs/York-Gothart Mix (Hg.), Von Almanach bis Zeitung. Ein Handbuch der Medien in Deutschland 1700-1800, München 1999, S. 388-402.

- Grundzüge der Medien- und Kommunikationsgeschichte. Von den Anfängen bis ins 20. Jahrhundert, Köln/Weimar/Wien 2000.

- Pressezensur im Alten Reich, in: Wilhelm Haefs / York-Gothart Mix (Hg.), Zensur im Jahrhundert der Aufklärung. Geschichte - Theorie - Praxis, Göttingen 2007, S. $27-44$.

- Korrespondenten und geschriebene Zeitungen, in: Johannes ARNDT/Esther-Beate KörBER (Hg.), Das Mediensystem im Alten Reich der Frühen Neuzeit 1600-1750, Göttingen 2010, S. 59-72.

- (Hg.), Öffentliche Meinung. Theorie, Methoden, Befunde, Freiburg i.Br./München 1992. 
- /Rosenberger, Bernhard, Die Nachrichten-Macher. Zu Strukturen und Arbeitsweisen von Nachrichtenagenturen am Beispiel von AP und dpa, Köln/Weimar/Wien 1991.

Willaschek, Marcus (Hg.), Realismus, Paderborn 2000.

Willems, Alphonse, Les Elzevier. Histoire et annales typographiques, Brüssel 1880 (ND Nieuwkoop 1962).

Windt, Franziska, Preußen 1701. Eine europäische Geschichte. Ausstellung des Deutschen Historischen Museums Berlin in der Orangerie des Schlosses Charlottenburg, 6. Mai bis 5. August 2001, 2 Bd., Berlin 2001.

WinkLer, Heinrich August, Der lange Weg nach Westen, 2 Bd., München 2000.

Winkler, Karl Tilman, Wörterkrieg. Politische Debattenkultur in England 1695 bis 1750, Stuttgart 1998.

Winterling, Aloys, Der Hof der Kurfürsten von Köln, 1688-1794. Eine Fallstudie zur Bedeutung »absolutistischer Hofhaltung«, Bonn 1986.

Witkowski, Georg, Geschichte des literarischen Lebens in Leipzig, Leipzig/Berlin 1909.

Wittmann, Reinhard, Der gerechtfertigte Nachdrucker. Nachdruck und literarisches Leben im 18. Jahrhundert, in: Giles BARBER/Bernhard FABIAN (Hg.), Buch und Buchhandel in Europa im 18. Jahrhundert, Hamburg 1981, S. 293-320.

- Geschichte des deutschen Buchhandels. Ein Überblick, München 1991.

- Gibt es eine »Leserevolution« am Ende des 18. Jahrhundert?, in: Roger Chartier/Guglielmo Cavallo (Hg.), Die Welt des Lesens. Von der Schriftrolle zum Bildschirm, Frankfurt a.M. 1999, S. 419-454.

WohlfeIL, Rainer, Art. »Reformatorische Öffentlichkeit«, in: Ludger GrenzmanN/Karl StACKMANN (Hg.), Literatur und Laienbildung im Spätmittelalter und in der Reformationszeit. Symposium Wolfenbüttel 1981, Stuttgart 1984, S. 41-52.

Wolf, Hans-Jürgen, Schwarze Kunst. Eine illustrierte Geschichte der Druckverfahren, Frankfurt a.M. ${ }^{2} 1981$.

Wolf, Hubert, Index. Der Vatikan und die verbotenen Bücher, München 2006.

- (Hg.), Inquisition, Index, Zensur. Wissenskulturen der Neuzeit im Widerstreit, Paderborn 2001.

- (Hg.), Verbotene Bücher. Zur Geschichte des Index im 18. und 19. Jahrhundert, Paderborn u.a. 2006.

Wolf, Peter u.a. (Hg.), Der Winterkönig Friedrich von der Pfalz. Bayern und Europa im Zeitalter des Dreißigjährigen Krieges, Augsburg 2003.

Worstbrock, Franz-Josef (Hg.), Der Brief im Zeitalter der Renaissance, Weinheim 1993.

Wrede, Martin, Das Reich und seine Feinde. Politische Feindbilder in der reichspatriotischen Publizistik zwischen Westfälischem Frieden und Siebenjährigem Krieg, Mainz 2004.

- /CARL, Horst (Hg.), Zwischen Schande und Ehre. Erinnerungsbrüche und die Kontinuität des Hauses. Legitimationsmuster und Traditionsverständnis des frühneuzeitlichen Adels in Umbruch und Krise, Mainz 2007.

Wriedt, Marcus, Die theologische Begründung der Bildungsreform bei Luther und Melanchthon, in: Michael Beyer/Günther Wartenberg (Hg.), Humanismus und Wittenberger Reformation. Festgabe anläßlich des 500. Geburtstags des Praeceptor Germaniae Philipp Melanchthon am 16. Februar 1997. Helmar Junghans gewidmet, Leipzig 1996, S. 155-184.

WÜRGLER, Andreas, Unruhen und Öffentlichkeit. Städtische und ländliche Protestbewegungen im 18. Jahrhundert, Tübingen 1995.

- Medien in der Frühen Neuzeit, München 2009.

Wuermeling, Henric L., Die Sendlinger Mordweihnacht. 1705 - die erste europäische Revolution, München u.a. 1985.

Wüst, Wolfgang, Censur und Censurkollegien im frühmodernen Konfessionsstaat, in: Helmut GieR/Johannes Janota (Hg.), Augsburger Buchdruck und Verlagswesen. Von den Anfängen bis zur Gegenwart, Wiesbaden 1997, S. 569-586.

Wuketits, Franz, Soziobiologie. Die Macht der Gene und die Evolution sozialen Verhaltens, Heidelberg/Berlin/Oxford 1997. 
- Warum uns das Böse fasziniert. Die Natur des Bösen und die Illusionen der Moral, Stuttgart/Leipzig 2000.

- Was ist Soziobiologie?, München 2002.

WUNDER, Bernd, Die bayerische »Diversion« Ludwigs XIV. in den Jahren 1700-1704. Kurbayern, Schwaben und Franken zwischen Habsburg und Bourbon zu Beginn des Spanischen Erbfolgekrieges, in: ZBLG 37 (1974), S. 416-478.

Wurm, Johann Peter (Hg.), Beziehungen Mecklenburgs zu Kaiser und Reich, Österreich, Brandenburg und Preußen (1450-1888). Findbuch des Bestands 2.11-2/1 Acta externa, Schwerin 2000.

Wyduckel, Dieter, Ius publicum. Grundlagen und Entwicklung des Öffentlichen Rechts und der deutschen Staatsrechtswissenschaft, Berlin 1984.

Zedelmaier, Helmut, Bibliotheca universalis und bibliotheca selecta. Das Problem der Ordnung des gelehrten Wissens in der frühen Neuzeit, Köln/Weimar/Wien 1992.

- De Ratione Excerpendi. Daniel Georg Morhof und das Exzerpieren, in: Françoise Waquet (Hg.), Mapping the World of Learning. The Polyhistor Daniel Georg Morhof, Wiesbaden 2000, S. 75-92.

- Lesetechniken. Die Praktiken der Lektüre in der Neuzeit, in: Ders. / Martin Mulsow (Hg.), Die Praktiken der Gelehrsamkeit in der frühen Neuzeit, Tübingen 2001, S. 11-30.

- /Mulsow, Martin (Hg.), Die Praktiken der Gelehrsamkeit in der frühen Neuzeit, Tübingen 2001.

ZeHnder, Frank Günter (Hg.), Im Wechselspiel der Kräfte. Politische Entwicklungen des 17. und 18. Jahrhunderts in Kurköln, Köln 1999.

Zernack, Klaus, Das Zeitalter der nordischen Kriege von 1558 bis 1809 als frühneuzeitliche Geschichtsepoche, in: ZHF 1 (1974), S. 55-79.

- Schweden als europäische Großmacht in der frühen Neuzeit, in: HZ 232 (1981), S. 327-357.

ZimmermanN, Walter, Entwicklungsgeschichte des Nürnberger »Friedens- und Kriegskuriers« (»Nürnberger Kurier«) von seinen ersten Anfängen bis zum Übergang an den »Fränkischen Kurier«, 1663-1865. Ein Beitrag zur Geschichte des deutschen Pressewesens, Nürnberg 1930.

ZunKel, Friedrich, Art. »Ehre, Reputation«, in: GG 2 (1975), S. 1-63.

Zwahr, Hartmut/Topfstedt, Thomas/Bentele, Günter (Hg.), Leipzigs Messen 1497-1997. Gestaltwandel, Umbrüche, Neubeginn, 2 Bd., Köln/Weimar/Wien 1997.

ZwierLein, Cornel, Gegenwartshorizonte im Mittelalter. Der Nachrichtenbrief vom Pergamentzum Papierzeitalter, in: Jahrbuch für Kommunikationsgeschichte 12 (2010), S. 3-60. 


\section{Personen- und Ortsregister}

\subsection{Personenregister ${ }^{1}$}

Abelein, Johann Philipp 168f.

Absalom, biblischer Prinz 363

Achenbach, Heinrich von 395f., 411

Acxtelmeier, Stanislaus Reinhard 110-112, $118,326-328,338,370-373,393$, 414416,425

Adam, biblische Gestalt 241

Adelung, Johann Christoph 24

Aeneas 128

Alba, Fernando Alvarez de Toledo, dritter Herzog von 86

Alsted, Johann Heinrich 221

Althusius, Johannes 208

Alvensleben, Oberappellationsrat von 440

Amalie, Kaiserin, Witwe von Josef I. 483

Amiot, Kaufmann 319

Amman, Jost 171

Andert, Frank 114

Andreas, Apostel und Heiliger 274

Angelike, Karin 20

Anna, Königin von England und Schottland $298,530,533$

Anthyrius, Obotritenkönig 498

Appenzeller, Bernhard 351

Aretin, Karl Otmar Freiherr von 15, 303, 510

Aristoteles 93

Arndt, Johann 208

Arnold, Martin 143

Augustus, Gaius Julius Caesar Octavianus 241

August der Starke, König von Polen und Kurfürst von Sachsen 157, 159, 162, 164,298

Bacon, Francis 130,193
Baden-Baden, Markgraf Ludwig Wilhelm von 310,325

Banquard, Diplomat 475

Bauer, Martin 25

Bauer, Volker 28, 211f., 214, 218f., 515, 521

Baumanns, Markus 27

Baumgart, Peter 12

Bayern, Herzöge und Kurfürsten von 297

Bayern, Herzog Clemens August von, Erzbischof und Kurfürst von Köln (Bischof in vier weiteren Fürstbistümern) 265, 404f., 424, 531, 534

Bayern, Herzog Ernst von, Erzbischof und Kurfürst von Köln 86

Bayern, Herzog Josef Clemens von, Erzbischof und Kurfürst von Köln 43, 116, 123, 265, 283, 289f., 310, 346, 354, 356, 358, 360, 364-366, 370, 373f., 379-386, 389-391, 393, 463, 523

Bayern, Herzog Maximilian I. von, später Kurfürst 262, 274, 293, 342, 444

Bayern, Kurfürstin Maria Antonie von 218

Bayern, Kurfürst Ferdinand Maria von $262,264,272,276-278,342$

Bayern, Kurfürst Max Emanuel von 6f., 43, 116, 264f., 276, 289, 305, 310, 339394, 416, 463, 512, 522f., 525, 530, 532

Bayern, Kurfürstin Henriette Adelaide von 387

Bayern, Kurfürstin Maria Antonie von 340

Bayern, Kurfürstin Therese Kunigunde von 340,346

Bayern, Kurprinz Joseph Ferdinand von 341

Becker, Frank 33

Behr, Hans-Joachim 395, 398, 400, 404

Behringer, Wolfgang 15, 29, 92f., 192-197, 199, $506 f$.

1 Nennungen nur in den Anmerkungen sind kursiv gesetzt. Das Vorwort wurde nicht indiziert. Monarchen stehen unter ihren Vornamen, andere Adlige unter ihrem Familiennamen. 
Beiderbeck, Friedrich 312

Beier, Adrian 174

Benz, Stefan 388

Bernard, Jacques 110

Bernsdorff, Andreas Gottlieb (Graf) von 437f., 461, 476

Besold, Christoph 246

Beust, Joachim Ernst von 131, 192

Birghden, Johannes von den 197, 281

Blanc, Thomas 387

Blickle, Peter 16

Blindow, Ulrich 73

Blome, Astrid 114

Blühm, Elger 101, 205, 520

Bodin, Jean 246, 500

Bodmer, Familie 58, 102

Bödeker, Hans-Erich 14, 201

Böff, Justus 285

Böning, Holger $56,99,147,179,188,227$, 228

Bösch, Frank 18, 234

Bogel, Else 58, 102, 205, 520

Bohr, Freiherr von 482

Boineburg, Johann Christian von 272

Botero, Giovanni 214, 245

Bots, Hans 125

Bourbonen, französische hochadlige Dynastie 341f.

Brachthäuser, Christian $396 f$.

Brachwitz, Peter 505

Brandenburg, Kurfürst Friedrich Wilhelm von, der Große Kurfürst 98, 340

Brandenburg, Kurfürst Friedrich III. von s. Friedrich I., König in Preußen

Brandenburg, Prinzessin Maria Amalia von (später Herzogin von Sachsen-Zeitz) 164

Brasch, Bürgermeister von Dömitz 442, 494

Braun [Braunen], Johann Friedrich 118, 157,158

Braunschweig- Celle, Herzöge von 320, $322 \mathrm{f}$.
Braunschweig-Celle, Herzog Georg Wilhelm von 301, 305, 309, 530, 532

Braunschweig-Lüneburg, Herzöge von $313,323,334,336,436$

Braunschweig-Lüneburg, Herzog/Kurfürst Ernst August von, Bischof von Osnabrück 42, 299- 305, 312, 314, 321f., 324, 327, 332f., 336

Braunschweig-Lüneburg, Herzog Georg Ludwig von s. Georg I., König von England und Schottland

Braunschweig-Lüneburg, Herzog Johann Friedrich von 299

Braunschweig-Lüneburg, Herzog Maximilian Wilhelm von 301

Braunschweig-Wolfenbüttel, Herzöge von 43, 320f., 323, 329, 332, 336, 482

Braunschweig-Wolfenbüttel, Herzog Anton Ulrich von 43, 302, 304, 306-310, 315, 318-320, 328f., 338

Braunschweig-Wolfenbüttel, Herzog August d.J. von 66,509

Braunschweig-Wolfenbüttel, Herzog August Wilhelm von 440, 455, 457, 464, 470, 493f., 531, 533

Braunschweig-Wolfenbüttel, Herzog Ludwig Rudolf von 160

Braunschweig-Wolfenbüttel, Herzog Rudolf August von 302, 308f., 315, 328f.

Breuner, Graf von 302

Brischar, Leutnant 420

Bülow, Cuno Josua von 457,470

Burgdorf, Wolfgang 18f., 84, 141f., 210, 253

Burgund, Herzog Karl »der Kühne« von 385, 386

Burke, Peter 342

Burkhardt, Johannes $18,25,79,81,173$

Caesar, Gaius Julius 62

Calvin, Johannes 83

Campe, Joachim Heinrich 24, 103

Carl, Matthias 431

Carolus, Johann 68, 91, 93f. 128f., 185

Castells, Manuel 195

Cervantes, Miguel de 232 
Chartier, Roger 232

Chladenius, Johann Martin 127

Clerc, Carlo de 395

Cicero, Marcus Tullius 369, 517

Cochenheim, Ernst von 403

Colomba, Sieur de, später Graf Jonquiers 399,414

Comenius, Johann Amos 222

Conring, Hermann 250, 271-275, 513

Consbruch, Caspar Florenz von 356

Consentius, Ernst 98

Crécy, Louis Verjus Comte de 71

Cresset, James 304

Croce, Benedetto 142

Damberg, Wilhelm 164f.

Daston, Lorraine 130

Deckherr, Johann 276

Deer, Wolfgang 124

Delorme, Höfling 319

Diani, Johann Franz 387

Diestelkamp, Bernhard 16

Dipper, Christof 18

Dohna, Gräfin von 215

Drexel, Jeremias 222

Duchhardt, Heinz 12, 16, 18f., 519

Ducros, J.A. $\quad 319,337$

Dumont, Jean 110

Eberhardi, Caspar 418

Eckhardt, Nils 20

Eichholtz, Johann Dietrich Freiherr von 440, 441, 450

Eitzing, Michael von $86-90,144$

Elias, Norbert 211

Eltz, Rittmeister von 319

Elzevier, Familie 182

Endter, Familie $184 f$.

Endter, Wolf Moritz 187

Endter, Johann Andreas 187

Engel, Gisela 41
Engelsing, Rolf 98, 221, 235

Ens, Caspar 88f.

Erbach, Grafen von 169

Esebeck, Frieda Freiin von 299

Estermann, Monika 178

Etheredge, Sir George 71

Eva, biblische Gestalt 241

Faber, Anton (Pseud.) s. Leucht, Christian Leonhard

Fagel, Gaspard 525

Fassmann, Daniel 5, 37, 38, 48, 121-125, 155, 158-166, 215, 231, 333f., 353, 384386, 393, 484-486

Faulstich, Werner $17,20,34,39,75,77 f$., 181

Felbinger, Rudolf 342,348

Feldmeier, Franz 353, 366

Felsecker, Familie 184

Felsecker, Eberhard 107, 109

Fénelon (François de Salignac de La MotheFénelon)

Ferdinand II., Kaiser 144, 197, 242, 262

Ferdinand III., Kaiser 42, 253, 261, 263, $268,271,529,532$

Ferdinand (IV.), Römischer König 263

Fischart, Johann 57, 144

Fischer, Helmut 92

Fischer, Ludwig 24

Flender, Johann Thomas 400

Flender, Friedrich $\quad 400,408,416,531,533$

Flender, Jakob 400

Förster, Friedrich 37, 161, 216

Fontenelle, Bernard le Bovier de 123

Forstenheuser, Georg 66

Francke, August Hermann 121, 159

François, Etienne 235

Franz I. (Stefan), Kaiser 281, 289, 489, 529, 534

Freher, Marquard 293

Freist, Dagmar 13

Friedländer, Ernst 71,215 
Friedrich I., König in Preußen 215, 298, 304, 324, 400, 401, 419

Friedrich II., der Staufer, Kaiser 274

Friedrich II., der Große, König von Preußen 141, 216, 237

Friedrich Wilhelm I., König in Preußen 37-40, 72-74, 117, 121, 159-161, 215f., 401, 404, 439f., 455f., 468, 487f., 503, 523

Friedrich, Susanne 70f., 84, 103, 106, 125, $135,388,510$

Fritsch, Ahasver 38, 131, 153, 192, 235

Fritsch, Verleger 179

Froboese, Julius 346, 347

Fürstenberg, Fürst Froben Ferdinand Dominik Christoph von 462,464

Fürstenberg, Fürst Wilhelm Egon von, Bischof von Speyer 277

Fugger, Kaufmanns- und Adelsfamilie 66, 197, 509

Gadamer, Hans-Georg 21

Gauger, Hans-Martin 202

Gay, Peter 12

Gebhardi, Kanzleibeamter 74

Gemmingen, Weyprecht von 271

Georg I., König von England und Schottland 305, 308-310, 318, 332f., 392, 419, 437, 438, 443, 444f., 464, 467f., 470, 472, $476,491,493,530-533$

Georg II., König von England und Schottland $464,487,493$,

Gestrich, Andreas 28, 84, 214, 245

Gewold, Christoph 293

Giesecke, Michael 172, 173, 254

Glaser, Hubert 341, 342

Gleditsch, Johann Friedrich 114, 116, 179

Glüer, Juliane 90

Goldast von Haiminsfeld, Kaspar Melchior 112,252

Goldfriedrich, Johann 124, 175

Gott 33, 45, 78, 81, 223, 241, 245f., 311

Graff, Harvey J. 202

Greflinger, Georg 147f., 190, 222
Gribner, Michael Heinrich 279

Grimm, Heinrich 176

Grimmelshausen, Johann Jacob Christoffel von 521

Grosse, Verleger 90

Grote zu Schauen, Otto von 302, 313f., 322,324

Groth, Otto 55, 92, 193

Grübel, Zacharias 72

Gstettner, Hans 70

Gundling, Nicolaus Hieronymus 137

Gundling, Jacob Paul 38, 159f.

Gustav II. Adolf, König von Schweden 26, 525

Gutenberg, Johannes 75, 97, 161

Haacke, Wilmont 126, 162

Habermas, Jürgen 21-24, 29, 194, 211, 311, 506

Habsburger, hochadlige Dynastie 42, 87, 196, 198, 242, 297, 300f., 341, 352, 373, 377,386

Hackemann, Friedrich August 160

Haller, Johannes 179

Hammerstein, Notker 16, 136-138

Happel, Eberhard Werner 108, 390

Harms, Wolfgang 205

Hartmann, Johann Ludwig 235

Hartmann, Peter Claus 343

Hartnack, Daniel 5, 36, 61, 129-133, 151f., 183, 187, 192

Haug-Moritz, Gabriele 432

Heimbuch, Hofrichter von 440

Heinrich I., Kaiser 137

Heemskerk, Konrad van 305

Henning, Aegidius 166

Hennis, Wilhelm 193

Henshall, Nicholas 12, 18

Hergot, Hans 176

Hermkes, Wolfgang 261, 263, 295

Hessen-Darmstadt, Landgraf Ernst Ludwig von 420 
Hessen-Kassel, Landgraf Friedrich I. von (später König von Schweden) 298, 354

Hessen-Kassel, Landgraf Karl von 333, 425

Hessen-Kassel, Landgräfin Ulrike Eleonore von (später Königin von Schweden) 298

Hinrichs, Ernst 18, 201, 203, 244

Hölscher, Lucian 23

Hoffman, Dustin 246

Hoffmann, Verleger 109

Hoffmann, Christian Gottfried 113, 114, 119, 381f., 421, $483 f$.

Hogenberg, Frans 87

Hohenlohe-Pfedelbach, Grafen von 152

Hohenthal, Peter von 103

Hohenzollern, hochadlige Dynastie 72, $161,298,369,436,439$

Holdinghausen, Adelsfamilie 398

Holstein-Gottorp, Herzöge von $445 f$.

Hüttl, Ludwig 341, 342

Hughes, Hugh 70

Hughes, Michael 449, 458

Huhold, Marcus Paul 112, 119f.

Hunold, Johann 222, 513

Hurter, Friedrich von 144

Hus, Johannes 81

Hyperius, Andreas 207, 232

Innozenz XI., Papst (Benedetto Odescalchi) 384,385

Irnichen, Gottlob Friedrich 157f.

Isenmann, Moritz 30

Iserloh, Erwin 80

Israel, Jonathan I. 14

Jacklin, Jean (= Jäcklin, Johann) 269

Jahns, Sigrid 432, 434f., 439, 442, 444

Jakobus, Apostel und Heiliger 180

Jansz, Broer 144

Jargow, Christoph Georg 497-501

Jesus s. Gott
Job, Johannes 148

Jobin, Bernard 57, 91, 94, 102, 144, 185

Johann Ohneland, König von England 380

Johann II. Casimir Wasa, König von Polen 234

Johann III. Sobieski, König von Polen 340

Johannes, Evangelist 82

Johannes XXII., Papst (Jacques Duèse) 25

Josef I., Kaiser 43, 180, 261, 264, 265, 275 , 282, 290, 294, 310, 312, 314, 318, 330f., 333, 346f., 355f., 361, 366, 372, 378, 384f., 390, 399, 400, 401f., 405, 424, 463, 529f., $532 \mathrm{f}$.

Josef II., Kaiser 261

Juncker, Christian 113

Jung, Hermann 397f., 400

Kalipke, Andreas 395,401

Kalmus, Ludwig 193

Kambyses II., persischer Großkönig 515

Kapp, Friedrich 175

Karl II., König von Spanien 307, 341f.

Karl IV., Kaiser 262, 268

Karl V., Kaiser 196, 242, 269, 347, 377, 436, 525

Karl VI., Kaiser 121, 155, 164, 234, 253, 261, 265, 266, 280, 282f., 290f., 342, 367, 380, 384, 404-406, 419, 421, 436, 438, 439-443, 447, 454f., 459-463, 468, 476, 478, 480-486, 489-493, 499-503, 523, $529-534$

Karl VII., Kaiser 261, 266, 279, 286f., 292, 464, 529, 534

Karl IX. Wasa, König von Schweden 333

Karl X. Gustav, König von Schweden 234

Karl XII., König von Schweden 347, 434, 500

Kaufmann, Thomas 83

Kaunitz, Familie 149

Kaschmieder, Käthe 162

Katharina I., Zarin 162

Katharina II., die Große, Zarin 210

Kayser, Werner 147

Kees, Johann Jacob 148 
Keller, Ernst Friedrich 395-397

Keller, Katrin 178

Kenny, Neil 130

Kiesel, Helmuth $\quad$ 19, 34

Kinsky, Franz Ferdinand Graf 310, 324326,330

Kintz, Jean-Pierre 93, 94

Kirchner, Joachim 106, 109, 126, 186

Kleinhans, Hans Jacob 189, 198

Kleinpaul, Johann 69

Klingenstein, Grete 149

Klopstock, Meta 225

Klüver, Hans Henrich (Pseudonym) s. Jargow, Christoph Georg

Kniphausen, Baron von 469

Kobenzl, Hans von 144

Kobuch, Agatha 156, 164

Köhler, Hans-Joachim 76

Köhler, Johann David 222, 337, 497

König, Johann C. 279f.

Königsegg, Grafen von 302

Körber, Esther-Beate $\quad 28,104,248,506$, 512

Koppmeyer, Jacob 109

Kormart, Georg 148

Koselleck, Reinhart 13, 22, 127

Kubach, Michael 208

Kühn, Balthasar 351

Kues, Nikolaus von 245

Küster, Sebastian 311

Kulpis, Johann Georg von 316

Kunisch, Johannes 18

Lamberg, Johann Philipp Graf, Bischof von Passau, Kardinal 324

Lang, Franz Christoph Ludwig von 279

Lange, Gottfried 114

Lapide, Hippolythus / Hyppolithus a (Pseudonym) 315,336

Latomus, Sigismund 89

Lautenbach, Conrad 88

Lehmann, Peter Ambros 354, 361
Leibniz, Gottfried Wilhelm 250, 299f., 307, 311f., 313, 316, 513

Leopold I., Kaiser 27, 42f., 263f., 274, $276-$ 278, 282, 291, 294, 300f., 305, 310, 316, $323,326,329,332-335,340,344,346 f$., $351,363,371,373,375,388,529,532$

Leopold II., Kaiser 261

Lepel, Christine Dorothea von 448

Leucht, Christian Leonhard 133, 317, 389, $391,424,427$

Levinson, Barry 246

Lewin, Kurt 54

Lilienstätt, Oberst 471

Limbach, Johann Christian Freiherr von 310, 312, 314, 322, 324f., $330 \mathrm{f}$.

Lindenfels, Gibellini de 326

Lippmann, Walter 54

Lipsius, Heinrich 410

Lipsius, Justus 58, 214

Lisola, Franz Paul Freiherr von 27

Locke, John 517

Löscher, Valentin Ernst 115

Lohse, Bernhard 81

Lorenz, Erich 126

Lothringen, Herzog Leopold von 333

Lothringen, Herzog Karl III. Joseph von, Kurfürst und Erzbischof von Trier 420

Lotter, Michael 83

Lottes, Günther 82

Lucius d.J., Jacob 93

Ludewig, Johann Peter (von) 70, 113, 133, 137, 145, 180f., 190, 192, 216, 222, 236f., 524

Ludolf, Georg Melchior von 336, 391, 392, 490-493

Ludwig der Bayer, Römischer König 25

Ludwig IX., der Heilige, König von Frankreich $123,385 f$.

Ludwig XIV., König von Frankreich 22, 69, 145, 242, 299, 306, 310, 342, 347, 351, $354,369,392,505,522,530,532 \mathrm{f}$

Lühe, Joachim Friedrich von der 465

Lünig, Johann Christian 134, 252f., 294, 336f., 366, 423, 513, 514, 
Luhmann, Niklas 30-35, 61, 249, 258

Lukian von Samosata $121,123,127$

Lundorp, Michael Caspar 112, 133, 252

Luther, Martin 14, 25, 78-83, 90, 172, 207, 246

Lyser, Johann 450

Machiavelli, Niccolò 214, 246, 259

Maes, J. J. 400

Magnus, Marcus 161

Maintenon, Françoise d'Aubigné, Marquise de 380

Malvezzi, Virgilio 246

Manheim, Ernst 24

Mantua, Ferdinand Karl von Gonzaga-Nevers, Herzog von $385 f$.

Marlborough, John Churchill, Herzog von $345,360,369,530,532$

Marnix, Philipp van 58

Marperger, Paul Jacob 37, 145, 231

Martinitz, Maximilian Guidobald Graf 356

Marx, Karl 21f.

Maschenbauer, Andreas 109, 111

Maximilian I., Kaiser 196

Maximilian II., Kaiser 86

Mecklenburg, Herzöge von 433, 446, 448

Mecklenburg-Schwerin, Herzog Christian I. Louis von 432, 438

Mecklenburg-Schwerin, Herzog Christian Ludwig von 44, 443-446, 462f., 466, 475, 477-479, 486-489, 494, 532, 534

Mecklenburg-Schwerin, Herzog Karl Leopold von 6f., 44f., 431-503, 512, 523, 531-534

Mecklenburg-Schwerin, Herzogin Catharina Iwanowna von (aus dem Hause Romanow) 437, 448, 479

Mecklenburg-Schwerin, Herzogin Sophia Hedwig von 448, 498, 531

Medick, Hans 233

Meiern, Johann Gottfried von 464

Melanchthon, Philipp 136f., 207

Menck, Johann Burchard 116
Mencke, Otto 108, 222

Mentz, Georg 257

Merian, Matthäus 135f., 169

Messerli, Alfred 205

Metternich, Graf Ernst von 164

Meyer, Johann 189, 198

Moepps, Emmy 179

Mörke, Olaf 77

Moltke, Otto Friedrich von 301

Monasterol, Ferdinand Solar Graf 342

Montaigne, Michel de 517

Montesquieu, Charles de 509

Moretus, Jan 182

Moser, Friedrich Karl von 519

Moser, Johann Jacob 193, 253, 257, 395, 493f., 513

Mühlbach, Christoph 198

Münch, Paul 19, 34, 396

Mulz, Jakob Bernhard 109

Nagel, Michael 114, 179

Nassauer, hochadlige Dynastie 396f., 413, 428

Nassau-Dillenburg, Graf Wilhelm der Reiche 297

Nassau-Siegen, Graf Johann VIII. von 397, $409,424,426$

Nassau-Siegen, Fürst Franz Hugo Ferdinand Gereon von 405

Nassau-Siegen, Fürst Friedrich Wilhelm Adolf von 400, 402, 408, 411, 419, 424f., 428

Nassau-Siegen, Fürst Johann Franz Desideratus von 401

Nassau-Siegen, Fürst Wilhelm Hyazinth von 43f., 395-428, 530-534

Nassau-Siegen, Prinz Emanuel Ignatius von 405, 531, 534

Natonek, Hans 60

Naumann, Christian Nikolaus 388

Naumann, Hans 232

Nepos, Cornelius 222

Neubourg, Ludwig Ernst von 198 
Neukirch, Johann Georg 224

Neuser, Wilhelm 395

Niro, Robert de 246

Noelle-Neumann, Elisabeth 516f.

North, Michael 228

Opel, Julius Otto $19,92,93$

Oranien-Nassau, hochadlige Dynastie 397, 428

Oranien-Nassau, Prinz Moritz von, Generalstatthalter der Niederlande 144

Oranien-Nassau, Prinz Wilhelm I. von, Generalstatthalter der Niederlande 26, 397

Oranien-Nassau, Prinz Wilhelm III. von, Generalstatthalter der Niederlande, König von England 180, 329, 407, 416

Oranien-Nassau, Prinz Wilhelm IV. von, Generalstatthalter der Niederlande 44, 406, 413, $421 f$.

Oranien-Nassau, Prinzessin Anna von 414

Oranien-Nassau-Diez, Prinz Johann Wilhelm Friso von 406

Ortgies, Johann Hermann 37, 72f.

Ostfriesland, Fürst Georg Albrecht von 72

Oxenstierna, Bengt 304

Paas, John Roger 205

Pachner von Eggenstorff, Johann Joseph 252

Parsons, Talcott 30,35

Paul, Jean 24

Pecquerau, Adrian von 357,359

Peter der Große, Zar $114,162,437,440$, 448, 485

Petkum, Edzard Adolf von 441

Philipp II., König von Spanien 525

Philipp V. von Anjou, König von Spanien 342f., 351, 381

Pfalz, Kurfürst Friedrich V. von der (zeitweilig König von Böhmen) 84f., 262, 365,443

Pfalz, Kurfürst Johann Wilhelm von der 222, 264f., 276, 282f., 289f., 298, 346, $360,392,402,417,419,423$
Pfalz, Kurfürst Karl Ludwig von der 99, 100, 272-274, 290, 297

Pfalz, Kurfürst Karl Philipp von der 265

Pfalz, Kurfürst Karl Theodor von der 261

Pfalz, Kurfürst Ruprecht von der 270

Pfalz-Neuburg, Herzog Franz Ludwig von, Erzbischof von Trier und später von Mainz 265

Plantin, Christophe 182

Pörner, Moritz 94

Polo, Marco 196

Poppe, Johann Gerhard 454

Potemkin $=$ Potjomkin, Grigori Alexandrowitsch, Fürst von Taurien 210

Praetorius, Johannes 125

Press, Volker 16, 299

Prutz, Robert E. 92

Raabe, Paul 20

Rabener, Justus Gotthard 113, 114, 117, 333

Ramus, Petrus 221

Rathen, Major von 467

Reck, Legationssekretär 330

Reich, Philipp Erasmus 175, 181

Reinhard, Wolfgang 16

Repgen, Konrad 26f., 267f., 320, 508

Reuß, Grafen von 152

Richter, Georg Sigmund 71

Ricous, Louis Gaspard de 344, 349, 353, 393, 522

Riephan, Wilhelm 89

Riepl, Wolfgang 78

Ries, Paul 190

Rinck, Gottlieb Eustachius 388

Ritzsch, Timotheus 96, 129, 198

Roden, Oberstleutnant 473

Roderique, Jean Ignace 216

Roeck, Bernd 16, 138, 300

Roelker, Nancy L. 12

Römer, Christof 299

Rohr, Bernhard von 225, 252

Rohrschneider, Michael 519 
Rosenberg, böhmische Adelsfamilie 89

Rosseaux, Ulrich 115

Roth, Paul 76, 92

Rousseau de Chamoy, Louis 111

Rousseau, Jean-Jacques 230, 509, 517

Rüdiger, Johann Andreas 73, 122, 285, 475

Ruehlmann, Gottfried 364f.

Sabrow, Martin 38

Sachsen, Kurfürst Johann Georg II. von 148

Sachsen-Eisenach, Herzöge von 157

Sachsen-Gotha, Herzöge von 154

Sachsen-Gotha, Herzog Ernst von 237

Sachsen-Meiningen, Herzog Ernst Ludwig I. von 310

Sachsen-Merseburg, Herzöge von 152

Sachsen-Zeitz, Herzöge von 362

Sachsen-Zeitz, Herzog Moritz von 164

Salm, Karl Theodor Otto Fürst von 356

Salomon, Ludwig 66,92

Savoyen, Prinz Eugen von 345, 354, 368f., $388,434,483,530,532$

Schaper, Johann Ernst 441, 471f.

Scharff, Geheimsekretär $\quad 442,461,485$, 494

Schauroth, Eberhard Christian Wilhelm von 424,427

Schenda, Rudolf 205

Schevius, Johann 451f., 455

Schilling, Heinz 16

Schilling, Michae 124

Schlick, Leopold Josef Anton Graf 385

Schlemm, Johann Philipp 198

Schlöer, Christian 275

Schlögl, Rudolf 25

Schlosser, Heinrich 396

Schmauss, Johann Jakob 332f., 415, 418, 427

Schmidt, Georg 522

Schmidt, Elmar 351

Schnath, Georg 299, 302, 307, 318

Schneider, Daniel 169, $495 f$.
Schön, Erich 203, 209, 238

Schönborn, Friedrich Karl von, Bischof von Würzburg und Bamberg, Reichsvizekanzler 355, 440, 442, 444, 446, 476

Schönborn, Lothar Franz von, Kurfürst und Erzbischof von Mainz 381

Schönborn, Johann Philipp von, Kurfürst und Erzbischof von Mainz 272

Schöpfer, Johann Joachim 441, 471

Scholz, Susanne 41

Scholz Williams, Gerhild 125

Schorn-Schütte, Luise 36

Schubart, Christian Friedrich Daniel 40

Schubert, Friedrich Hermann $15 f$.

Schultheiß-Heinz, Sonja 512

Schulze, Winfried 16, 174

Schumacher, Martinus 99

Schumann, Christian 421

Schutte, Johann Eberhard 400

Schwartzkopf, Johann 273

Schwarzburg- Rudolstadt, Fürsten von 446

Schwarzburg-Rudolstadt, Graf Albert Anton von 217

Schwarzburg-Sonderhausen, Fürsten von 73

Schwarzenberg, Fürst Ferdinand Wilhelm Eusebius von 314

Schwerin, Generalmajor von 457

Schwitalla, Johannes 105

Scribani, Petrus 122

Scribner, Robert W. (Bob) 206

Seckendorff, Friedrich Heinrich Graf 74

Serlin, Wilhelm 135

Siegert, Reinhart 204, 237

Simmel, Georg 245

Sinold von Schütz, Philipp Balthasar 5, 70, 113-117, 151-155, 328-330, 368, 373380,415

Sinzendorff, Philipp Ludwig Graf 442

Sisamnes, persischer Richter 515

Sleidanus, Johann 137

Sötern, Philipp Christoph von, Erzbischof und Kurfürst von Trier 373, 522 
Solemacher, A. J. 400

Solms-Laubach, Grafen von 152

Solms-Laubach, Graf Ernst von 169

Sombart, Werner 194

Sonnenfels, Joseph von 23, 256

Sophie Charlotte, Königin in Preußen 307

Spalatin, Georg 172

Spanheim, Ezechiel 271

Spieringk, Nikolaus 151

Spörke, Geheimrat von 440

Sporhan-Krempel, Lore $66 f$.

Starhemberg, Graf von 476

Steger, Tobias 89

Steinberg, Hofrat von 440

Steinbock, Magnus 156

Steinhausen, Georg 144

Stenger, Johann Melchior 151

Stieff, Christian 114

Stieler, Kaspar $38,65,71,93,103,133-$ 135, 187, 191f., 210, 217, 223f., 228-230, 236, 257,

Stöber, Rudolf 103,142

Stollberg-Rilinger, Barbara $\quad$ 17, 218

Stolleis, Michael 214

Stratemann, Wilhelm 37, 74, 160f.

Struve, Burkhard Gotthelf 276-278, 426, 428

Stübel, Andreas 5, 119f., 128, 154, 169, 289f., 330f., 378, 381, 383, 482

Süßmann, Johannes 41

Tallard, Camille d'Hostun de la Baume, Herzog von 354

Taxis, Familie s. Thurn und Taxis, Familie

Taxis, Alexandrine Gräfin von 189

Thomas, Apostel und Heiliger 154

Thomasius, Christian 108f., 137f., 164, $169,229,517$

Thurn und Taxis, Familie 15, 191, 195-198

Tortarolo, Edoardo 254

Toskana, Großherzog von, Cosimo III. de' Medici 152
Trautson-Falkenstein, Leopold Johann Donat Graf, später Fürst 356

Trefurth, Johann Zacharias 163

Troßbach, Werner 244, 395, 404, $405 f$.

Truchseß von Waldburg, Graf 288

Truchseß von Waldburg, Graf Gebhard, Erzbischof und Kurfürst von Köln 365

Ukena, Peter 25, 29

Veblen, Thorstein 211

Vec, Miloš 218

Vehse, Eduard 211

Viereggen, Victor August von 454

Viktor Amadeus II., Herzog von Savoyen, König von Sardinien 298, 310

Villars, Claude-Louis-Hector de 368

Vittinghoff, Oberst 471

Voigt, Sekretär 74

Volmer, Annett 20

Wächtler, Johann Christian 277

Wahrenberg, Hermann von 278

Waldstein, Karl Ernst Graf von 312, 314, 356

Wallenstein, Albrecht von 525

Weber, Johannes 64, 91, 94, 103f., 109, 145, 151,521

Weber, Max 40, 193

Wehler, Hans-Ulrich $\quad$ 13, 220, 226, 235

Weidmann, Moritz Georg 124, 179, 253

Weinsberg, Hermann (von) 128, 230

Weise, Christian $145,192,214,259,508$

Welfen, hochadlige Dynastie 297f., 324, 328, 331, 333, 436, 444, 486f., 513

Wendessen, Balthasar Henning von 488f., 494

Wettiner, hochadlige Dynastie 42, 270, 293, 298, 369

Welke, Martin $18,60,91,94,106,183,225$, $228,233,238,506$

Wick, Peter $432,439,445,455,468,502$ 
Wied, Graf Hermann von, Erzbischof und Kurfürst von Köln 365

Wiering, Thomas von 146f., 190, 390, 498

Wilke, Jürgen $17,35,55,77,96,97,100$, 107, 126, 183, 191

Willenberg, Samuel Friedrich 450

Willer, Georg 175

Windischgraetz, Ernst Friedrich Graf von 483

Winkler, Heinrich August 241

Winkler, Karl Tilman 53, 56

Winterling, Aloys 28, 211f., 243

Witkowski, Georg 113, 114, 158, 162

Wittelsbacher, hochadlige Dynastie 42f., 46, 116, 261f., 264-266, 269, 272, 275, 278, 280, 283-287, 289, 291, 293-296, 309f., 327, 331, 333, 340-342, 347, 354, 359f., 363, 366-368, 373, 377f., 380$391,463,530,533$

Wittmann, Reinhard $166,168,175,201$, 207, 237

Wohlfeil, Rainer 25, 79

Wolf, Hubert 255

Wolff, Richard 37, 74, 160

Wolff-Metternich, Franz Arnold von, Bischof von Paderborn 402-404

Wolffradt, Hermann Christian von 441f., $459,461,485,494$
Wrede, Martin 28

Würgler, Andreas 28, 512

Württemberg, Herzöge von (mit Nebenlinien) $73,152,311,316$

Württemberg, Herzog Carl Eugen von 40

Wüsten, Balthasar Christoph 187

Wuketits, Franz 243

Wunder, Bernd 345

Zech, Bernhard von (Pseud.: Friedrich Leuthoff von Franckenberg) 293, 294, 335

Zedelmaier, Helmut 208, 221, 222

Zedler, Johann Heinrich 131, 136, $180 f$.

Zeller, Johann Sigismund Baron von 390

Zenner, Gottfried 368, 393

Zimmermann, Matthias Benjamin 279

Zimmermann, Walter 184

Zindt, Kaspar Marquardt Baron von 346, $351,353,371,382,390$

Zinkgraf, Julius Wilhelm 416f., 424

Zunnern, Johann David 187

Zschackwitz, Johann Ehrenfried 5, 118f., 154-158, 162, 294, 332, 380, 383, 390f., 417-420

Zwantzig, Zacharias 336 


\subsection{Ortsregister ${ }^{1}$}

Aachen 12, 289, 400, 415

Affolderbach 404

Altbreisach 383

Altdorf 121, 158

Altona 156, 188-190, 349, 522

Amsterdam 97, 110, 182, 215, 319

Antwerpen 182

Armenien 298

Athen 130

Augsburg, Bistum 280

Augsburg, Stadt 48, 66, 71, 109, 112, 118f., 157, 188, 256f., 265f., 278f., 284f., 288, $291,301,344,345,370,375,387,393$, $413 f$.

Aurich 72, 275

Baden, Stadt $43,347,367,383,392,530$, 533

Baden-Baden, Landgrafschaft 303, 335

Baden-Durlach, Landgrafschaft 335

Balkan 66, 88, 339, 436

Bamberg, Bistum 280, 446

Basel 185

Bayern, Kurfürstentum 6, 42, 46, 204, 264-296, 302, 305, 331, 337, 339-394, 413, 522, 529f., 532

Bayreuth 163

Belgien s. Niederlande (südliche)

Berg, Herzogtum 425, 428

Bergamo 195

Berlin 38, 71-74, 98, 122, 159-161, 164, 190, 215, 217, 284, 288, 428, 471, 487, 503

Bernstadt/Schlesien 152

Bietigheim 234

Böhmen 262, 264, 310, 324f., 330f., 336f., 530,533
Boizenburg/Elbe 458, 461

Bonn 28, 362, 385f.

Brandenburg, Kurfürstentum 71, 97-99, 164, 300, 302, 305f., 425, 431, 435, 439, 447, 503, 523, 529, 532

Brandenburg-Ansbach, Markgrafschaft 335

Brandenburg-Kulmbach, Markgrafschaft 335

Braunschweig, Stadt 37, 74, 307, 308, 321, 440

Braunschweig-Lüneburg, Herzogtum/Kurfürstentum $6,97,198,280,297-338$, 425, 436, 438-440, 442, 444f., 447, 457, 467, 470, 472, 474, 477-479, 481f., 492, $503,523,529-533$

Braunschweig-Wolfenbüttel, Herzogtum 6, 43, 46, 74, 273f., 303-305, 309, 315, 317, 319, 328f., 335, 336f., 440, 445, 457, 467, 470, 474, 477-479, 482, 492, 493f., 531, 533

Bremen 64, 188, 319, 368

Breslau 37, 66, 215

Brüssel 190, 342, 345, 348, 350, 373, 377, $405 f$.

Budapest 342

Butjadingen 203

Calenberg 299

Campen, Amt 309

Celle 112, 299, 301, 304, 307, 309, 320, 328,332

Coburg 155

Compiègne 345,346

Cuenca, Diözese 232

Dänemark 97, 111, 156, 189, 303f., 306, $310,317,320,326,335,437,452$

1 Nennungen nur in den Anmerkungen sind kursiv gesetzt. Das Vorwort wurde nicht indiziert. »Heiliges Römisches Reich« und »Deutschland« wurden ebenfalls nicht indiziert. Aufgenommen wurden vor allem europäische Staaten, Territorien, Städte und Gewässer. 
Danzig 66, 68, 231, 440

Detmold 74

Deutsche Demokratische Republik (DDR) 431

Dillenburg 422

Dillingen 344

Dömitz 45, 442, 459, 461-463, 465, 472, 475, 478, 484, 487f., 494, 503

Donauwörth 354, 373, 376, 382, 444

Dresden 96, 115, 154, 157f., 162f., 440

Düsseldorf $361,397,402,412,427$

Eichstädt, Bistum 280

Eisenach 155

Eiserfeld 397, 401, 405

Elbe 156, 468, 469, 472-474, 479

Elsass 71

Emden 433

England (Großbritannien) $56,66,88,111$, 115, 307, 333, 380, 407, 438f., 447, 452, 457, 461, 464, 469, 473, 476, 478f., 481f., $487,492,503,525,530,533$

Erfurt 98, 191

Eschenbach 404

Franken 276, 284f., 374

Frankfurt am Main $37,58,69,71,86,88$ 90, 96, 99, 101f., 108, 121, 134f., 147, 159, 175, 177f., 185, 187, 194, 197, 215, 233, 255, 273, 285, 289, 325, 359f., 361, $363,367,398,411,471$

Frankreich 17, 23, 43, 57, 66, 88, 104, 107, 111, 115f., 146, 159, 196, 242, 301, 303f., 306-310, 315, 318, 320f., 326, 328f., 333, $335,338,342,343 f ., 345,351,355,363$, 367, 369f., 372-374, 379, 382f., 385, 388, 389f., 392f., 486, 516, 522, 530, 532

Freiburg im Breisgau 383

Freising, Bistum 284

Gifhorn 198, 306

Goldberg 169

Goslar 308, 335

Gran 342
Griechenland 202

Güstrow 449f., 454, 471

Den Haag 71, 110, 118f., 322, 379

Haarlem 215

Hadamar s. Nassau-Hadamar, Fürstentum

Halberstadt 319

Halle an der Saale $121,137,155,159,169$, 180, 363, 409, 411f., 467

Hamburg 5, 36f., 48, 66, 71, 96-99, 146f., 151, 156f., 179, 188-191, 197, 215, 227, 231, 283, 286, 350, 366, 390, 411, 448f., 470, 477, 498

Hanau 166, 285, 469, 471

Hannover s. Braunschweig-Lüneburg, Herzogtum/Kurfürstentum

Hannover, Stadt 74, 93, 301, 322, 332, 476

Heidelberg 69, 262, 268-275, 291, 361, 367

Heiligenhofen/Mecklenburg 498

Helmstedt 93, 251, 271, 274f., 498, 513

Herborn 221

Hessen 113

Hessen-Darmstadt, Landgrafschaft 335, 403,420

Hessen-Kassel, Landgrafschaft 198, 303, $307,317,425,518$

Höchstädt 116, 345, 353f., 372, 376, 379, $387,389,391,530,532$

Hohenasperg 40

Holstein-Gottorp, Herzogtum 445f., 469

Ingolstadt 383

Italien $66,88,107,111,115,122,159,196$, 271,398

Jena 113,152

Jülich, Herzogtum $\quad 289,428$

Jülich, Stadt und Festung 399

Kaan 397, 401, 405

Kaiserswerth 386

Karlsbad 163

Kassel 414 
Kehl 383

Kempten 375

Klagenfurt 346

Kleve 198, 412

Köln, Kurfürstentum 28, 43, 86, 88, 211, 265, 271, 283f., 303, 334, 337, 347, 358f., 361, 364-368, 370, 372, 378, 385f., 389f., 393, 397, 400-402, 409, 425, 428, 523, $529-532$

Köln, Stadt $66,71,86 f ., 89,96,101,128$, 144, 188, 200, 216, 230, 362, 366, 406, $422,425,427$

Königsberg 198, 298

Köstritz 152

Konstantinopel 190

Kopenhagen 190

Kulmbach 192

Laichingen 233

Landau 367

Laubach 169

Lauenburg, Herzogtum 309

Lauingen 344

Leiden 182,215

Leipzig $37,48,86,90,94,96,101,104$, $108,113,114,118-121,124,129,134$, 137, 148, 152, 154f., 157-159, 161-164, 175-181, 185, 193, 198, 215, 222, 253, $256,292,368,393,478,482,507$

Lille 379

Limburg, Herzogtum 367

Limburg, Stadt 401

Lippe, Fürstentum 149

Lissabon 190

Loccum, Zisterzienserabtei (lutherisch) 98

London 190, 307, 332, 379, 438, 440, 442, 472f., 493

Lüttich, Bistum 282f., 290, 355, 358, 362, $372,383,386$

Luxemburg, Herzogtum 366f.

Lyon 17

Madrid 190, 341f., 406
Magdeburg 83

Mainz, Kurfürstentum 133, 180, 263, 265, 271, 278, 280, 302, 305f., 330, 334, 477, 529,532

Mainz, Stadt 69

Malplaquet 346

Marburg 207

Mecklenburg-Güstrow, Herzogtum 433

Mecklenburg-Schwerin, Herzogtum 6, 44, 46, 323, 431-503, 523, 531-534

Mecklenburg-Strelitz, Herzogtum 433, 446

Memmingen 344

Mesopotamien 202

Michelstadt 169

Mons 345, 379

Moskau 111, 115

München 218, 269f., 273, 274, 280, 282f., 285-288, 291, 292, 321, 323f., 338, 342f., $348,352,359,371,372$, 382f., 387, 393, $470,472 \mathrm{f}$.

Münster, Bistum 303, 317, 335, 419

Münster, Stadt 12, 27, 32, 317

Nassau-Hadamar, Fürstentum 397, 399, 401, 405f., 417, 531, 534

Nassau-Siegen, Fürstentum 43, 395-429, $459,530-534$

Netphen 397, 426

Neuburg/Donau 344, 351

Niederlande (Republik) 20, 26, 57, 66, 71, 86-88, 111, 115, 159, 350, 374, 397, 405, 525

Niederlande (südliche) $111,264,341,360$, 380f., 383, 386f.

Nienburg 198, 306

Norden/Ostfriesland 274

Nürnberg $\quad 66-68,71,107,109,121,158$, 176, 184, 187f., 190, 204, 222, 231, 306, $335,359,411$

Oberpfalz 346, $382 \mathrm{f}$.

Österreich (Oberösterreich, Niederösterreich) $204,242,262,331,335,349,522$ 
Ofen s. Budapest

Oldenburg 237

Oranien, Fürstentum (Orange) 397, 407, 416

Osmanisches Reich s. Türkei

Osnabrück 27, 299, 317, 323

Ostfriesland, Fürstentum 72, 273, 432f.

Ostende 444

Ostsee 268, 437, 441, 444, 480, 483, 489f., 494

Paderborn, Bistum 402

Parchim 449f., 455, 463

Paris $17,69,190,215,306,321,329,342$, $345,349,363,380,393,522$

Passau 344, 349, 375, 378, 387

Peine 308

St. Petersburg 438, 471

Pfalz, Kurfürstentum 6, 42, 69, 85, 262f., 265-296, 301, 303, 311, 317, 331, 334, $335,367,392,402,413,417,419,425$, $428,513,529,532$

Polen 111, 115, 268, 298, 340, 434, 440f., 469

Portugal 111

Potsdam 159

Prag 66, 197

Preußen, Herzogtum 28, 248, 452

Preußen, Königreich 72, 117, 164, 241f., 307, 317, 425, 428, 431, 444f., 447, 473, $479,486,488,523$

Ramillies 345

Rastatt 43, 347, 367, 383, 392, 530, 533

Ratzeburg 323, 437, 451, 454, 471, 499

Regensburg 70f., 111, 112, 133, 141, 145, 179f., 219, 231, 234, 281, 283f., 296f., 317, 323-325, 328, 330f., 344-346, 348f., 353, 357-362, 369, 371f., 375, 378, 382, 387, 389f., 392f., 395, 399f., 409412, 415-418, 425, 427, 462, 467, 475f., 481, 487f., 501, 503, 510, 513, 522, 523, $530,532 \mathrm{f}$.

Rhein (Oberrhein, Niederrhein) 57, 345, $367,374,378$
Rheinberg 386

Rheinland $88,276,283-285$

Rheinpfalz s. Pfalz, Kurfürstentum

Rhône 407

Riga 469

Rijswijk 352f., 402

Rijssel 386

Rödgen 426

Rom 115, 190, 202

Rostock 44, 431, 435, 444, 449, 453, 455, $458,468-473,475,484,488,492,494$ $498,501,523$

Russland 437, 452, 481

Sachsen, Kurfürstentum 42, 71, 163, 178, 198, 204, 238, 262, 264, 278, 290, 292f., $302,305,440,529,532$

Sachsen-Gotha, Herzogtum 303, 317, 335

Salem, Zisterzienserabtei 98

Salzburg, Erzbistum 303

Salzwedel 98

Sardinien 298

Sauerland 407

Savoyen 298, 387, 434

Schiffbek 48

Schlesien, Herzogtum 141

Schwaben 276, 283-285, 350, 374

Schwarzburg-Rudolstadt, Fürstentum 446

Schweden $26,97,111,124,154,156,189$, $268,298,315,326,333,335,434,437$, $486,516,518,525$

Schweiz 20,66, 71, 111

Schwerin 45, 440, 443, 449f., 455, 459, 461, $463,465,471,478,480,483,488,502 \mathrm{f}$.

Siebenbürgen 335

Siegen 6, 43f., 46, 395-428, 530-534

Skandinavien $66,71,88$

Spanien 66, 88, 111, 115, 328, 342f., 353, $381,398,525$

Speyer 235, 249, 263, 362, 510

Stade 156

Sternberg/Mecklenburg 455, 492 
Stettin 98

Stockholm 234

Straßburg, Bistum 277

Straßburg, Stadt 57f., 68, 89, 91, 93f., 97, $102,129,144,185$

Stuttgart 234

Thüringen 151, 178, 204

Tirol 344, 389

Toskana 152

Trient 379, 384

Trier, Kurfürstentum 265, 284, 303, 334, $373,403,420,522,529,532$

Türkei $111,242,360,436,522$

Ulm 294, 344, 348, 350f., 353, 368, 370, 371, 374f., 377f., 387, 393, 530, 532

Ungarn $111,115,336,360,376$

Utrecht $121,159,165,215,298,381$

Valenciennes 386

Venedig 66, 68, 190, 323, 346

Versailles 342

Walsmühlen 440, 457, 471

Warschau 190
Weidenau 397, 400f., 404f., 411f., 420f., 427

Weißenfels 152

Weißer Berg (bei Prag) 85

Westerwald 406f., 420

Westfalen 88, 407

Westindien, Inseln 245

Wetzlar 145, 249, 263, 510

Wien $37,44,56,66,68,109,145,155,188$, 190, 216, 249, 259, 290, 300, 302, 304, 313f., 321, 324, 341f., 352f., 355-358, 360f., 368, 371, 372, 378f., 383, 385, 390, 393, 405, 411, 428, 438, 439-444, 447, $449,450,454,460,462,465,473-476$, $483,503,523,530-534$

Wilgersdorf 398

Wilnsdorf 397, 398, 426

Wismar 431

Wittenberg 80

Wittstock 439, 523

Wolfenbüttel $67,69,74,98,125,299,301 f$., 306-308, 319-321

Württemberg, Herzogtum 233, 280, 291, $432 \mathrm{f}$.

Würzburg, Bistum 280, 335

Zittau 259

Zürich $58,102,514$ 


\section{Veröffentlichungen des Instituts für}

Europäische Geschichte Mainz

Band 229: Justus Nipperdey

Die Erfindung der

\section{Bevölkerungspolitik}

Staat, politische Theorie und Population

in der Frühen Neuzeit

2012. 679 Seiten, Leinen

ISBN 978-3-525-10118-6

Band 228: Klaus Bümlein / Irene Dingel / Wolf-Friedrich Schäufele (Hg.)

Gustav Adolf Benrath

Reformation - Union - Erweckung

Beispiele aus der Kirchengeschichte

Südwestdeutschlands

2012. 391 Seiten mit 1 Abb., Leinen

ISBN 978-3-525-10110-0

Band 227: Katharina Reinholdt

\section{Ein Leib in Christo werden}

Ehe und Sexualität im Täufertum der Frühen

Neuzeit

2012. 325 Seiten mit 11 Abb., Leinen

ISBN 978-3-525-10107-0

Band 226: Galaxis Borja Gonzalez

Die jesuitische Berichterstattung über die Neue Welt

Zur Veröffentlichungs-, Verbreitungs- und

Rezeptionsgeschichte jesuitischer Americana

auf dem deutschen Buchmarkt im Zeitalter der

Aufklärung

2011. 377 Seiten, 9 Abb. und 8 Tab., Leinen

ISBN 978-3-525-10109-4
Band 223: Vera von der Osten-Sacken

Jakob von Vitrys

"Vita Mariae Oigniacensis"

Zu Herkunft und Eigenart der ersten Beginen

2010. 270 Seiten, Leinen

ISBN 978-3-525-10102-5

Band 222: Christiana Brennecke

\section{Von Cádiz nach London}

Spanischer Liberalismus im Spannungsfeld von nationaler Selbstbestimmung, Internationalität und Exil (1820-1833)

2010. 393 Seiten, Leinen

ISBN 978-3-525-10104-9

Band 221: Kestutis Daugirdas

Andreas Volanus

und die Reformation im Großfürstentum Litauen

2008. VII, 324 Seiten, Leinen

ISBN 978-3-525-10055-4

Band 220: Ivan Parvev

\section{Land in Sicht}

Südosteuropa in den deutschen politischen Zeitschriften des 18. Jahrhunderts

2008. VIII, 229 Seiten, Leinen

ISBN 978-3-525-10054-7

Band 219: Karen Bayer

\section{"How dead is Hitler?"}

Der britische Starreporter Sefton Delmer und die Deutschen

2008. VI, 349 Seiten, Leinen

ISBN 978-3-525-10053-0

\section{Vandenhoeck \& Ruprecht}




\section{Veröffentlichungen des Instituts für Europäische Geschichte Mainz}

Band 218: Ceorg Kreis

\section{Frankreichs republikanische}

Großmachtpolitik 1870-1914

Innenansicht einer Außenpolitik

2007. X, 662 Seiten, Leinen

ISBN 978-3-525-10052-3

Band 217: Thomas Ott

\section{Präzedenz und Nachbarschaft}

Das albertinische Sachsen und seine Zuordnung zu Kaiser und Reich im 16. Jahrhundert

2009. 654 Seiten, Leinen

ISBN 978-3-525-10090-5

Band 216: Bernd Klesmann

\section{Bellum solemne}

Formen und Funktionen europäischer Kriegserklärungen des 17. Jahrhunderts

2007. X, 357 Seiten, Leinen

ISBN 978-3-525-10051-6

Band 215: Claus Bernet

\section{"Gebaute Apokalypse"}

Die Utopie des Himmlischen Jerusalem in der Frühen Neuzeit

2007. XIV, 518 Seiten, Leinen

ISBN 978-3-525-10050-9

Band 214: Sabine Ullmann

\section{Geschichte auf der langen Bank}

Die Kommission des Reichshofrats

unter Kaiser Maximilian II. (1564-1576)

2006. X, 456 Seiten mit 6 Abb., Leinen

ISBN 978-3-525-10049-3
Band 213: Wolf-Friedrich Schäufele

\section{Defecit Ecclesia}

Studien zur Verfallsidee in der

Kirchengeschichtsanschauung des Mittelalters

2009. VIII, 408 Seiten, Leinen

ISBN 978-3-525-10048-6

Band 212: András Forgó

\section{Kirchliche Einigungsversuche in Ungarn}

Die Unionsverhandlungen Christophorus Rojas y Spinolas in der zweiten Hälfte des 17. Jh.

2007. VI, 211 Seiten, Leinen

ISBN 978-3-525-10047-9

Band 211: Andrea Weindl

Wer kleidet die Welt?

Globale Märkte und merkantile Kräfte in der europäischen Politik der Frühen Neuzeit

2007. IX, 289 Seiten, Leinen

ISBN 978-3-525-10046-2

Band 210: Andreas Rutz

\section{Bildung - Konfession - Geschlecht}

Religiöse Frauengemeinschaften und die katholische Mädchenbildung im Rheinland (16.-18. Jahrhundert)

2006. XI, 505 Seiten, Leinen

ISBN 978-3-525-10045-5

Band 209: Matthias Schnettger

\section{Principe sovrano oder civitas imperialis?}

Die Republik Genua und das Alte Reich in der Frühen Neuzeit (1556-1797)

2006. VII, 694 Seiten, Leinen

ISBN 978-3-525-10044-8

\section{Vandenhoeck \& Ruprecht}

